

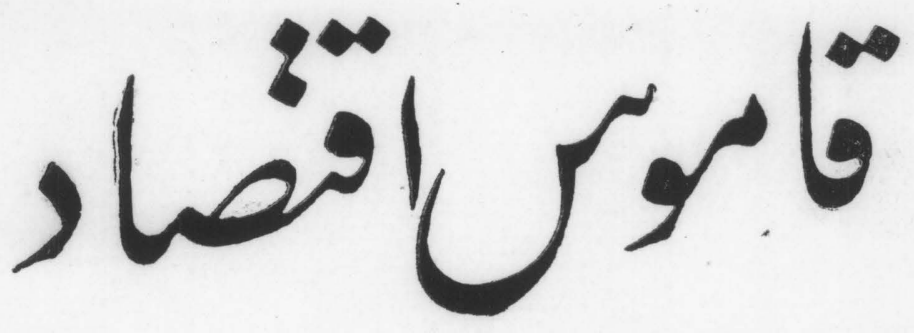

$$
\begin{aligned}
& \text { ا } \\
& \text { شامل اصطلا حات }
\end{aligned}
$$

مبادىاقتصاد كماليه ، تجارت، احصائيه ؛ محاسبه ؛ بيمه و بانكدالرى

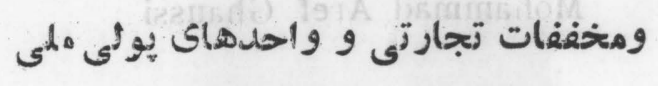

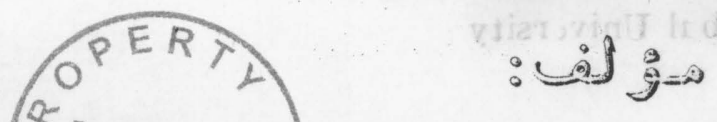

$$
\text { زها }
$$

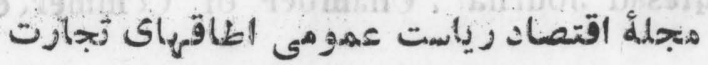

$$
\begin{aligned}
& \text { S } \\
& 100002
\end{aligned}
$$



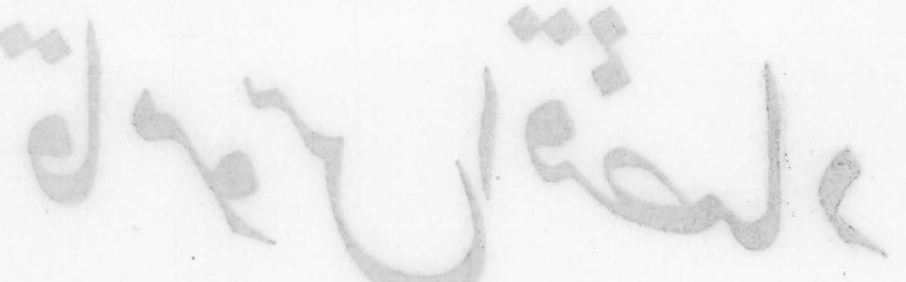

DICTIONARY OF FCONOMICS A.D BUSINESS

English - Persian

by

Mohammad Aref Ghaussi

Instruct r of Economiss .

K b al Univirsity

lst. edition

Published by:

Iqtesad Journal ، (hamber of Ccmmeric

Printed in Matbaa-é Milli, Kabul 1961

000903 


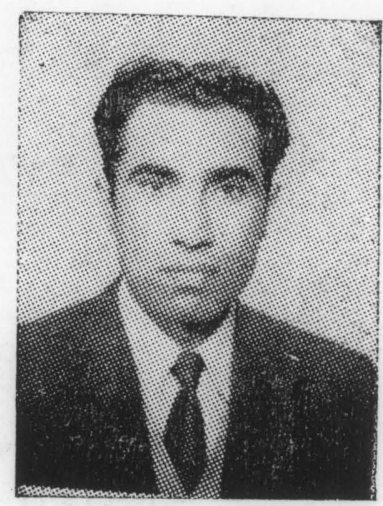

مؤلف : متمل عارفغوثى

The Author

000904 


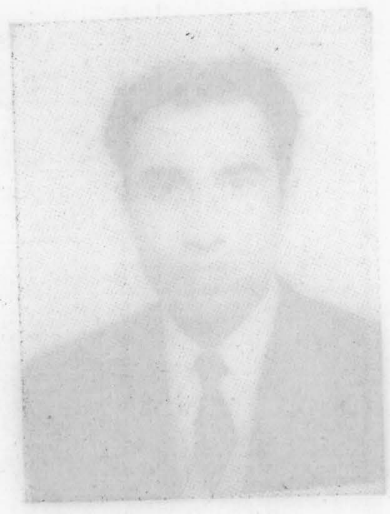

ร )กำ sil

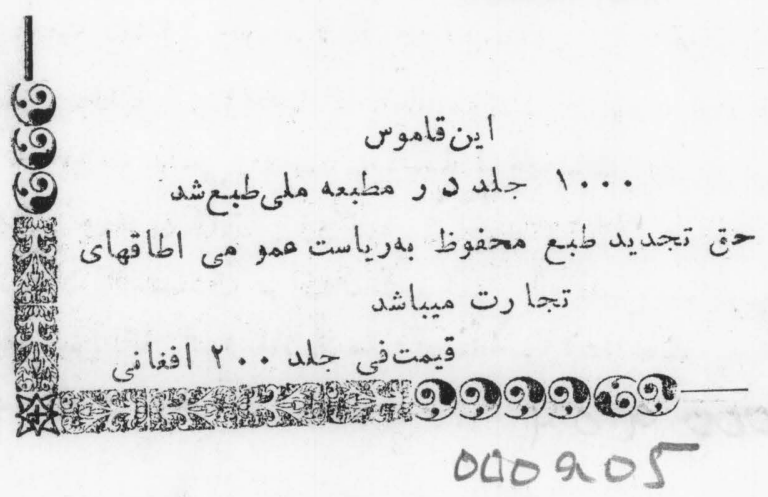




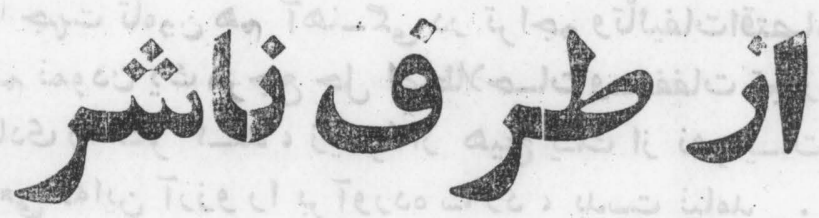

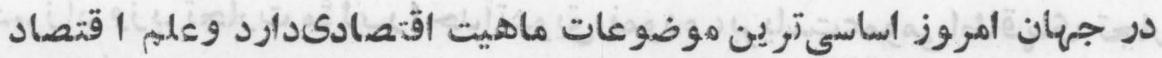

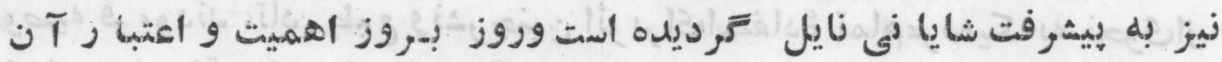

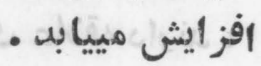

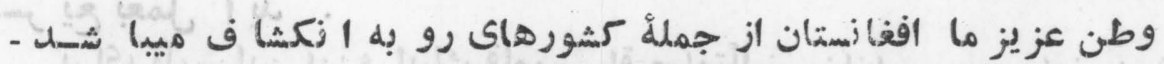

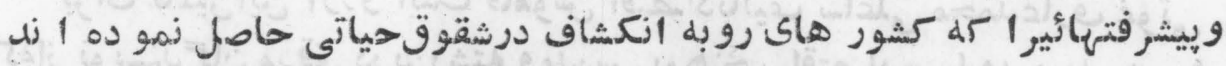

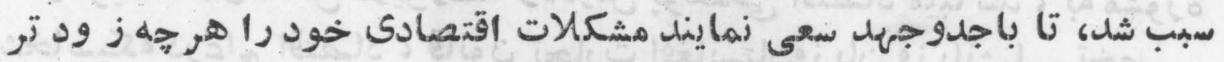

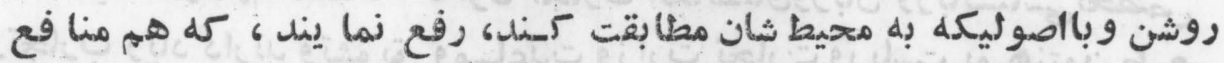

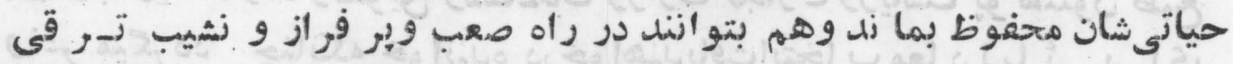

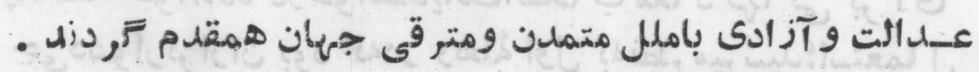

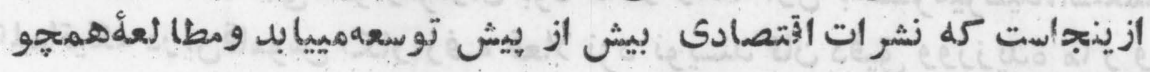

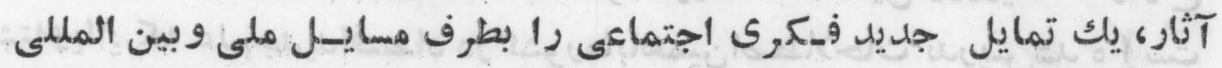

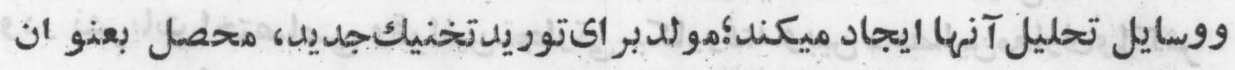

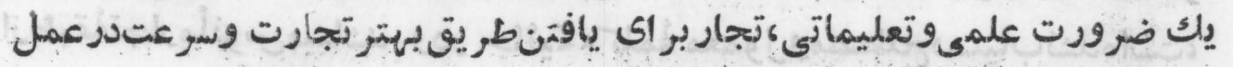

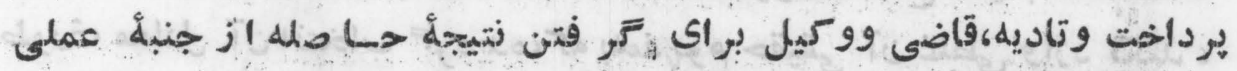

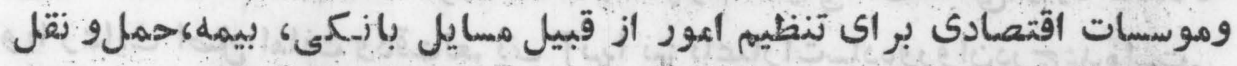
روابط بين كار

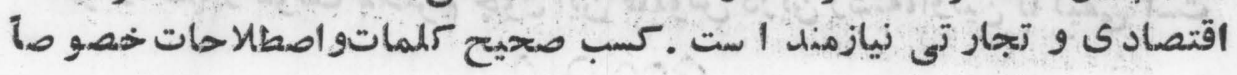
000906 


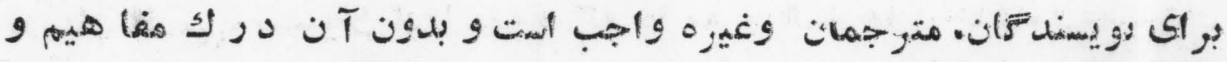

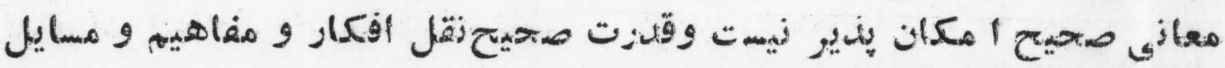

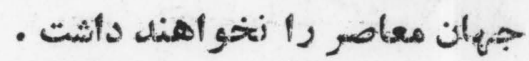

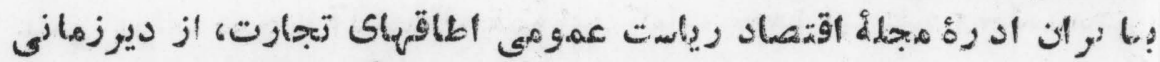

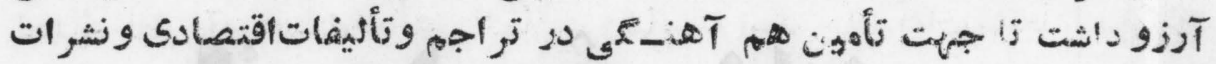

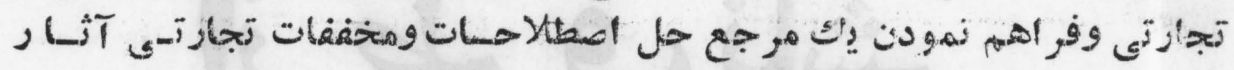

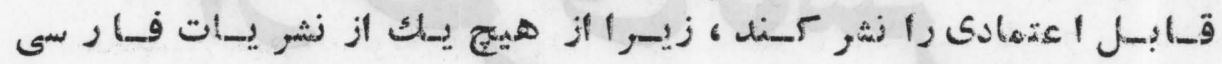

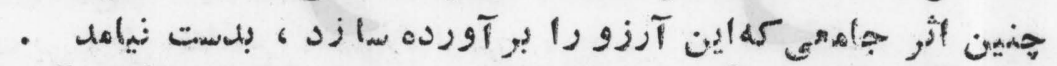

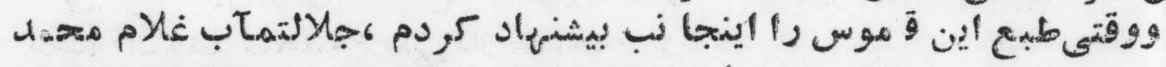

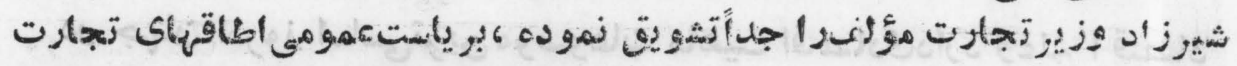

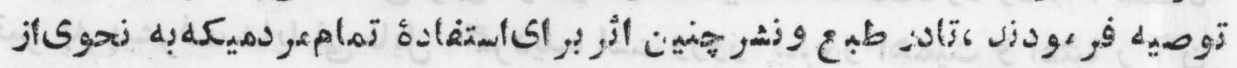

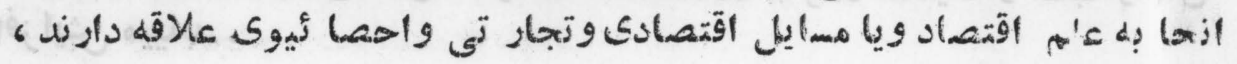

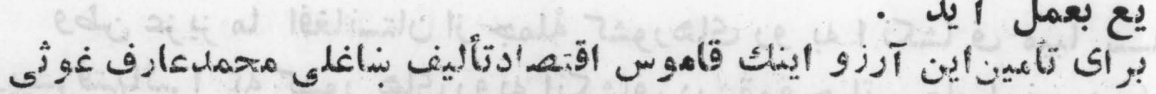

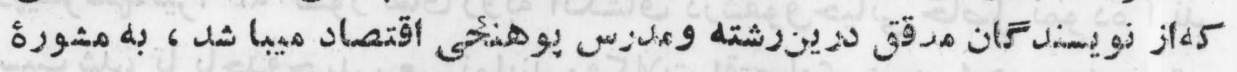

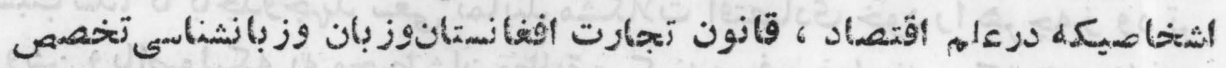

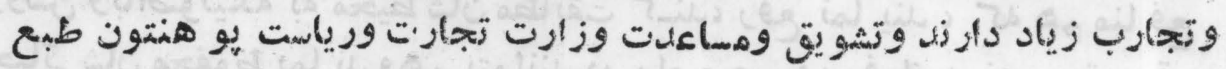

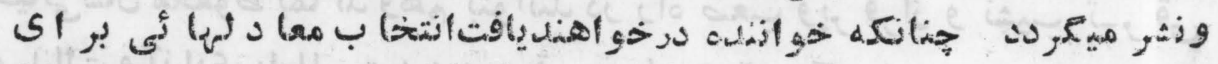

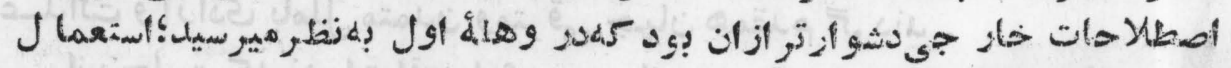

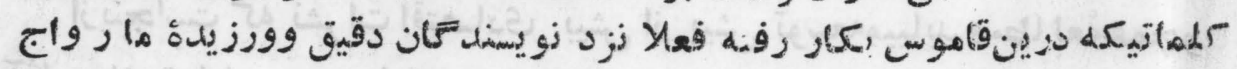

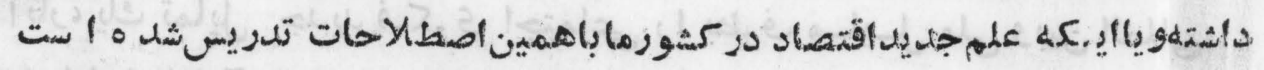

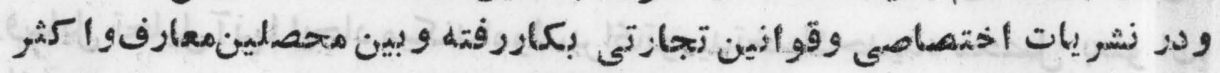

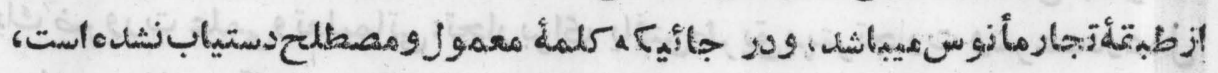

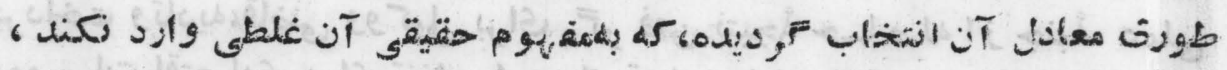

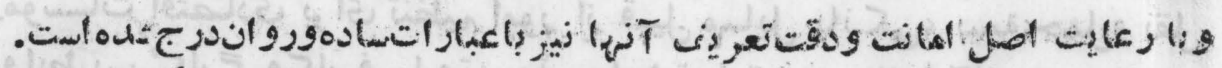

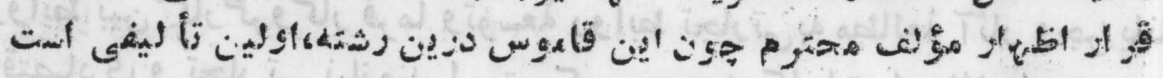

$$
000907
$$




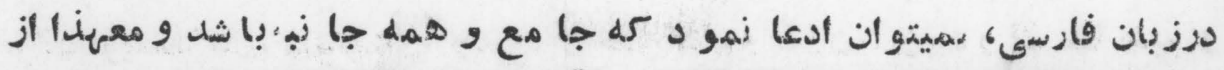

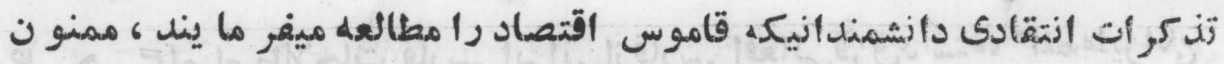

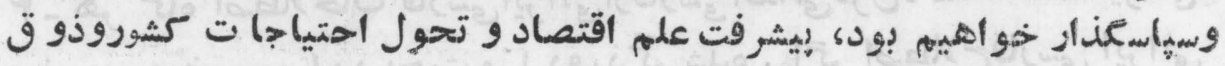

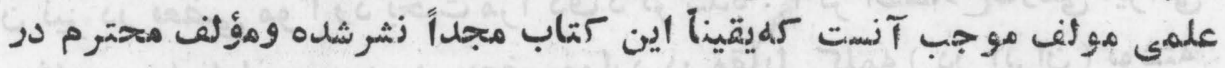

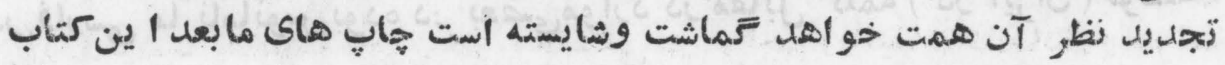

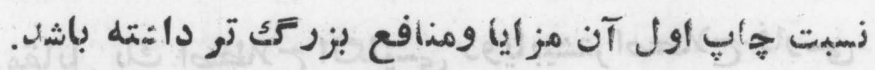

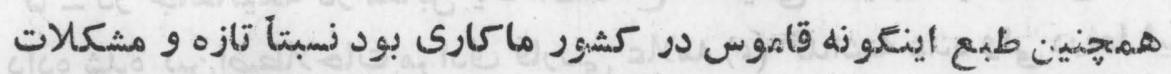

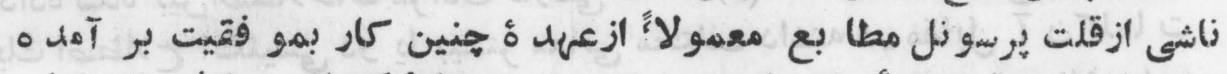

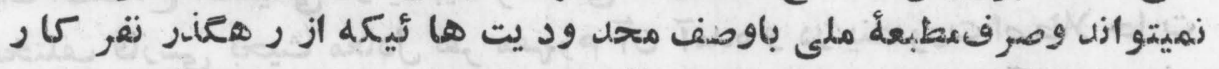

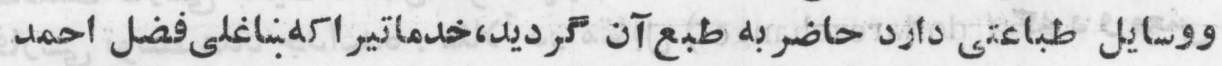

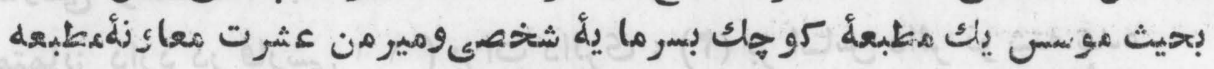

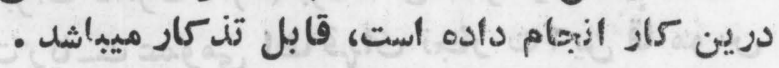

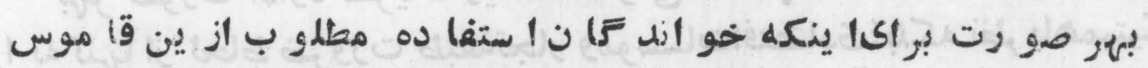

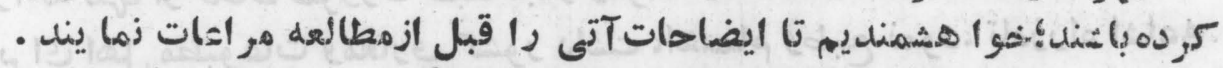

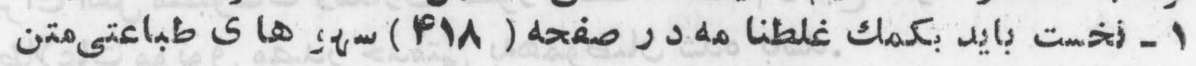

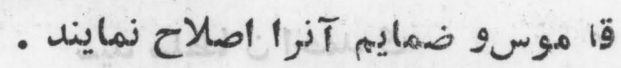

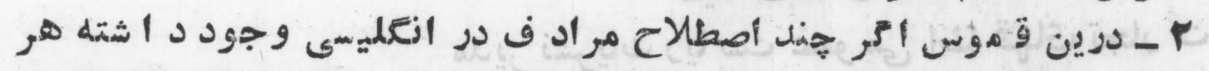

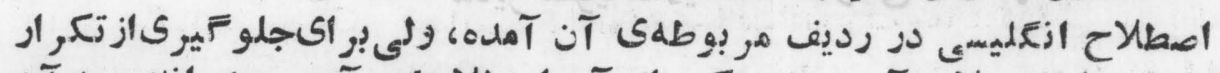

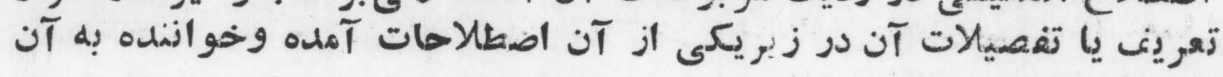

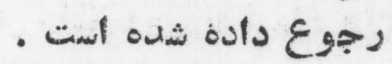

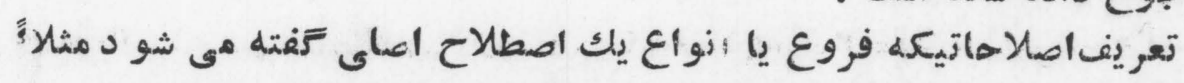

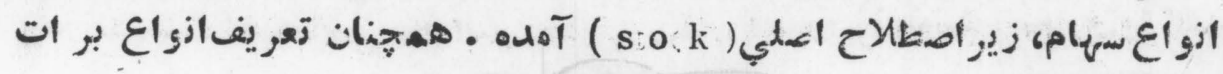
زير ( Bill )

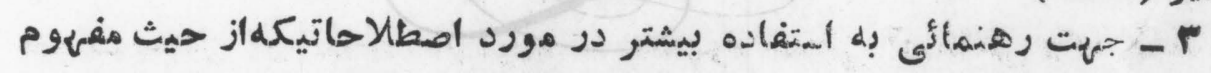

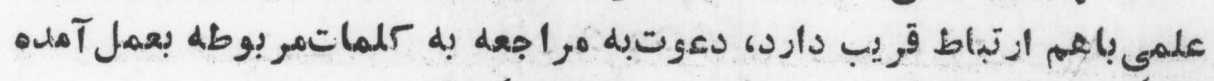

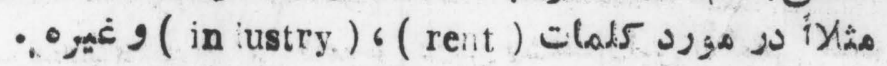
000908 


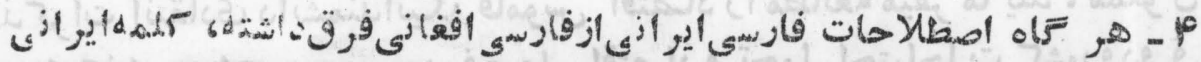

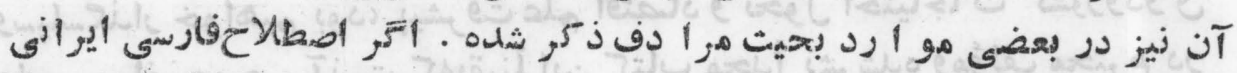

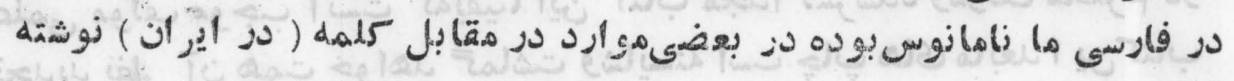
شله .

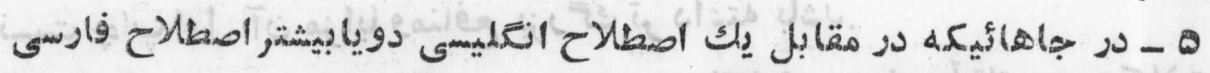

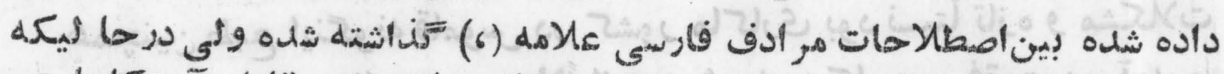

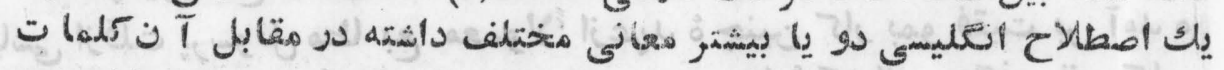

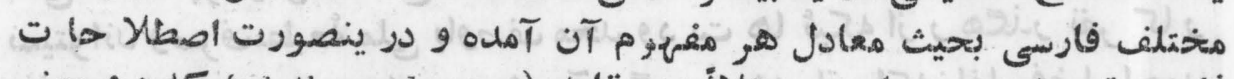

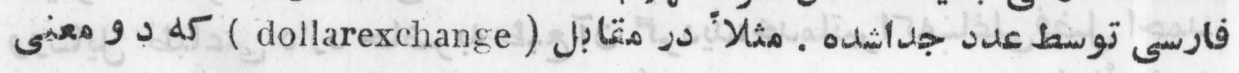

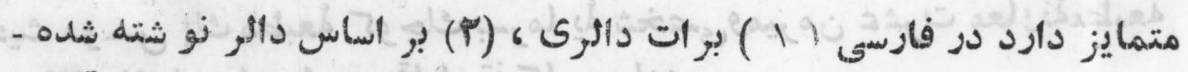

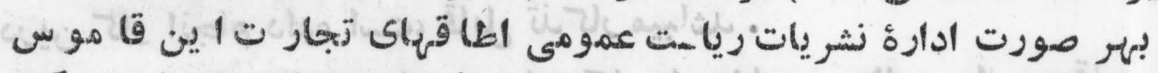

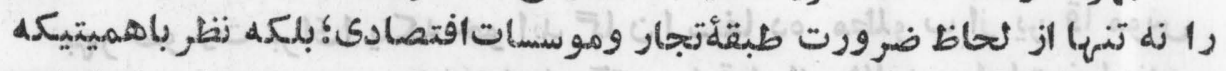

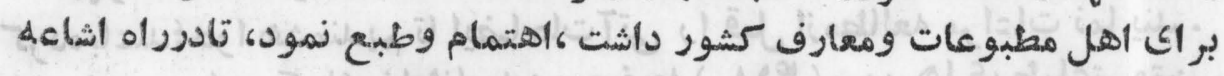

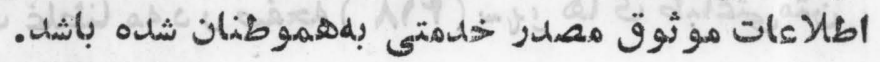

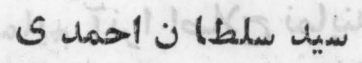

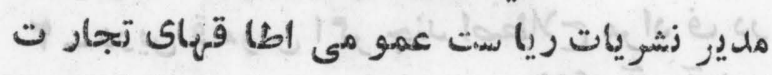

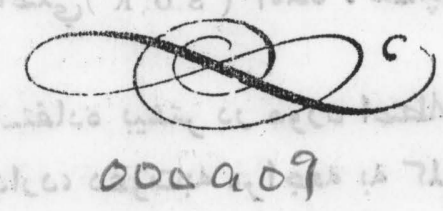


| (متنان

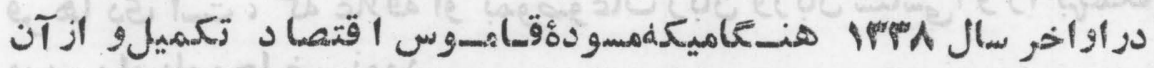

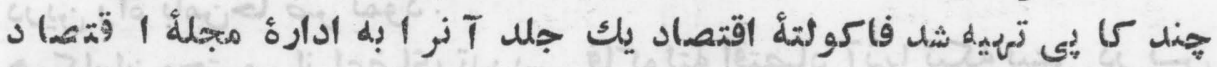

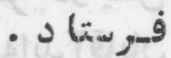
مديو زثر اترياست عمومى اطاقها ى تجارت زويسند ذُ فاضل سيدسلطاناحملى

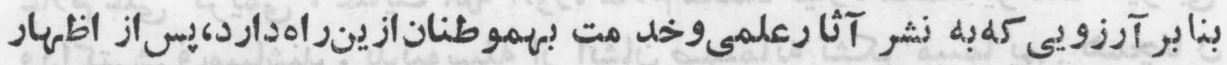

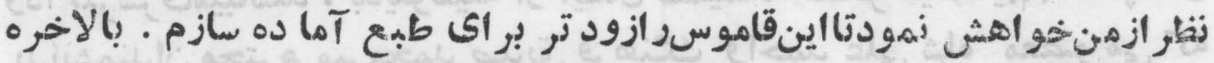

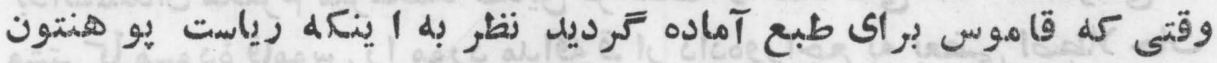

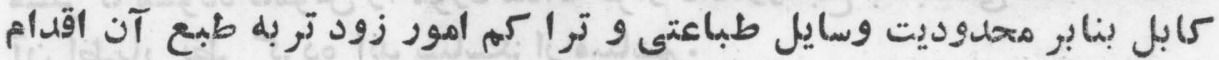

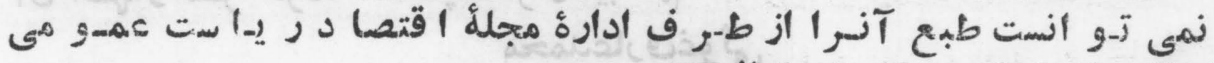

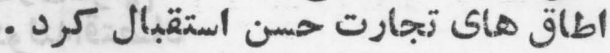

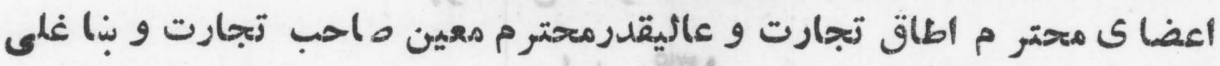

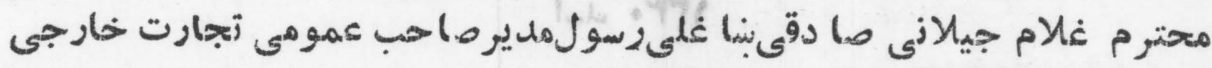

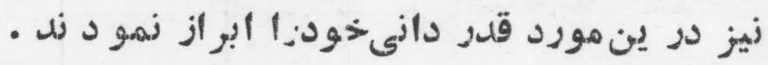

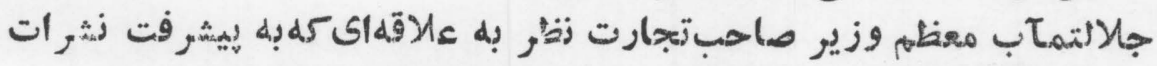

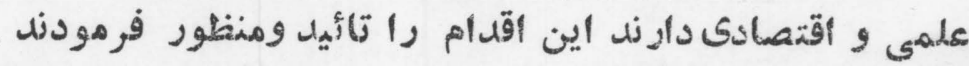

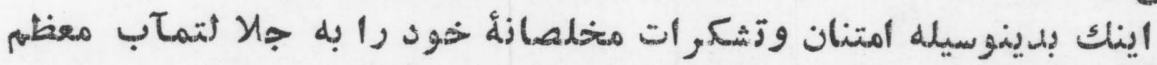

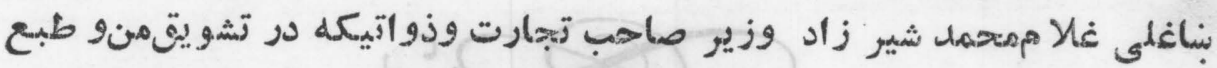

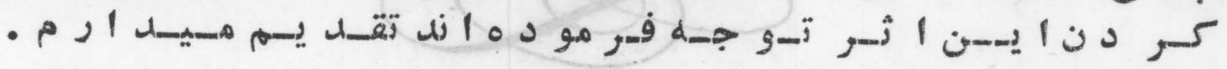

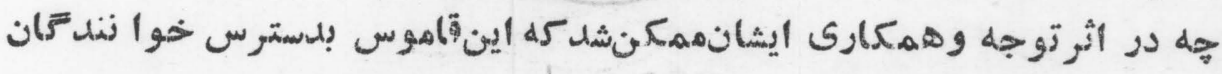

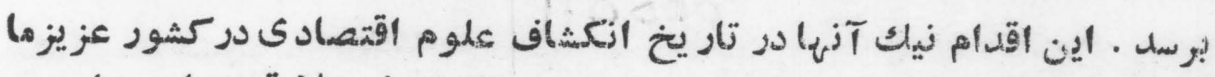

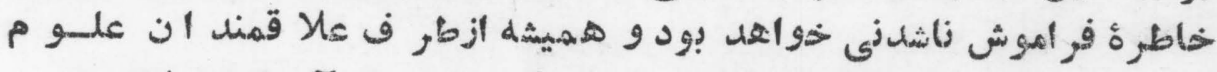

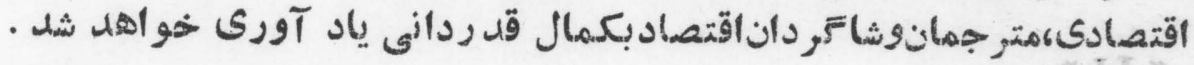

000 a 10 
عاوةًُ درظرف مدتيكه بهتجديدنظر مسوده قاموس مشغول بو دم بعضى

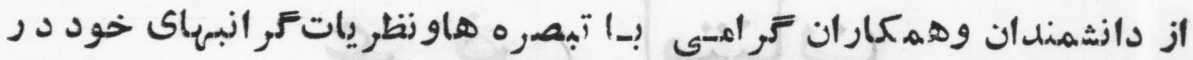

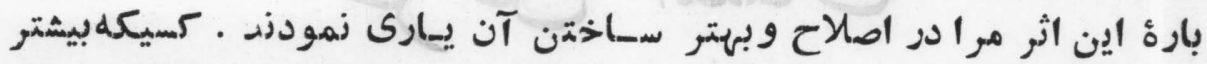

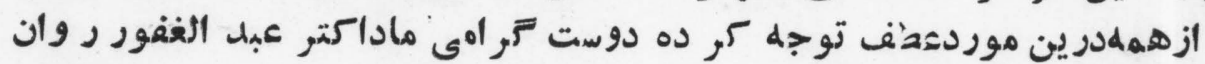

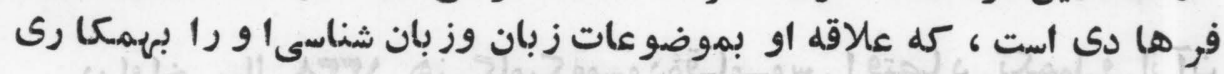

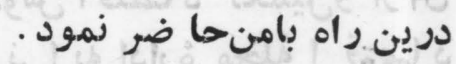

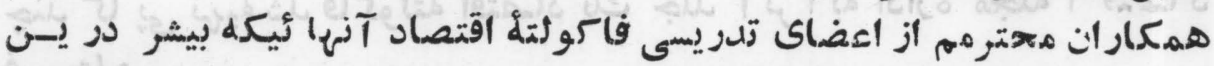

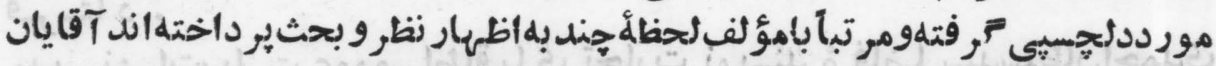

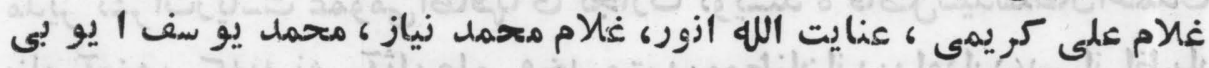

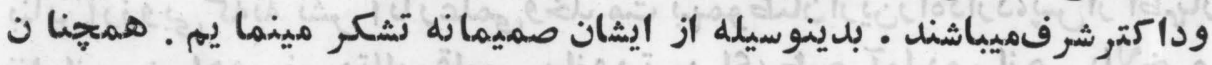

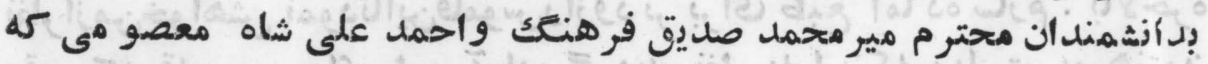

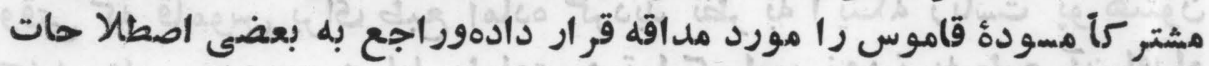

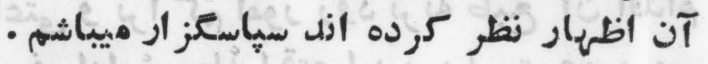

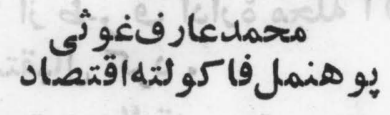

\section{IMP. I I}

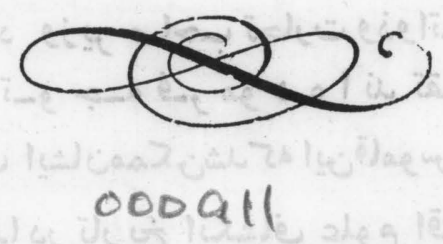




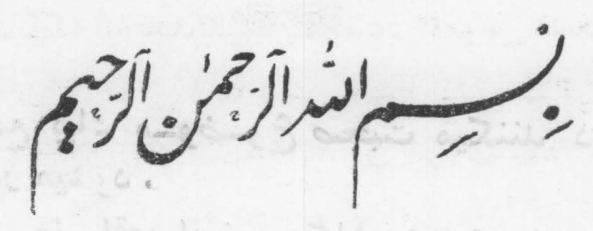

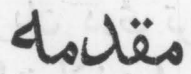

زبان درى بـاوجو د غنا ى كه در اد بيات دا رد از حيث اصطلك حـات

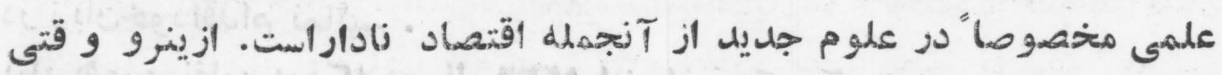

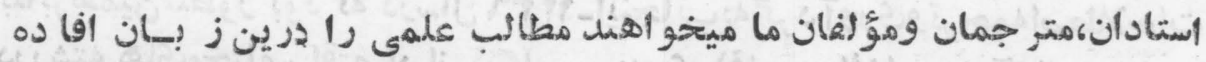

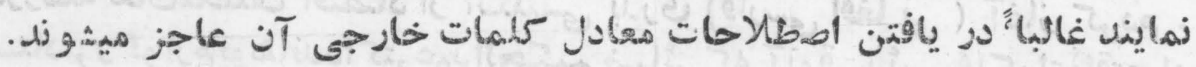

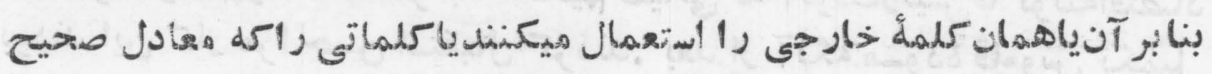

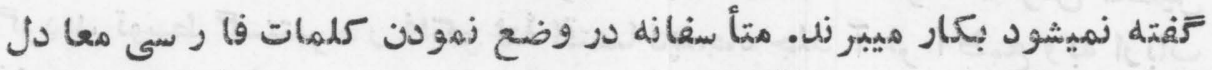

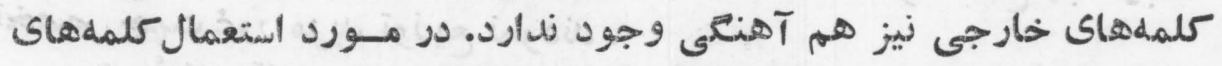

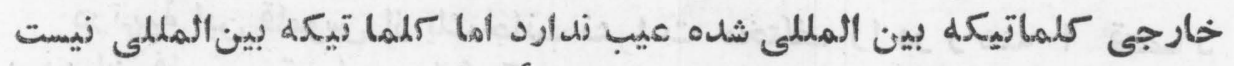

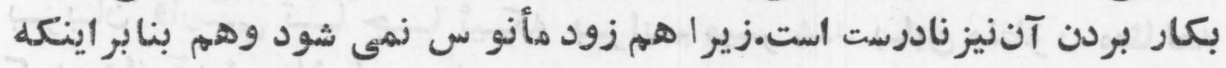

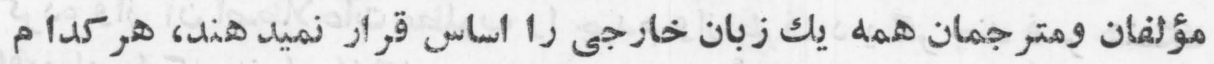

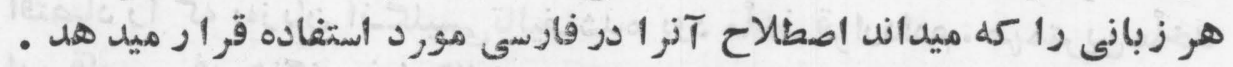

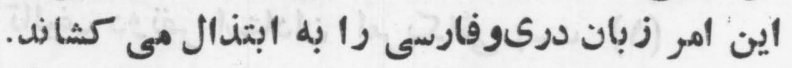

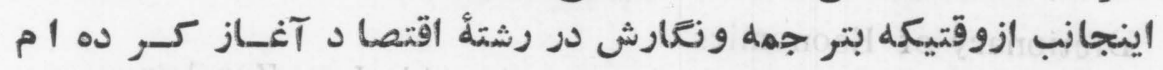

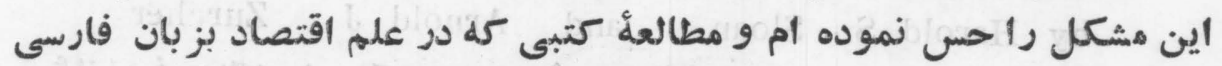

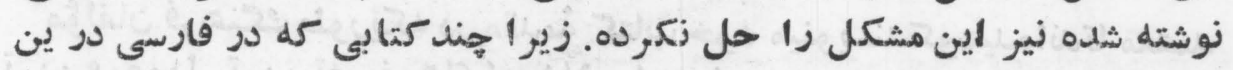

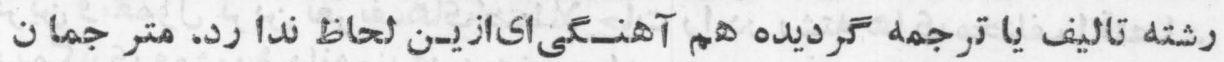

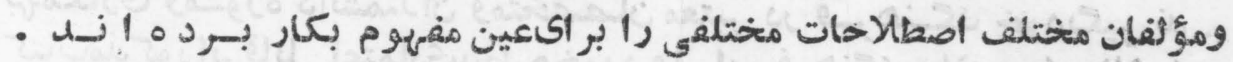

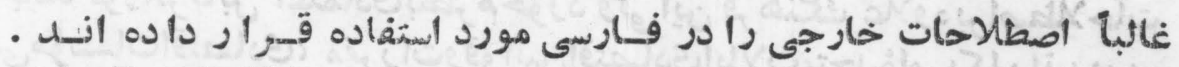

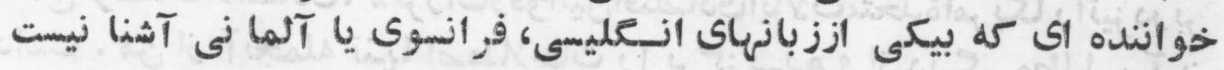

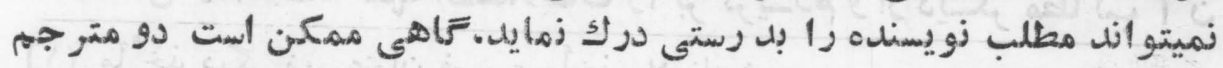

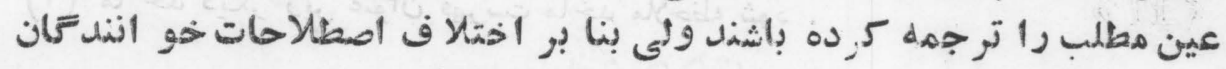

\section{0 a 12}




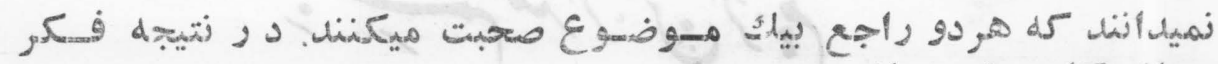

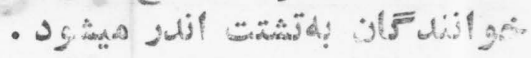

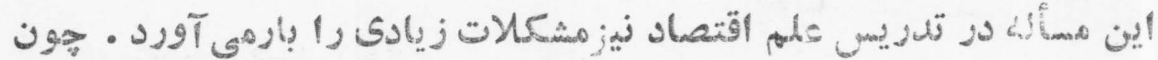

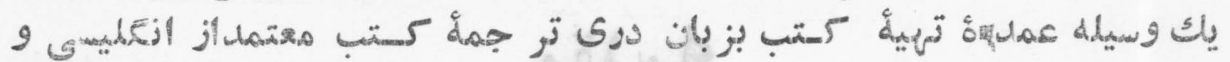

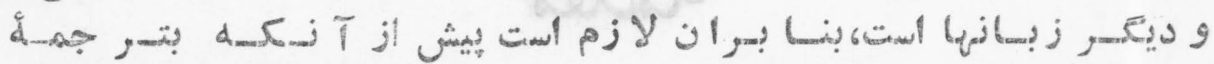

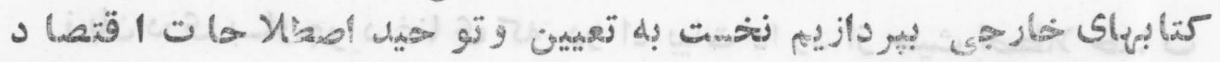
-

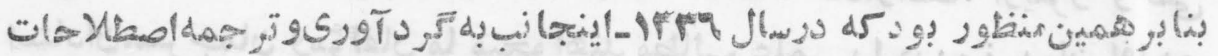

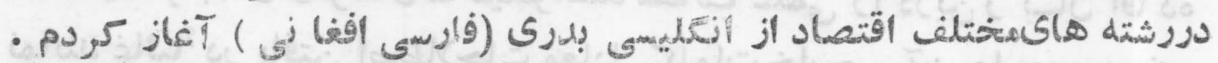

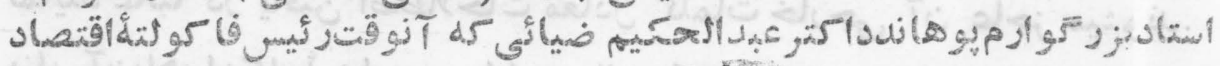

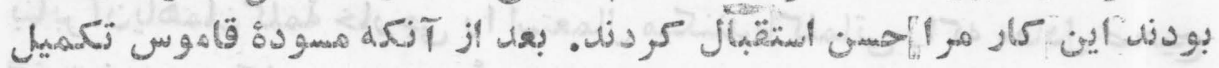

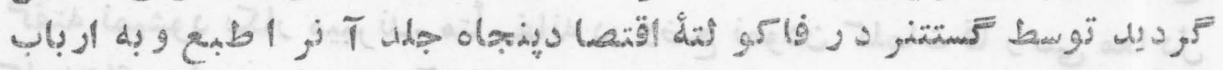

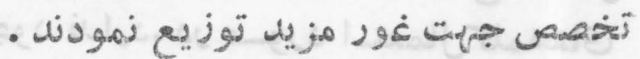

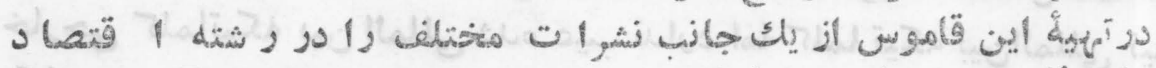

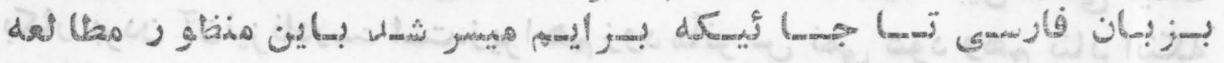

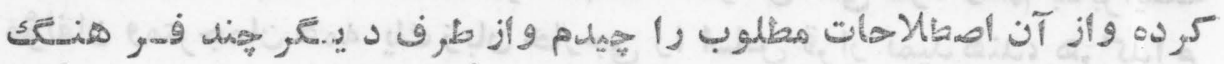

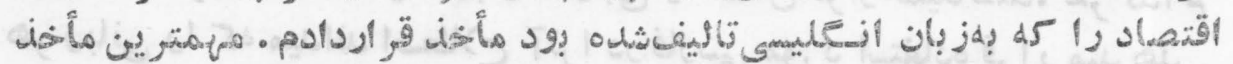

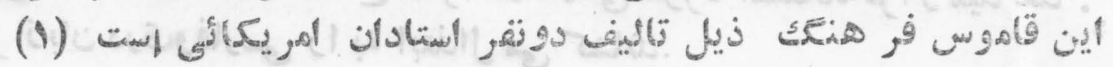
Dictionary of Economics

by Harold S. Sloan and Arnold $J$ Zurcher

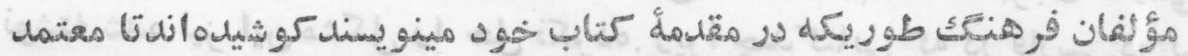

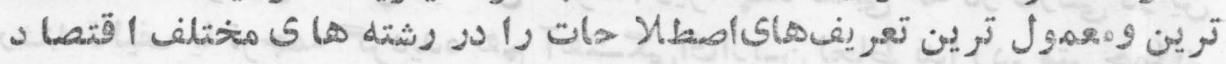

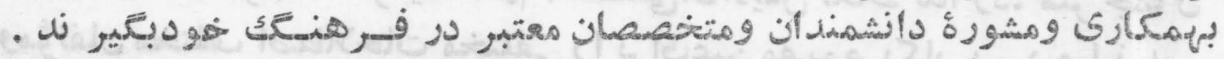

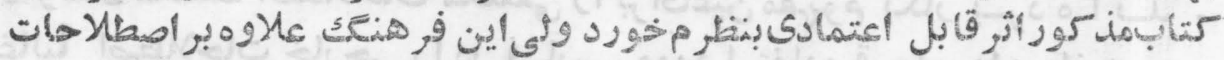

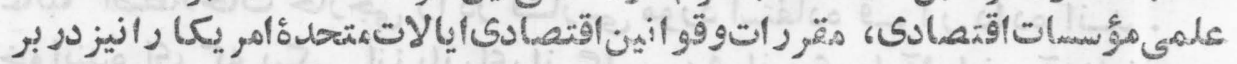

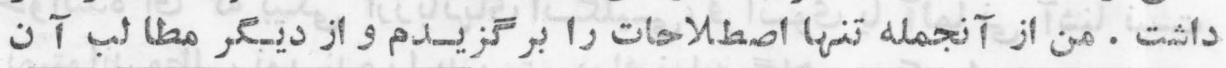

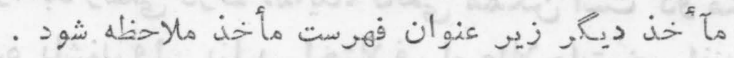

$$
\begin{aligned}
& 000913
\end{aligned}
$$




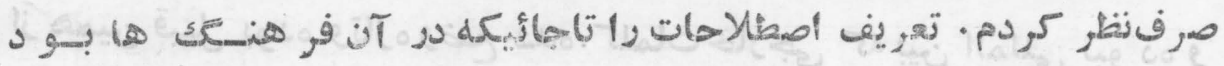

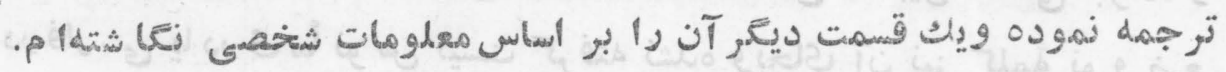

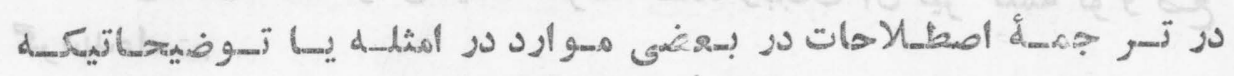

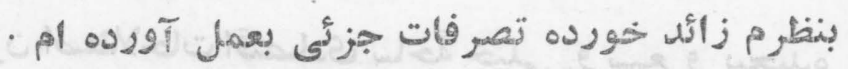

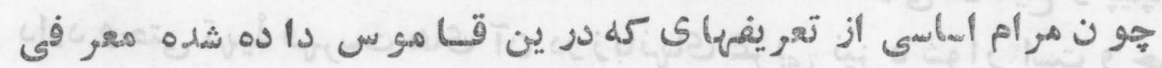

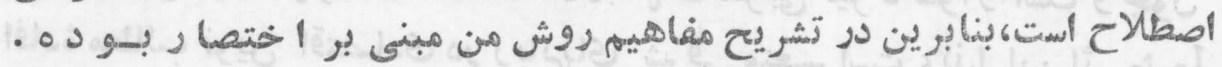

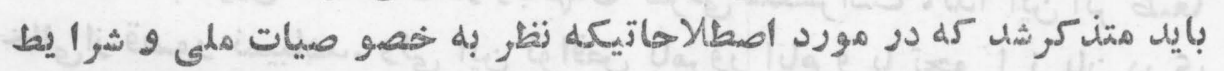

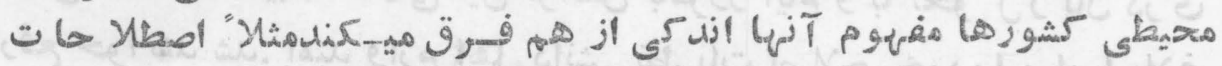

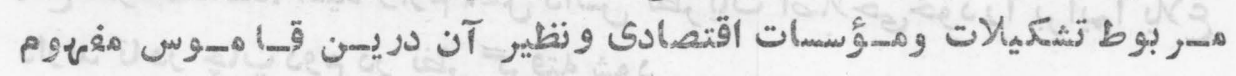

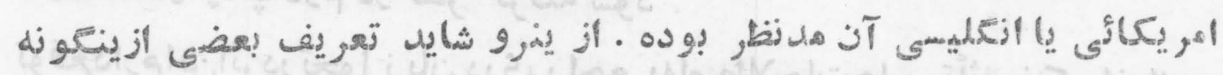

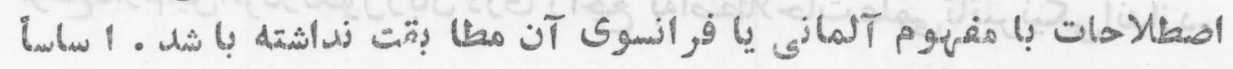

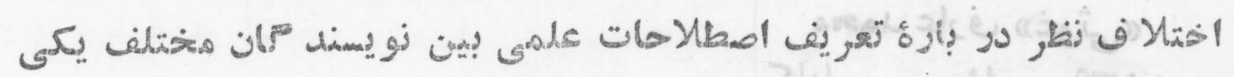

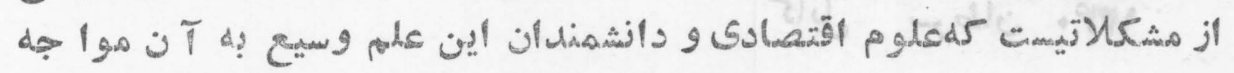

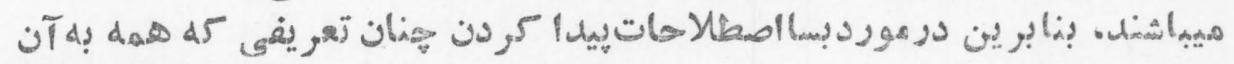

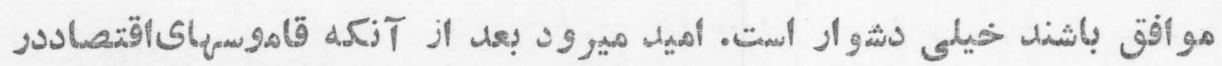

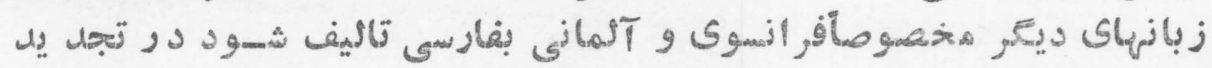

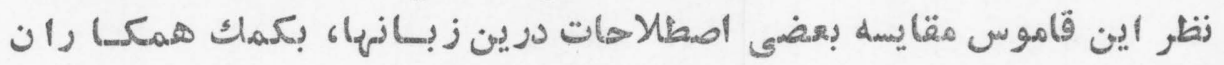

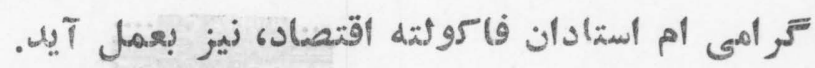

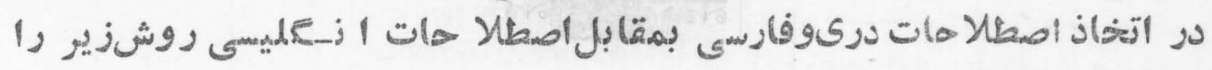

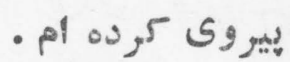

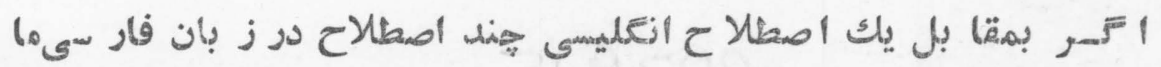

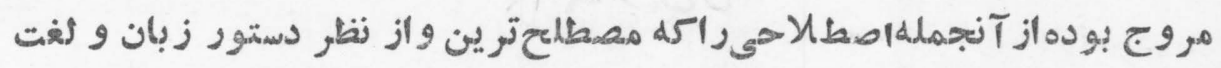

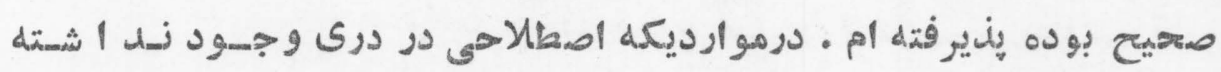

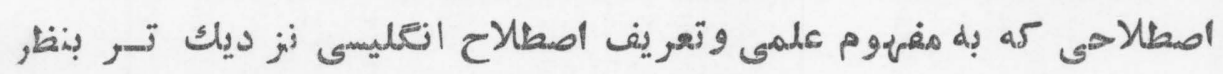
(ج) $000 a 14$ 


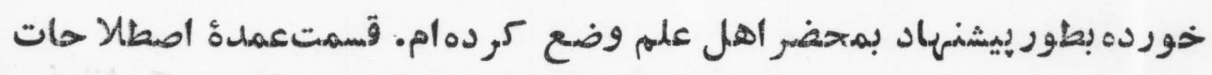
از همين قبيل بوده وتازه وضع شده.كلمات >ارجى كاه بين المهلملى نبو ده و

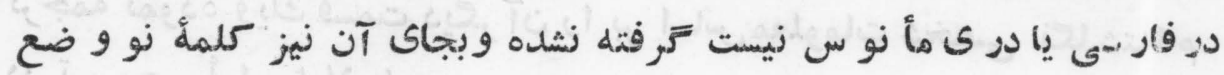
توديل دواست

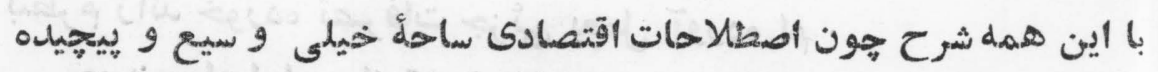

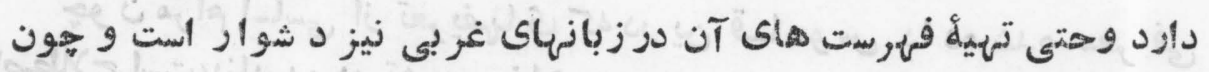

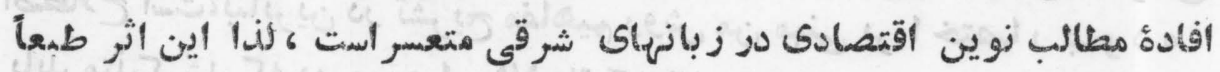

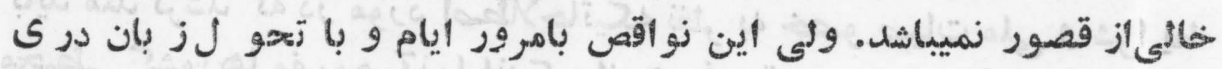

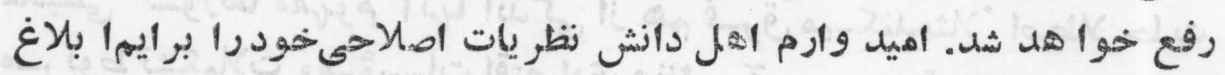

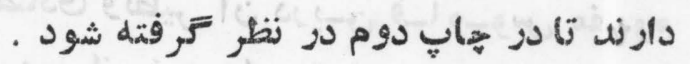

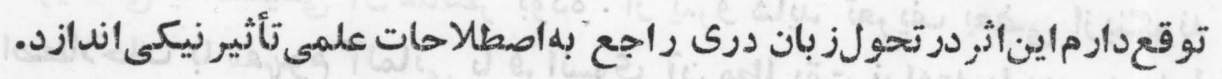

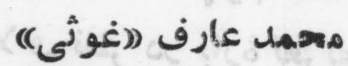

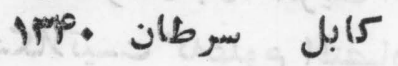

\section{5}




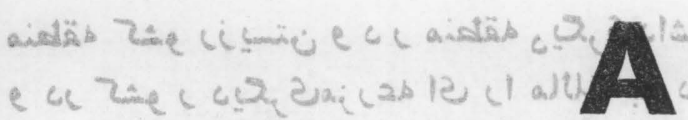

abondoned merchandise. $\quad$ gी

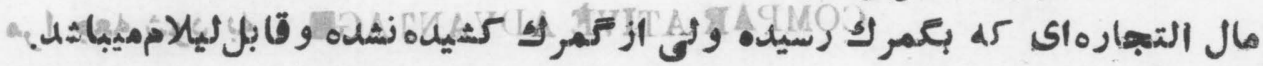
abatement $\oplus$ is o

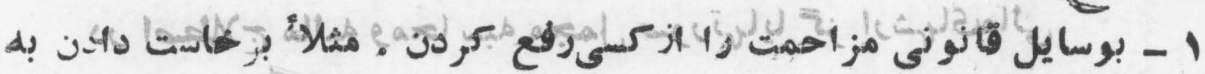

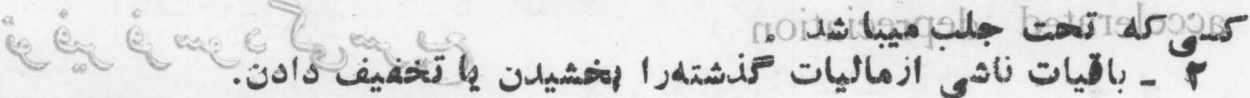
fability -to-pay priniple of taxation.

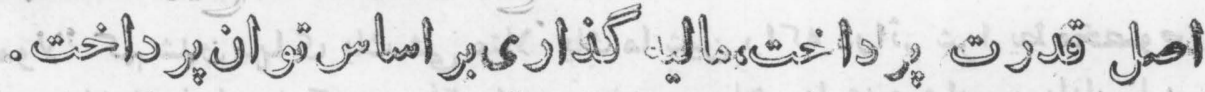

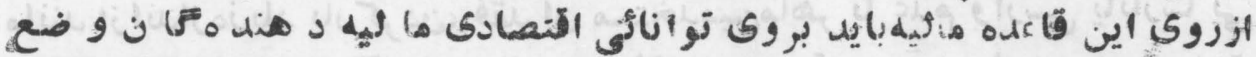

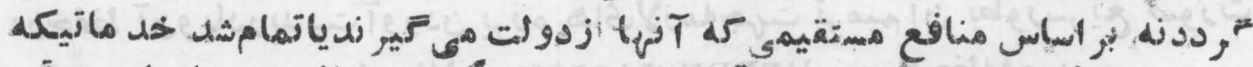

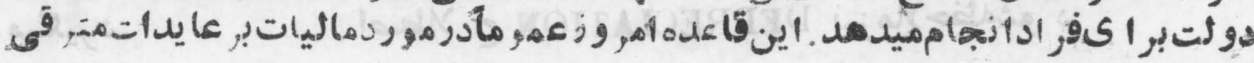

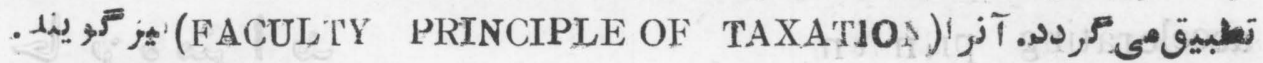
abrasion ( of coin)

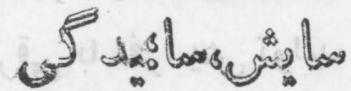

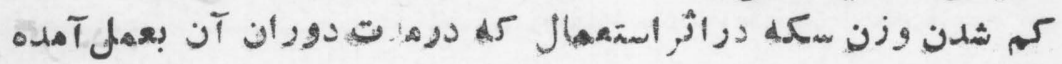

absenteeism rate

$$
\because 1 \ldots+\infty \underbrace{\infty}_{0}
$$

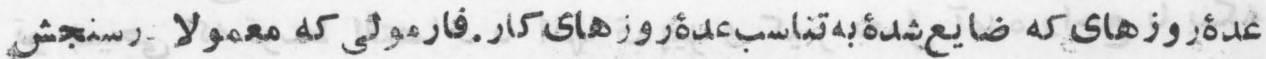

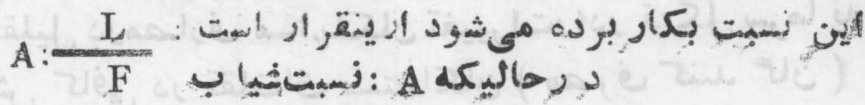

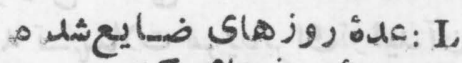

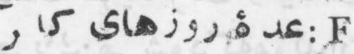

absentee ownership.

A I I

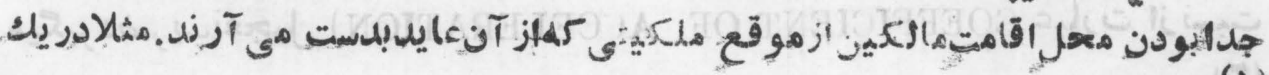




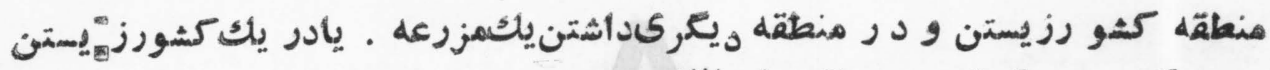

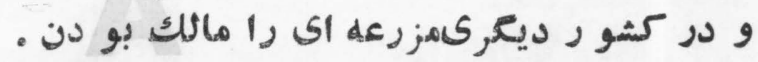

absolute advantage

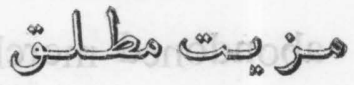

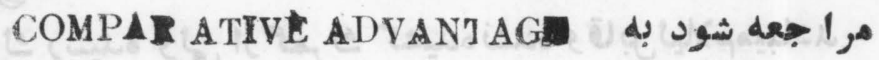

abstract

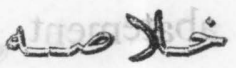

در اصطالاج ماليه ومهحا سبه مجمل صورتهايا تز ارشهاىمالى accelerated depreciation

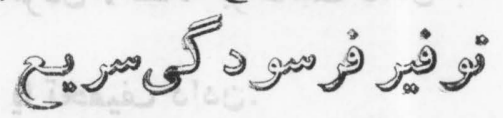

LP. C C

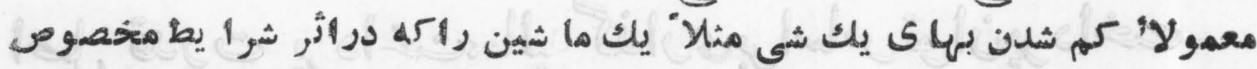

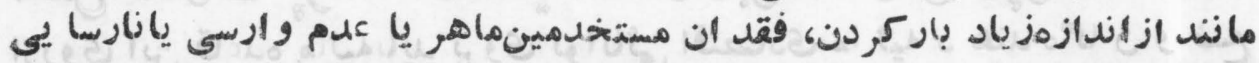

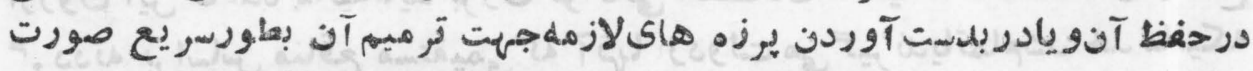

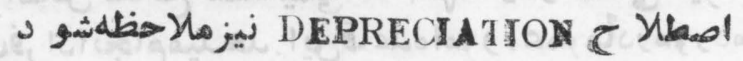

ميغيرد. - مئ.

accelerating punin $\mathrm{n}$

له

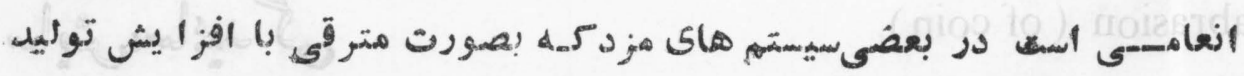

acceleration principle

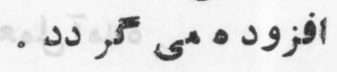

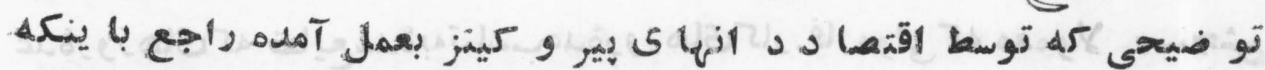

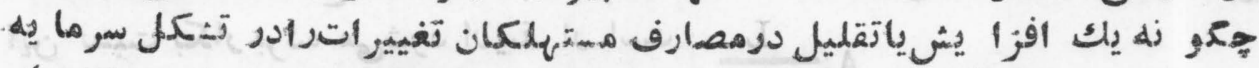

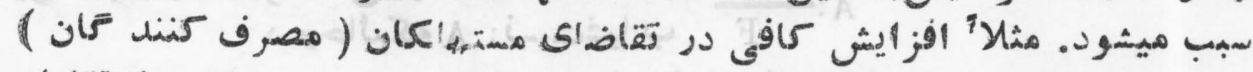

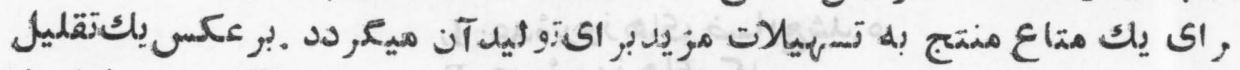

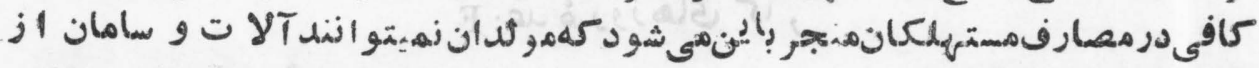

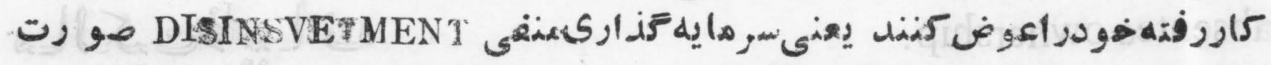
ميعير دضر يبتعجيل COEFFICIENT OF A( CELERATION) عبارت از نسبت (F) 


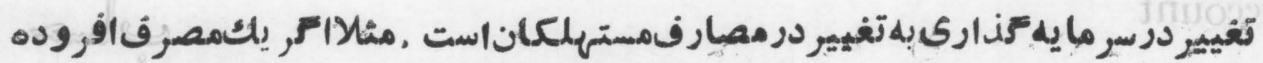

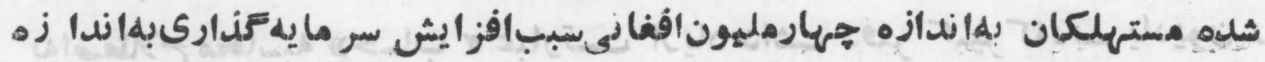

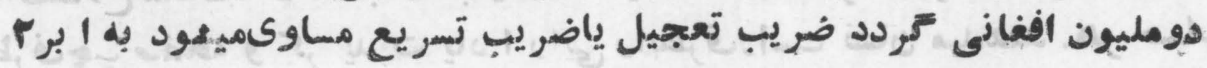
acceptance

$$
\text { ه }
$$

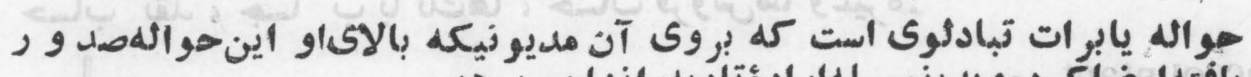

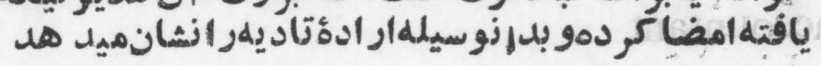

acceptance houses

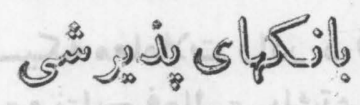

بإنكهاى كلهبر وات وسفته هاىتجاروموسسات كو هاكاقتئادىراقبولىهينويسد acceptance bill

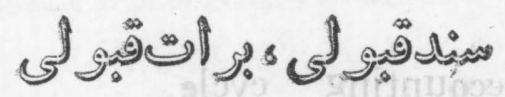

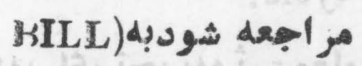

acceptance supra protest

$$
\text { जी }
$$

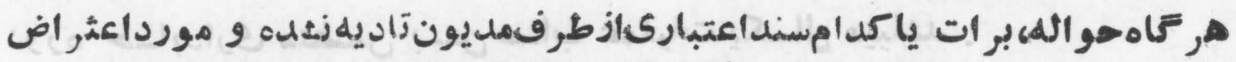

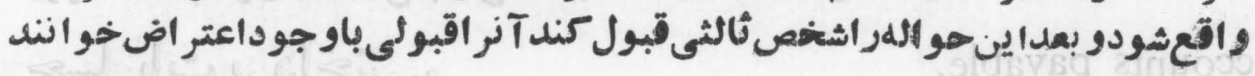
accessorial services

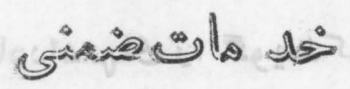

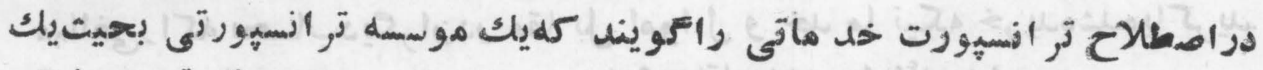

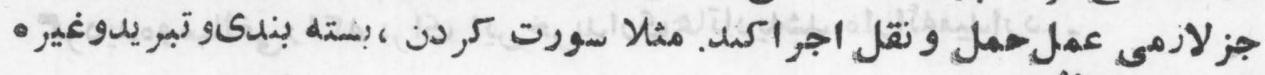
accident insurance

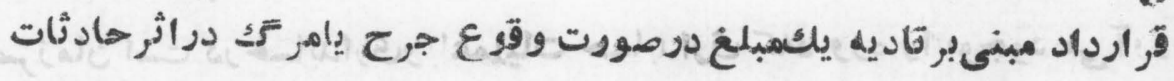
acrommodation paper

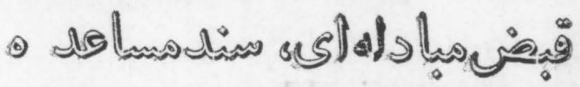

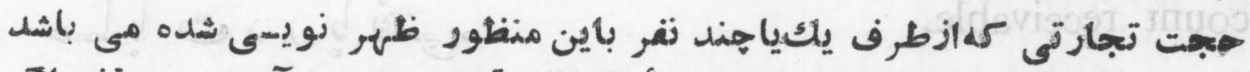

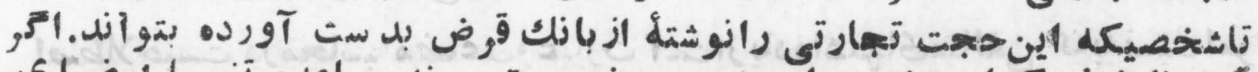

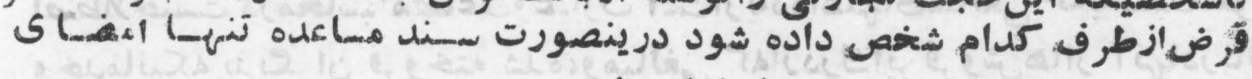

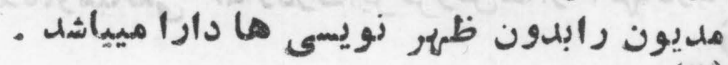


account

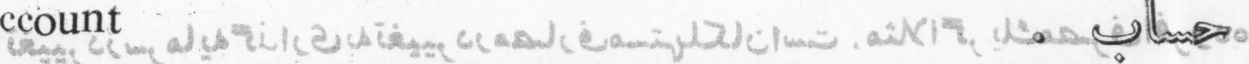

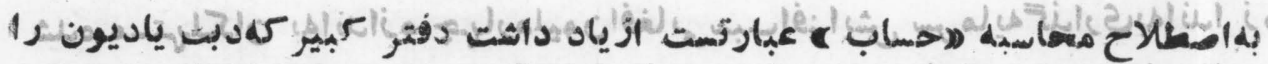

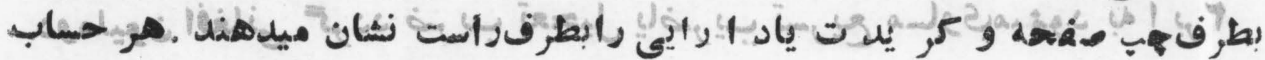

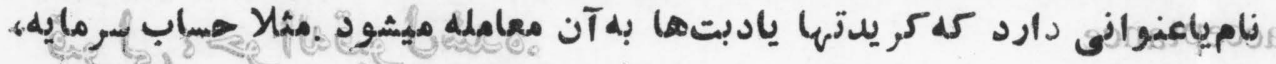

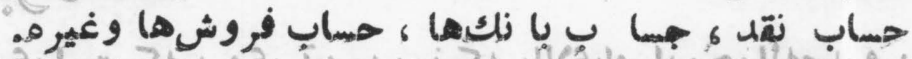

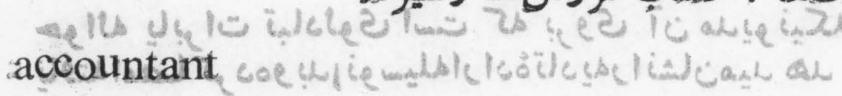

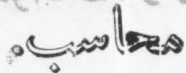

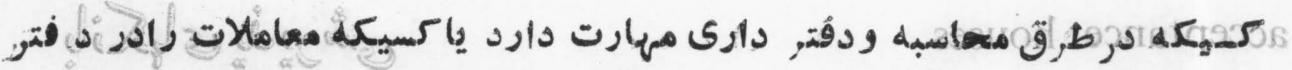

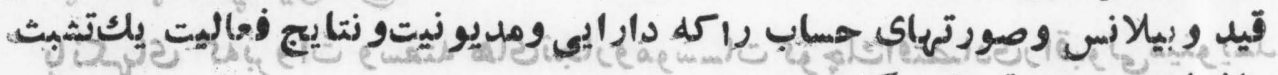
accounting cycle.

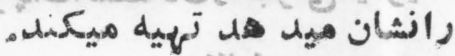 (S)

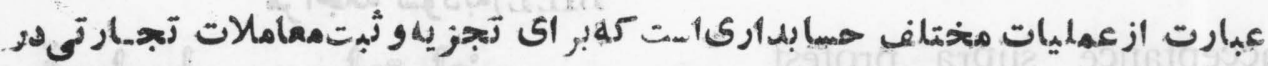

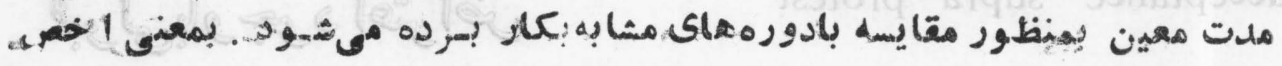

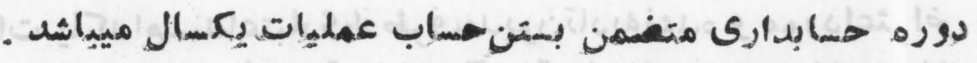
accounts payable.

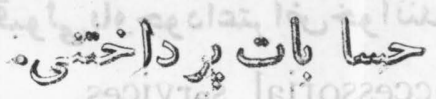

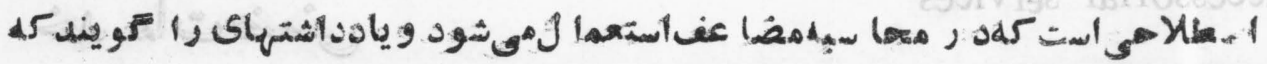

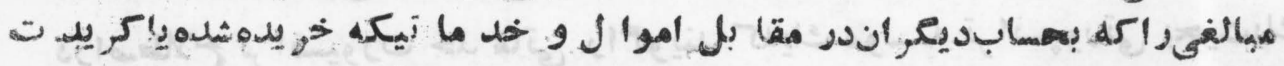

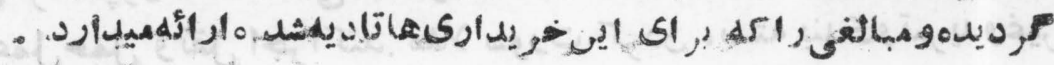
accounting period.

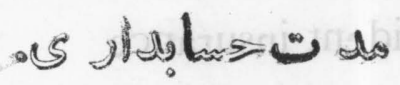

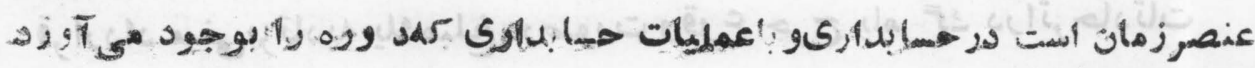

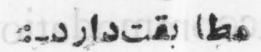

account receivable. a

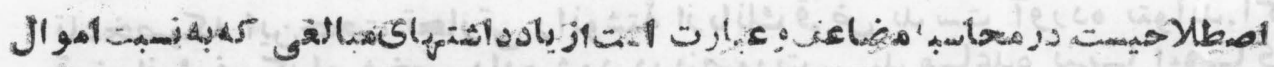

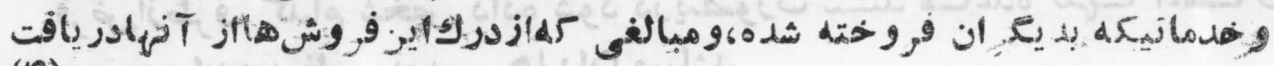
(P) 
accrual basís

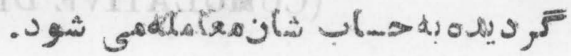
C5

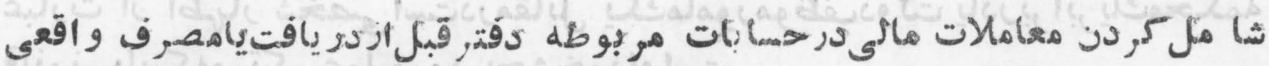

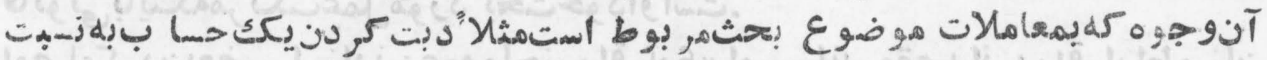

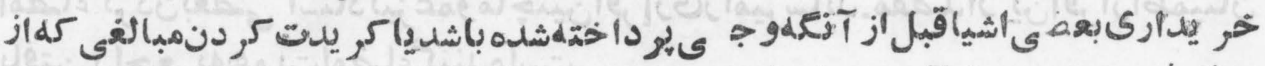

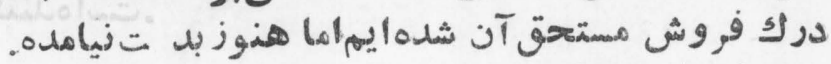

aecrual mothod of accounting •L

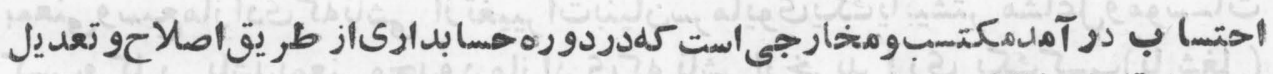

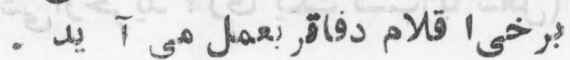

accrued interest

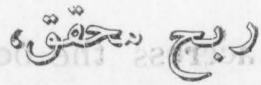

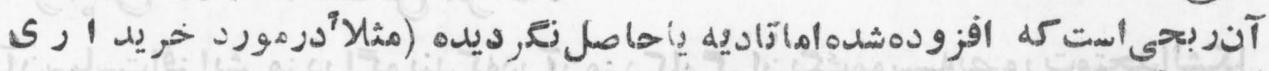

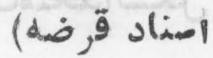

accrued items

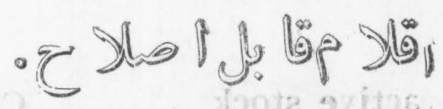

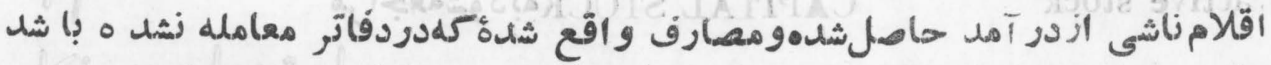

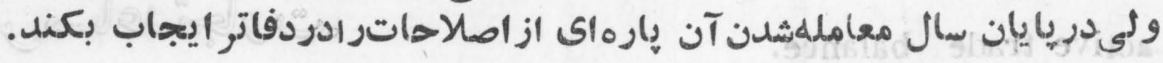
accumullated dividend In

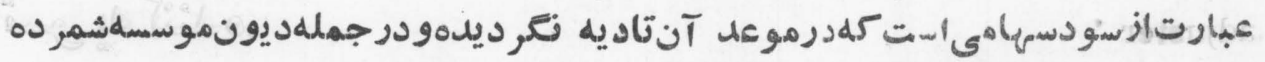

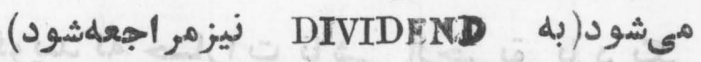

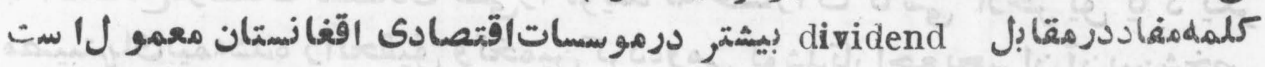
accumulation

$$
\text { - }
$$

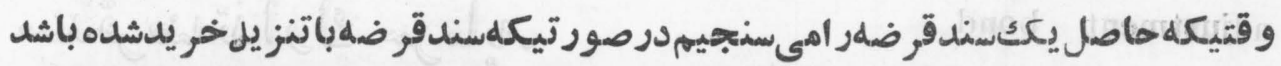

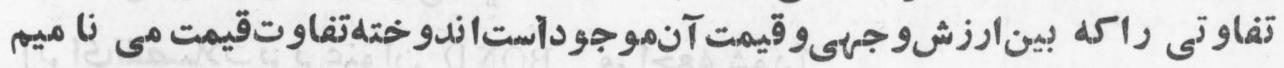
accumulative dividend

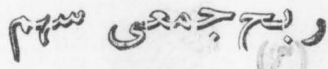


(CUMULATIVE DIVIDEND (براىتوضيحاتمر اجعهشو دبd)

acknowledgment.

की

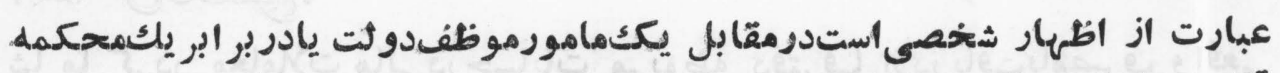

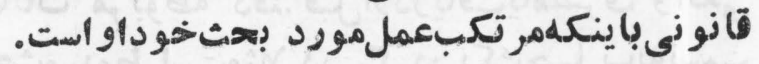

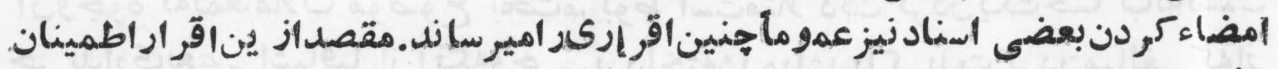
يافتن راجع بهاء كردويتامضاء كنندهاست. acquired surplus.

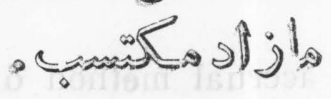

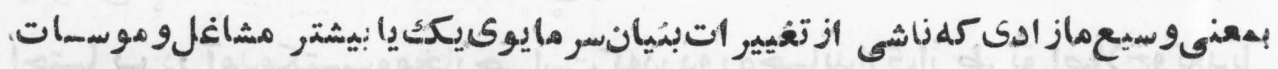

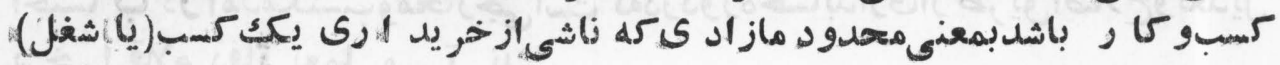
توسطكسب ديكر باشدز.

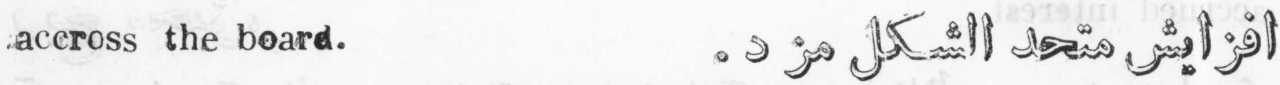

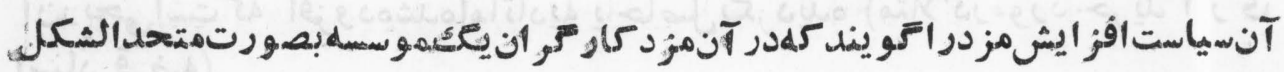
زيادمه نوده.

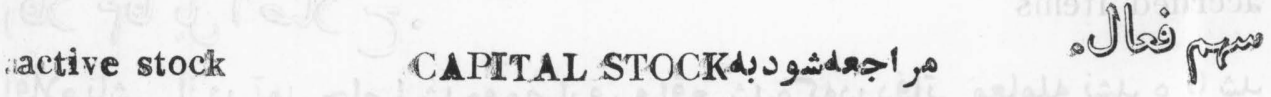
active trade balance.

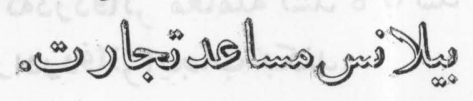

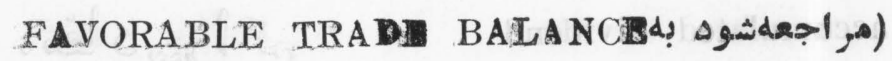

adjuster •

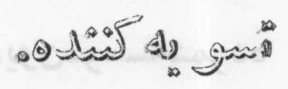

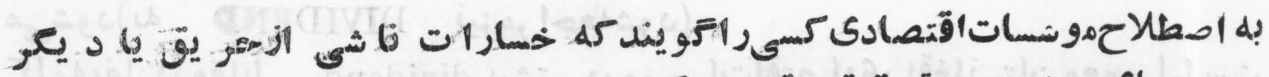

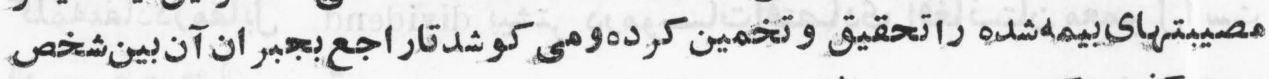

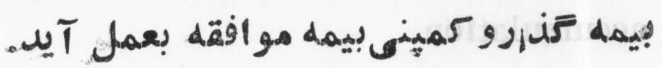

adjussment bond.

$$
\text { م }
$$

(!واىتغصيلات بزيو عنوان BOND ) 
administered price

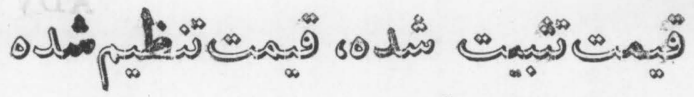

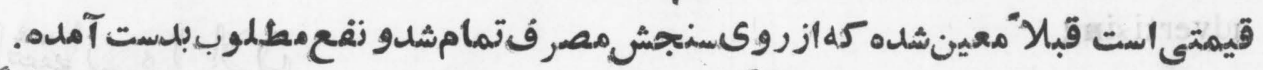

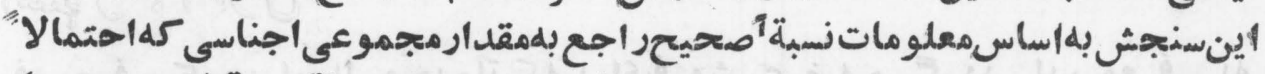

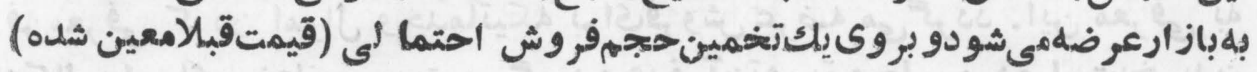

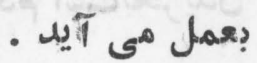

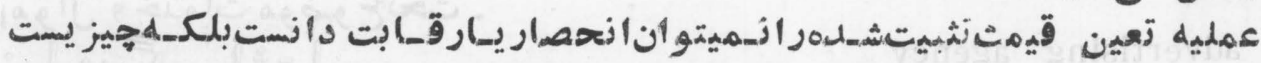

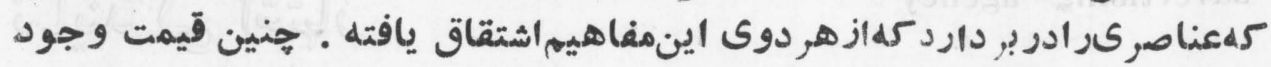

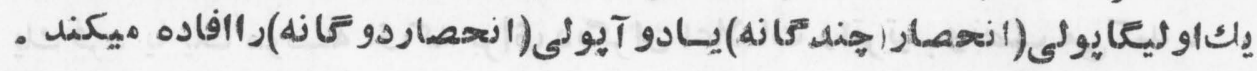
administrator.

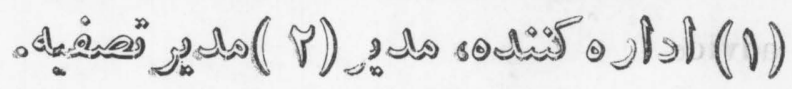

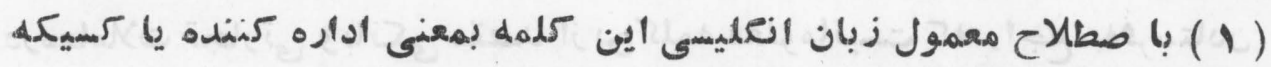

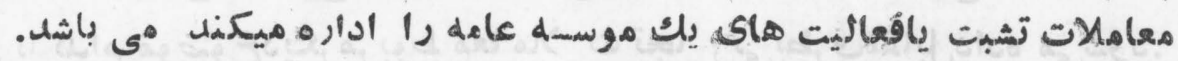

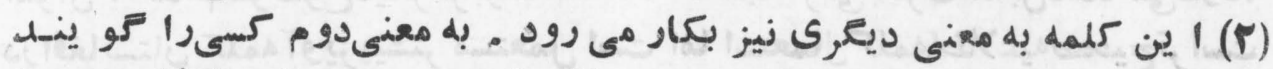

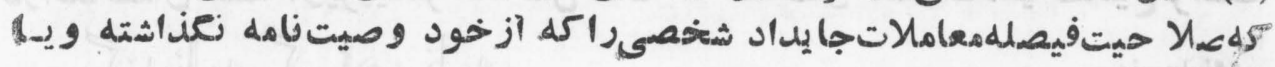

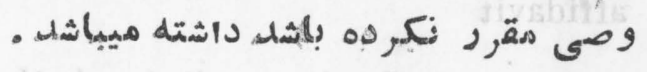
admission temporaire.

$$
\text { (2922) }
$$

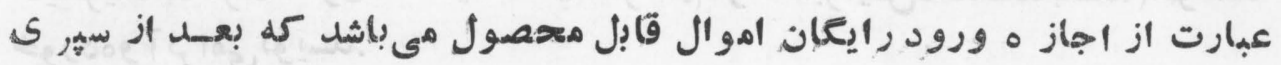

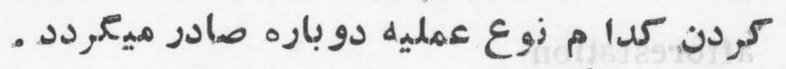
advalorem duty .

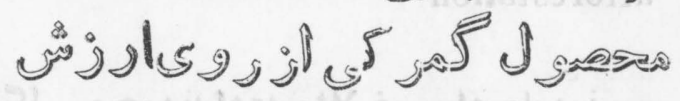

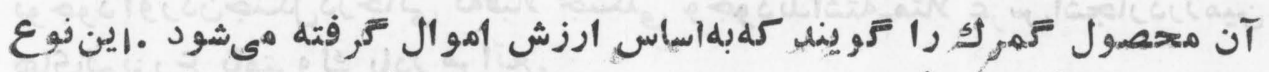

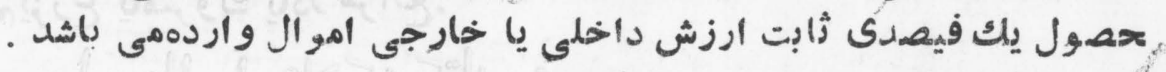

advance.

$$
\begin{aligned}
& \text { ه } \\
& \text { إكقرض }
\end{aligned}
$$

advance bill.

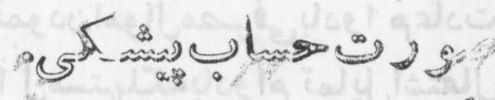




\section{ADV}

advertising

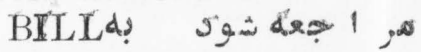

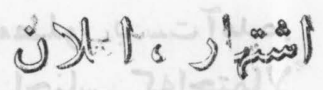

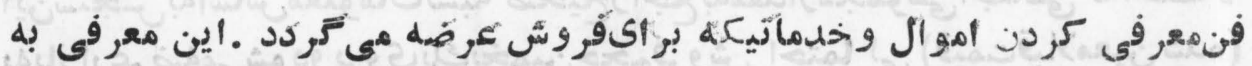

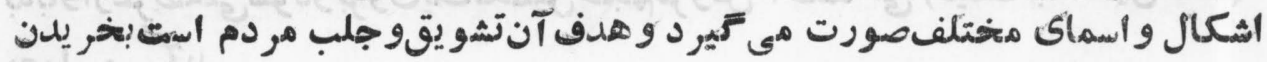

advertising agency

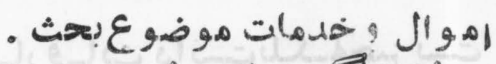

$$
\begin{aligned}
& \text { ) }
\end{aligned}
$$

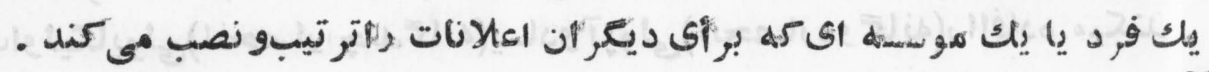
advice

$$
\text { a. }
$$

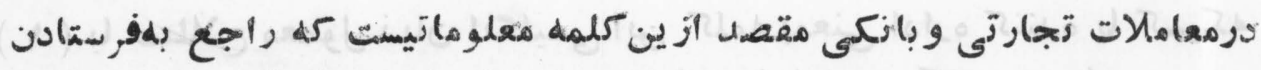

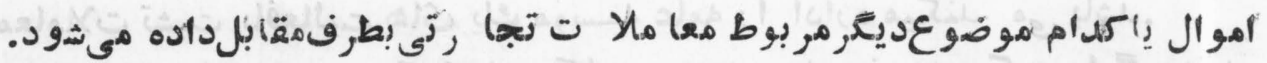

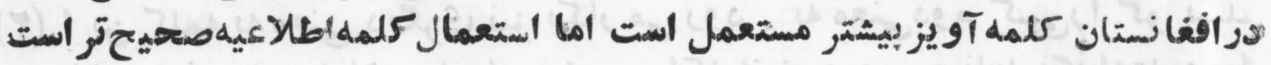
affidavit

$$
\text { ه }
$$

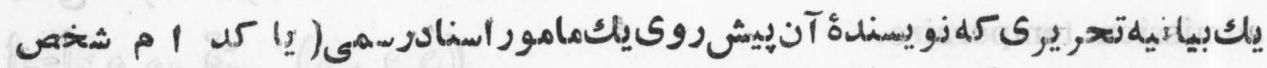

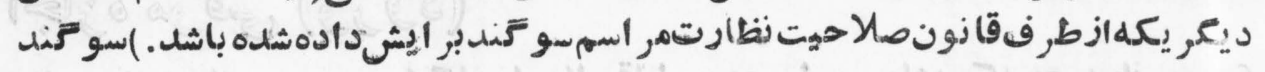

afforestation

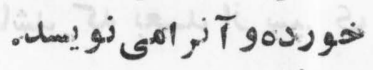

$$
\text { as i lis }
$$

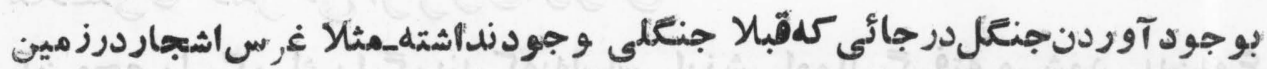

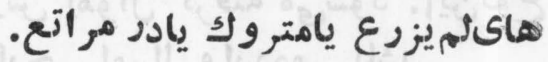
age of high mass - consumptions g ons

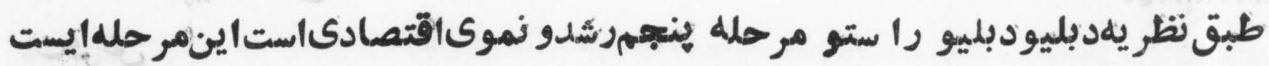

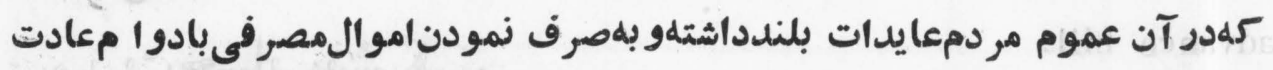
Fر فتهميباشندوشقو قمهم|اقتصادنيز بلهتوليداموا ل لمستهلكهلبادو ام تمايل اشتفال (A) 


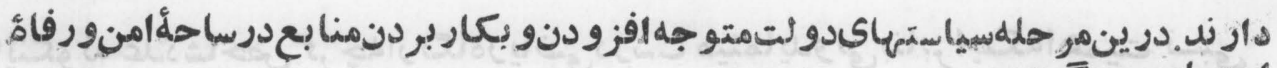

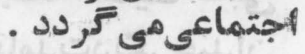

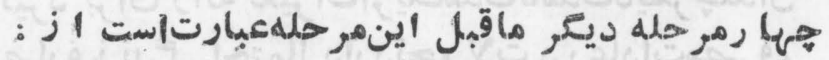
1- THE TRADITIONAL SOCIETY.

2- THE PRECONDITIONS FOR TAKE - OFF。 3- THE TAKE - OFF

4- THE DRIVE TO MATURITY.

agent .

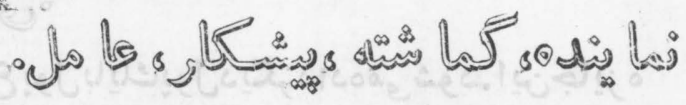

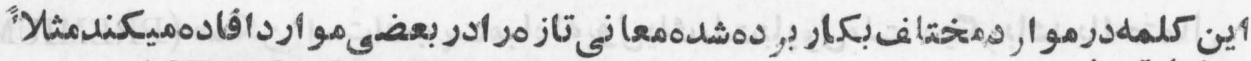
AGENTS OF PRODUCTION.

AGENT AND PRINCIPAL. عو امل توتو ليد

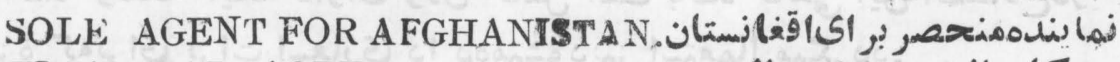
FINANCIAL AGET.

aggregate corporation.

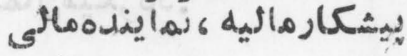
ه

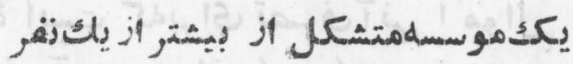

aggregative index numder. NG\%

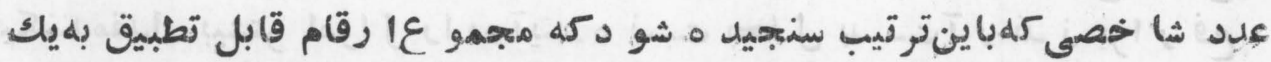

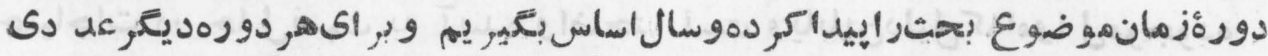

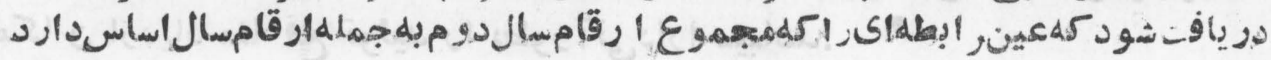
مارابابثد.

\begin{tabular}{|c|c|c|}
\hline \multicolumn{2}{|c|}{$ت$ lo } & \multirow[b]{2}{*}{ م2101 } \\
\hline 1981 & 194. & \\
\hline 1. & 9 & al \\
\hline$\varphi$ & (2) & ب \\
\hline 8 & $v$ & c \\
\hline Pr & $P$ & $\varepsilon, 0,0$ \\
\hline $1.960 \mathrm{P}$ & 1.0 & $a>6$ \\
\hline
\end{tabular}




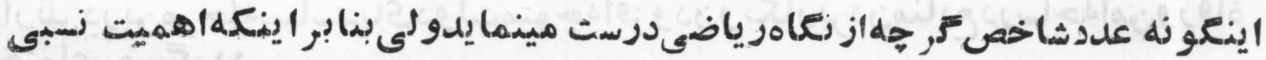

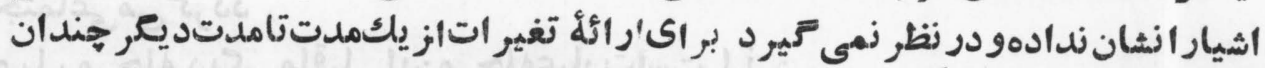

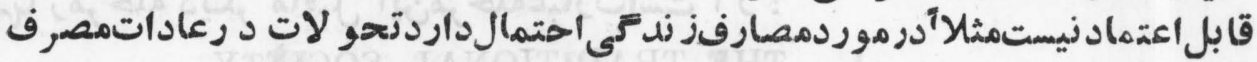

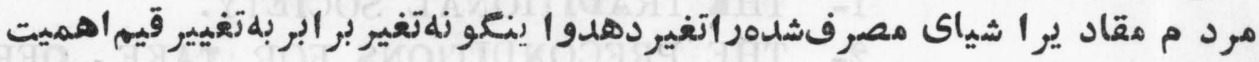
دارد.ازينوو يكك شا خصص ئرض يبدار بهتر است.

agio.

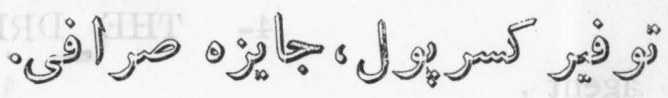

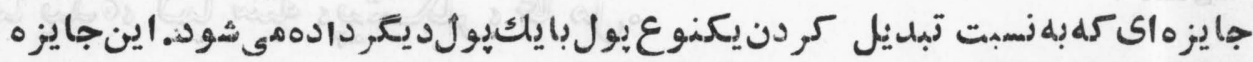

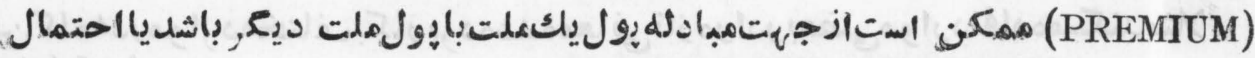

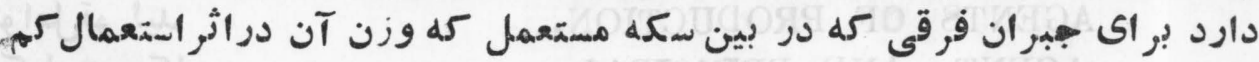

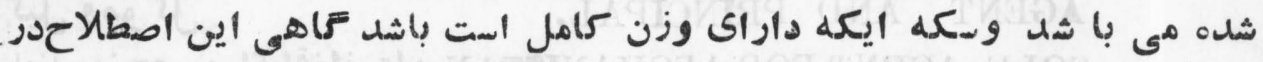

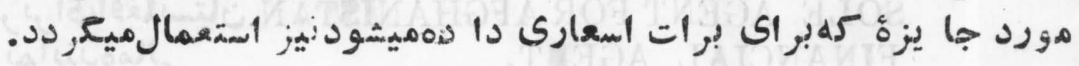
agio theory of interest. $\quad 0$ is

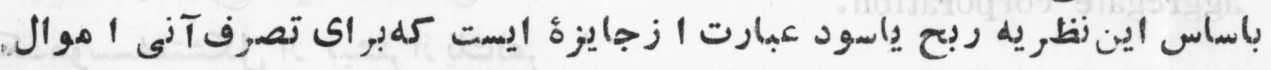

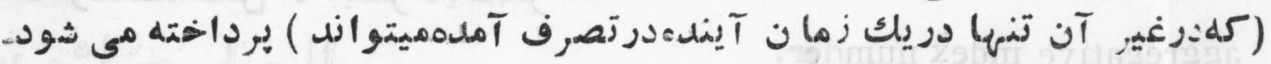

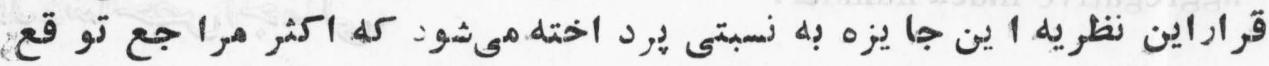

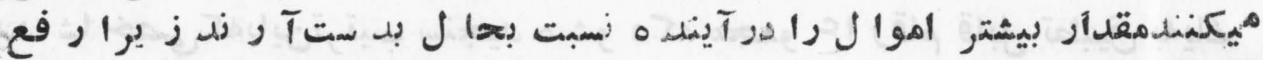

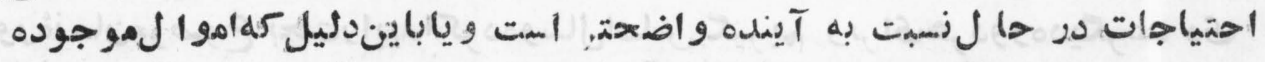

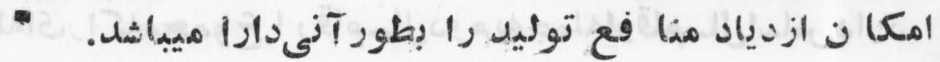
agrieultural economics.

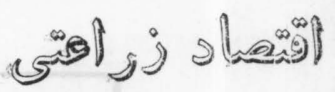

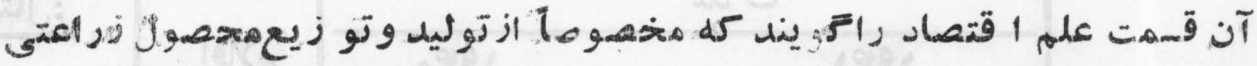

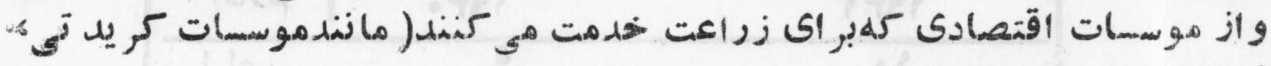

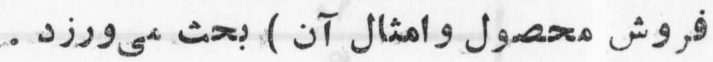
agricultural ladder.

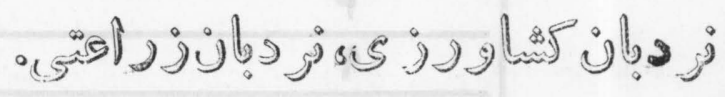

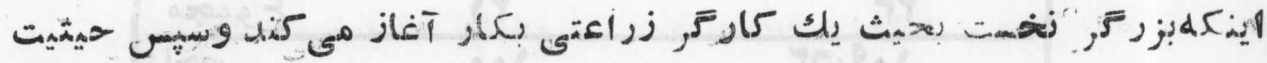
(1.) 


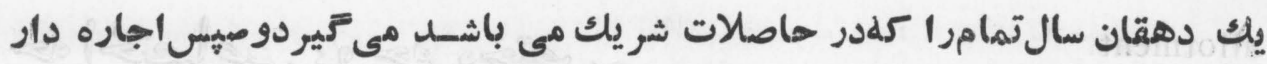

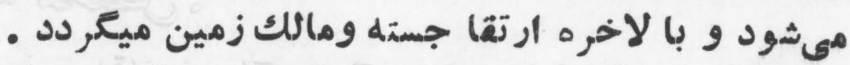

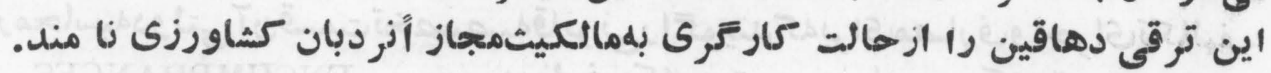
agricultural parity. -

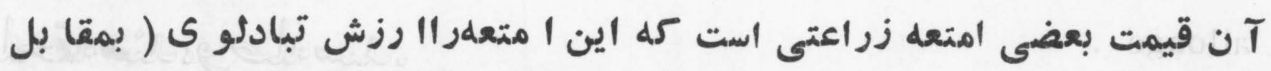

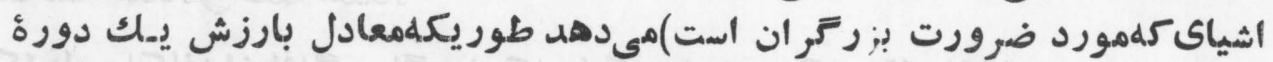

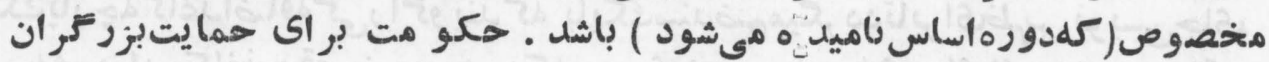

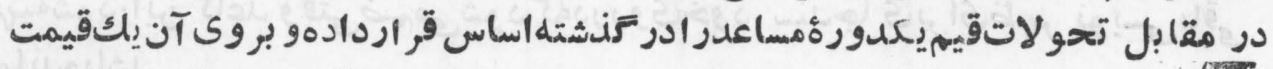

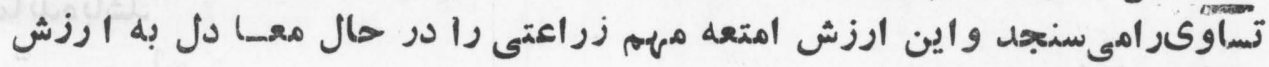

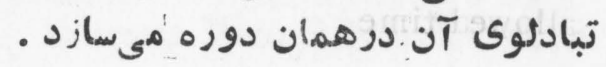

agricultural revolution.

$$
\text { - آل }
$$

انقلاب زر اعتى بدومعنى بكار ميرود ـ اول تطبيق علموو تكنو لوزىى عصرىاست

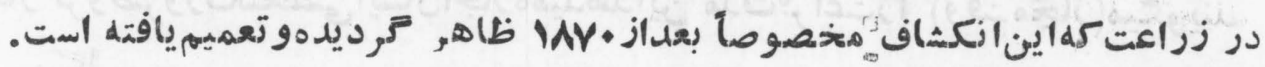

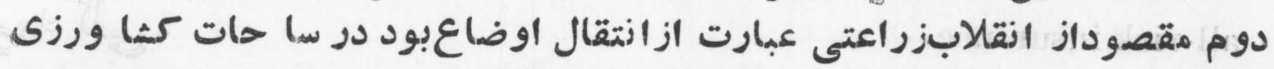

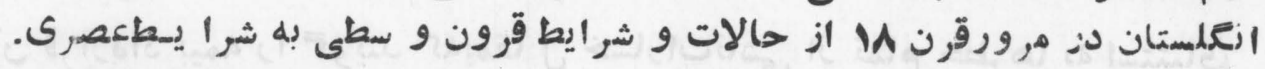

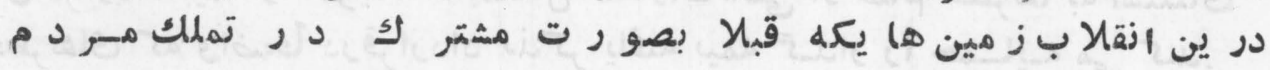

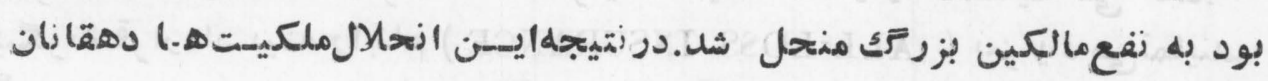

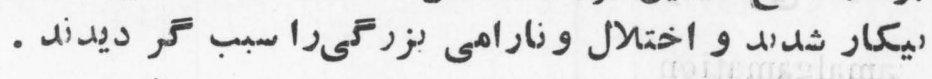

allocation.

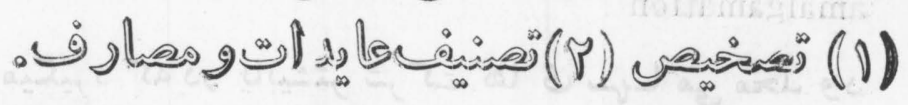

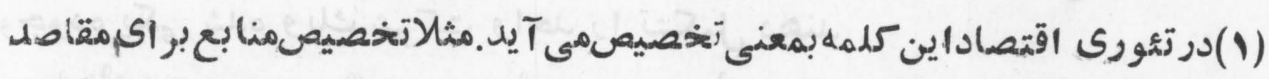

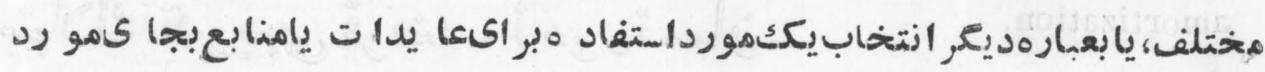

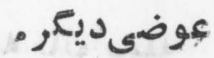

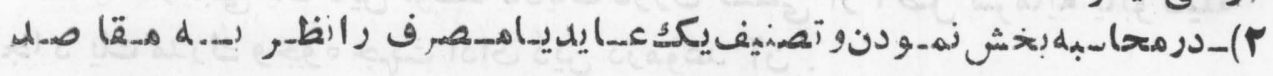

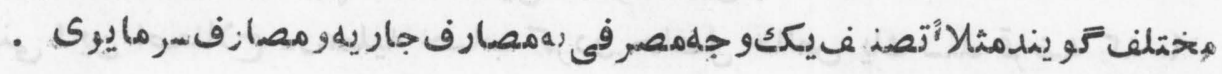




\section{ALL}

allotment.

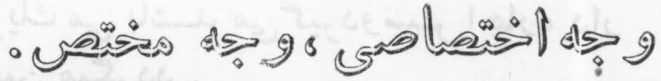

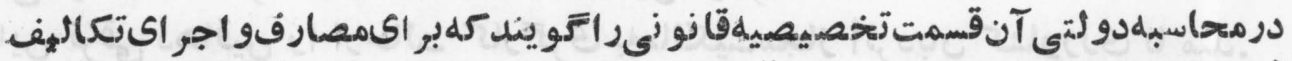

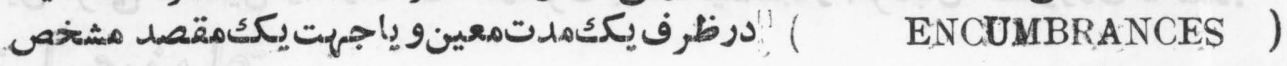
اختصاصيافتهاست.

allonge .

- lingullogolim díndo

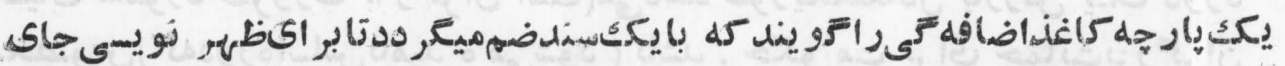

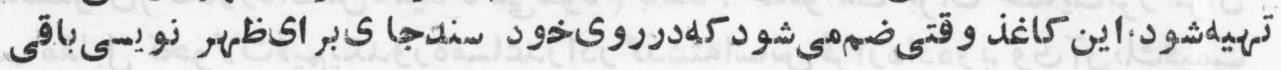
- نماندهباشل allowed time .

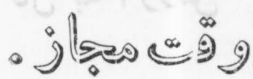

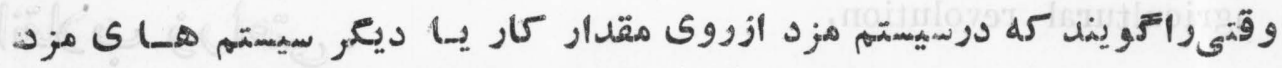

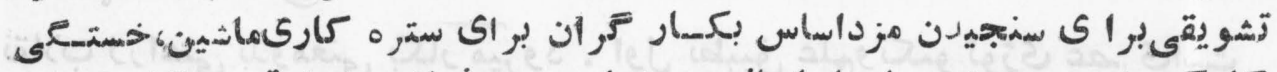

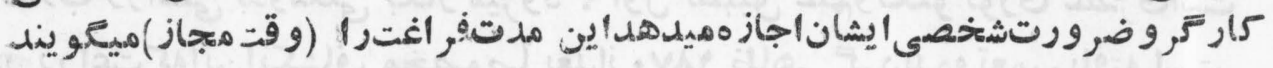
all-risk insurance.

- The

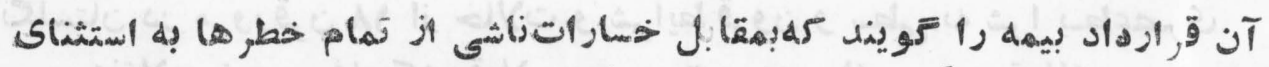

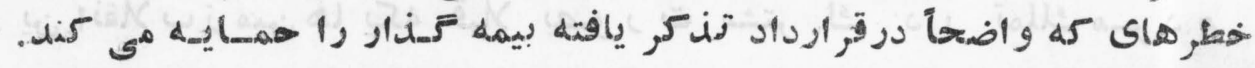

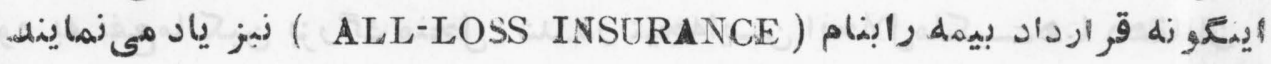
amalgamation

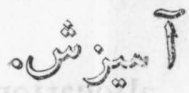

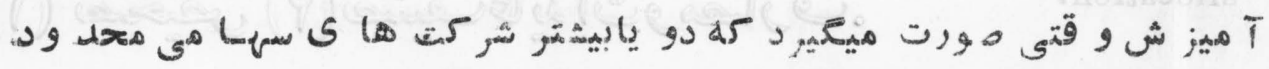

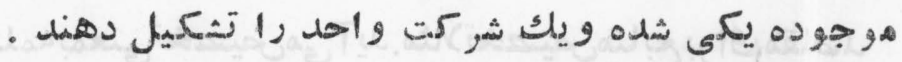

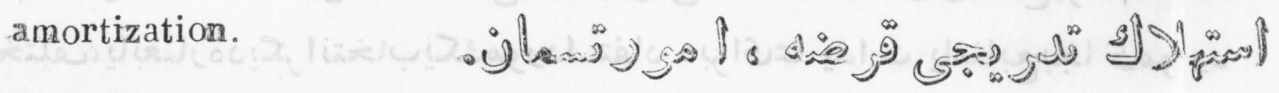

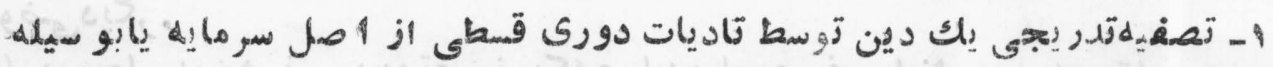

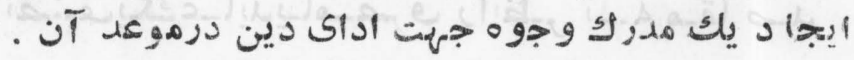

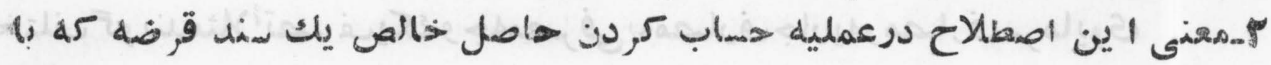
(Mr) 


\section{AN T}

annuity .

$$
\text { هـ }
$$

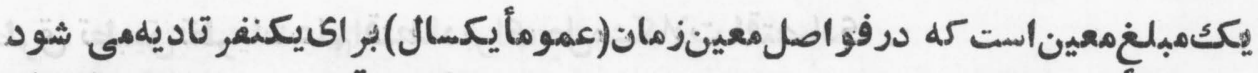

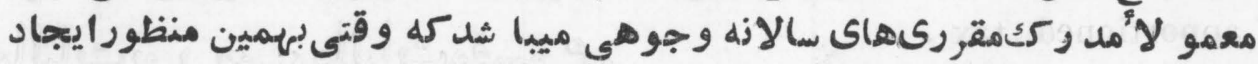

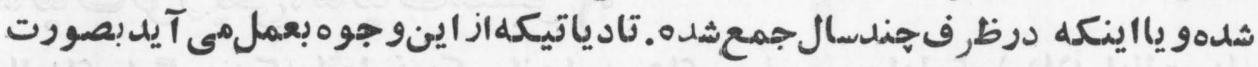

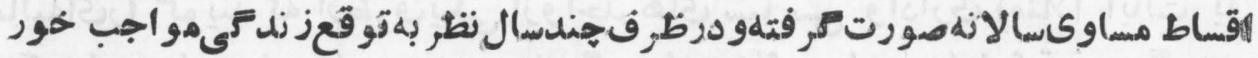

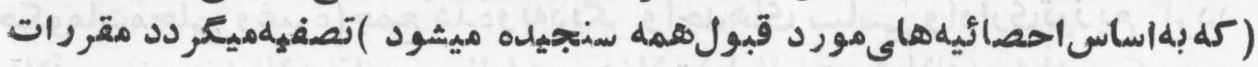

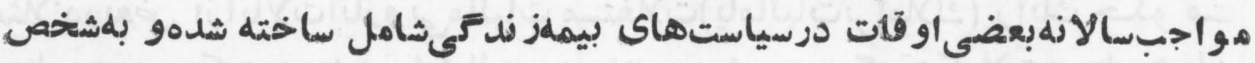

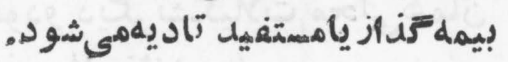

annuity bond.

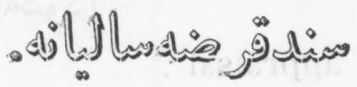

\section{(راىتفصيلات به زير عنوان BOND Dم اجعلشود)}

antagonistic cooperation .

$$
\text { هي }
$$

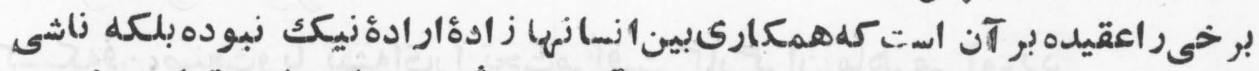

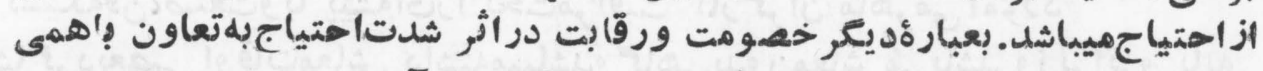

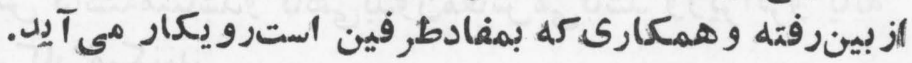

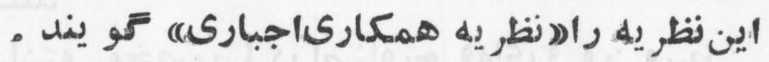
anticipation rate.

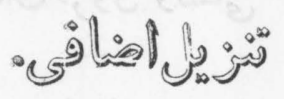

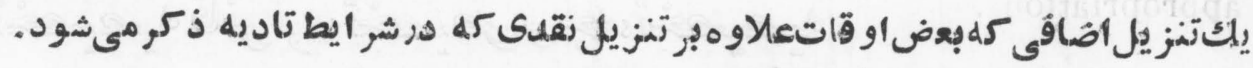

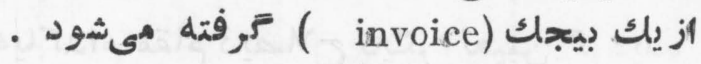
antidumping duty. S

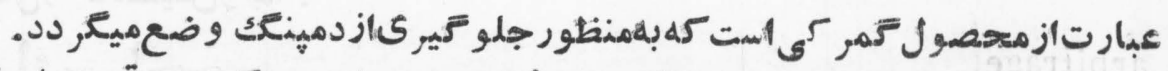

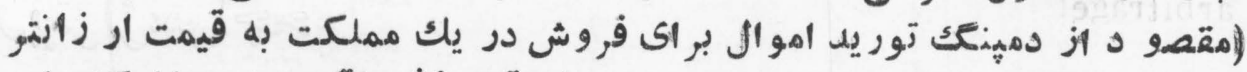

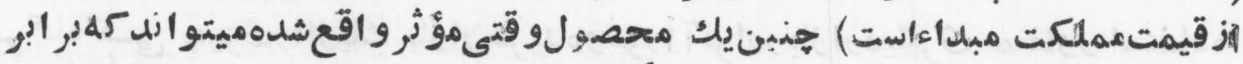

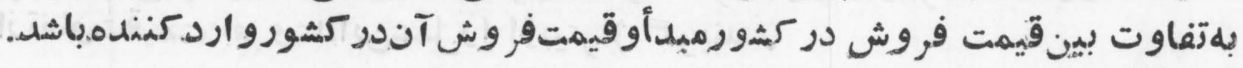


applied economics .

( $\mathfrak{5}_{\infty}^{\infty}$

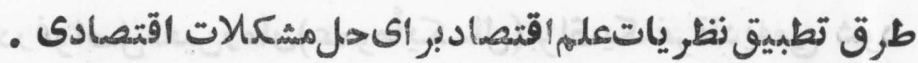

apportioned $\operatorname{tax}$.

$$
\text { - P g }
$$

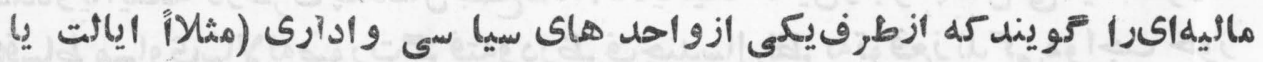

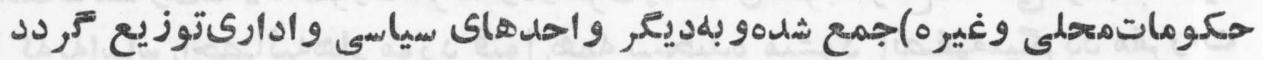

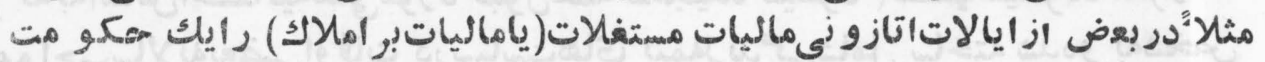

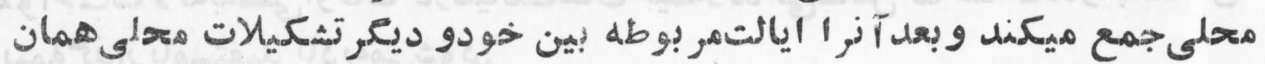

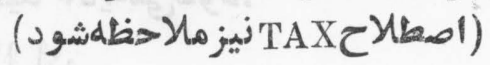

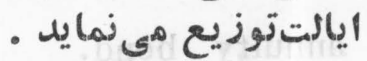
appraisal .

$$
\text { ज. () }
$$

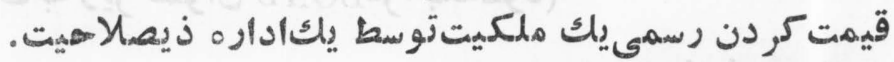
apprentice .

$$
\text { - j300 }
$$

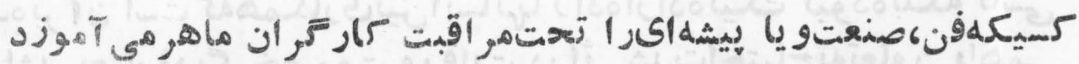

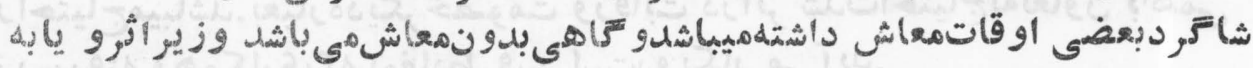

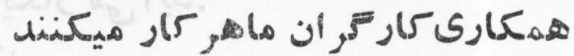

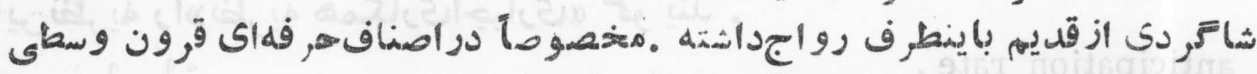

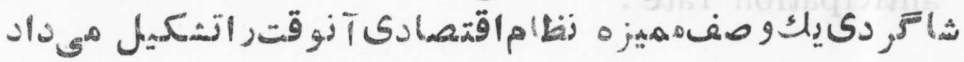
appropriation .

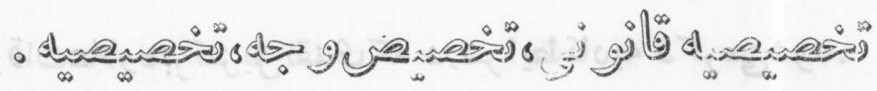

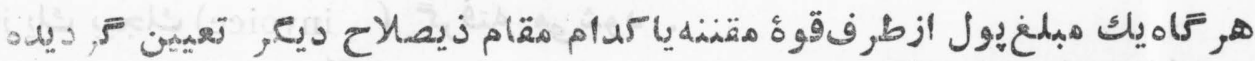

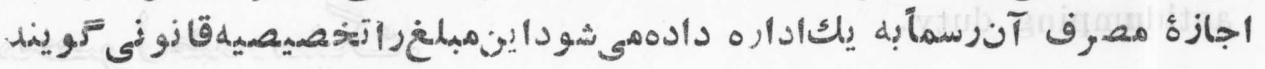

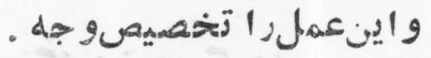
arbitrage.

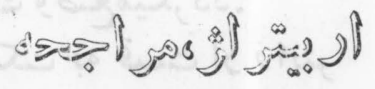
هر ماهك كسى جيز

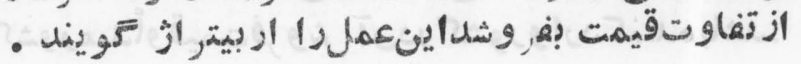




\section{ARE}

arbitration .

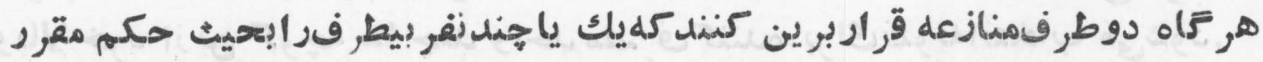

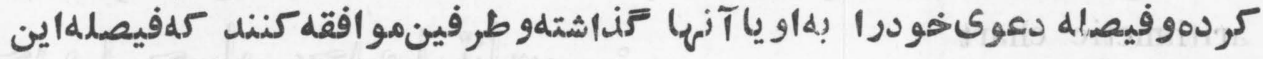

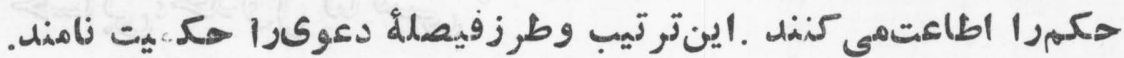
arbitration of exchange .

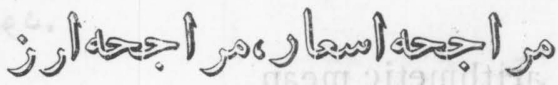

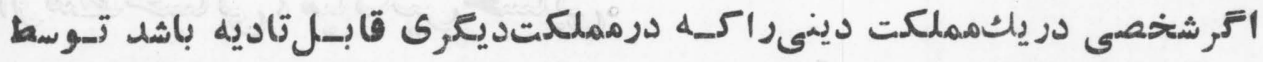

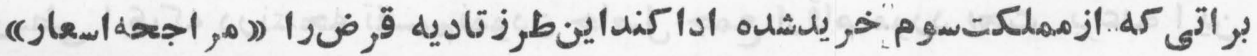

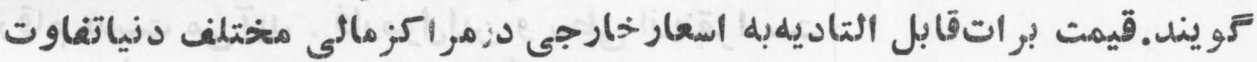

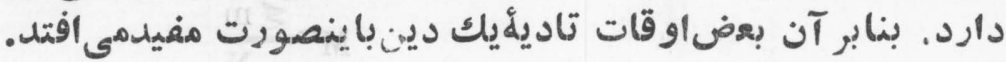

arbitrator.

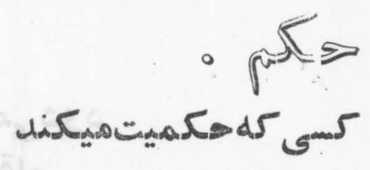

area agreement. (1)

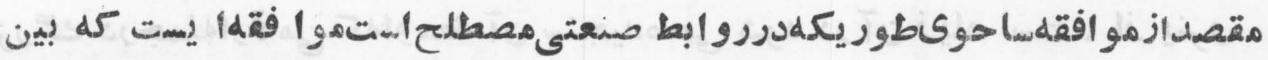

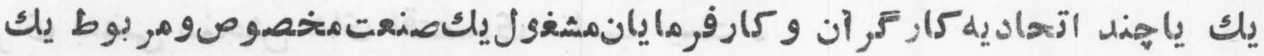

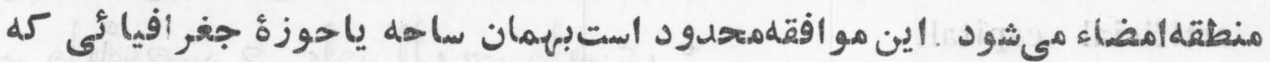

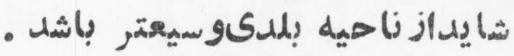
area sample.

$$
\text { जs }
$$

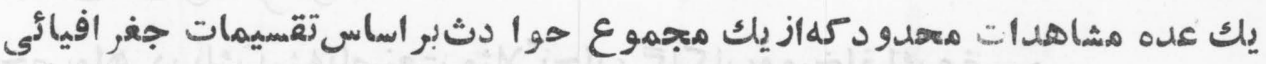

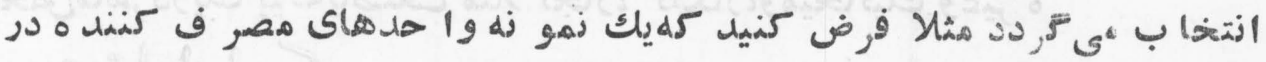

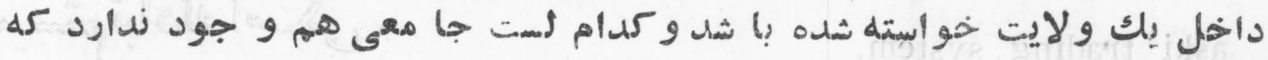

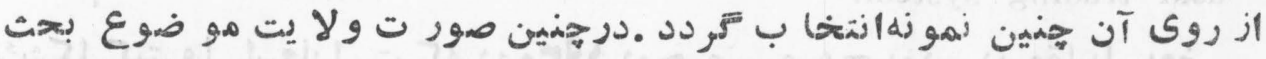

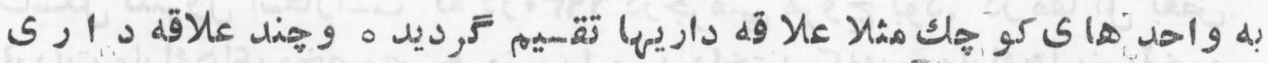

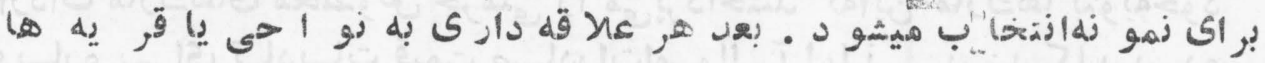


تقسيم ميشود واز آزجمله جند قريه انتخا ب ميشو د و هر قو يه يه ياناحيه به بهند

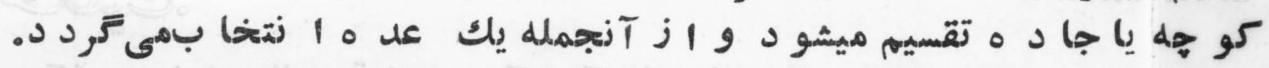

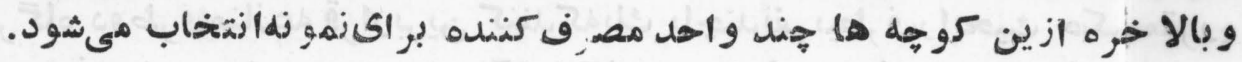
arithmetic chart

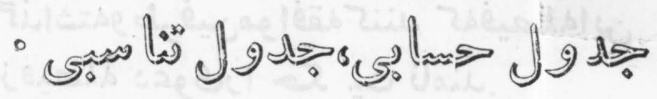

تفصيلاتزير ملرحة شوى.

arithmetic mean.

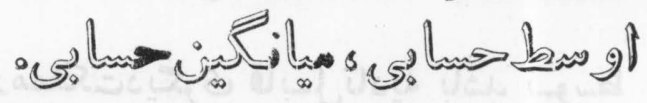

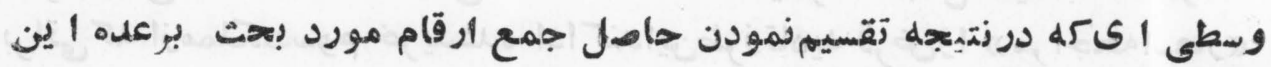

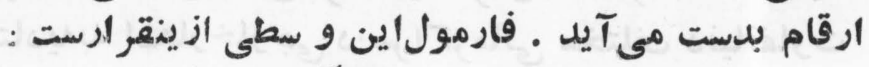

$$
M=\frac{\sum m}{N}
$$

$$
\text { در حاليكه : M : M : اوسط حسابى }
$$

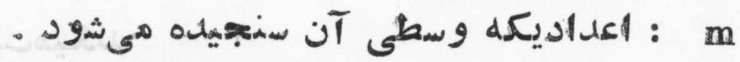

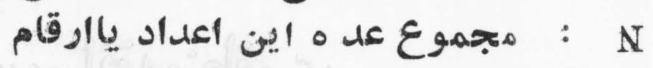

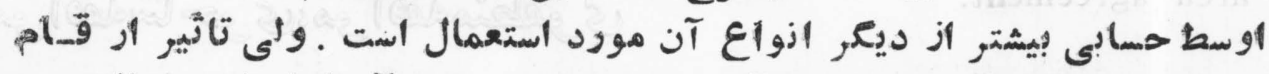

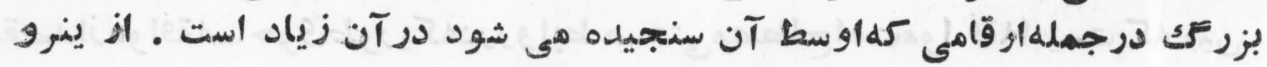

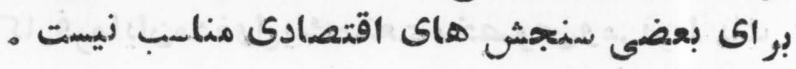
artificial capital.

$$
\begin{aligned}
& \text { - ज va } \\
& \text { به CAPITAL GOODS بر اجعه شود. }
\end{aligned}
$$

artisan.

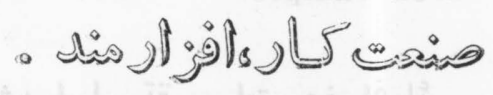

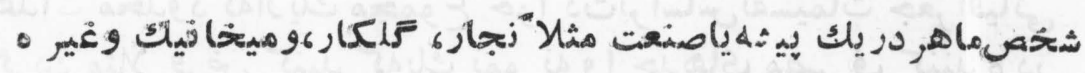

aski trading system.

$$
\text { - ज大 }
$$

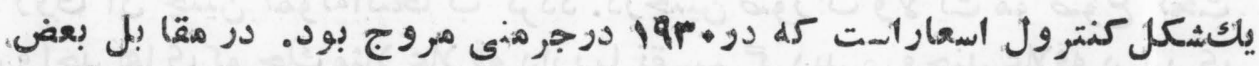

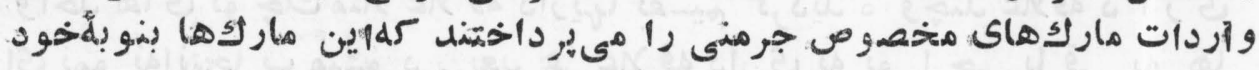

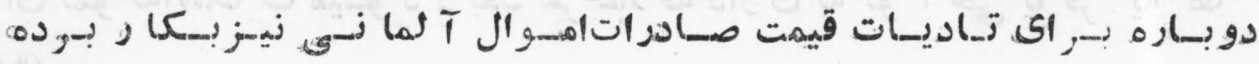
(6) 


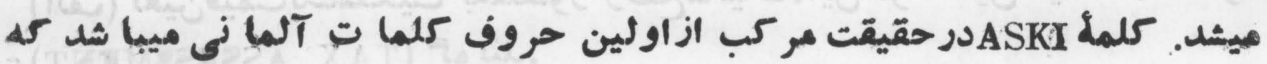

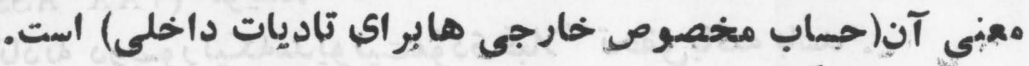
ass $\mathrm{y}$ office.

$$
\text { ( ) }
$$

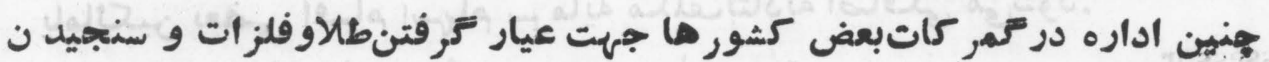

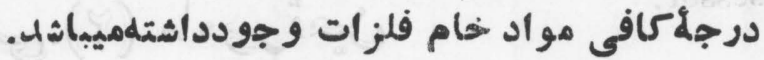

assembly - line technique.

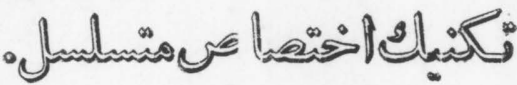

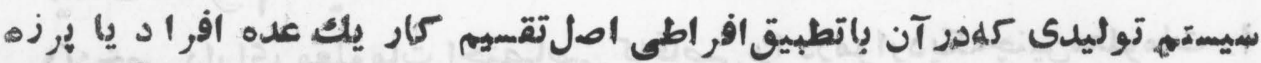

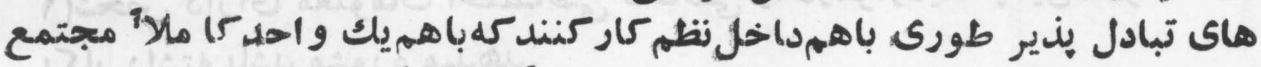

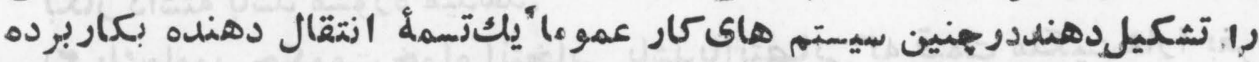

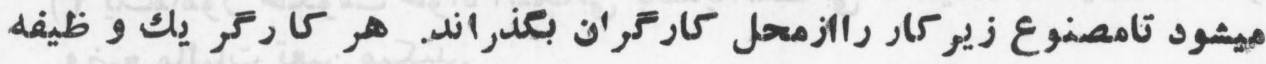

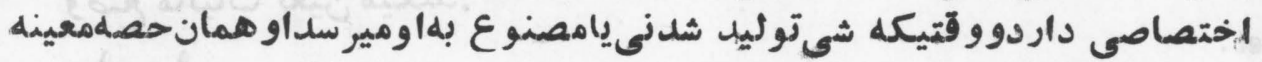

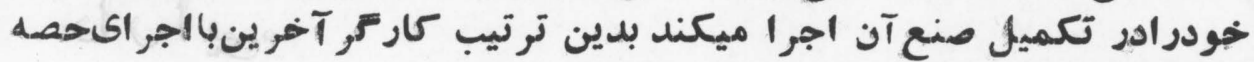

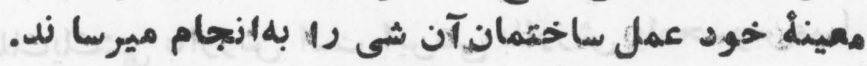

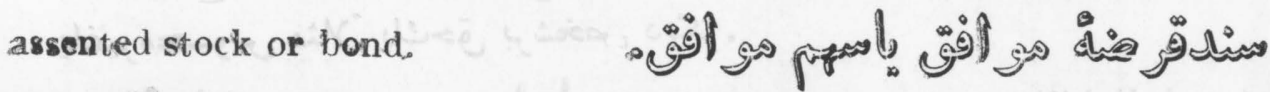

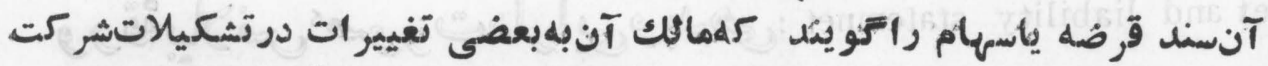

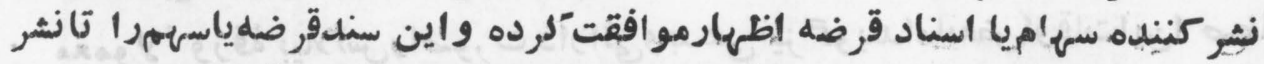

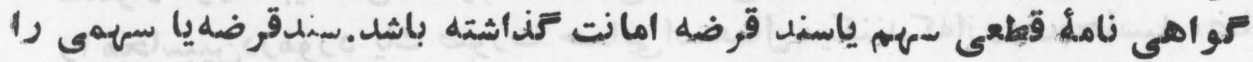

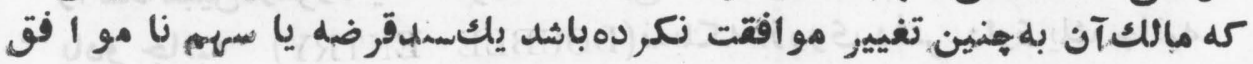

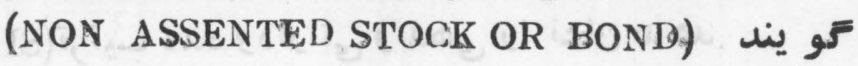
assessble stock.

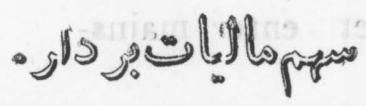

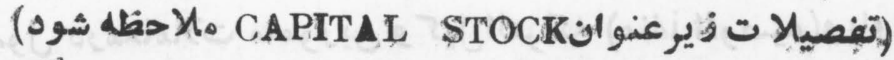

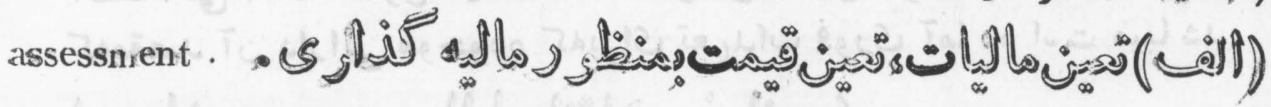

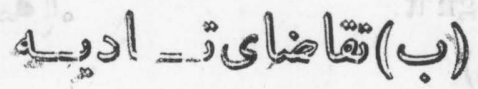




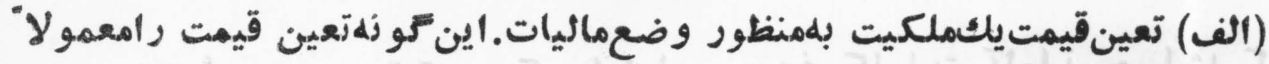
تو ينل (TAX ASSESSMENT)

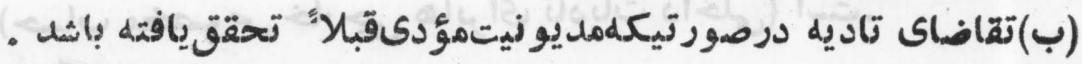

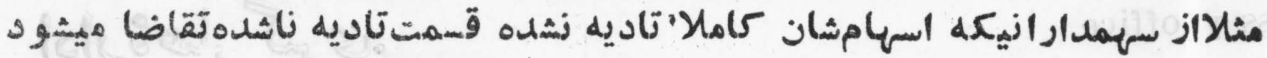

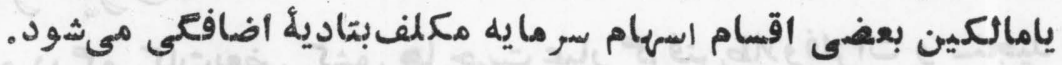
assessor.

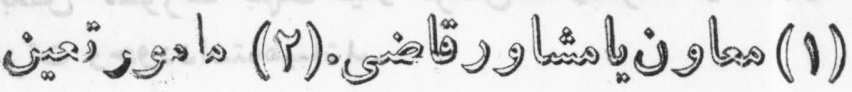

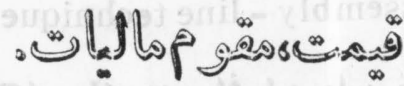

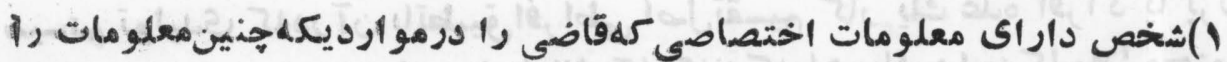
بعار داشته باشد مشوره ميدهد.

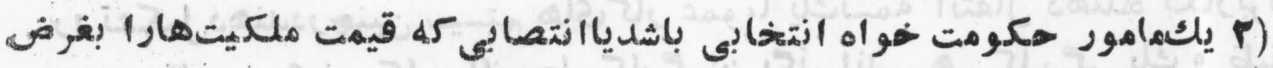
وضع ماليات تعين ميكند.

Asset.

$$
\text { बis }
$$

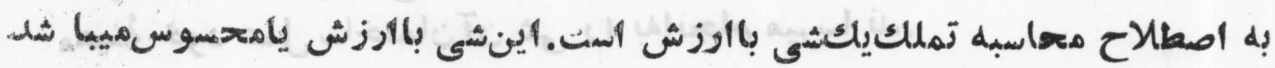

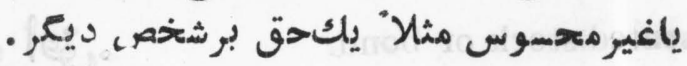

asset and liability statemnet :

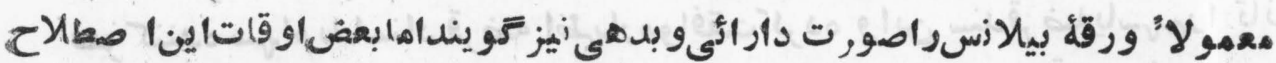

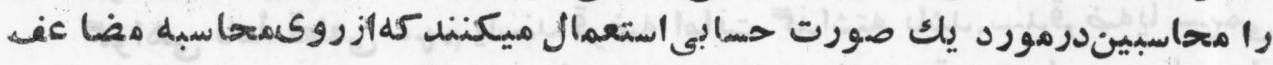

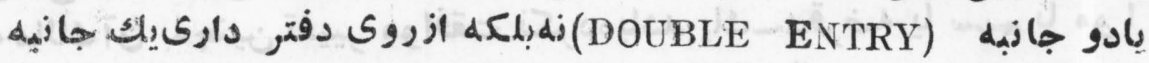

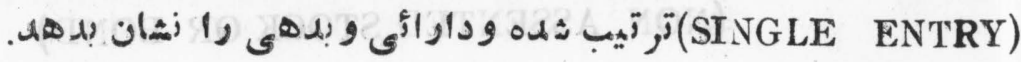

asset enter mains-

$$
\text { ه }
$$

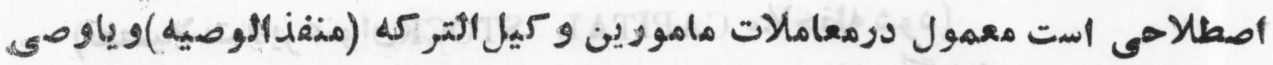

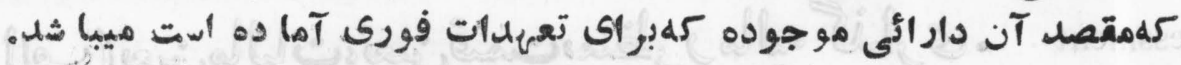
assignat.

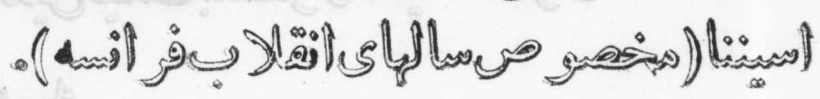




\section{ASS}

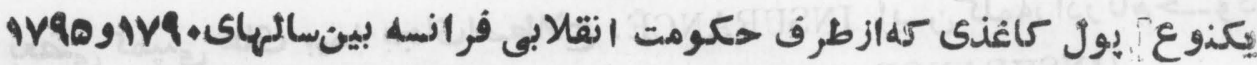

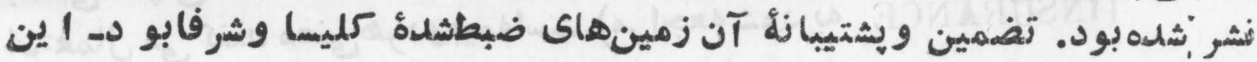

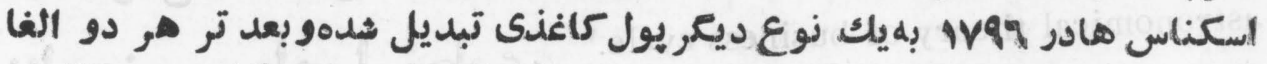

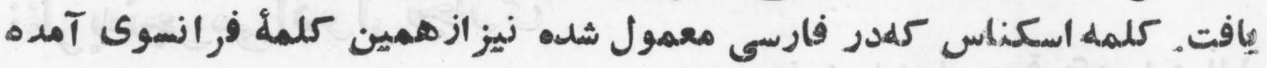
assignee.

$$
\text { - S }
$$
كَّسيكه بهاو يكنوع لقب كمفاد وياحقى انتقال يافتهباشد.

assignor.

$$
\text { هو }
$$
كسيّكه يكنوع عنوان"مفاد ياحقى رابديعرى انتقال ميكنُ.

assignment. انتقال رسمى كدامملككيت ياحق ازيك شخص بديكرى. assimilation

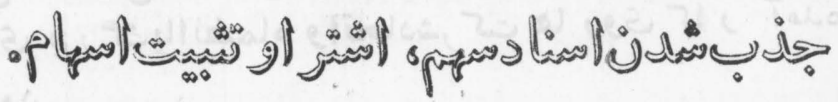

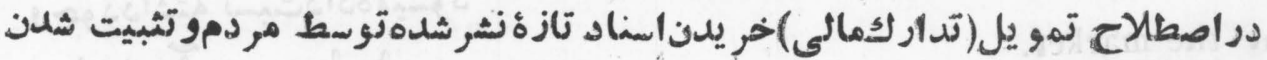

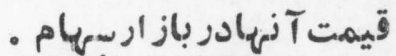

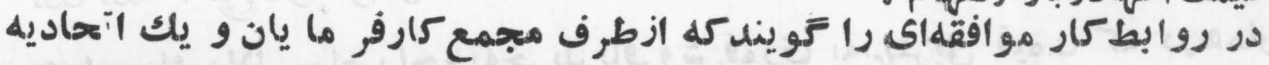

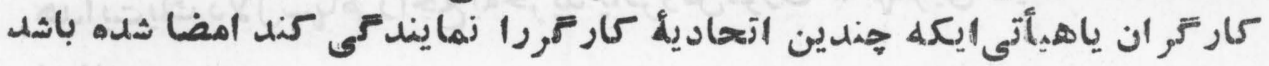
assumed bond.

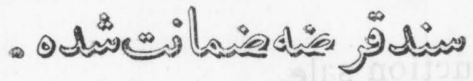

$$
\text { (تفصيلات زير BOND (تميدهشود) }
$$

assumption of risk.

$$
\text { 要 }
$$

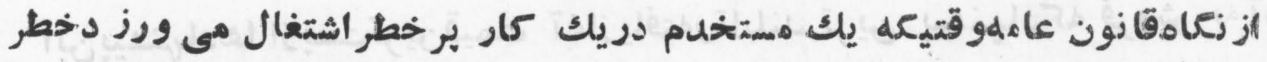

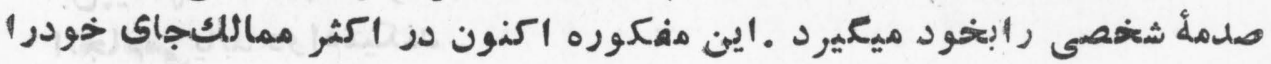

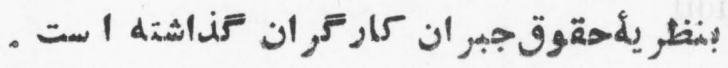

assurance. 


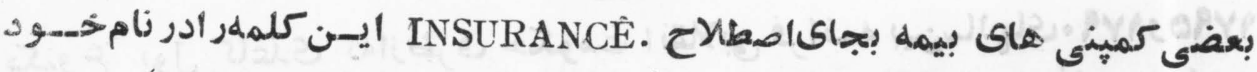

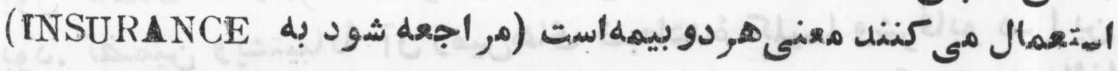
astronomical theory of business cyele.

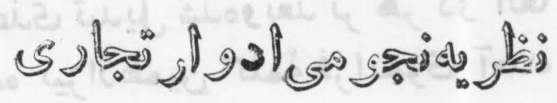

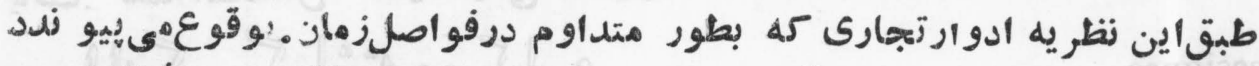

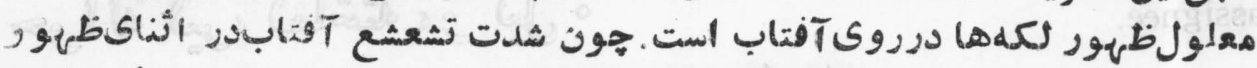

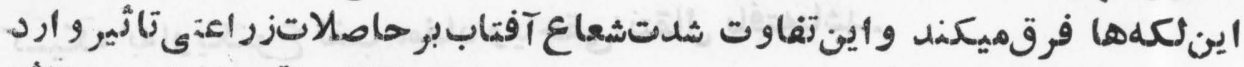

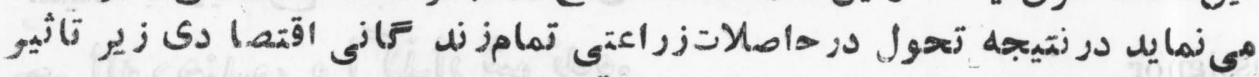

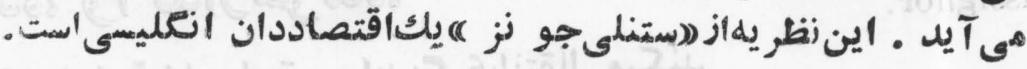
atomistic society. - 3 ك

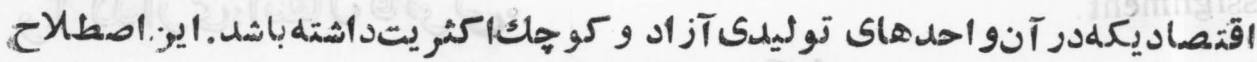

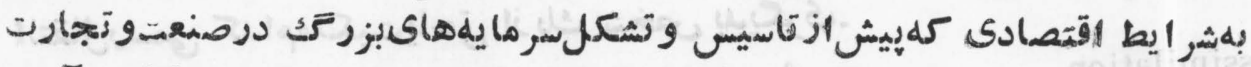

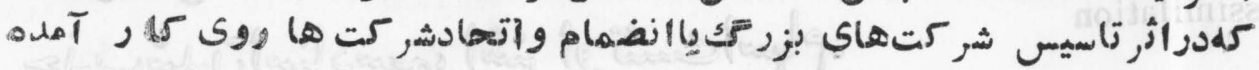

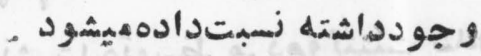
at the market.

$$
\text { - गj jos }
$$

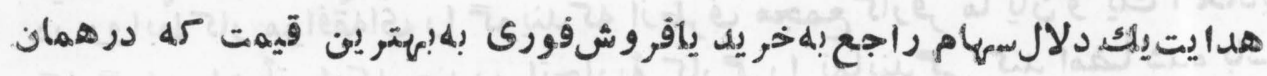

auction sale.

أحظdميسر شود.

$$
\text { o }
$$

آن نوعقروش الهو الرراتويند كهاهو ال به بيشتههاد دهندة بلجندترين قيهت عرضه

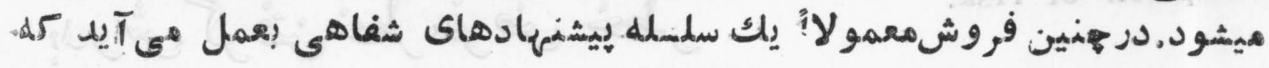

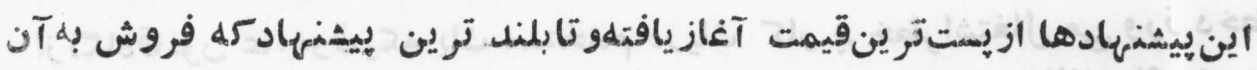
audit

$$
\text { 药 }
$$

دراصطللح منحاسبه بازرسى توضيع يك دقتر حساب وراتويتّ. 
austerity program.

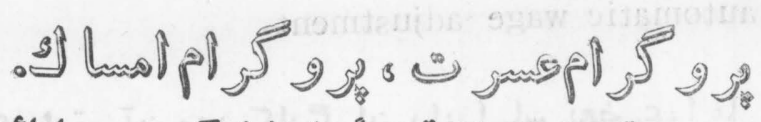

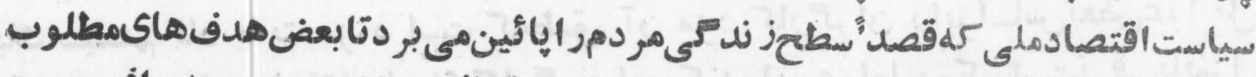

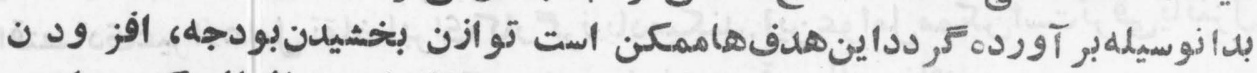

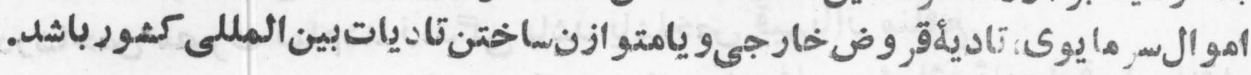
austrian school.

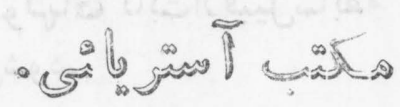

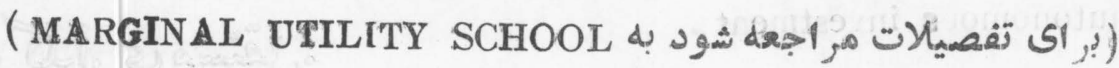
autarchy .

$$
\text { م }
$$

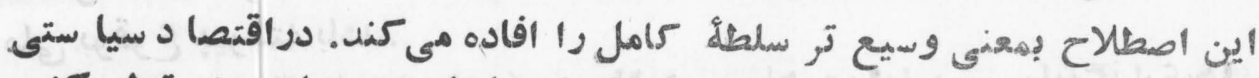

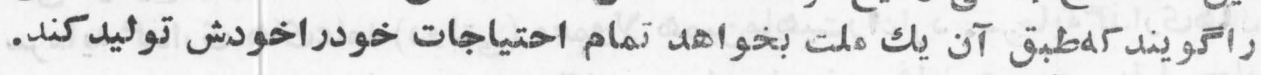
automatic balance.

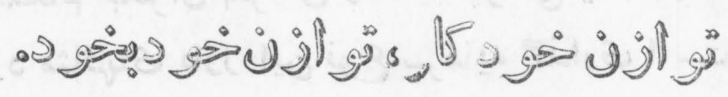

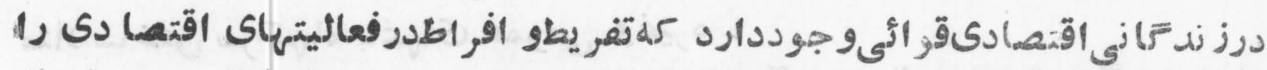

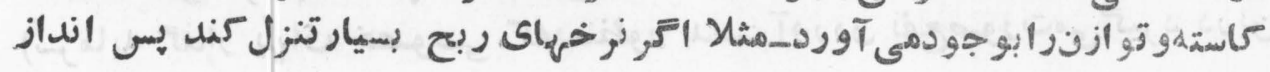

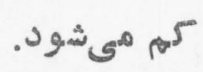

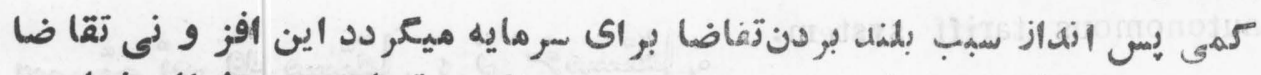

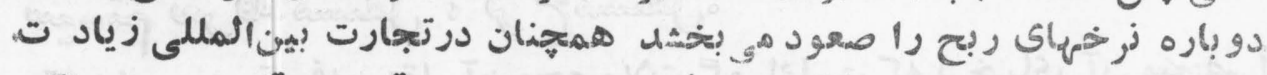

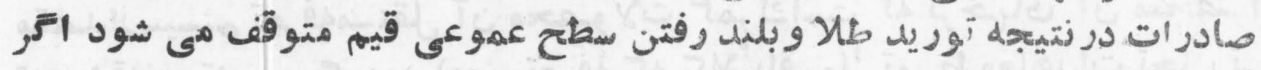

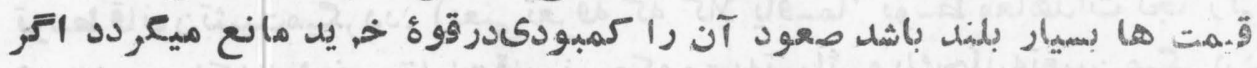

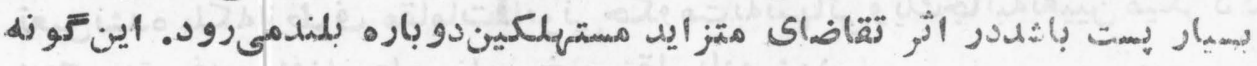

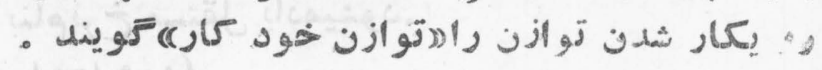

automatic check off .

$$
\begin{aligned}
& \text { b. } \\
& \text { 争 }
\end{aligned}
$$

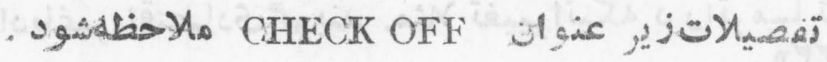


automatic wage adjustment.

$$
\text { - Sis of }
$$

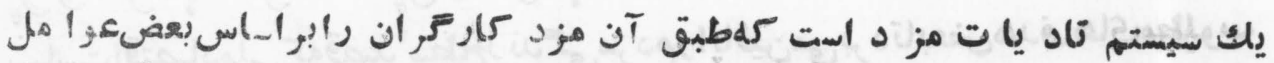

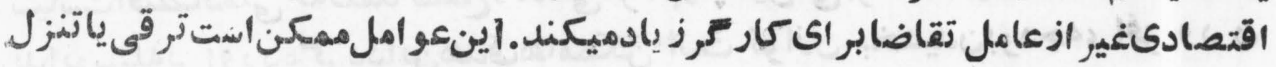

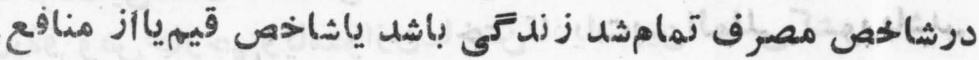

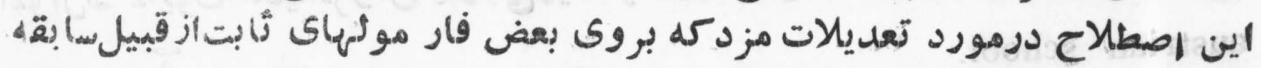

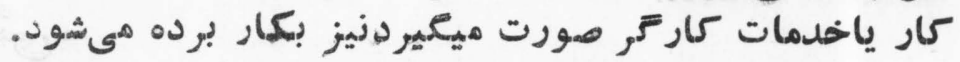

autonomor investment.

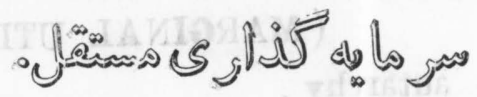

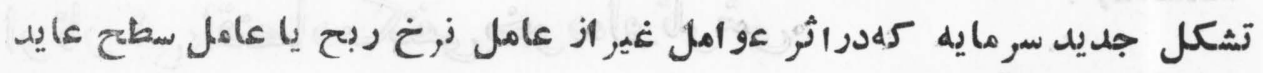
ملى بوقوع بيوسته باشله

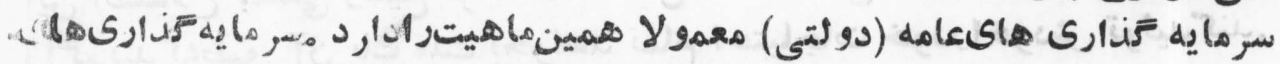

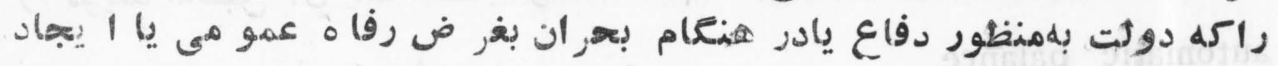

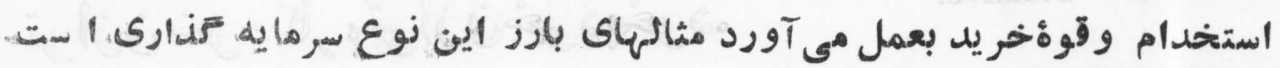

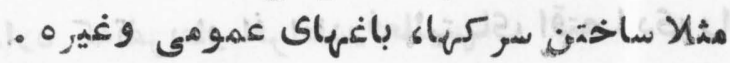

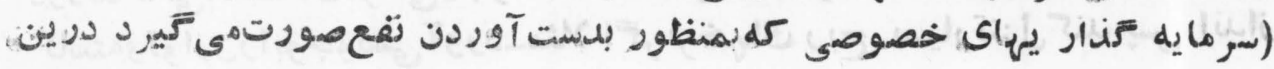
جمله زيست. autonomous tariaf system.

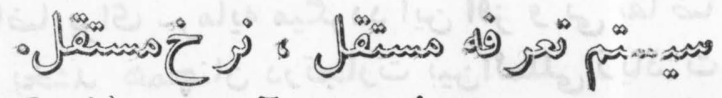

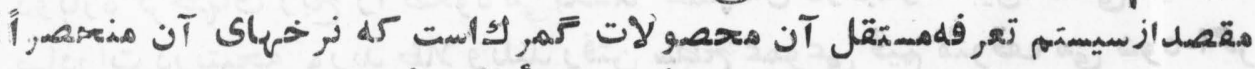

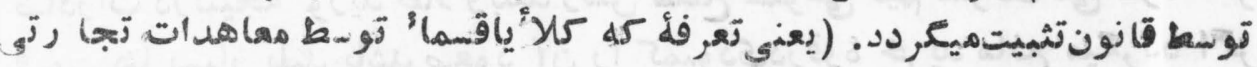

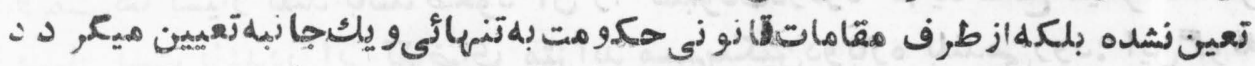

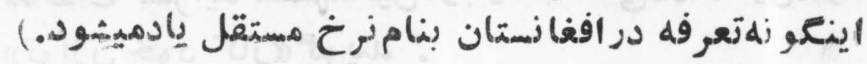

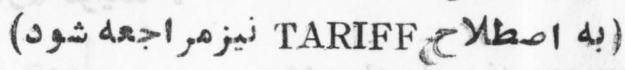

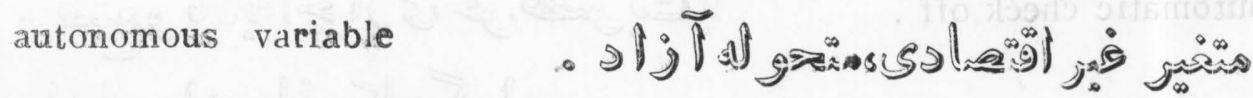

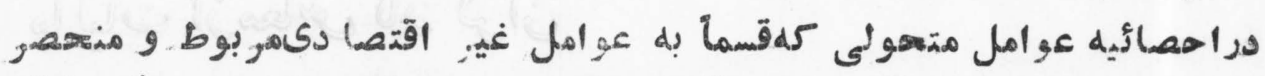

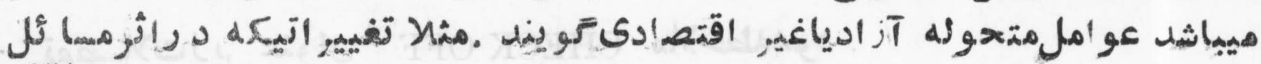
CPPD 


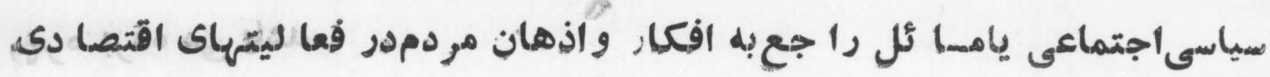
avail. رخميدهد . راستراع - Ulobslia

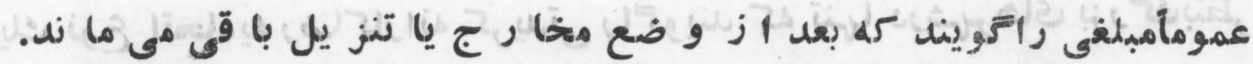

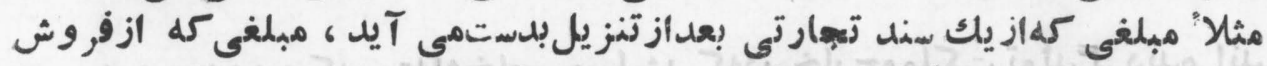

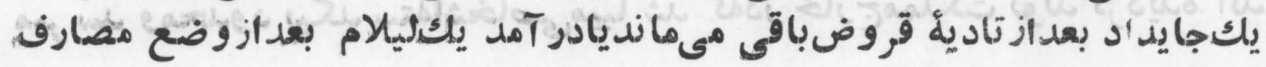
فروش. average.

- bia gas

يكعددمتوسط كهازروى اعدأدنامساوى ديعر سنجيده شدهباشد يابهانسبت ديكر

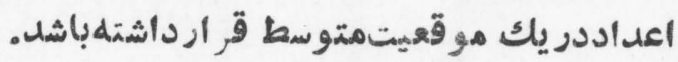

average cost.

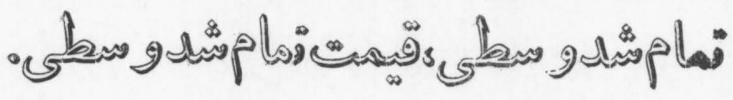
مصر فتمامشد مبهموعى تقسيمعده واحدهاىتوليدشده . average revenue.

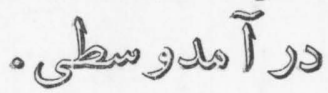

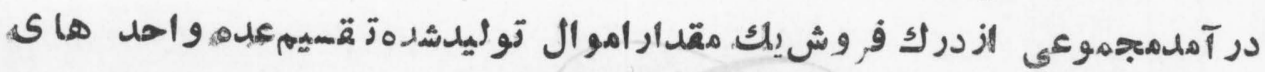
فروختهشده. ave raging down.

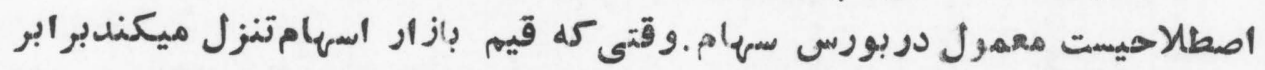

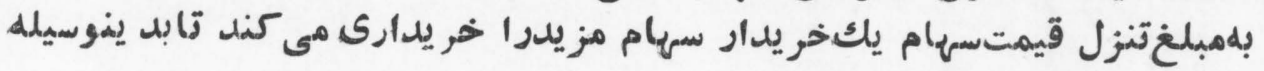

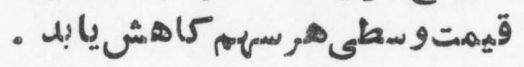

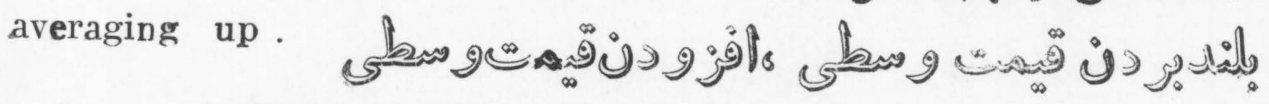

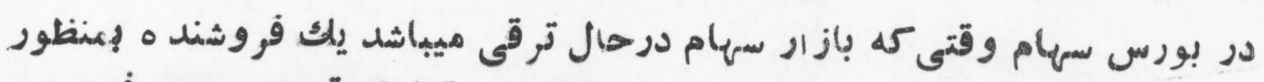

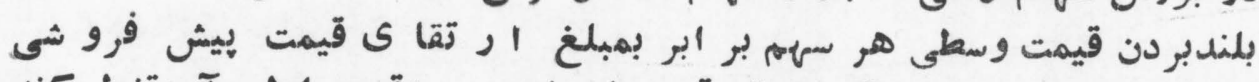

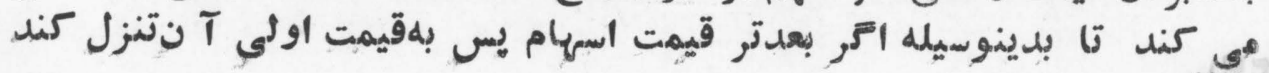
STP 
AXI

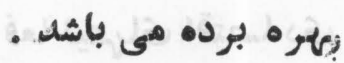

axia

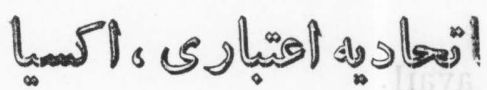

يك نوع اتحاديه رضاركارانه كريدتى راتويند كله تنها درشهر هاى بزرتكبنظر هير سل ومحدود إيكل ستهاشتخاصى ميببا شل كلدر خارجمملككت تولن ترديله انل. و درين موسسه اسناد واسمام ظهر نويسى شله بـحيث تضمين بمقـا بل قروض.

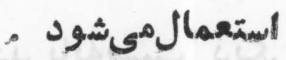

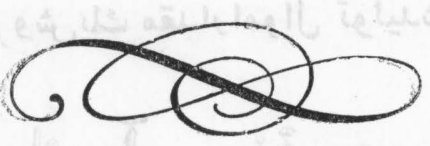

(PP) 
backlog.

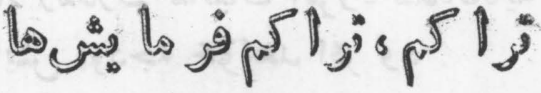

$$
\begin{aligned}
& \text { مثلا" تراكم فرمايشهاى اجر ا ناشده. }
\end{aligned}
$$

backtracking .

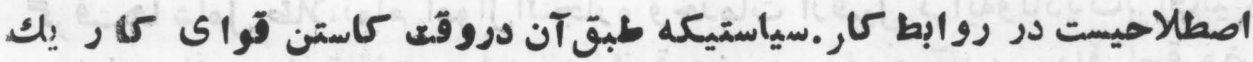

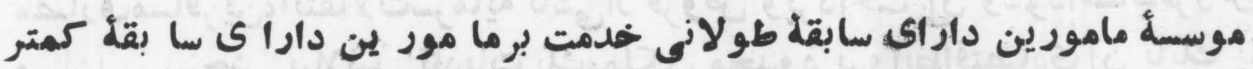

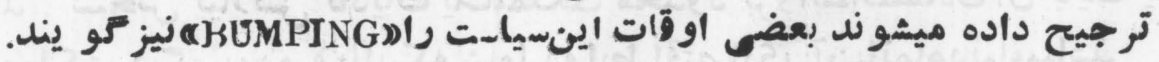
bailment. : il بلاصطtلح اقتصاد عموما انتقال اجناس،يول ياديـعر اموالشخصى اتوريند كه

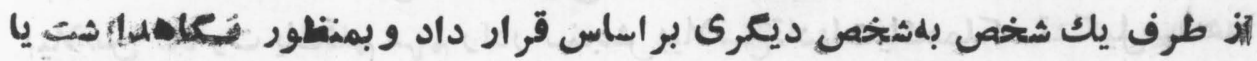
كدام مقصد مثخص ديكر صبورت ميكيرد.

balanced budget .

$$
\text { نी }
$$

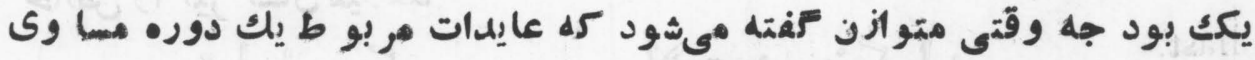
بامصارف آن دوره باشديا بيثتراز آن.

balanced budget multiplier.

$$
\text { - ن jod }
$$

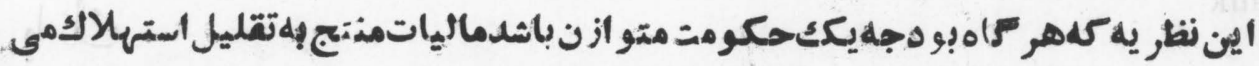

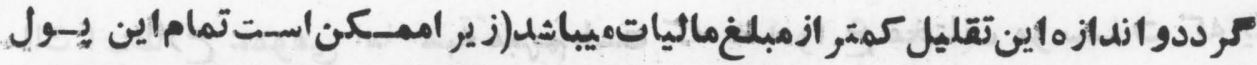

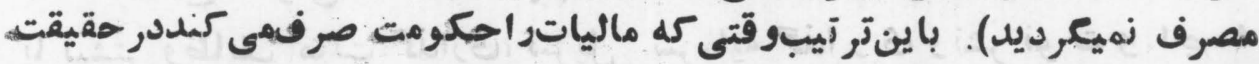

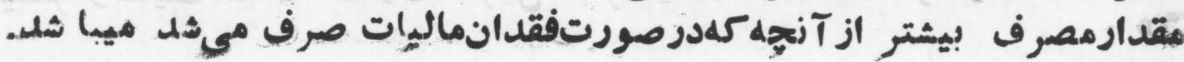
arop 
balanced budget theorem.

$$
\text { نो }
$$

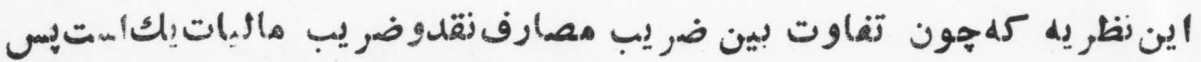

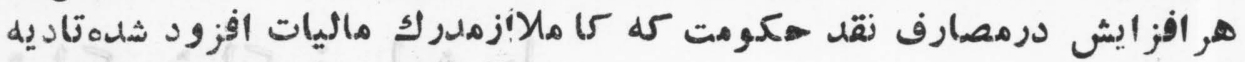

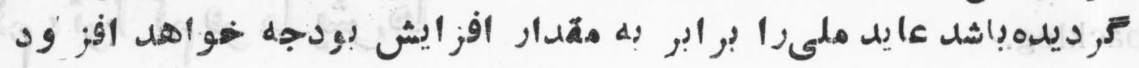
balance of paymint.

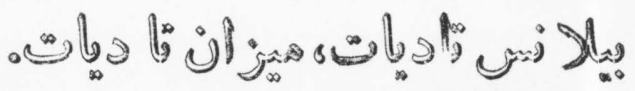

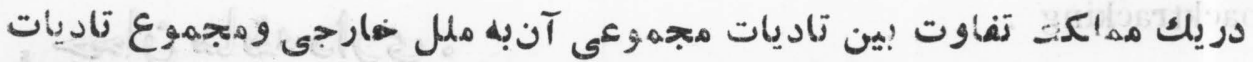

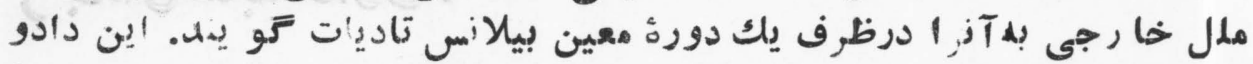

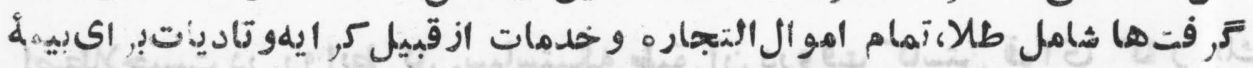

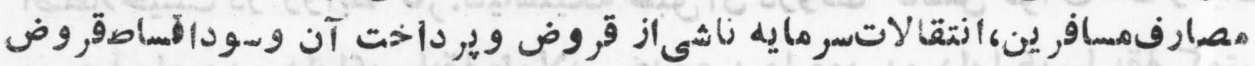

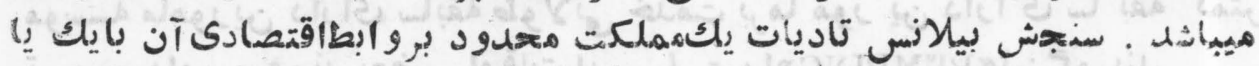

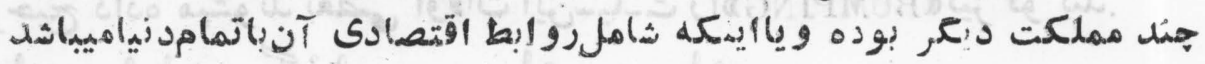

balance of trade

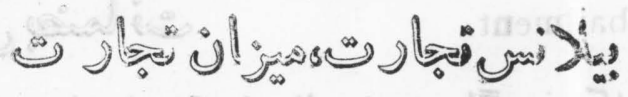

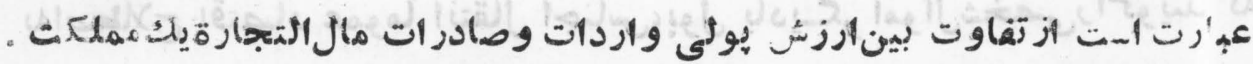

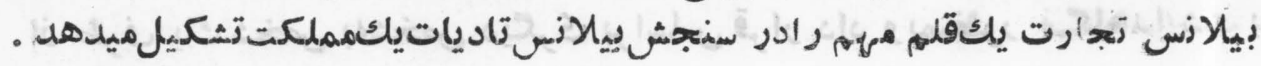
balance sheet.

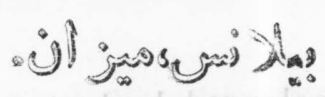

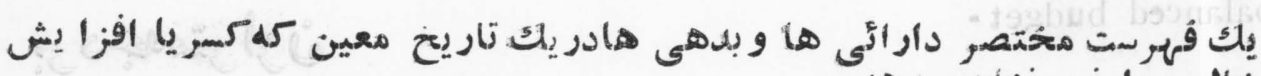
b. 11 ast.

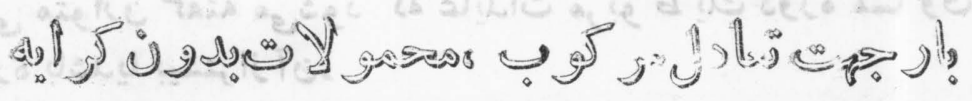

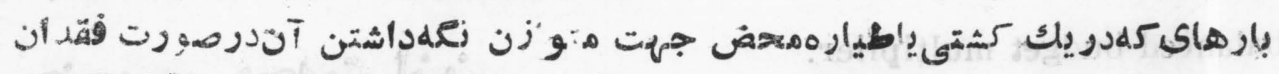

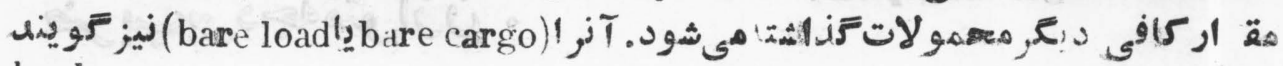
bank

3)

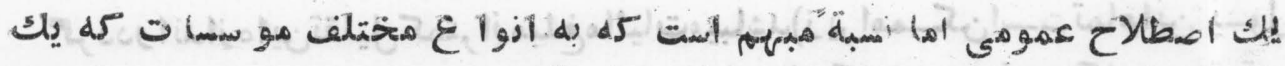

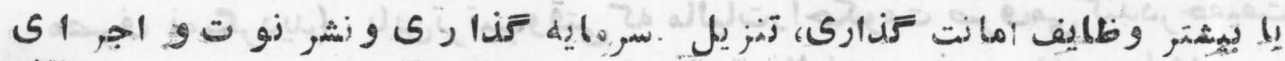
(1Pप) 
حدمات متنوع مالى ديكُر وابعههه دارد نسبث داده ميشود.

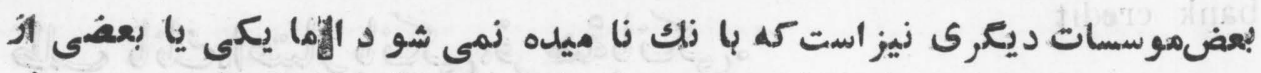

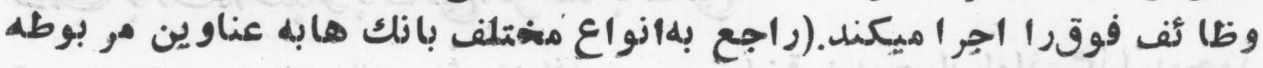
bankable bill.

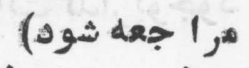

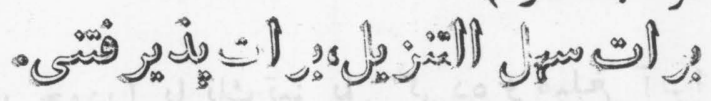

\section{هرسيدل تجارتى كنهاز طرف باركها بزودى جهت تنزيل بذّير قته شدهبتواند.} bank accepsance.

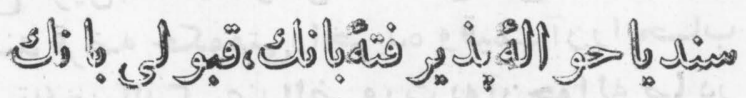

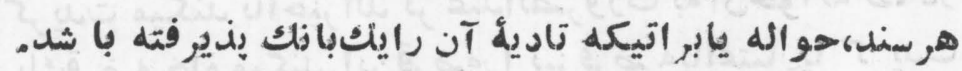

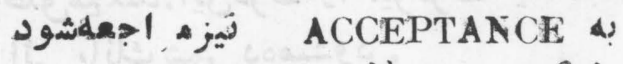

bank call.

$$
\text { ه }
$$

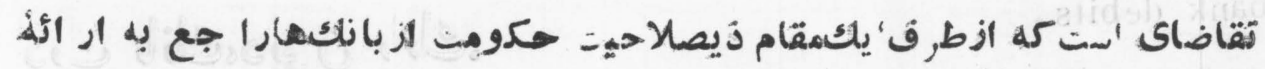
bank commission

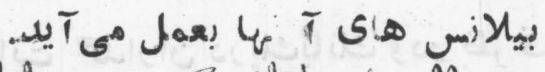

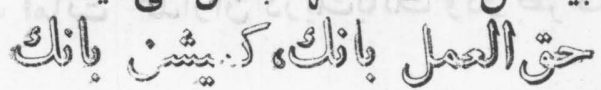

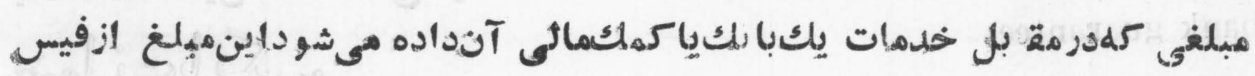

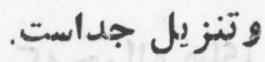
bank correspondent.

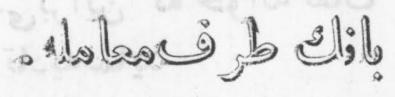

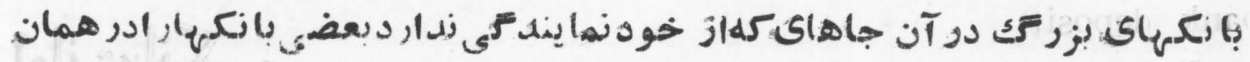

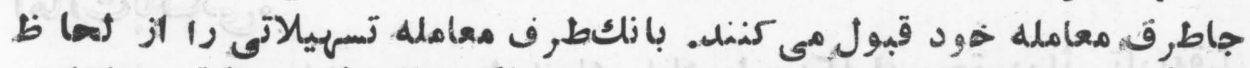

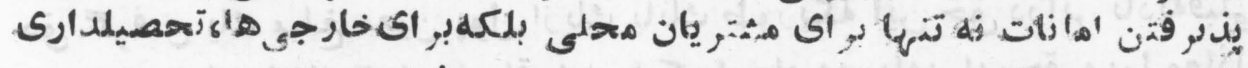

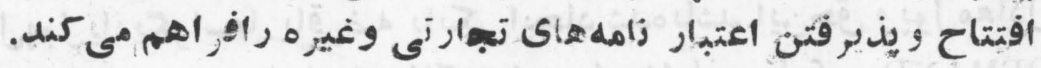
bank clearings.

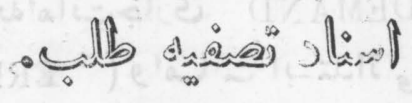

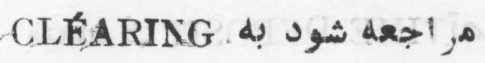


bank credit

م

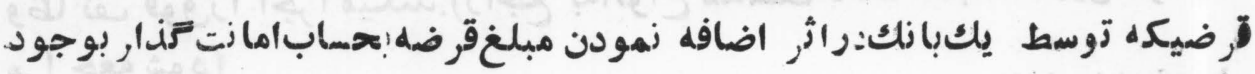

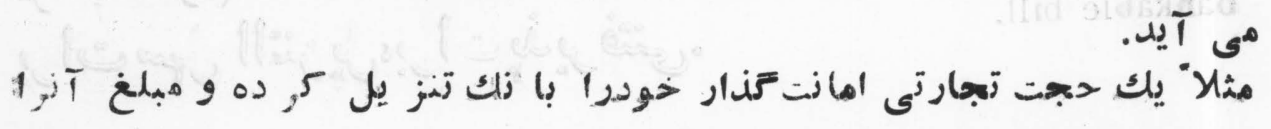

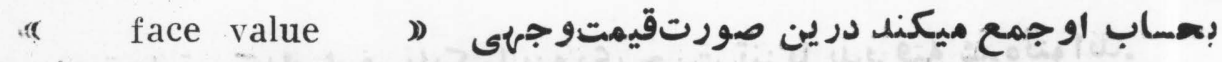

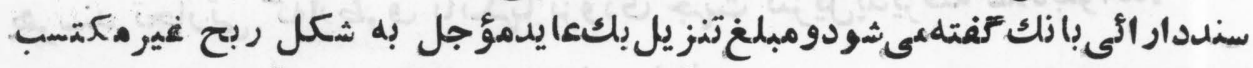

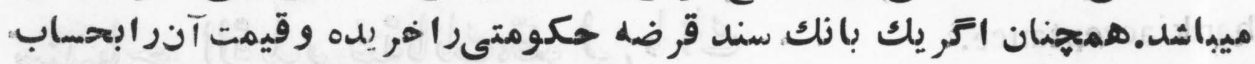

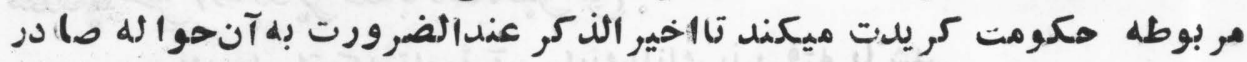

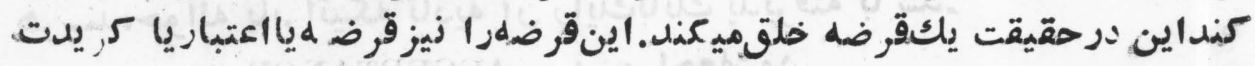

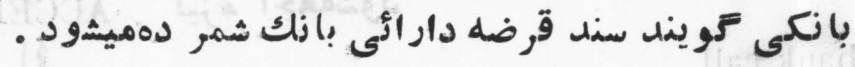

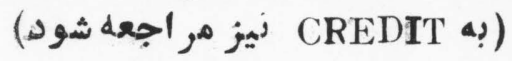

lbank debits.

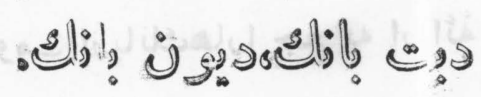

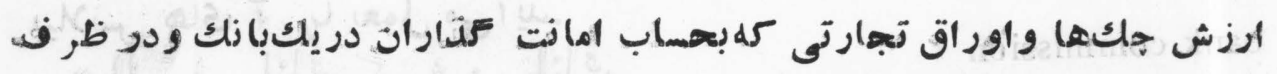

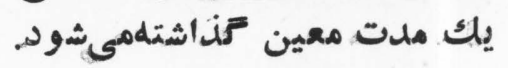

lbank guarantee.

ه

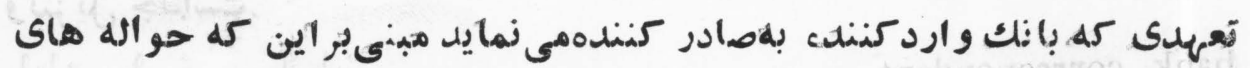

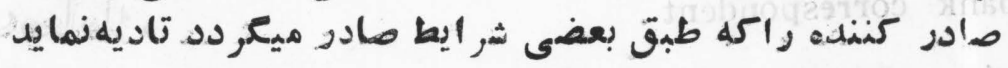

bank deposit.

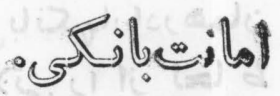

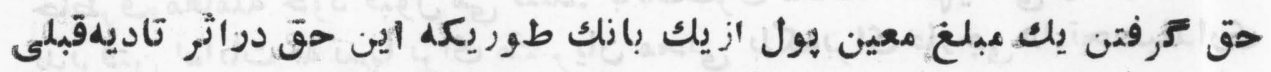

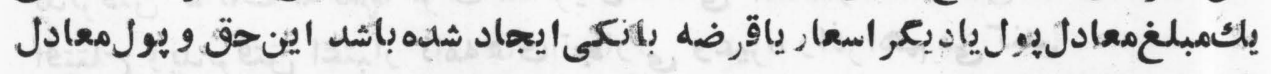

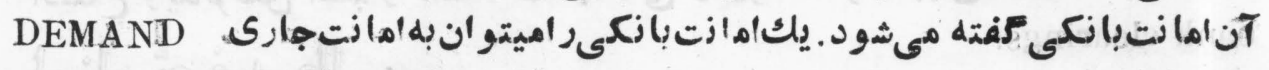

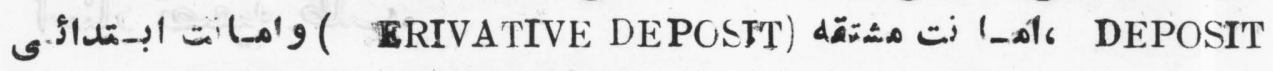

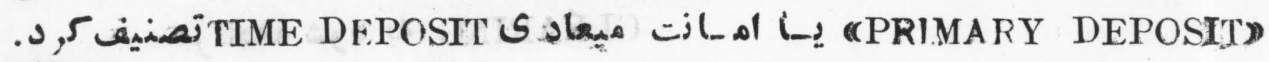
(PAD) 
banker's bill.

$$
\text { - ) }
$$

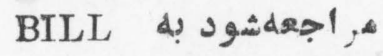

bank examiner.

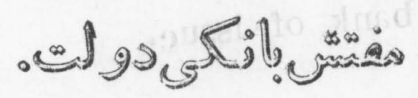

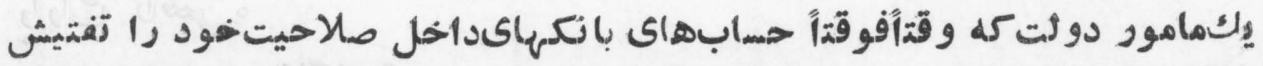

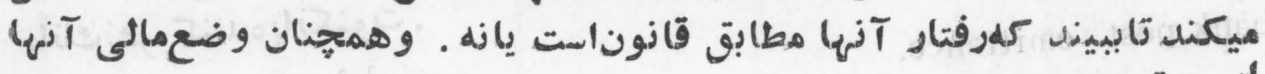

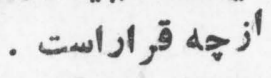
bank for internatianal settlements.

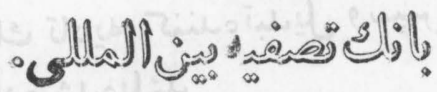

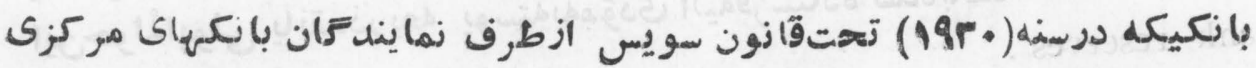

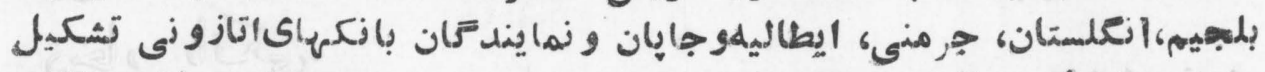

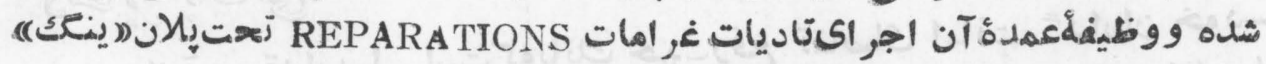

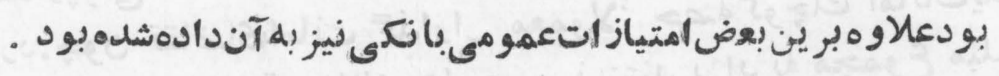

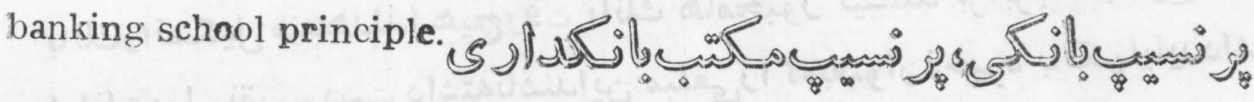

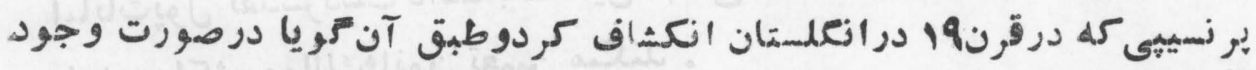

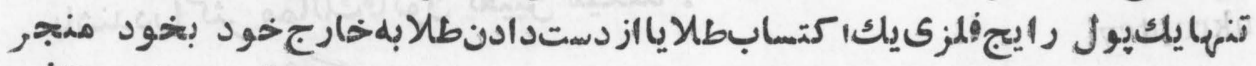

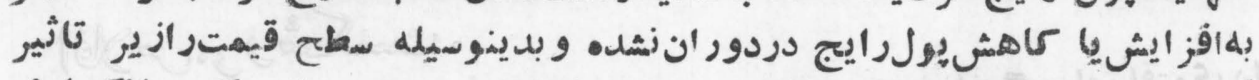

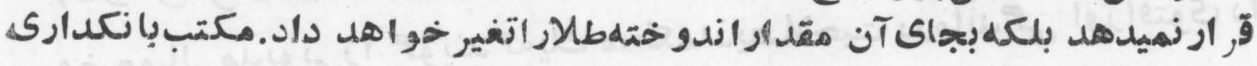

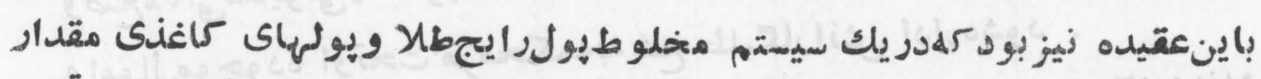

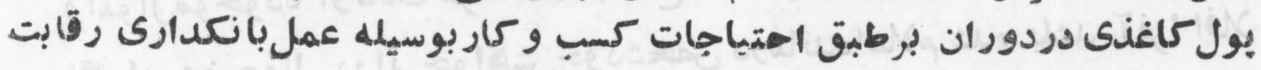

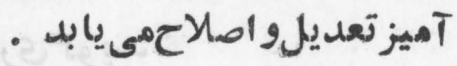
banking system.

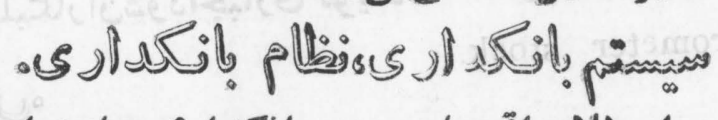

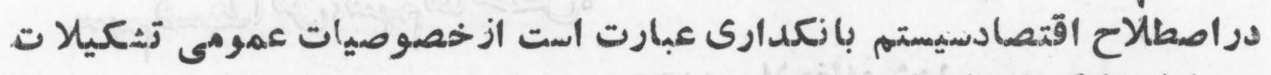

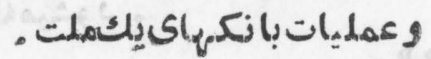
crq. 
banknote.

$$
\stackrel{\infty}{=} \text { sises gisib }
$$

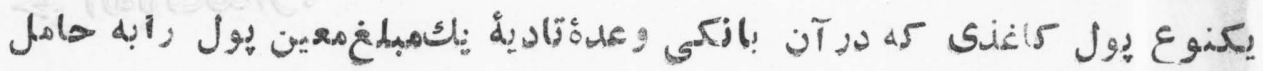
bank of issue.

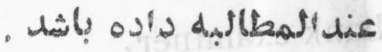

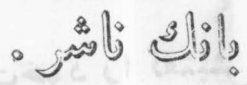

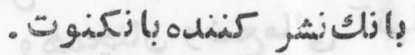
bank post i emittance.

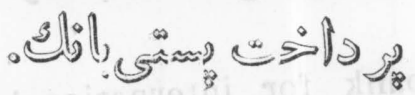

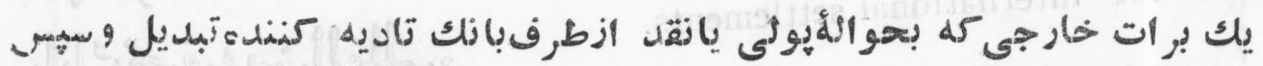

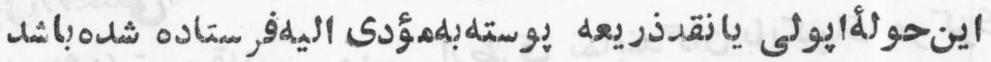
bank reserves.

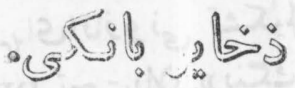

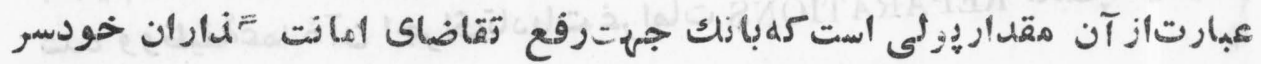

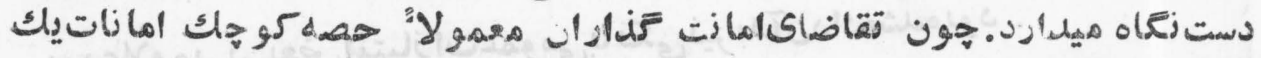

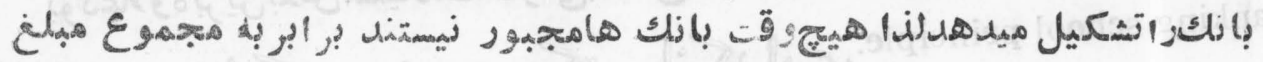

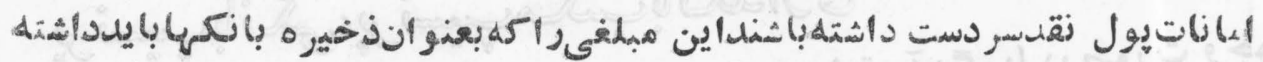

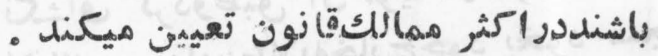
bankruptcy. -

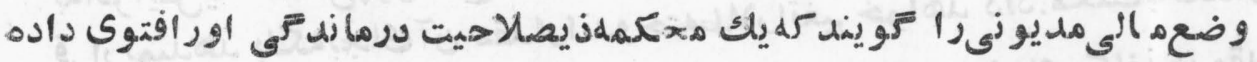

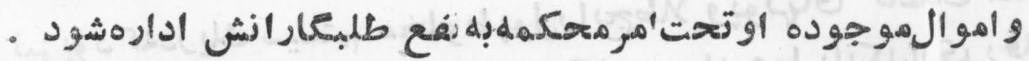

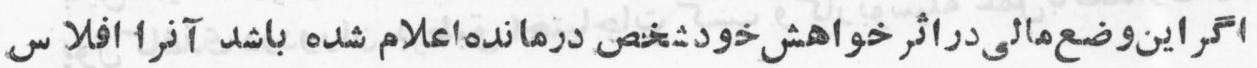
أر ادىواتر دراثر درخواسهت طلبعار انشوداجمبارى تموينل barometer stock. ن

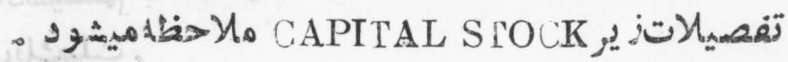


barter.

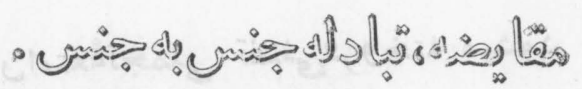

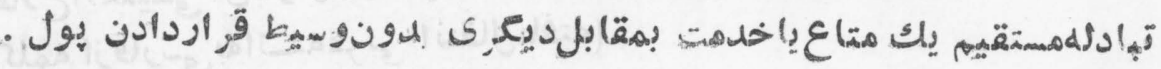
base pay . ه

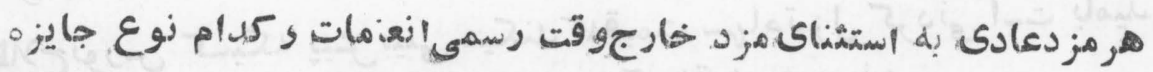
base rate.

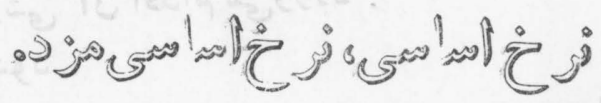

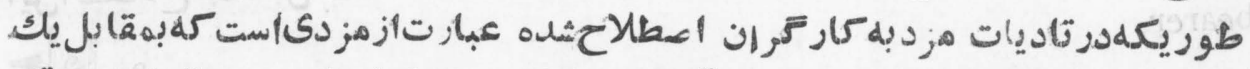

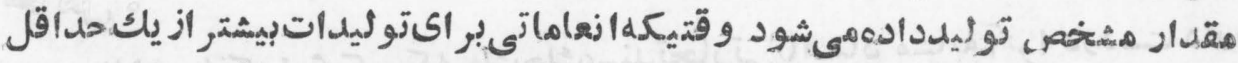

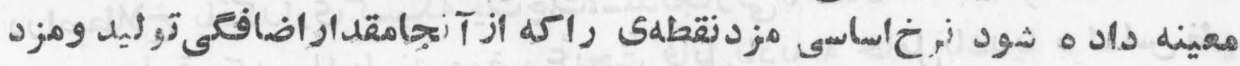

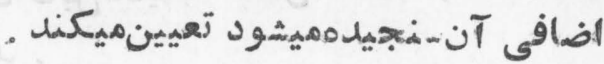

basic yield

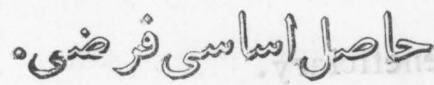

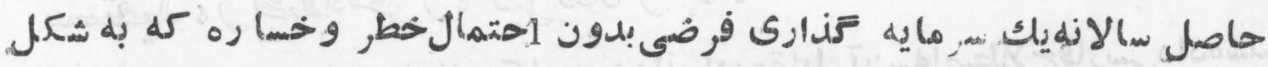

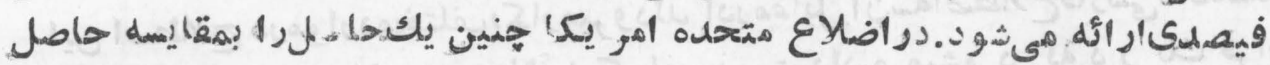

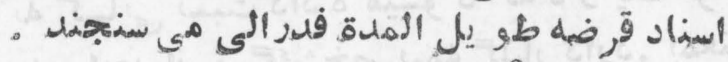

basing-point system.

$$
\therefore e_{0}^{\infty}
$$

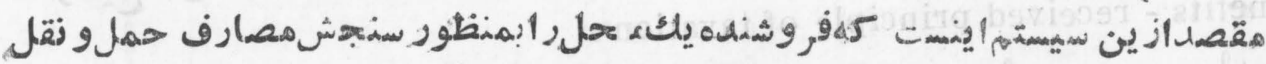

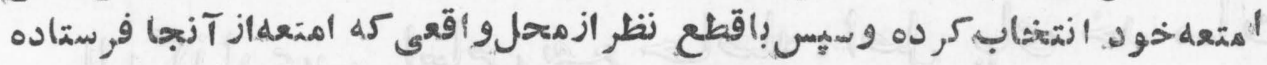

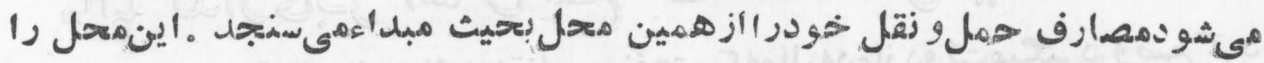

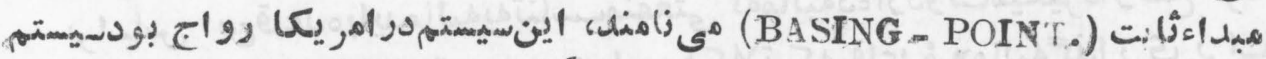

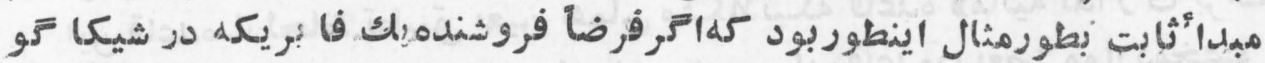

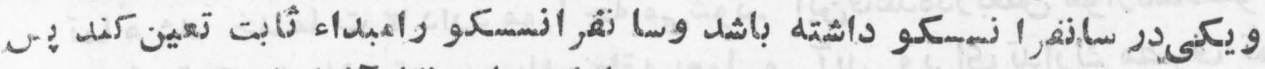

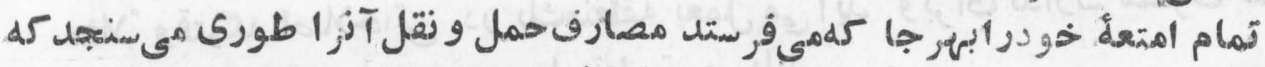

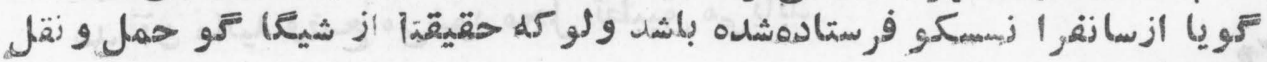
شله باشيد هـ 
bazaar.

- गीjँ

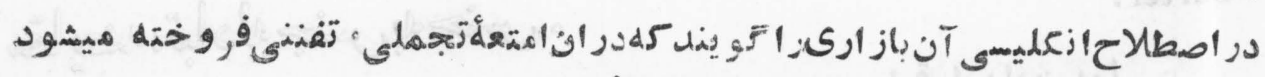

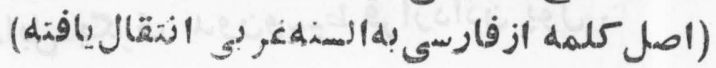

bear.

נקו

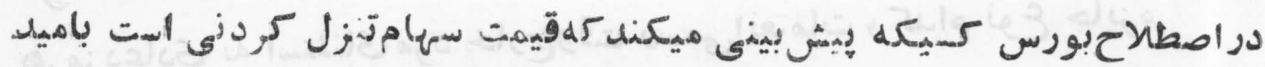

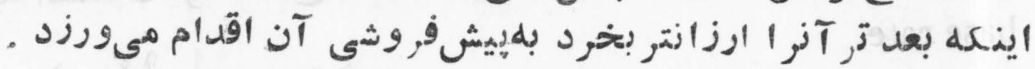

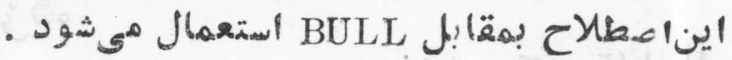

bearer. - كolos

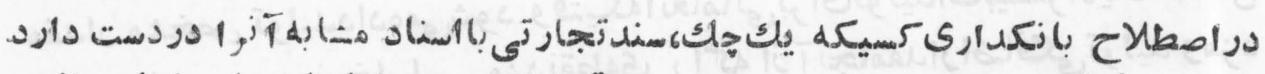

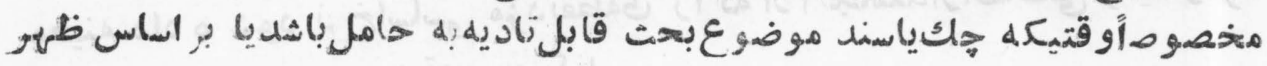

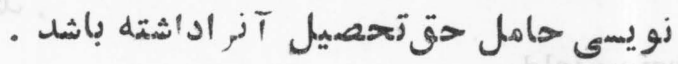

beneficiary.

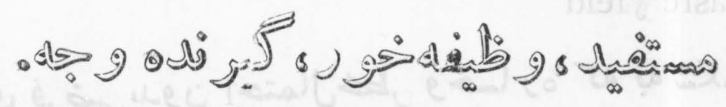

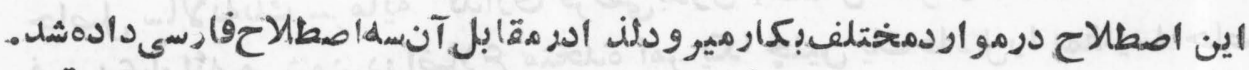

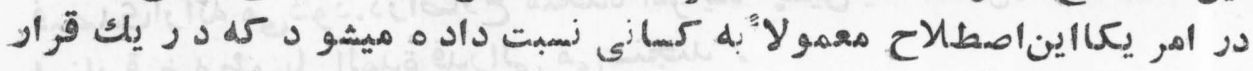

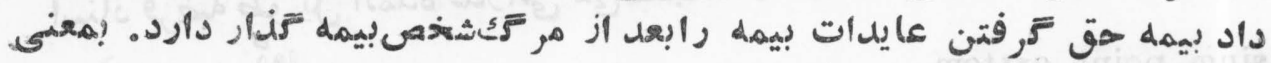

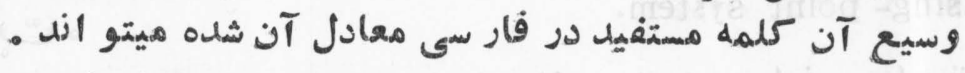
benefits - received principle of taxation.

ه

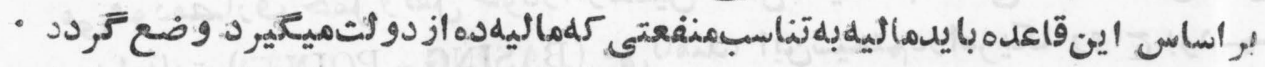

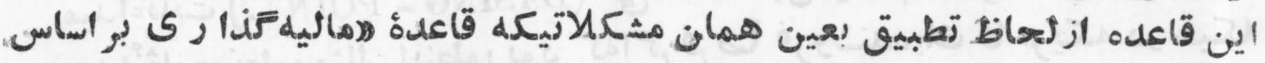

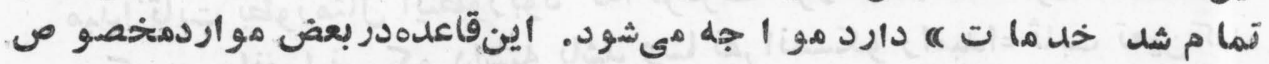

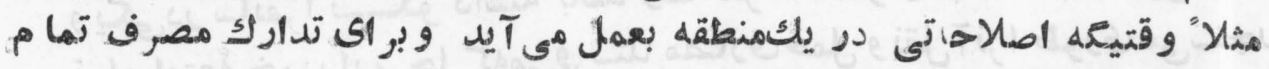

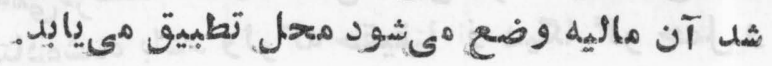

arpo 
bequest .

$$
\text { 莙 }
$$

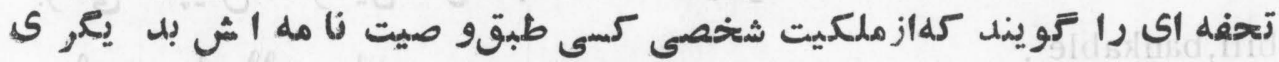

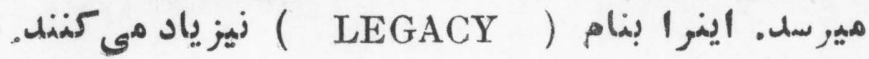

bid.

$$
\text { 岁 }
$$

مقصود الزيش زهراد خريد است بيكقيمت معين.

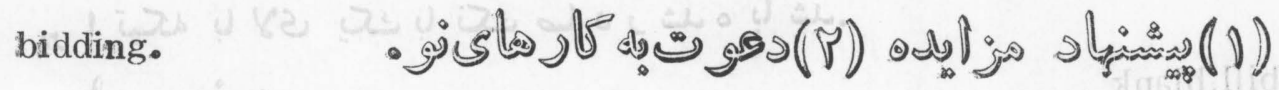

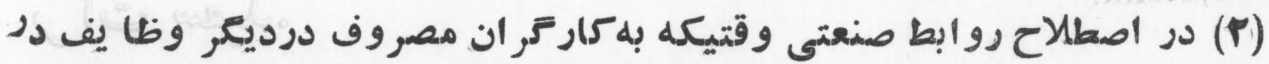

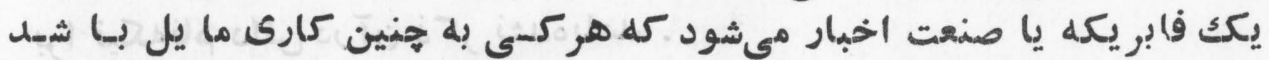

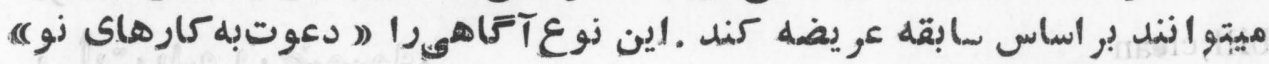
( Fوينهد (BIDDING . )

big board.

$$
\text { : 30 }
$$

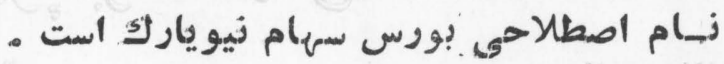

bilaterál agreement .

$$
\text { هو }
$$

قرار دادى ته بين دوطرف عقد شلده باشد .

bill.

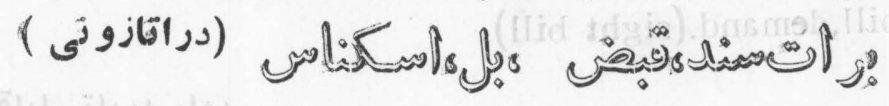

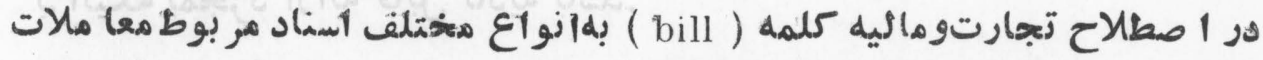

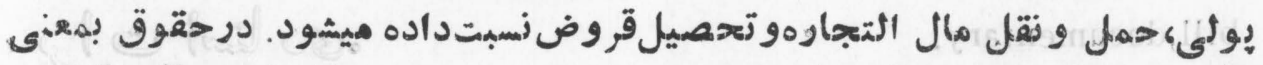

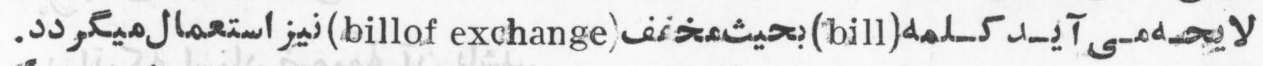

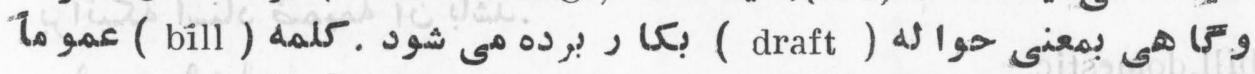

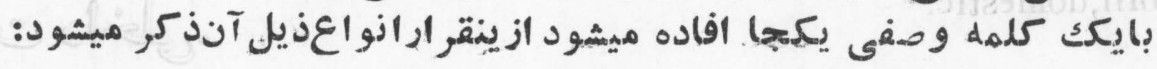

bill, acceptance.

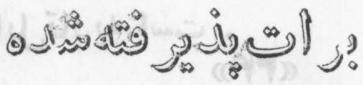

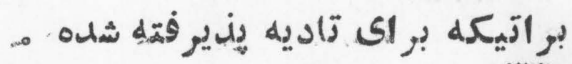


bill,advance.

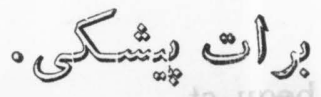

براتى كلييش ازترسيل مال التجاره صادرميشود.

bill,bankable .

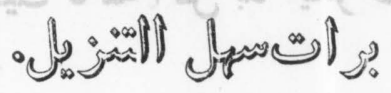

bill,banker,s .

بر اتيكه بهآسانىاز طرف بانكتنزيل شود)

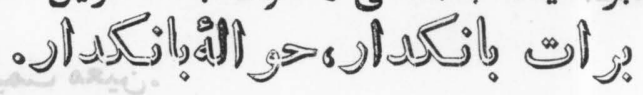

بر ا تيكه با لاى يكك با نكك صا د ر شده با شد.

$$
\text { व }
$$

برا تيكهنام دأئ درآن ذكر زشلدهباشد.

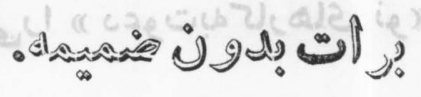

برا تيكه اوراق ضميمه نداشته باشد)

bill,continental .

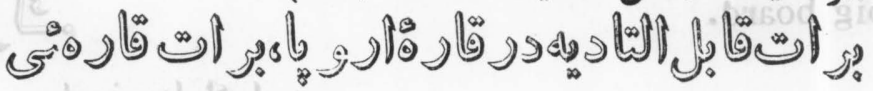

bill,credit .

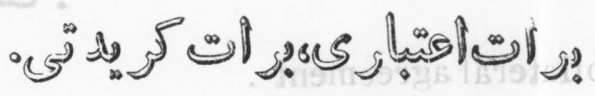

(بر اتيكه بdمقابل كريدت مديون صادر شده باشد .

bill,demand.(sight bill)

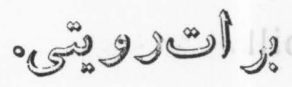

$$
\text { براتيكه بمجرد ارائه قابل تاديه باشد. }
$$

bill,documentary.

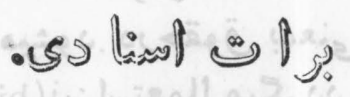

براتيكله اسناد ضميمل آن باشد.

bill,domestic.

$$
\text { जी }
$$


(نوت: دراتازو زي، بر اتيكه تنهادرايالتى كه هادرشله قابل تاد يهباشد. ) bill, finance.

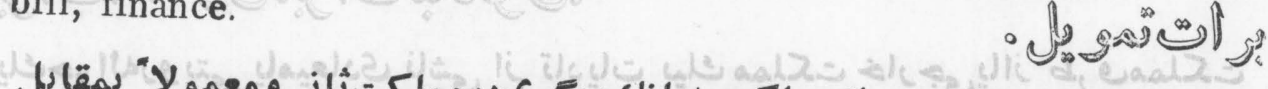

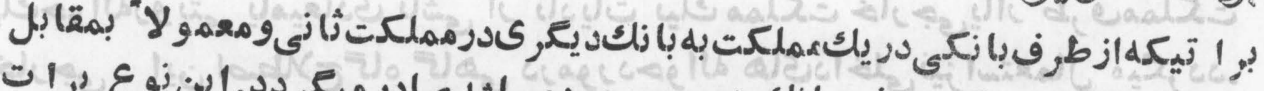

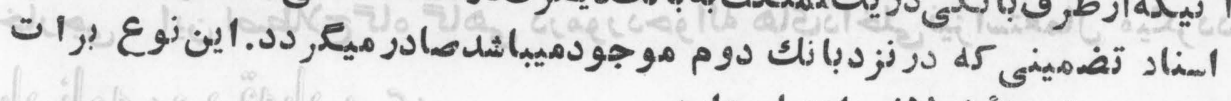
bill,foreign.

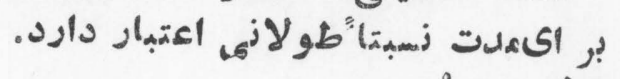

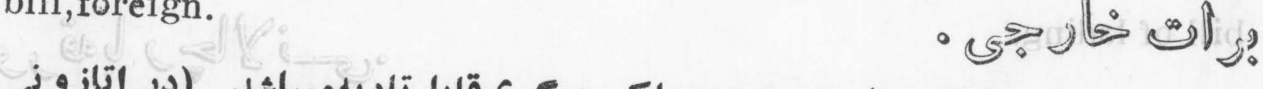

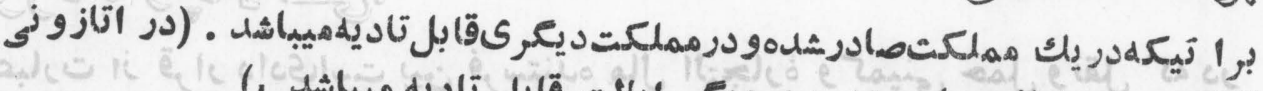

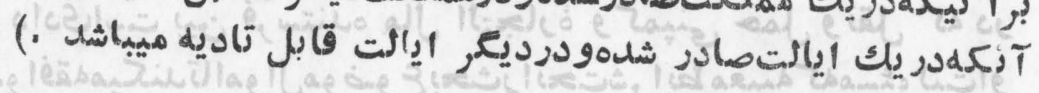
bill'inland .

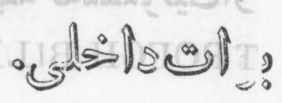

برا تيكلهدريك مملكت صادر ودرهمان مملعكتقابل بل تاديه ميباشل. bill'investment.

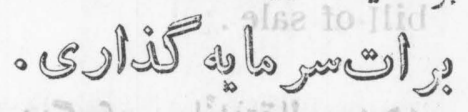

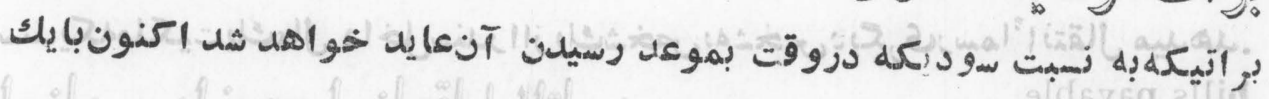

b , payment.

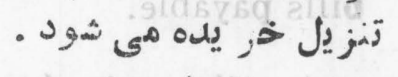

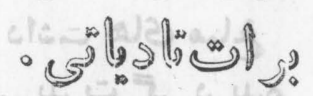

- براتيعه بغرض تاديه ارأيهميشود زله بر اى قبولى

bill,prime .

مj

bill,time .

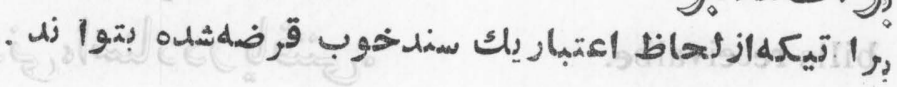
- CSSlasenes? راتيكه در ريك تاريخ آئلده تاديه شد نى باشهل .

bill of credit.

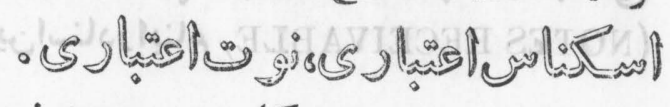

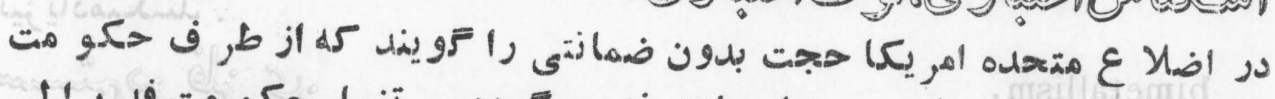

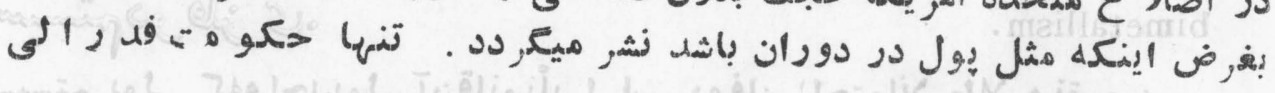


حق نشر جنين اسكناس هاىاعتبارى أرادارد .

bill of exchange.

$$
\text { ( }
$$

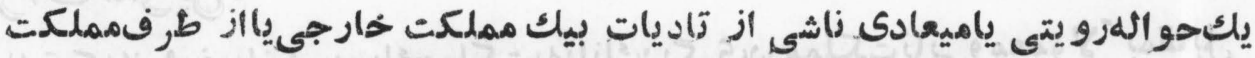

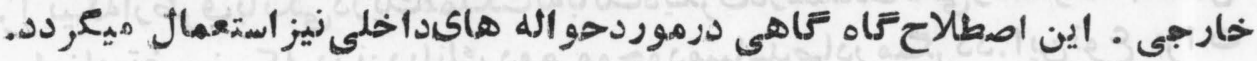

$$
\text { o s }
$$

bill of lading.

$$
\text { ज }
$$

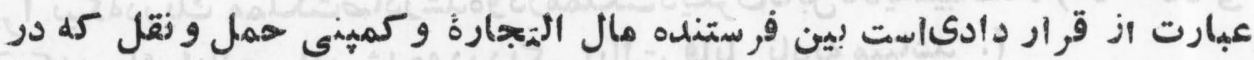

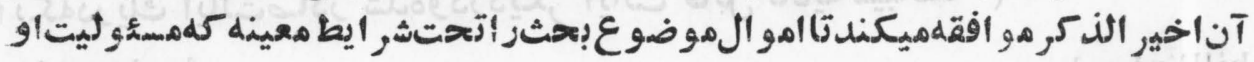

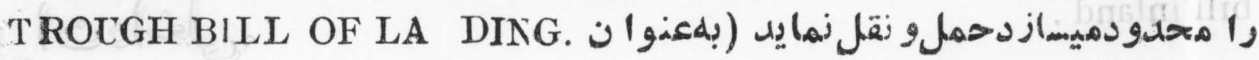

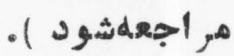

bill of sale .

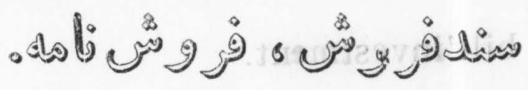

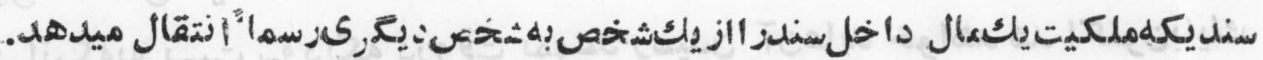
bills payable.

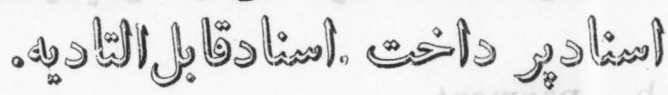

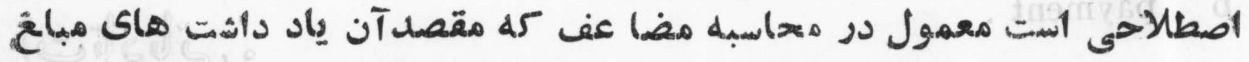

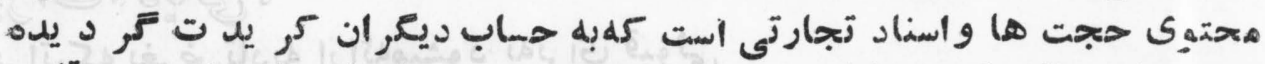

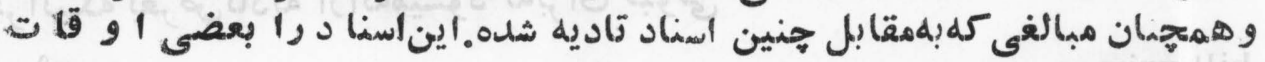

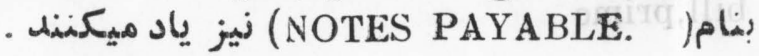

bills receivalbe.

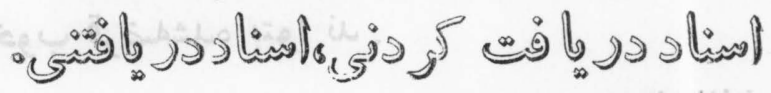

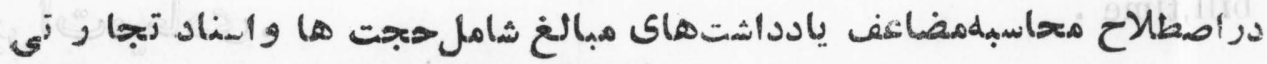

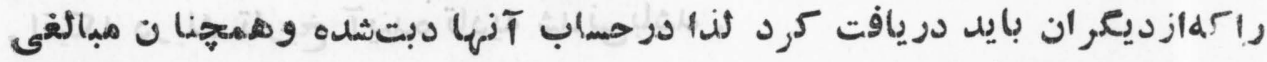

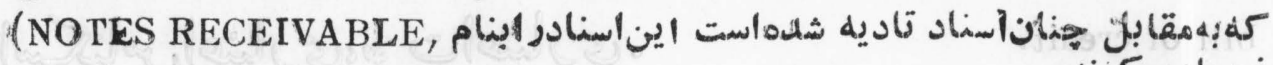

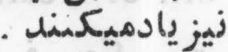

bimetallism .

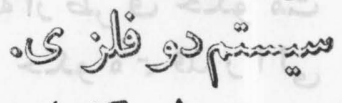

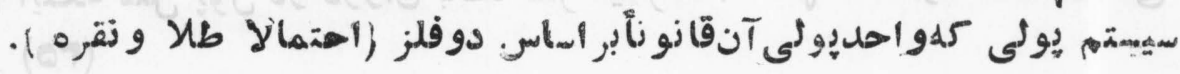
(1) 


\section{BLA}

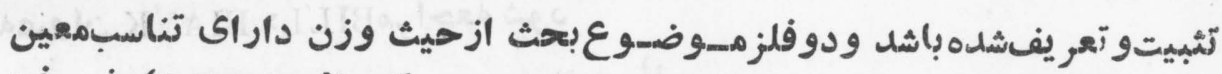

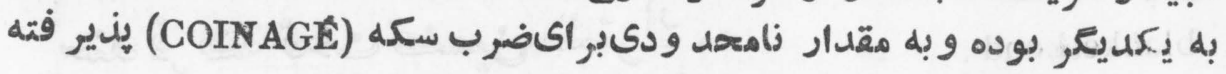

binder.

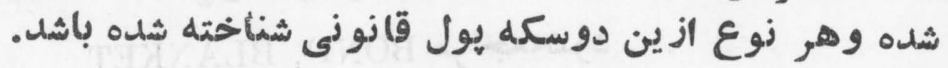

$$
\text { - dang dija }
$$

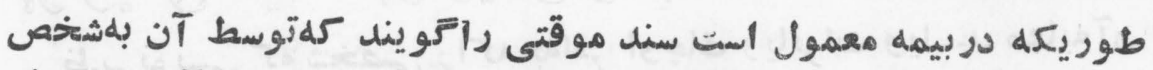

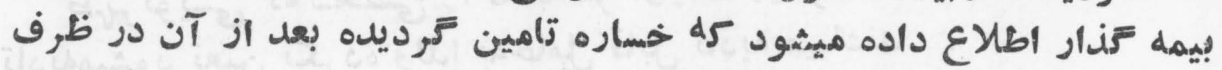

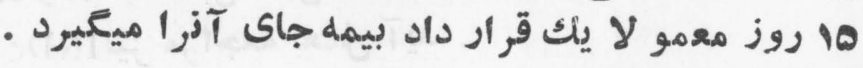

birth rate.

$$
\text { - }
$$

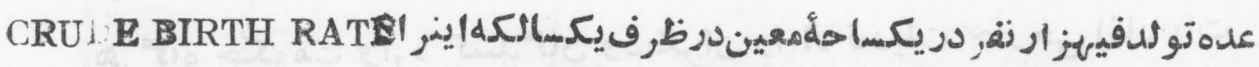

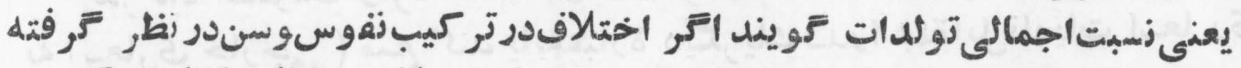

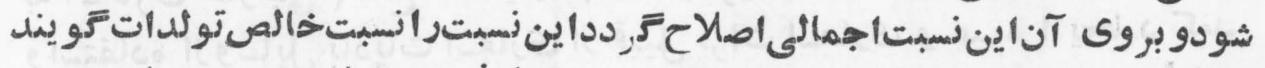

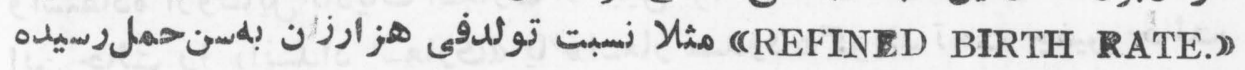

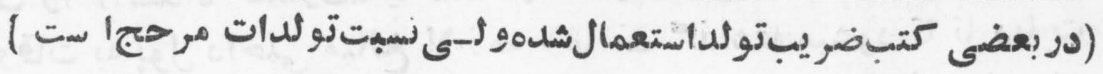

black list.

$$
\text { - ه ه }
$$

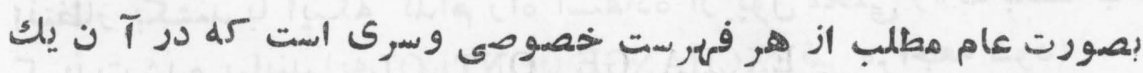

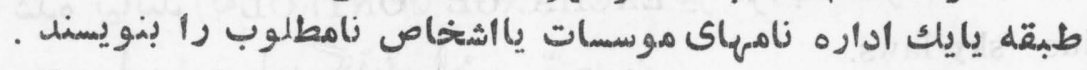

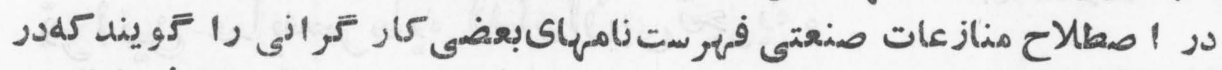

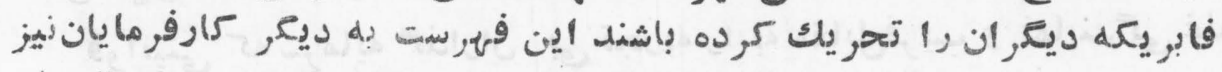

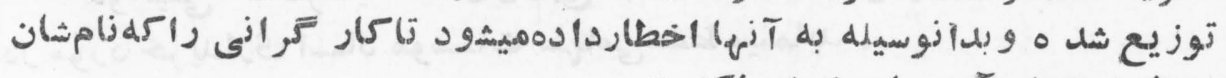

black market.

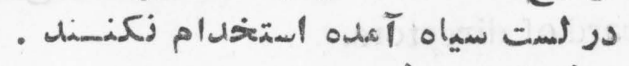
- Olim gijo

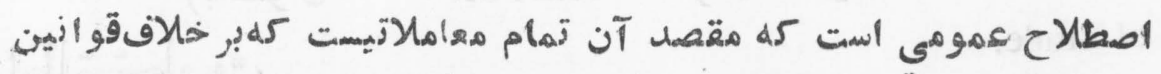

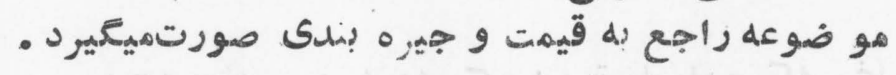

blank bill

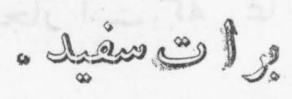


بهر اجعه شود BILL, BIA K K بود

blanketlond. . 3) هـ

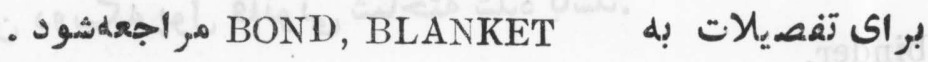
blank indorsement .

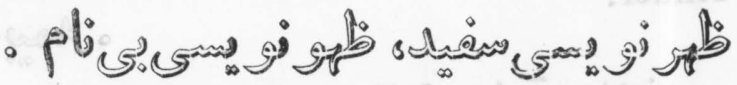

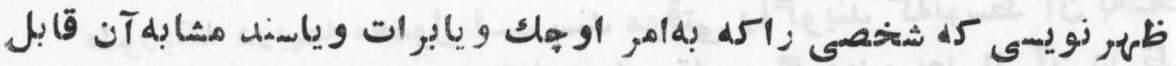

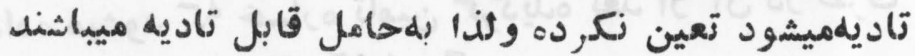
به عنوان . نيز هر اجعه بعهل آيل .

blocked exchange-

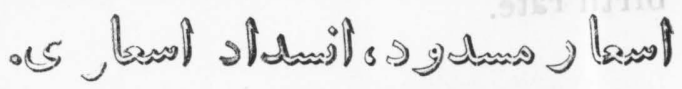

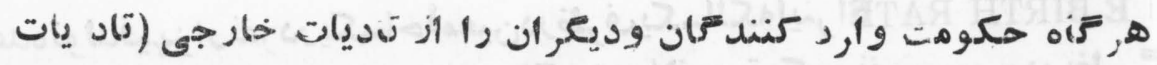

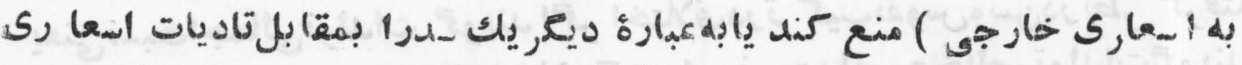

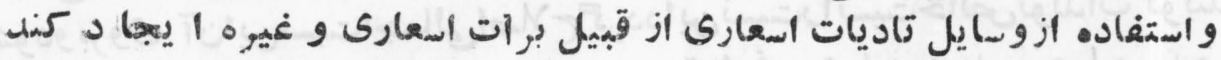

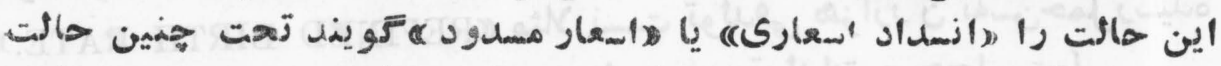

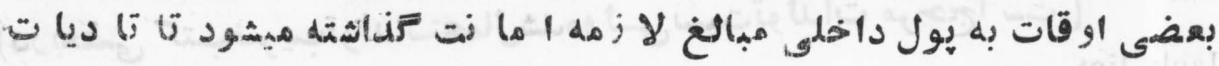

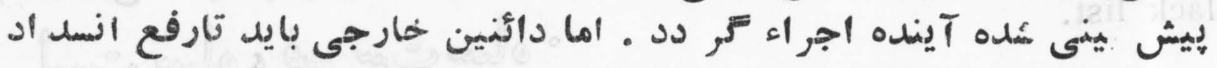

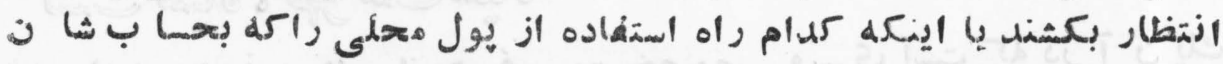

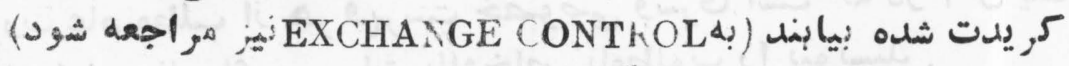

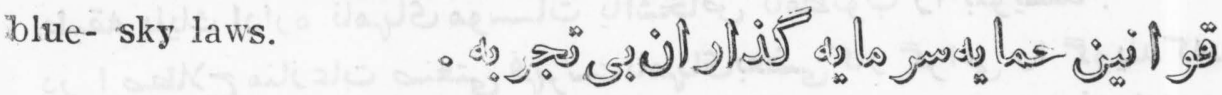

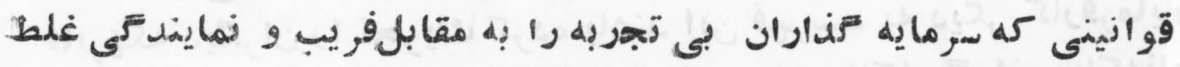

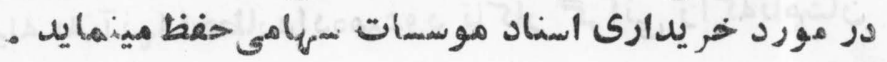
board of directors.

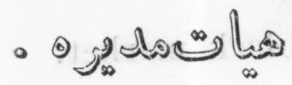

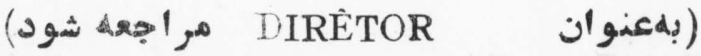

board of trace.

$$
\text { . }
$$

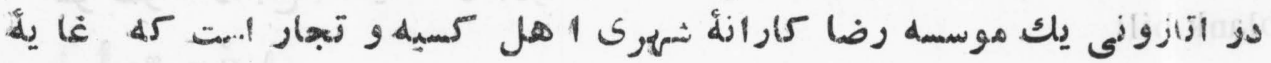
(rAD 


\section{BON}

آن ريثبرد رفا ه عمومى اجتماعى ، صنعتى ، ومدنى ميبا شل در د ئكر جاها

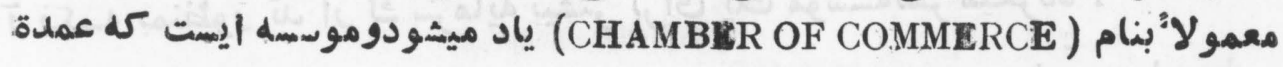

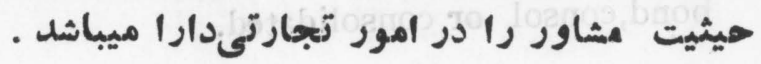

bond.

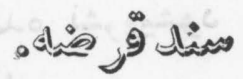

يك تصديق زامه مليو نيت است.باينمعنف كلدر بازائ 1 سنا د بيثتر معمو ل هلم

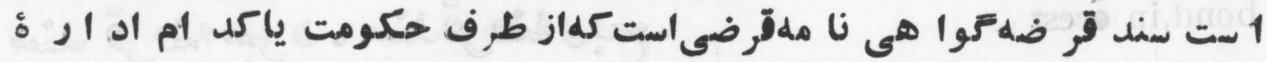

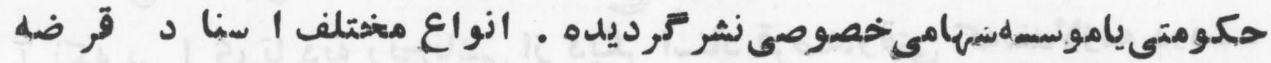
از ينقر الر اسهت: -

bond,colonial or bond,insular.

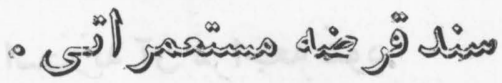
Tنكله توسط يك مستعمر s زشر شلهمباشل. bond,municipal.

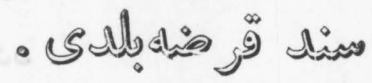

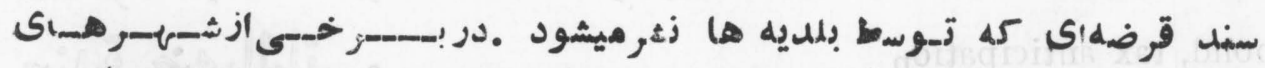

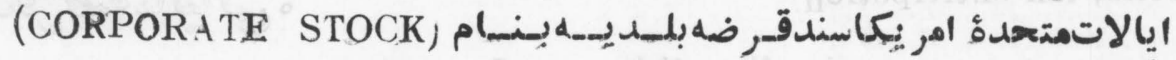

bond,public. يأد ميرشود.

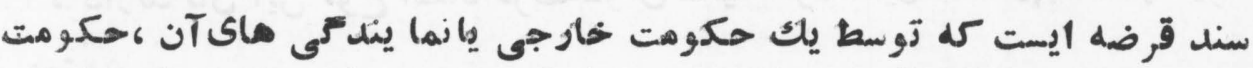

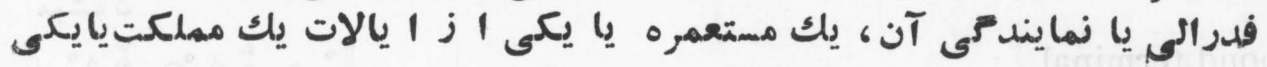

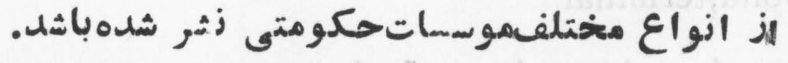

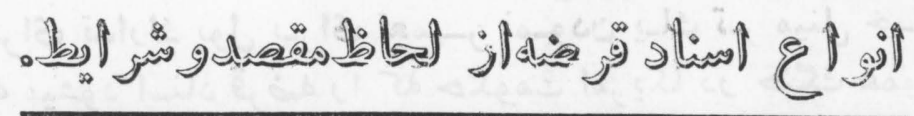

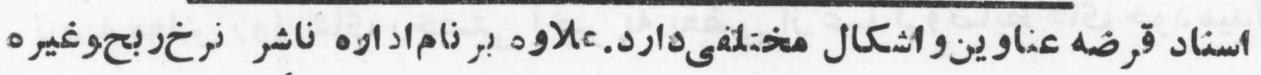

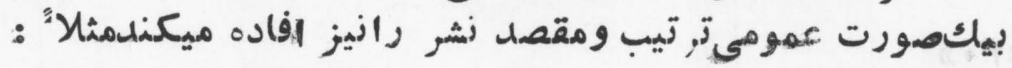




\section{BON}

bond,adjustment

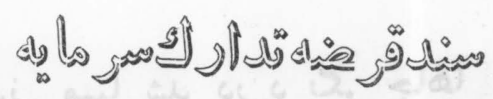

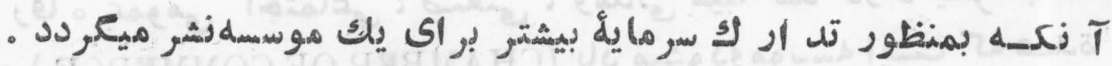

bond,consol or consolidated.

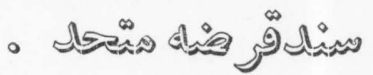

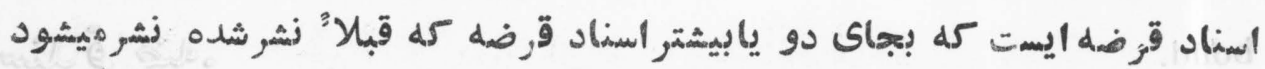

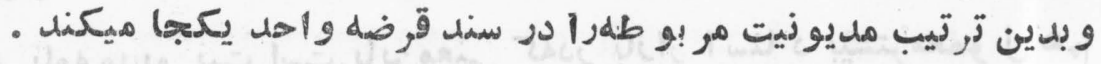

bond,in erest .

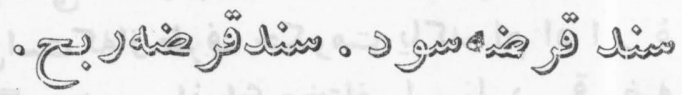

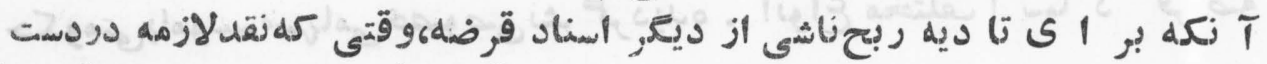

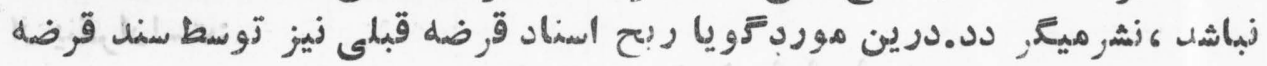

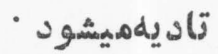
bond,reorganisation . - به استووبه آن مر اجعه شود. (BONDADJUSTMENT ) UAisto

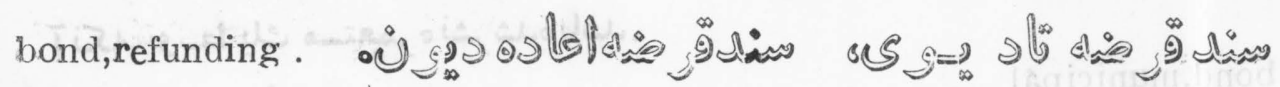

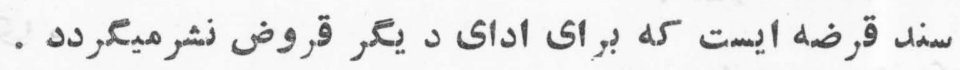
bond, tax anticipation.

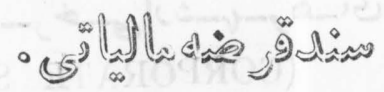

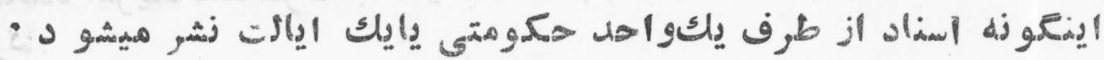

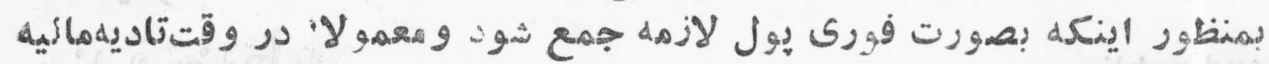

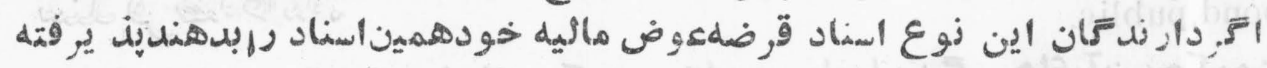

bond,terminal . هيشود . مير

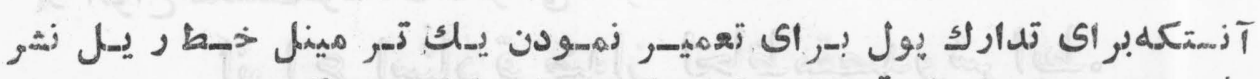

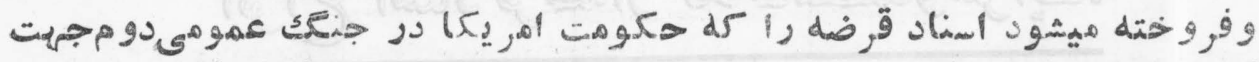

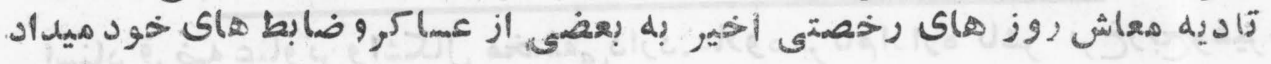




\section{BON}

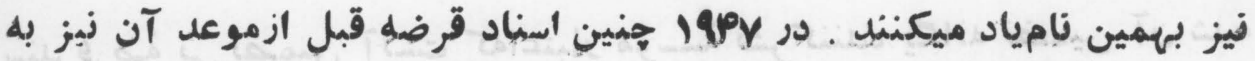
bond, unified

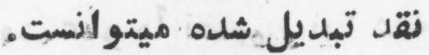

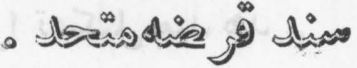
عينا" ماننل (CONSOLIDATED BÒND) است كهدر فوق تعر يف شيد.

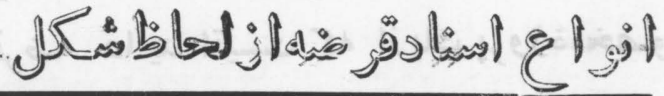

bond, coupon.

$$
\text { - Jी }
$$

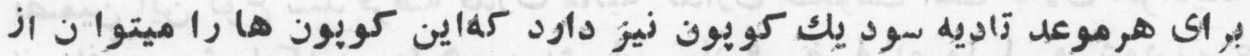

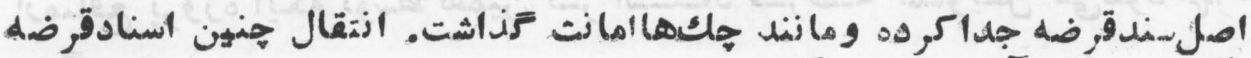
bond,interchangeable.

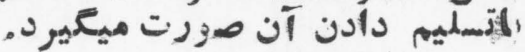

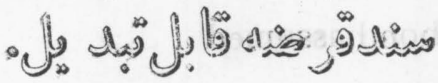

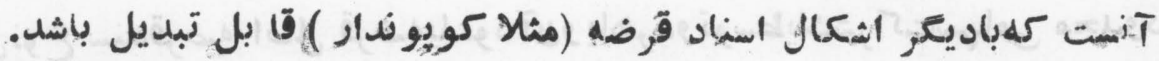
bond,interim. (

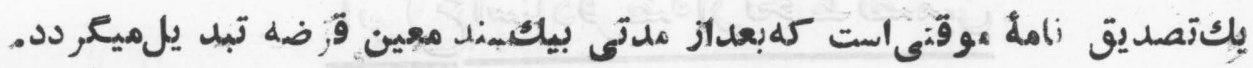
bond, registered. sodi心

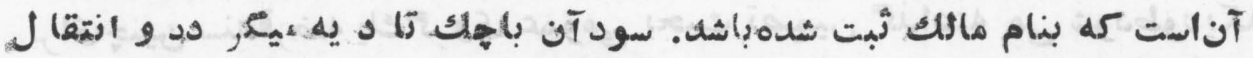

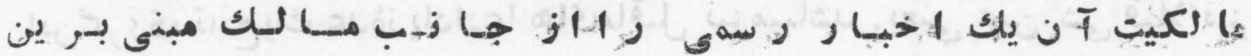
bond, registered coupon.

$$
\text { هU }
$$

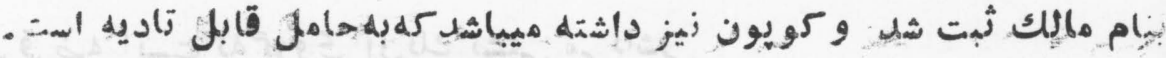

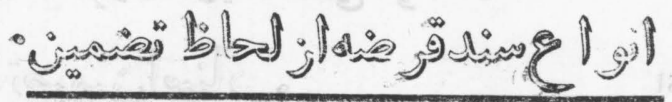

bronil, debenture.

$$
\text { - C }
$$




\section{BON}

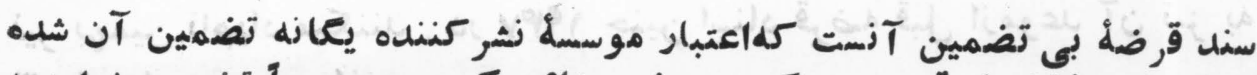

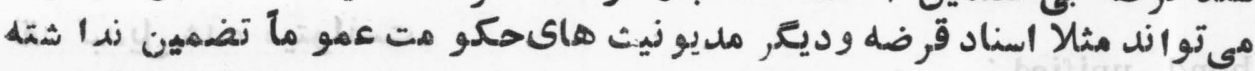

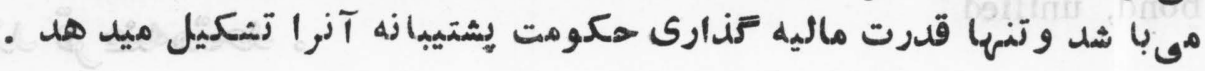
.band,rerenue.

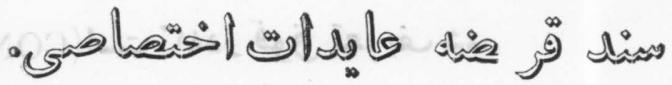
تضمين جنين سند قرضه عا يد اتيست كه ازيك هروزؤمنصصوص بلدسثمى آيد.

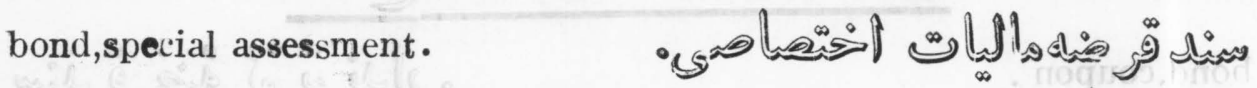

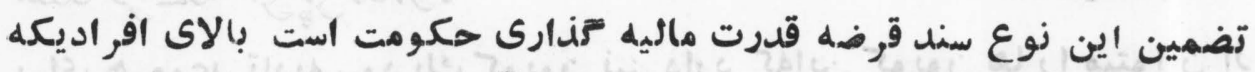

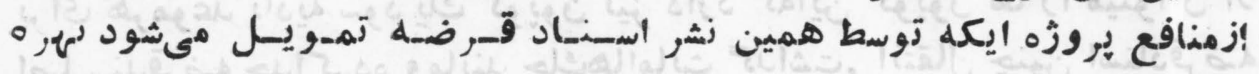
مى تىير نل.

bond,assumed .

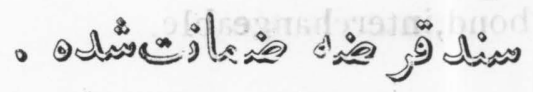
درين نوع سندقرضه اصل قرضهياسود آنو ياهردو توسطيكشر كتسهامى محدود

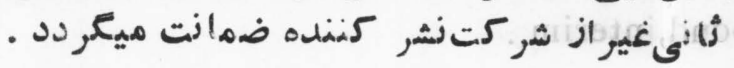

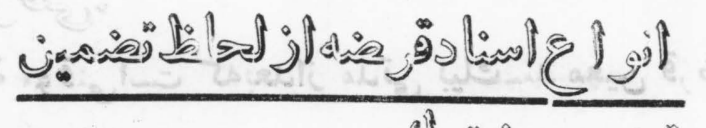

bond, blanket .

$$
\text { - 3) 告 }
$$

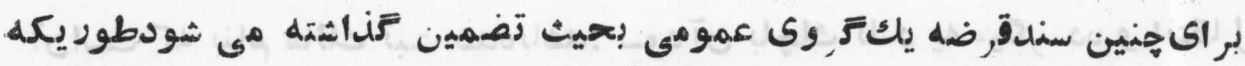

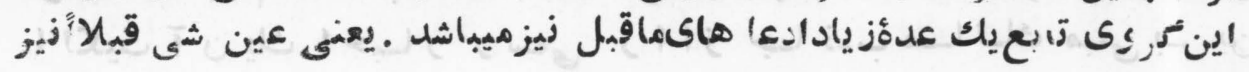

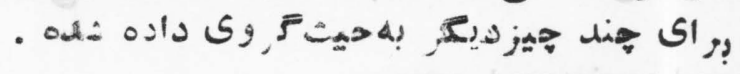

bond, botțomry.

$$
\text { ज院 }
$$

$$
\text { سند قرضه اليست كله تروى آن ياك كشثى مو بأثر }
$$

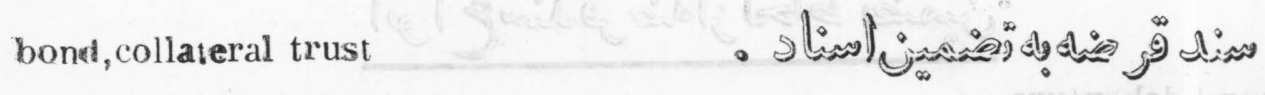

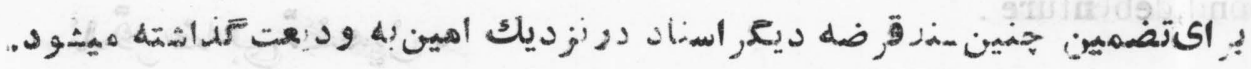


bond, divisional .

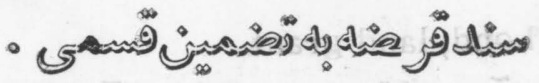

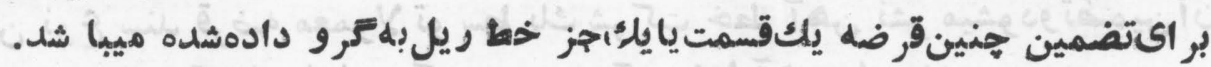
bond, equipment trust - نا

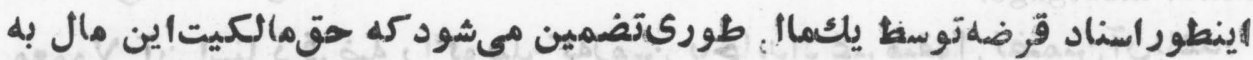

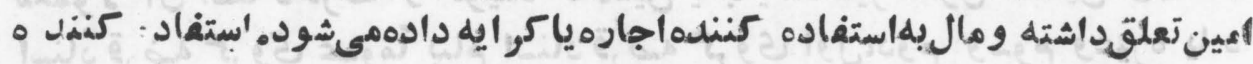

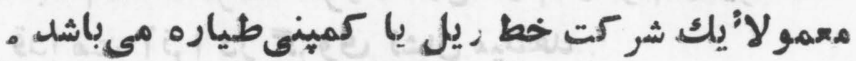
bond,extension.

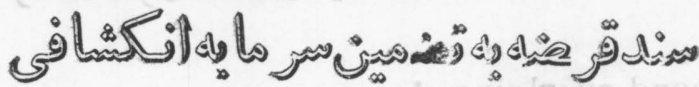

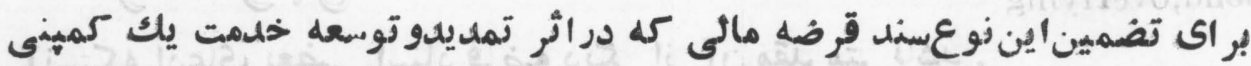

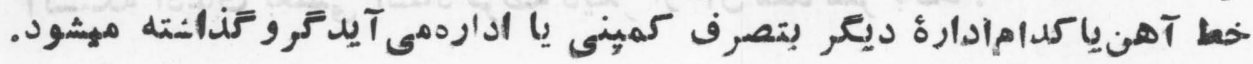
bond, first - lien. -

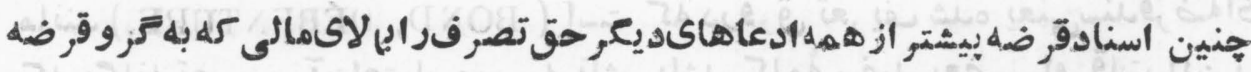
bond, guaranteed.

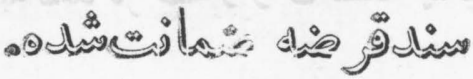
عاننل مCND , ASSUMED است كهدروقوقتعريف شده . bond, indorsed - Oـ

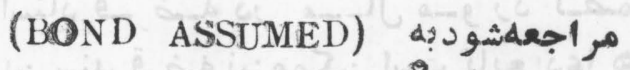
bond, junior - lien.

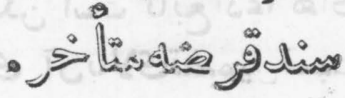
آنست كلدر حتوادعاى خوددر يكتروى نسميت به د يتر اسفاد قرضه د' راى عين - الستحقاق

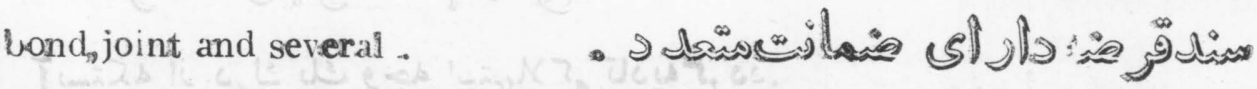

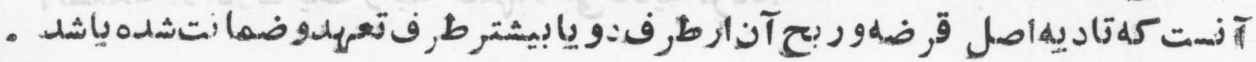


bond, land grant.

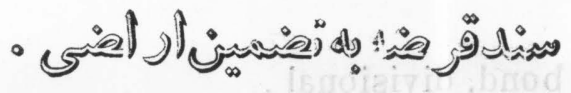

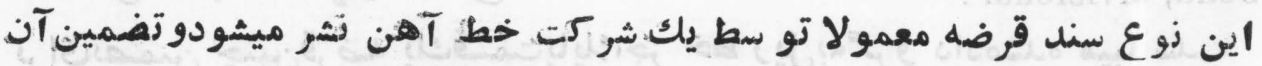

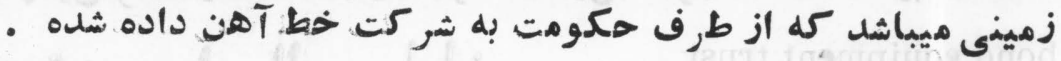

bond, mortgage.

- ज9s

هعهولا آن اسنا د قرضه راتوينل كلزمين ياجإيلأ غير منقول تضمين آن بإشد.

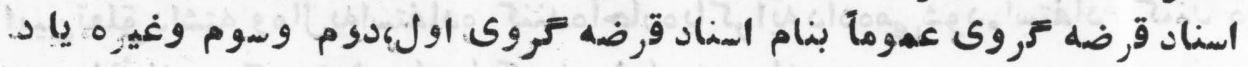

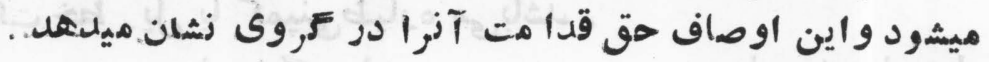

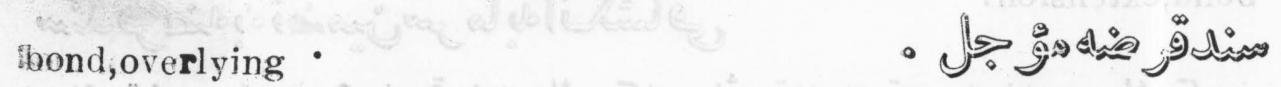
آنستكه ادعاى بعضى اسناد قوضه ديعر از آن مقد متر بإشل .

ibend,plain .

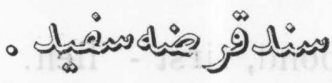

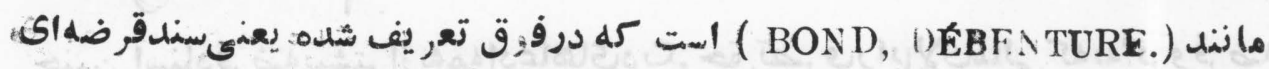

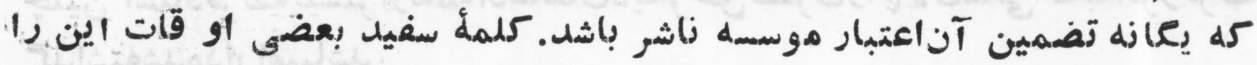

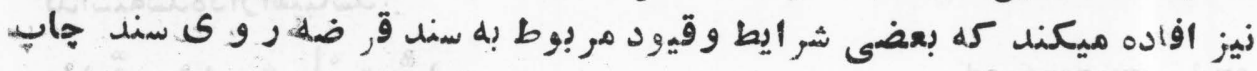

$$
\text { نكرديده }
$$

bond, prior-lien.

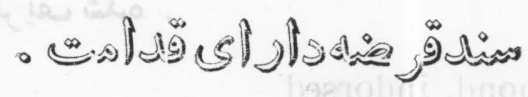

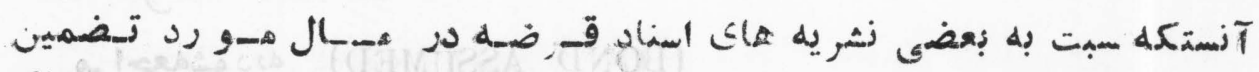

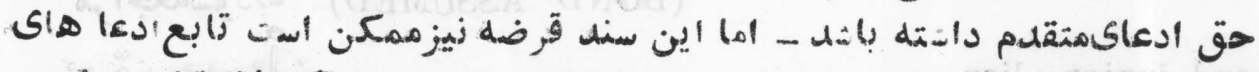

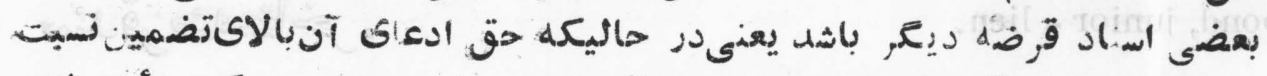

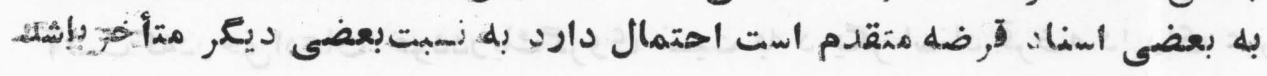
bond, sinking-fund.

$$
\begin{aligned}
& \text { ه }
\end{aligned}
$$

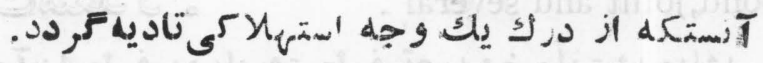


bond,stamped .

C C آنستكه شر ايط ومقرراتمخصوص بالاى آننوشته شله باشد . bond, underlying.

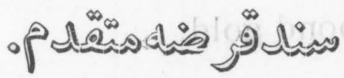
سند قرضه اى كه حق ادعاى مقدم رابالاى مال مورد تضمين داراميهاشله. bond, aunuity.

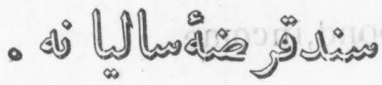
سند قرضه ايست كلموعلد بسر, رسيدن ذدارد وربح آن بطور ثير مجدل ود بو قت

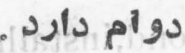
bond,callable.

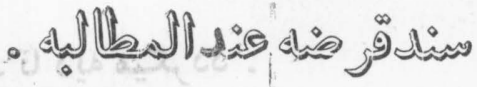
آنستكه بمجرد داطلل ع علهامل قابل ابتياع باشه . bond, eontinued. - P 9 dutiodi

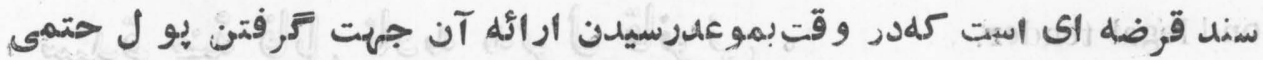

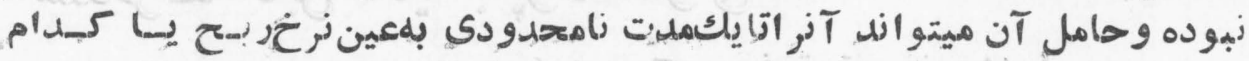

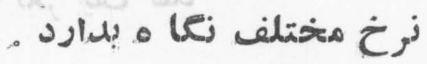
bond, convertible.

$$
\text { - 署 }
$$

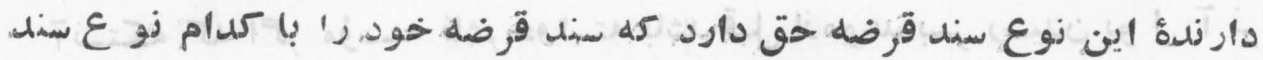

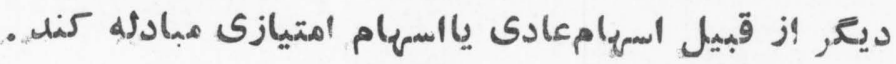
bond, curcency . bond, de ierred.

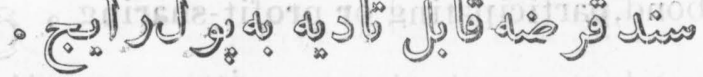

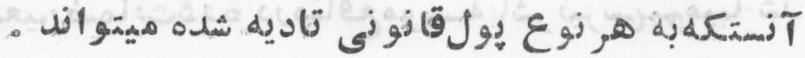

$$
\text { ه人: }
$$

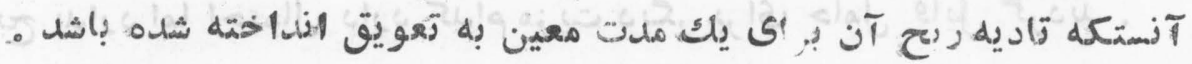


bond, extended .

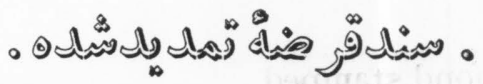

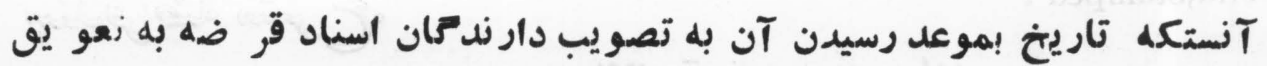
bond gold. انداخته شده باشل . T. Tنستكه تاديلّ" Tان به سCه طلأكى دار اى يك وزن و عيار معين صورت ميعيرد . band,income.

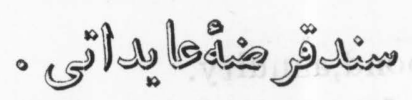

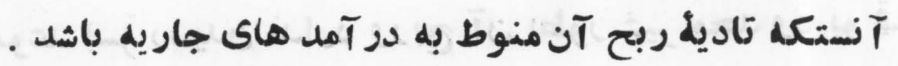

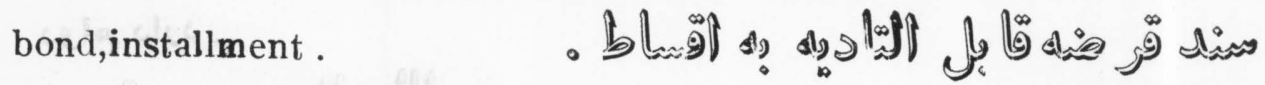
اينظور اسناد قرضه در ظرف حند سال بهاقساط تا ديه ميكردد .

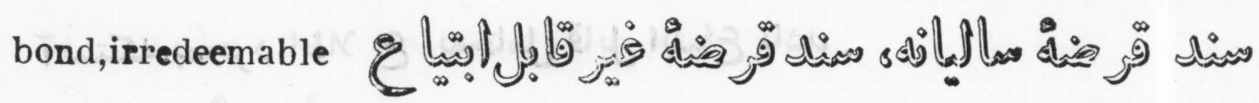
مانندسندقرضهس.اليانهاست (مر اجعهشودبه. BOND , ANNUITT) bond legal tender.

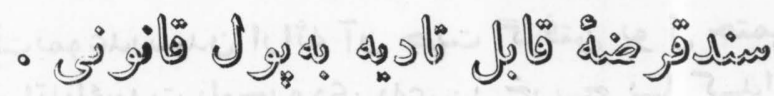
مانند ( BOND , CURRENCY) است كله در فوق تعر يف شد • bond,optional. - ज)

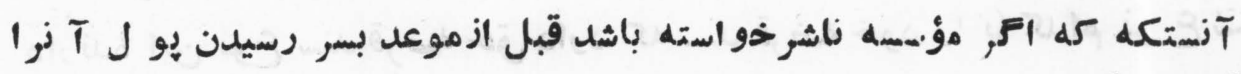
تاديه همكند . bond,participating or profit-sharing •

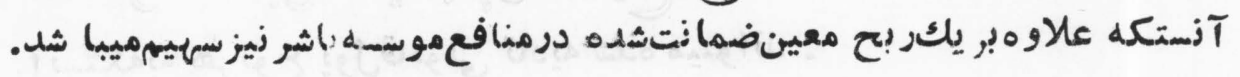
bond, passive.

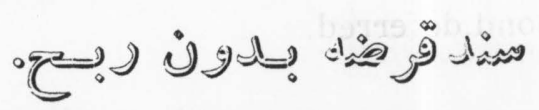

ربح ندارد امل احتملال دارد كدام مزيت ديع.: بر ایى حامل قايل ترددند . 
bond,perpetual.

- ज行 مانند سندقرضه شاليازه) (AÒND , ANNUITY) مت كه د ر فوق تعريف شده.

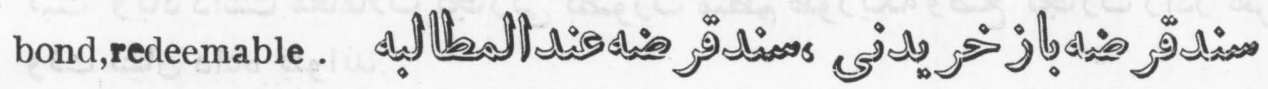
مائن BOND, CALLABLE است وبهآن رجوع شود bond,serial .

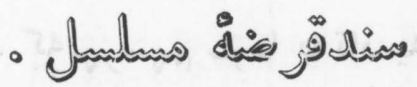
يك نشريه اسناد است كه موعد سروسيد آن در ظرف جند سال بيى هم تـر تيب شده باشده.

bonded goods .

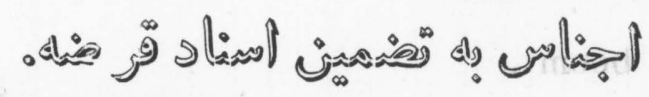

اجناس وارده ايكه دريك تدام رهنى تمهركى تحو يل و نعاه دار ى مى مشود.

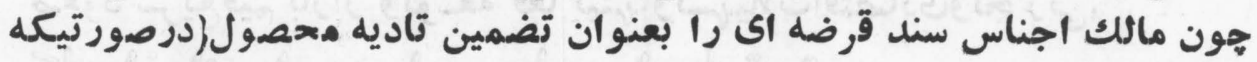

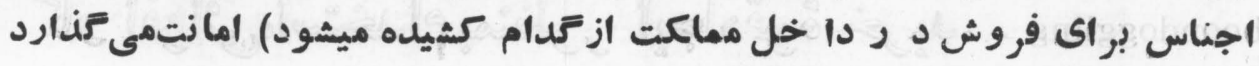

bonded ware house.

$$
\begin{aligned}
& \text { لنا اجناس باين نام ياد مي شود. } \\
& \text { s }
\end{aligned}
$$

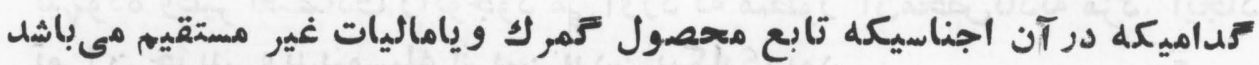

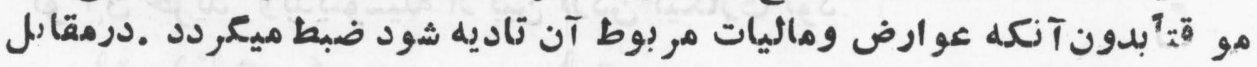

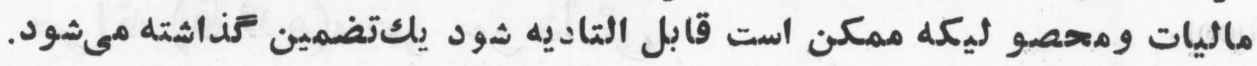
bypnus .

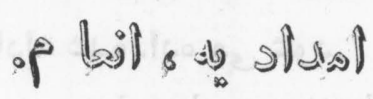

امدا ديه ایى 14 عللاوه برتاديات معمولى(مزديامعاش)درمقابل خدمات بر دا خته له

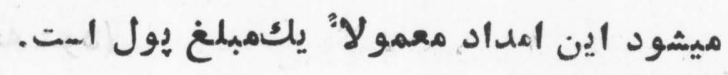
bonus stock.

$$
\text { ه }
$$

( STOCK, BONUS ( ) رجوعثود به 
bookkeeping. - E S ثرت و ياد داشت معاملات تجارتى بصورت منظميم طوريكه وضع تجارت رادر هر

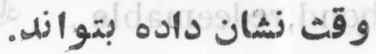
book value.

$$
\text { (5) }
$$

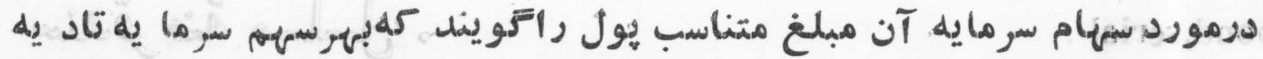

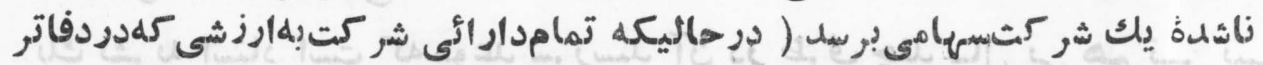

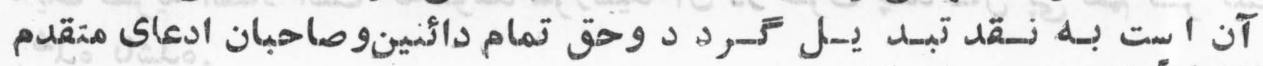

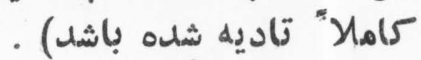
boom.

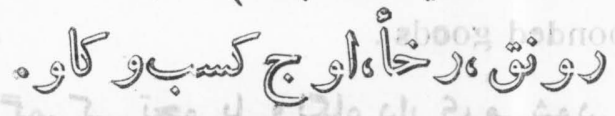

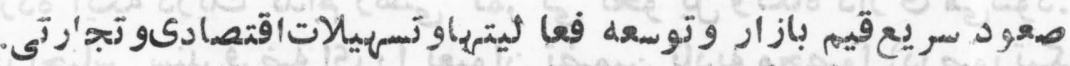
boondoggling. Ad .

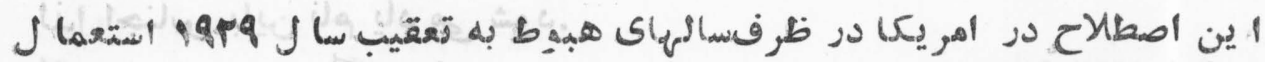

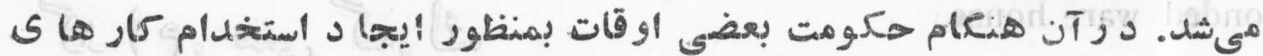

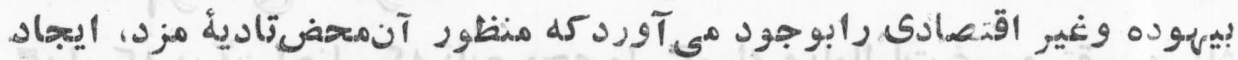

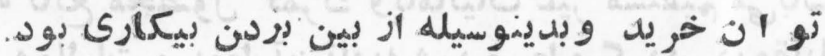

boot.

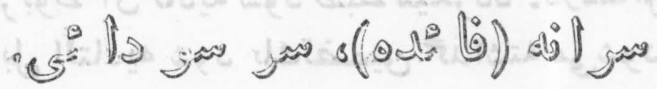

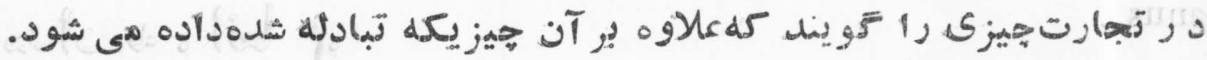
bottomry bond.

$$
\text { ( }
$$

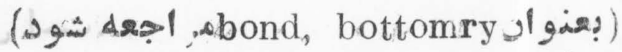

bounty.

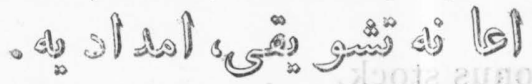

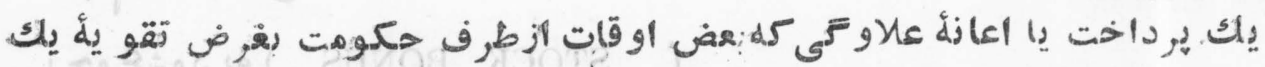
صن: 
bourgeoisie .

يعنى شمهر ا ست و مطلب

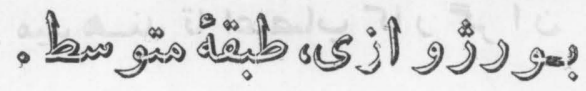

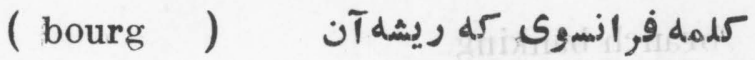
از ازهل تجارت شهر ميباشد .

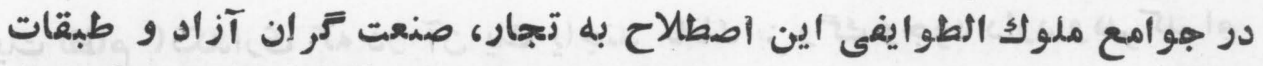

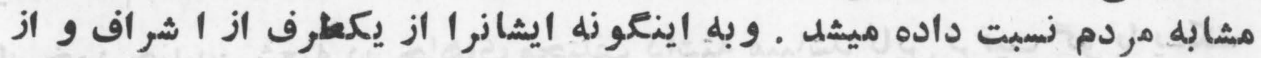

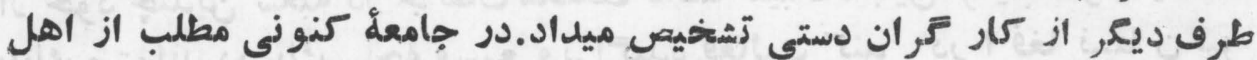

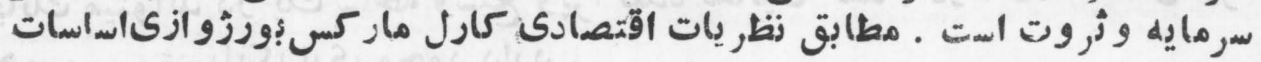
جامعله قد إم رامنقلب ساخته قدرت را بلدست آورده وخود توسط طبقه كاته

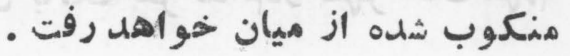

bourse.

- $\mu^{N} g=?$

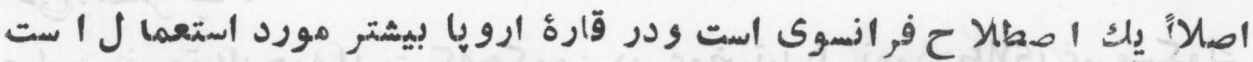

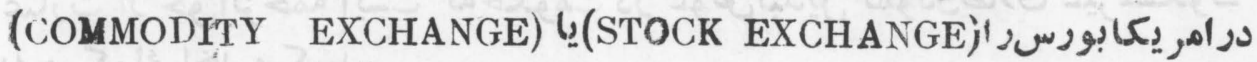

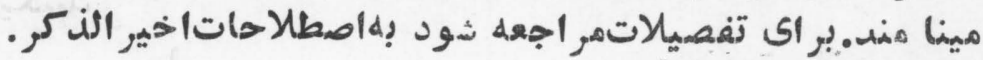

boycott.

- ¿10

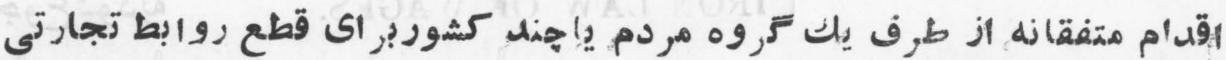

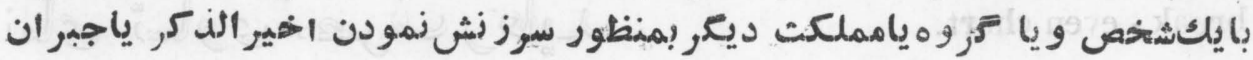

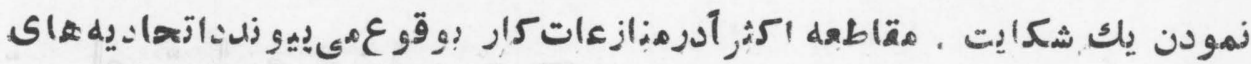

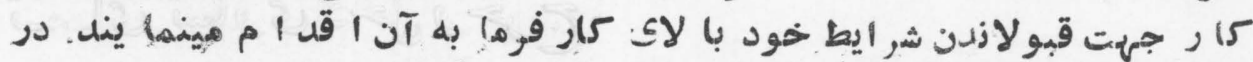

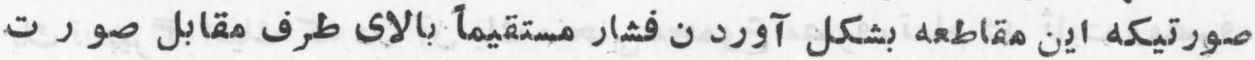
بعيو, د مقاطعه البتدلأزي (PRIMARY BOYCOTT)

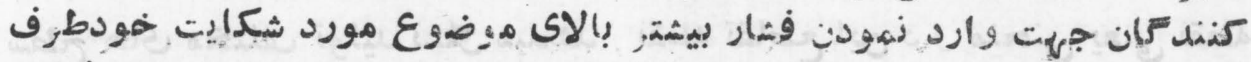

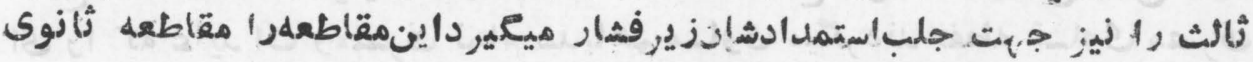
(SECONDARY BOYCOTT)

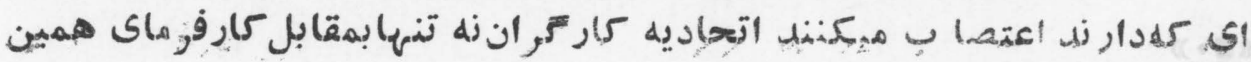




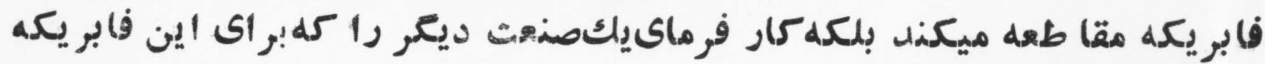

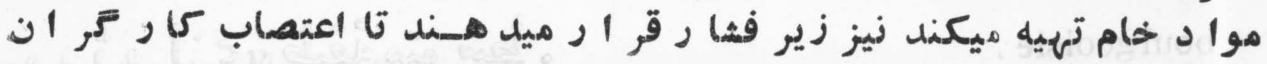
branch banking

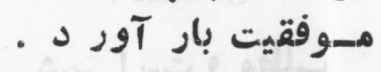

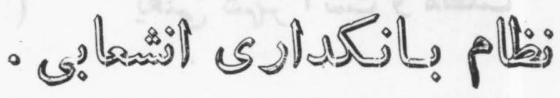

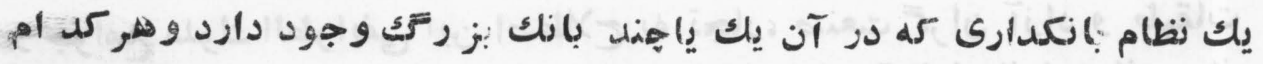

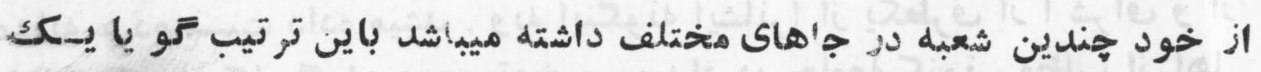

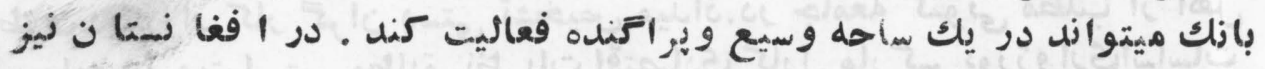

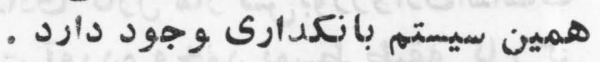

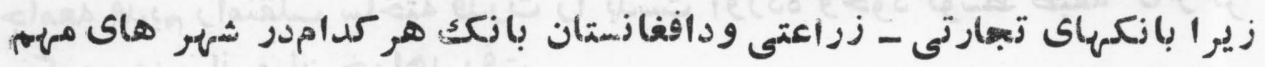

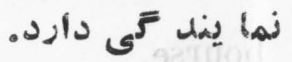

brassage.

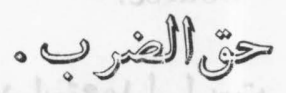

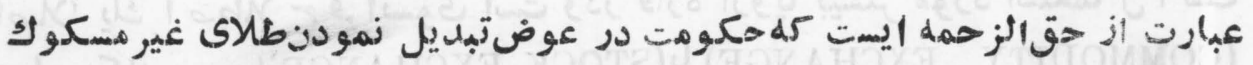

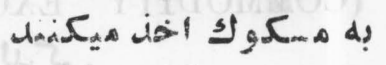

brazen 'aw of wages.

- Los

(IRON LAW OF WAGES. נجوع

break - even chart.

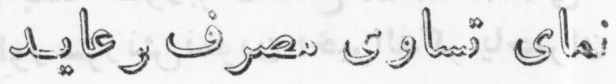

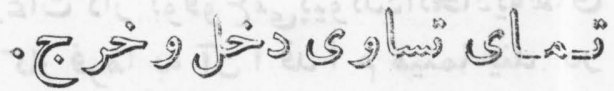

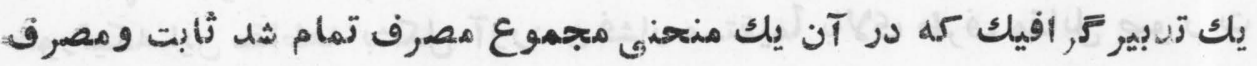

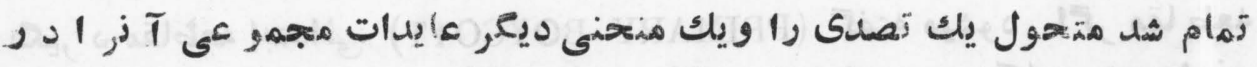

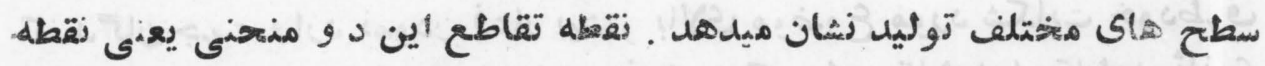

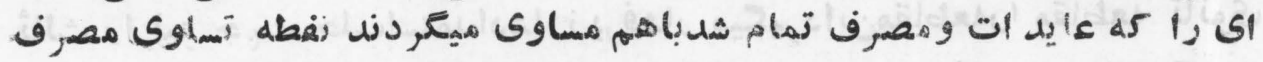

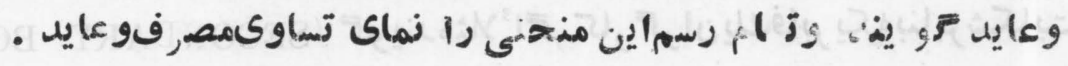


broad market .

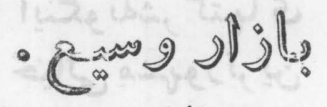

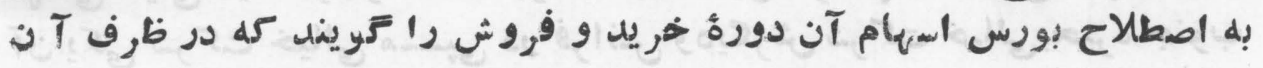

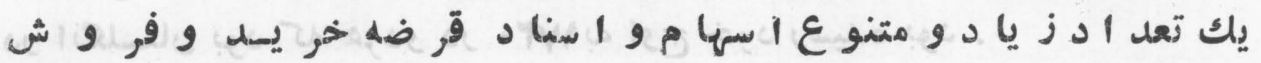
broker . ميشود . - لעs

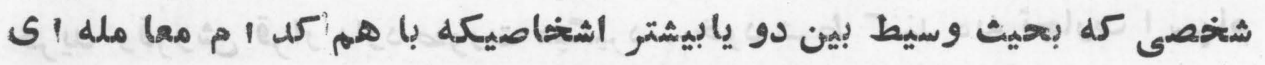

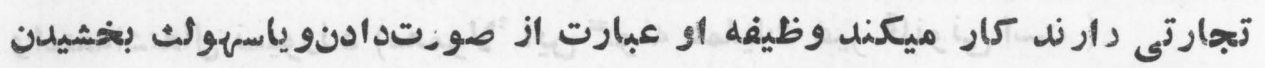

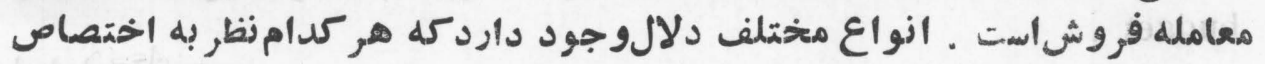

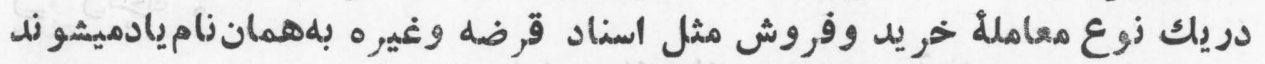

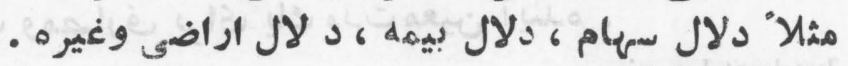
brokerage.

$$
\text { - जل }
$$

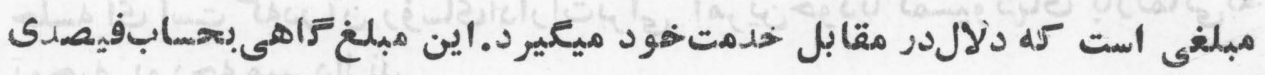

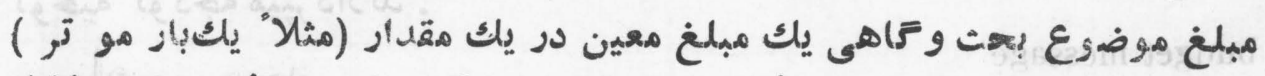

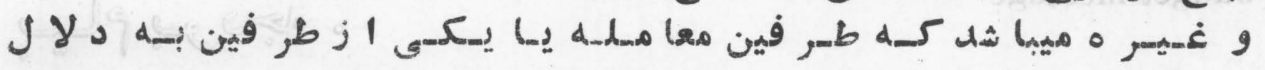
مـيـل هـد

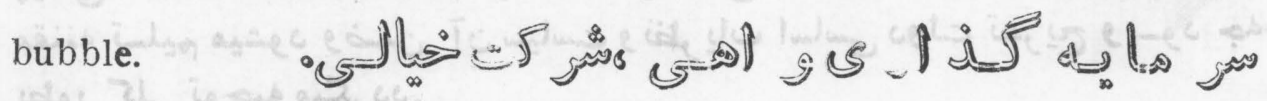
در اصطلاح اهتكار آن نوع كسب ، ياشغل مخاطره آميز غير مصئون اقتصادى

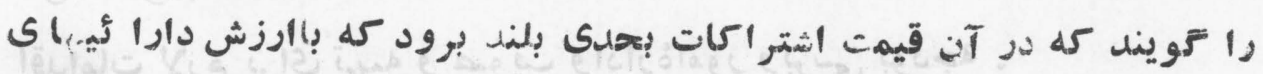

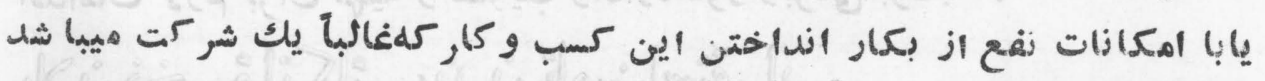

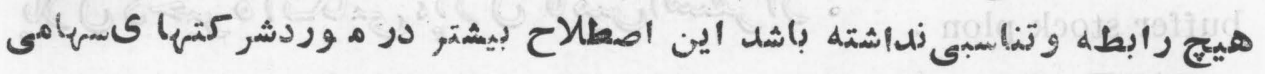

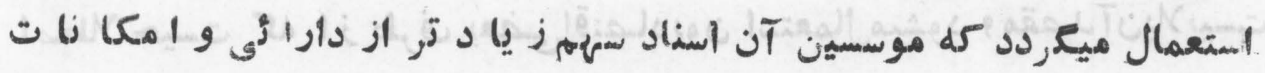




\section{BUC}

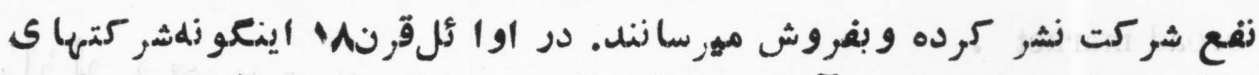

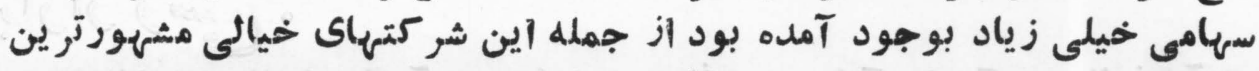

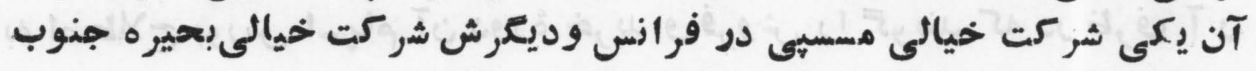

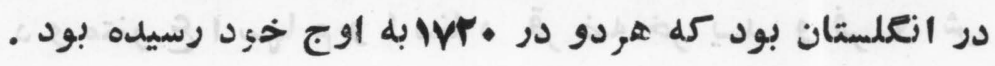
bucket shop.

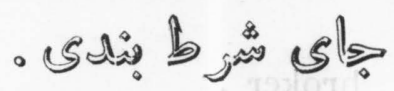

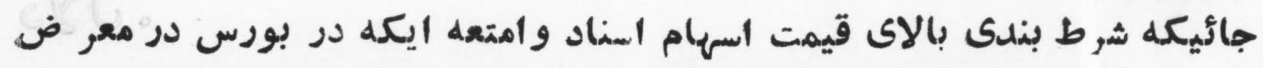

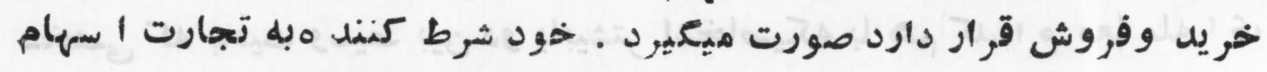

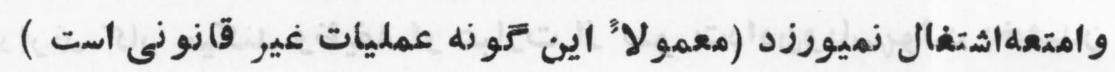
budget .

- drs $=$ ?

يك ثرمين رسمى عايدات ومصارف براى يك مدت معين آينده . budget hearing.

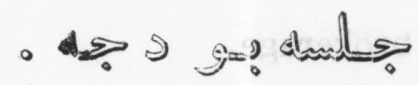

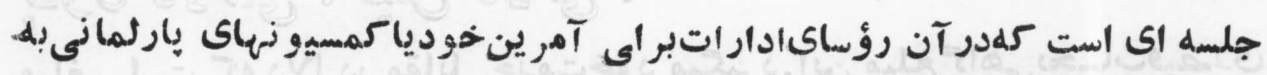
تو جيه بو دجه ميهير داز نل . budget message

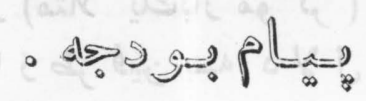

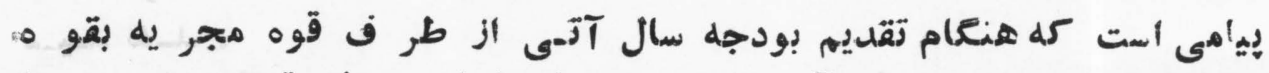

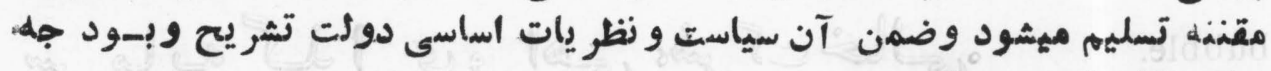
بطور كلى توجيه ميكردد.

budget process.

$$
\text { - ه }
$$

اقدامات لازم براى تهيه و تصو يب وادارة:امور وبوسى بودجه . buffer stock plon. - ol to إصطلا حيست كه از طرف إعضى اقتصاديون استعمال ميثود و مقصد آنيلانيست (OF) 


\section{BUL}

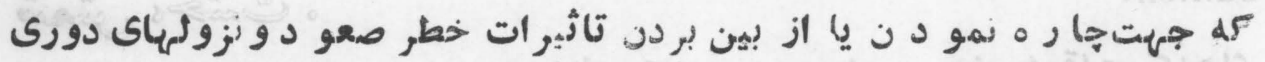

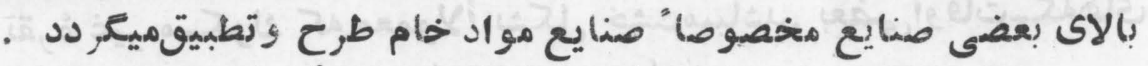

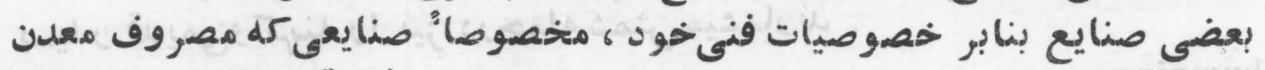

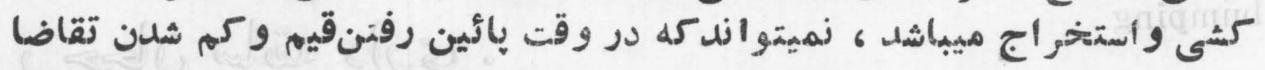

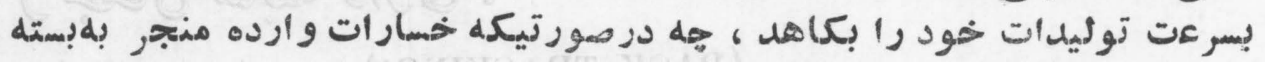

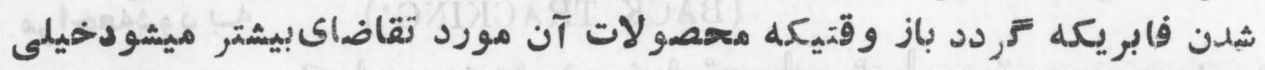

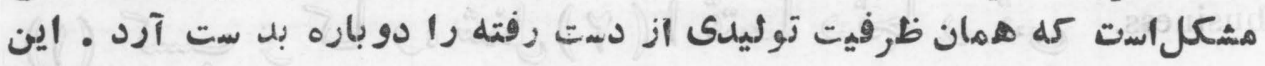

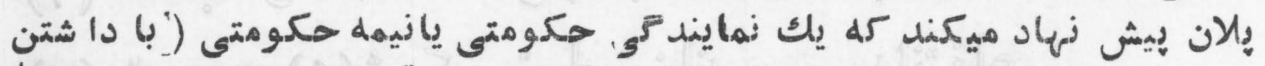

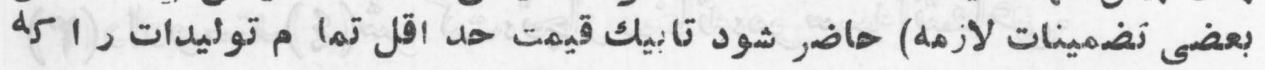

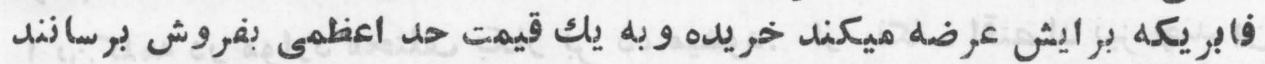

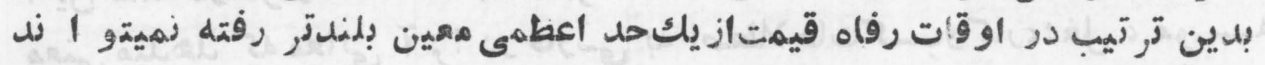

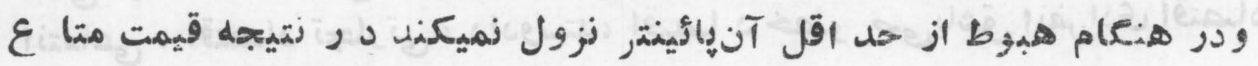

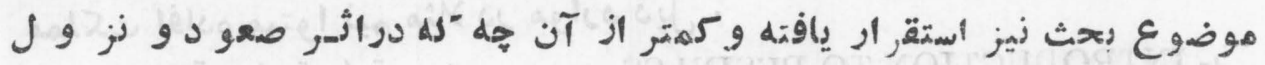

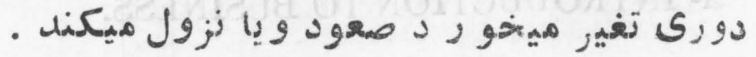
bulk line cost. o 1 la

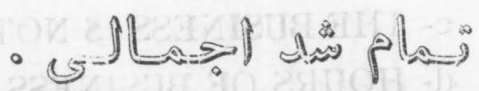

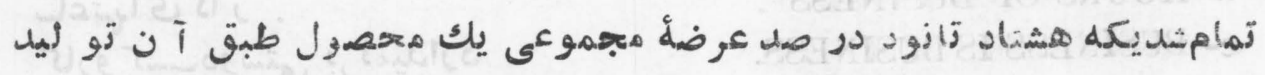

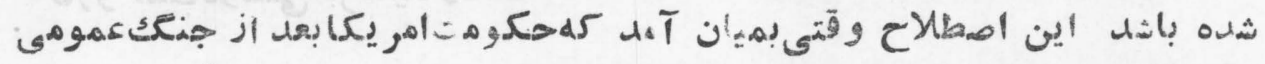

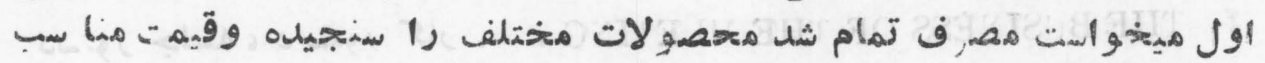

bull. bull.

$$
\begin{aligned}
& \text { 10. Thai } \\
& \text { - Odia d- }
\end{aligned}
$$

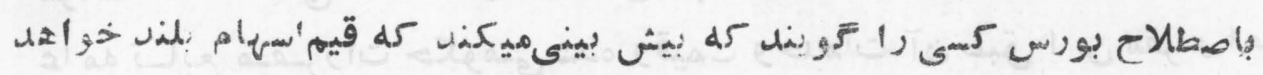

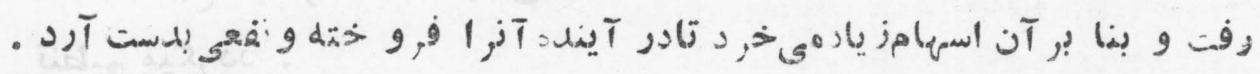
.BEAR ح'ضil 
bullion.

- 巴事实

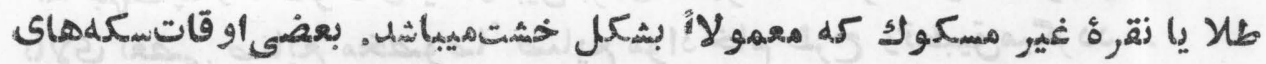

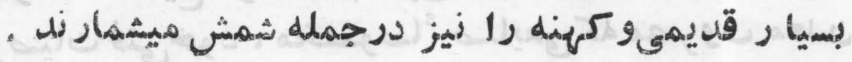

bumping

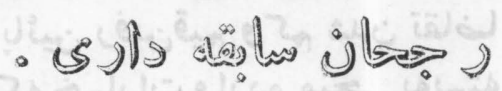

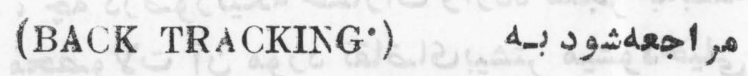

busivess. $\sigma^{2}$ \&

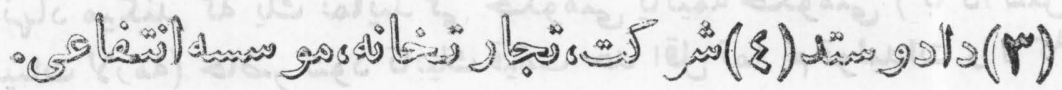

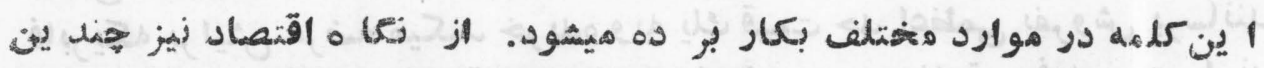

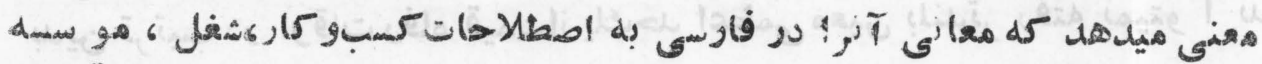

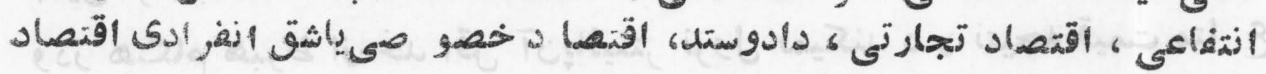

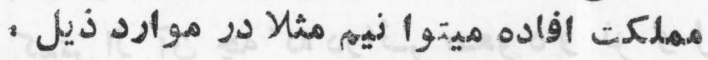
a- INTRODUCTION TO BLSINLSS.

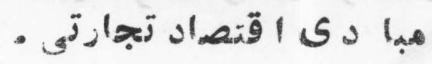

3- GOVERNMENT AND BUSIN ESS. مكو

C- THE BUSINESS IS NOT GOOD.

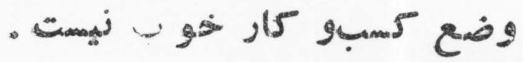
d- HOURS OF BUSINESS. . e- BUSINESS IS BUSIN ESS.

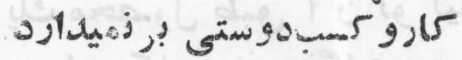

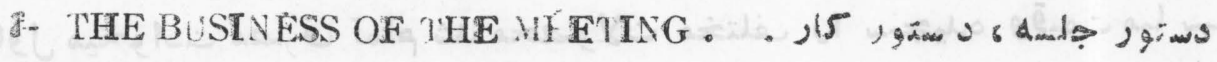

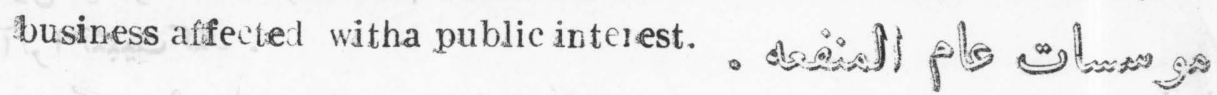

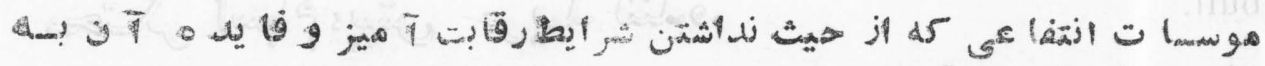

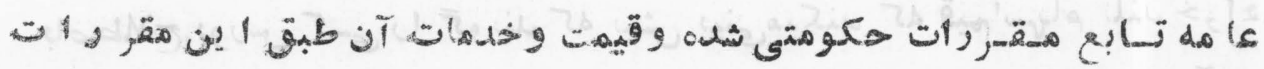
(C) - 20, دo 
business agent.

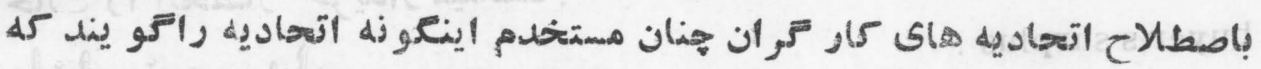

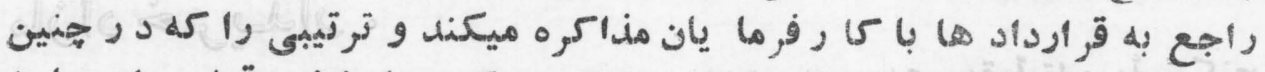

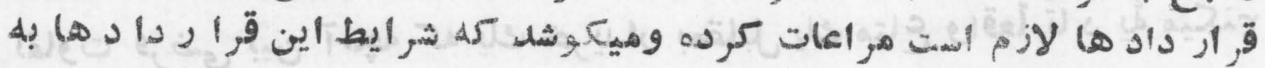
نحواحسن الزجام يابد

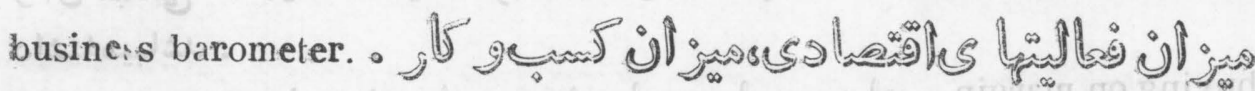

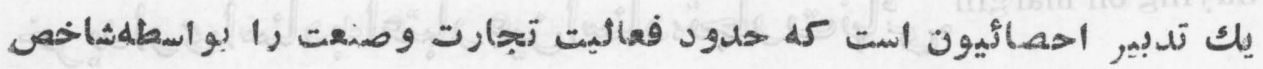

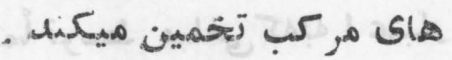

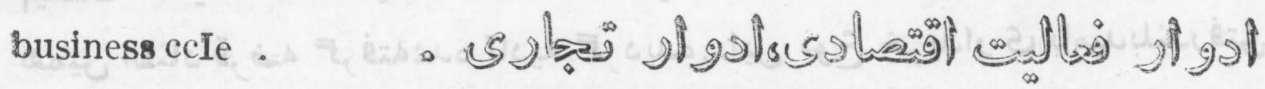

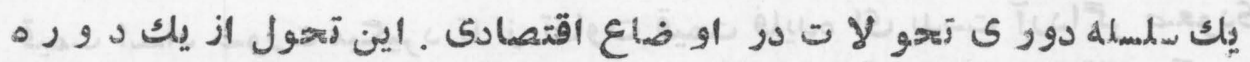

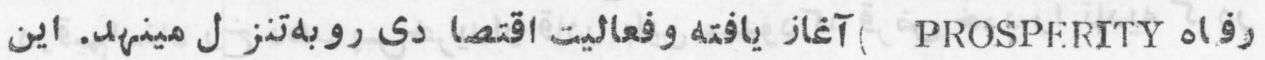

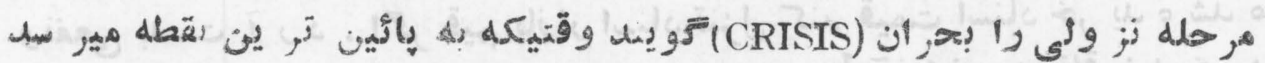

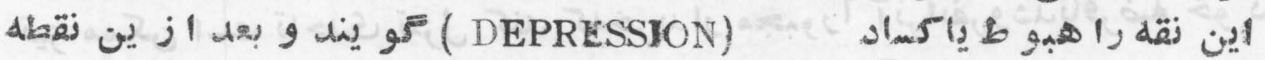

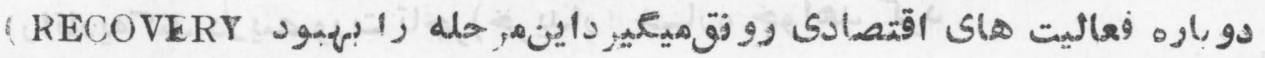

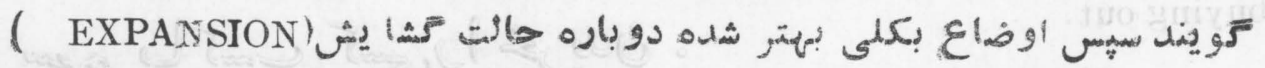

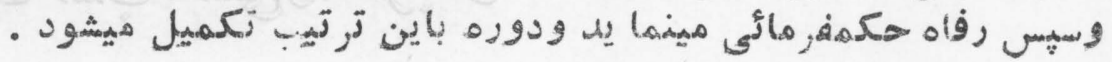

buyer,s market.

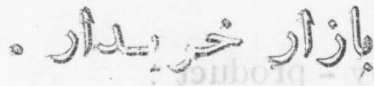

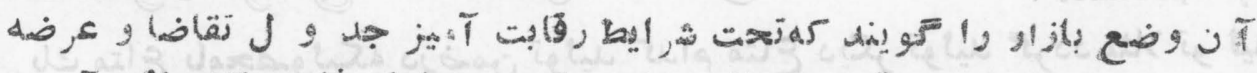

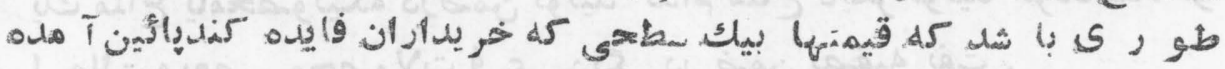

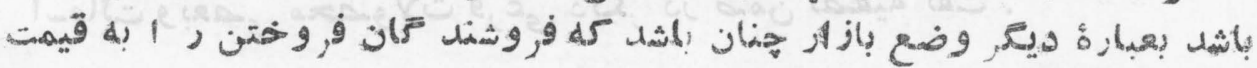

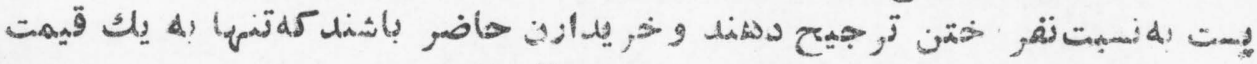

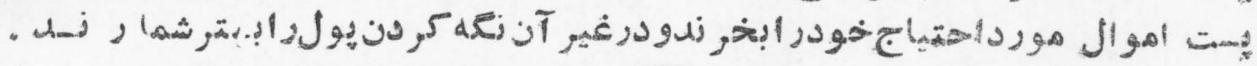
buyer's monopoly. - J) 
وقتيكه جهندين فروشنده اما تنها يكخر يسدار بر اى يكتماعوجود داشتهباشداين buyer,s surplus .

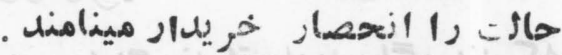

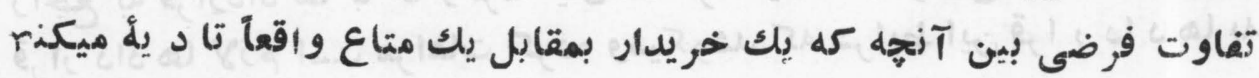

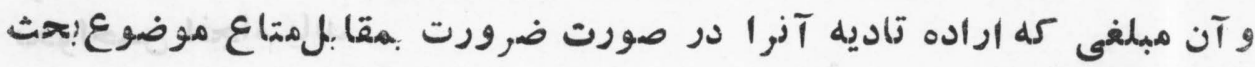

داشتهميباشله ميلفى

buying on margin

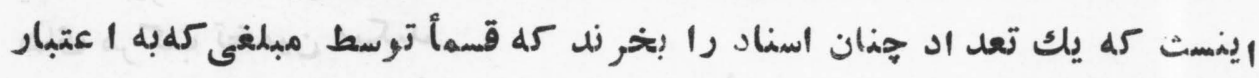

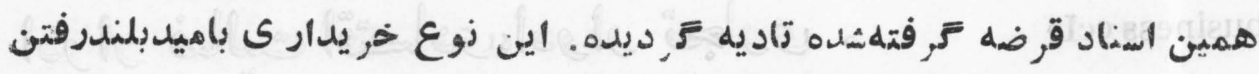

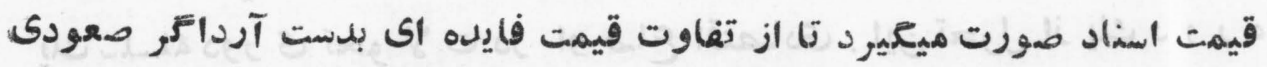

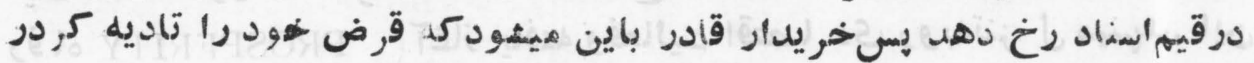

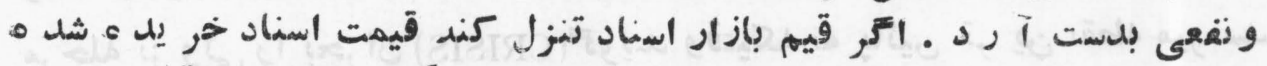

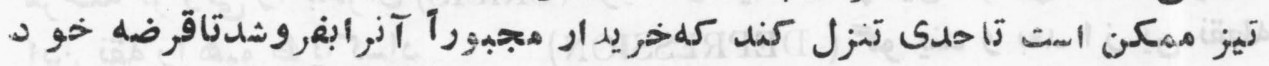
buying out.

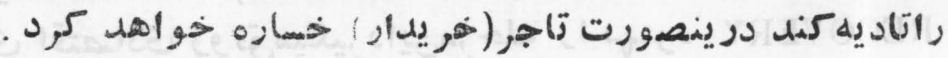

$$
\begin{aligned}
& \text { - ذل }
\end{aligned}
$$

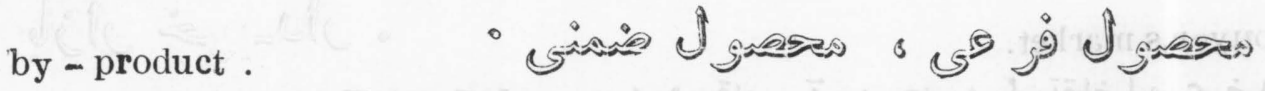

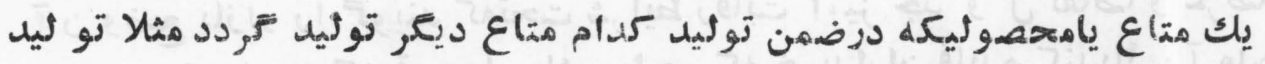

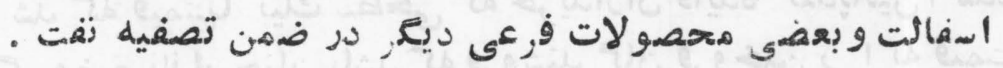

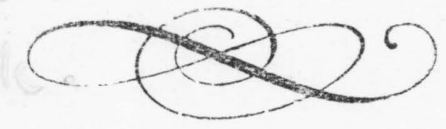


cable transfer.

$$
\text { ० जी }
$$

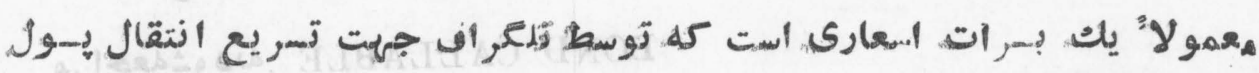
صادر ميثود . eadastre.

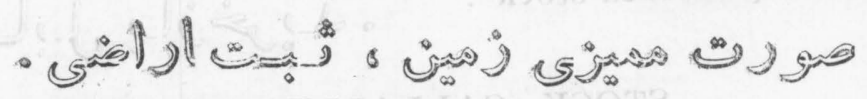

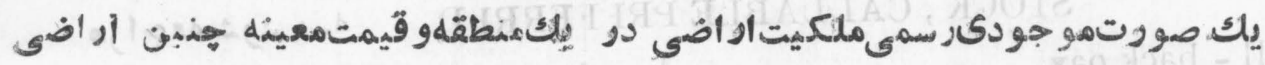

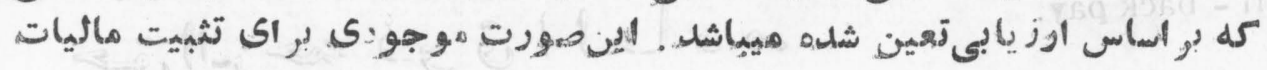

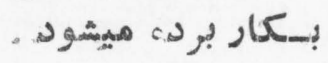

ea,canny

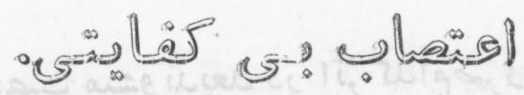

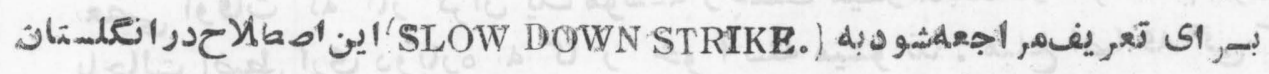
caeteris paribu"=other things bing equal.

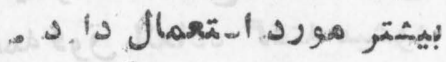

$$
\begin{aligned}
& \text { S } 5 \text { ब }
\end{aligned}
$$

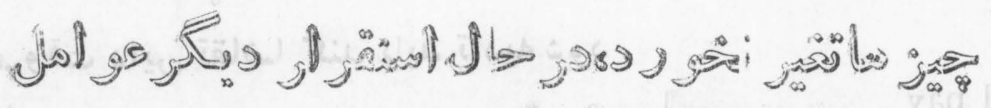

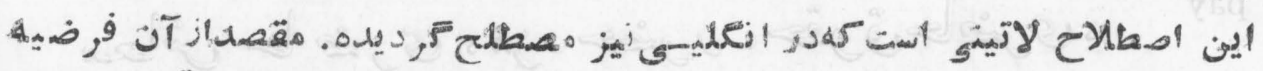

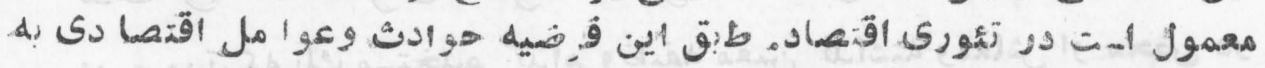

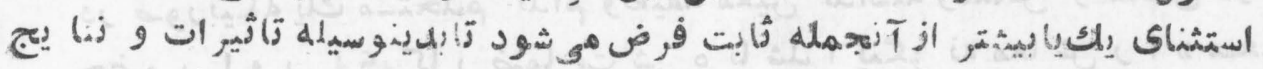

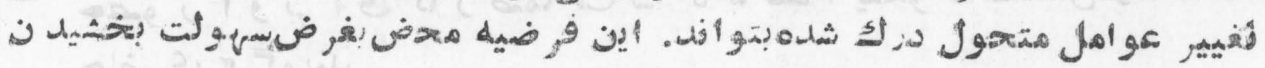

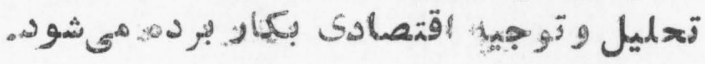
call.

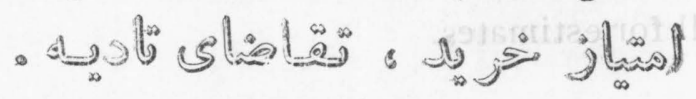

(1)

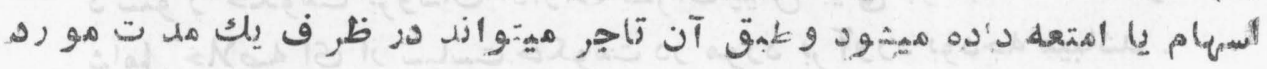




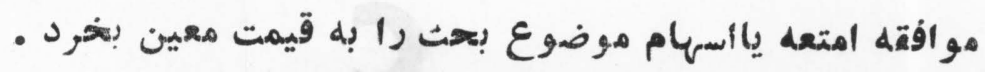
callable bind .

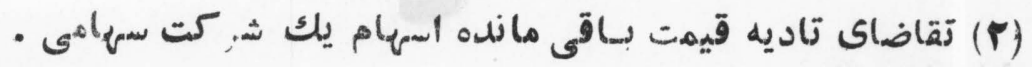

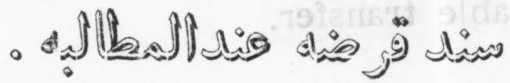

\section{مر اجعهيشودبه. BOND CALLABLE}

callable preferred stock .

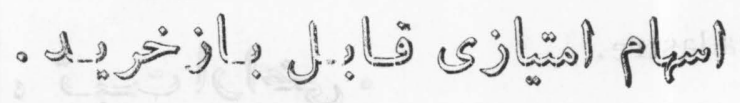

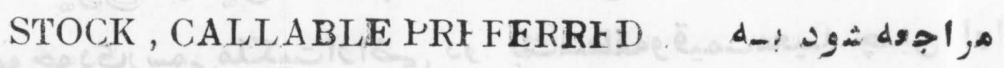
call - back pay.

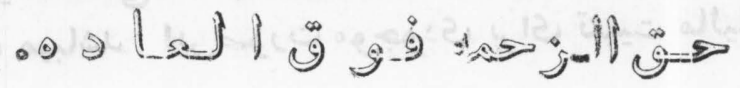

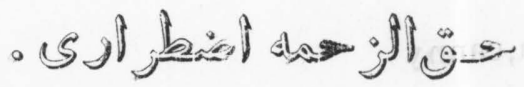

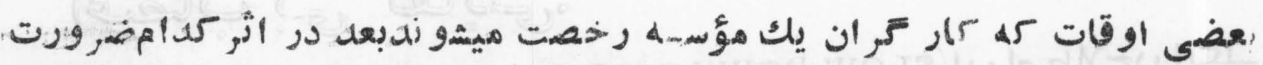

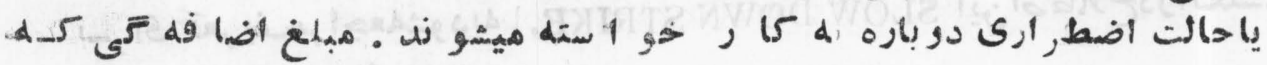

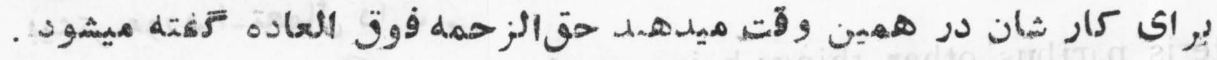
call loan.

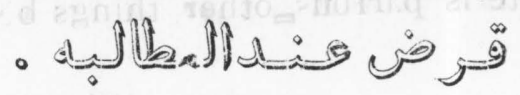

$$
\text { قر هى كه هروقت داين تقاضا كنل ب! يد تاديه.شود. }
$$

call pay

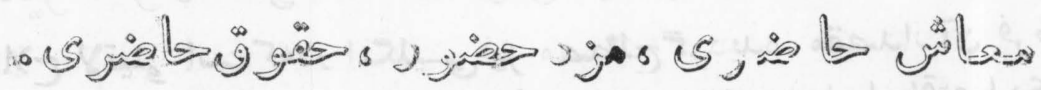

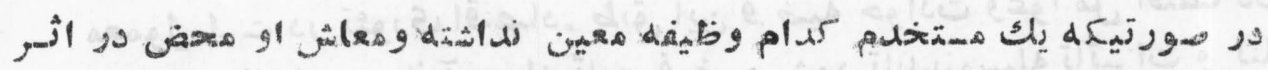

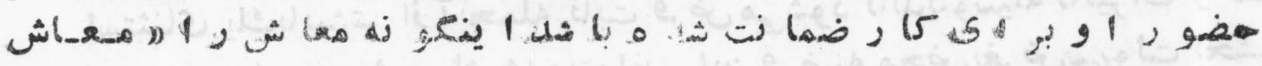

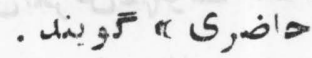

call for estimates.

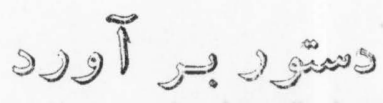

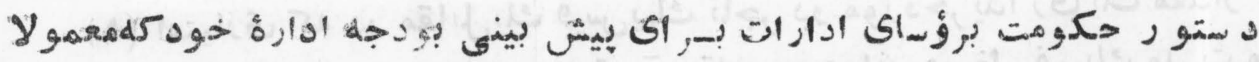

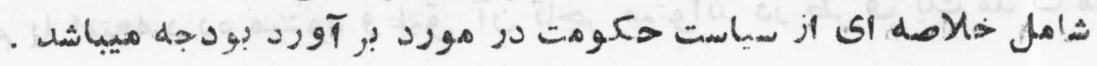


ca mbist.

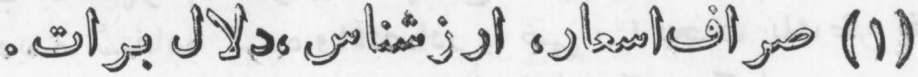

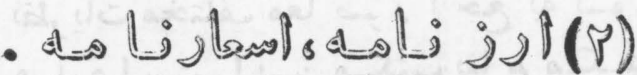

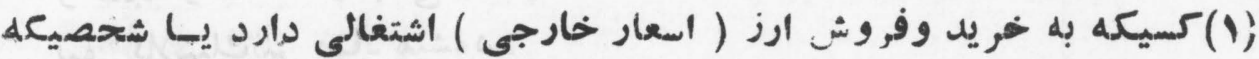

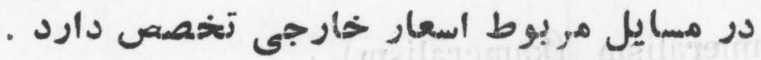

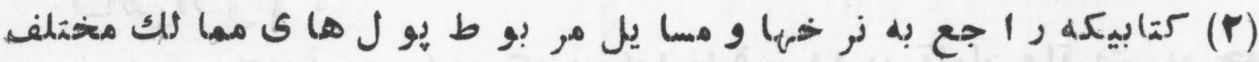
ملو مات ميله camqridge equation. $\bar{C}=$ $\mathbf{P}=\mathbf{M} / \mathbf{K T}$

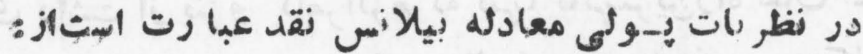
درين معادله - P Jو مقد ار - M - T K

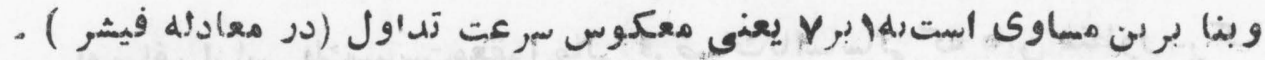
cambridge school,

$$
\text { Ceक }
$$

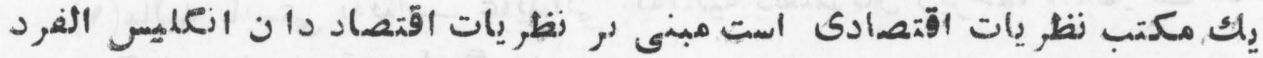

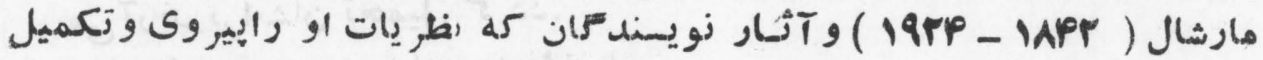

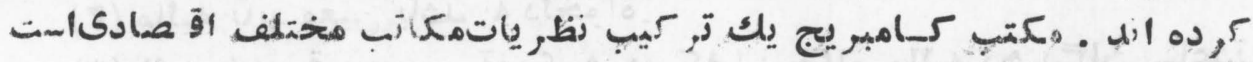

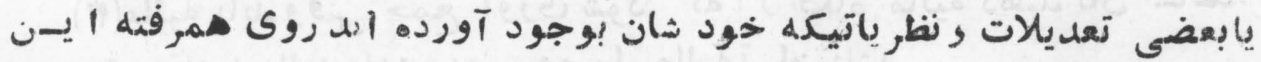

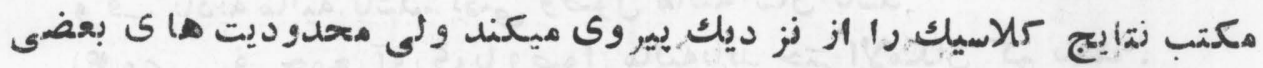

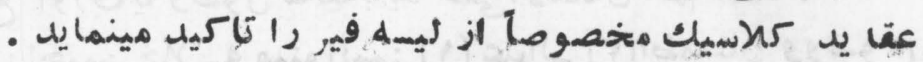

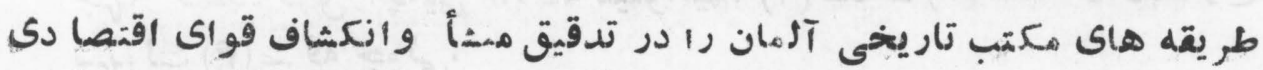

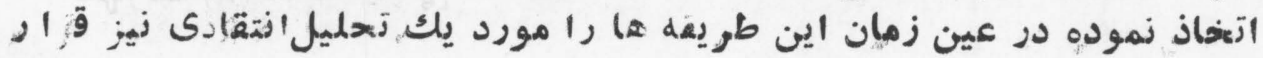




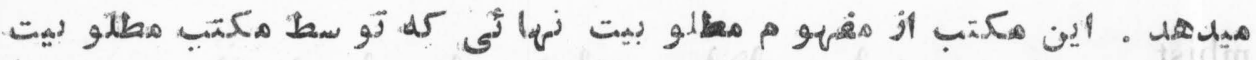

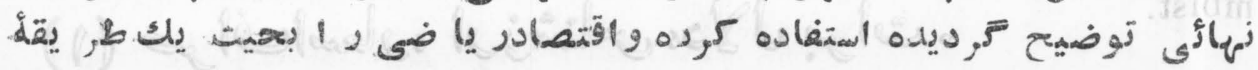

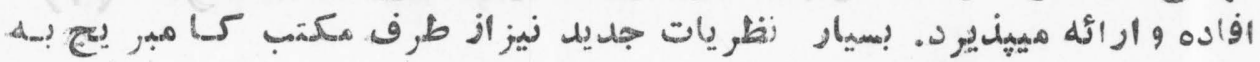

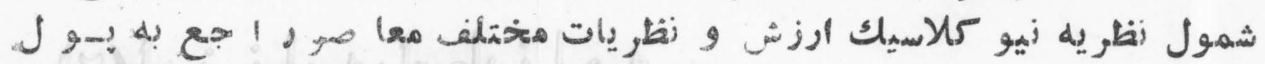

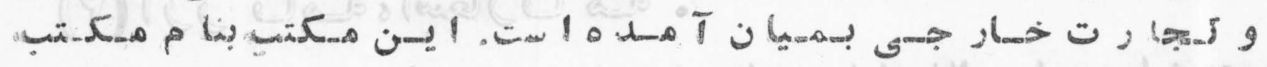

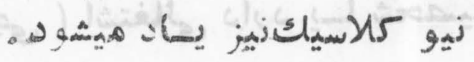
cameralism (kameralism) -

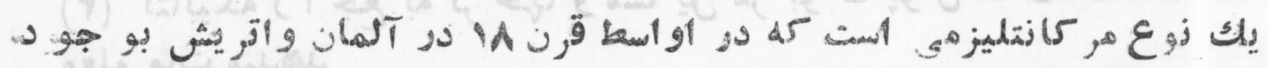

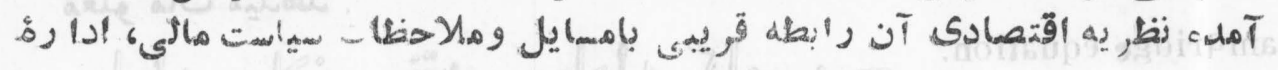

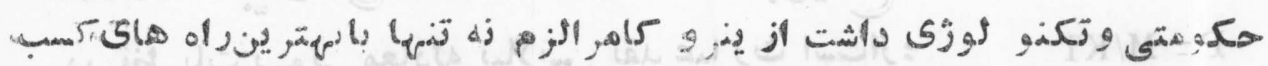

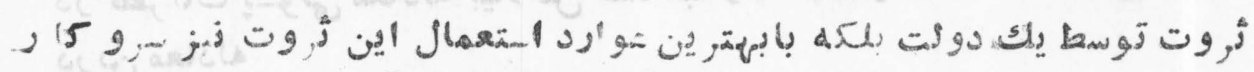

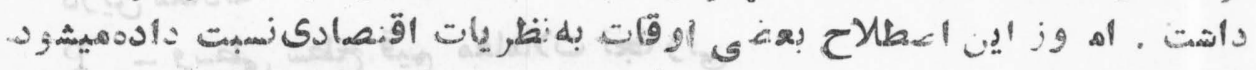

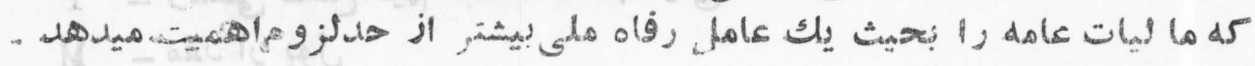

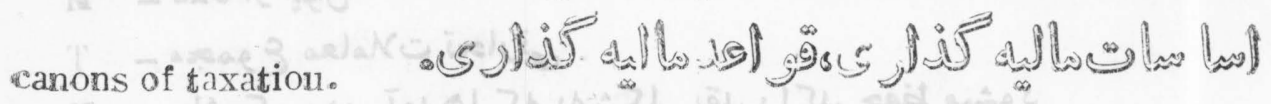

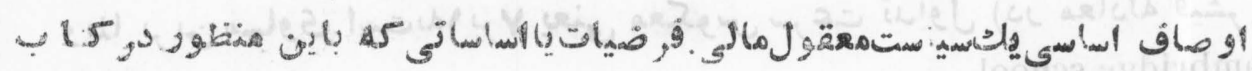

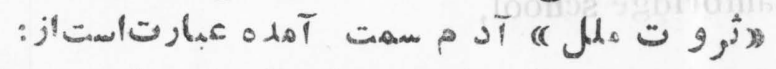

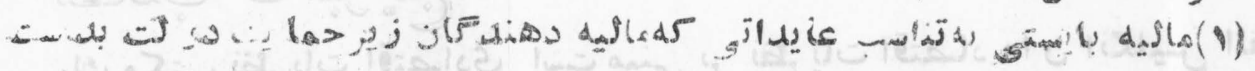

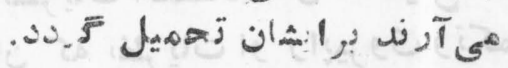
(P)

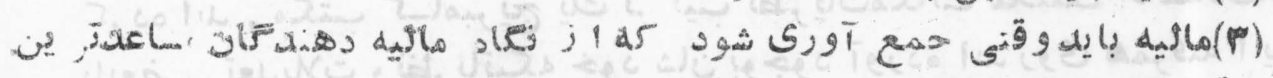

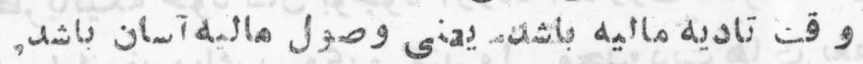

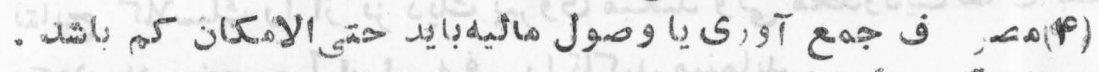

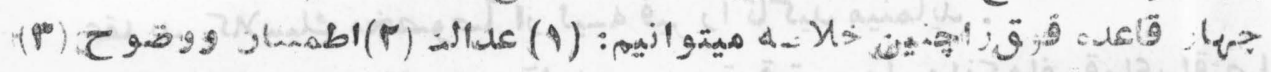

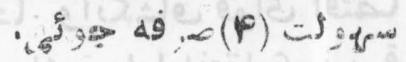


(P) مصرف جمع آورى ماليه بايل حتى الامكان كمباشل. يعنو. اقتصادى باشل. capital

$$
\text { - de lo jac }
$$

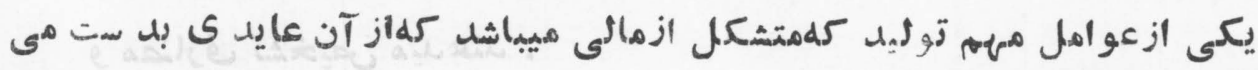

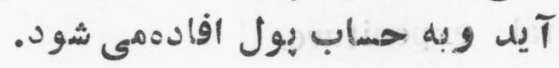

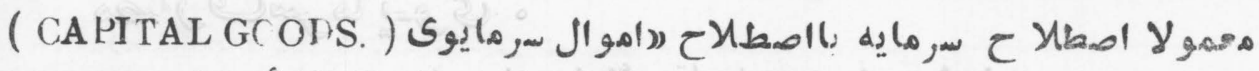

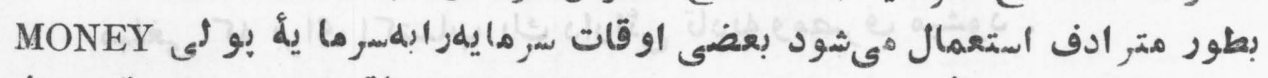

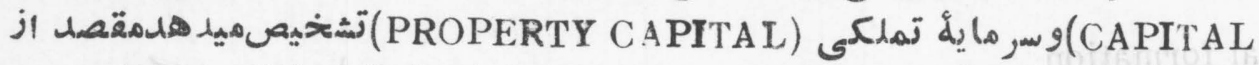

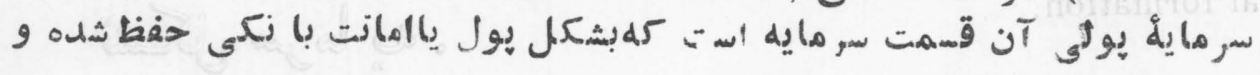

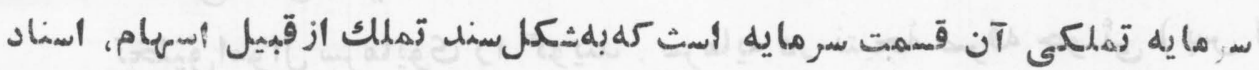

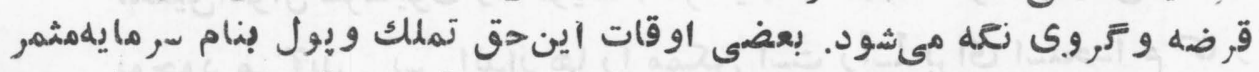

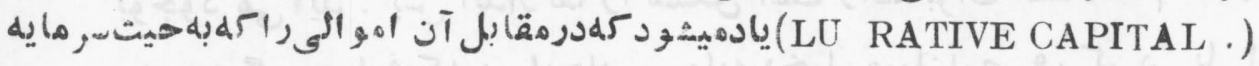

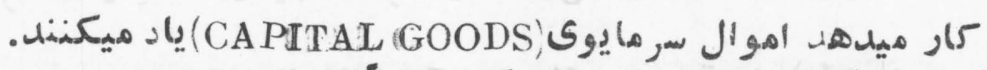

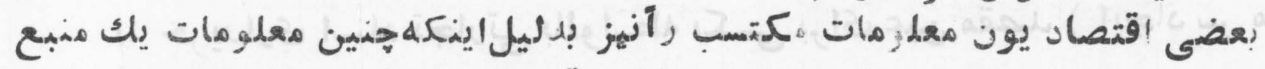

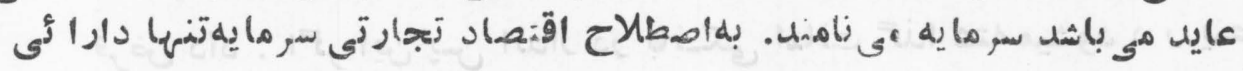

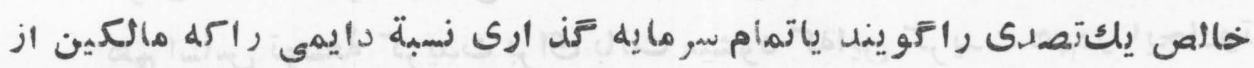

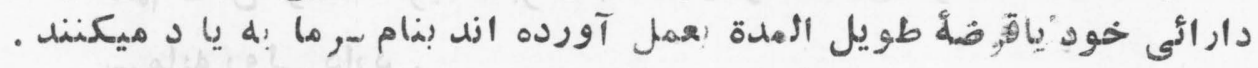

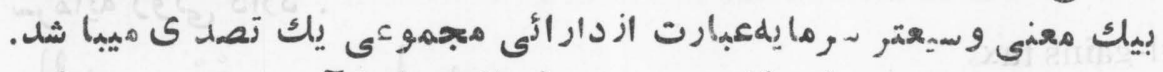

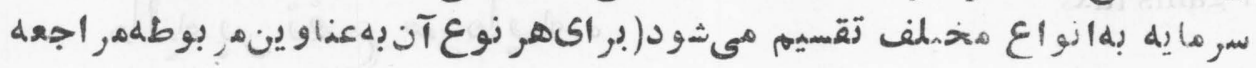
capital asset .

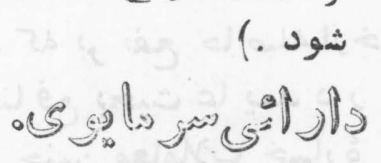

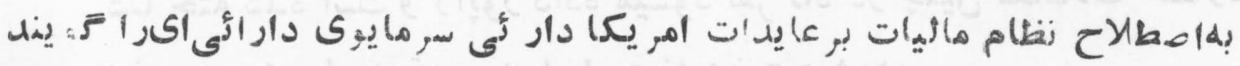

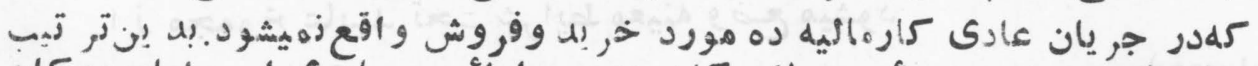

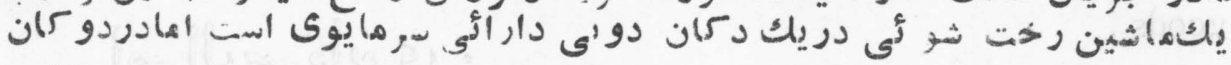

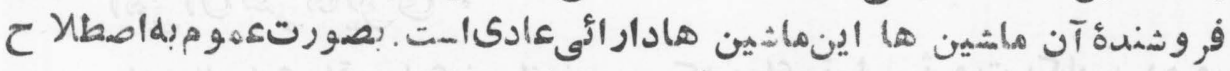

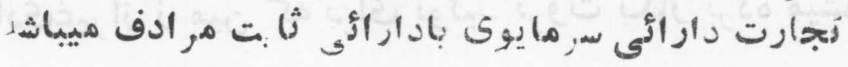


capital budgt.

$$
\text { - S } 2=0
$$

آن قسمت يك بودجه كه خريد وفروش هاى سرمايوى را از ديكر عا يد ا ت

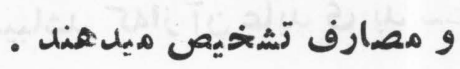
capital expeniture.

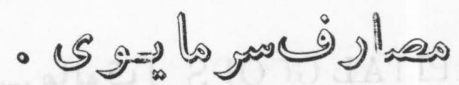
مبلغیى كله بر اى اكتساب يك دار دائى تاديه ومصرف ف ميشود .

capital formation.

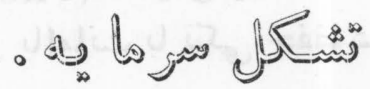

تخليقاموال سرمايوى را تويند . سر مايه در زتمبجه صرفه جو نئ ( دي انداز)

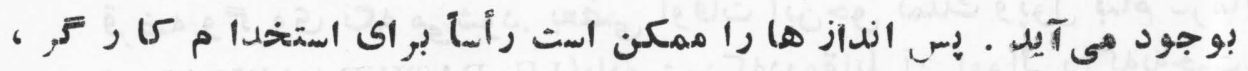

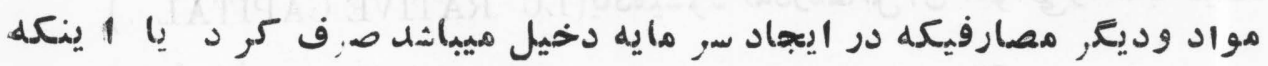
ب! خر يدارى اسناد تجارتى بالو اسطه بكسى براى عين مقصد ( إيجاد سر ما يه ) )

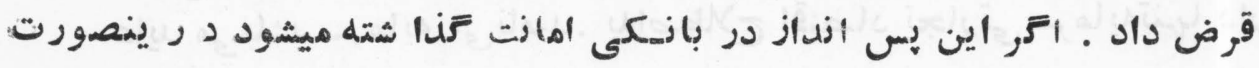

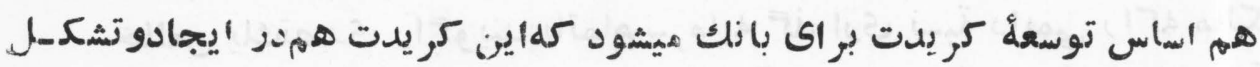

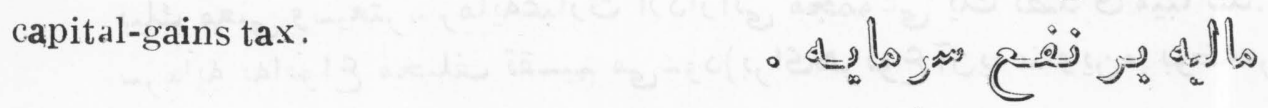

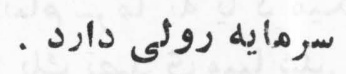

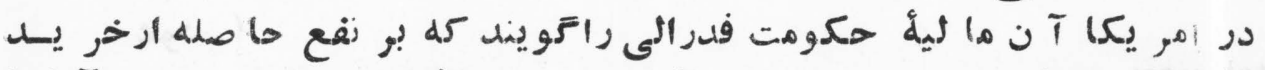

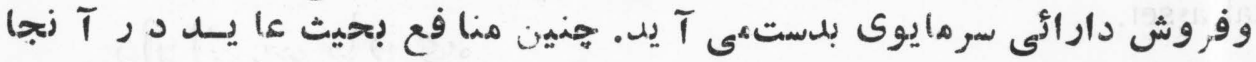

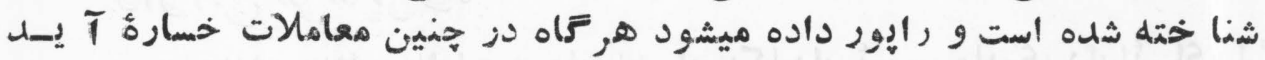

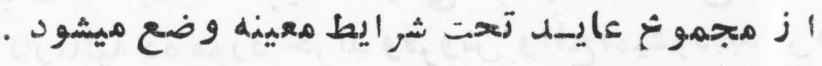
capiral goods .

$$
\text { - ज S }
$$

يك مالرمادى اقتصعادىغير از ز مين كله بر اى توليد ثروت بكار برده ميشود . 


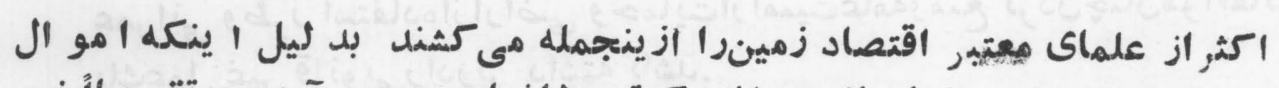

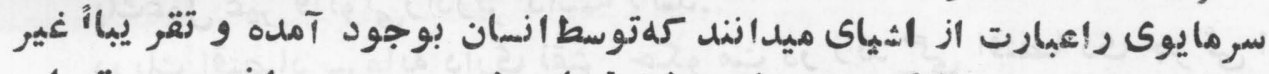

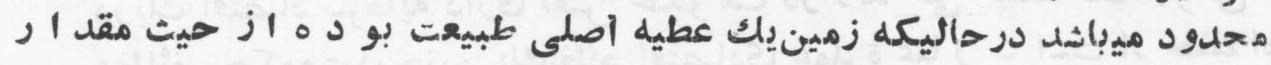

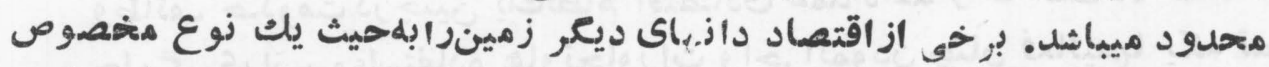

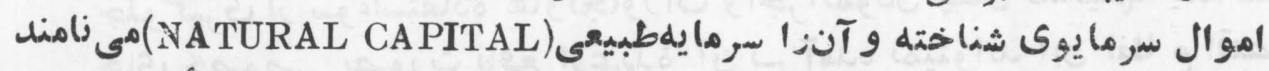

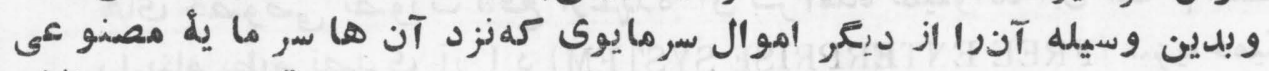
ARTIFICIAL CAPITAL

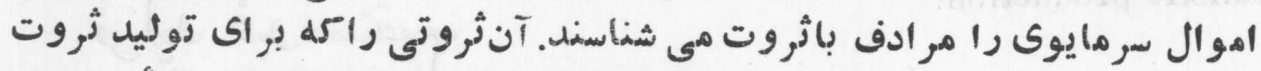

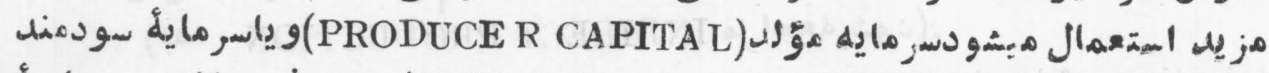
(م) INSTRUMENTAL CAPITAL)

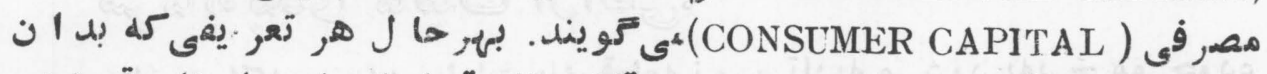

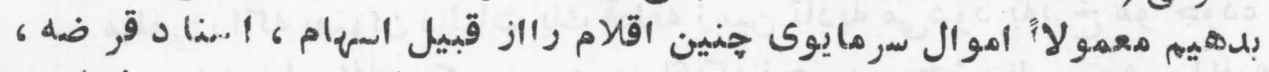

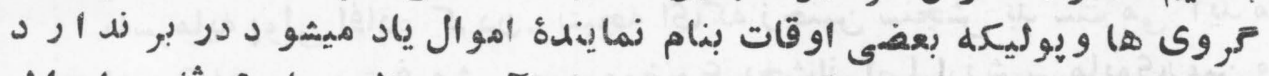

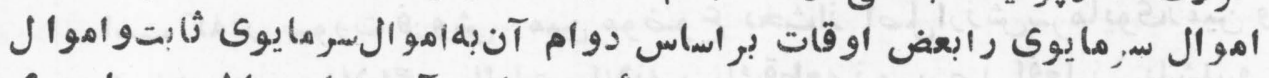

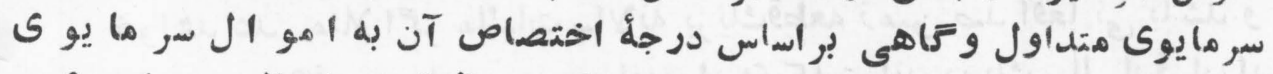

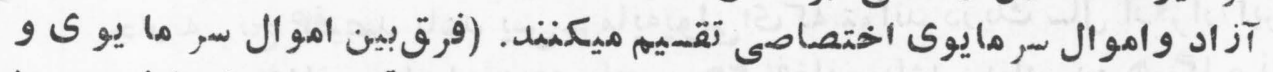

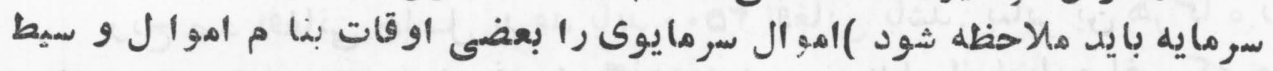
(INTERMEDIATE GOODS) بر اى رفع احتياج مستههلكين حدهت ميكند.

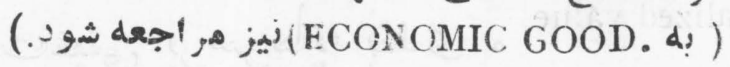

capitalism.

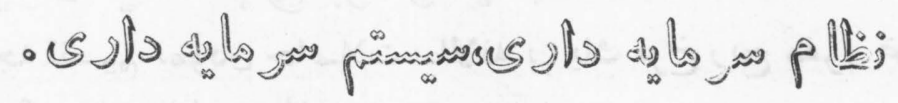

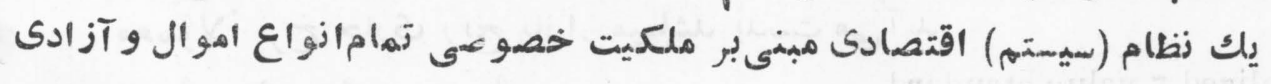

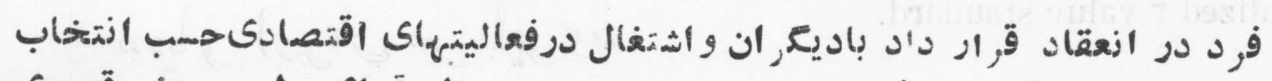

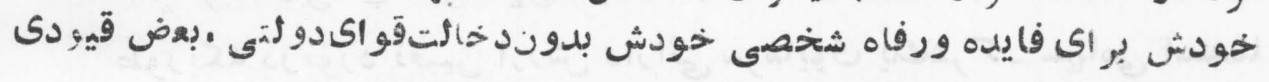

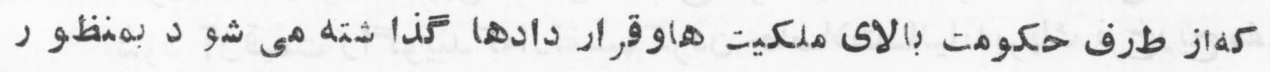

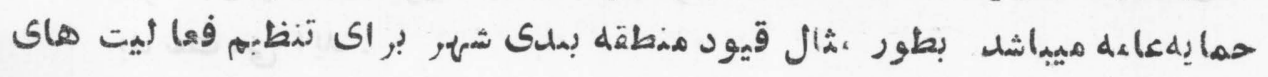




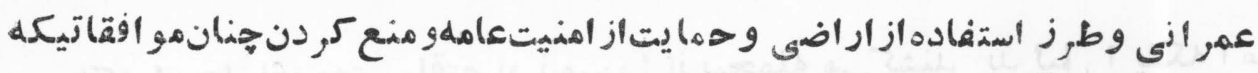

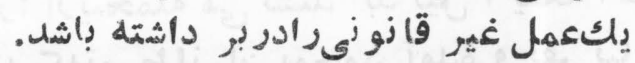

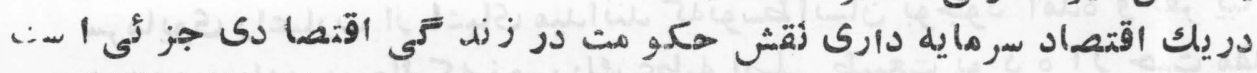

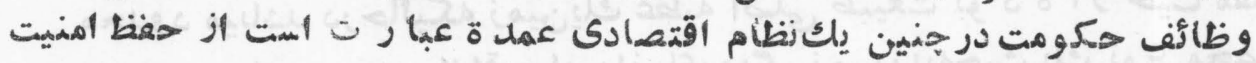

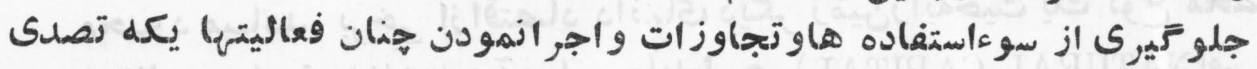

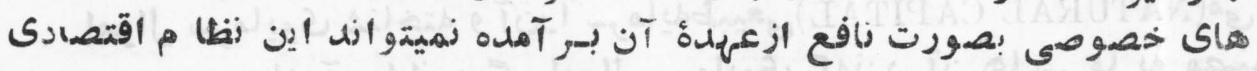

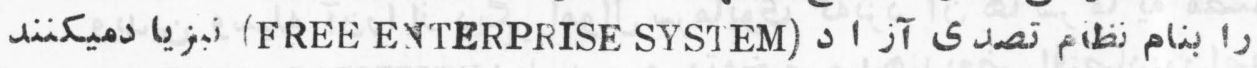
capitalistic production.

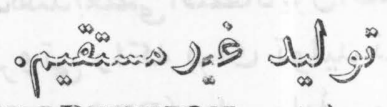

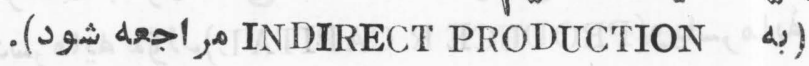

capitaization of land taxes.

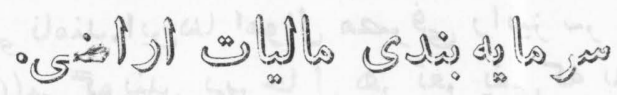

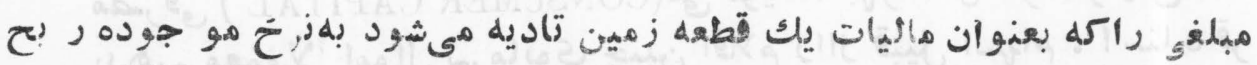

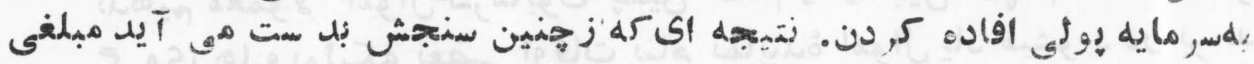

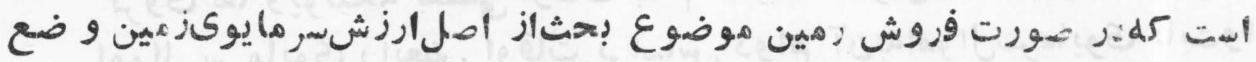

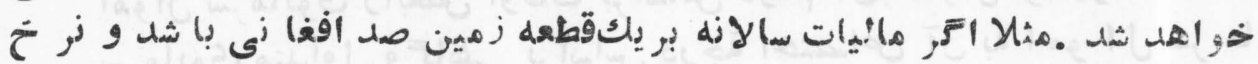

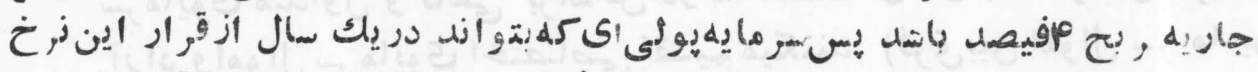

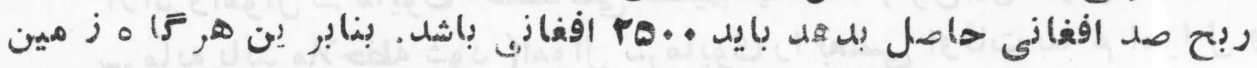

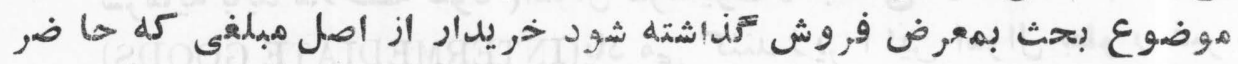

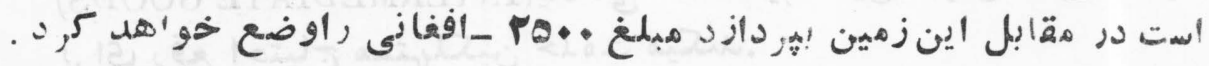

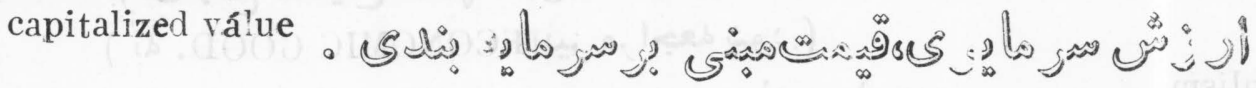

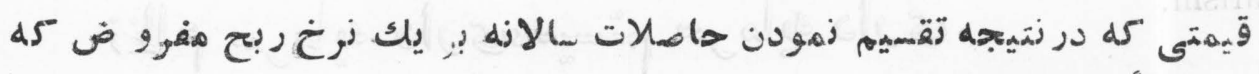

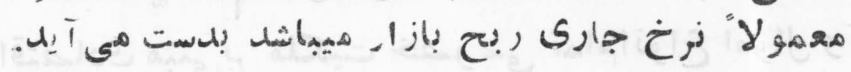
capitalized - value staudard.

$$
\text { ه }
$$

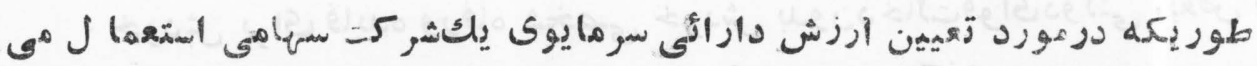

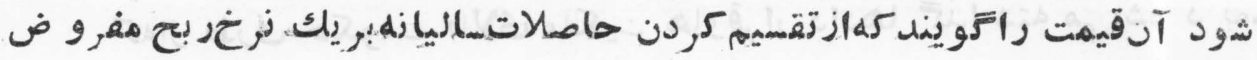

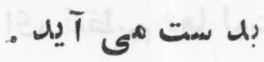


capital levy •

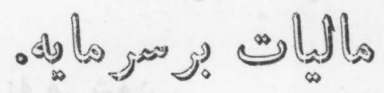

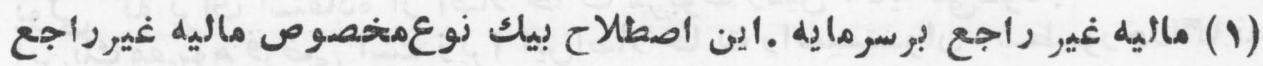

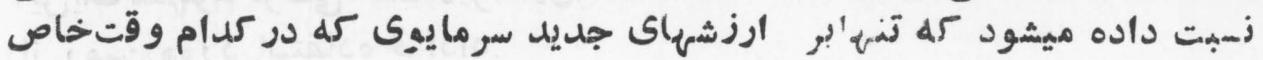

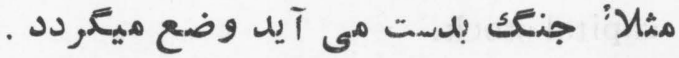

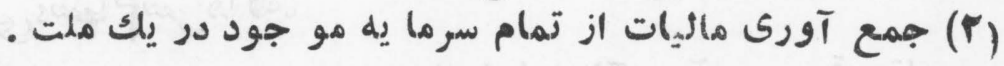
capital liability.

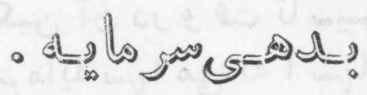

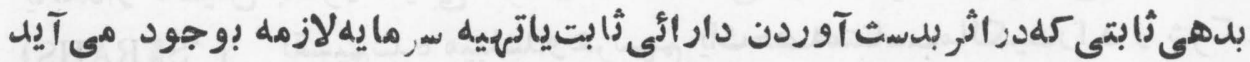

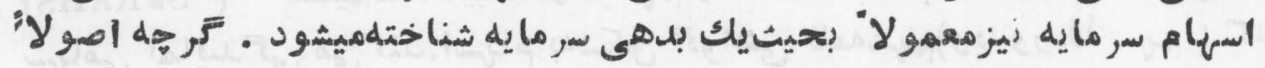

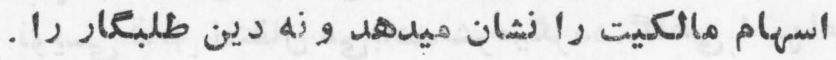

capital markel.

$$
\text { - a.g la jas jijlo? }
$$

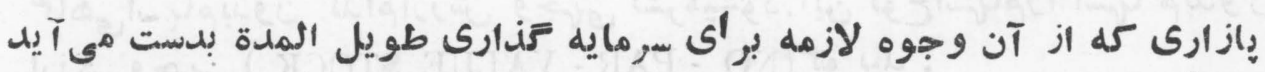

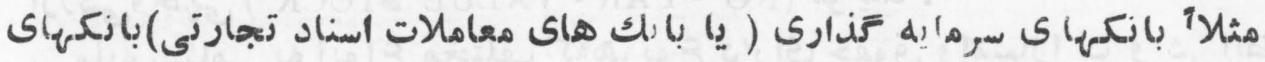

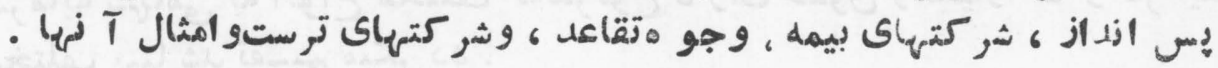
capital movement.

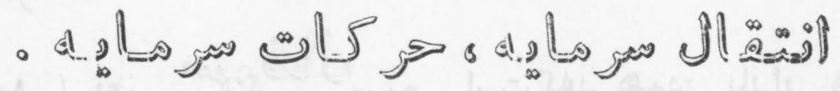

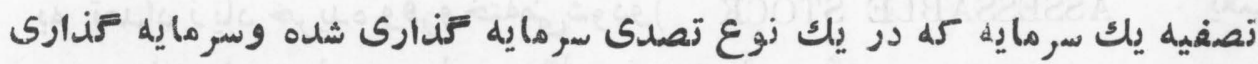

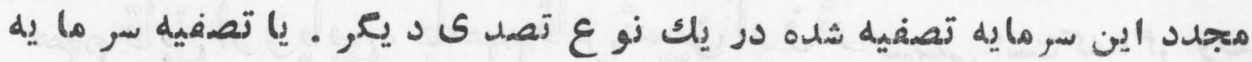

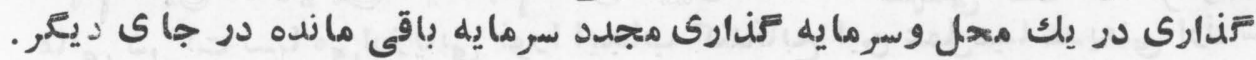

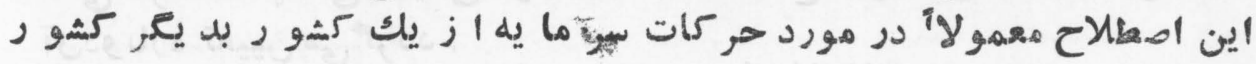
استمعمال ميشود .

capital net worth

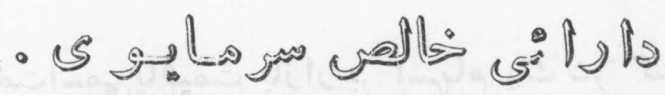

مجموع دار ائى يك موسسه ازتتفا عى هنفى بـد هى هاى آن . 
capital rent.

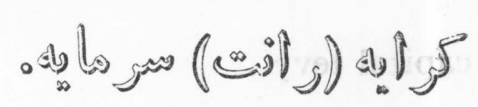

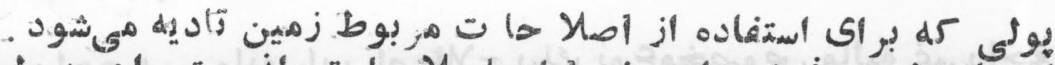

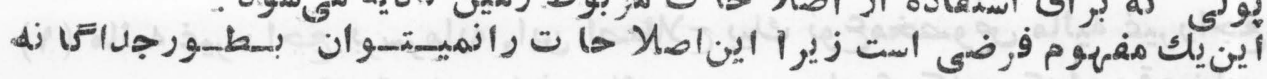
capital stock.

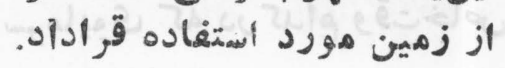
- 岁

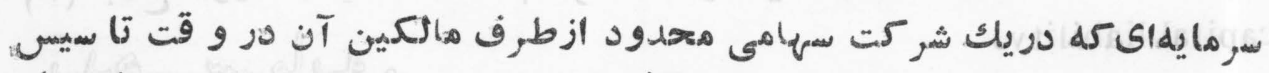

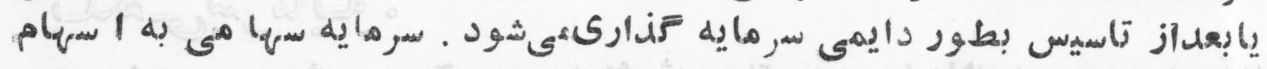
('SRRAHS)

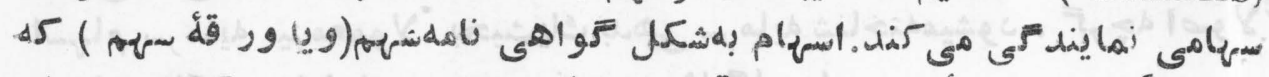

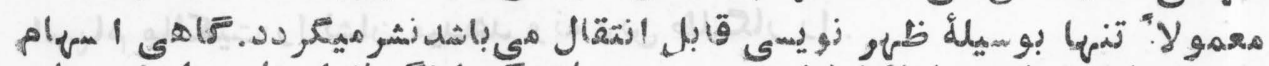

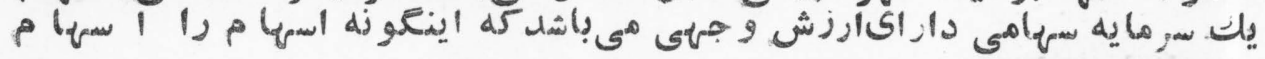

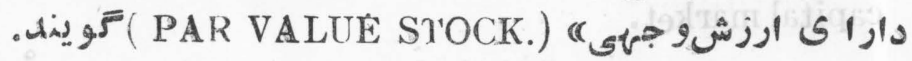

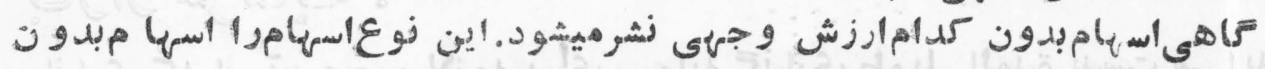

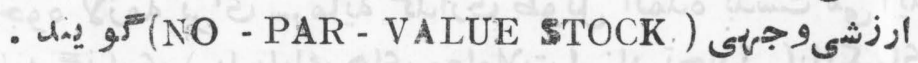

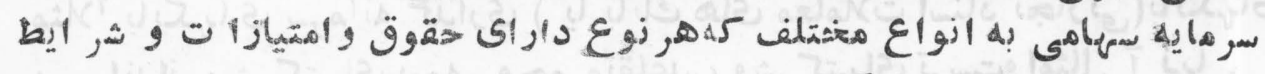

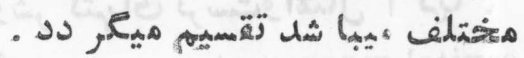

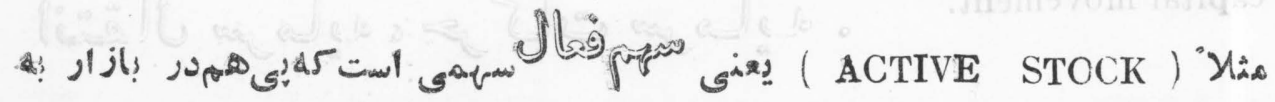

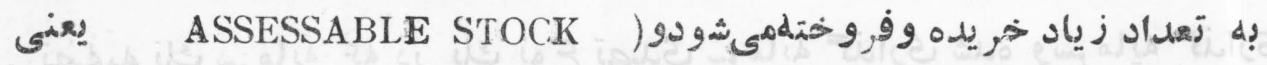

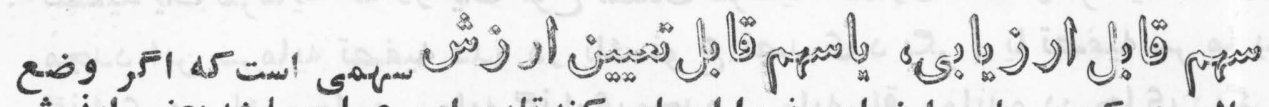

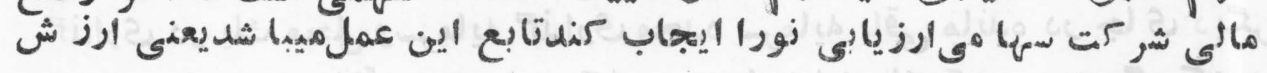

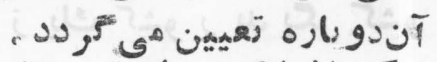

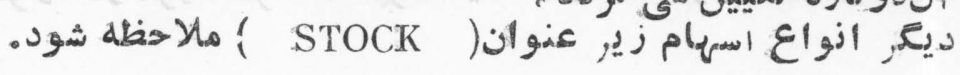
caiptal stock tax .

$$
\text { مالئه }
$$

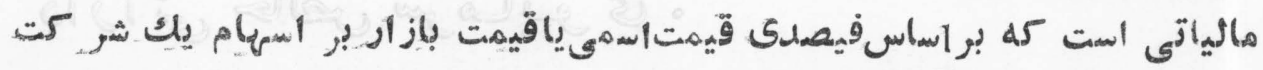

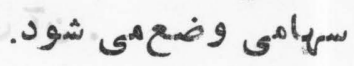




\section{CAR}

capital structure.

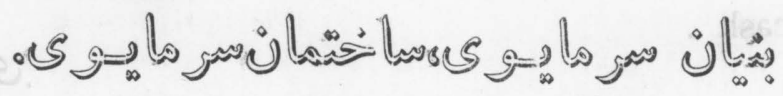

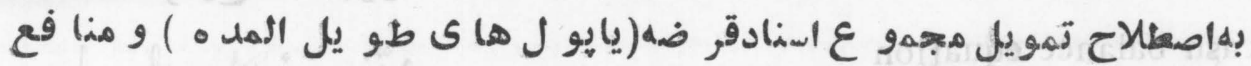

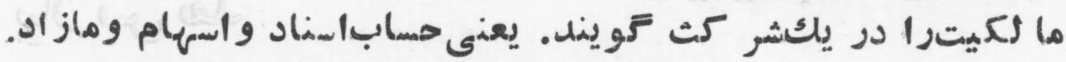

CAPITAL STOCKSURPLCS

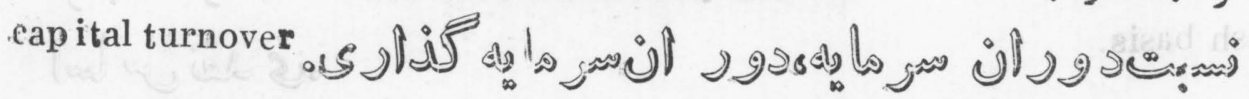

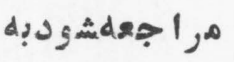

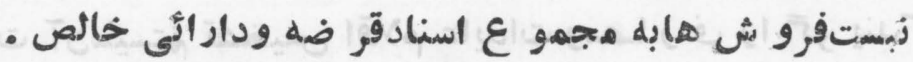

capitation tax.

$$
\text { - }
$$

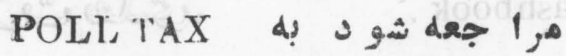

aptive mine .

$$
\text { - } \sin _{\infty}
$$

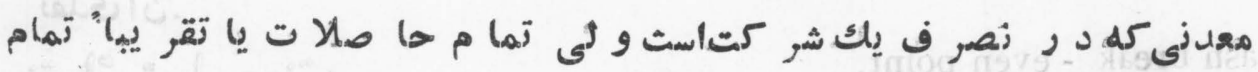
حاصلات آنر اخود شر كت صرفميكند.

captive shop .

jais

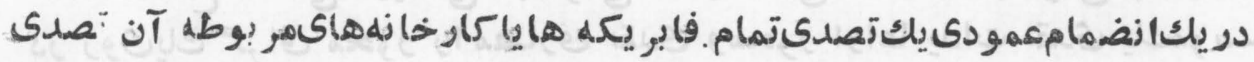

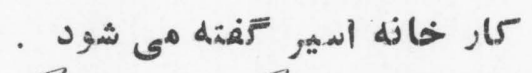

carloadings .

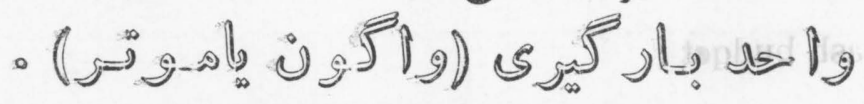

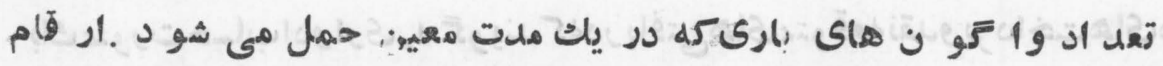

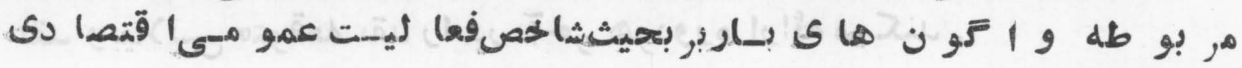

cartel

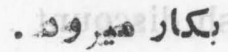

$$
\text { . }
$$

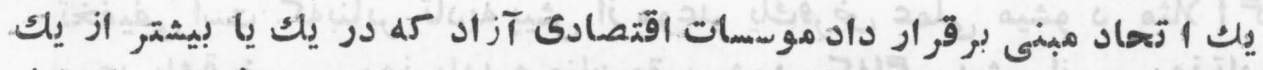

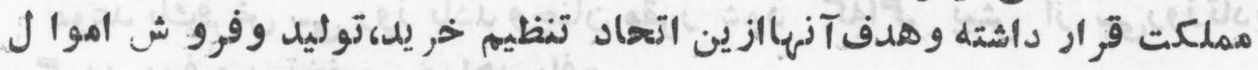
توسط اعضا ميى باشل. 
cash .

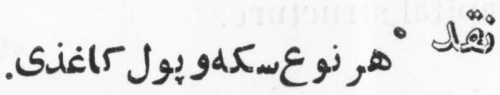

cash balance equation

$$
\text { तथे }
$$

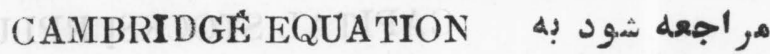

cash basis.

$$
\text { - }
$$

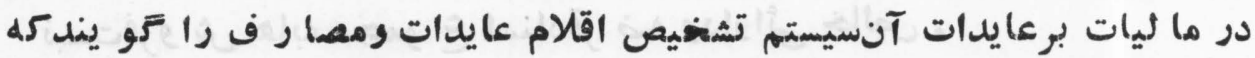

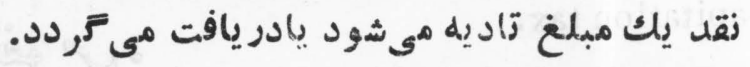

cashbook .

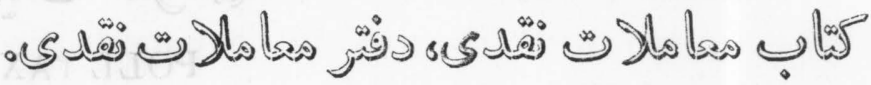

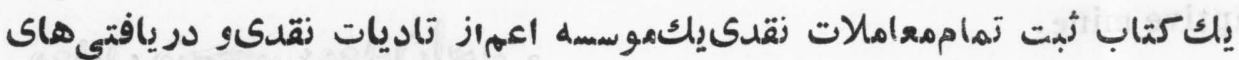
زقدى آن. cash break - even point.

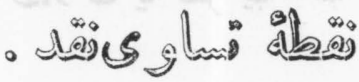

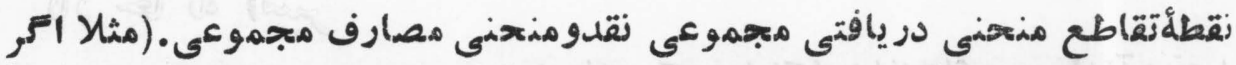
در روىيك F, اف محمور را مصارف زقدى ومحور أراعا يدات زقدى يكمو سمأه

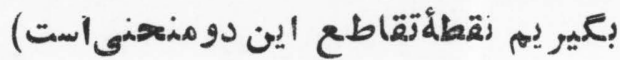

cash budqet . -

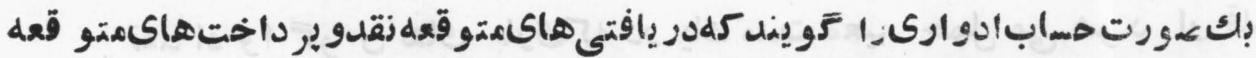

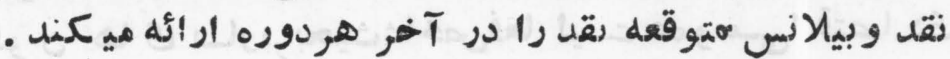
cash discount .

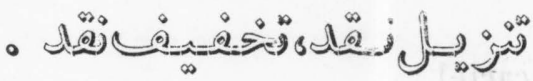

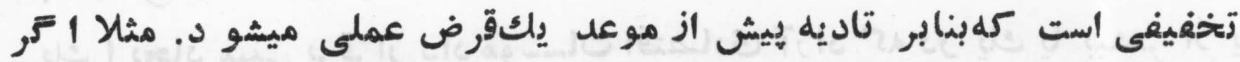

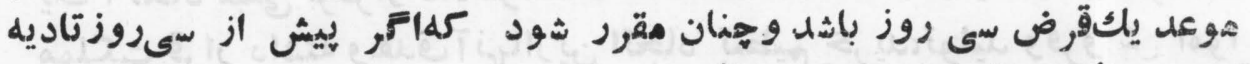

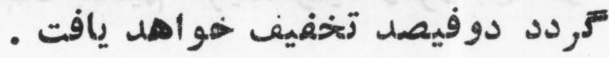




\section{CAS}

sash flow.

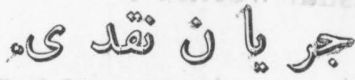

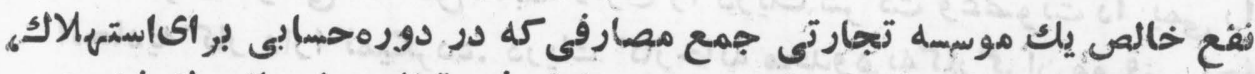

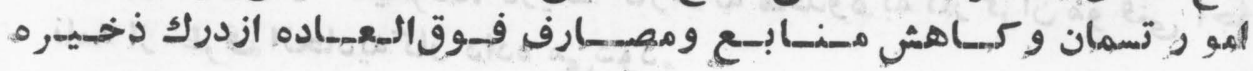

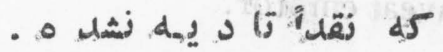

درحقيقت اين نقليست كله درحال عدم تغيرديعرحساباتدريك دوره بوجود آمده. eashier.

قִ

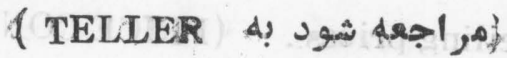

cashier's check.

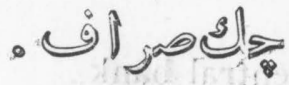

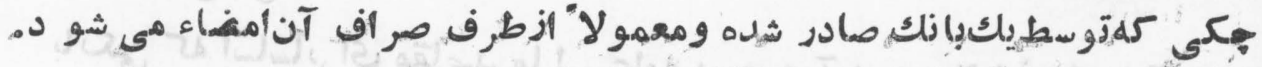

caste system.

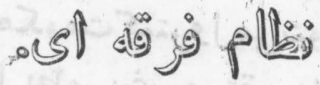

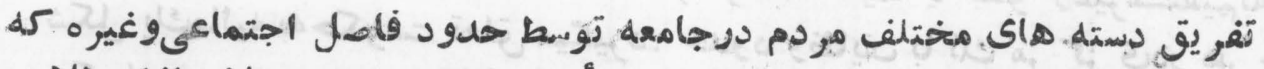

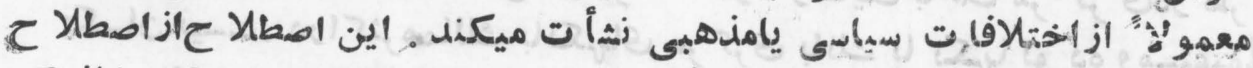

(CLASS)

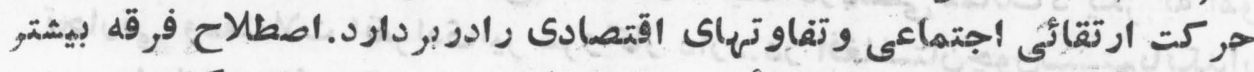

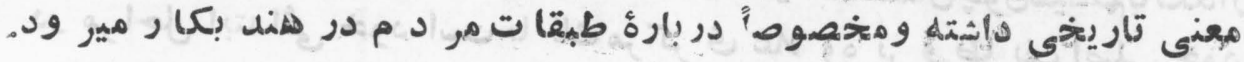

casualty insurance.

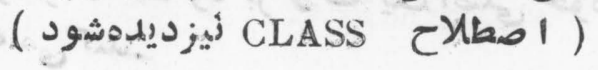

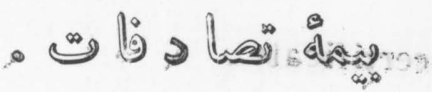

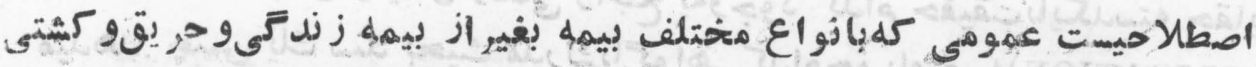

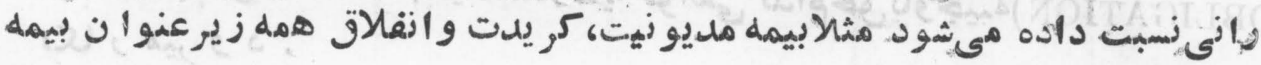
تصادفات مي آيده. 
casual worker.

$$
\text { (15 }
$$

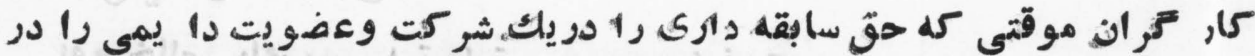

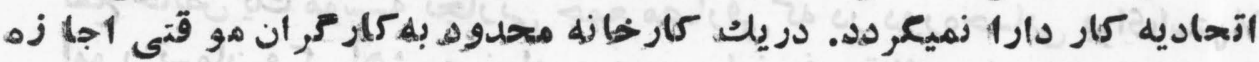

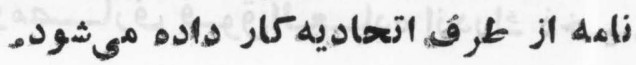
caveat emptor.

$$
\text { - ) }
$$

caveat venditor.

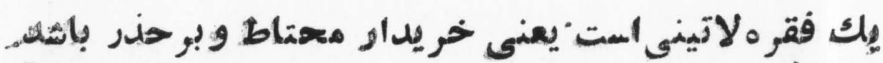

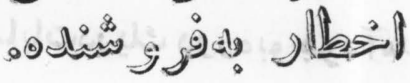
يك فقر ه لاتينى است يعنى فر وشنده آتاهومحتاط باشد.

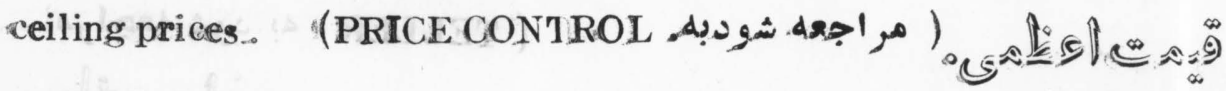
central bank.

$$
\text { - जis }
$$

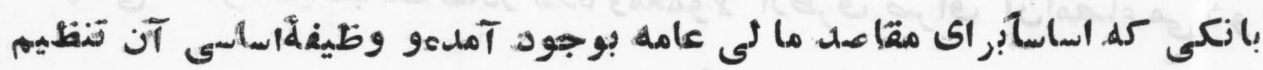

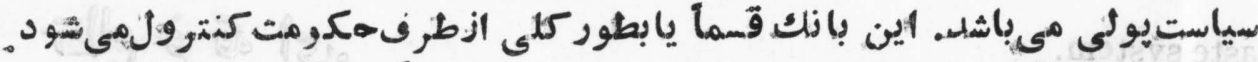

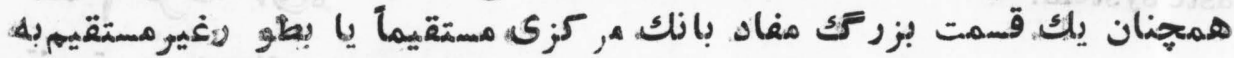

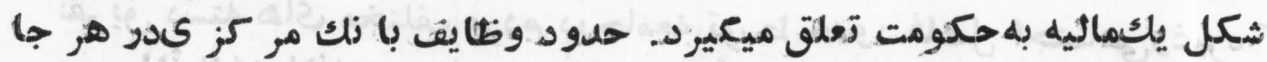

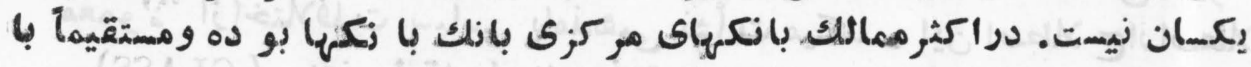

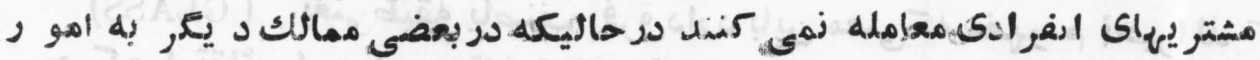

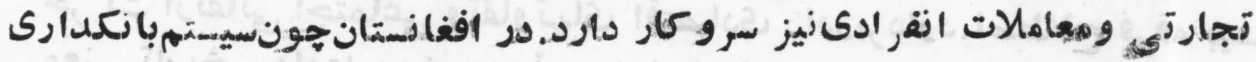

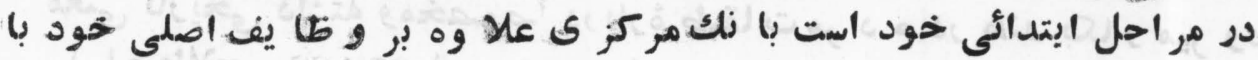

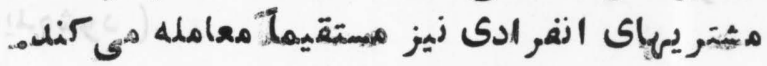
certificate.

$$
\text { ه }
$$

سندى كه اطمينان وايقان رسهى والجع بهوجود كدام حليقت يا يكلدسته حقايق

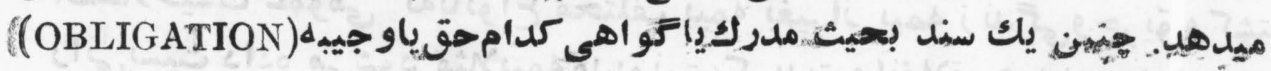

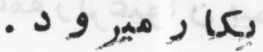


certificate of beneficial interest .

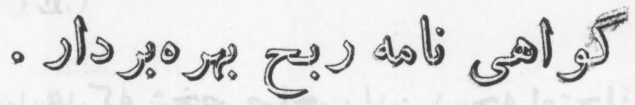

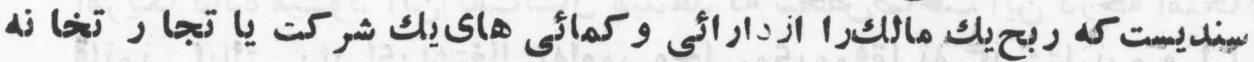

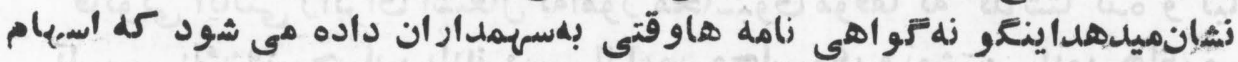

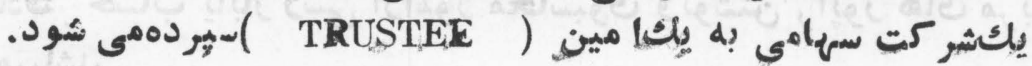
certificate of deposit .

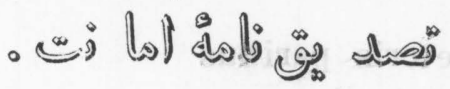

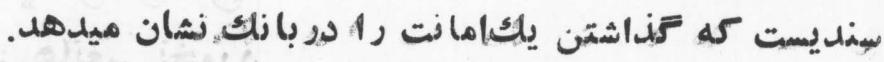
centificate of incorporation.

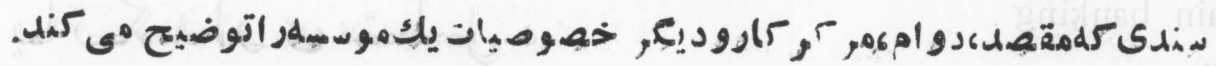
certifieate of indebtedness .

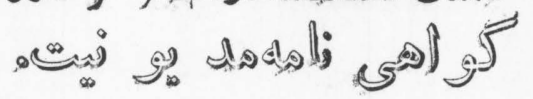

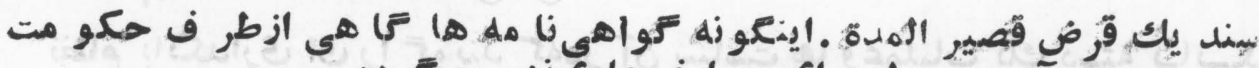

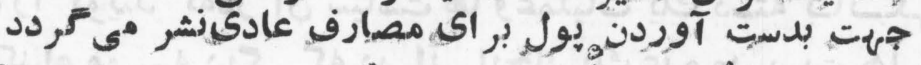
çertificate of origin.

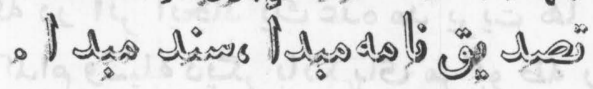

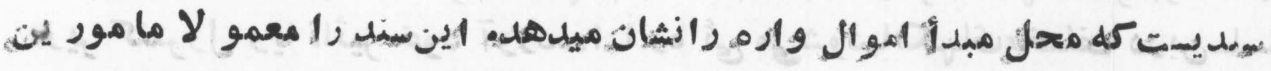

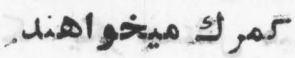
.certificate of public convenience andne cessity ab a

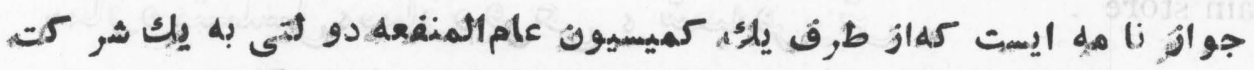

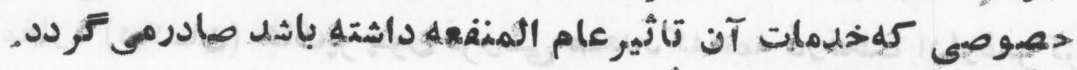

certified check.

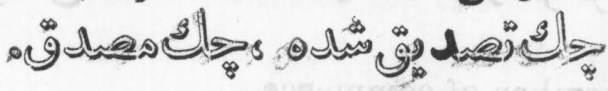

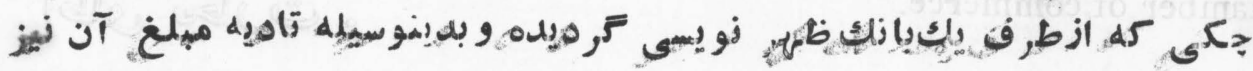

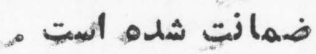
certified Publie aecountant.

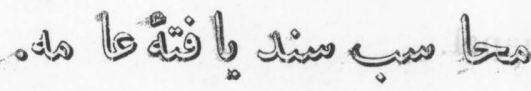

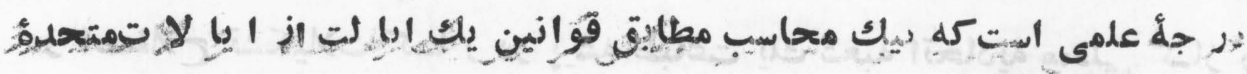




\section{CET}

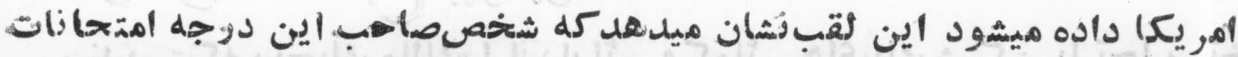

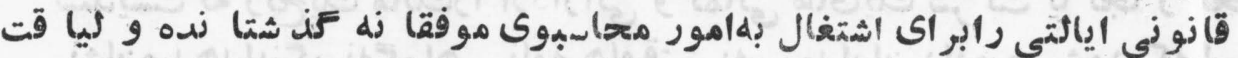

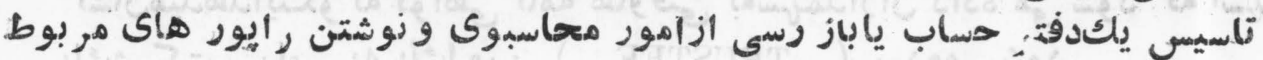

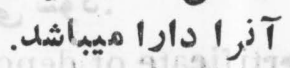

ceteris paribus

$$
\begin{aligned}
& \text { ه } \\
& \text { در حا ليكه ديعر جيز هانغير زخورد }
\end{aligned}
$$

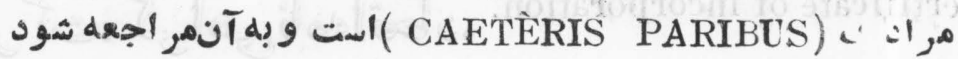

chain banking.

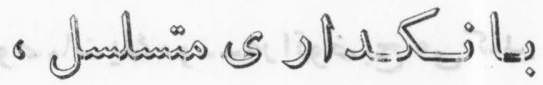

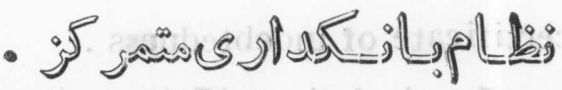

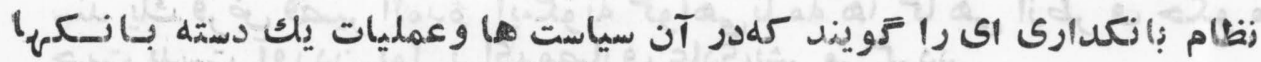

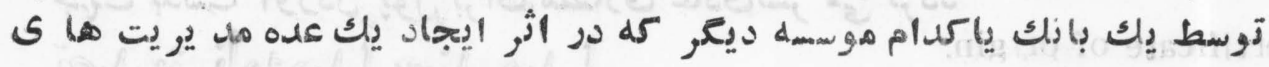

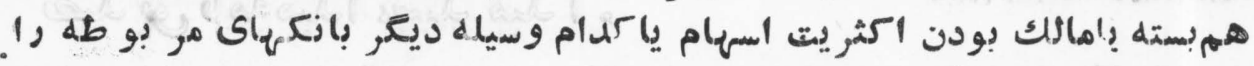

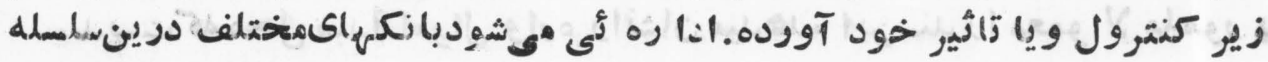

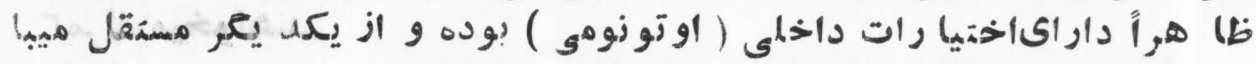

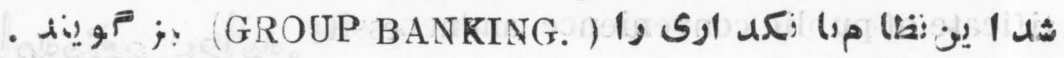

chain store .

$$
\text { - }
$$

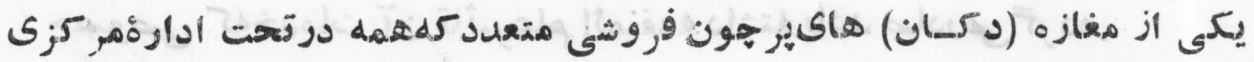

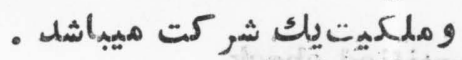

chamber of commerce.

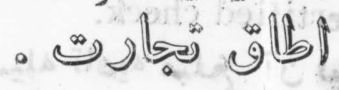

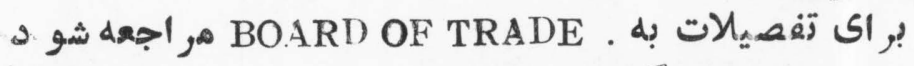

chapel.

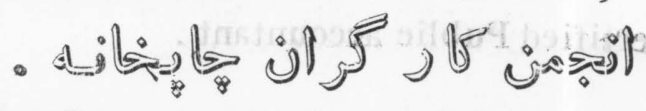

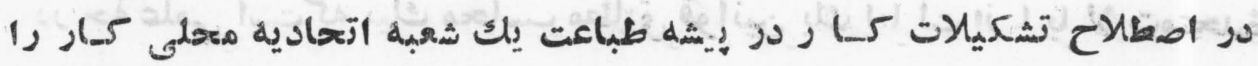

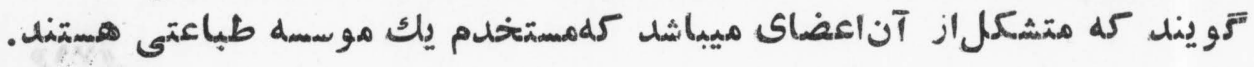


charge

$$
\begin{aligned}
& \text { @l }
\end{aligned}
$$

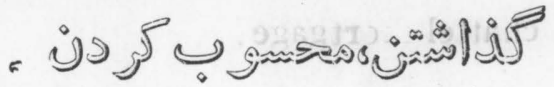

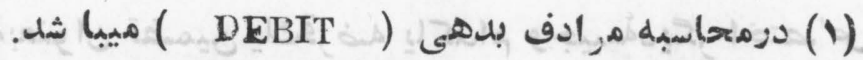

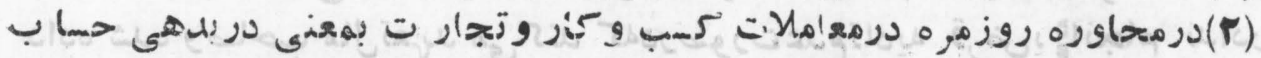

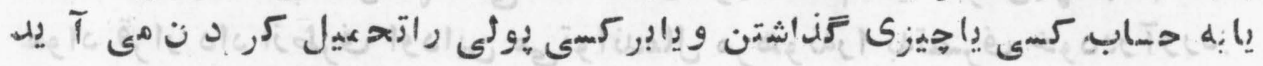

charta partita .

$$
\text { ن }
$$

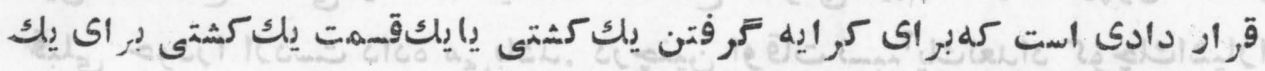

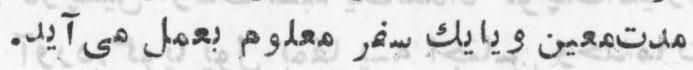
charter.

$$
\text { -) }
$$

$$
\text { - }
$$

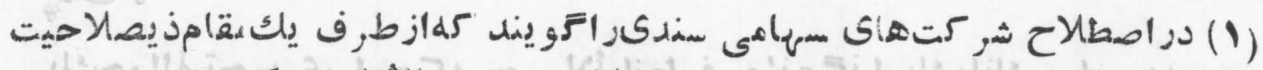

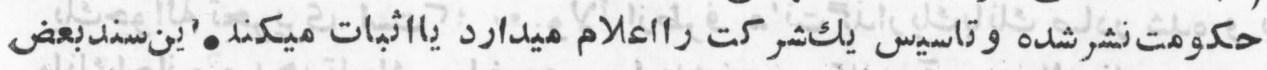

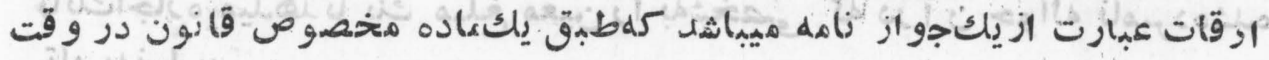

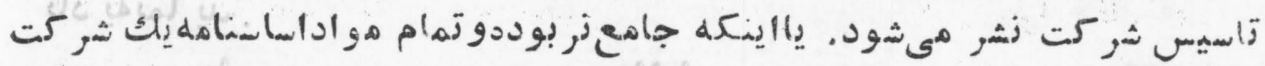

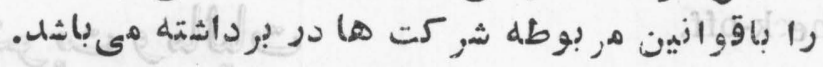

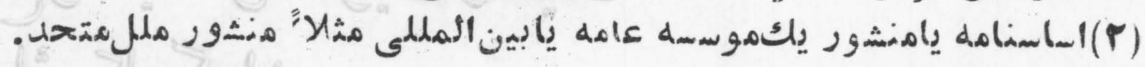
(r) يا إشخا ص. chattel. d.

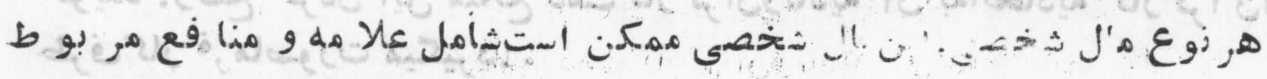

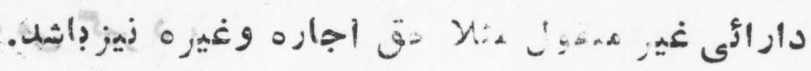


chattel :..

$$
\text { - versis dos }
$$

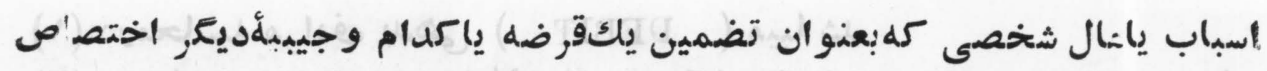

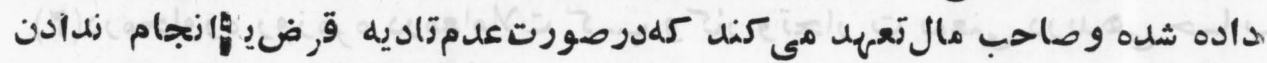

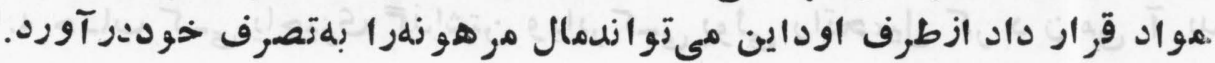
cheap money.

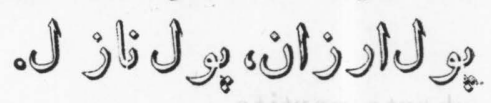

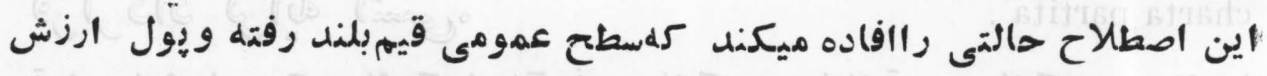

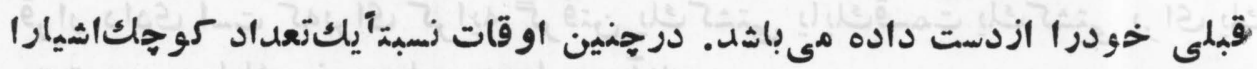

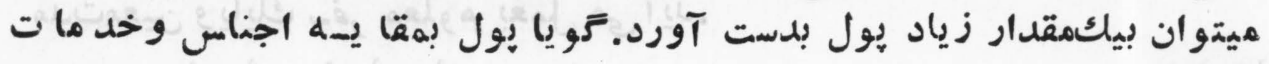

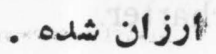

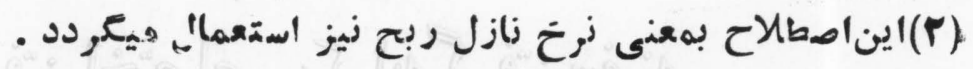
check.

$$
\text { - } \int_{8}^{3 / 8}
$$

يك يكو اله تموريرى است

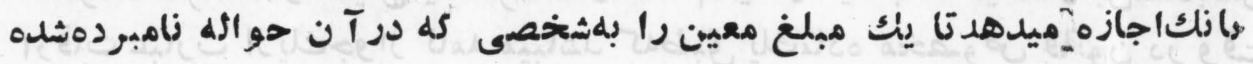
تاد يفزما يداج. che?k-off.

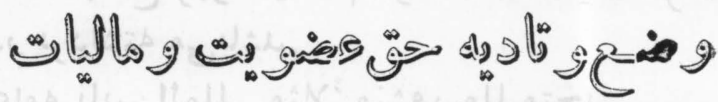

$$
\begin{aligned}
& \text {-i) }
\end{aligned}
$$

دراصطلاح دوابط كار (روابط صنعتى )وضع كرد ن حف عضو يت اتحاديه

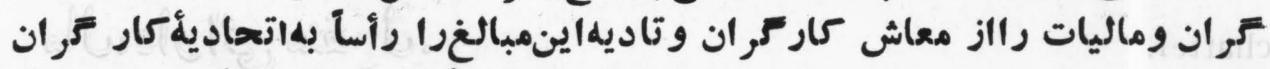

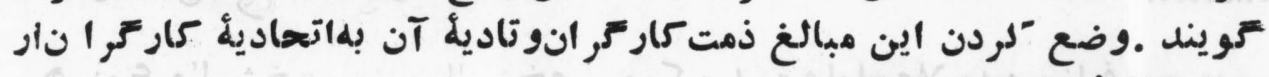
طوف

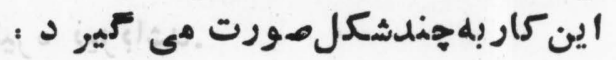

(1) (1ضعوتاديه اختيارى(VOLUNTARYCHECKOFF) دن ينصورتوضعايزمبالغ (y) 


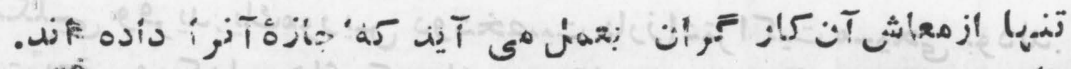

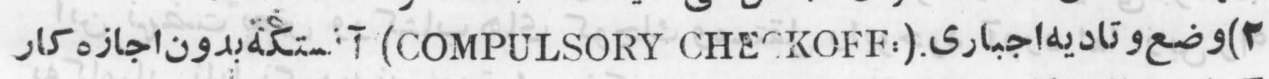

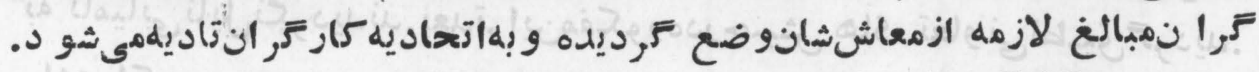

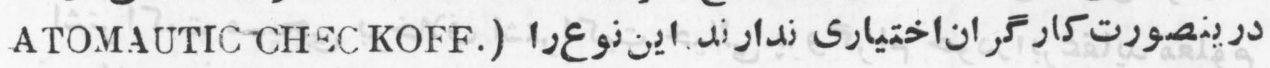

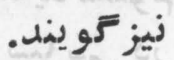

check weigh̀man.

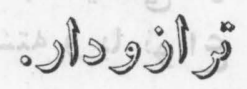

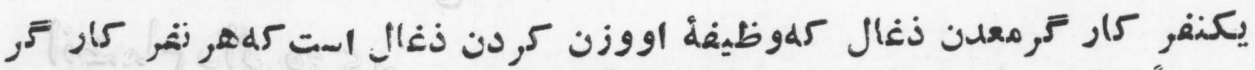

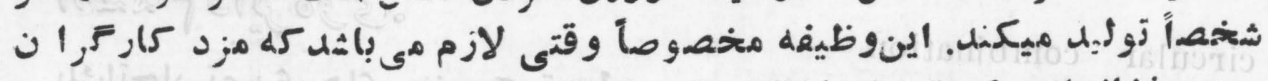

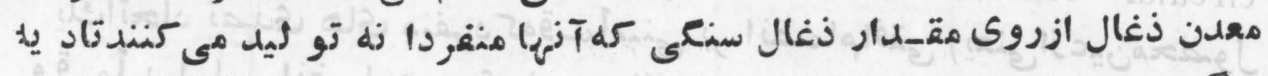

child labor.

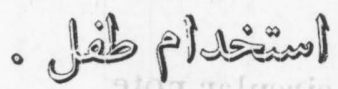

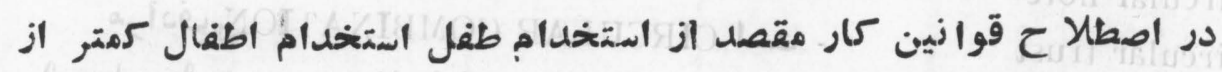

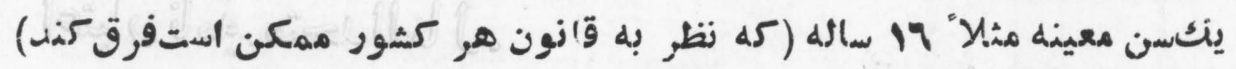

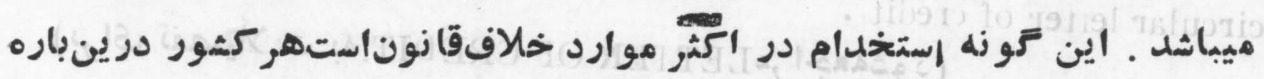

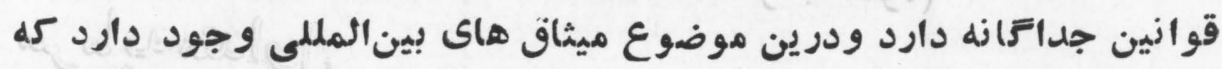

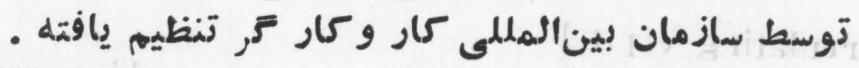

chinese auction.

christian socialism.

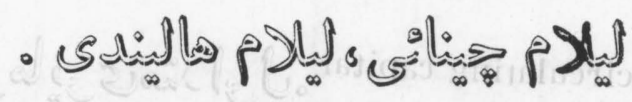

(CDUTCH AUCTION)d مراجه شود به

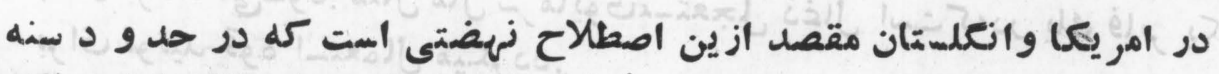

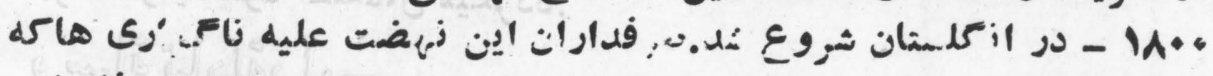

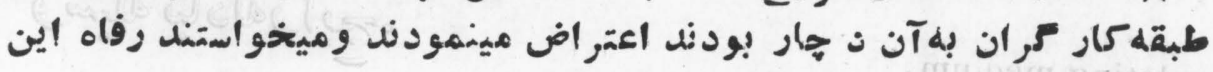

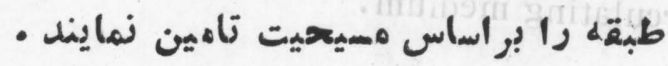

(VD) 


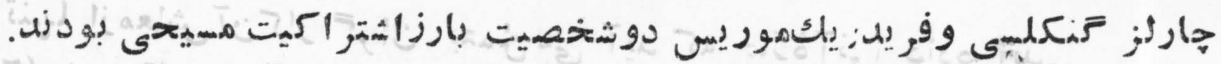

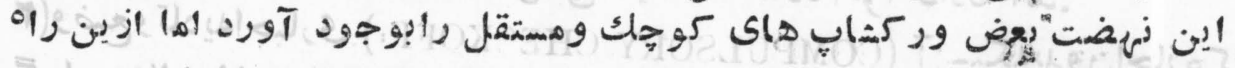

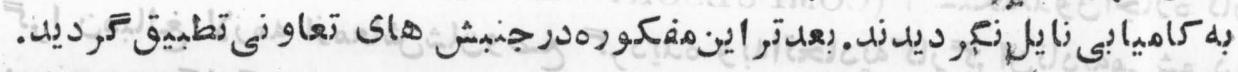

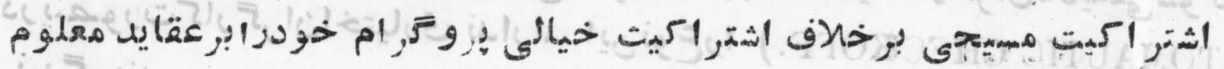

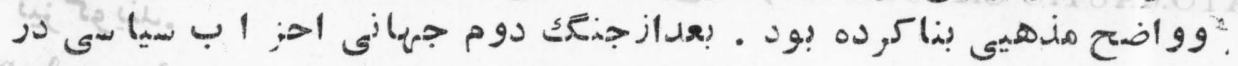

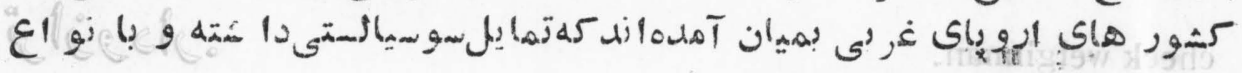

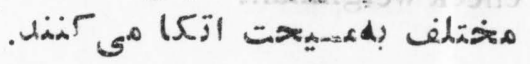

circular combination

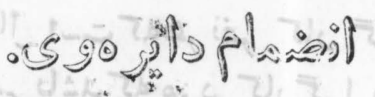

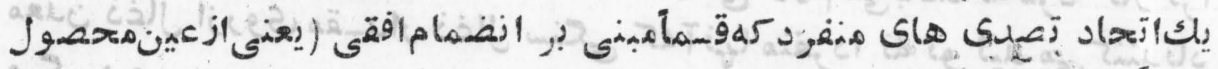

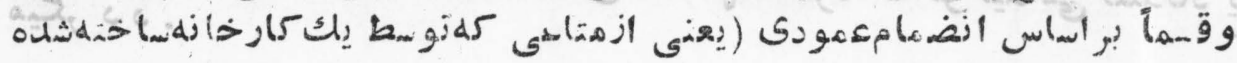

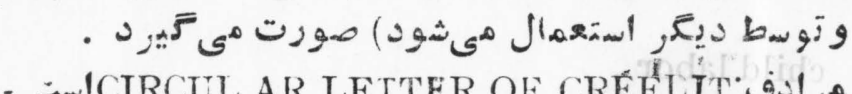

circular note circular trust circular leiter of credit .

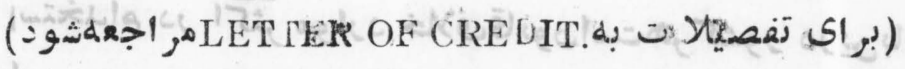
circutairg ceritellJ $9 \int_{0}$

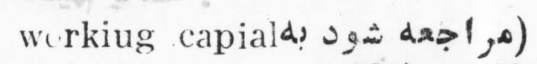

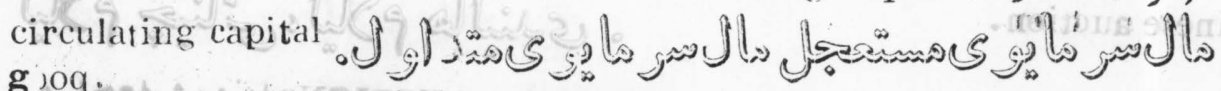

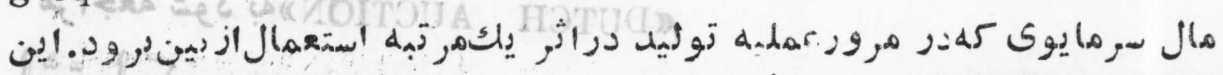

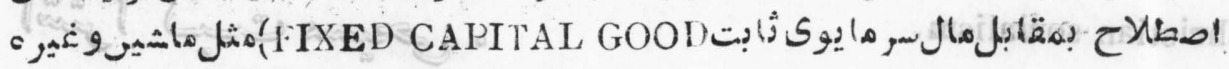

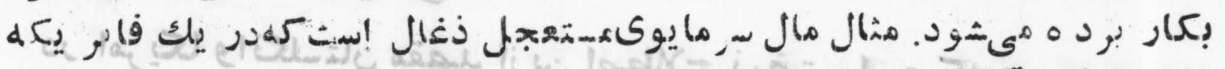

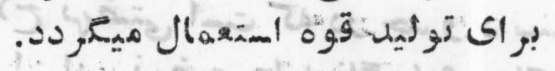
circulating medium.

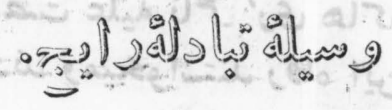
$r m$ (C)Y 


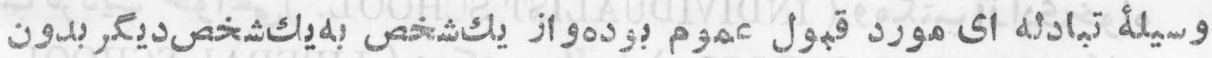

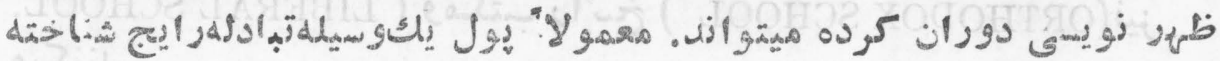

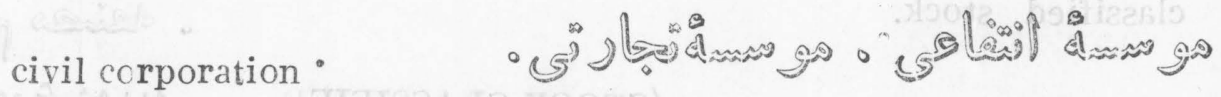

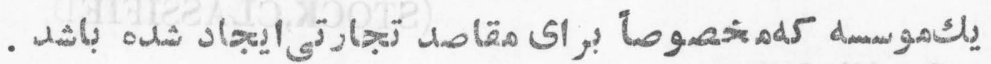

class.

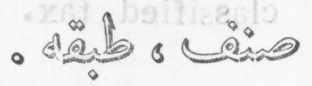
در اقتصهأ

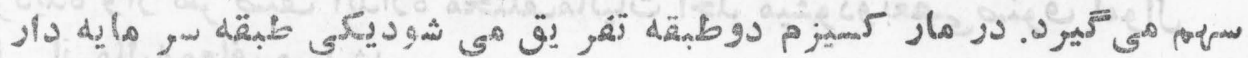

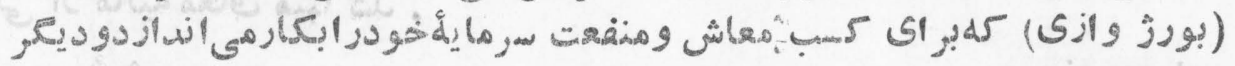

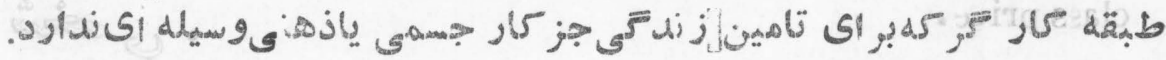

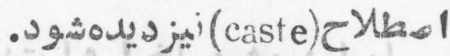
ssical school

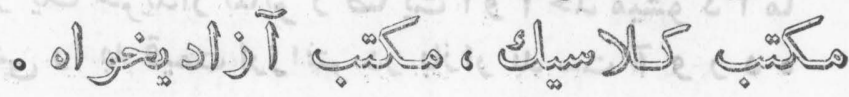

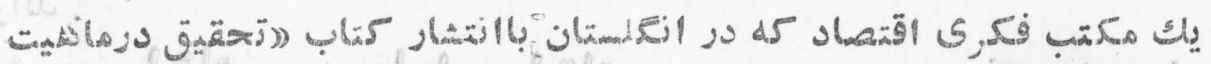
و و

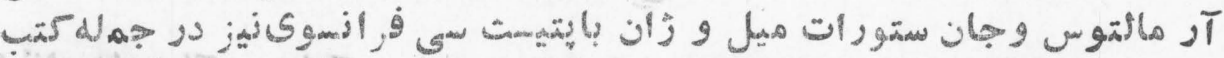

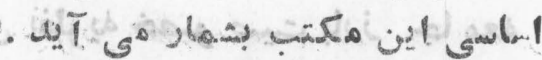
د ر

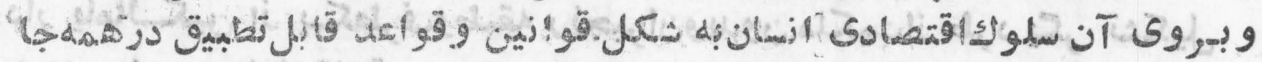

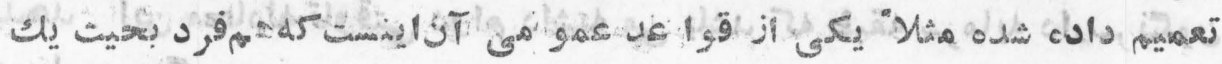

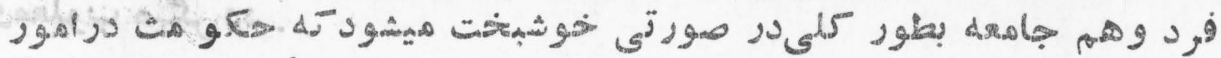

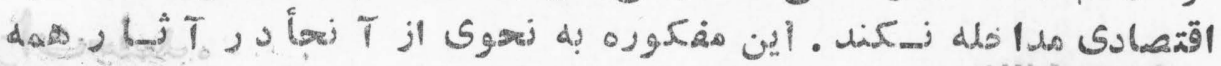

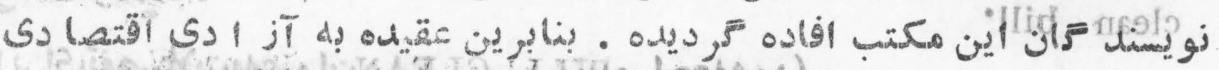

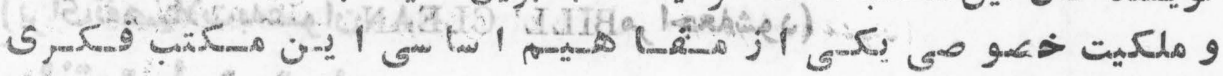

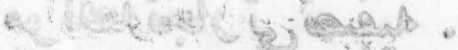

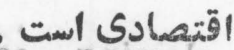

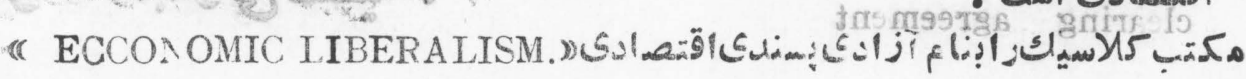


ومCتب فرديت خواهي ( INDIVIDUALIS'N SCHOOL ) و وكتب آزادىخواه (ORTHODOX SCHOOL ) ومكتب رالسيز (LIBERAL SCHOOL. ) ياد ميكنتل.

classified stock.

(STOCK,CLASSIFIED إجوع شودبه )

classified tax.

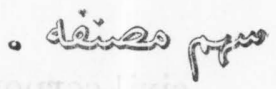

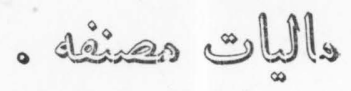
يلك زنظام ماليات كه در آن أموال برورى ماهيت ومهورد استعمال آن تصنيف

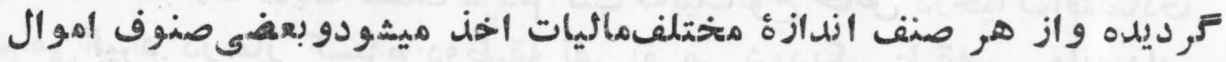

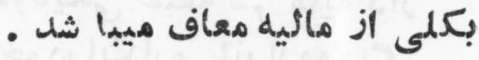

class price.

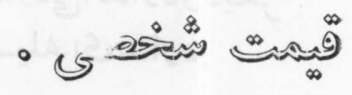

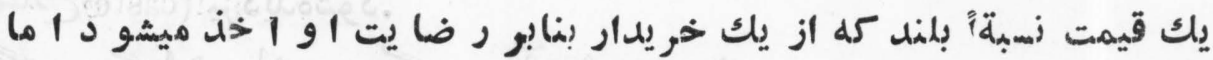

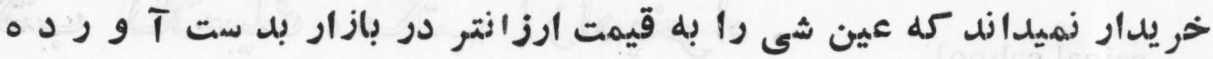

class struggle .

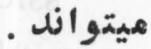

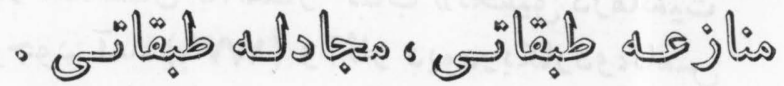

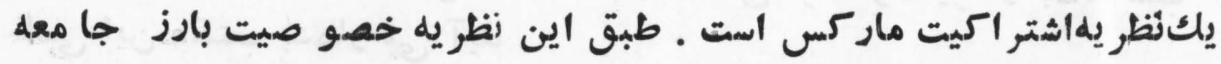

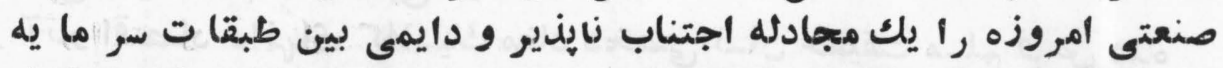

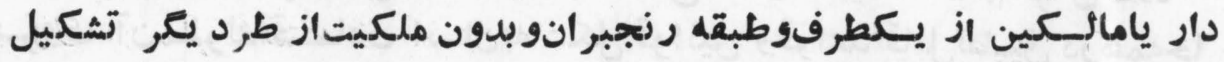

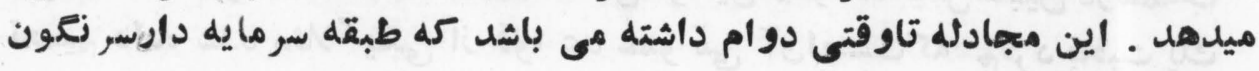

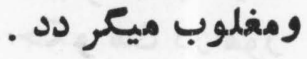

clean bill ${ }^{\bullet}$

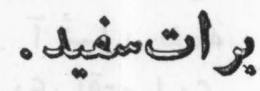

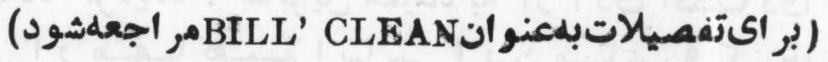

clearing agreement

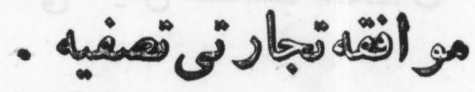




\section{ज" जी}

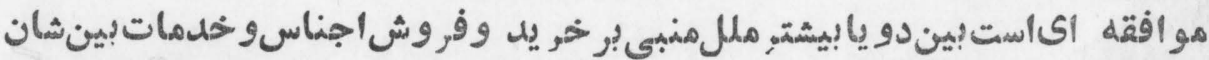

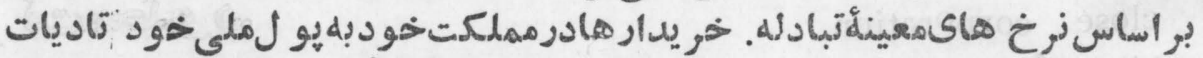

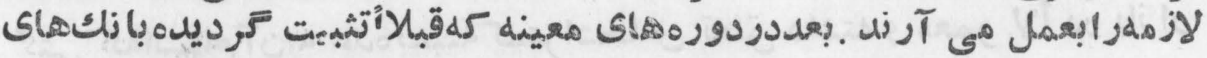

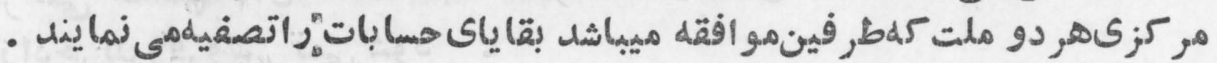

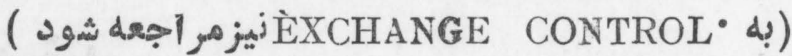

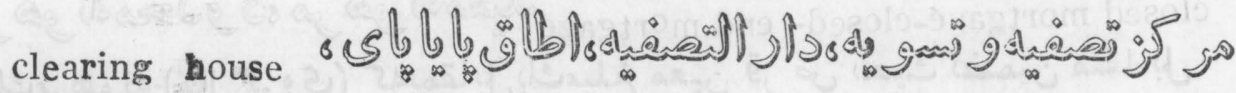
(1)

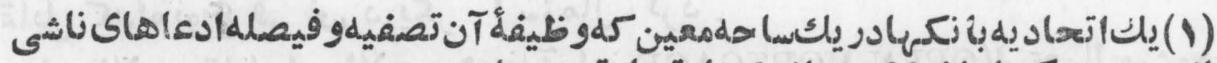

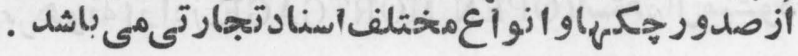

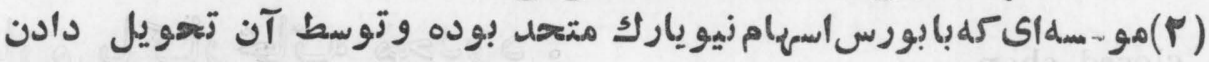

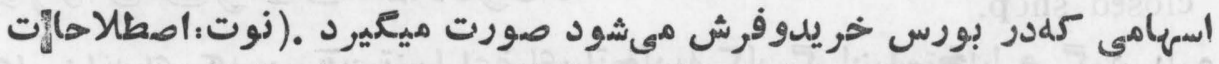

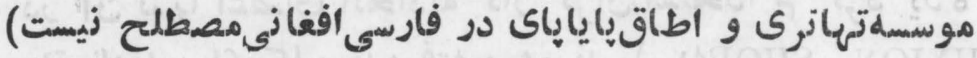
clearing house agent

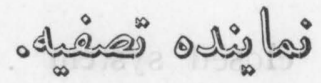

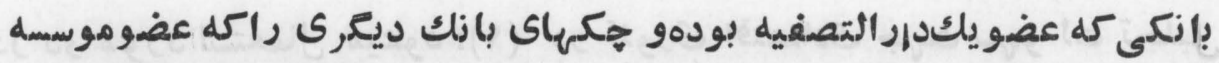

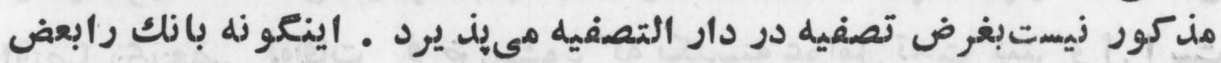

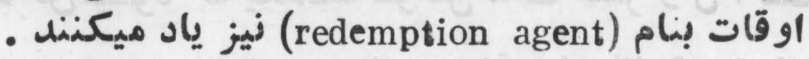

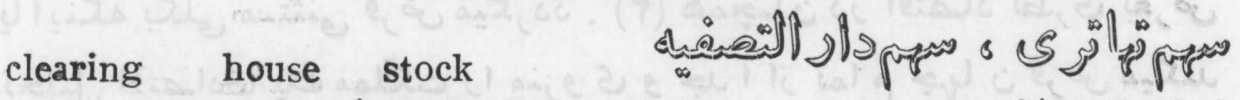
(براى تفصيلات به اجه stock, cleariug house )

clearings - لإ جكمها ، حجت هاوديع, اسنادنظير آنها كه جهتد ريا فت ازطرف يكبانك به

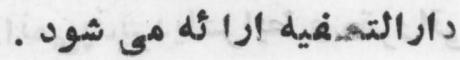


close corporation

- gulareses

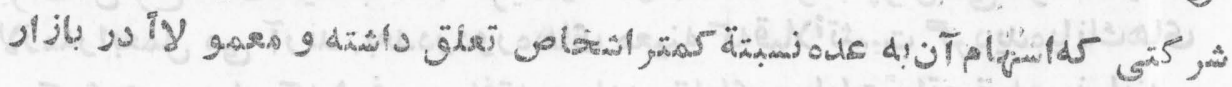
-

closed mortgagé-closed- end mortgage d-

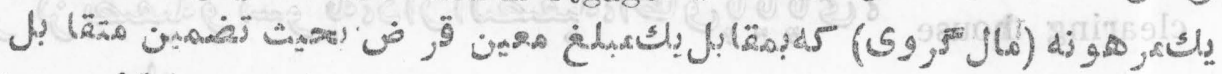

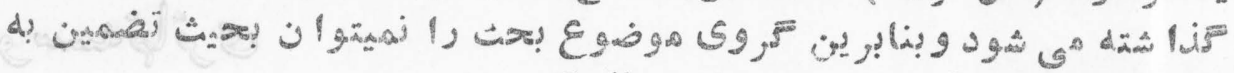

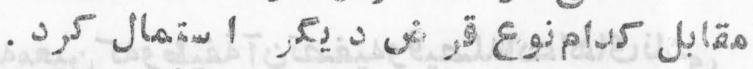

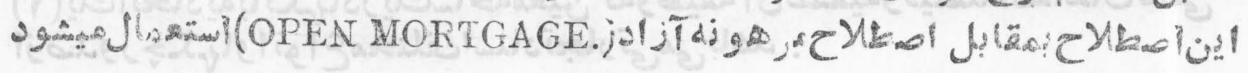

closed shcp.

$$
\text { - Ogusta ailis job ojlio }
$$

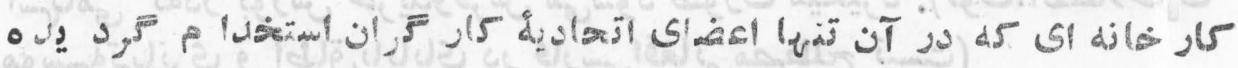

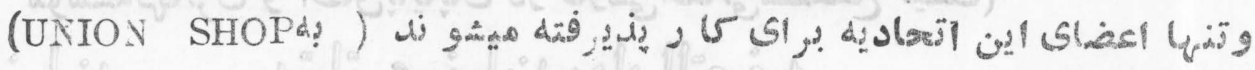

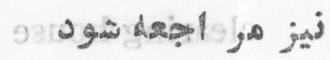

closed system .

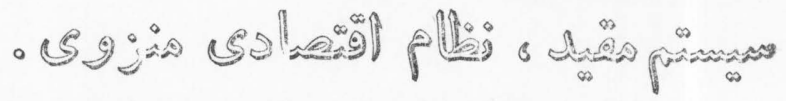

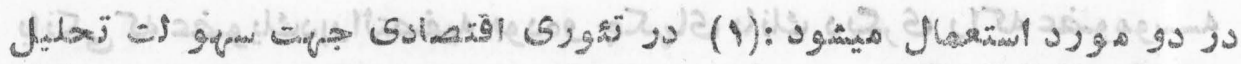

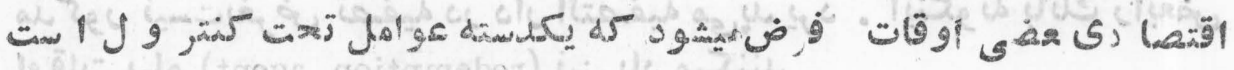

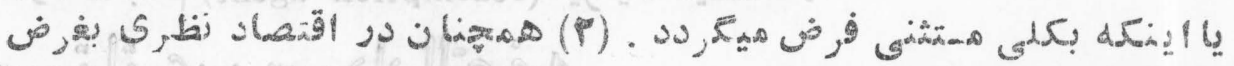

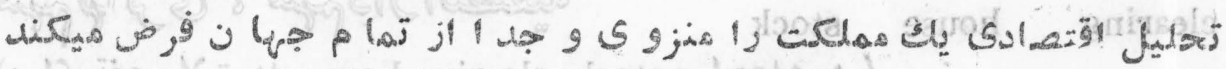

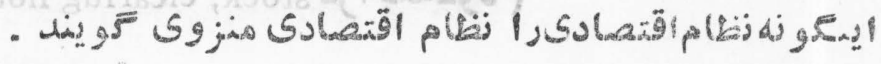

closed union

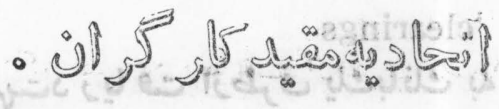

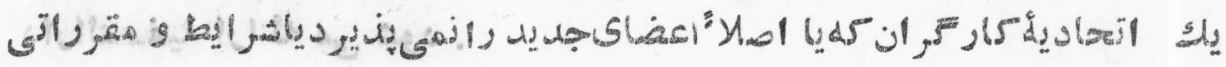
$((A \cdot))$

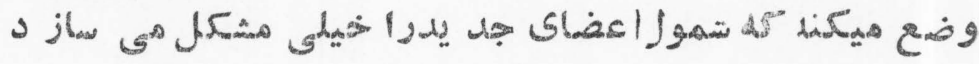


closing price.

- U[@])

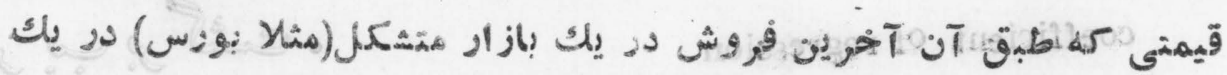

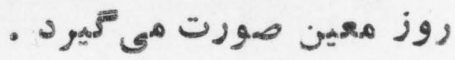

cobwebthe rem (or prob'en)

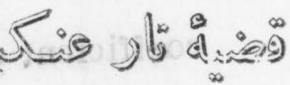

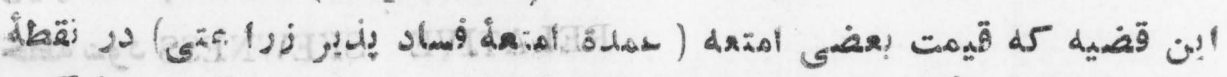

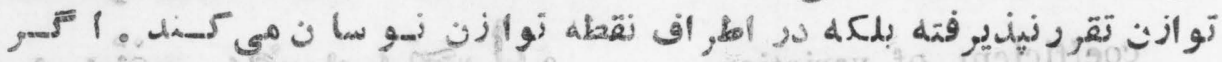

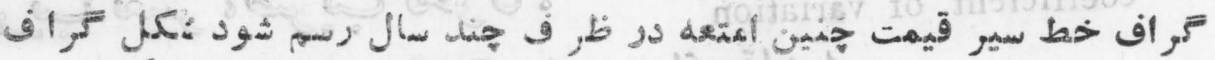

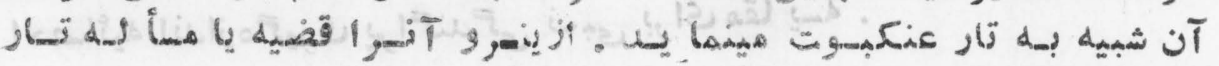

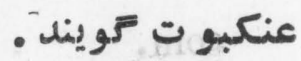

coefficiont of acieleration

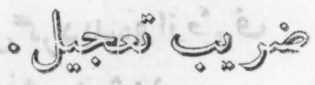
- ACCELERAIION PRLNCIPJE . مورأ

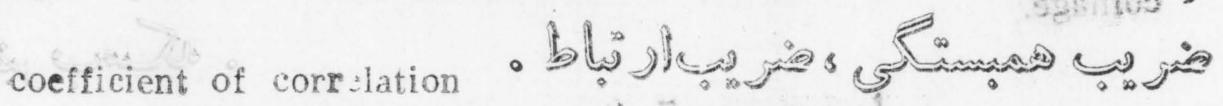
(CORRELATION) ه coefficien of determination . ling coeffient of dispe sion

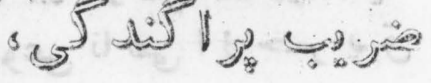

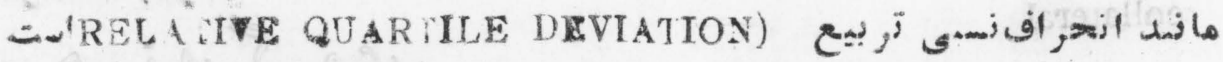
cefficient of elasticity r tar to

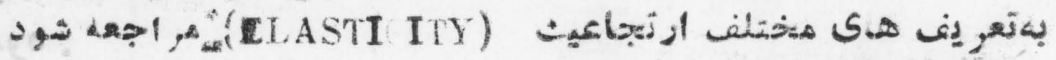
cofficient of quartile ceiaticn

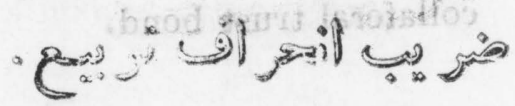




\section{$\mathrm{CO} \mathbf{E}$}

مرادف (RELATIVE QUARTILE DEVIATION) 'ست

coefficient of regression

درجه نشيب خظ تابع (REGRESSION LINE) - د 象 مELATIVE SKEWNESS مظه شود RES

coelficient of variation

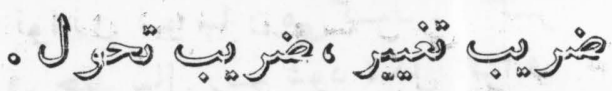

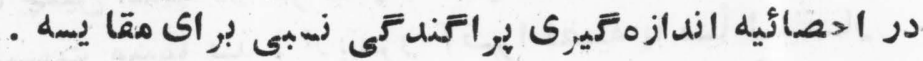

coin.

coefficicnt of skewness

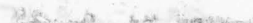

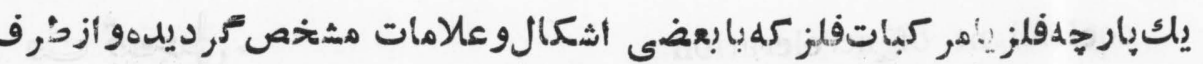

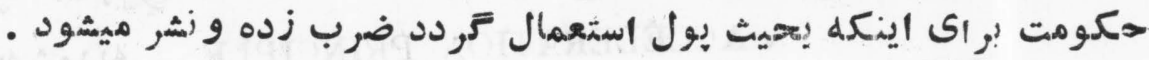
coinage.

coinsurance.

$$
\text { ساختن وضرب زدن سكه بمنظور استمعال آن بحيث بـول . }
$$

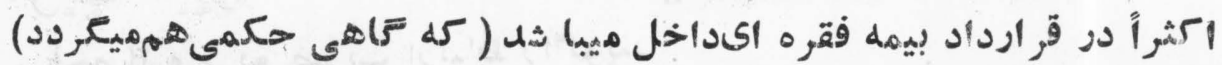

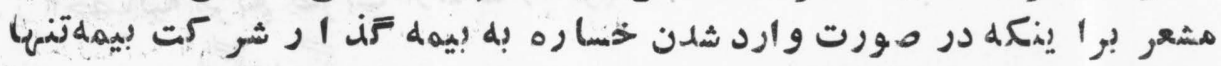

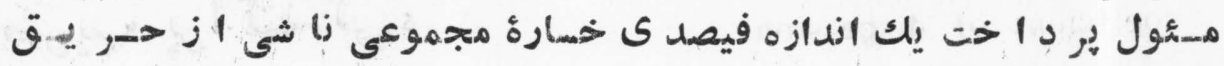
collateral .

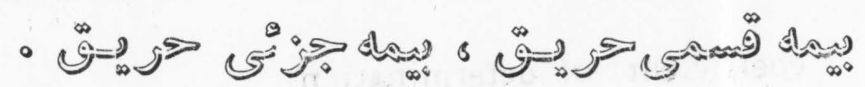
خواهـد بـود .

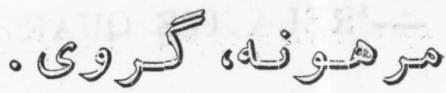

مال ياكدام مدرك آنكه به نزد طلبعار ان جهرت آضمين تاديه قوضه 1 ما نت

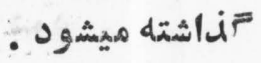
collateral trust bond.

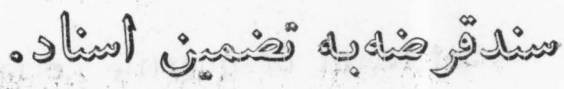


BOND,COLLATERAL TRUST مر اجعd شود به

collective bargaining .

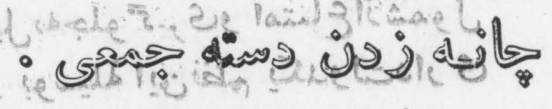

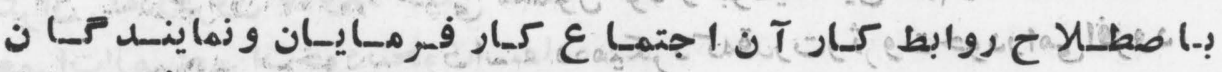

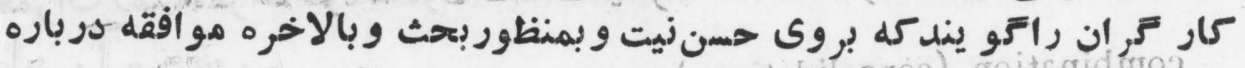

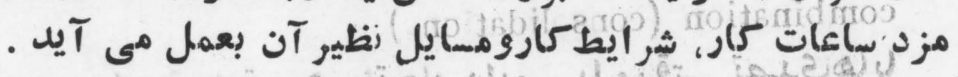
collective ownership.

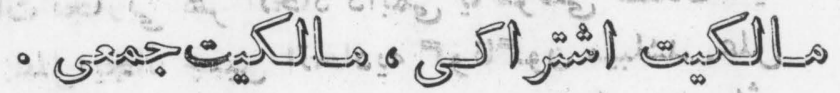

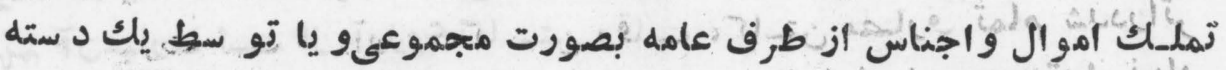

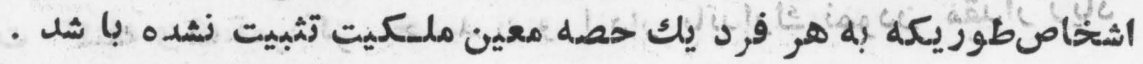

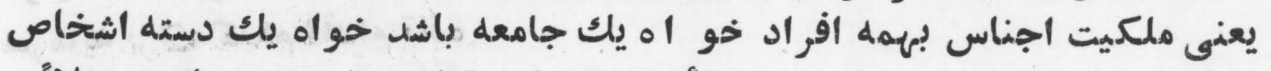

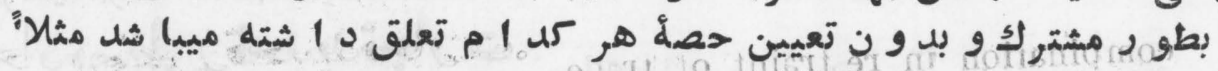

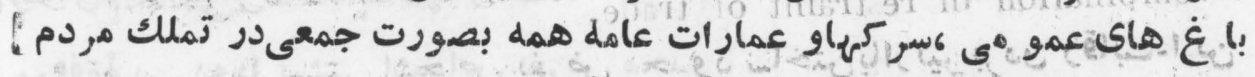

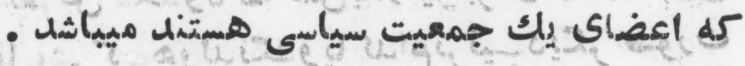

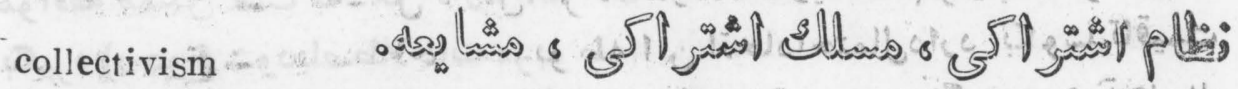

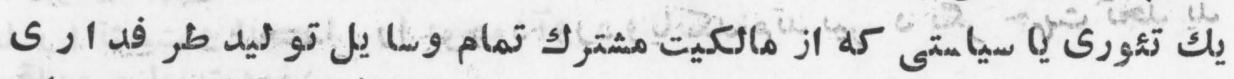

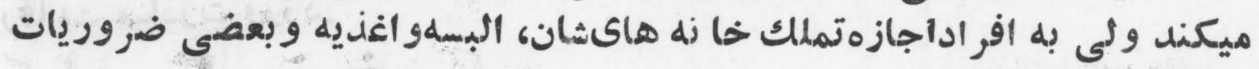

collector

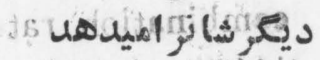

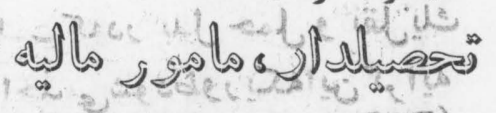

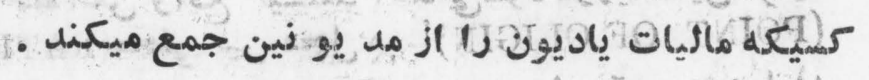
colonial bond. - जी J o

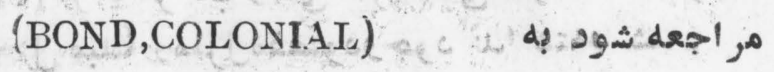
collision insurance - $\oplus$

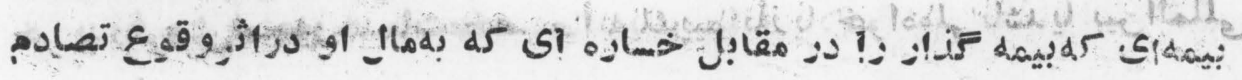

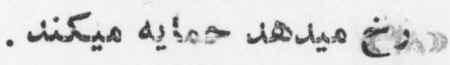
(AAPD 
colonial system.

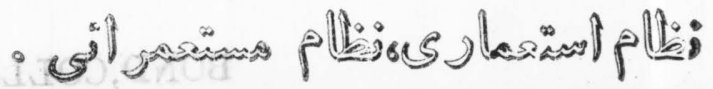

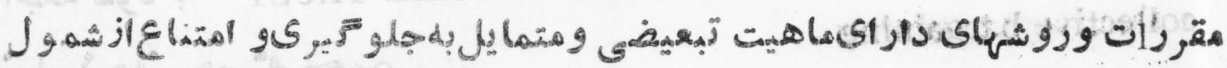

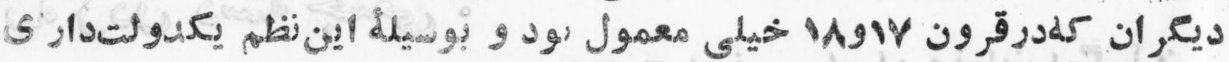

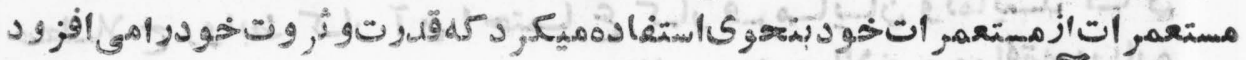

conbination (cons lidation.)

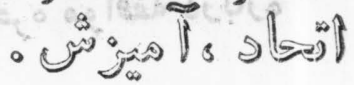

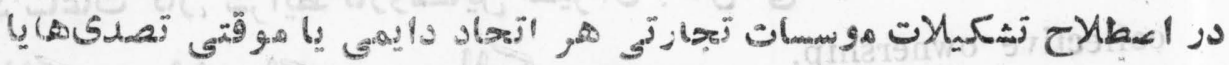

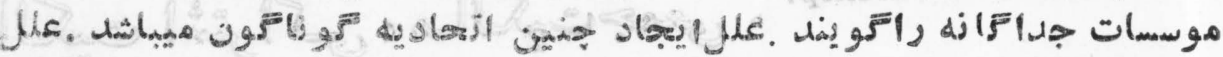

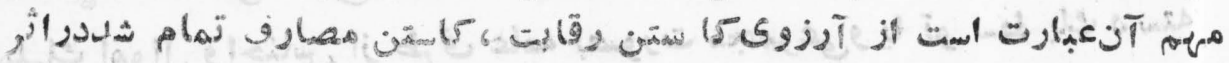

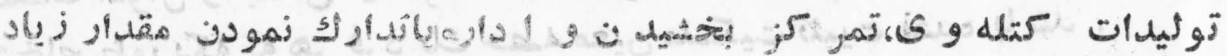

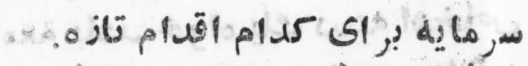

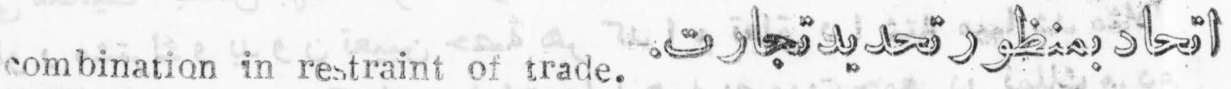

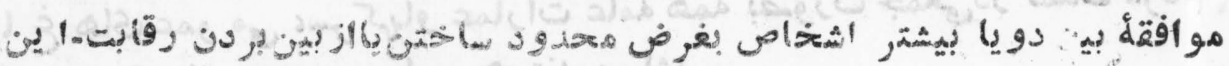

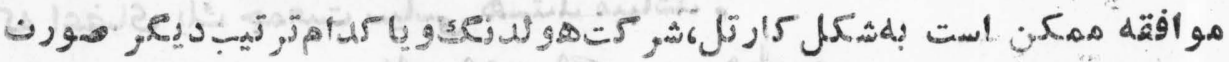

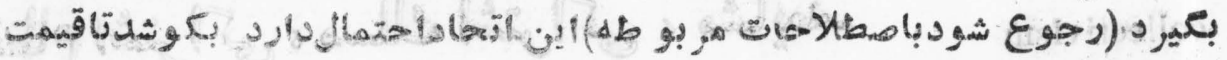

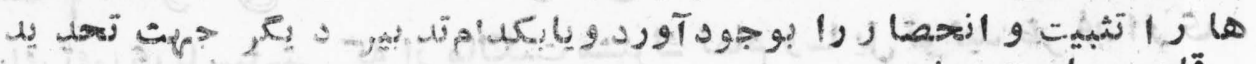

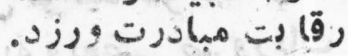

combination rate

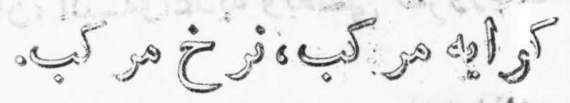

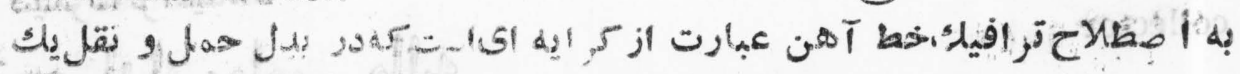
شى بين دئ دها (POINT OF OTIGIN) ه A di A jos

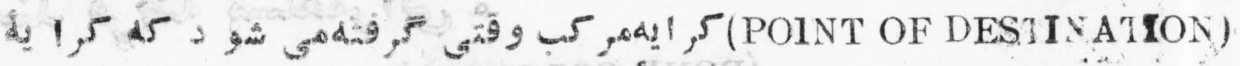

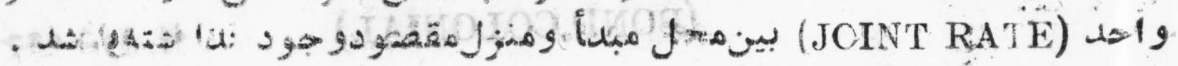

fommerce:

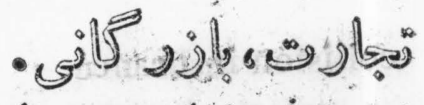

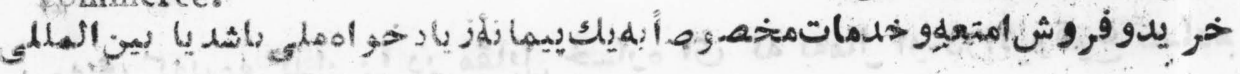


conmercial bank.

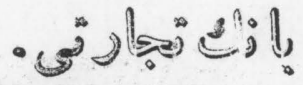

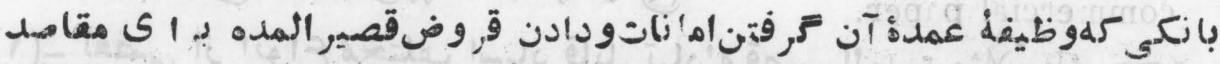

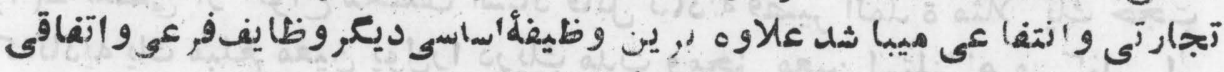

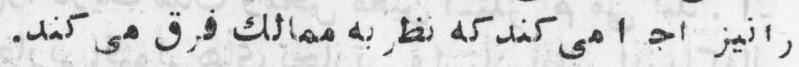

commer ial bill.

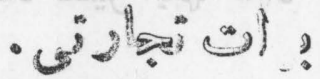

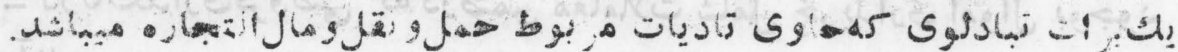

commercial credit.

- जiय

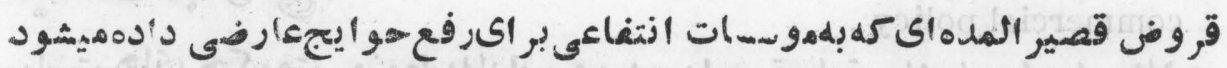

comercial eredit compàny.

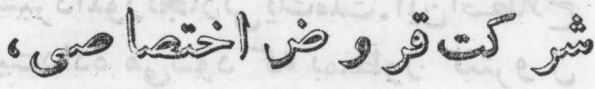

$$
\begin{aligned}
& \text { - ज J }
\end{aligned}
$$

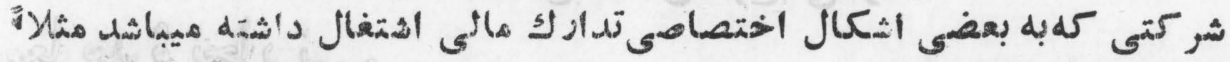

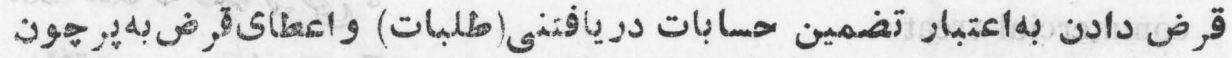

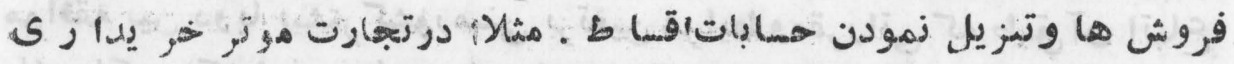

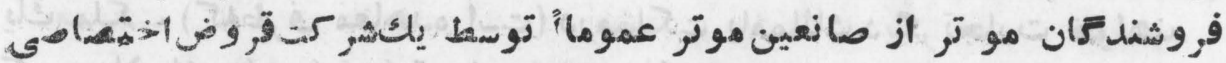
دز مقال يل يكرسيد اعتماد ) (TRUST RECEIPT)

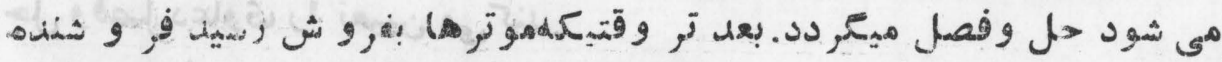

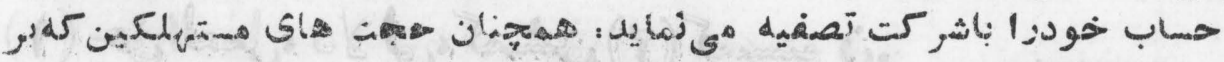

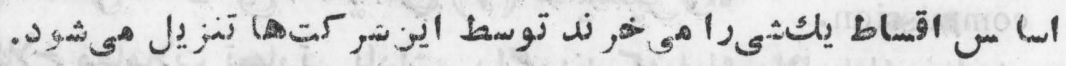
(DISCOUNT HOUSE OR FINANCE CCMPANY) اين نوع نيز ياد مي كند أند

commerci 1 overhead.

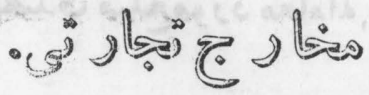

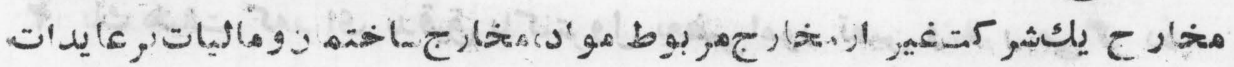
(ANO) 
commercial pзper.

$$
\begin{aligned}
& \text {. }
\end{aligned}
$$

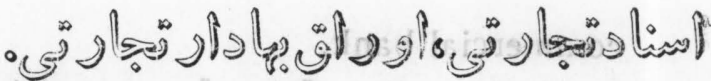

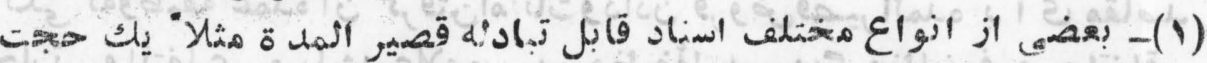

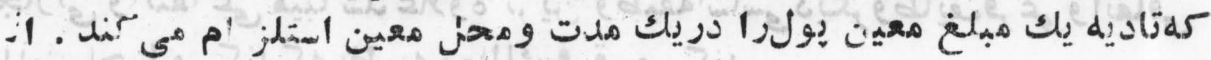

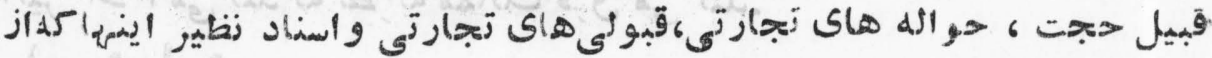

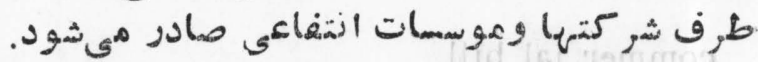

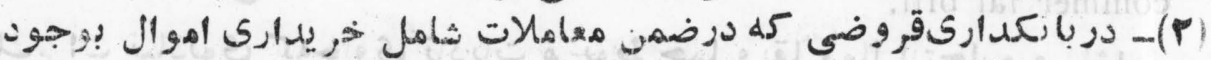
مى آني

commercial policy .

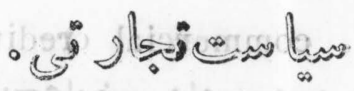

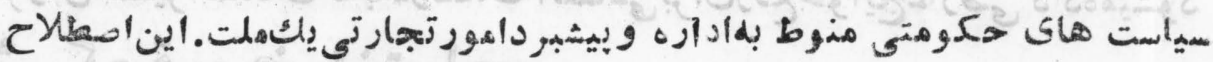

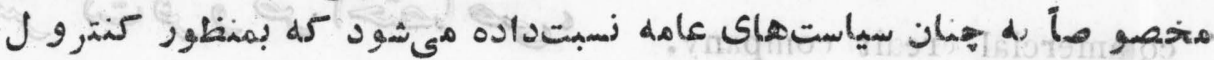

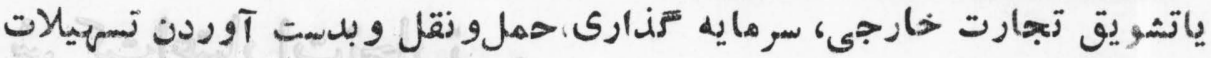

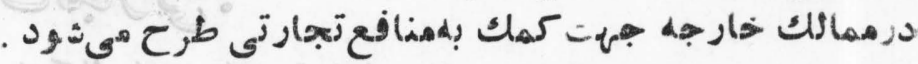

commercial treat. - जु

موافقه نين دو يا بيشتر كشورومنفى بوتهين شر ايط ومقر راتى كله طبنق آن اتبهاع

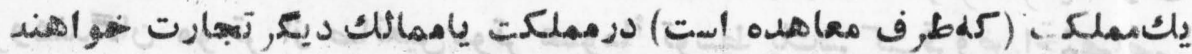

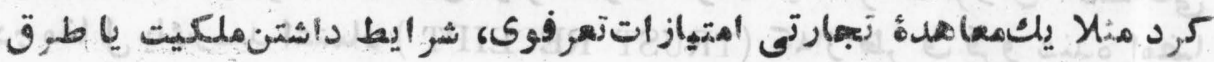

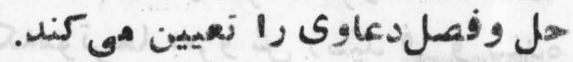

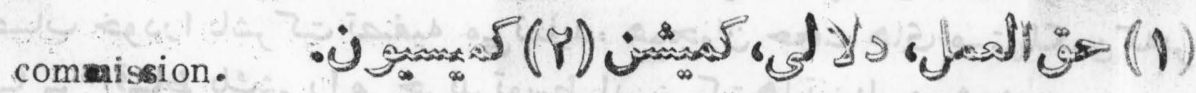

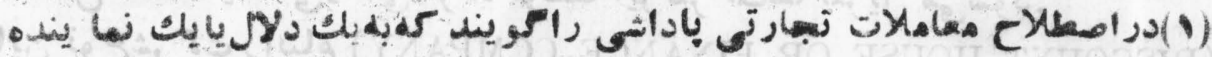

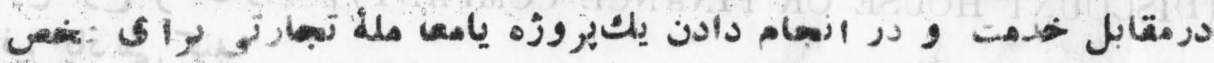

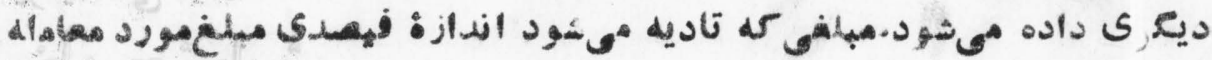

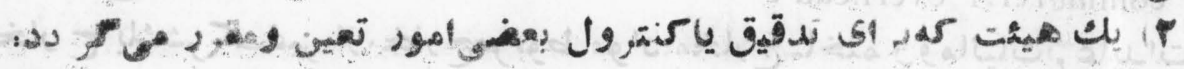


commi sioner of cust ms.

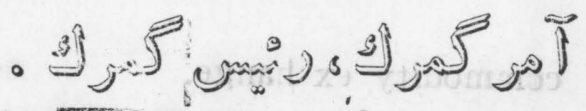

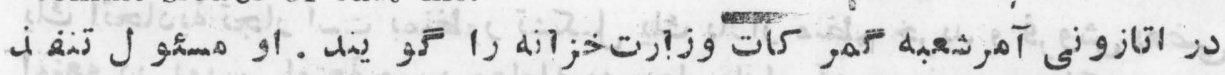

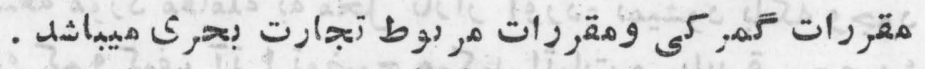

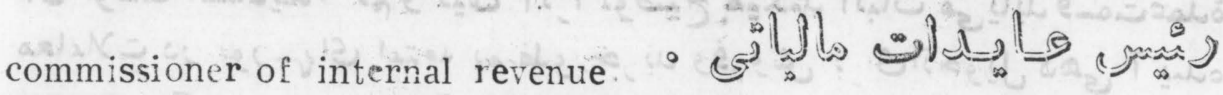

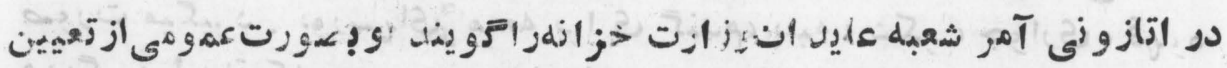

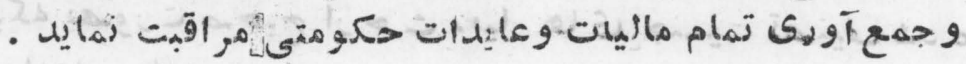

commodity. - mis of

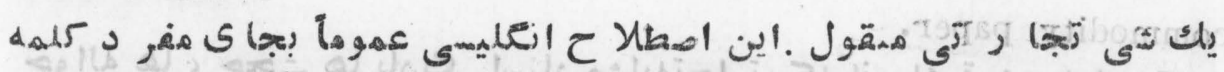
دئي عوض (GOODS)

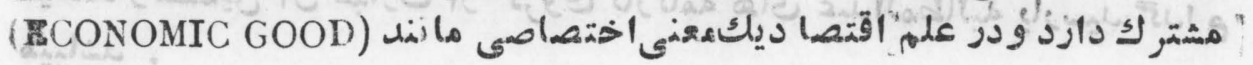

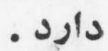

cummodity agreement.

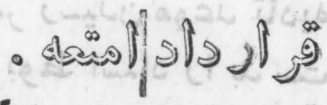

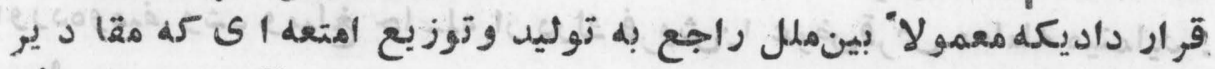

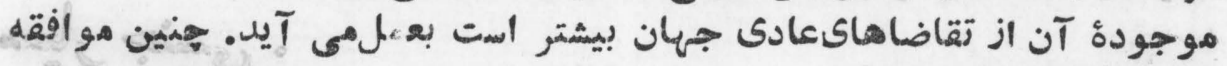

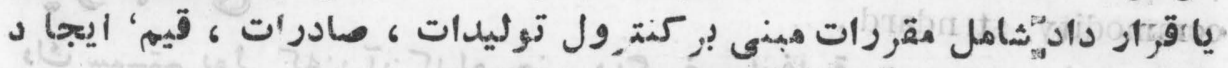

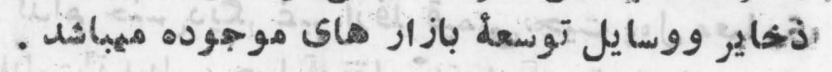

commodity dollat.

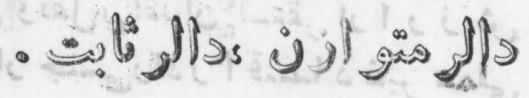

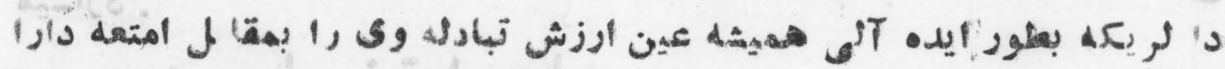

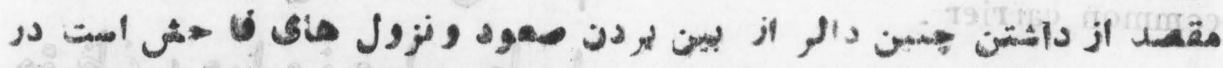

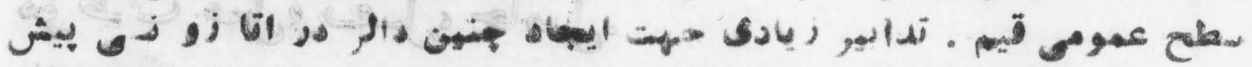

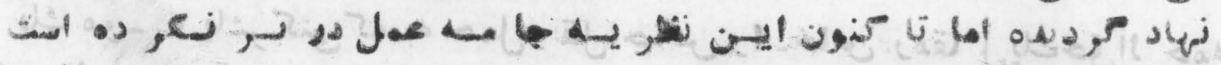

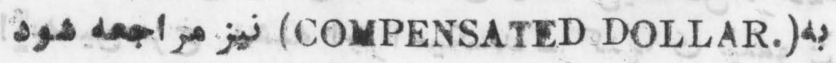


commodity $\mathrm{ex}$ hange.

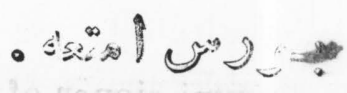

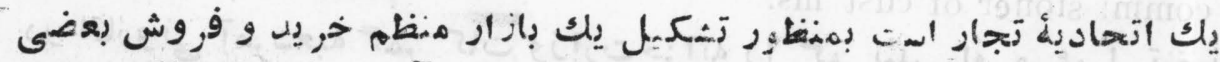

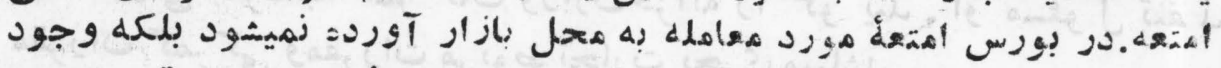

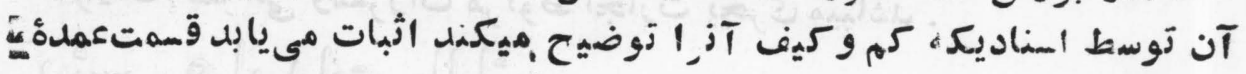

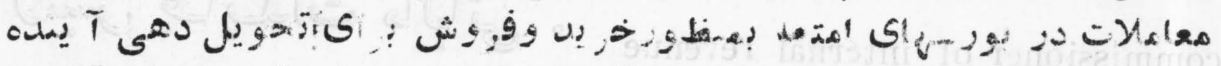

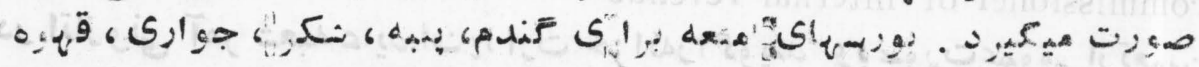

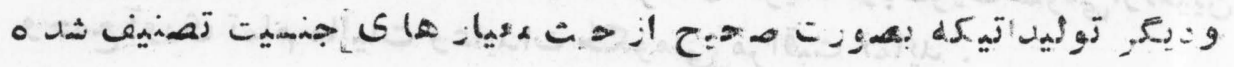

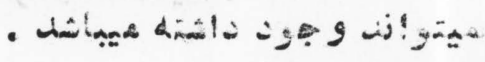

commodity paper.

- Asios I diso

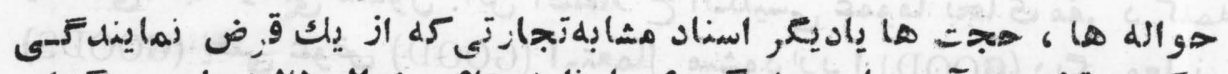

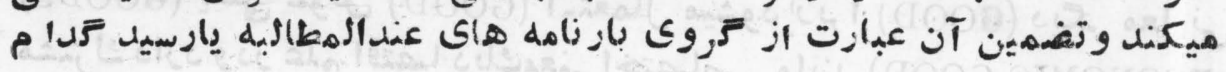

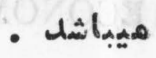

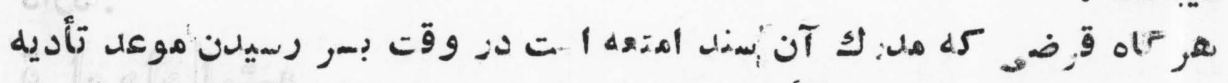

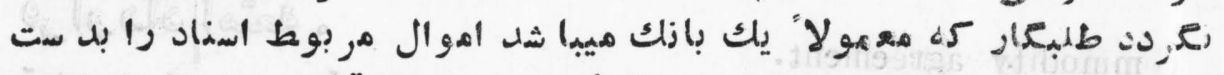

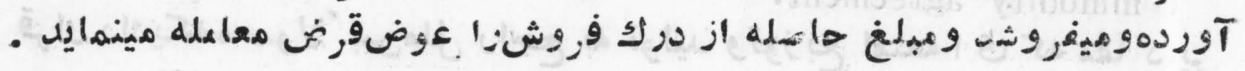
commodity stindard. - जasiz slision

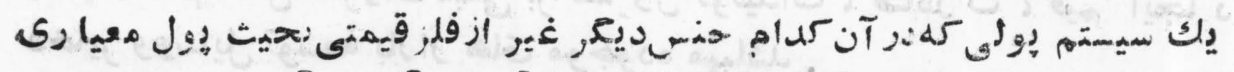

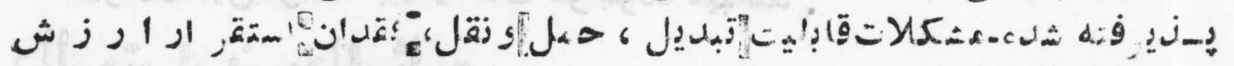

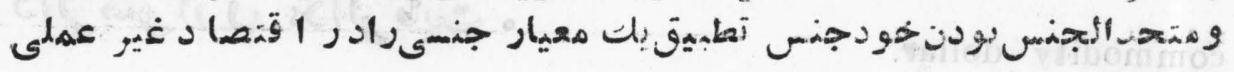

$$
\text { هي- ومازد }
$$

ccmmon car rier.

$$
\begin{aligned}
& \text { opl=s Ja; of }
\end{aligned}
$$

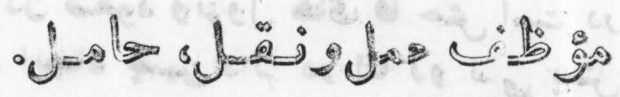

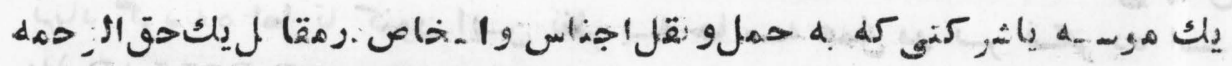

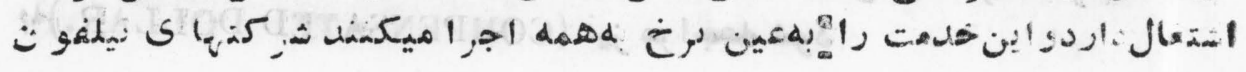

\section{(AA)}




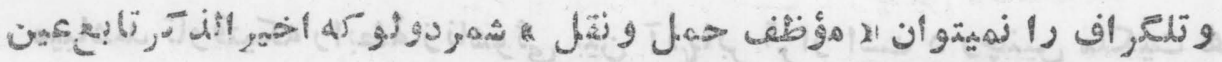

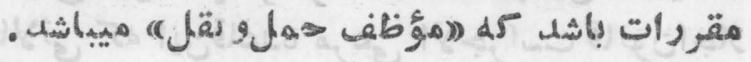

common stock.

(STOCK'COMMON)

- 159 logan

common trust .

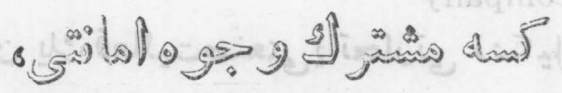

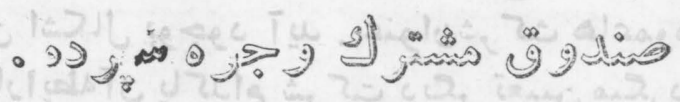

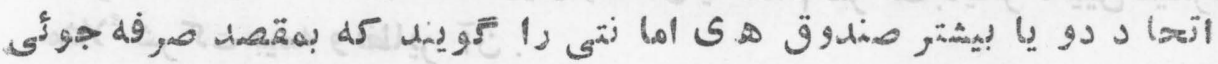

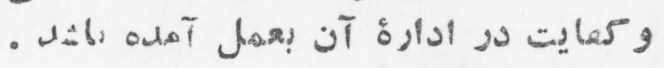

communism.

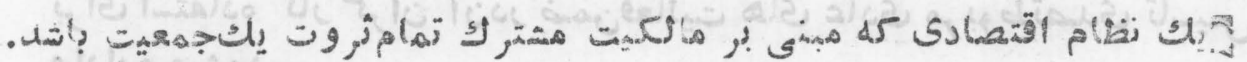

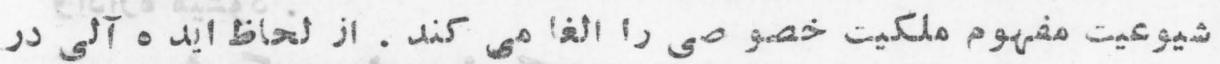

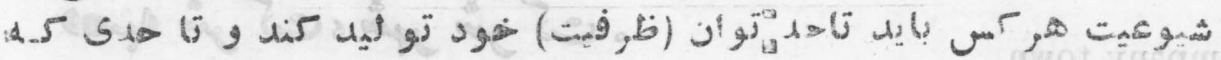

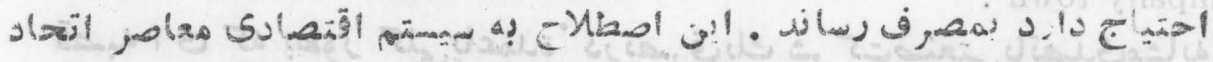

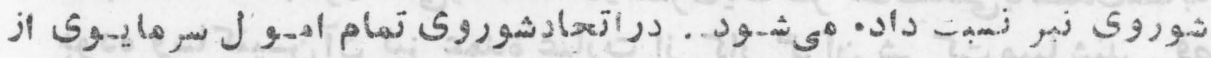

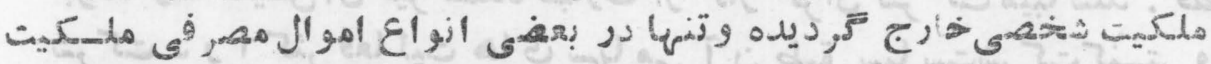

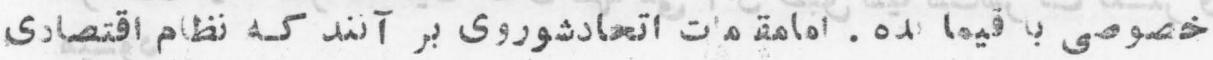

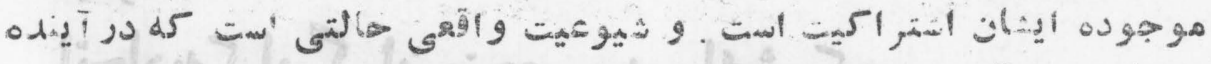

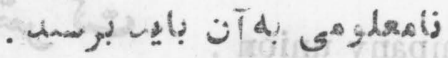

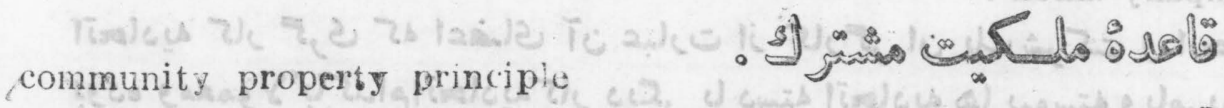

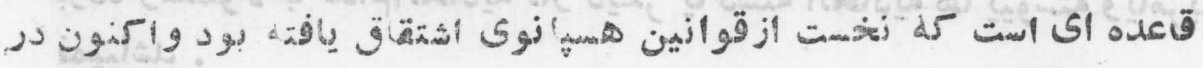

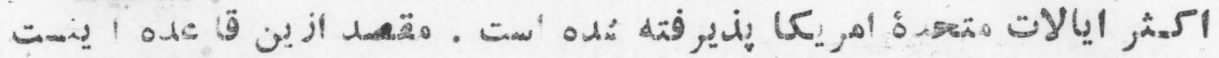

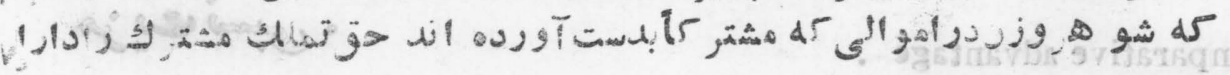




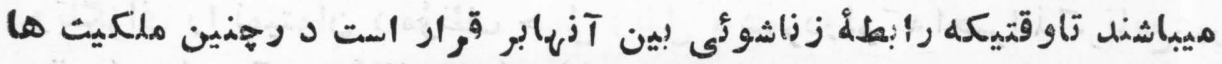

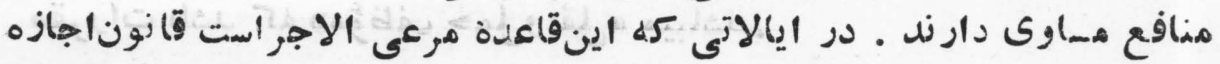

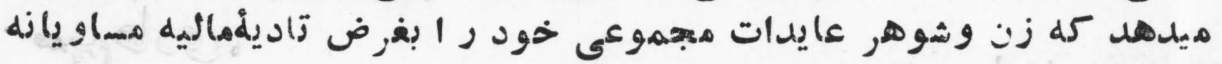

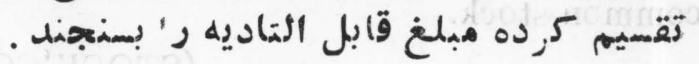

company

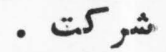

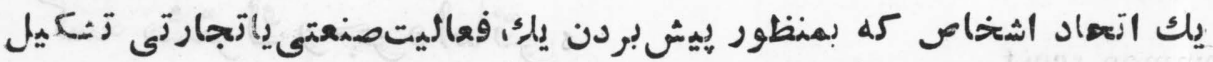

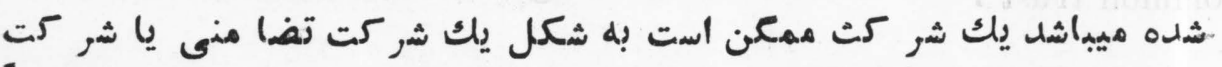

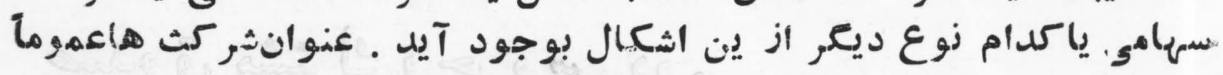

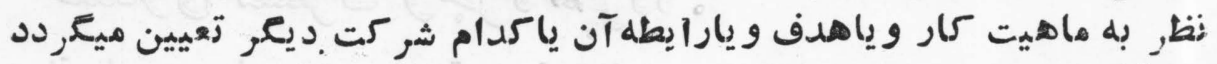

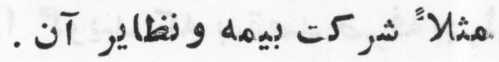

company store .

-

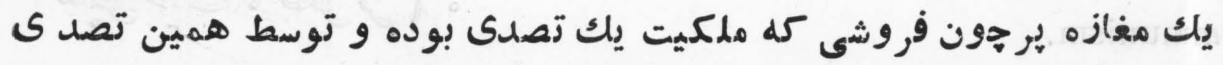

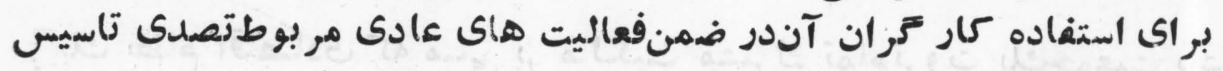

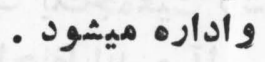

company town .

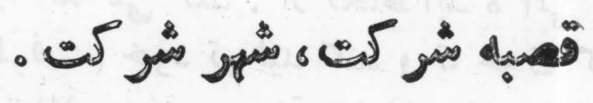

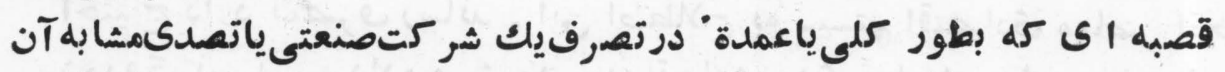

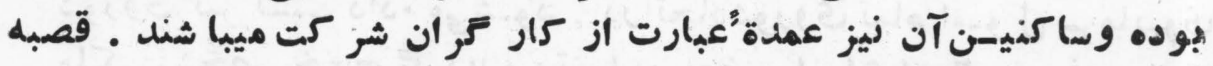

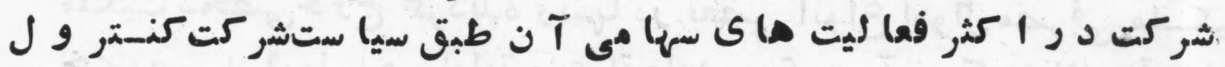
ميشود.

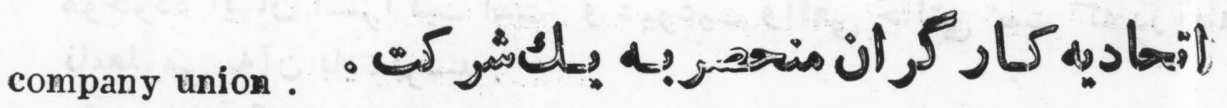
آتحهاديه كار Fرى كه اعضاى آن عبارت از كار

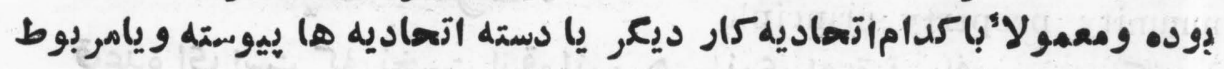
لمميثاشل . comparative advantage .

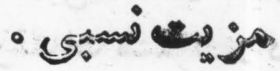




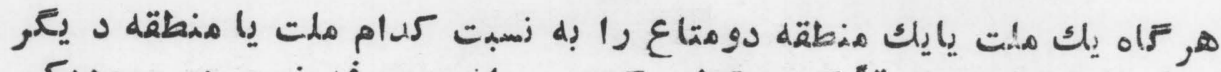

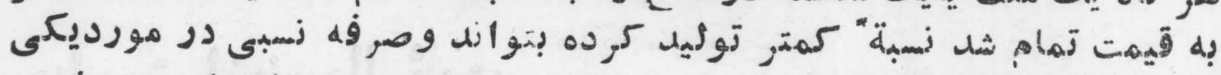

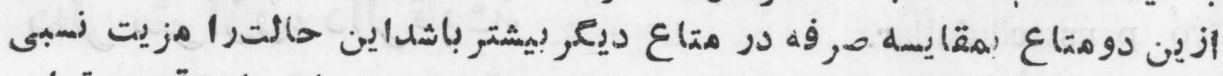

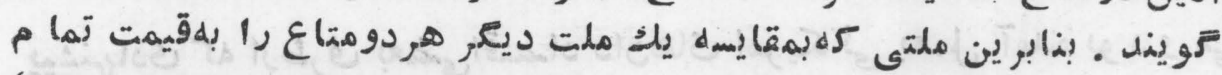

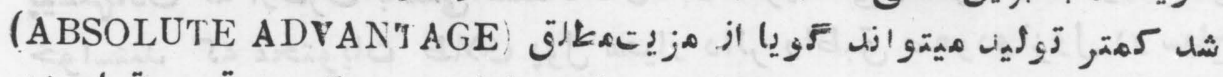

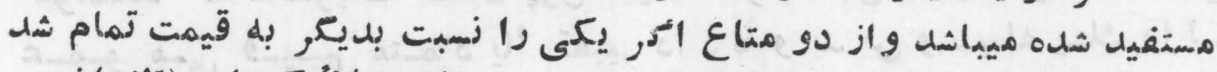

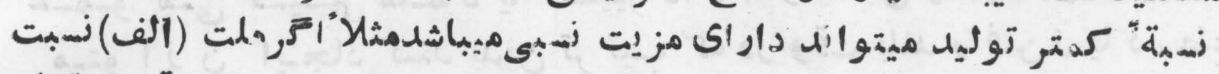

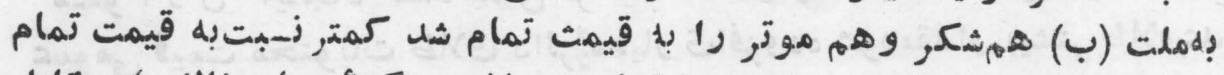

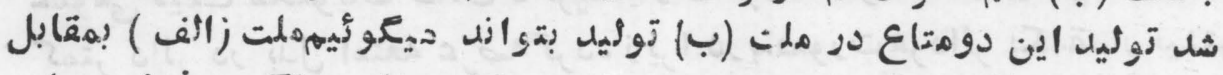

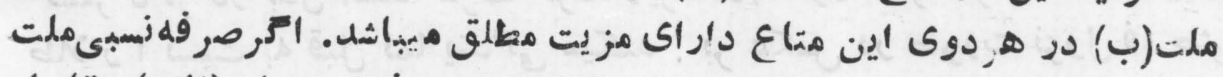

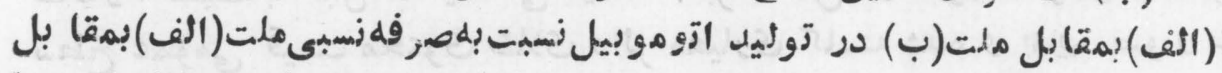

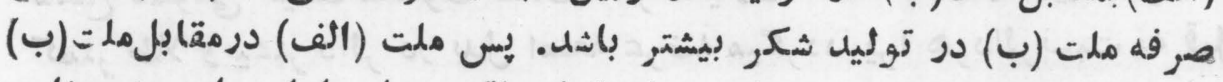

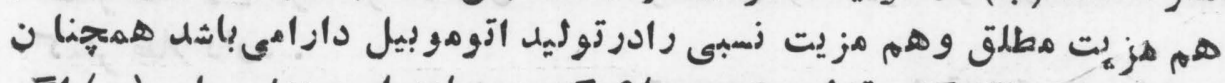

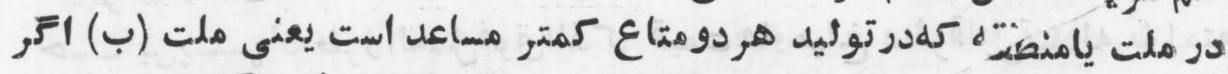

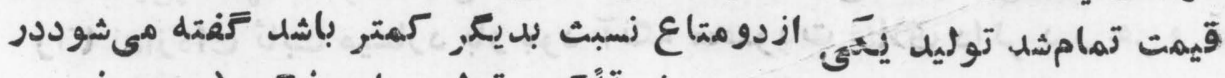

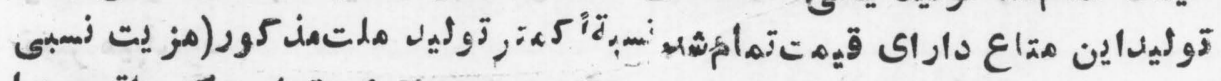

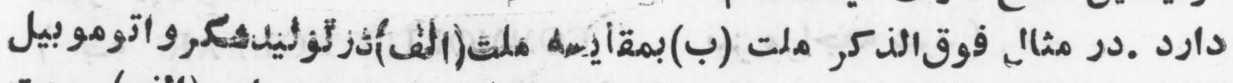

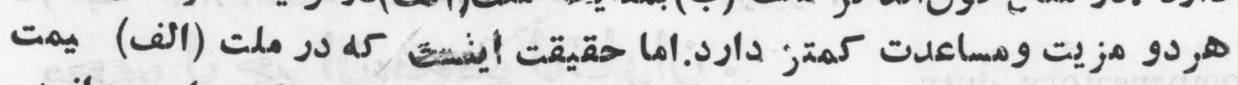

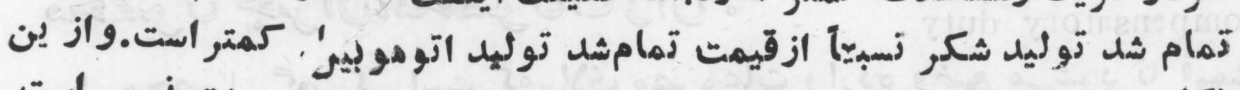

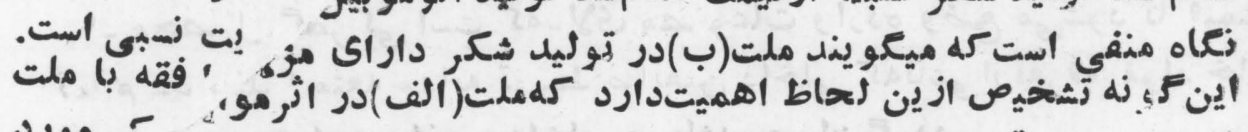

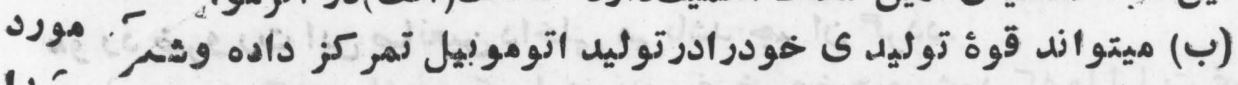

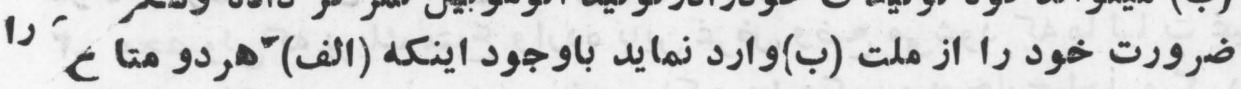
ميتوازل ارزانتر توليد زمايد. مزيت نسبى رابعضىاوقات تمام شدنسبه(COMPARATIVE COS'J) نيز توري:ه comparative cost.

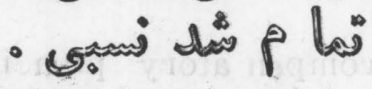

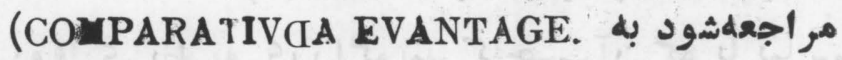


co pensuted dailiar.

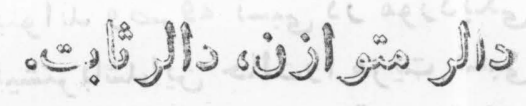

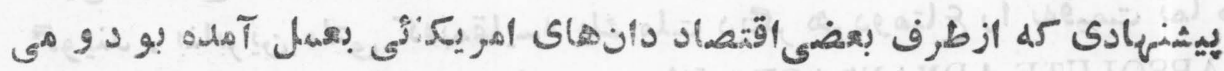

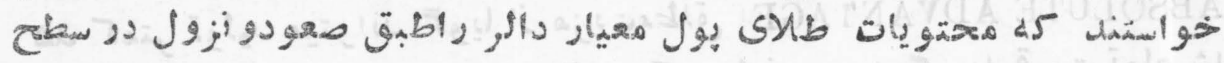

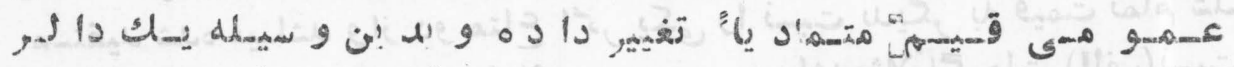

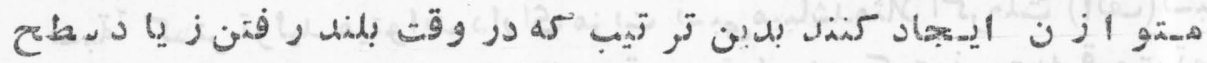
oلd

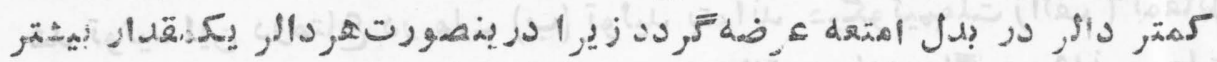

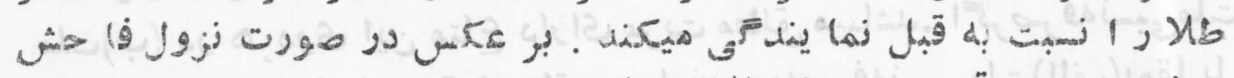

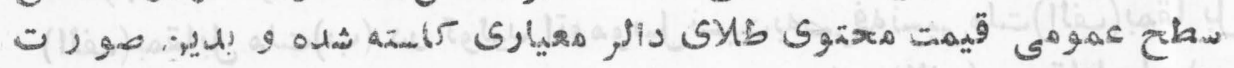
然 - Dis Xb gás

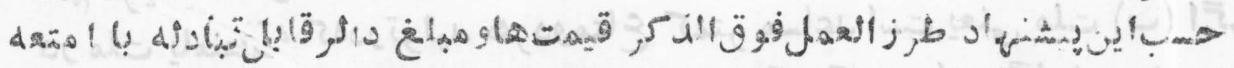
زقأ

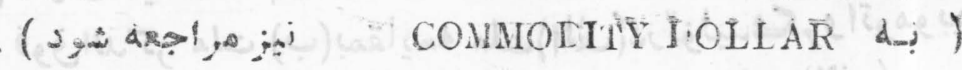

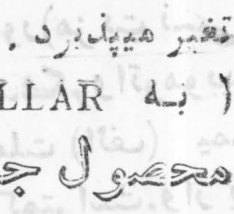
compensatory duty .

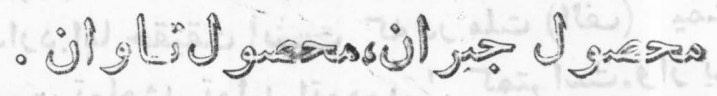

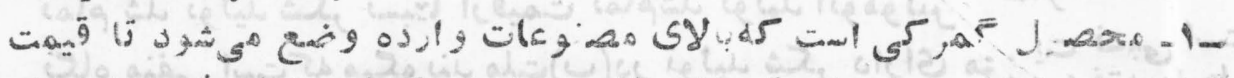

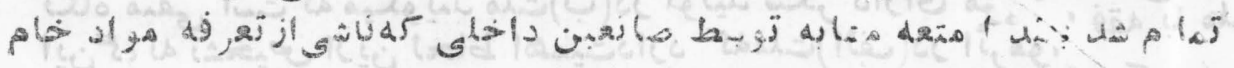

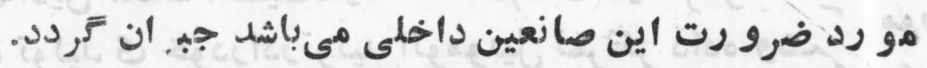

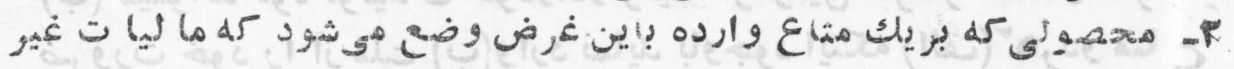

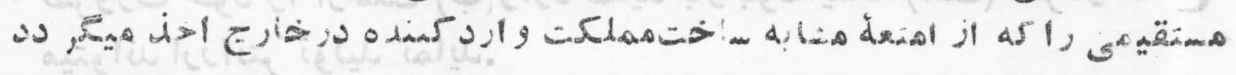

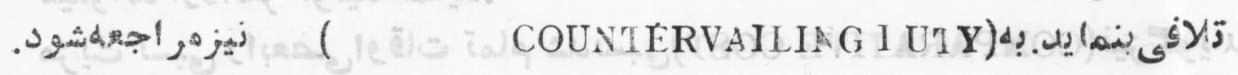
compen atory principle of mire! •

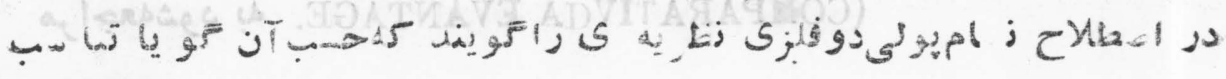
${ }^{2}(\mathrm{~V})$ 


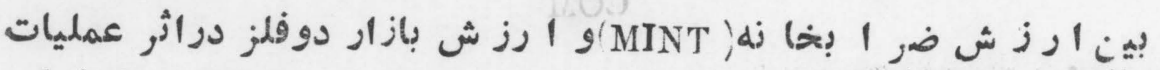

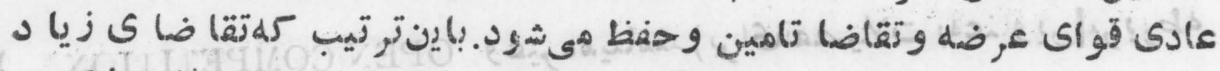

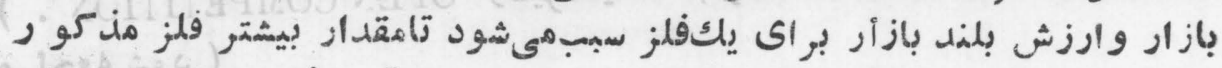

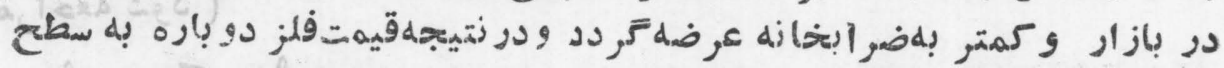

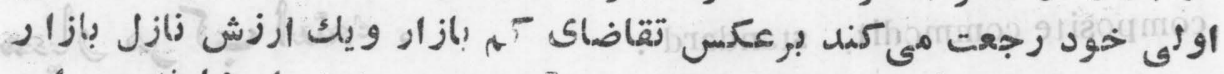

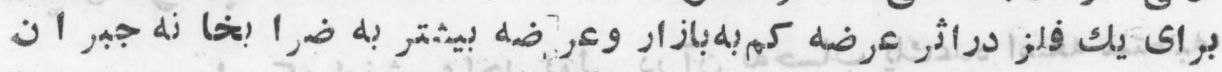

compensatory principle cf taxation.

$$
\begin{aligned}
& \text { مع كر د د. } \\
& \text { ज shis }
\end{aligned}
$$

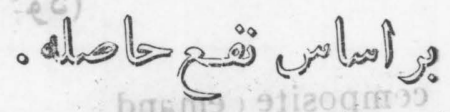

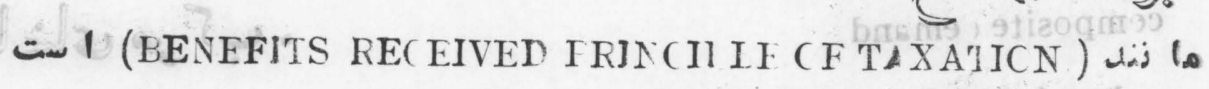

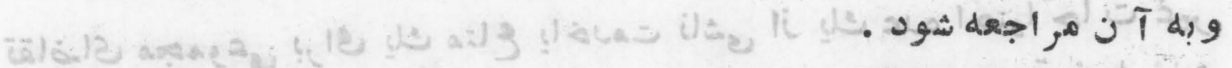
compensatt $\mathbf{r}$ spending .

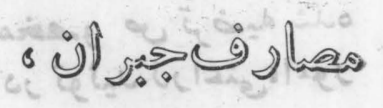

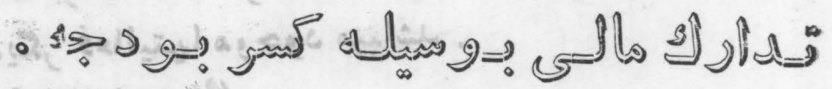

$$
\begin{aligned}
& \text { (جوع شود) DEFICIT FINANCING . }
\end{aligned}
$$

competition.

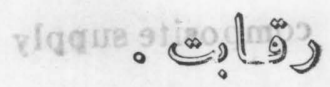

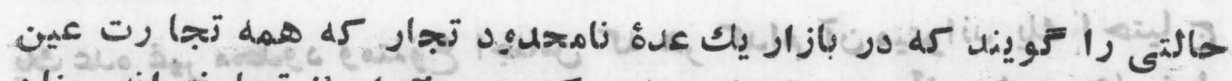

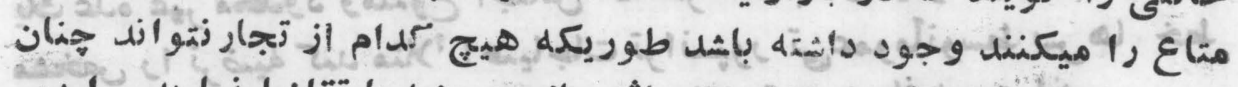

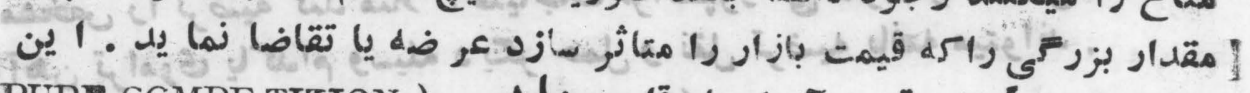

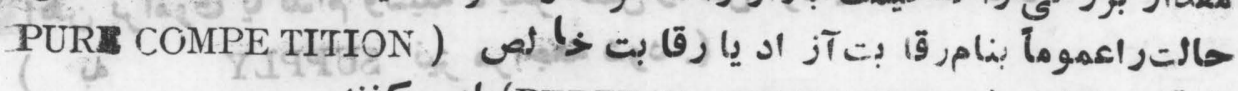
يارقابت كاريل

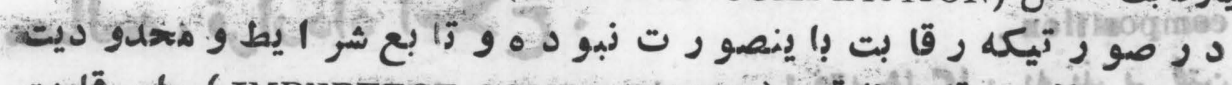

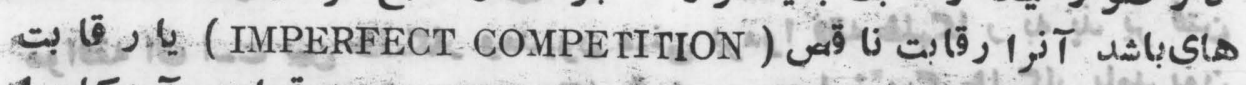
1, J T T

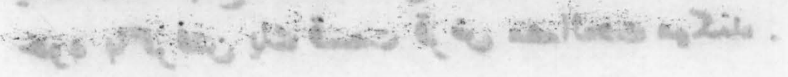


وغير OopeN COMPEIIIION . )

$$
\text { مراج ( ) مود ( }
$$

composite commodit standard .

$$
\text { - Exidiol }
$$

يك سيستم إولى كه ارزش وإحل يولى در آن بله

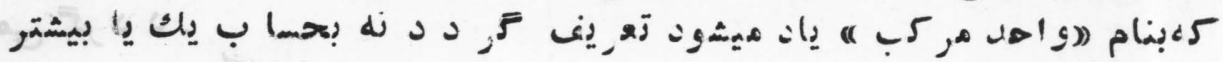

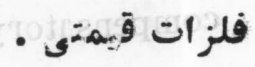

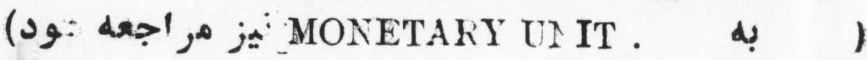

composite iemand

- Y S o lis

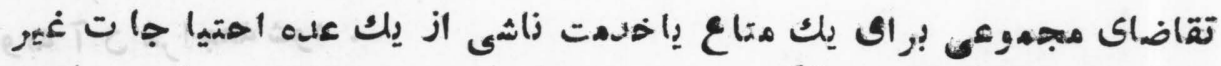

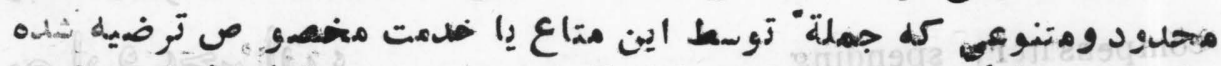

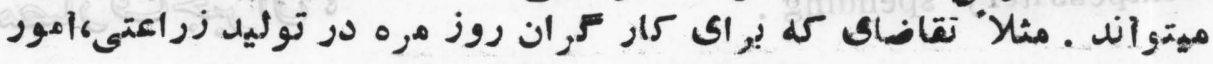

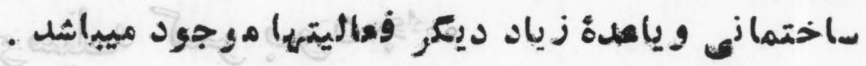

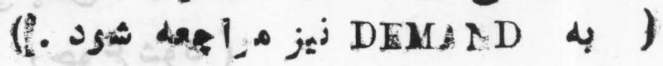

composite supply •

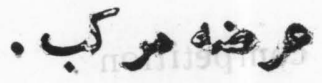

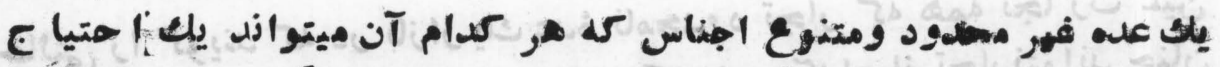

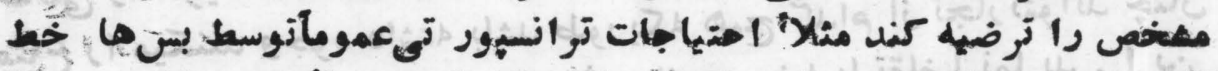

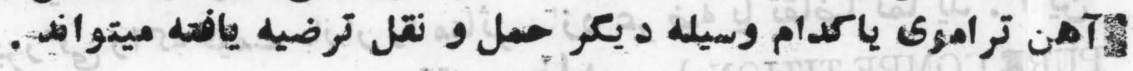

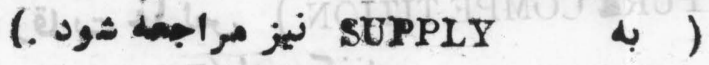

camporiller.

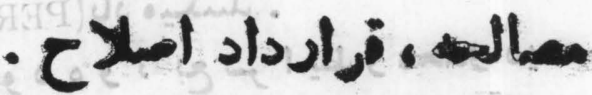

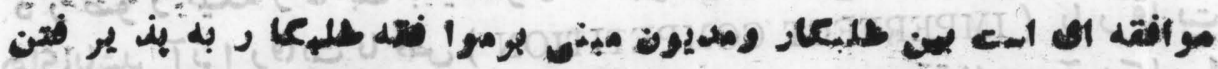

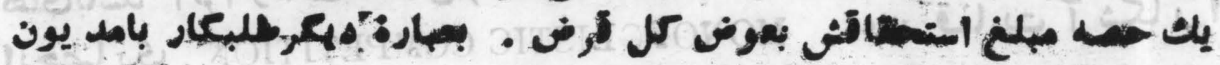

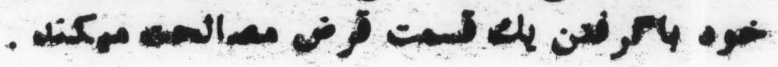

AP, 
compouni duty.

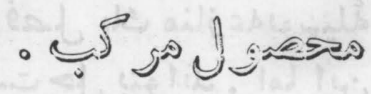

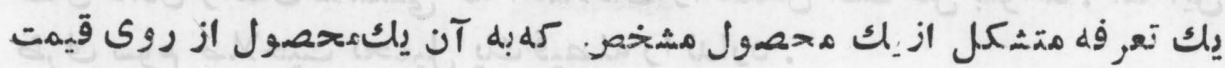

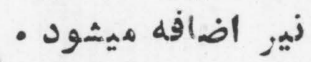

compound interest

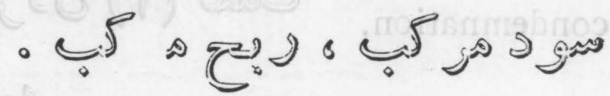

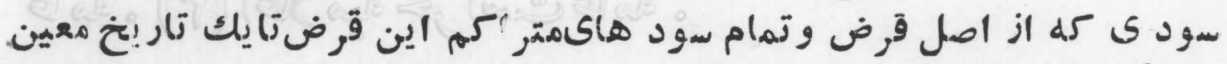

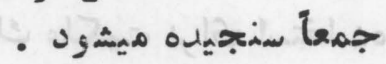

compulsory check off

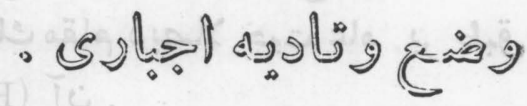
( تفصيلات زير عنو ديده شود CHECK OFF ) centraticn - $j=\int_{j} S^{\infty}$

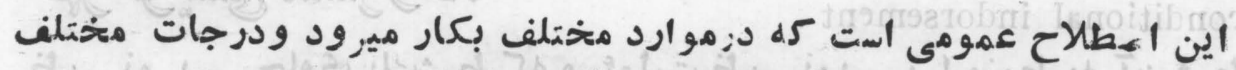

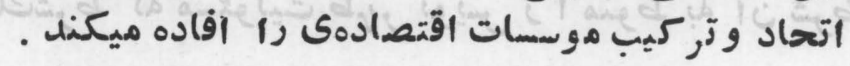
AMALGAMATION , INTEGRATGIN به اصطلاحات ذيل مراجعه شود ماتر

co ncess on .

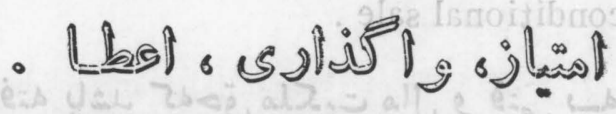

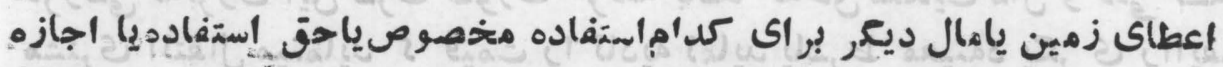

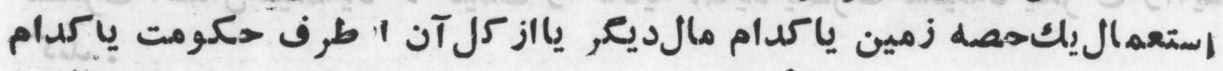

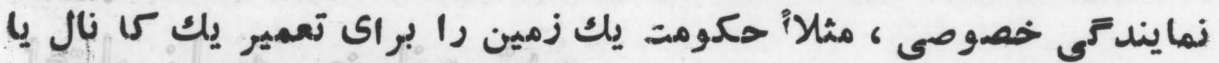

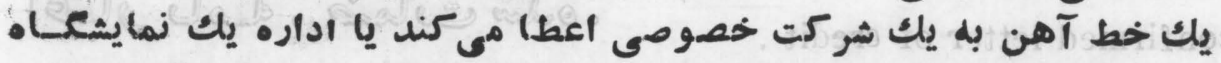

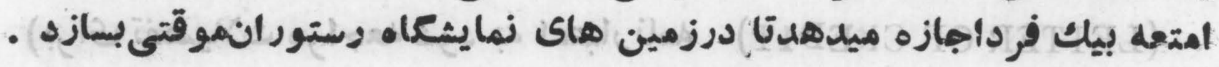
conciliation,

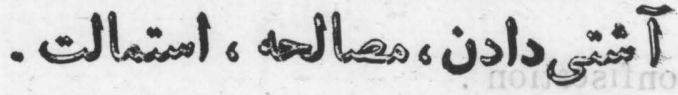

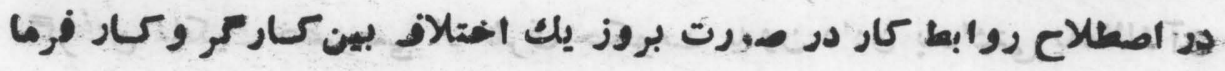




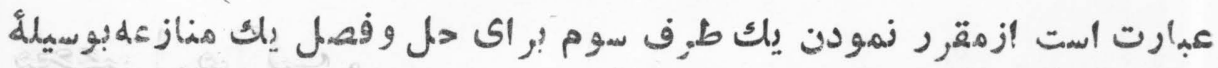

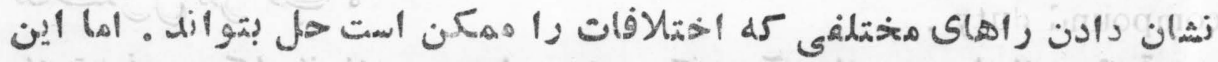

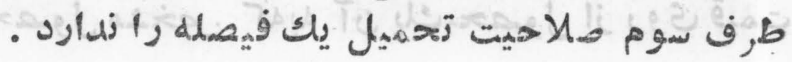
condemnation.

$$
\begin{aligned}
& \text { 3ी }
\end{aligned}
$$

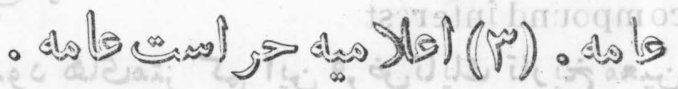

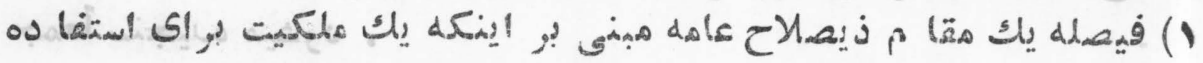

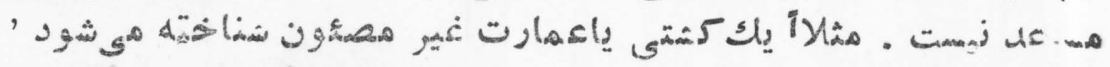

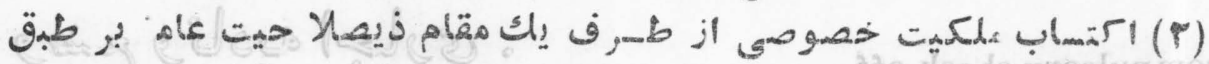
- it (EMINENT DOMAIN) do le silaj

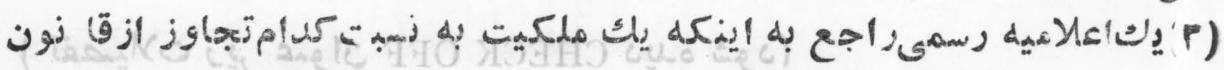

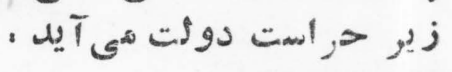

conditional indorsement .

$$
\text { - b } 9 \text { 总 }
$$

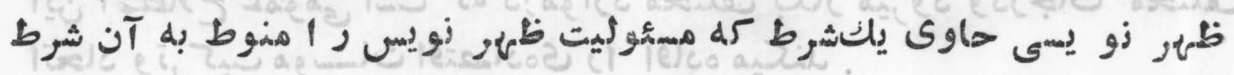

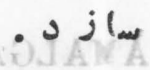

conditional sale.

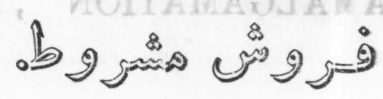

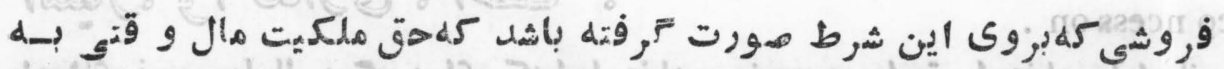

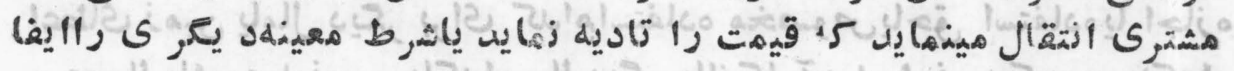

confirmed letter of credit.

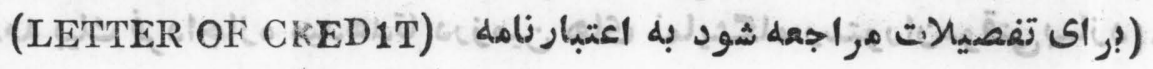
confiscation .

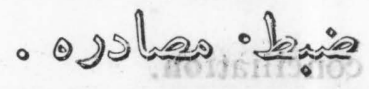

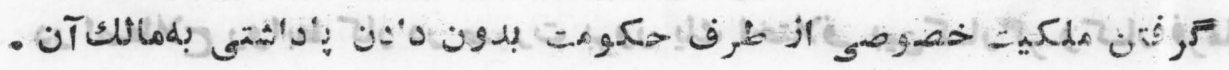


consent deres. $\quad$ -

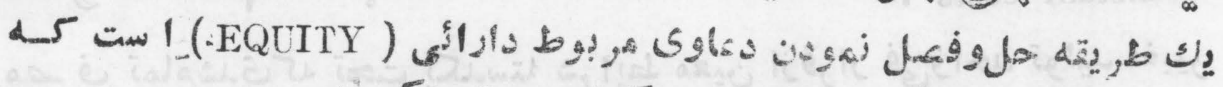

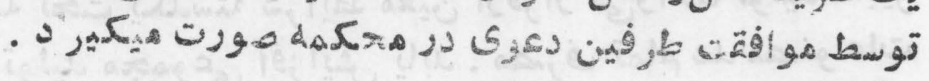
conservation .

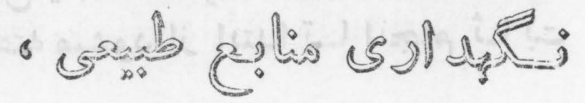

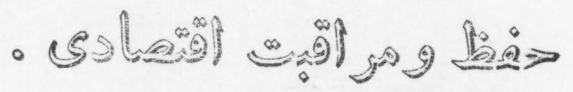

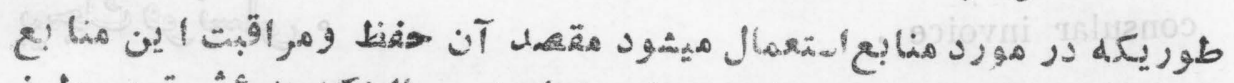

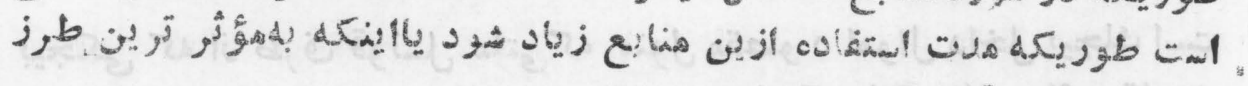

consignes

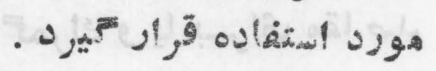

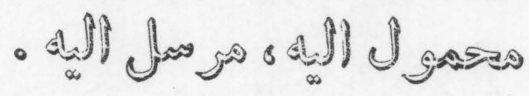

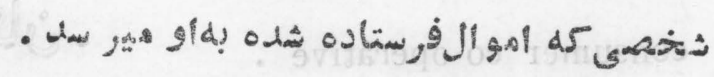
consignment

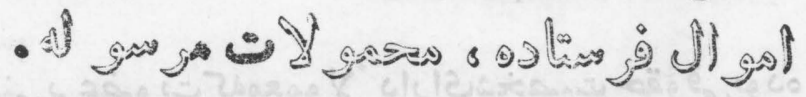

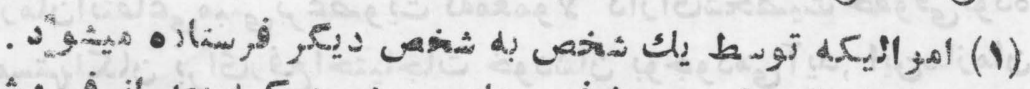

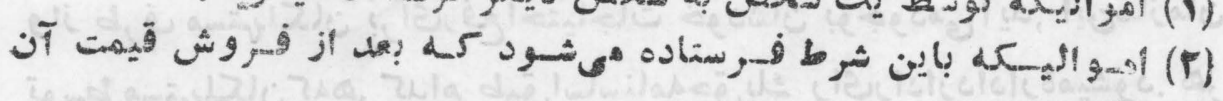
تاديه كردن

consol bond $12 i^{*}+4$ cons slidation.

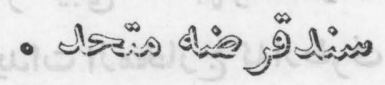

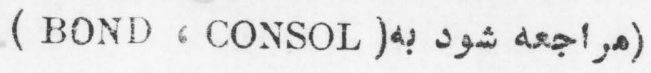

$$
\begin{aligned}
& \text { - } 9(50)
\end{aligned}
$$

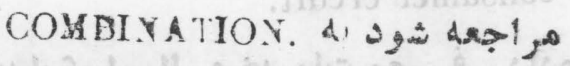

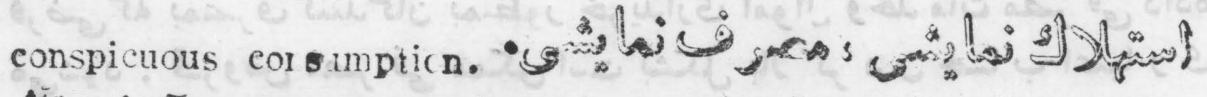

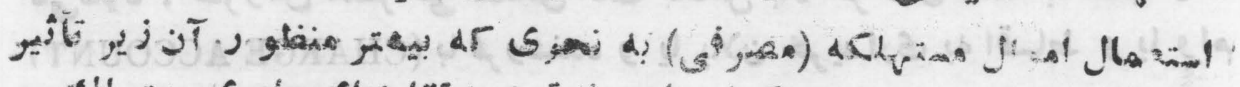

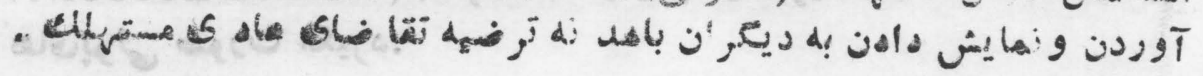




\section{CON}

constant costs .

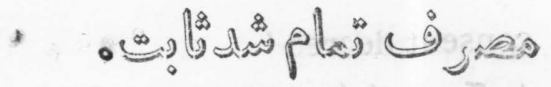

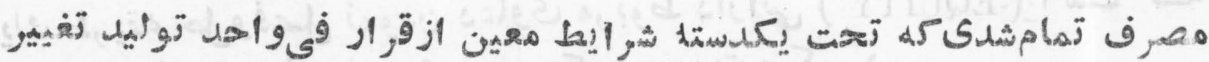

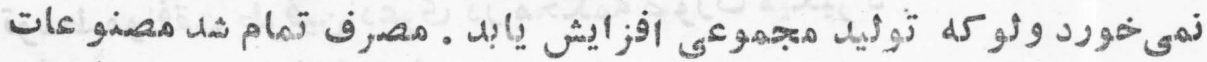

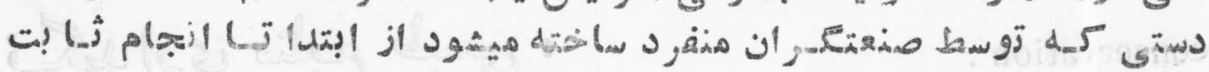
في

consular invoice. - ज雨

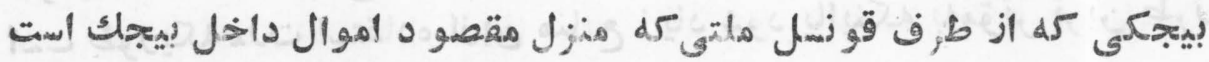

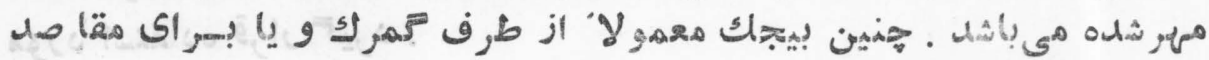
.

consumer co-operative. - نी

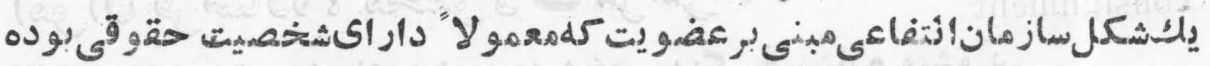

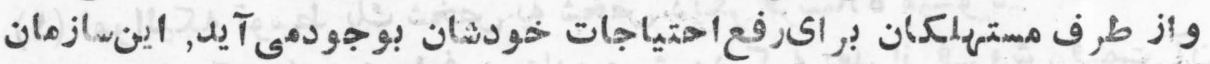

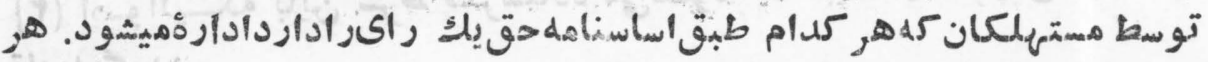

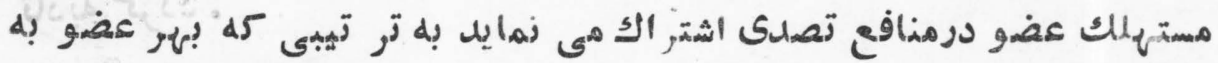
تناسب حر يبارى اش سمهمى از آنقسهت اضافعى عايدات ازمخارج كهازطرف

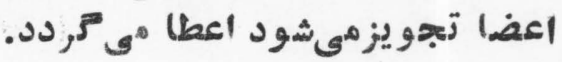

consumer credit. ن

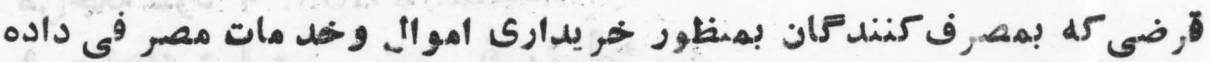

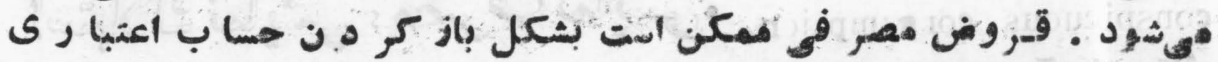
(CHARGE LCCOUNT)

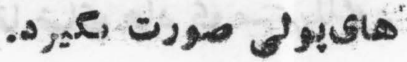


consumer economics.

ه -

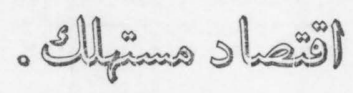

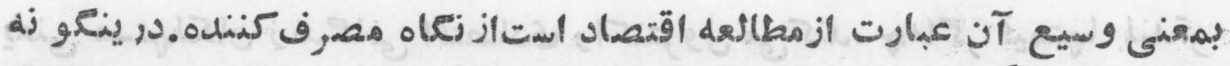

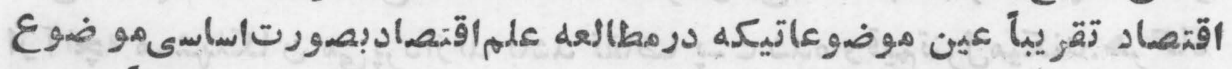

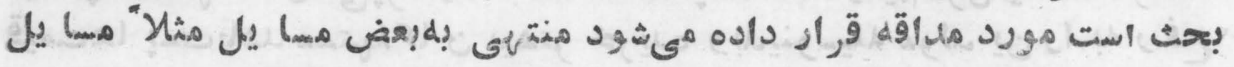

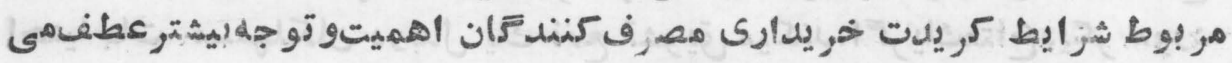

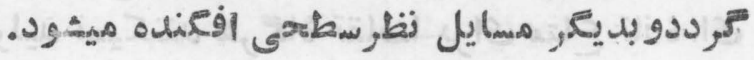

consumer good.

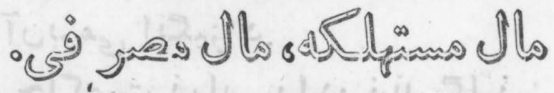

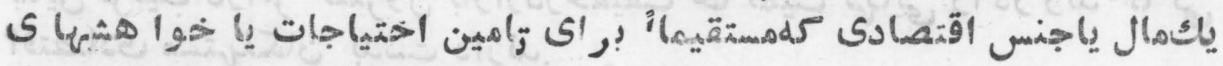

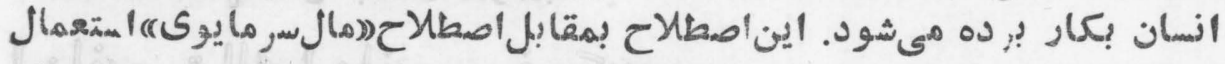

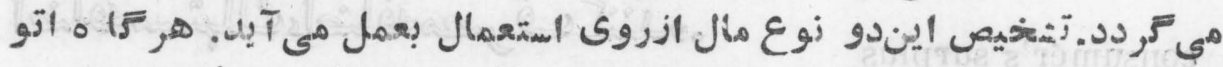

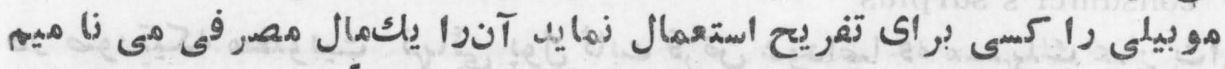

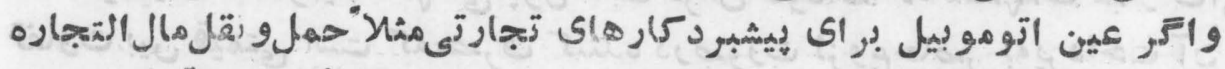

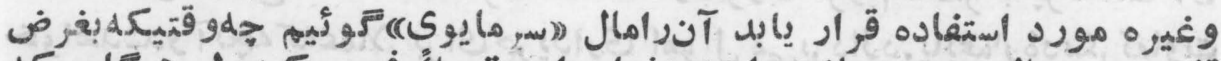

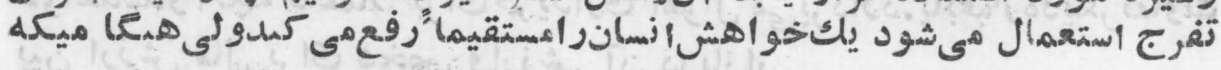

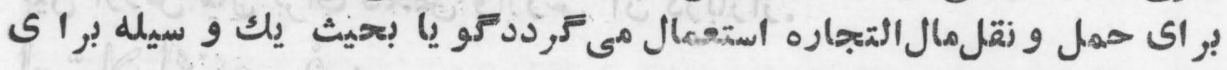

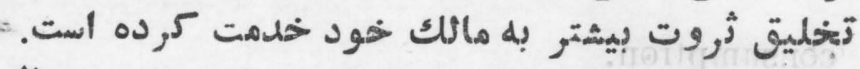

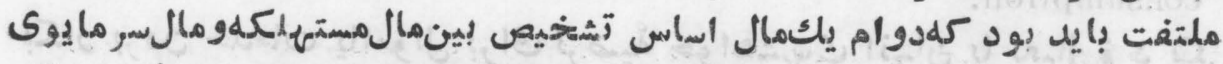

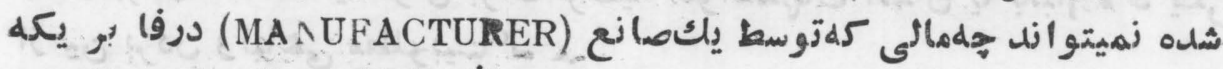

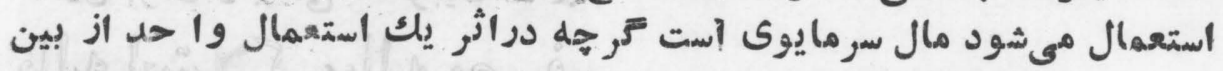

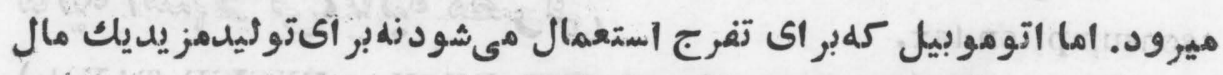

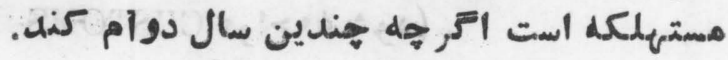
censumer's capital •

CAPISAL GOOD.d رجوع شود به 
consumer soreraignty.

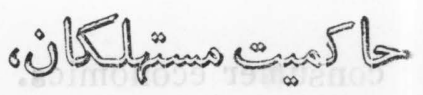

$$
\text { O }
$$

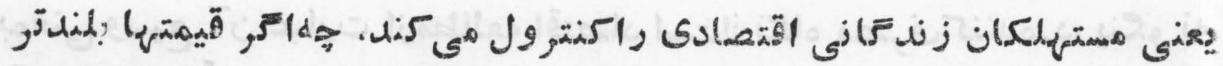

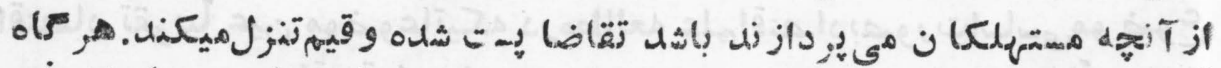

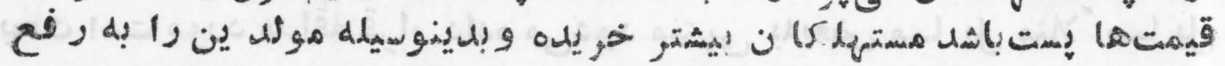

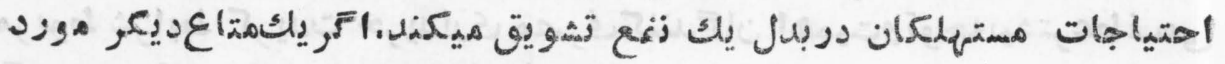

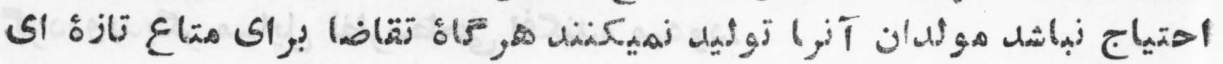

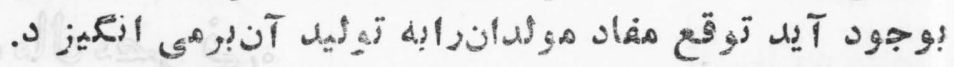

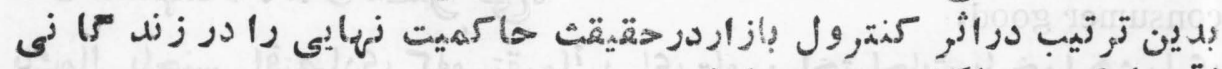

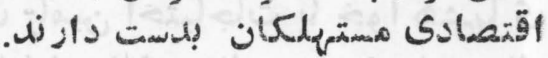

consumér's surplus -

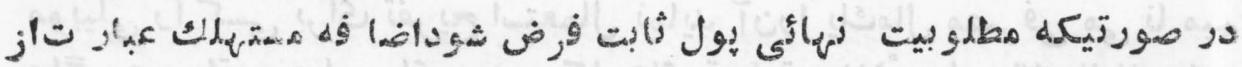

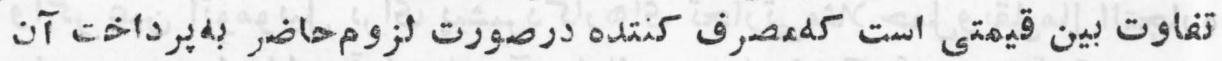

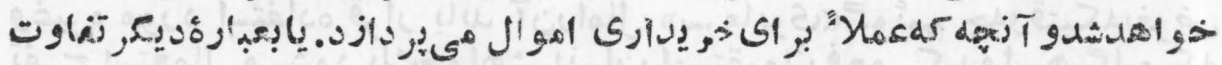

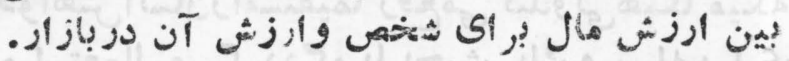

corsumption.

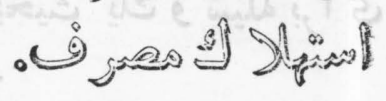

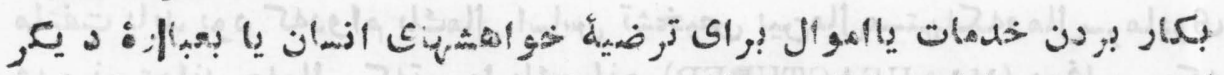

consumption tax.

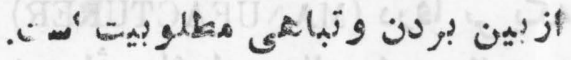

$$
\begin{aligned}
& \text { (ज) }
\end{aligned}
$$

(د) de? , CUSTOKS DUTY. S EXCISE TAX di)

cortincr 12! bill.

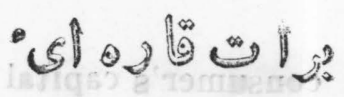

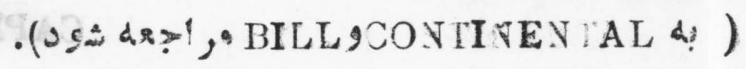


contingent duty .

$$
\text { S }
$$

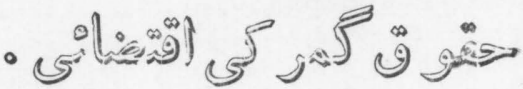

\section{(. ( )}

contingent funp .

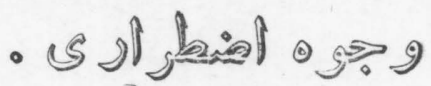

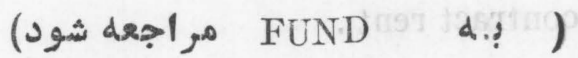

contingent liability

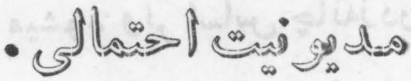

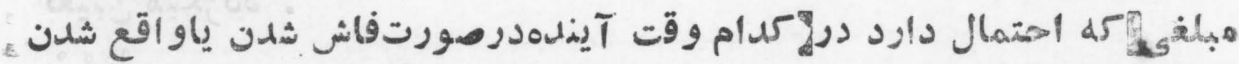

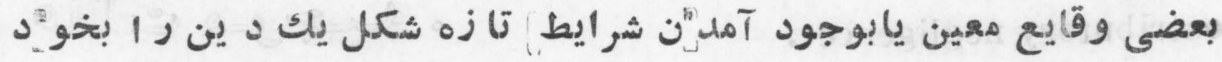

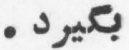

continurd bond .

P gी

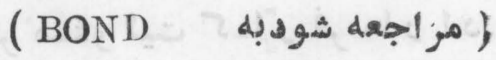

continuous market •

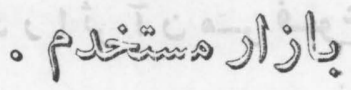

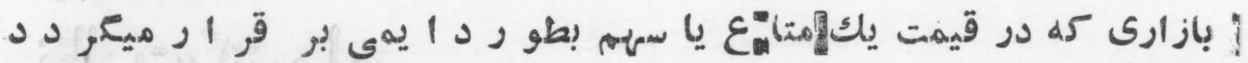

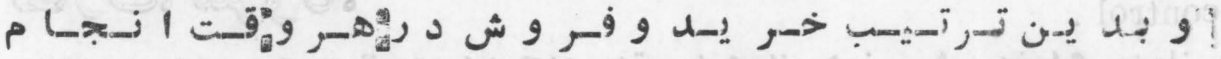

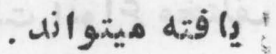

contract .

$$
\text { - } 2 \int_{2}^{2} 2 \int^{2}=9
$$

موافقهايست بين دو يا بيشترإطرف كه قانو أ الزز ام آور بوده وحسب آن بيك

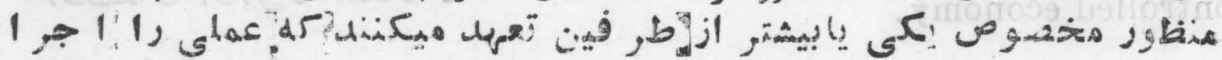

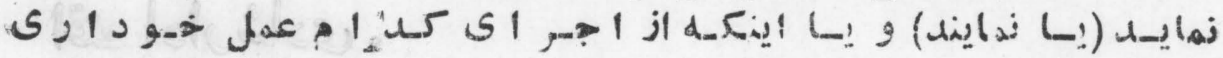


contract labor.

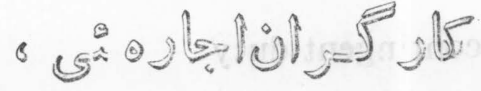

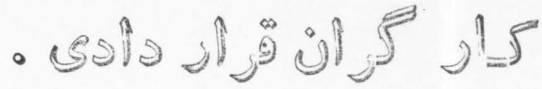

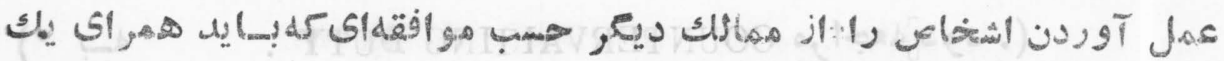

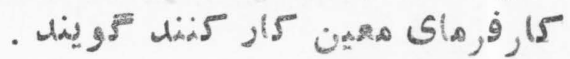

contract rent .

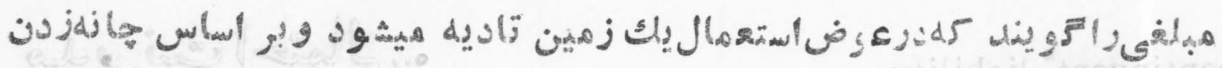

- $30, \mathcal{L}_{\mathrm{L}} \mathrm{i}: 4 \mathrm{~s}$

contributory negligence.

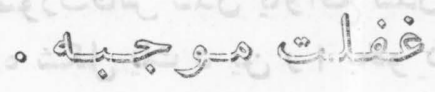

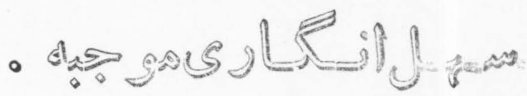

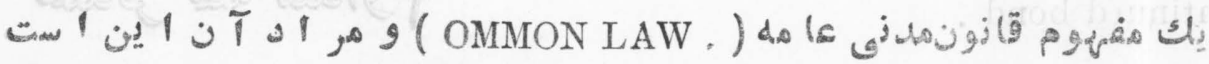

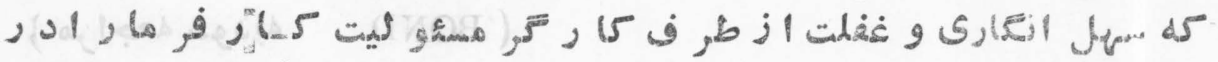

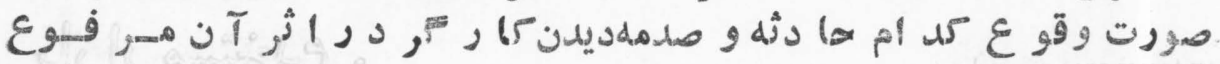

control .

- 3 j Imano

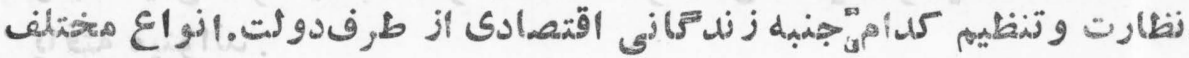

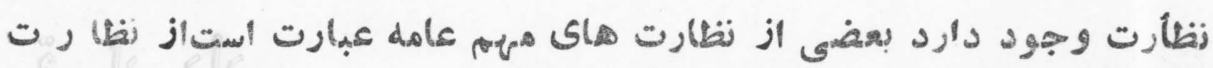

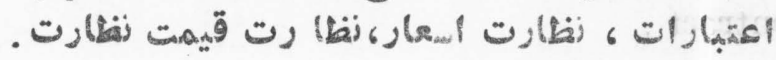

controlled economy.

$$
\text { - } 3 \sin a n
$$

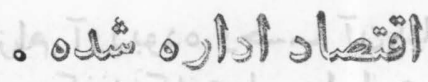

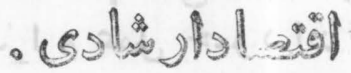

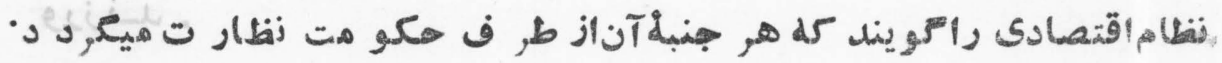




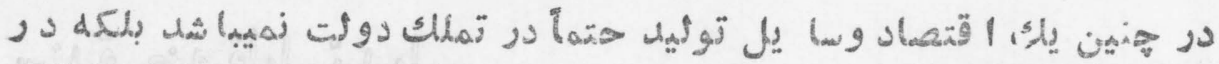

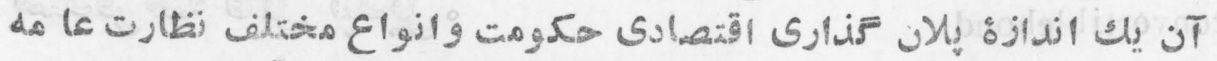

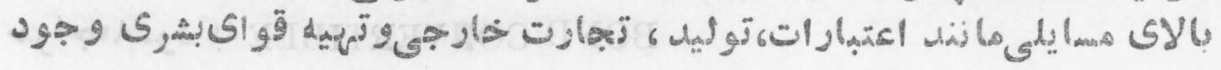

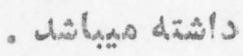

axtiving acconnt.

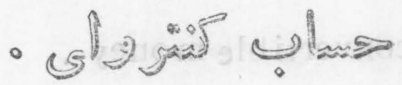

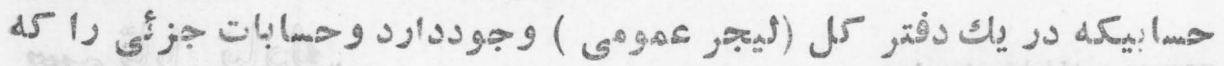

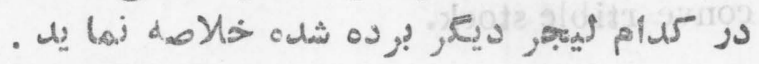
controlling company .

- blimes

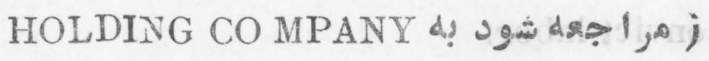
convential tariff system .

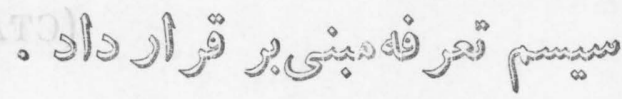

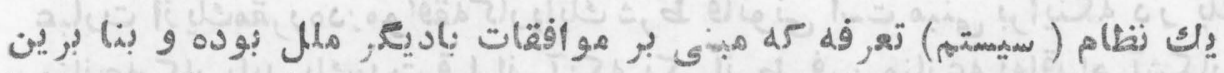

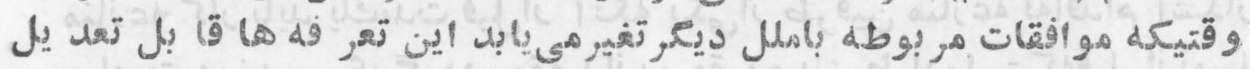

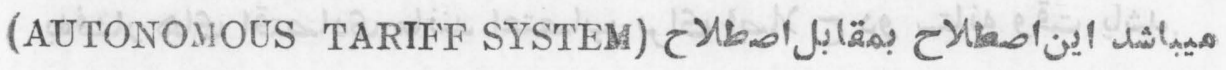

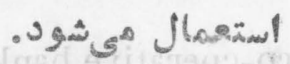
converion price. - (S)

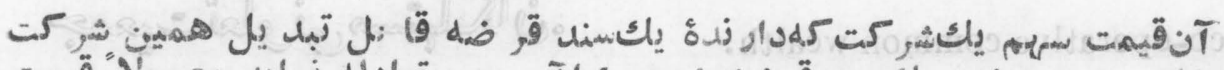

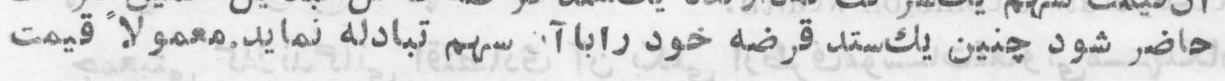

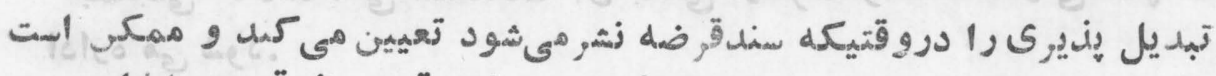

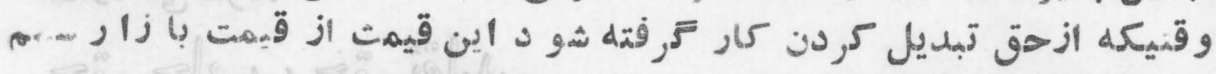

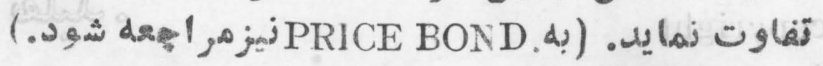


convertiblebond.

convertible money .

conve rtible stock.

convict labor.

cooling-off period

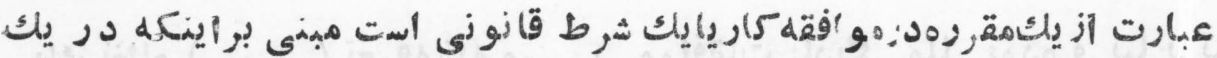

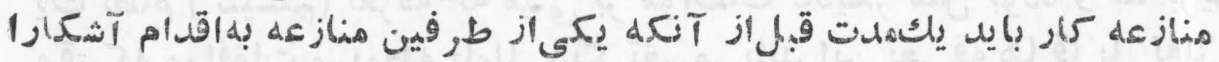

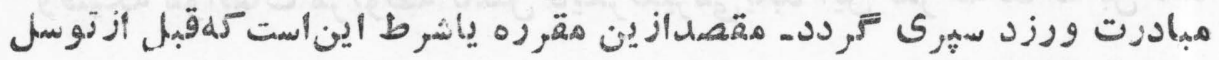

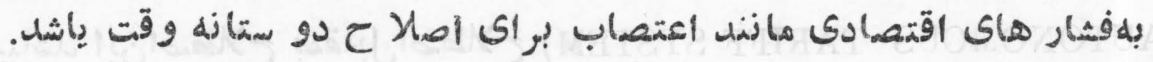

co-cperative bank. (9)

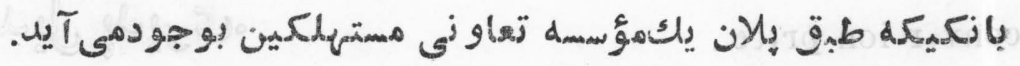
co-operative common wealth.

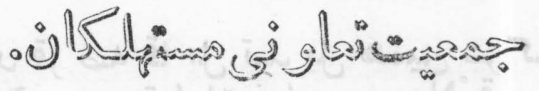

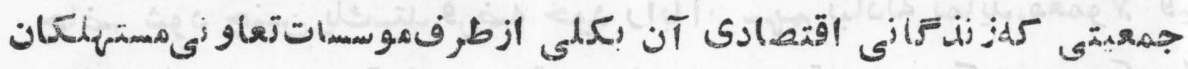

$$
\text { اداره مي شوند }
$$

copyingt - لd ف

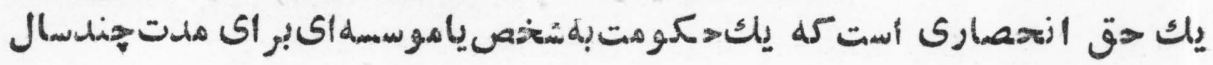




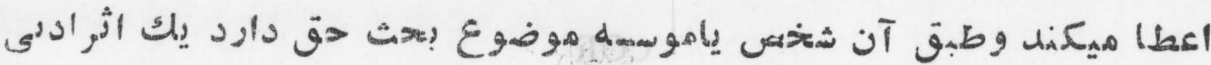

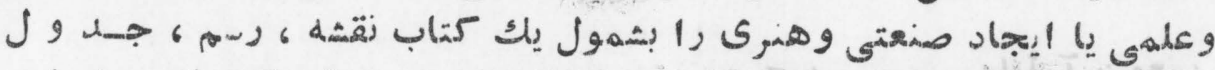

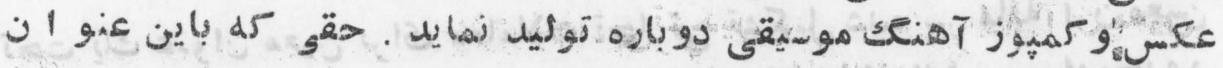

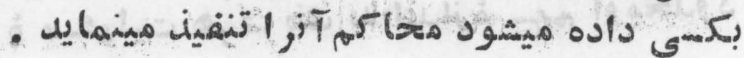

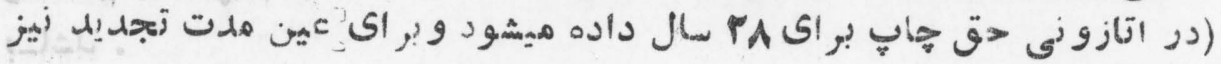

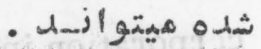

corner , -

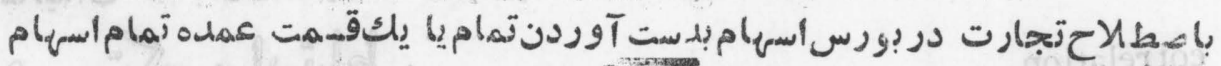

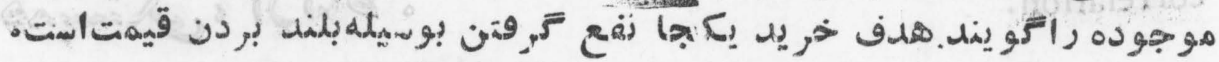

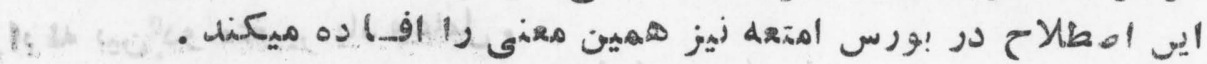
corporate ock.

corporation . .

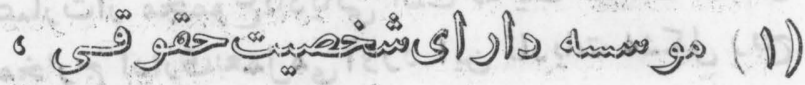

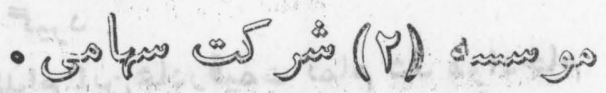

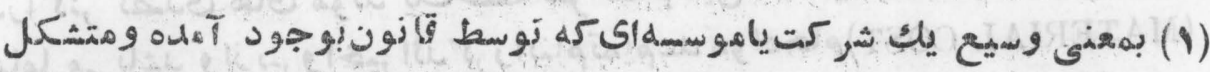

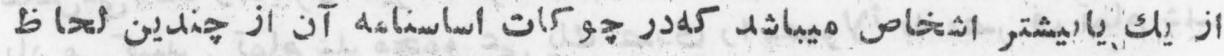

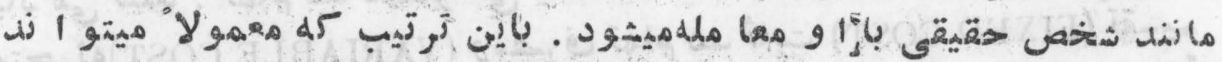

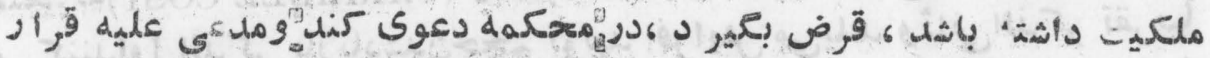

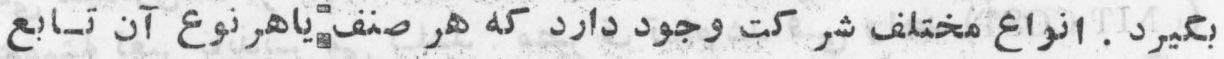

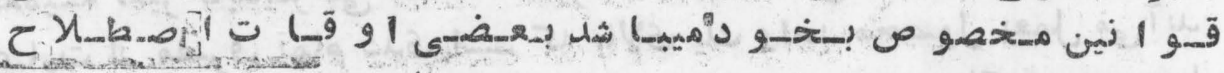

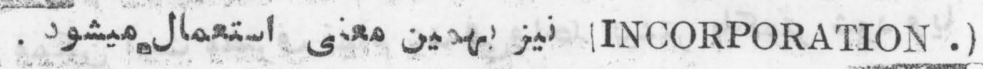
و

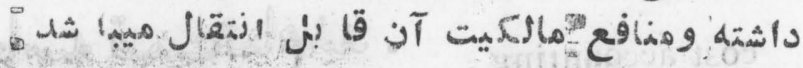

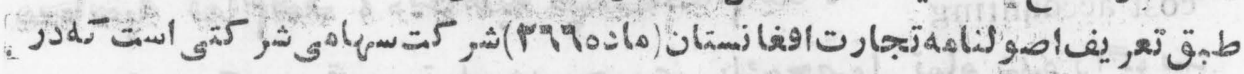


LOR

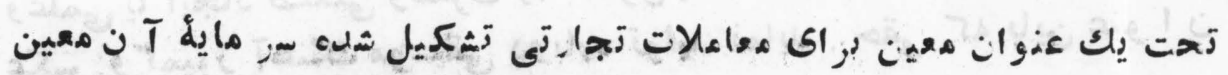

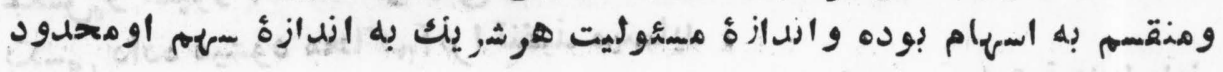

- UÁl一

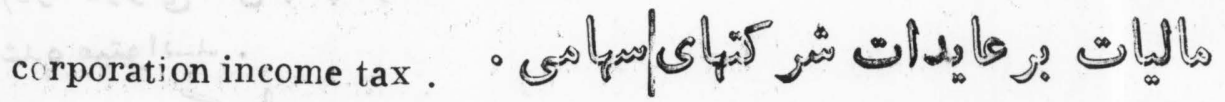

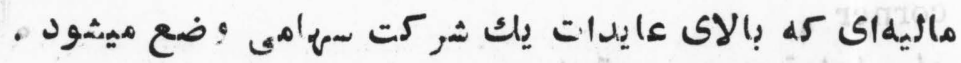
cor relation.

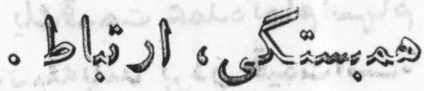

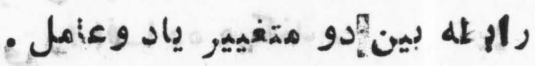

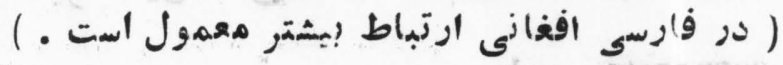

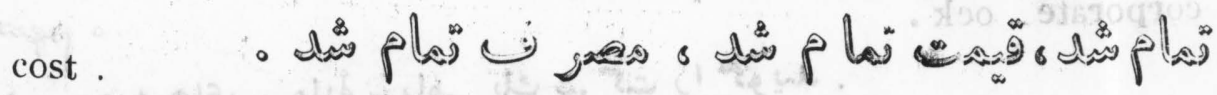

در اصطلاح اقتّاد نظرإى عمارتاز مجموع تادياتى است كه ياك تصدى در بدل

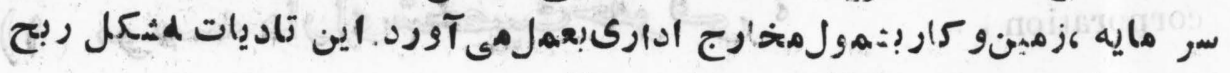

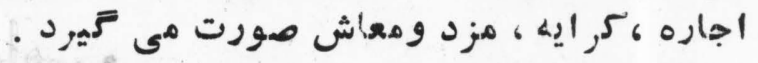

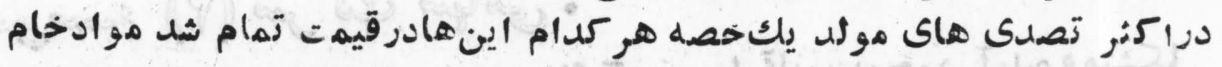

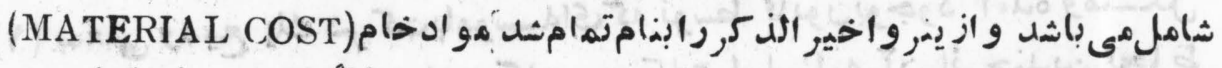

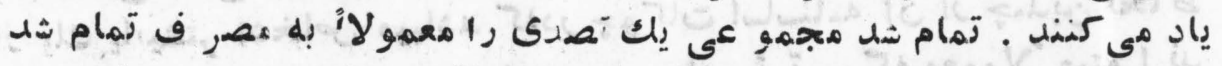

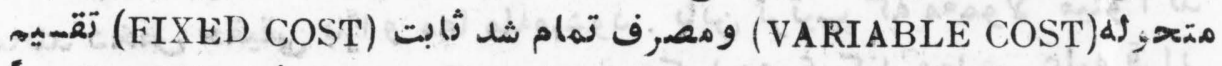

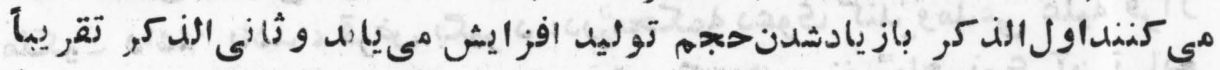

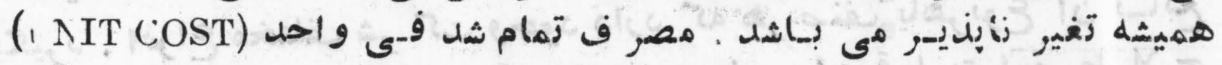

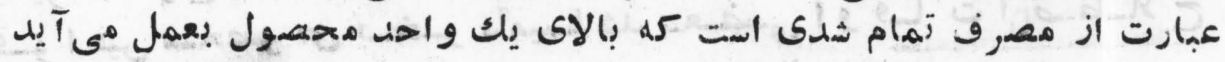

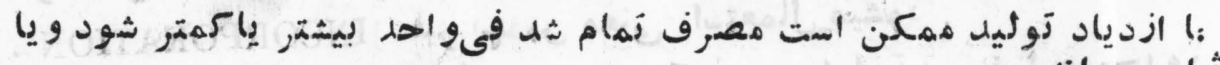

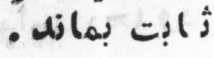

cost accounting o diّم

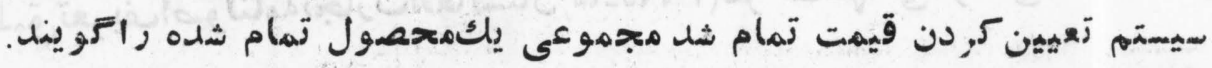

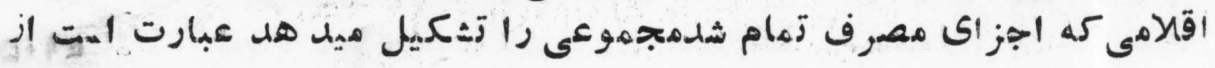
((1) 7) 


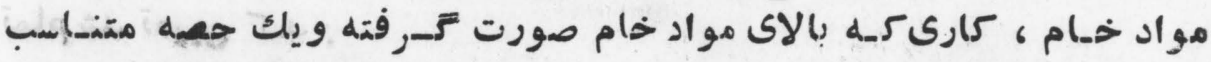

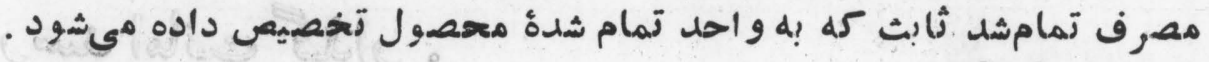

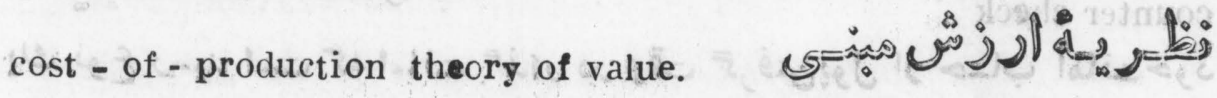
- $\int_{\infty}=\int_{5}=0$ طبق اين نظر يه ارزش يك محصول مر بوط بهمقدار كار ووقتح. كله درتوليد

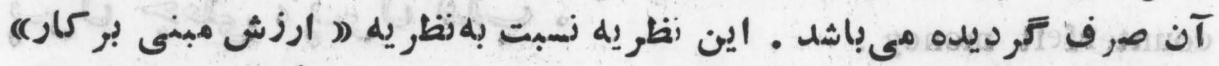

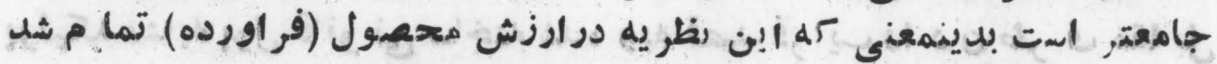

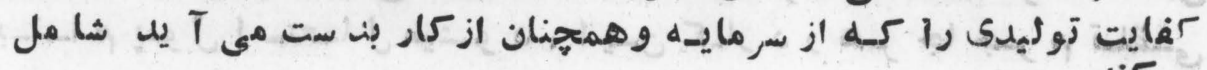
مى كند , cost of - service principle of taxaticu s? S - Cols dis

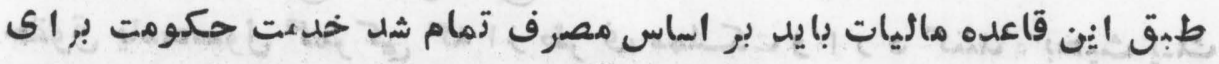

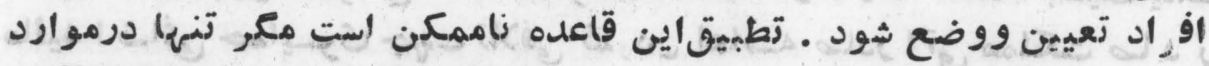

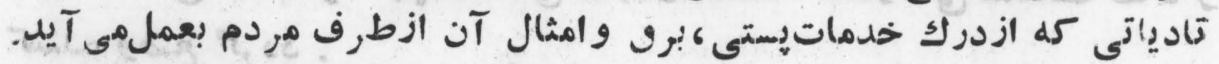

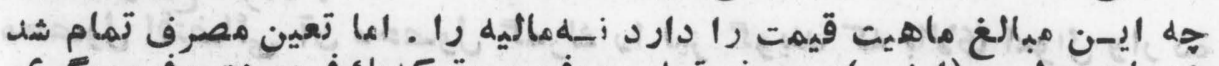

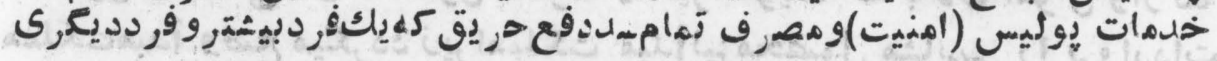

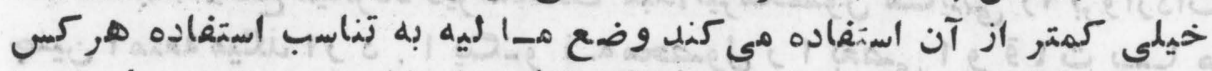

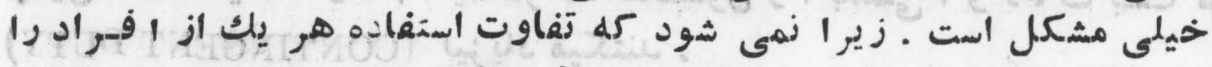

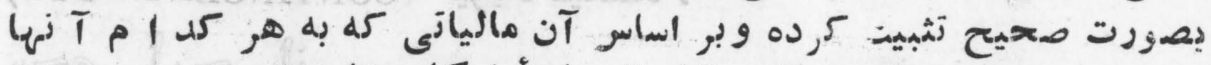

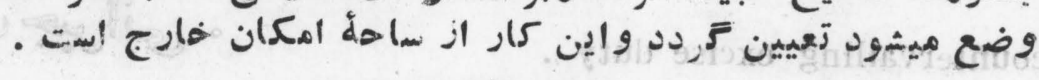
cost plus contract .

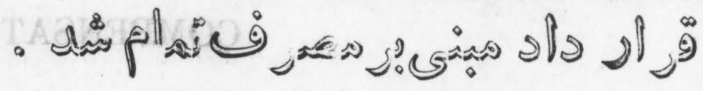

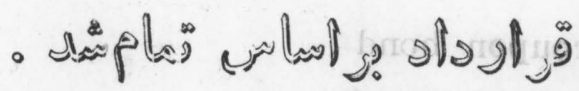
قرار دادى كه در آنقيهت فروش بطور ثابت تعيمين زشيده باشدبلكه به فروشنله. ( $) \cdot(1)$ 


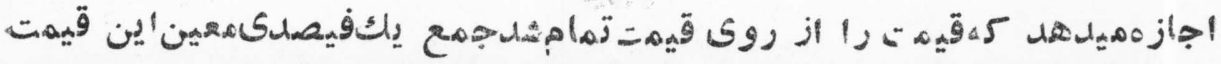

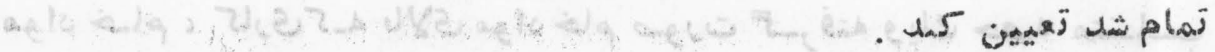
counter check .

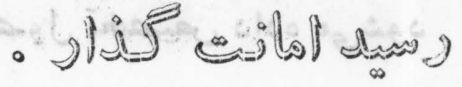

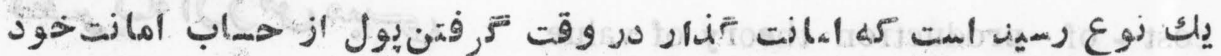

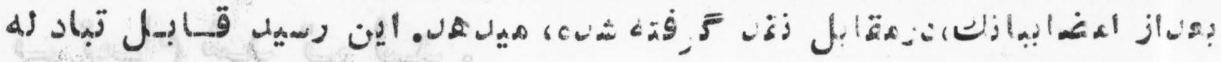

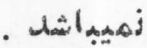
counterfeit money.

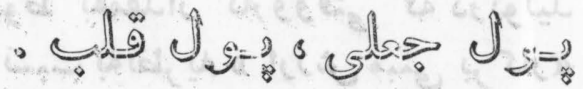

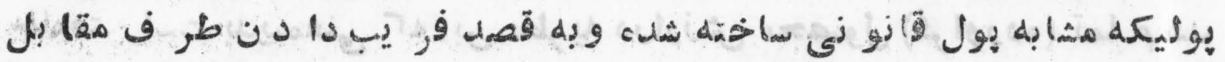

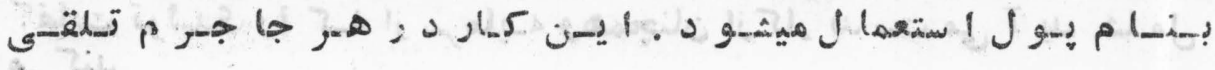

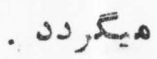
countervailing duty . Q ज्l.

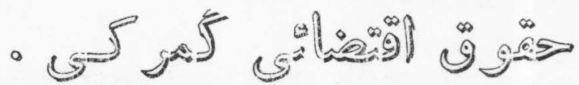

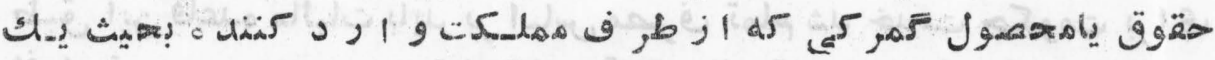

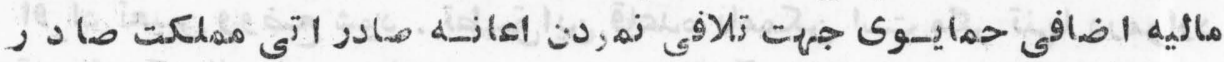

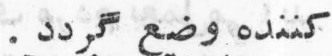

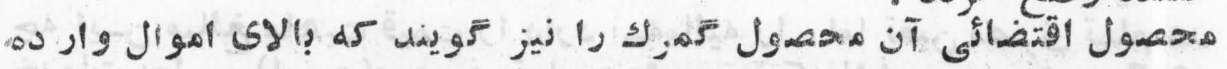

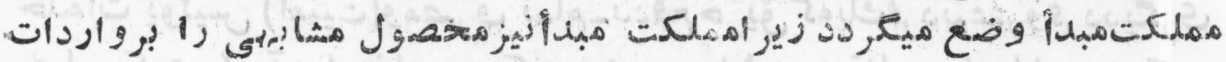

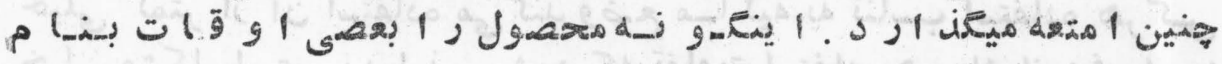
- أيز ياك ميكندل (CONTINGENT DUTY) countervailing excise duty. - जil

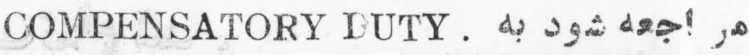
coupon bond.

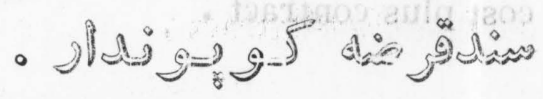

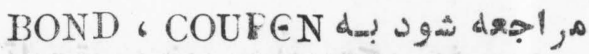


coveaant.

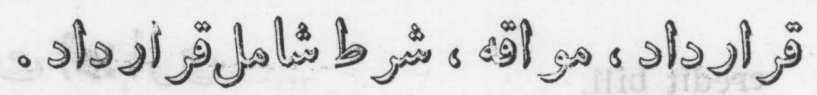

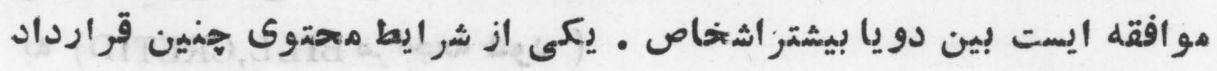

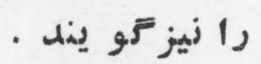

craft guild • نो, يك اتحاديه صنعتكاران كلدروقرون وسطىرواجد اشت وازيحصار واقعى توليد

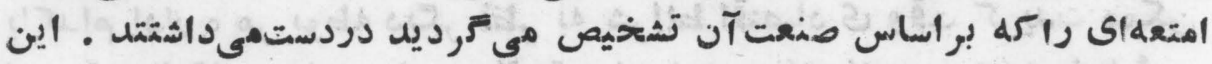

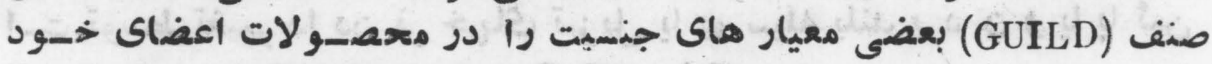

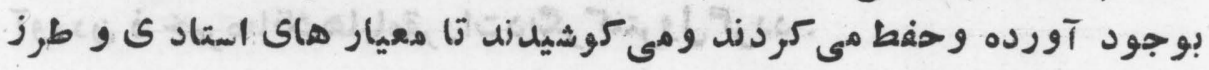

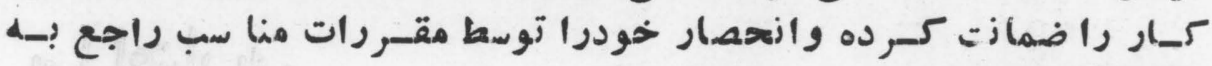

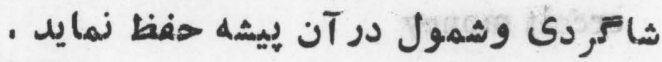

craft union o نोs, di - نो

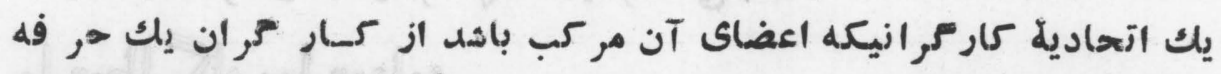

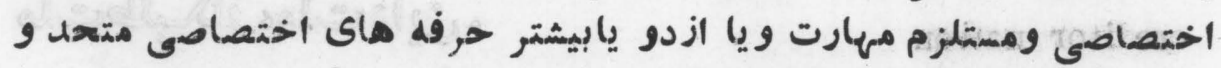

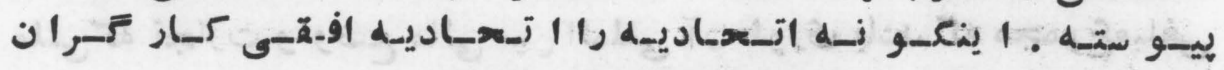

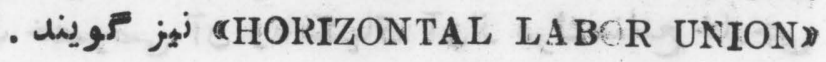

\section{credit}

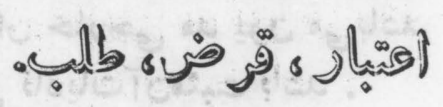

اـ وعدة تاديه آينده جنسيا بول دربدل بول اموال يا خدماتى كه در حال ه

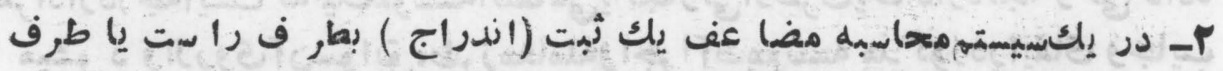

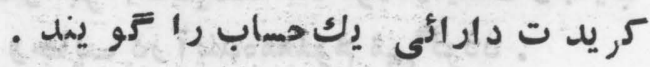




\section{CRE}

credit bill.

(redit control

$$
\begin{aligned}
& \text { - जग! :0ी } \\
& \text { ( م, BILL,CRETID) d? } \\
& \text {. }
\end{aligned}
$$

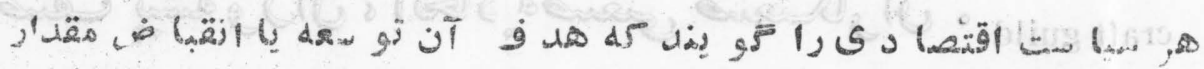

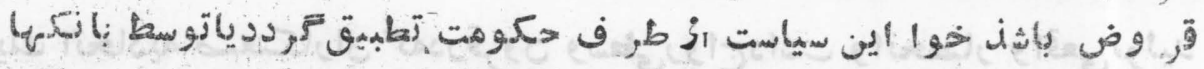

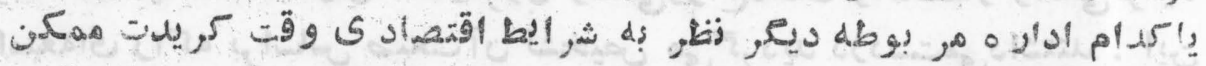

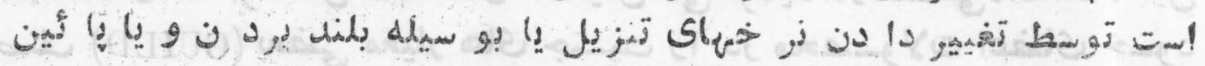

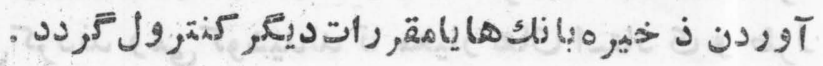

creait money

$$
\text { - Anghas }
$$

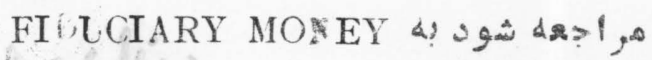

creuitor

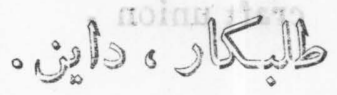

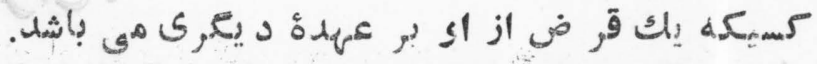

creditor nation

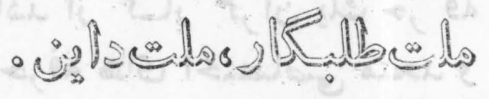

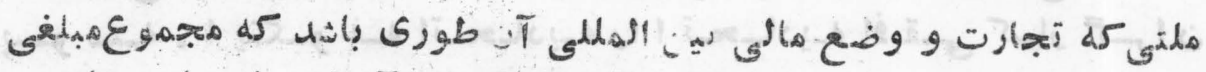

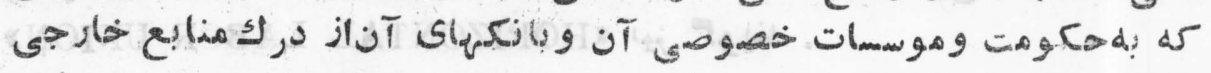

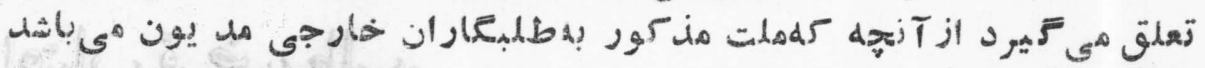

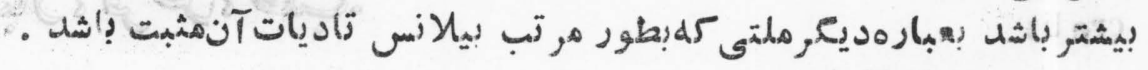

credit rating

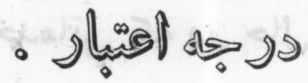

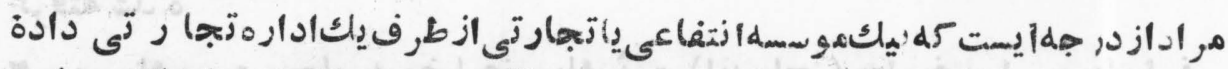

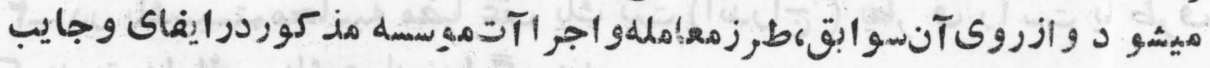

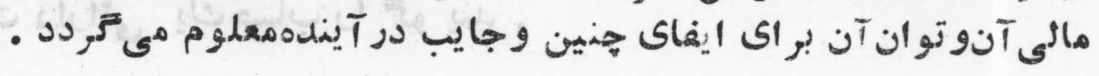




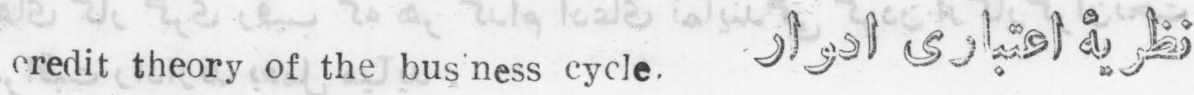

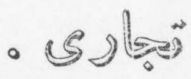

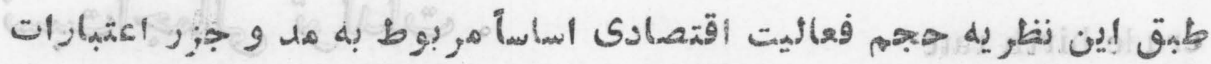

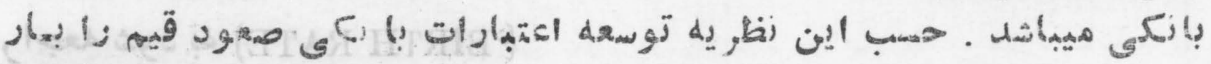

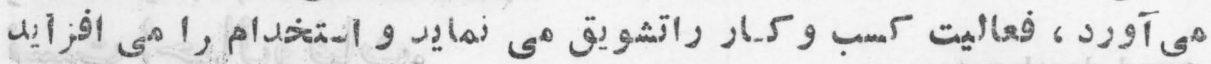

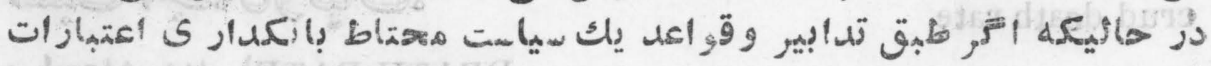

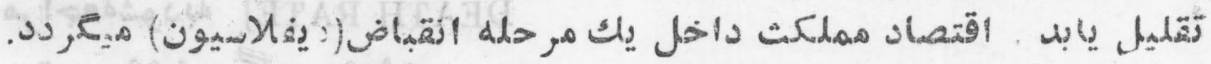

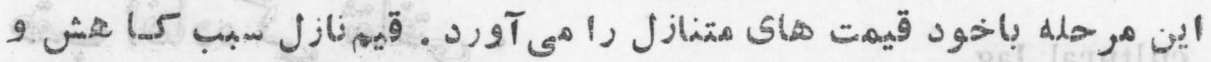

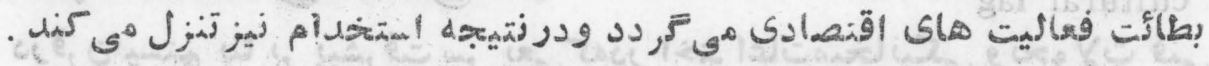

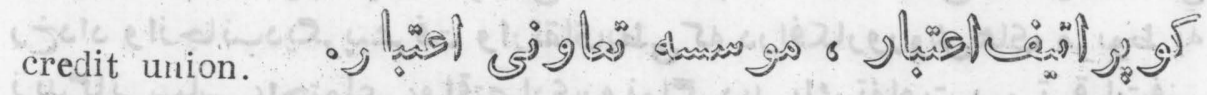

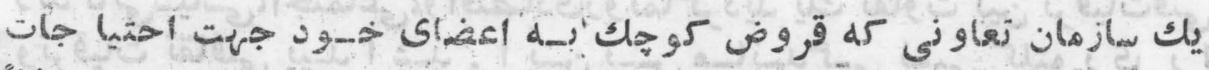

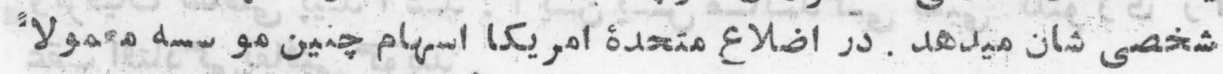

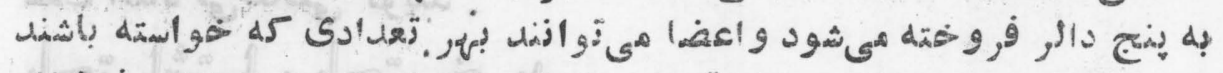

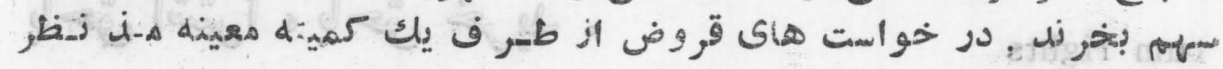
نि

critical material .

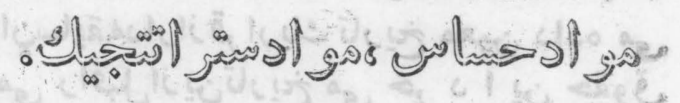

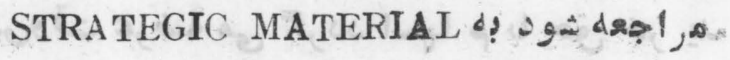

crop insurance. -

بيمه كه در مقابل تلف شدن بعضى حاصلات (غألباً زراعتى) دراثر خطرات

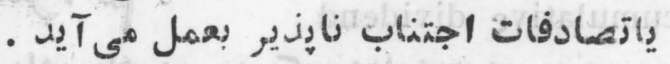

cross picketing.

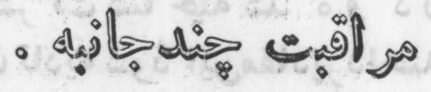
مر اقبت و إاسدارى كار تر أن در حال اعتصاب كله ازطرفدويابيشتر اتحاديه 


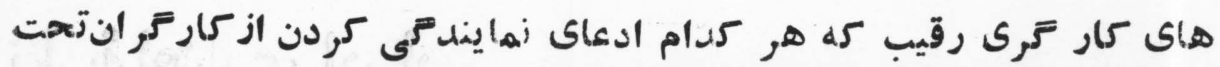

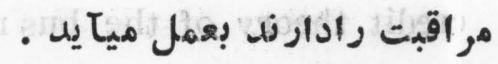

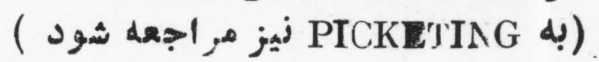

crude birth rate

crud death rate

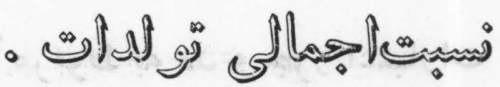

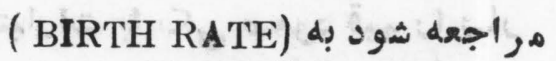
ه

DEATH RATE) مراجعهودبه

cultural lag - ى

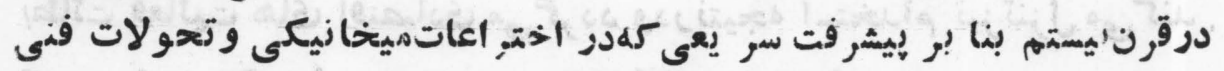

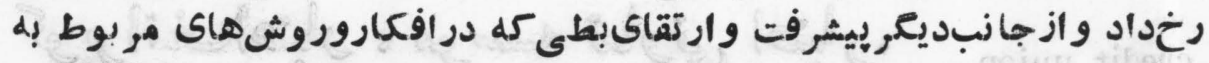

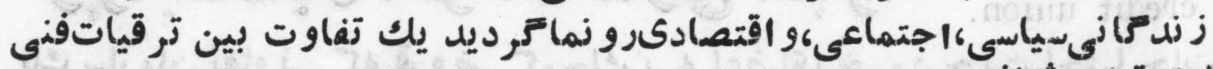

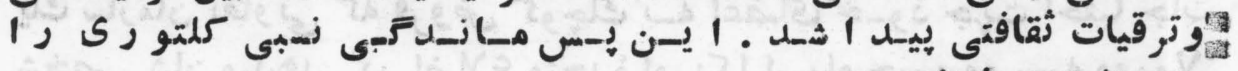

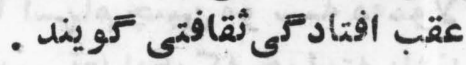
cum rights.

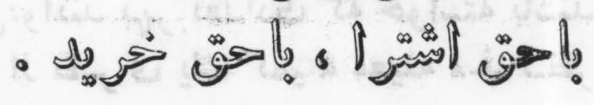

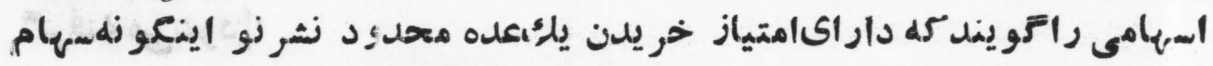

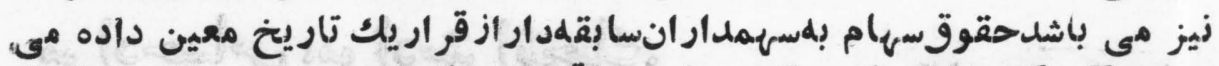

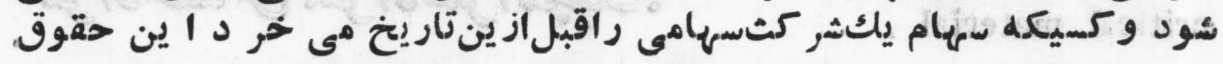

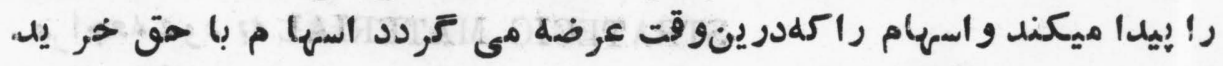

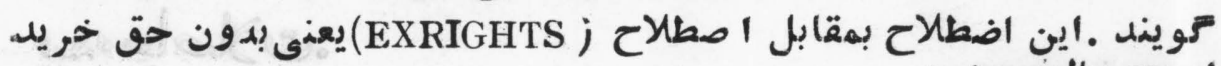

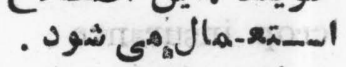

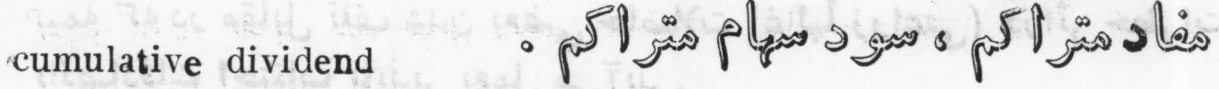

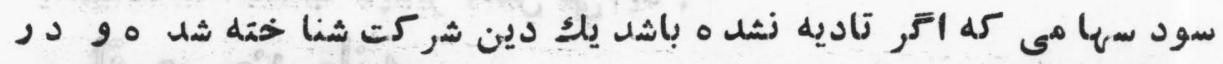

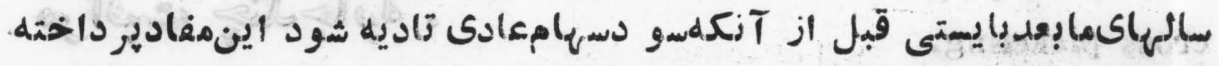

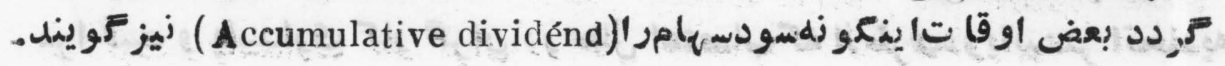


cumulative siock. op ( مر اج STOCK,CUMULATIVEdب)

cumulative voting.

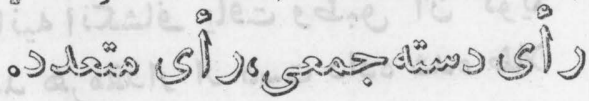

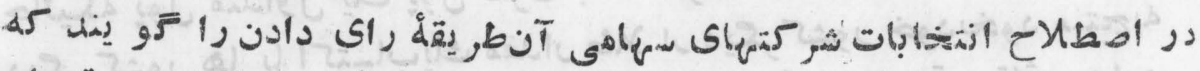

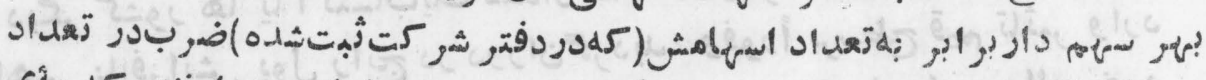

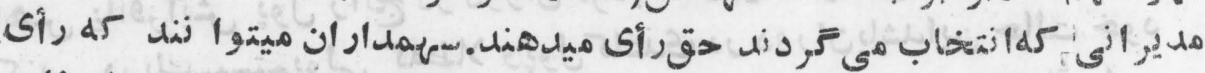

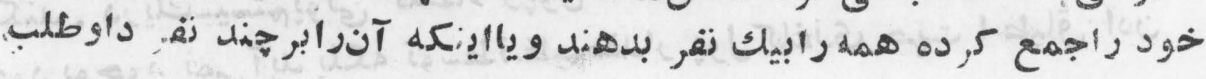

curb stock. 影 (STOCK'CURB)d, رجوع شود

currency.

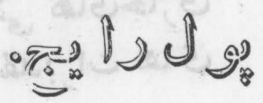

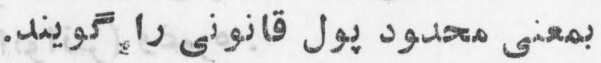

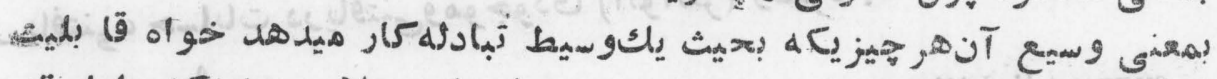

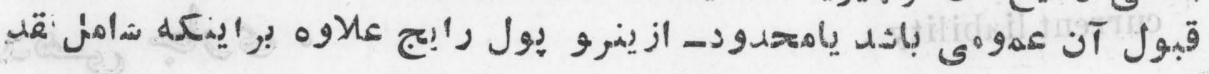

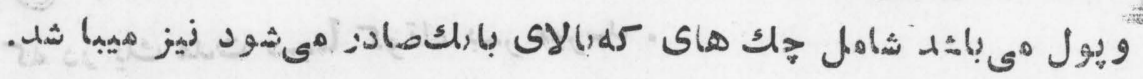

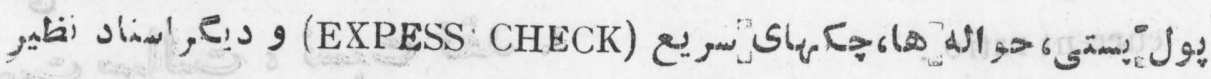

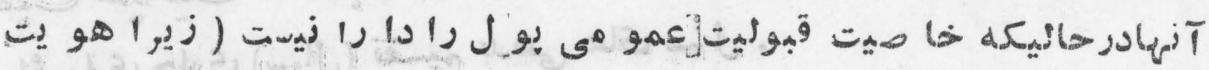

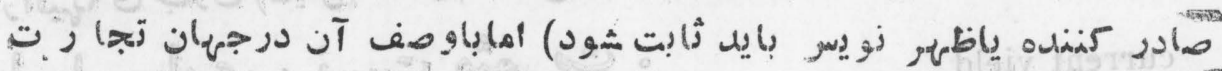

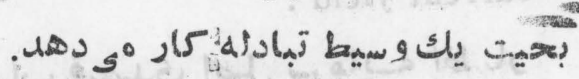

currency bond. • مر اجهوشودد. BOND,CURRENCY 
currency school principle.

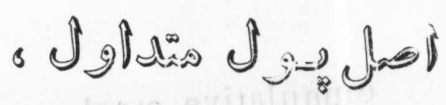

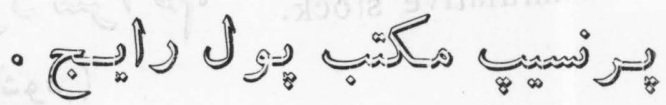

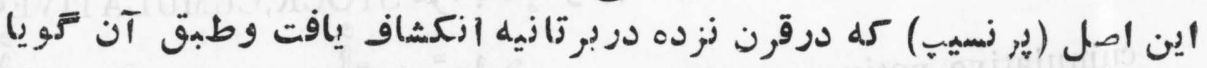

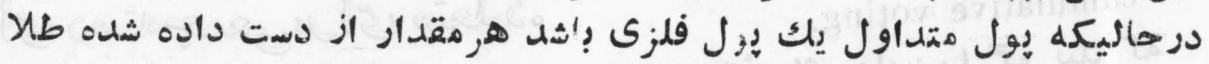

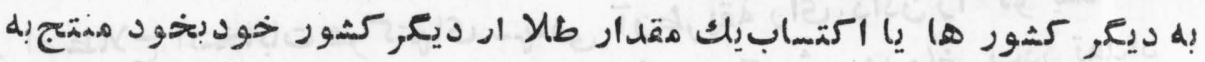

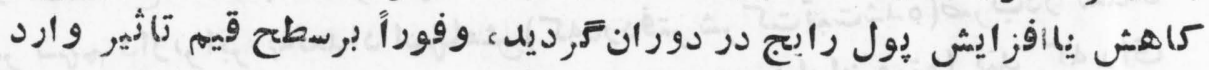

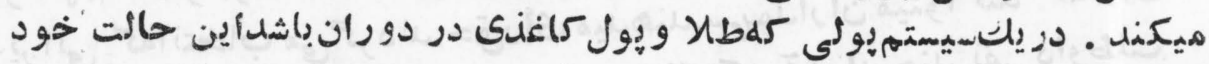

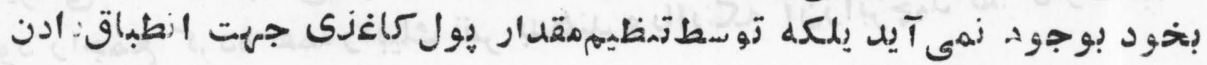

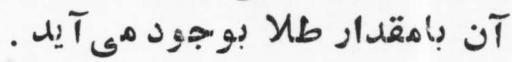

current asset .

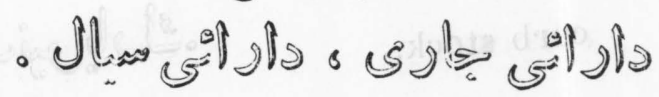

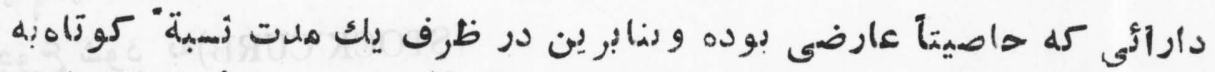

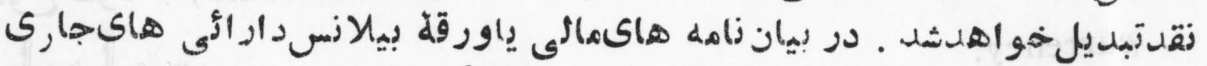

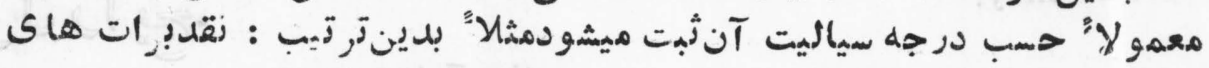

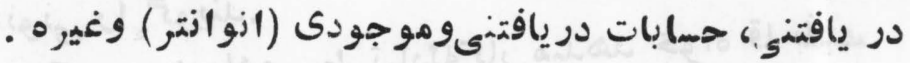
current liability .

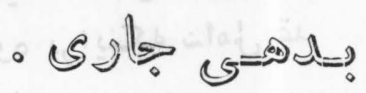

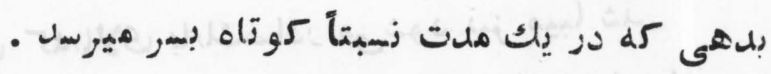
current ratio .

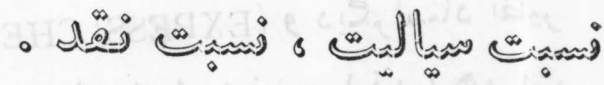
دارائيرلا ى جارى (سيدال) تقسيهم بلهى هاى سم ل current yield . - $\underbrace{\infty}_{\infty}$

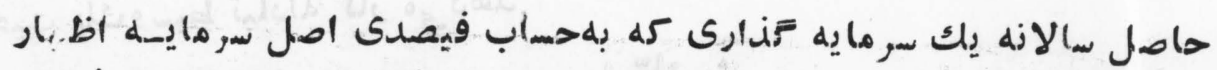

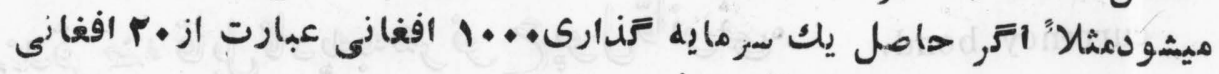

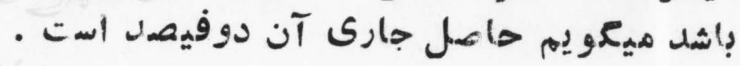

\section{(I)}




\section{CUS}

custodian account .

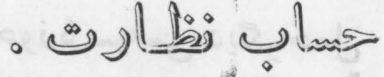

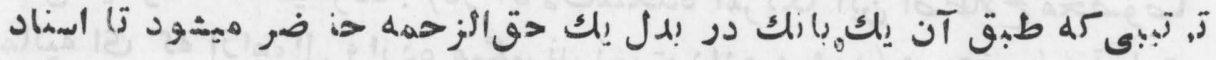

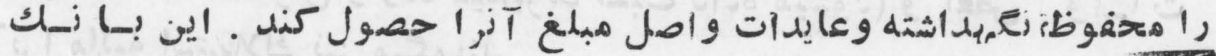

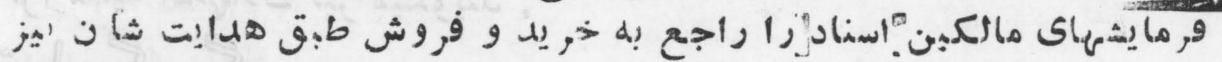

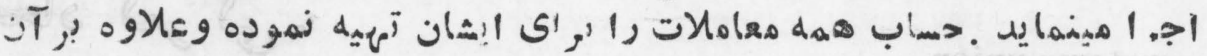

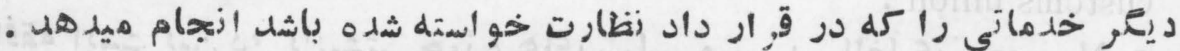

custom house.

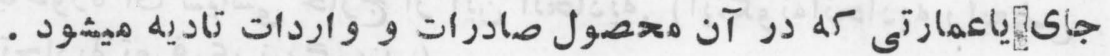
vustomer costs. •la

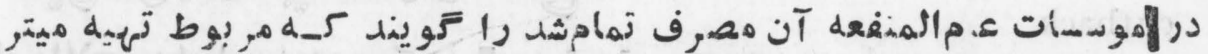

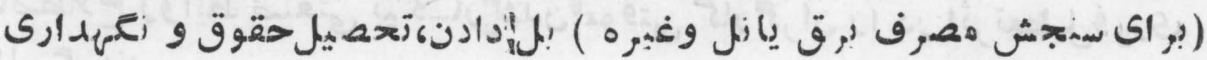

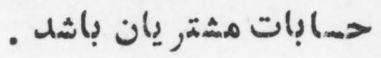

customer rate.

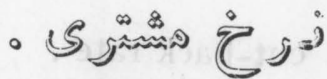

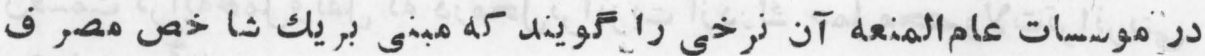

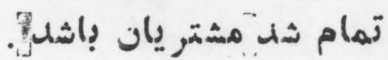

customer ' sman

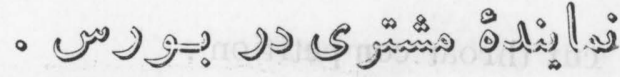

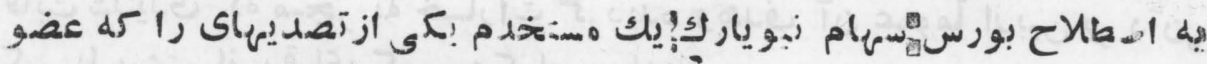

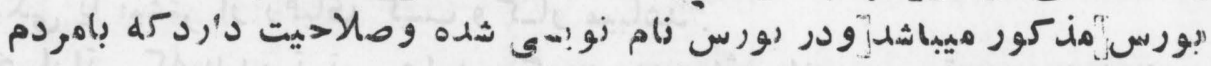
custons . cusțoms duty .

$$
\text { - }
$$




\section{CUS}

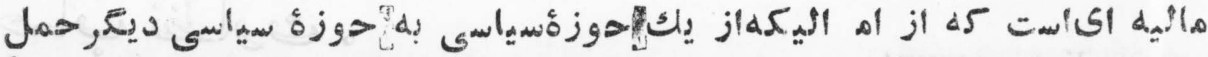

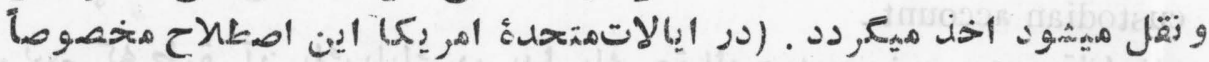

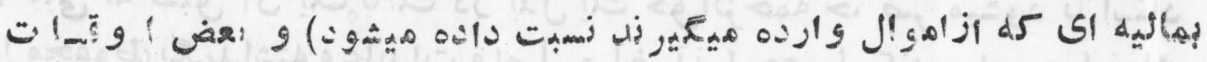
-

customs union .

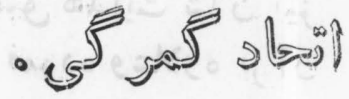

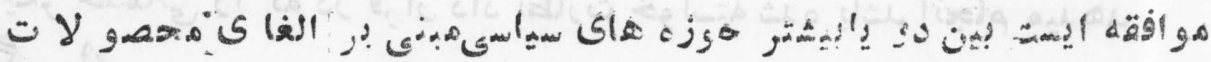

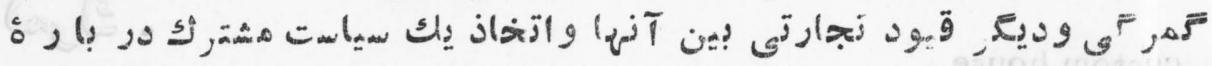

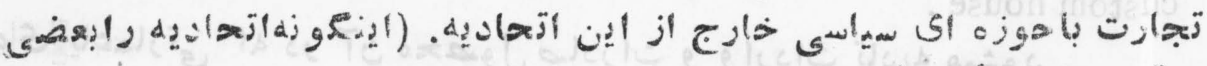

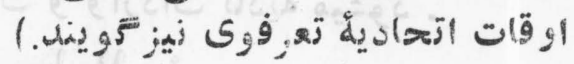

cutback.

- ज行

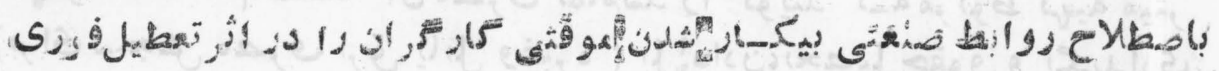
cut-back rate . . $2 . \operatorname{sig}^{2} 15$

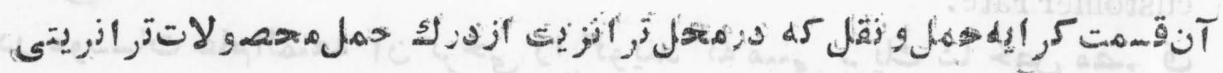

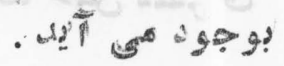

cut throat competition.

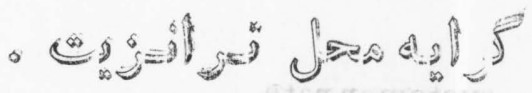

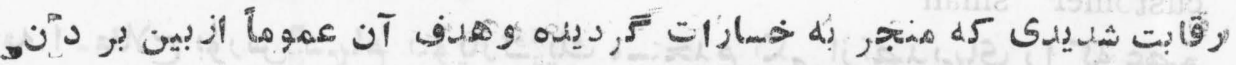

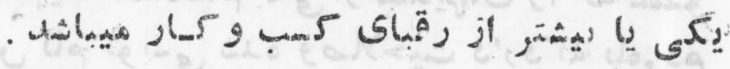

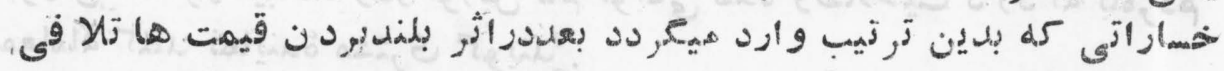

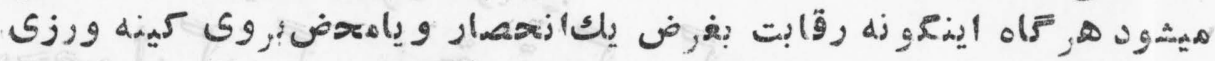

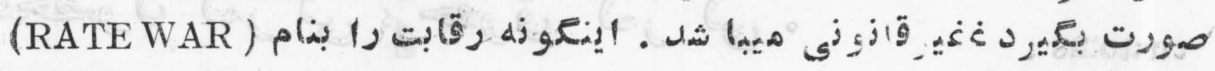

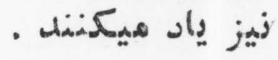
cyclical fluctuatiors

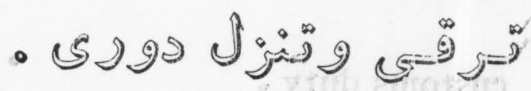




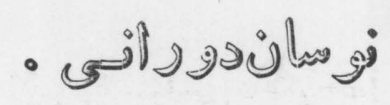

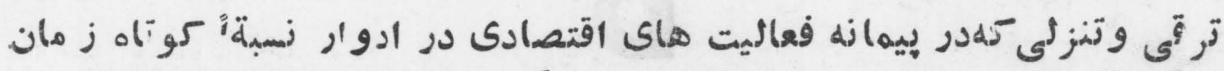

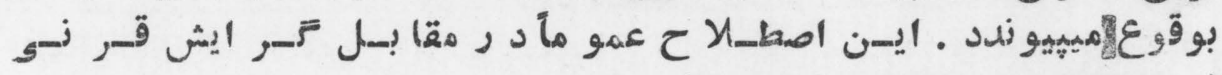
الستعمال ميعردد (SECULAK TREND . )

cyclical unemployment .

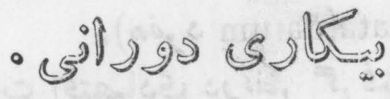

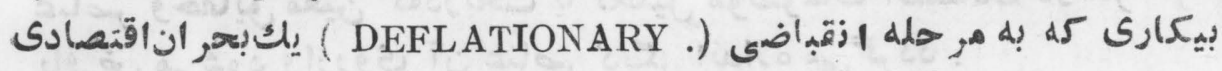

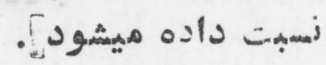




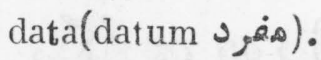

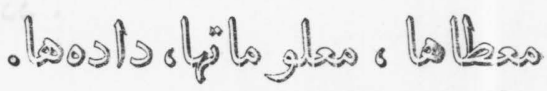

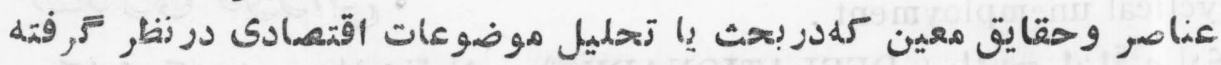

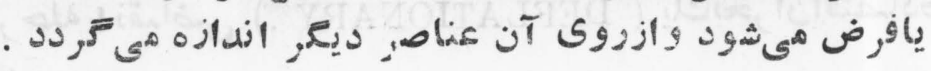
daşs of grace.

- $\oplus$ -

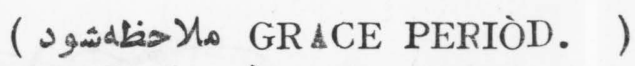

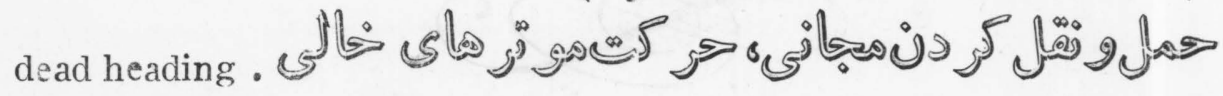

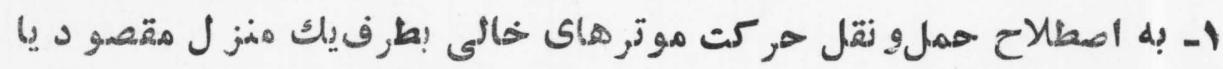

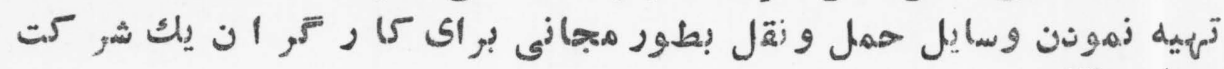

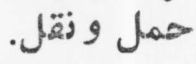

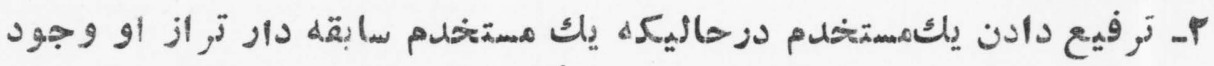

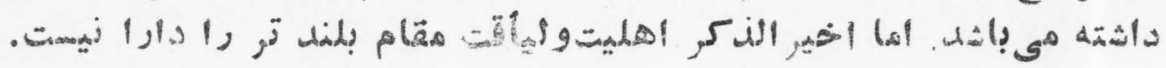

dead rent.

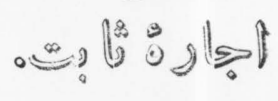

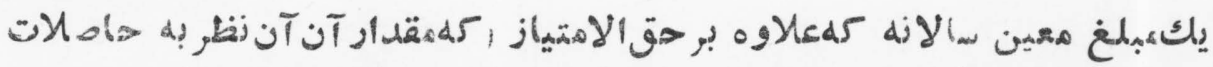

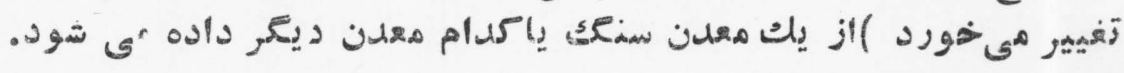

dead time.

○ी

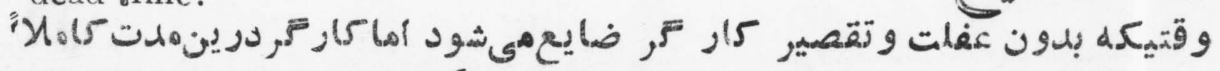

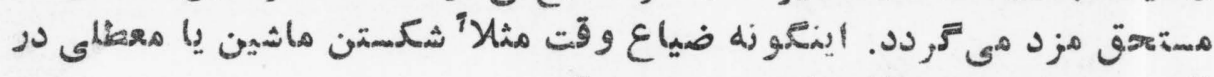

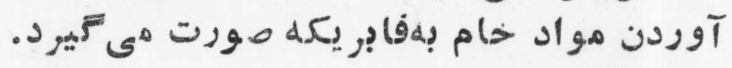

dear money. - id 0

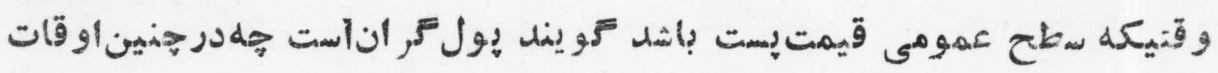




\section{DEB}

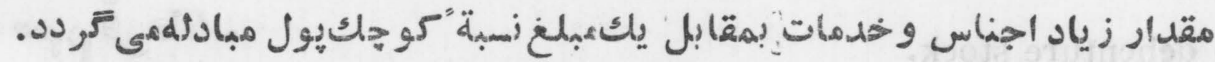

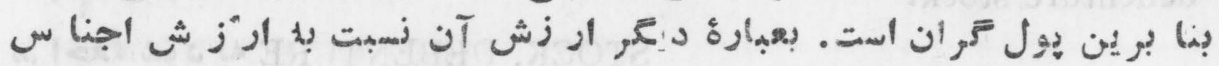
وخدمات بلمند تو مئ باشيد.

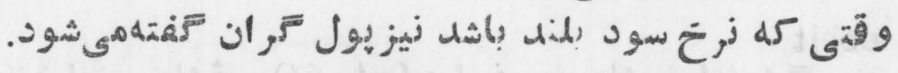
death rate

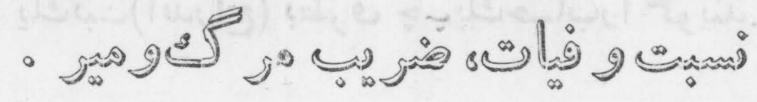

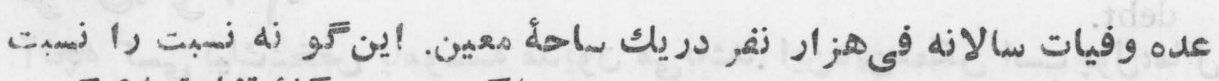

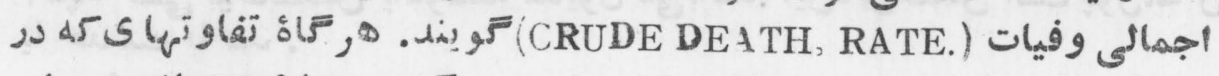

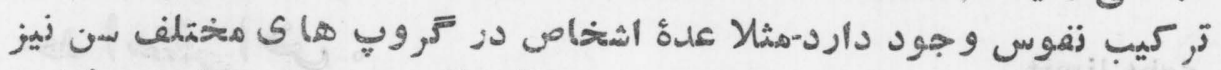

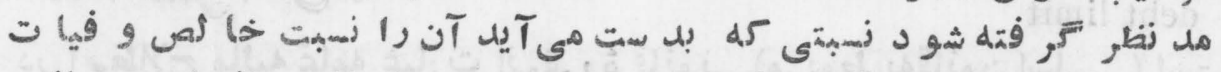

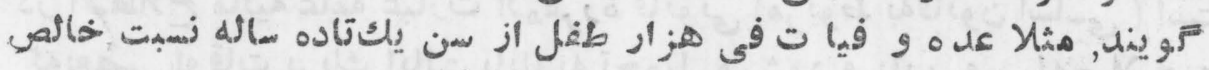

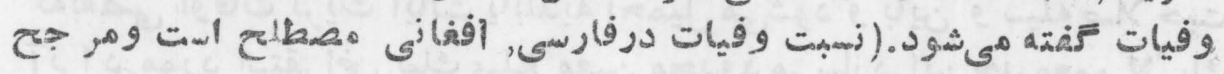

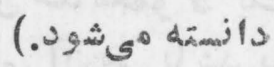

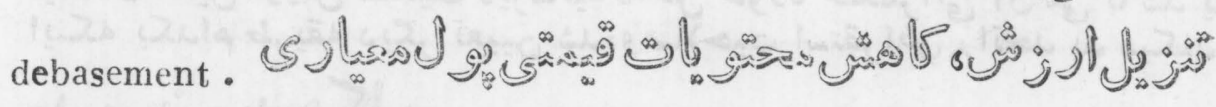

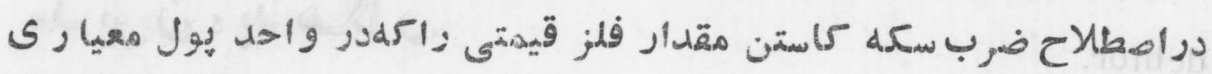

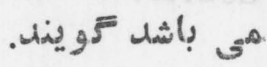
de benture bond

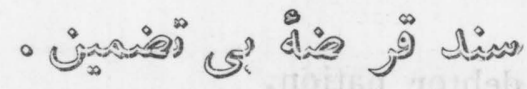
. debenture certificate. $\quad$ ज

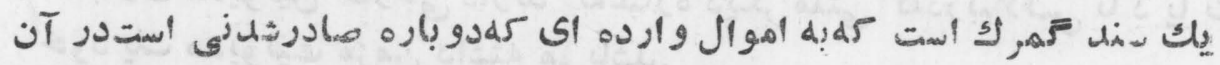

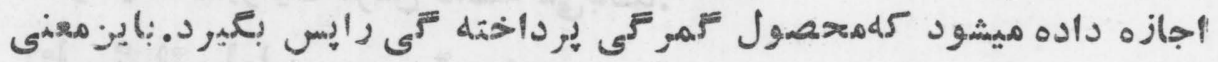

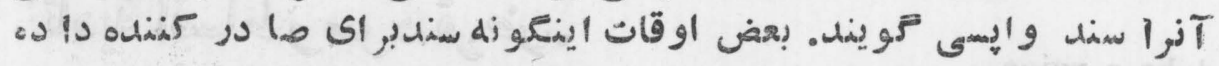

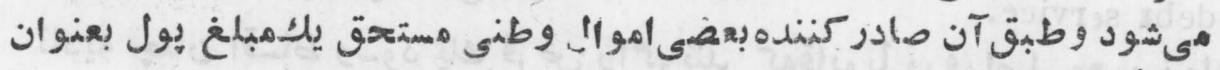

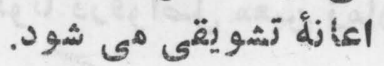


debenture stock.

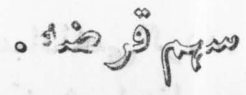

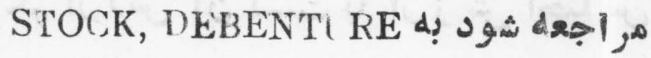

debit.

$$
\text { ० }
$$

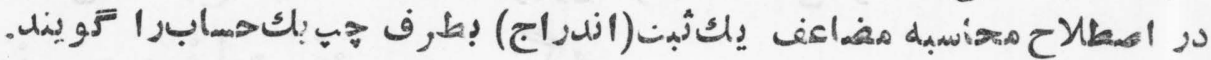

debt.

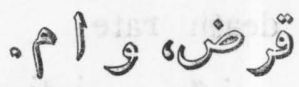

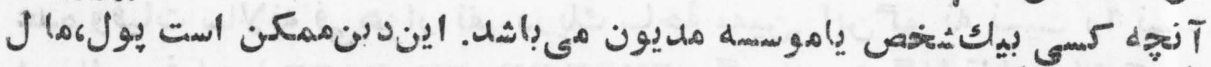

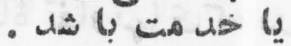

debt limit - $\iint^{2 \infty} \int_{\infty}^{\infty} \int d s$

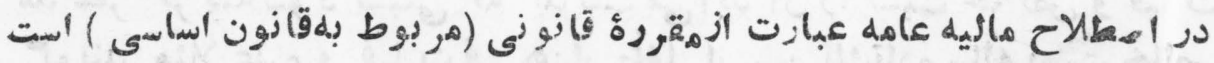

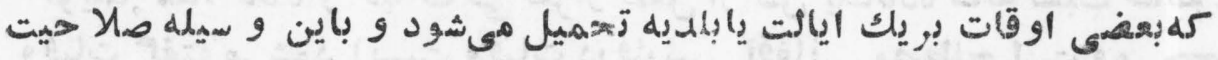

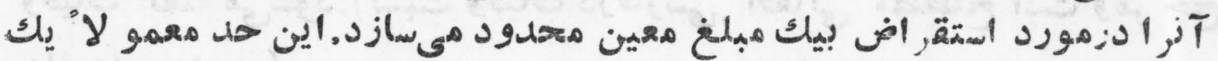

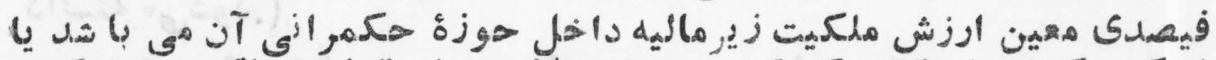

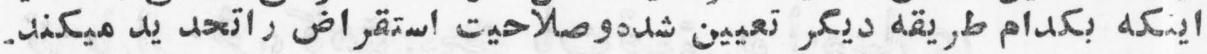

debtor.

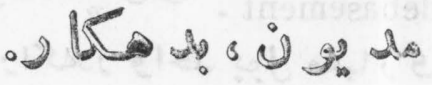

debtor nation.

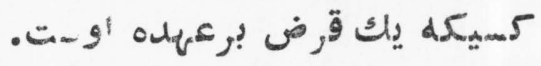

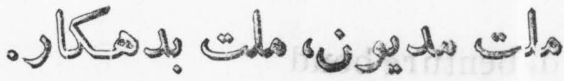

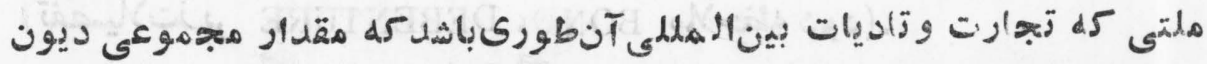

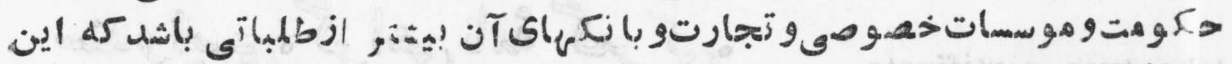

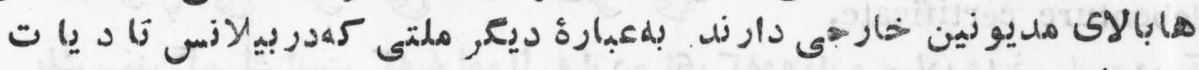

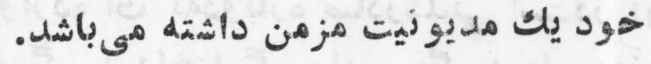

deb strvice.

$$
\text { - ए }
$$

تاديه هنان اقتساط وسمود يك قوض راتَوينل كهوقازو أ درفواصل همين زمان. 
DEC

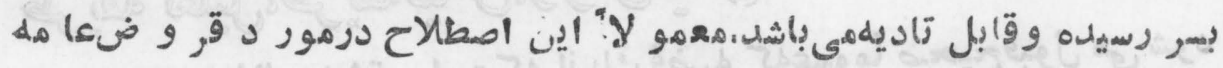

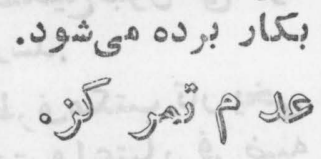

decentralization.

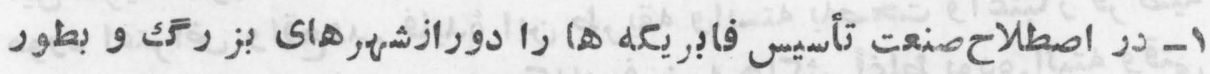

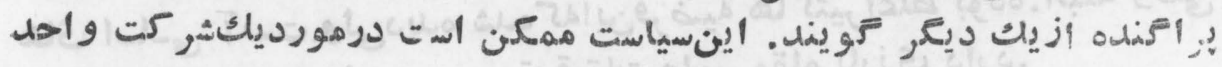

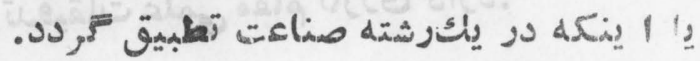

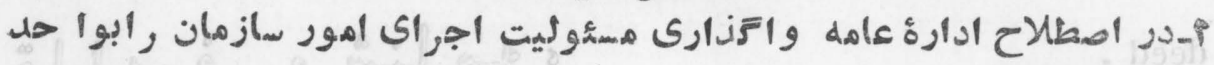

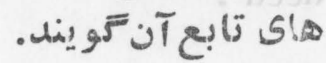
declining-.marginal- efficiency-of-capital theory. $\iint_{5}$

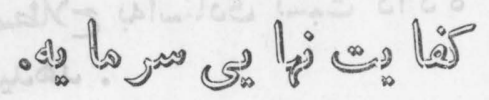

نظر يه ايست كهازطرفاقتصاد دانهاى بيرو كنز اظظهار شهه وعبارتاز اينست

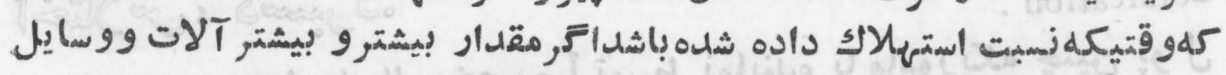

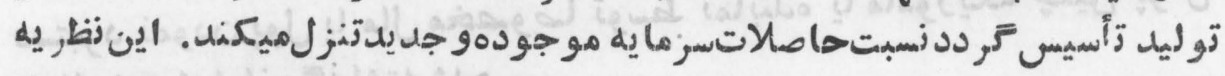

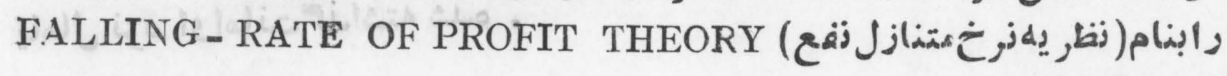

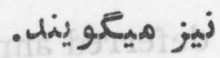

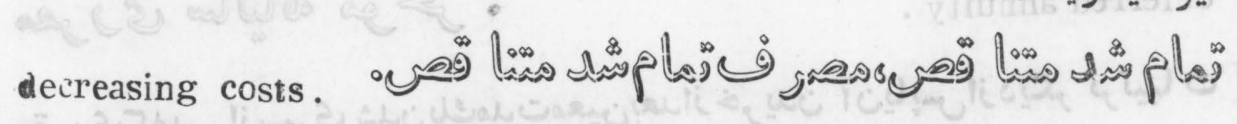
تحت بعضى نئر أيط با افزايش تو ليل مجمو عى مصر ف تمل م شد في وا حلد محصول كم مىشود. اينغو زه مصرف تمامشل را (مصرف زمام شل هتشناقصه) تو ينل. مون. صرفـه هاى كـه در اثٔر توليدات كميتله وى ( MASS PRODUCTION )

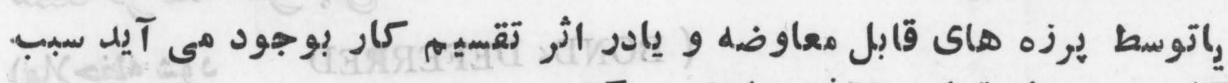

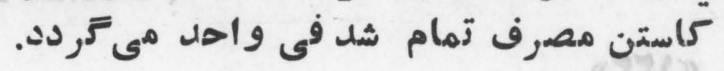


deductive method.

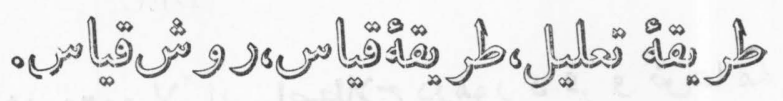

يلك،نوع استل لال منطقى است كه ازيك قضيه كهعموماً صنحيحقبول مهى شود

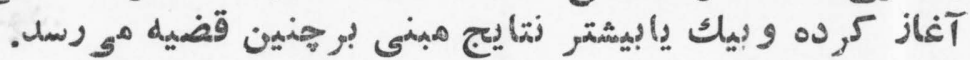

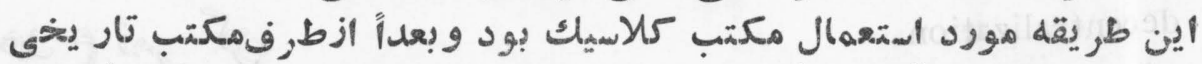

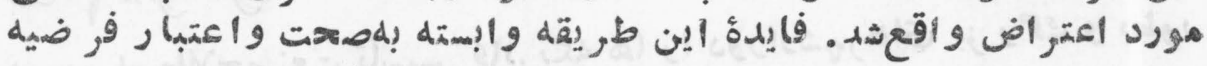

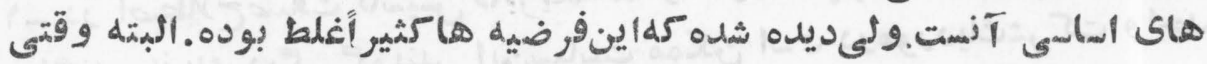

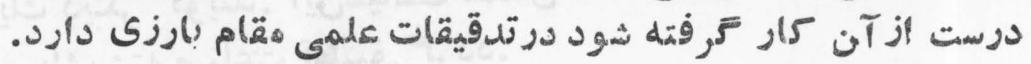

deed .

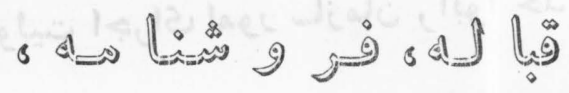

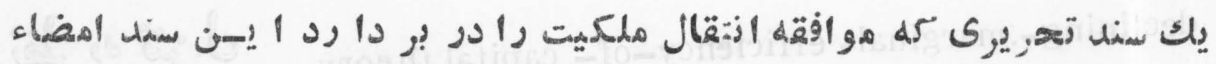

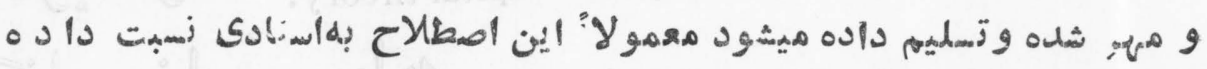

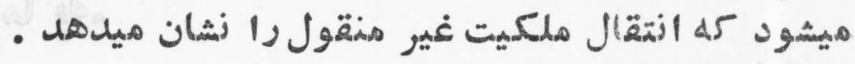

defalcation .

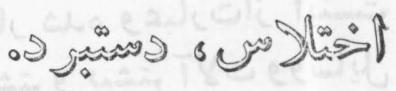

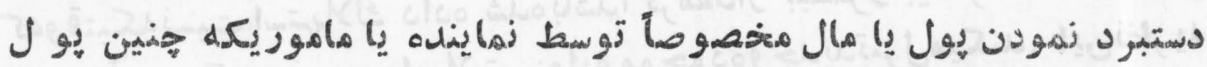

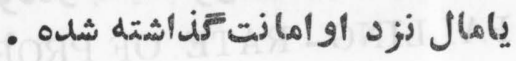

deferred annuity •

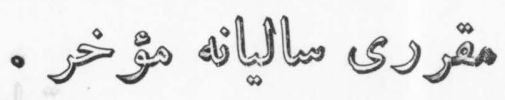

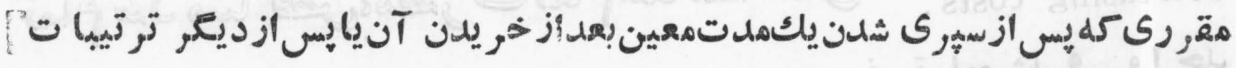

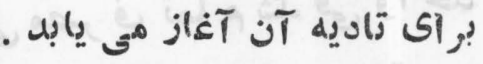

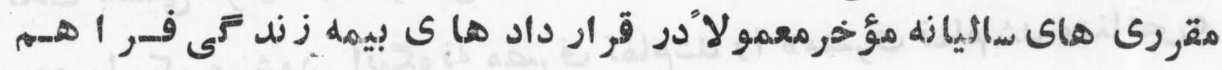
deferred bond".

- Jج

( BOND6 DEFERRED
(م)

\section{QIFPD}


de ferred demand.

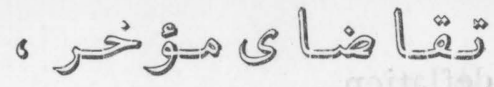

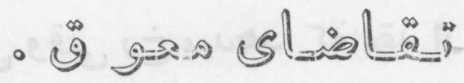

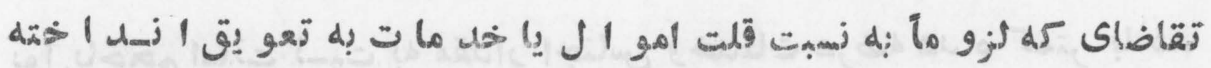
deferred income .

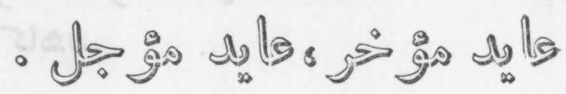
(UNEARNED INCOME . شود ش ( )

deficit financing •

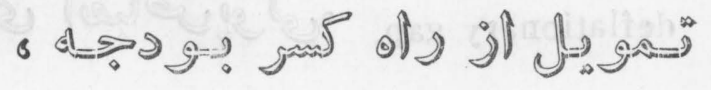

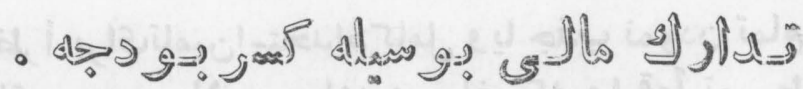

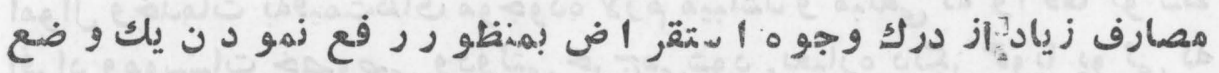

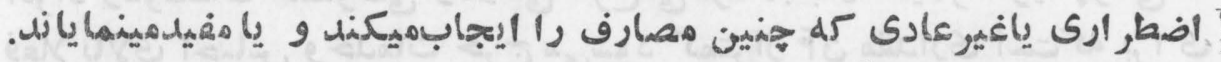

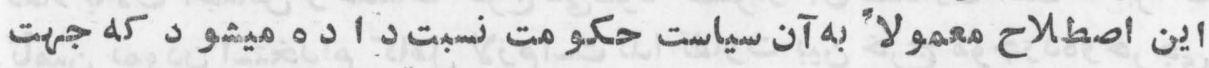

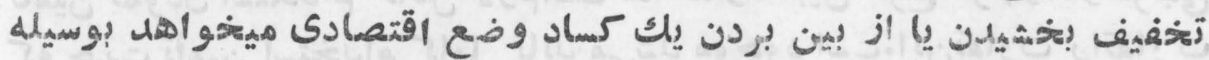

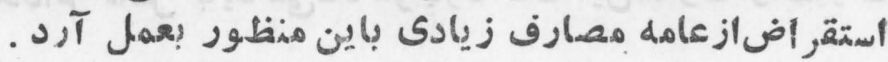

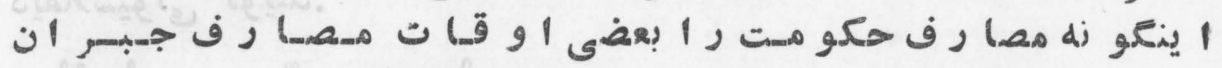

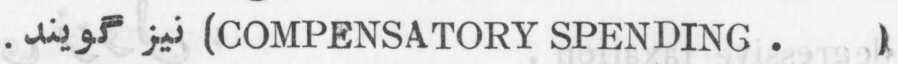

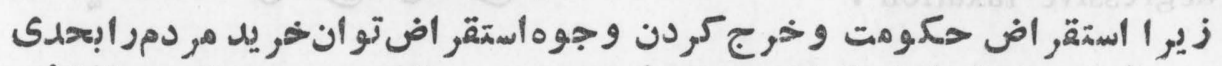

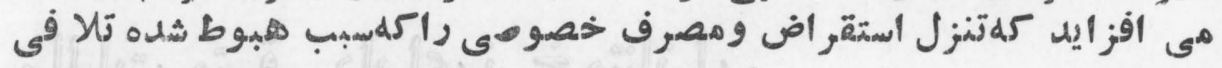

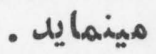
definitive .

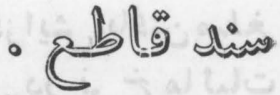

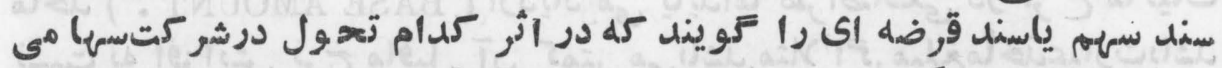

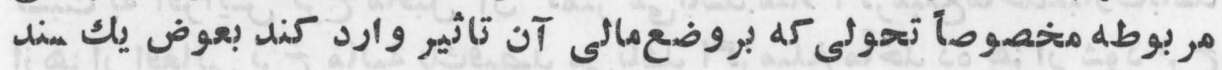

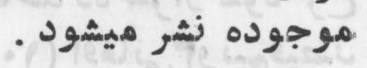


deflation •

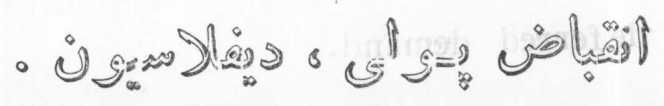

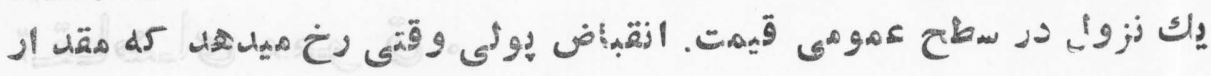

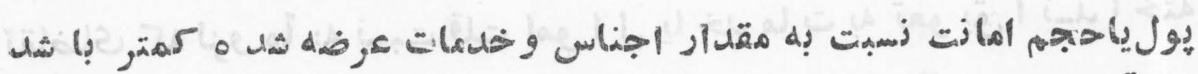

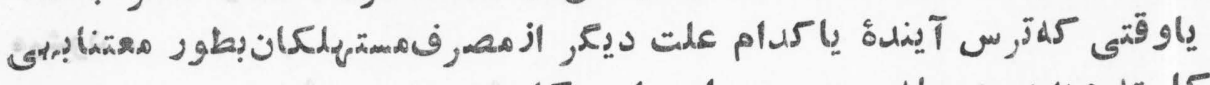

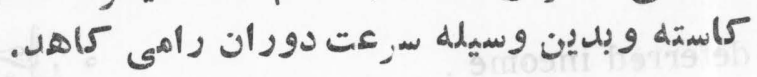

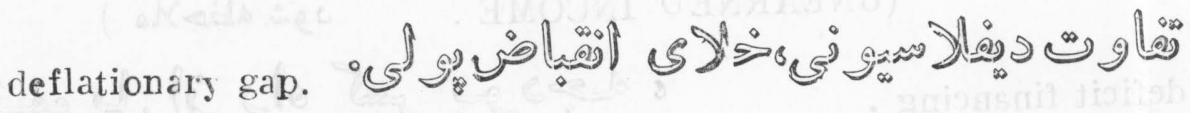

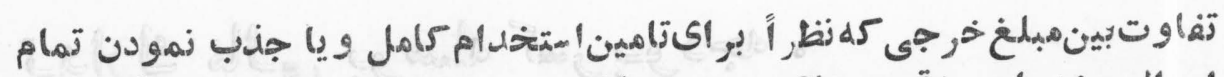

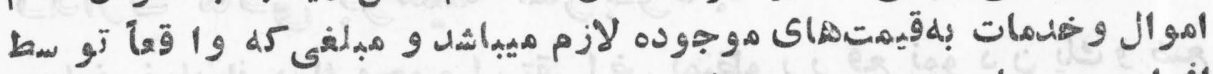

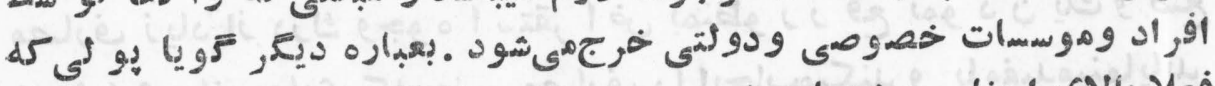

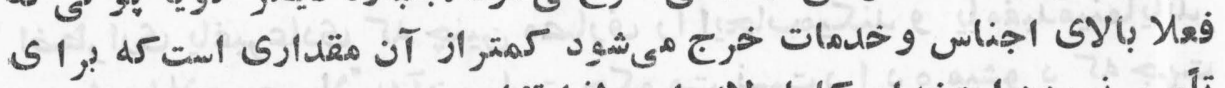

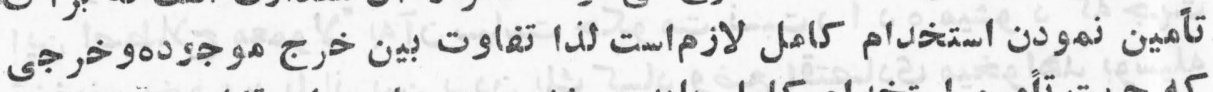

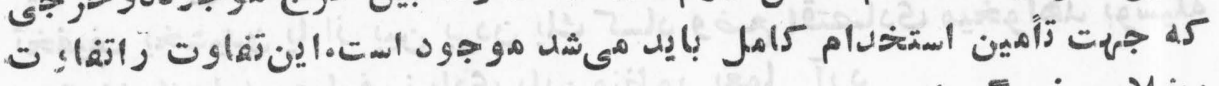
ديفانسيوزى تمويند.

degressive taxation

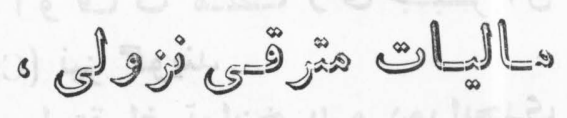

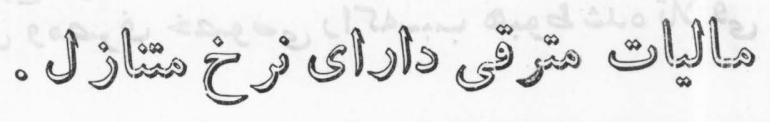

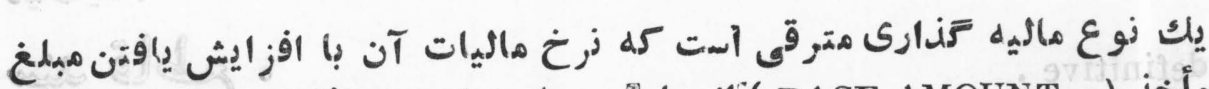

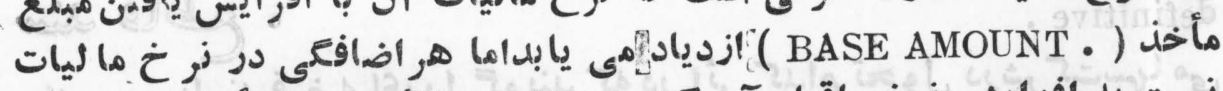

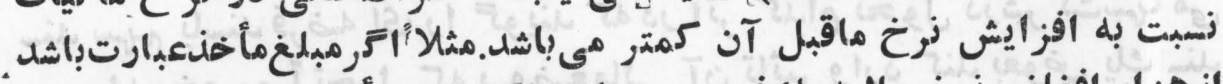

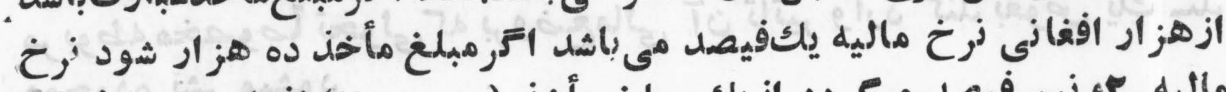

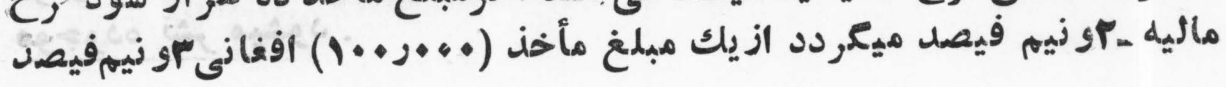

\section{源( (I)}


ماليه اخذ ميشود وازيك مبلغ مأخن يك مليون افغانى هاري و نيمفيصل مانئيه :

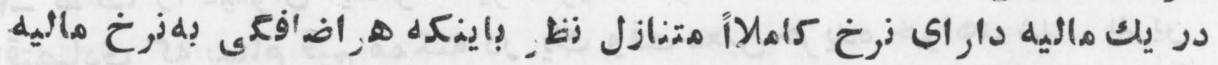

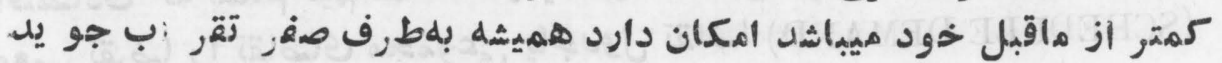

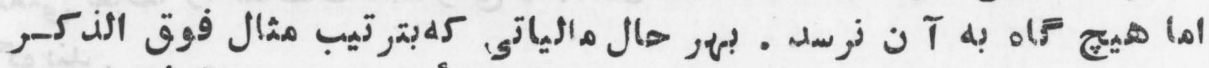

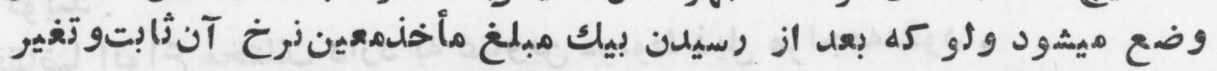

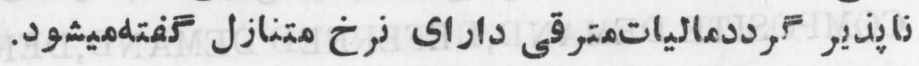

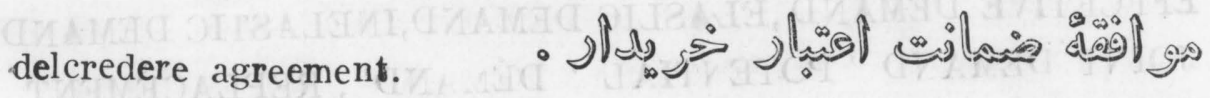

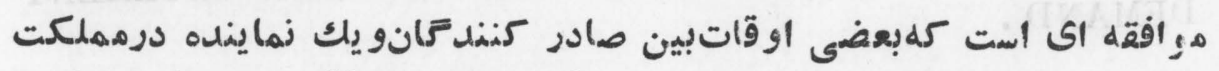

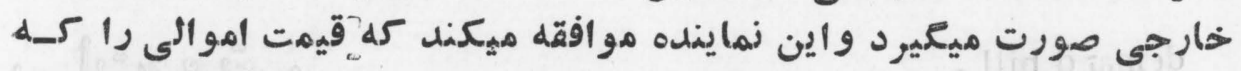

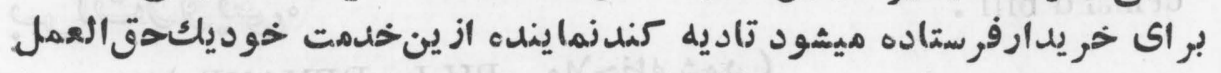

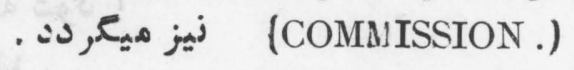

de nquent tax. $\quad$ •

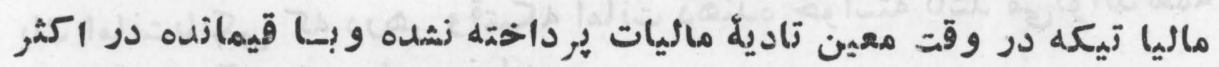

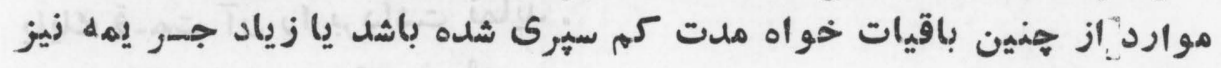

demand .

اخذ ميشود .

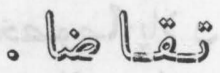

1- آن مقدار يكمال اقتصادى كه در يك وقت معين بيك قيمت معين خر يده

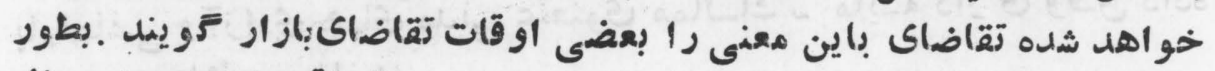

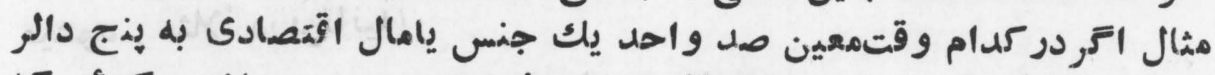

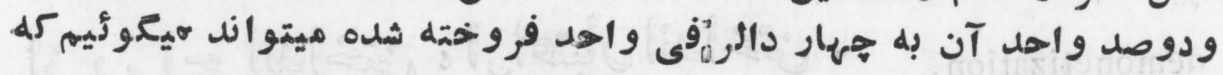

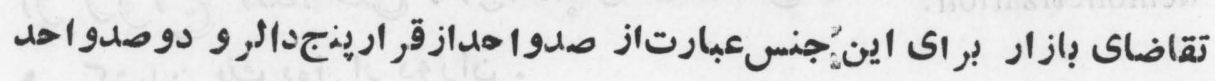

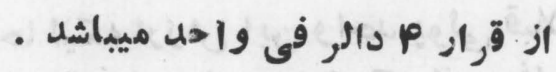

(ITO) 


\section{DEM}

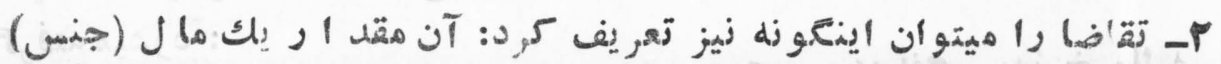

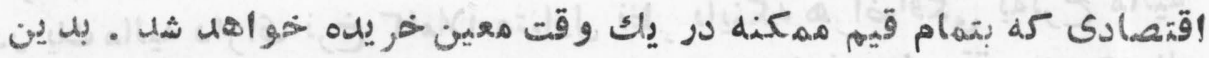

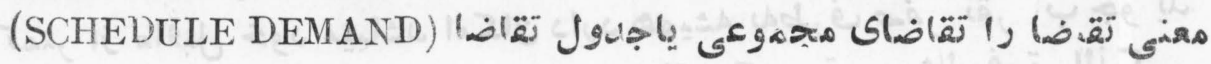

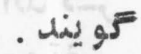

تقاضا انواع مختلف دار دارد به عناو ين مر بوط ذيل مر اجعه شود ـ COMPOSITE DEMAND,DEFERRED DEMAND,DERIVED DEMAND EFFCETIVE DEMAND,ELASLIC DEMAND,INELASTIC DEMAND JOI TI DEMAND ' PJPEVTIAL ' DELAND , REPLACEMENT DEMAND .

demard bill .

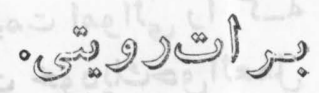

\section{(}

demand deposit.

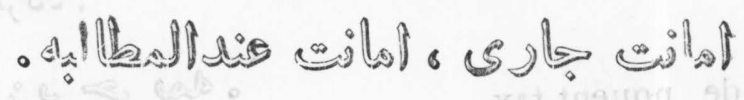

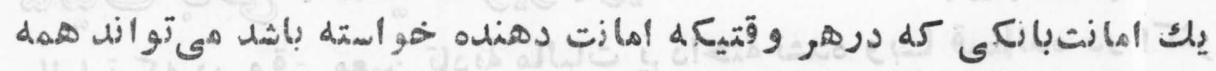

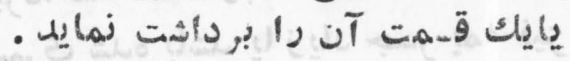

democratic socialism.

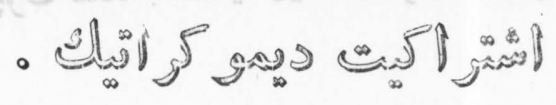

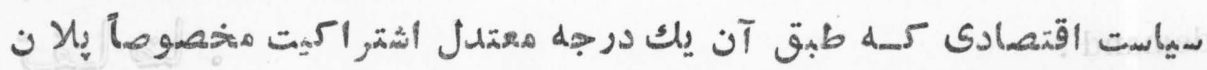

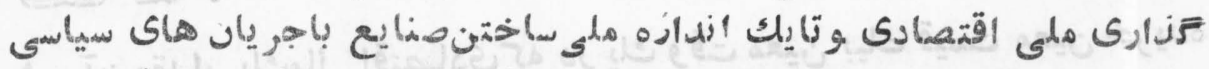

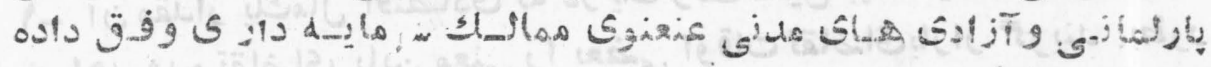

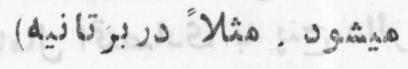

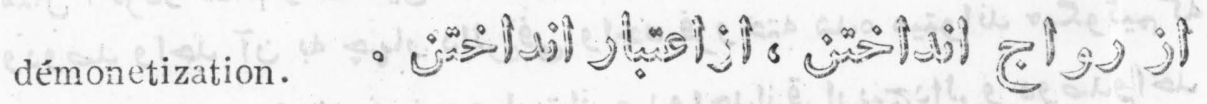
- 1

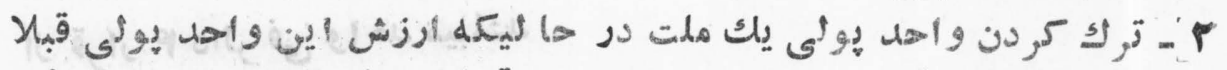

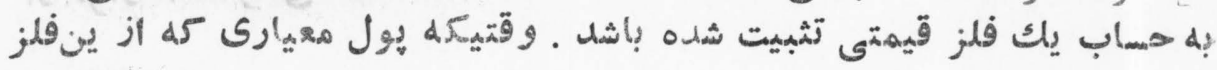




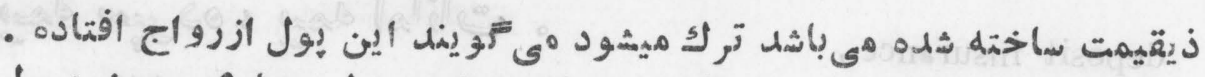

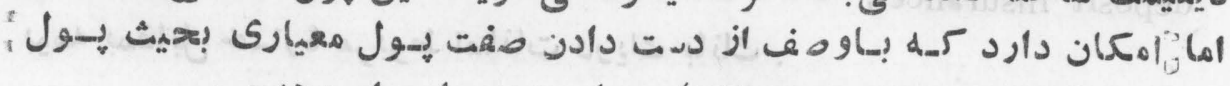

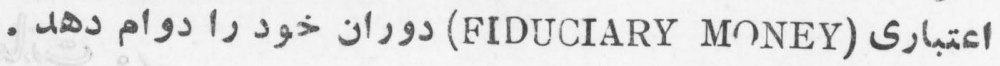

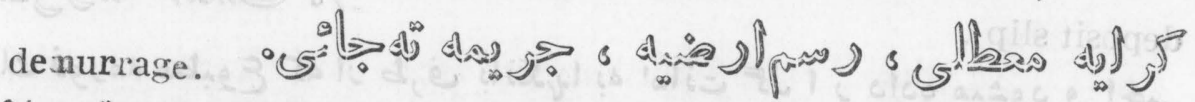

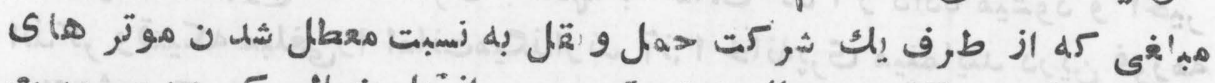

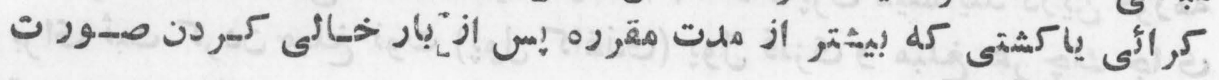

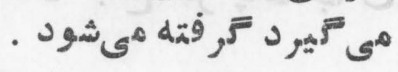

denominational value. ارزش وجهى سكه ها،يول كاغذى وازواع مختلف اسناد .

depositary .

- C o gisas

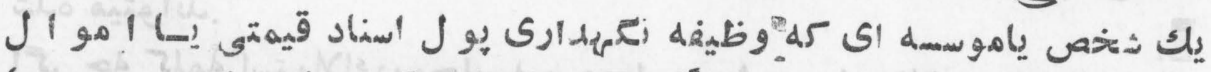

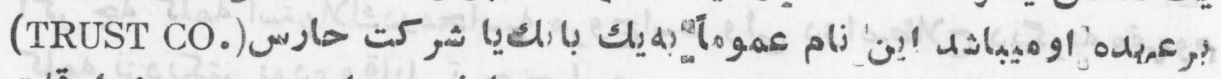

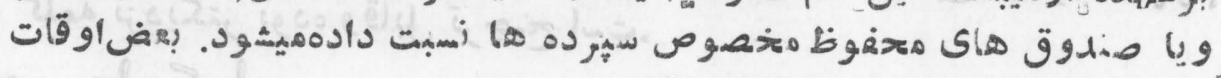

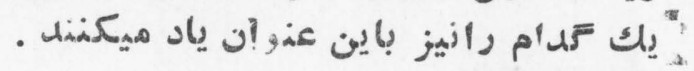

deposit currency .

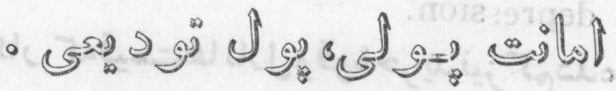

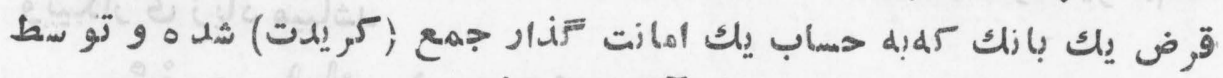

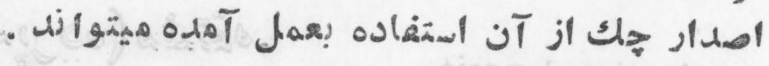

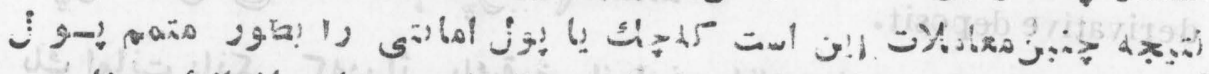

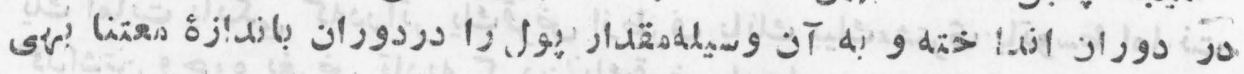

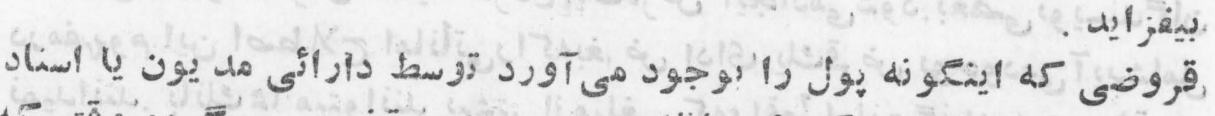

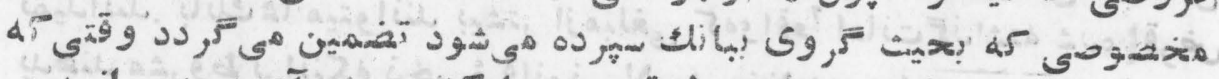

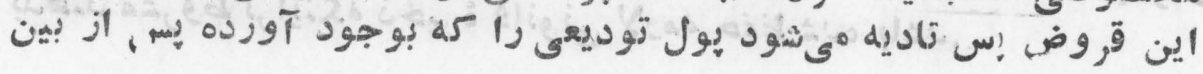
مي برد • 
deposit insurance.

$$
\text { - }
$$

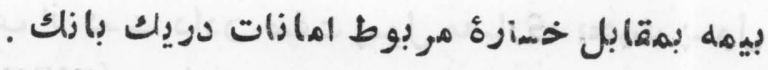

deposit slip .

- 定

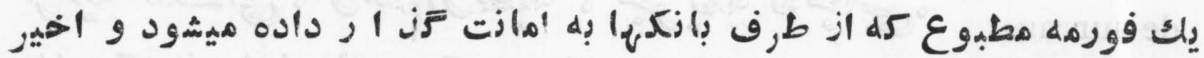

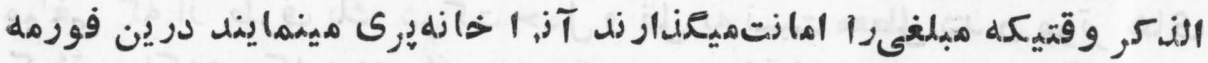

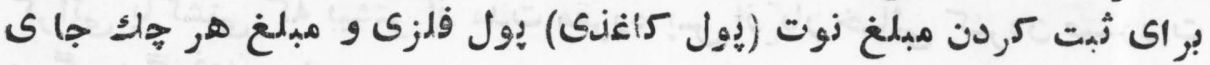
تهيه شله ميبهاشل .

depreciation. $0 \underbrace{\infty}_{\infty}$

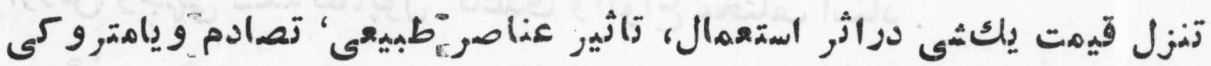

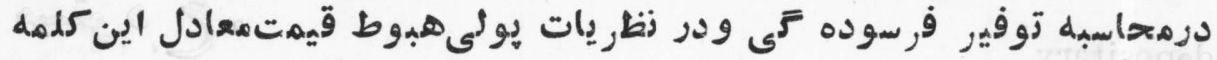
푤

شلده ميتوانل.

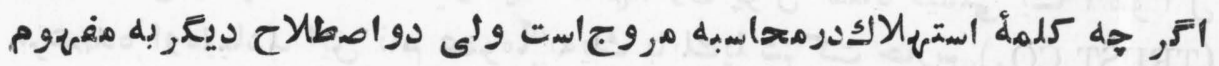

depression.

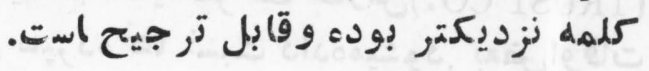

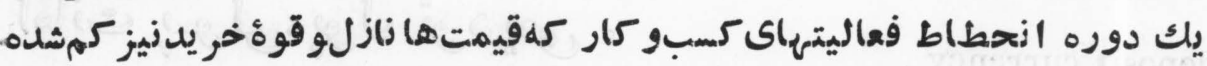
و بيكار ى زياد ميماشل

derivatire deposit.

$$
\text { ه }
$$

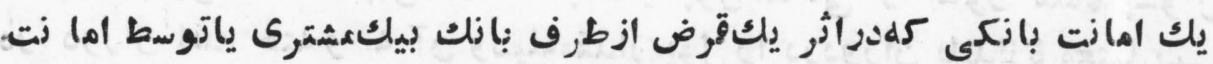

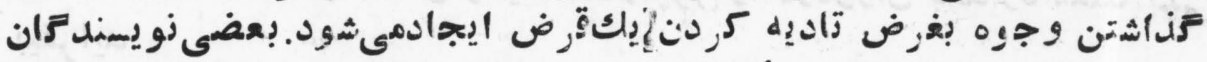

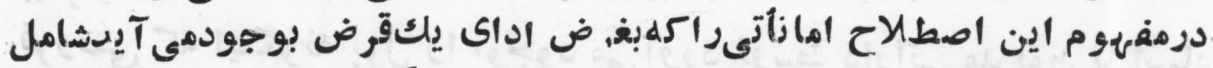

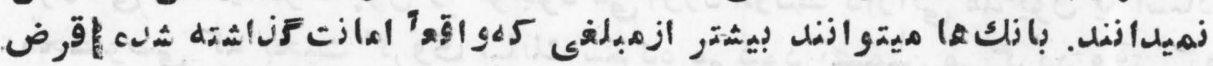

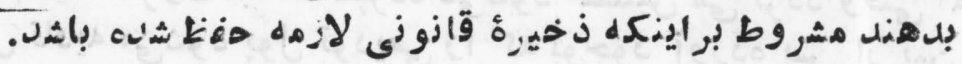


derived demand.

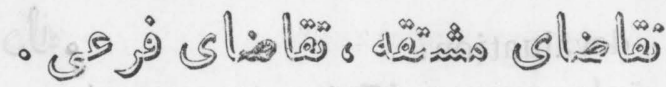

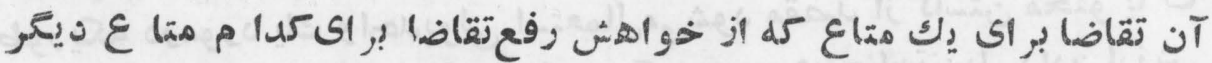

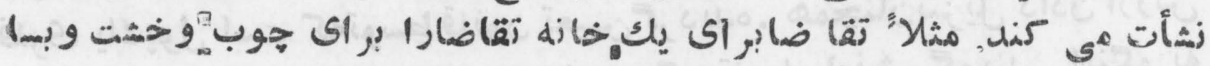

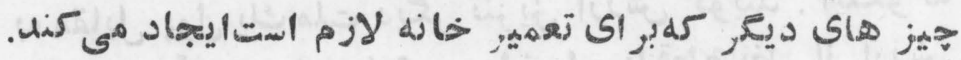

descriptive economics. - ज海

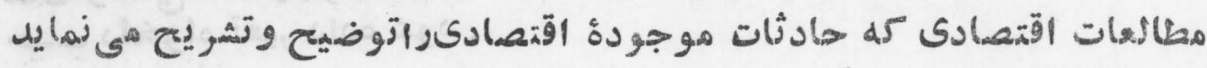

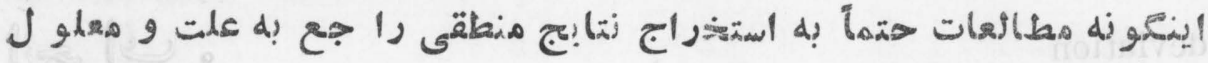

$$
\text { 荘 }
$$

descriptive labeling.

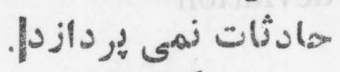

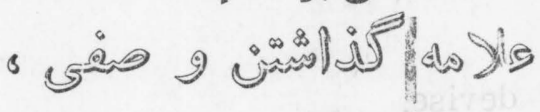

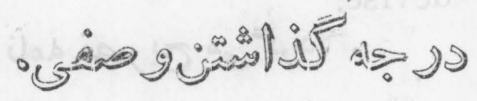

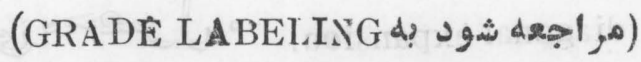

desterilized gold.

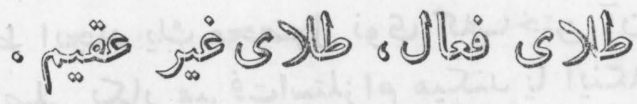
( مر اججه شود (به . STERILIZED GLOD)

ructiv e competition.

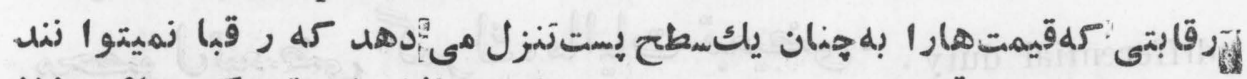

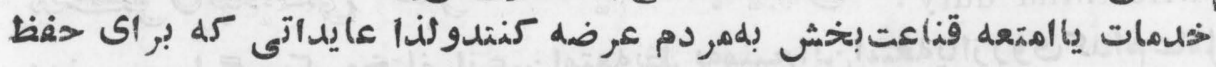

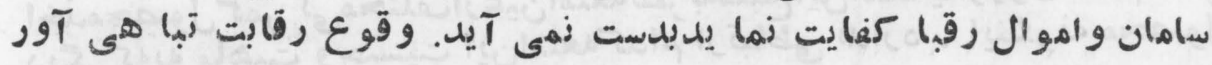

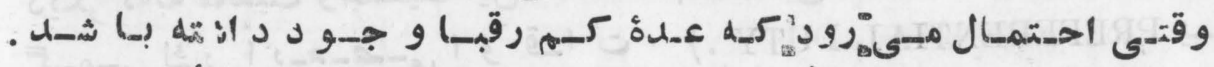

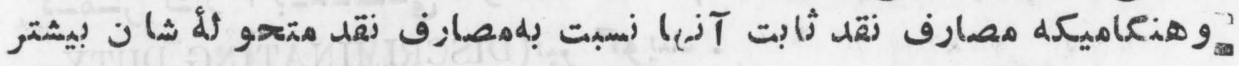

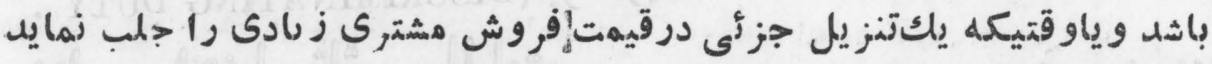

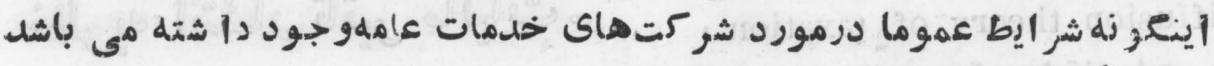

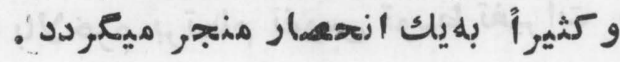


devaluation .

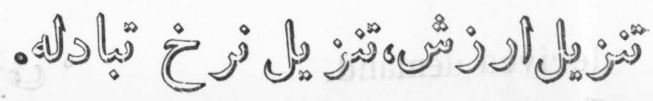

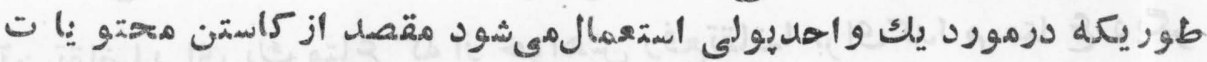

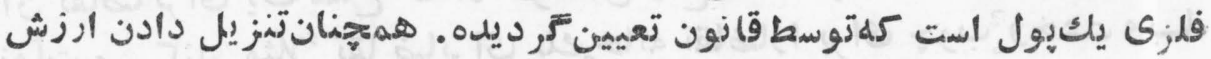

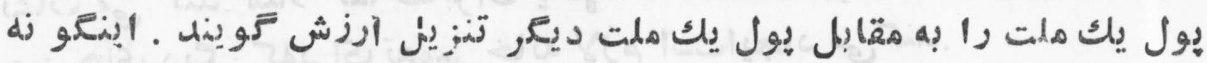

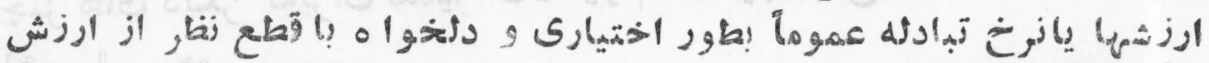

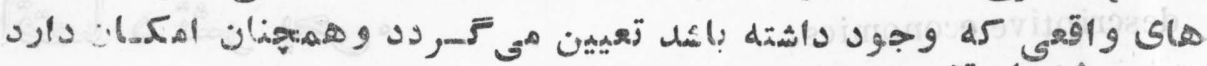

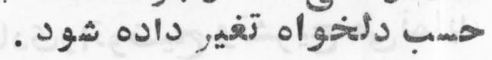

deviation

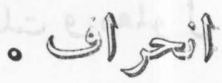

دورشدن ازيك زتقطه ياارزش مهمين •

devise.

$$
\text { - }
$$

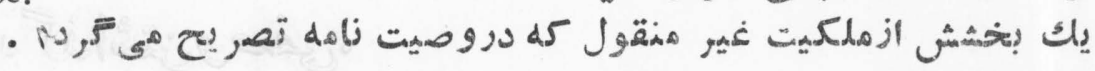

diagonal expansion. • لी

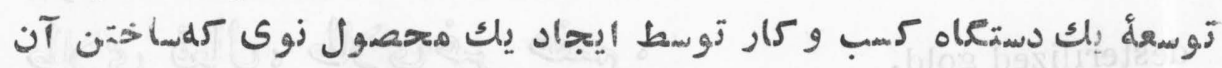

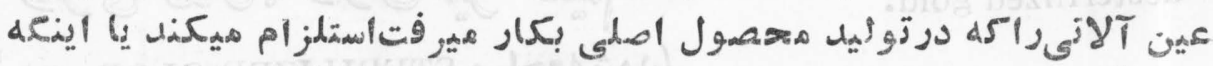

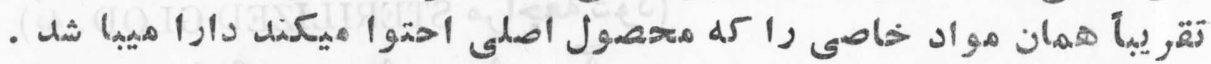

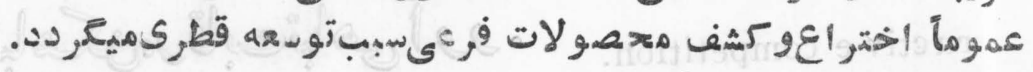

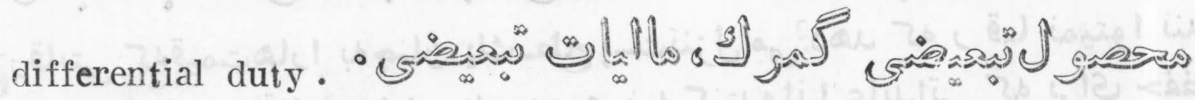

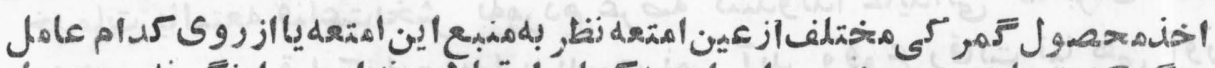

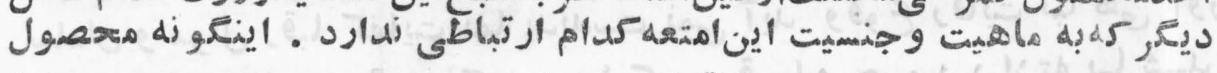

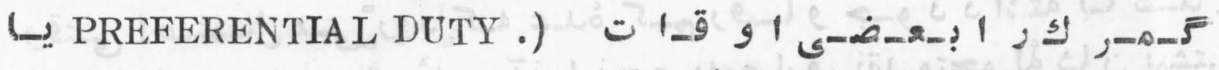

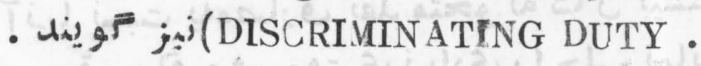
diffusion theory of taxation.

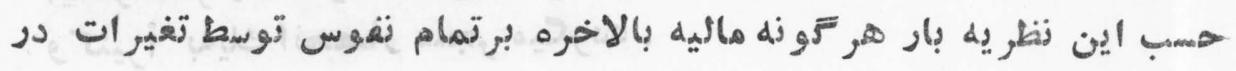
(I) $P$ D 


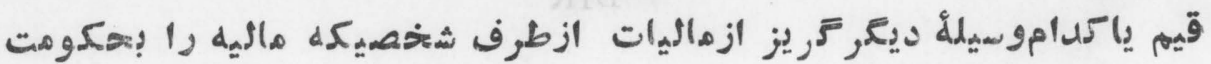
diminishing productivity •

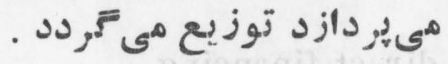

$$
\begin{aligned}
& \text { - }
\end{aligned}
$$

(مر اجعه شود DIMINISHING RETURNSA )

diminishing returns, law of .

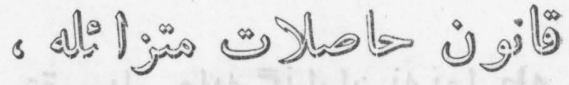

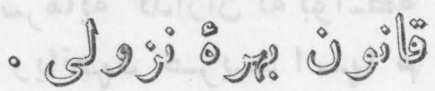

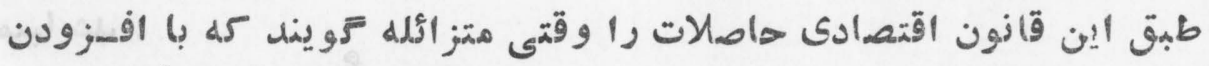

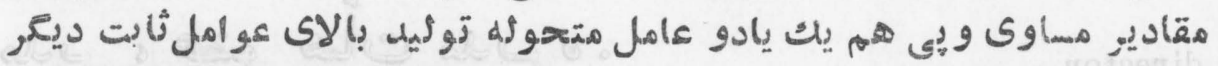

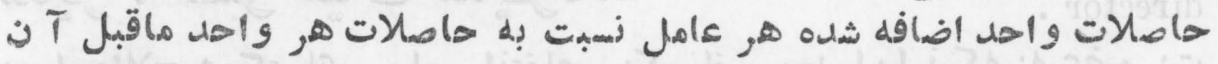

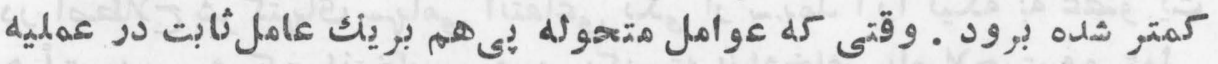

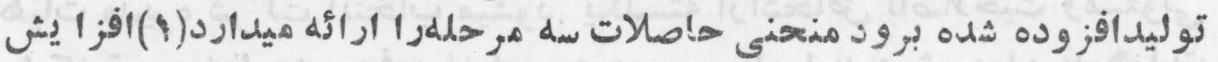

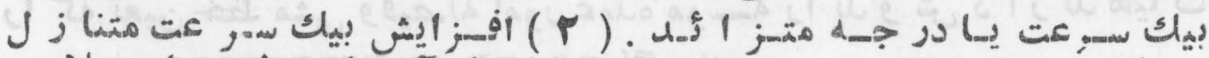
(r)

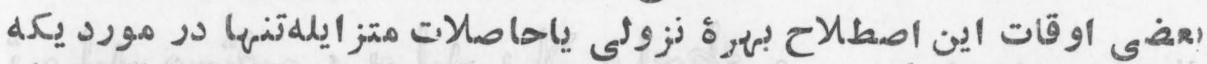

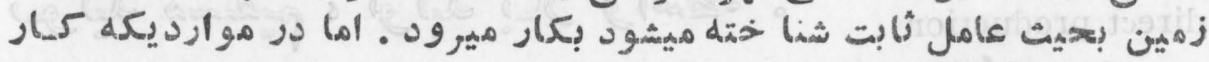

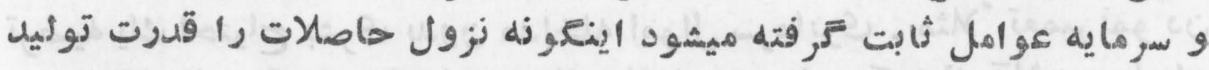

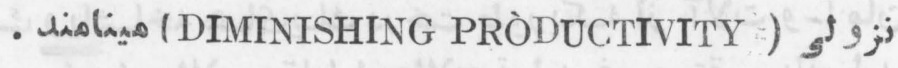

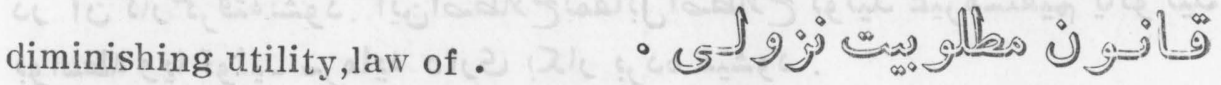
(ماحظه مود MARGINAL UTILITY . )

direct cost .

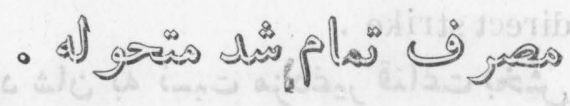

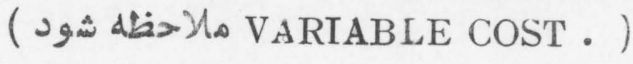

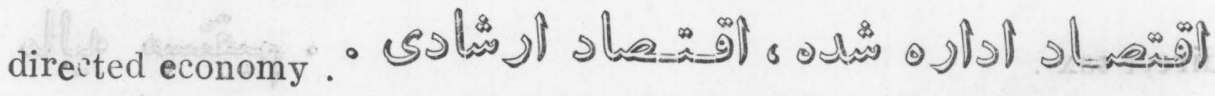
( CONTROLLED ECONOMY .-) 
direct financirg .

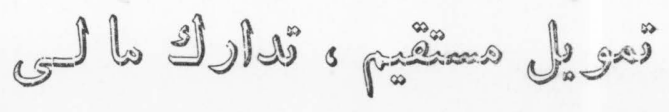

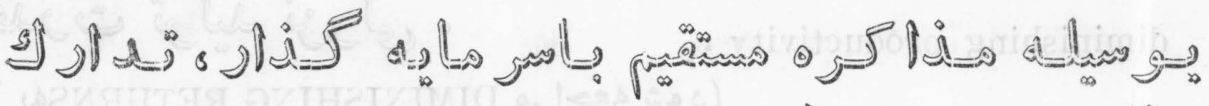

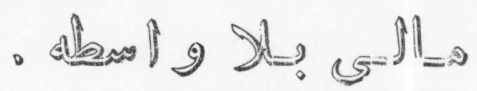

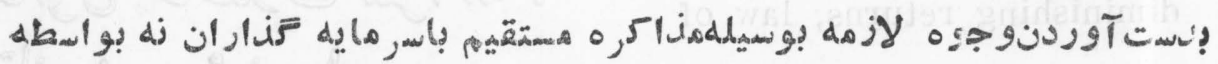

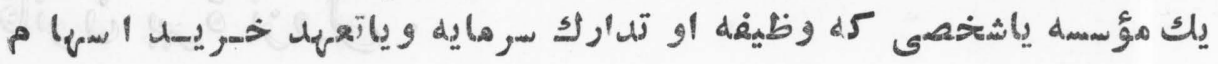

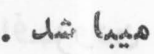

director .

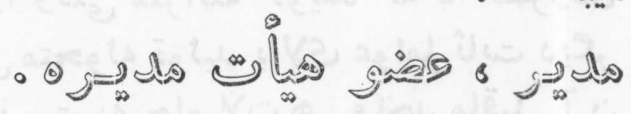

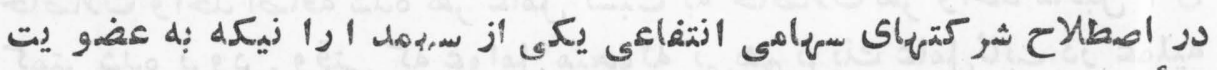

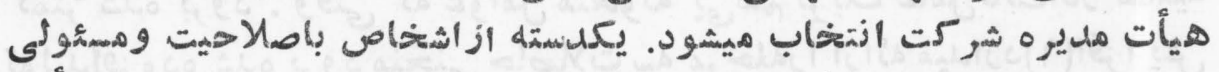

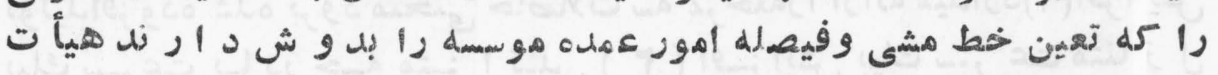

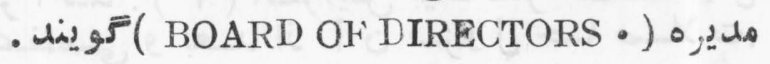

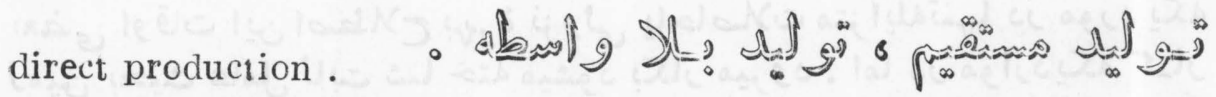

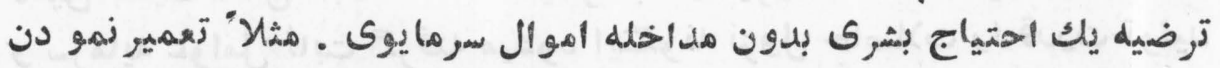

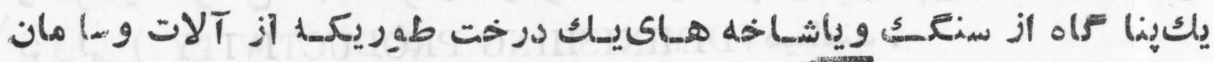

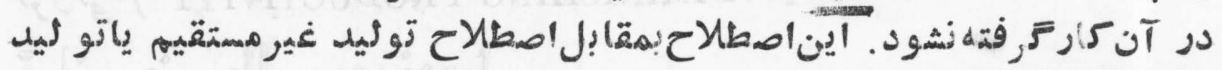

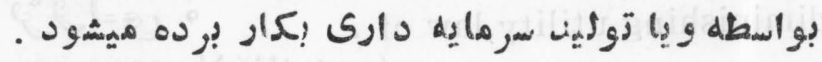

direct strike . اعتصاب كار تران علميه كار فرهاى خود شان به نسبت مزدغير قناعت بخش

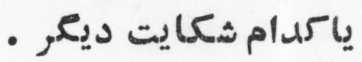
direct tax . - $\int_{\infty}$

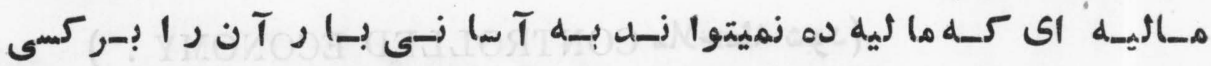

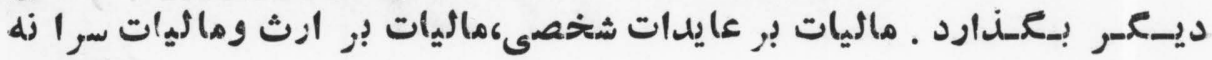

\section{(C)}




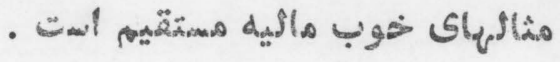

discount . - $\int=\sum_{\infty}=i j$

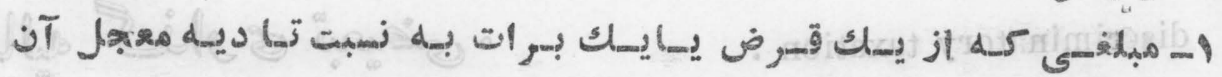

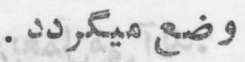

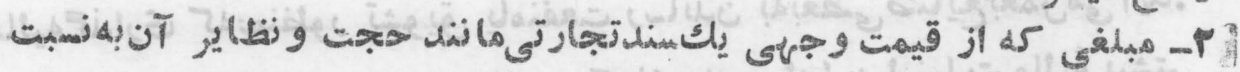

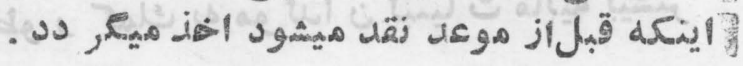

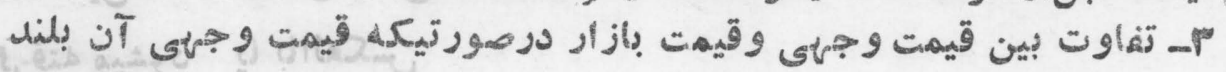

discount house .

$$
\begin{aligned}
& \text { - ज }
\end{aligned}
$$

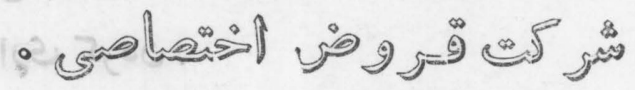

(

discounting the news.

- Vulis

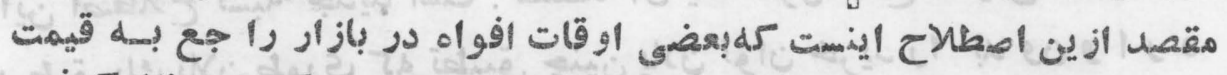

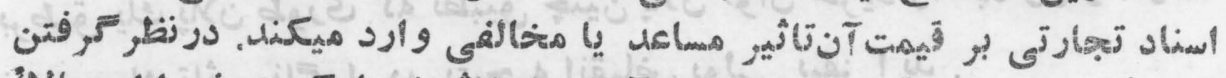

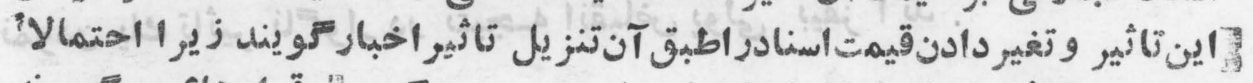

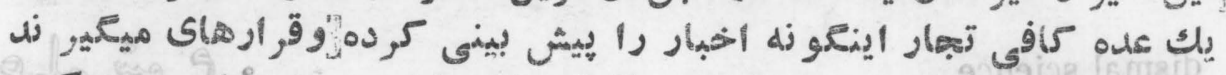

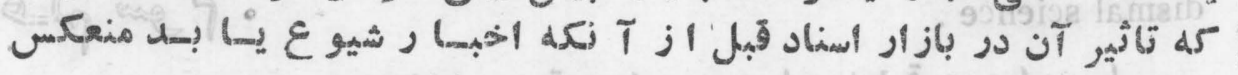

discretionary trust. $\quad$ - जo

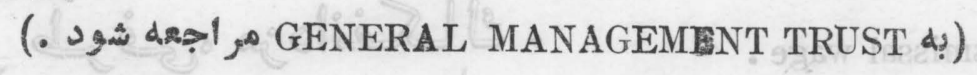
riminating duty. Uc (DIFFERENTIAL DUTY. شوله شود )

(c) $(p))]$ 
DIS

discriminatory taxation .

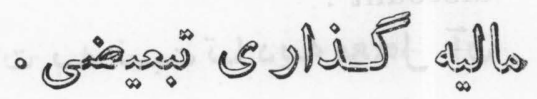
ماليهزتارى كه:بمنظور تشويق يأهنفعت رساندن بهبعضى صنا يع بعملمى آيد.

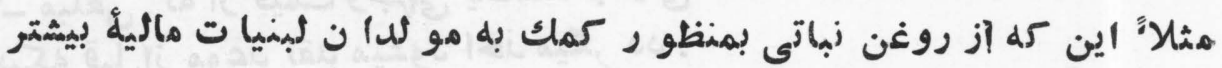

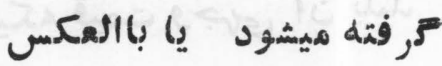

dishoarding .

- - O

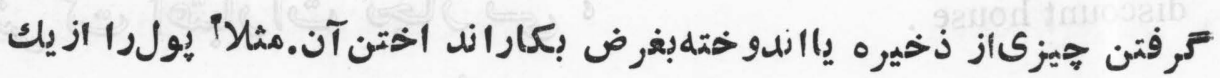

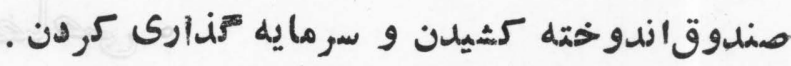

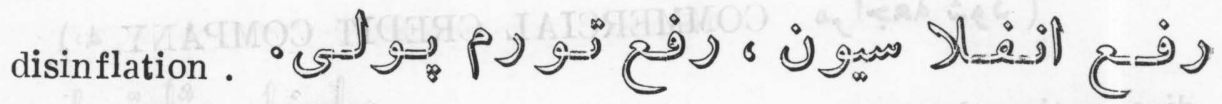
اين اصهالكاح نسبة" جديد است ـ مقصد آن يك تنزل سطع عمومى قيم است

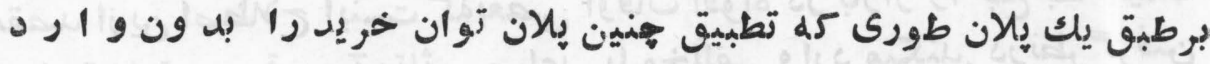

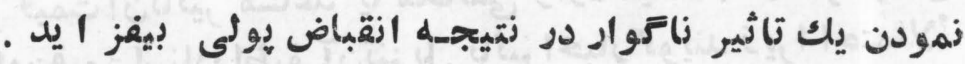
dismal science . - P

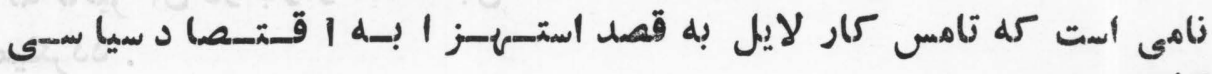

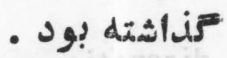
dismissal wage .

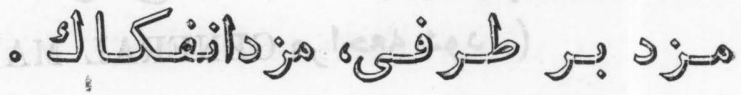

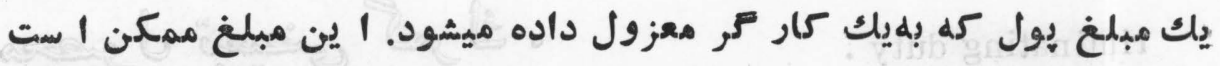

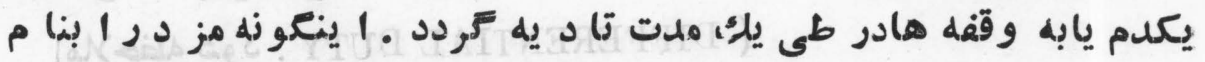

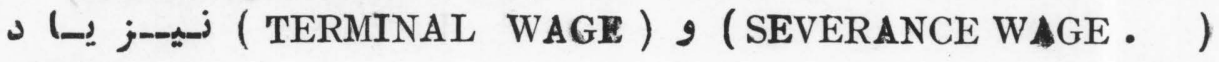




\section{DIS}

disposable income .

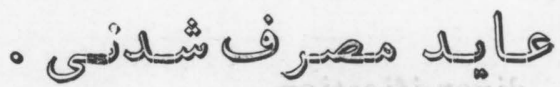
- Sـ آن مقدار عايد كه بعد از ثاديه ماليات شخصىوديع, زاديات بحكو مت بر اى

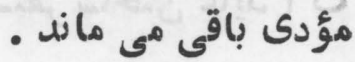

dissaving .

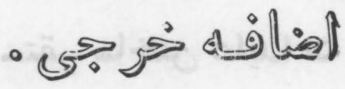

مصرف بيثتر از در آملد يا فاضله مصرف بردر آهل .

distributioñ .

$$
\text { - } \mathbb{C}=0
$$

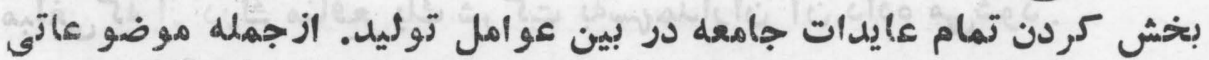

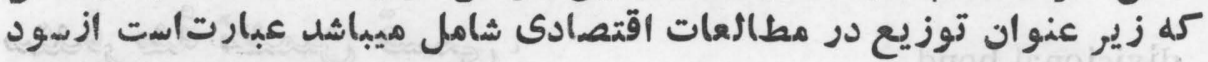

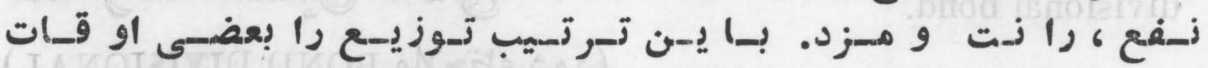

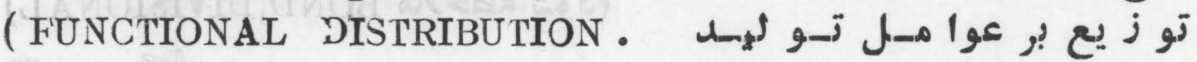
- F

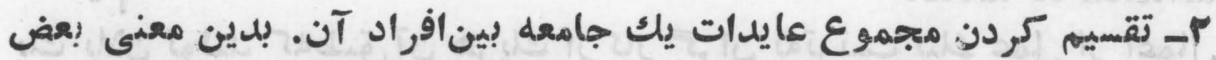

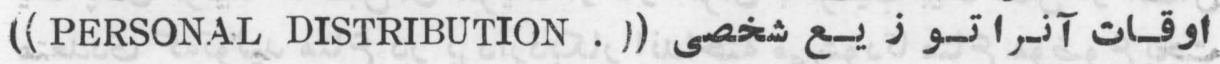

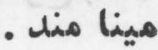

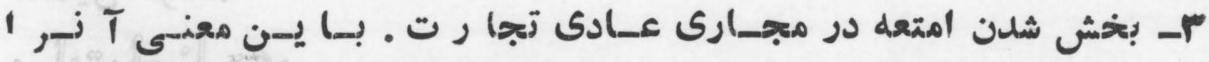

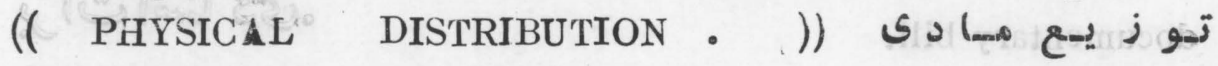
,

disutility .

-

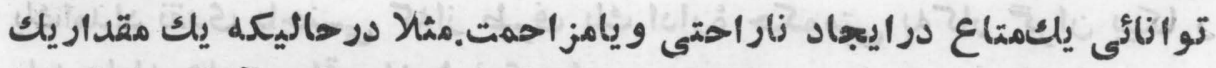

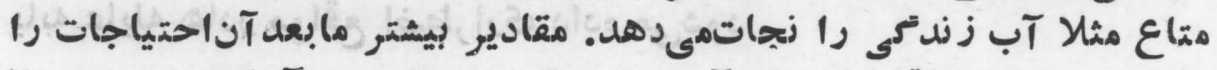

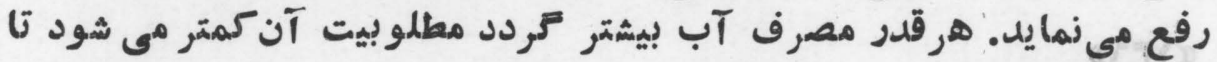

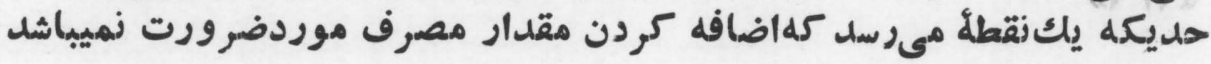




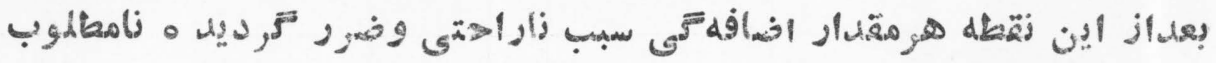

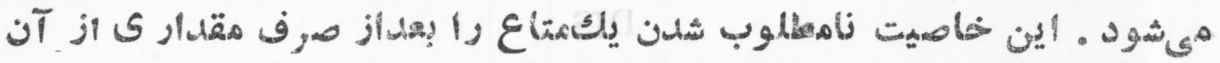

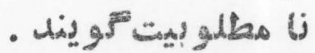

diversification .

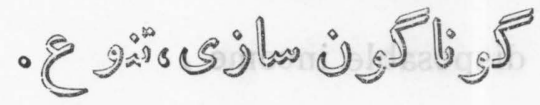

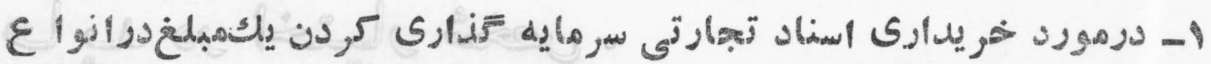

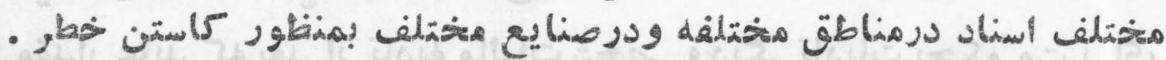

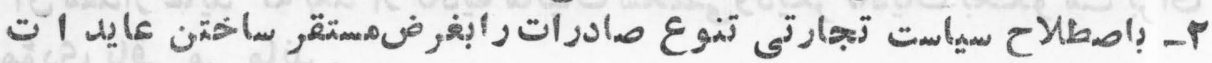

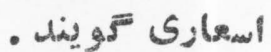

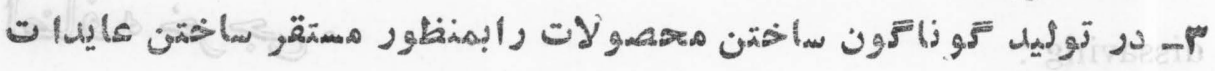

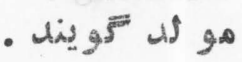

dividend,

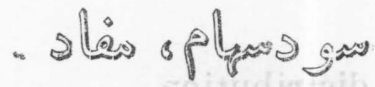

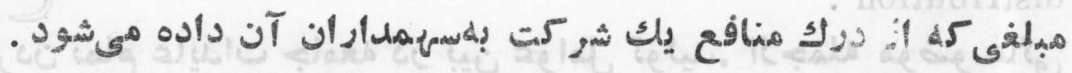
divisional bond. ى ى

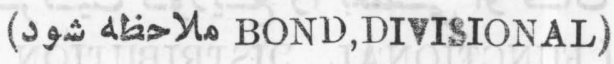

division of labor. - 15

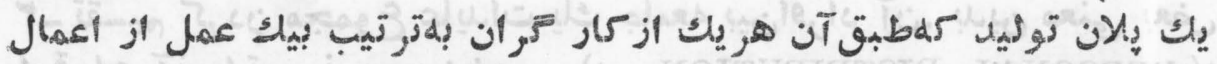

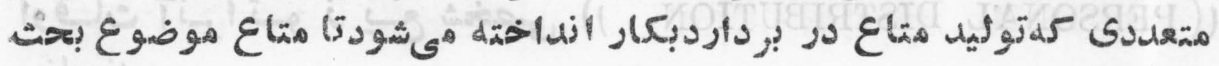
documentary bill.

$$
\begin{aligned}
& \text { تكميل تئرد } \\
& \text { - जs liandeी? }
\end{aligned}
$$

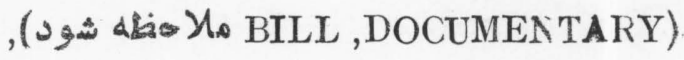

dole - Apglubloged?

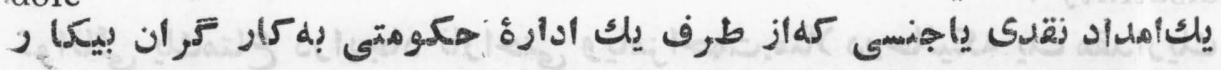

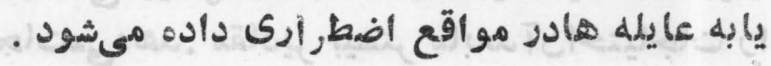


dollar deficit .

(t)

(DOLLAR (iAP d!دو da dra)

dollar exchange.

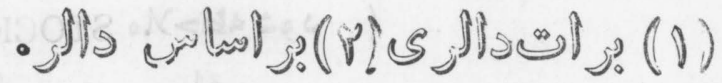

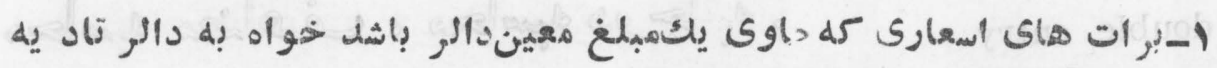

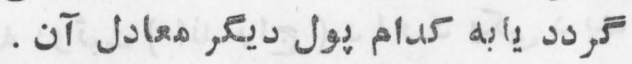

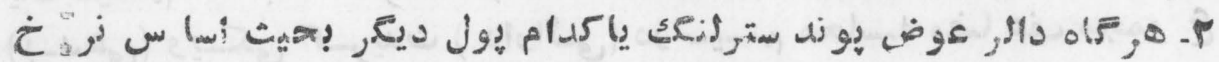

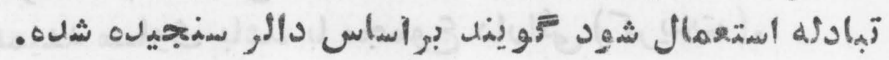

dollar gap $=$ dollar deficit

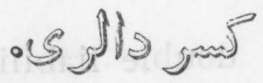

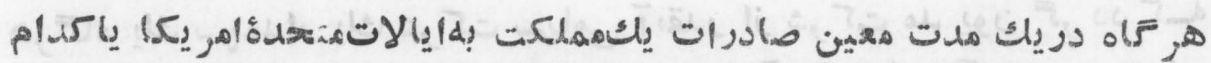

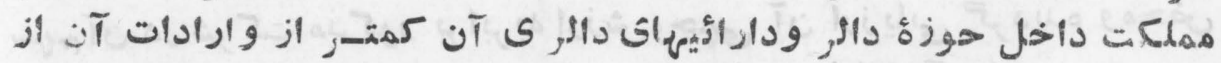

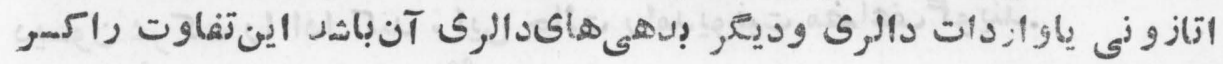
مارئر

domestic bill.

• .

domestic industry.

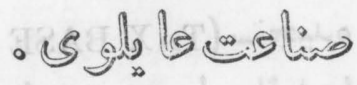
- شود مـ HOUSE HOLD SYSTEM

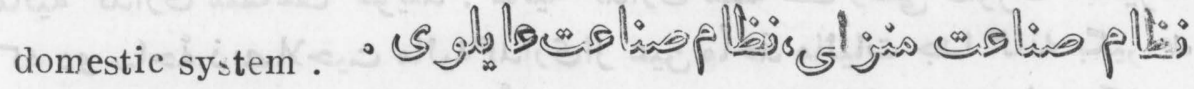

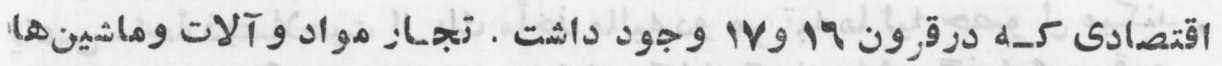

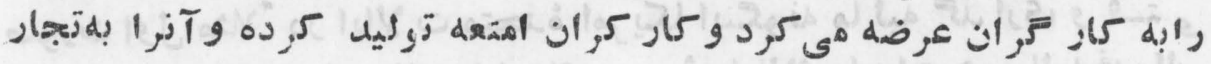
ميد الد دمار

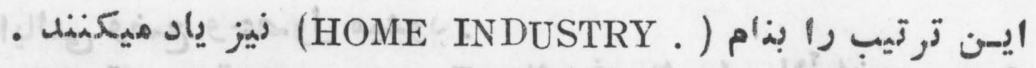

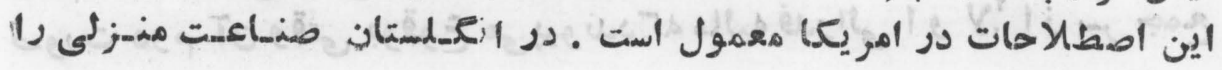


- (PUTTING OUT SYSTÊM)

donated stock .

$$
\text { - Gydedol proso }
$$

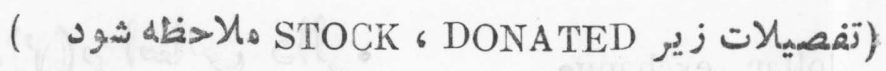

double entry .

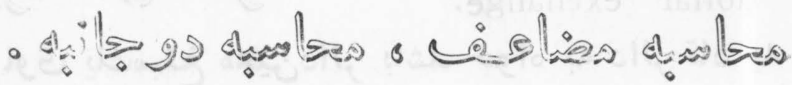

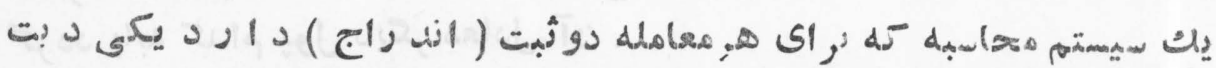

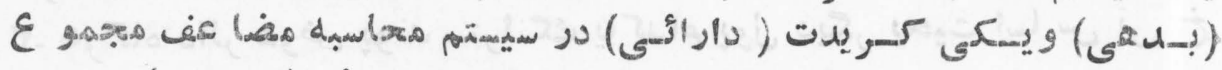

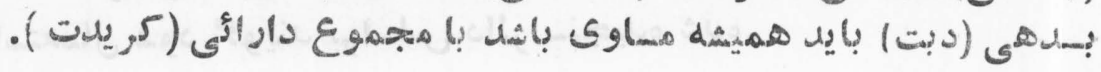

double liability •

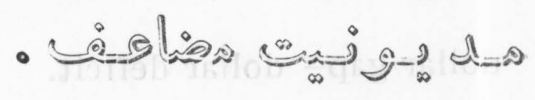

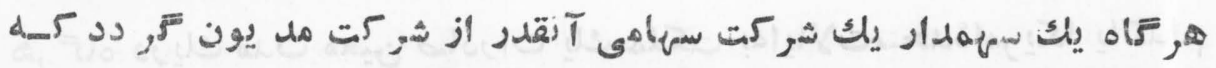

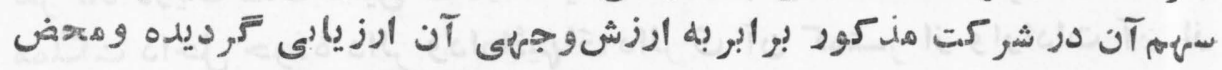

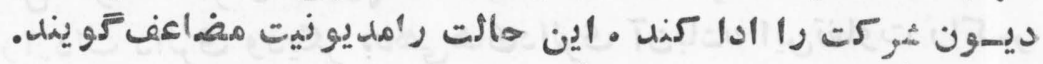
double standard .

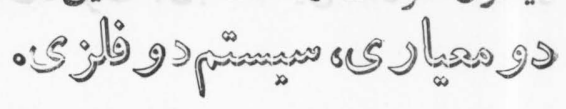
(BIMETALIISM . بود

double taxation .

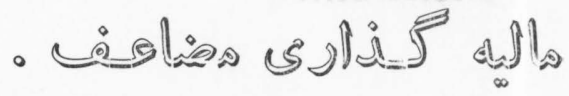

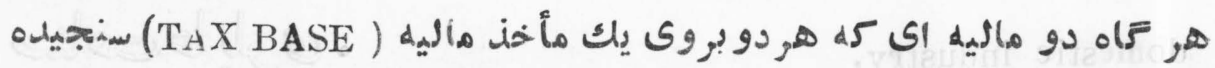

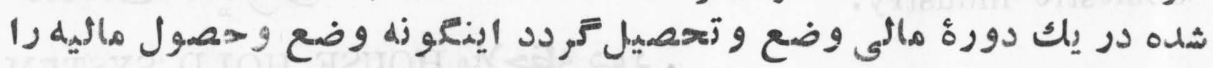

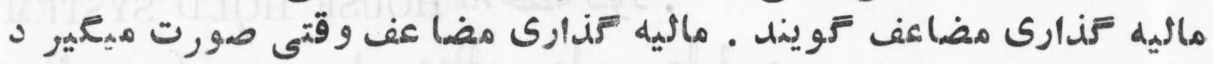

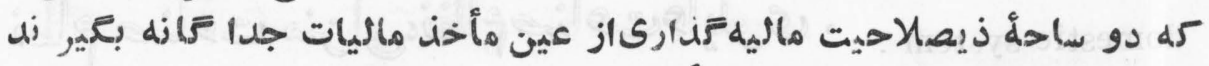

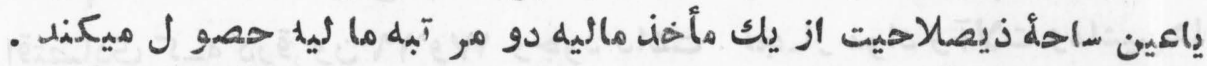

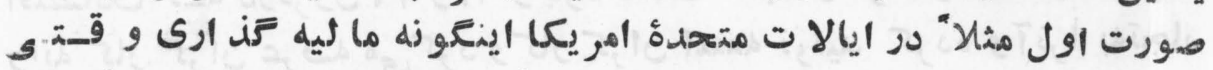

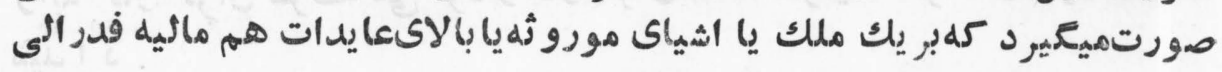

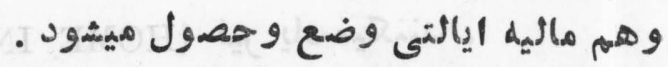

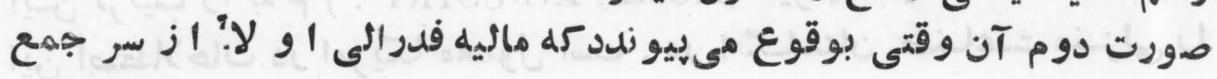

\section{()พค"}




\section{DRA}

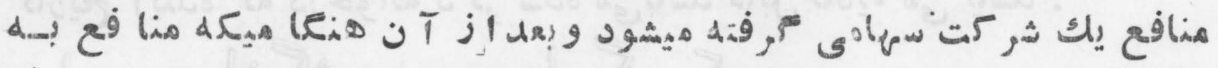

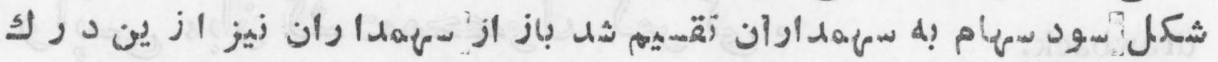

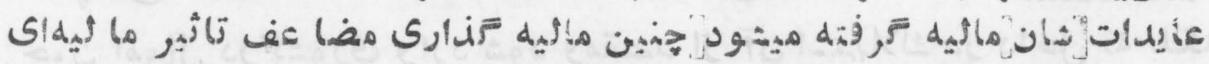

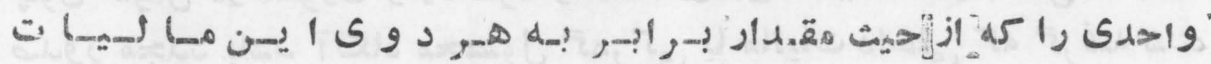
?

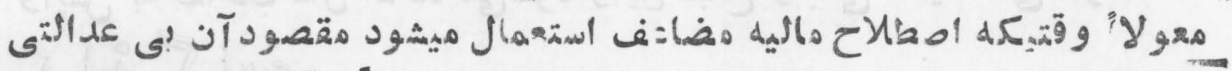

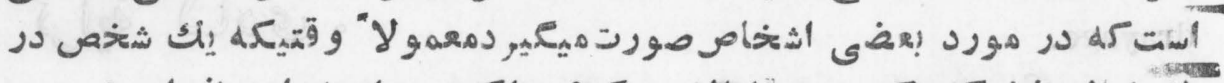

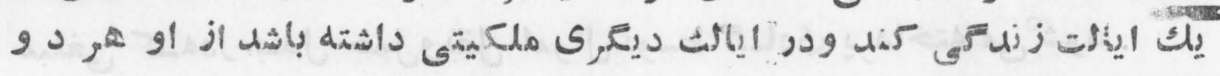
ايالت ماكيه ميعمير د . .

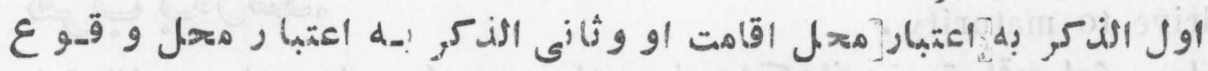
ملفيت اول

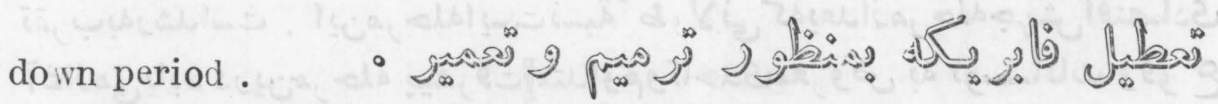

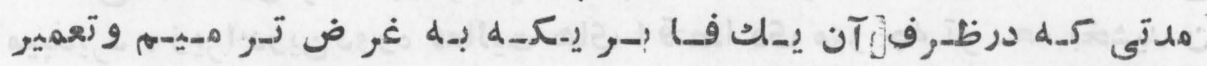

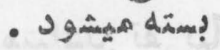
dow theory .

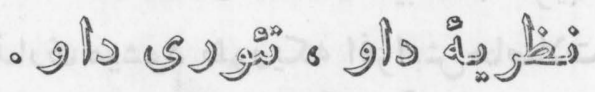

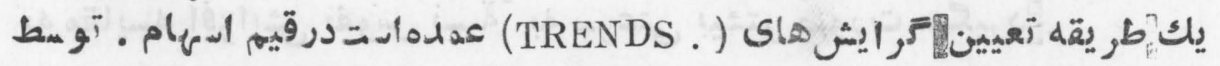

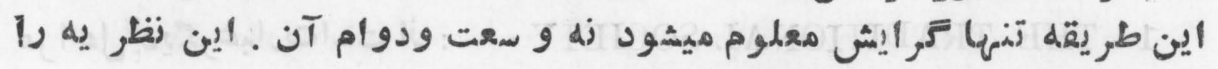

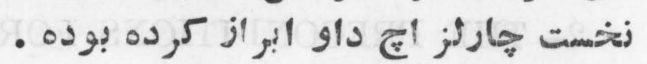
draft .

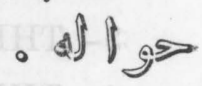

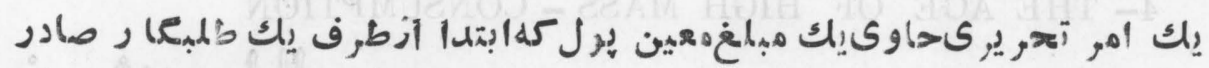

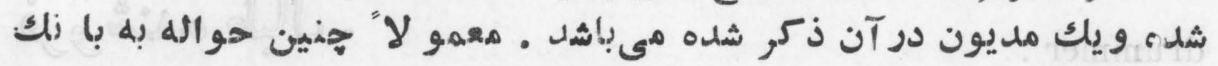

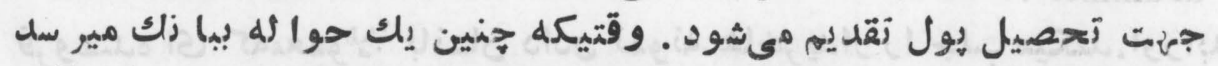

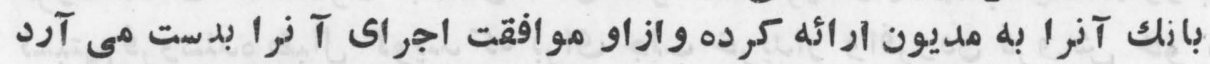

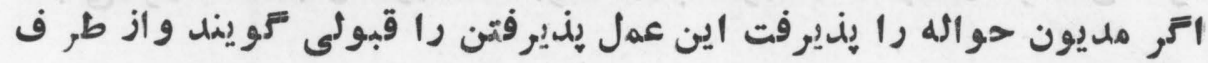

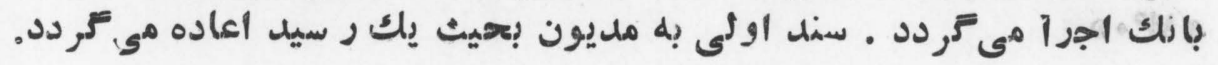


حهوا

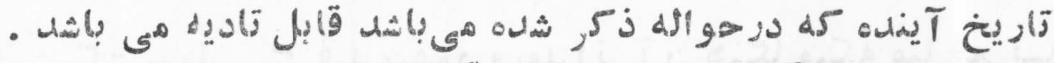

drawback.

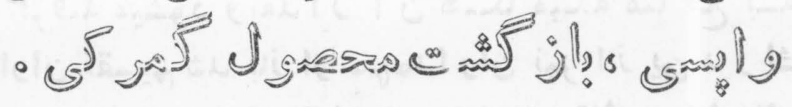

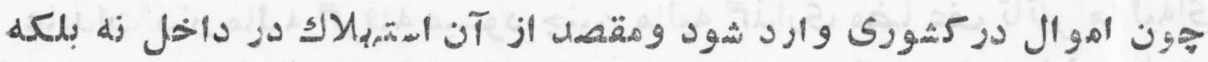

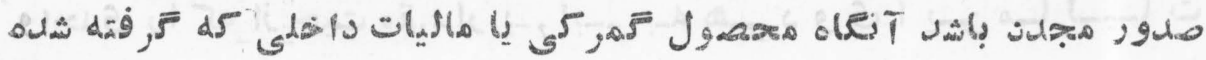

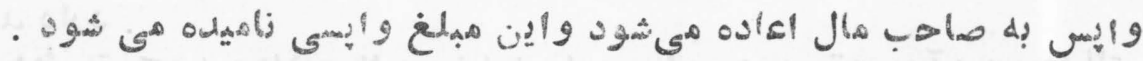

drayage.

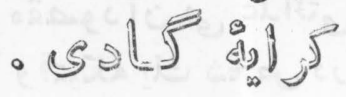

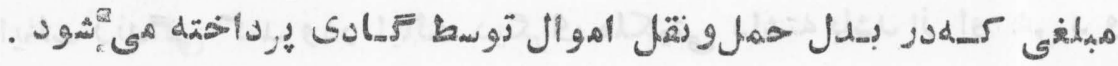
drive to maturity • Od总

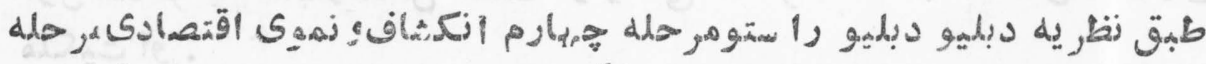

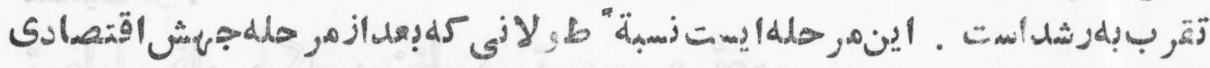

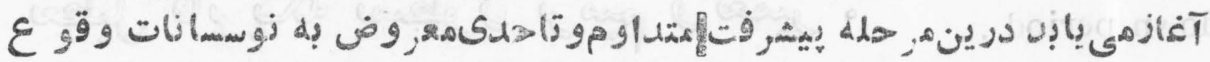

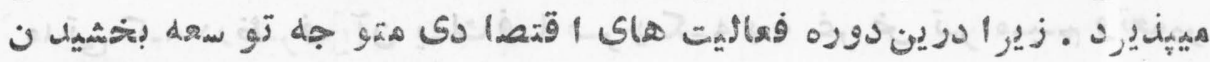

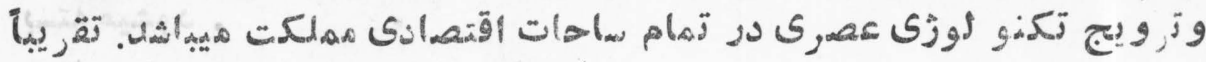

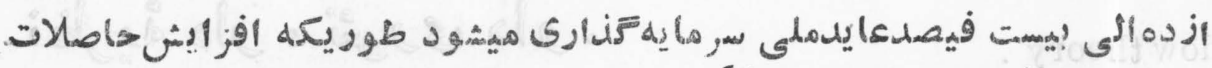

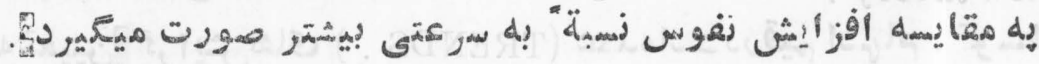

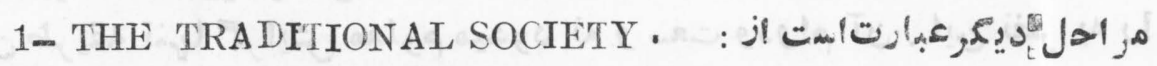
2- THE PRECONDITIONS FOR TAKE-OFF •

3- THE TAKE -- OFF

4- THE ACE OF HIGH MASS - CONSUMPTION

drummer .

- Jub od:

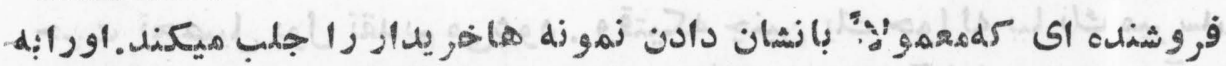

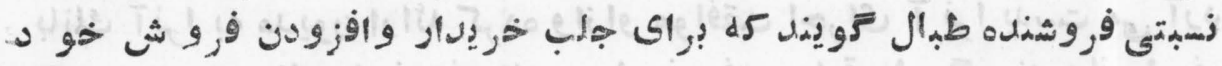

\section{(IP.)}




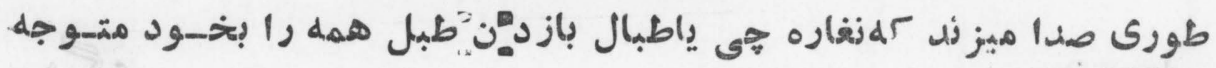
ميسازد.

dry farming .

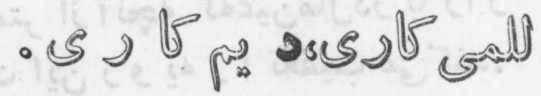
تمام آن طرق زراعت راتو يند كلدرزمين هاى نيملباير صورتميعير ن. درجنين

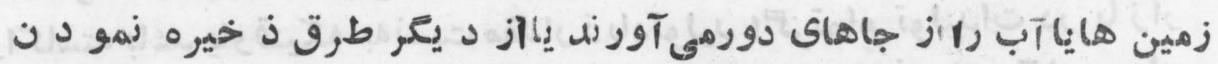

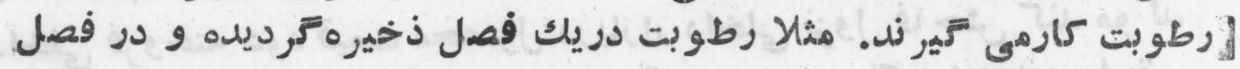

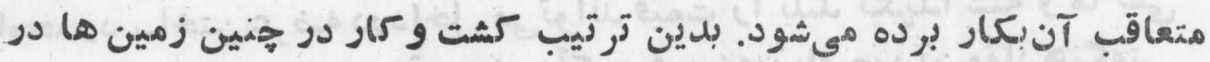

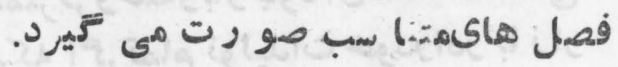

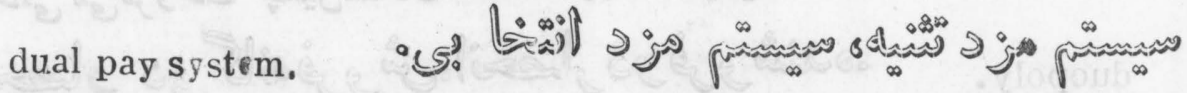
يك طر يقه سنجش مزد كار تر ان استدرشر كت هاى حمل و نقل . اينطور كه

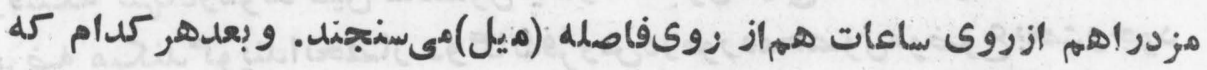

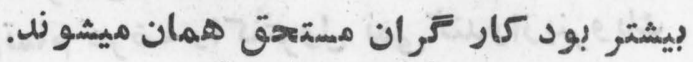

dummy in corporators. ن - ज

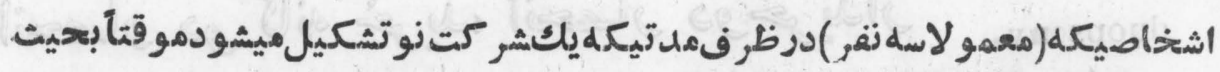

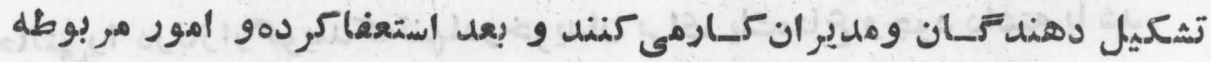

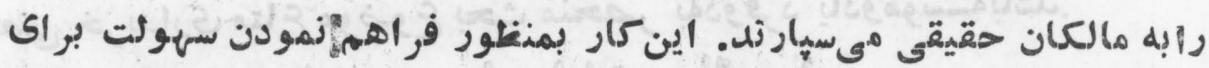

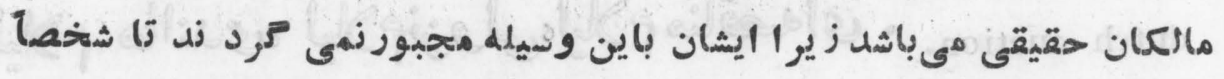

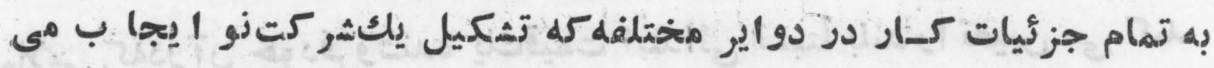
كند رسيدكى كرده وحاضر شونل. 


\section{DUM}

dumping •

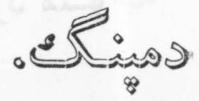

فروختن يكمال دربازار خارج بيكقيمت كمتر از آزحها كهئهينمالردر بأ زار

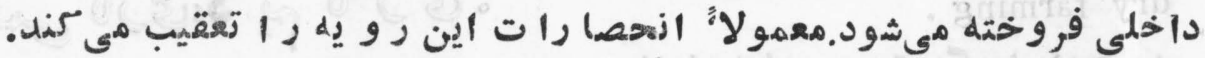

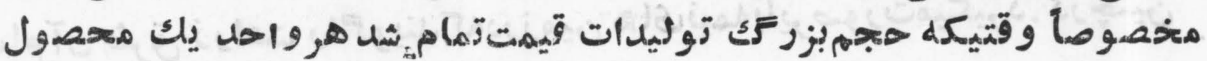

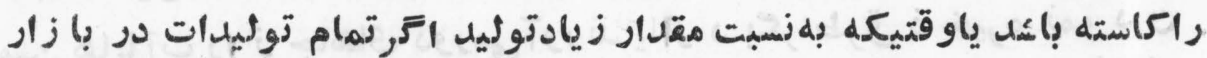

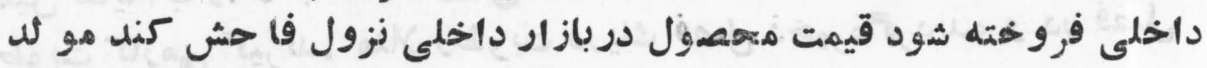

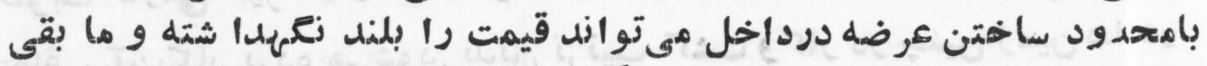

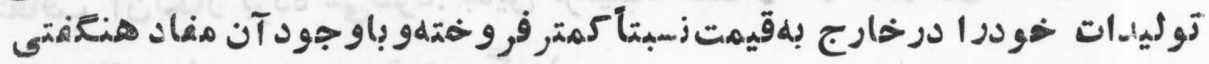

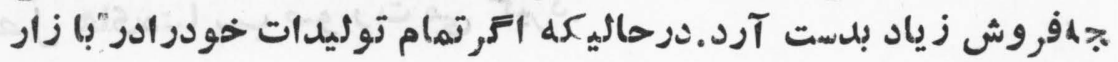

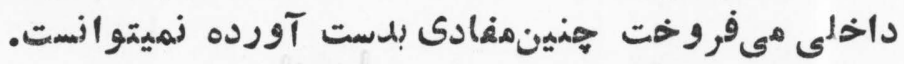

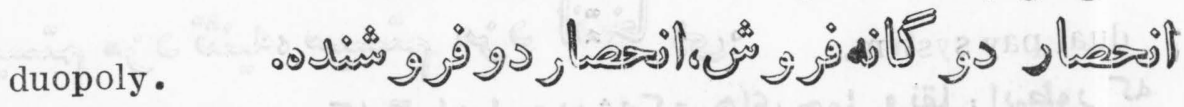

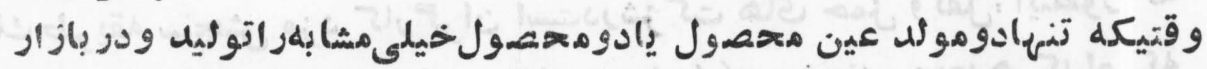

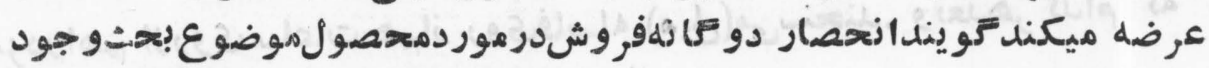

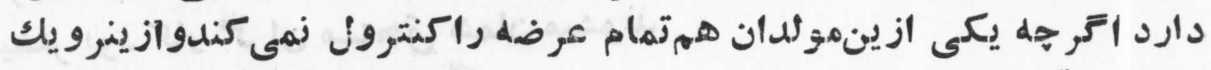

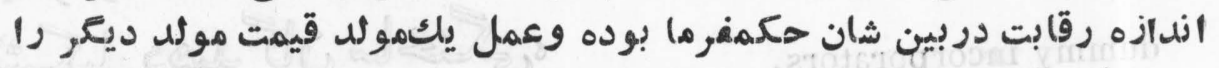

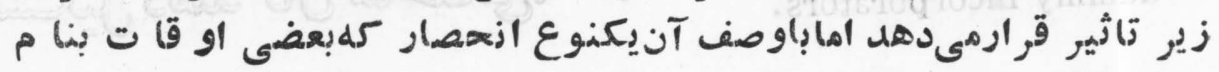
انحصارقسمى . ياد مي فيوددر بازار بنظر ميرسد.

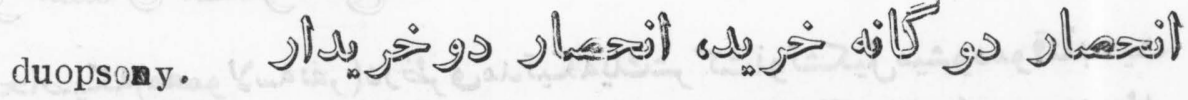

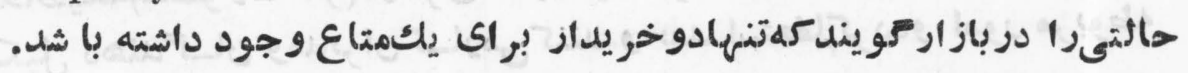

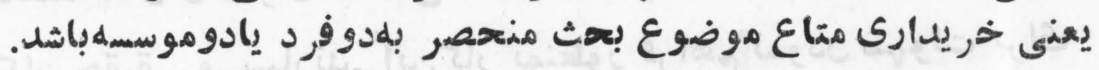

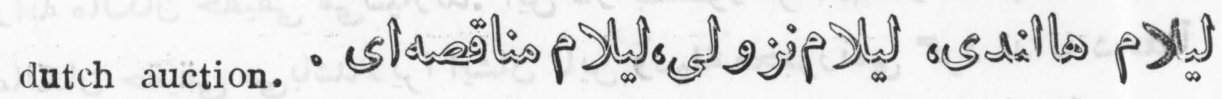
كيلاعى كهدر آن خودفروشنده يكقيمت ابتـدأى نسبةأ بلمند را تعيين مى كند

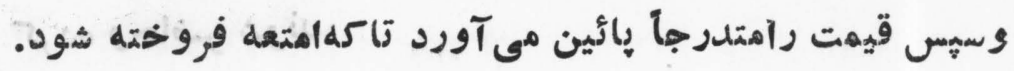


DYN duty.

- Sी

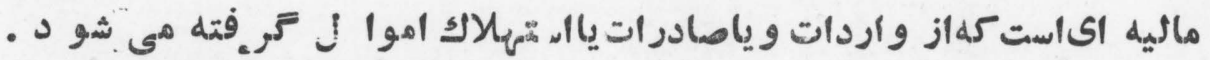

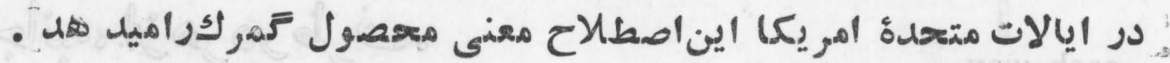
dj namic economics or dynamics -

- ك

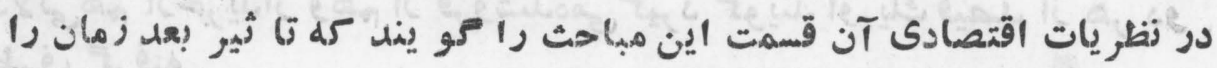

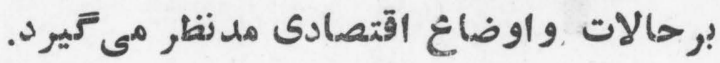

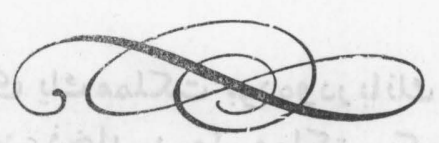

- blog bolusureg

smosni bomso

[(IPr) 
each way.

$$
\text { - . }
$$

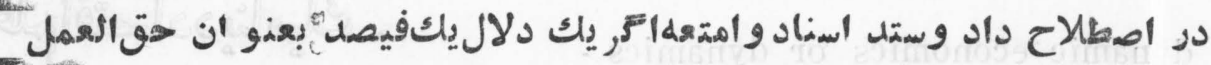

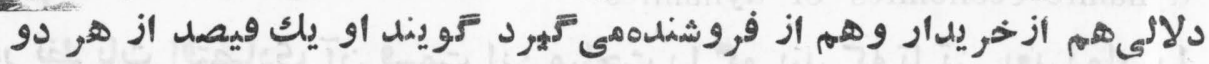
帠

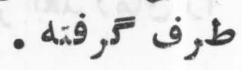

eagle •

- जs

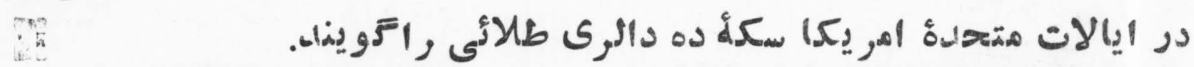

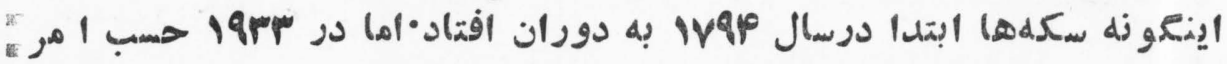

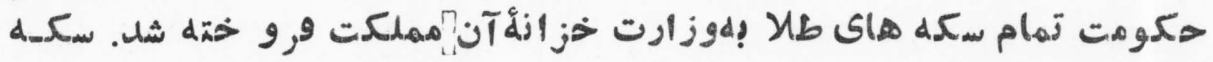

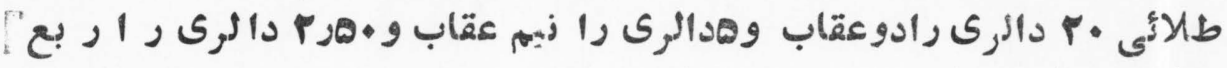

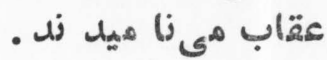

earmarked gold.

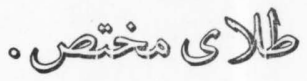

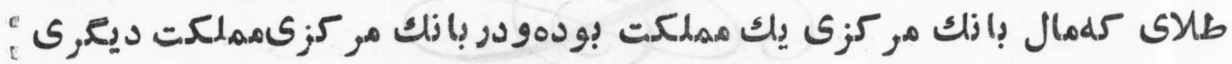

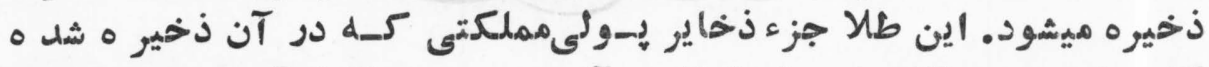

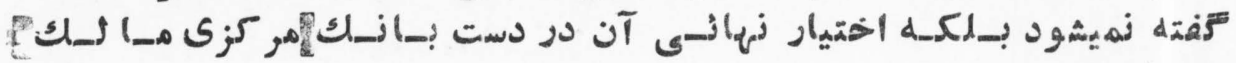
earned income.

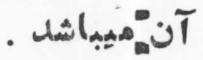

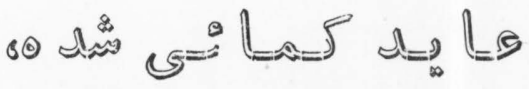

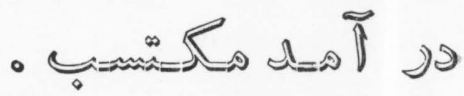

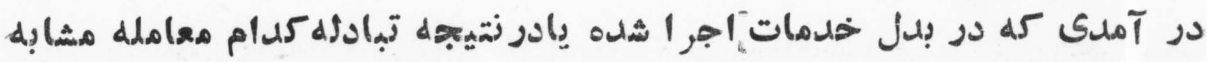

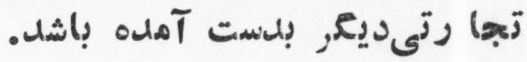


earned surplus.

- Caña silo

آنمنافع يكتصدى كه توزيع نعرديدهودر نتيجلففعاليس عادىتصدى موضوع

earning asset.

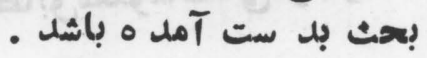
- ogi

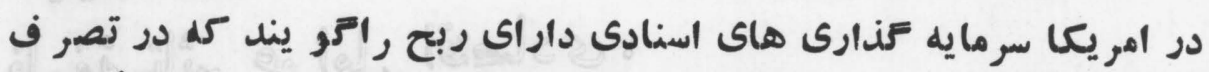

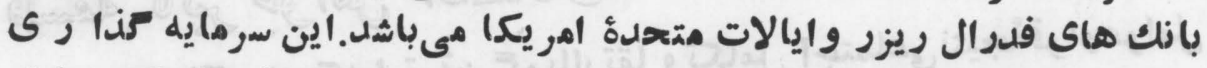

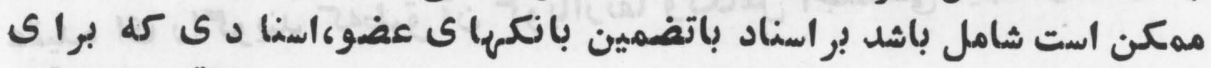

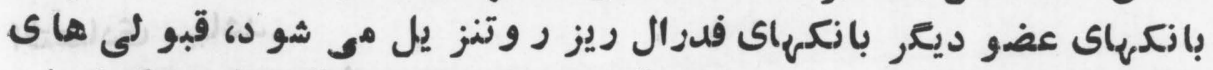

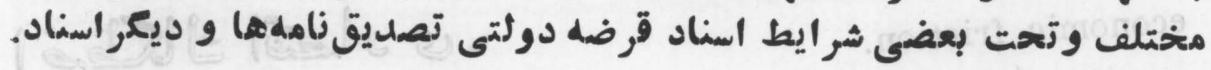
earning- capacity standard.

$$
\begin{aligned}
& \text { - जil } \\
& \text { - دماء }
\end{aligned}
$$

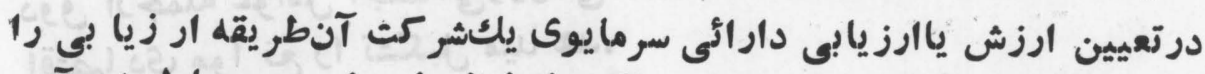

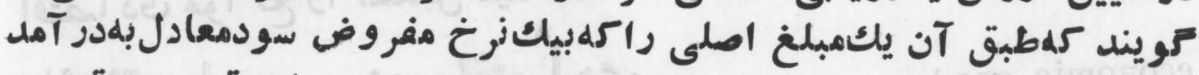

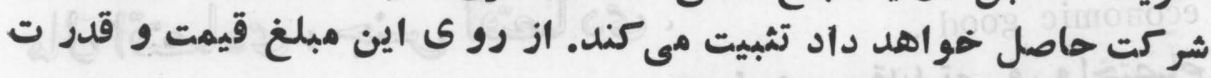

$$
\begin{aligned}
& \text { كمائى دارائى را ميتوان شوان تعيين كرد د. } \\
& \text { (نيز ملاحظه شود. VALUATION) }
\end{aligned}
$$

easement.

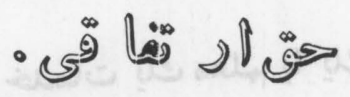

هر حقى كهبر اى يكشخص درملكيت حقيقى شخص دينرى قايل مىشو زن. econometrics.

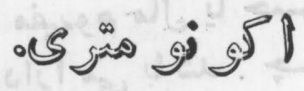

مقياسات اقتصادى كل بمنظور آزمايش كردن و انكدها ف دا دا د ن نظر يات

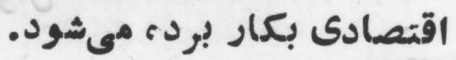

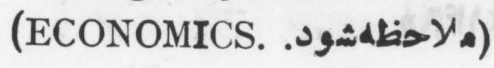


economic.

$$
\text { - S S }
$$

هر عمليه ياكارى كه باتخليق مطلوبيت يا خدمات جهرت تر ضيه 'امتيا جالت

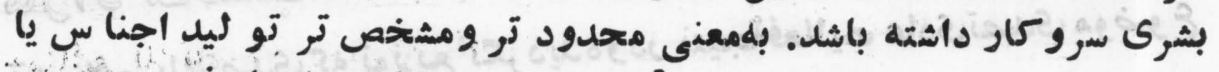

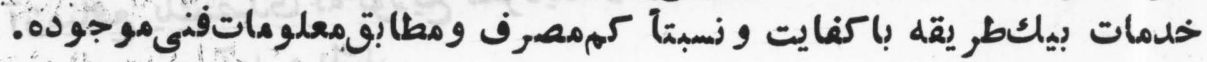

economic determinism.

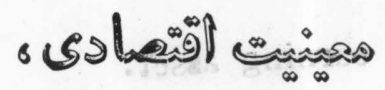

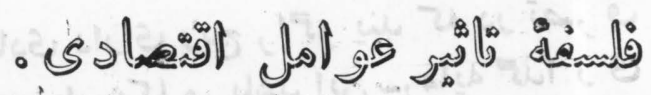
عقيده اى راتويند كلطبق آن Fوياارتقا وتعامل اجتماءي نتيجهةقواوعوامل اقتصادى ميبهاشد.

economic friction.

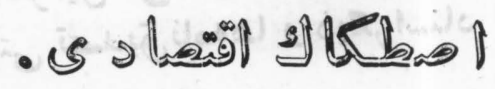

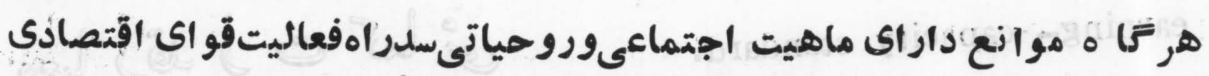

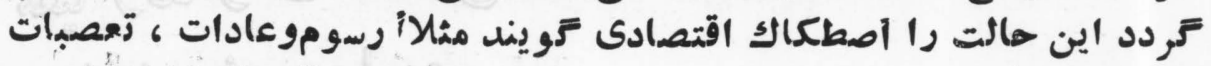

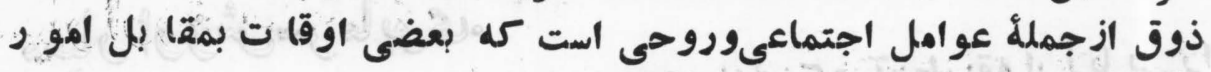

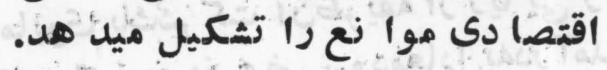

ecoñomic good.

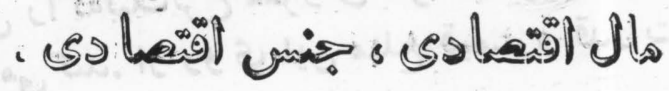

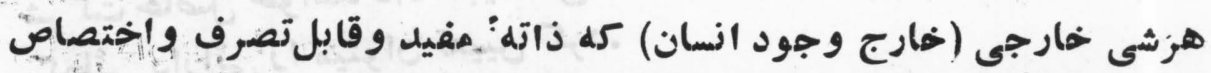

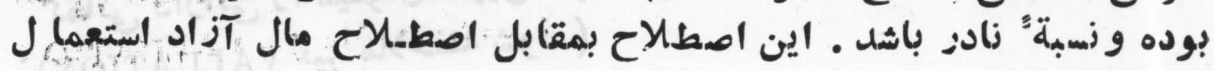

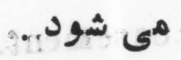

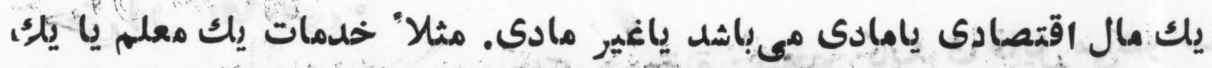

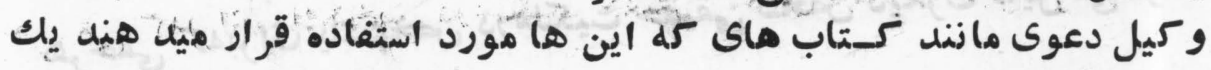

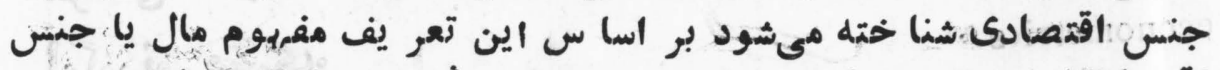

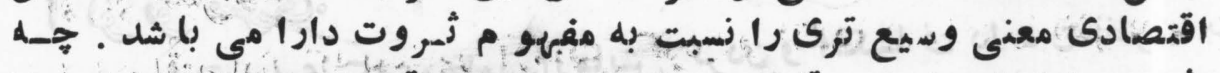

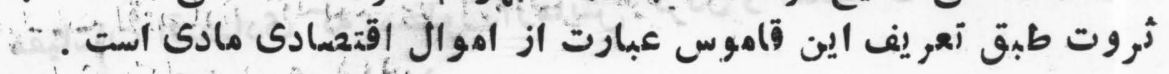

a) 157 
economic harmonies .

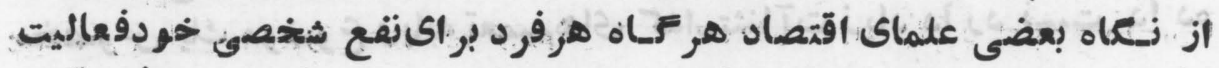

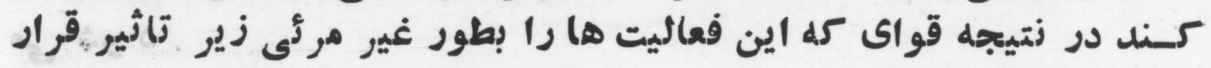

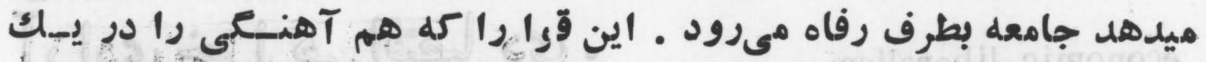

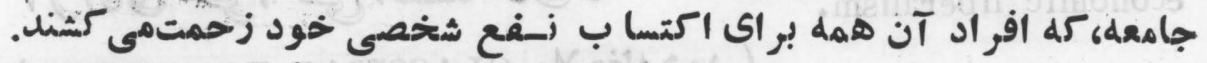

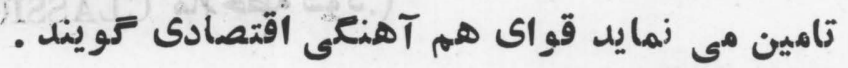

economic imperialism.

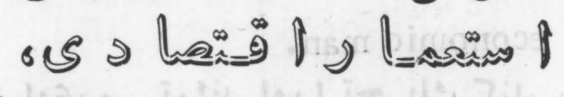

- जsha

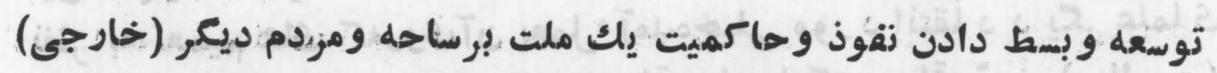

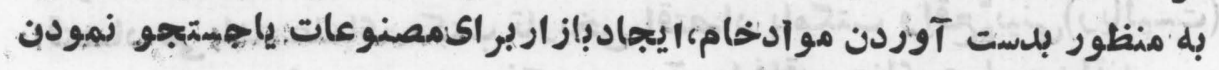

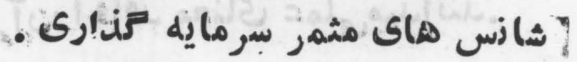

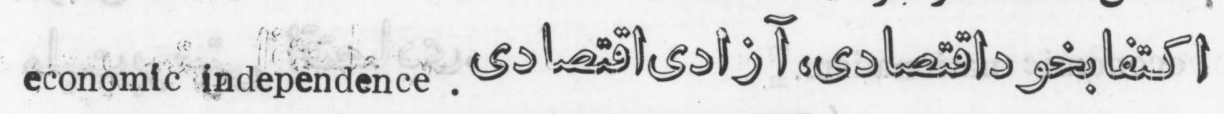
(ب. A economic interpretation of history. -

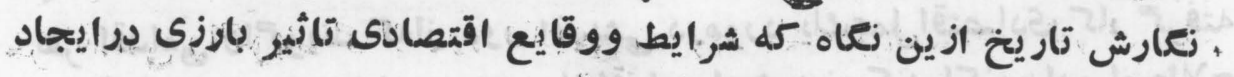

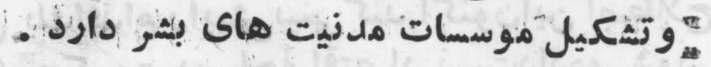

economic law

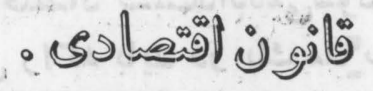

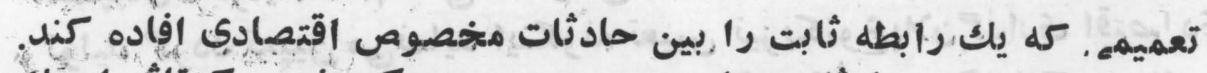

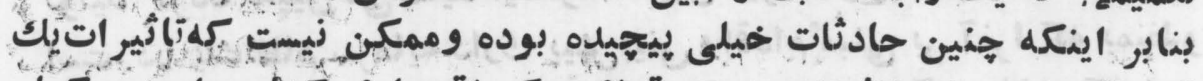

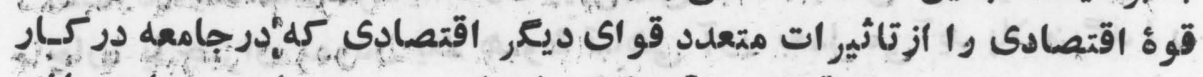

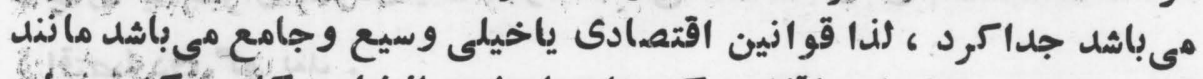

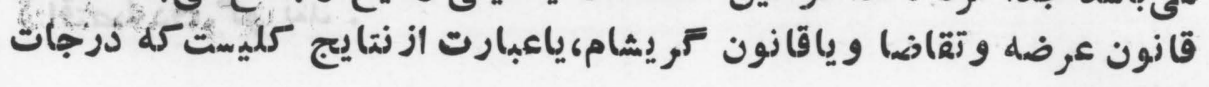




\section{ECO}

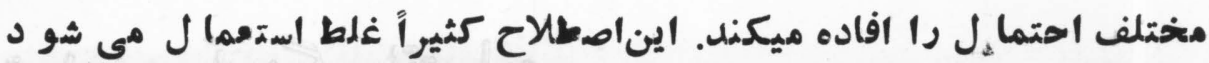

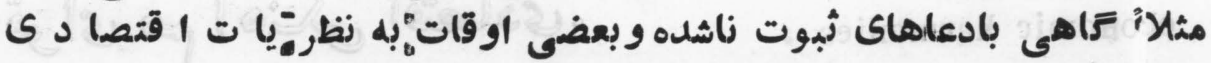

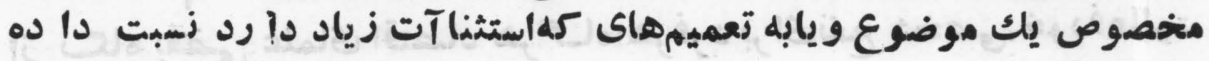

economic liberalism. (ملاحظه شود. CLASSICAL ECONOMICS.) economic man. - va

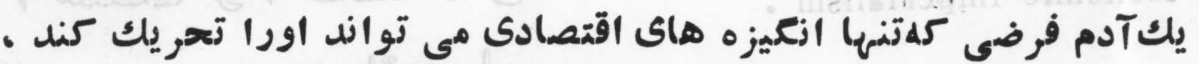

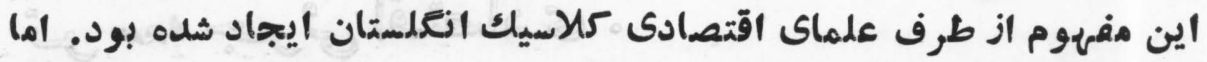

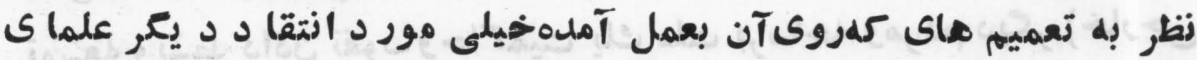

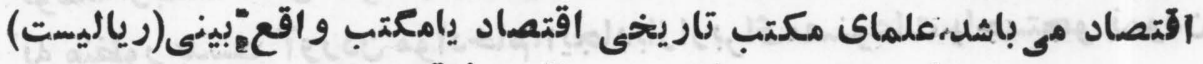

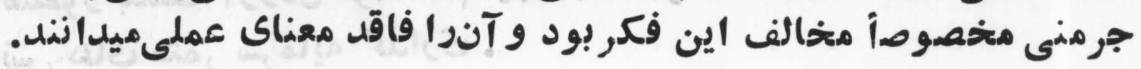
economic nationalism. هال

(مر اجعه شود به (مله economic planning. - जs (1)

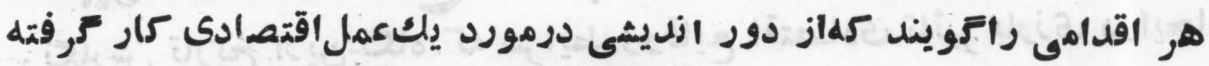

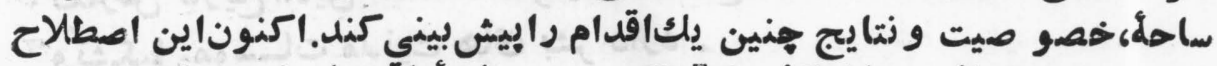

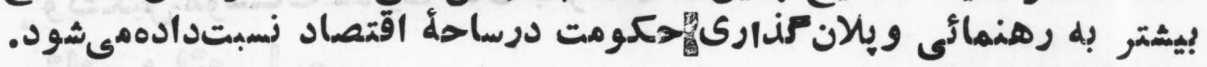

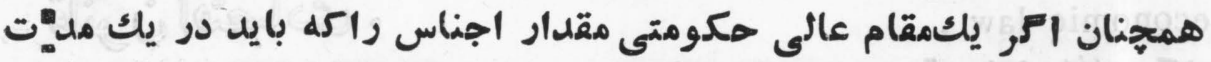

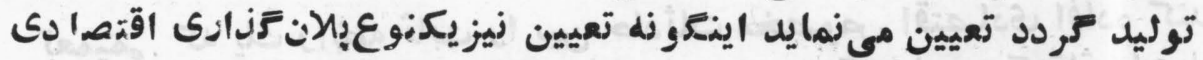

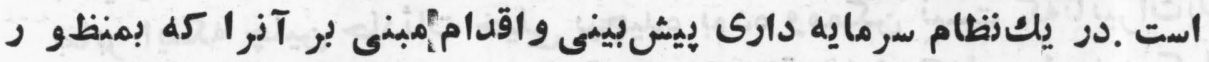

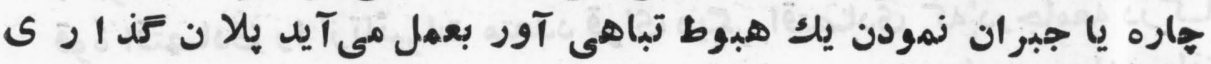
اقتصا دى Fو ينل . 
economic rent .

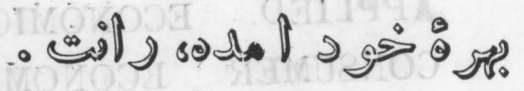

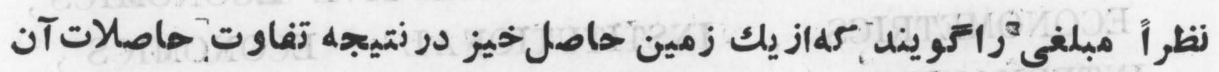

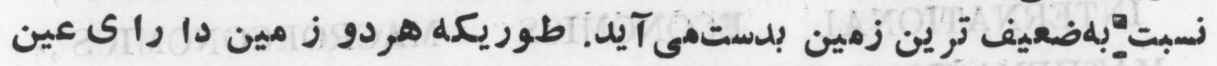

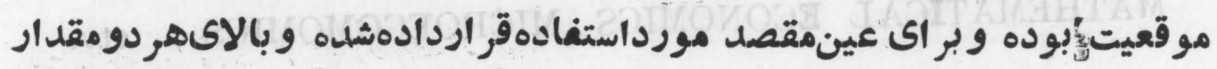

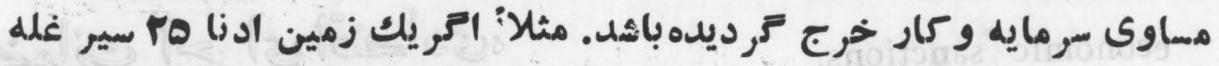

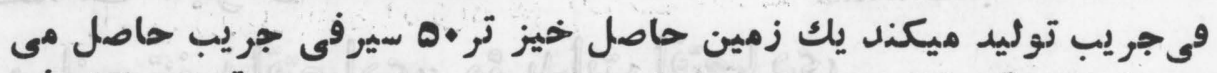

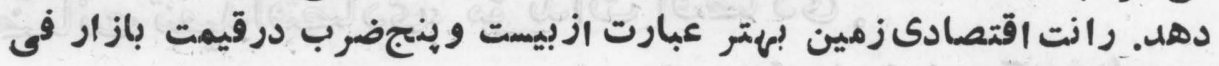

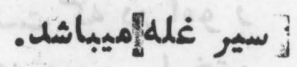

باين هعنى ظرفيت توليدى زمين ممكن ازهندنعاه افاده ترودد.مثلكا "از زعاه

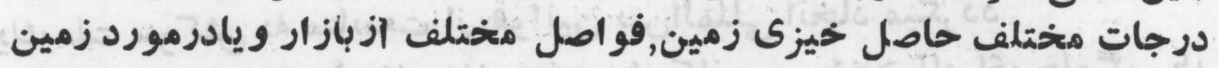

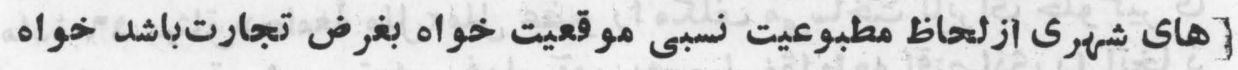

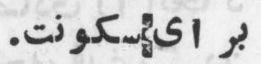

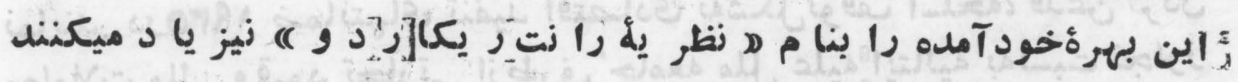
( RENT.)

economic royalist.

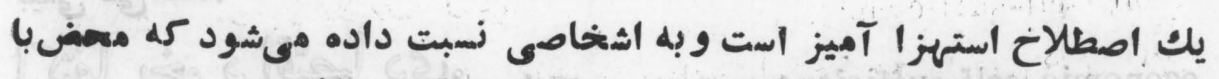

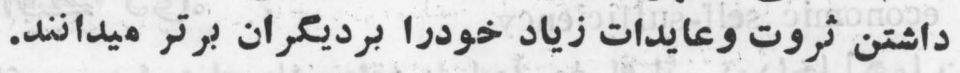

economics.

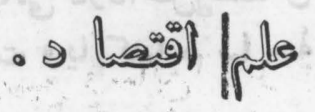
علمى كه از توكيد وتخصيص اجناس وخدمات براىزئرفـع اهتيا جات بشرى

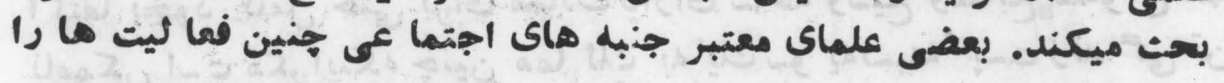

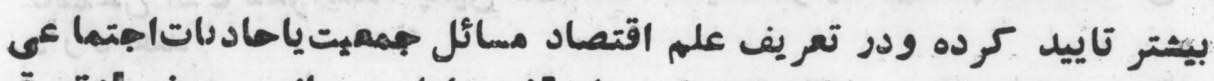

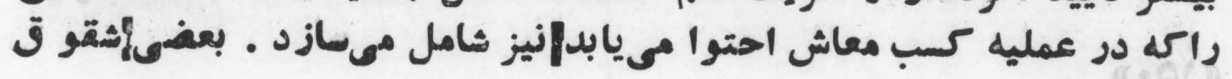




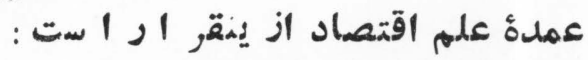
APPLIED ECONOMICS, AGRICULTURAL ECONOMICS ، CONSUMER ECONOMICS, DESCRIPTIVE ECONOMICS, ECONOMETRICS, INSTITUTIONAL ECONOMICS, INTERNATIONAL ECONOMICS, MACROECONOMICS, MATHEMATICAL ECONOMICS, MICROECOMOMICS, etc. economic sanctions. जS,

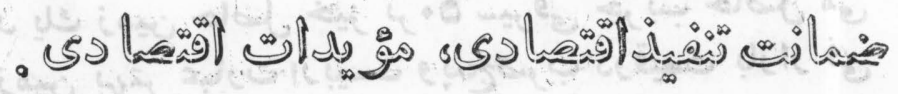

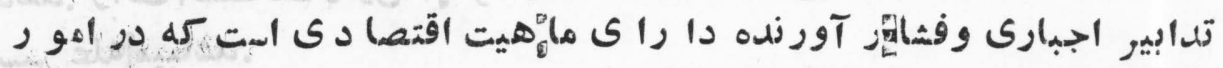

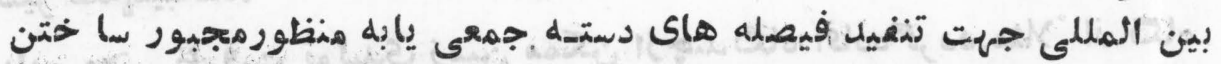

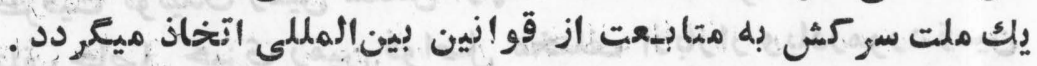

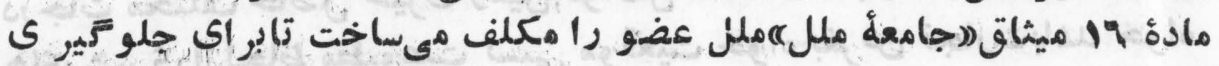

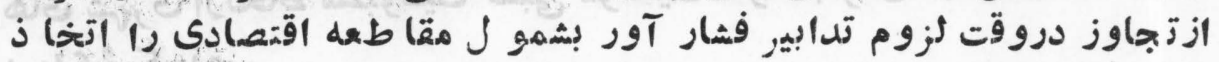

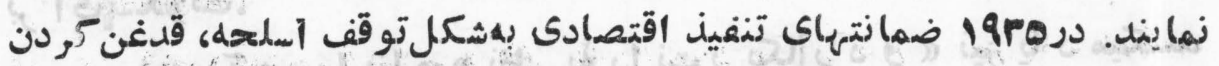

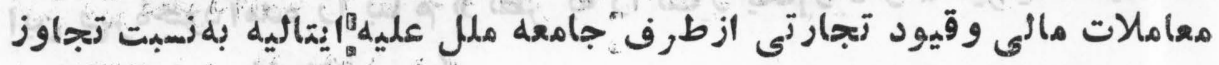

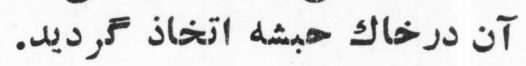

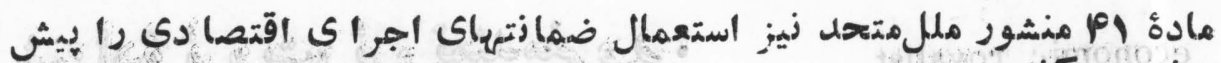

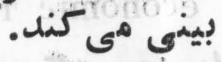

economic self-sufficiency.

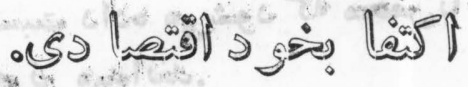

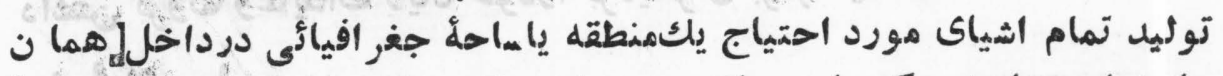

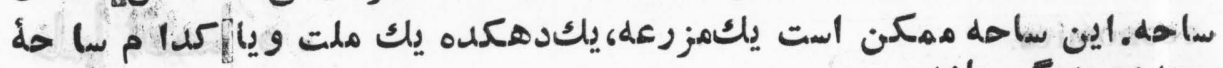

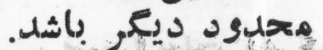

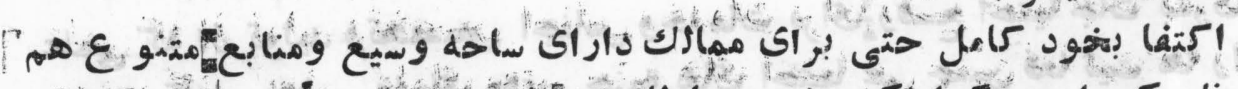

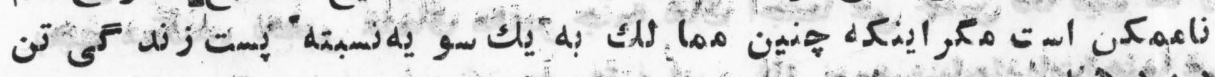
ins is 5

(10.)

4896 
economic system.

- SSL L

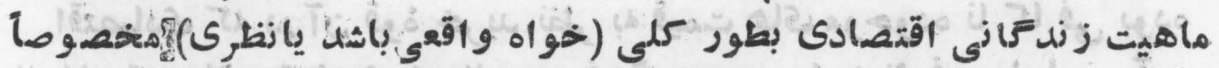

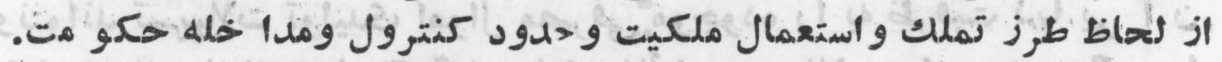
راجع به زظام هاى منغتلف إقتصادى اصطاحلاحساتذيل ملاحهظه شود: ANARCHISM CAPITALISM , COMMUNISM , SOCIALISM FASCISM , ETC.

economic union.

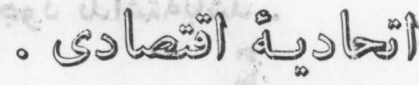

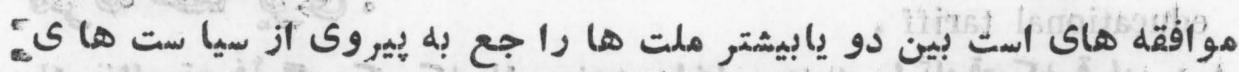

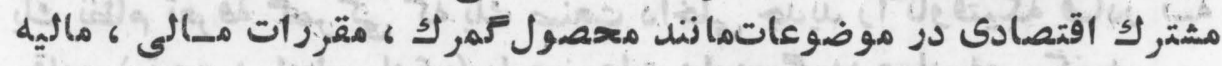

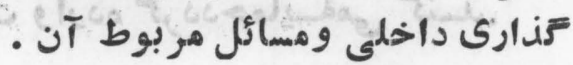

economic warfare. - ssliaid e

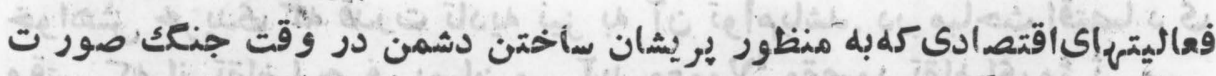

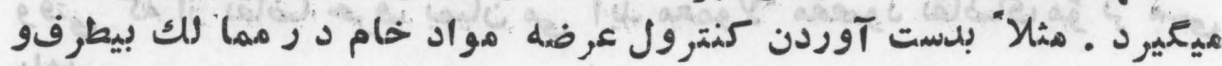

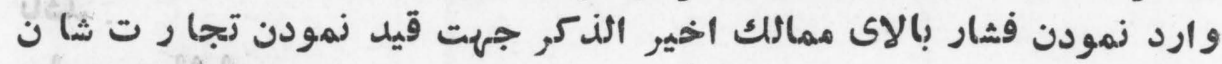

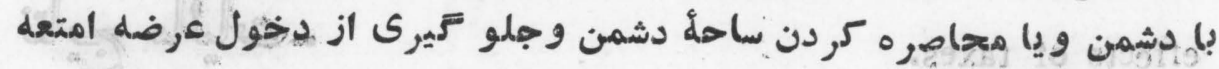

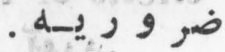
economic wealth. - vslaid $\underbrace{\infty}_{j=0}$

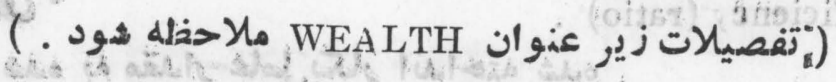
economy of abundancè

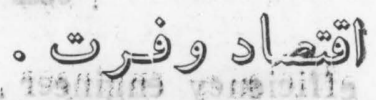

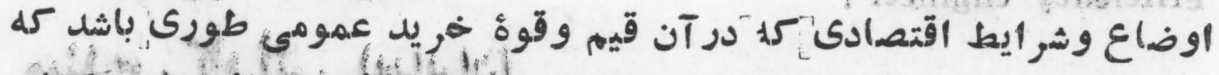

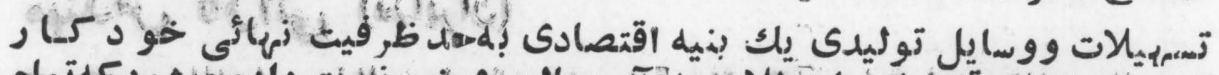

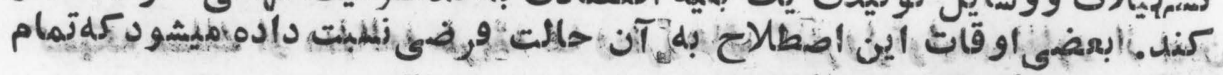

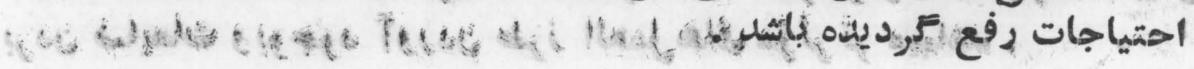


economy of scarcity .

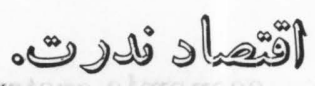

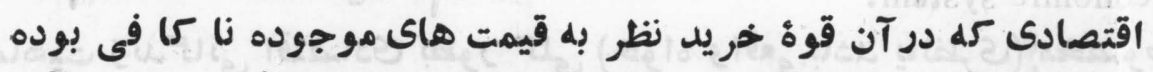

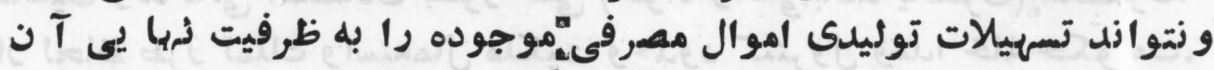

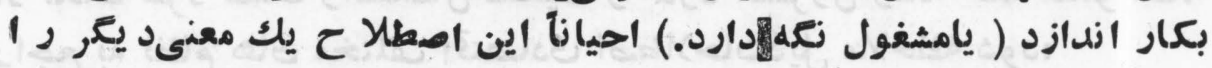

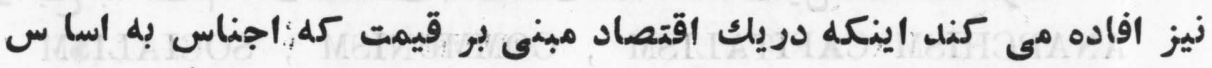

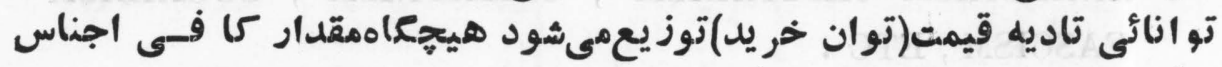

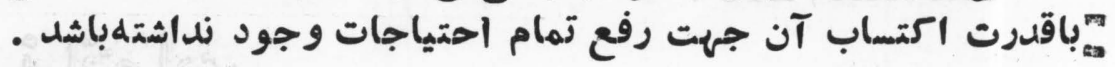
n

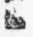

educational tariff .

- S

يك نظام تعرفو تمهر كى كه يك صنعت داخحلى جديل را تاوقتيكه قـادر بـه

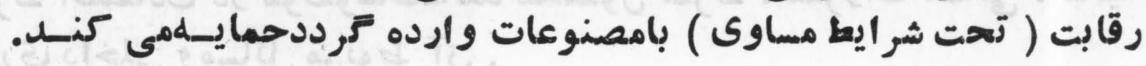

effective demand.

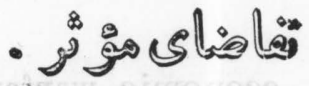

خواهش لحريدى كه قدرت تاديه نيز به آن توأمباشد. در مباحث اقتصا د دى

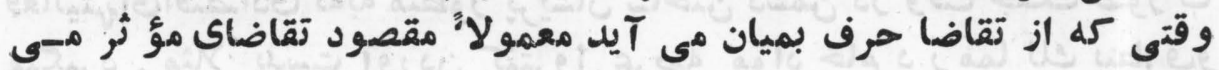
باهد. .

effects of taxes.

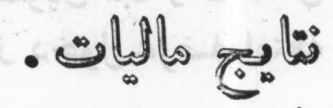

اثراتىاستزّمهماليات دراوضاعاقتصادىواجتماءى بوجود مى آورد.

efficiency (ratio) .

- ك

نسبت مقدار توليد دلده به مقدار عامل بعار انداخته شله .

efficioncy engineer.

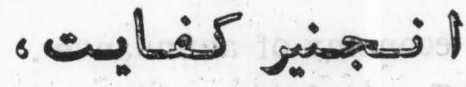

$$
\text { (درايران) }
$$

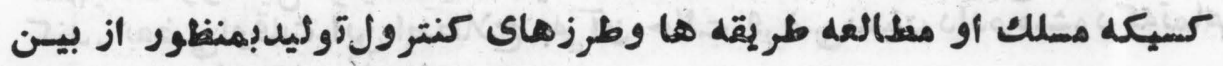

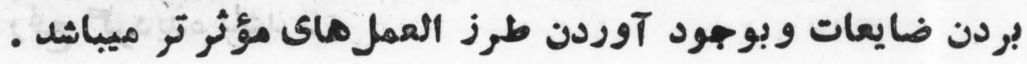

alop 
elastic demand .

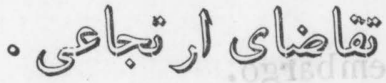

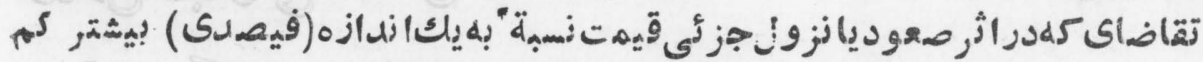

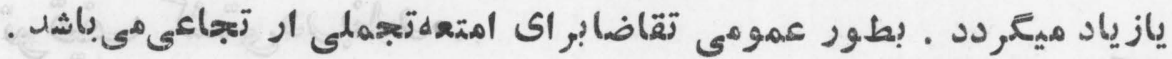
elasticity . -

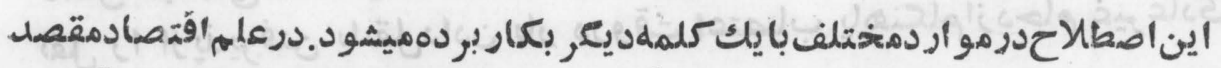

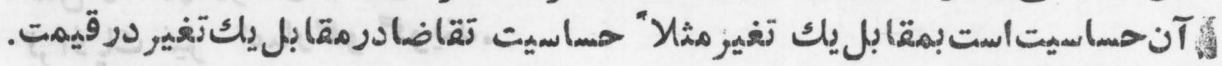

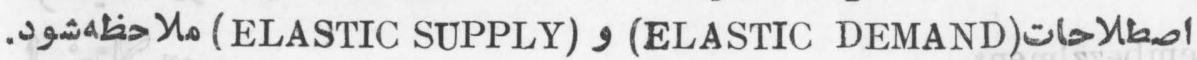
elastic money .

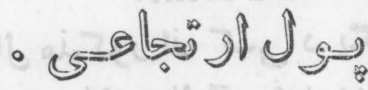

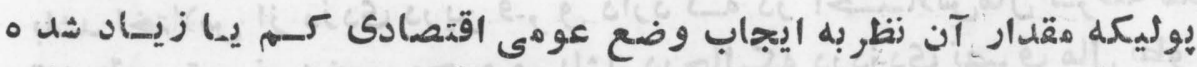

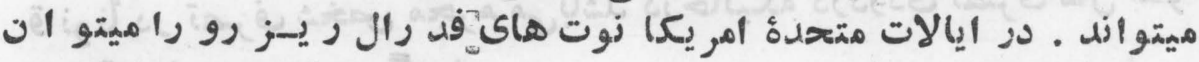

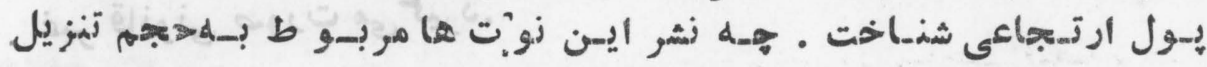

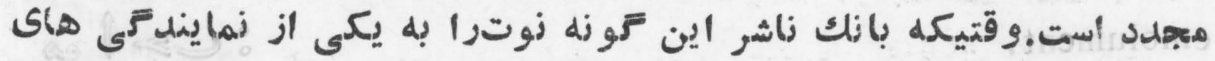

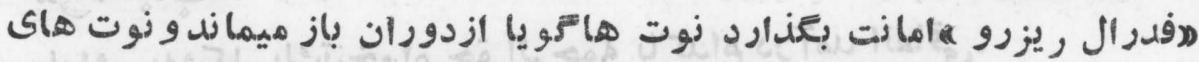

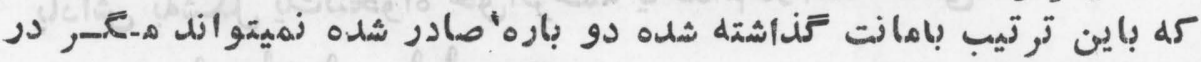

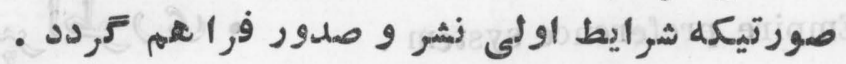

elastic supply . - قر

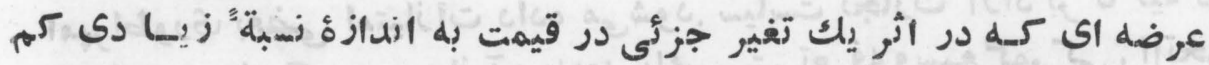
يازياد ميك.سردد .

eleemosynary corporation .

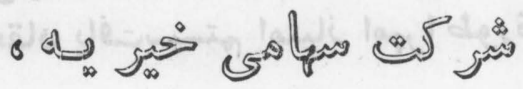

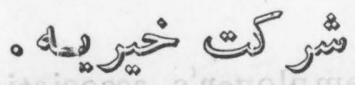

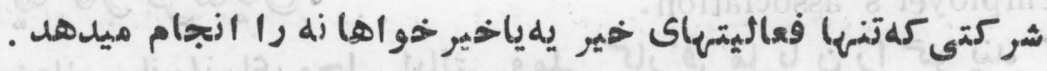




\section{LMB}

embargo.

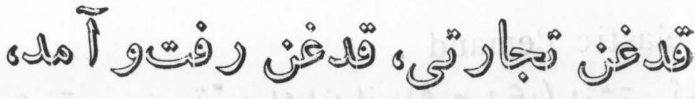

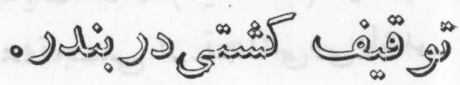

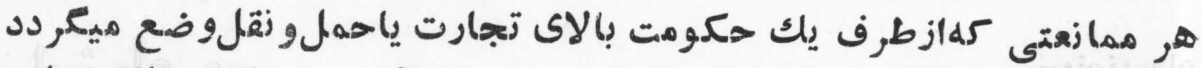

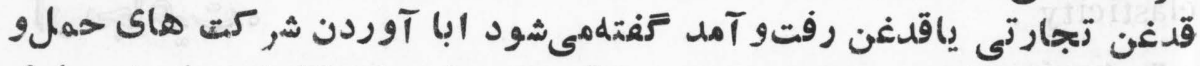

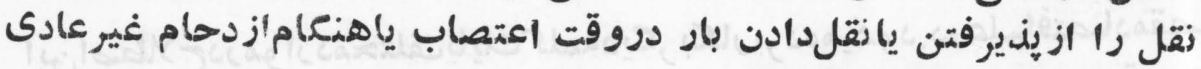
تر افيك نيز أمبار تمو توريند.

embezzlment .

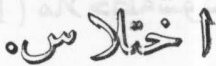

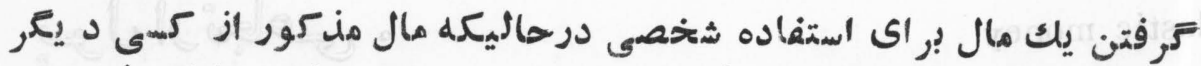

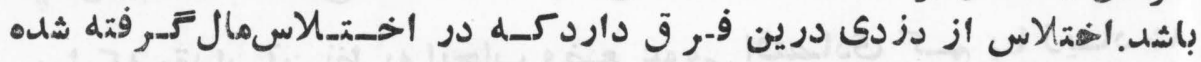

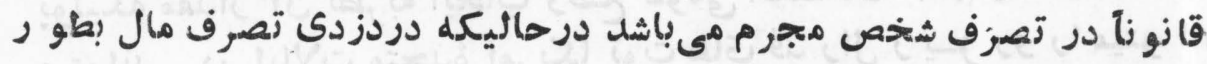
غير قانونى صورت من تحيرد. emolument. $\therefore \int_{0} \%$ هاداش بلهشعل يكتنخواه حقالزحمل ياكدام در آمد اتفاقى. Empire prefercnce system .

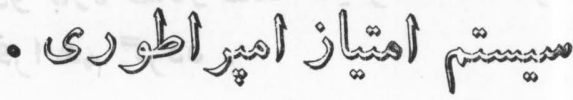

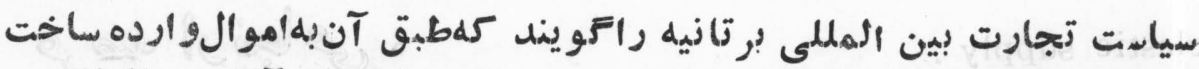

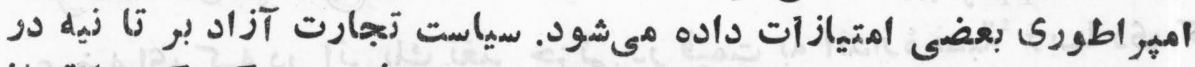

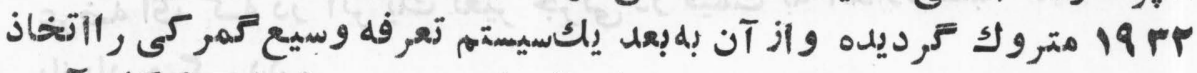

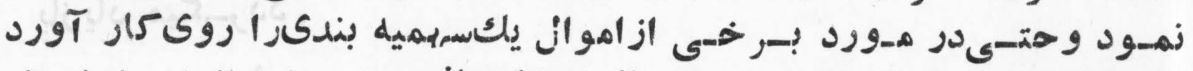

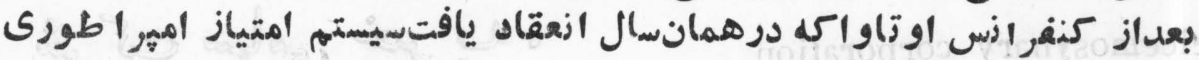
بيشتسر و سمحت داده شل .

employer's association.

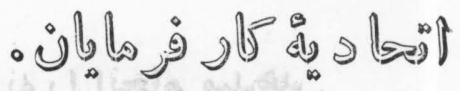

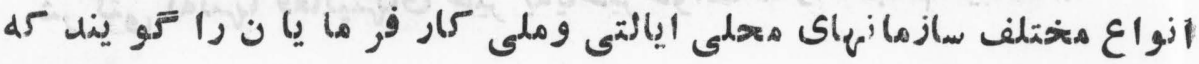
( $(\mid \nabla))$ 
بمنظور ويشثبردن مفاد مشتر لك آنها (درموضوعاتغير ازموضوع كدام حـيرفهـه

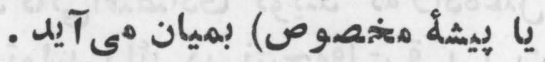

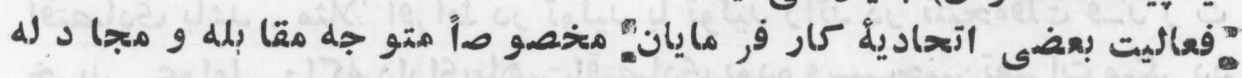

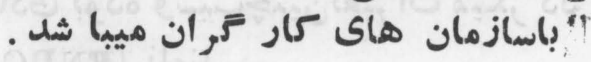

employer's liability insurance.

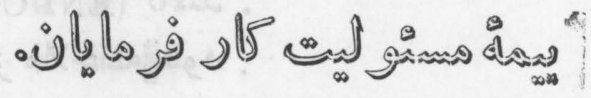

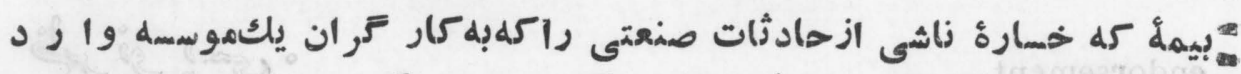

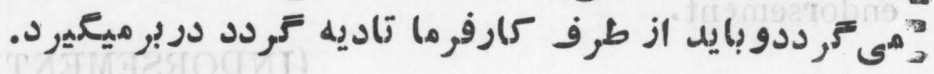

employer's liability law .

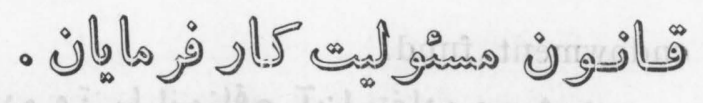

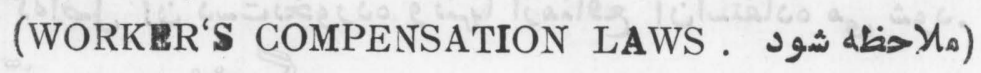

employment .

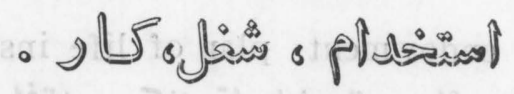

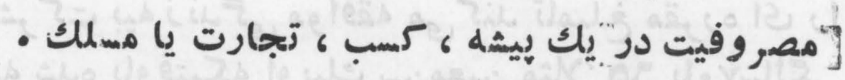

employment multiplier .

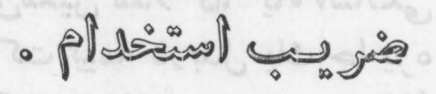

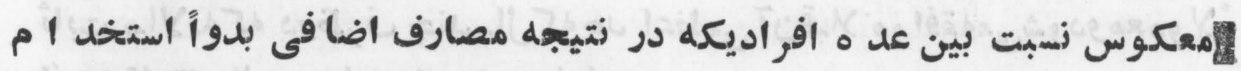

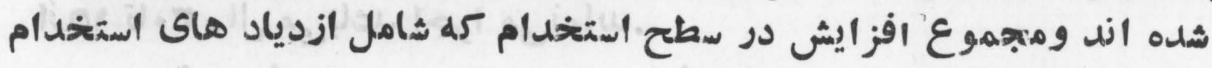

emporium.

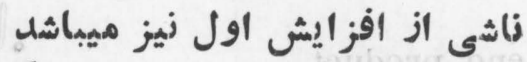

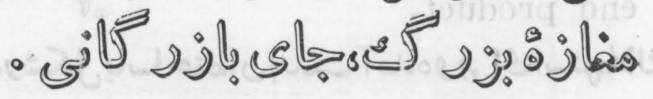
يكمركز تجمارتى، جاقتجارتيإيك مغازه بزرتى كلدر آنانواعمال الثتجاره enclosures. فروخته مىثود. - sil

AGRICULTURAI REVOLUTION, تفصيلات

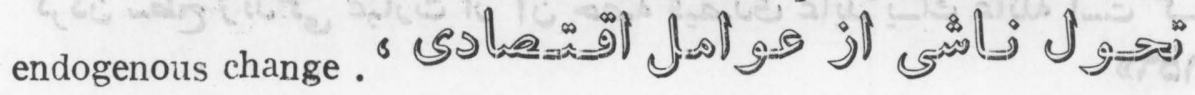
( (DD) 


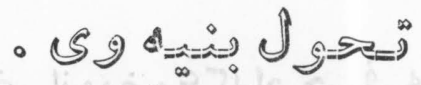

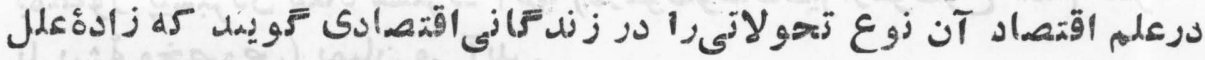

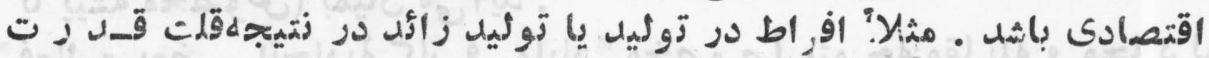

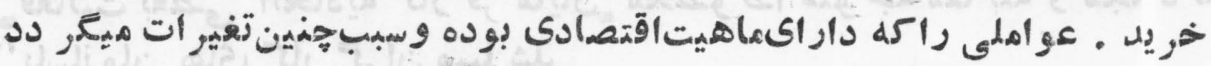

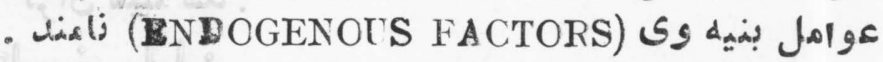

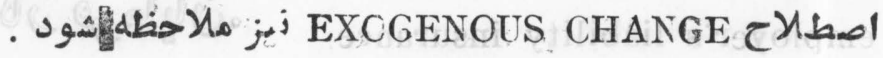

endorsement.

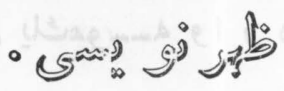

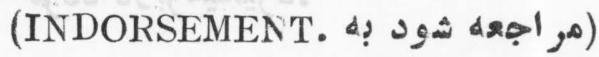

endowment fund.

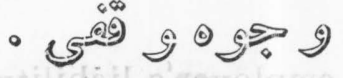

وجوهى كراصل آن دست زتخورنه وتنهلا ازمنافع آناستةفاده مى شود. endowment plan of life insurance. ' والانى كه طبق آن يكثر كت بيه زند

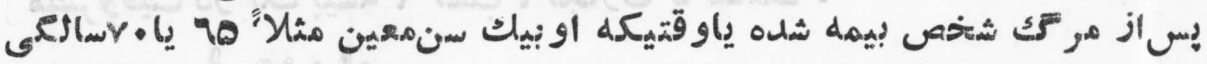

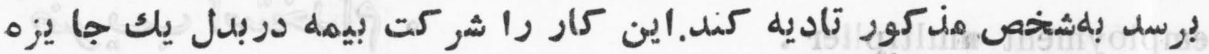

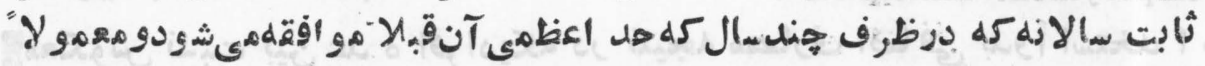

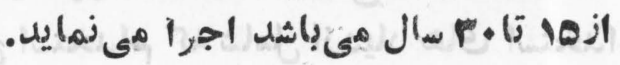

end product.

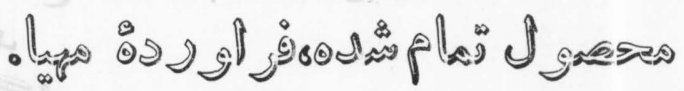

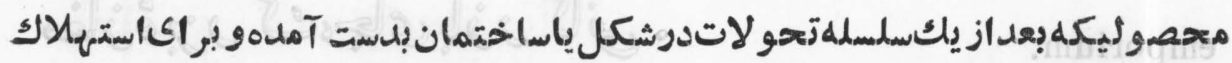

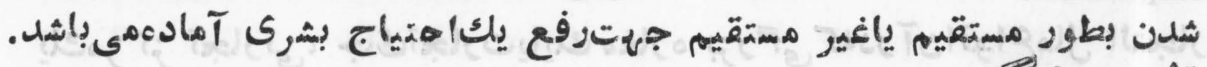
Engel's law •

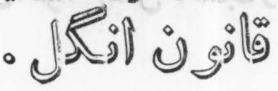

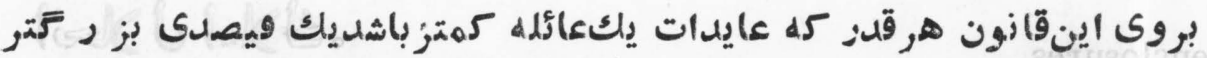

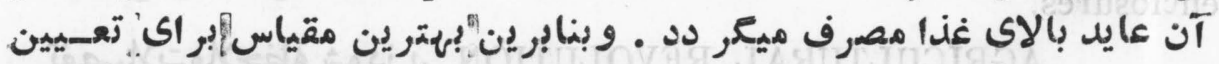

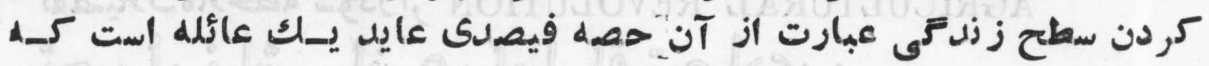
(10)) 


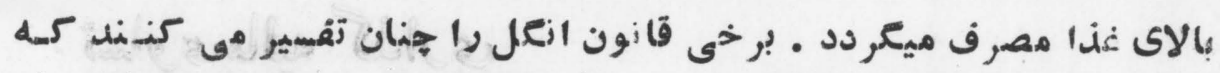

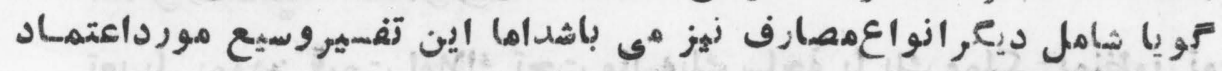

enterprise .

زياد نيست .

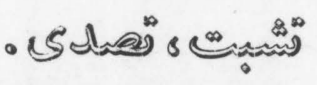

يك موسسيه انتفلاعى كه در آن خطر بردو باخت با شد .

entrepreñeur. = enterpriser

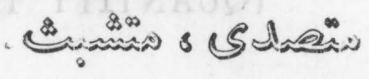

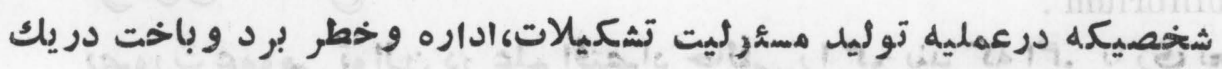

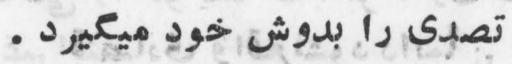

entrepreneurship . - जs

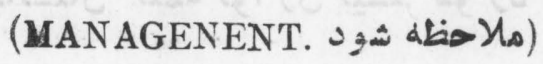

entry .

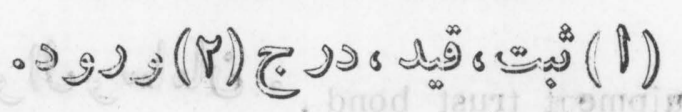

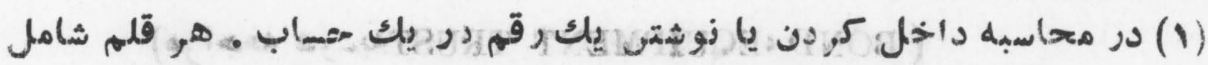

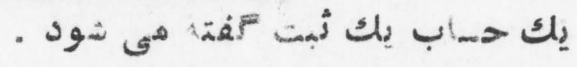

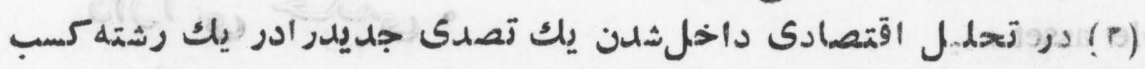

equal zation fee . . $0 \mathrm{sg}: 0$

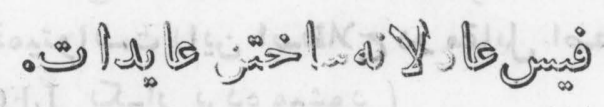

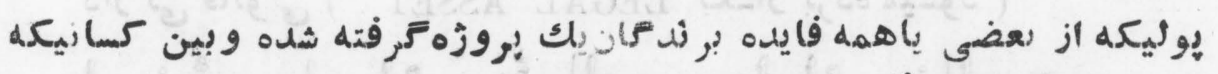

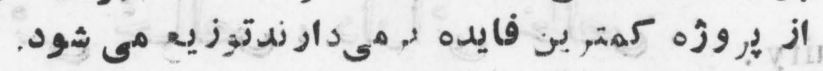

equalization of assessnients. - जolols glat. 


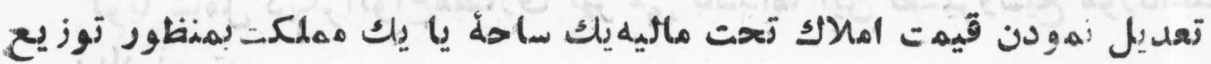

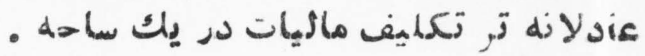

equation of exchange .

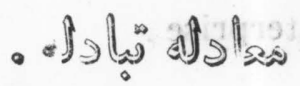

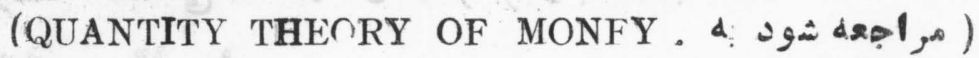

equilibrium .

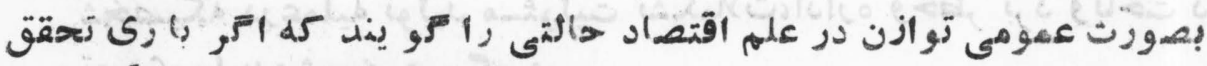

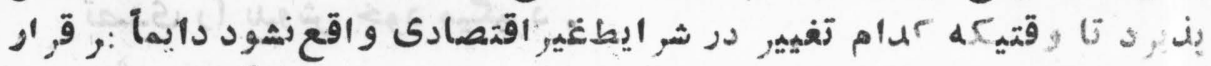

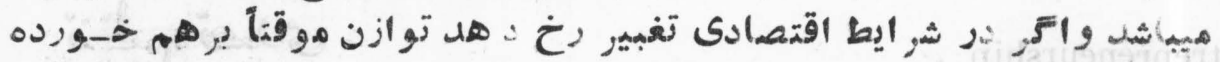

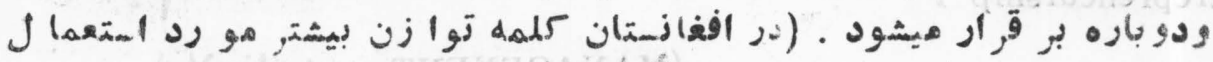

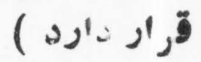

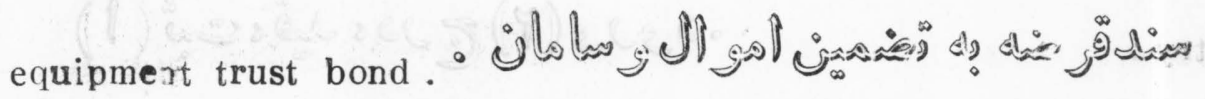

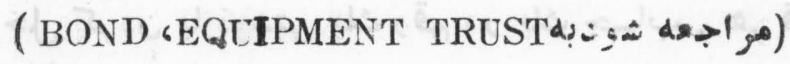

epuitable asset.

- जars vilo

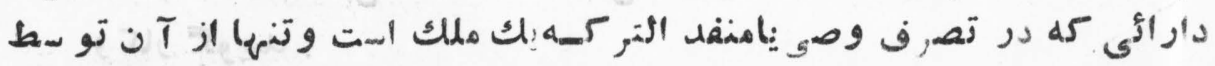

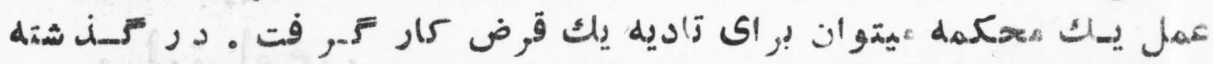
(EQTITABLE AsSET .

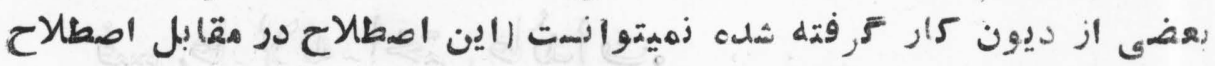

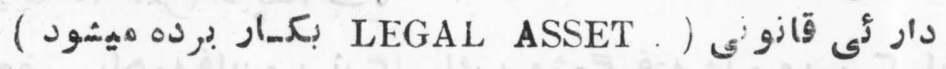

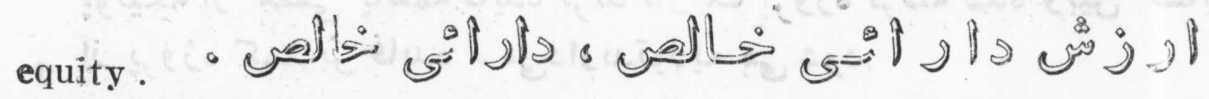
ارزش خا لص يك دا رائى كله بعد از وضع تمام حقوقارتغا قى ياديوناز

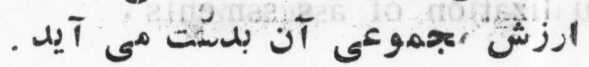




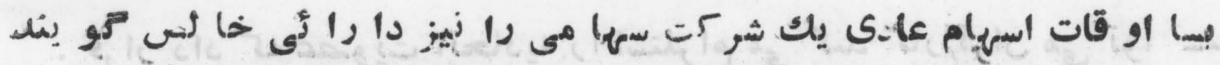

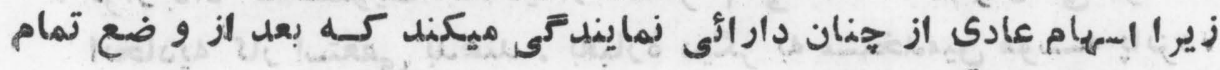
- ديون شرك

equity trading.

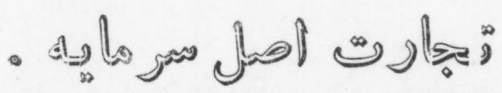

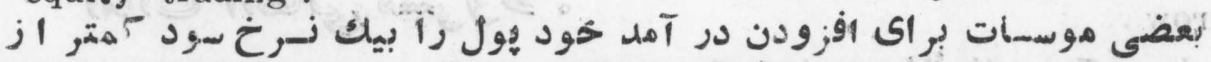

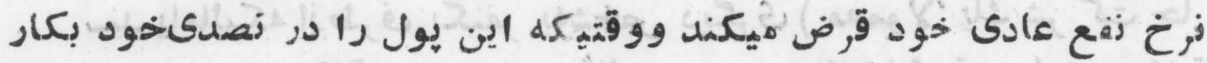

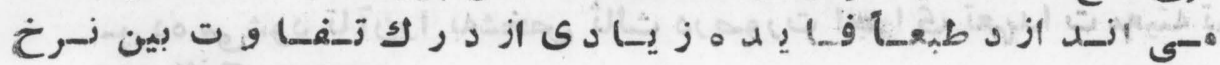

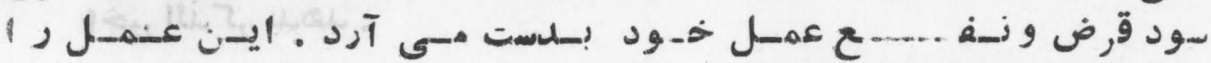
- EQUTTY TRADING

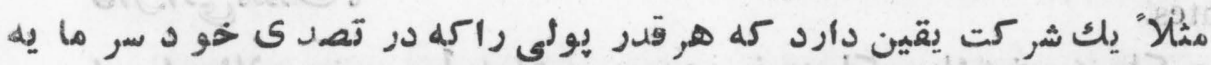

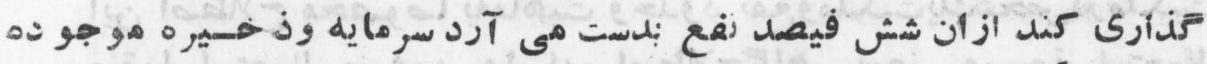

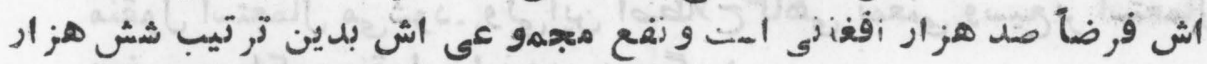

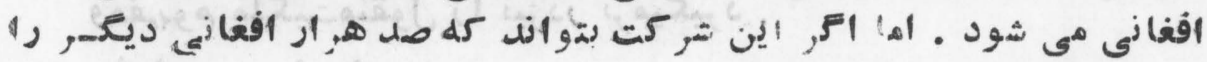

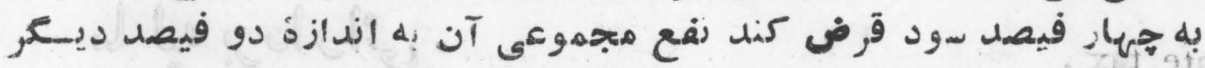

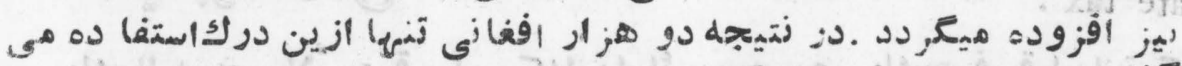

escalator clause

$$
\text { 1. I TAT \& }
$$

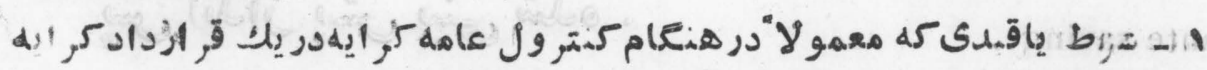

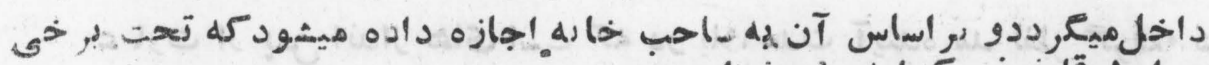

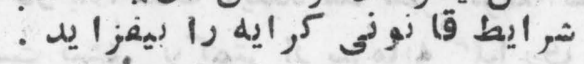

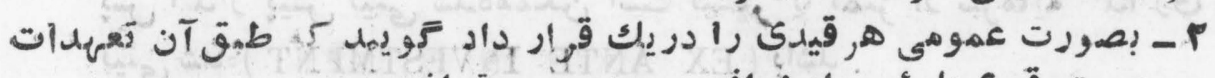

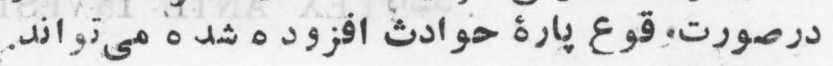

e cap clause .

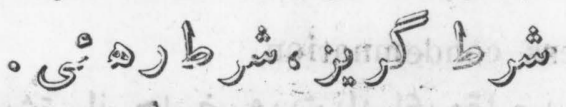

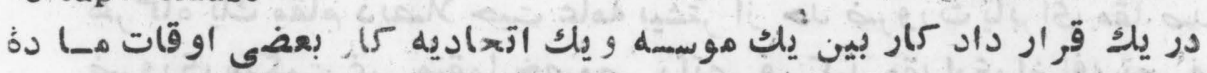

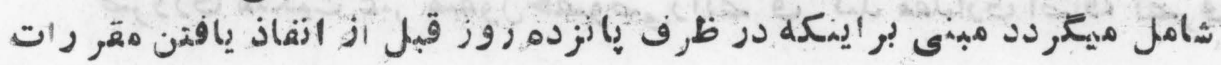




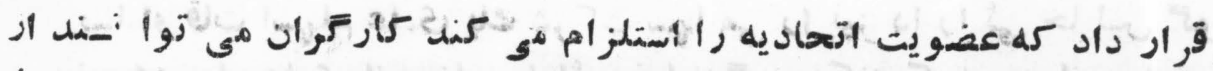

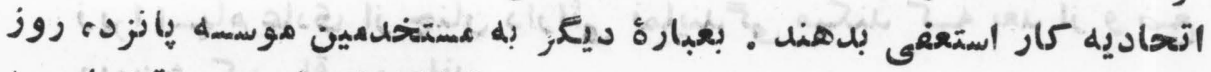

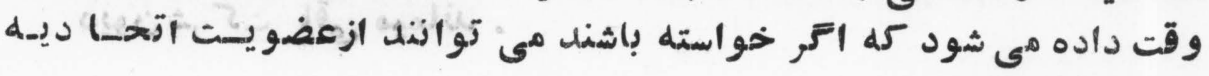
صرف زسظر كنند .

escrow - b 8 总

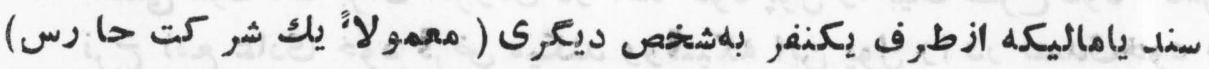

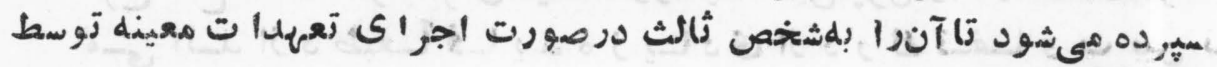

estates.

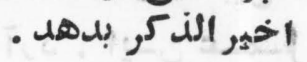
- Ellos iोis اين إصطلاح مخصوصا بهماهيت و هدود زفعوملكيت يكشخصدردماكلكيت غير

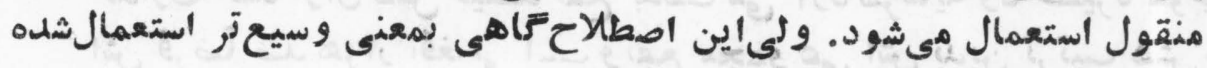

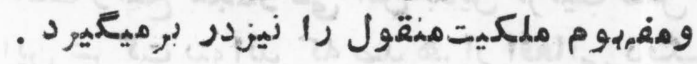
estate tax . - जoly bo a do do

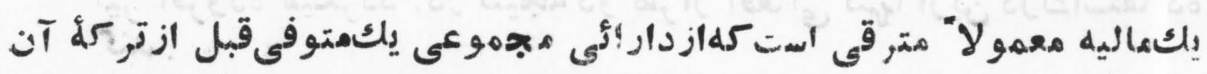

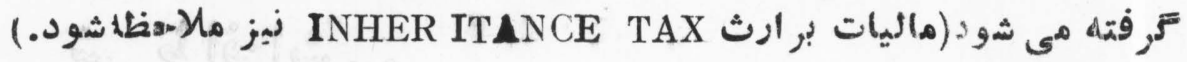
ex ante saving. - Od

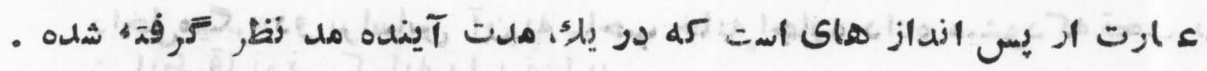

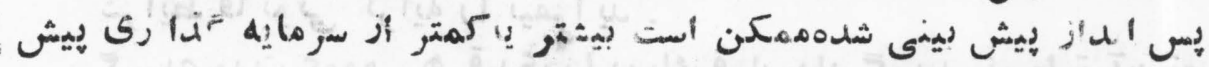

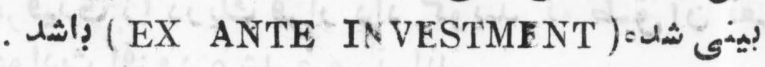

excess condemnation.

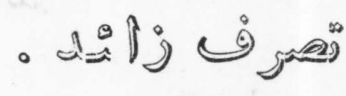

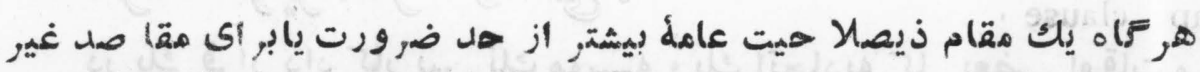

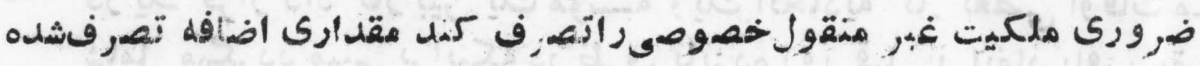




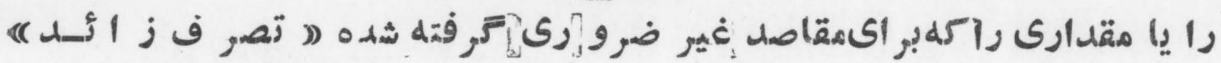

excess - profits tax

$$
\text { - لق }
$$

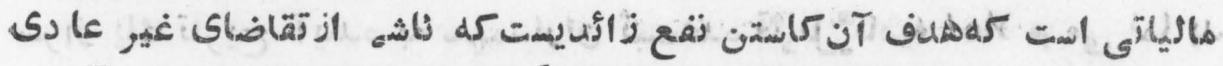

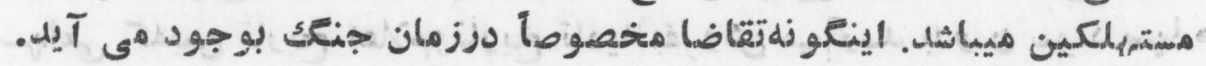

excess reserves.

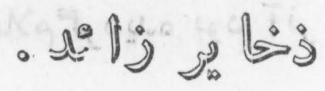

ذخأير بازنكى كلبيشتر أزحل هعينه قاذونى باشيد.

exchange.

$$
\text { - 4 } 5
$$

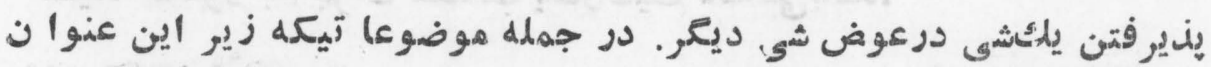

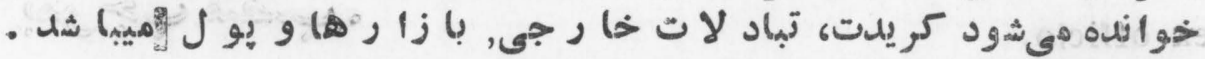

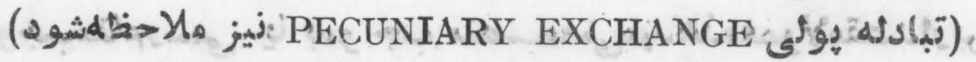

exchange control .

$$
\text { - J }
$$

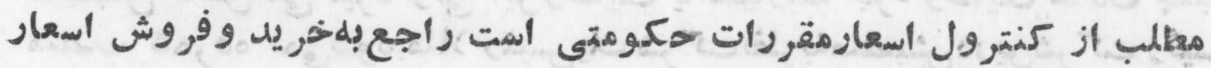

exchange equalisation fund.

- 1 (3)

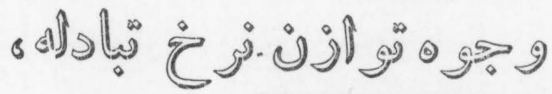

$$
\begin{aligned}
& \text { - gl }
\end{aligned}
$$

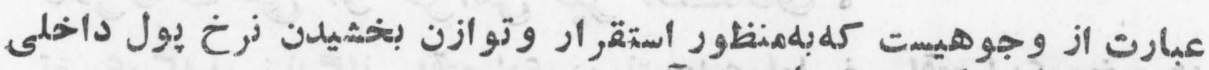

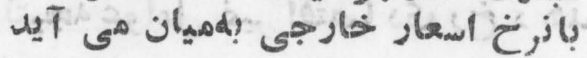

excise tax,

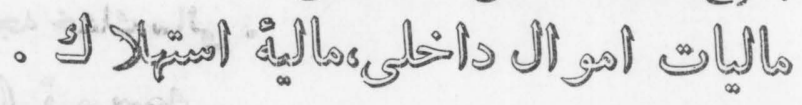

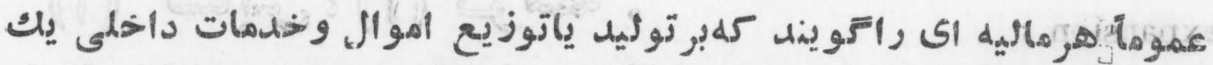

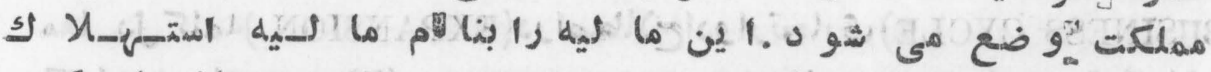
نيز يادميكمند (INTERNAL REVENUE TAX) (CON\$UMPTION TAX) 
ex dividend .

$$
\text { - Plon a }
$$

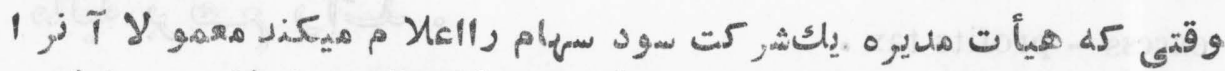

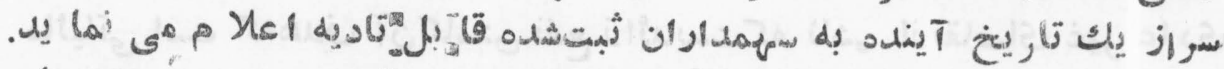

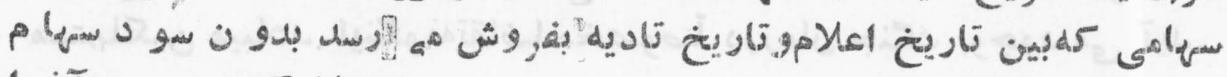

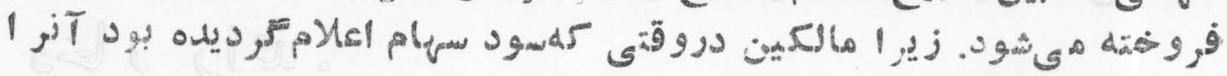

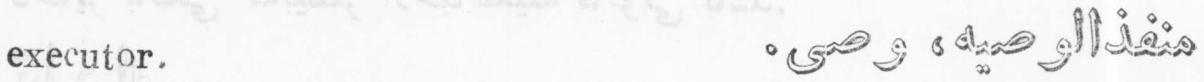

$$
\text { مى تمير ذن. }
$$

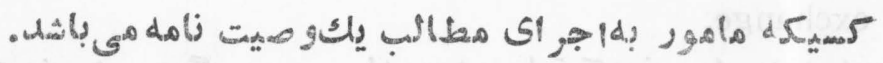

ex officio. -

أزروى نغت بمهوجبمقامرسمى يأ بمو جب منصبمعنى ميلهدمعمو لامقصدازين

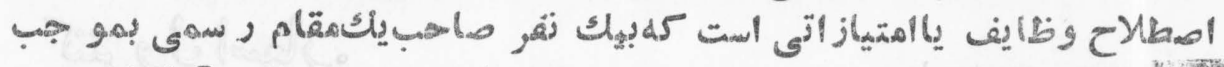

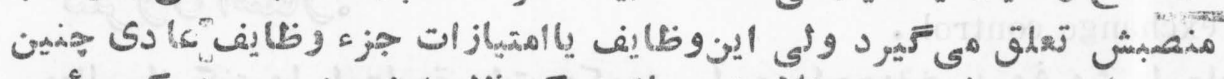

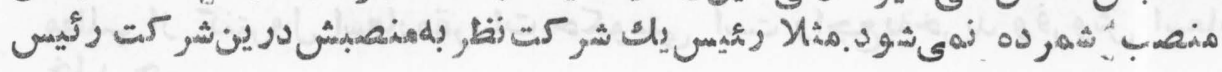

exogenous change .

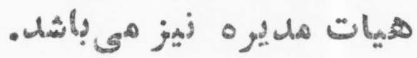

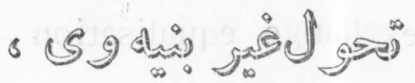

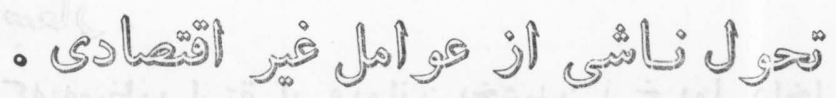

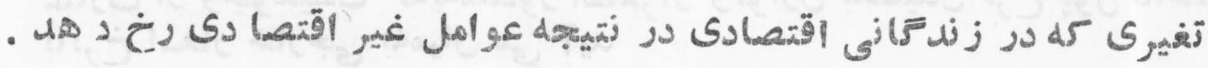

expansion .

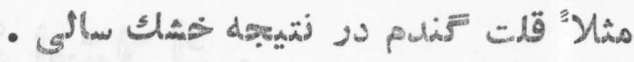

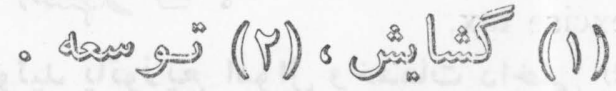

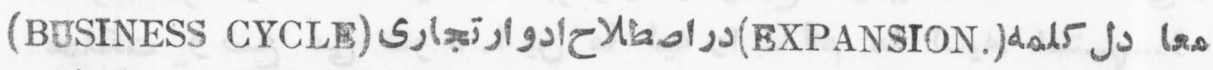

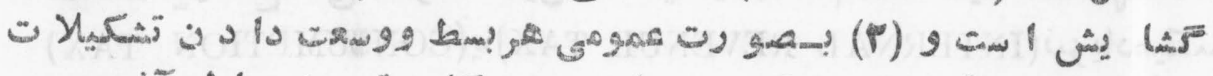

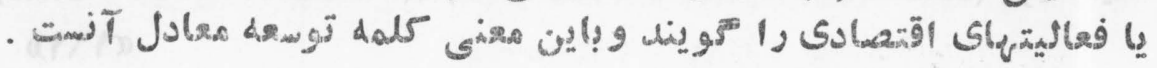


expenditure .

- @ lias

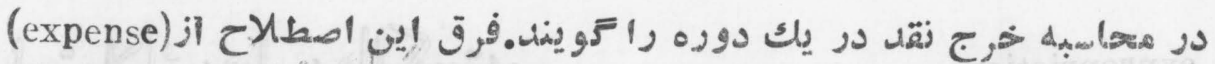

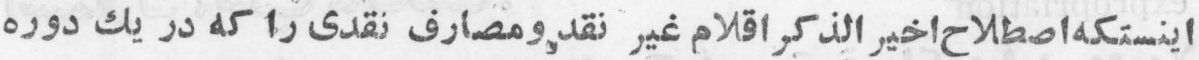

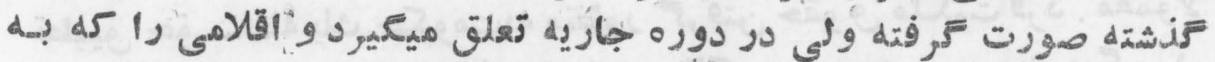

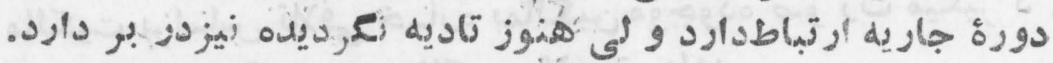

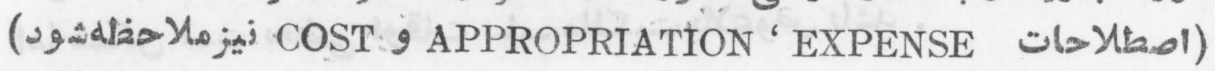
expenditure equation .

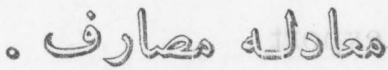

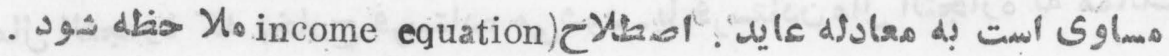

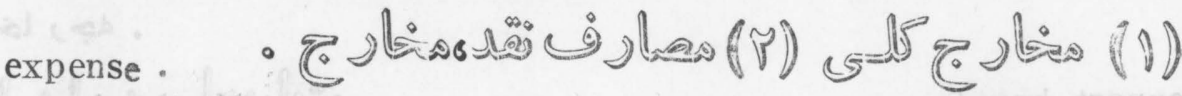

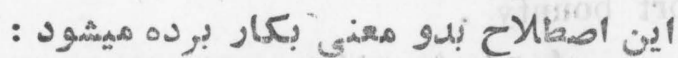

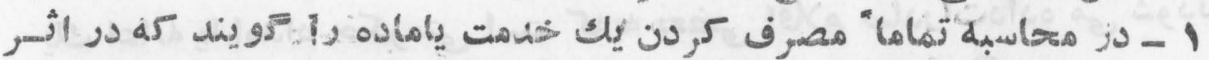

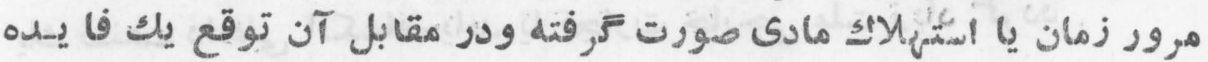

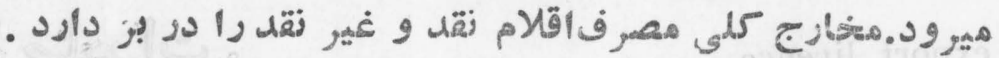

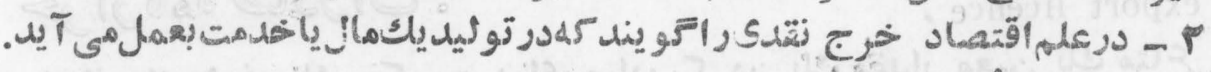
expense ratio.

- Cgliea लami

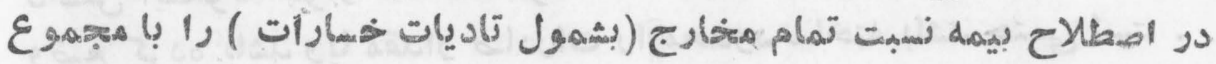
- >قوقو

explicit interest.

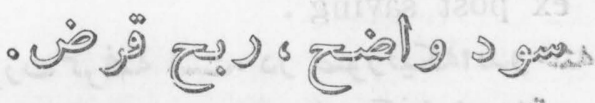

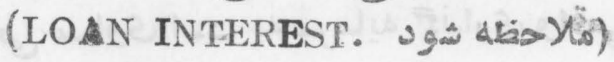

explicit rent. - نं

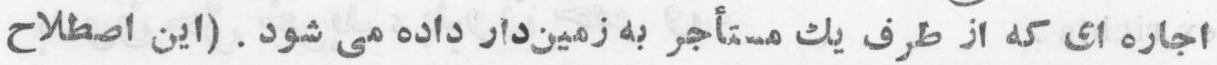
أسة (IMPLICIT)

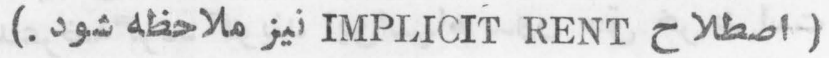
exploitation of labon . (1) date $)$

《19 
expropriation .

-

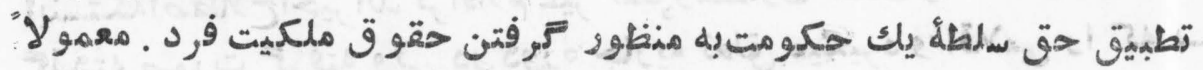

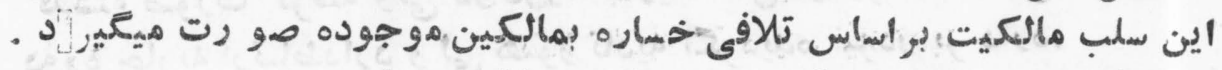

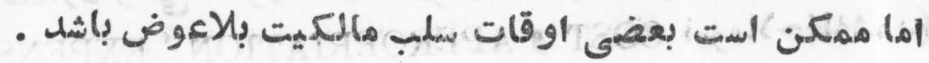

export .

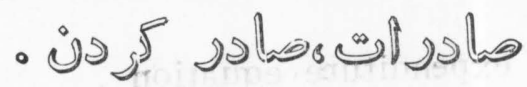

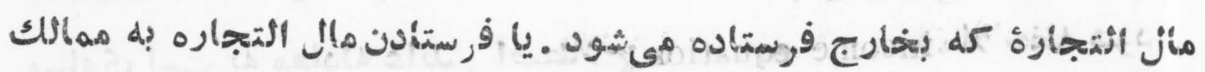

export bounty.

- حا

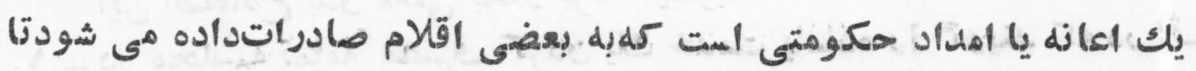

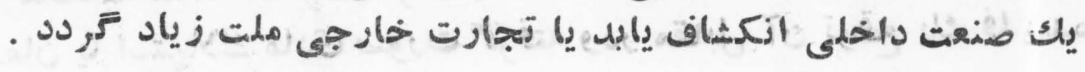

export licence.

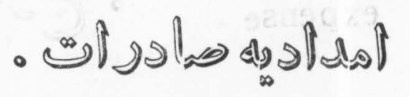

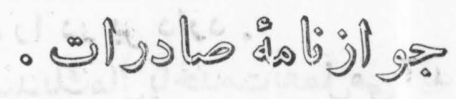

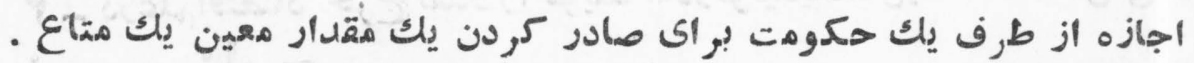

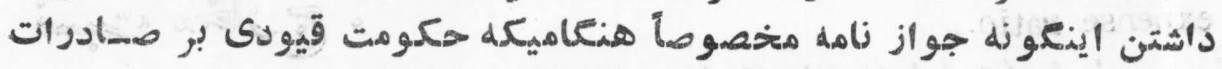

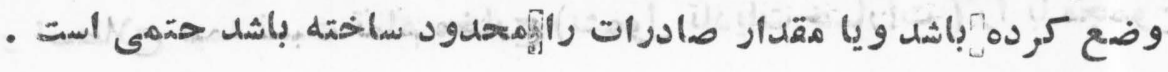

ex post saving.

$$
\text { - ज्ञ }
$$

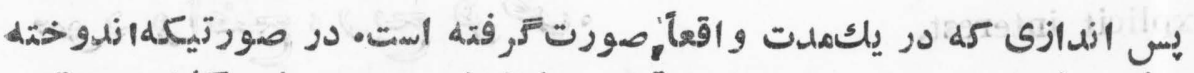

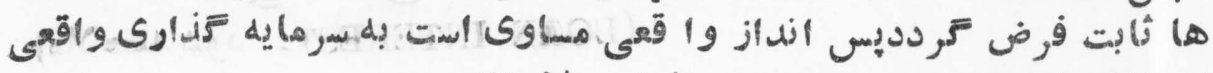

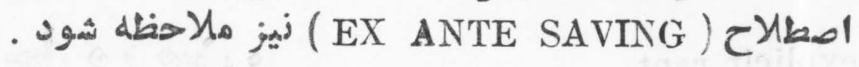

ex rights .

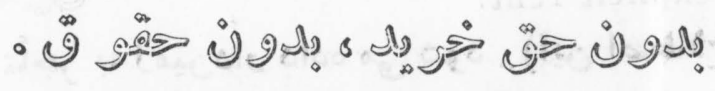

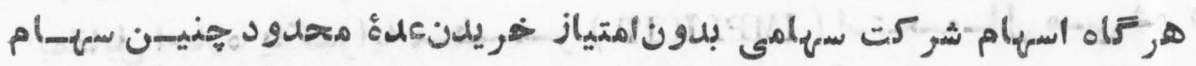

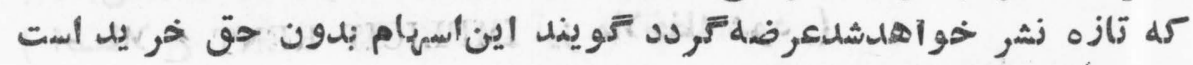

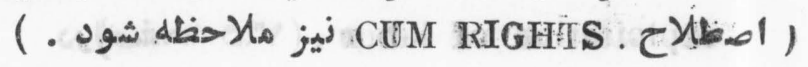


exploitation of labr .

$$
\text { - ن إل }
$$

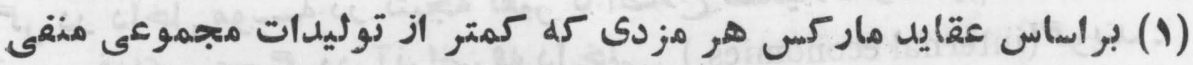

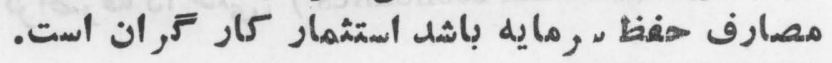

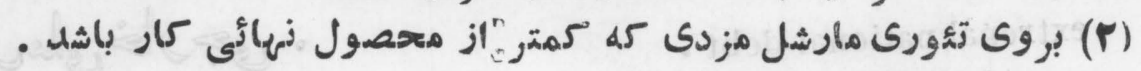

extended. - ه ف

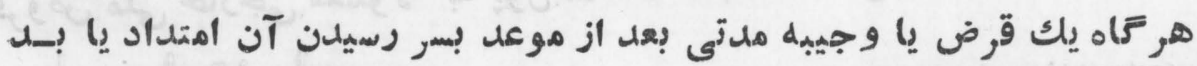

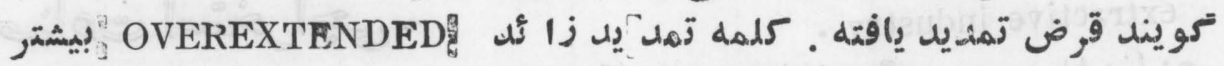

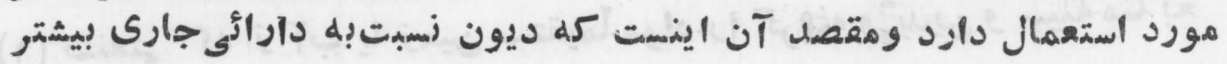
شده باثلد . extended bond. - ه ه

(BOND 6FXTENDED شود ماحه )

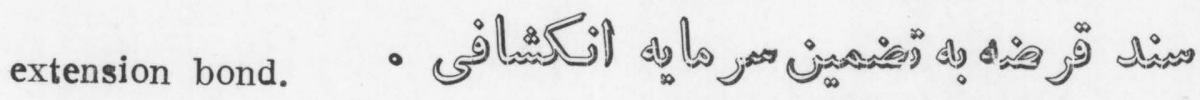

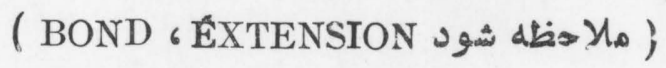

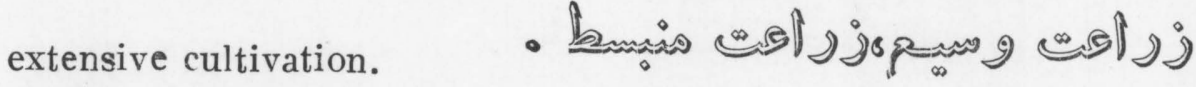

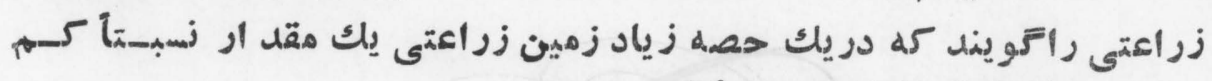

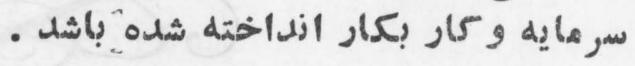
external economies .

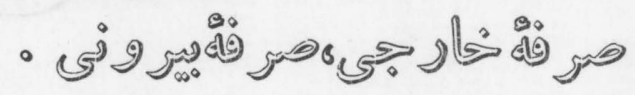

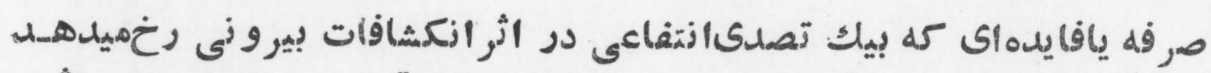

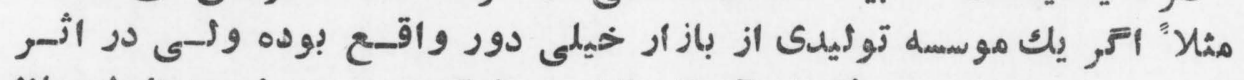

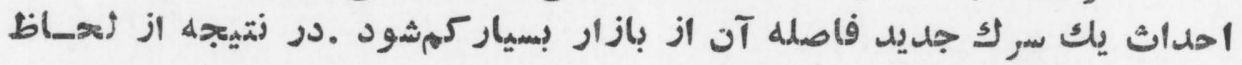

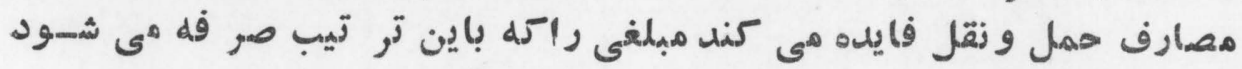

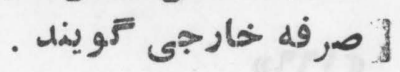


EXT

أحر درنتيجه ضدآن واقع شود آزرا صرفه منفى(DISECONOMIES) خارجى زامند در ندا

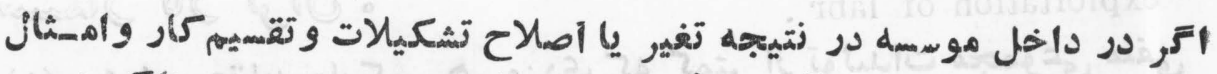

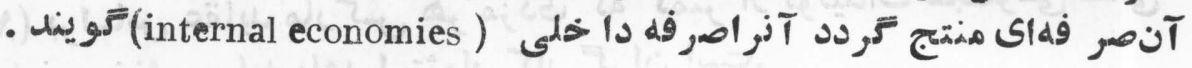
extrenal national debt .

- ज实

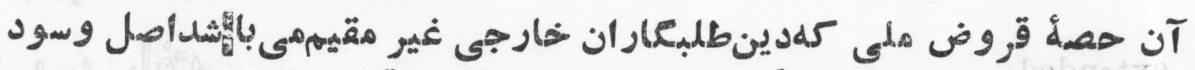

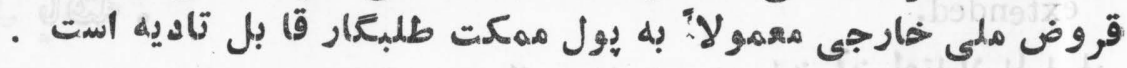

Extractive industry .

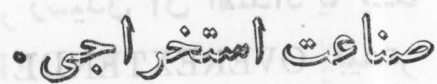

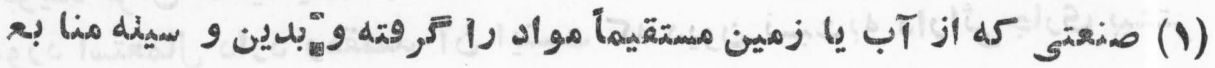

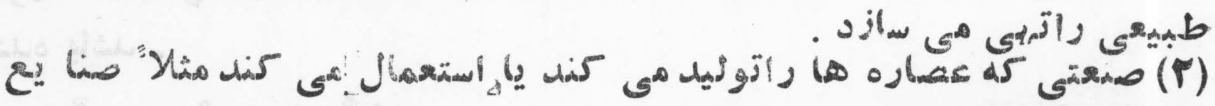

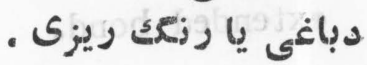

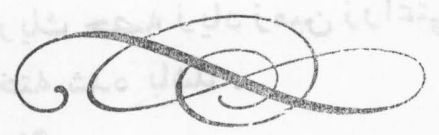

(19า) 
fabian socialism

- ज院

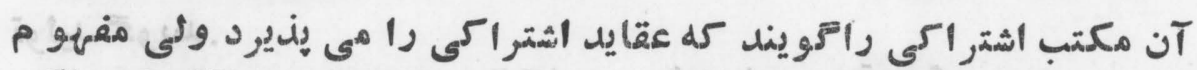

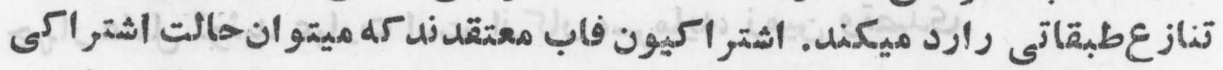

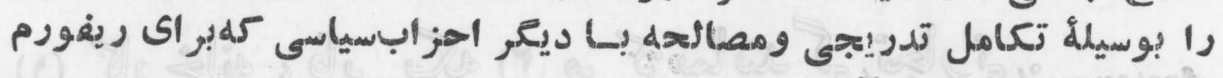

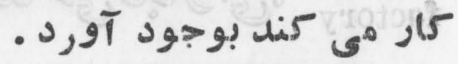

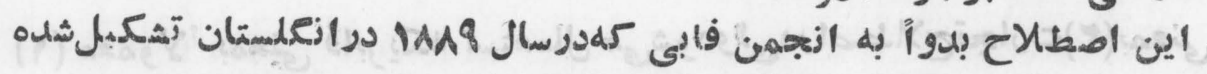

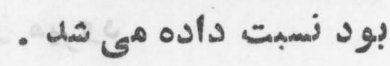

factor .

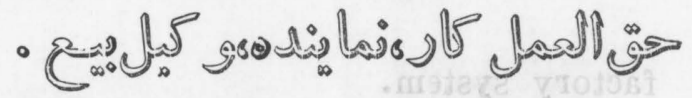

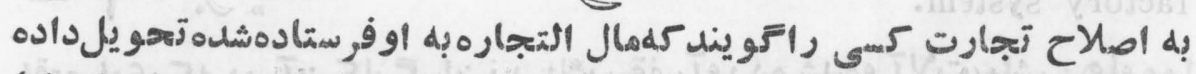

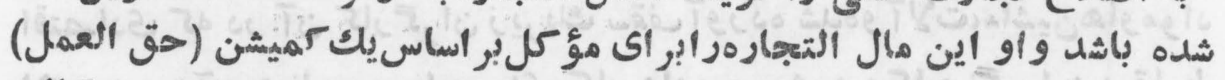

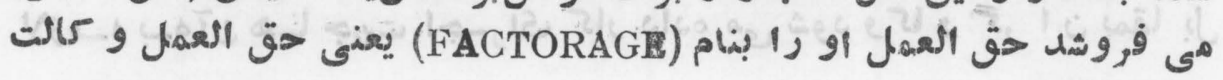

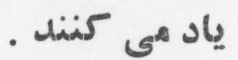

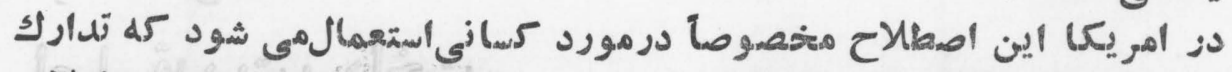

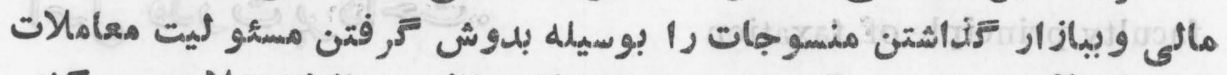

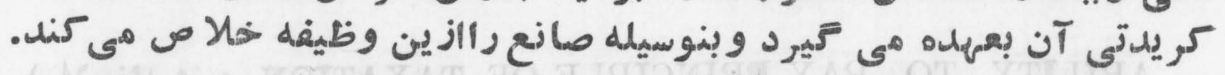

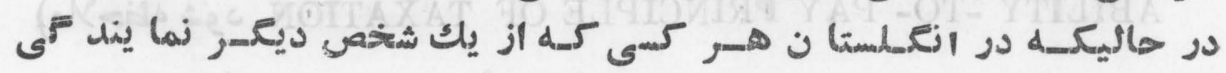

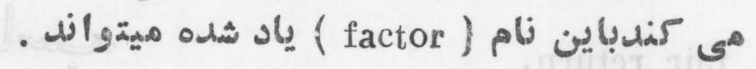
factorage .

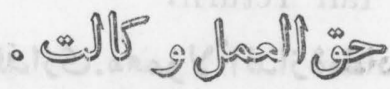

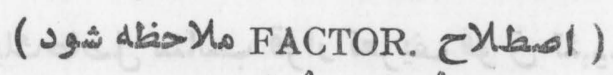
factor cost. - blelinglos can

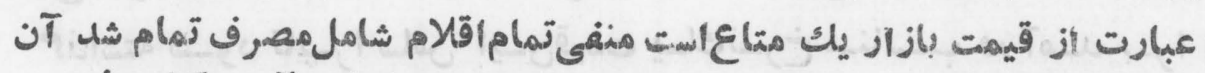

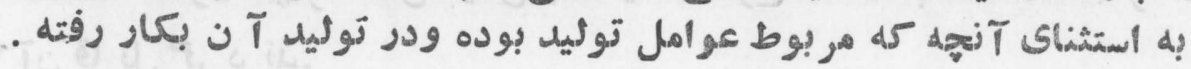


FAC

factors of prodcution.

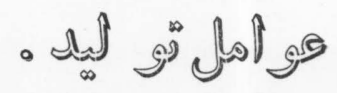

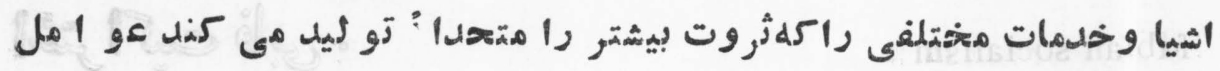
توليد تورينل.

جهار عامل توليد عبارت است ازليد كار كسر مايه، زمين وتصدى.

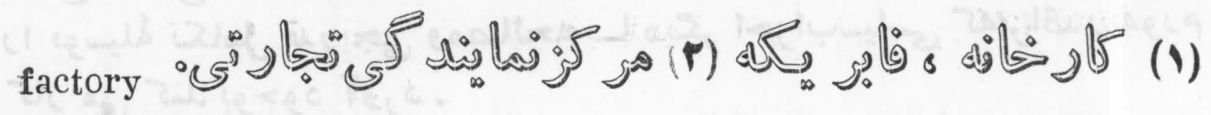

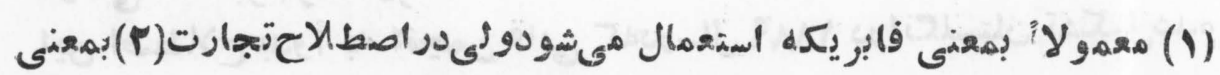

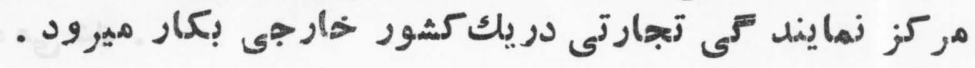

factory system.

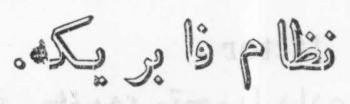

اقتصادى كه در آن كار Fر ان زيريك سقف آورده شلدةو آلات،ماشين هاومواد

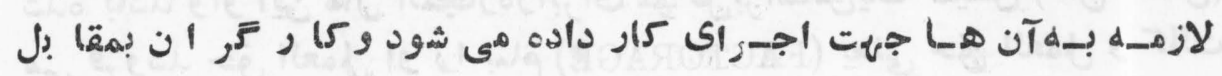

$$
\text { مزد كار مي كنمنل. }
$$

faculty principle of taxation

$$
\text { . }
$$

ABILITY -TO- PAY PRINCIPLE OF TAXATION مون شلح

fair return.

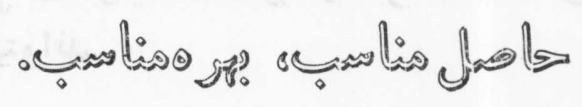

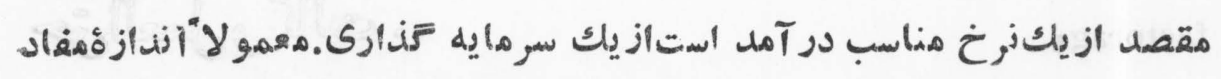

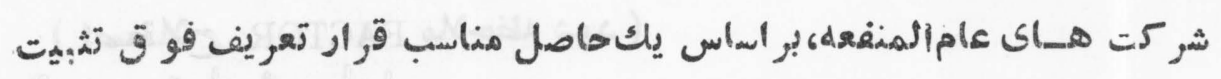

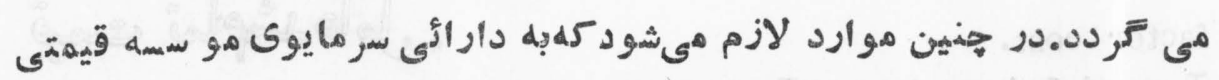

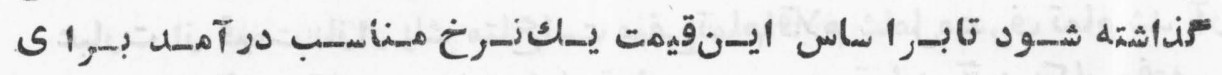

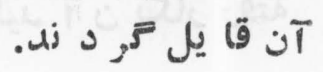


falling - rate - of-profi theory. - (مر اجعه شودبه

(DECLINING-MARGINAL EFFICIENCY OFCAPITAL THEORY family industry. ن مر اجعه شودبه.HOUSE HOLD SYSTEM

farm bloc - (1) 159 lis

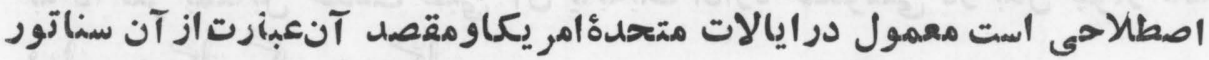

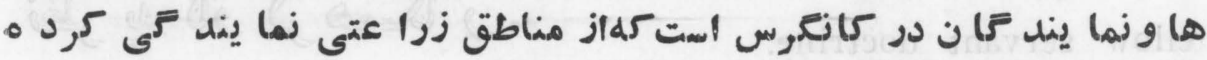
وهميشه ازتلابير بهنفع زارعين حمايه ميكند.

fascism. of

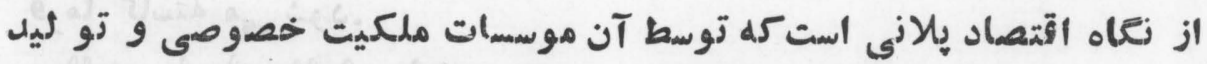

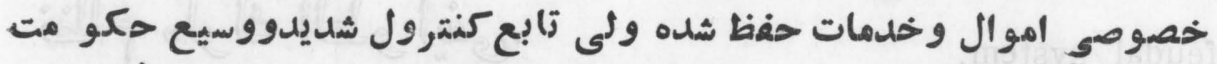

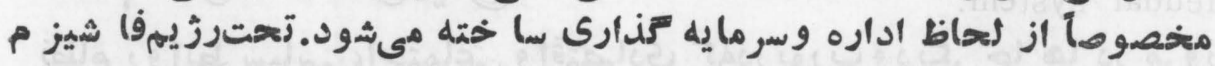

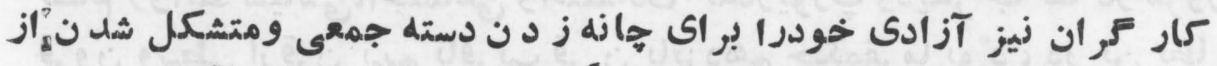

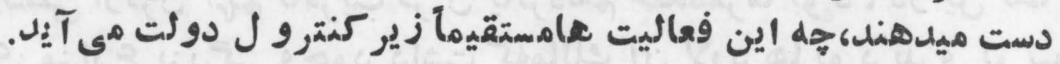

favorable balance of trade.

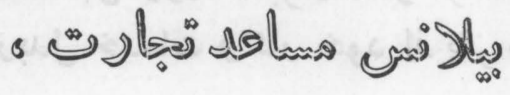

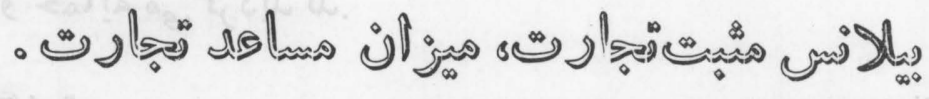

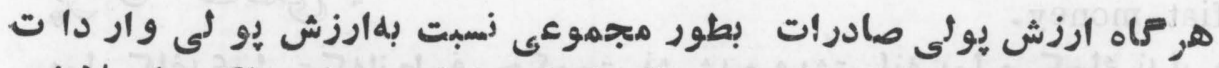

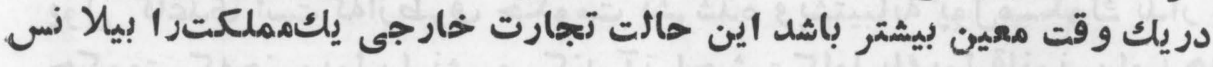
مساعد تجارت تَوينل.

featherbedding.

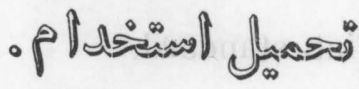

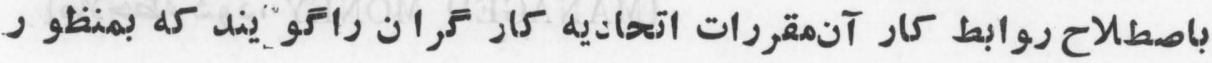
(1) $49 \%$ 


\section{FEE}

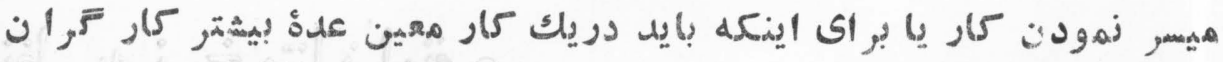

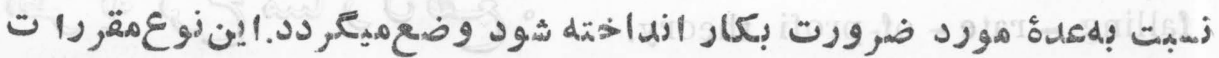

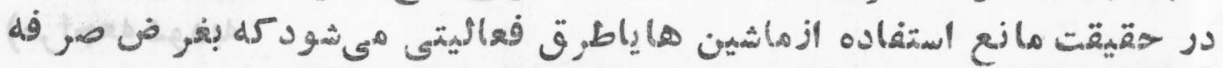

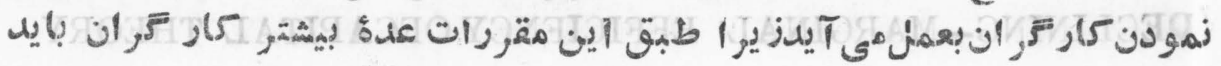

fee

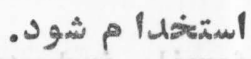

$$
\begin{aligned}
& \text { - c }
\end{aligned}
$$

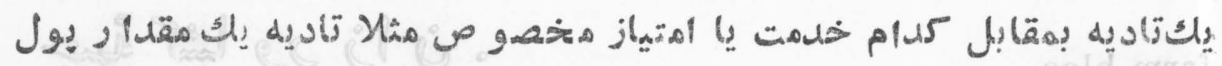

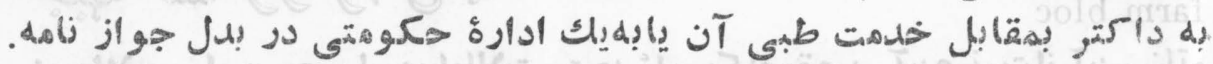

fellow servant doctrine.

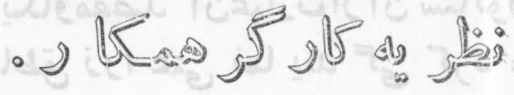

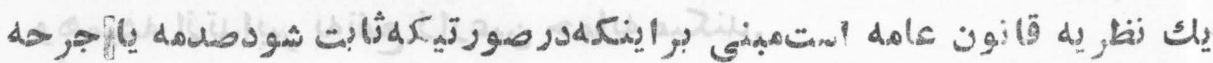

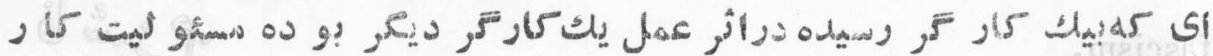

$$
\text { فو ف }
$$

feudal system.

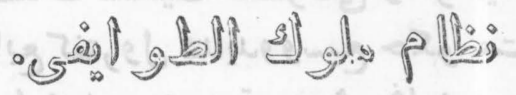

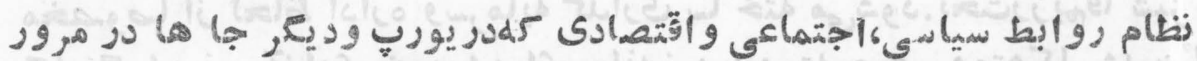

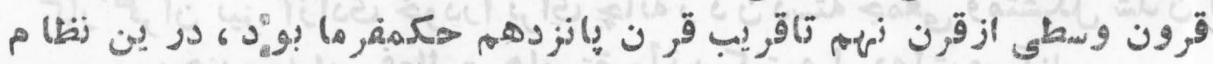

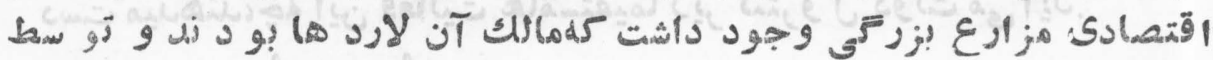

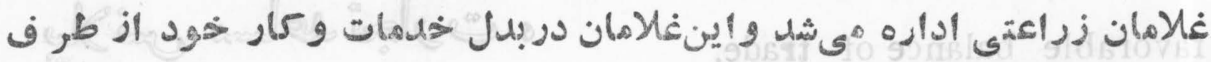

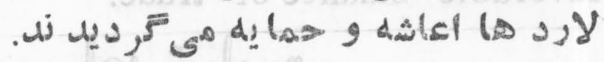

fiat money .

$$
\text { - लSNS }
$$

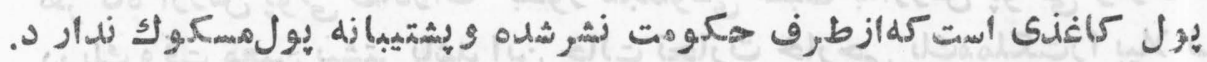

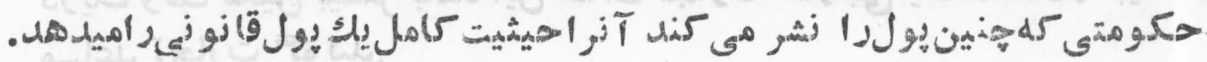

fiat standard.

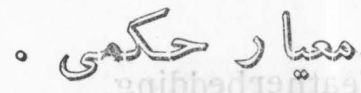

(MANAGED MONEY • A ش 
fidelity bond.

$$
\text { - }
$$

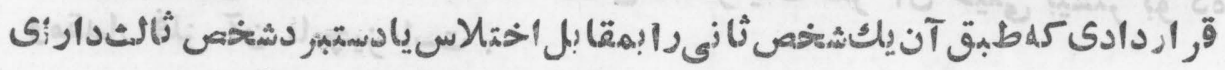

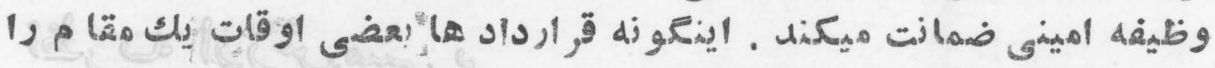

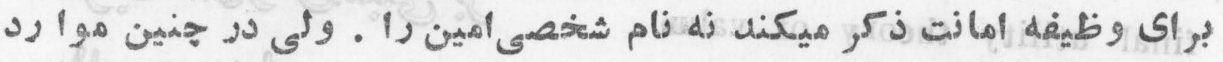

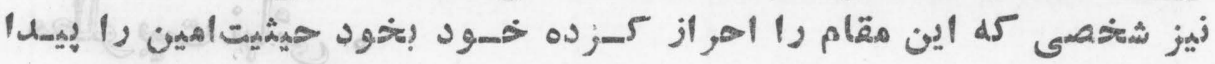

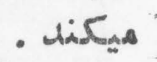

fidelity insurance.

$$
\text { - } \underbrace{0}_{\infty} \text { di }
$$

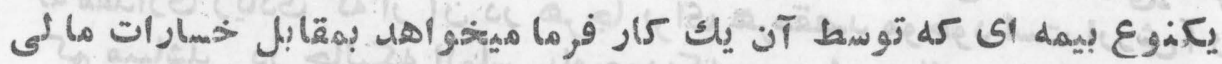

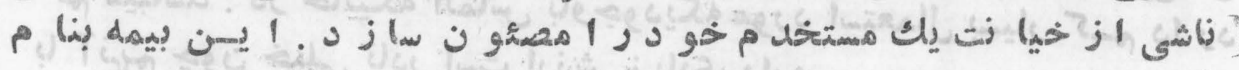
(SURETYSHIP INSURANCE)

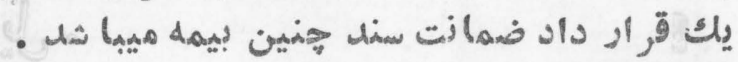

fiduciary .

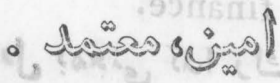

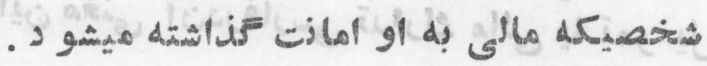

fiduciary standard.

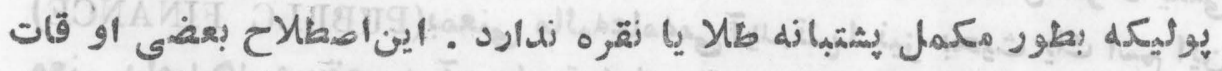

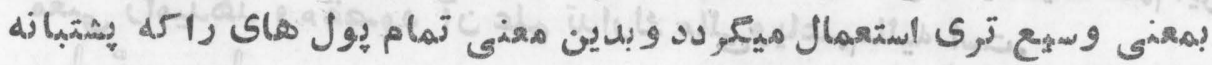

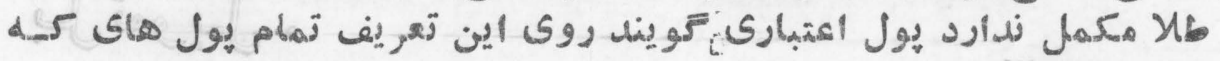

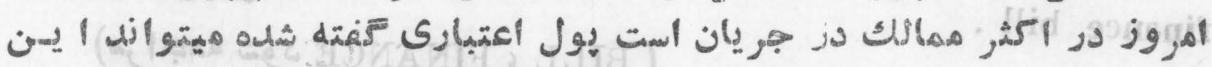

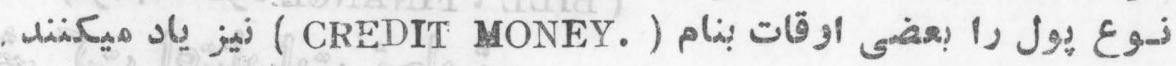

fiduciary standard.

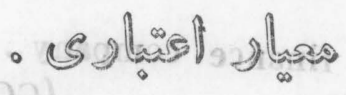

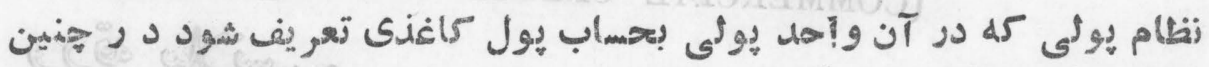

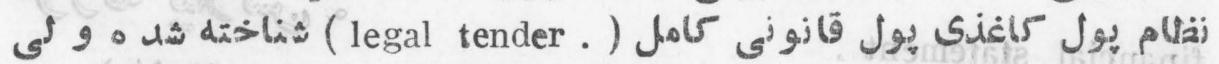

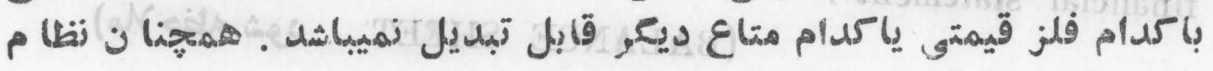




\section{FIN}

يولى را كه اساس آن فلز قيمتىوسكه جنين فلز باشدتويند ولى فورينصورت

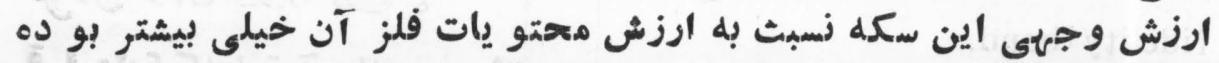

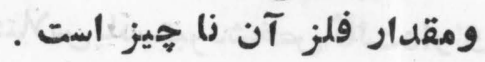
final utility theory of value.

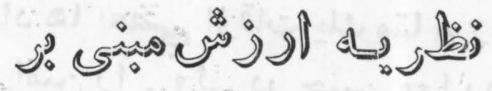

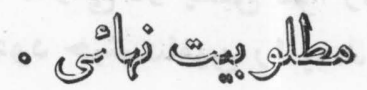

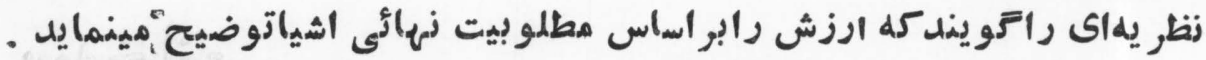

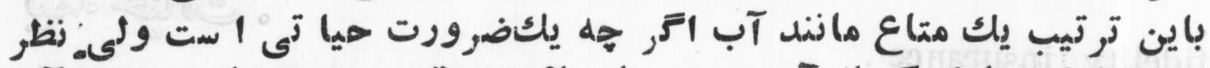

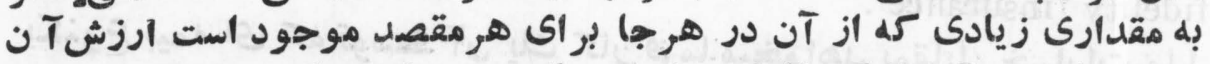

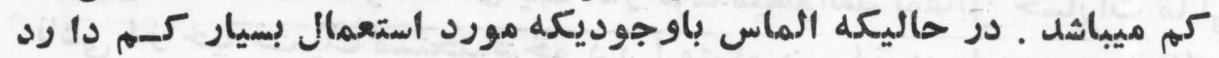

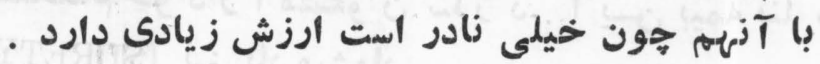

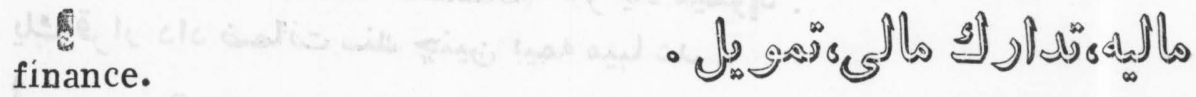

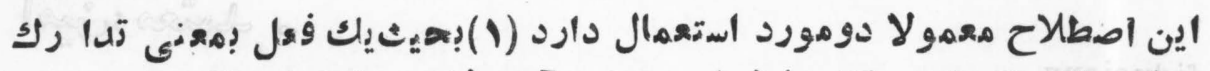

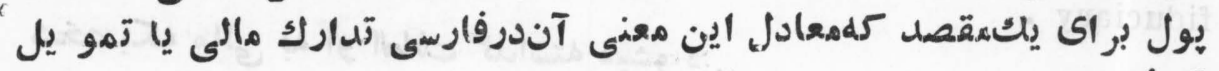

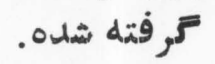

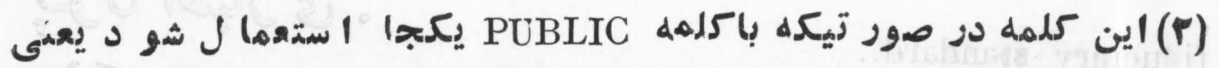
(PUBLLC FINANCE)

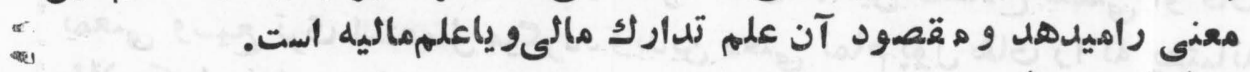
finance bill .

$$
\text { - } \int_{\infty}^{3} \nabla^{\infty} \int^{\infty}=\text { ? }
$$

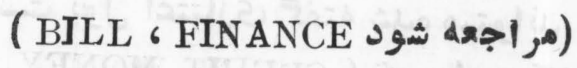

finance company .

$$
\text { (ग) }
$$

(COMMERCIAL CREDIT CO . مراجعه شود به

financial statement.

$$
\text { - Ving }
$$

(BALANCE SHEET . ملاحظه شود)

\section{(IV)》}


financial stanđing

$$
\text { - } 10
$$

fink .

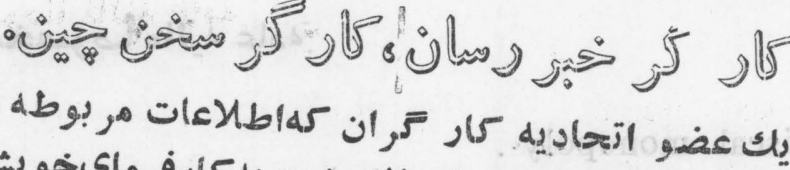

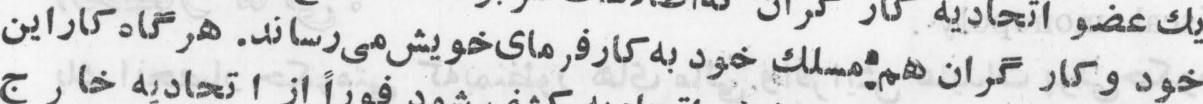

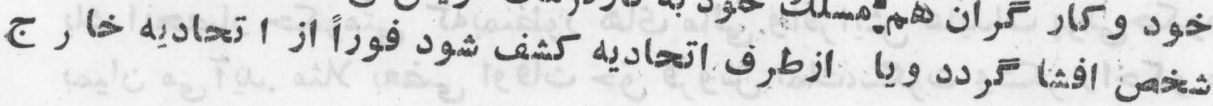

firm .

$$
\text { S D }
$$

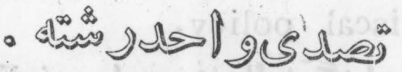

"ملمهل ف, م (FIRM)

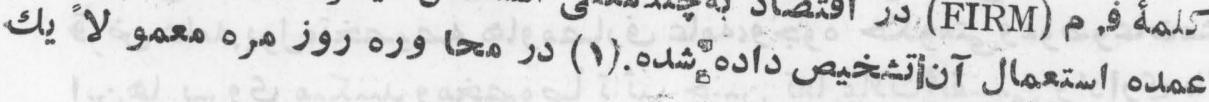

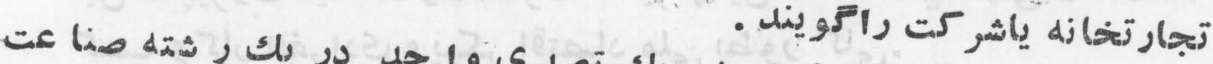

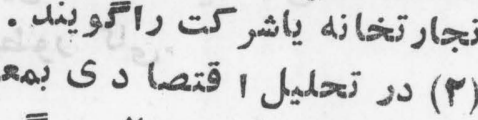

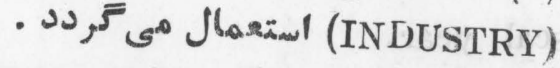

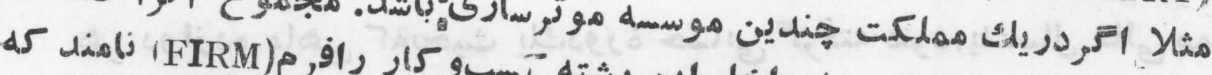

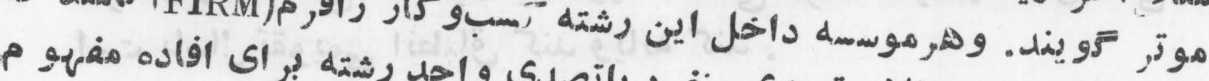

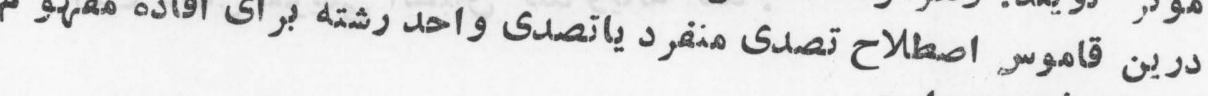

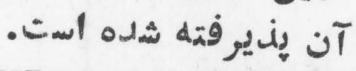

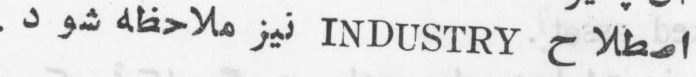
first lien bond,

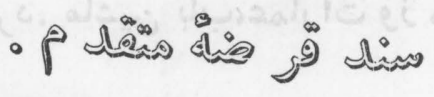

(BOND 6 FIRST LIEN. شود (م) ه

first international.

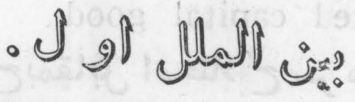

اولين جمعيت بينالمللى كار كران كلماركس تشعيل كرده بود . 
fiscal .

$\circ \int_{G}$

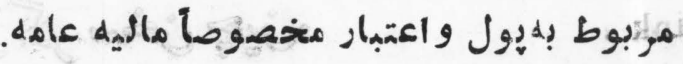

fiscal monopoly .

- जo glasil

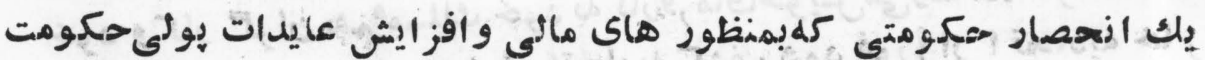

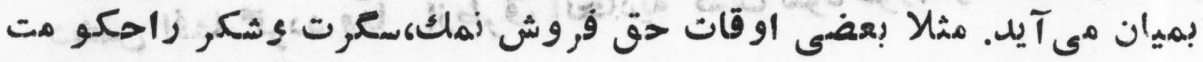

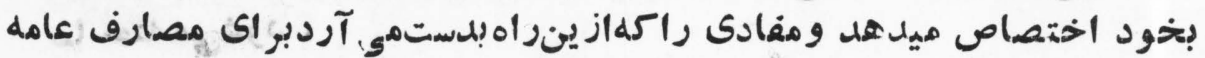

fiscaì policy.

$$
\begin{aligned}
& \text { بكار هى أزدازد . }
\end{aligned}
$$

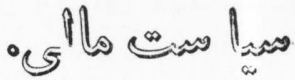

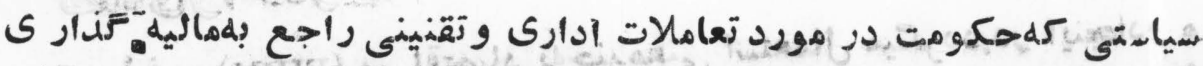

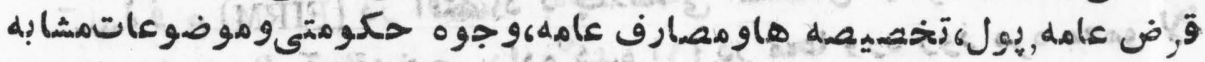

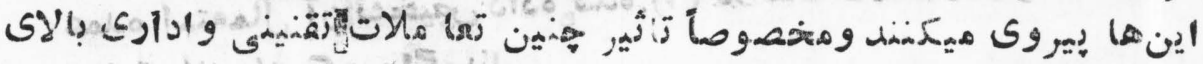

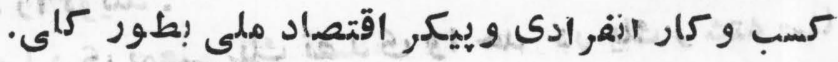

fiscal year.

- $\iint_{0} \log \lim _{0}$

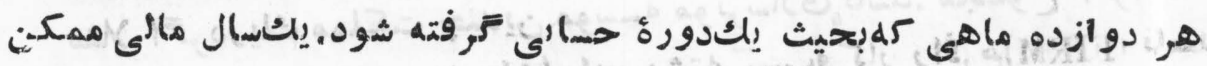

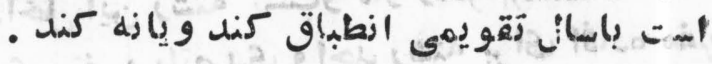

fixed asset?

-

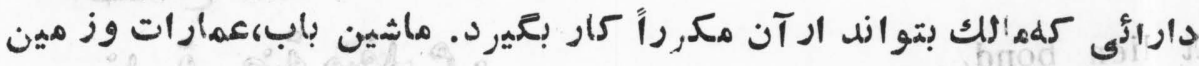

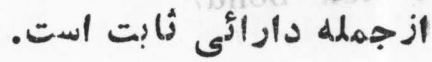

fixel capital good.

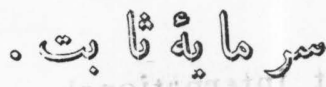

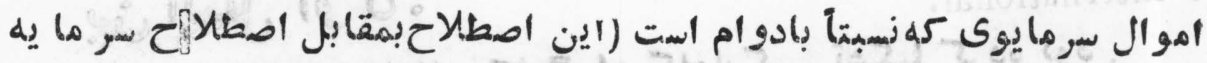
هتداول (م) CIRCULATING CAPITAL GOOD (IVP) 
fixed cost

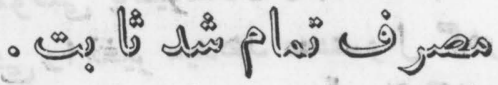

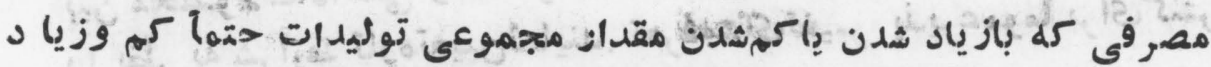

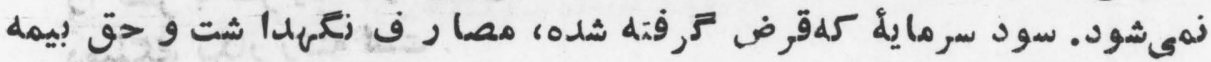

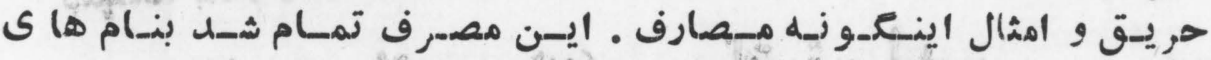
انيز يادمىثود (SUP 2LEMENTARY, INDIRECT ,OVERHEAD COST.) fixed liability .

$$
\begin{aligned}
& \text { ه }
\end{aligned}
$$

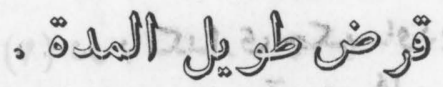

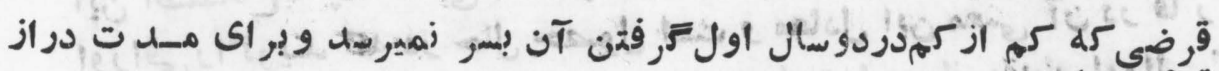
ترى تريباشلك

fixed shift .

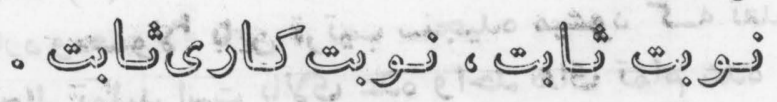

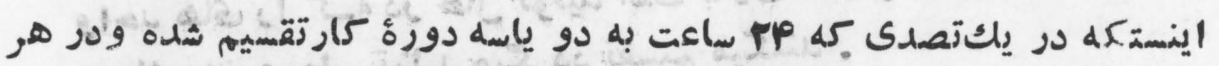

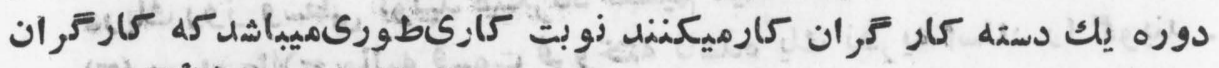

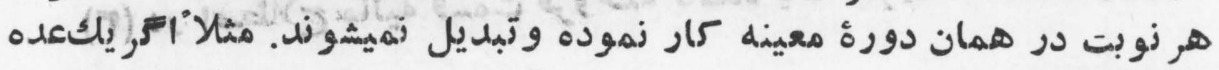

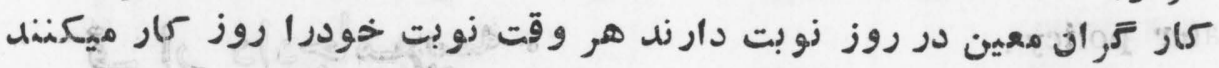

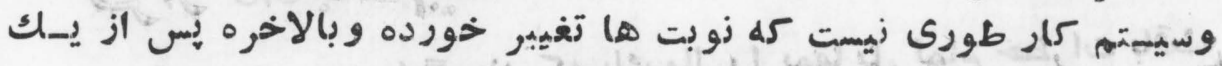

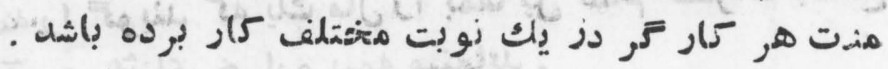

flexible schedule .

$$
\text { - ת מ }
$$

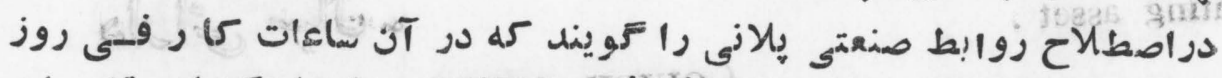

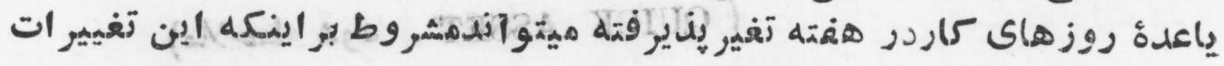

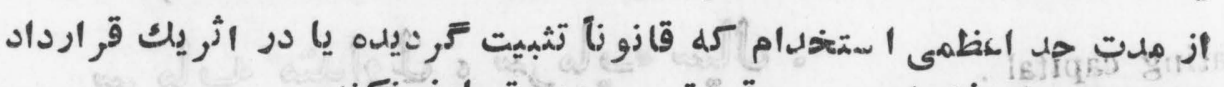

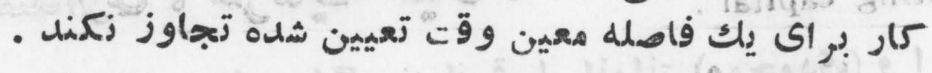

flexible tariff .

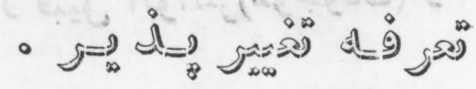

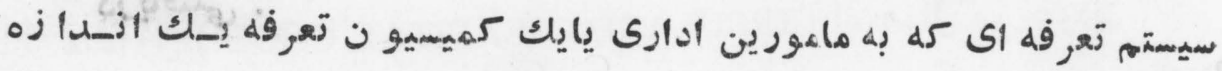


صلاحيث ميلهد تا در او قاتيكه شر ايط موقتى ياغيرغعادى رابطأه رقابت آميز

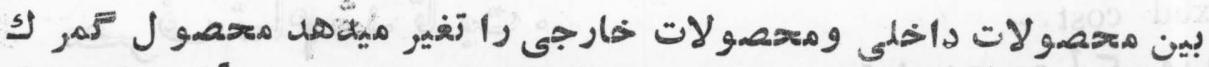

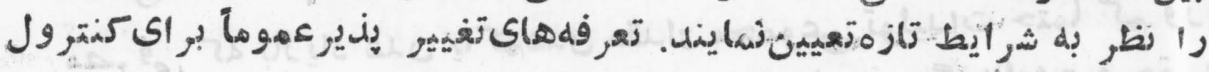
$\vdots_{2}, c^{2}$

flo,at

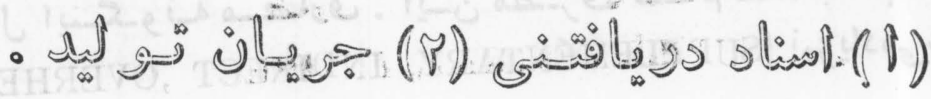

$$
\begin{aligned}
& \text { - ه व }
\end{aligned}
$$

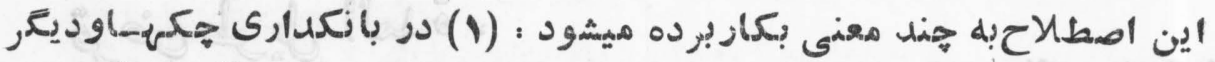

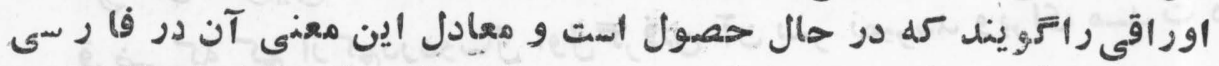

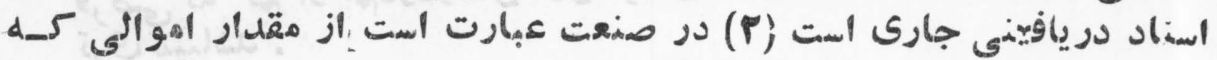

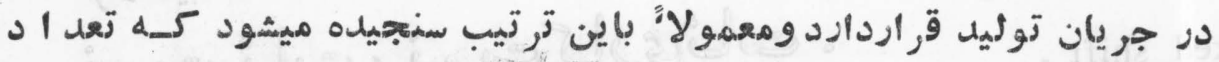

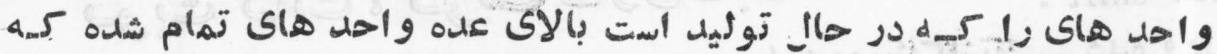

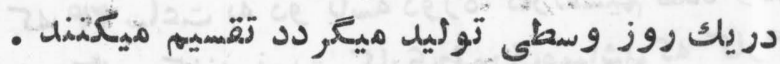

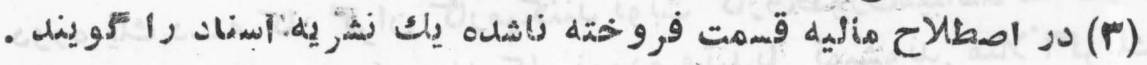

floater policy . $\therefore$ donsol آن قرار داد بيمه را تحويند كه يك مال را بمقا بل تمام خطر ات باقطع نظطار

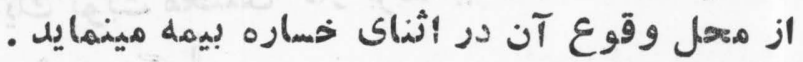

floating asset .

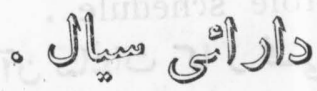

(QUICK ASSET . شود A A

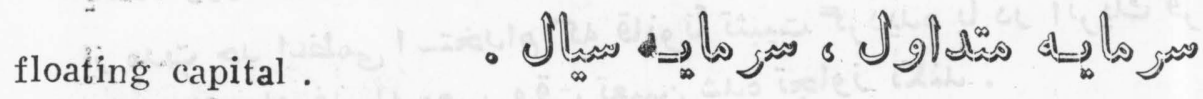
قسمت دارائى سيال يك سرمايه راتَوينل از قبيل انوانتز(موجودى) و ا سنا د دريافتنى 


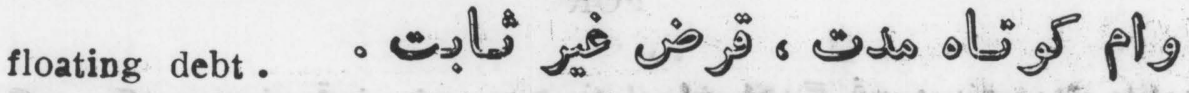

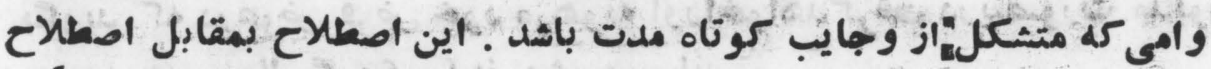

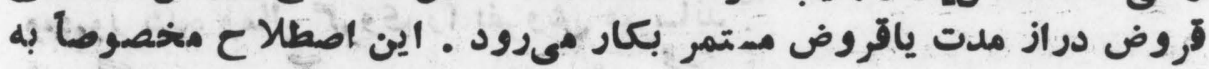

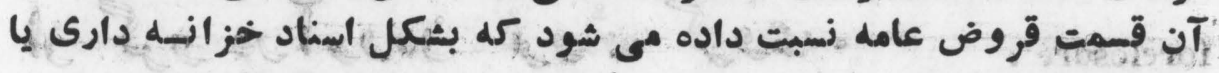

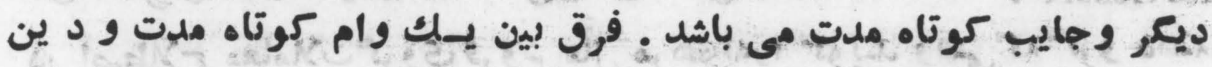

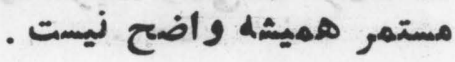

floor trader.

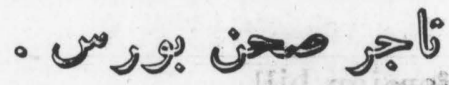

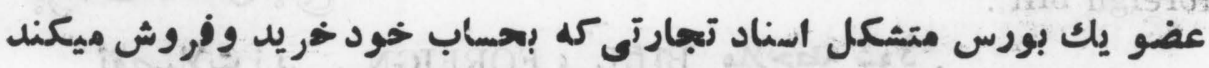

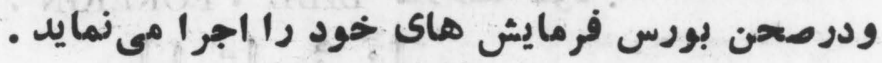
fluctuation .

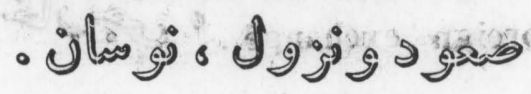

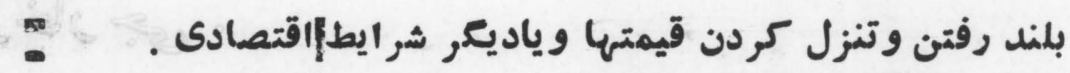
fluid savings .

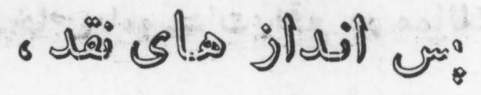

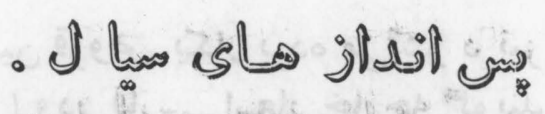

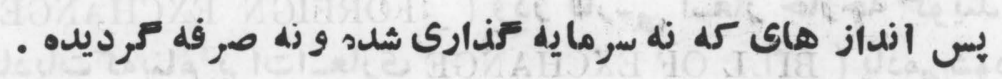
forced loan .

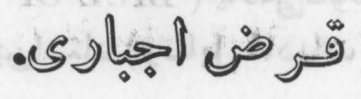

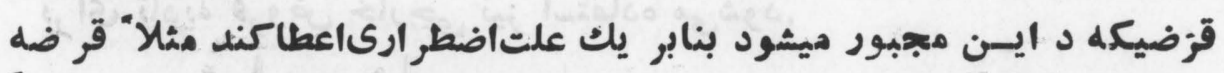

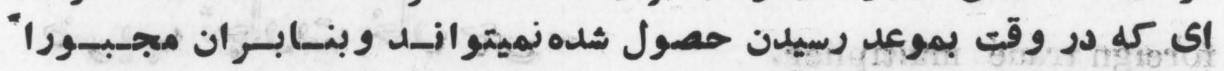

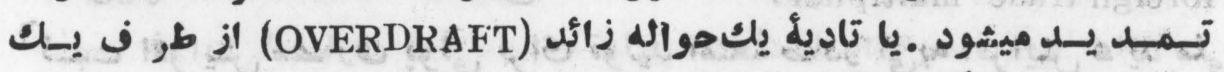
بـانك كه بعداً بيك قرض تبديل ميلك ميشود .

forced sale .

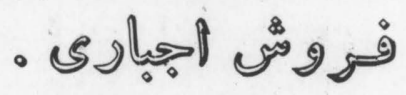
فروشى كه در اثر اقدام يك داين لازمى ميكردد ـ مثلا" دائن التر مديوندر 


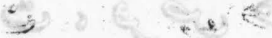

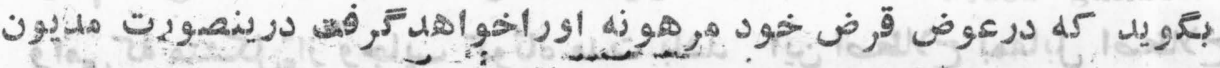
forclosure.

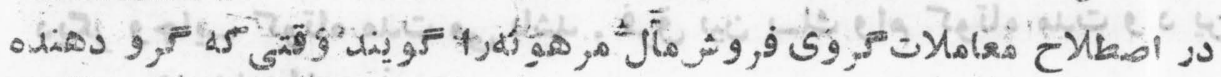

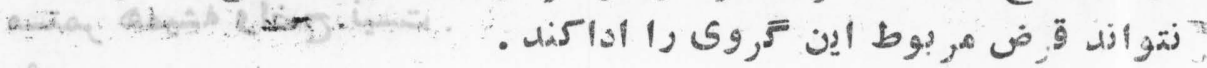

foreign bill .

$$
\text { : ज्ञ }
$$

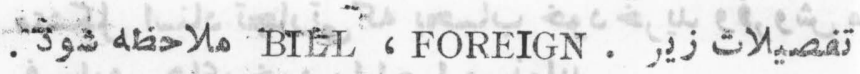

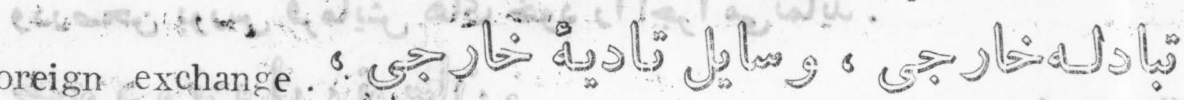

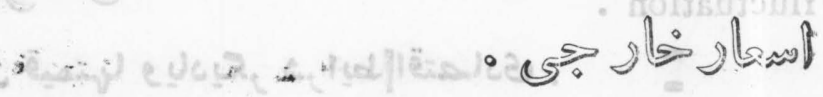

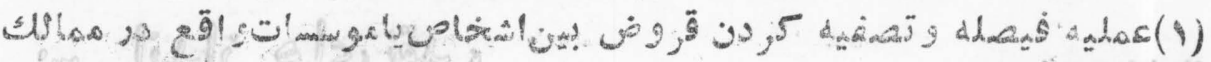
مختختف

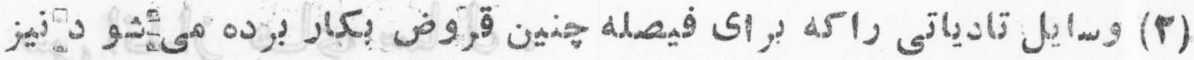

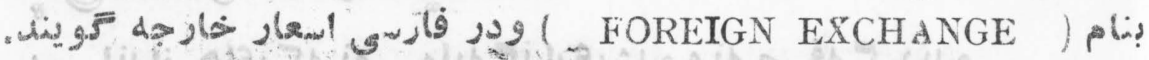

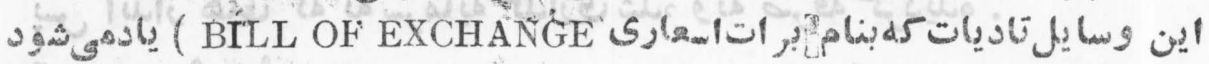

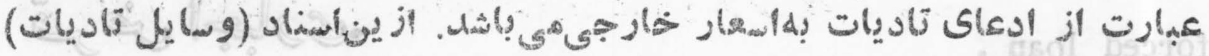

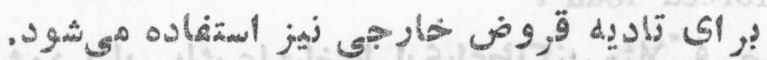

foreign trade multiplier.

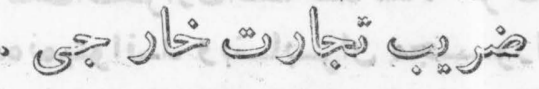

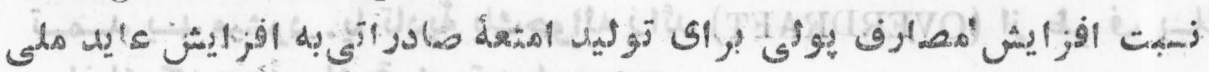

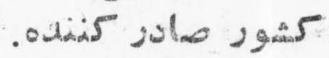
(MULTIPIIER foreeign tradee zone (free port)

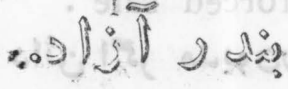

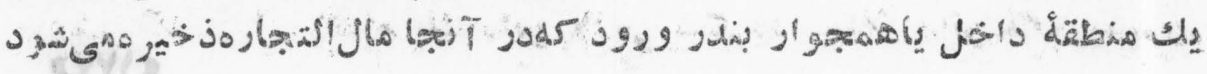




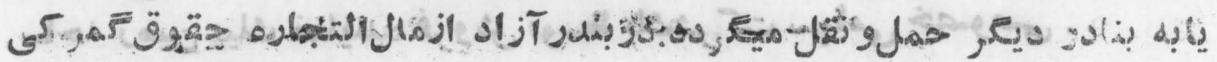

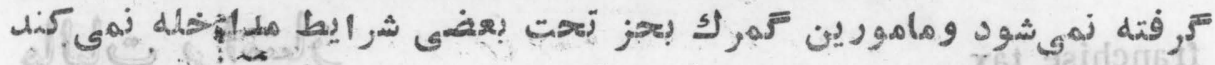

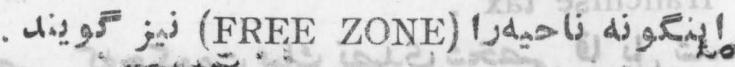
forms of business organisation.

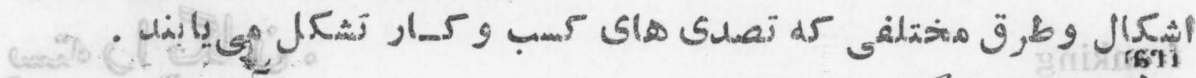

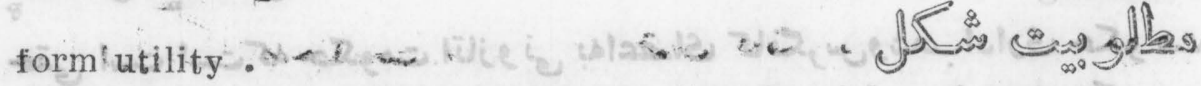

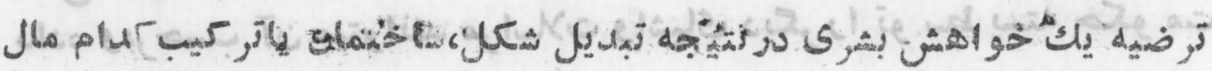

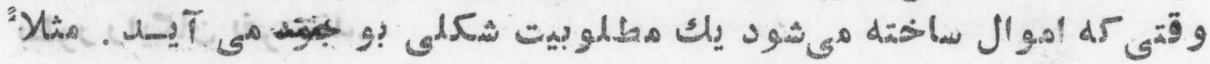

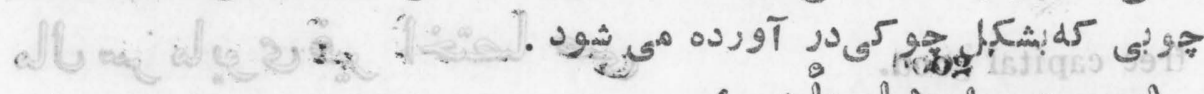

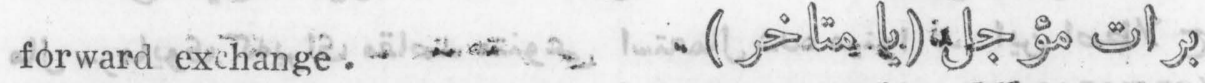

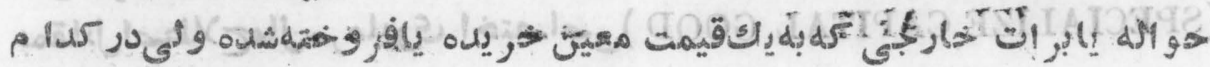

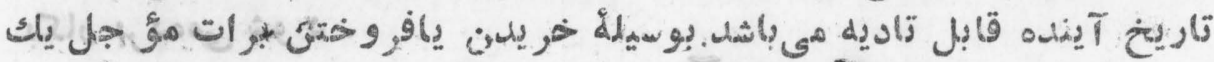

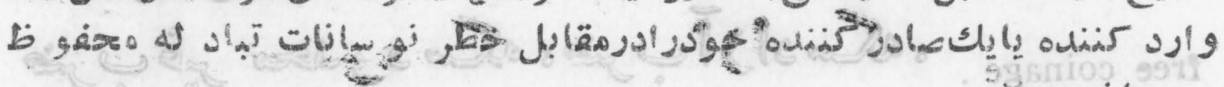
forwarding agent.

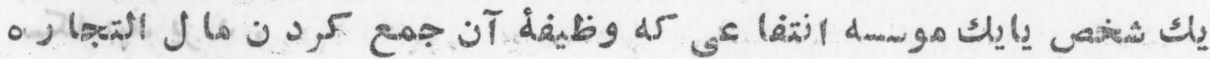
\&.

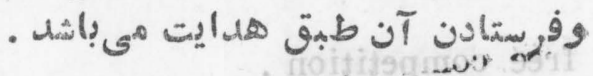

fractional money..

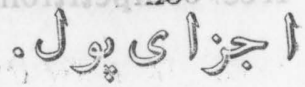

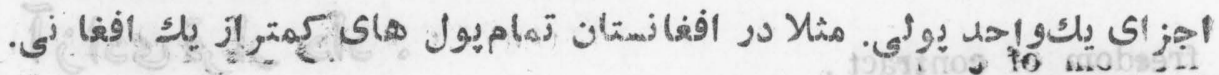

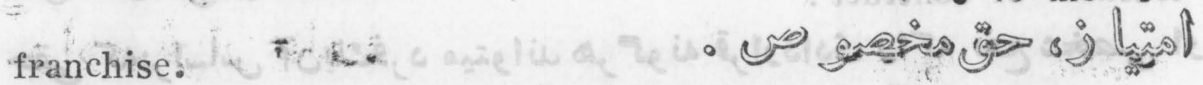

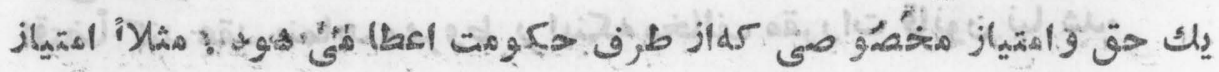

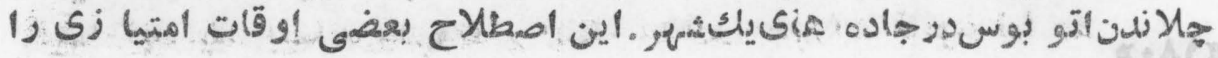




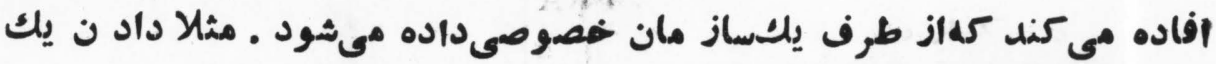

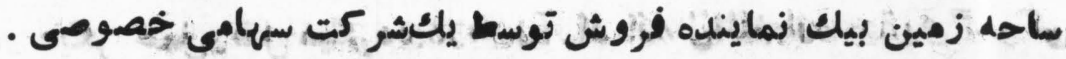

franchise tax.

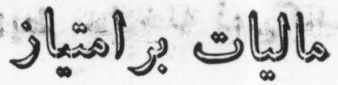
ماليه اى كهاز كدام حقمغضموصى كلهكومت بيك تصدى شخصى قا يل شده

franking

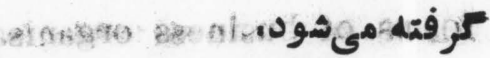
- is

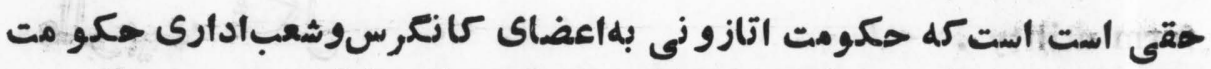

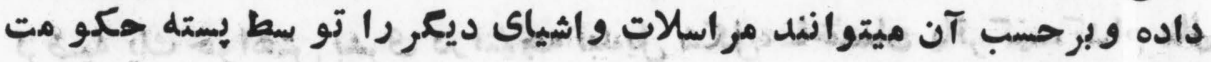
بطور رايعان بفرستند.

free capital good.

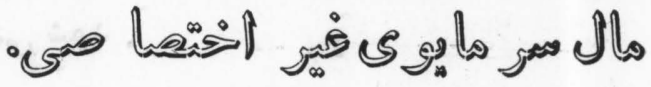

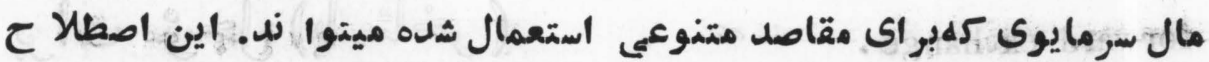

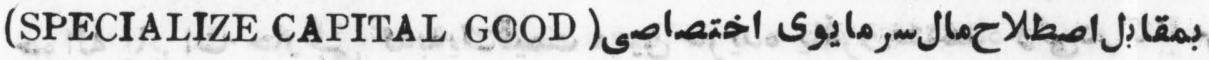

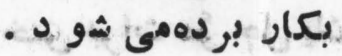

tree coinage. . ه

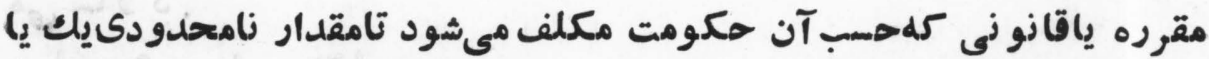

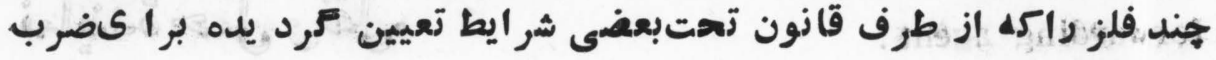

free competition .

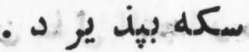

$$
\begin{aligned}
& \text { - } 91 j \pi=0
\end{aligned}
$$

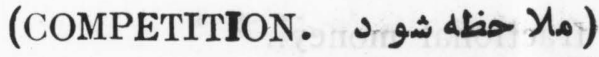

freedom of contract .

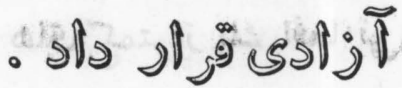

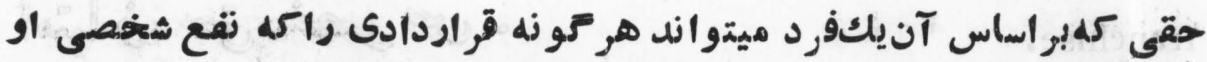

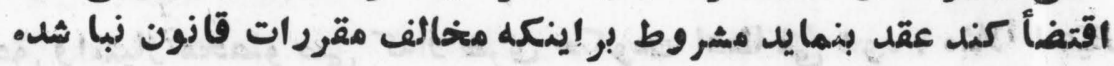

(IA)D 
free good.

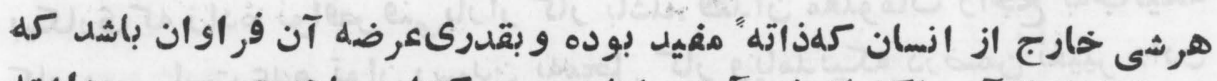

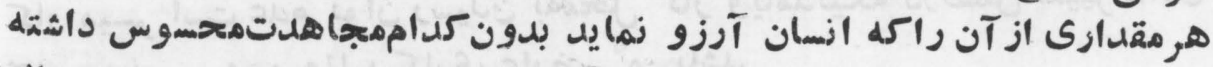

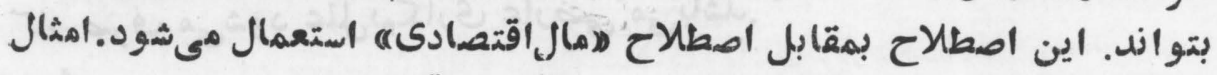

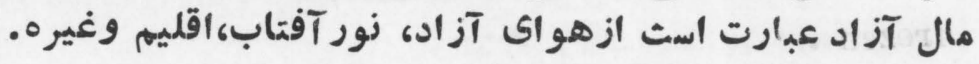

free list.

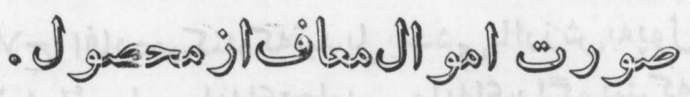

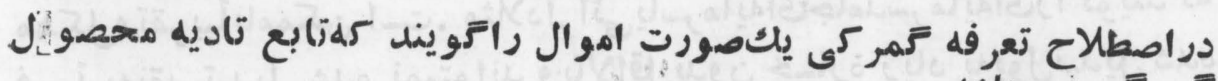

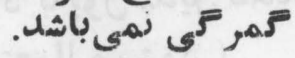

free market . - 20

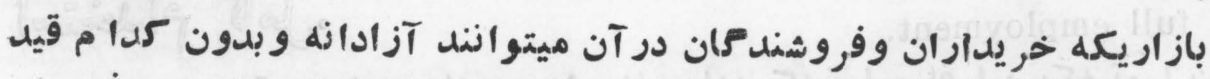

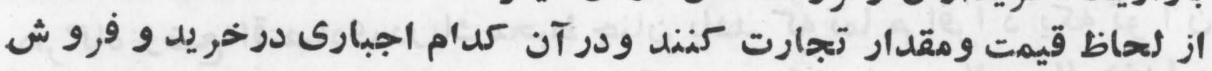

free port . نهى باشلد . ब

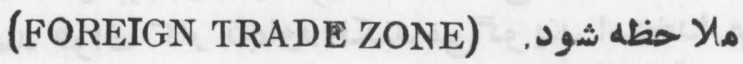
free silver .

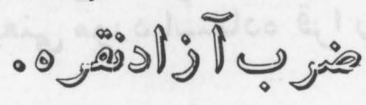

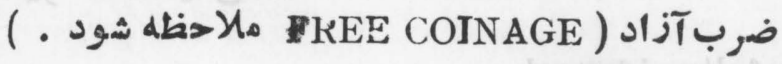
free trade. . 01 j

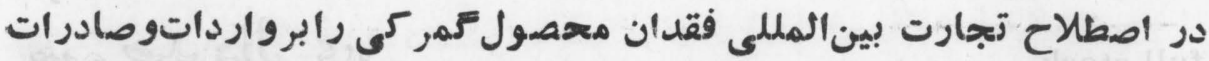

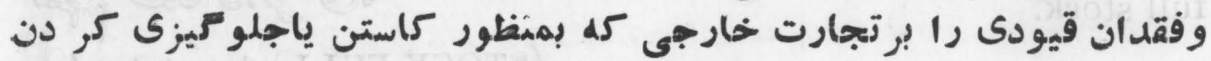

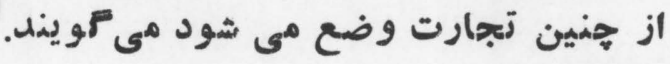


fr.quency.

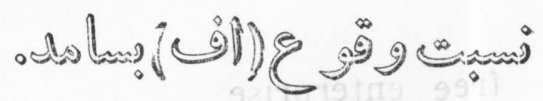

شدت وقوع زسبتى وقأيع.

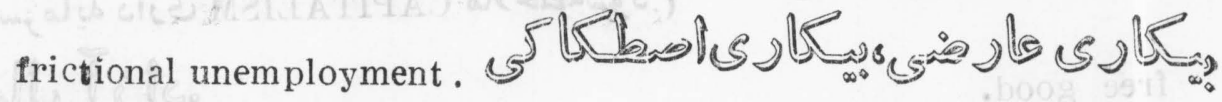

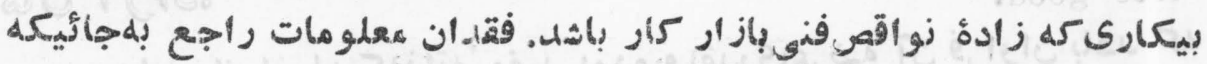

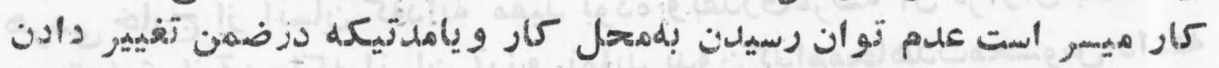

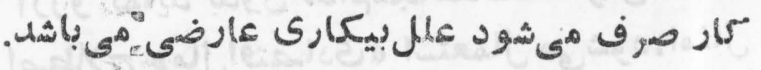

frozen . odo

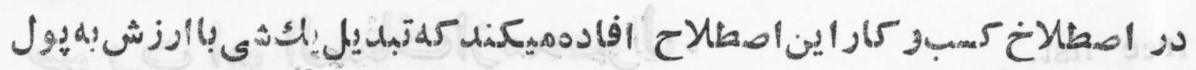

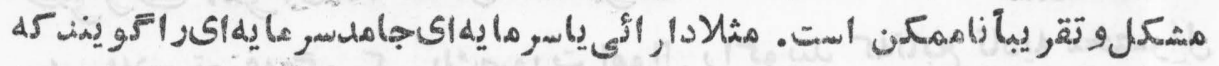

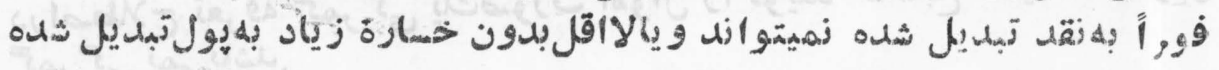

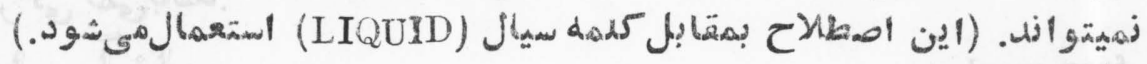

full employment. - J Plis plision

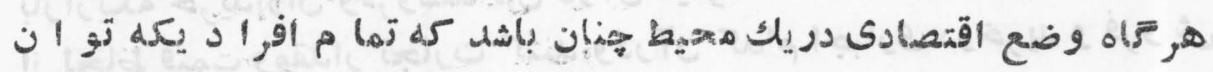

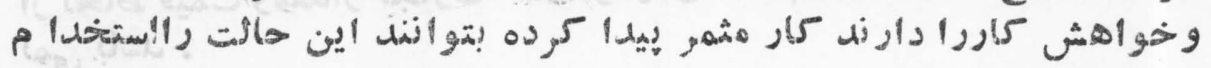

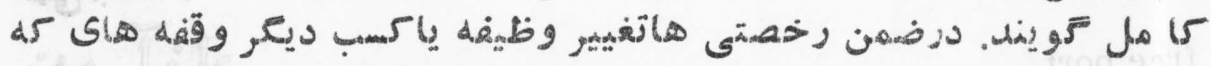

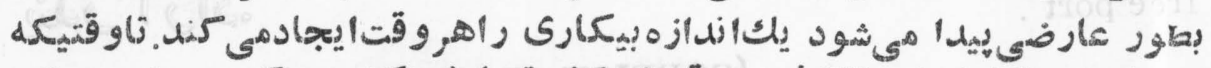

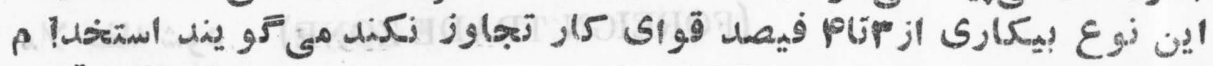

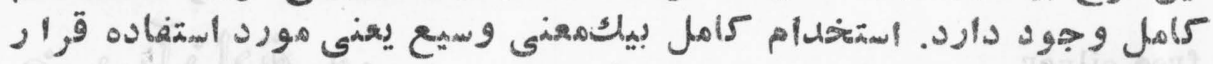

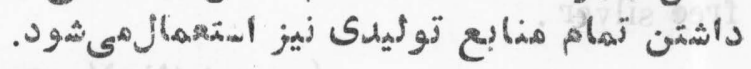
full paid stock.

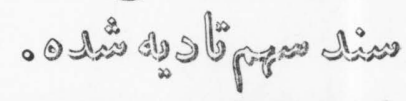

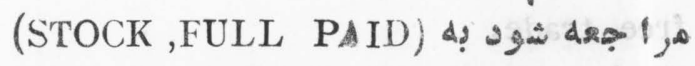
full stock.

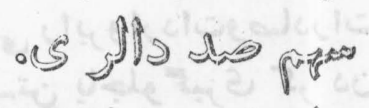
(\$TOCK,FULL) d ه

\section{(APD}


functional distribution .

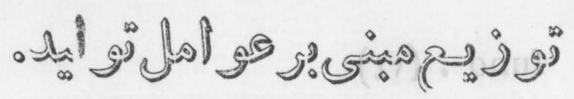

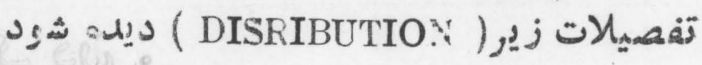

functions of money .

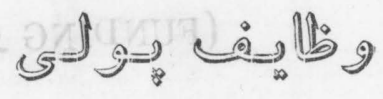

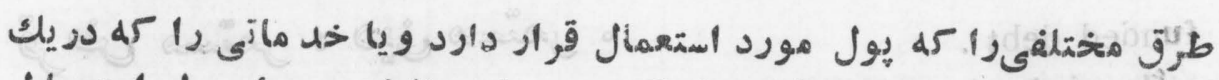

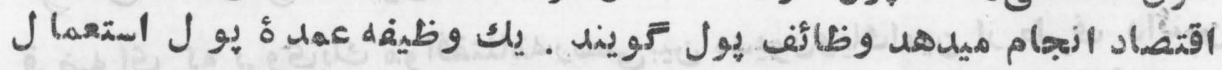

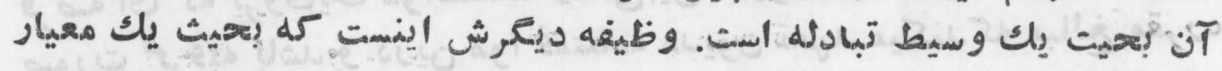

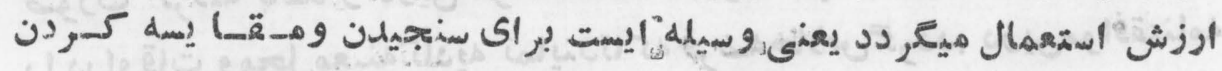

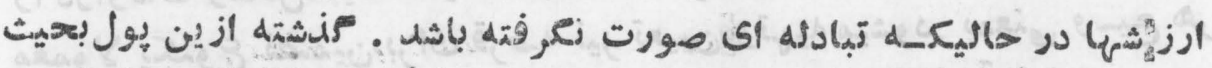

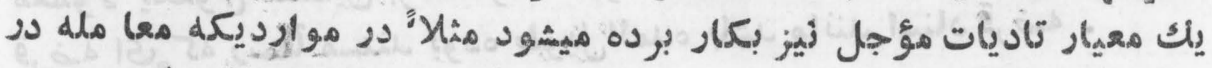

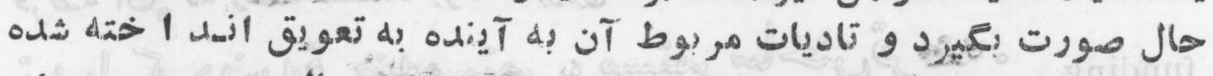

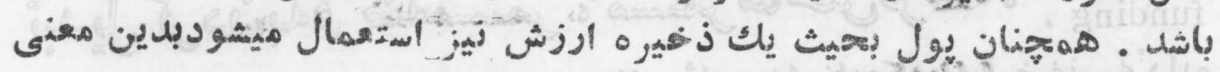

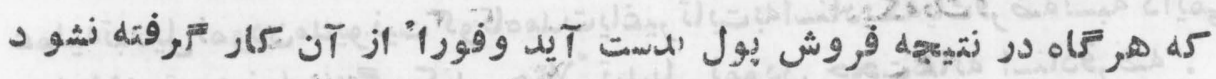

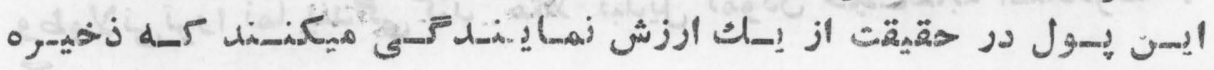

fund, $(\mathrm{n})$

S

$$
\text { - disis } \operatorname{sing} \text { din (ili) }
$$

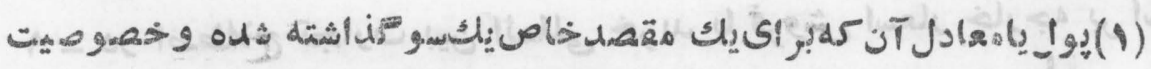

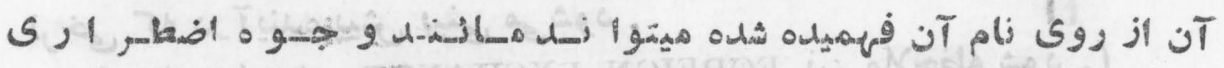
.

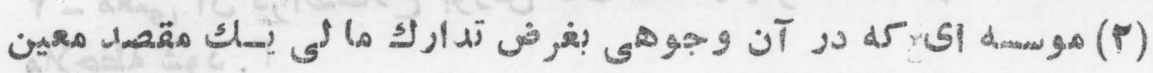

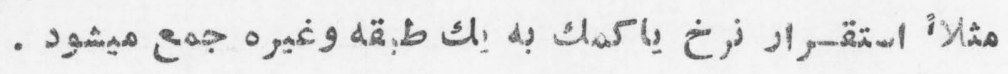


رجوع شود به اصطلحات FUNDING و FUDD DEBT)

funcied debt .

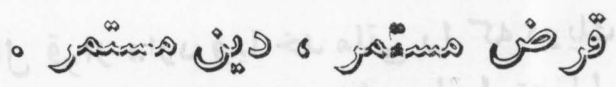

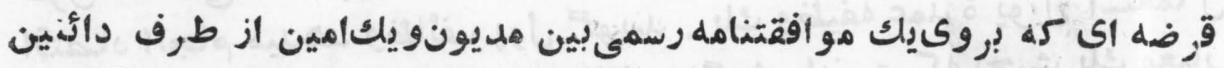

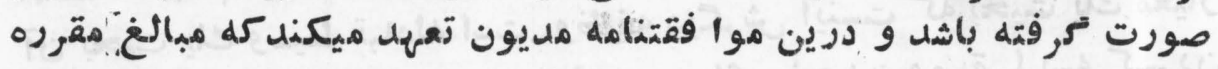

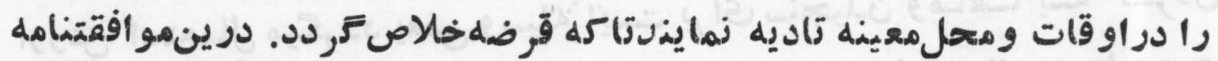

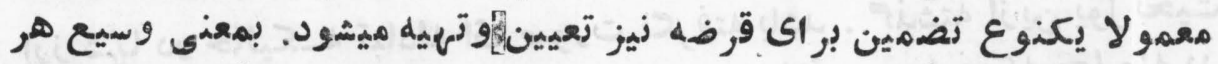

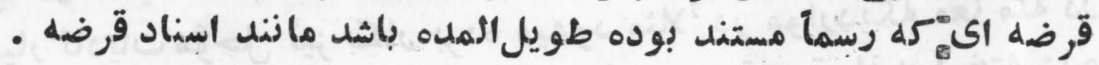

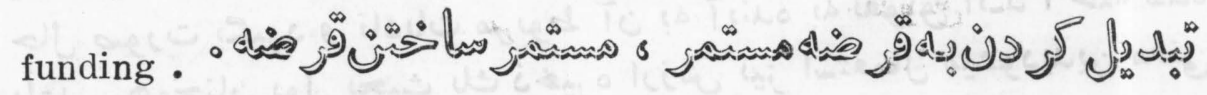

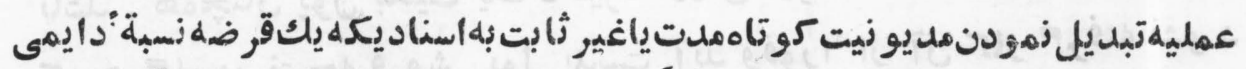

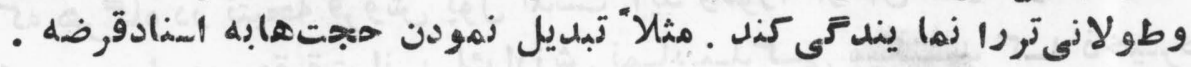

fusion . اين أصطلح مرادف AMALGaMatioN است و در زبان ا زعلييسى أد رتاً futures .

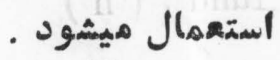
- als ا ـ در اصطلاح زجارت بين المهلى خريد يا فروش اسعار خارجه بر اسا سه

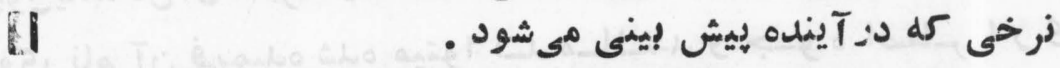
(اسمعار خارجه . FOREIGN FXCHANCE

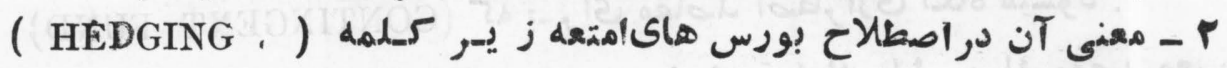
مالاحظه شود . مان 
gain sharing .

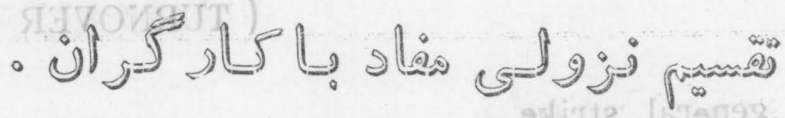

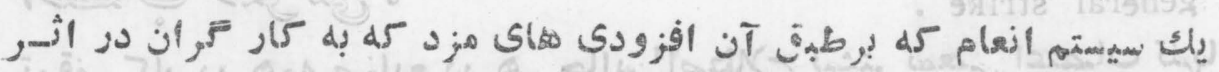

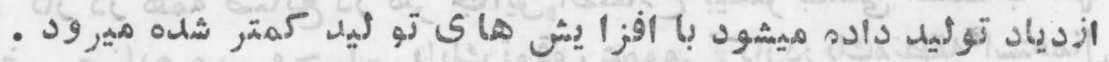

garnishment .

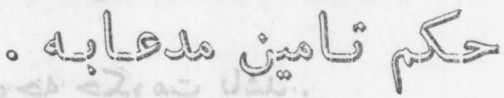
هـ

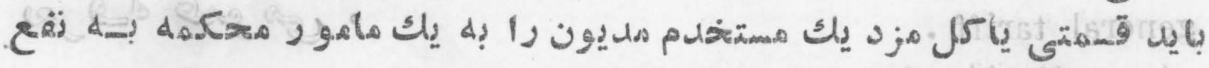

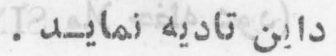

general depositary. - jagas c g ginana

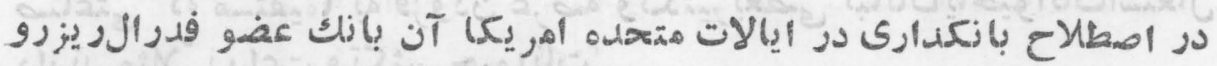

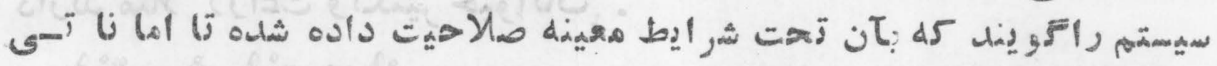

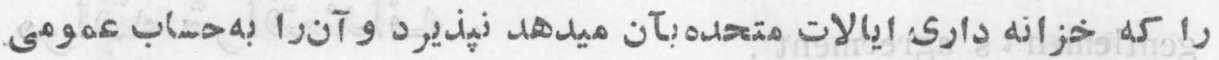

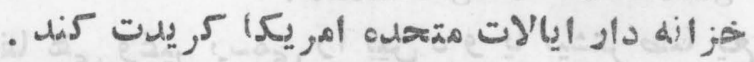

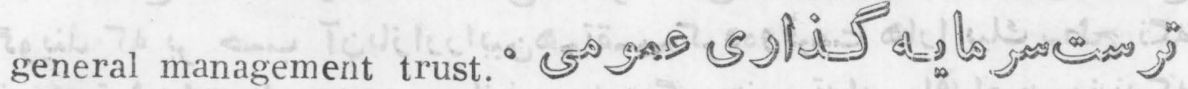

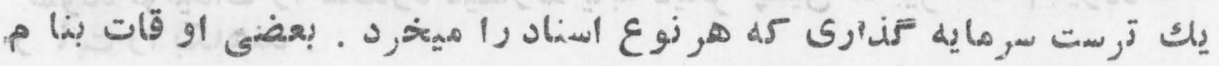
• نيز ياد هيشيون (DISCRETIONARY TRUST)

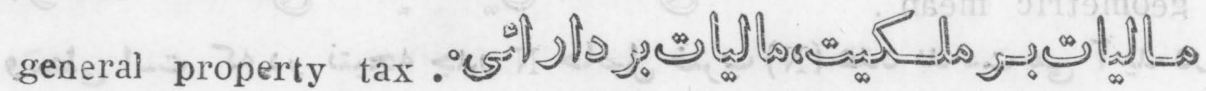

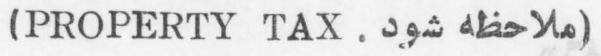




\section{GEN}

general sales tax.

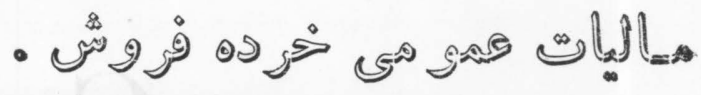

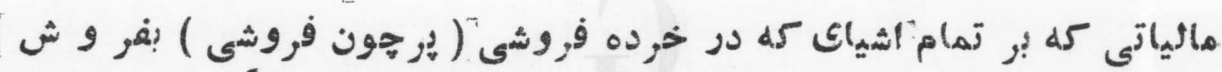

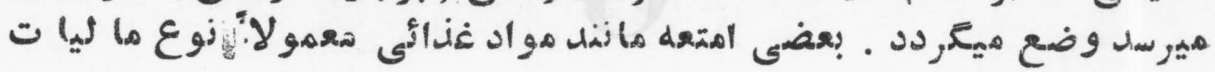

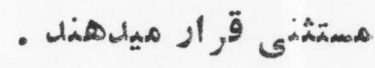

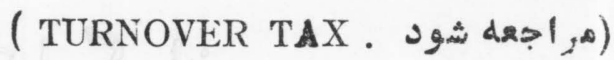

general strike .

$$
\text { - जo gos }
$$

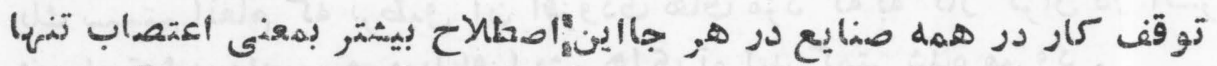

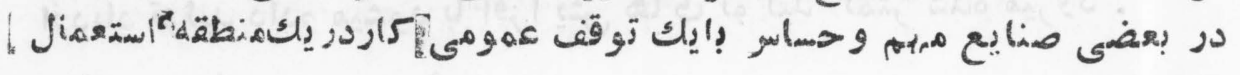
ميثيود .

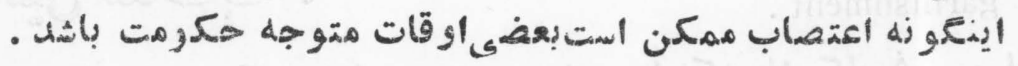
general tariff .

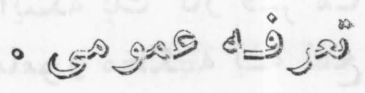

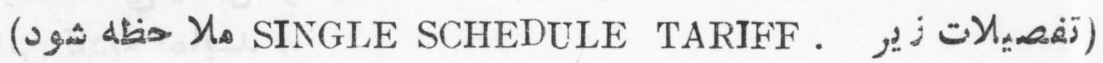
genetic industry .

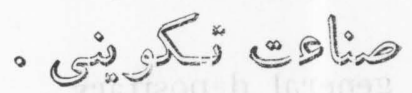

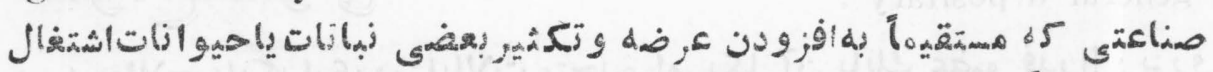

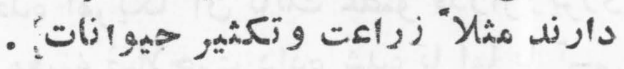
gentlemen $6 \mathrm{~s}$ agreement .

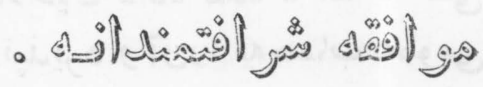

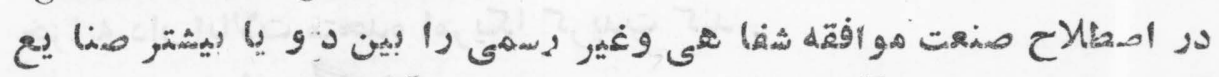

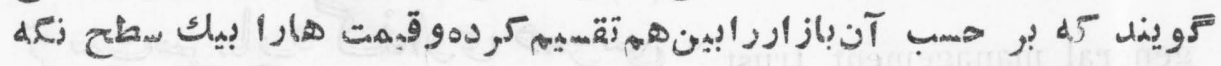

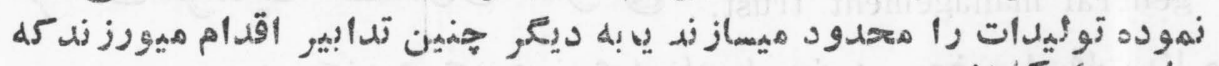

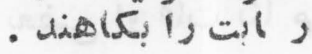

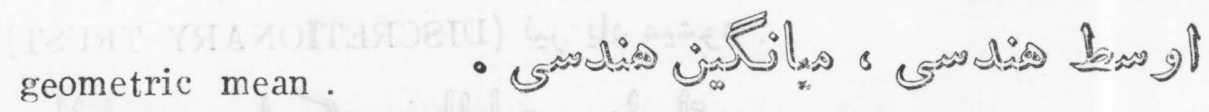

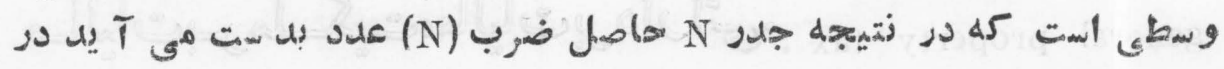


حاليكه (N) عده ارقامى است كله أوسط آذر ا ميخو اهيم دريا بيم

$$
\begin{aligned}
& M \xi=\sqrt[n]{a_{1} a_{2} a_{3}} \quad: v_{n} \\
& \text { vish }=m_{3}
\end{aligned}
$$

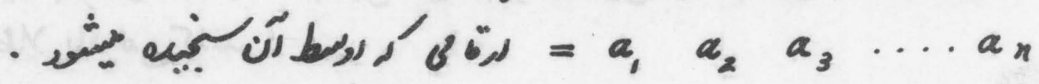
r en $n$,

gift tax.

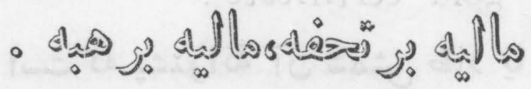

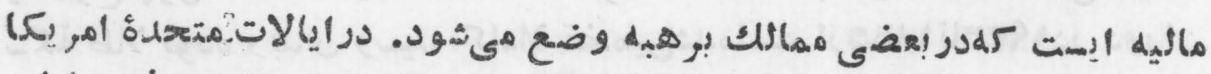

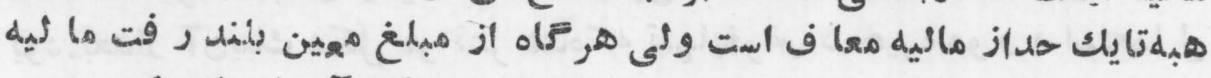

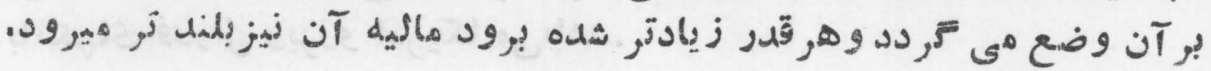

gift edge security .

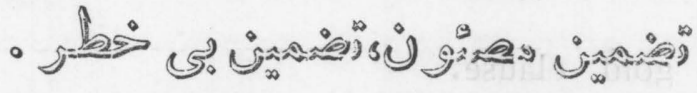

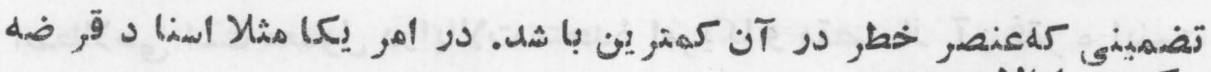
going value. حكومت ايالات متحدهد. -

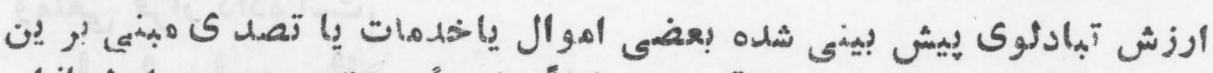

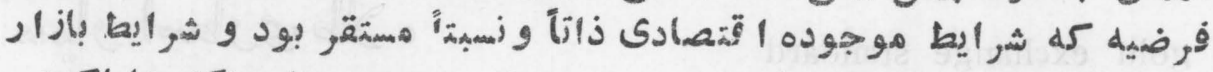

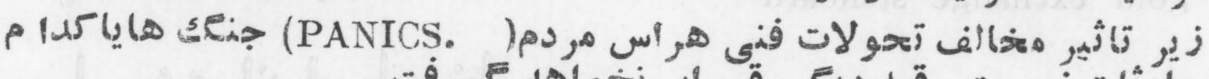

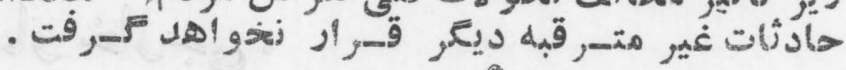

gold bond.

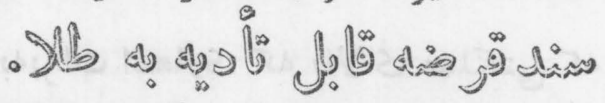

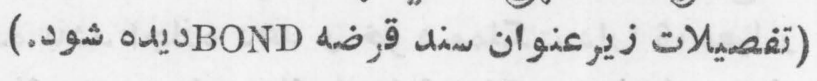

gold bullion standard.

$$
\text { \& لUb }
$$

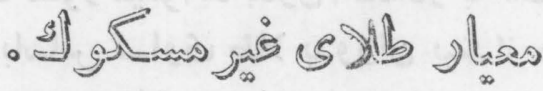

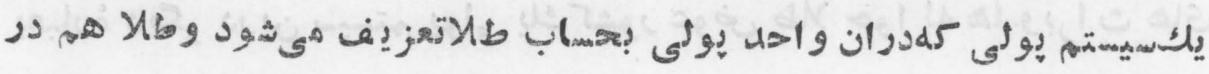


GOD

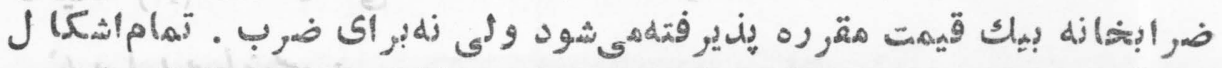

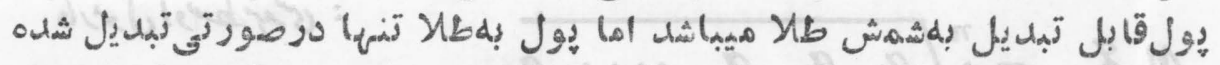

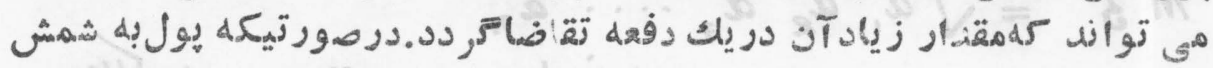

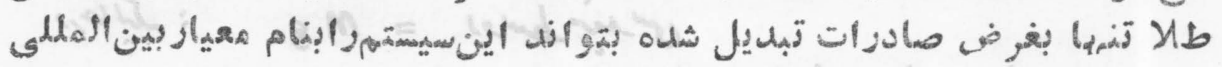

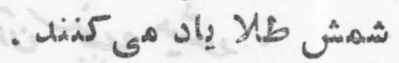
gold certificate.

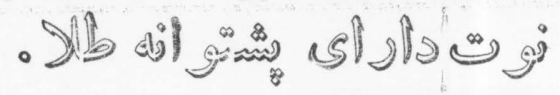

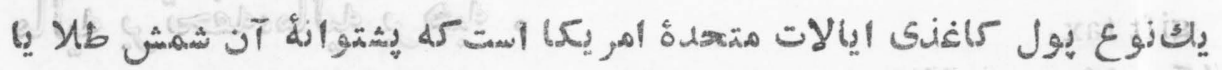
س.

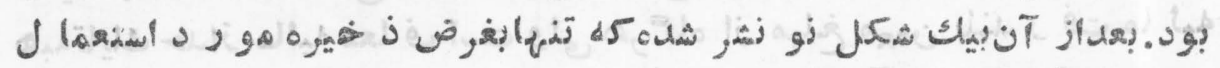

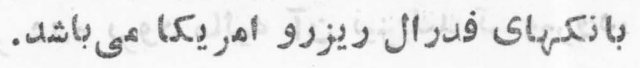
gold clause.

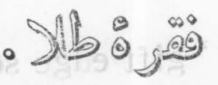

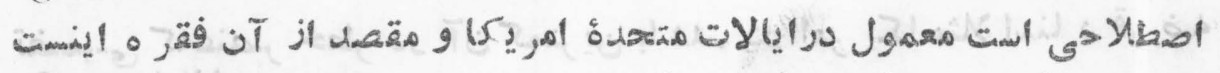

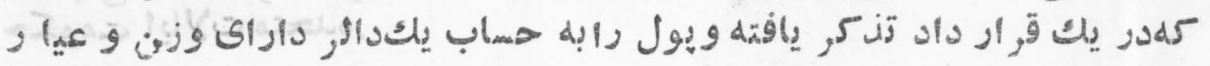

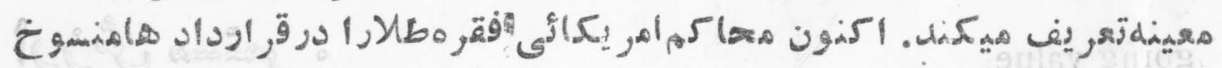

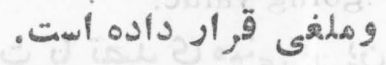
gold exchange standard

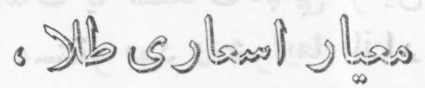

-

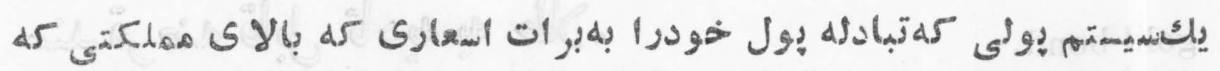

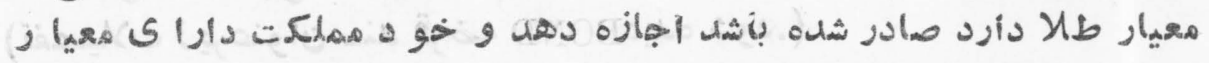

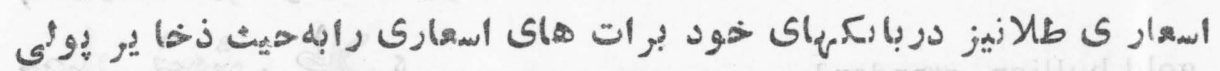

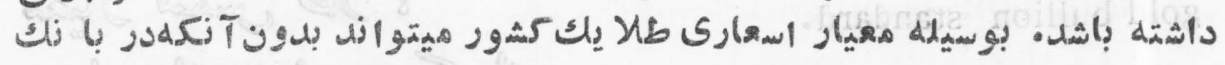

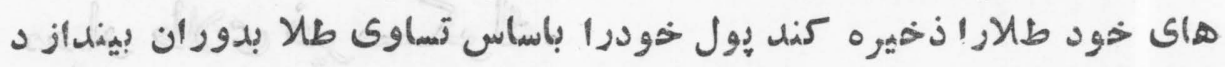

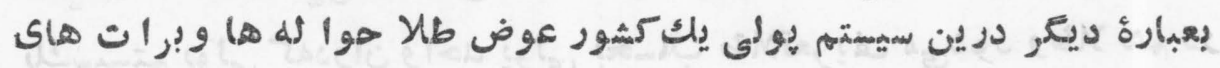

(I )ADD 


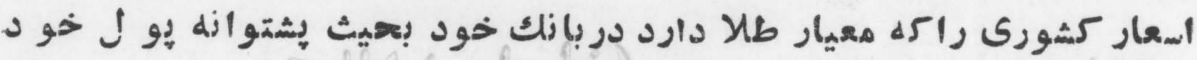

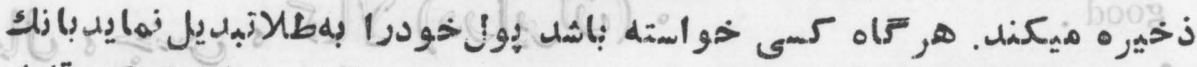

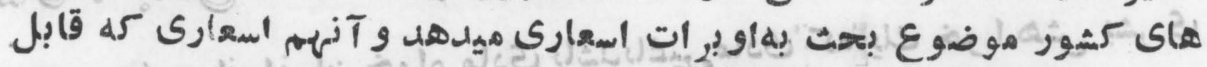

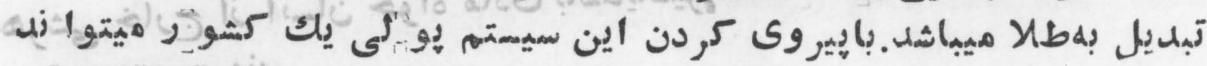

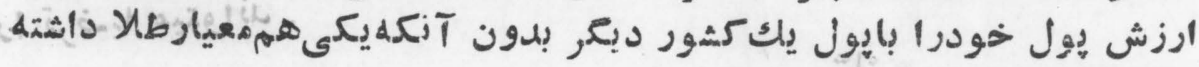

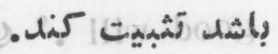

gold points.

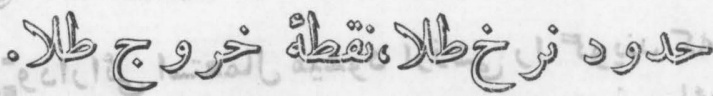

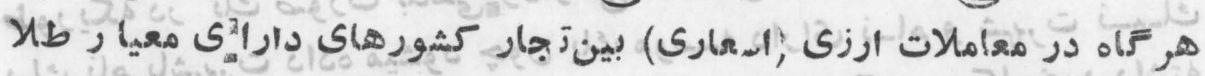

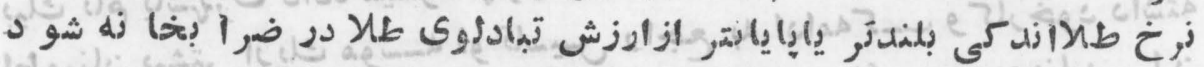

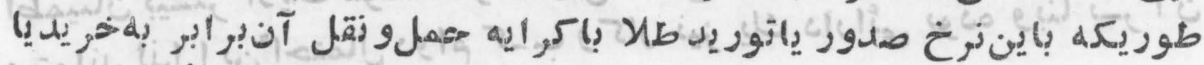

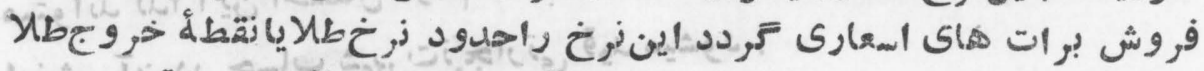

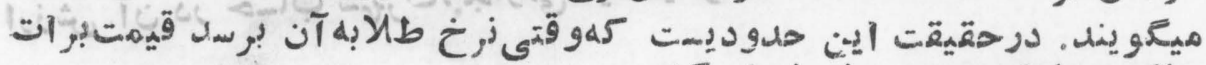

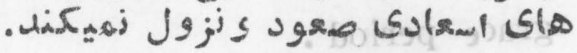

gold settlement fund.

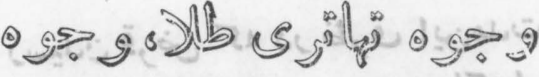

$$
\begin{aligned}
& \text { - Nb A }
\end{aligned}
$$

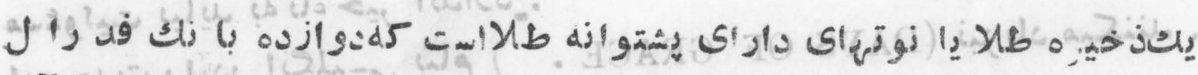

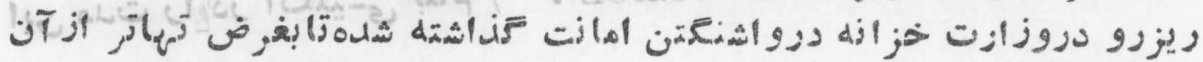

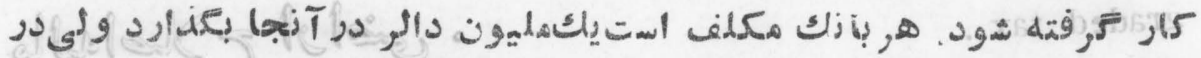

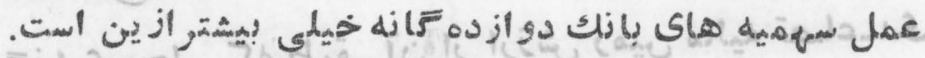

gold standard:

$$
\text { - Vhbs= }
$$

يكسمبستم مولى

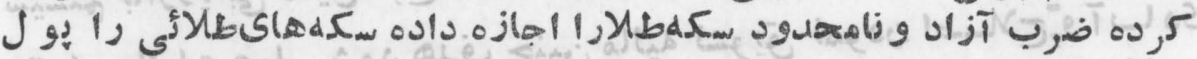

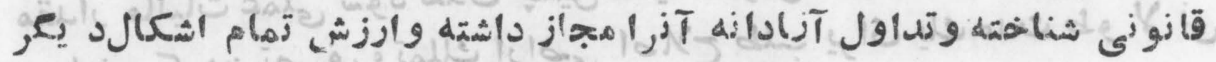

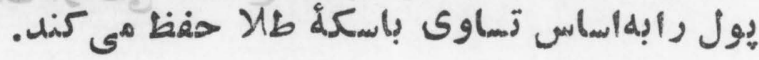


good .

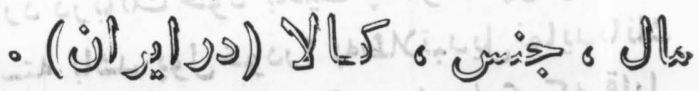

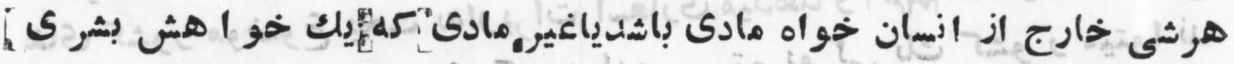

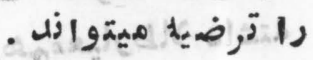

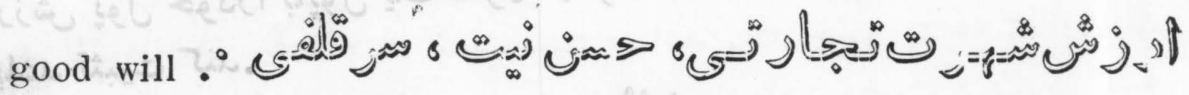

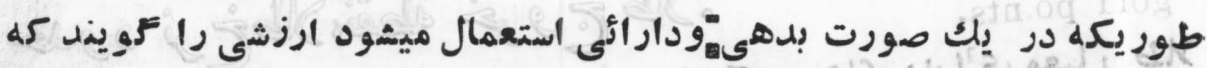

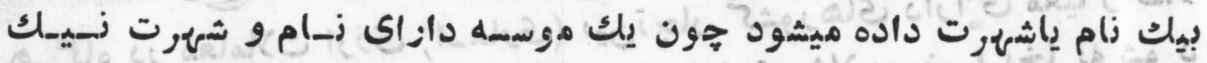

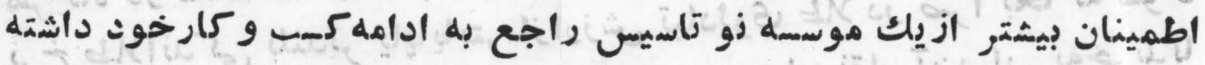

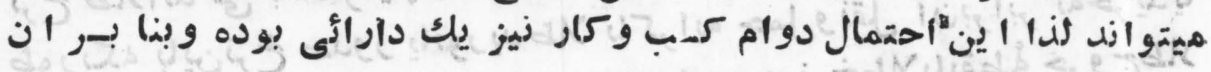

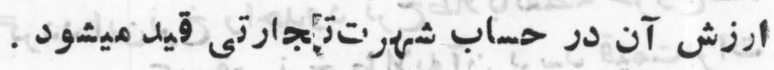

grace period.

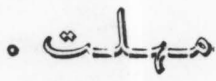

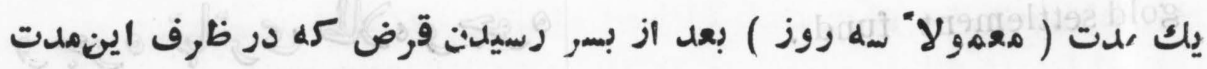

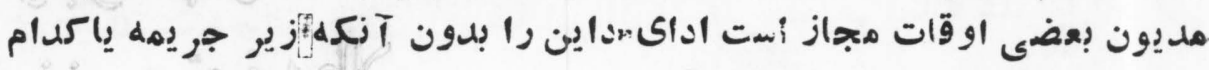

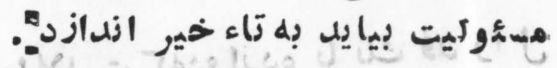

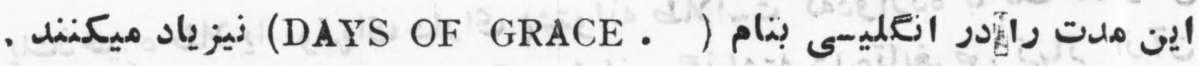
graded tax .

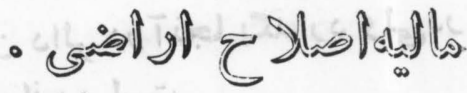

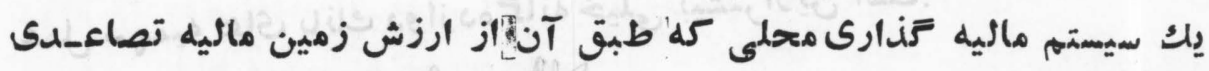

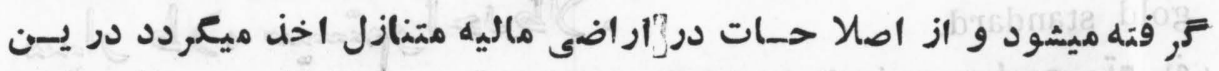

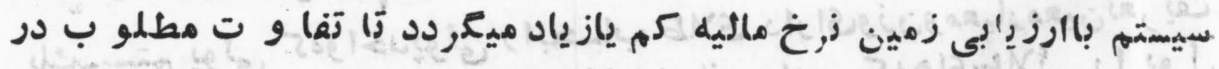

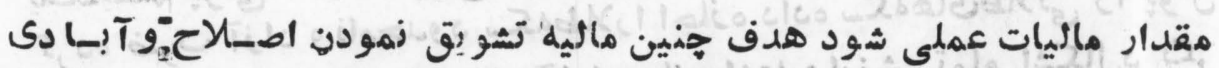

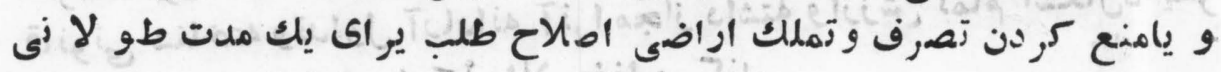
مييداشل . 
grade lebeling .

- inisis dos do

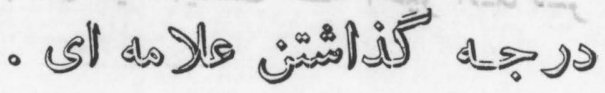

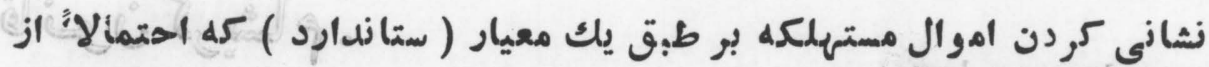

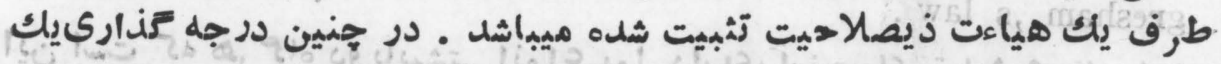

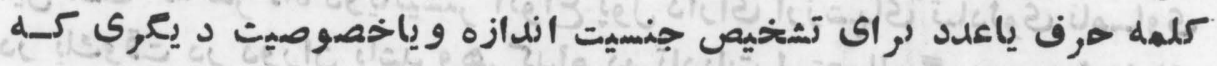

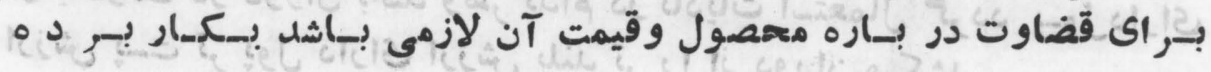
ميشود .

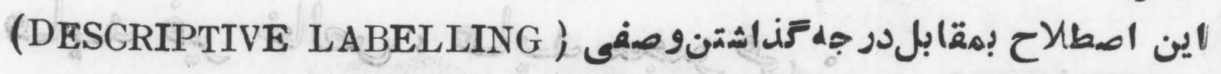

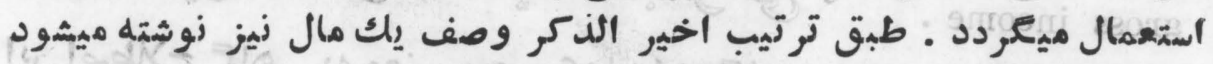
ولى آنرا به مدام معيار معرو موف نسبت زميدهند .

gratuitous coinage .

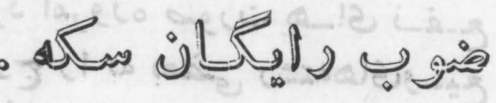

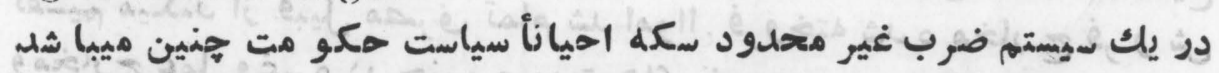

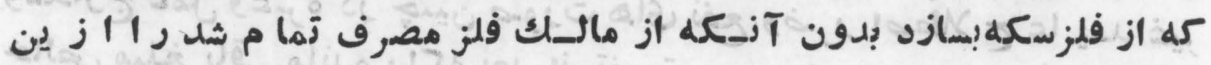
دركب بعيرد.

grave yard shift . O S

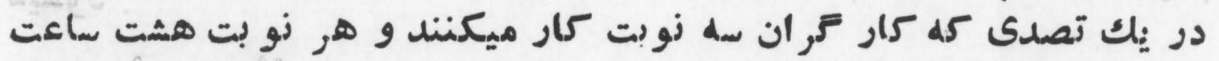

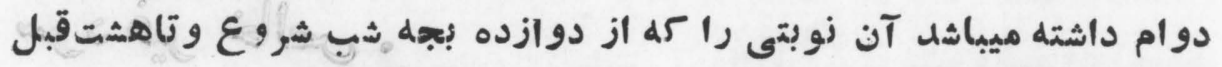

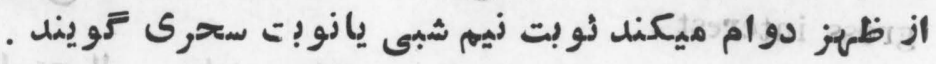

gray market.

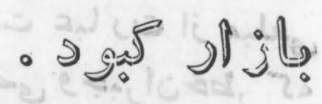

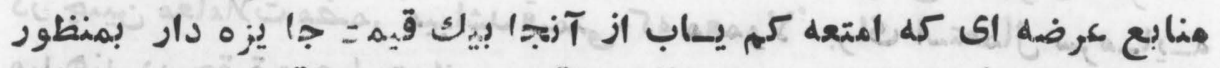

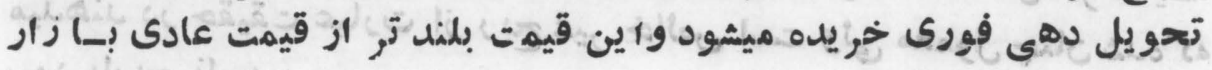
ميباشيل . 


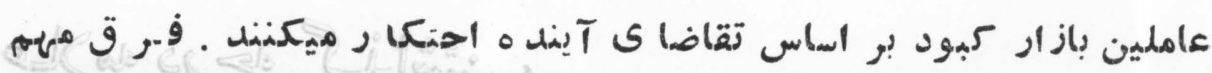

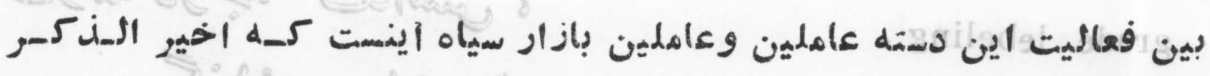

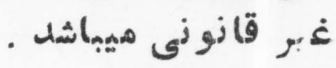

gresham,s law .

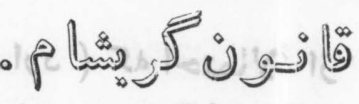

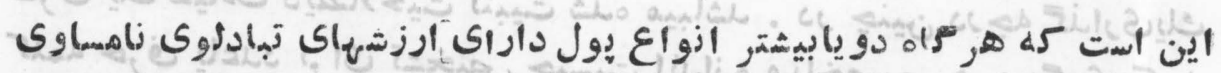

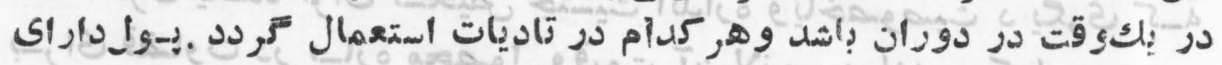

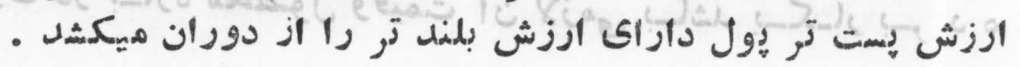

gross income.

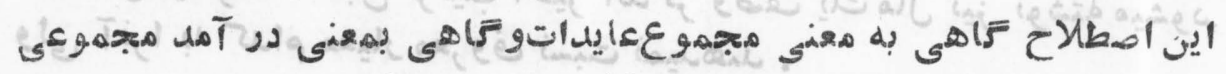

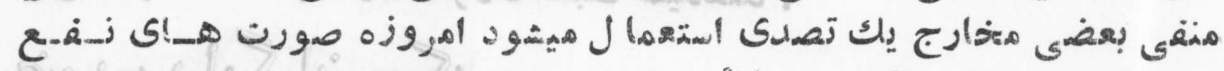

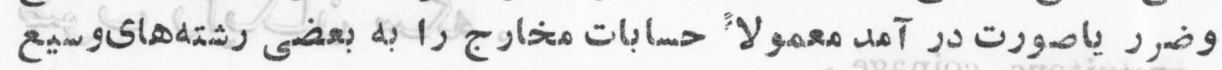

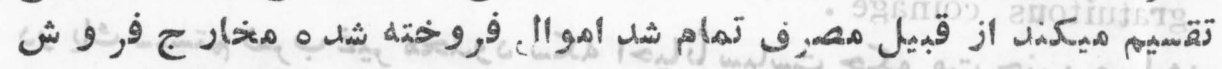

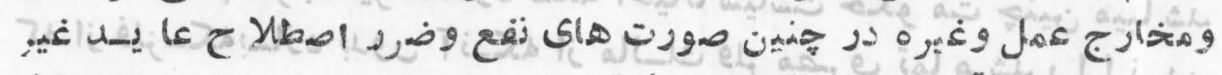

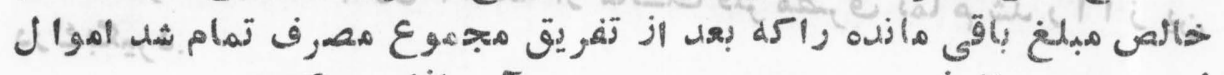

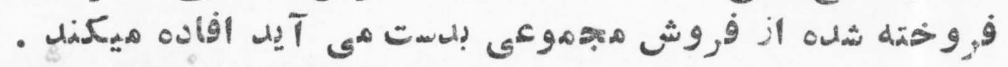

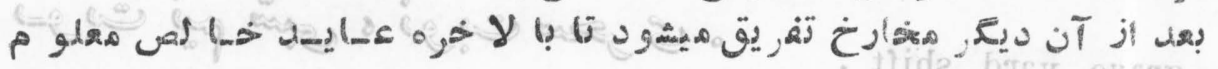

gross interest?

$$
\therefore 29
$$$$
\text { - volly ja }
$$

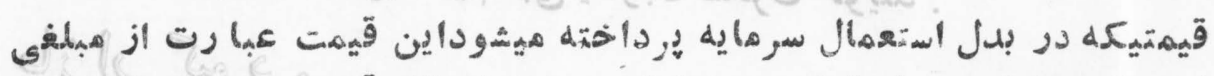

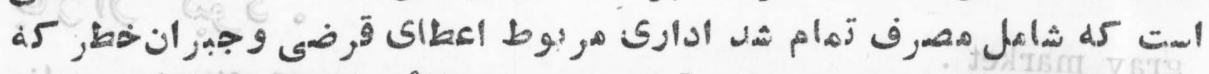

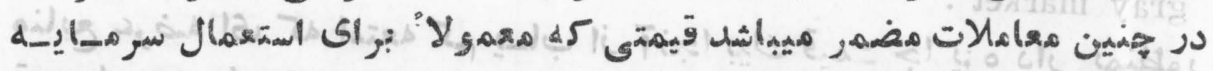

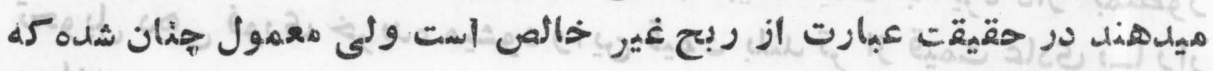

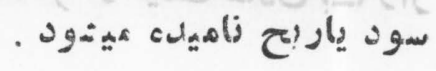


gross national debt . -

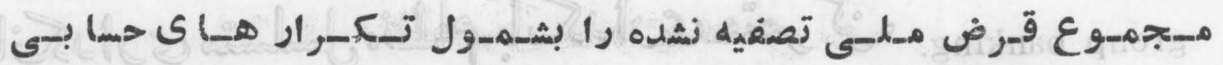
(DUPLICATIONS)

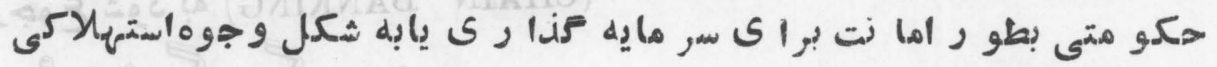

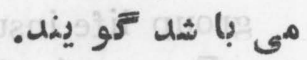

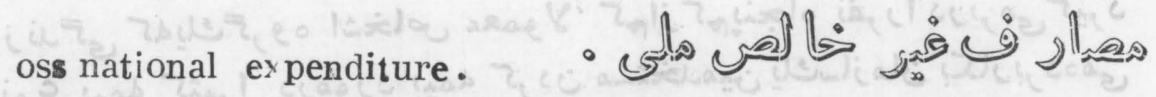

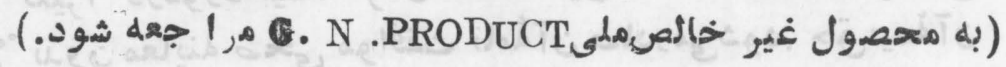
gross national product.

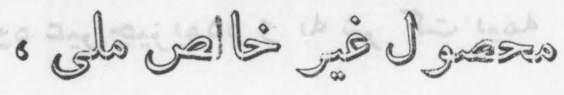
ن

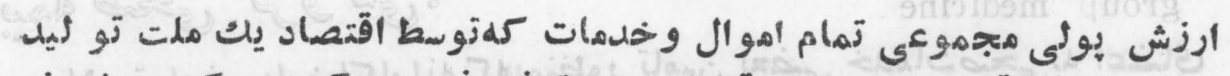

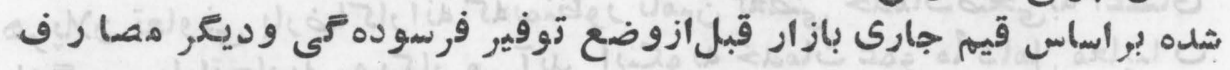

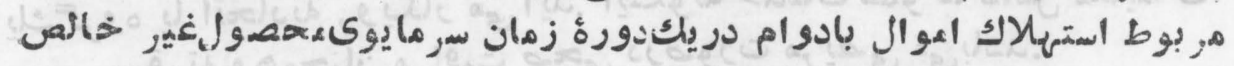

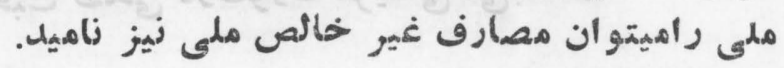

gross profit .

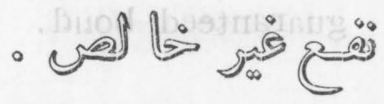

(تفصيلات زير نةع . ديده شود PROFIT)

gross receipts tax

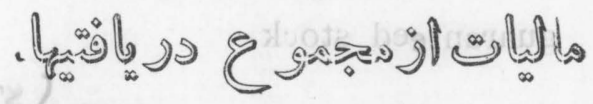
مالياتى كهاز روى مجموع دريافتى سنجيده واخل مى شود زه از تفع. ground rent. - نं:

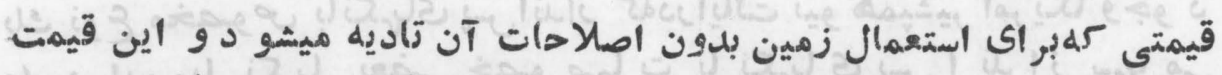

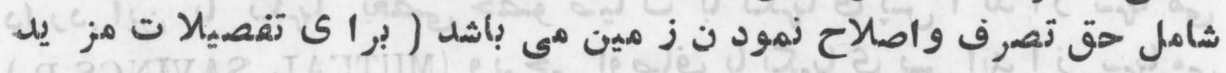

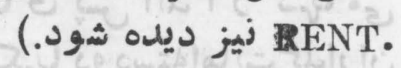
(c) 9 ro 


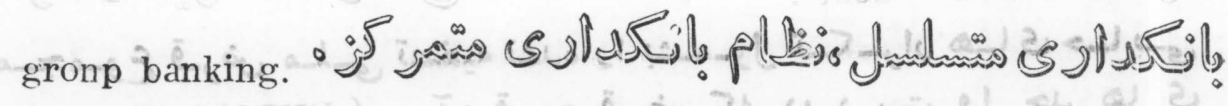

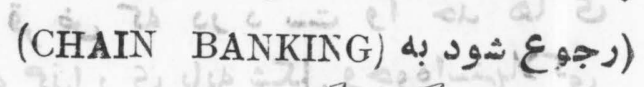
group life insurance. بيمه ز زند

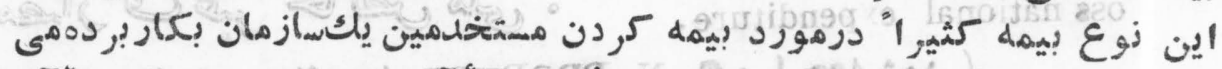

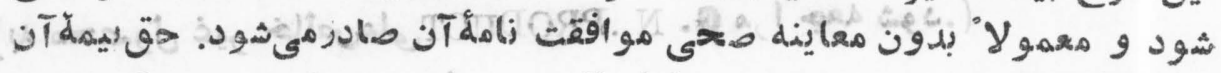

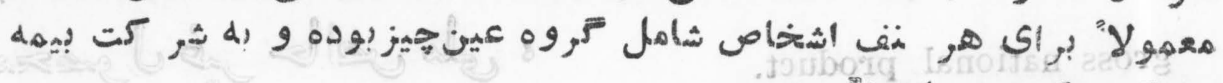

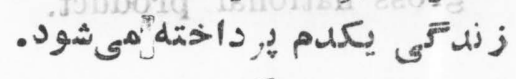

group medicine.

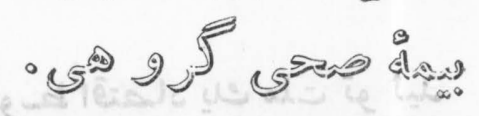

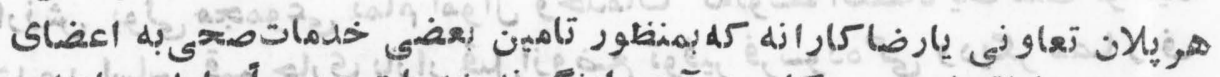

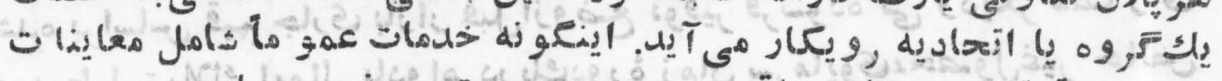

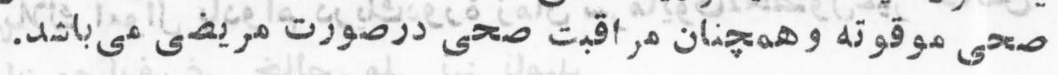

guaranteed bond.

$$
\text { - هU }
$$

(BOND,GUARANTEED) رجوع شود به

guaranteed stock.

$$
\text { - OA }
$$

(STOCK,GUARANTEED.) رجوع شودبه

guaranty savings bank.

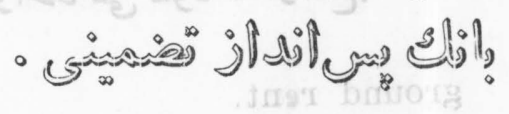

يك نوع مخصوص بانكمهاى يسانداز كلدرايالت نيو هميثير امر يكا وجو د

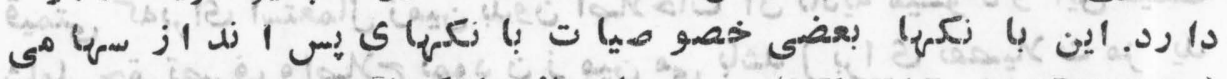

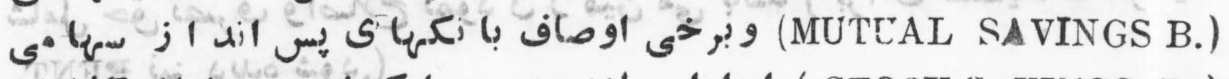

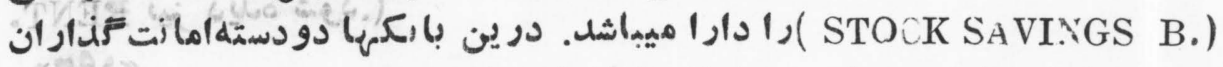

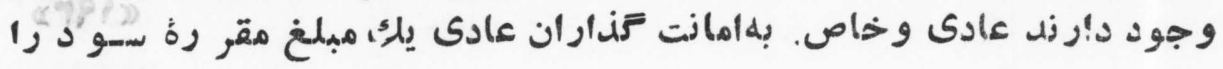




\section{GUI}

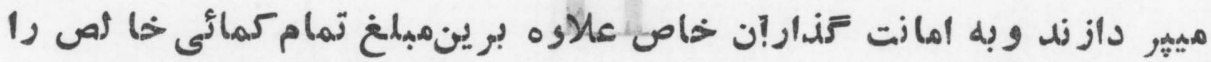
نيز تاديه ميكنتله...

guild.

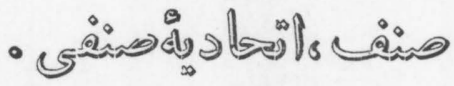

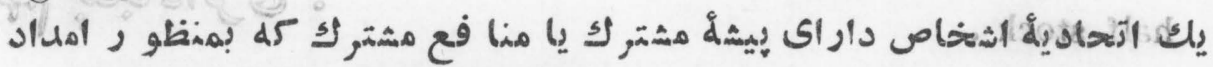

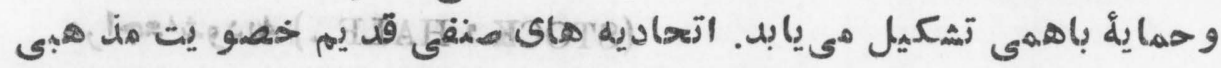

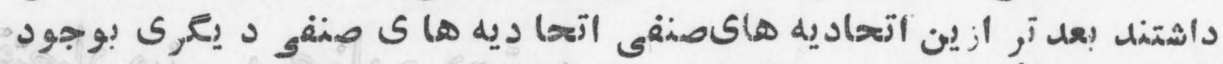

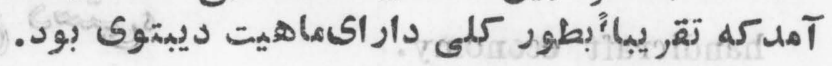

guild socialism.

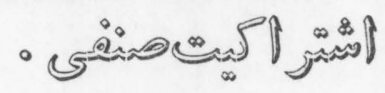

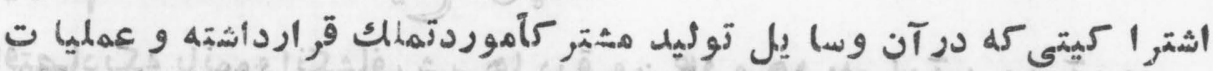

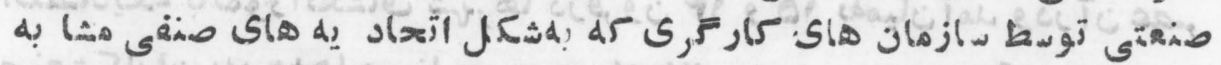

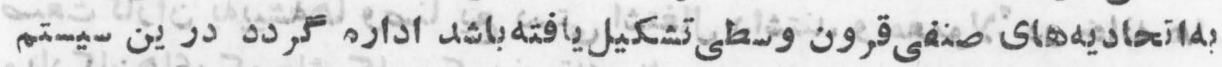

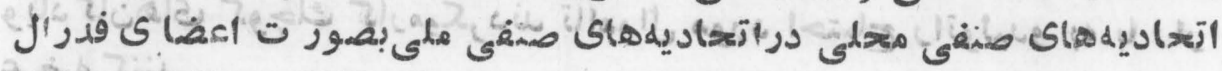

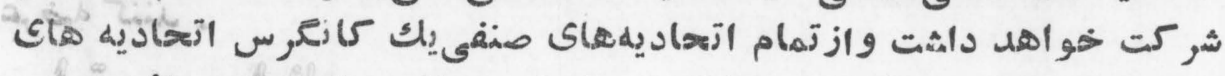

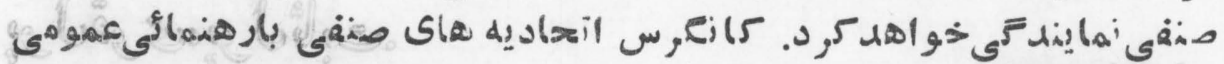

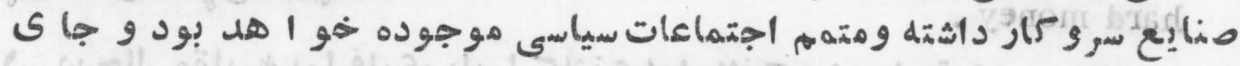

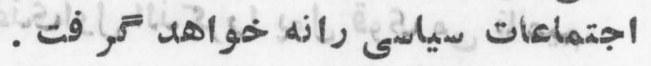

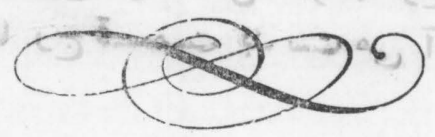




\section{H}

half stock .

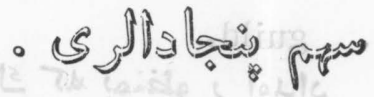

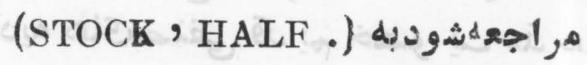

handicraft economy.

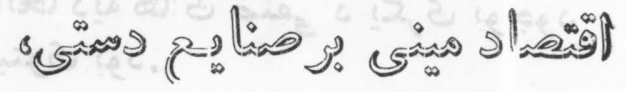

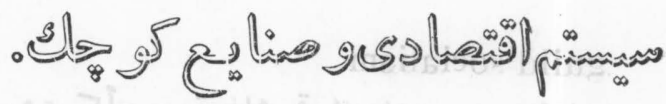

اقتصاديكه بانموو انكشاف شهر ها درقرون ها و ه1 بهميان آمله ودر آن عصر

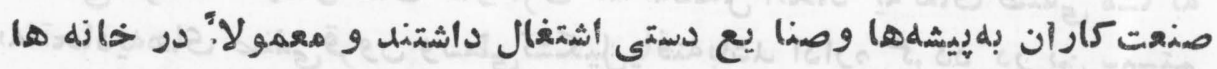

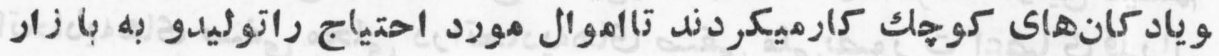

hard money .

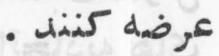
•?

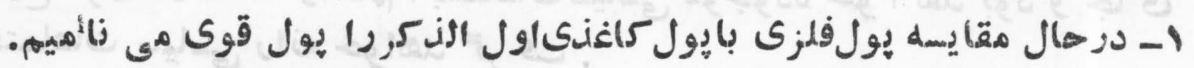

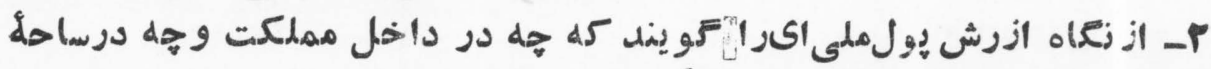

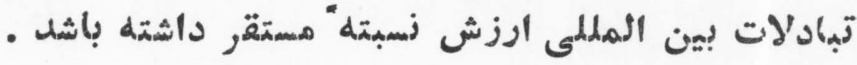

harmonic mean.

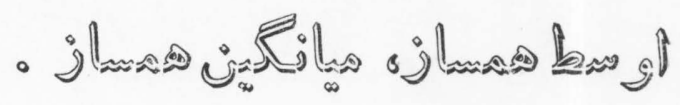

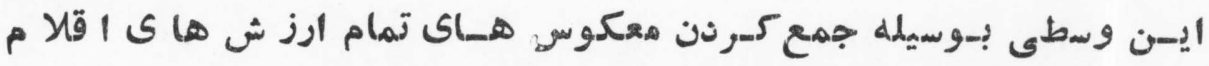

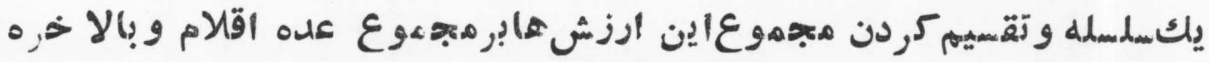

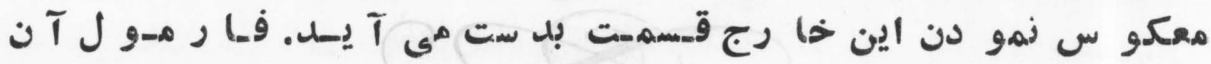
(1990 از ينقر اراست. 


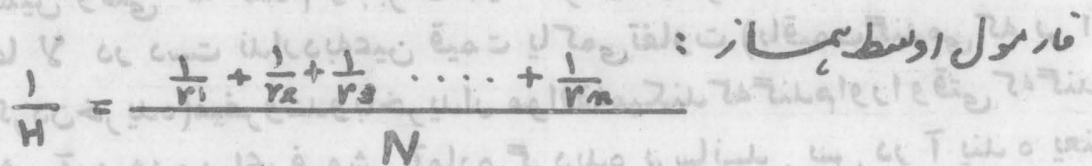

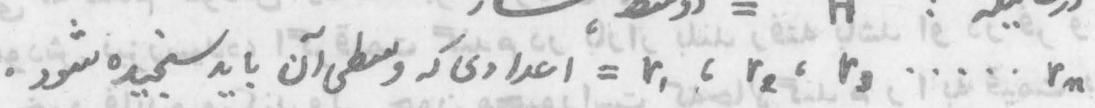

$$
\begin{aligned}
& \text { गe, } \varepsilon \text { ? }=N
\end{aligned}
$$

اصطلاحميا نعينهم-زيكاصطلاحاير انى استودرفارسى افغانىمأنوس زيست headright .

$$
\text { - @ }
$$

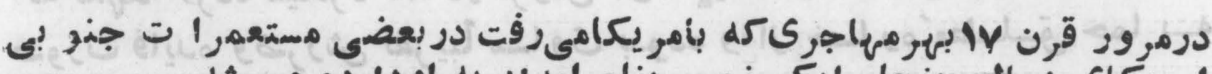

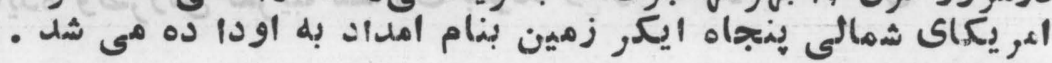

head tax.

$$
\text { - }
$$

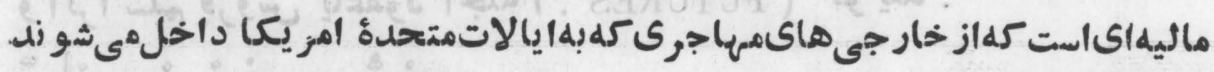

health insurance. اخذميع, ماريهائ

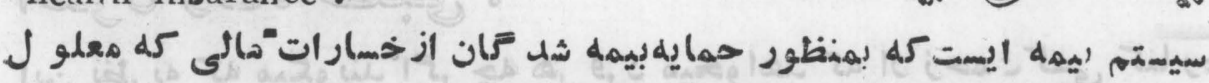

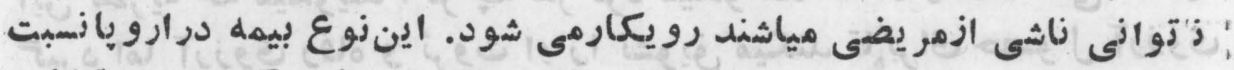

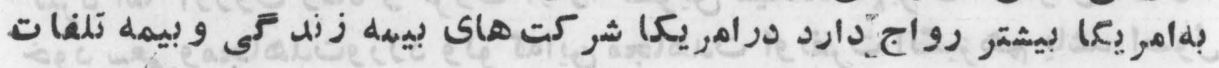

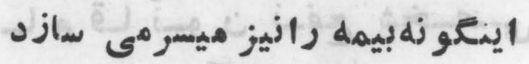

hedging .

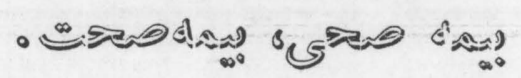

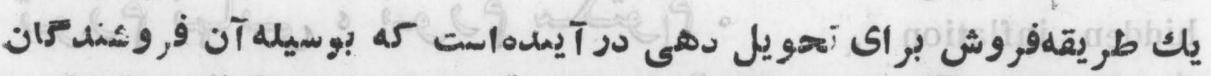
و ويروسس كنمند

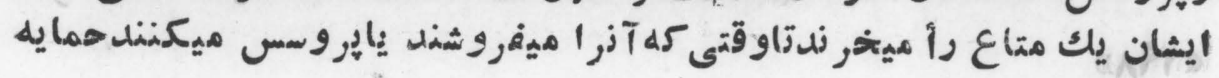




\section{HED}

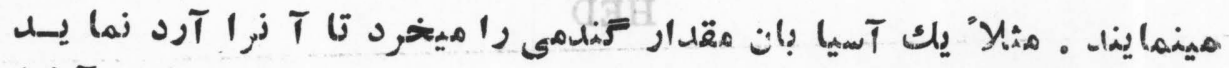

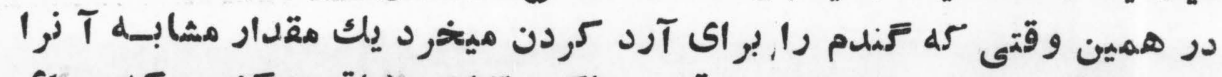

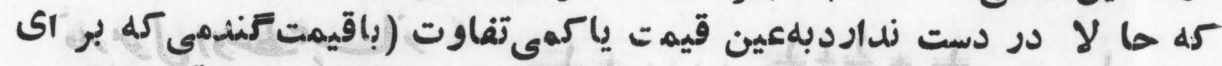

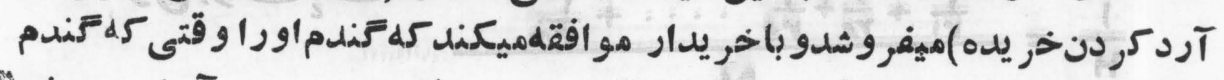

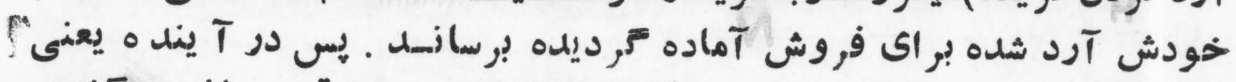

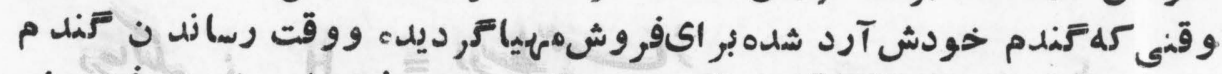

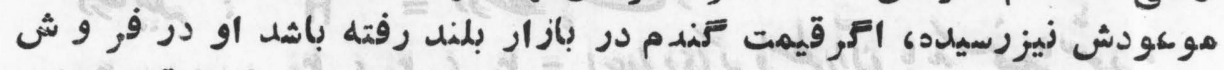

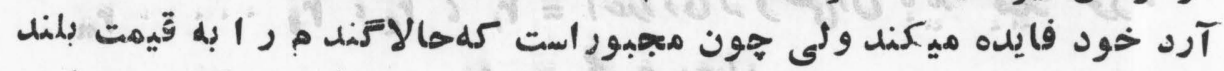

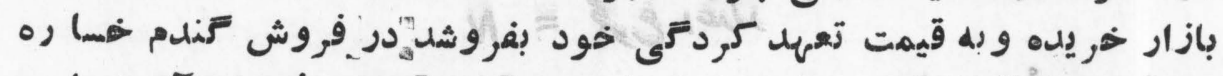

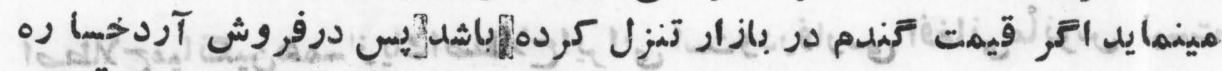

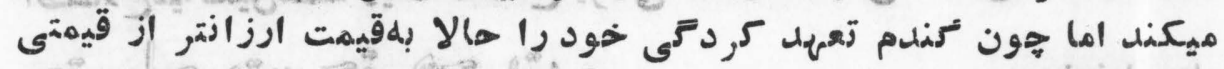

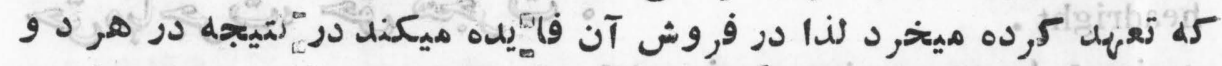

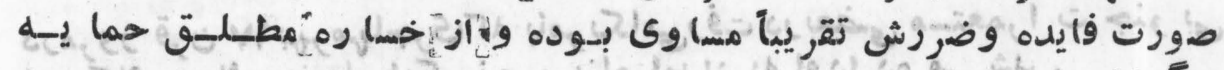

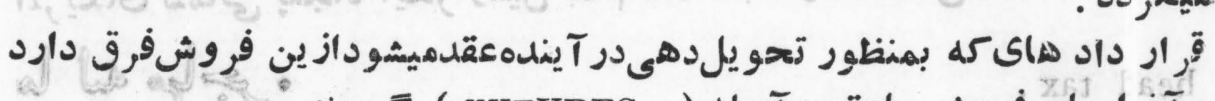

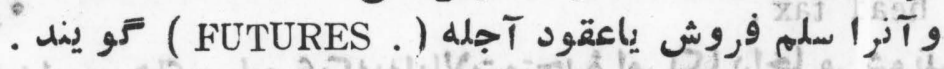

hedonistic principle.

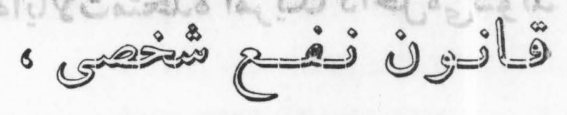

- $v=$ aldb oliga $\int_{g=0}$

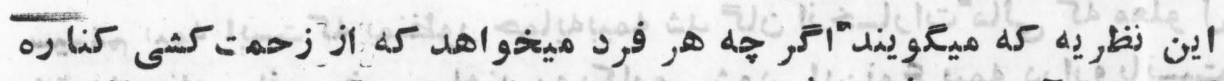

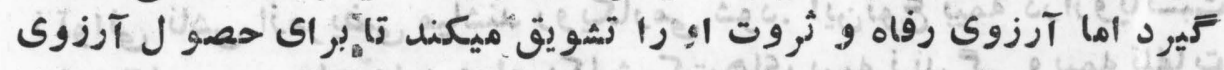

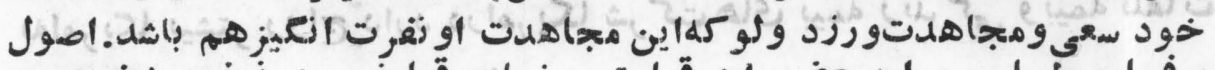

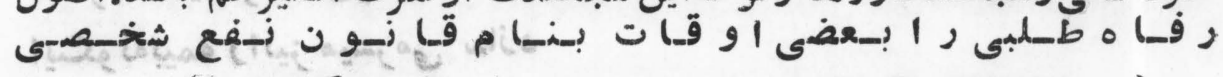

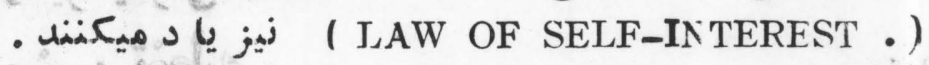

hidden inflation $\quad$ o

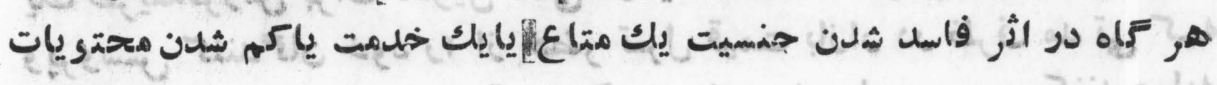
(1) 910 


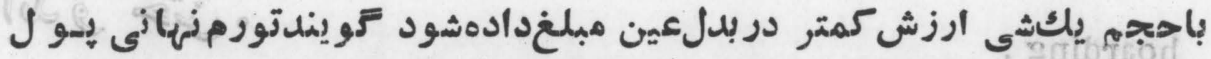

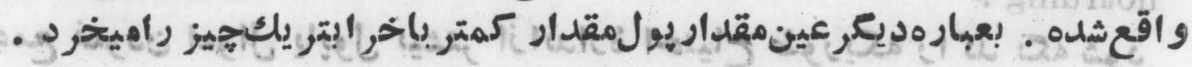
hidden tax.

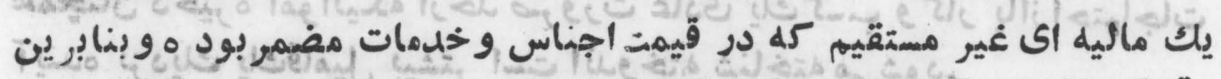

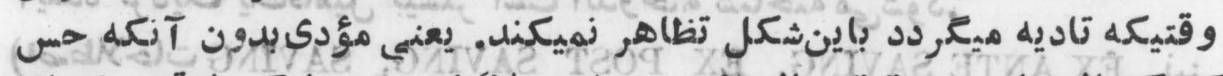

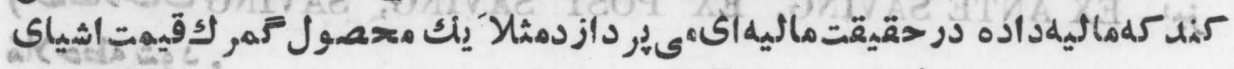

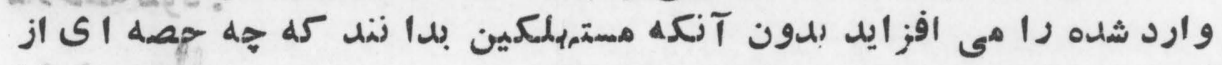

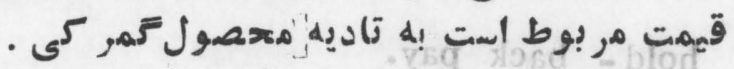

higgling .

- जij dil

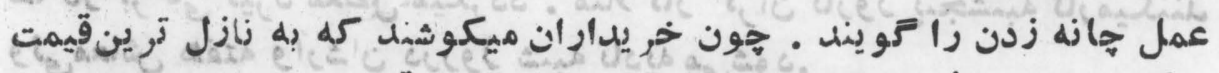

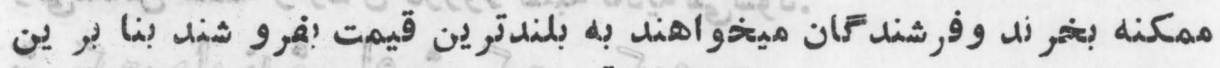

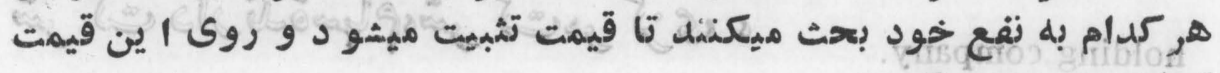

historical school. تجارت صورت ميعيرد . - ज串

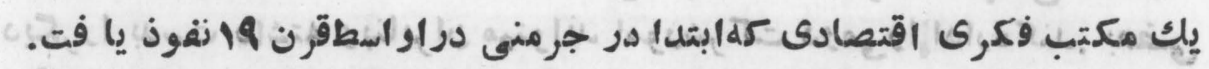

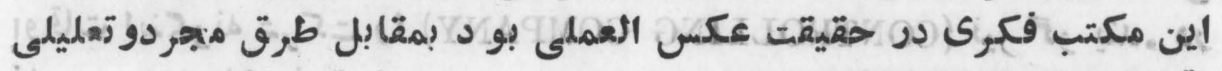

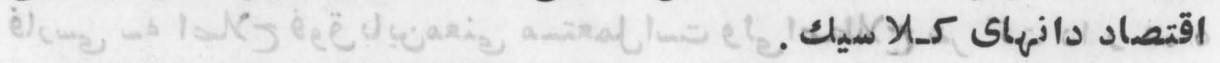

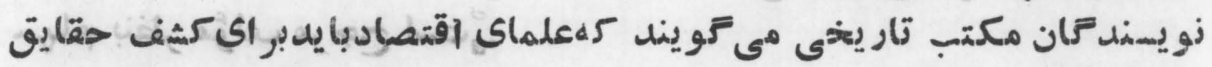

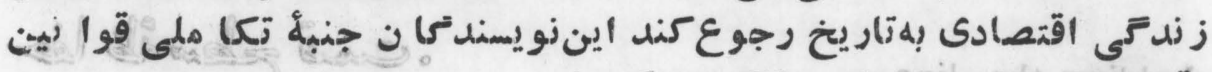

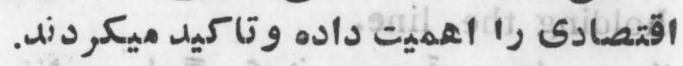

hoard. Alits

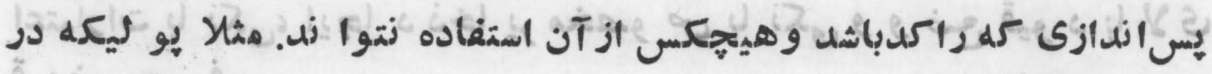
غورك مي تَنار نه. 
hoarding .

$$
\text { - ن் } 9 \text { बiी }
$$

جمع زمودن اموال يايول بيشتر ازاندازة احتياح طوريكه رواكو رواكد نعه شود.

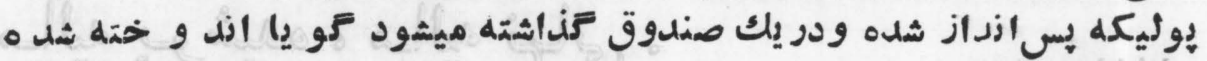

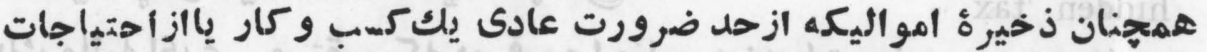

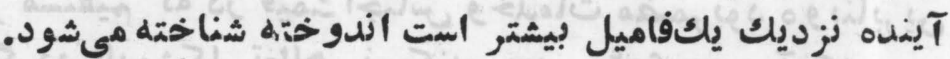

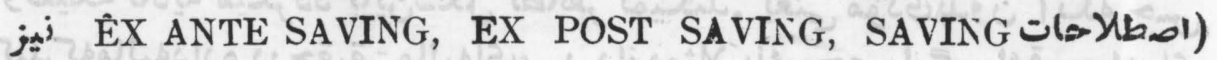
م.

hold - back pay.

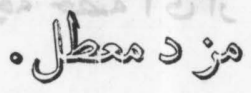

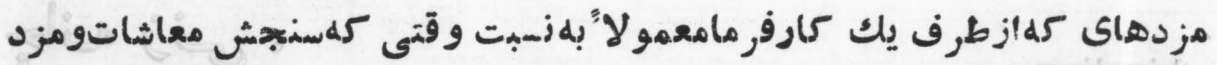

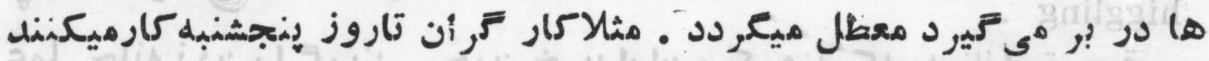

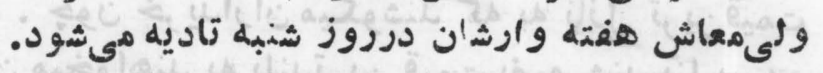

holding company.

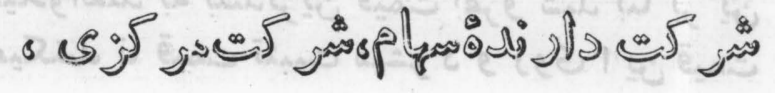

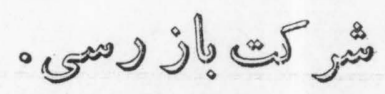

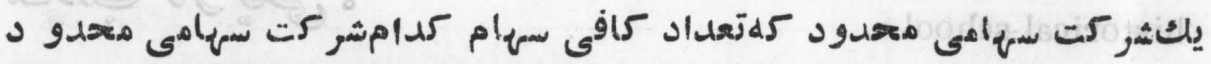

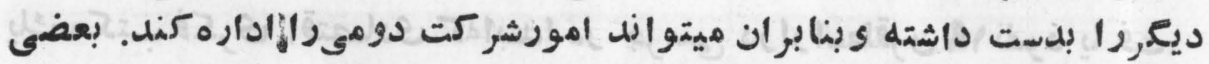

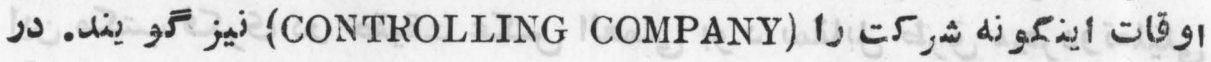

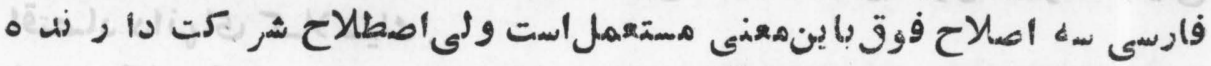

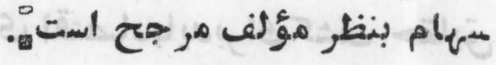
holding the line. -

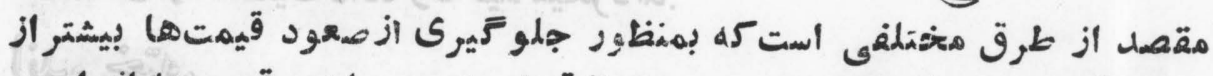

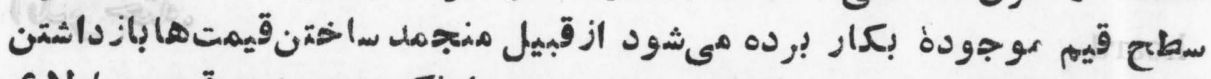

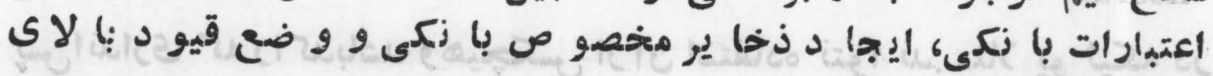

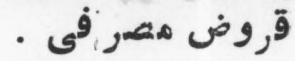




\section{HOR}

home industry.

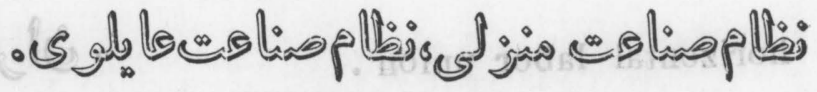
اصطלY

home work.

:

دربعضى صنايع رواجاست كهبله كار Fران خود مواد لازمه راميدهند زا آ زها

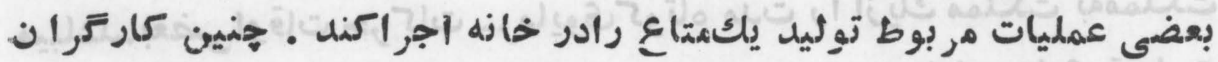

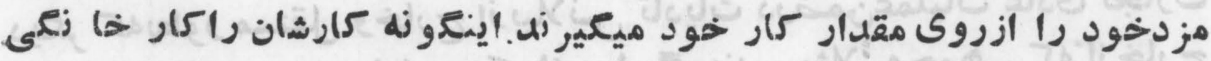
كو يند .

home port.

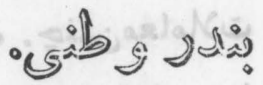

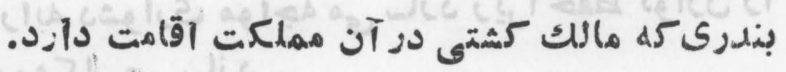

honoring institut on .

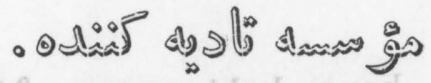
بانكى كله برات وحواله راتاديه مى كند. . horizontal expansion.

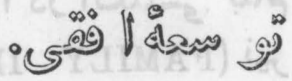

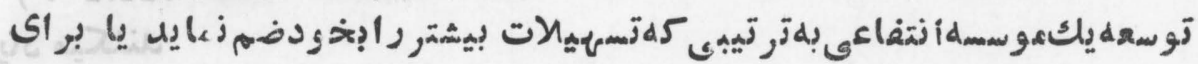

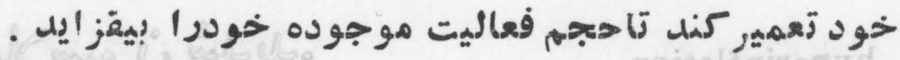

horizontal integration. -

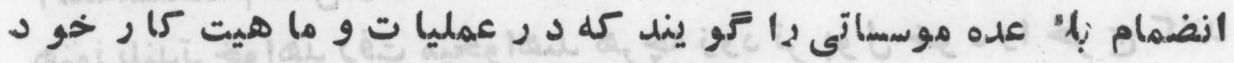

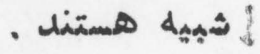




\section{HOR}

horizontal labor union .

$$
\text { - نी }
$$

تفصيلك ت زير مل مطة شيو د

hot money .

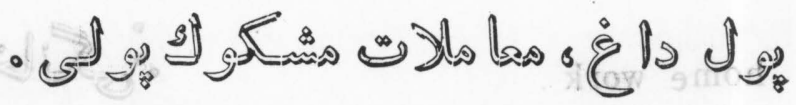

آنمعاملات يوكيى راتمو بند كهاز نعاه اقتصاد بطور كلى غير قانونى يأمشكوك

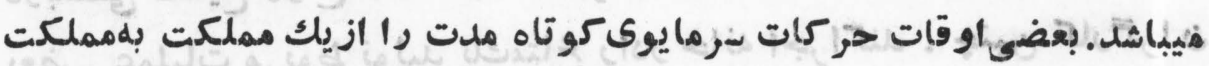

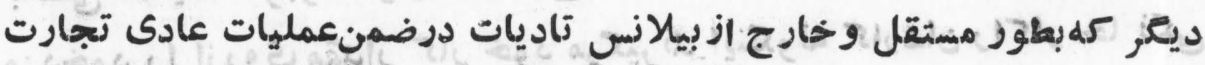

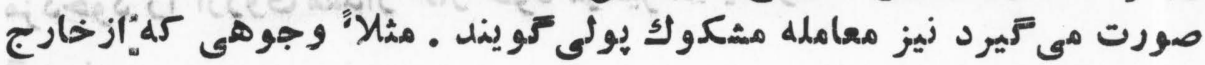

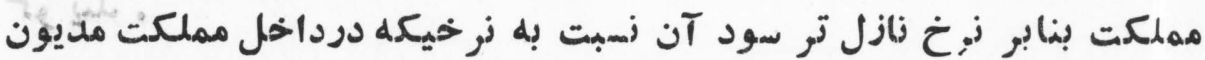

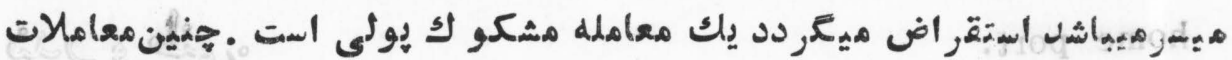

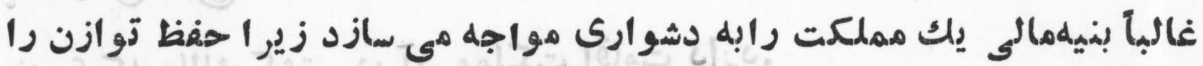

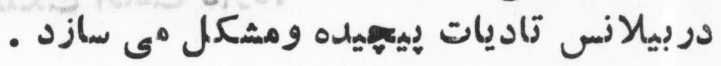

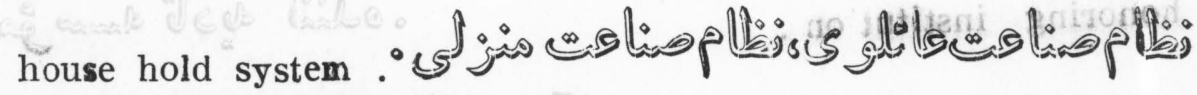

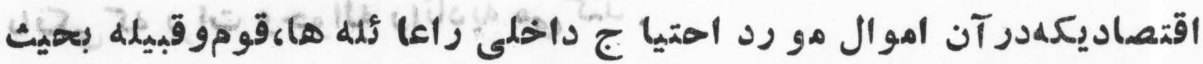

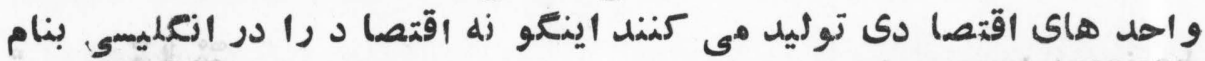
نيز (FAMILY INDTSTRY • ) (DOMESTIC INDUSTRY .)

ياك ميكنند

hyperinflation.

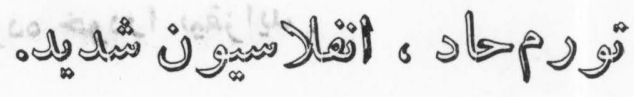

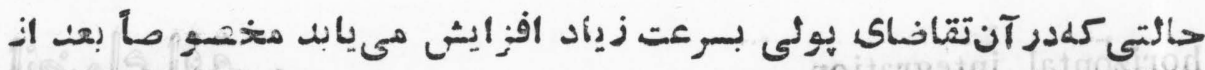

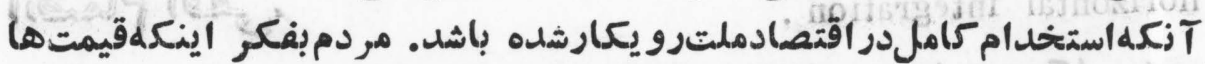

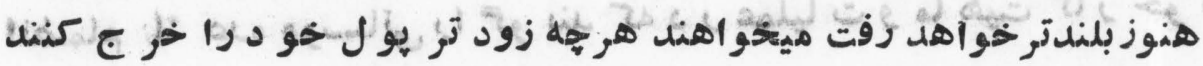

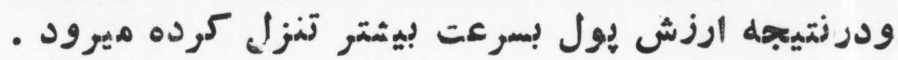


HYP

hypothecary creditor].

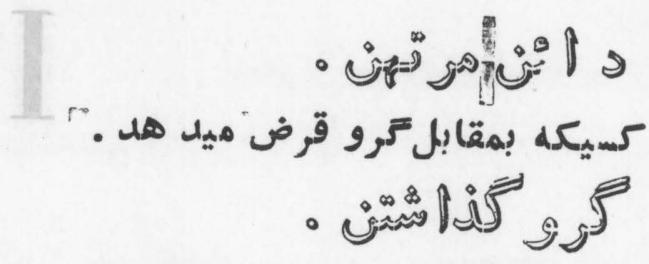

hypothecate -

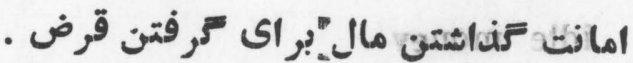

hypothesis.

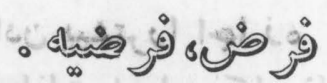

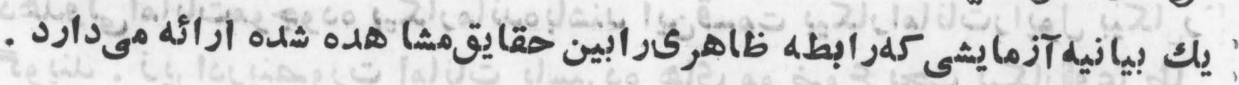

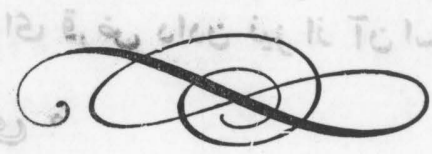




\section{I}

idle money .

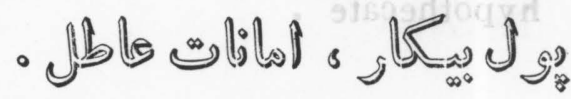

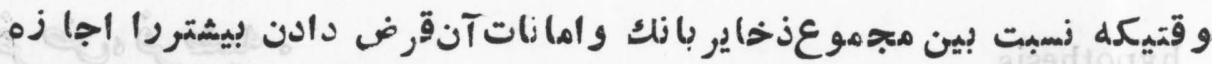

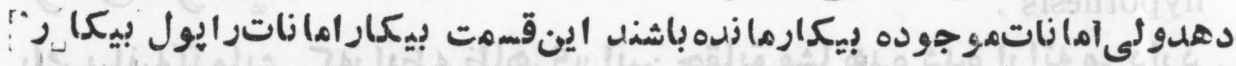

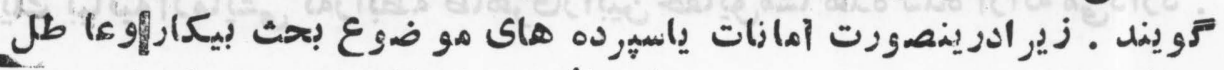

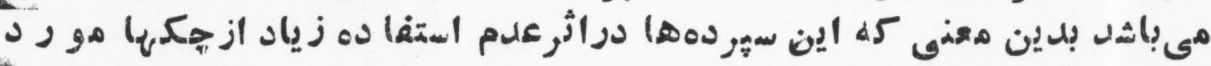

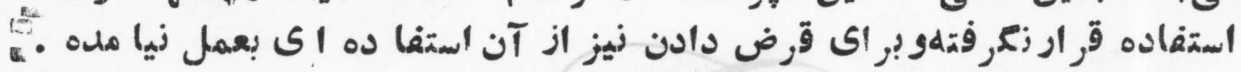

illegal strike.

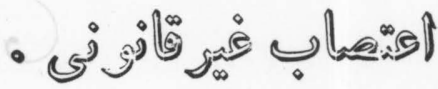

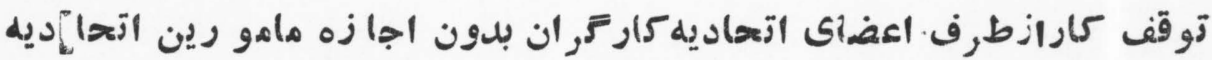

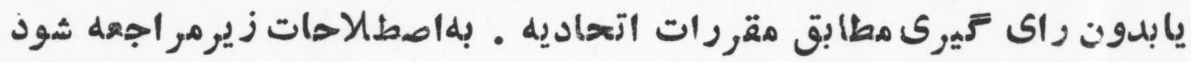
QUICKIE STRIKE, OUTLAW STRIKE, VILICAT STRIKE illth. ० م

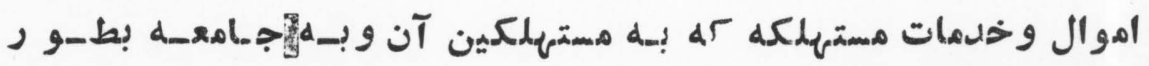

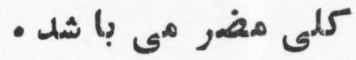
imigrant remittances.

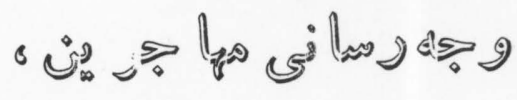

Ex) •

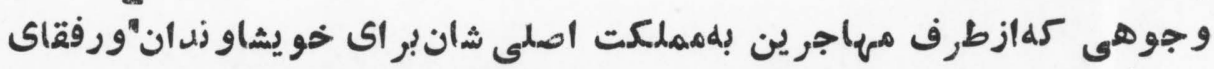

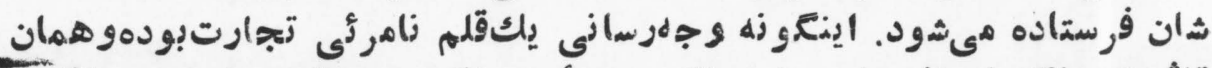

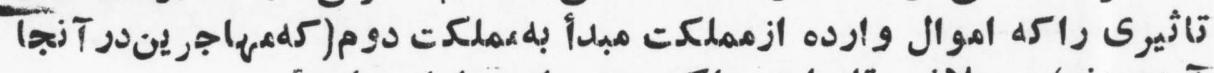

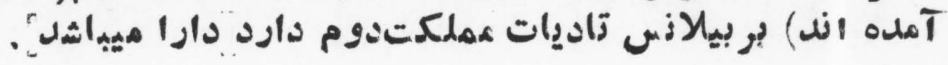


impair in resiment

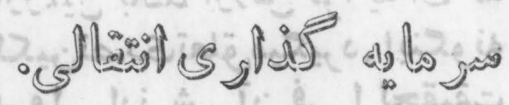

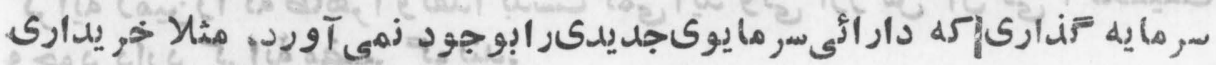

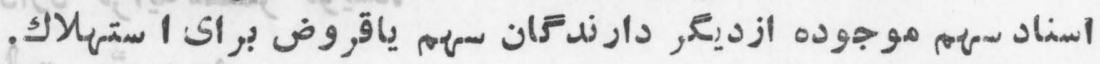
impartial chairmin. o

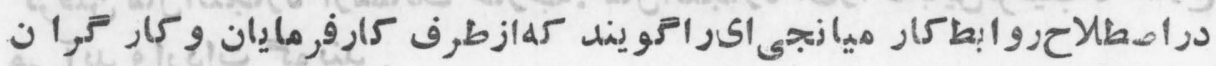

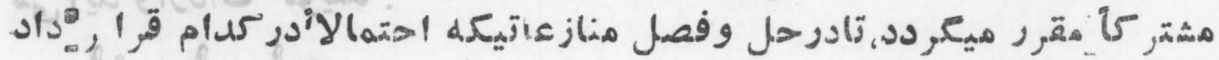
. . imperfect competition.

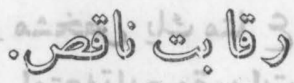

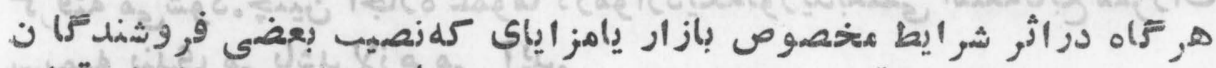

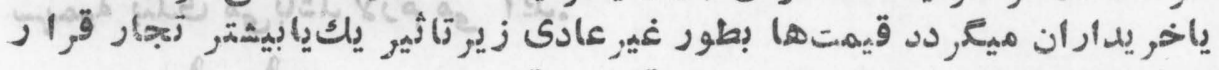

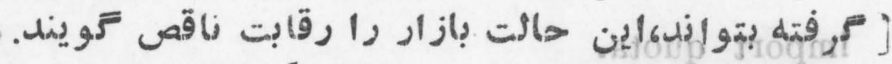

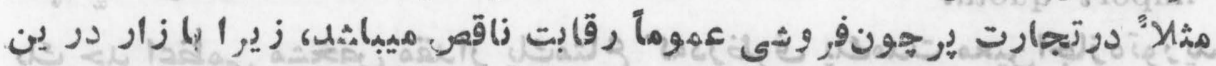

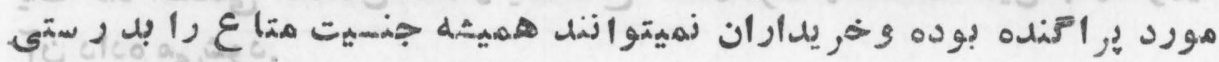

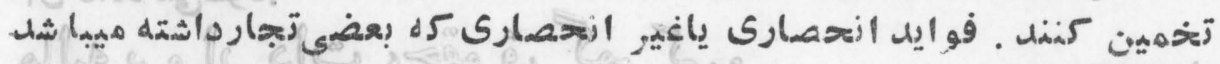

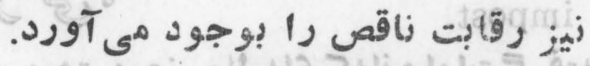

impersonal acceunt.

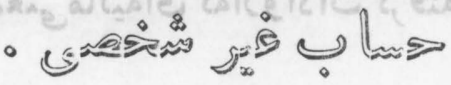

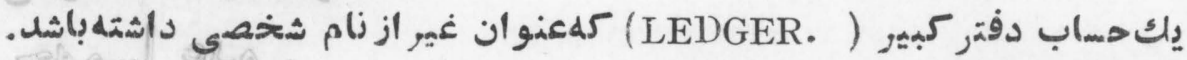

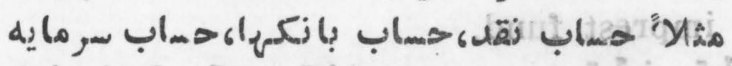

implicit interest..

رد

implieit rent.

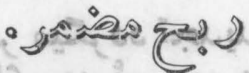

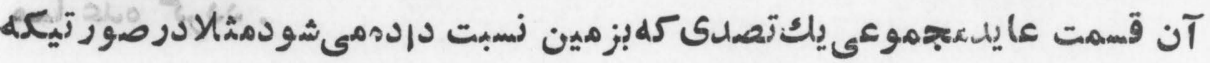




\section{IMP}

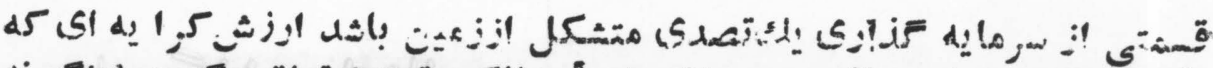

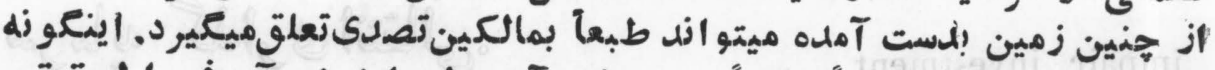

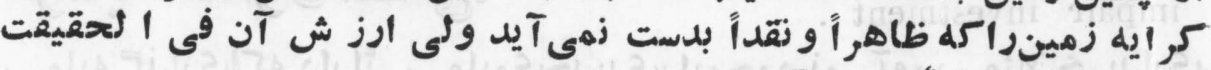
وجود دارد كرايل مضمر كويند.

import .

$$
\text { - = }
$$

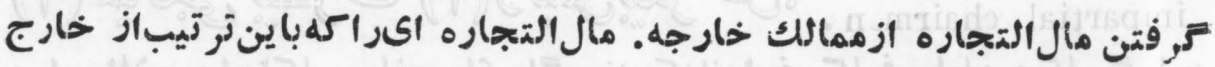

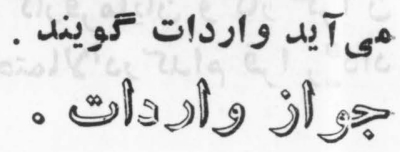

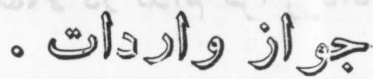

import license.

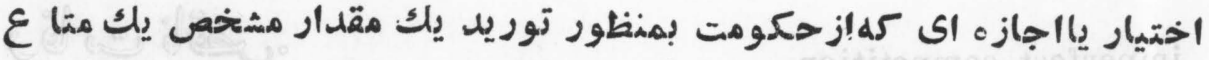

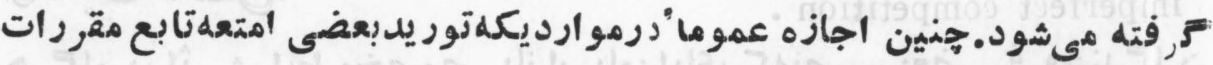

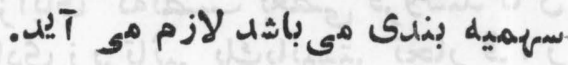

import quota.

$$
\text { - }
$$

يك حلد اعظمى مشخص مقدار ياكمتاع كdدرظرف ياكملت معيناجازهتوزيد

impost.

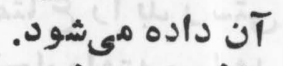

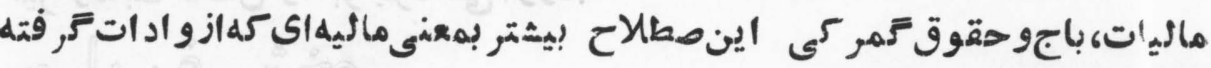

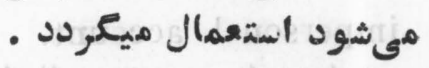

imprest fund.

- OAls

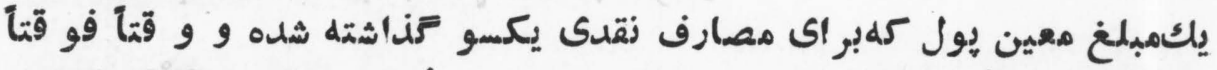

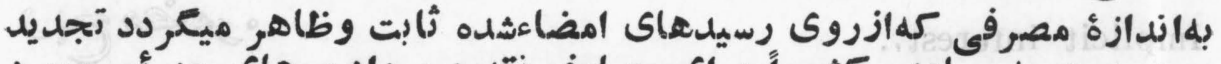

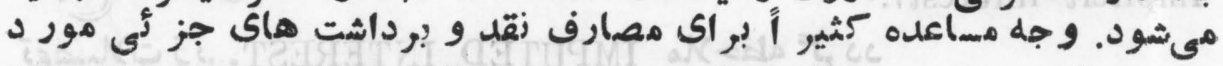

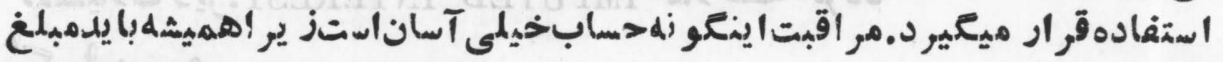

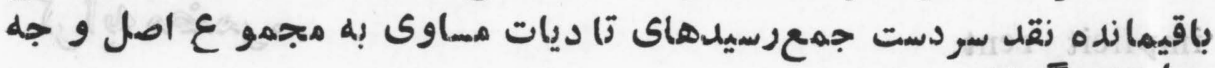


improved good.

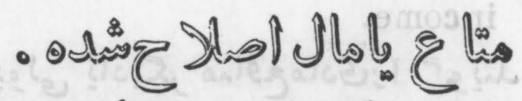

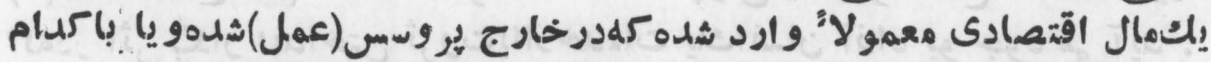

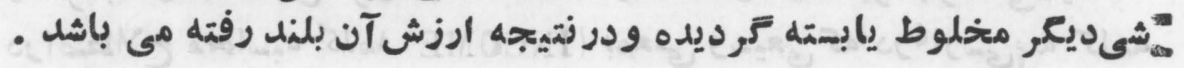

imputed interest .

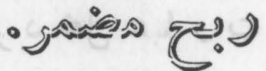

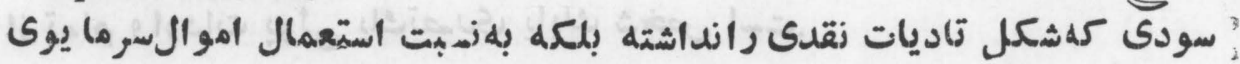

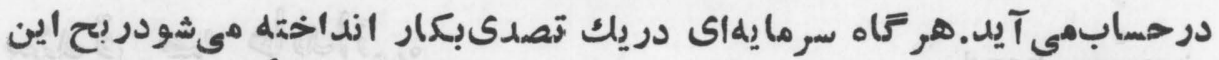

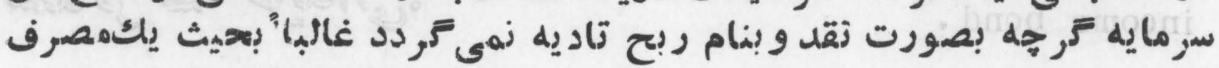

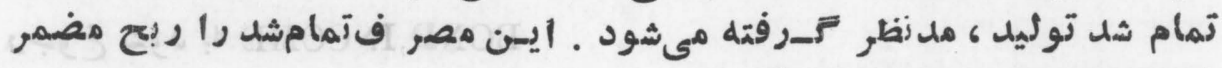
تحو ينله. (IMPLICIT INTEREST)

inactive stock.

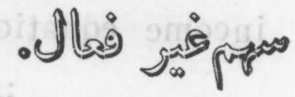
مر اججعه شودبه (STOCK,INACTIVE) incentive taxation.

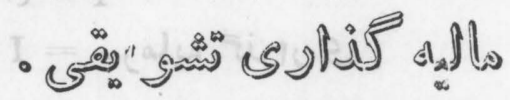

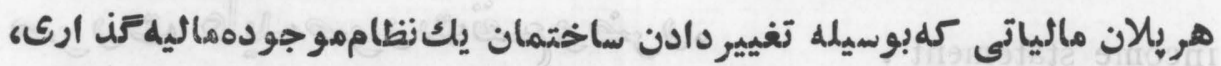

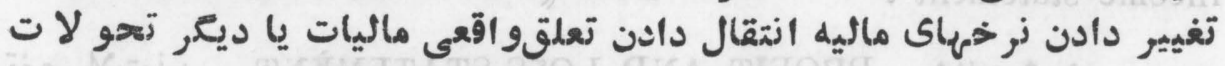

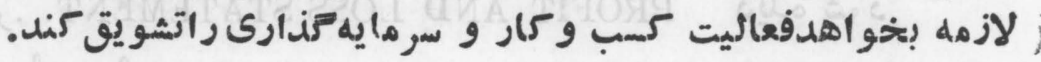
incentive wage system . - ى

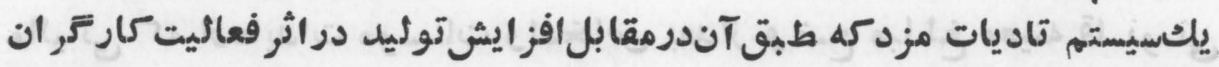
انعام نير داده مئشود.

incidence of taxation.

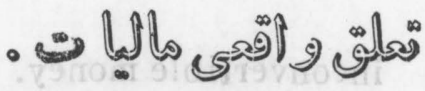

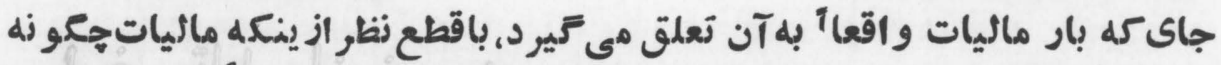

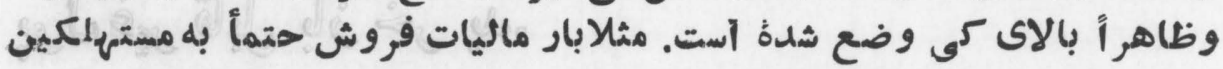

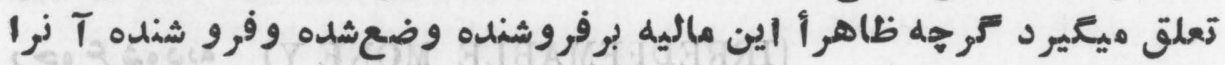

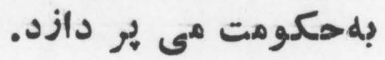


income.

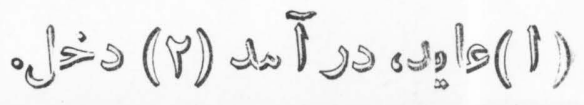

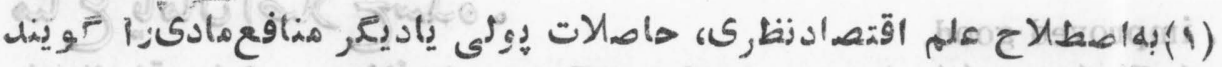

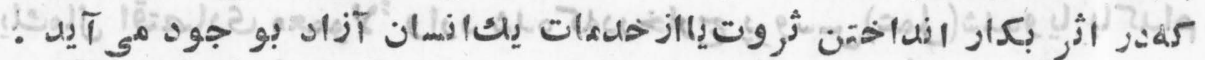

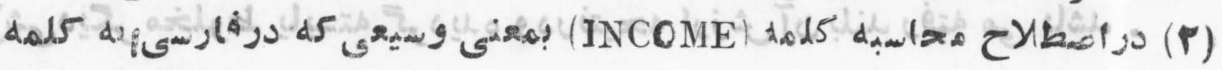

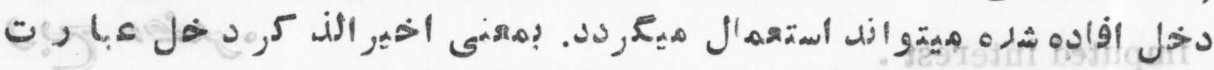

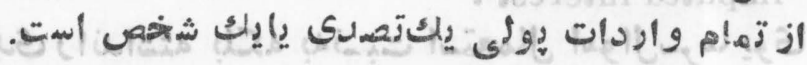

income bond.

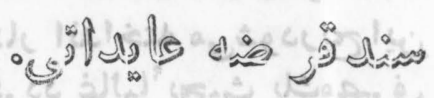

BOND,INCOME נجوع شود به

income equation .

$$
\text { ه }
$$

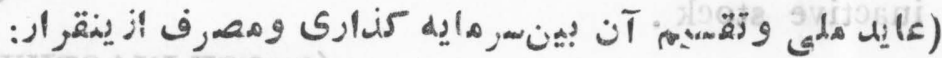

$$
\begin{aligned}
& \mathrm{Y}=\mathrm{C}+\mathbf{I}
\end{aligned}
$$

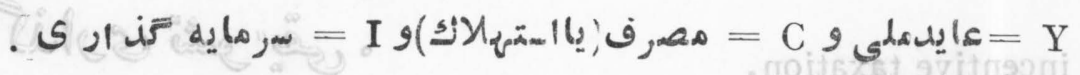

income statement. تفصيلات زيو. ميده شو 2. PROFIT AND LOSS STATEMENT

income tax.

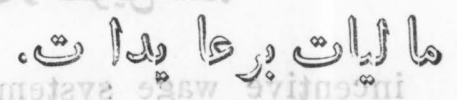

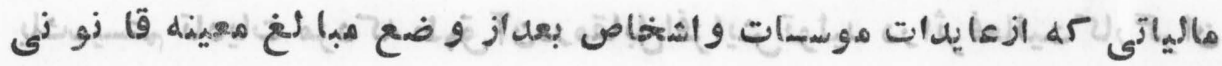

inconvertible money.

$$
\text { . }
$$

$$
\text { ○ }
$$

$$
\text { a }
$$

(IRREDEEMABLE MONE Y) . 
incorporation.

-

رجوعشود به. CORPORATION

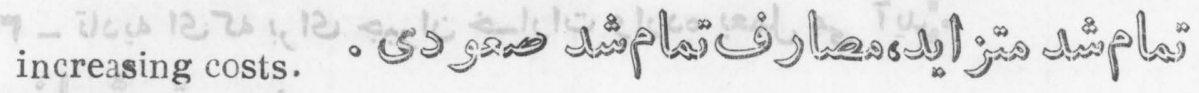

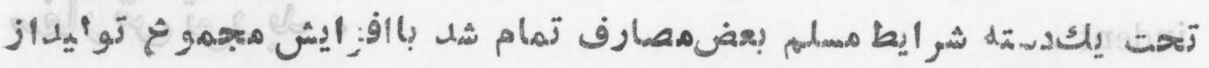

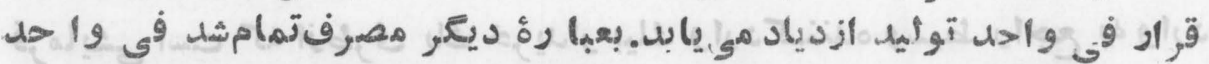

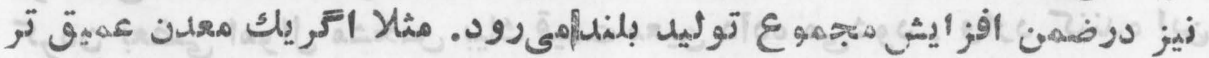

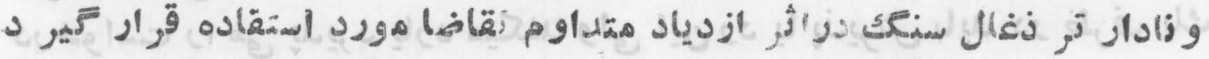

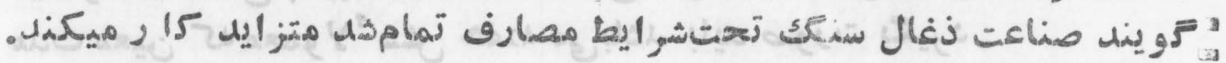
increasing returns.

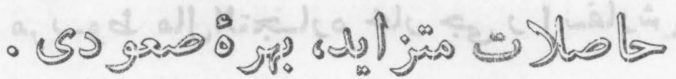

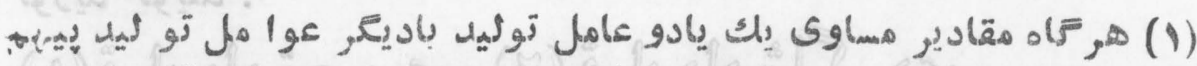

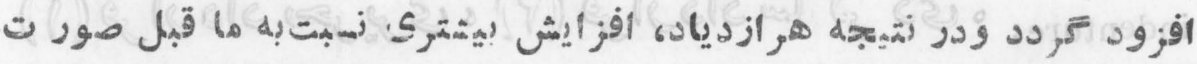

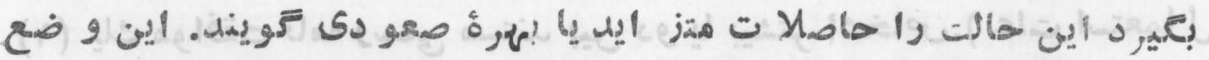

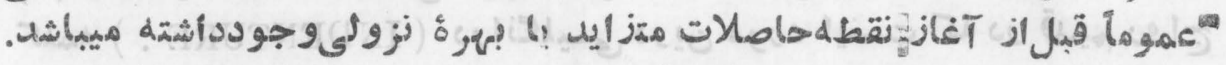

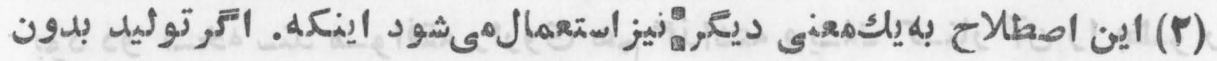

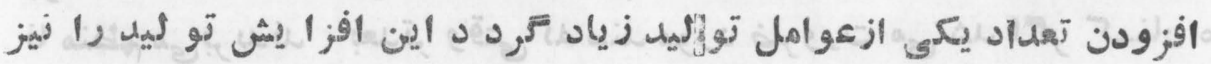

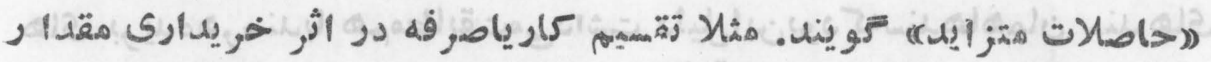

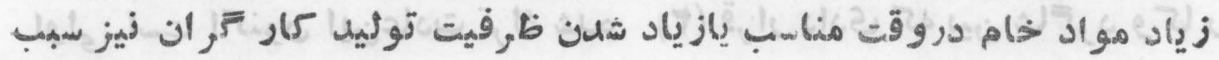

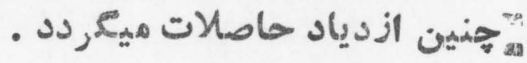

increment.

$$
\text { - Sljlos }
$$

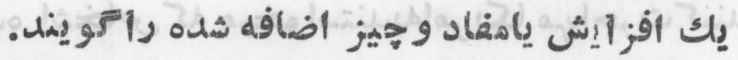

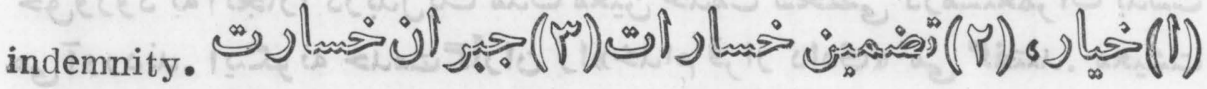

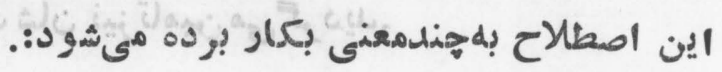


|- به|||صطلاح تجارت اختيار خريد يا فروش يك مقدار معين يك متاع بيك

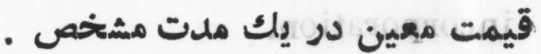

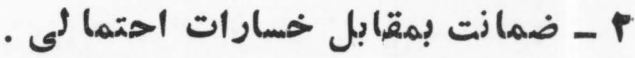

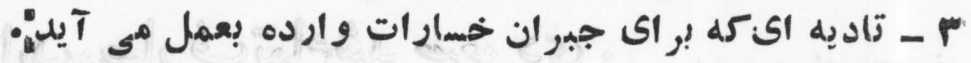
indent . -

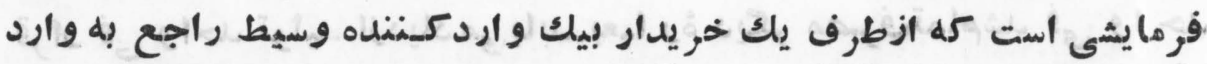

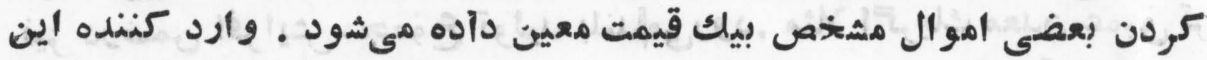

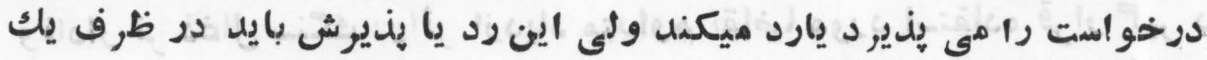

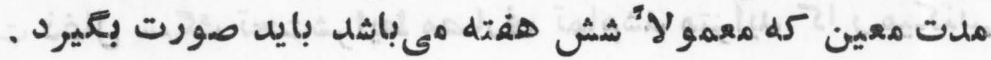

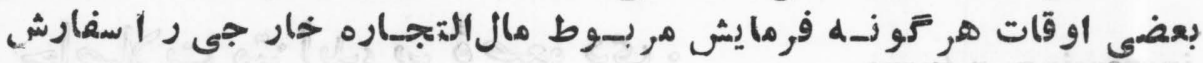

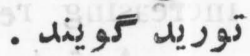

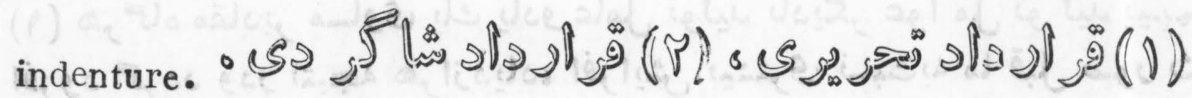

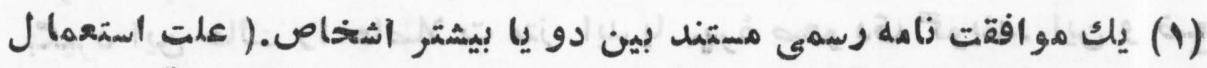

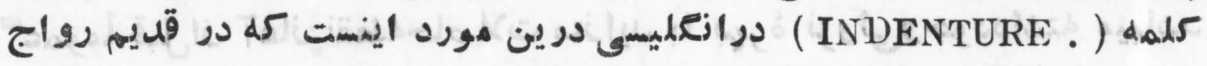

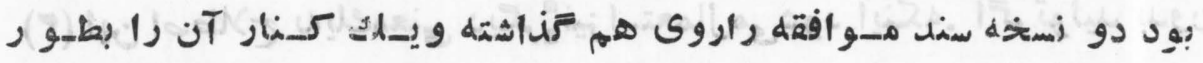

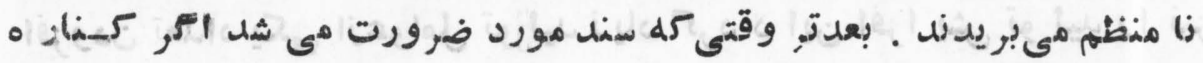

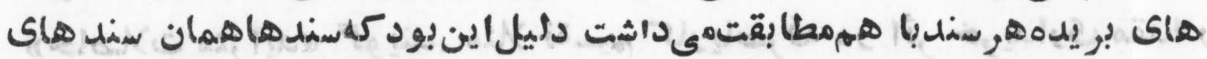

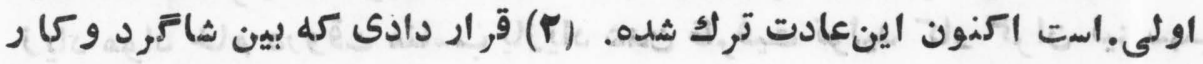

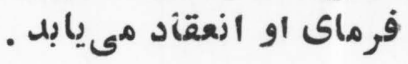

indentured servants.

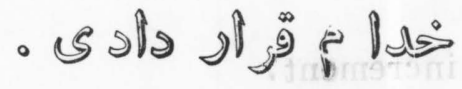

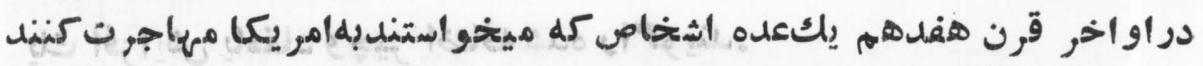

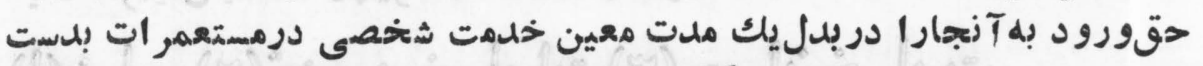

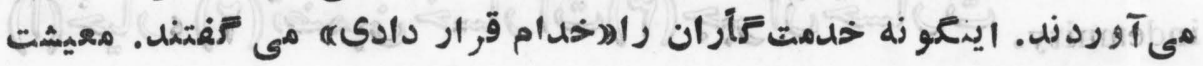

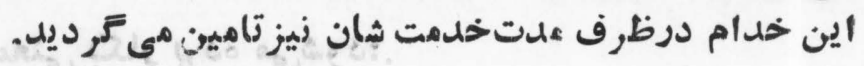


independent union.

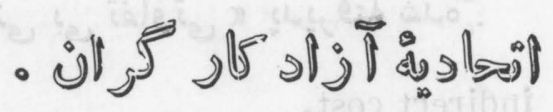

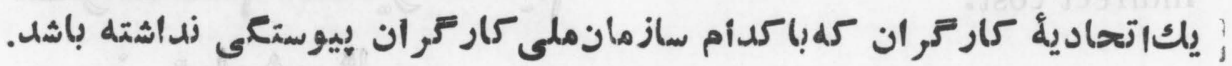

index number . - veri

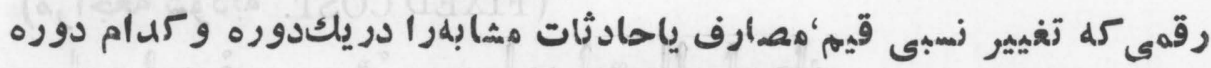

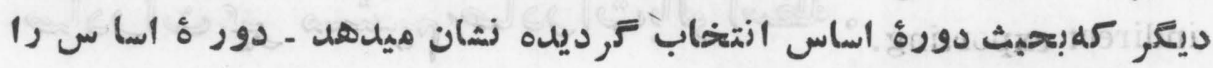

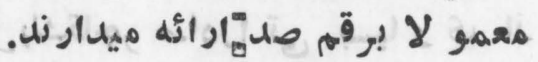

indifference curve . •

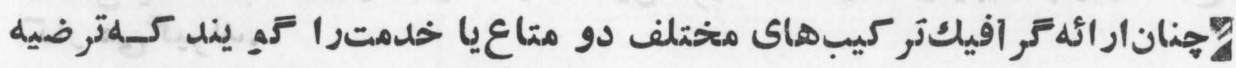

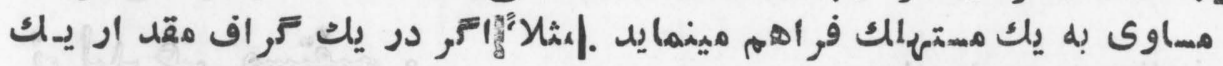

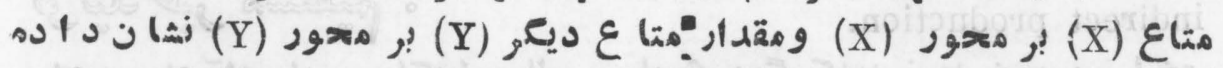

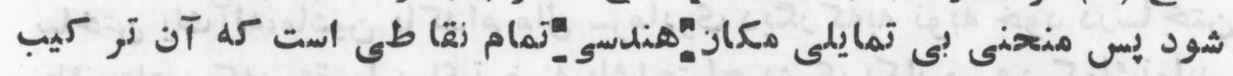

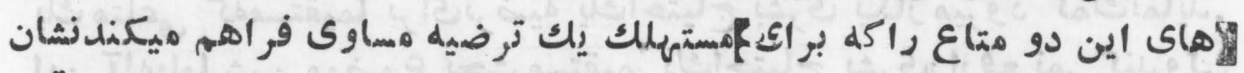

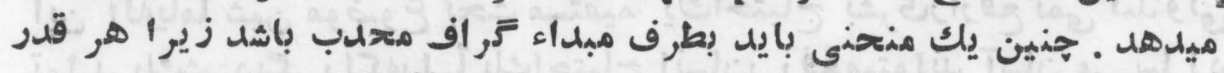

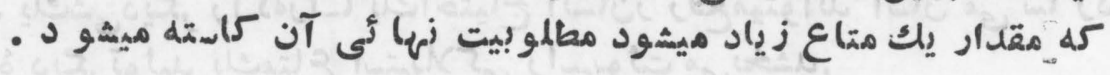
indifference map. • •

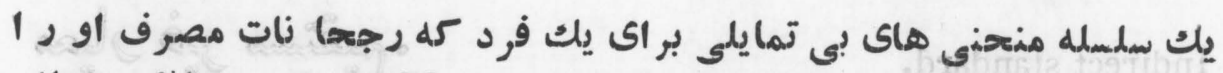

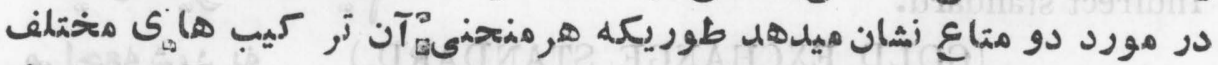

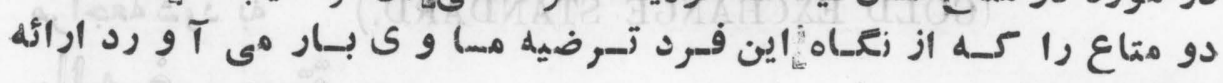

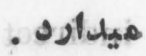

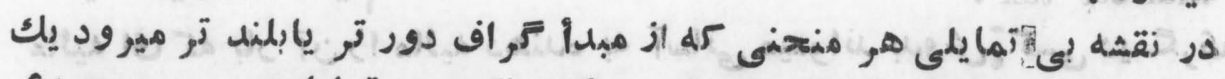

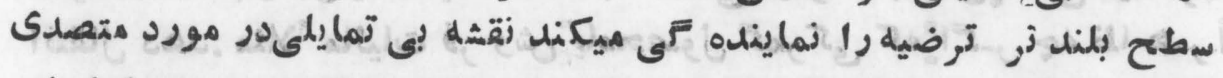

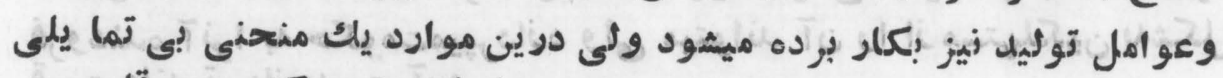

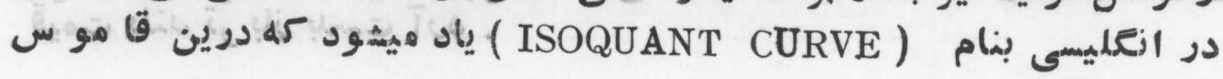




\section{IND}

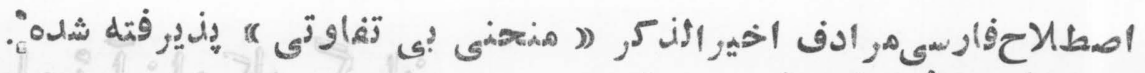
indirect cost.

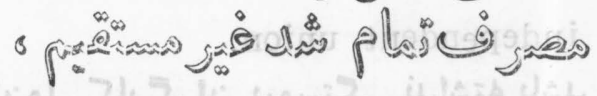

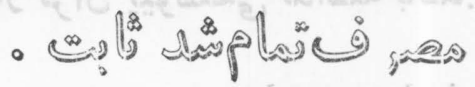

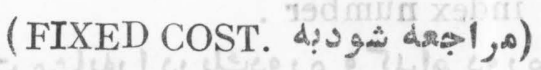

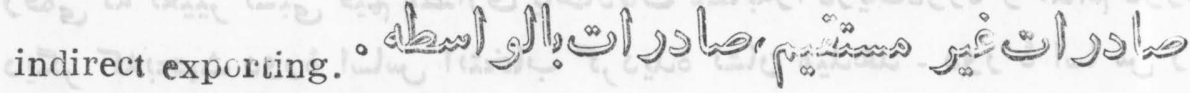

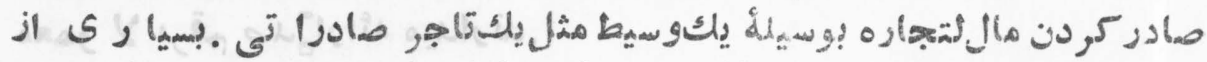

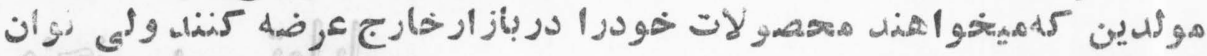

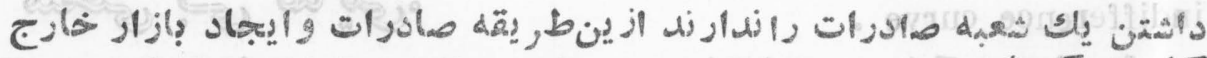

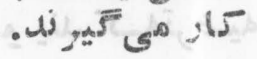

indirect production.

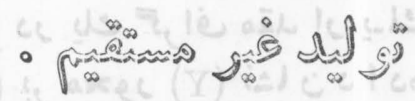

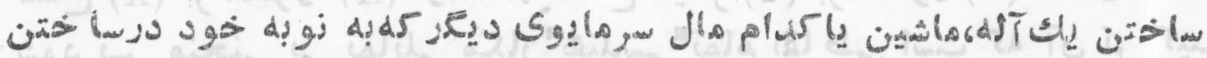

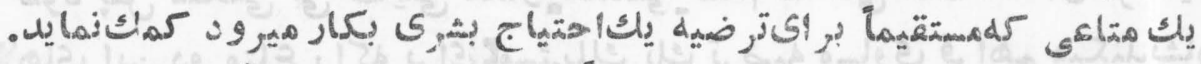

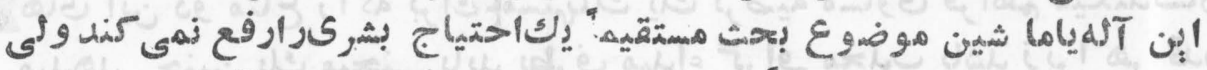

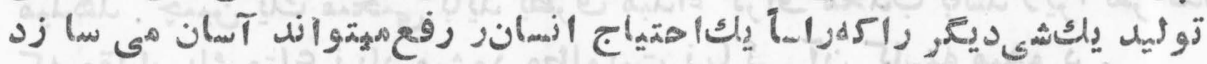

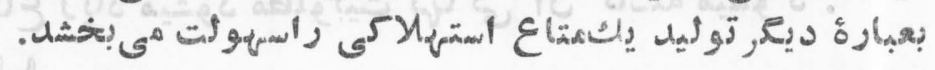

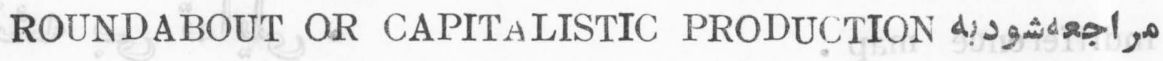

indirect standard.

$$
\text { - }
$$

(GOLD EXCHANGE STANDARD.) d د

indirect tax .

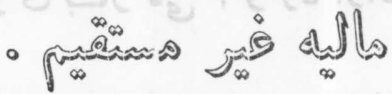

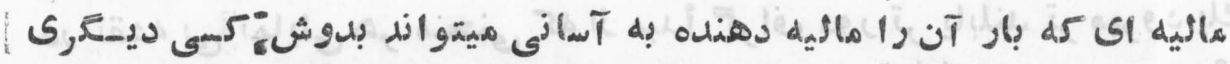

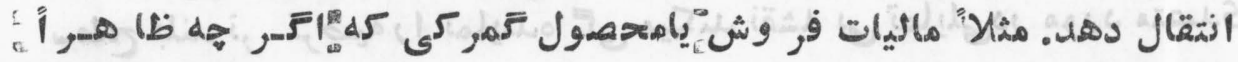

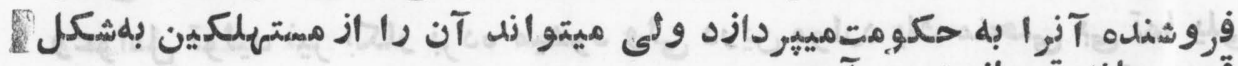

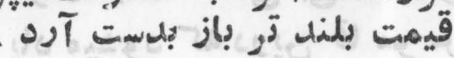


individual income tax

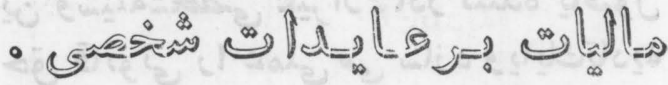

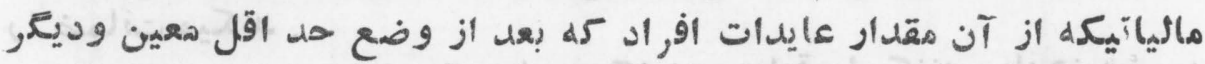

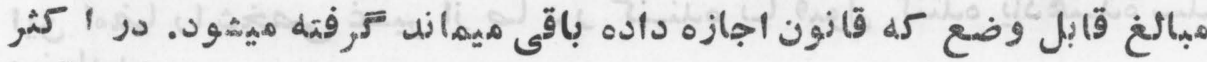

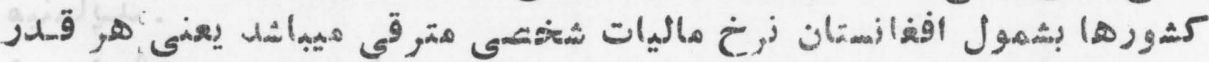

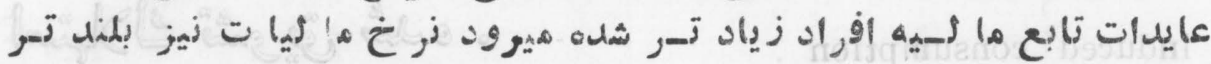
. دs,

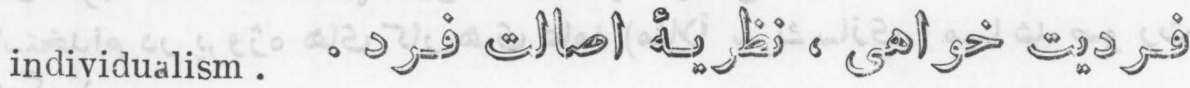

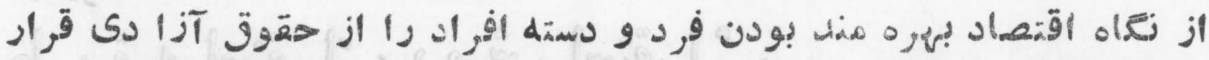

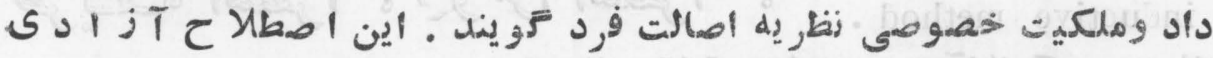

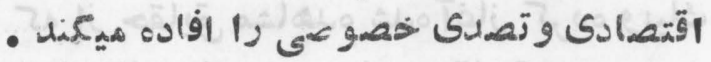
individualist school.

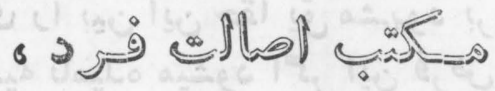

$$
\begin{aligned}
& \text { - I } 9 \text { 車 } \\
& \text { (CLASSICAL SCHOOL • مر أجم شود به }
\end{aligned}
$$

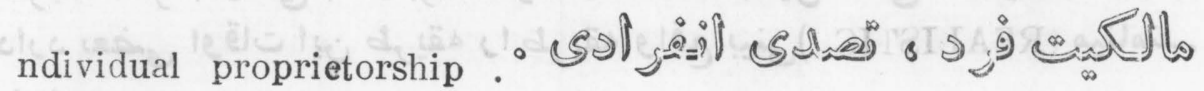

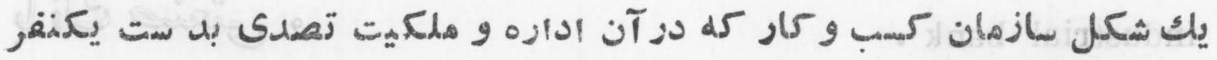

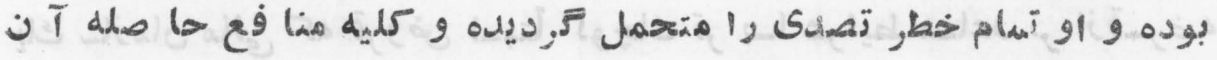
را تملك مينهايد ndorsed bond .

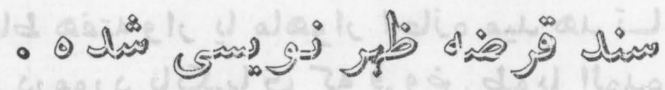

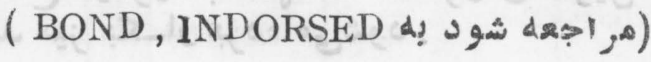

ndorsement . - ज萬

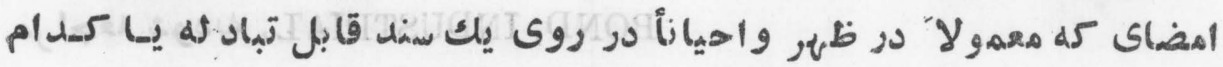




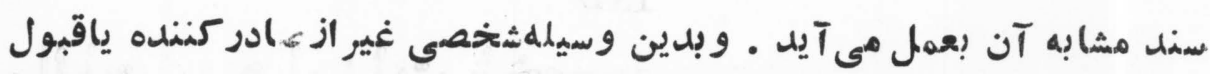

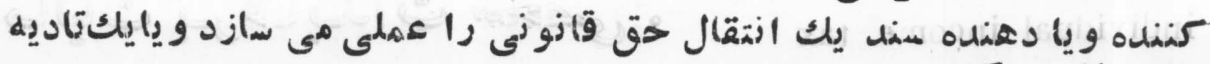

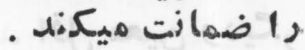

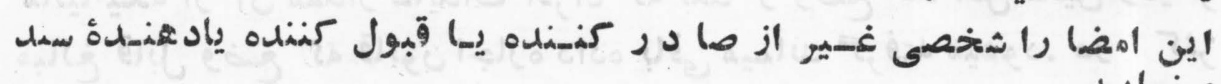
مينها يسلد .

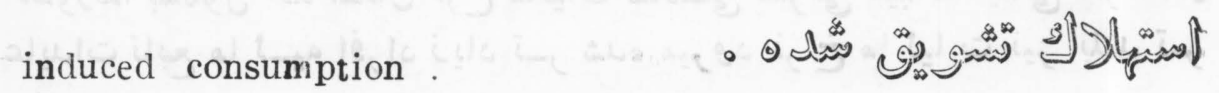

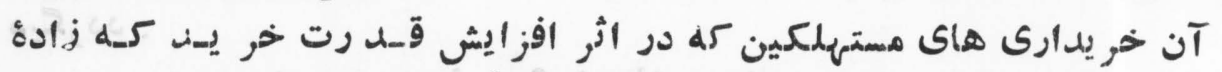

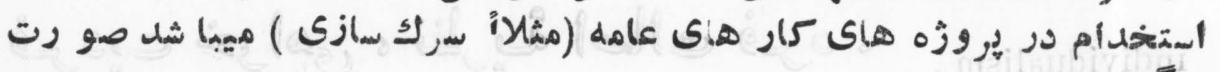

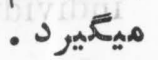

incuctive method.

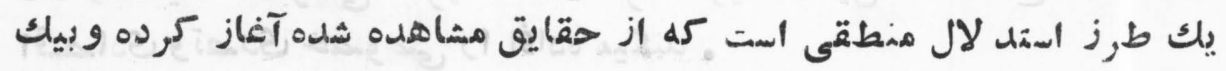

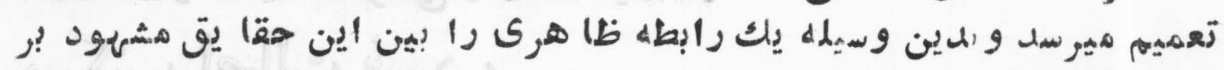

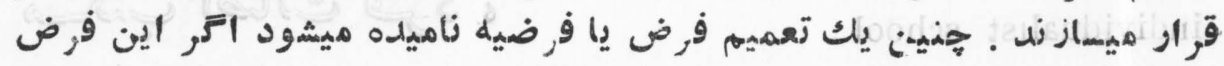

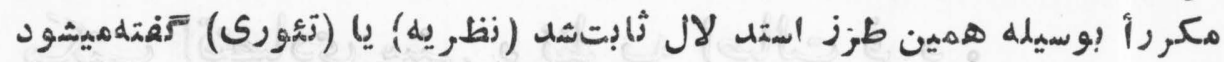

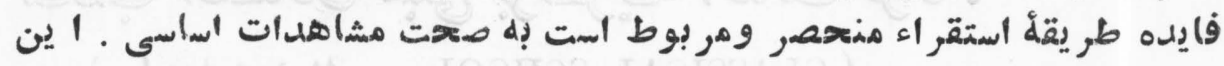

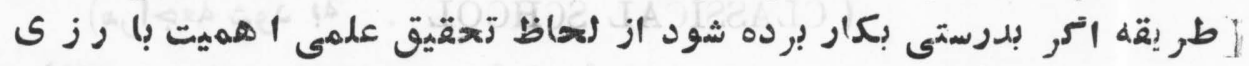

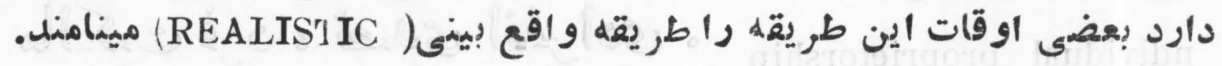
industrial bank .

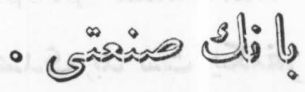

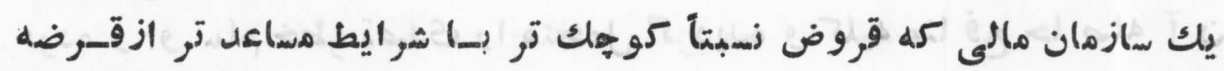

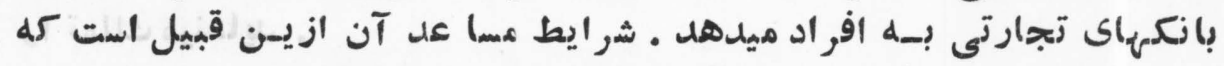

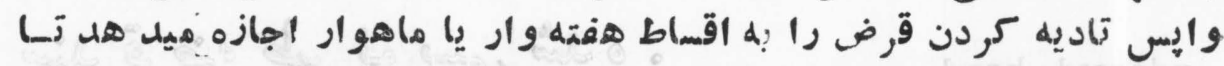

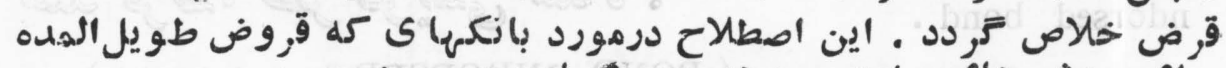

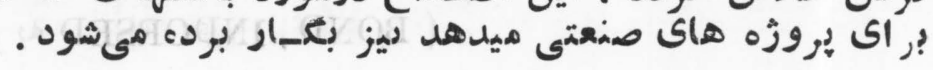

industrial bond.

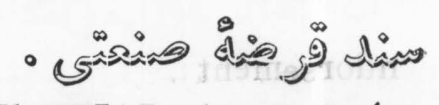
BOND, INDUSTRIAL. مر اججه شودبه

\section{arIFD}




\section{IND}

industrial democracy .

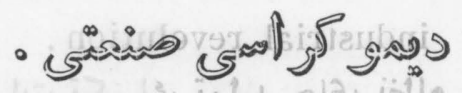

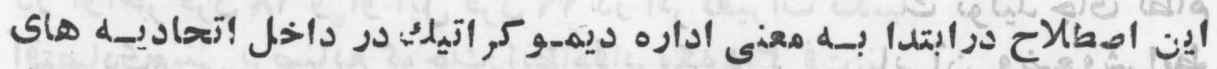

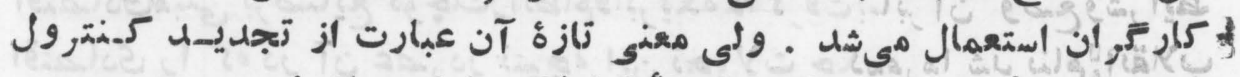

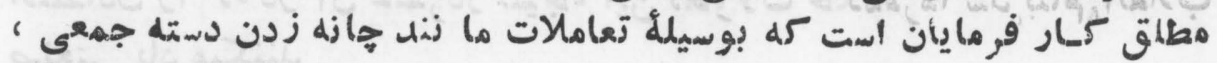

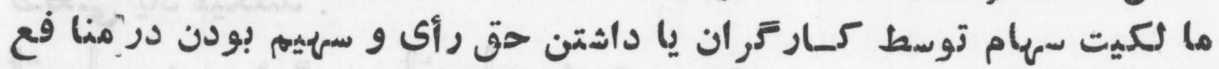

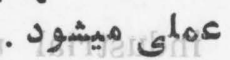

industrial life insurance . जisis of the dow

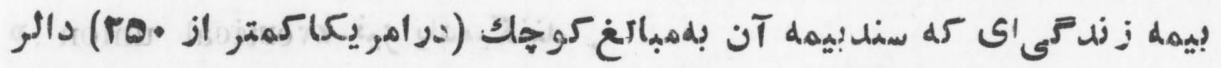

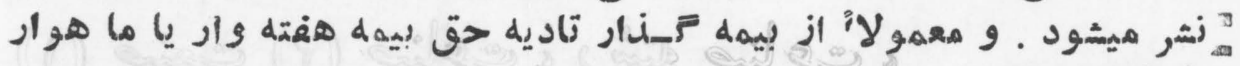

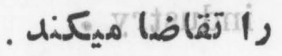

industrial relations $=$ (labor relations) o

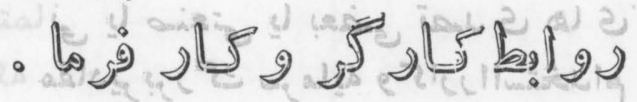

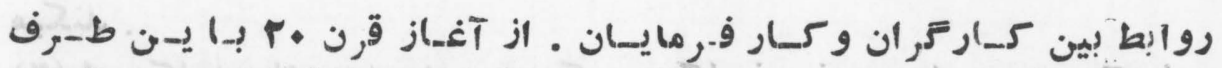

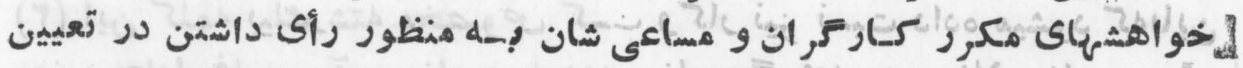

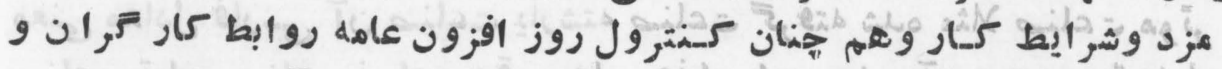

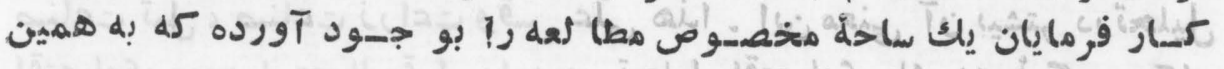
عنوان ياد ميثيود فان industrial research . - जisio @ @

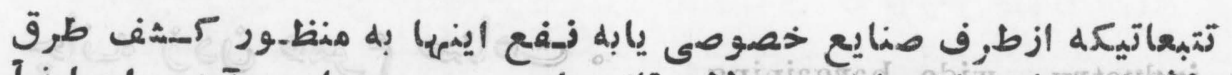

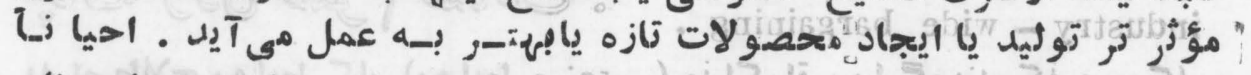

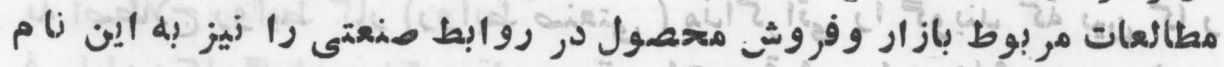

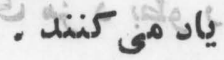


industrial revolution.

$$
\text { - }
$$

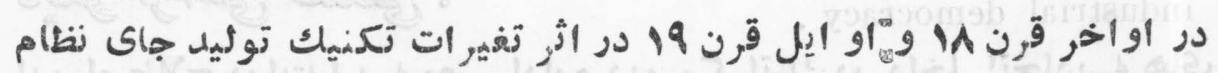

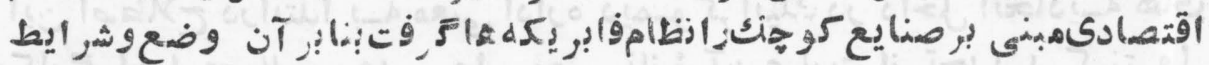

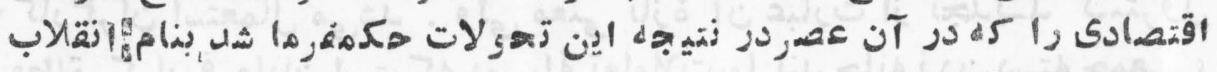

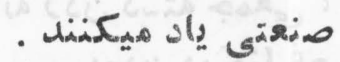

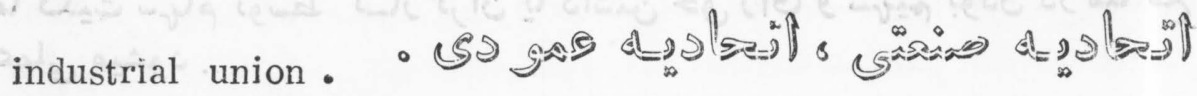

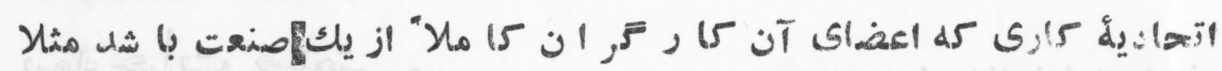

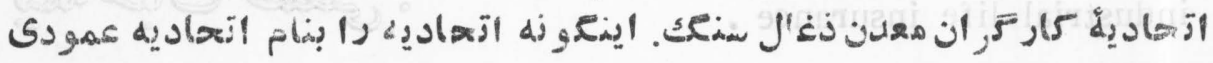

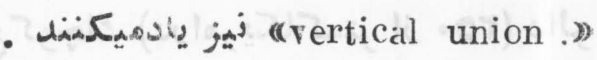
industry . o - 巳an dis

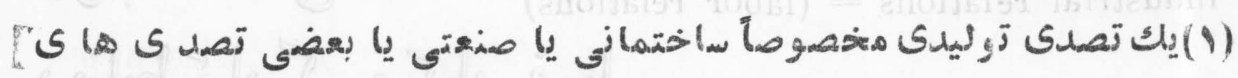

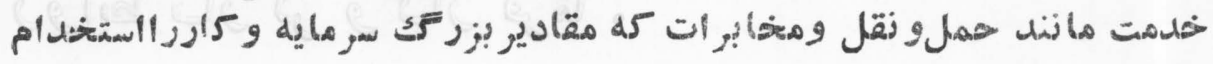
ميكن

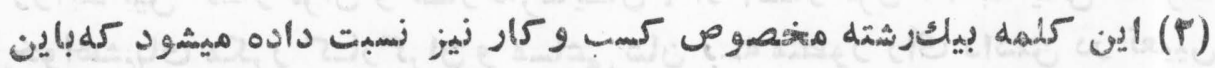

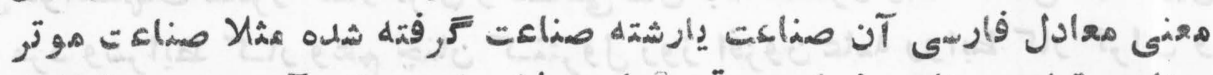

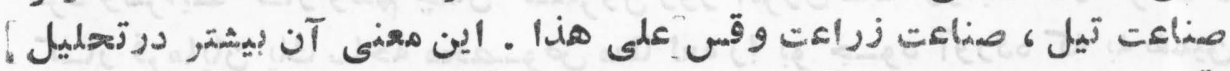

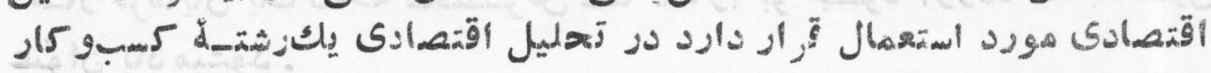

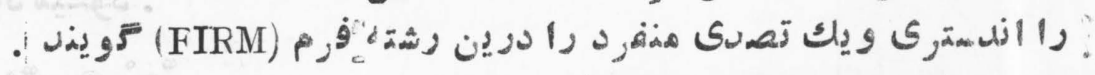

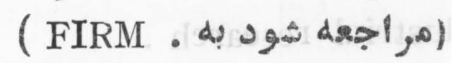

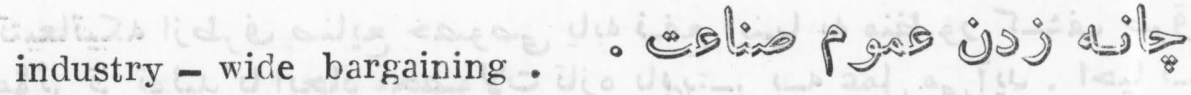

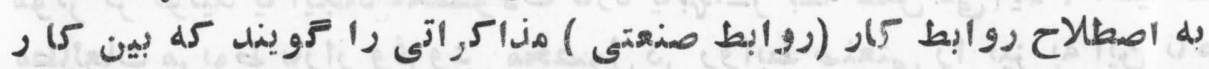

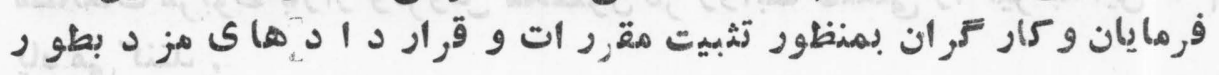




\section{INF}

متهلالشكل جراى تمام كار Fر ان يك صناعت صبورت ميعيرد .

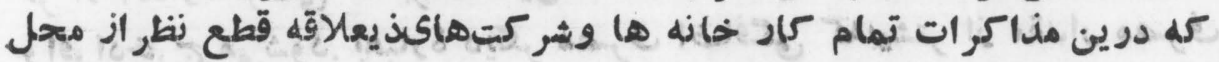

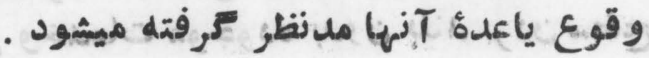

inelastic demand .

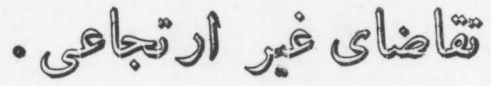

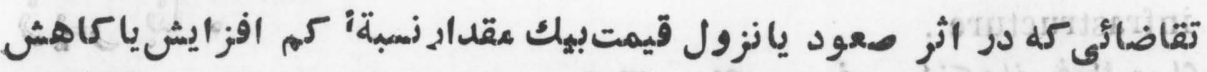

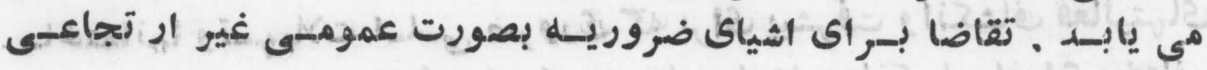
ميبشاشد .

inelastic supply .

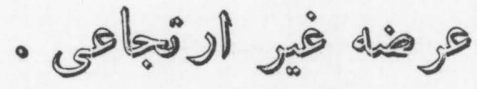
عرضه ايكه دراثٔز صعود يانزول زياد قيمت بسيار ك-م افسزايش يا كـاهش

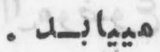

infant industry.

$$
\text { - } 20
$$

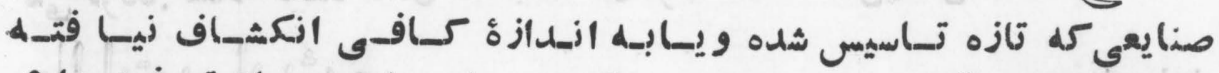

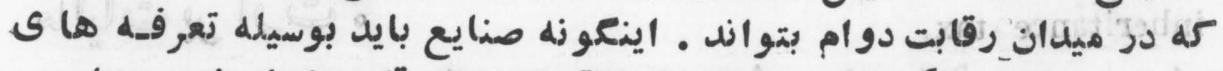

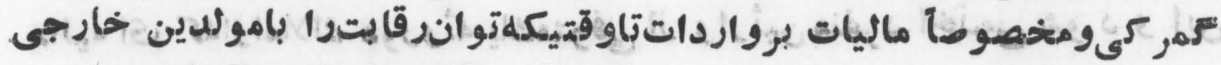

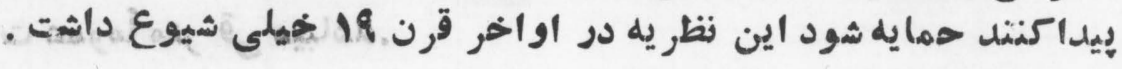

inflation .

$$
\text { - نे }
$$

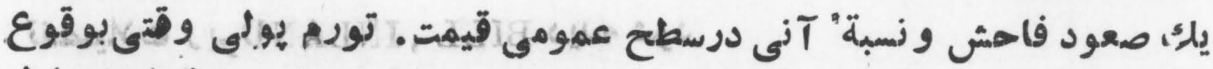

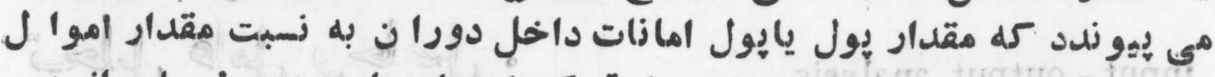

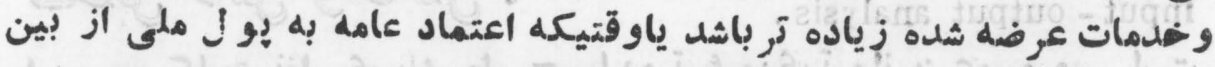

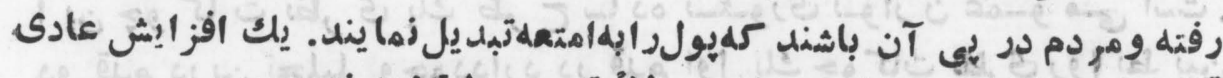

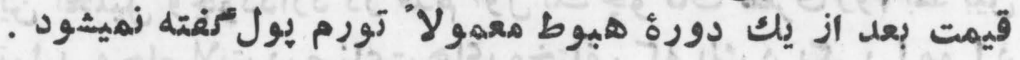

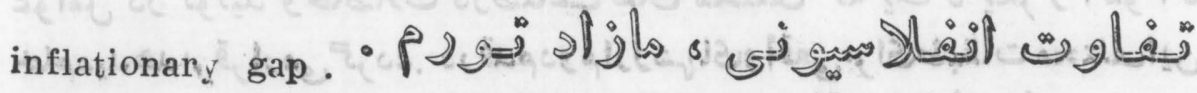
يك اصطلاح احصا كيوى است . مقصد از آن همانمقدار بولى اببيت كماضافه 


\section{I.NF .}

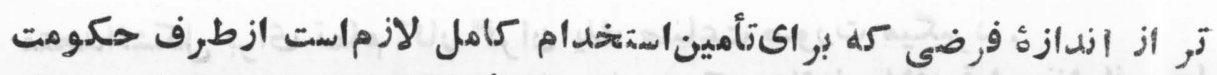

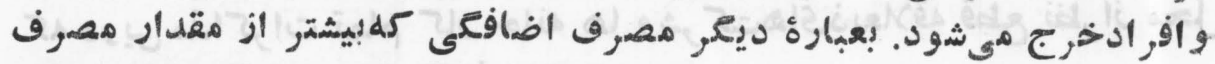

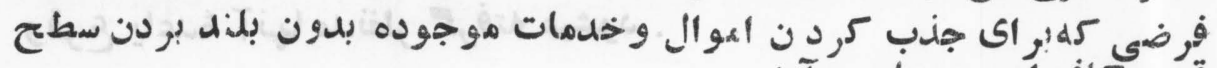

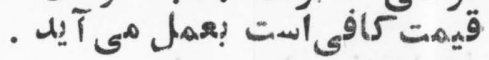

infrastructure .

$$
\text { - } \operatorname{lig} 0
$$

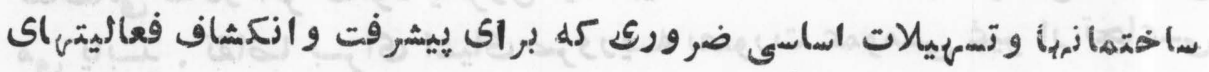

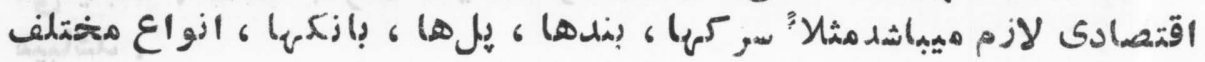

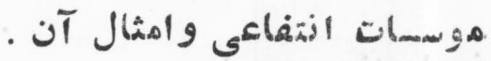

inherent vice .

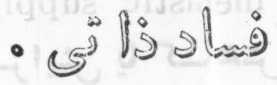

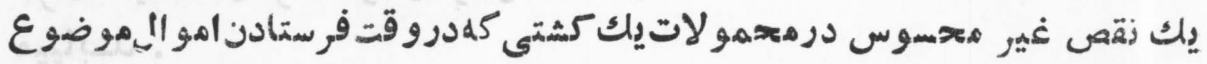

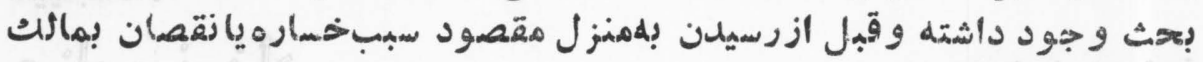

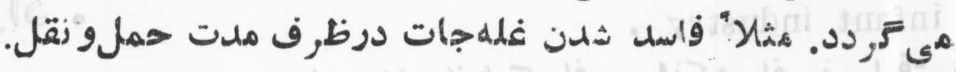

inheritance tax.

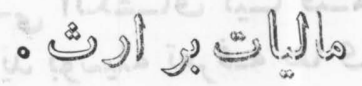

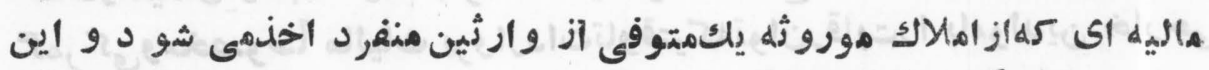

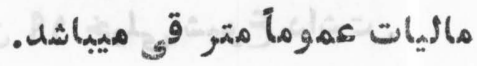
inland bill.

$$
\text { - जीञ }
$$

تفصيلات زير BILL, INLAND ديده شود.

input - output analysis .

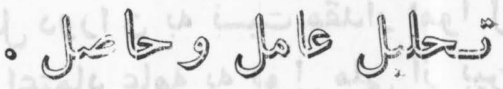

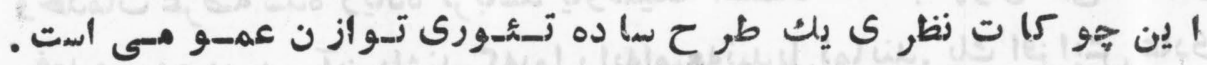

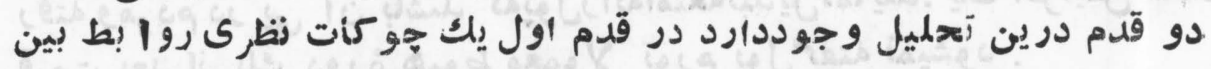

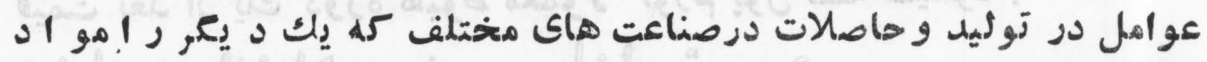

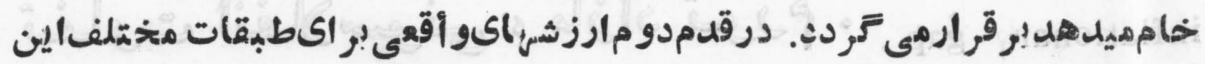

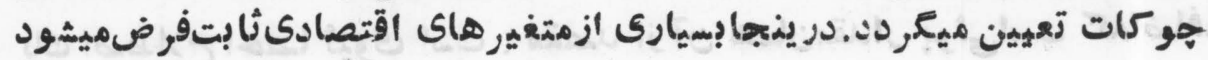




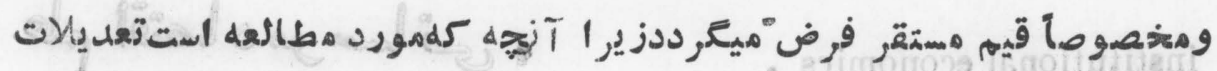
insolvent. . - a di lo jo

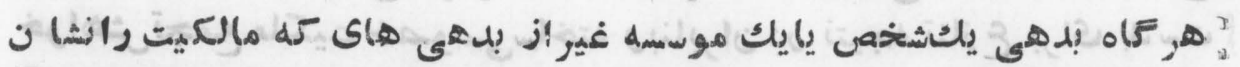

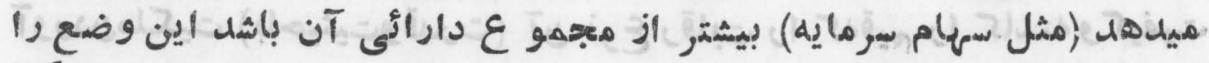

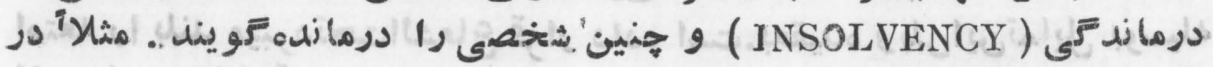

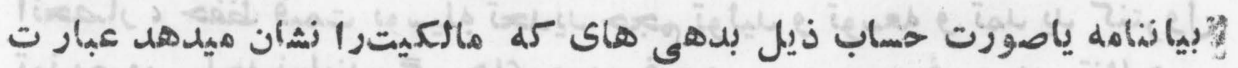

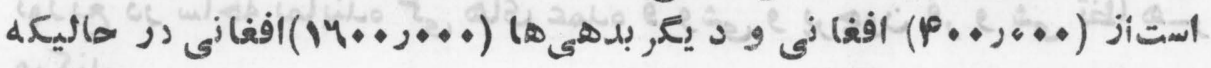

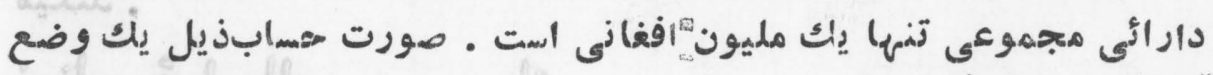

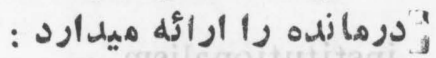

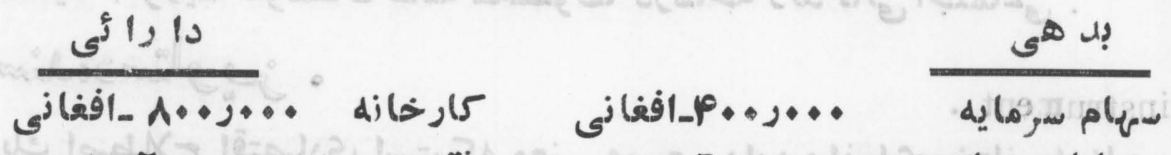

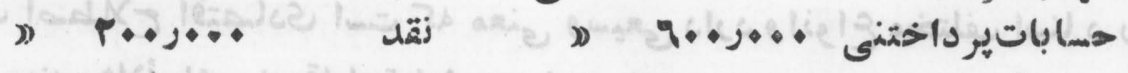

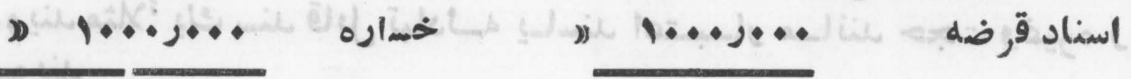

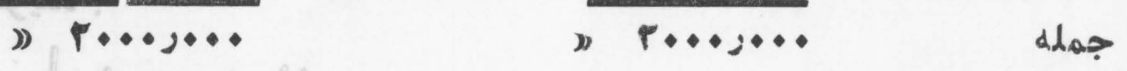

installment bond.

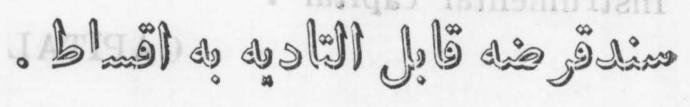

تفصيل زير INSTALLMENT

installment búging.

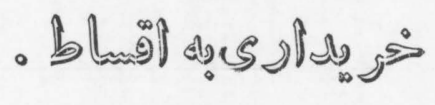

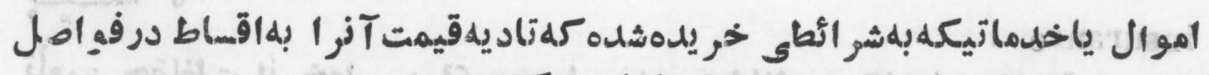

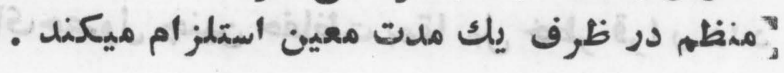




\section{INS}

institutional economics .

- ڤ

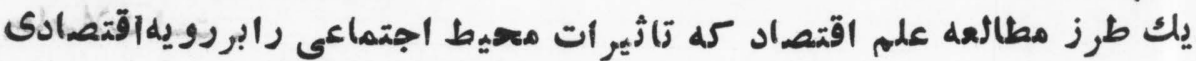

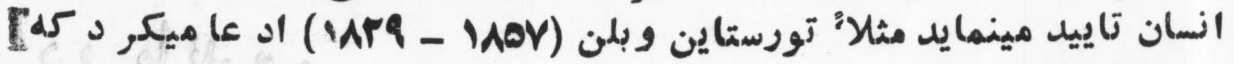

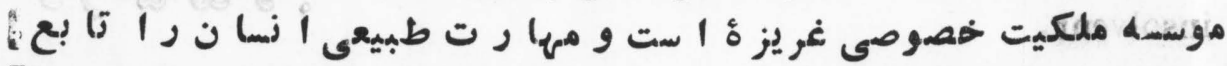

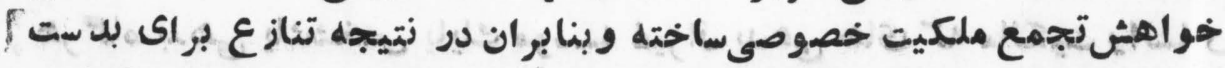

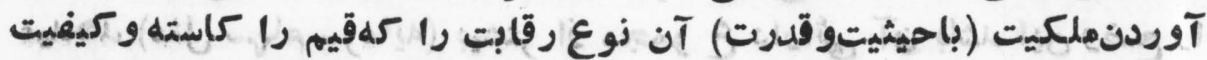

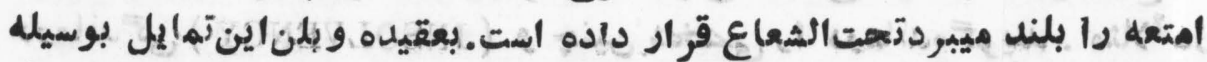

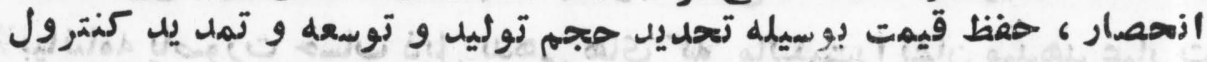

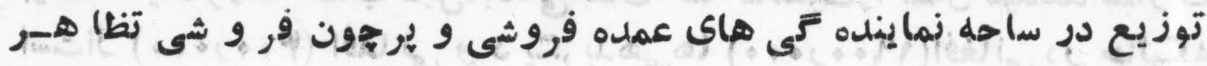

ميكنل .

institutionalism .

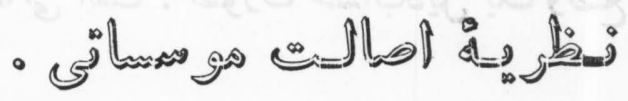

تملديد آتوريته موسسات عامه متخصوصا درساحله ززندFازى اجتماعى .

instrument .

$$
\text { - joglingodion }
$$

يك اصطلاح اقتصادى است كه معنى وسيعى دارد وانواع مختتلف اسنا د درا

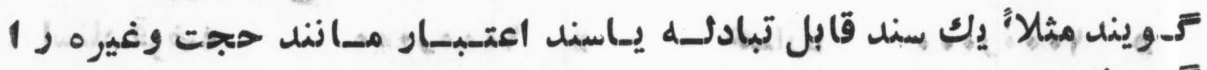

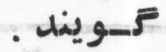

instrumental capital .

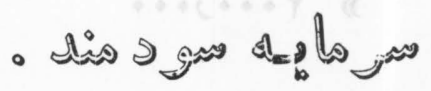

CAPITAL GOOD مر اجعه شود به م له

insular bond .

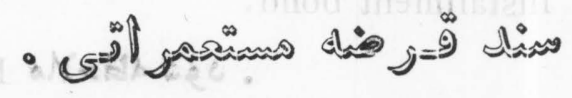

مر اجعه شو د به BOND , INSULAR

insuirance.

$$
\text { - } d a=0=\text { ? }
$$

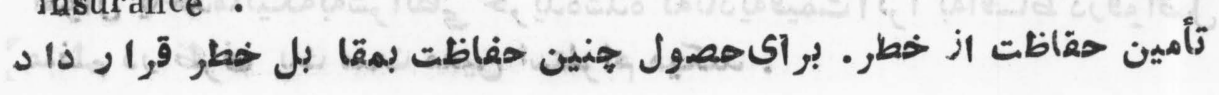




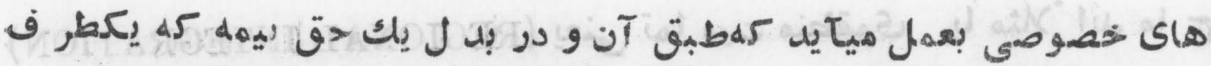

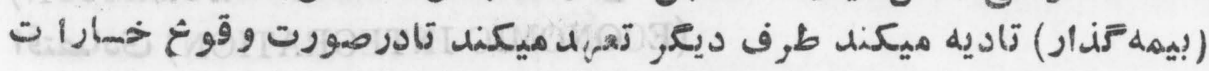

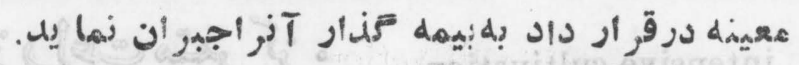

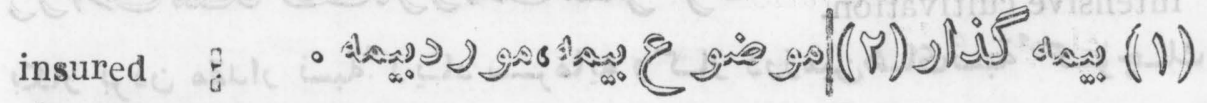

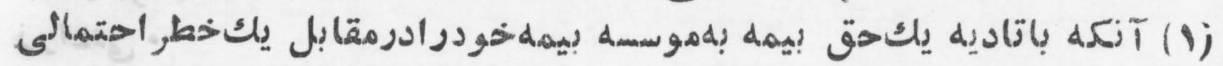

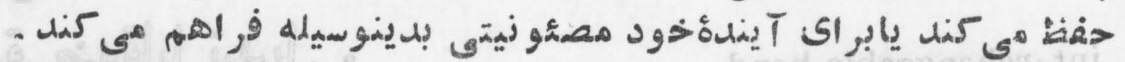

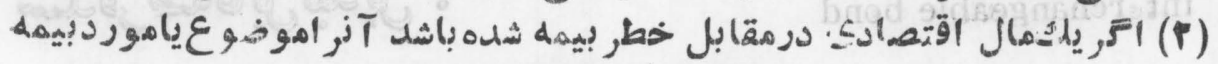

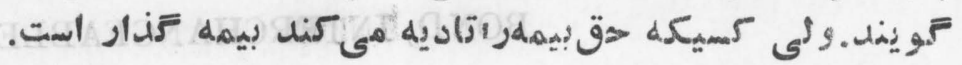

1:1 er - $\int_{\text {das. }}$

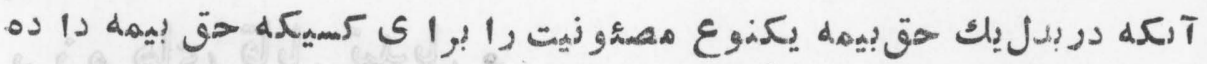

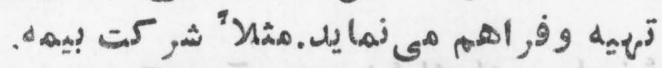

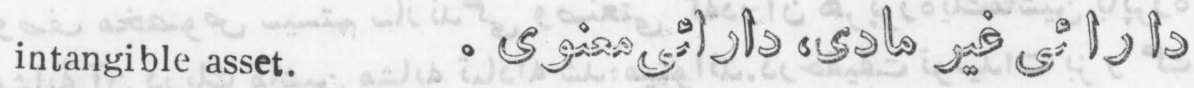

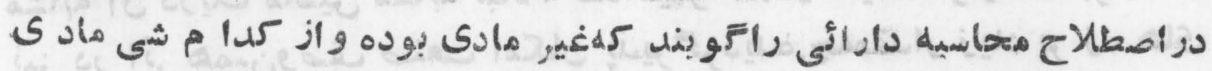

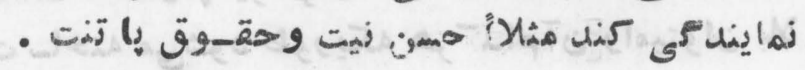
intangible property. " galo ga

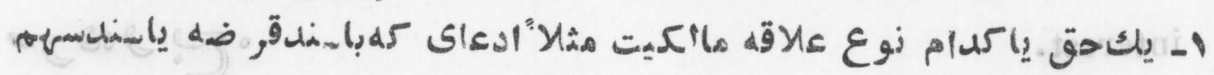
أبإت ميثوند

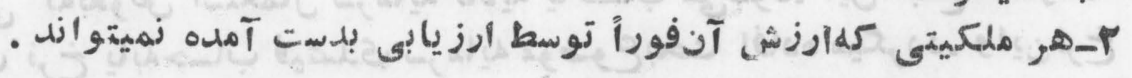
integration.

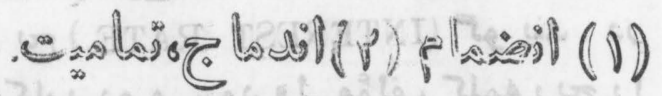

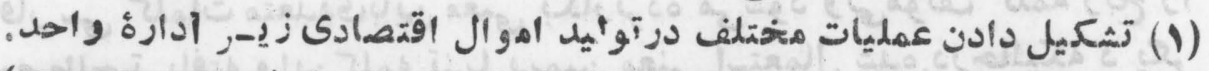

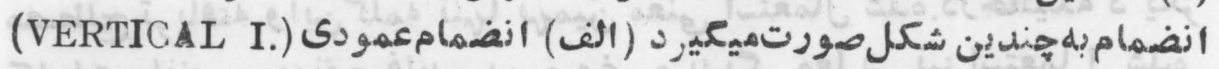

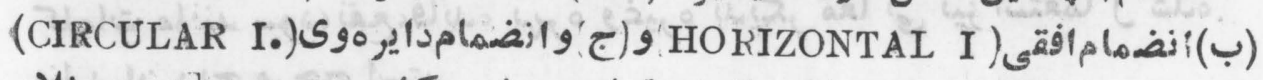

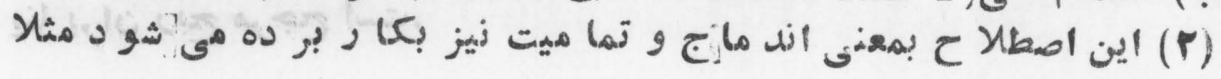




\section{INT}

(REGIONAL INTEGRA'IION) اقتصادى (ECONOMIC INTEGRATION)

intensive cultivation.

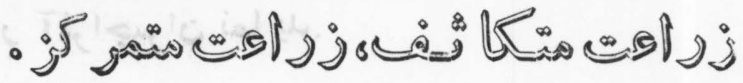

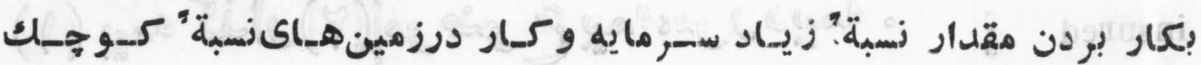

interchangeable bond

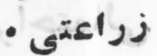

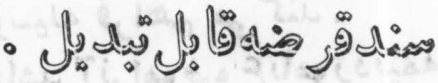

BOND, INTERCHANGEABLE تفصيلات زير

interchangeable parts.

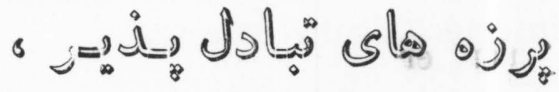

$$
\begin{aligned}
& \text { - 期然 }
\end{aligned}
$$

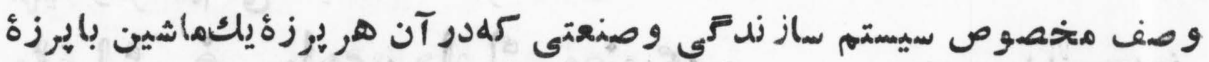

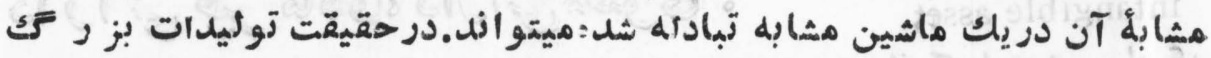

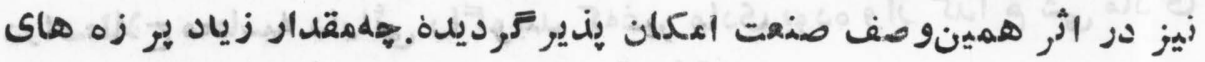

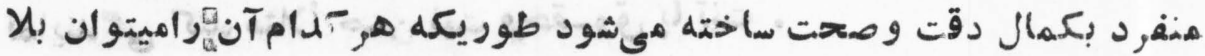

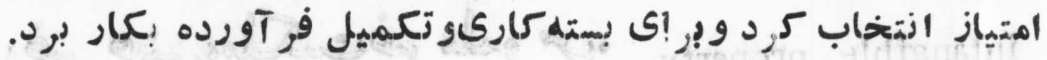

interest.

-

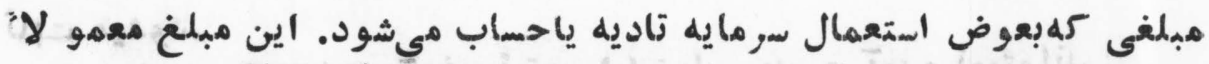

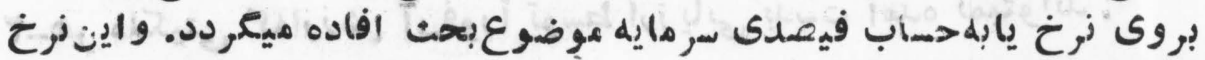

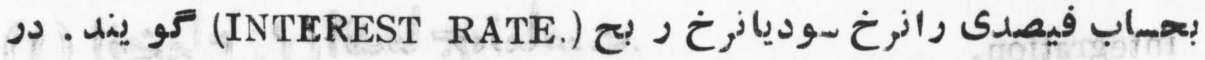

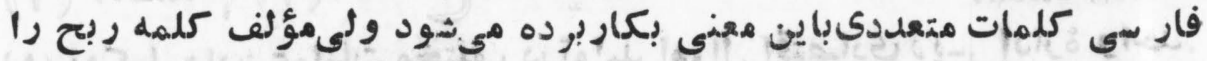

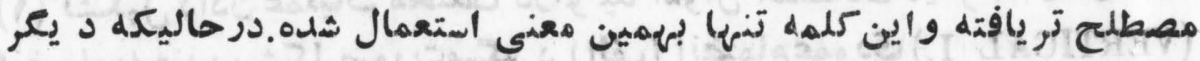

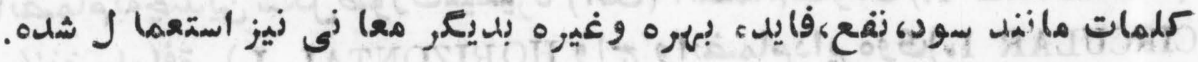

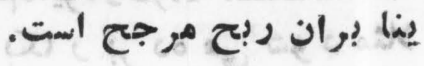


interest bond.

interest rate.

interim bond.

interlocking directorate.

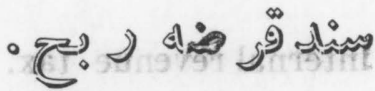

مراجعه شود به (BOND,INTEREST)

-ृ. गृ்

تفصيلات زير INTEREST ديده شود.

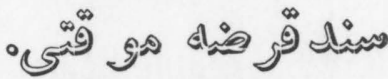
BOND,INTERIMAب اجعه شون

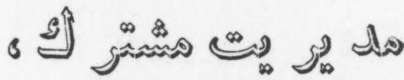

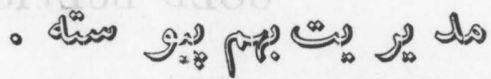

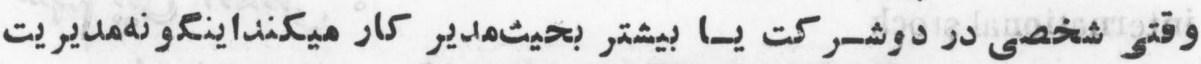
را مدبر يتمثترك كو يا بهمئيوسته تمويند.

intermediate good.

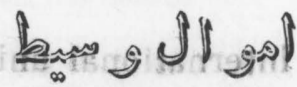

تفصيلات زيو (CAPITAL GTOD.) - ज्योi जी

internal improyement .

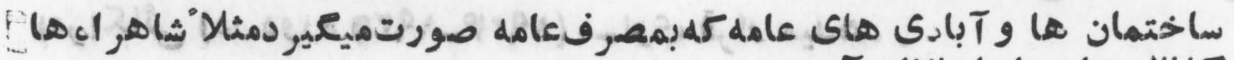

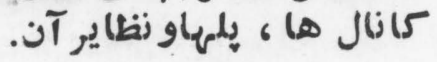
- जो internal national debt ${ }^{\circ}$

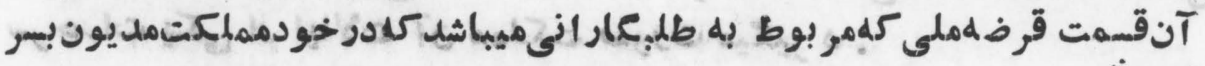

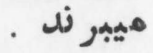
internal revenue. - ज文ls

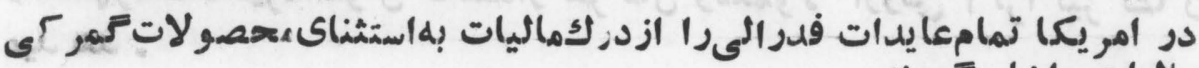
ماليات داخلمى تمو يند 
internal revenue tax.

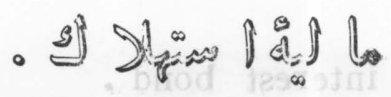

EXCISE TAX . هراجهود شود به

international economics.

$$
\text { - لlla }
$$

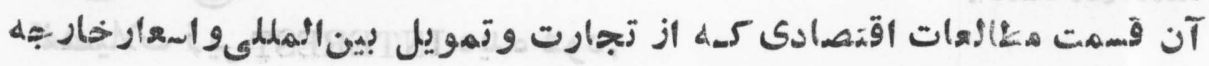

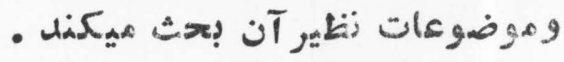

international gold-bullion standard.

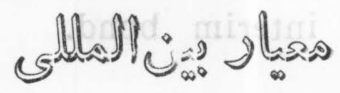

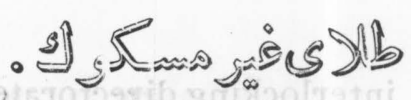

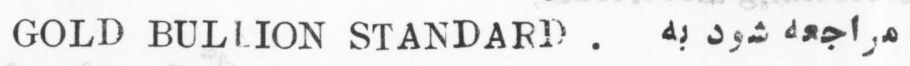

international stock

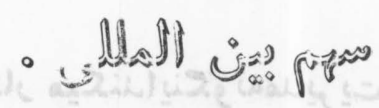

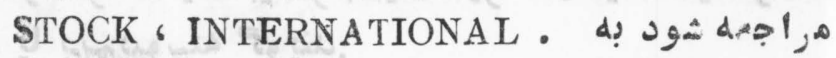

international unit."

- Uld

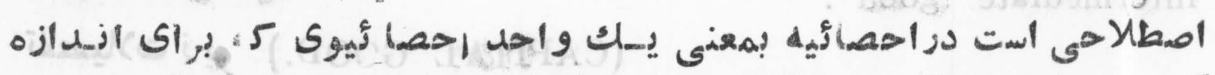

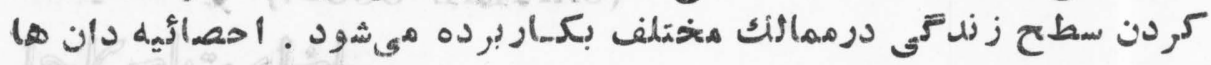

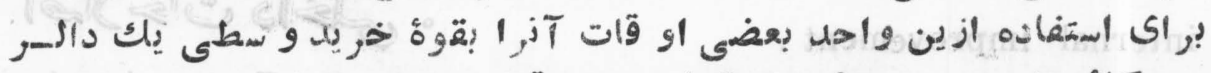

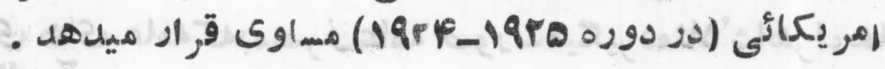
interstate commerce

$$
\text { - ل्ष }
$$

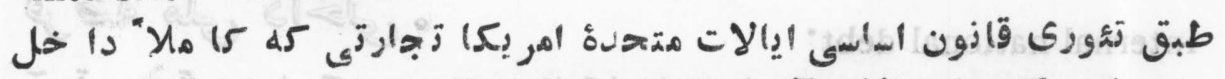

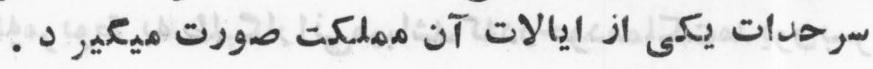
inventory. - जS

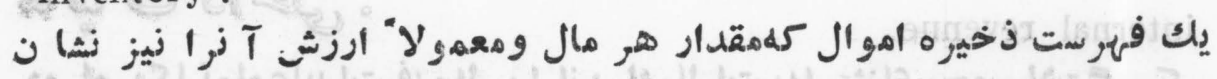
ميد هد . 


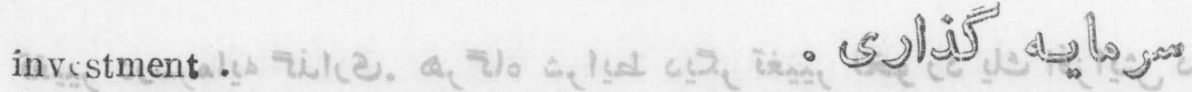

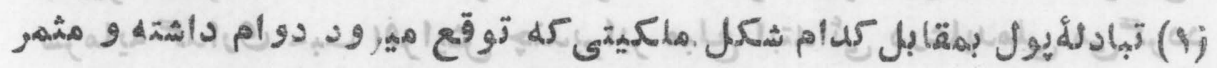

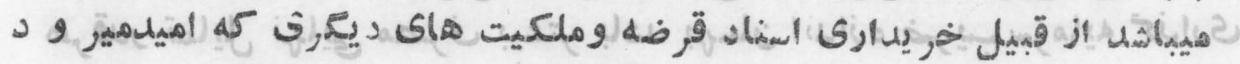

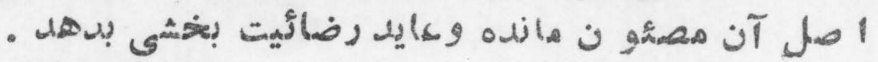

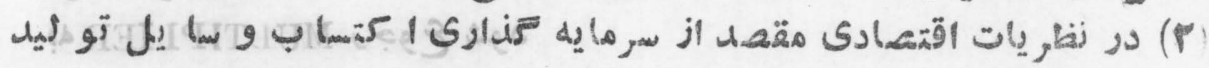

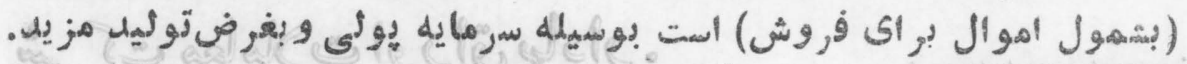
investment banking .

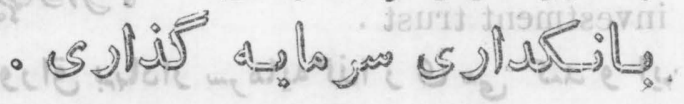

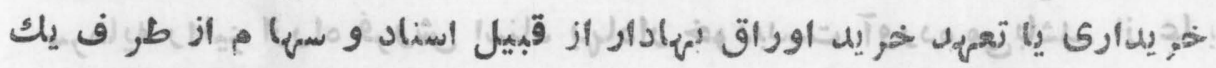

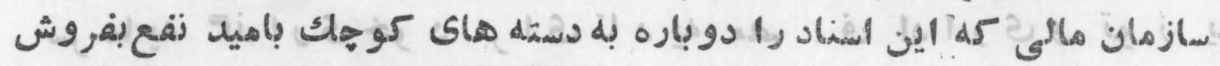

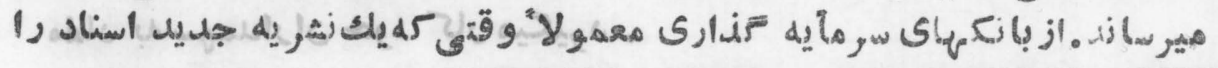

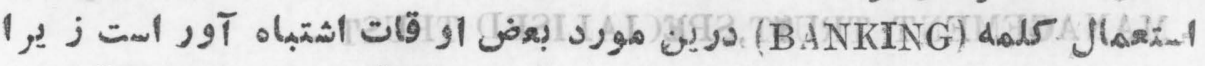

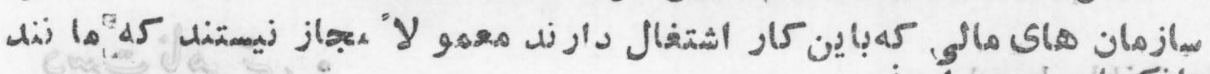

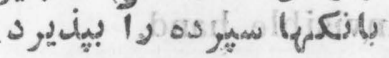
investment bill.

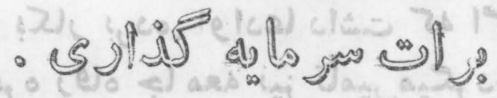

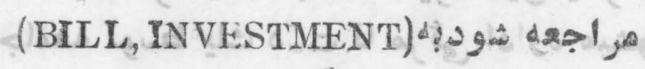
investment counselor .

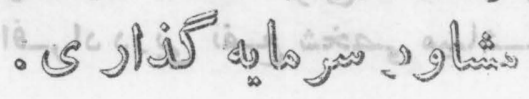

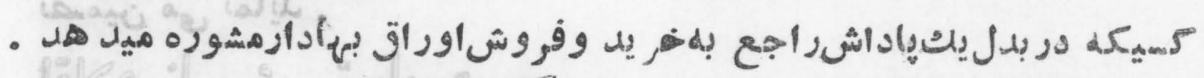

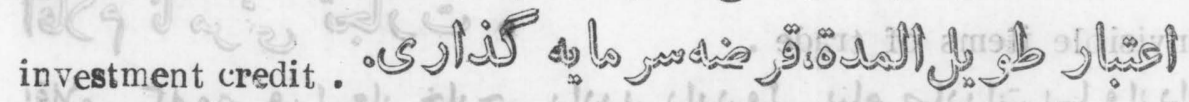

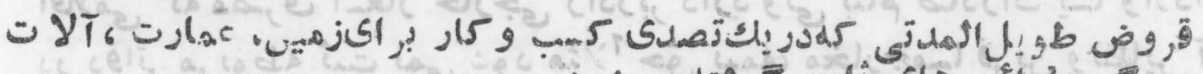

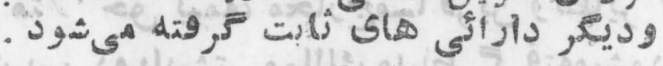
investment multiplier. जslis d

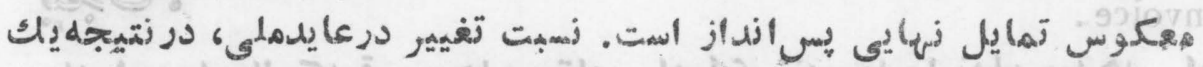




\section{INV}

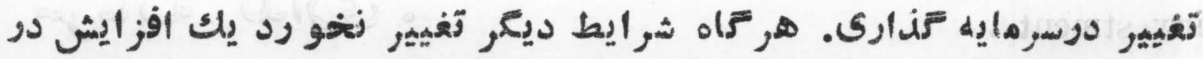

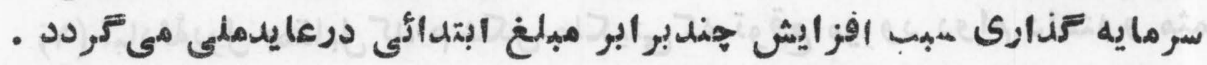

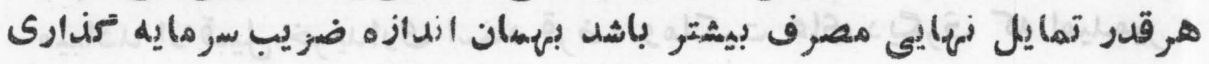

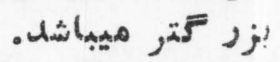
رجوع شور MULTIPIIER d?

investment trust .

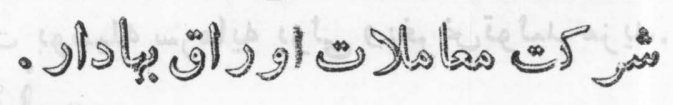

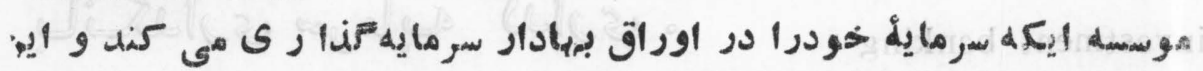

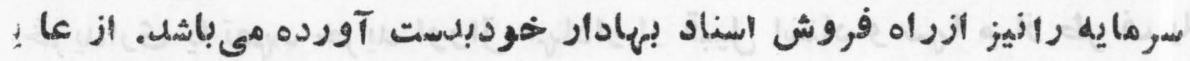

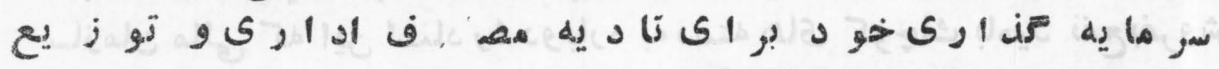
. FIXED INVESTMENT TRUST, GENERAL MANAGEMENT TRUST,SPECIALISED TRUST .

\section{invisible hand.}

$$
\text { - ज涫 }
$$

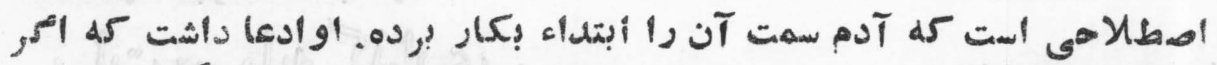

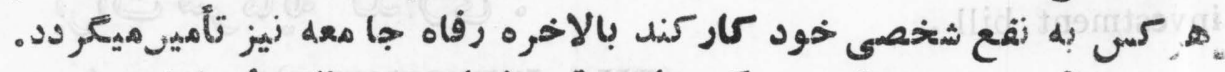

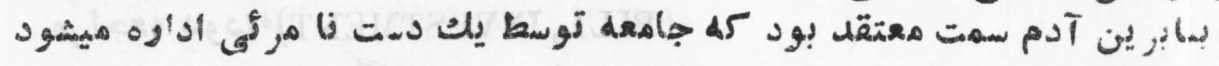

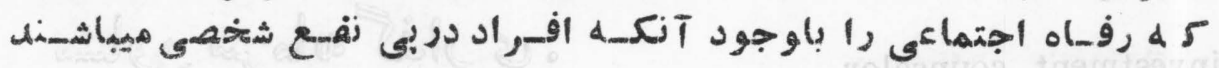

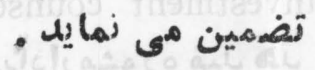

invisible items of trade.

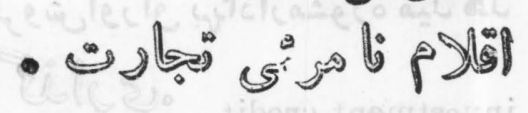

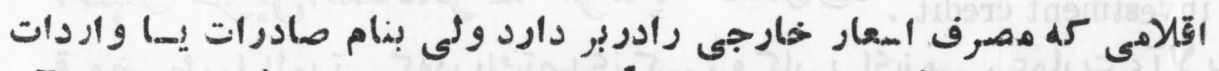

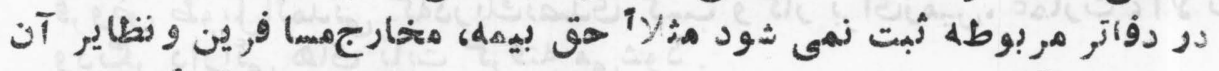

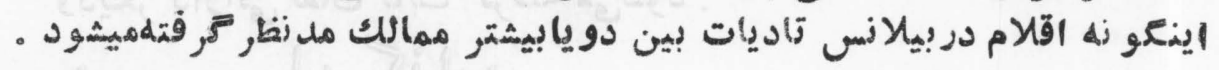

invoice.

$$
\text { - 仓्ञ }
$$

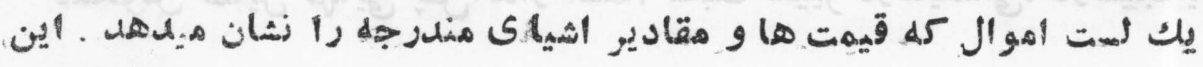




\section{IRR}

- .

involuntary bankruptey .

فر متاده ميثروده

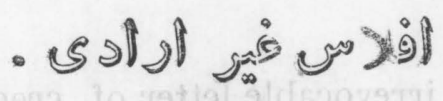

مر اججه شود به BANRCPTCY

iron law of wages. .

B 9 实

- Lo sis=a A

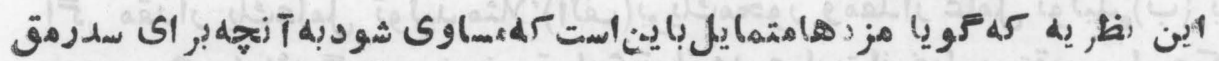

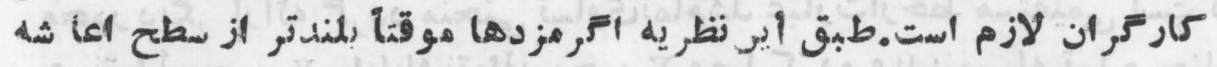

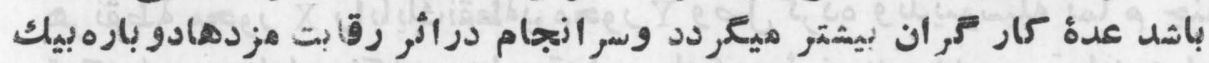

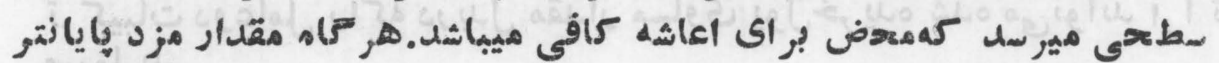

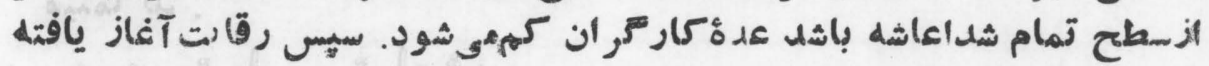

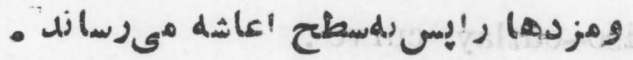

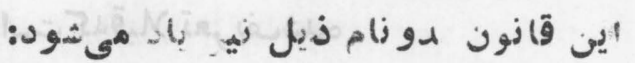

(SUBSISTEN(E LAW OF WAGES, BRAZEN I AW ( F WAGES)

irredeemable bond.

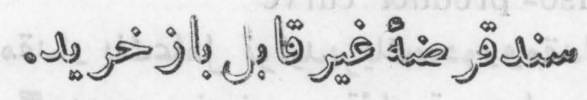

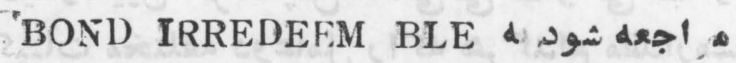

irr deemable f reign ex hang standard. C

(5) low

ها نند (هعيار السعازى طلاكله است .

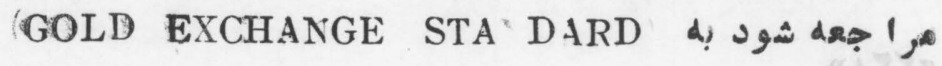




\section{IRR}

irredeemable money

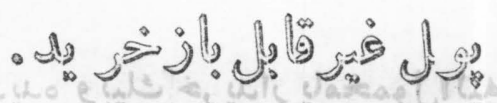

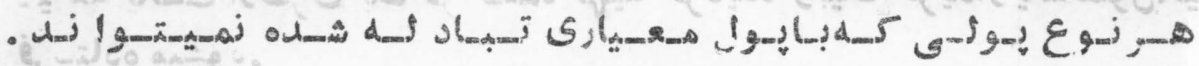
.

irrevocable letter of credit .

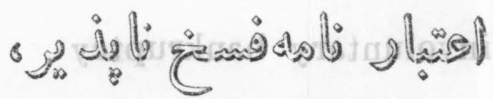

$$
\begin{aligned}
& \text { 。 }
\end{aligned}
$$

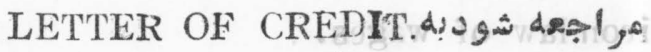

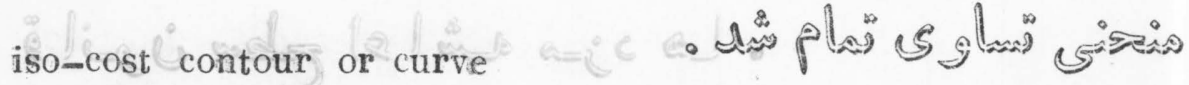

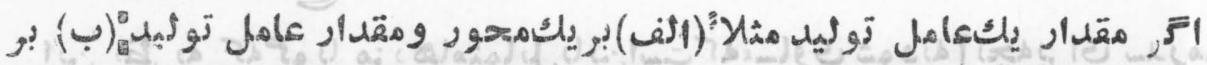

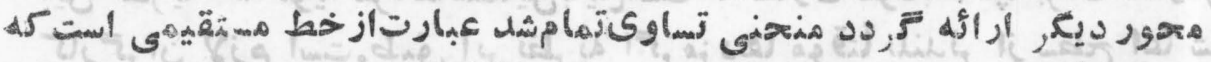

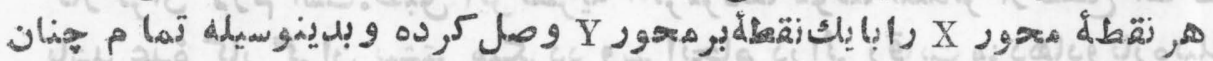

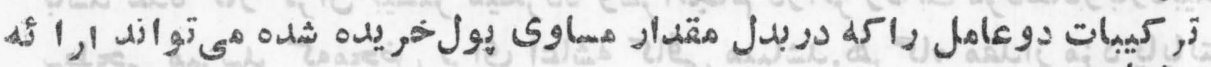
dis loins

iso-outlay cúrve.

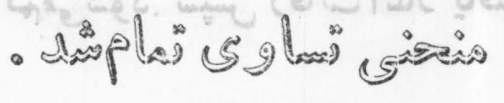

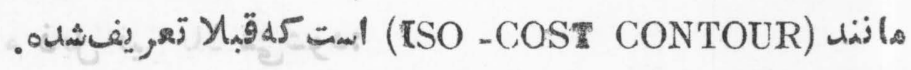

iso-product curve

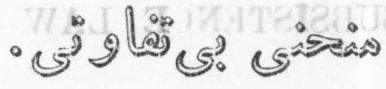

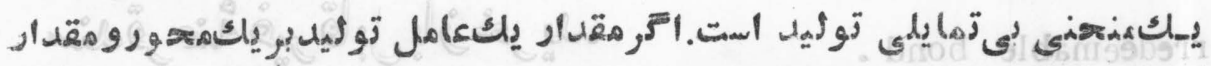

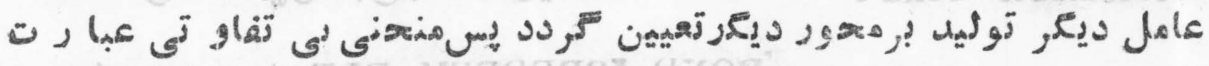

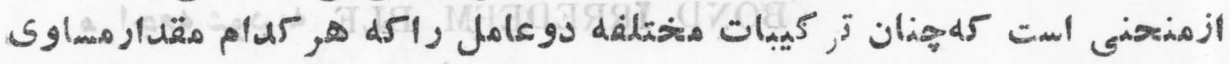

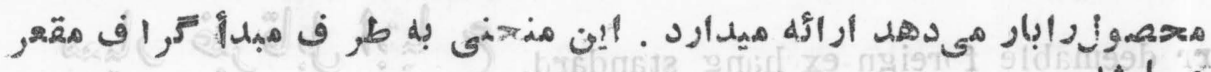

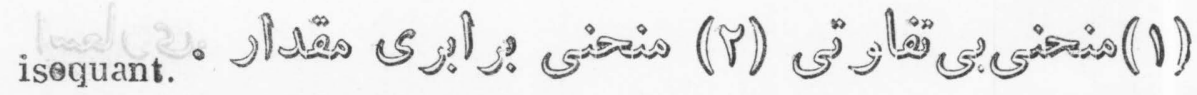

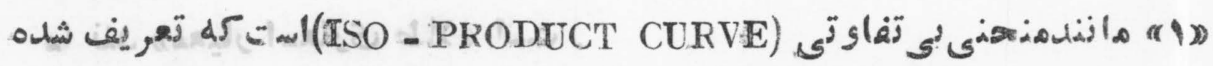




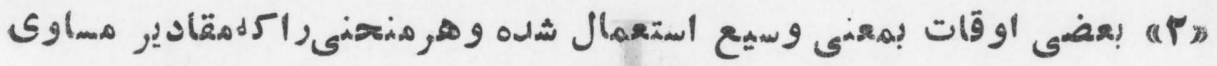

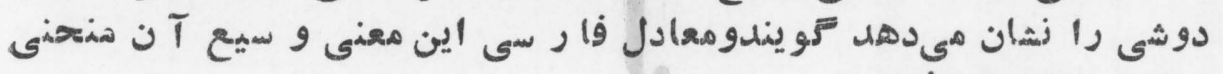

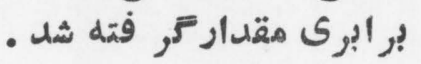
iso-utility curve.

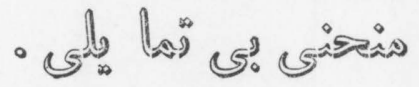
ماند INDIFFERENCE CURVE issue.

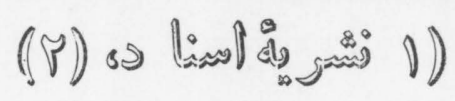

$$
\text { - As }
$$

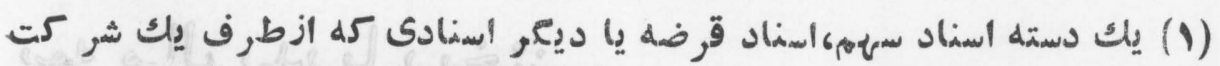

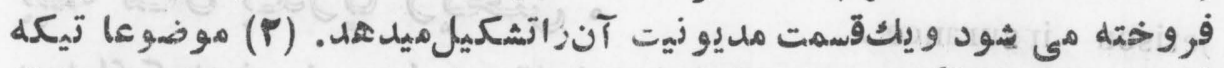

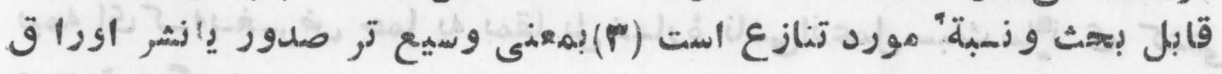

itemized appropriation.

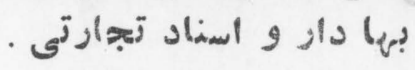

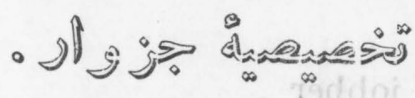

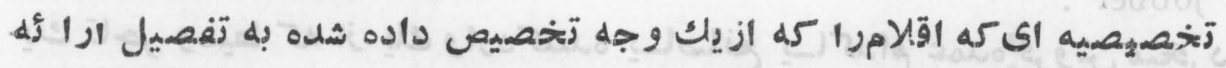

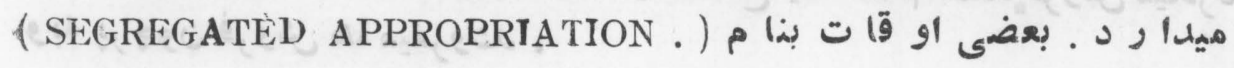

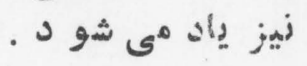

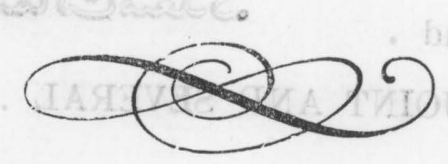




\section{J}

jettison .

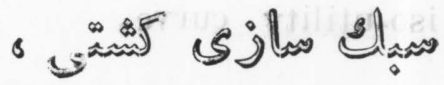

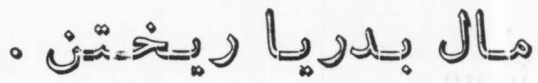

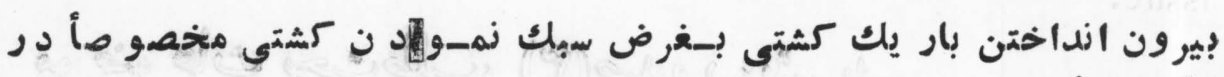

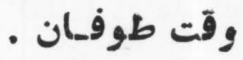

jetison ir surance.

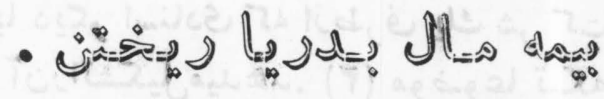

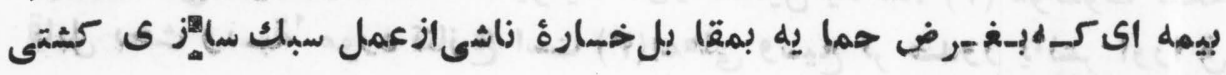
صورت ميعيرد .

jobber .

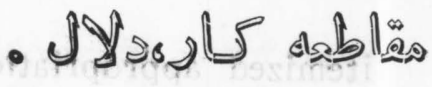

يك تاجر وسيط كه از يأك وارد كمنده يـاصانع يـاكدام عمده:فروش ميتخرد

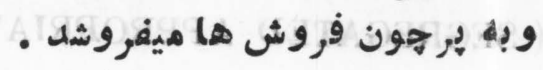

job evaluation .

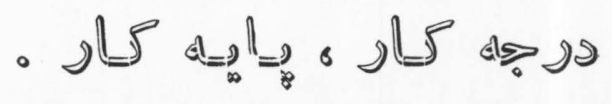

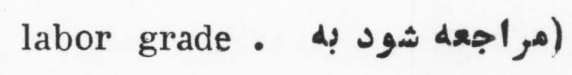

joint and several bond .

$$
\text { - S4 }
$$

BOND ، JOINT AND SEVERAL . مراجعه شود به

joint agreement .

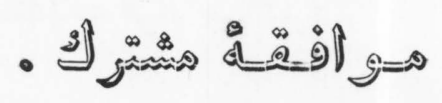

در اصطللاح روابط صنعتى موافقه اى را Fوينل كه از طرف دو يِابيشتر كار 
فر ما ودو يا بيشتر اتتحاديله كار F, ان ويا توسط يك كار فرما و دو يا بيشتر

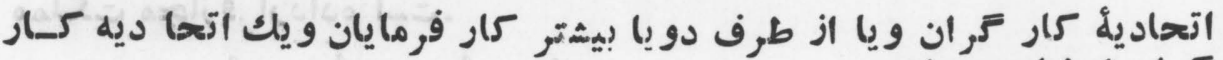
كران امضا شله بار ماند . joint costs .

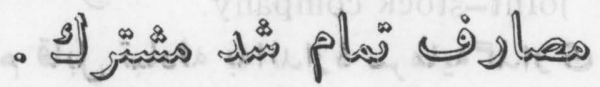

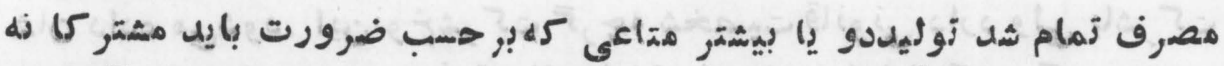

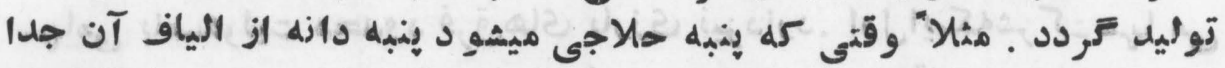

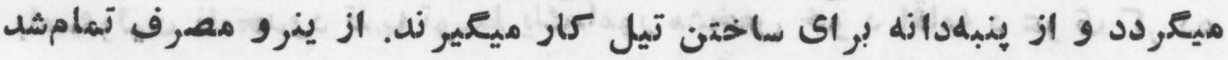

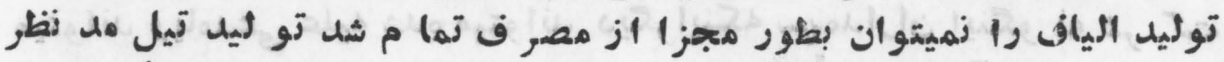

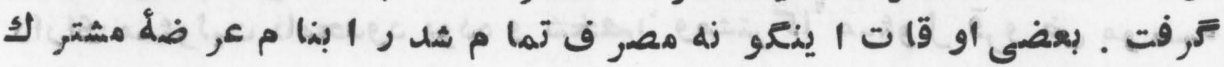

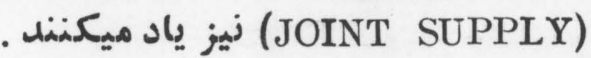

joint demand .

- 3ी

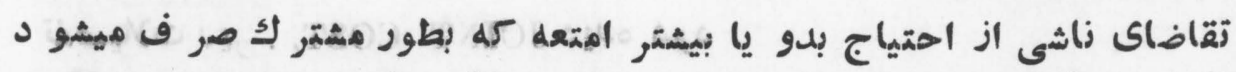

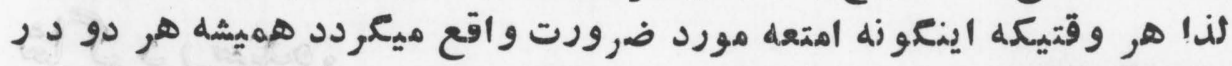

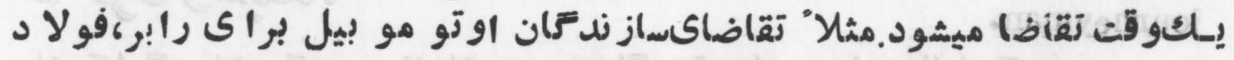

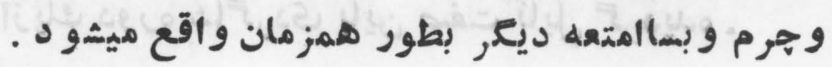

joint rate .

$$
\text { - 县 }
$$

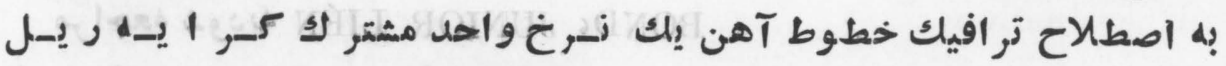

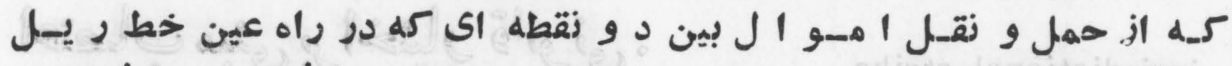

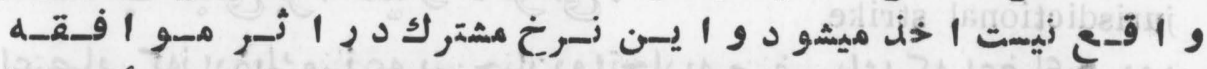

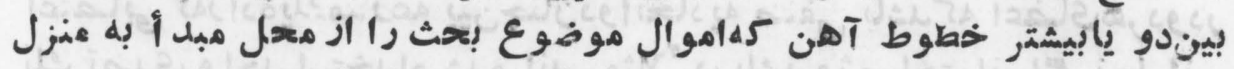

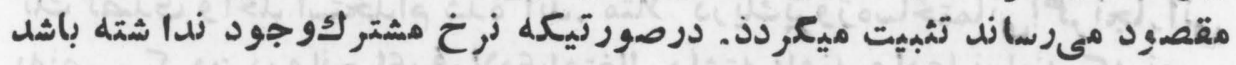

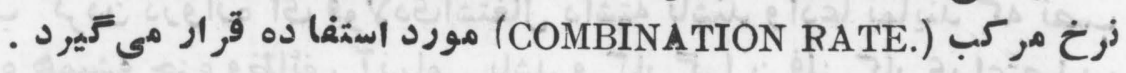

joint return .

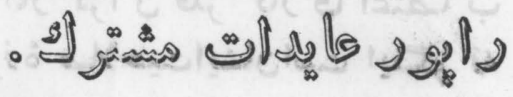

رابور مشترك عايدأت زن وشوهر كه تهيهآن را بصور ت مثمتر لو مقر رات 


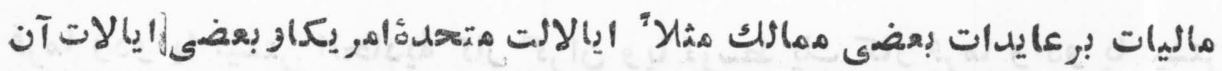

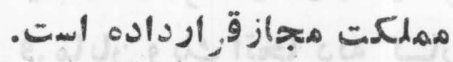

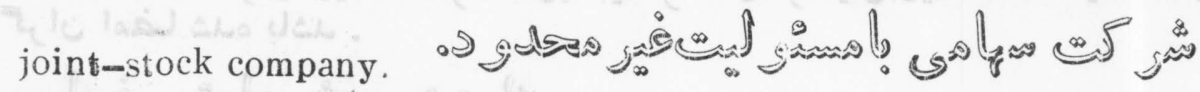

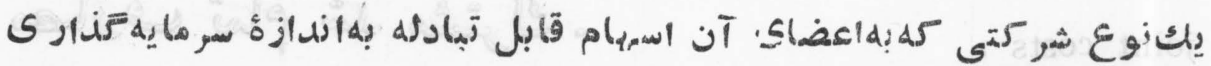

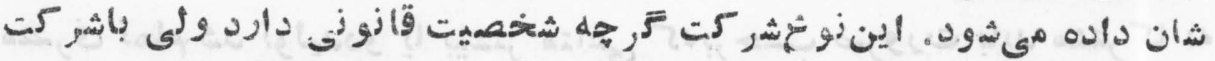

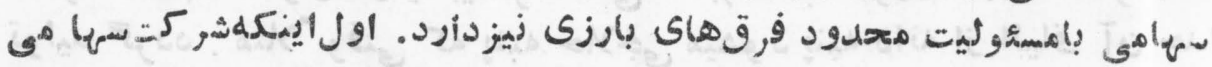

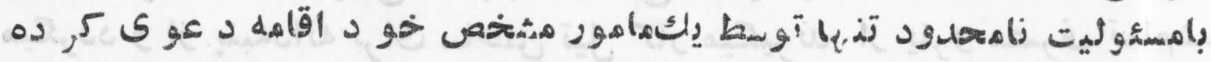

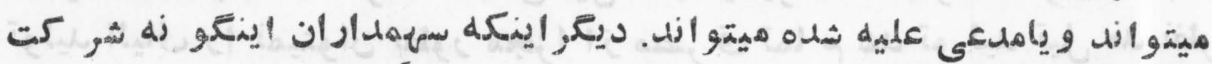

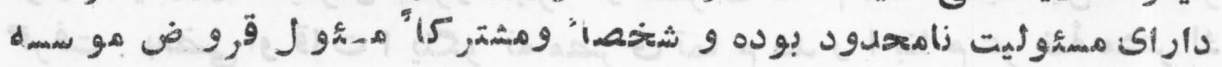
ميبا شنل . دار .

joint supply.

. S] تفصيلات زير . JOINT COST ديده شود

journeyman.

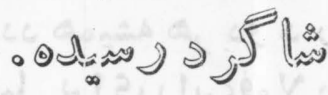
يك كارتر ماهر كهله junior-lien bond. ט

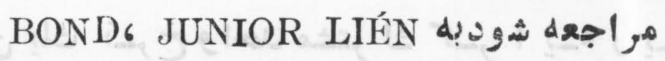

jurisdictional strike. - ज

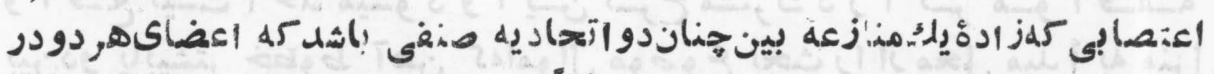

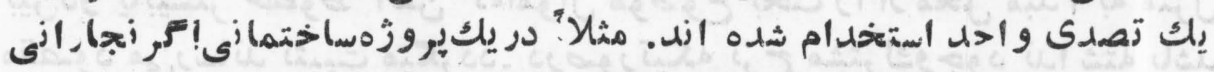

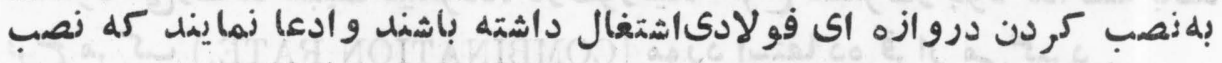

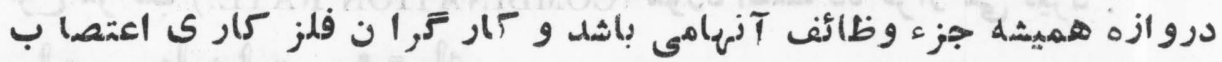

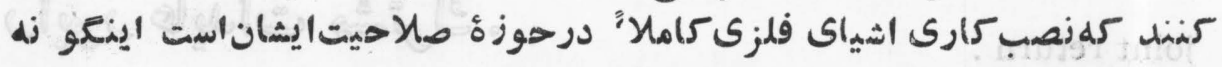

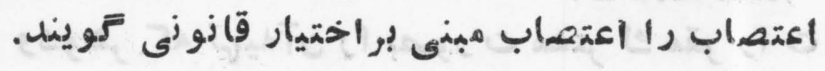


kameralism.

key industry.

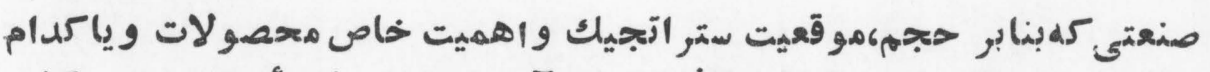

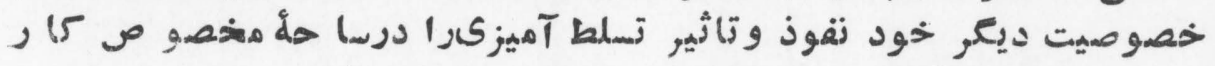

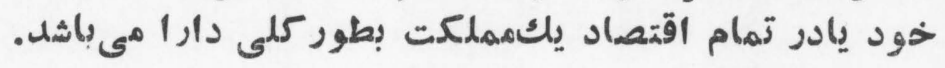

keynesian economics.

زظريات وسياستهاى اقتصادى كهازطرف اقتصاد دانمشهيو روان انعلميسى جان

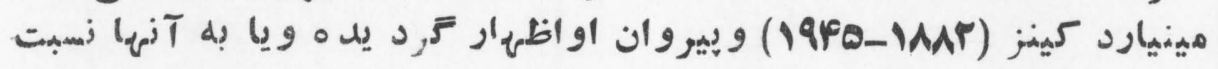
داده شده است.

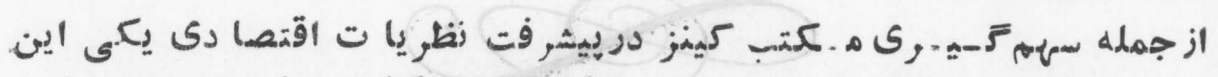

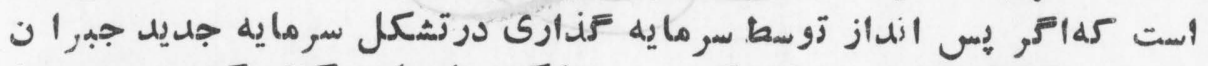

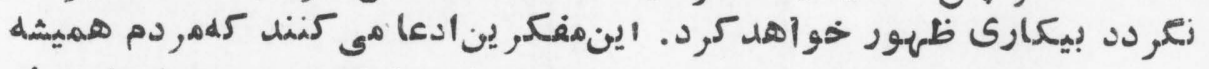

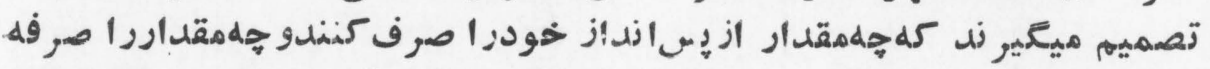

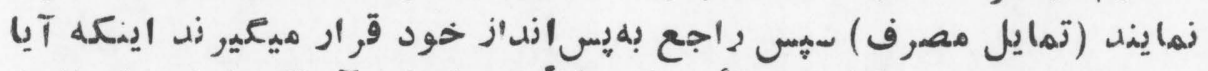

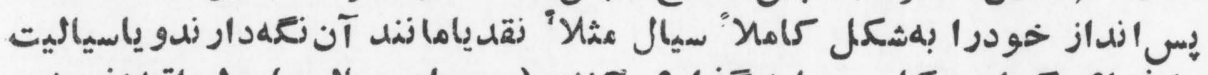

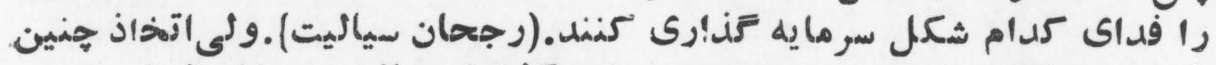

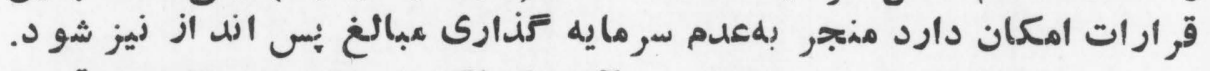

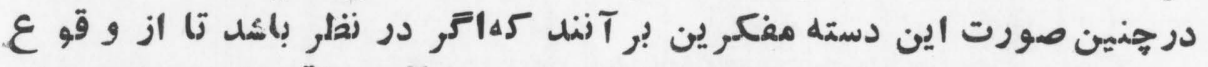

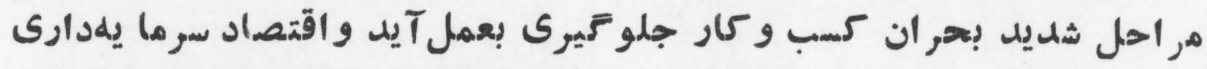

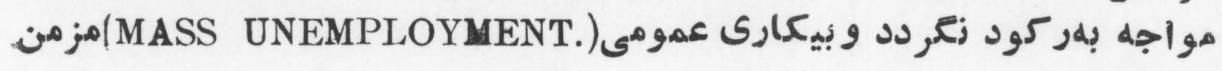


KIC

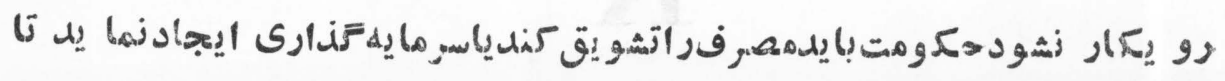

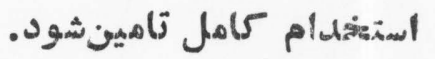

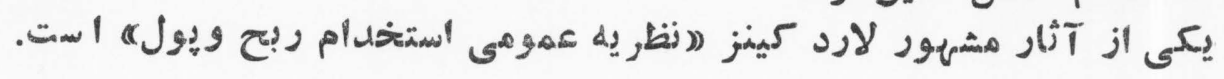
kickback .

- $\int$ d d

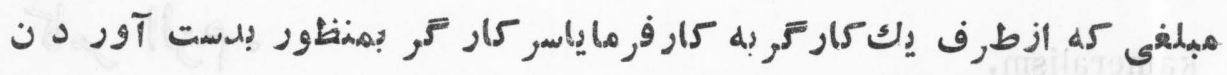
وياناه كردن كار تاديه مي شود.

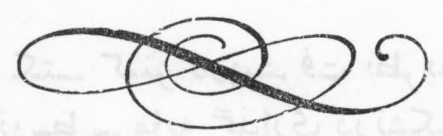

(PFP) 
labor .

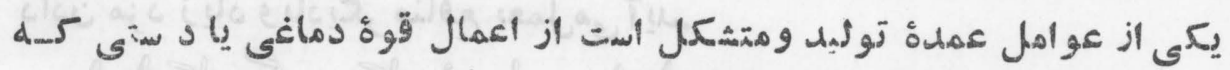

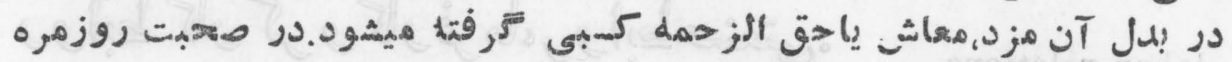

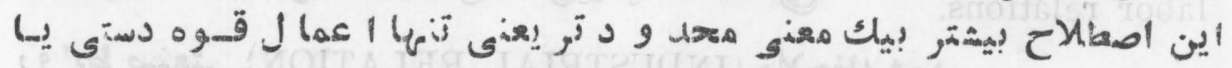

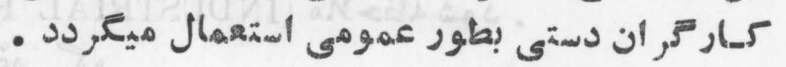

labor agreement .

$$
\text { - a }
$$

TRADE AGREEMENT . مراجه شود به به

labor exchange bank .

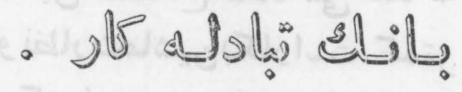

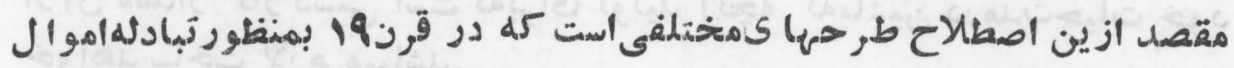

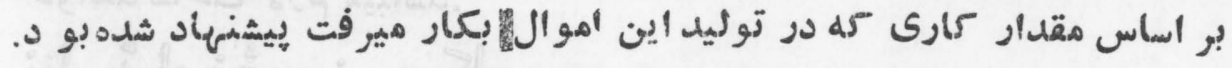

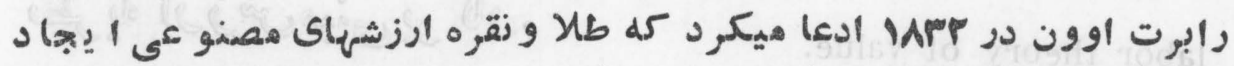

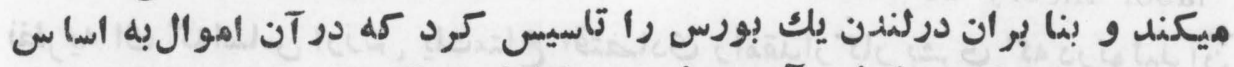

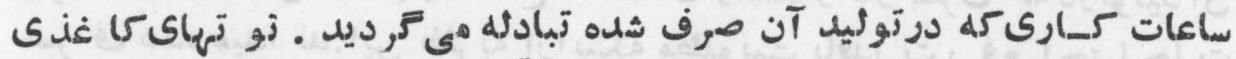

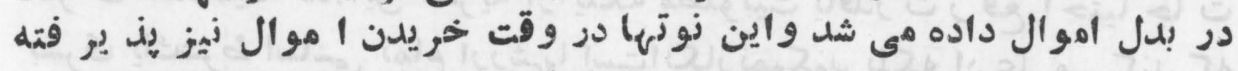

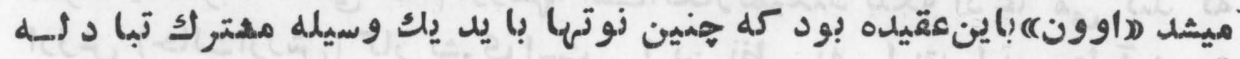
قبول تمر دو مون labor grade .

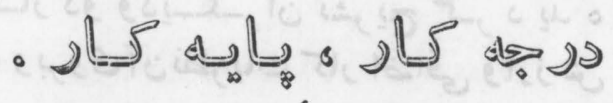

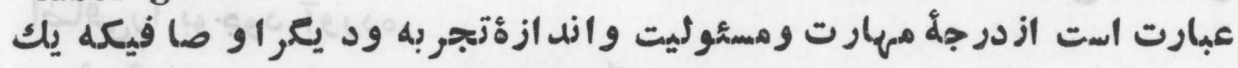

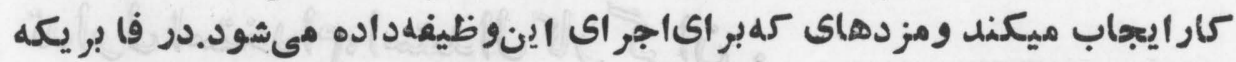

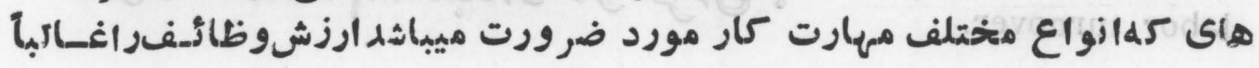




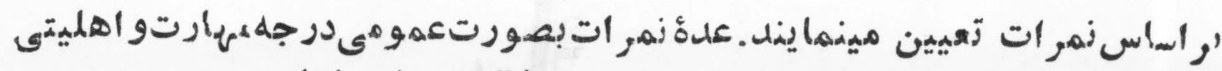

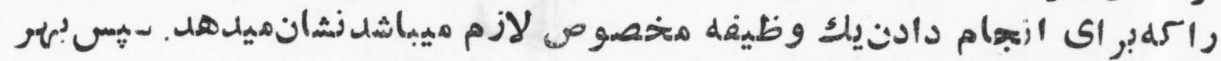

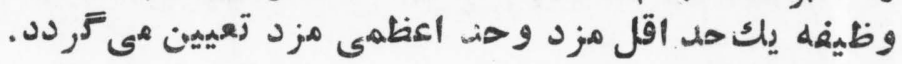

labor piracy.

-

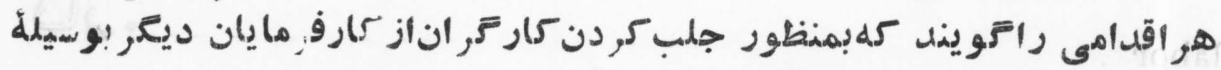

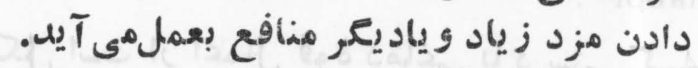

labor relations.

$$
\text { ن }
$$

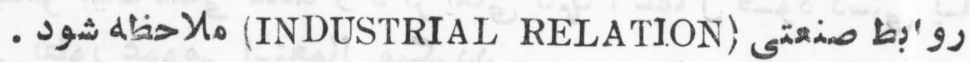
labor saving machinery - ن

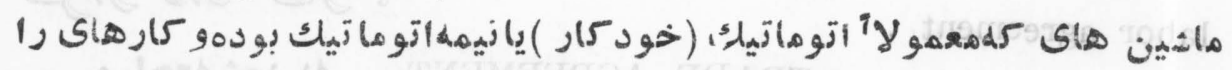

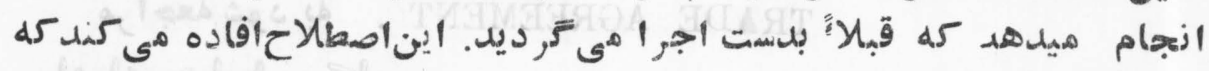

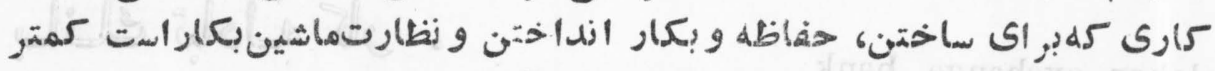

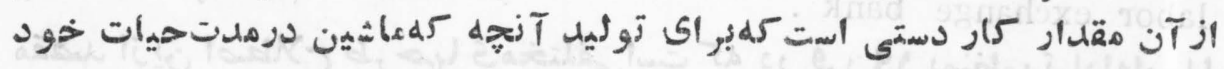

labor theory of value.

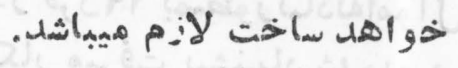
- gll jo

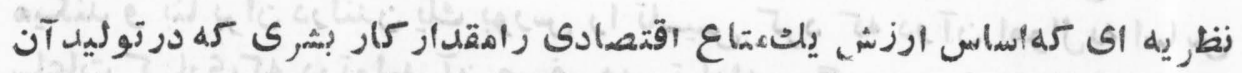

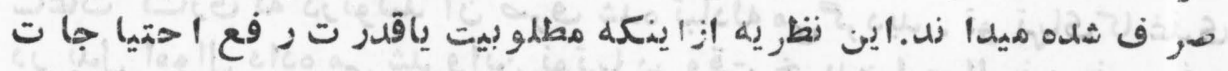

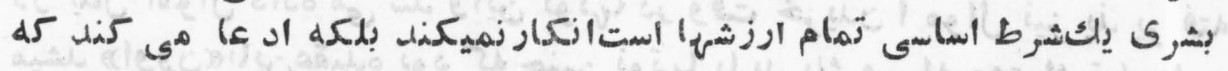

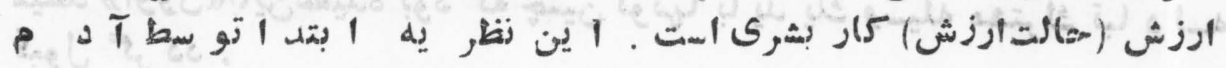

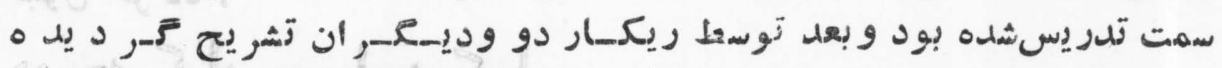

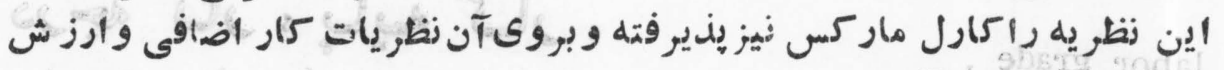

labor turnover.

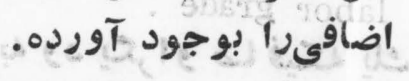

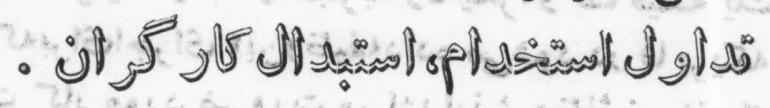

\section{arrqu}




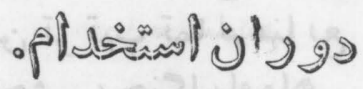

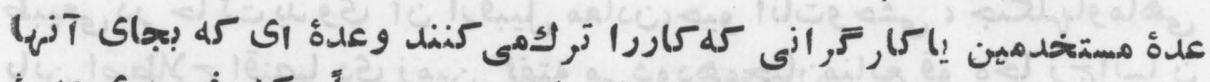

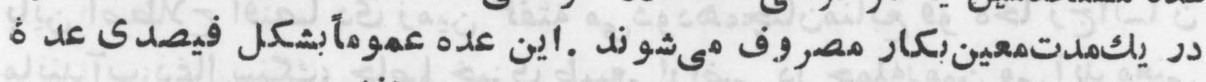

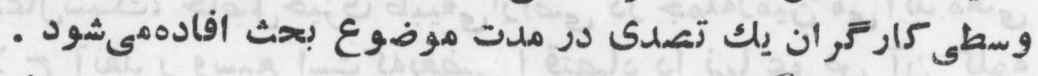
lab $>$ r union.

$$
\text { - iो }
$$

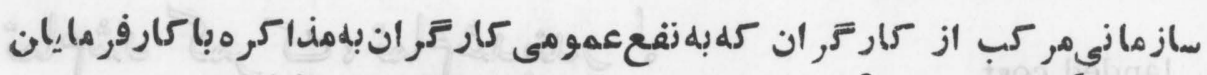

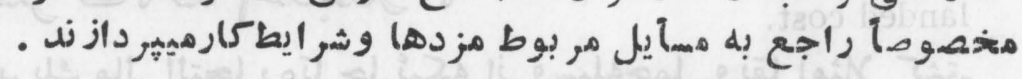
laissez faire (laissez faire,laissez passer.) ه ه - जshaid जs

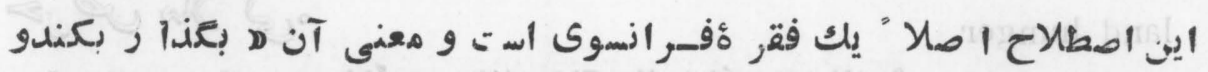

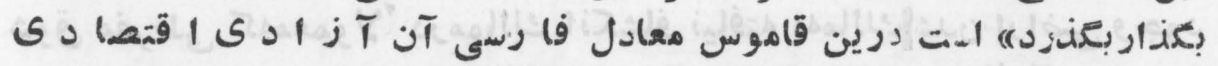

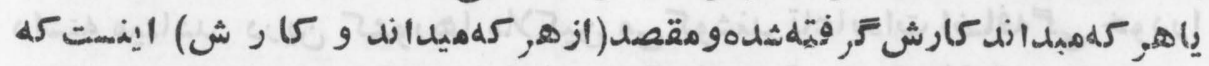

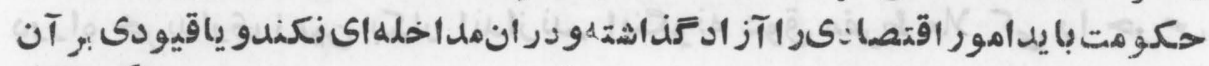

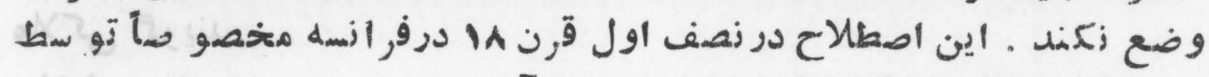

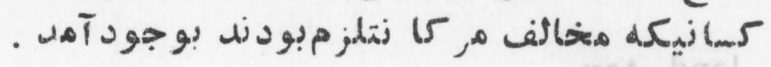

(lambs.)

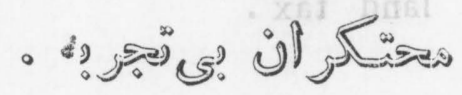

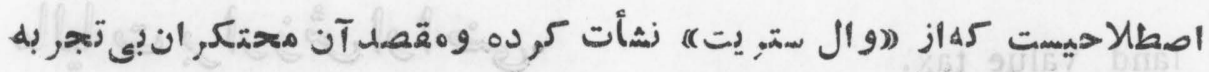

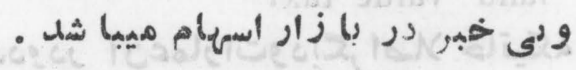
land

$$
\text { - exper }
$$

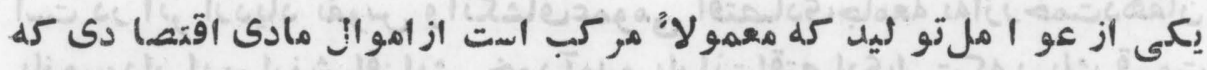

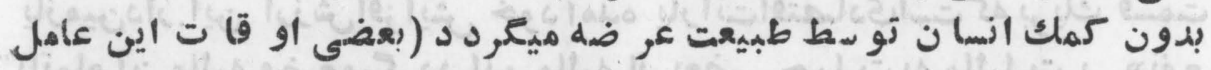

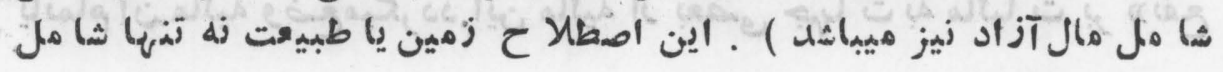




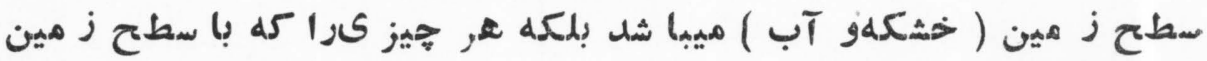

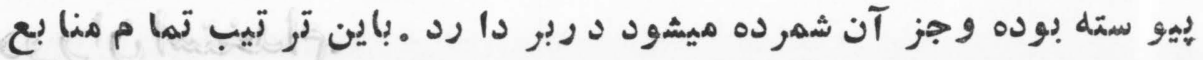

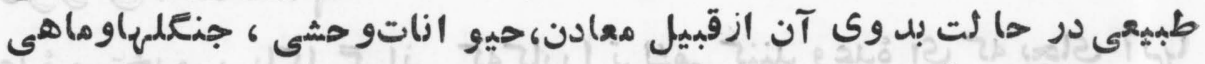

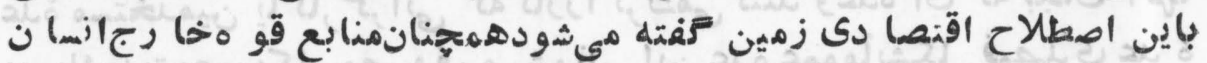

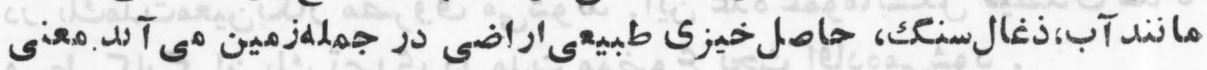

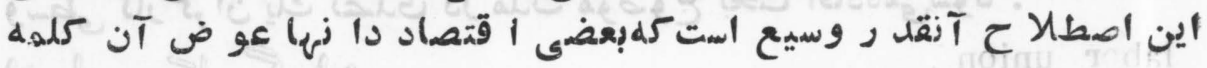

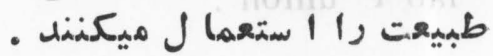

landed cost.

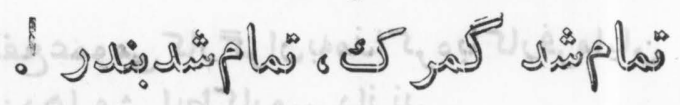

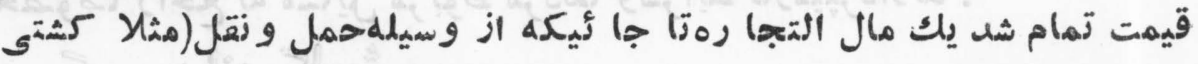

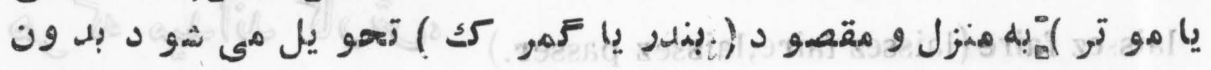
متحصول تمبر ك5.

land hunger.

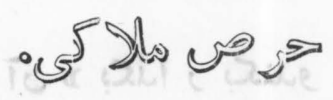

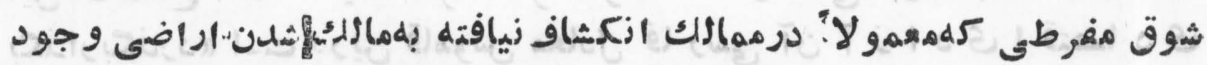

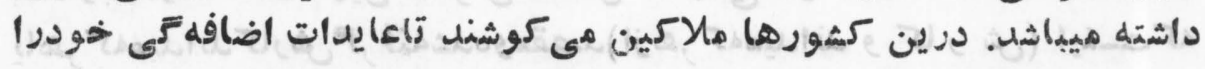

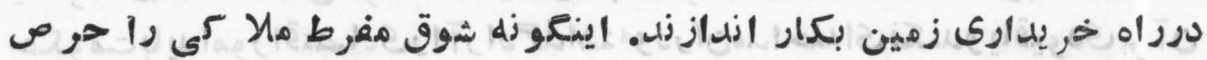
land $\operatorname{tax}$. ملاكى PROPERTY TAX • مر اجعه شود باس له

land value tax.

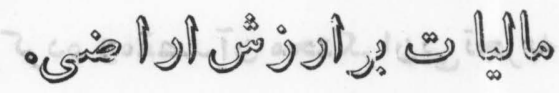

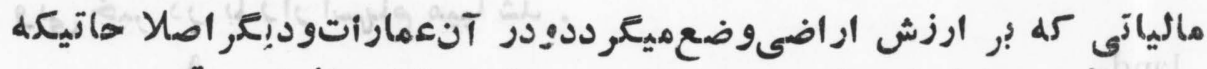

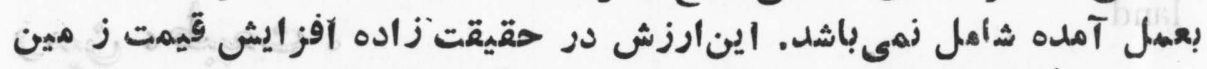

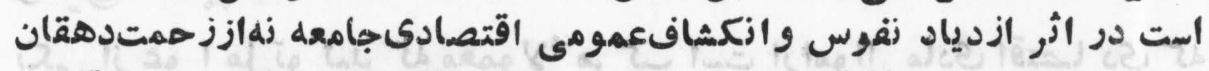

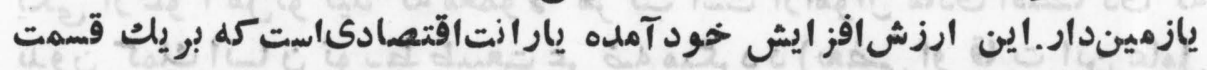

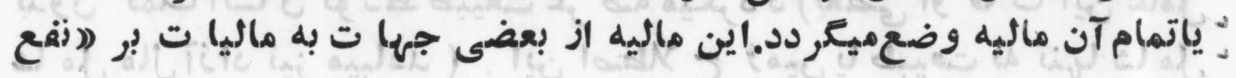

\section{aPrAD}




\section{LÉA}

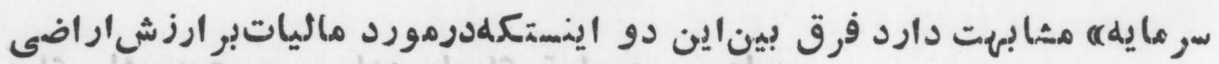

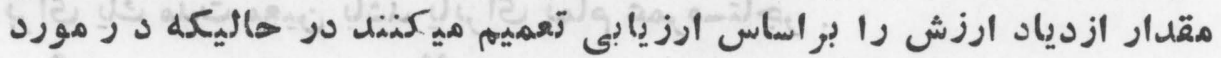

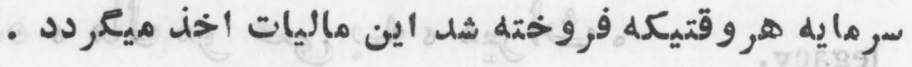
large scale production. $\quad$ ज

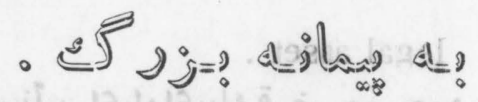
MASS PRODUCTION رجوع شود به

lawful money .

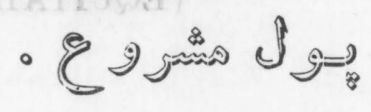

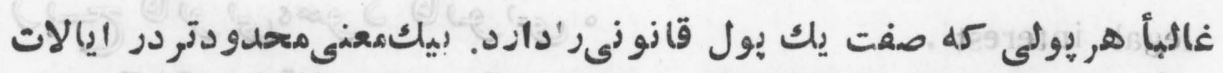

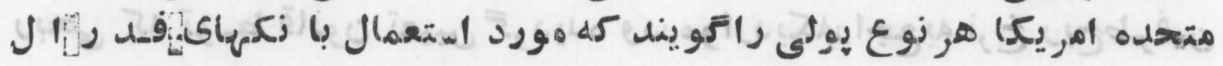

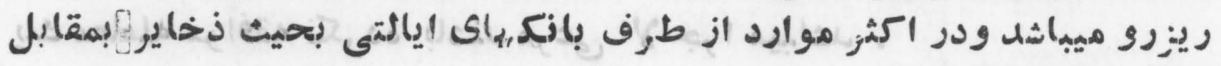

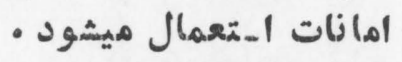

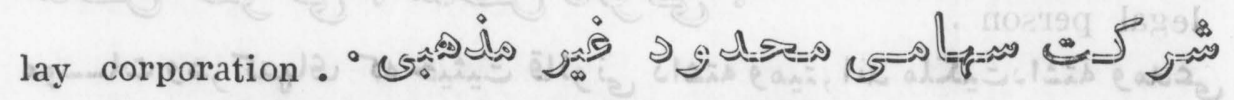

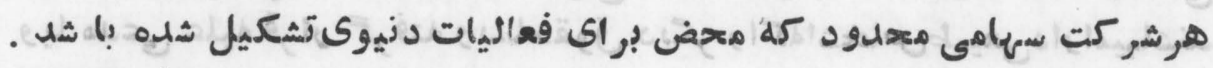

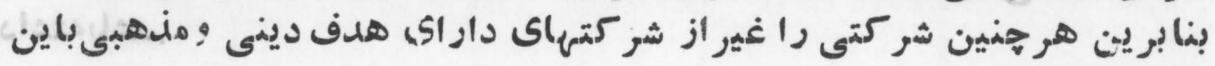

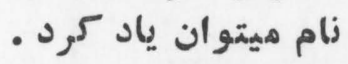

layaway plan .

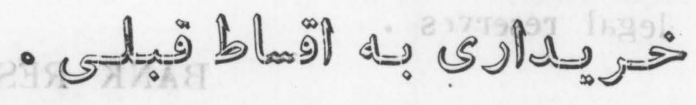

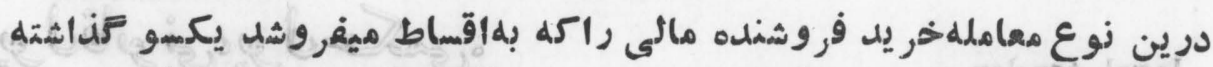

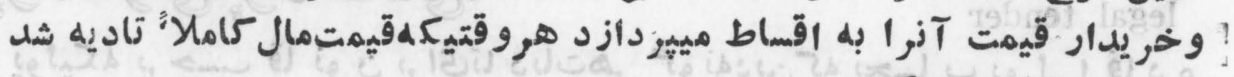

lease .

$$
\text { خريدار ما ل رأ ميعيرد. }
$$

قرار داد بمنظور تصرف يلك ملعيتمثخص. اين قرارداد مهكناست مو قتى 
legacy •

legal asset .

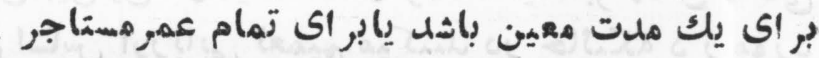

داراؤى كه بلدست وصى يـك جا يداث بوده وقانوزاً بر ایىاداىيكقوض مو جود

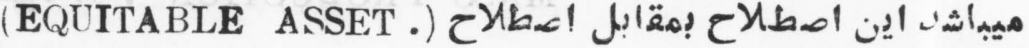

legal interest.

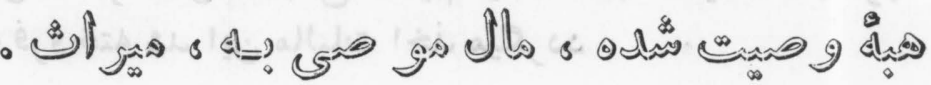

\section{BEQUEST • رجوع شود به}

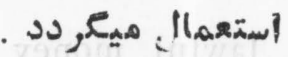

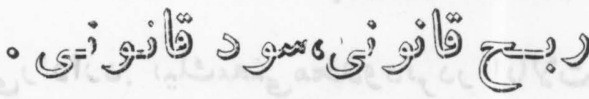

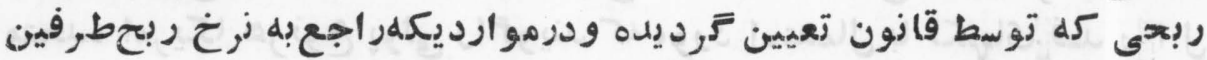

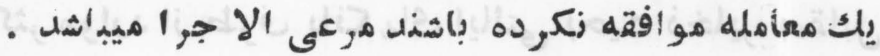

legal person , - ज ز

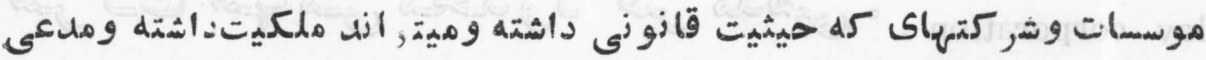

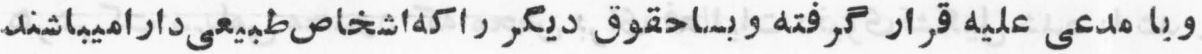
داشةداشهل.

legal reserves.

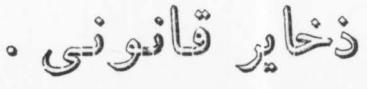

BANK RESERVES.

legal tender

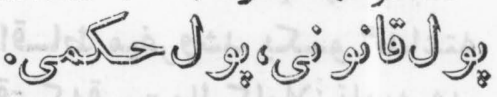

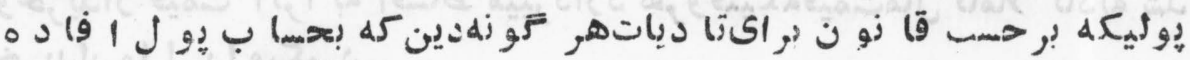

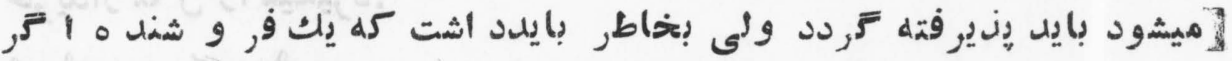

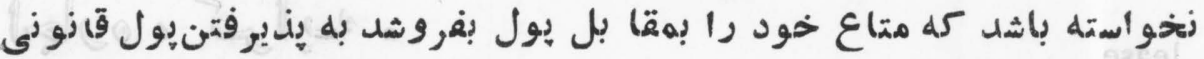

legal tender bond.

$$
\text { ( }
$$$$
\text { - }
$$ 


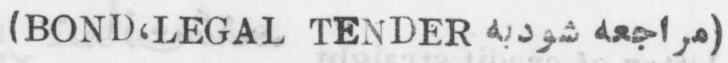

leisure class. - Juelé glo diab

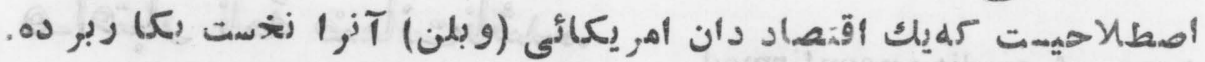

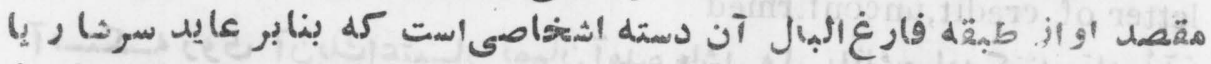

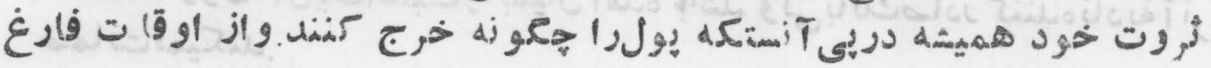

letter of credit.

$$
\text { - gatrses }
$$

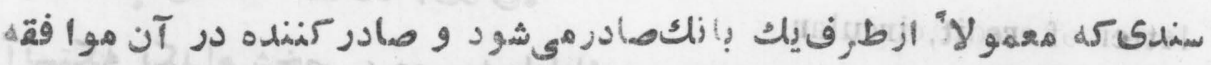

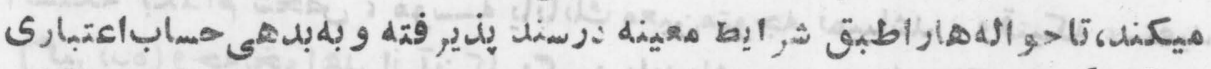

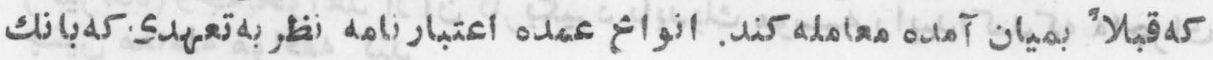

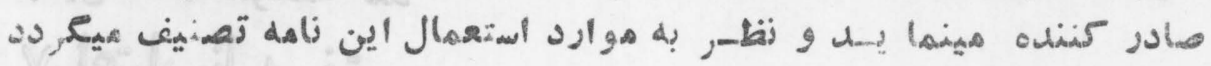

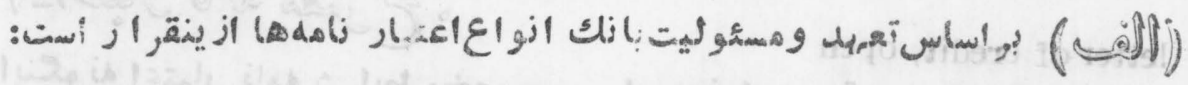
letter of cr dit 6 c cnfirmed .

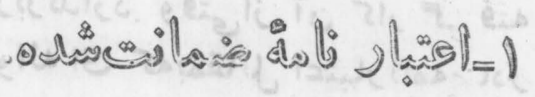

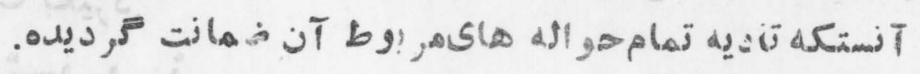

letter of credit,irrevocable.

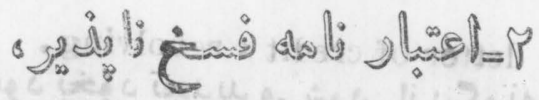

$$
\begin{aligned}
& \text { - }
\end{aligned}
$$

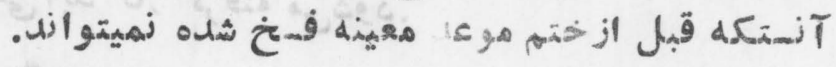

letter of creciit,revocible.

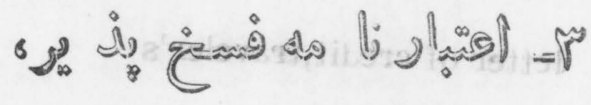

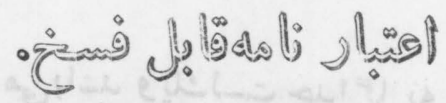

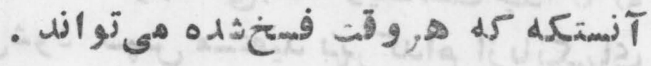




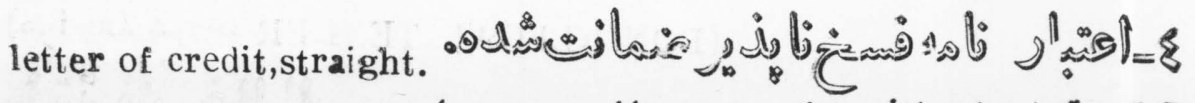

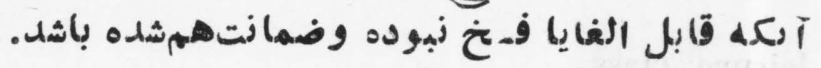

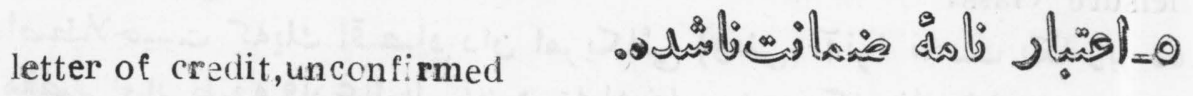

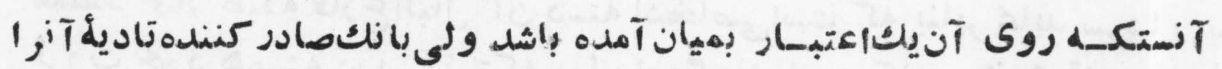
ضما نت زميكند.

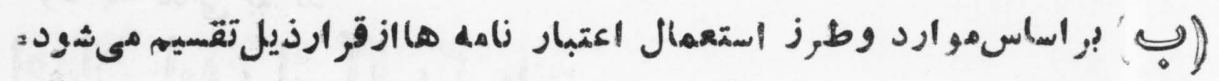

letter of credit,circular.

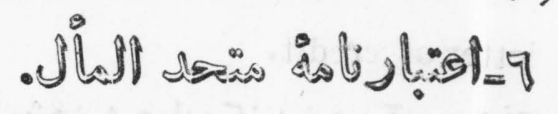

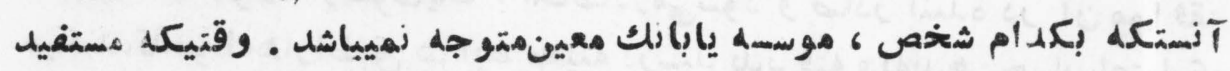

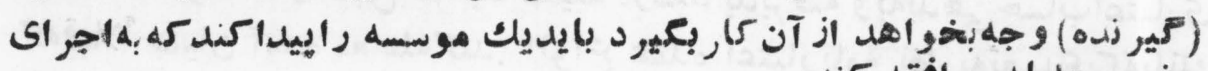

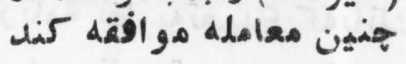

letter of credit, open

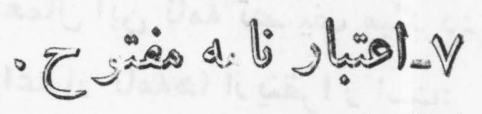

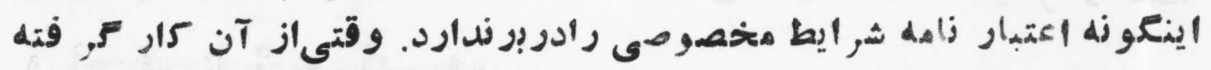

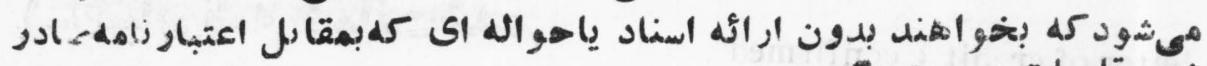

letter of credit 6 revolving.

$$
\begin{aligned}
& \text { شده تاديات صورت بغرت بعيرد. } \\
& \text { S }
\end{aligned}
$$

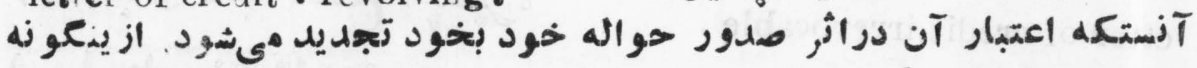

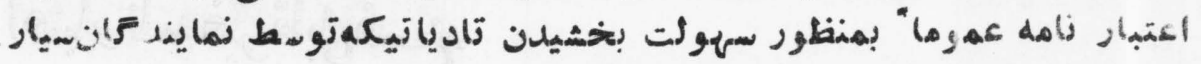

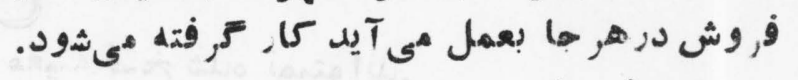

letter of credit,traveler's.

$$
\text { أl }
$$

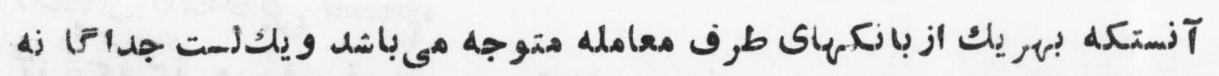

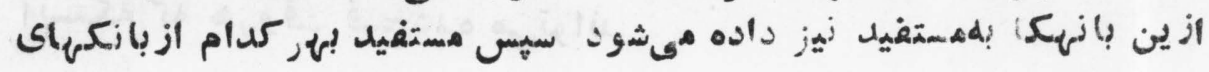

APFP 


\section{LET}

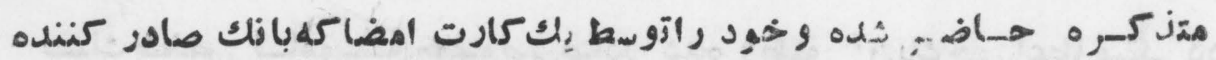

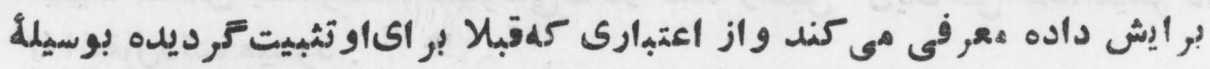

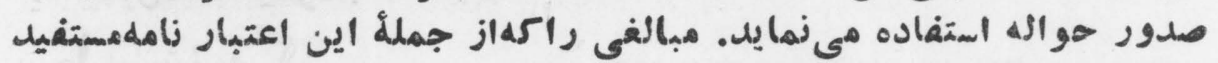

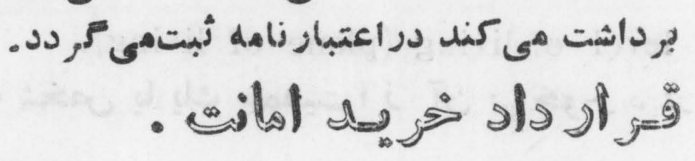

letter of lien

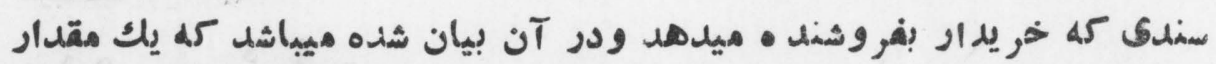

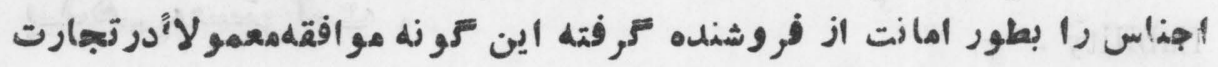

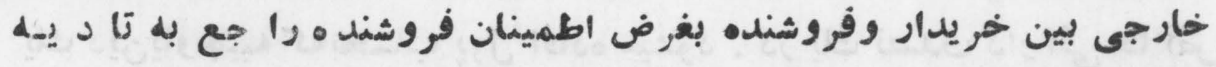

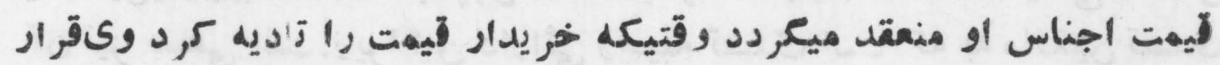

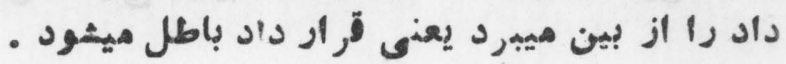

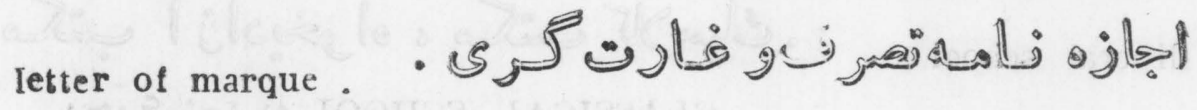

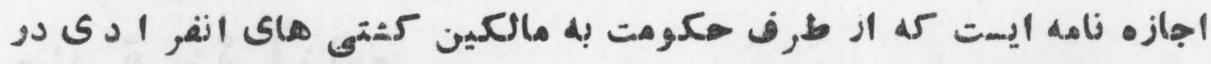

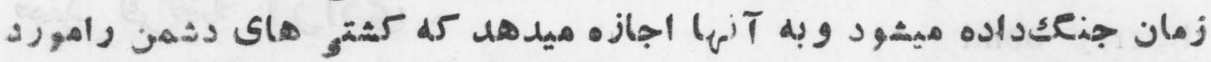

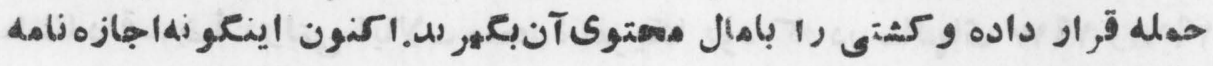
هن منسوخ شده .

letter of trust .

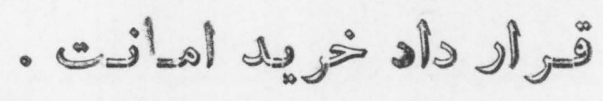

LETTER OF LIEN . رجوع شون به

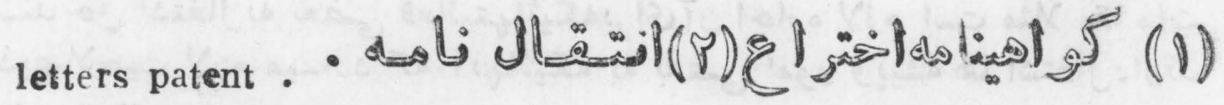

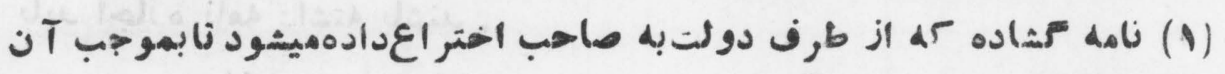

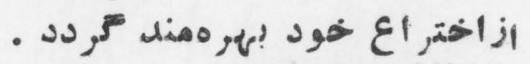

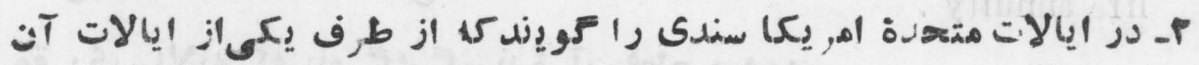




\section{LIF}

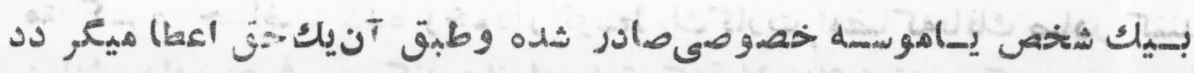

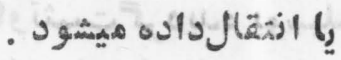

level of living (plane of living).

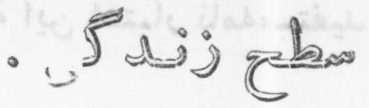

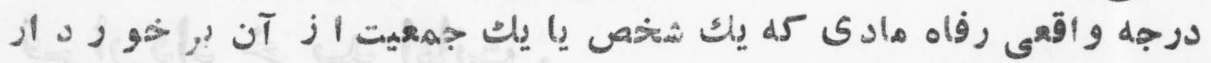

liability . - $\underbrace{\infty}_{\infty} \int_{\sin }$

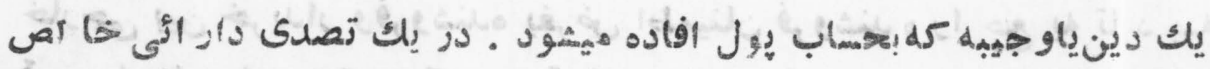

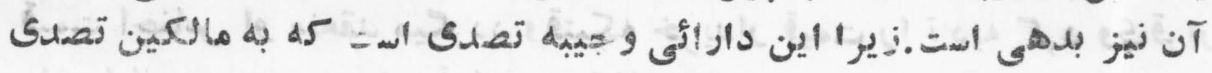

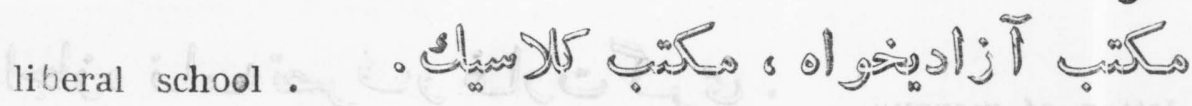
تعلق دارد CLASSICAL SCHOOL رجوع شون به

liberty bond - जslj

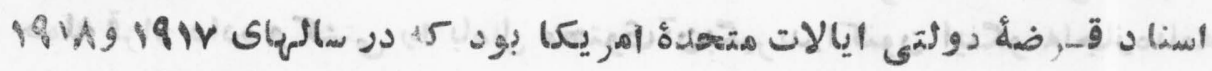

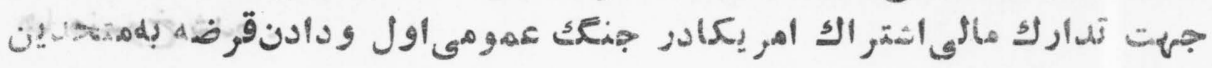

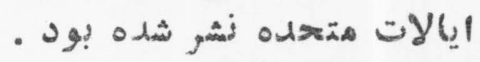

license.

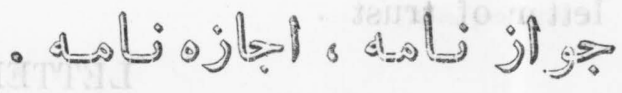

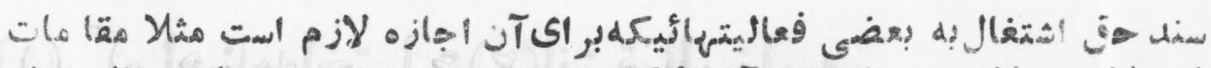

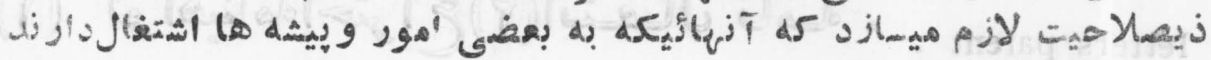

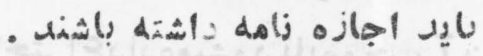

life annuity . - Sa هقر رى سالازله كا بأمر تحى Fير ندة آن قطظع ميشود . 
life insurance .

- $5 d i j a i$

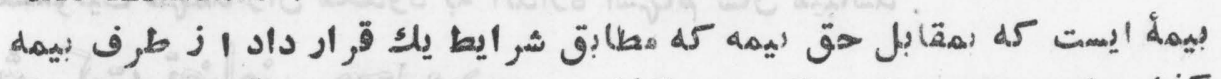

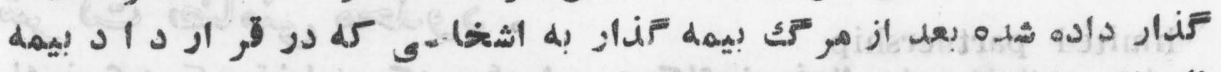

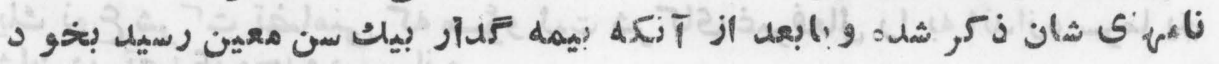
lifo. क S Sll=

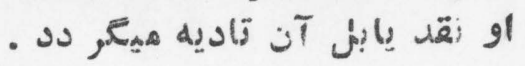
- जslum

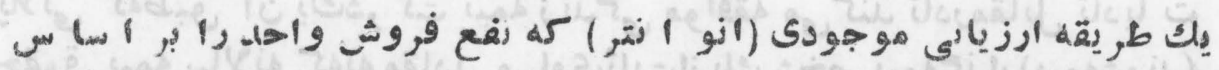

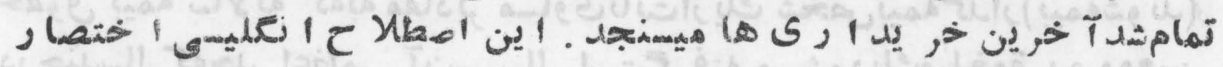
استت (LAST IN FIRST OUT )

limited depositary

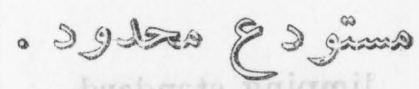

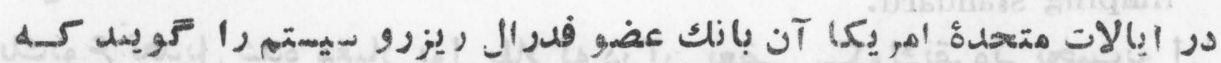

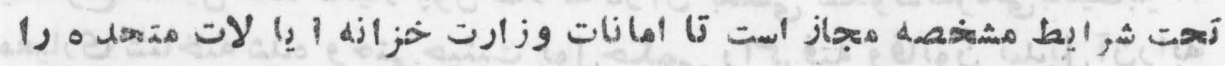

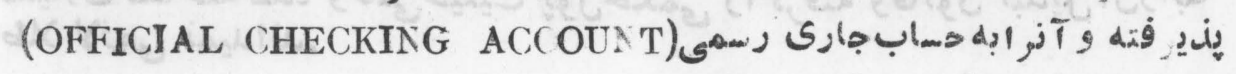

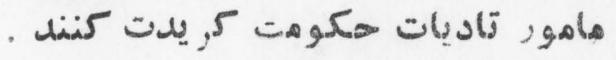

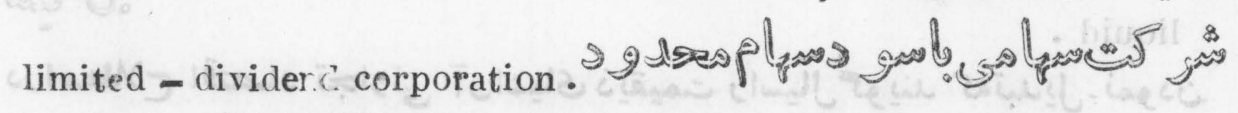

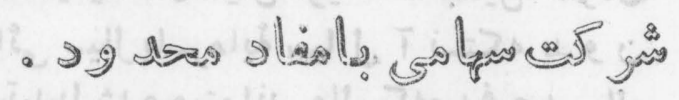

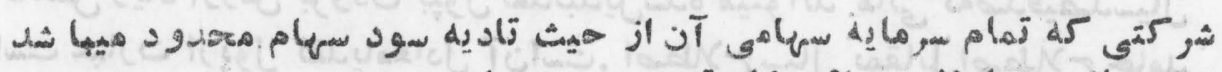

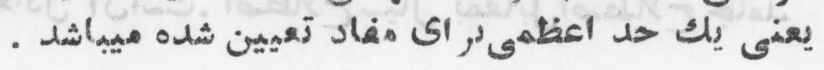
limited liability.

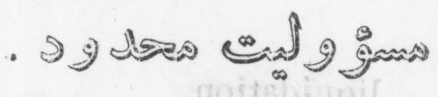

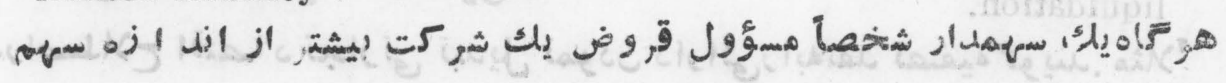




\section{IM}

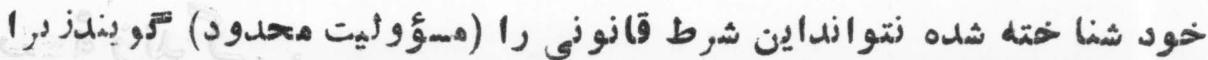

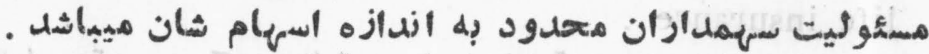

limited partnership

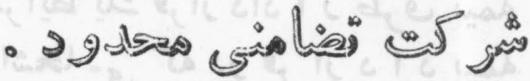

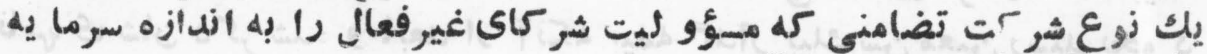

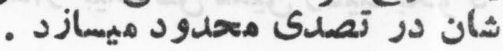

lim ed payment plan of life insurance.

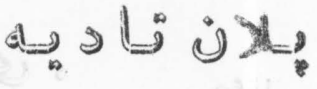

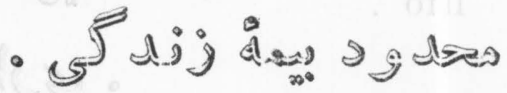

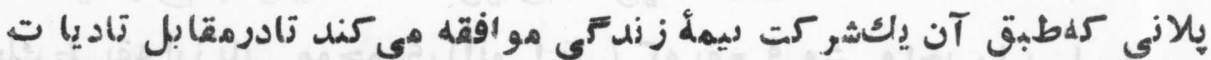

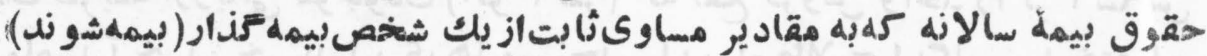

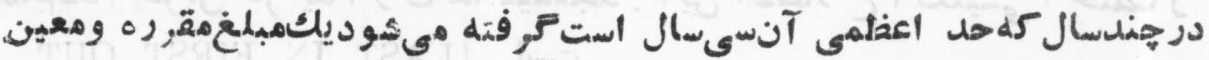

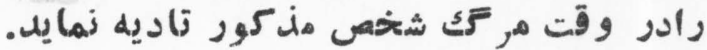

limping standard.

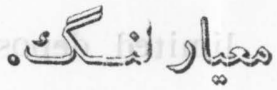

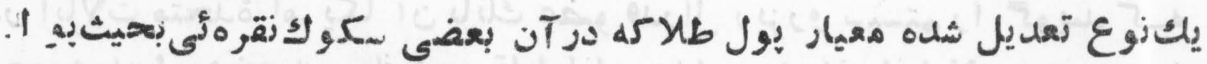

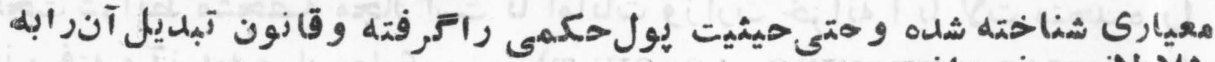

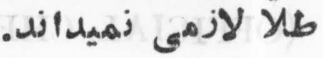

liquid .

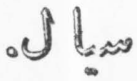

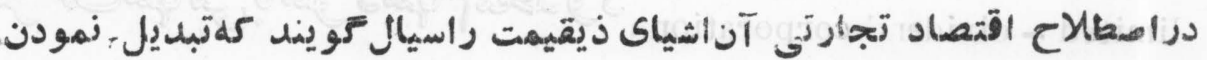

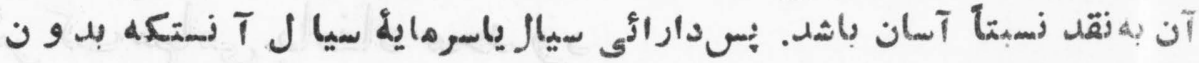

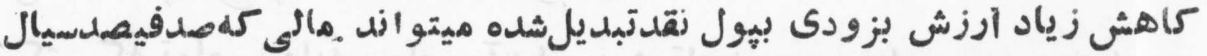

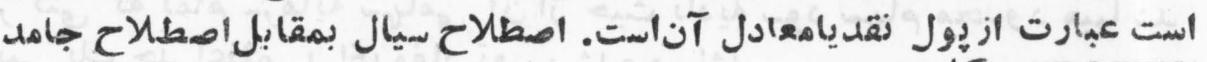
(ك) FROZEN)

liquidation.

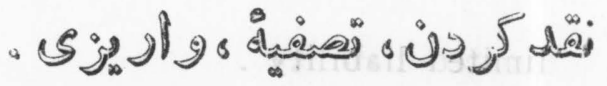

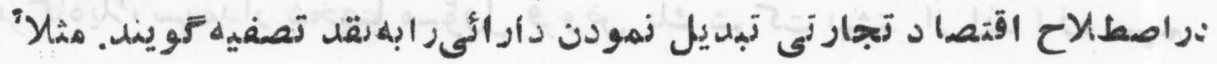
eprys 
liquidity preference.

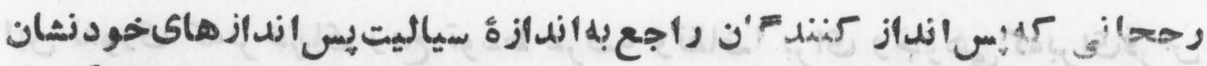

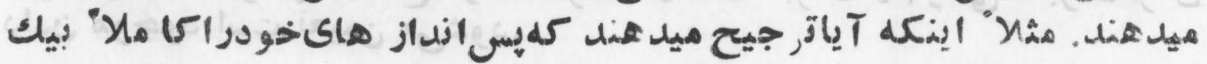

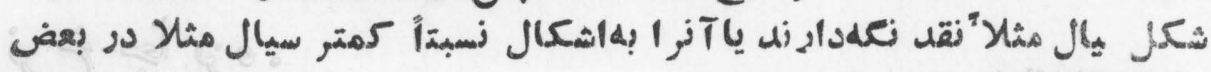

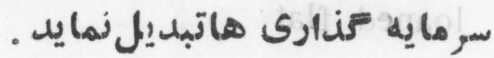

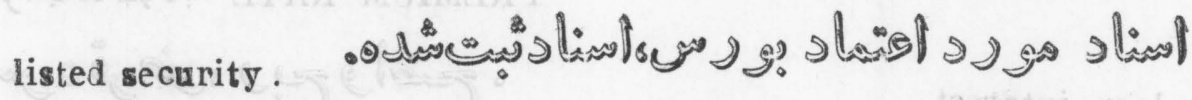

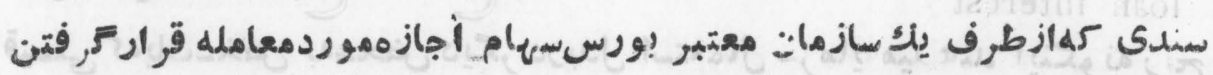
رادر صحن بورس دارا باشله.

listed stock. - O O d

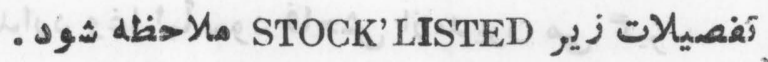
list price.

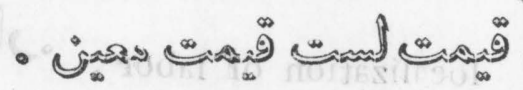

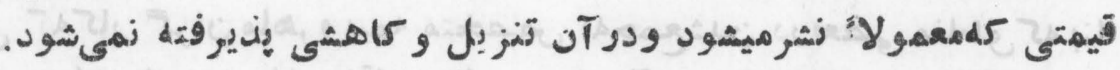
little stee.

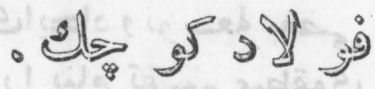

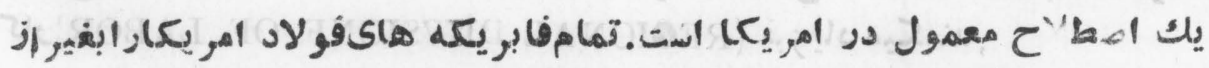

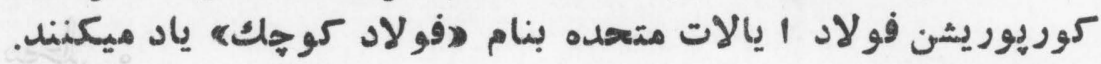

loan.

- Plgsiog

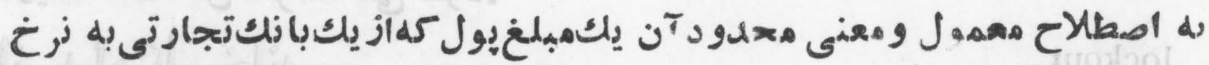

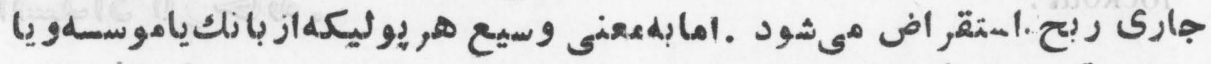

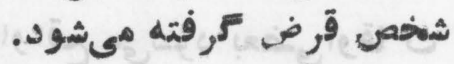


loanable funds theory of interest .

$$
\begin{aligned}
& \text { ज和 } \\
& \text { ڤ }
\end{aligned}
$$

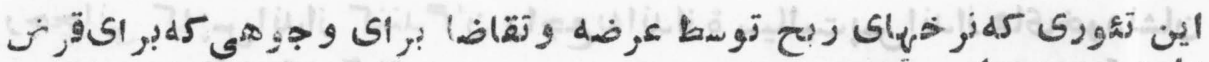

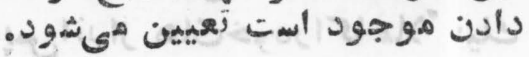

loaned flat.

$$
\text { - } j_{\infty} j_{0}
$$

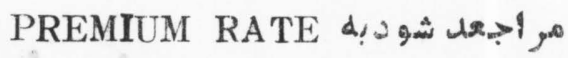

loan intercst.

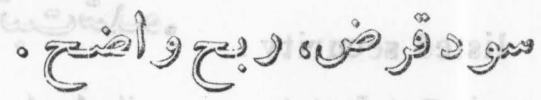

قيهمتى كهيك

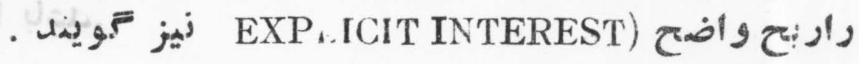

loan shark.

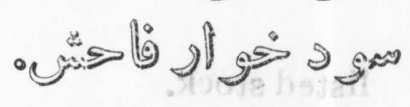

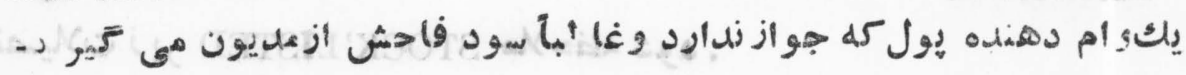

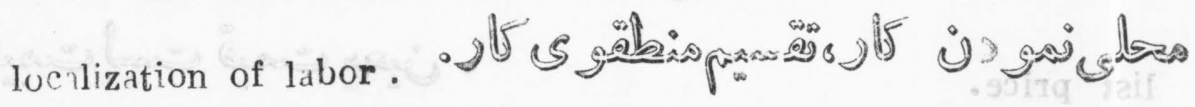

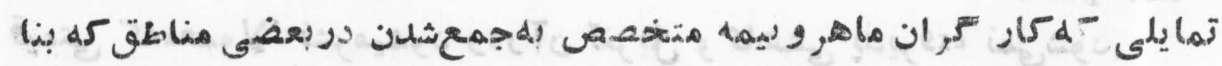

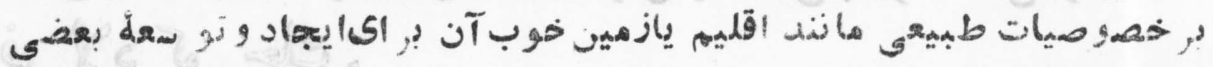

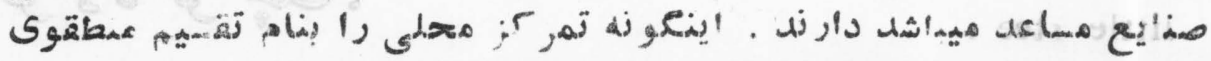
, (REGIONA L DIIVSIONF OF LABOR), local rate

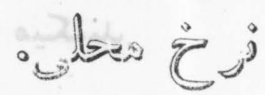

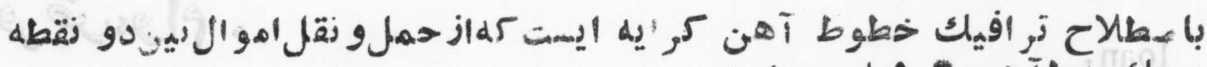

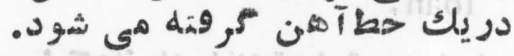

lockout.

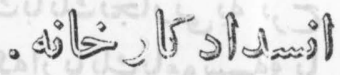

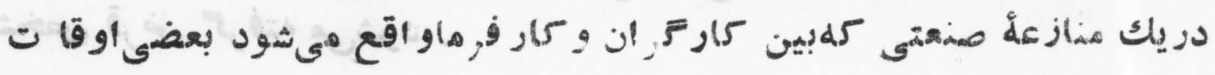

\section{TPFAB}




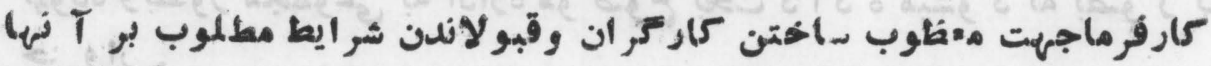

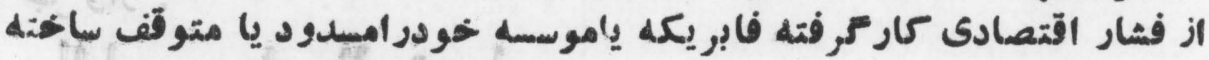

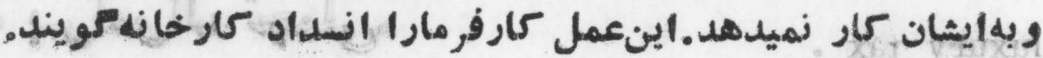

long run.

जी be do يك مدت بيشتر ازيكدورةتوليد.

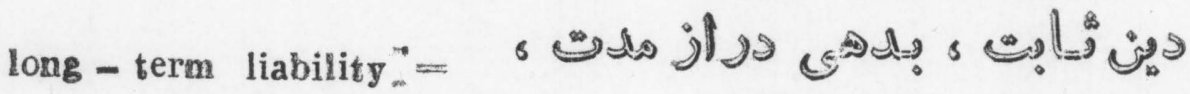

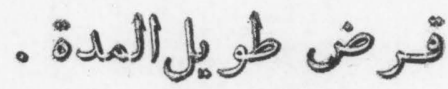
FIXED LIABILITY . رجوع شود به

loss leader. - ज)

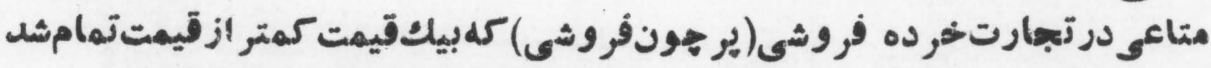

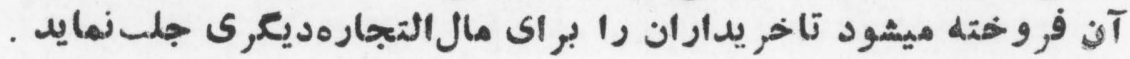
lucrative capital .

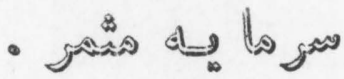
تفصيلات زيو . . CAPTTAL مظظه شوو

luddite . -

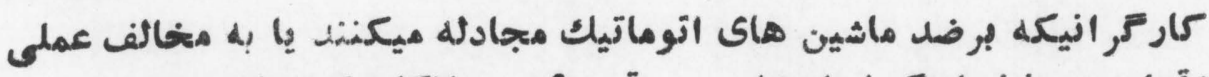

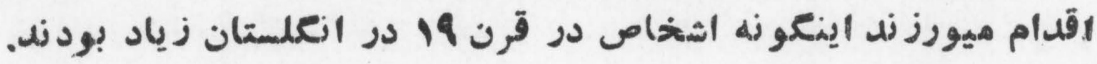
lump - sum appropriation . \& - لी

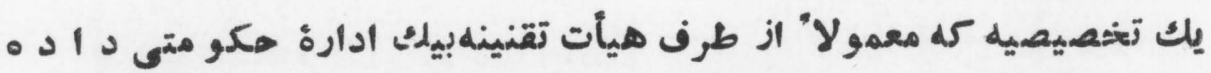

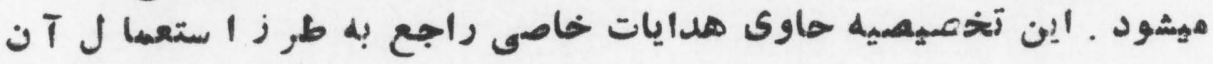


IUX.

زهوده و بطور مجموعى به ادارة مو ضوع بحث د أد م ميشو د زله بصو ر ت جز luxury tax.

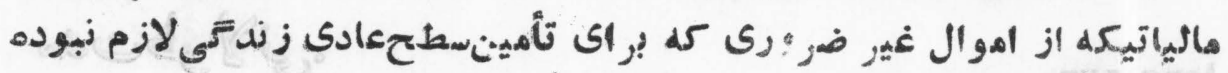

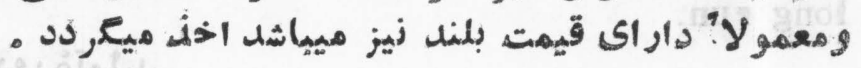

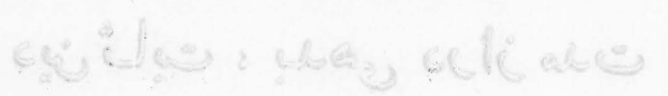

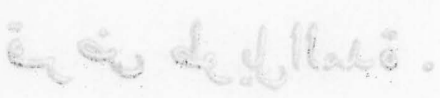

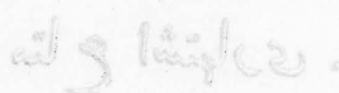

Tobsol seol

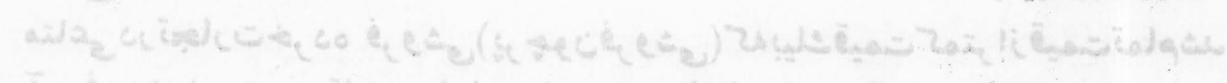

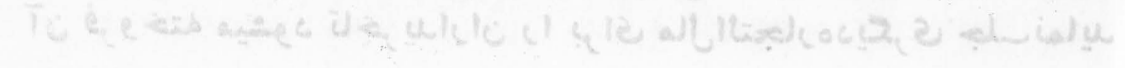

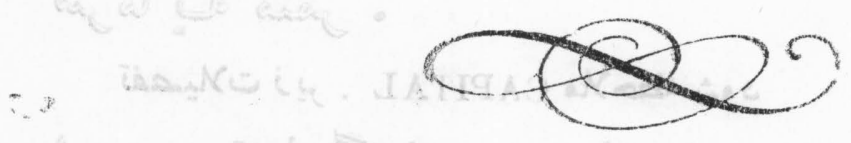

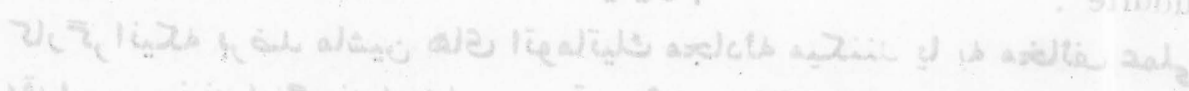

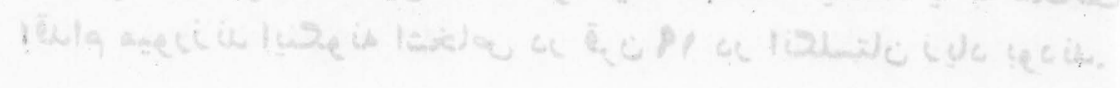

a TOD D. 


\section{M}

macroeconomics.

- $\int 50$ bais

افرو اد دي (AGGREGATES)

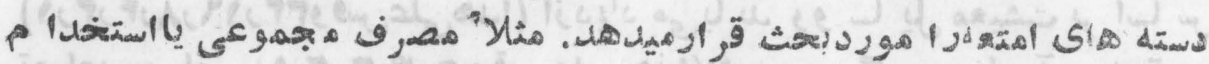

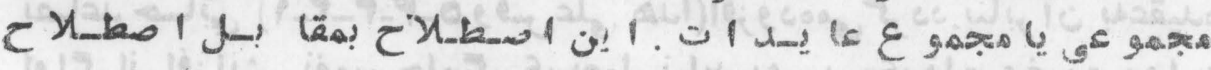

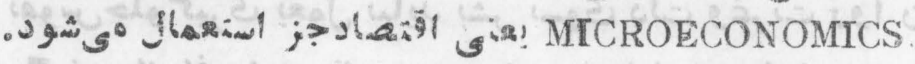

maintenance of membership.

- 2 gies bis

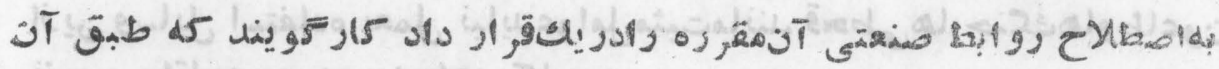

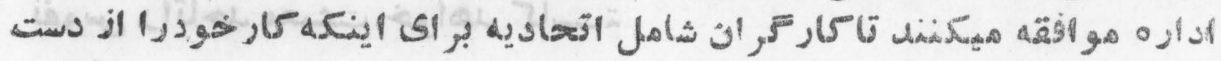

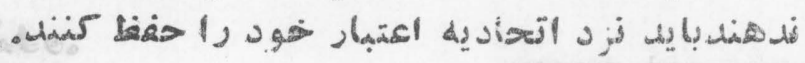

make work fallaey.

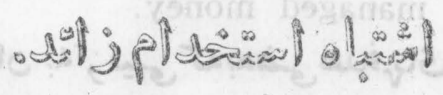

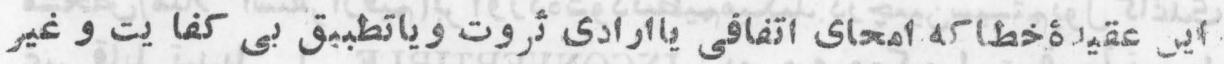

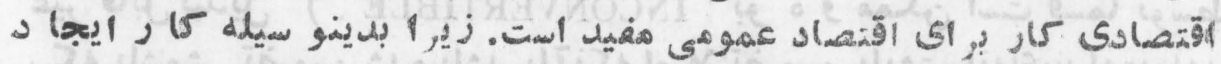

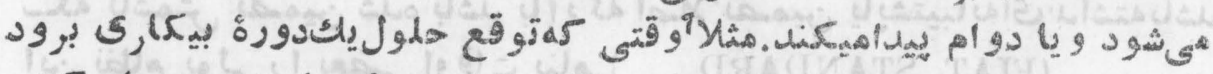

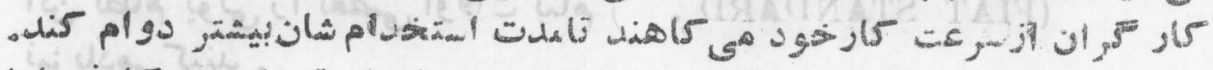

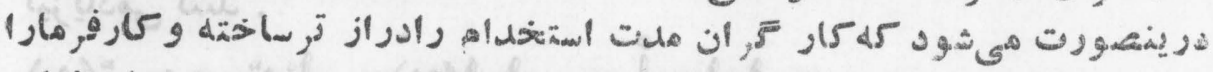

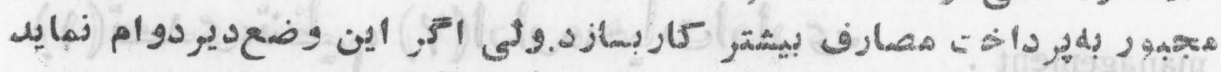

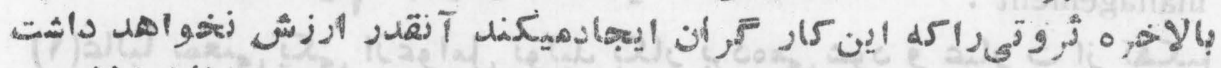

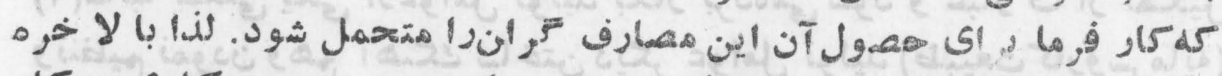

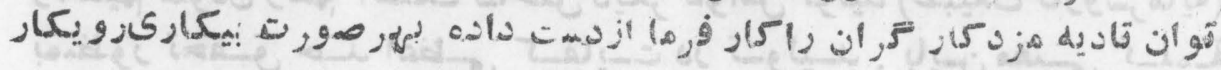

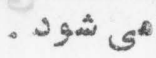




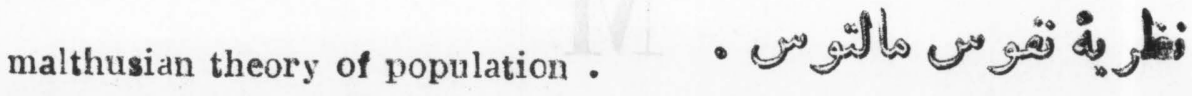

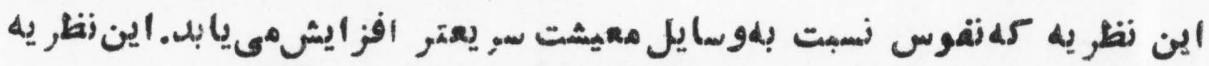

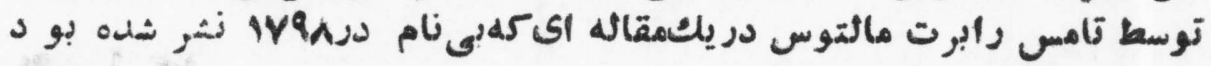

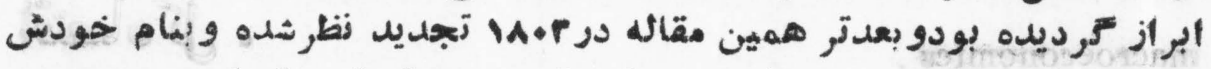

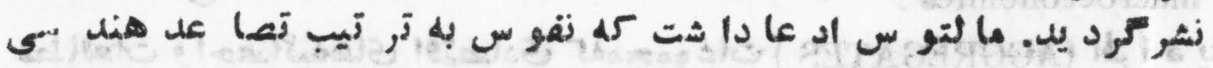

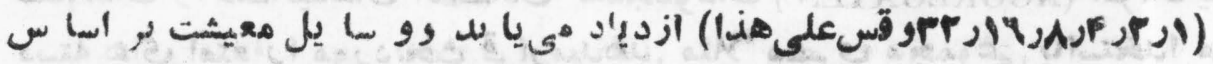

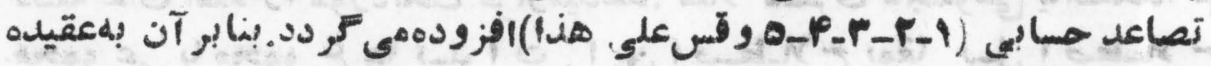

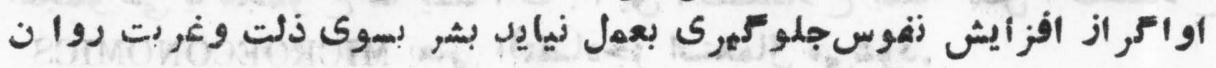

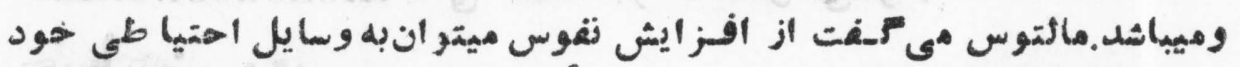

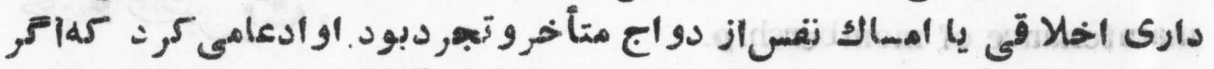

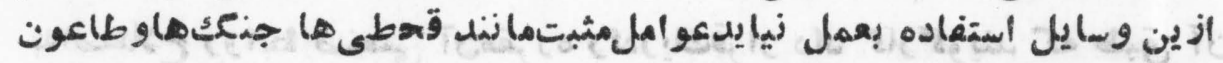

$$
\begin{aligned}
& \text { نغوس راتاحله معيثت خوأهد أراسيخة }
\end{aligned}
$$

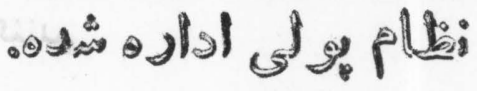

managed money.

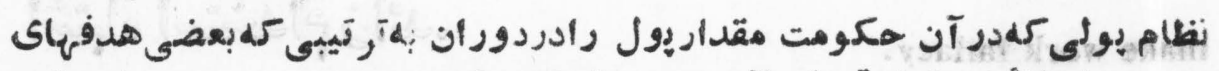

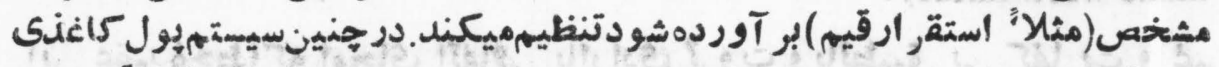

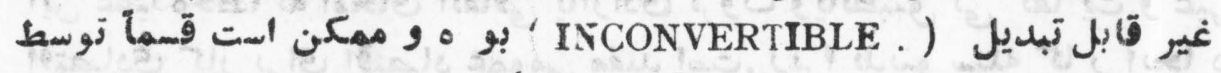

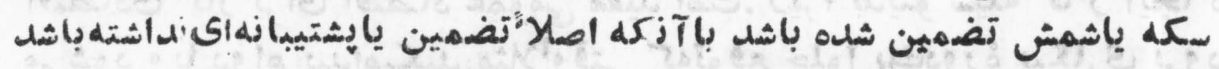

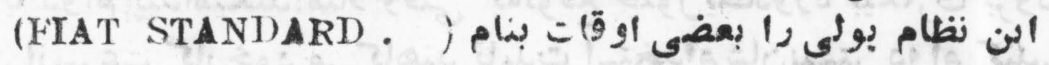
ن نيز يادمى كنئن

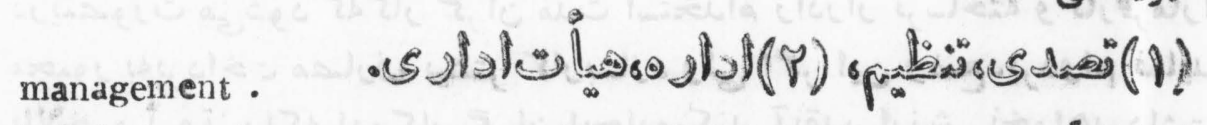

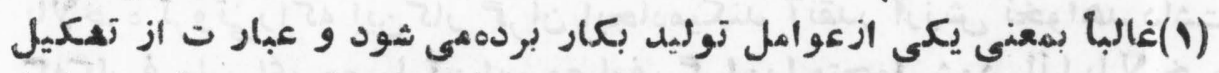

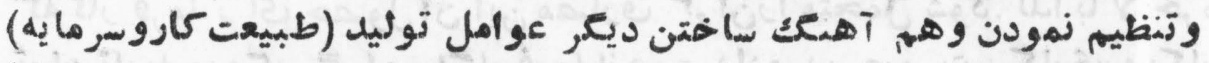

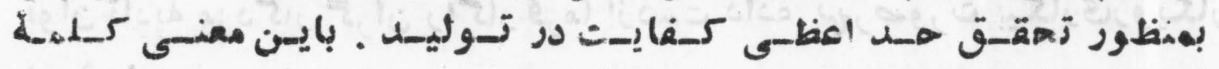

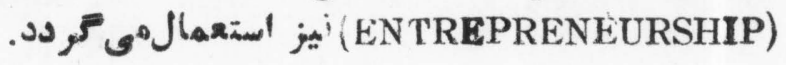

aroro 


\section{MaN}

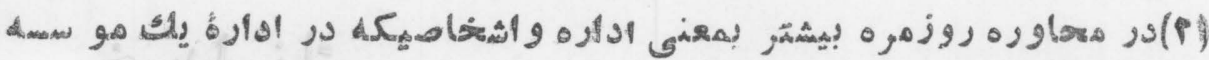

management wtcck。

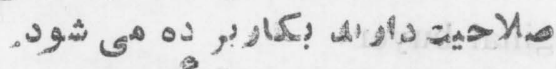

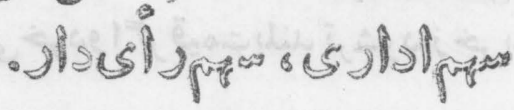

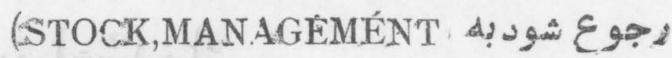

manch ster school. -

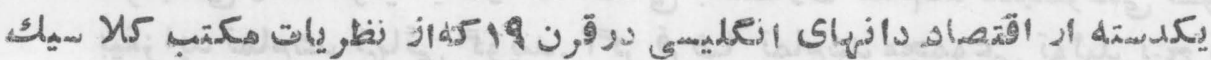

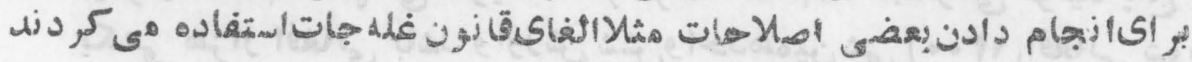
manifest .

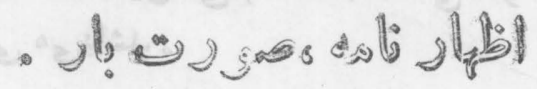

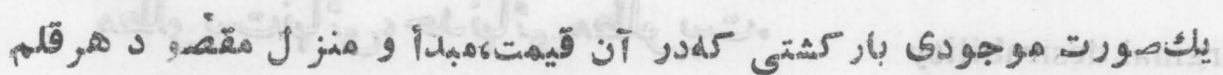

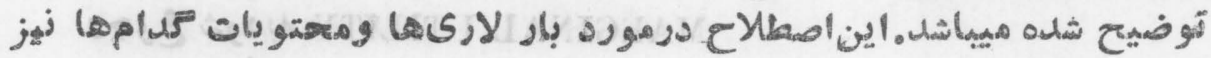
-

man-lasd ratio. - युت

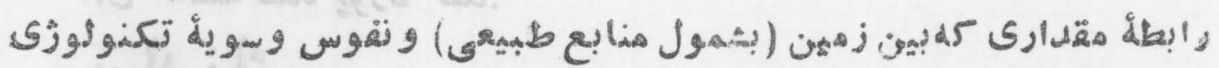

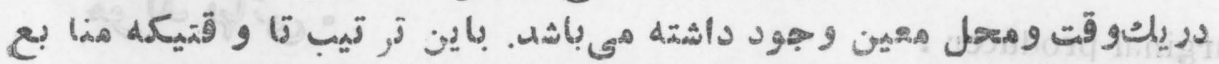

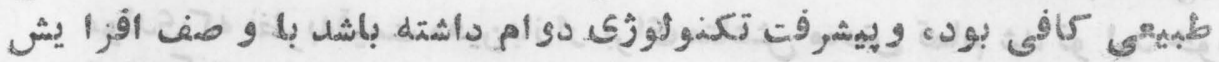

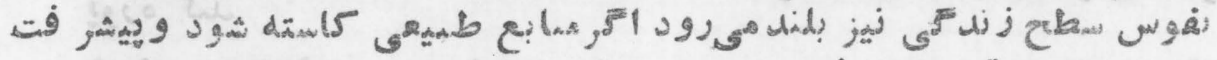

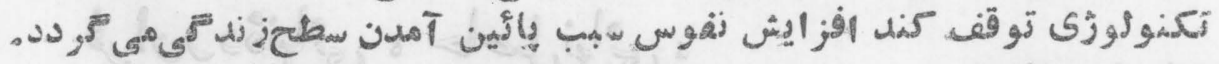
manorial system .

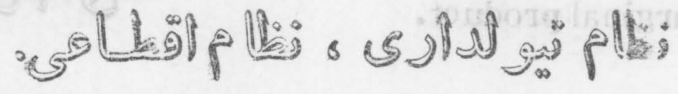

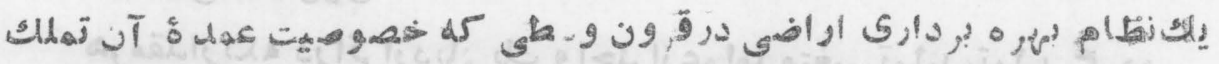

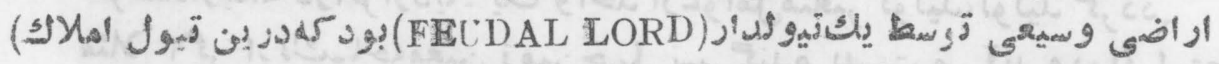

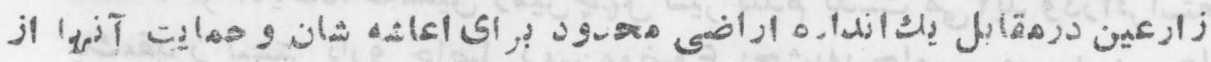

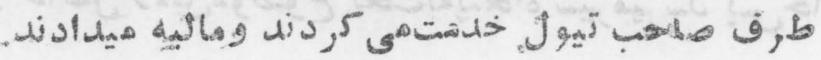


marginal buyer.

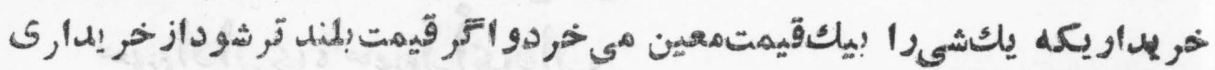
آن آبامي واروزنه marginal cost.

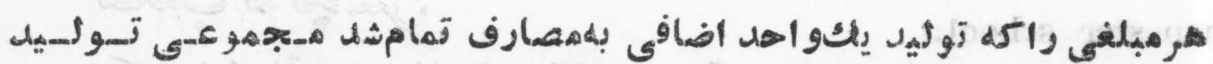

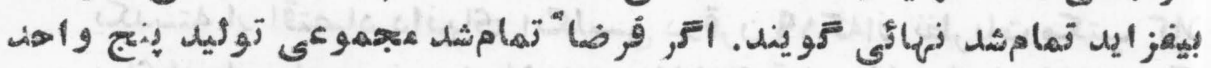

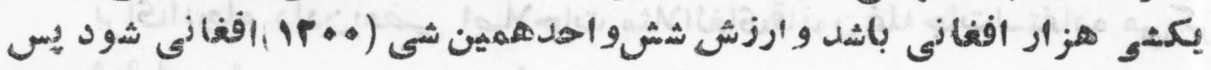

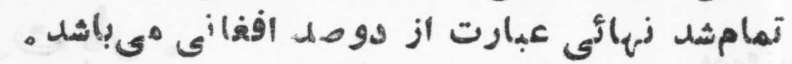

marginal desirability @ MAKGINAL UTILITY

marginall land

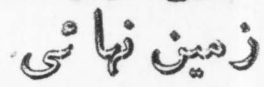

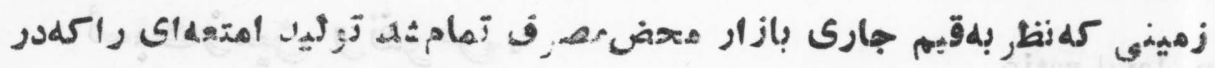
marginal producer .

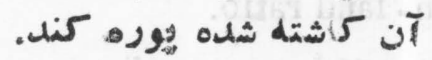
-

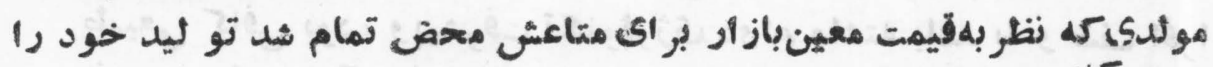
جوره كند. marginal producê.

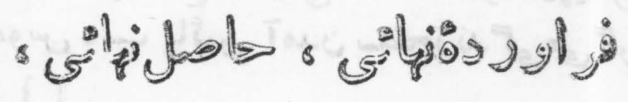
- نंगु

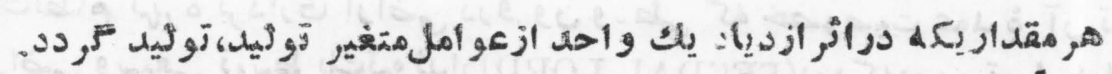

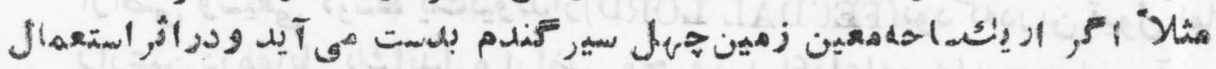

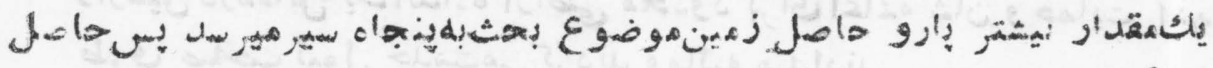
. 
marginal productivity.

$$
\text { ه }
$$

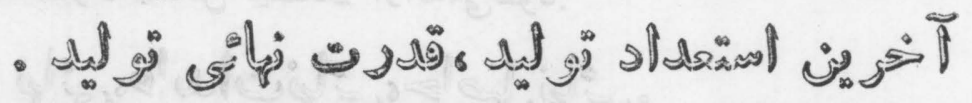

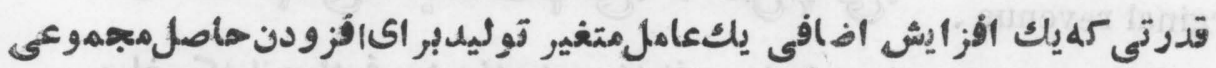

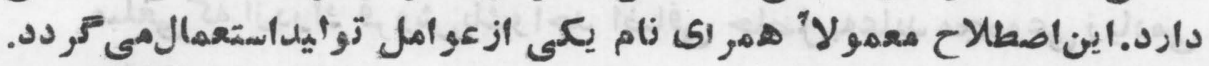

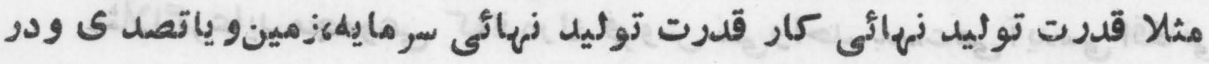

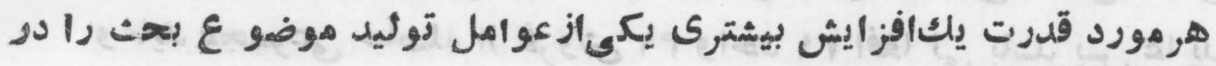

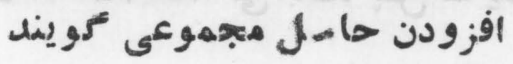

marginal productivity theory of wages.

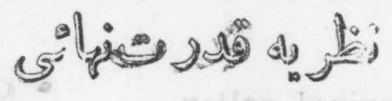

$$
\text { - } 0 \text { م }
$$

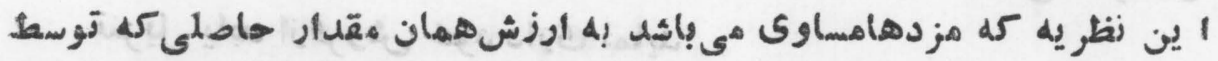

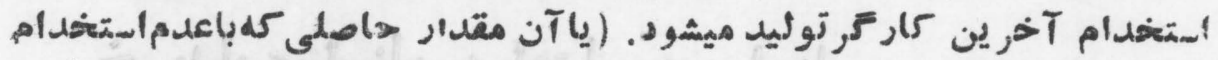

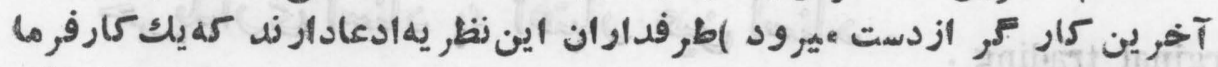

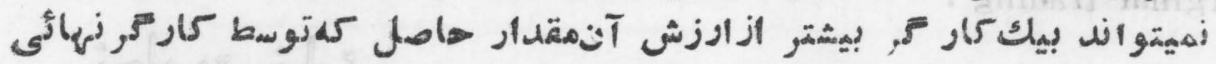

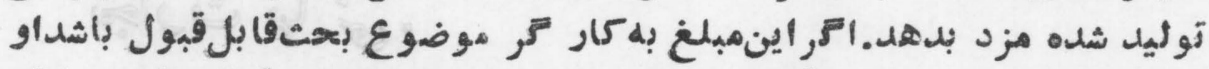

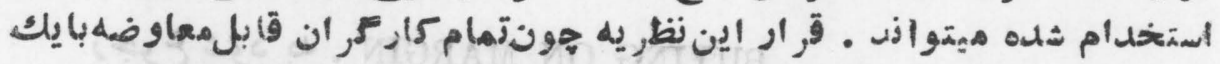

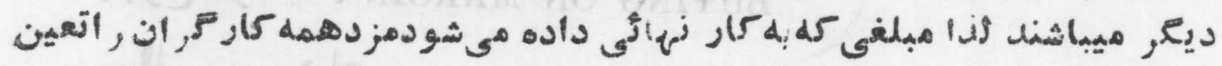

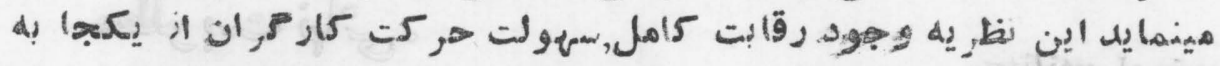

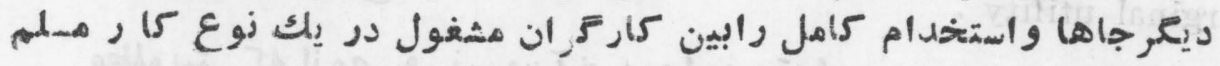

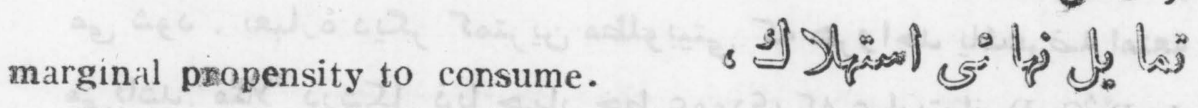

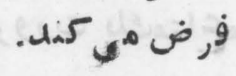

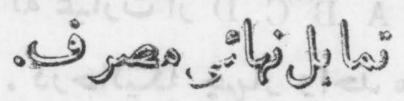

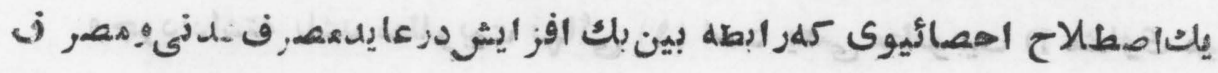




\section{MAR}

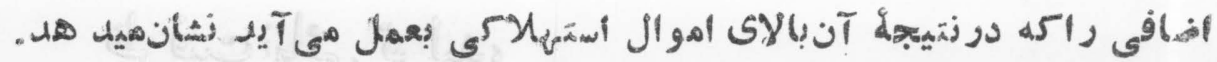

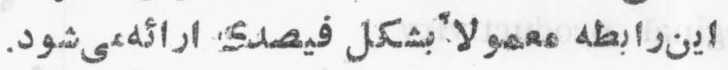

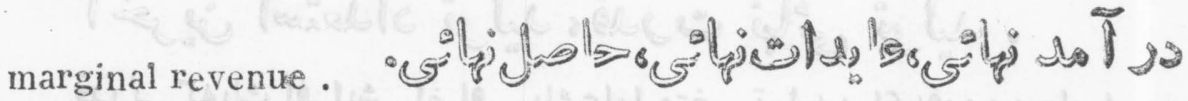

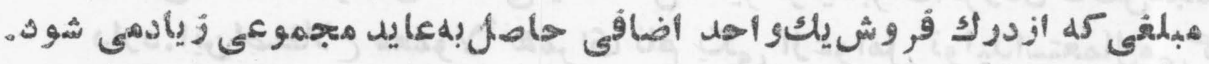

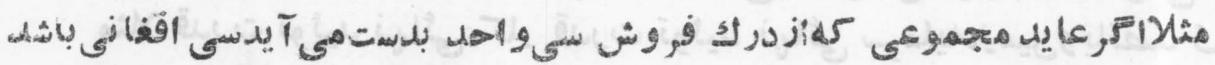

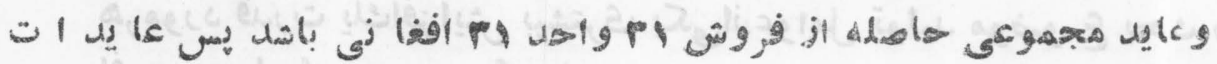

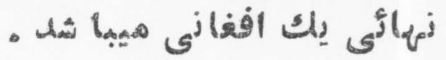

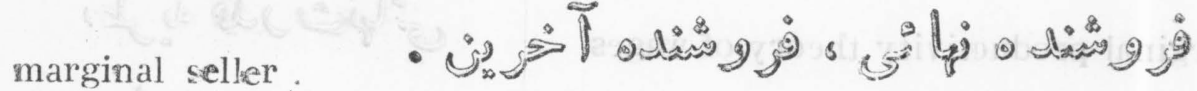

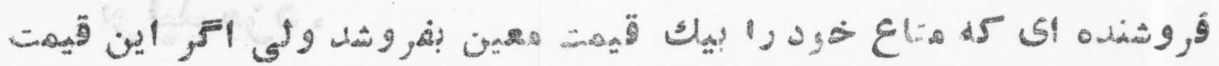

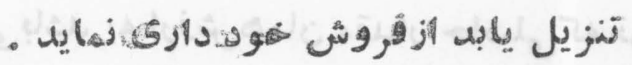

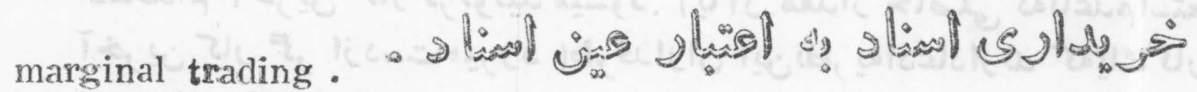

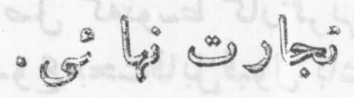

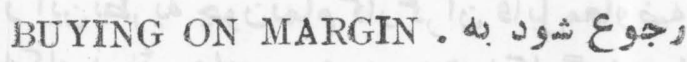
marginal utility .

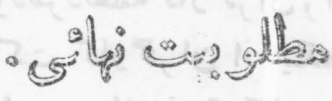

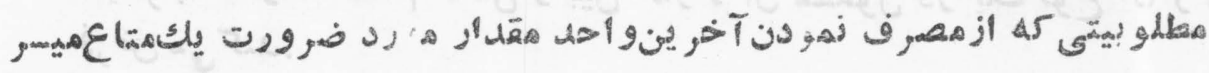

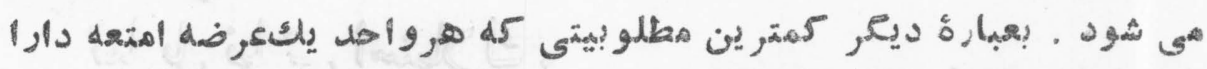

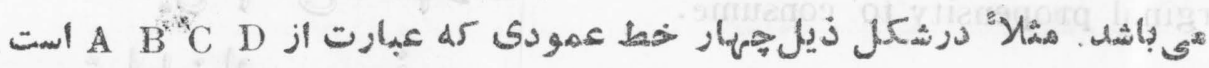

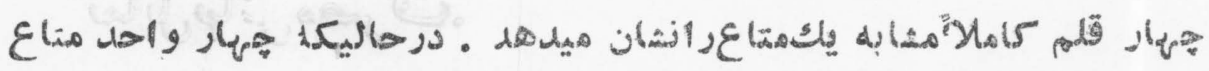

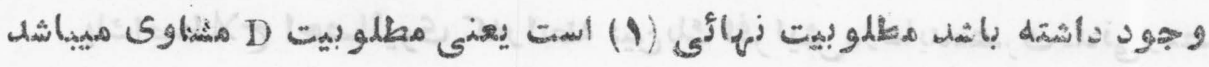
"rō: 


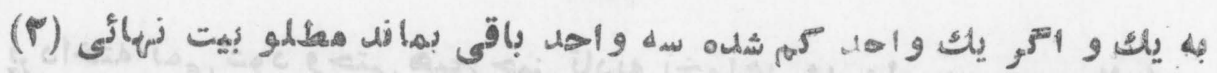

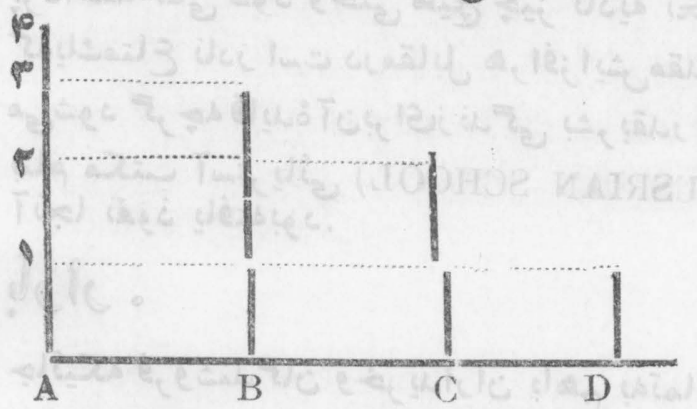

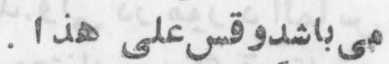

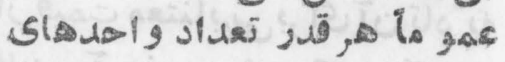

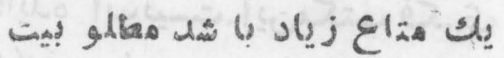

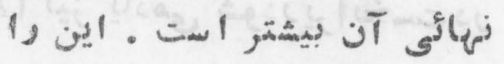

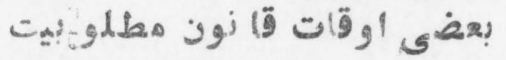
law of diminisining نزو

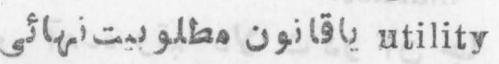

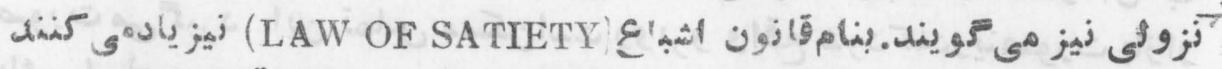

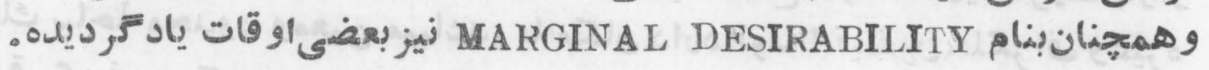

marginal utility school.

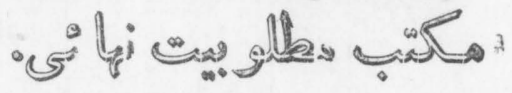

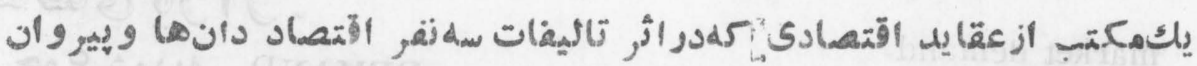

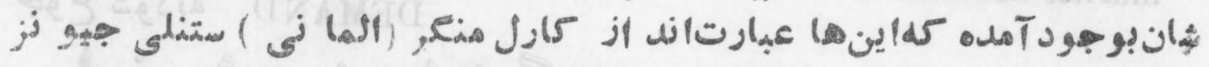

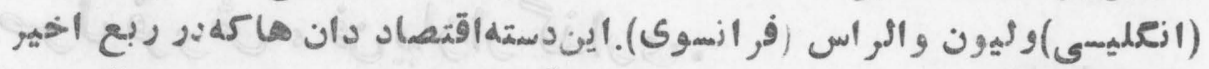

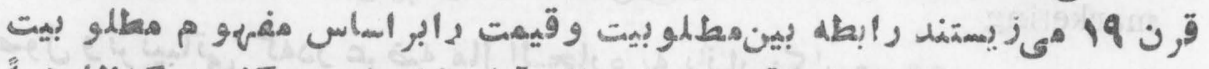

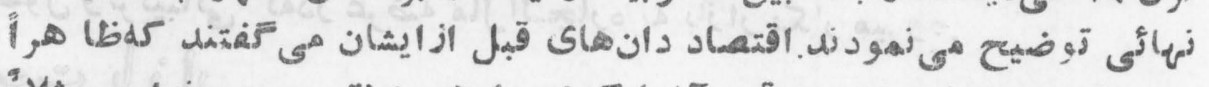

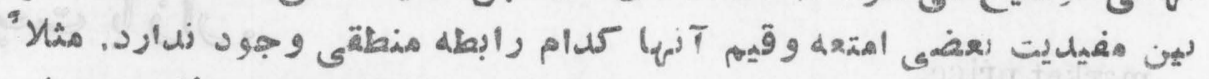

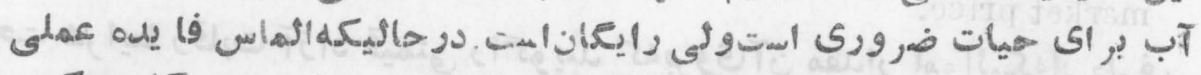

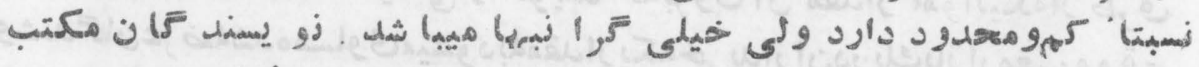

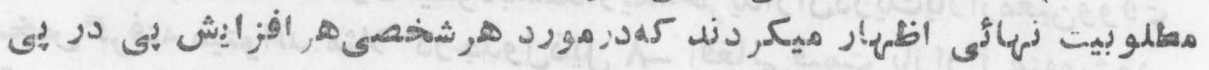

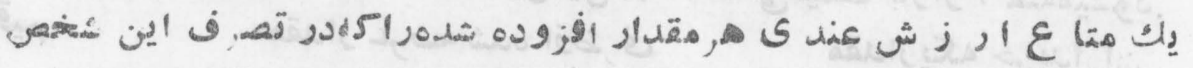

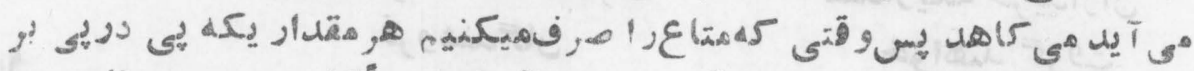

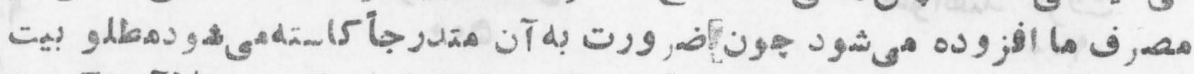

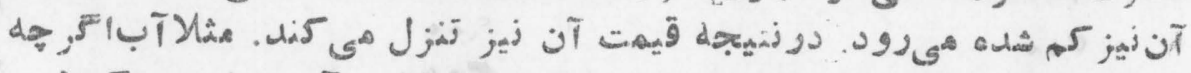

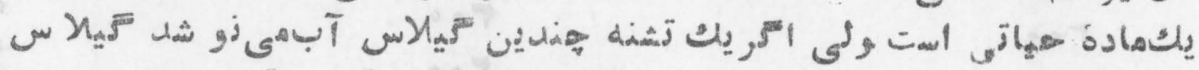

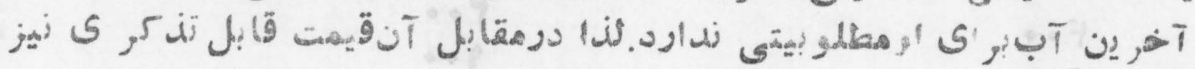




\section{MAR}

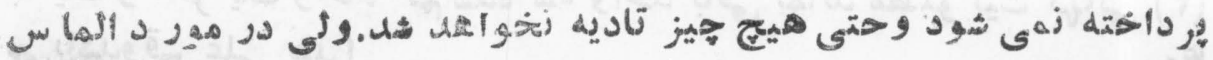

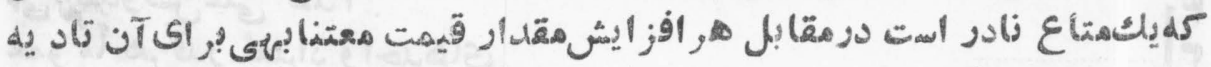

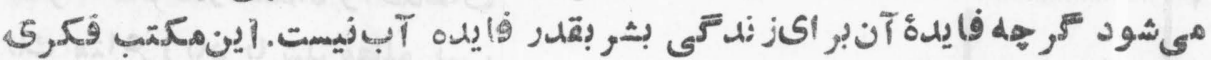

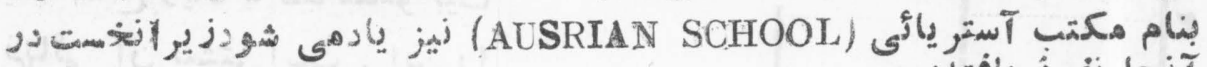

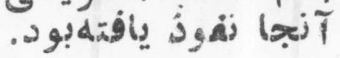

market.

- $91 j$ b.

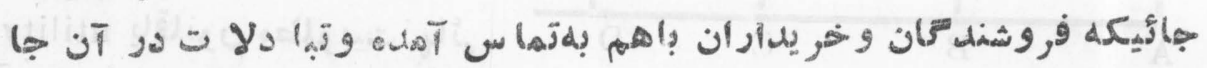

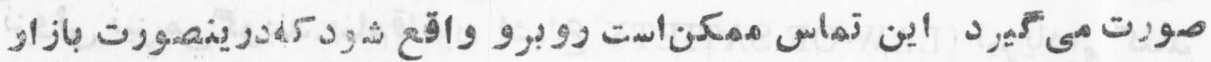

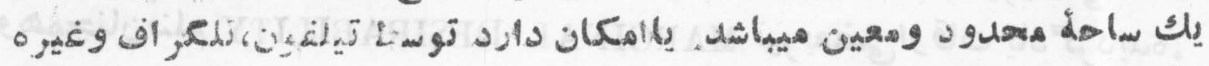

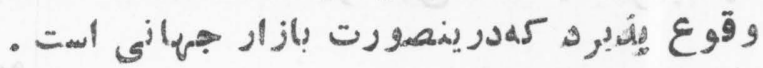

market demand.

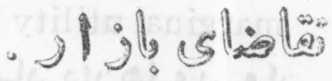

markelings

$$
\begin{aligned}
& \text { DEMAND d?دو }
\end{aligned}
$$

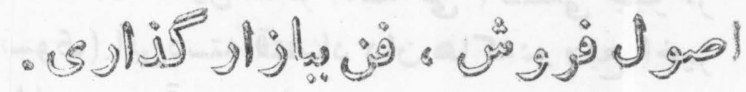

أl

market price.

$$
\text { - ग) b ? }
$$

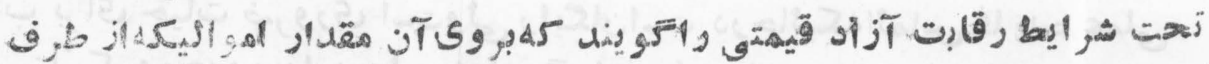

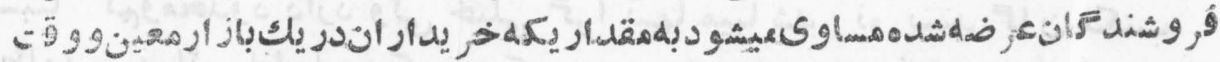

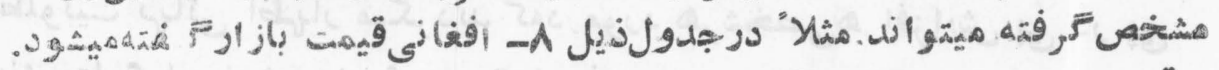

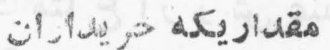

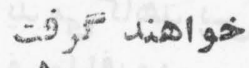

100

एक

r.a.

F⿻

0

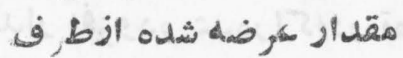

$$
\text { فورشنلف أنان }
$$

D.

is

...

$r \rightarrow$

10.
قيمب

1.

8

A

$\forall$

an 
markets, law of .

$$
\text { - La giju் gill }
$$

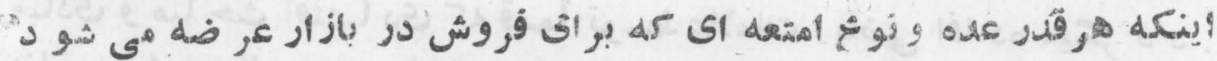

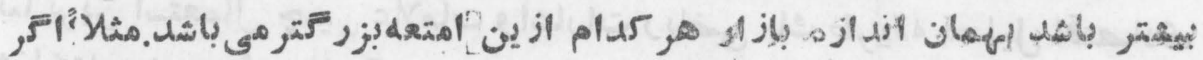

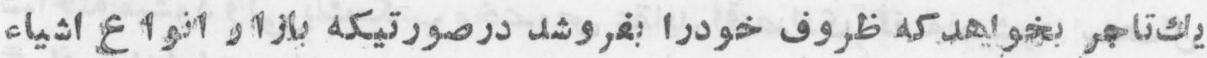

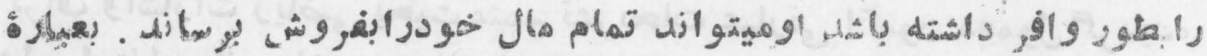

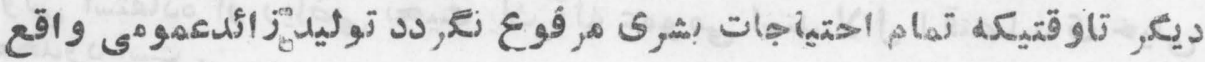

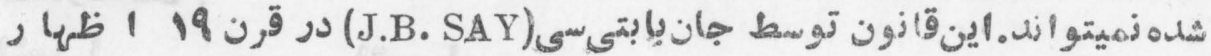
- ouls $9 g^{F}$ mark up. - A

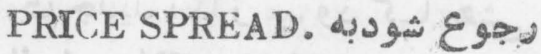
mass picketing.

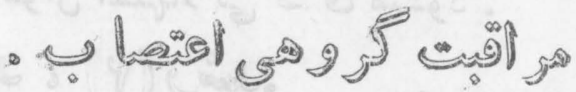

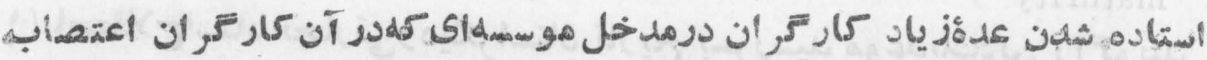

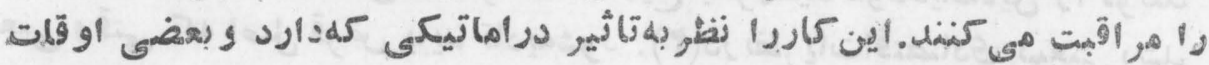

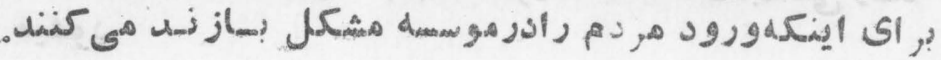
mass production . 0 es

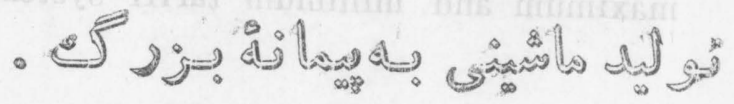

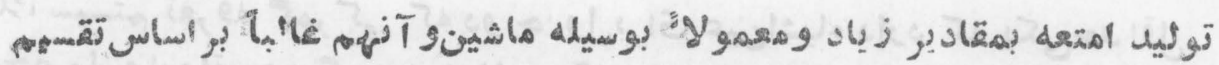

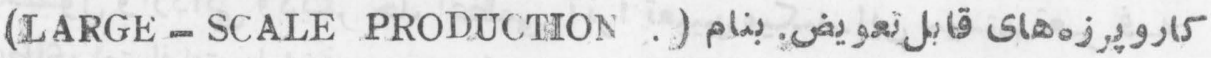
material cost .

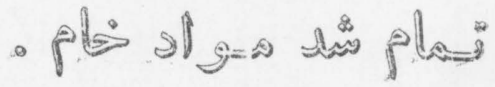

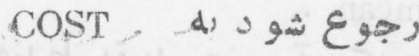


mathematical economics .

- 4.

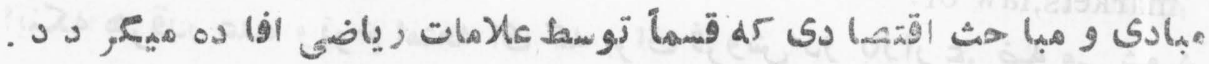

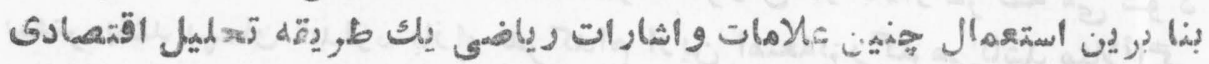

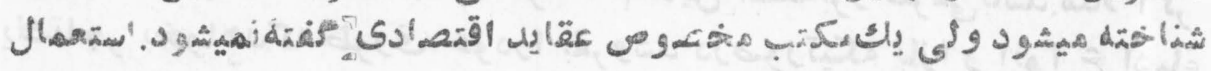

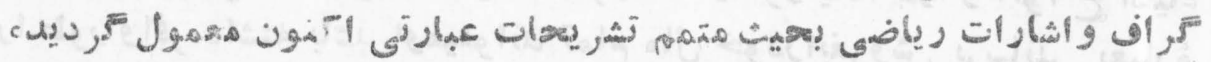

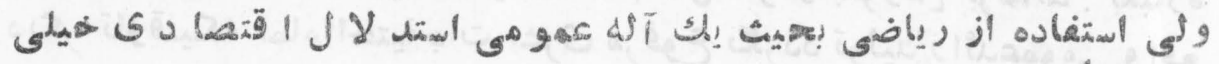

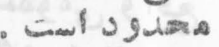

\section{mature economy .}

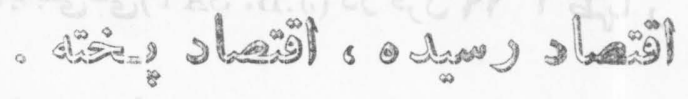

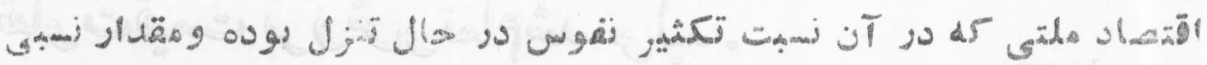

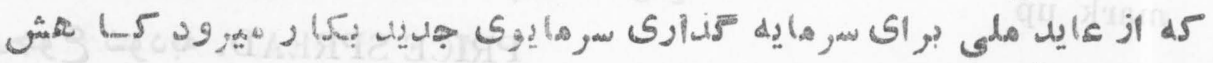

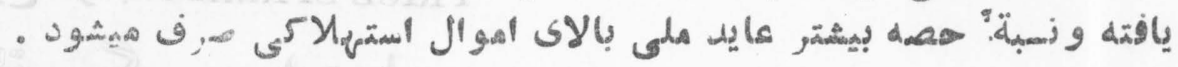
maturity .

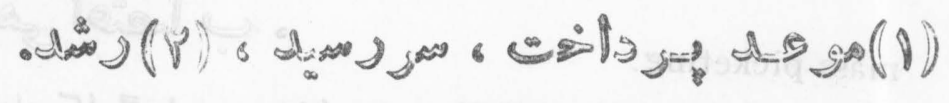

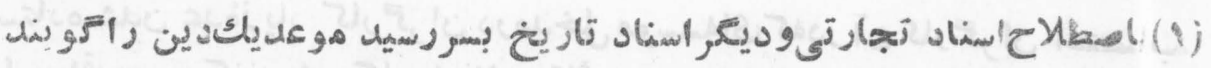

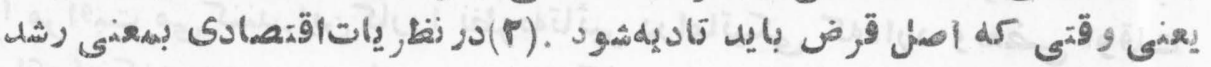

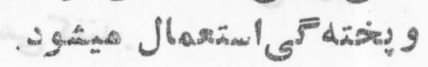

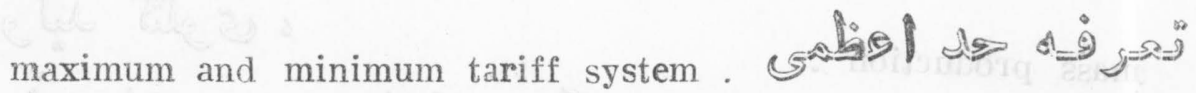
- जी $1=9$

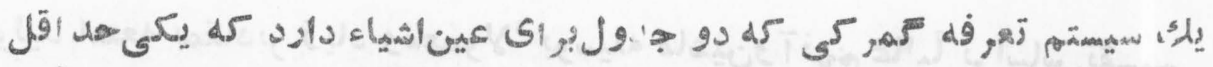

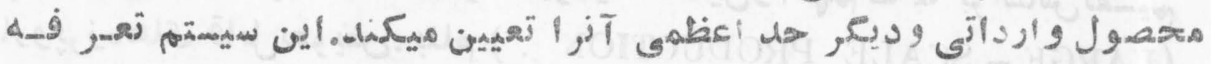

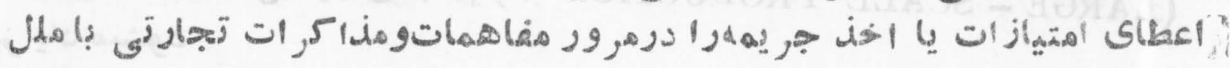

mean .

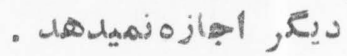
- ن

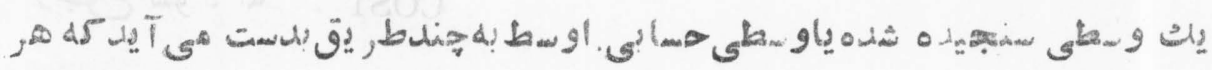
(cppop 


\section{MER}

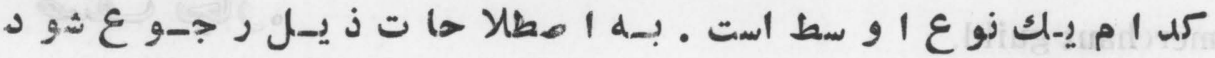
(ARITHMETIC MEAN, GEOMETRIC MEAN , HARMONIC MEAN .)

measured day rate.

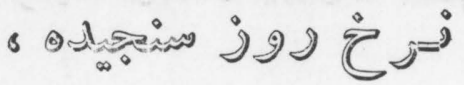

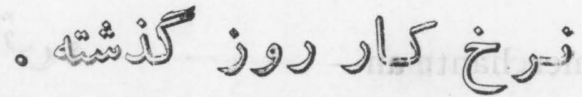

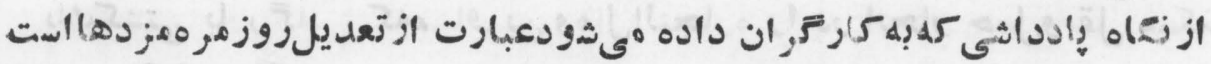

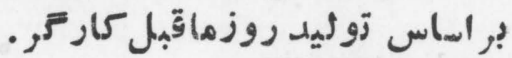

median .

- Aj D

عدد وسط يك سلمسله اعداد ماد

mediation .

$$
\text { - जs ज्ञ }
$$

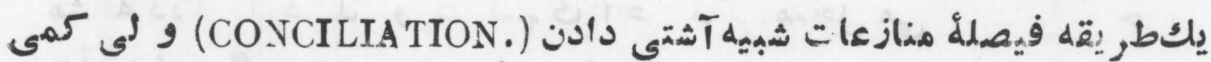

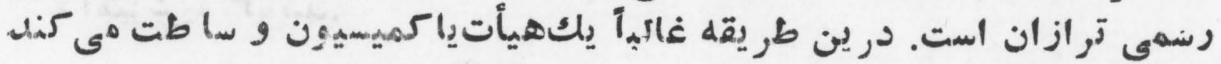

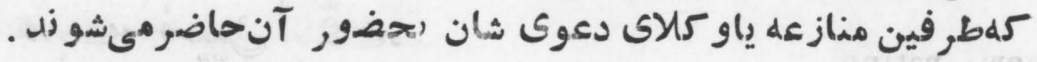

mercantile agency.

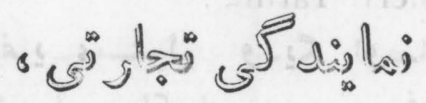

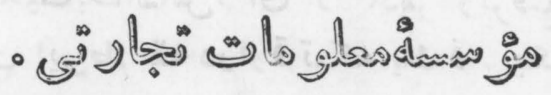

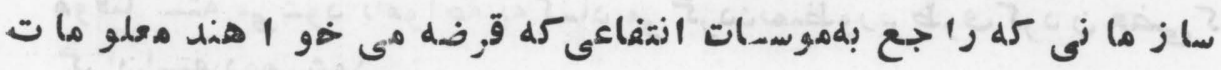
ميد هد ه مان

mercantilism .

- 每

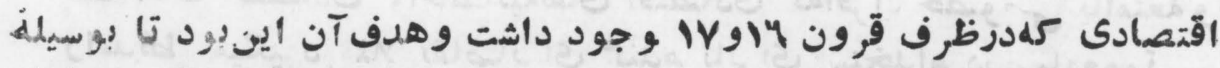

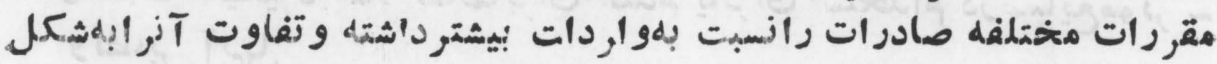

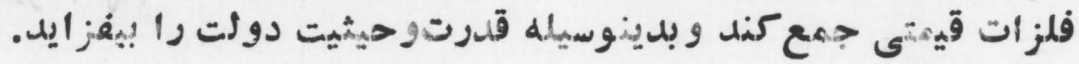


merchant guild.

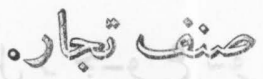

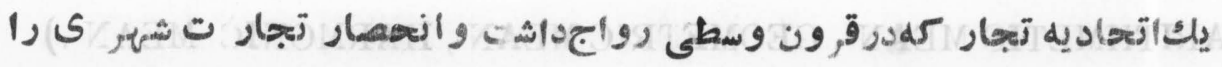

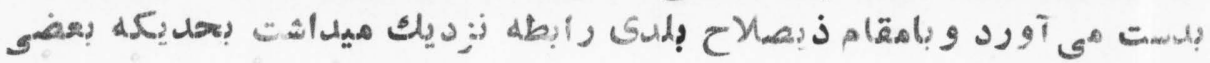

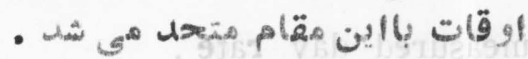

merchantman

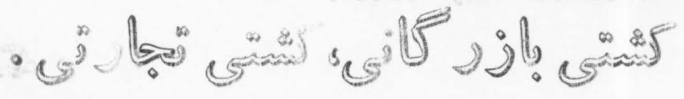

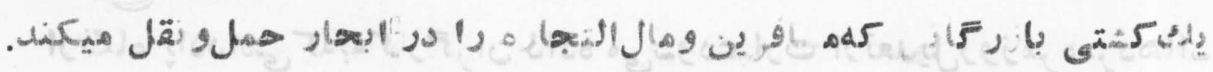
mer hant marine

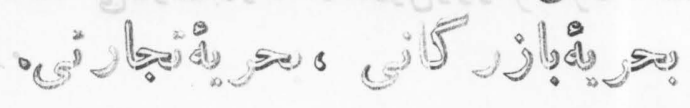

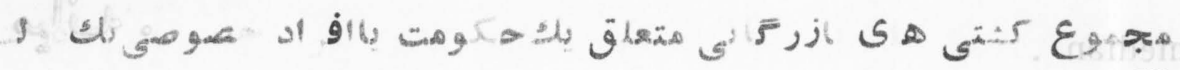

merg $\mathbf{r}$

$$
\text { is }
$$

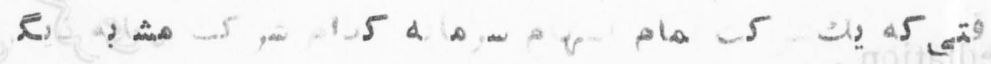

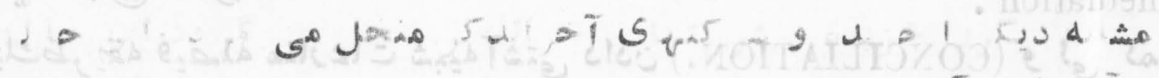

meru rating.

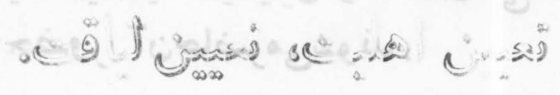

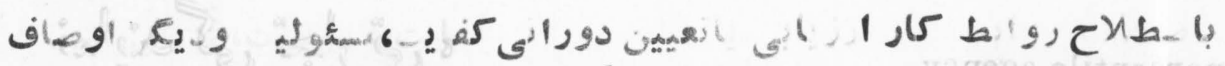
دإl

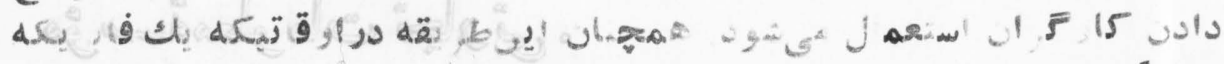

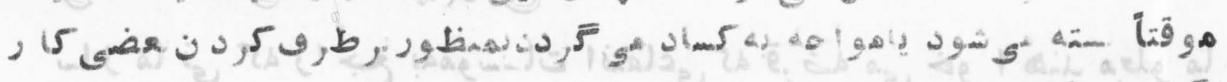
.

mic roecoon mics.

-

راهن

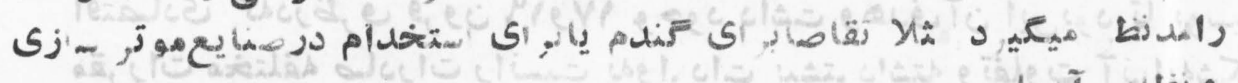
पि 
middle man.

و

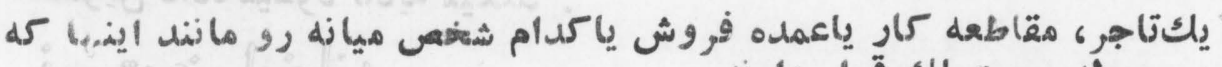

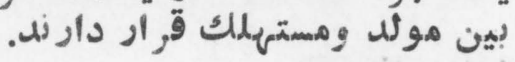

minimum wage

$$
\text { هو }
$$

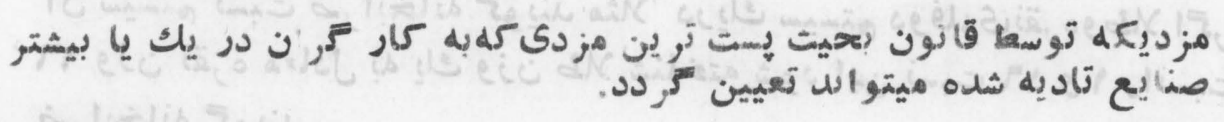

minor coin

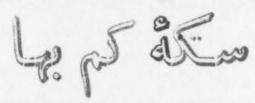

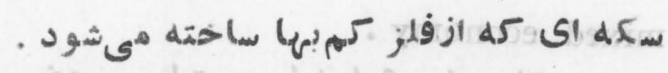

mint

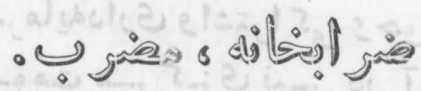

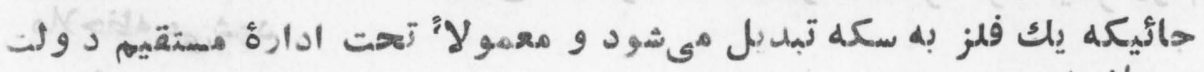

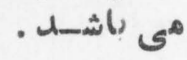

ni!ntage

$$
\text { • }
$$

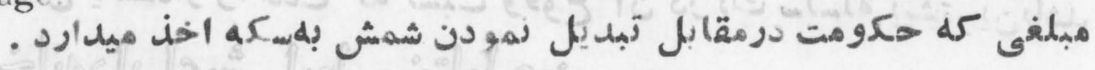

mint par of exchange

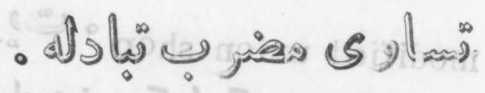

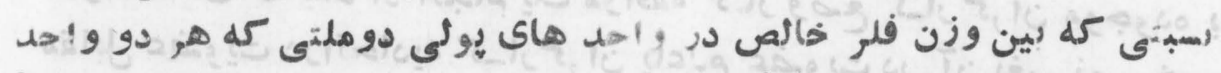

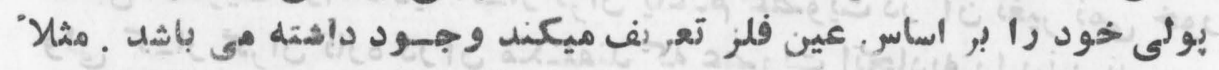

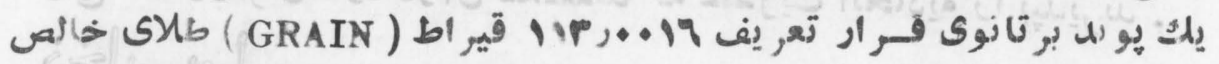

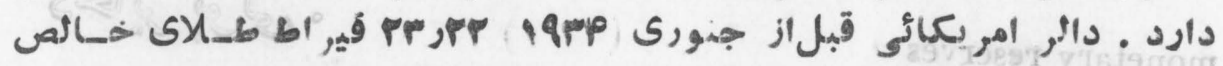

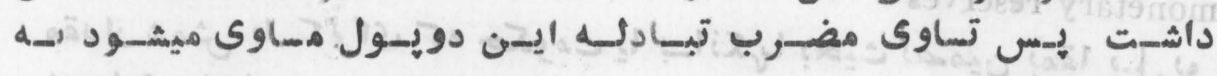

$$
\text { P,AYYO }=\frac{11 \%, \ldots 14}{\text { PPJP }}
$$

mint price of gold .

$\therefore$ - il

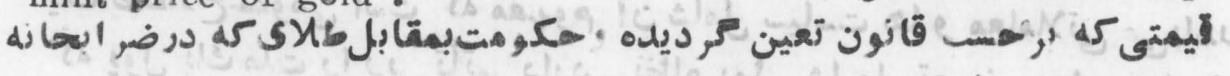


mint ratio .

تحو يل داده ميشود تاديه ميكنا. - Ajli

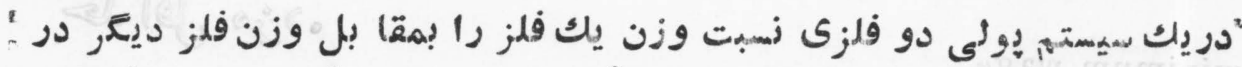

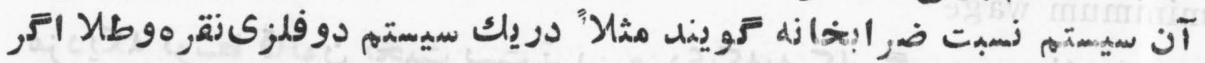

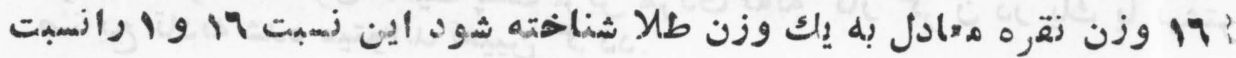

mixed economy . ض ضرابخانه

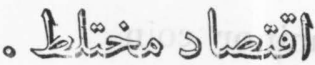

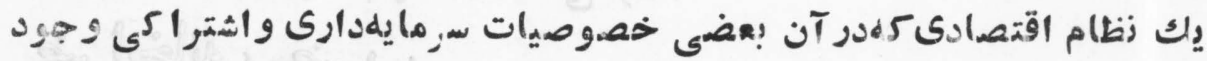

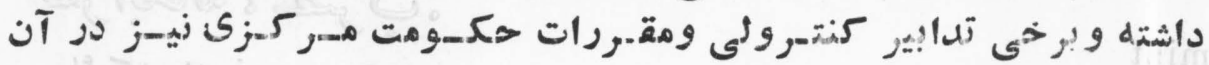
.

mode. - 2 ga of

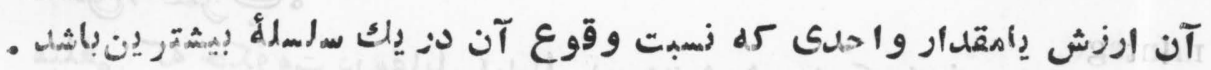

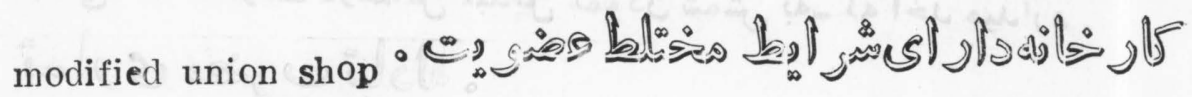

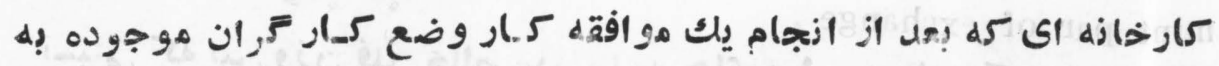

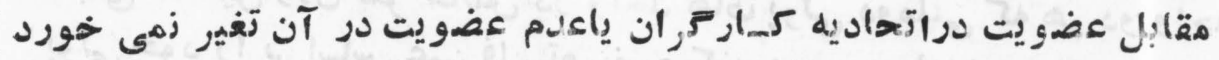

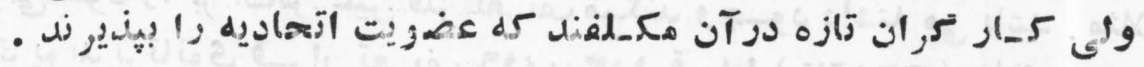

\section{monetary reserves}

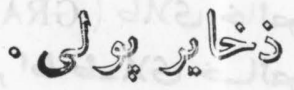

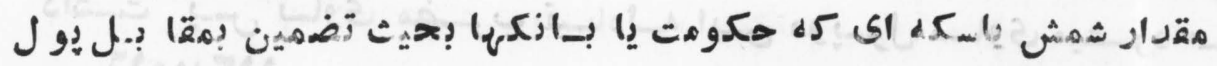

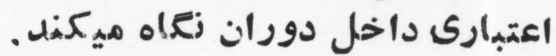

monetary system.

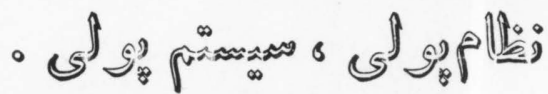

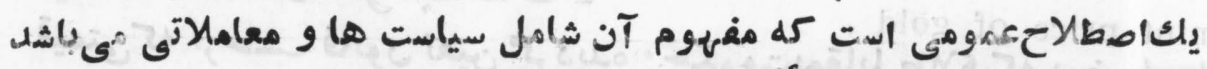

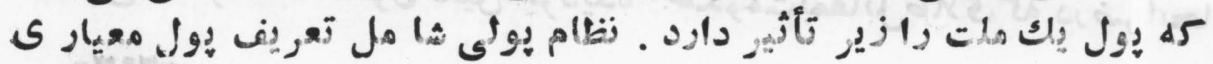
afypd 


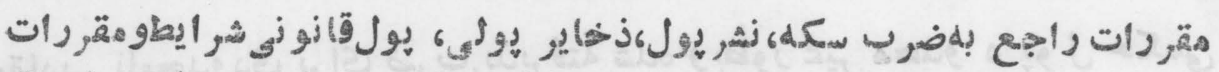

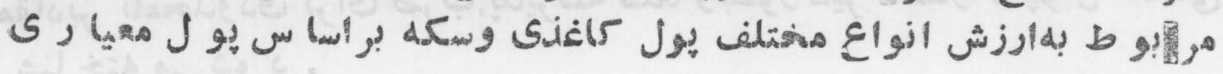
وغير ه هيياشلد.

monetary unit.

- ज $g_{0} d y$

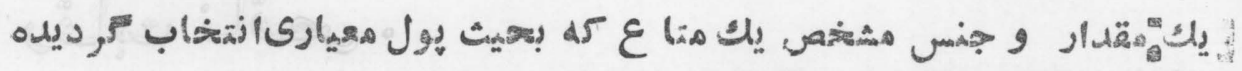

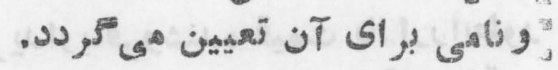

money.

- $\mathscr{S}_{*}$

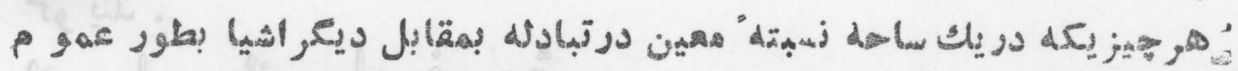

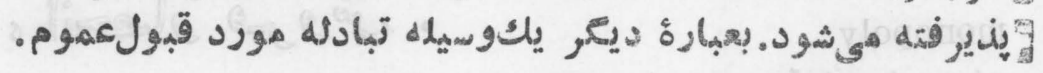

money capital.

- ज P O do ga

CAPITAL . رجو شود

money order.

- ज $\theta^{0}$ बो

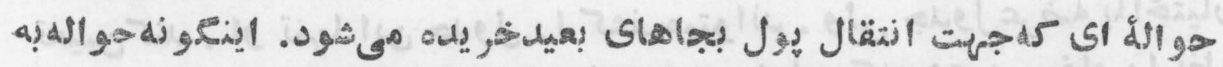

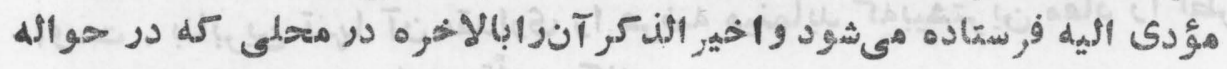

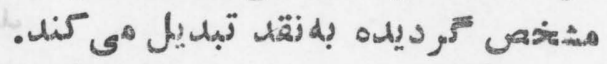

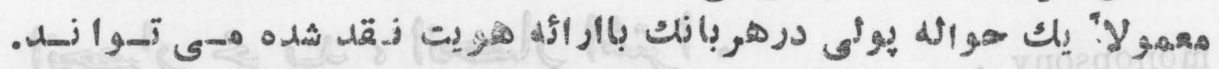

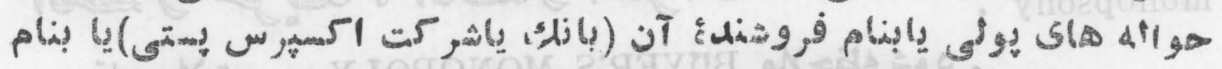

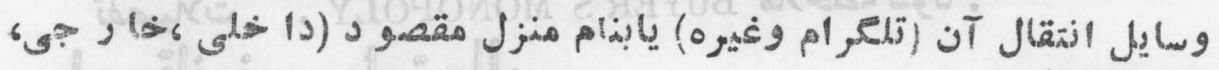

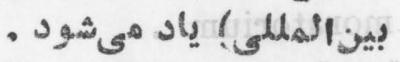

money wage.

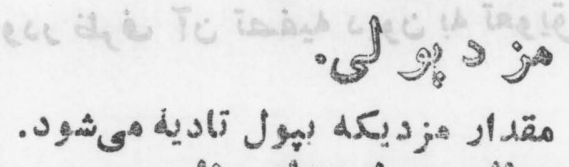

monometallism.

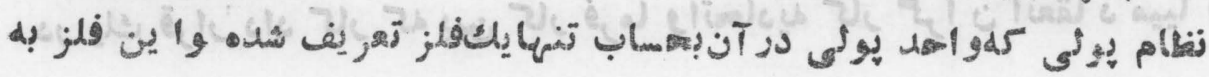




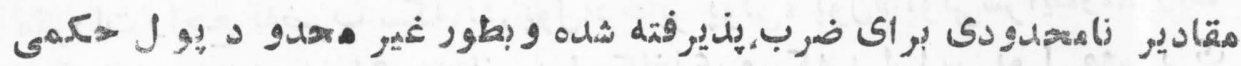
monopolistic competition .

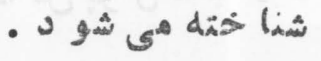

$$
\begin{aligned}
& \text { ० ज2la }
\end{aligned}
$$

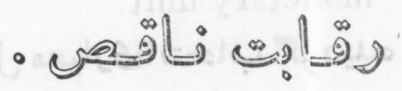

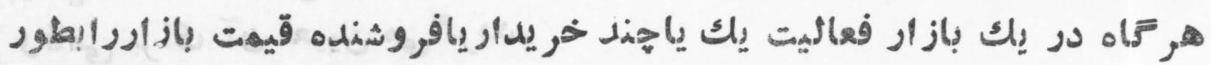

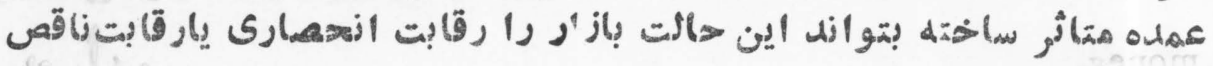
.

monopoly .

- ".

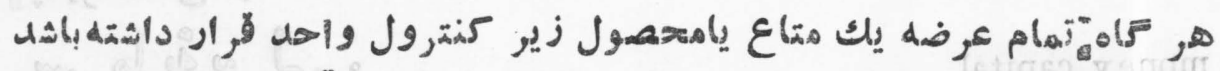

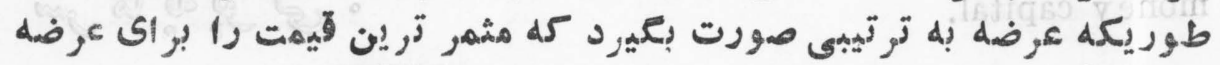

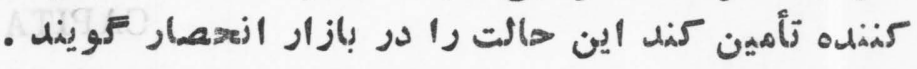

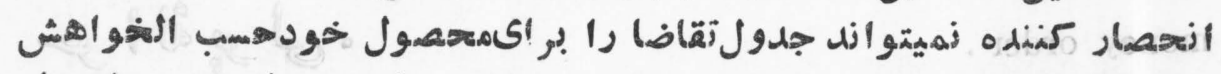

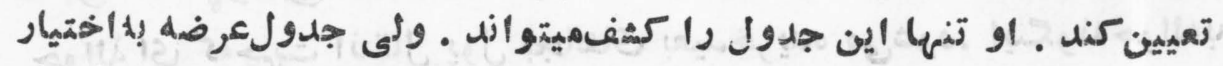

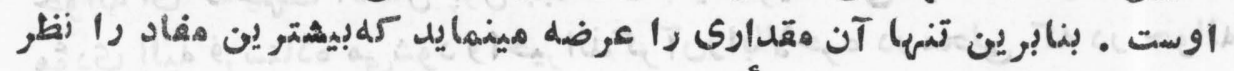

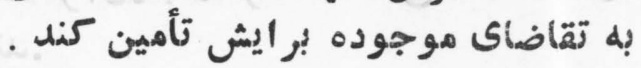

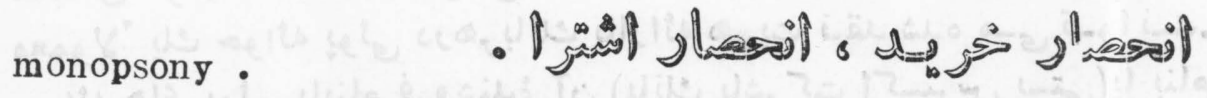
تغصيلات م ملاحظه شود . BUYER'S MONOPOLY moratorium •

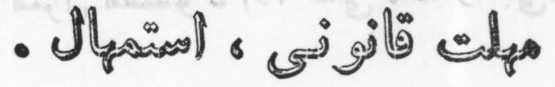
مهلمتيكه بزاساس قانون تعيين ترديده ودر ظرف آن تصفيه ديون به تعويق

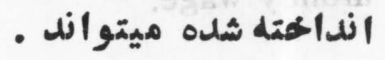

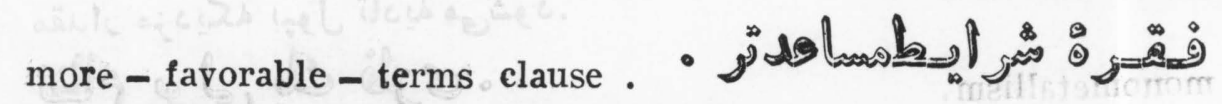
در ياك قرار داد كار كله بين كار فرما واتحاديه كار Fرا ن انعقا د مييا بد arาบD 


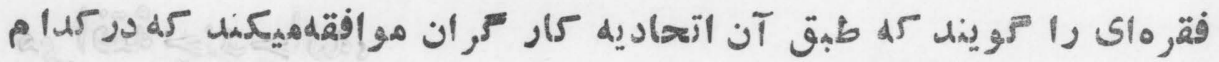

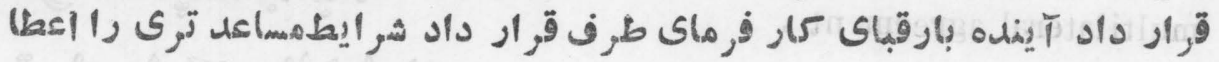
ز

morning loan. - نَا

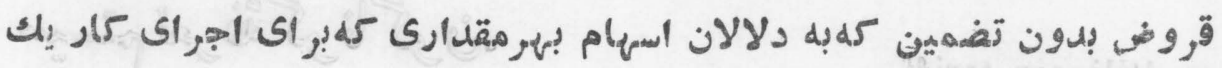

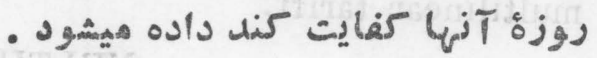
mortgage •

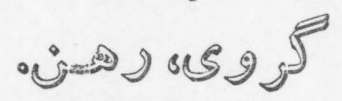

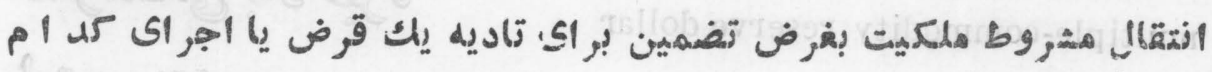
mortgage bond.

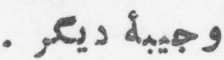
BOND, MORTGAGE. נجوع شود به

mortgagee .

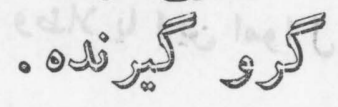

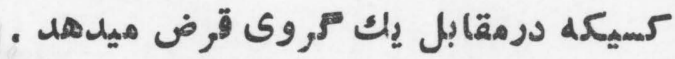

mortgagor.

$$
\text { ه dios g }
$$

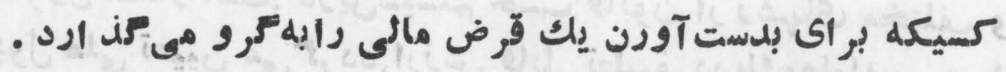

$$
\begin{aligned}
& \text { - Its 3ل }
\end{aligned}
$$

most-favored -nation clause.

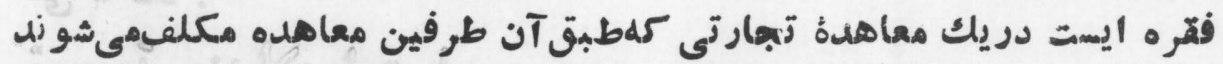

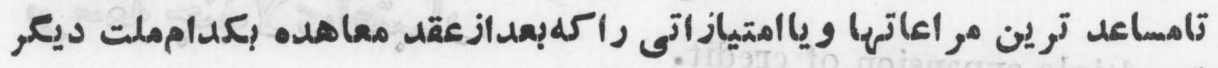

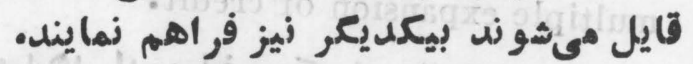

multicraft union .

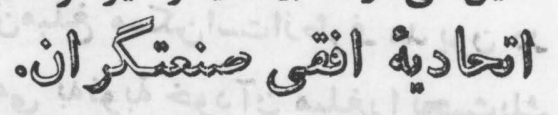

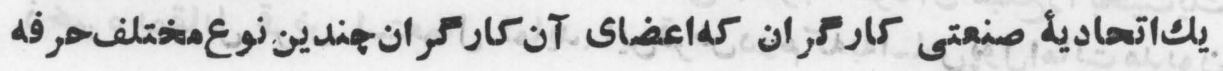

و وييشهرا دربر ميعيرد . 
multilateral agreement .

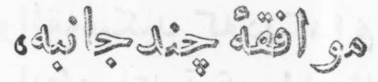

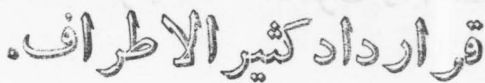

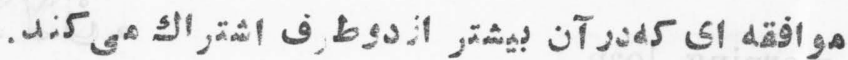

multilinear tariff.$$
\text { - (1) } 3
$$

MULTIPLE TARIFF SYSTEM. رجوع

multiple-commodity reserve dollar

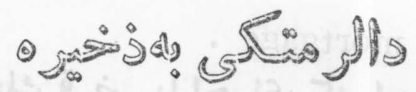

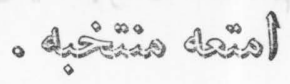

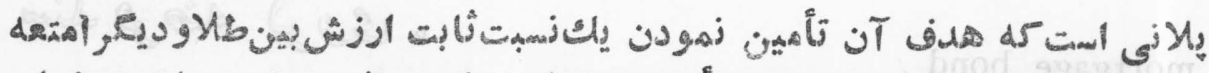

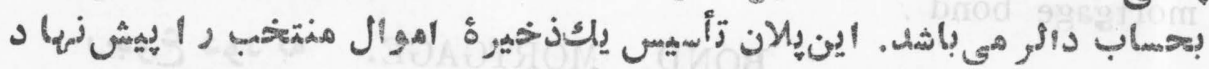

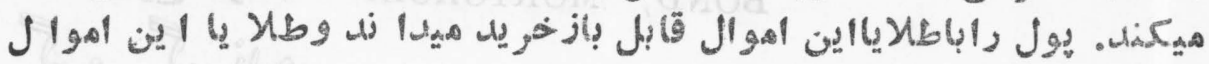

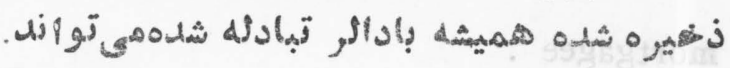
multiple currency system.

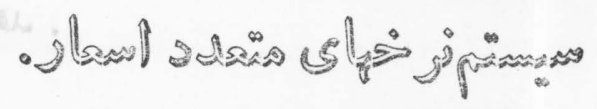

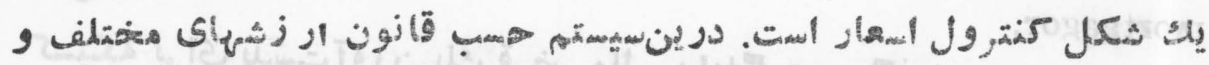

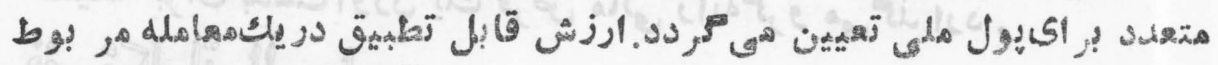

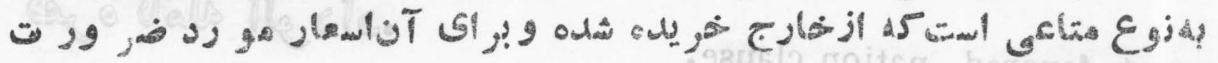

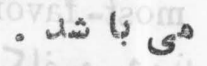

multiple expansion of credit.

$$
\text { - gl }
$$

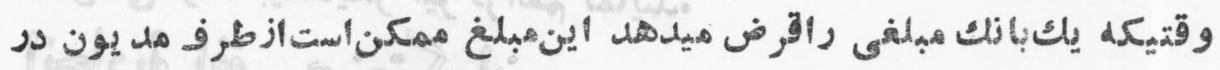

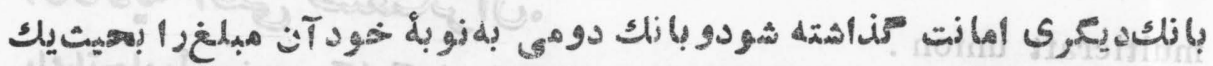

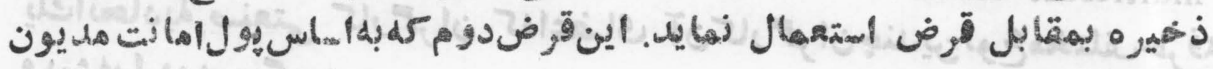

\section{(c)บัม}




\section{MUN}

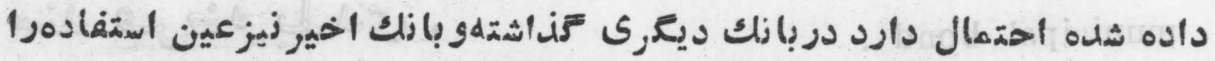

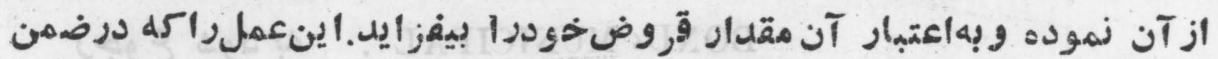

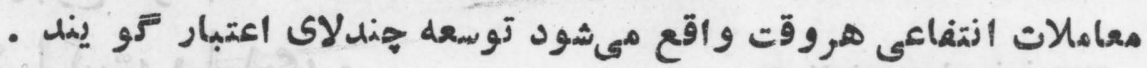
multiple tariff system. C

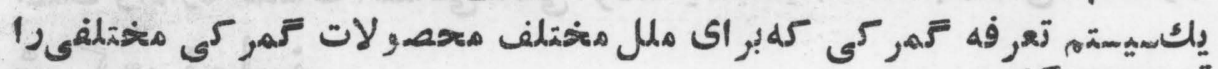

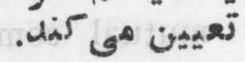
multiplier . -

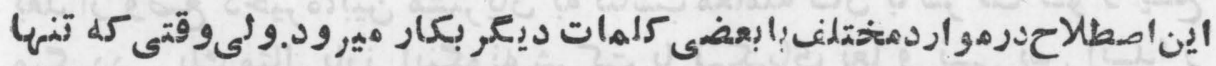

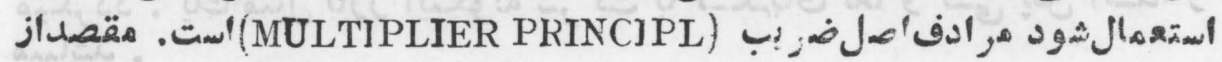

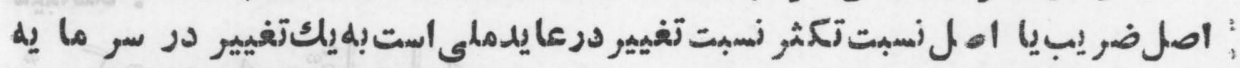

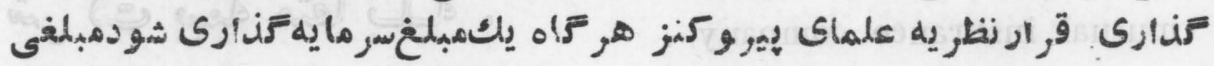

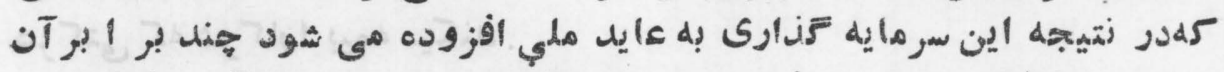

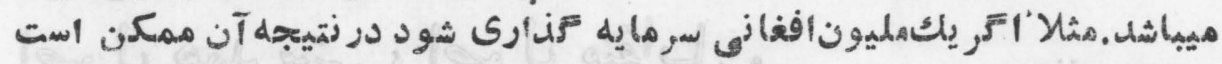

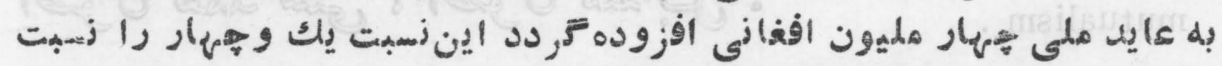

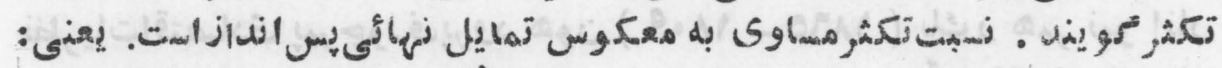

$$
\begin{aligned}
& K=\frac{1}{1-\frac{\Delta c}{\Delta y}}=\frac{1}{\frac{\Delta(y-c)}{\Delta y}} \\
& \text { درين فأرهاول } \\
& \text { s) }\left|X_{\text {fin }}\right|=C
\end{aligned}
$$

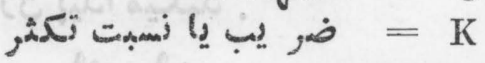

:

1 - BALANCED BUDGET MULTIPLIER .

2 - EMPLOYMENT MULTIPLIER.

3 - FOREIG TRADE MULTIPLIER.

4 - INV SBTMENT MULTIPLJER . 


\section{MUN}

municipal bond .

- जd_l-

BOND6 MUNICIPAL נجوع شود به

municipal socialism .

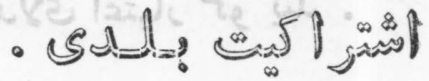

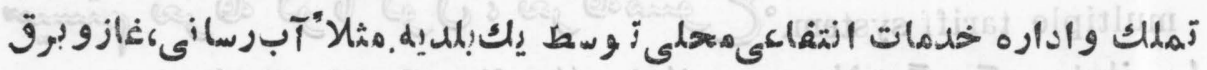

mutual company .

- $\doteq g$

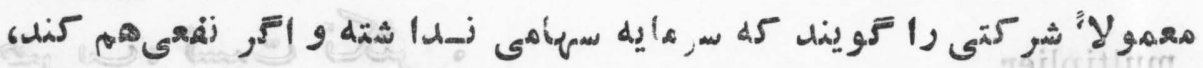

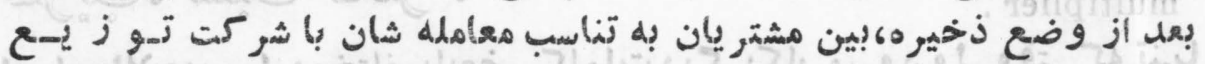

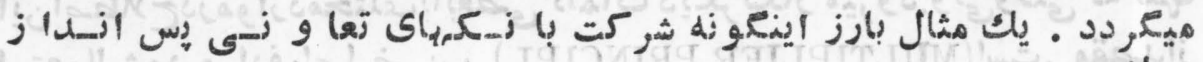

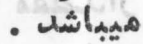

mutual insurance company .

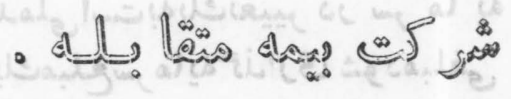
شركتى كله شركار ال بيمه ميكانل . mutualism .

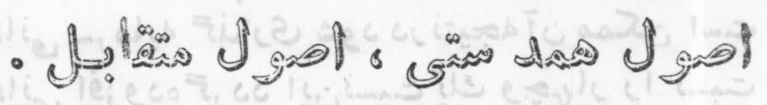

زظرياتاقتصادى بير جهزف يرود هون (

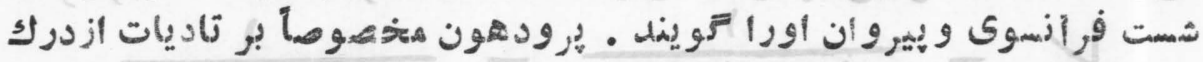

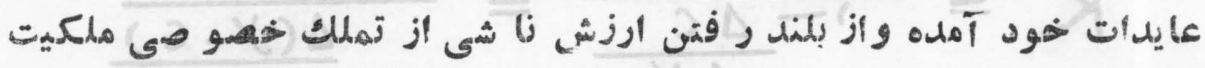

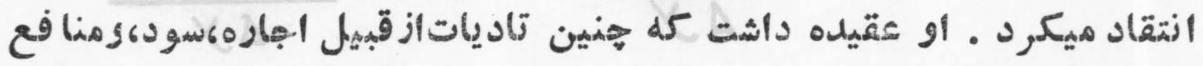

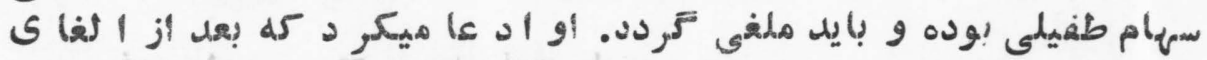

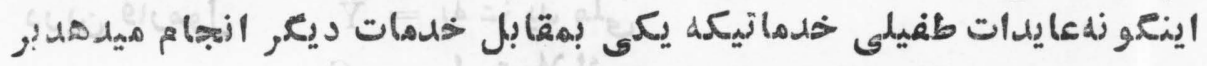

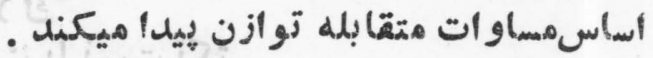

mutual saving bank.

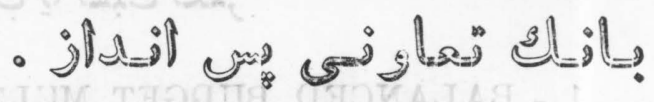

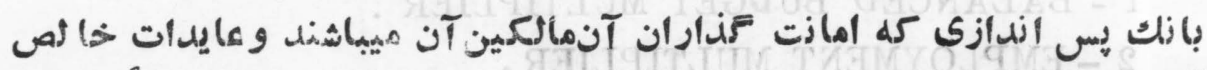

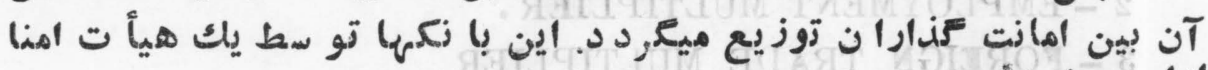

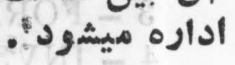




\section{$\mathbf{N}$}

narrow market $=$ thin market .

- 2gdrea dill=?

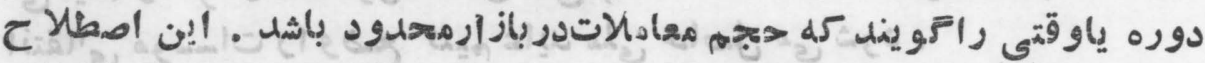

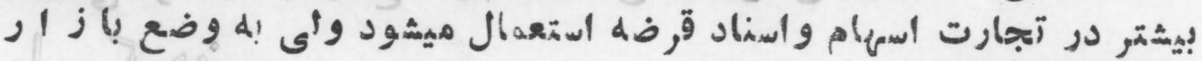

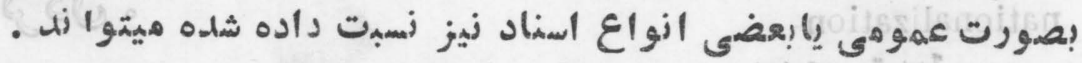

national debt .

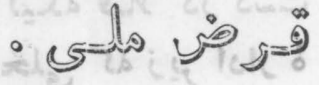

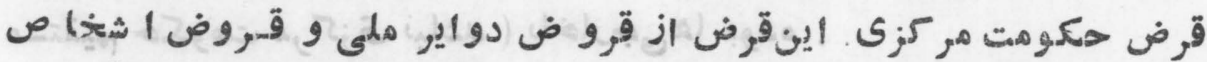

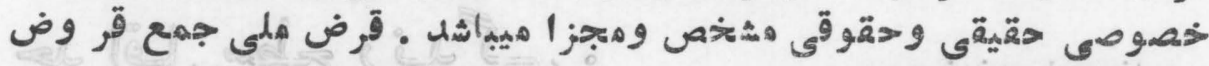

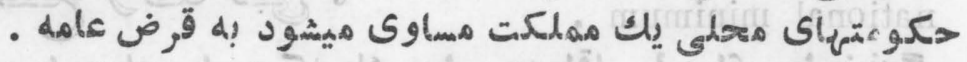
national economiy.

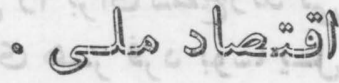

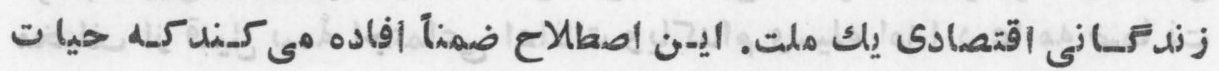

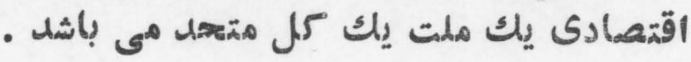
national equitable labor exchange.

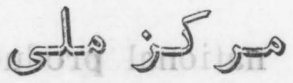

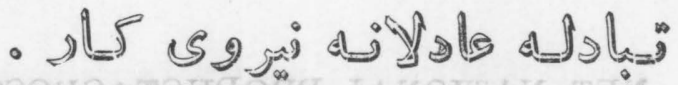

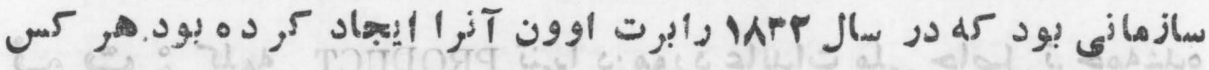

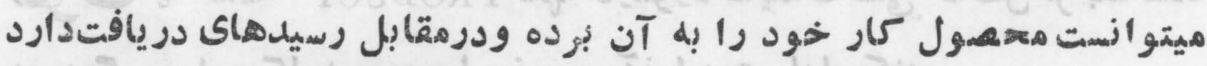

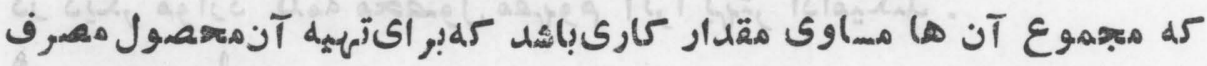

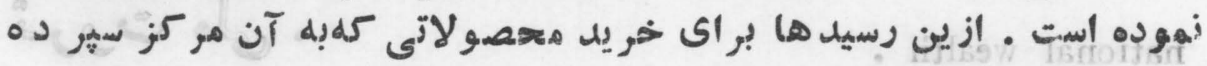

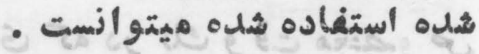


national income.

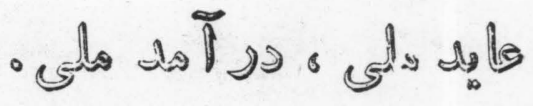

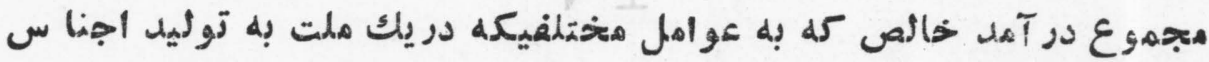

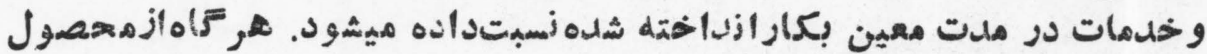

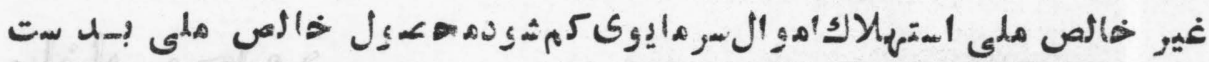

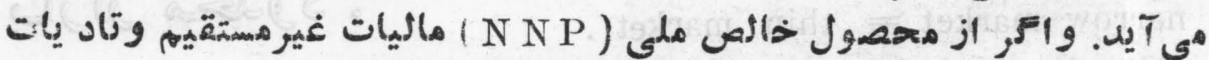

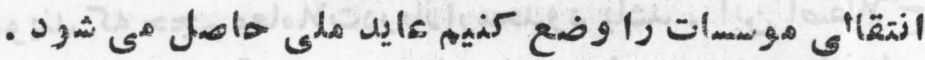

nationalization -

- iss slo

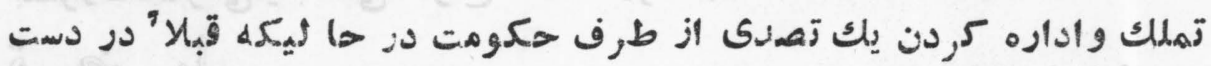

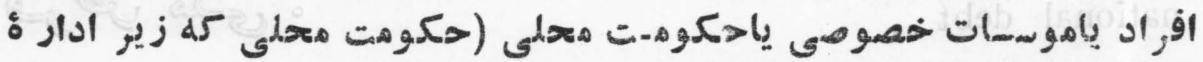

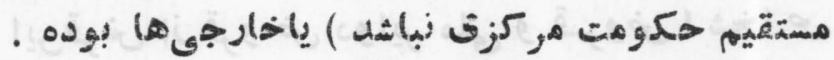

national minimum .

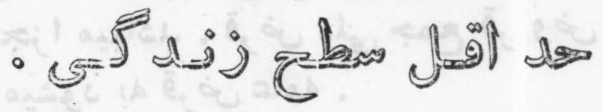

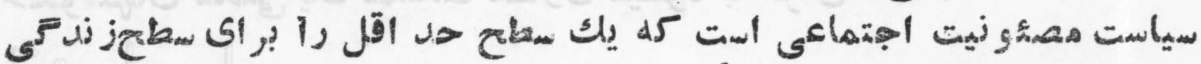

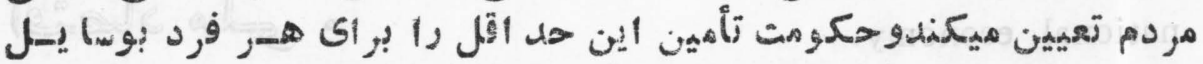

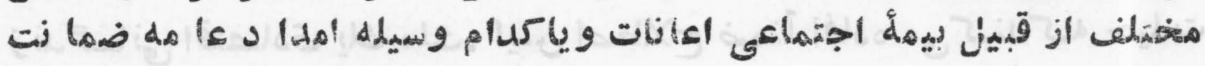

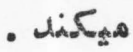
national product .

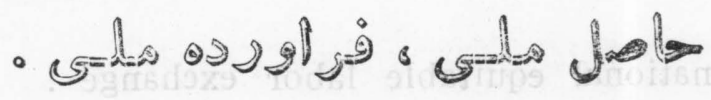
رجوع شوددبه:

NET NATIONAL PRODUCTgGROSS NATIONAL PRODUCT •

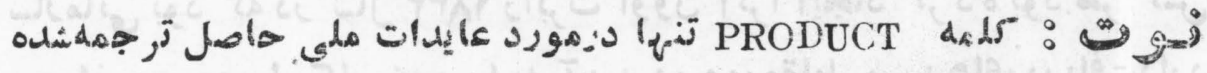

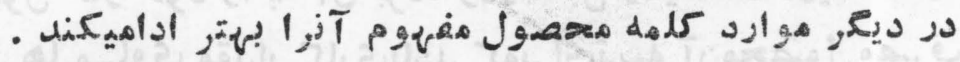
national wealtì . -

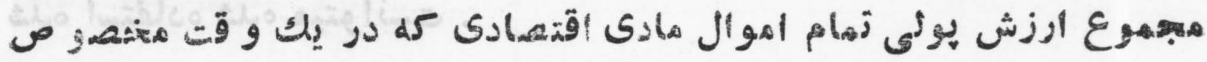
artirn 


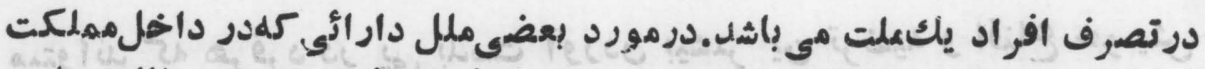

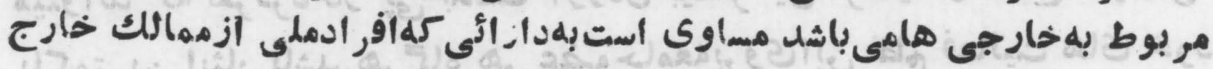

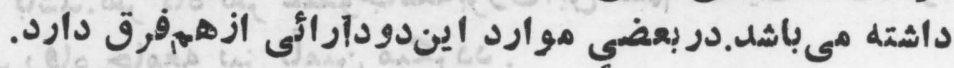

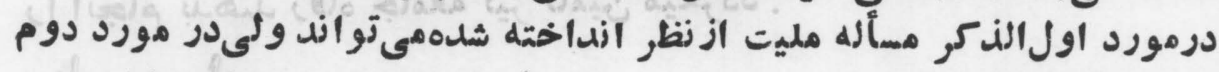

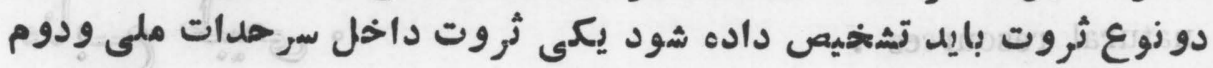

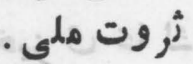
natural capital. - ज范 CAPITAL GOOD, رجوع شود به به natural monopoly . ' "

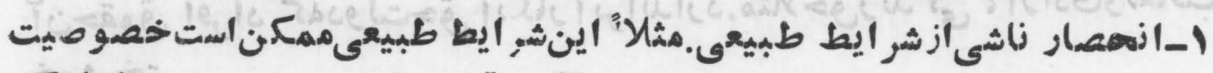

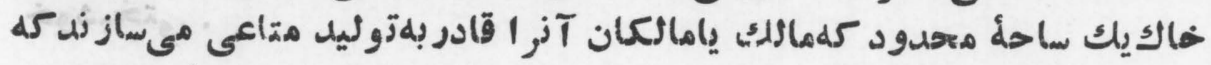

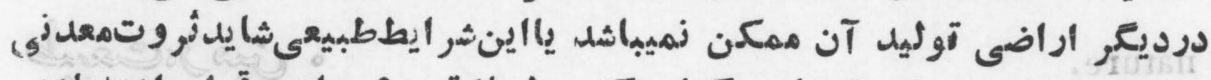

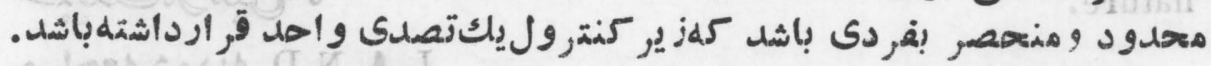

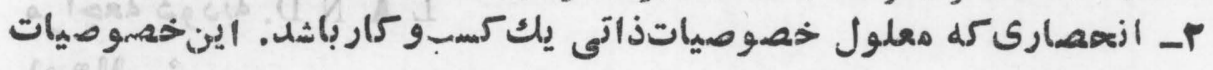

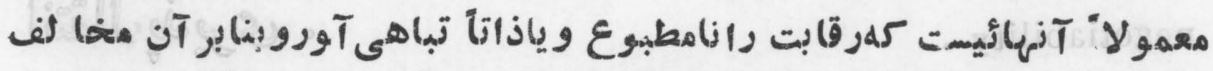

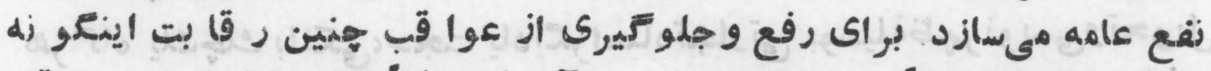

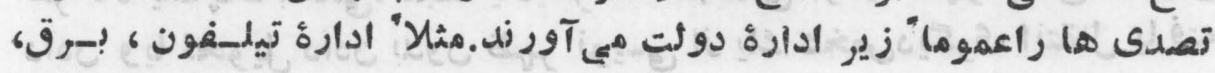

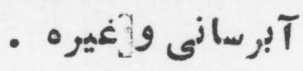

natural order.

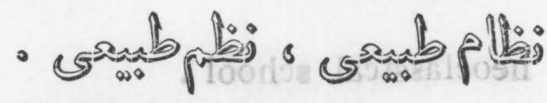

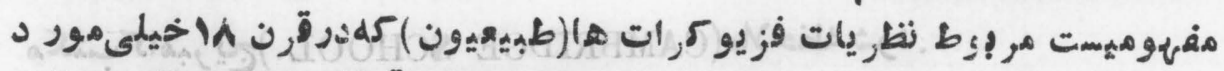

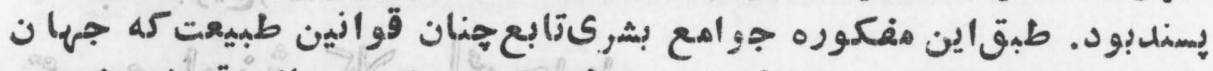

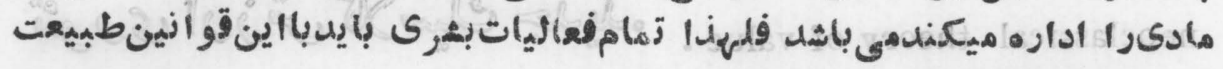

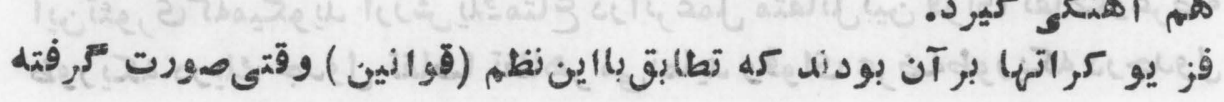




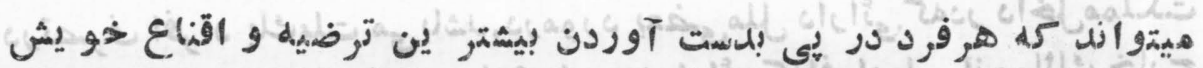

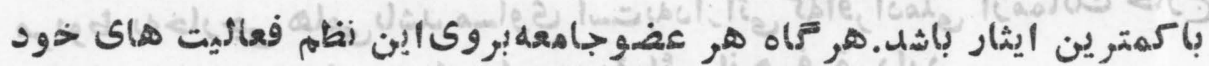

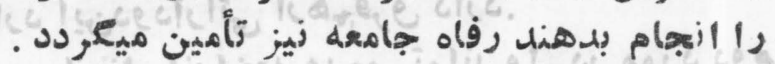
natural resources .

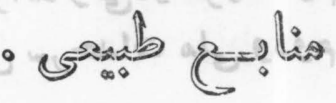

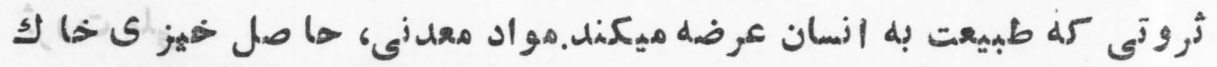

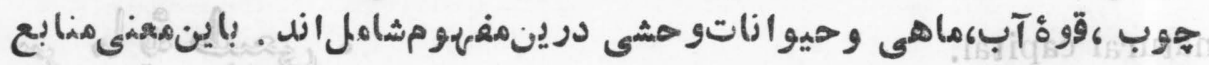

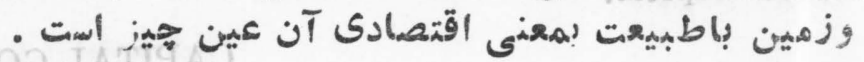
natural rights. - ज 19 آنحقوق افراد كهدولتحق انعار آنر اندارد. مثللاحقز ند تى ، آز ادىو تهاقب nature.

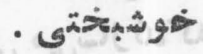

- isiojocesab

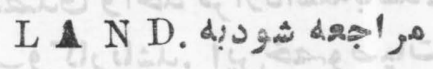
negotiability .

- जs jojd (limid

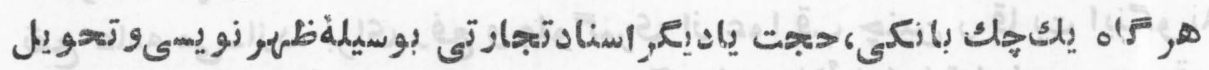

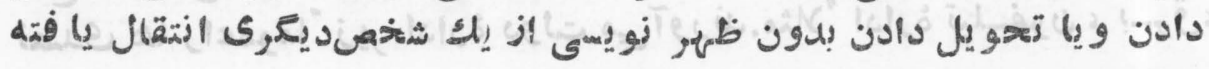

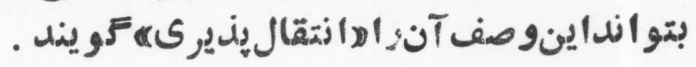

neoclassical school . ه d ه

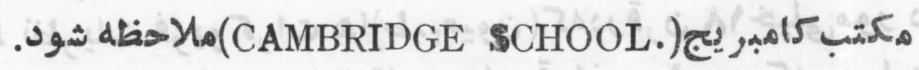
neoclassical theory of value.

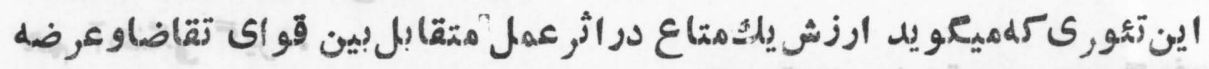

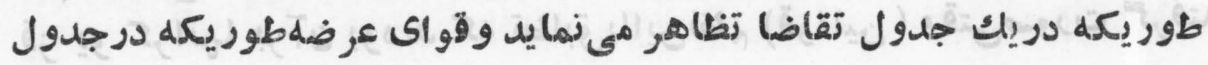




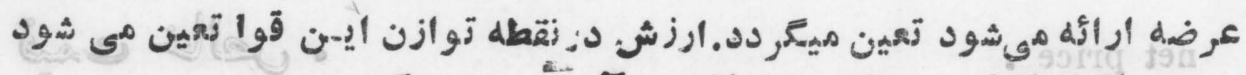

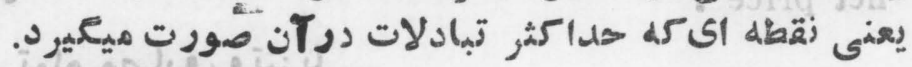

net income.

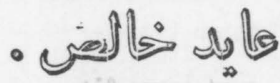

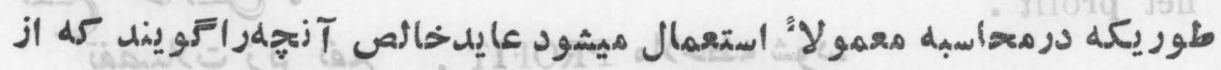

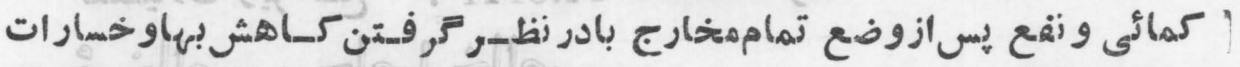

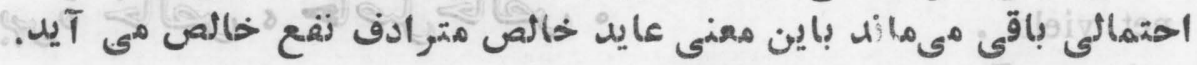

net interest.

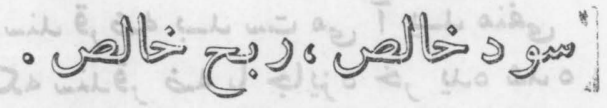

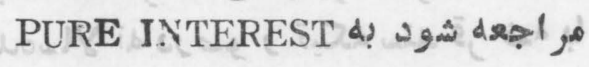

net lease.

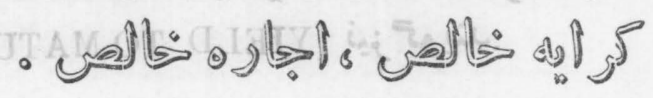

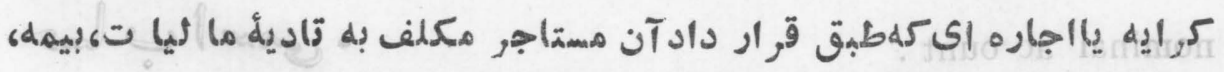

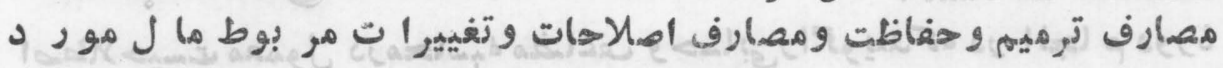

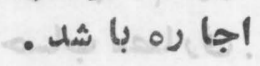

net national debt. - जela va

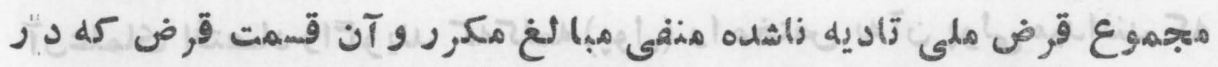

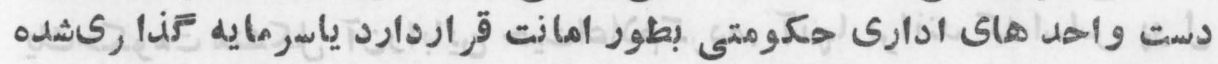

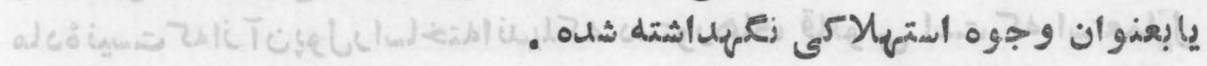

net national product . o $v=0$ all do do * ज

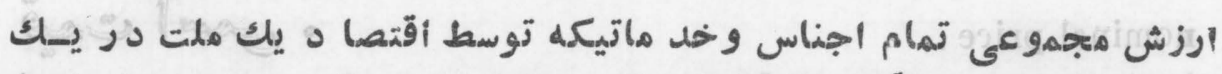

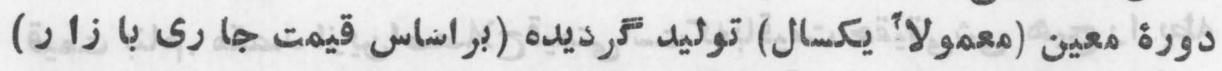

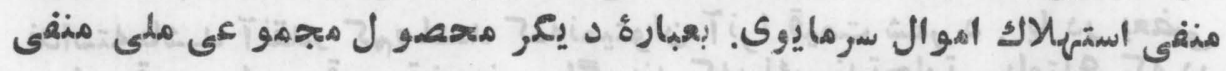

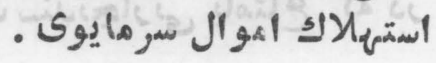


net price .

- صी

قيهت بعد از وضع تمام مصارف وتنزيل .

net profit .

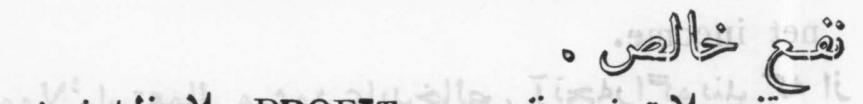

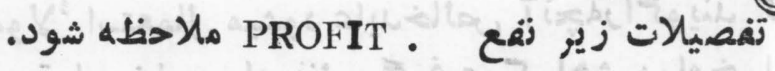

net yield .

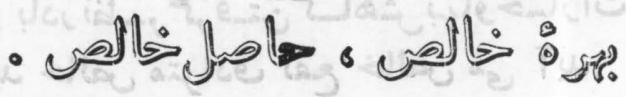

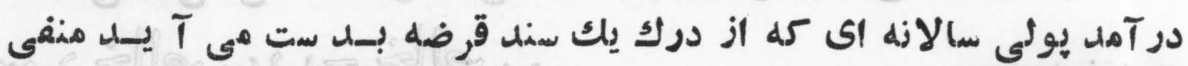

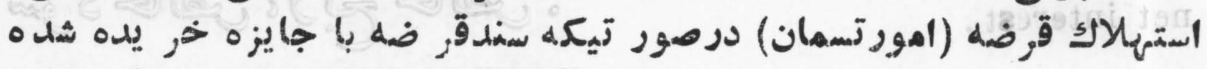

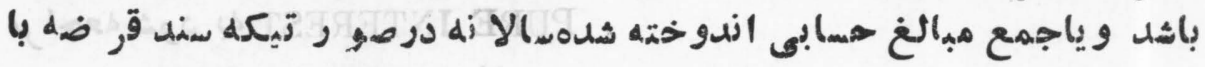

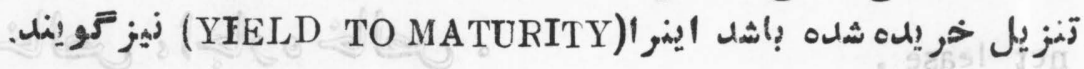

nominal ac ount.

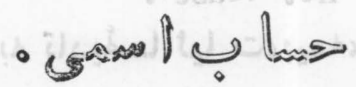

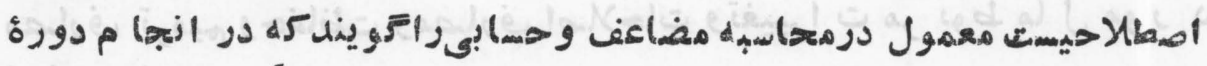

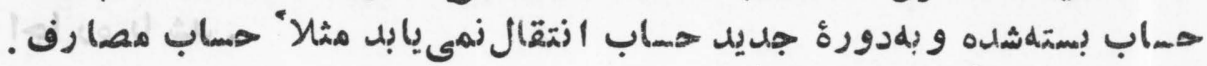
nominalists .

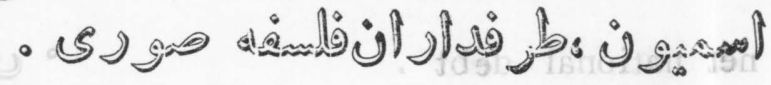

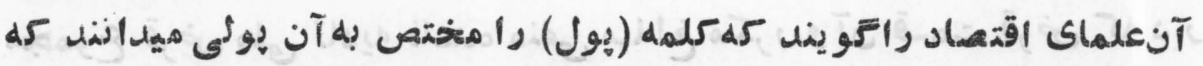

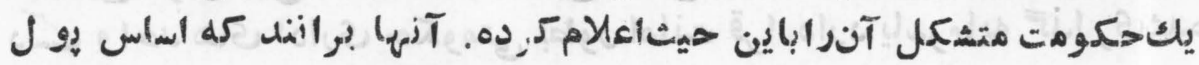

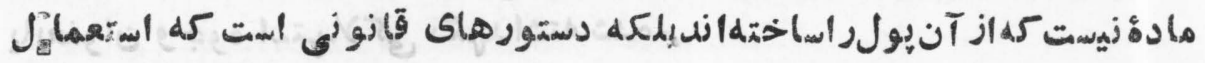

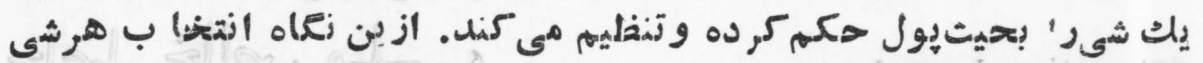

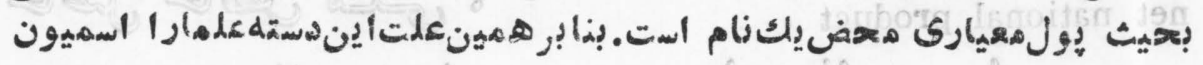

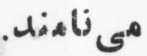
nominal price. - ज赵

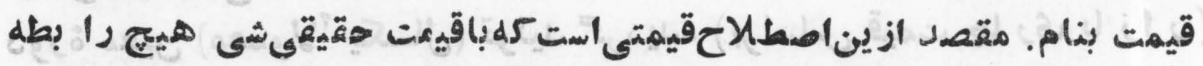

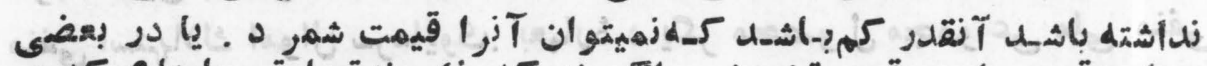

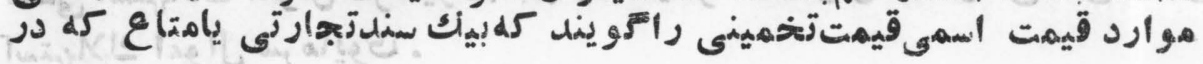

\section{"IVY)}




\section{NON}

بازار بقدر كأفى خريد وفروش : مأشتحك و قيمت باز ار آن معين نيهتنسيت

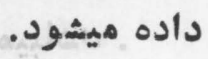

nominal yield .

- ज得

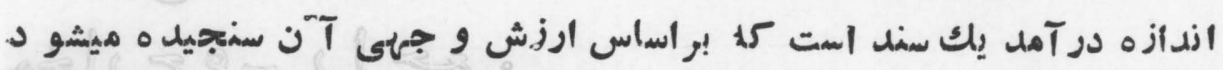

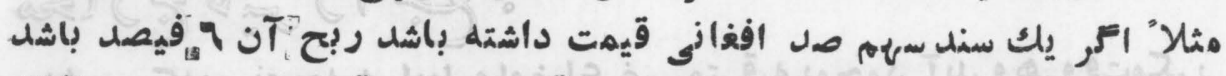

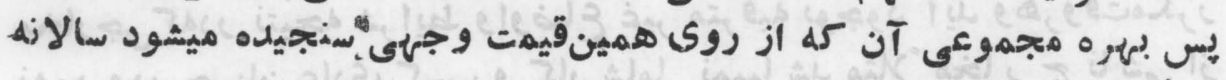

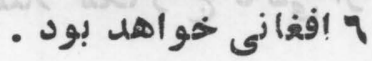

nonassented stock or bond. • ASSENTED STOCK OR BOND . رجوع شود به

nonassessable stock .

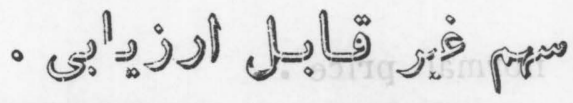
STOCK ، NON ASSESSABLE . رجوع شوث به

noncontributory penssion - csilanal $u=g(\stackrel{\infty}{0}$

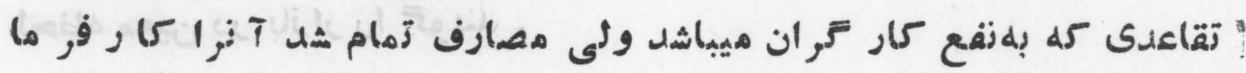
- (20)

nonclearing house stock. - जs 1

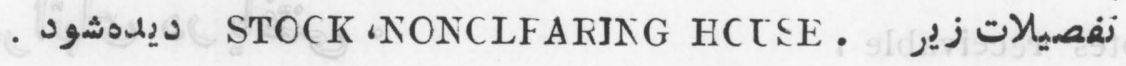
noncumulative stock .

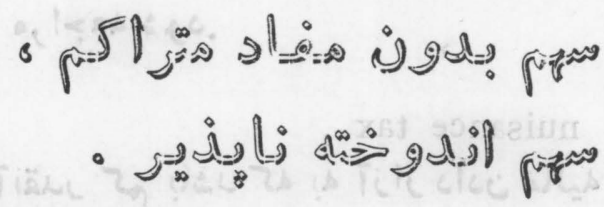
STCCK ، NONCUMULATIVE • رجوع شود به 


\section{NON}

noninterest-be ring discount bond.

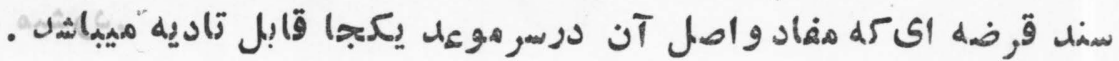

nonrecurring expelse.

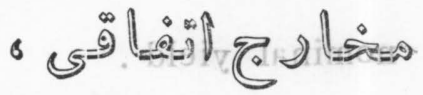

$$
\begin{aligned}
& \text { - है }
\end{aligned}
$$

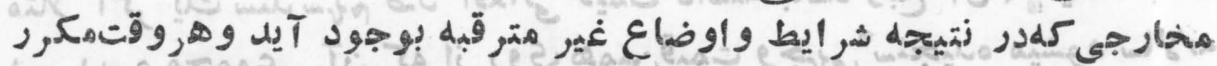

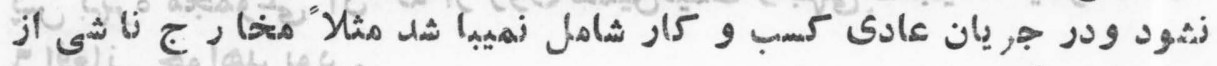
هر يق وسروقت مدور non-par-value stock .

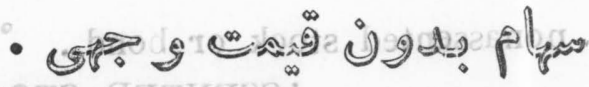

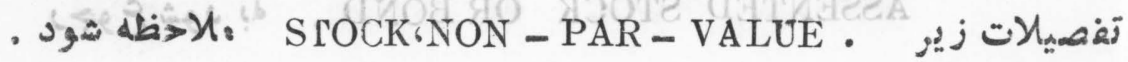
normal price . - $S 5 l=5 \underset{\infty}{\infty}$

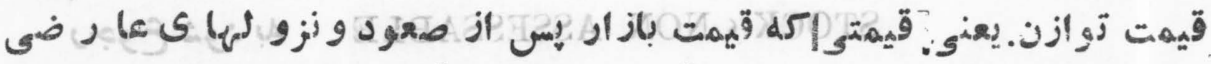

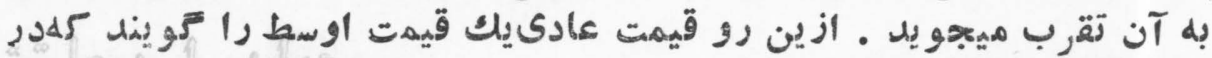

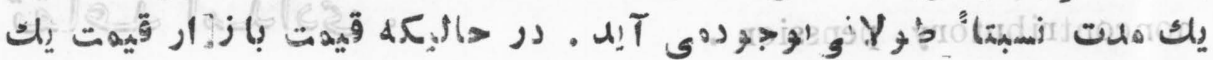
-

notes payable.

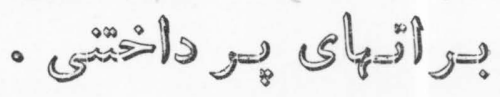

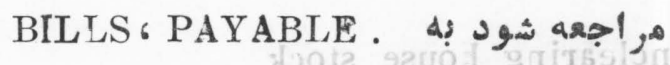

notes receivable .

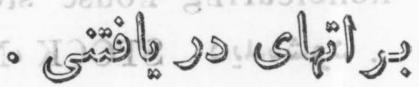

بون

nuisance tax.

- Miso

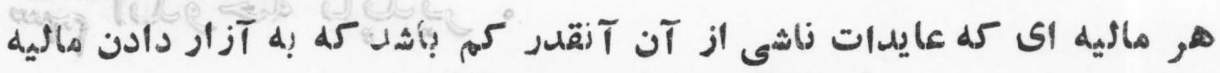

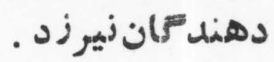


ebleq 2000

obsolescence .

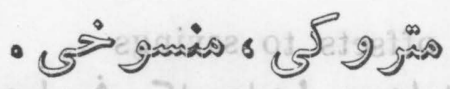

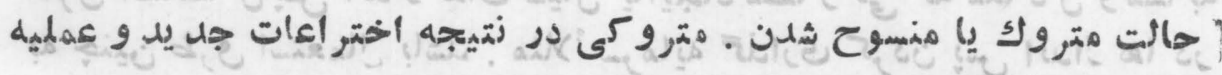

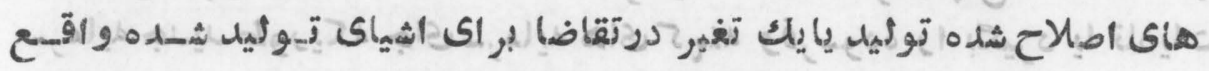

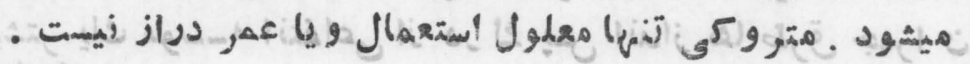
occupation money .

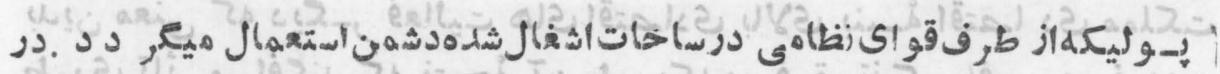

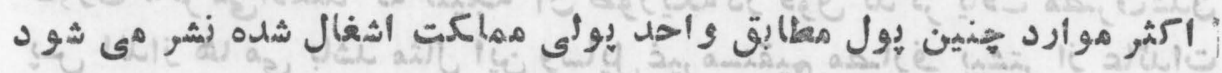

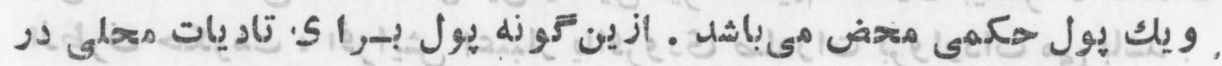

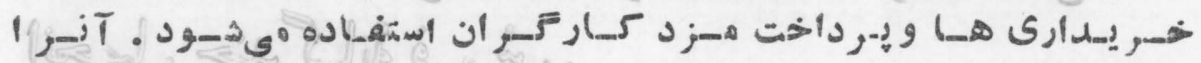

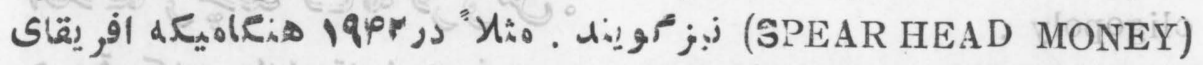
(YELLOW SEAL DOLLAR) يا

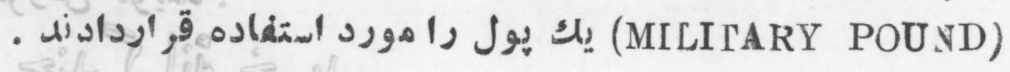

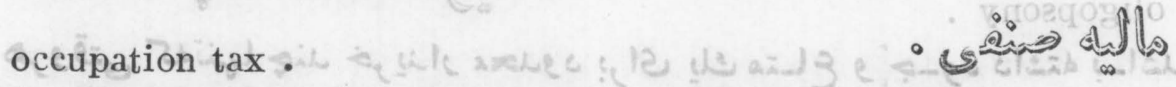

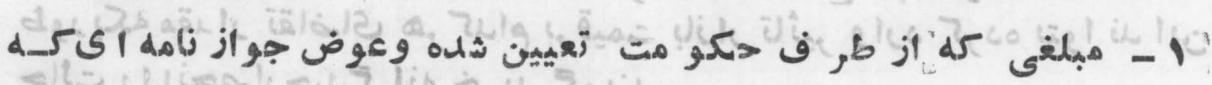

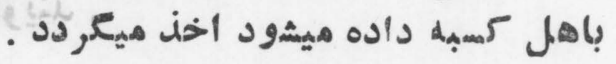

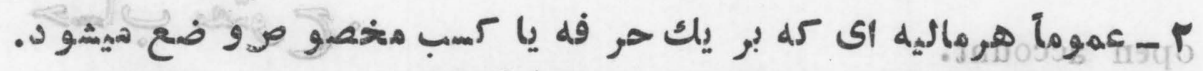

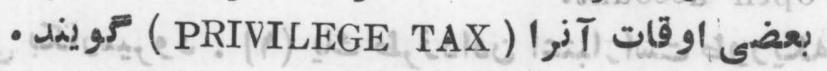


odd - lit broker.

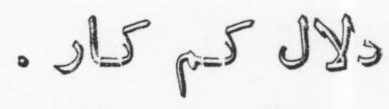

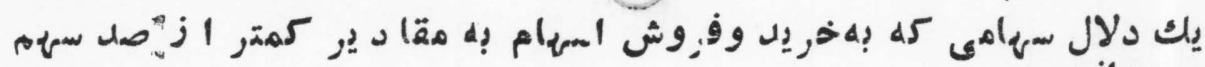
ميثردازد .

offsets to savings .

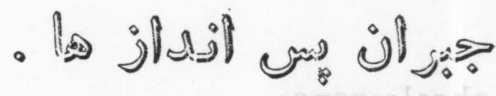

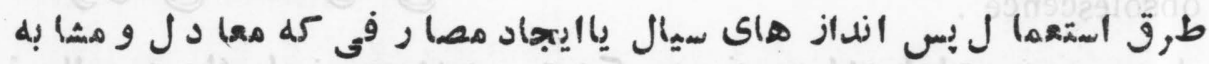

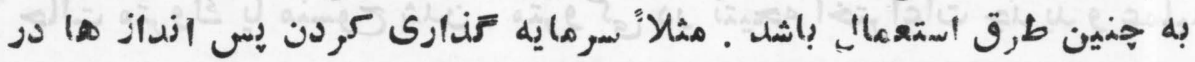

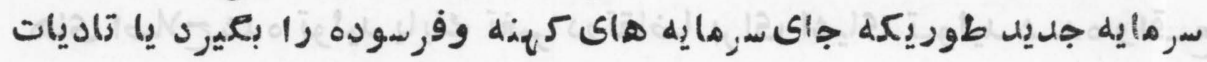

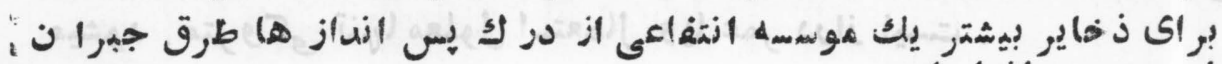

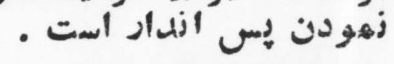

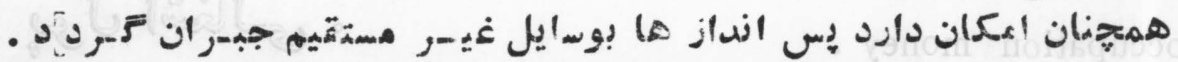

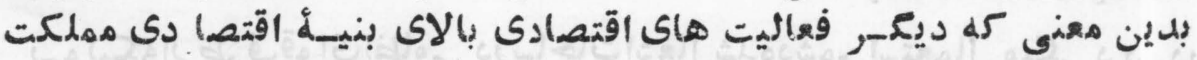

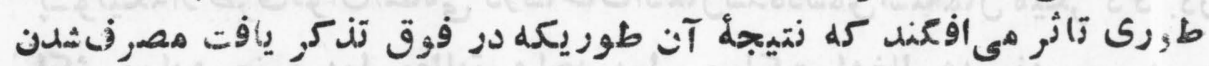

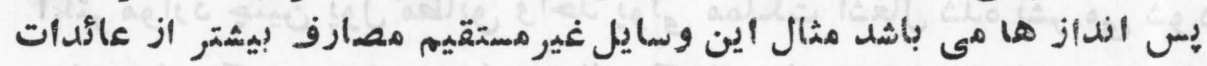

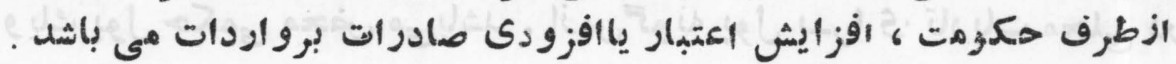
oligopoly .

$$
\text { - }
$$

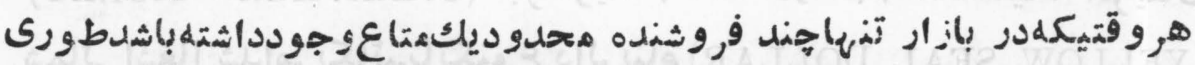

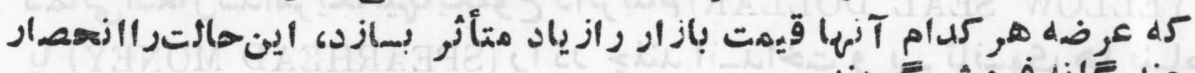

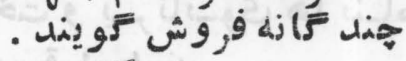

oligopsony .

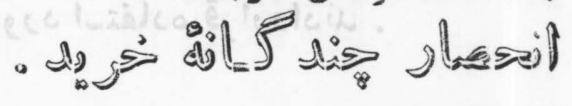

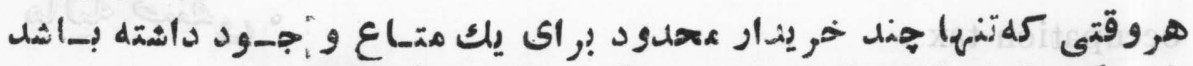

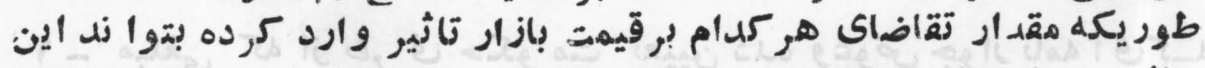

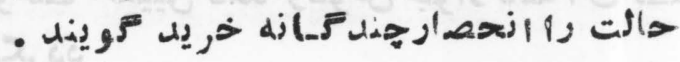

open account.

- C اين اصطالح بدو معنى بكارميزود ـ (1) يك طرزدادن اعتبازاست طوريكه 


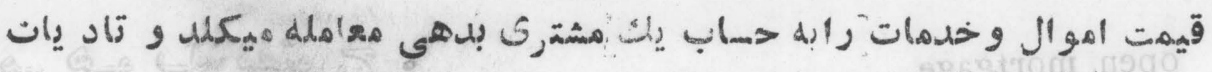

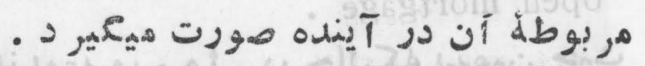

>

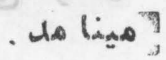

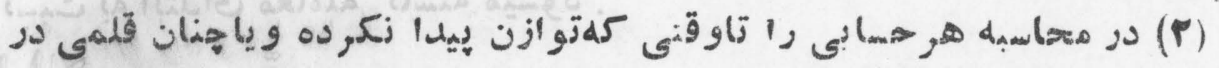

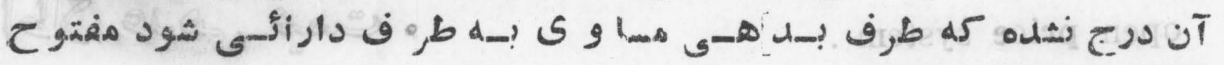
open - competition .

$$
\text { - JuLK }
$$

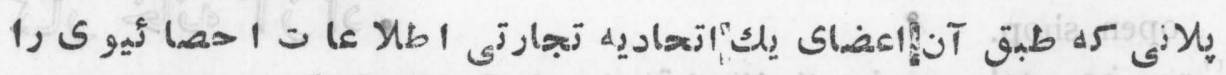

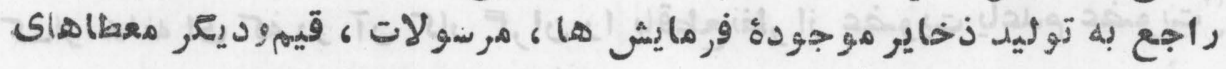

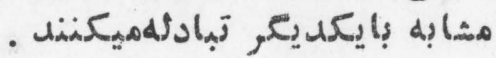

open - door policy

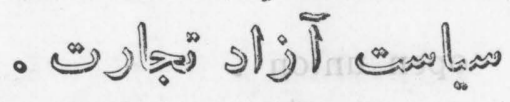

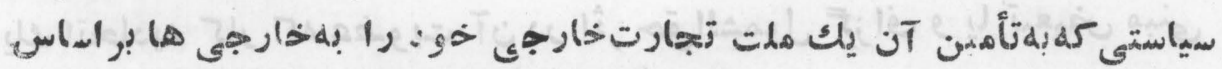

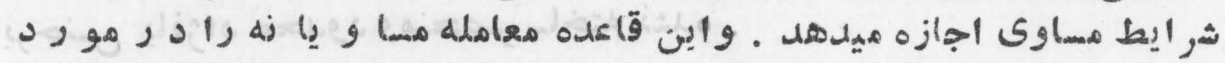

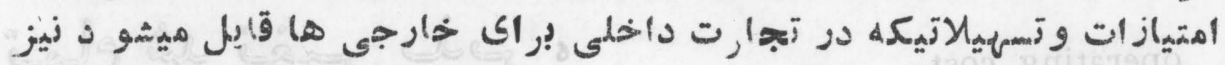
open - letter of credit.

$$
\text { - C }
$$

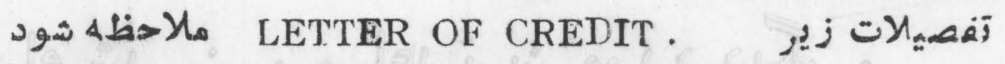

open market operations .

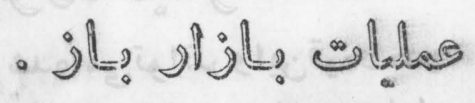

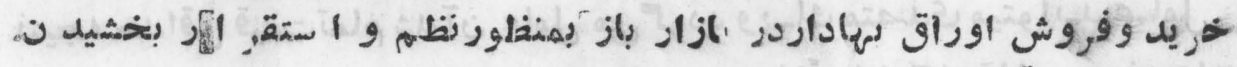

كريلت در اقتهاد 
open mortgage .

- $C \lim ^{\infty} d=i_{\beta}=0$

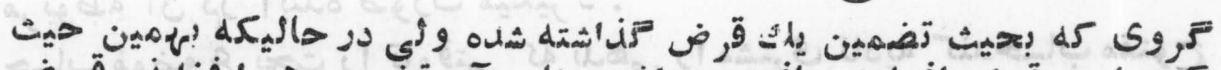

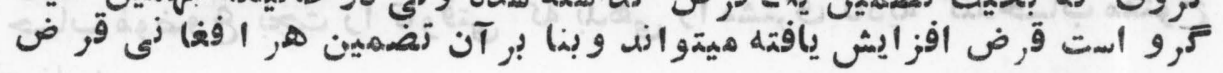

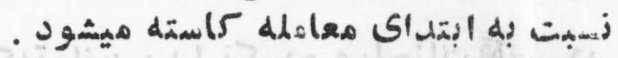

open price system .

-

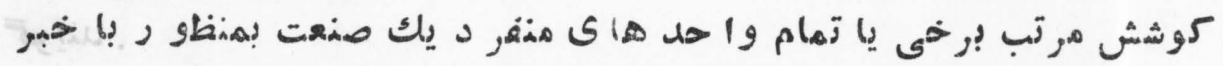

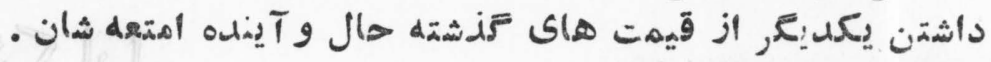
open shiop.

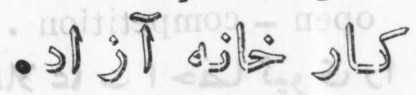

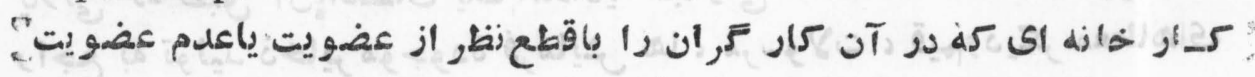

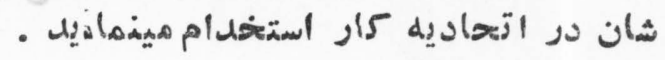

open union .

$$
\text { - } 3 \int j \text { i a }
$$

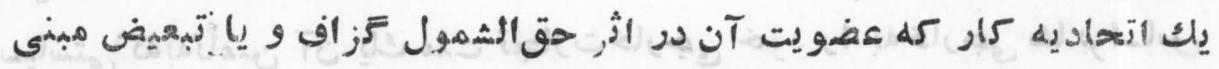

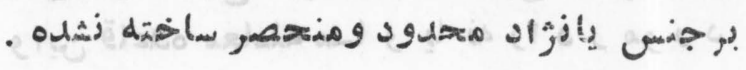

operating cost .

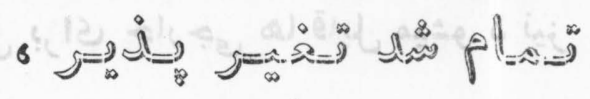

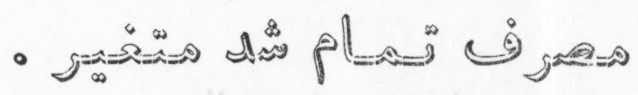
VARIABLE COST • جوع شودوبه

opportunity $\operatorname{cost}$.

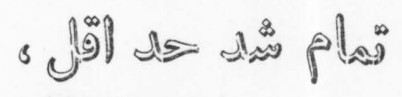

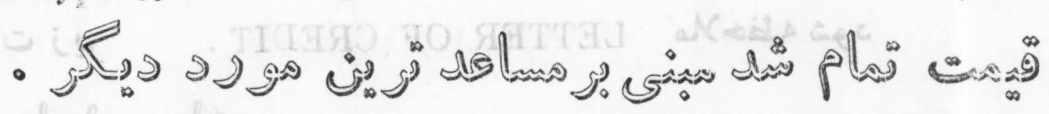

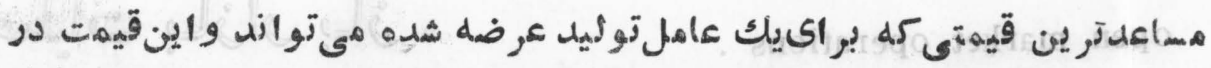

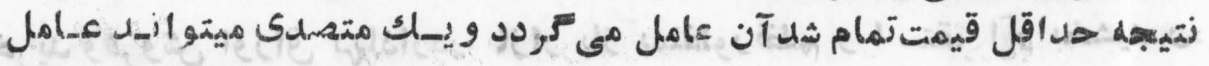

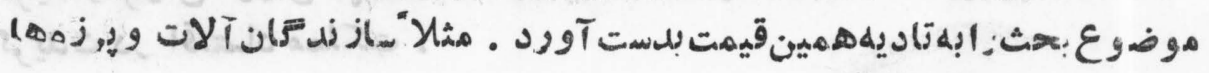

\section{(UPAT)}




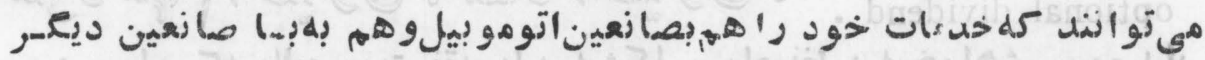

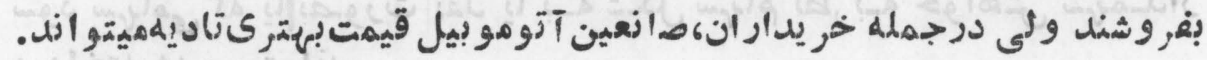

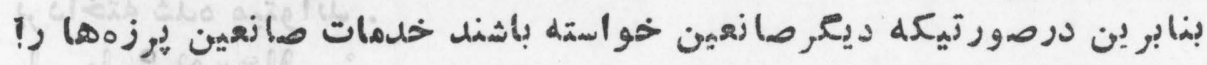

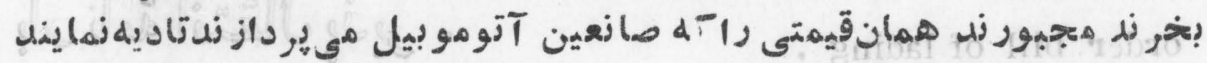

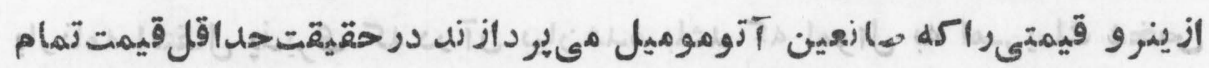

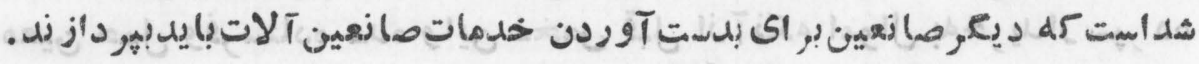
optimist school . م

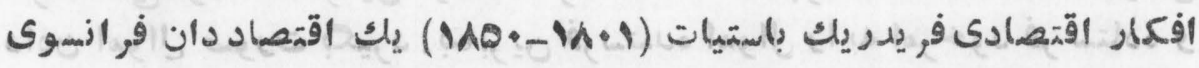

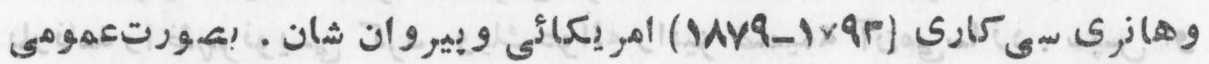

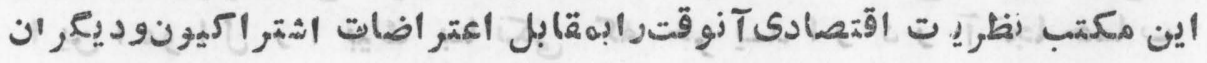

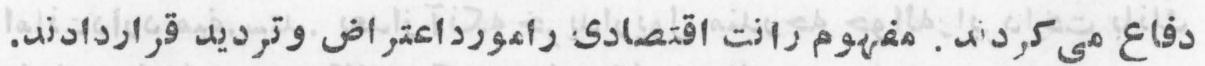

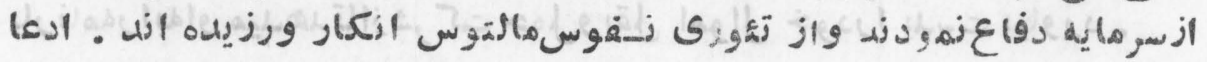

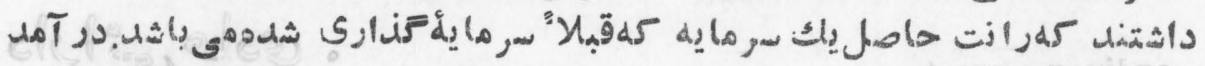

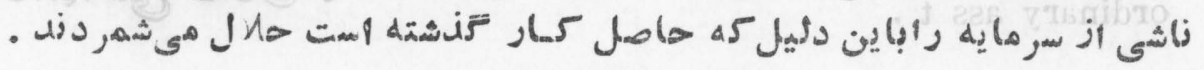

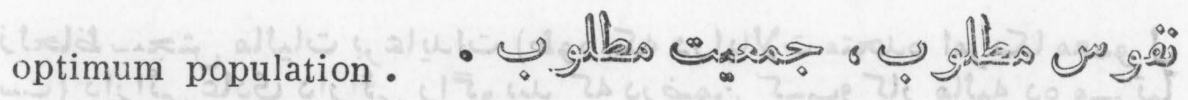

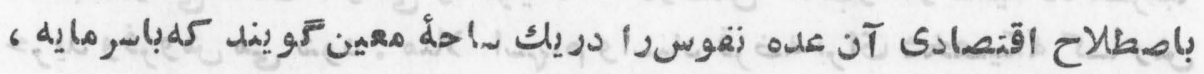

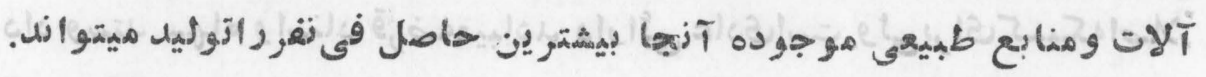

\section{option.}

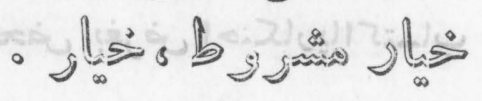

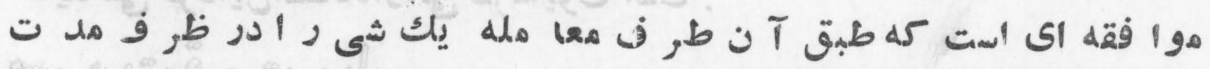

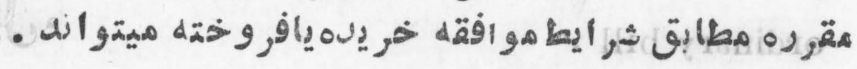
optional bond .
- जs

BOND ، OPTIONAL נجوع شودوبـ

(IPAPD) 
optional dividend. - S J l

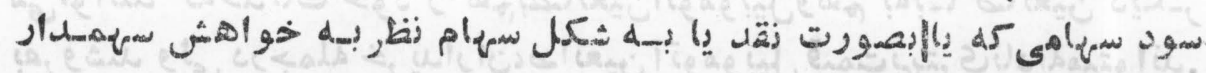

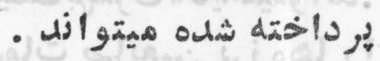
order bill of lading .

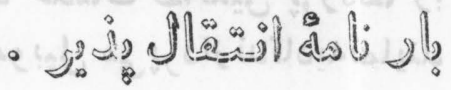

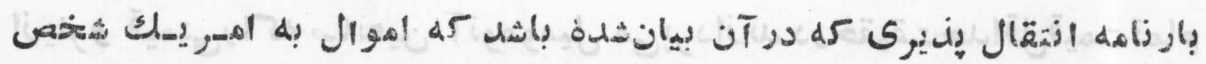

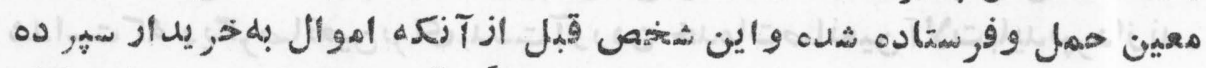

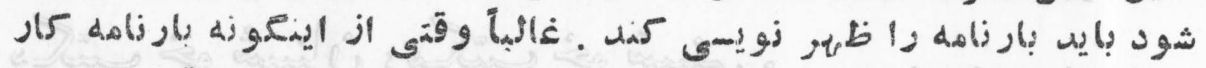

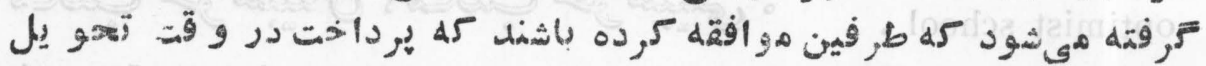

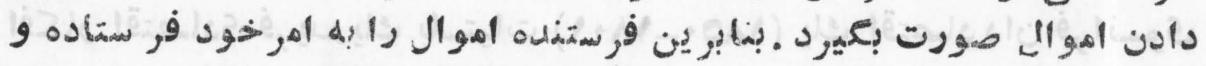

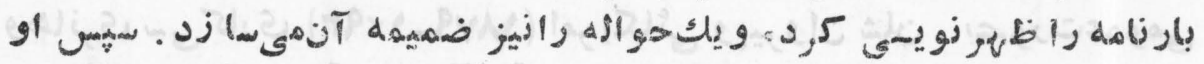

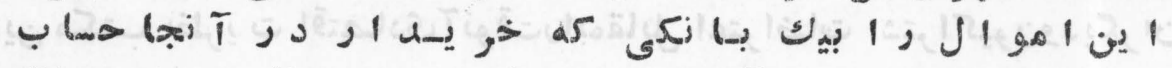

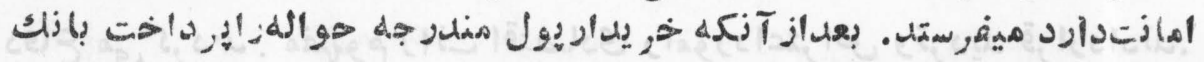

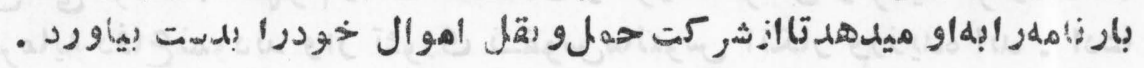

ordinary ass $t$.

$$
\text { - colocists }
$$

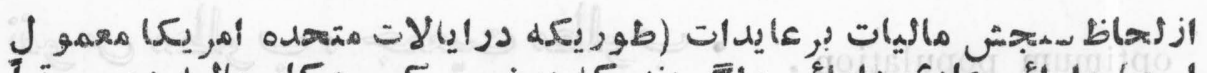

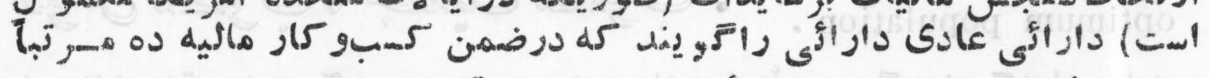

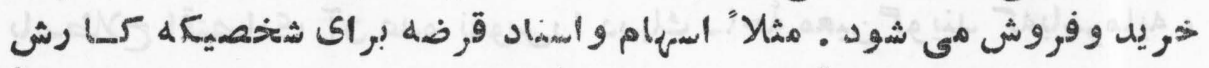

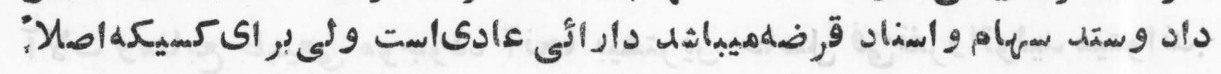

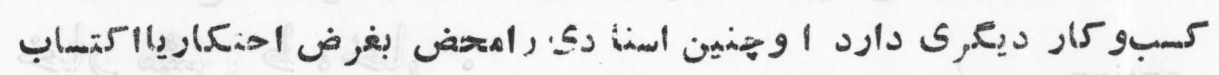

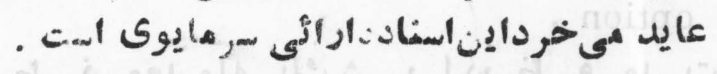

ordinary bill . - ل्वo

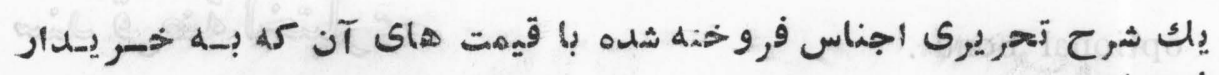

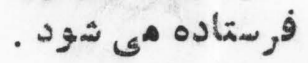

(FAP") 
ordinary rent.

ordinary stock.

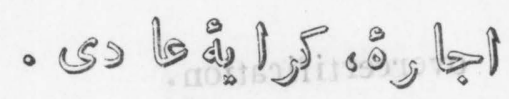

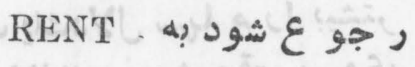
- csalopita

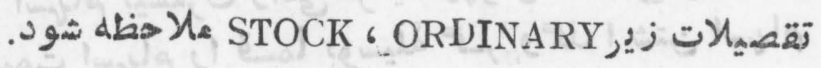

organic school.

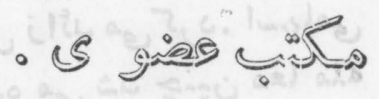

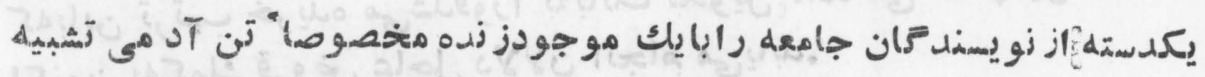

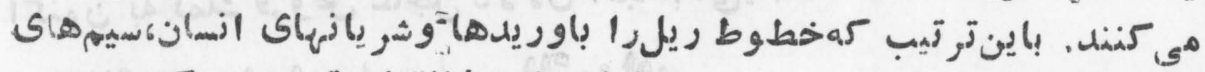

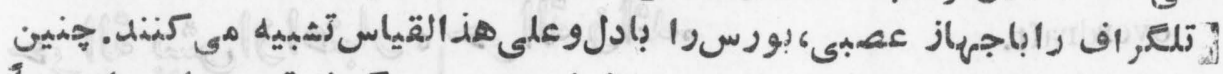

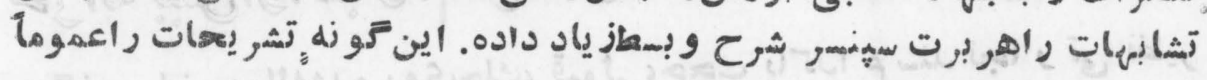
- ارزش علمهي أنميدهن

original-cost standard.

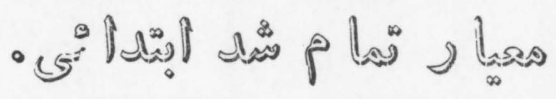

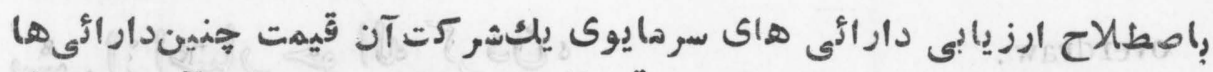

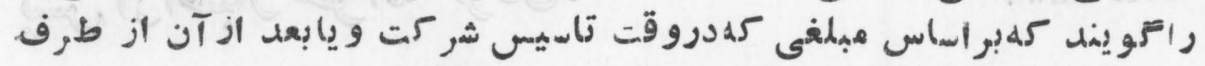

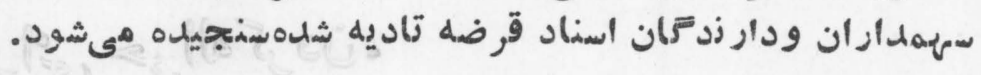

original-issue stock.

orthodox school.

out law strike.
- ज्ञ STOCK ، ORIGIN AL-ISSUE بوع شود به

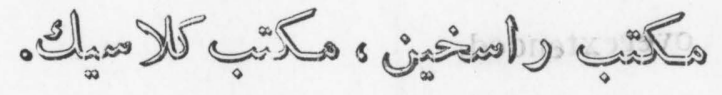
مر اجعه شود به CLASICAL SCHOOL ILLEGAL STRIKE. رجوع شودبه 
OVE

overcertification.

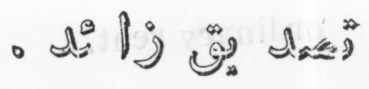

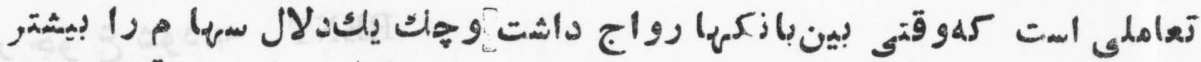

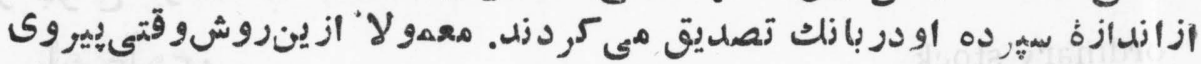

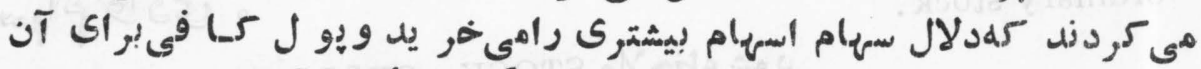

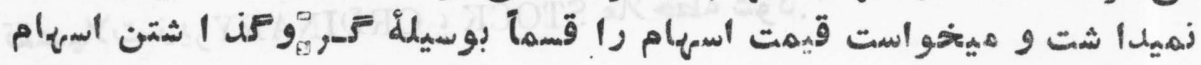

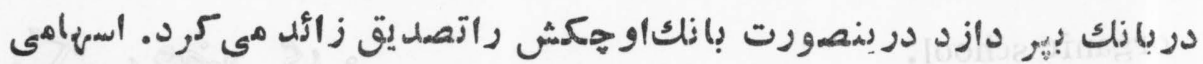

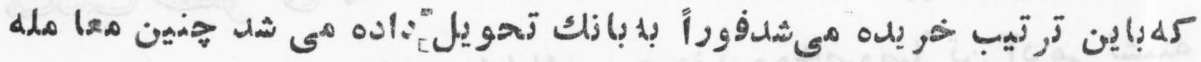

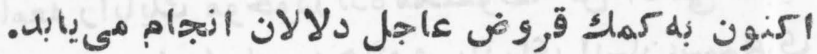

overdraft.

$$
\text { - वी }
$$

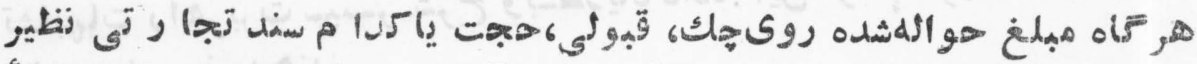

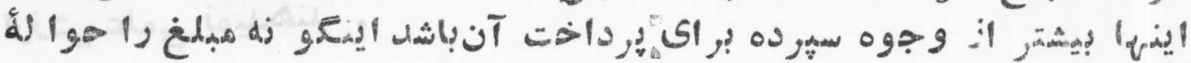

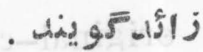

overdraw .

$$
\begin{aligned}
& \text { o }
\end{aligned}
$$

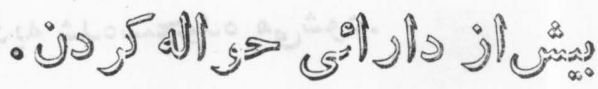

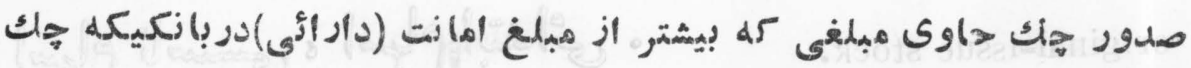
بالاى آن صادرتمرديدهي بأشده. $=$

orerextendcd.

$$
\text { - } d \int_{0}^{\circ} \int_{\infty} a_{a j}
$$

رجوع شودبه . رجو

overhead cost.

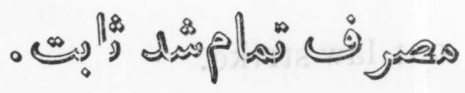
مIXED COST . مراجه شودبه 


\section{OVE}

overinvestment theory of the busines cycle. (S)

$$
\text { ०) }
$$

OVERSAVING THEORY OF THE BUSINESS CYCLE. مراجِ شهود به

overlying bond.

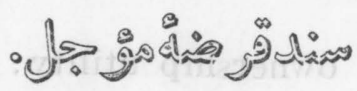

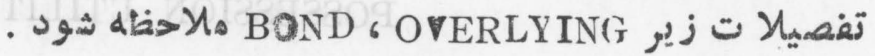

overproduction .

$$
\text { व }
$$

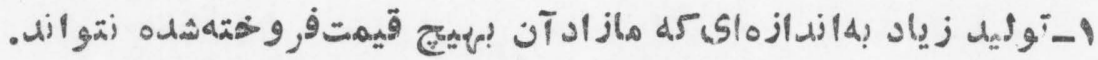

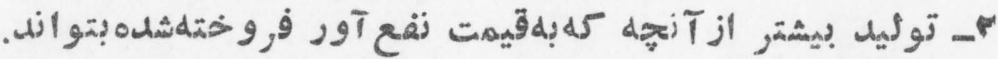

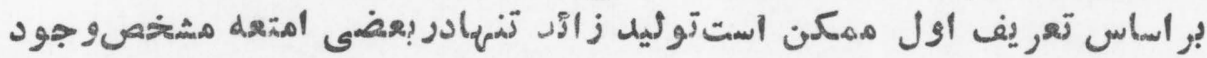

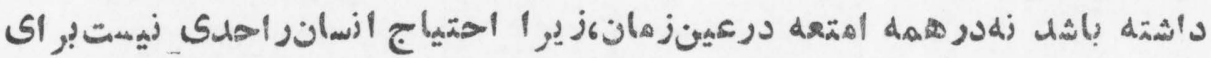

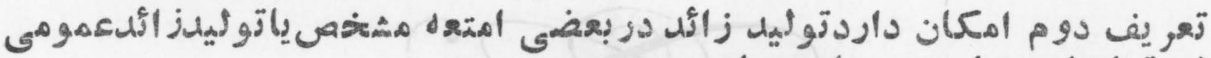

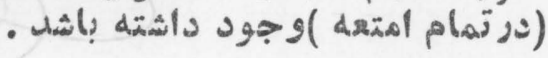

aversaving.

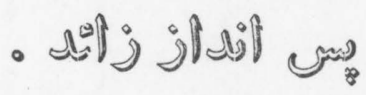

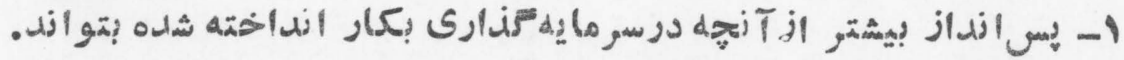

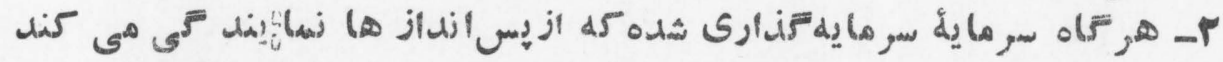

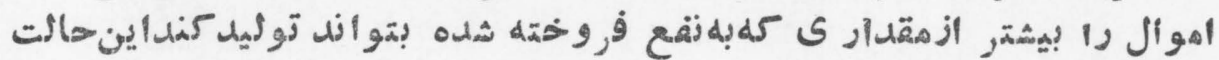

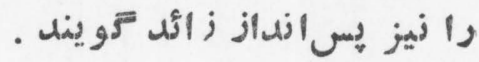

oversaving theory of the business cycle

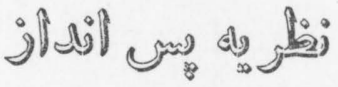

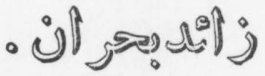

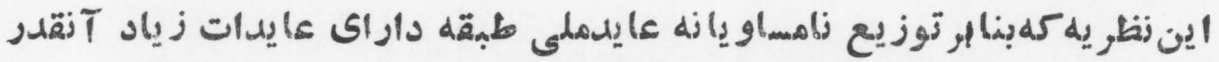

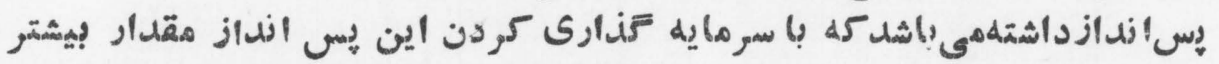

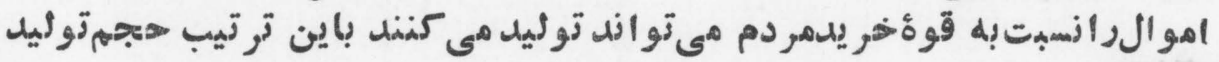


OVE

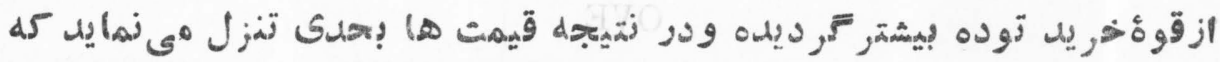

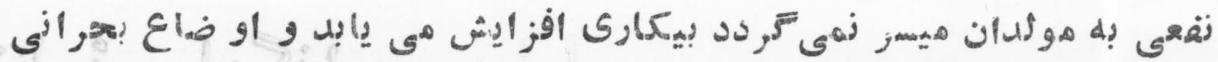

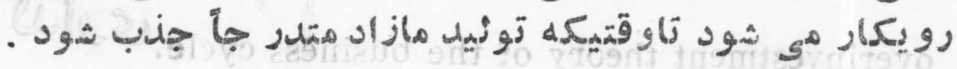

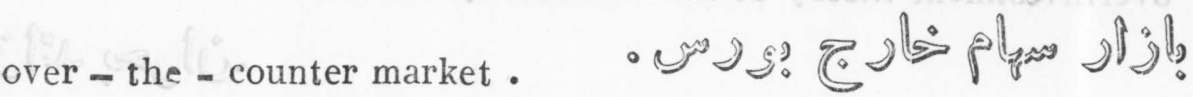

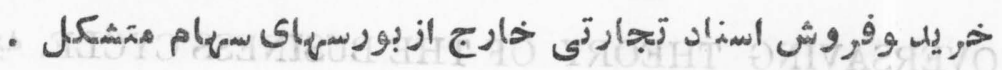
ownership utility.

- Ella

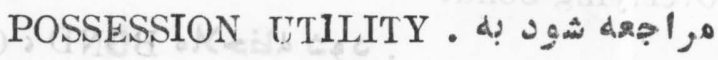




\section{$\mathrm{P}$}

pace setter.

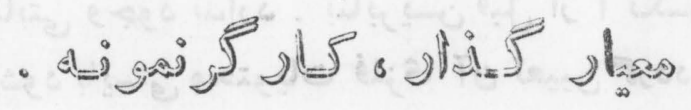

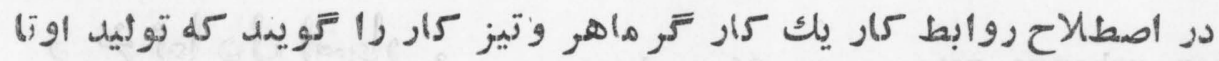

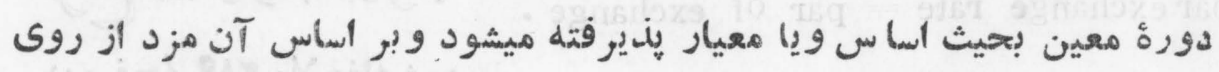

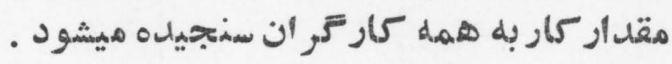

paid-in surplus .

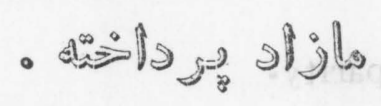

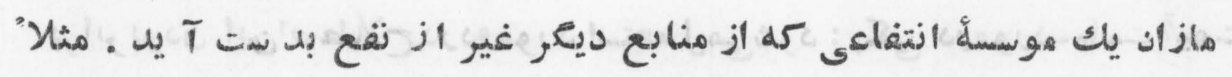

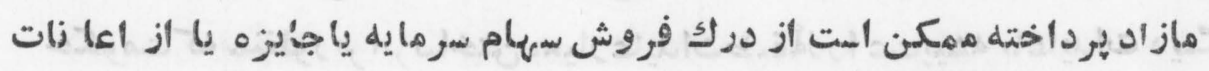

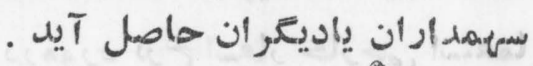
paid-up stock.

$$
\text { - OU }
$$

STOCK , PAID - UP • تفصيلات زير
paper money -

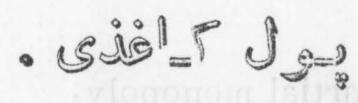

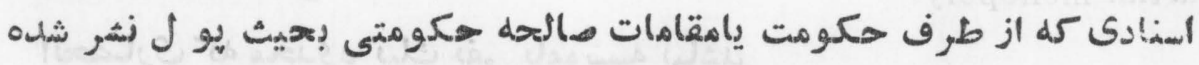

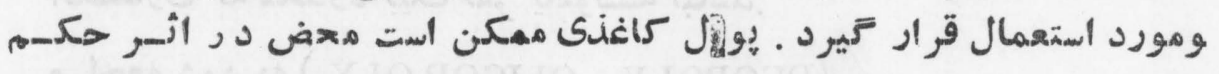

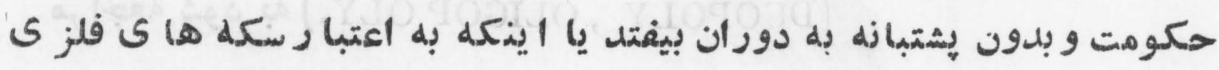

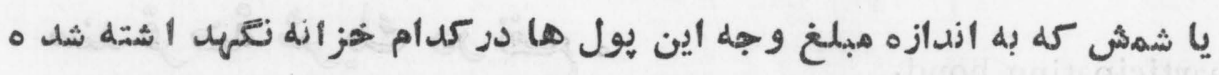

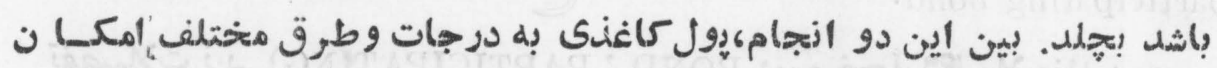
دارد تضـمين Fرديده باشلد . 
parallel standards .

- जjo

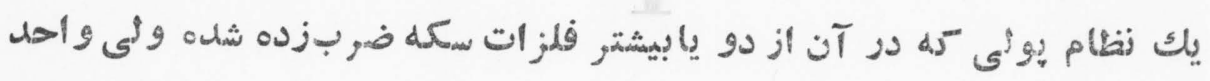

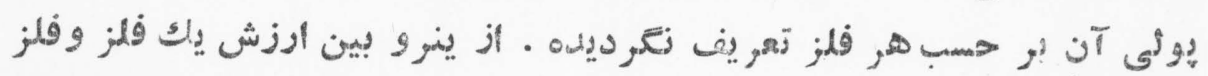

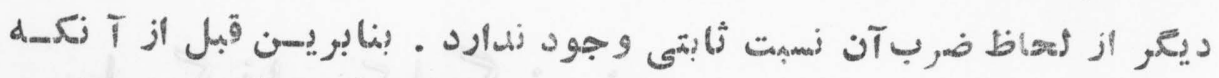

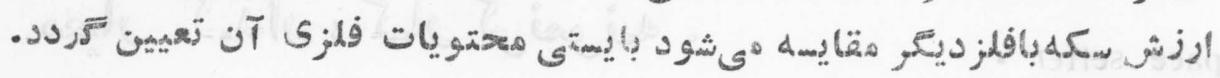

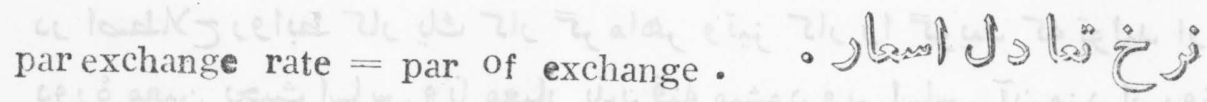
- د ش

parity

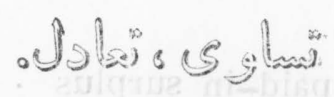

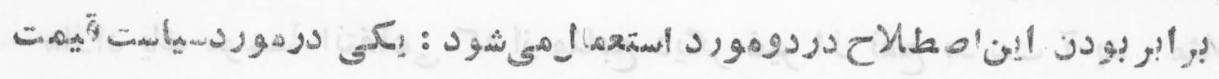

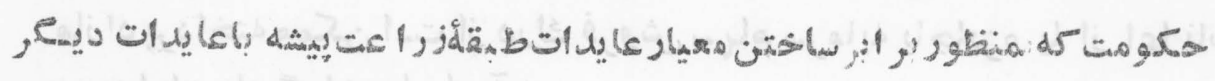

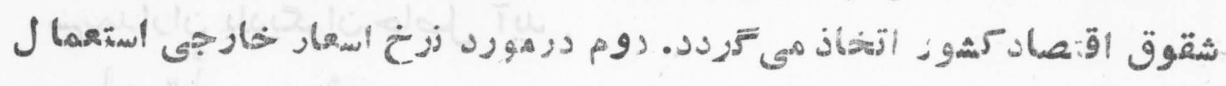

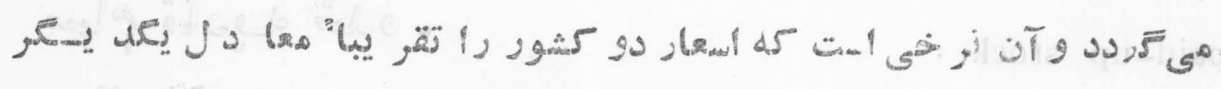

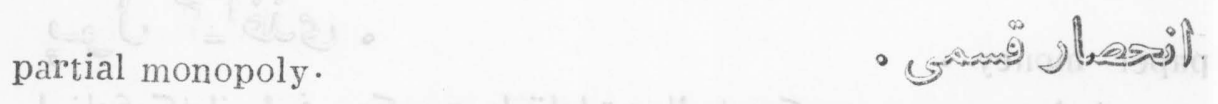

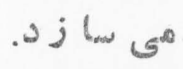
أill

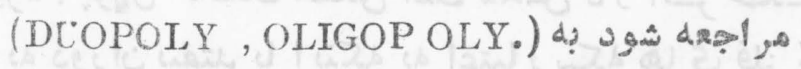
participating bond.

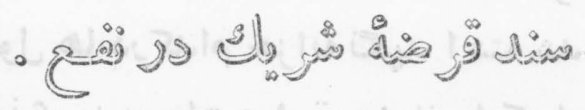

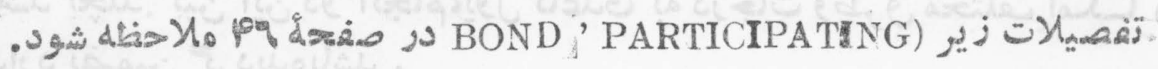




\section{$a^{2}$}

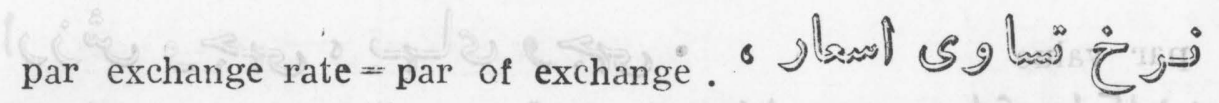

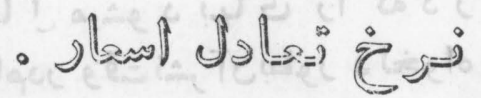

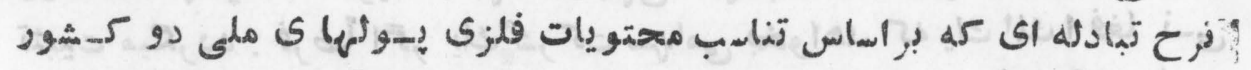

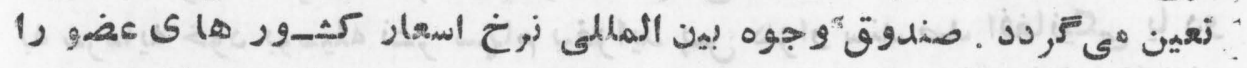

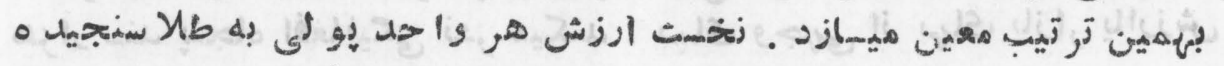

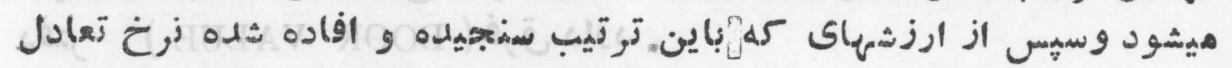

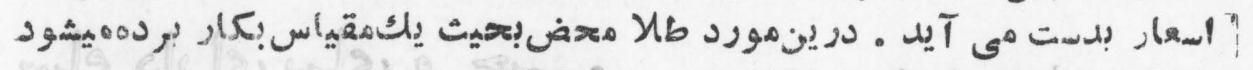
:

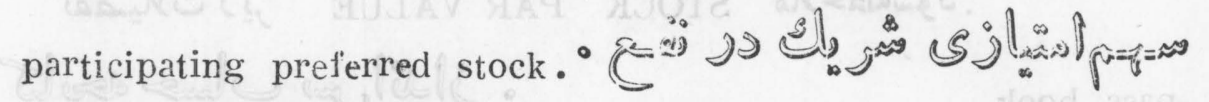

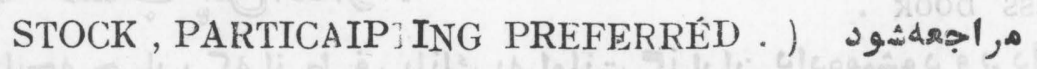

participation certificate .

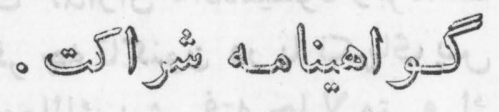

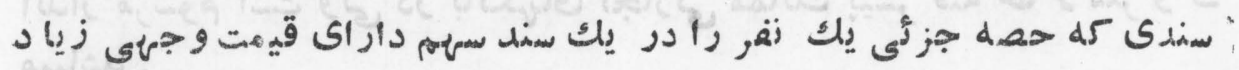

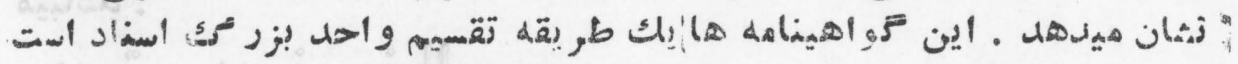

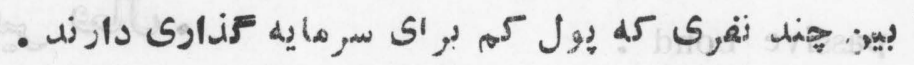
partnership .

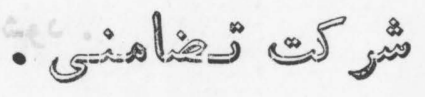

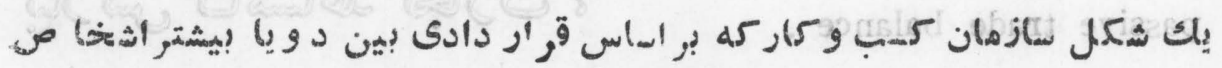

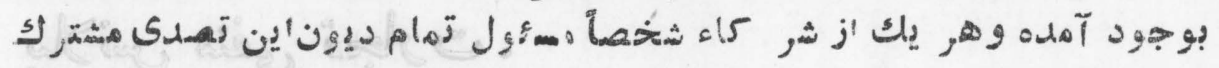
ميهاثلد . 


\section{$P A^{R}$}

part - paid stock .

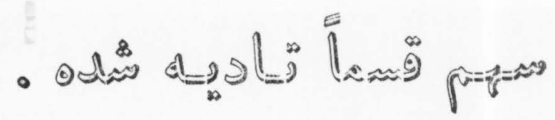

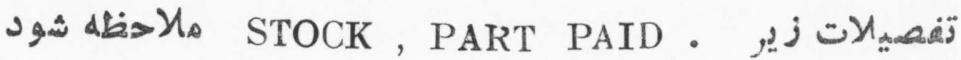

par value .

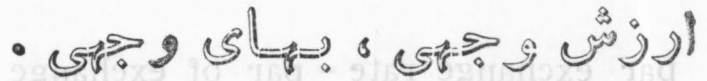

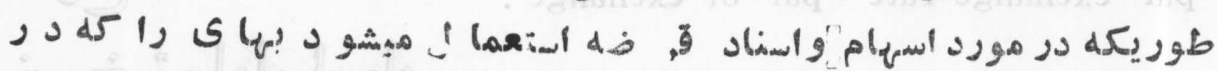

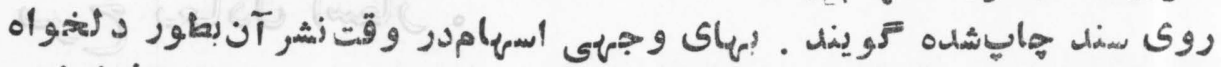

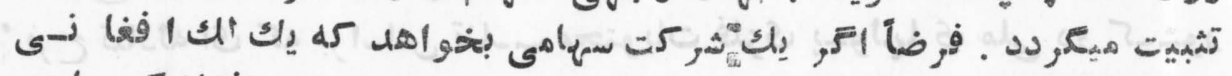

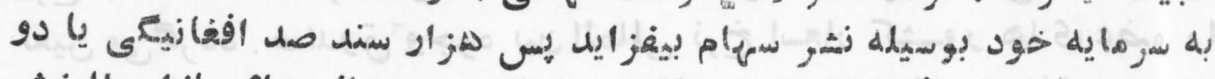

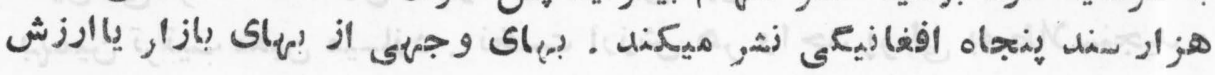

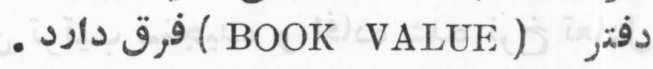
par-value stock.

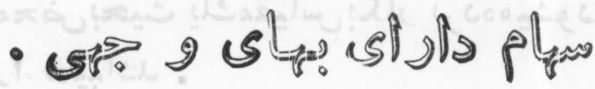

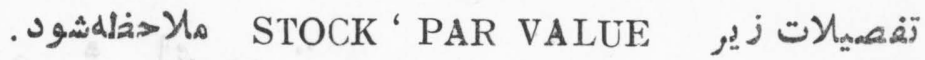

pass book .

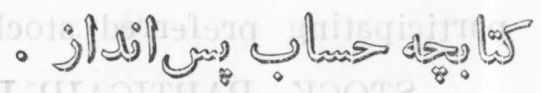

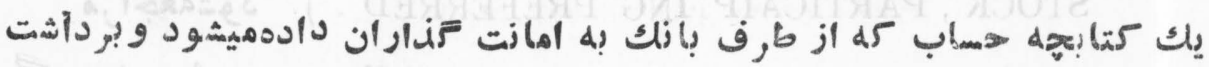

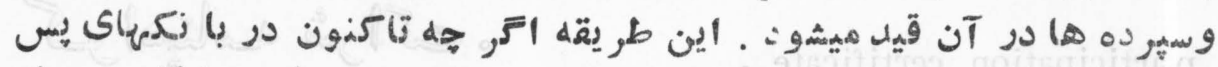

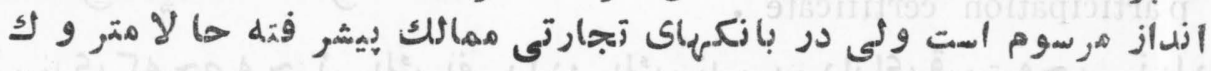
ميباشلد . ميدات passive bond .

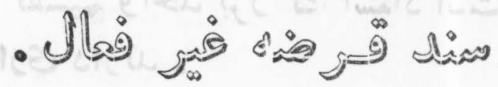

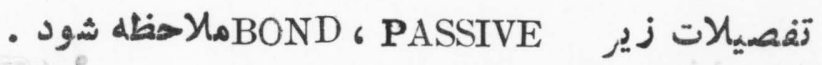
passive trade balance.

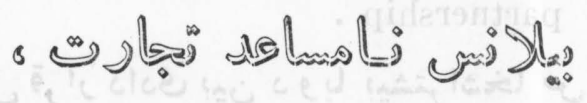

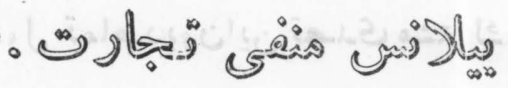

UNFAVORABLE BALANCE OF TRADE. مراجعه شود به 


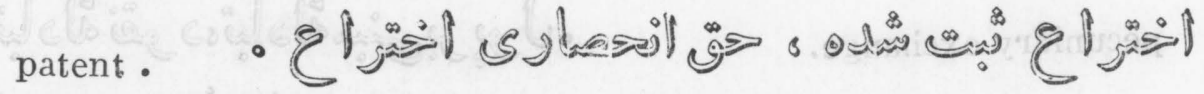

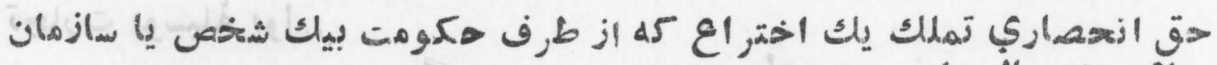

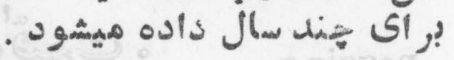

paternalism .

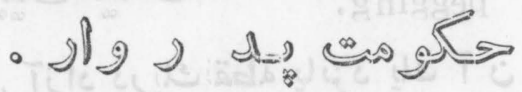

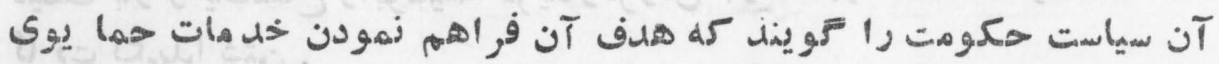

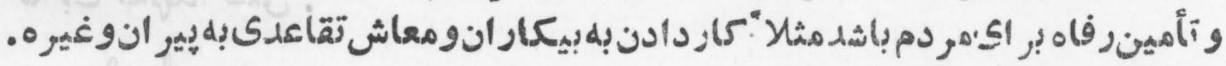

pawnbroker.

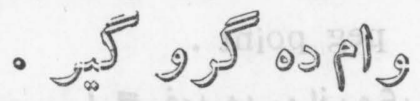

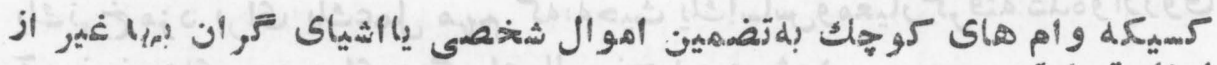

payee.

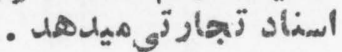

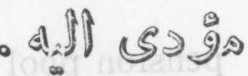
كسيكهة به الويول تأديه مى شود.

payment bill . - ज尚 تفصيلات زير (BILL ، PAYMENT) ديل ه شود . pay-roll tax .

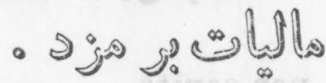

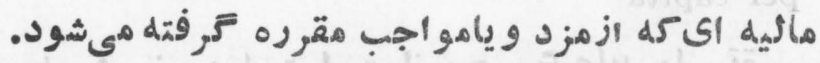
peasant movement .

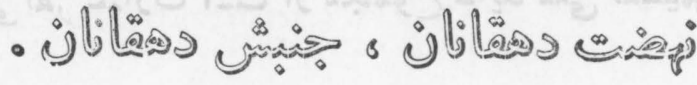

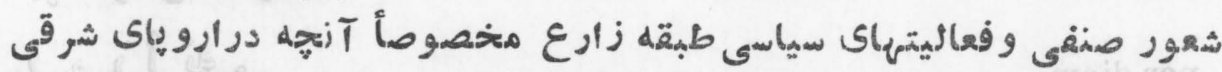

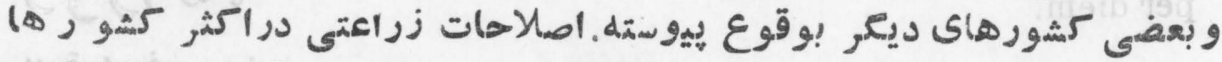

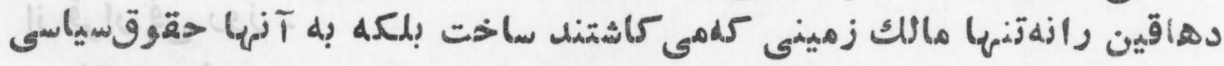

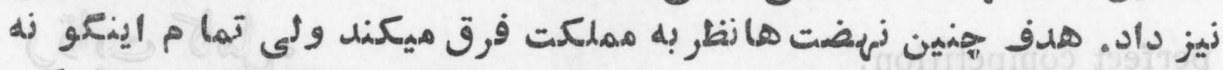

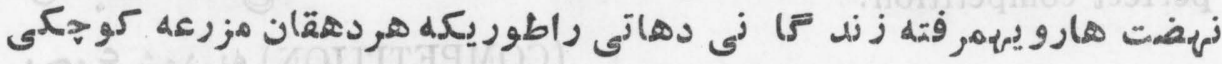

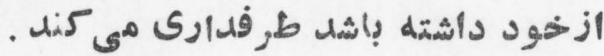


pecuniary exchange.

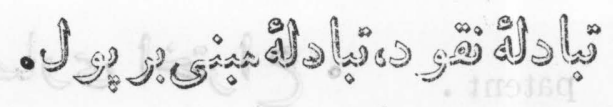

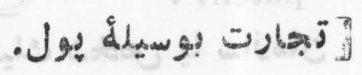

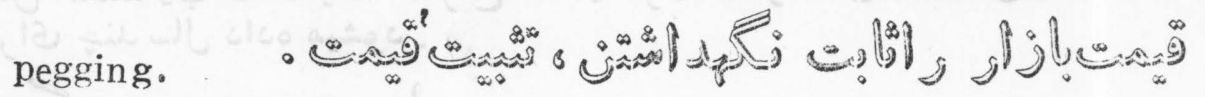

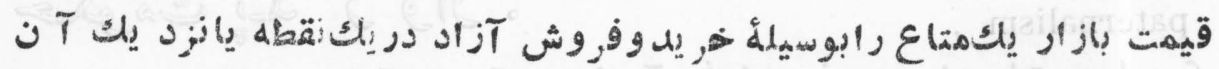

peg point .

$$
\text { - آ }
$$

- هoja

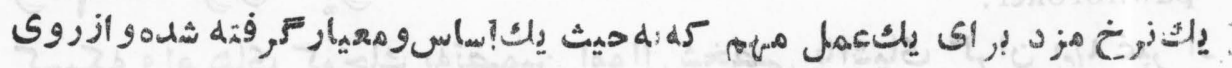

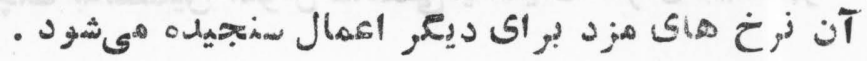

pension pool .

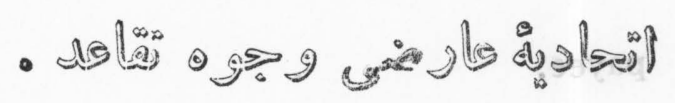

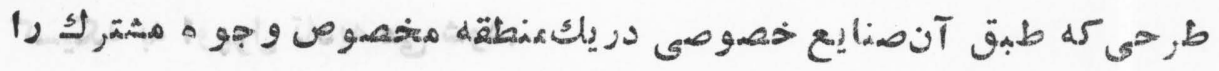

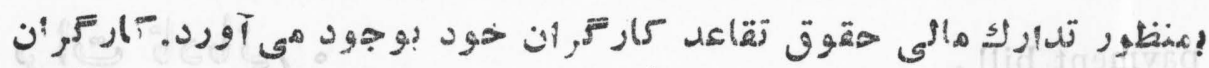

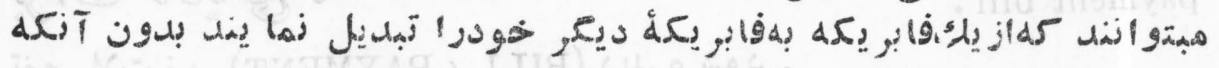

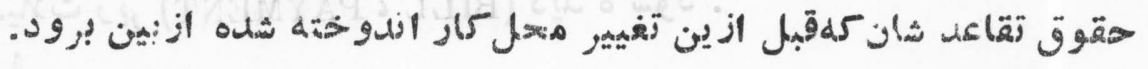

\section{per capita}

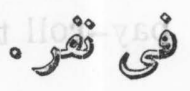

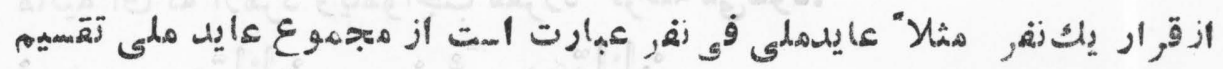

per diem.

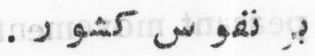

$$
\begin{aligned}
& \text { - di } \\
& \text { از قور في روز - }
\end{aligned}
$$

perfect competition.

- Colle

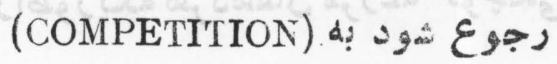




\section{PER}

permissive wage-adjustment clause.

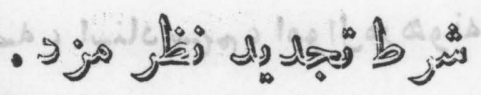

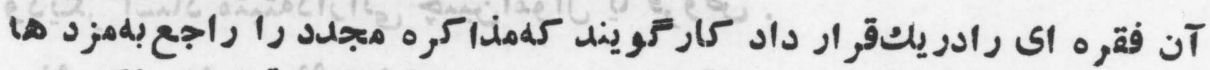

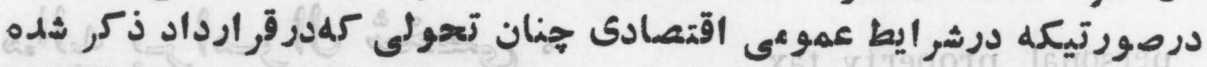

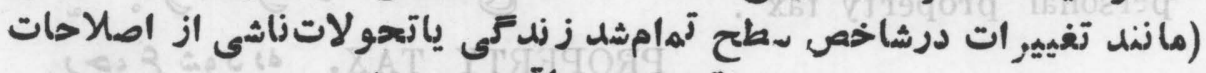

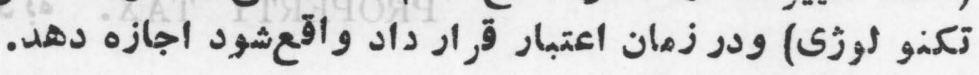

permit .

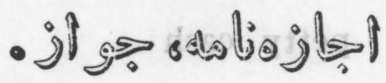

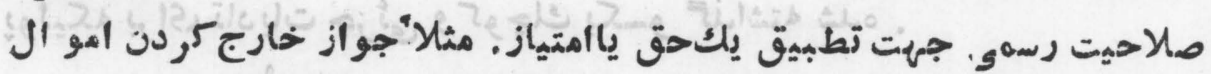

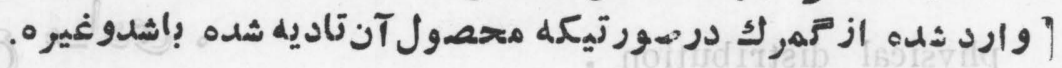

perpetual bond. - ज得

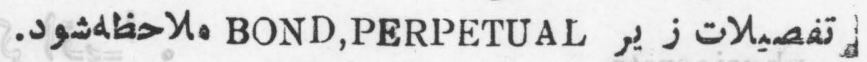

perquisite.

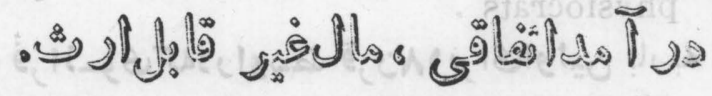

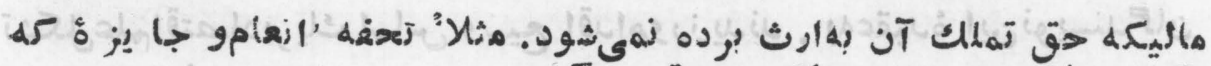

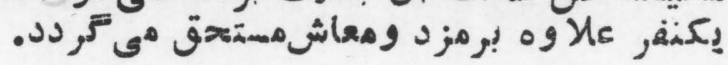

perisonal aecount .

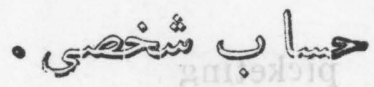

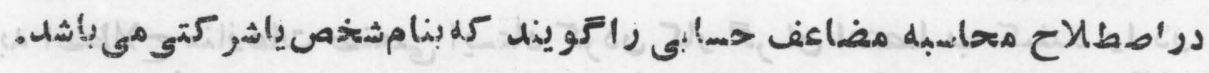
personal distribution.

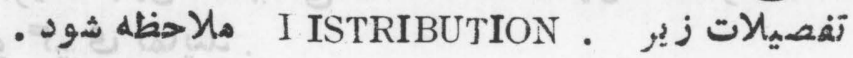

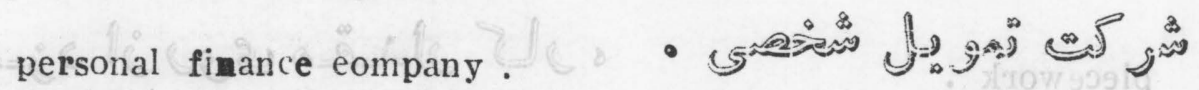

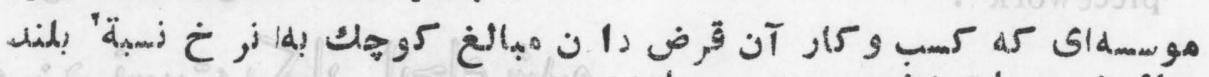

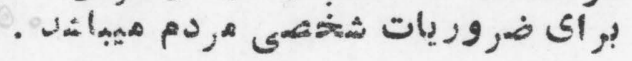

personal preperty.

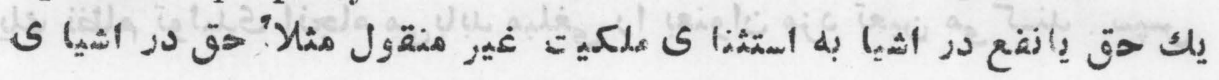




\section{PI R}

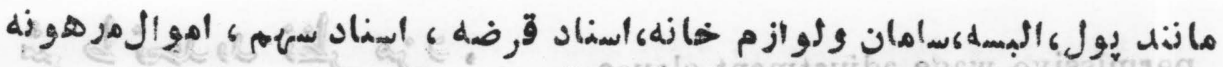

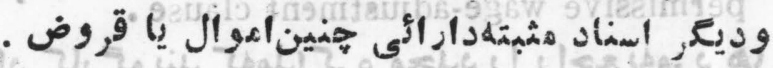

personal property tax.

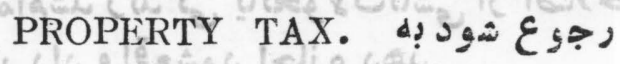

petty cash .

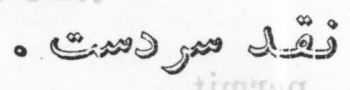

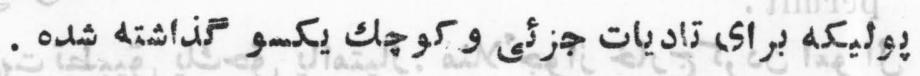

physical distribution

- $C S S=0 \quad \varepsilon=0 ;=0$

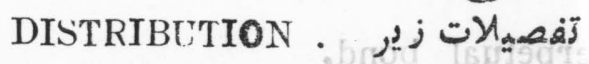

physiocrats.

$$
\text { - }=\text { = }
$$

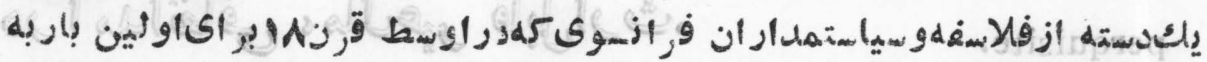

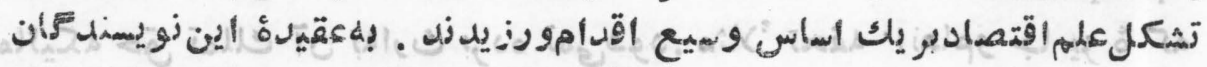

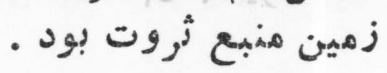

picketing

()

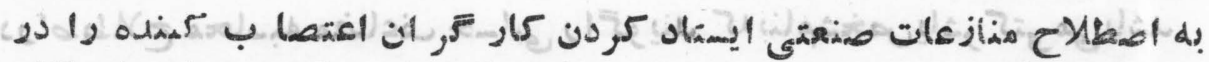

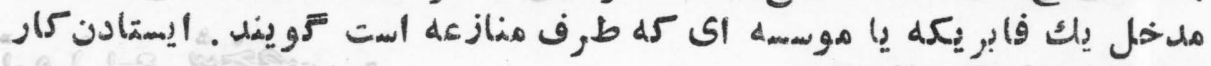

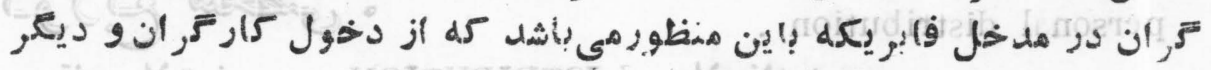

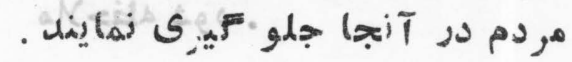

piecework .

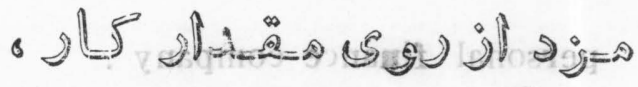

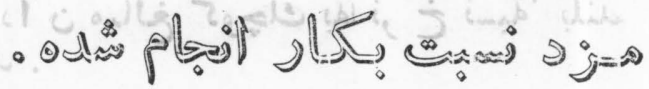

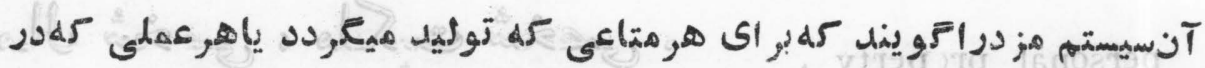

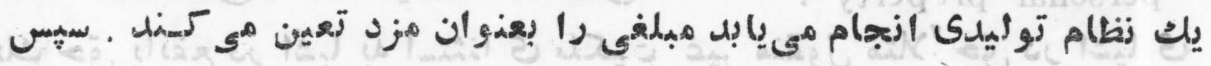


PLA

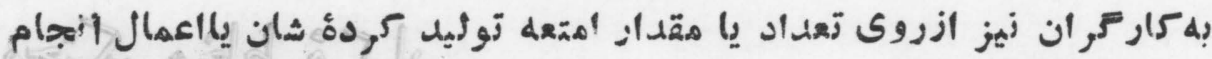

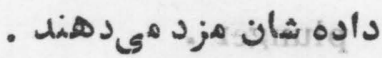
pit . - जo 30

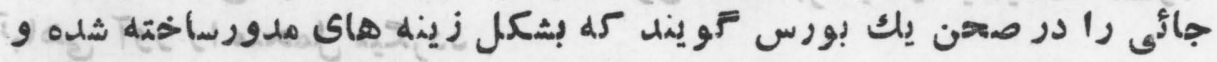

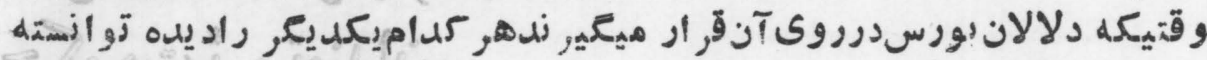

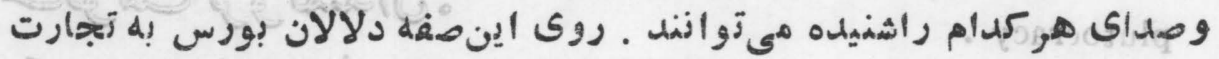

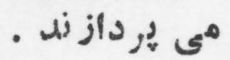

place utility .

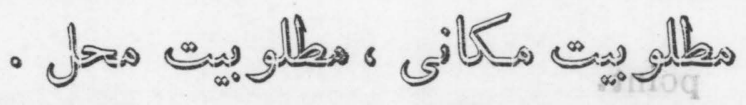

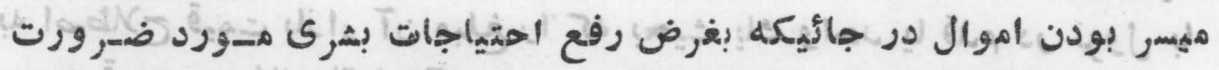

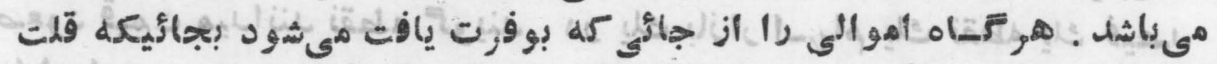

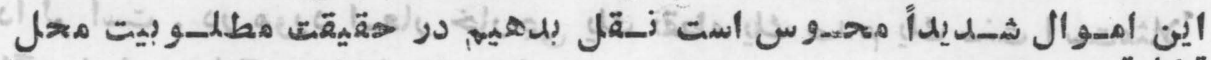
تخخليق مى شود .

plain bond.

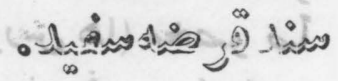

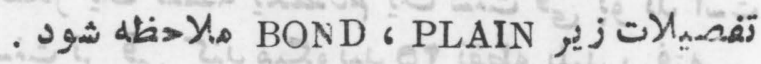

plane of living .

planning .

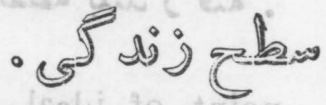
LEVEL OF LIVING נجوع شود

- जsil i עo

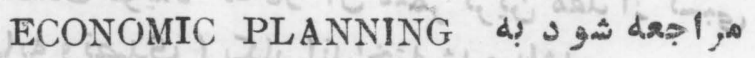

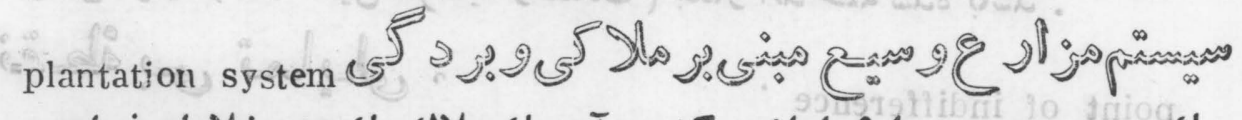

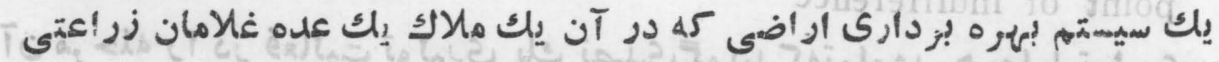

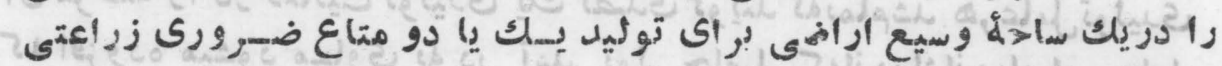

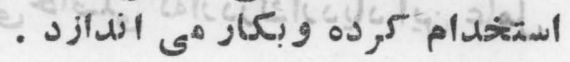


UPL

plunger .

- $15: 3$ bli:a

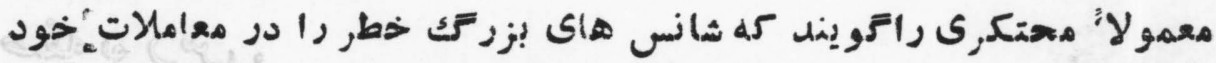

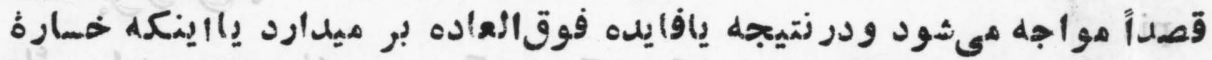

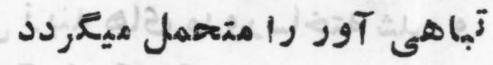

plutorracy .

- जी

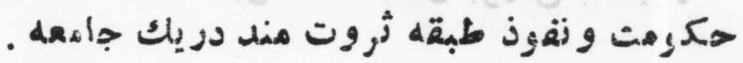
pcint.

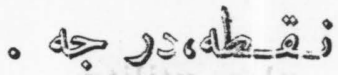

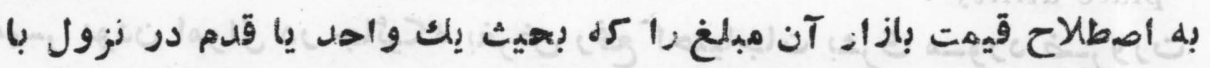

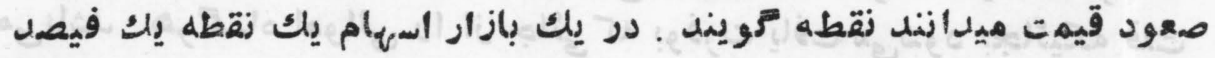

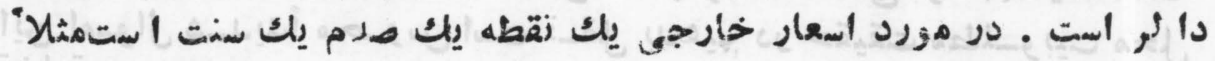

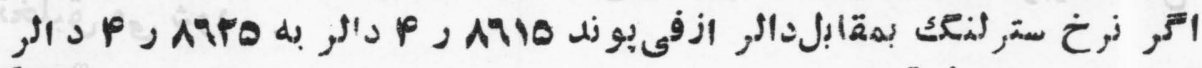

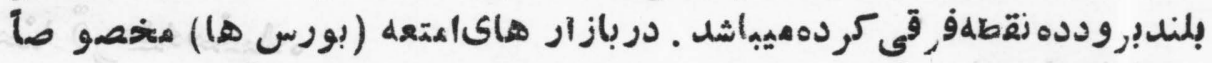

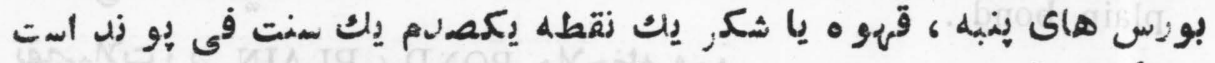

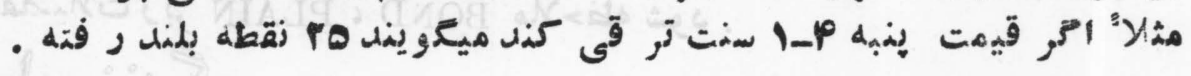
point of ideal proportion .

- ب

- بg

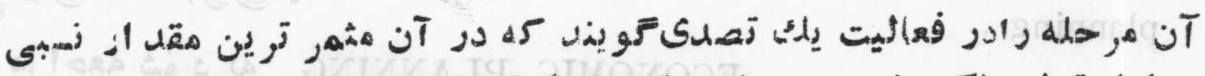

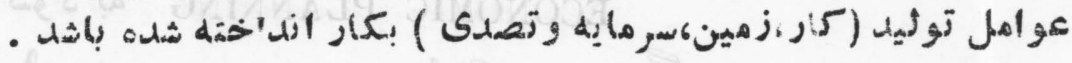
point of indifference

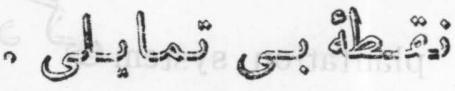

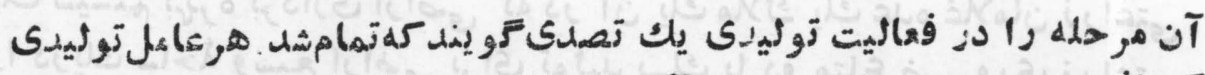

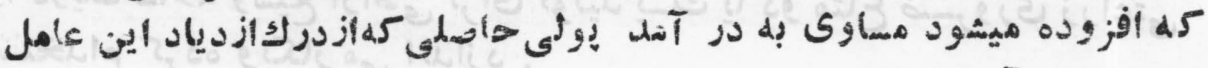

بوجود هو آيد ميشأشلد .

"PQ⿱一⿻上丨 


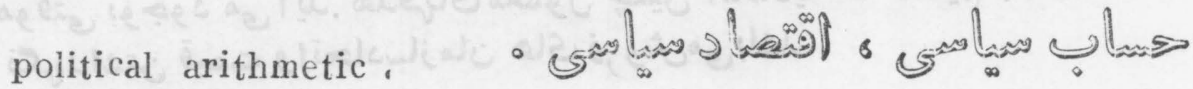

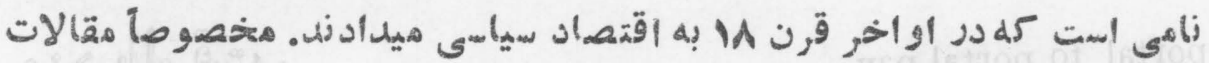

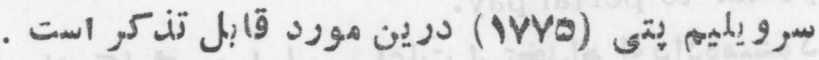

political economy .

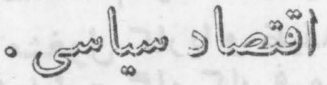

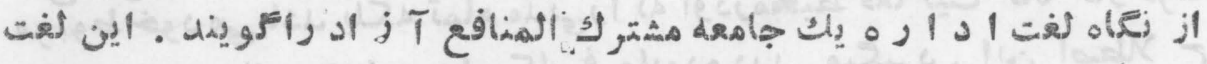

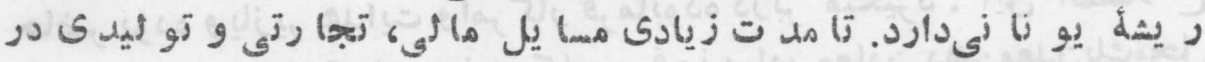

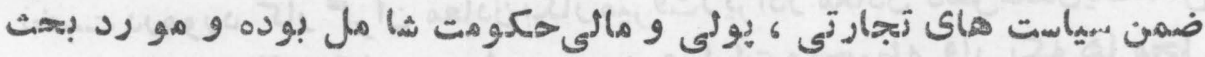

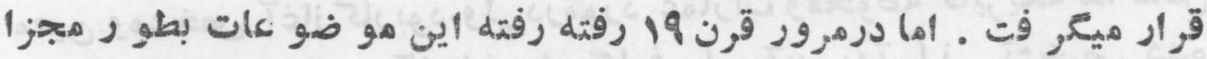

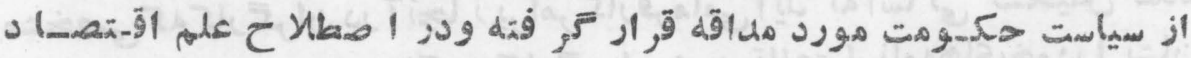

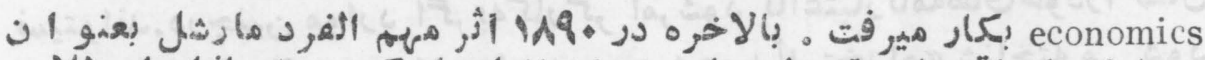

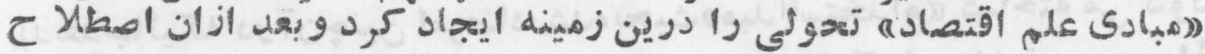

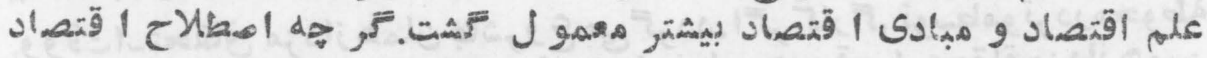

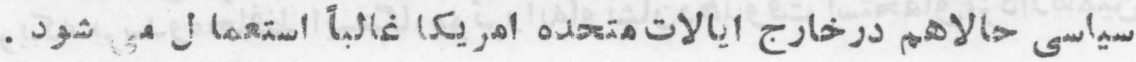

poll tax

$$
\text { - Aij }
$$

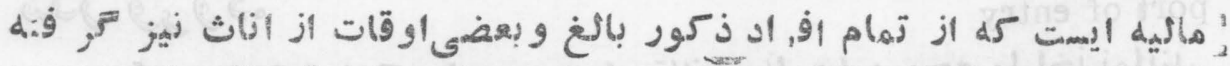

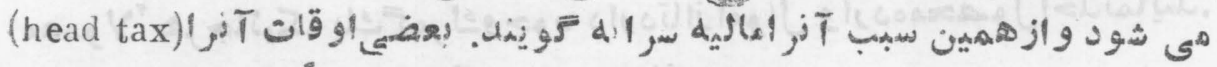

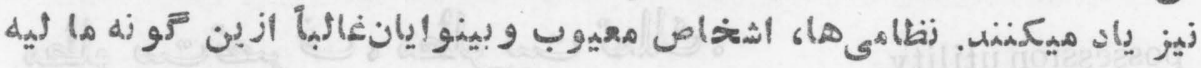

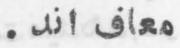

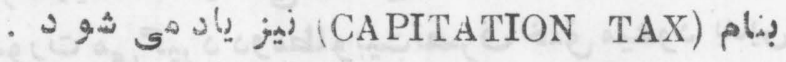

polymetallism-

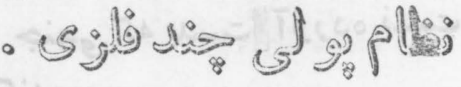

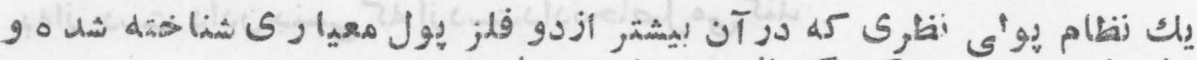

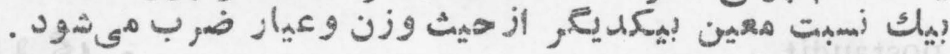

poal.

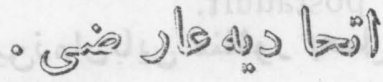

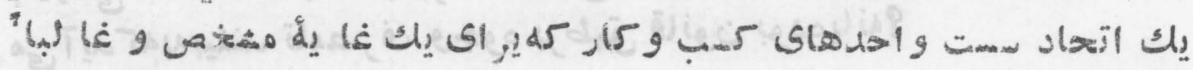




\section{POR}

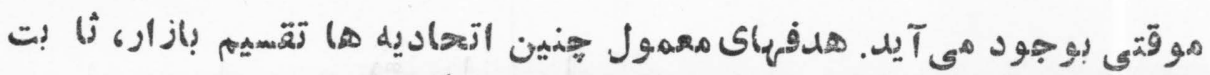

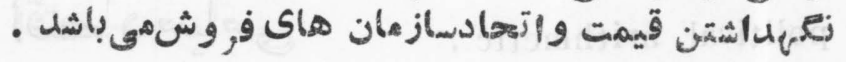

portal to portal pay.

$$
\text { - هو }
$$

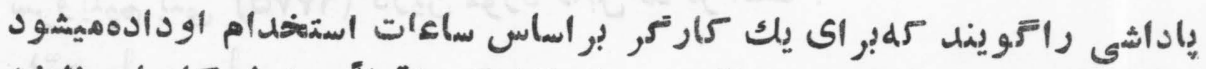

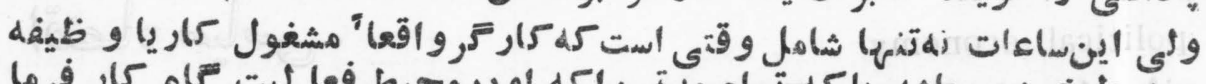

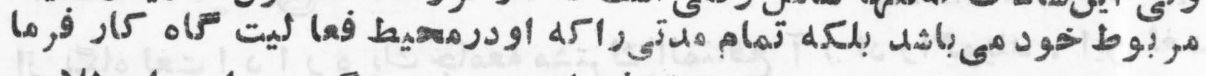

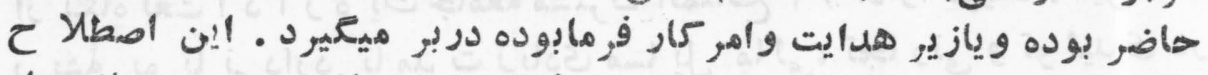

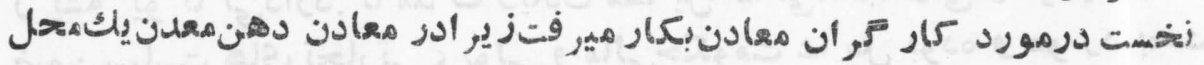

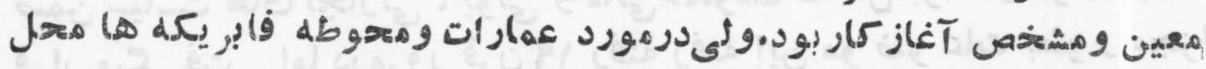

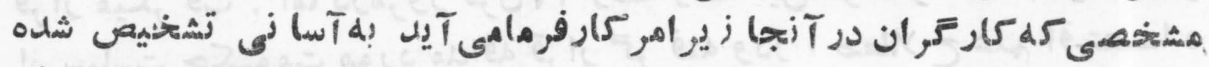

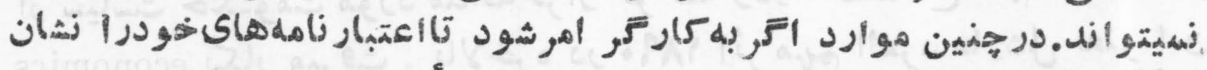

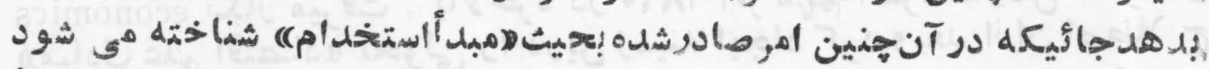

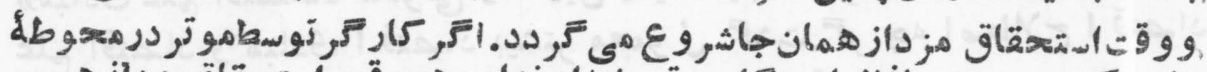

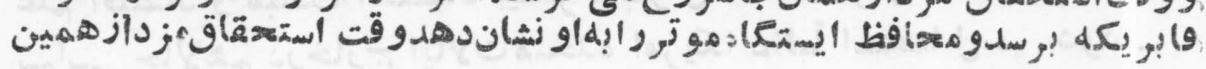
روهنمائى آغازمي يابلد.

port of entry

$$
.99890000
$$

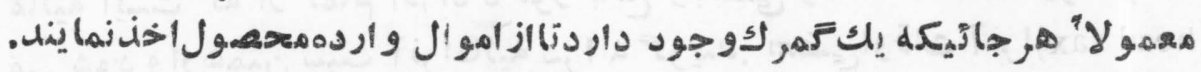
possession utility.

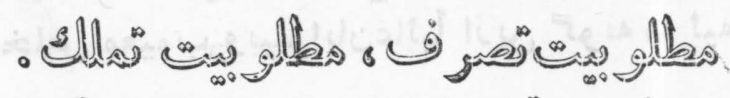

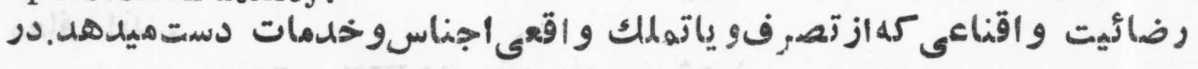

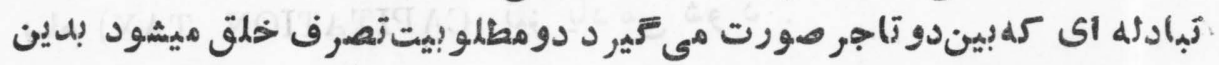

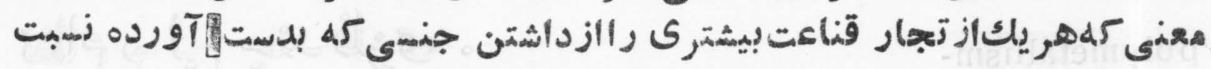

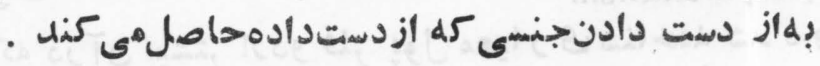

postaudit.

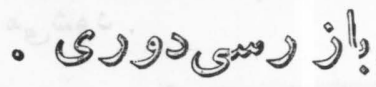

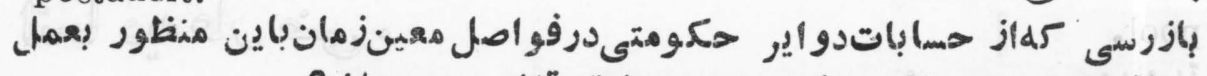

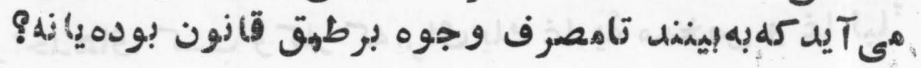

(सQA) 
potential demand.

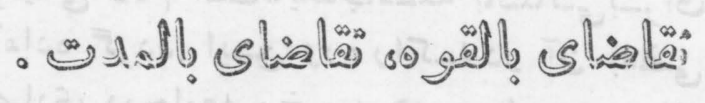

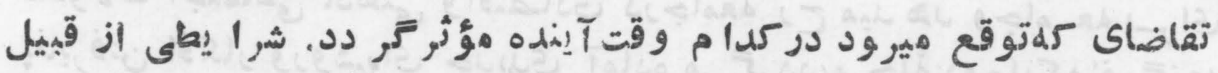

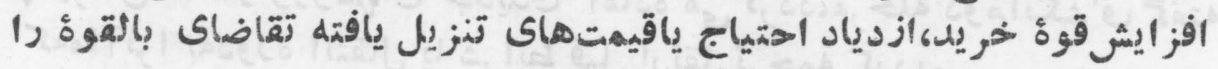

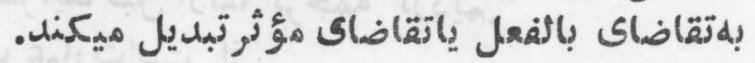

potential stock.

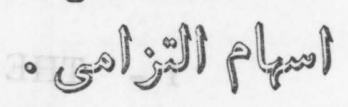

تفصيلاتزير U. STOCK , POTENTIAL

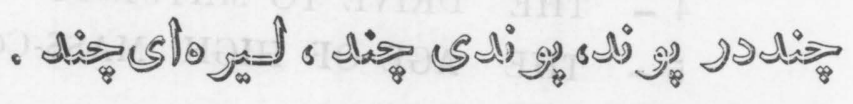
poundage .

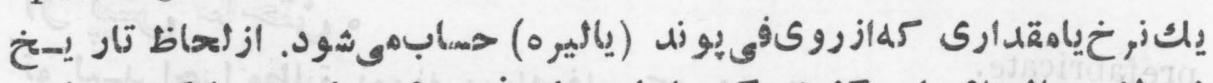

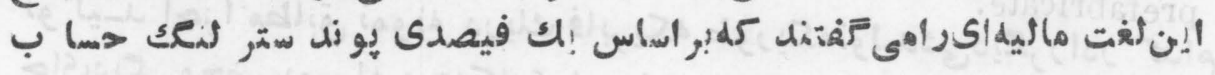

preaudit .

$$
\begin{aligned}
& \text {. }
\end{aligned}
$$

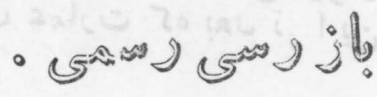

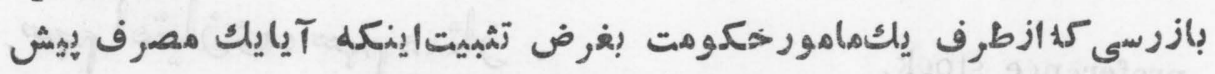

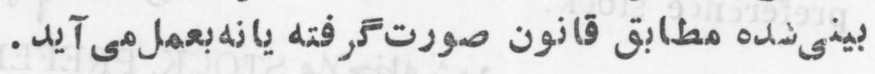

preclusive buying •

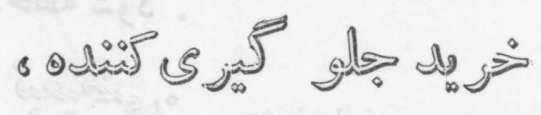

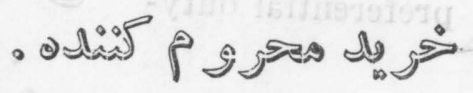

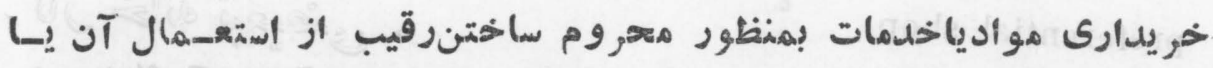

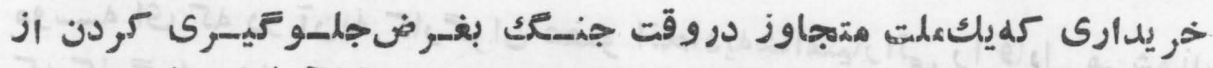

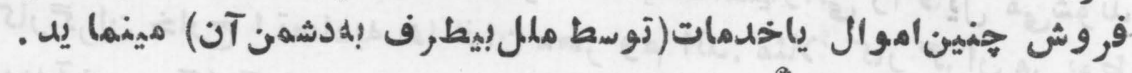

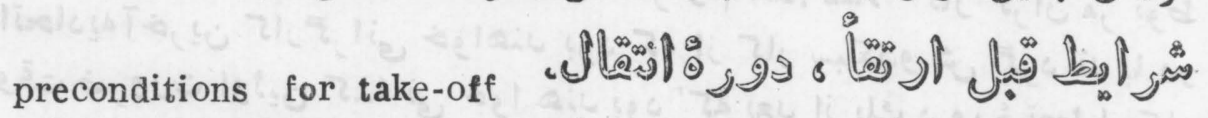

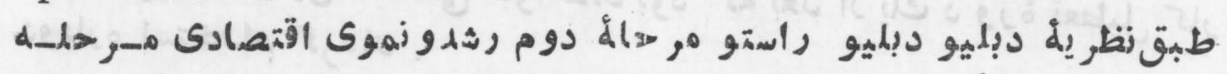

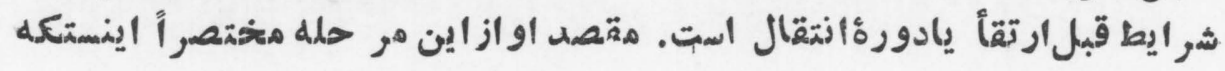




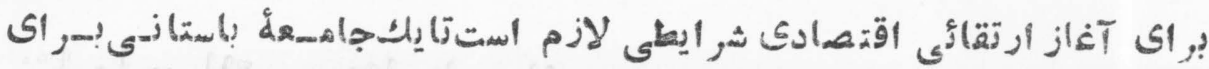

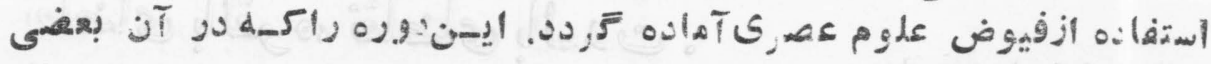

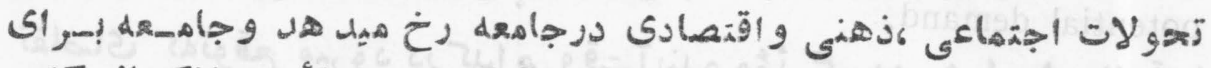

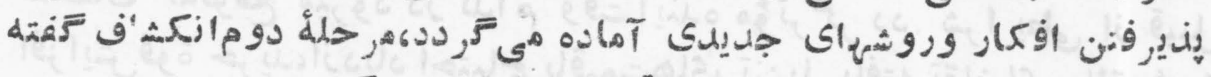

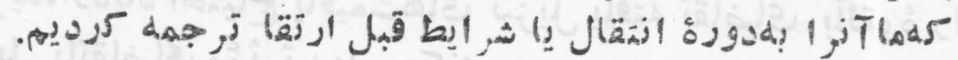

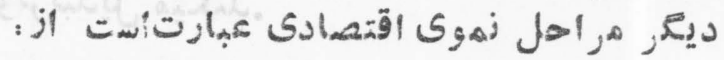

1 - THE TRADITIONAL SOCIETY.

3 - THE TAKE-OFF

4 - THE DRIVE TO MATURITY

5 - THE AGE OF HIGH MASS-CONSUMPTION .

prefabricate.

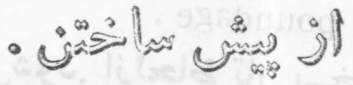

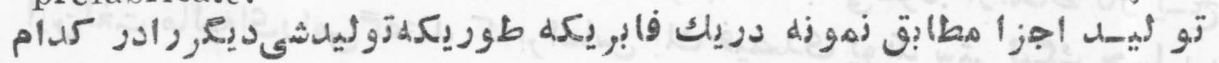

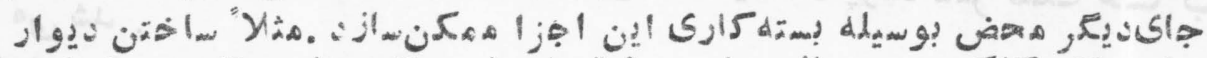

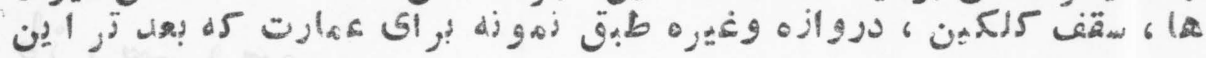

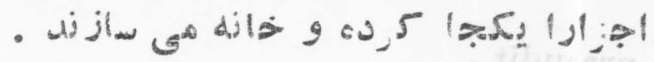

preference stock.

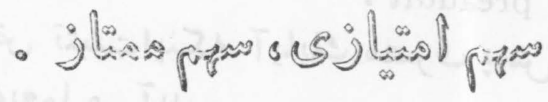

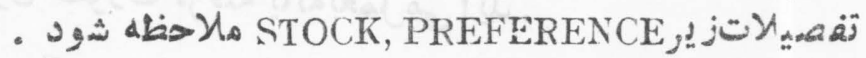

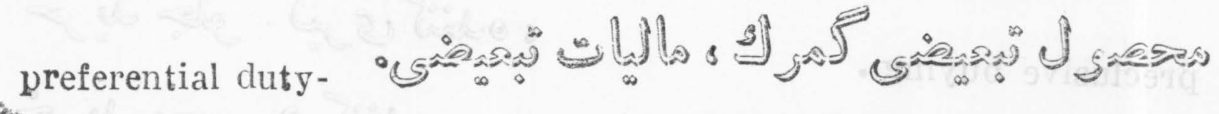
مر أجad DIFEERENTIAL DUTY d preferential shop :

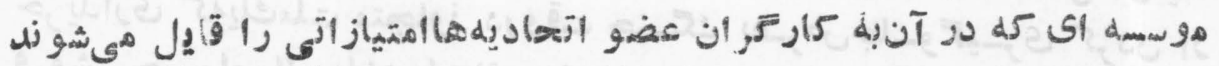
اتحار

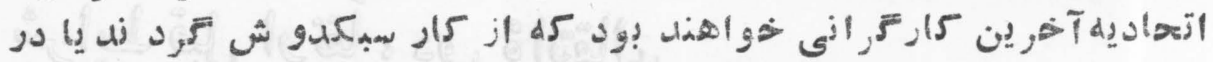

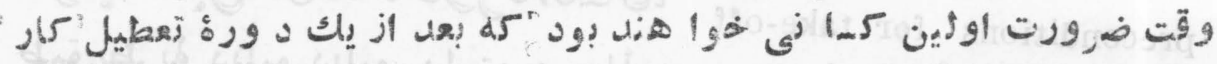

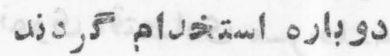


preferred stock.

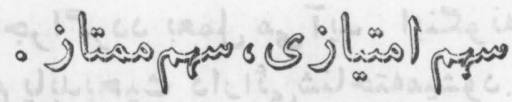

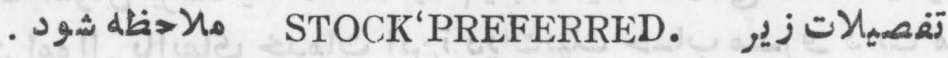

premium

$$
\text { - A }
$$

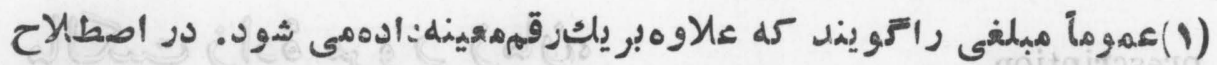

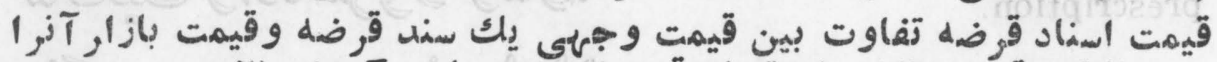

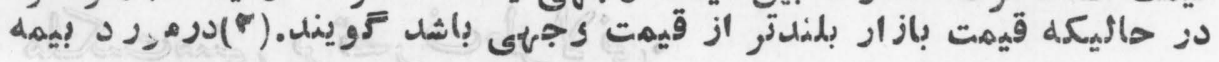

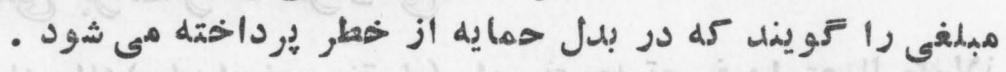

premium for risk. - bْ

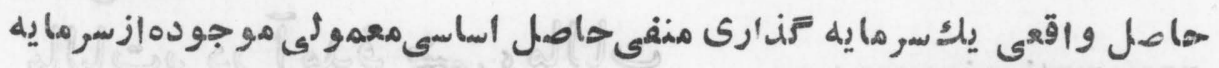
.

premium pay

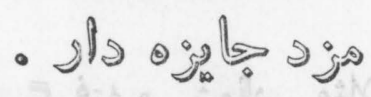

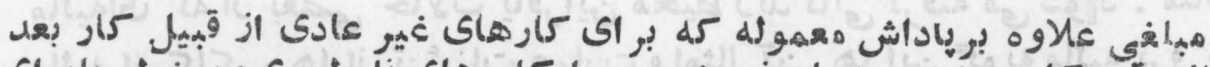

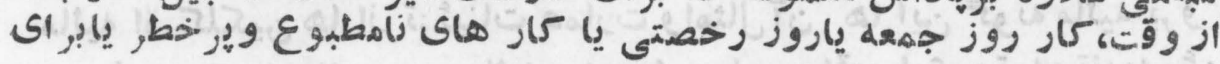

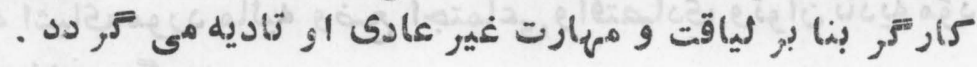

premium rate

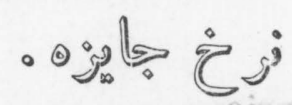

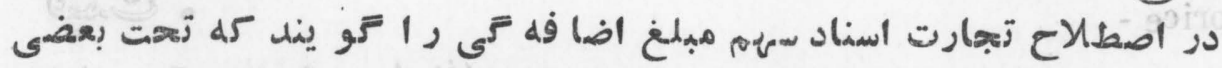

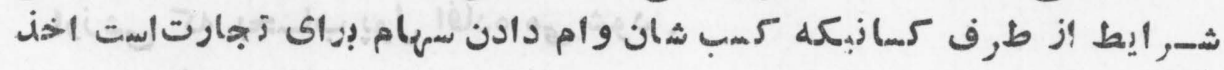

premium stock.

$$
\text { - مئردد . }
$$

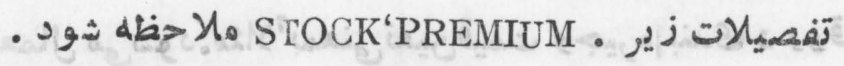

prepaid expense.

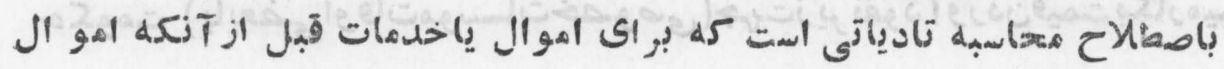




\section{PRE}

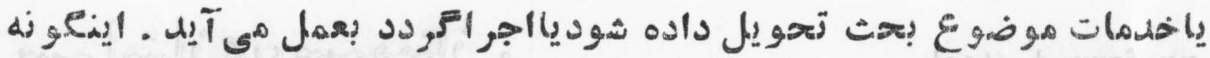

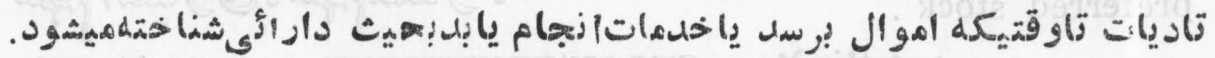

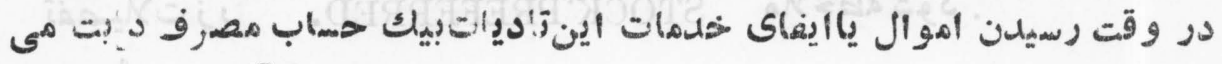
a

prescription.

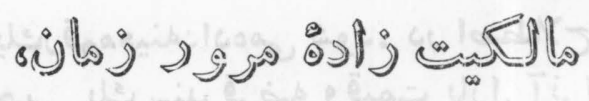

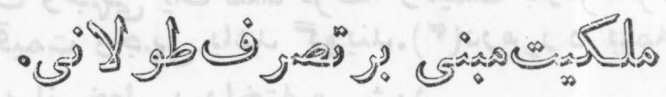

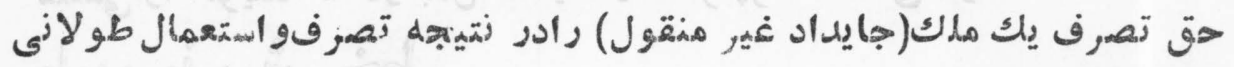

presumptive income tax.

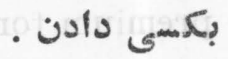

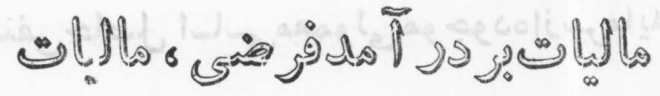

$$
\begin{aligned}
& \text { • }
\end{aligned}
$$

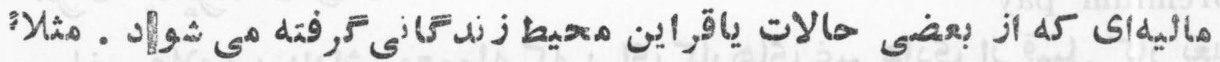

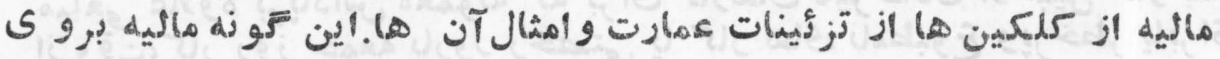

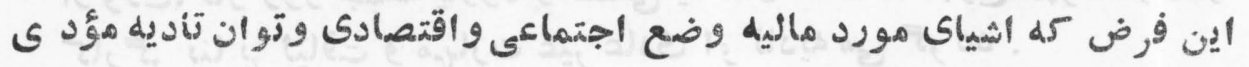

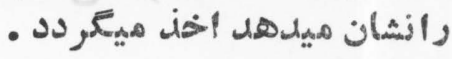

price -

$$
\text { - }
$$

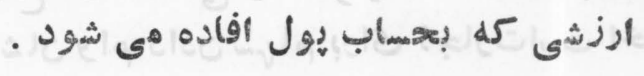

price control .

$$
\text { - }
$$

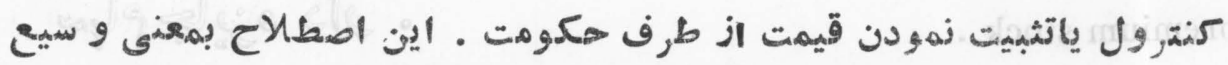

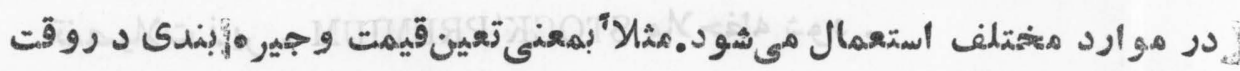

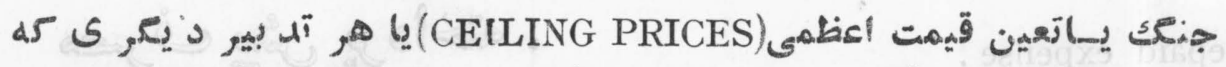

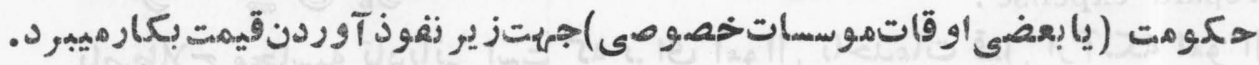




\section{PRI}

price fixing .

- ज)lis

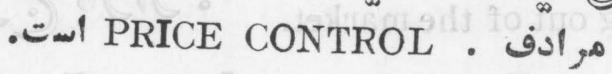

price level .

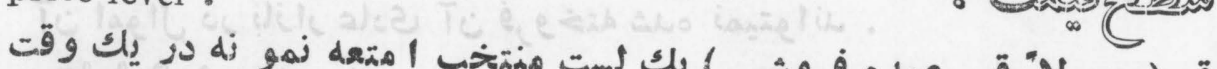

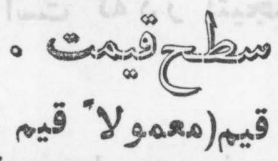

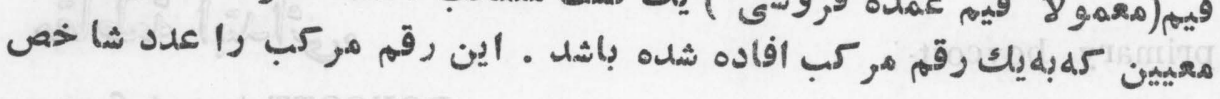
ميعوبئل . معين.

price loco .

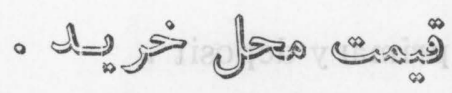

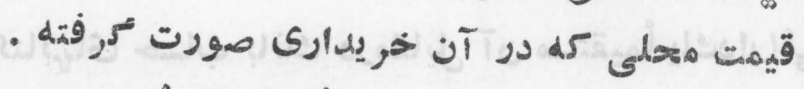

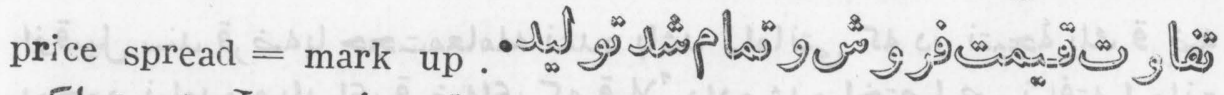

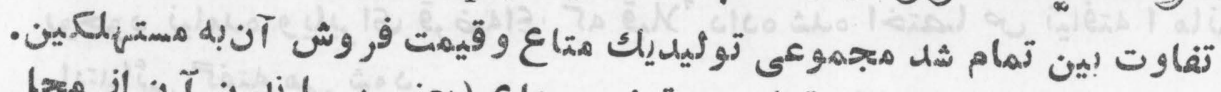

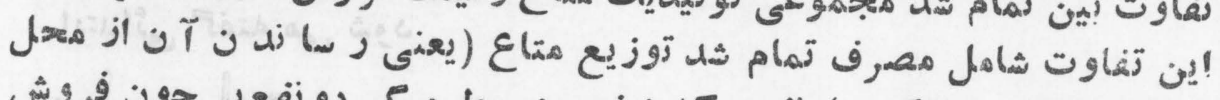

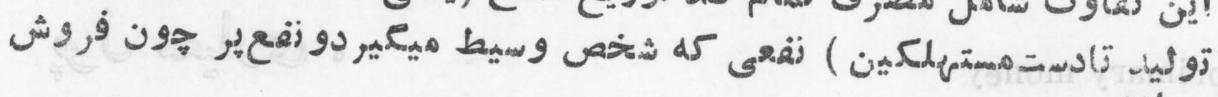

price support .

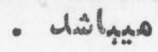

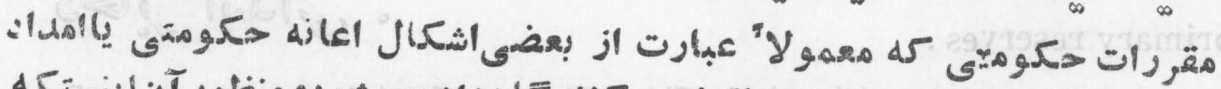

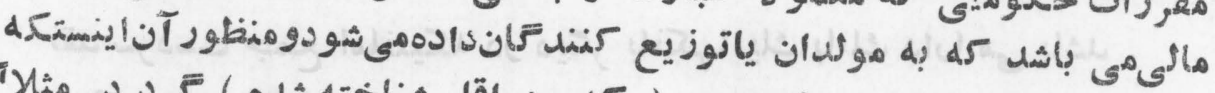

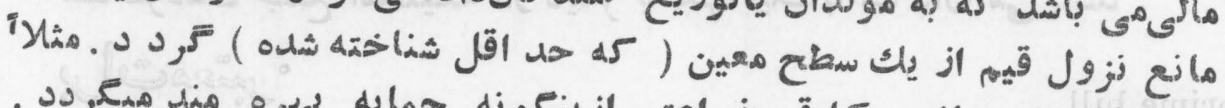

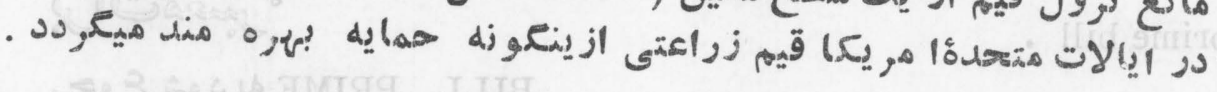

price system.

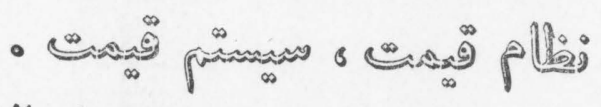

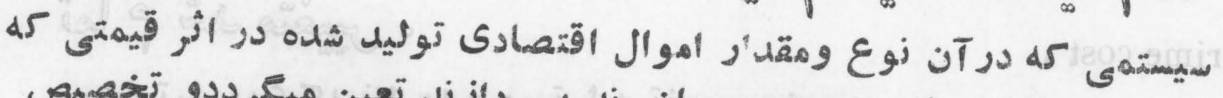

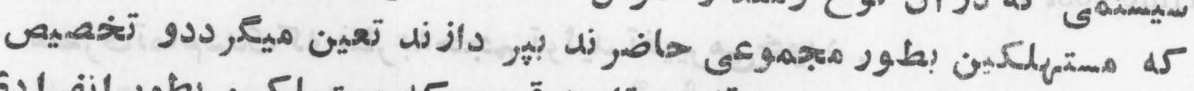

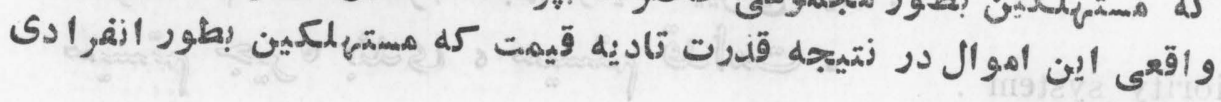

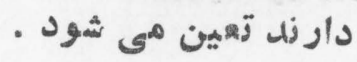




\section{PRI}

pricing out of the market.

$$
\text { - गj! C }
$$

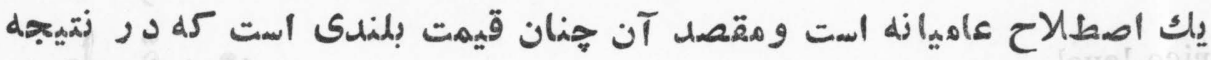
آن اموال در بإزار عادى آن فروخته شلهه زهيتوانله .

primary boycott.

जी

BOFCOTT رجوع شون به

primary deposit .

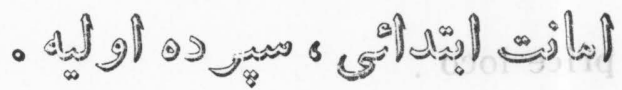

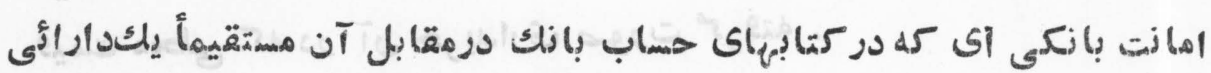

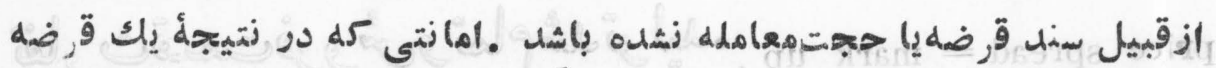

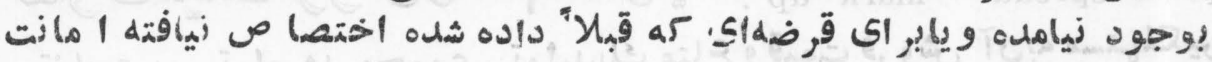

primary money

$$
\begin{aligned}
& \text { إبتاءأئى } \\
& \text { - SJlasa Jo }
\end{aligned}
$$

STANDARD MONEY- رجوع شودإه

- ज्ञ

primary reserves .

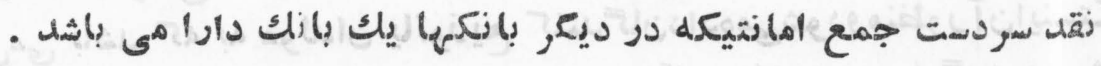

prime bill .

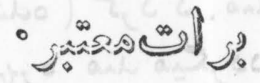

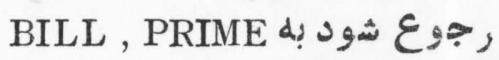

prime cost .

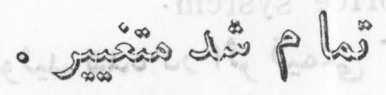

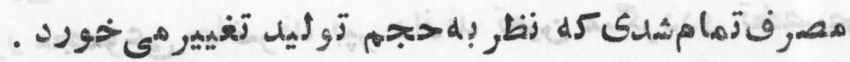

priority system .

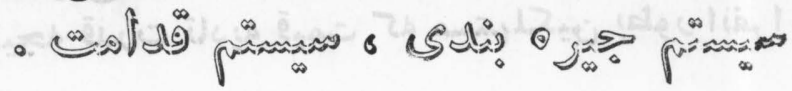




\section{PRI}

prior l'en boud.

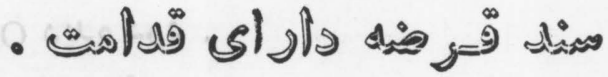
BOND 'PRIOR LIEN • رجوع شود به

prior stock .

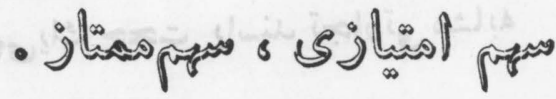

STOCK , PRIOR شواجله بود به

private corporation .

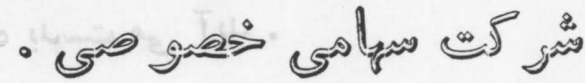

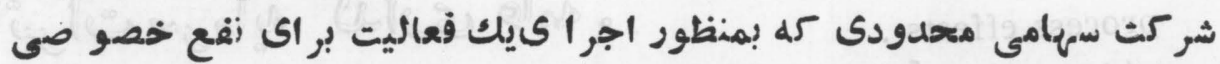

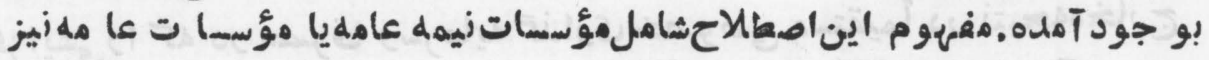

ميماشدل

private debt.

- ज

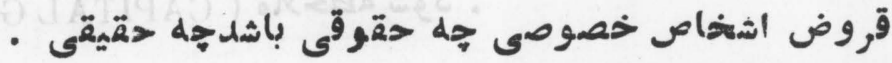

private enterprise .

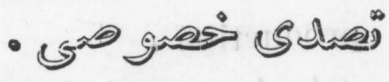

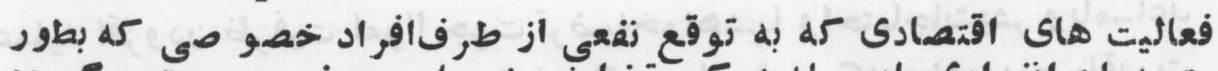

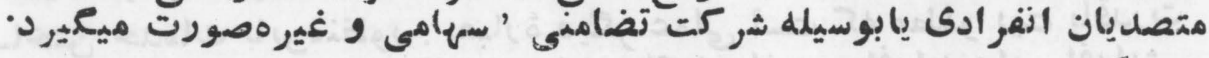

p rivateiring.

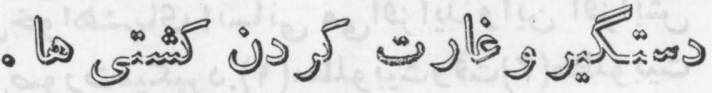

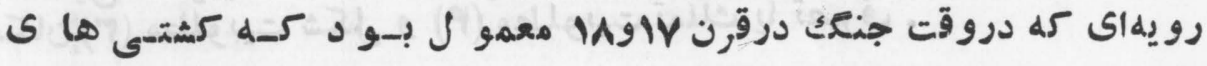

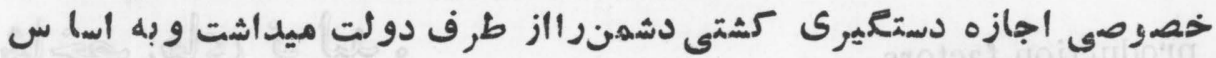

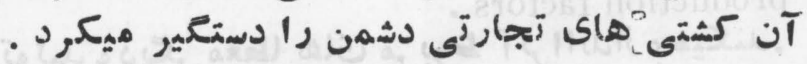

private property

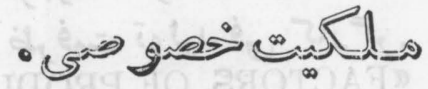

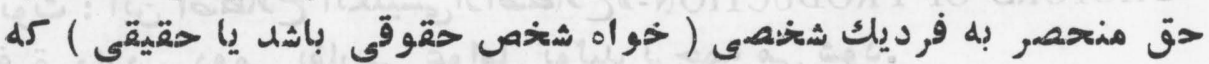

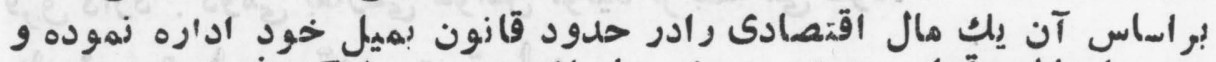

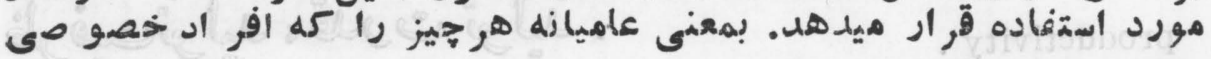

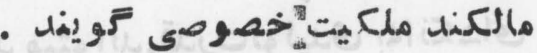




\section{PRO}

privilege tax

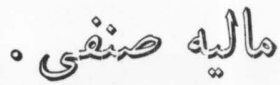

تعريف زير . OCCUPATION TAX ديده شود .

proceeds .

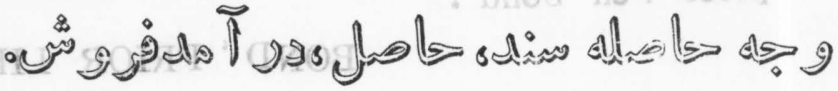

ا- بوليكله بعداز وضع تنزيل ازقيهت وجهيى يك حجت مإسند تجارتى مشابه آن باقى مي ماند

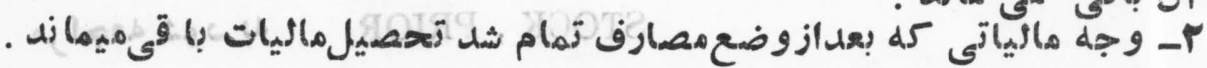

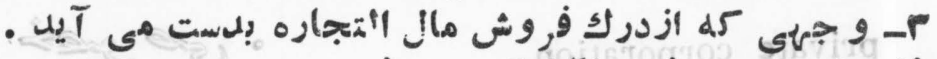

process effects .

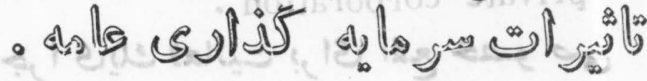

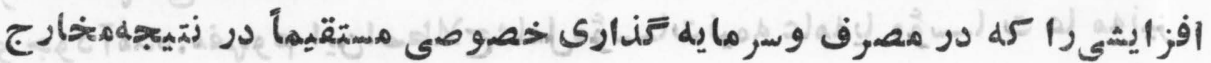

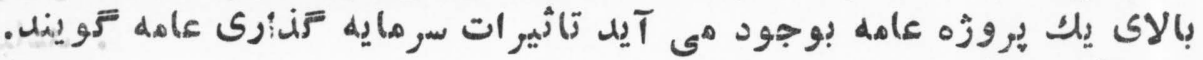
producer,s capital .

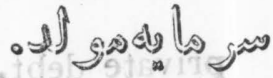

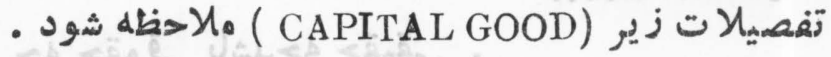

production • - ل्य

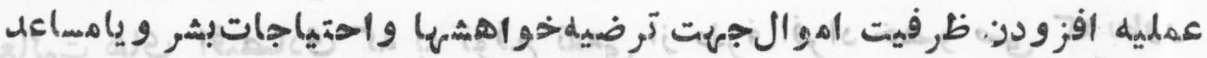

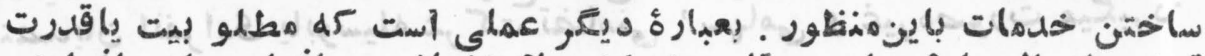

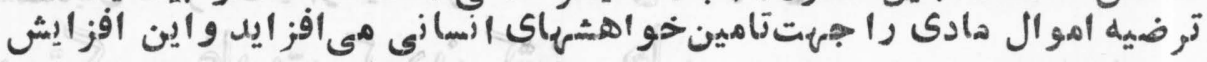

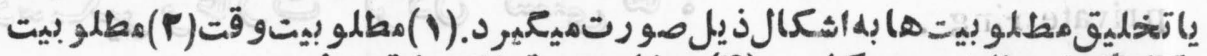

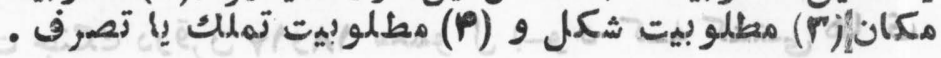

production factors.

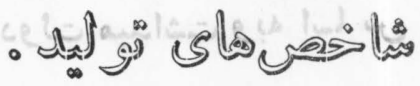

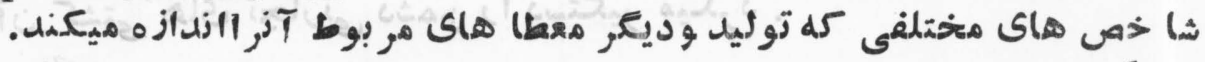

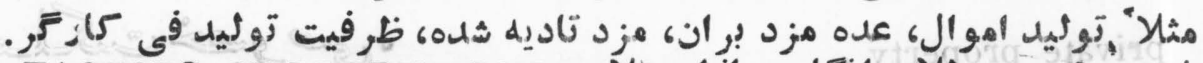

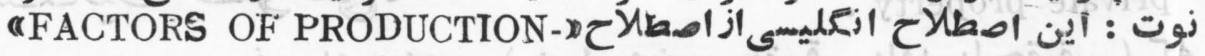
فرق دارد ـ دومي بغارسى عوامل اصوليل درجمه مى شود. productivity .

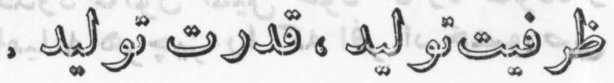
مقدارى كه هر كار Fردريك وقت معينت توليد ميتواند.قدرت توليدى بها نكشاف $\left(\left(r \cdot{ }^{9}\right)\right)$ 


\section{PRO}

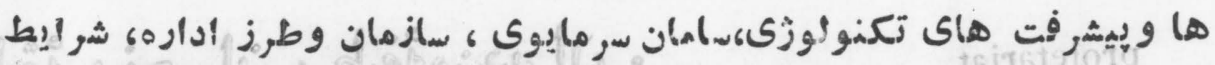

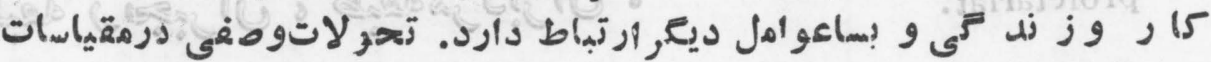

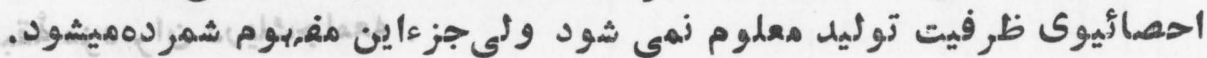

\section{profit .}

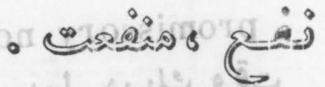

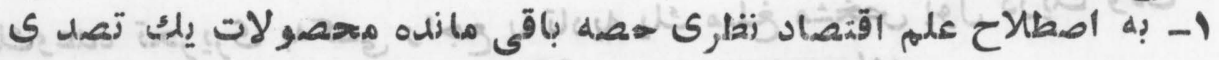

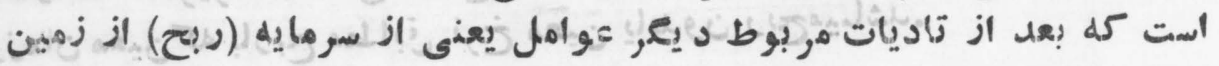

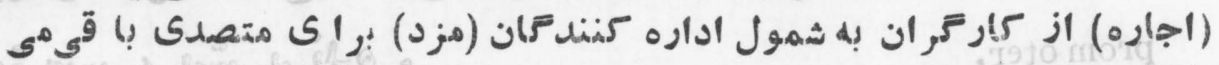

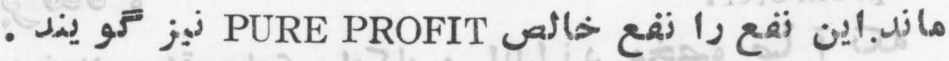

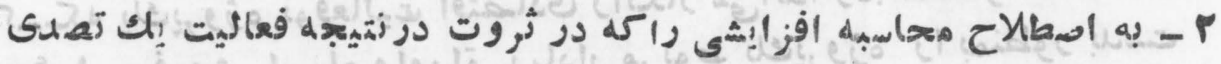

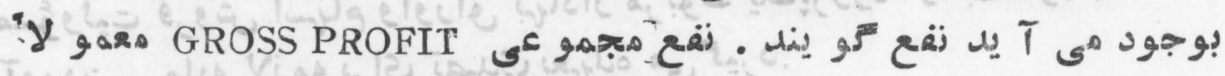

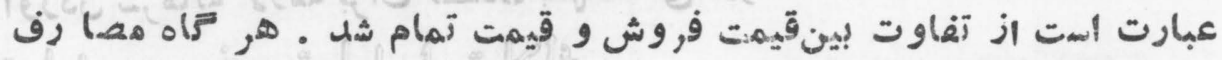

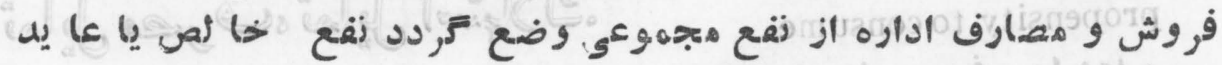

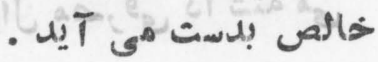

profit-and-loss statement . - ป

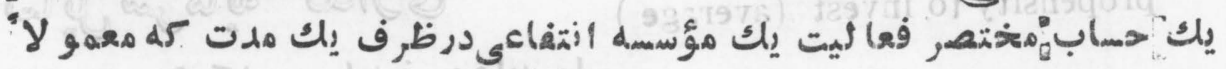

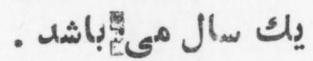

profit-sharing bond

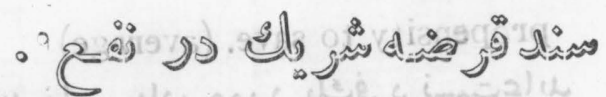
BOND ، PROFIT-SHARING - مر اجعه شود به progressive taxation

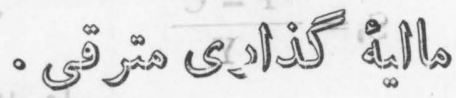

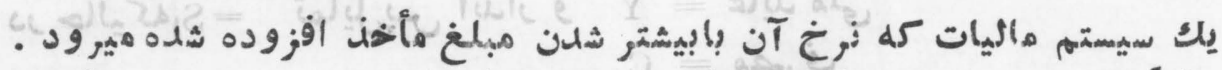

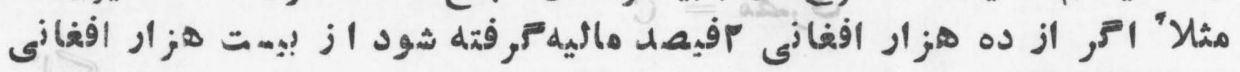

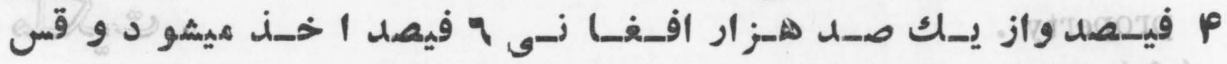
. 1is sic 


\section{$\mathrm{PR}_{\mathrm{O}}$}

proletariat.

- نl طبة مز دبر ان دريكجامعه .

promissory note.

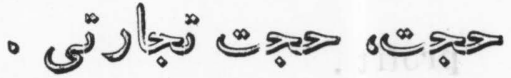

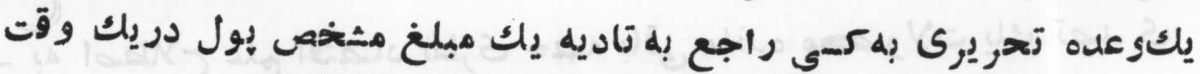

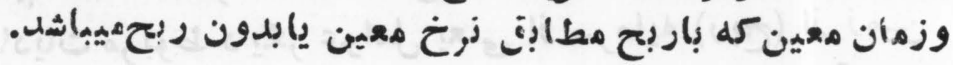

prom oter.

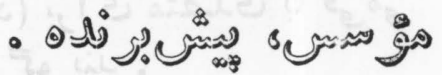

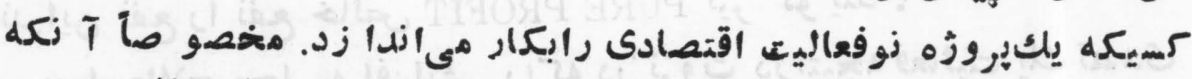

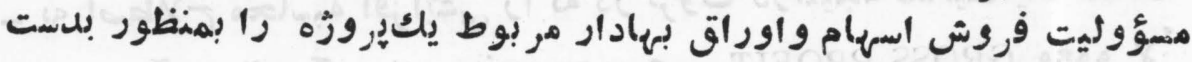

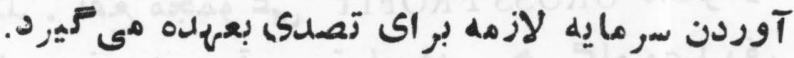

propensity to consume.

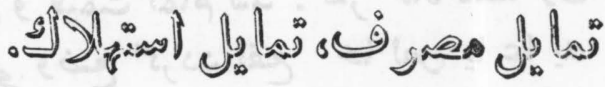

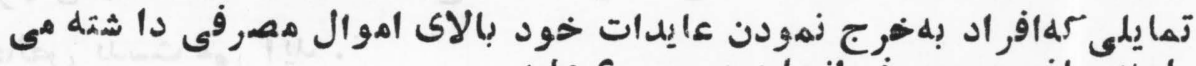
باشنلـ.يا نسبت مصرف ف از عايد ومجمهوع عايد.

propensity to invest (averige)

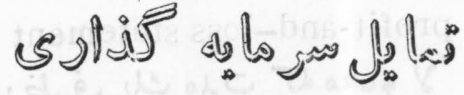
زسبت بين تشكل سرمايه نور وعايد ملى •

propensity to save. (average)

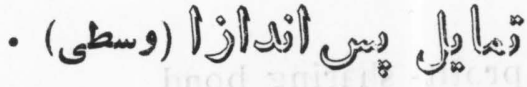
نسبت بين عايدى كه مصرف نشده و عايد ملى. يادر مورد يك يكفرد نسبتعايل

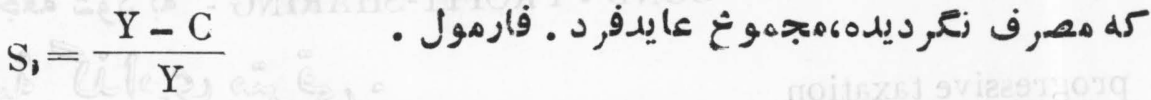

$$
\begin{aligned}
& \text { در حالي كل } \\
& \text { ف مصرف }
\end{aligned}
$$

property •

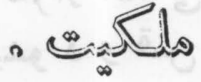

حقى كه انسانبهمنا فع آيندة اشياىاقتصادى(خواهمادى)شد خواهغير مادى) 


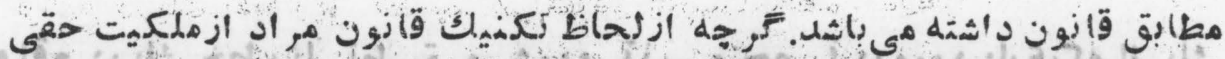
مونه

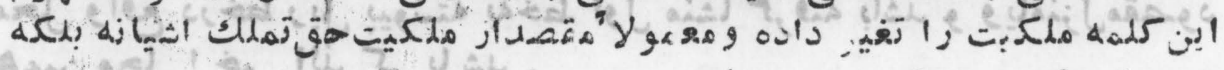

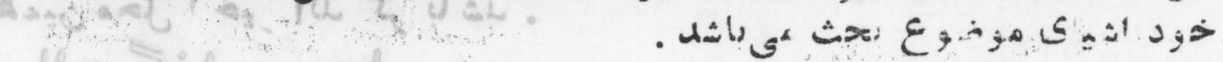

property ac ount.

- estor is

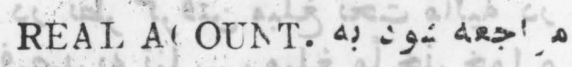
prop rty capital.

तर्ड

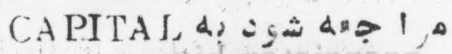
property tax.

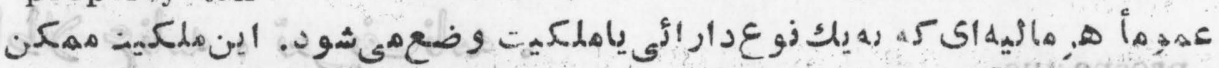
ا

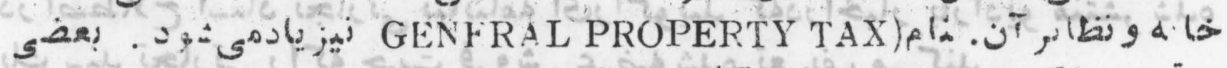

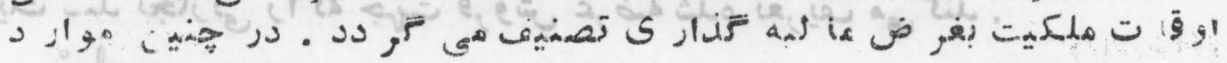

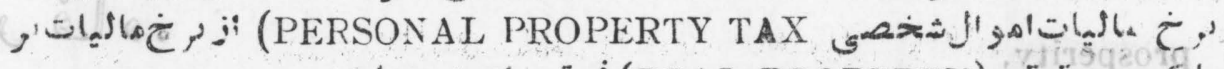
(REAL PROPERTY)

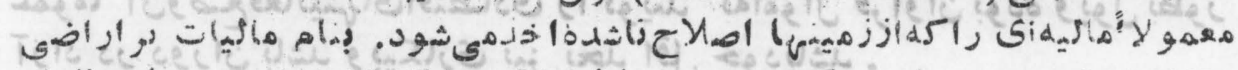

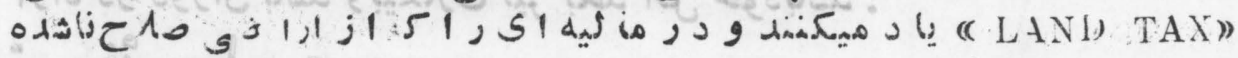

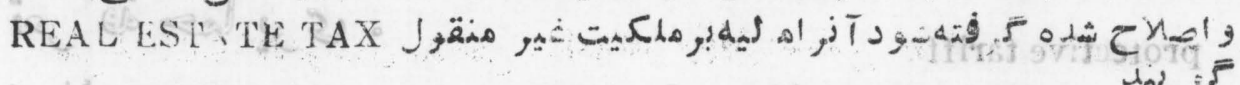

prop rtionalitr, law of.

$$
\text { - }
$$

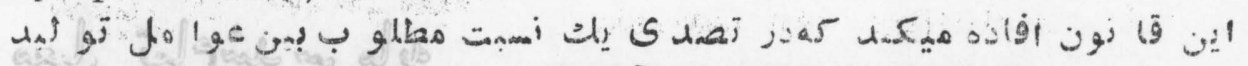

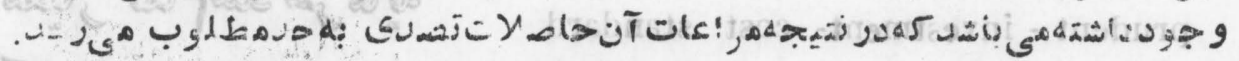

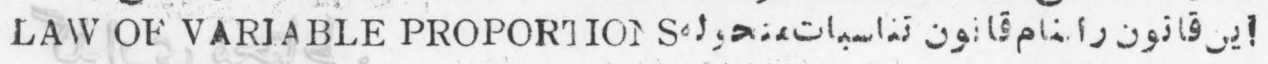

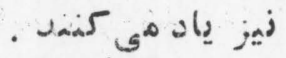

proprti nil rate.

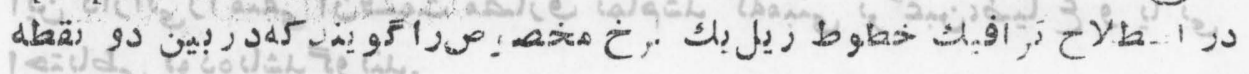




\section{PKO}

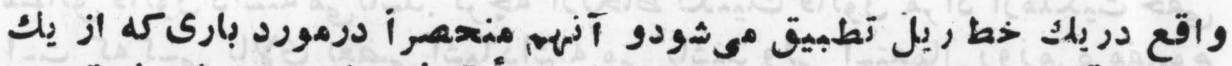

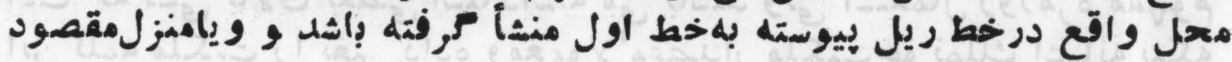

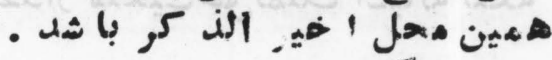

proportional taxation.

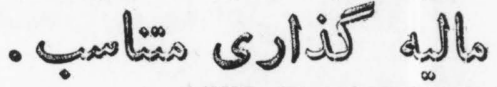

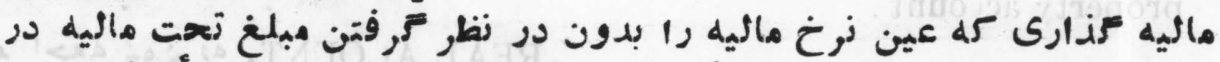

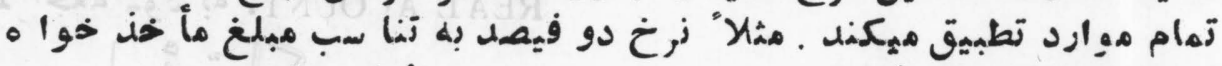

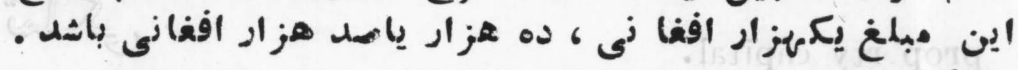

proprietorship .

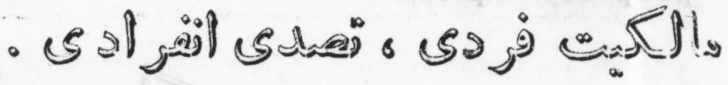

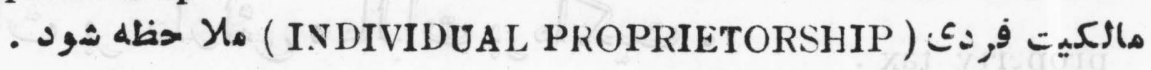
prospe tus .

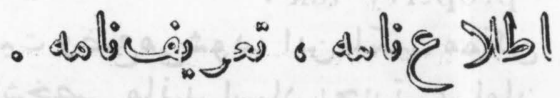

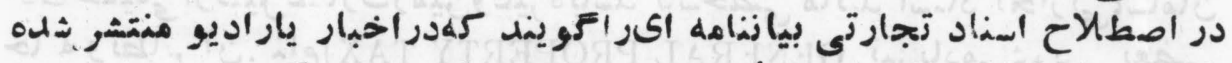

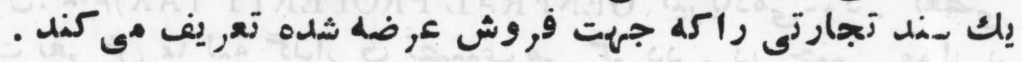

prosperity,

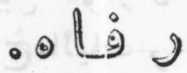

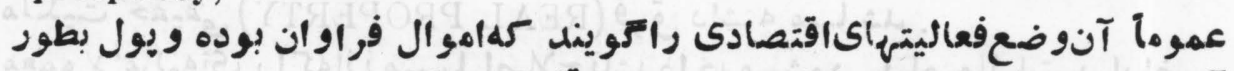

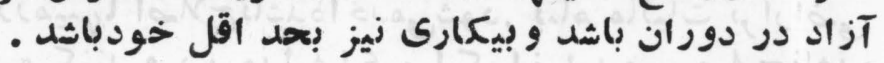

protective tariff

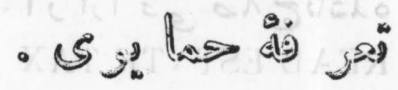

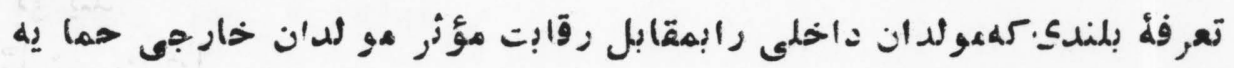

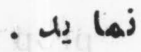

prudent - investment- cost standard. - bliszo callis

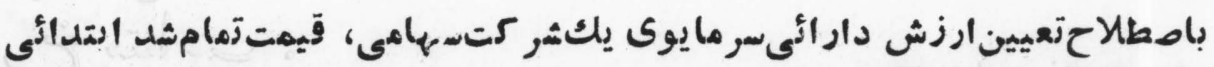

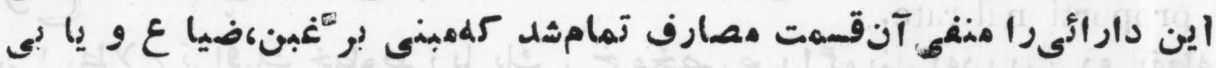
احتياطى بوده باشيد دوريند. 


\section{PU B}

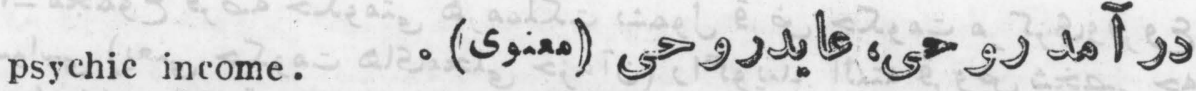

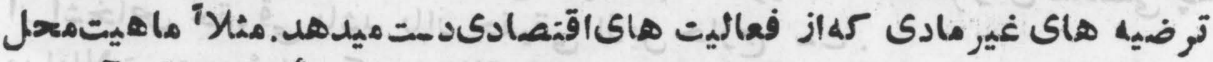

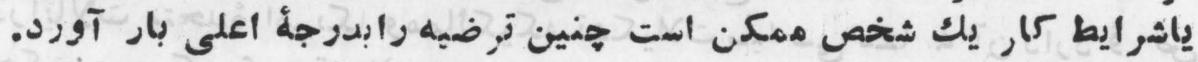
psychological the ry of business cycle. की iी

$$
\text { - डो, ज्ञ }
$$

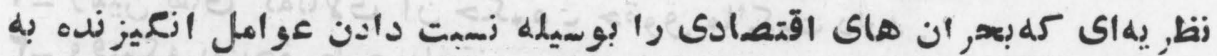

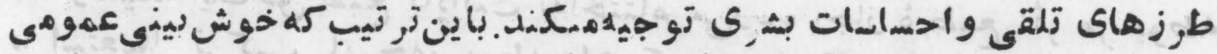

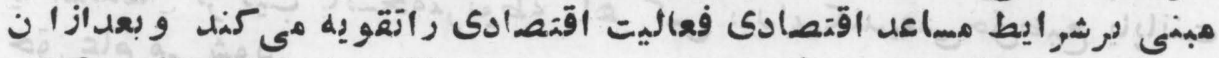

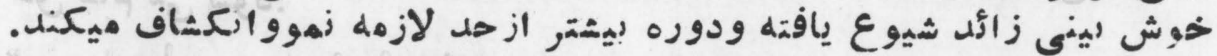

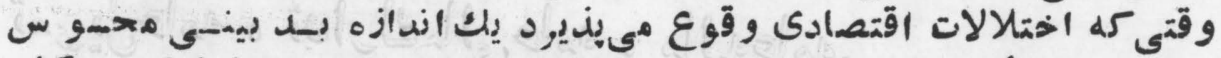

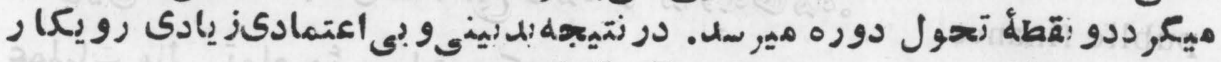

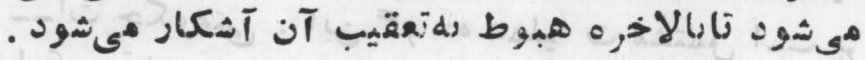

public bond.

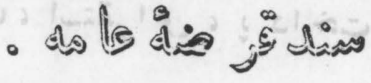

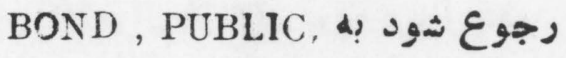

public consumption monopoly -

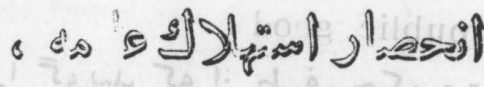
- dolag gas gill

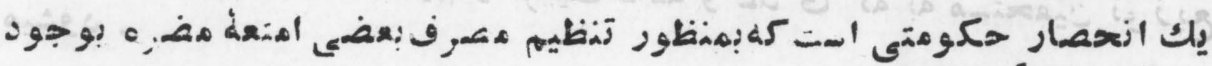

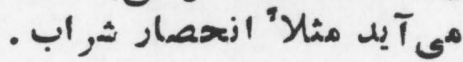
public corporation.

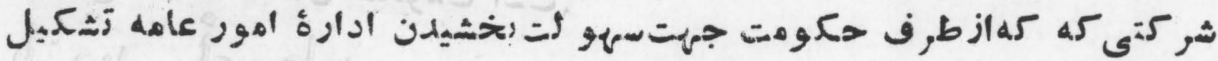
مى شو د د. public debt.

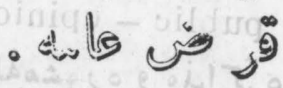
1- قرض هرو احد ادارى حكو هتى را توريند . 


\section{PCB}

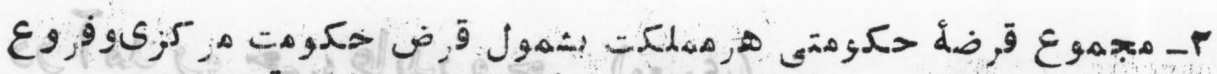

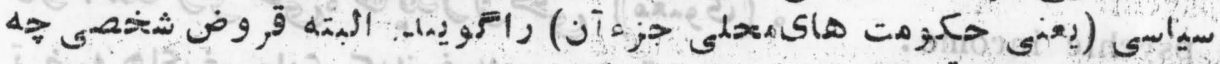

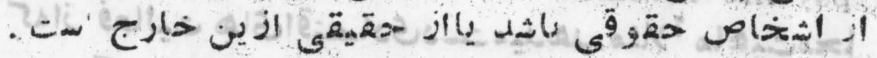

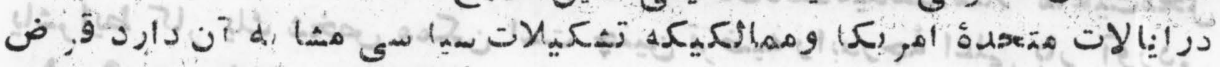

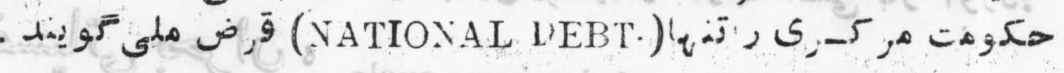

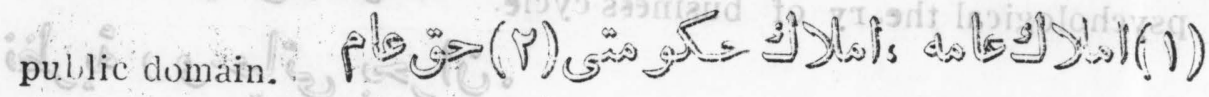

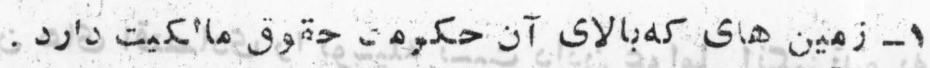

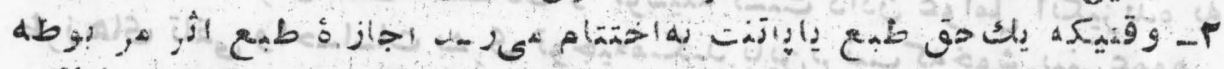

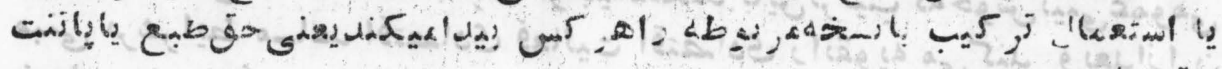
حق عام مي شون.

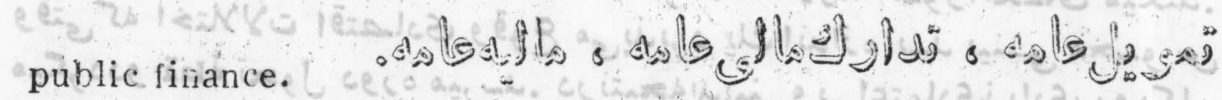

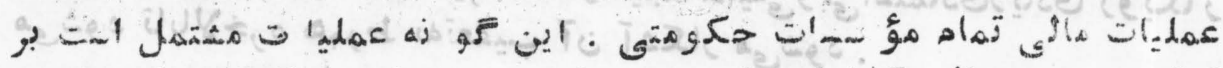

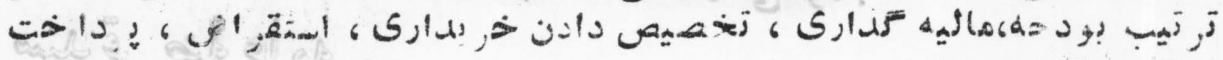
- J

public good.

$$
\text { - do lo do }
$$

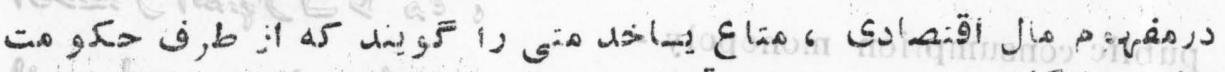

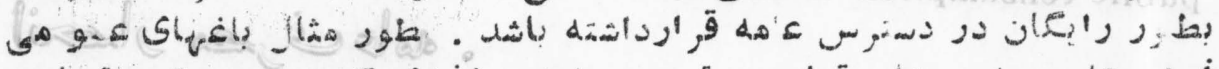

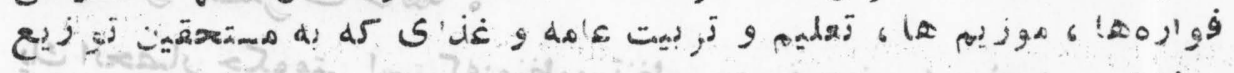

public lands.

$$
\text { - All (s) }
$$

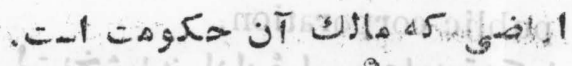

$$
\begin{aligned}
& \text { - As le est; dos? }
\end{aligned}
$$

puklic - cpinion survey

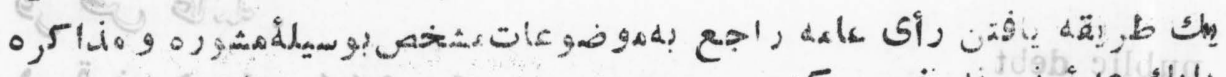

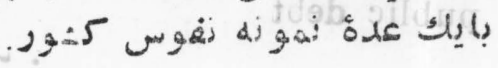


PUB

public ownership.

- dole

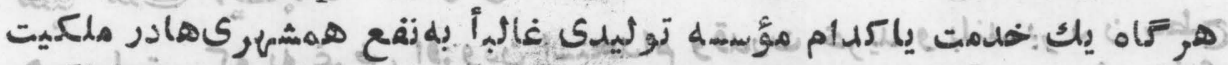

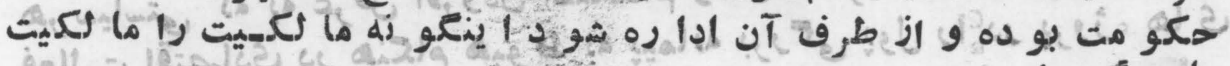
el مه كو ينل public revenue.

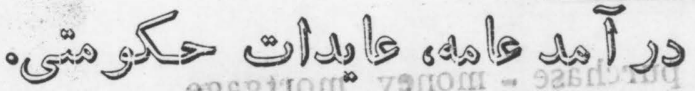

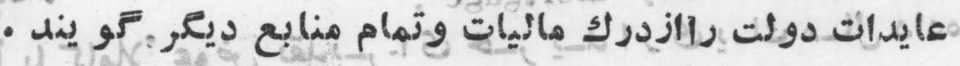
public - service corporation -

- dariole places

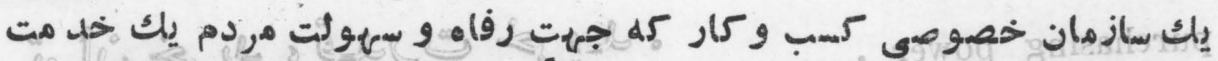

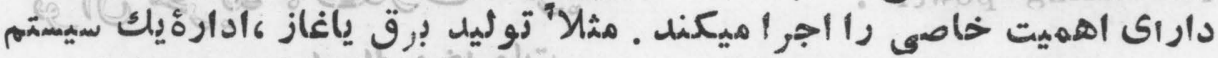

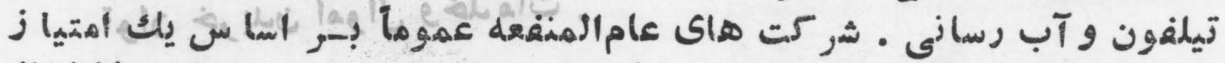

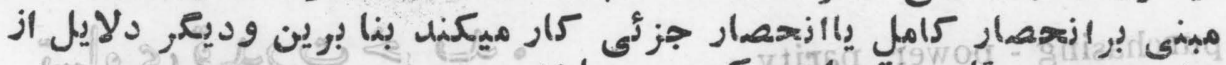

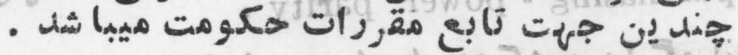
public utility.

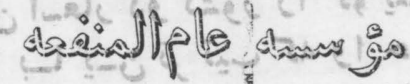

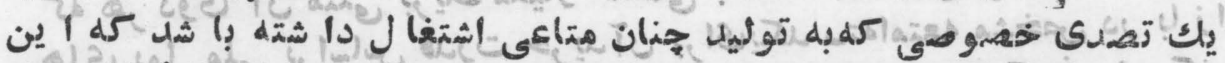

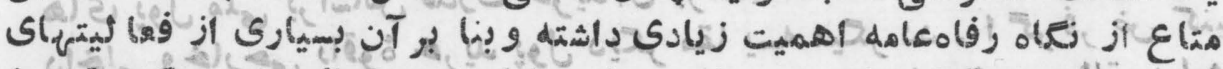

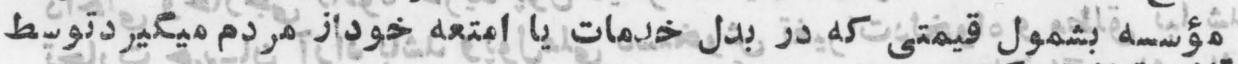

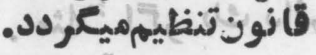
public Works.

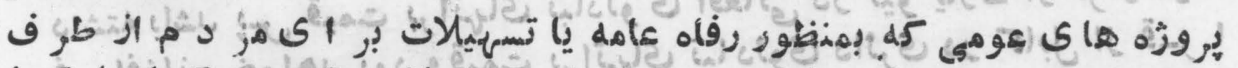

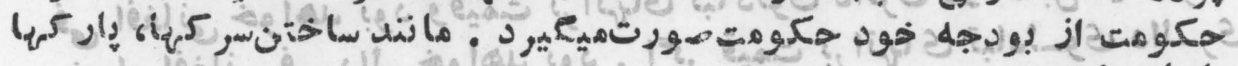
. public works - and-ways system

iso gros pllisionl

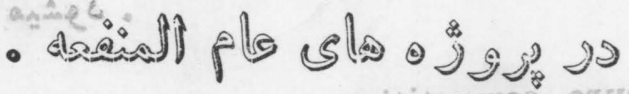

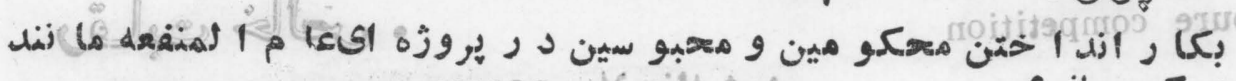
شر Sc سماز

(《) 


\section{PEM}

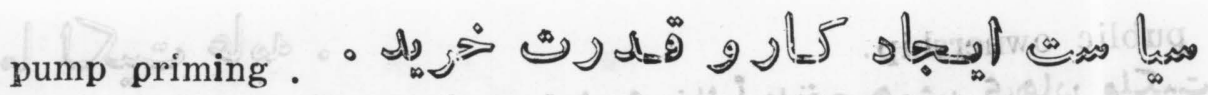

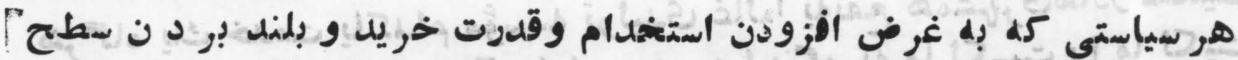

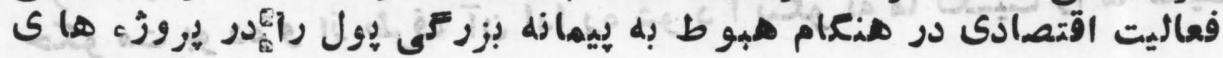
in:

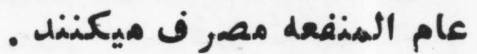

purchase - money mortgage .

$$
\text { - यु }
$$

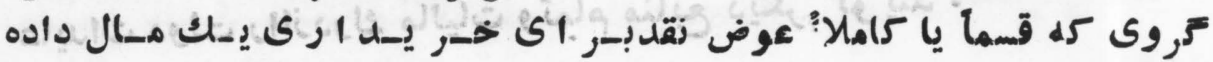

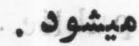

purchasing power.

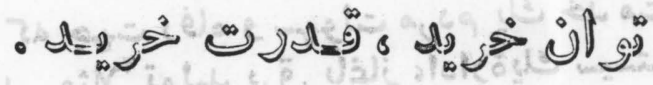

$$
\begin{aligned}
& \text { آوان خريدن اموال وخدمات . }
\end{aligned}
$$

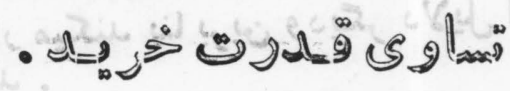

purchasing - power parity .

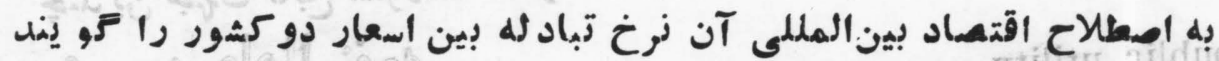

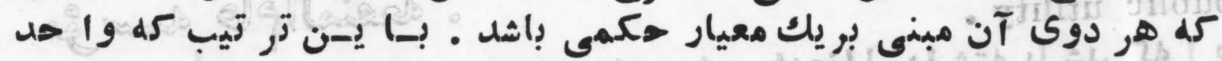

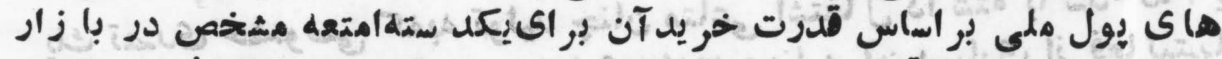

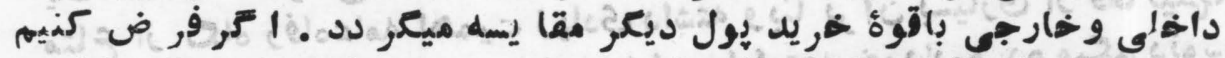

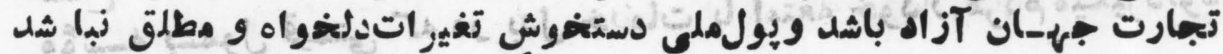

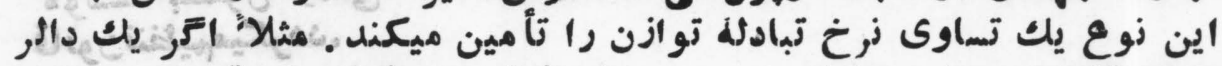

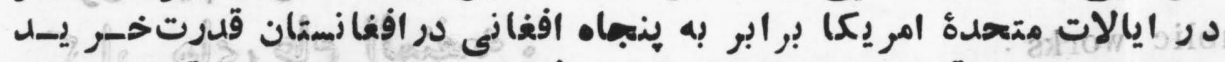

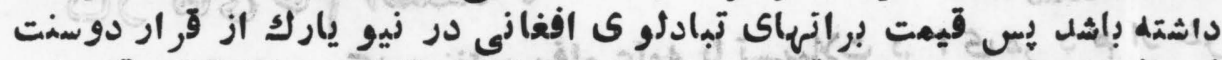

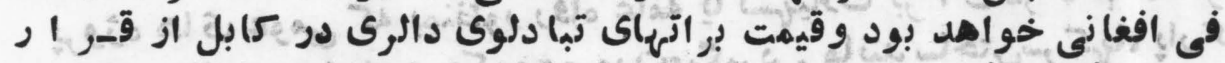

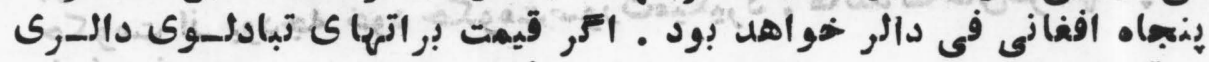

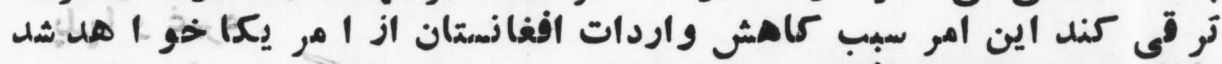

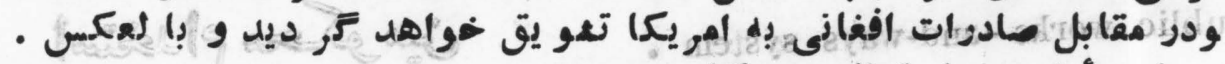

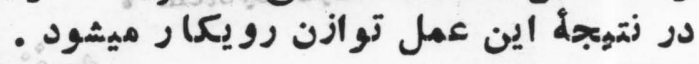

pure competition

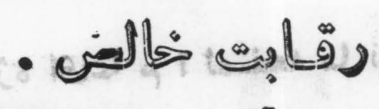

رآ) COMPETITION. مل مظة شود . 


\section{PUT}

pure interest .

- ألص

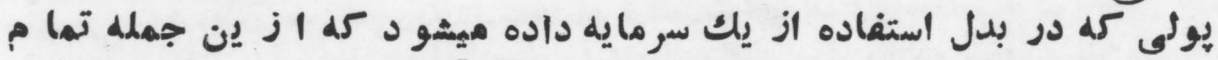

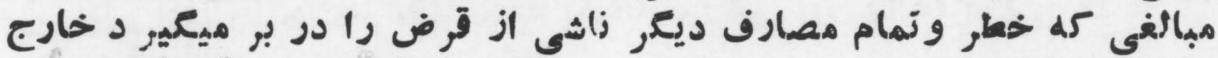

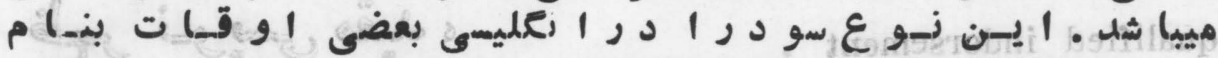

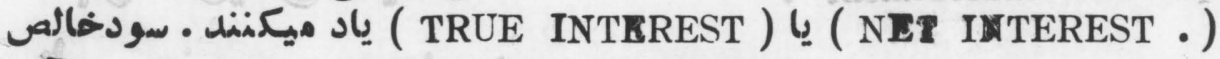

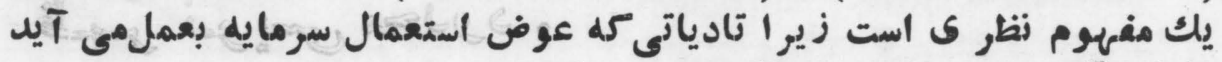

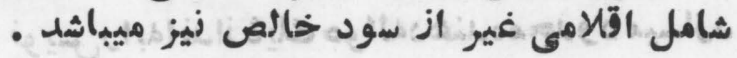

pure profit .

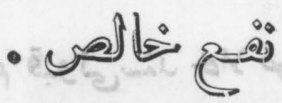

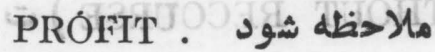

put -

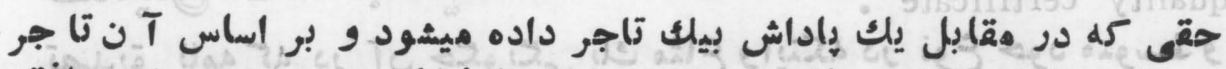

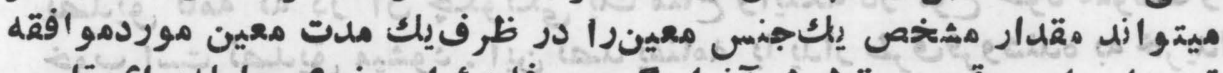

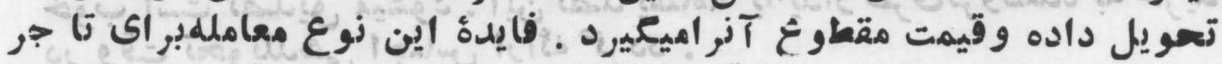

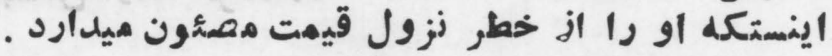

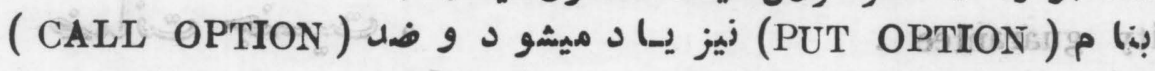

است

putting out system

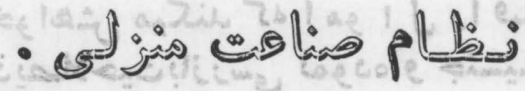

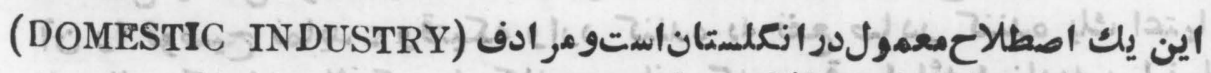

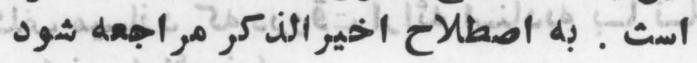

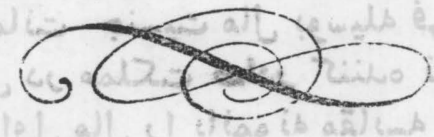




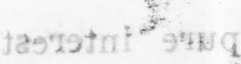

qualified indorsement

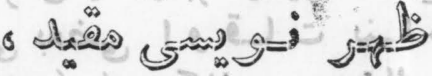

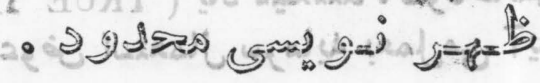

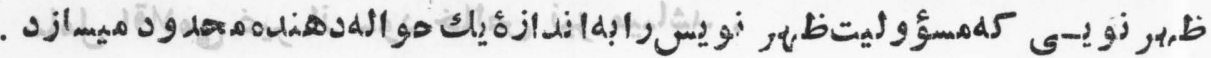

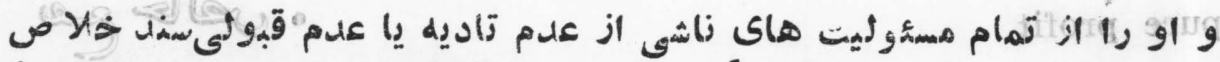

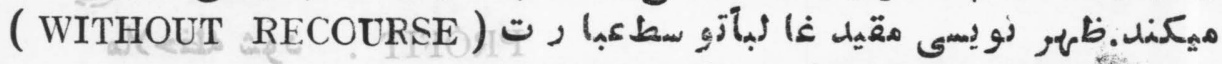

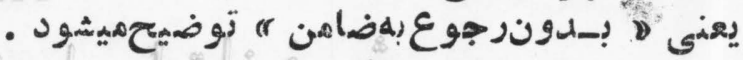

quality certificate

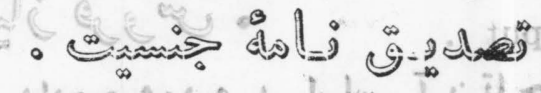

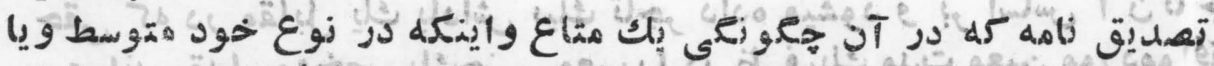

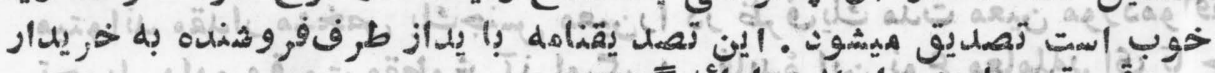

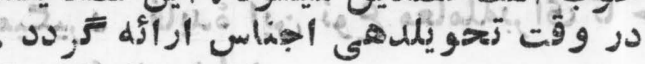

quality guarantee .

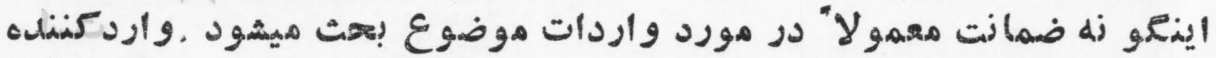

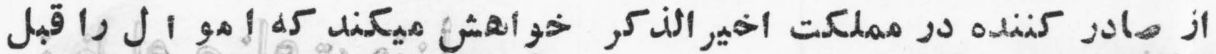

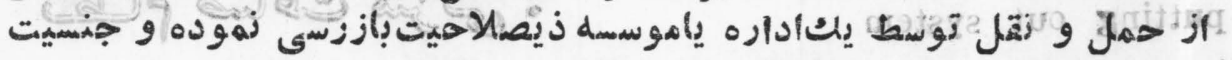

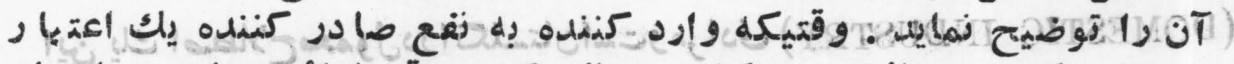

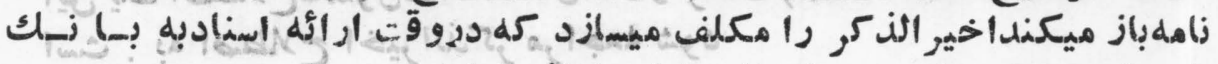

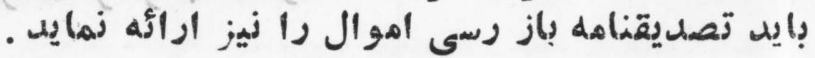

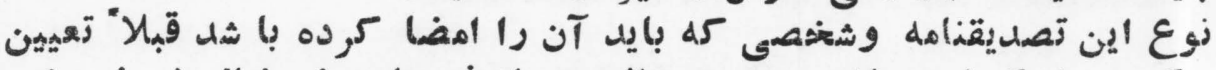

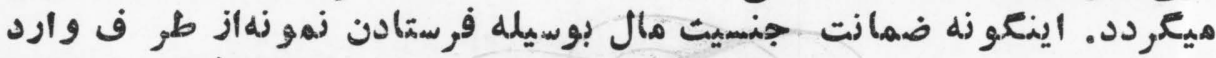

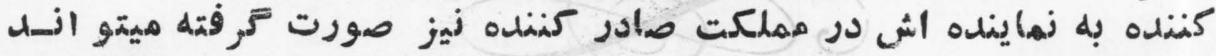

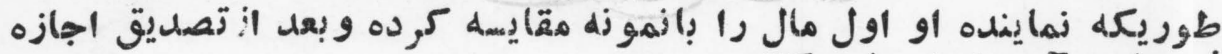
(r) (Y))

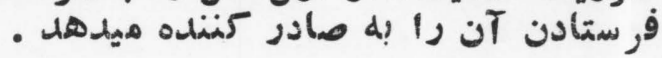


quantity theory of money -

- J

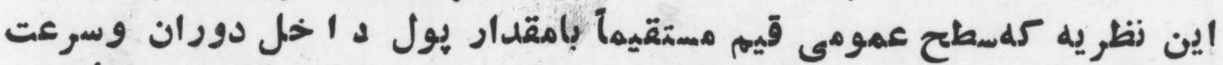

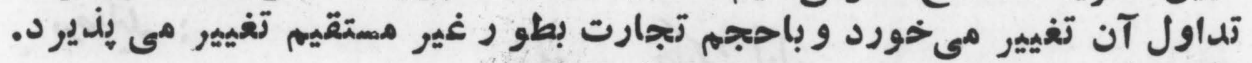

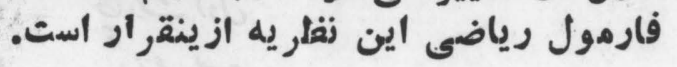

$$
P=\frac{M r+M r}{T}
$$

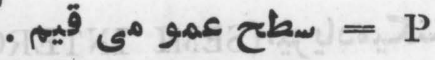

$$
\begin{aligned}
& \text { يول داخل تداول (دوران) = M }
\end{aligned}
$$

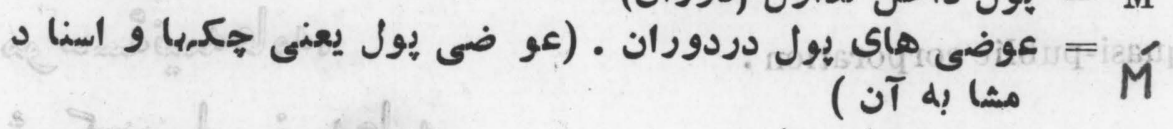

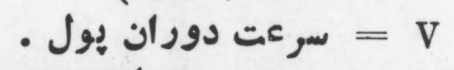

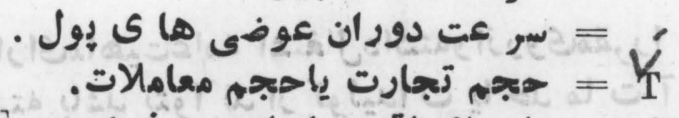

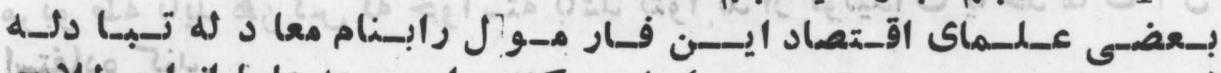
(EQUATION OF EXCHANGE)

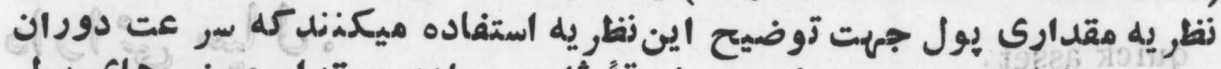

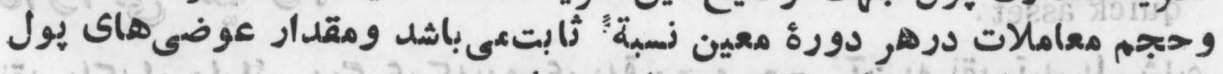

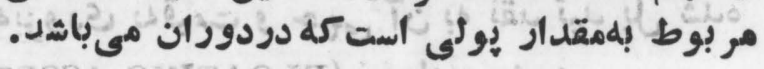

quarter stock .

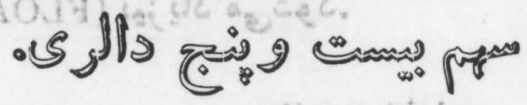
STOCK,QUARTER رجوع شود به

quartile .

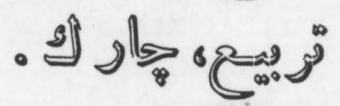

فاطله بين ربع هاى مختلف ترووه اعداد احصائيوى.

quartile deviation.

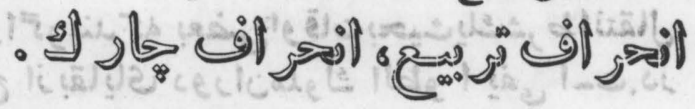
تفاوت بين ارزش نقاط تربيع اول وسوم تقسيم دو - 


$$
\begin{aligned}
& \text { QUA } \\
& Q . D=\frac{Q_{3}-Q_{1}}{} \\
& 2 \\
& \text { J }
\end{aligned}
$$

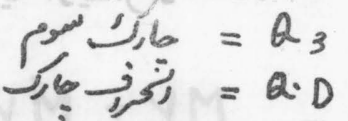

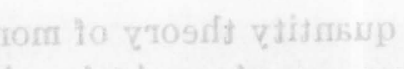
asto,

أنحر اف تر بيع را بنام (SEMI INTERQUARTILE RANGE) نيزيادميكنند. quasi-public corporation.

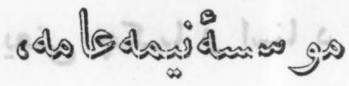

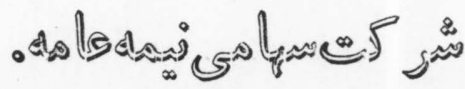

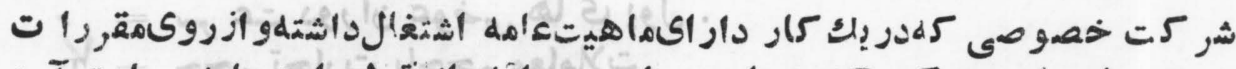

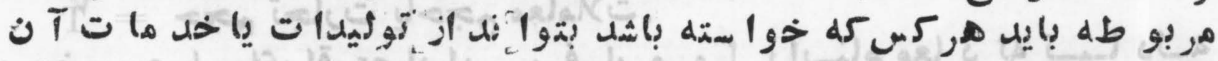

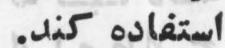
quick asset.

- I

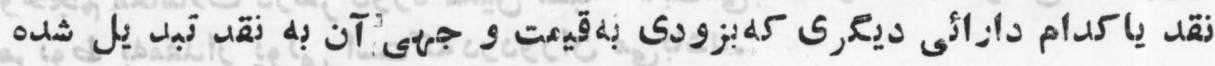

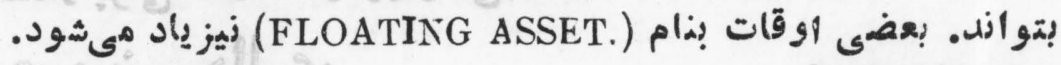
quickie strike.

إ إ:

مر اجعه شون به (ILLEGAL STRIKE.)

quitrent.

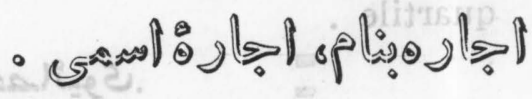

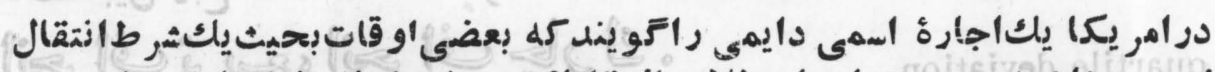

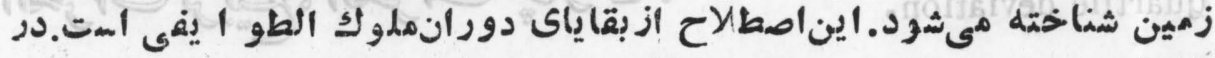

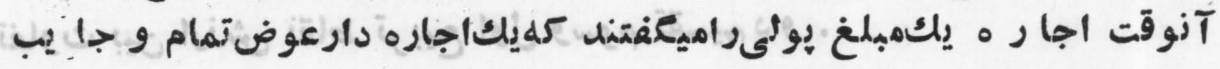
خود بطور دايمىبه تيولدار تعهد كرده مئ يروداخت. ( ( $(r)$ ( ) $)$ 
quota.

- darapas

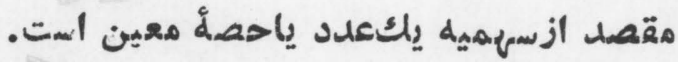

quotation.

C

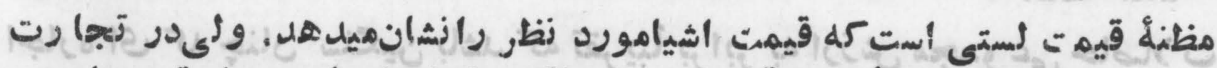

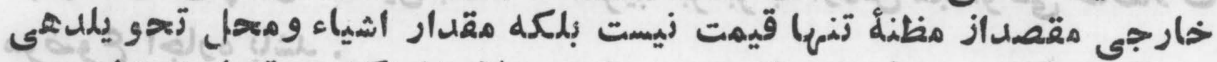

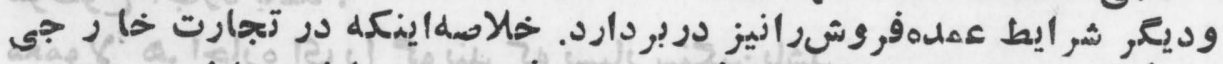

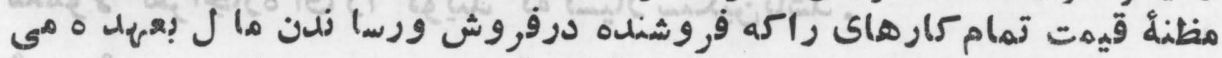

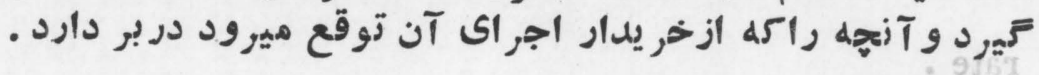

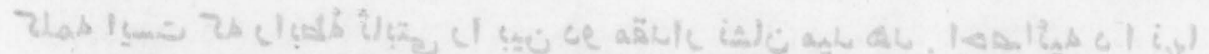

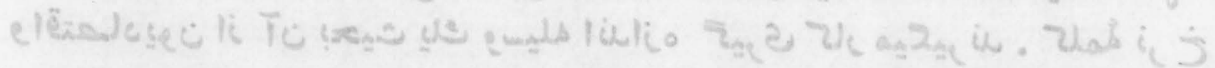

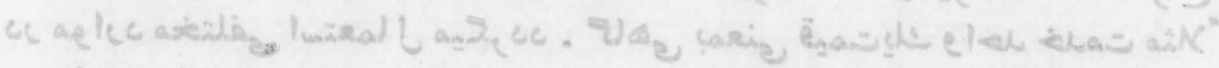

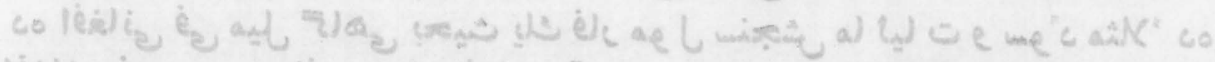

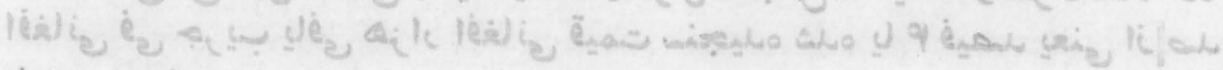

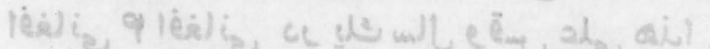

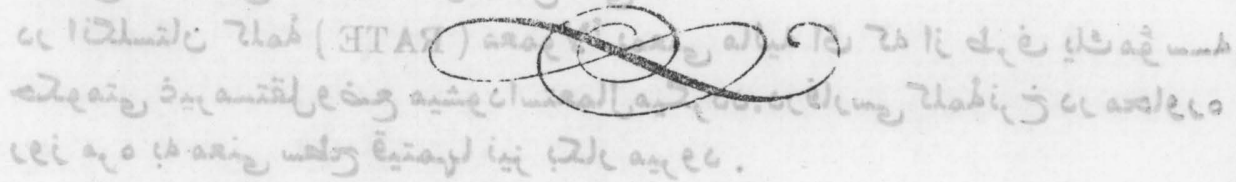
i. शी

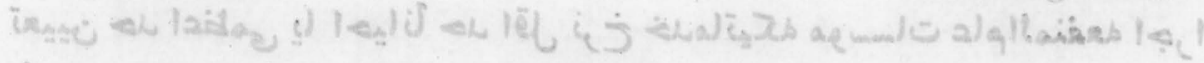

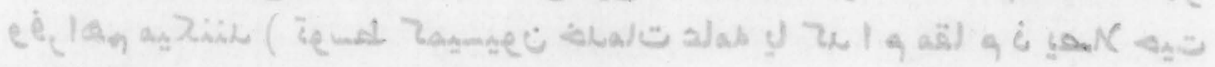
cole

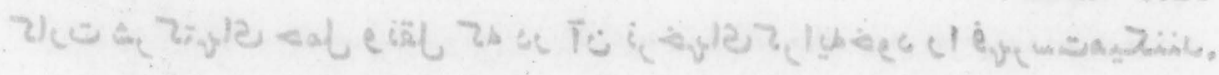




\section{R}

rack rent .

-

اجاره اى كه جهنان سنعين باشد كه تقريباً برابر به ارزش مجمو عى حاصلات

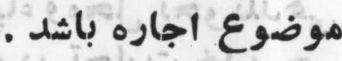

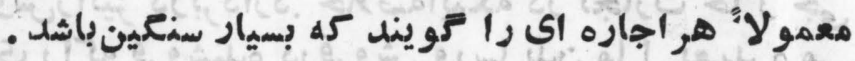

rate .

- ¿ீ

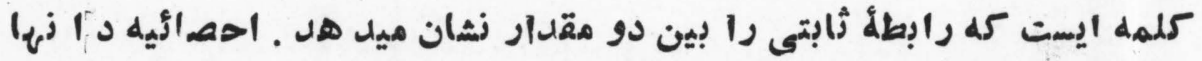

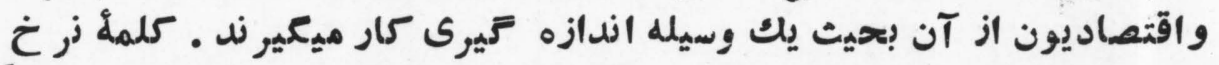

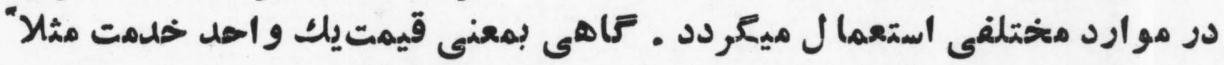

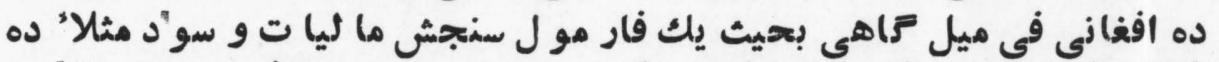

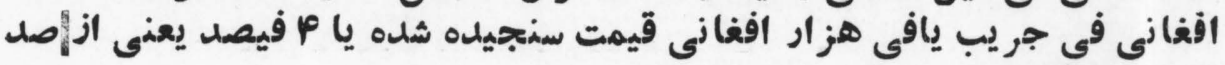

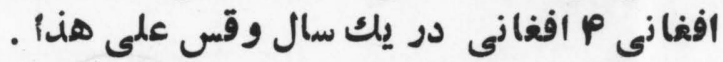

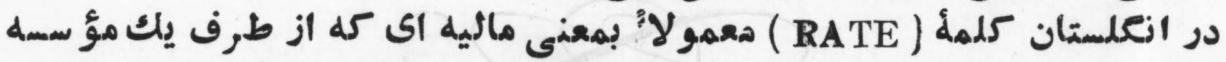

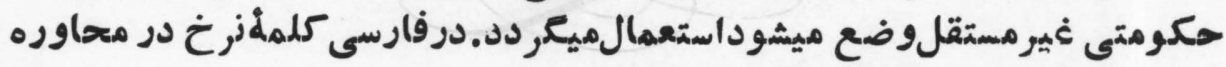

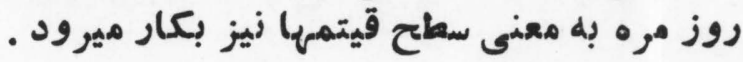

rate regulation .

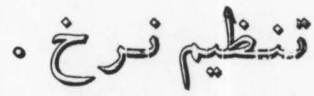

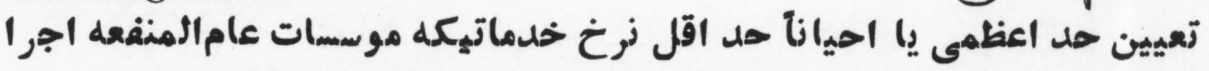

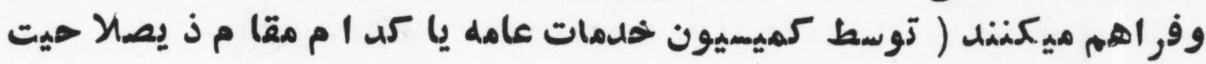

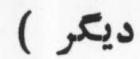

rate eards .

- Eه O D

كارت شر كتهاى حمل و نقل كه فو آن نرخهاى كرايهخود را فهوستميكننه. $((P r+))$ 
rate war.

كارتهاى مشابه ديكر موسسات رانيز تو يند. - ن

(CUT THROAT COMPETITION مراجه شود به

ratio of exchange.

- Aी

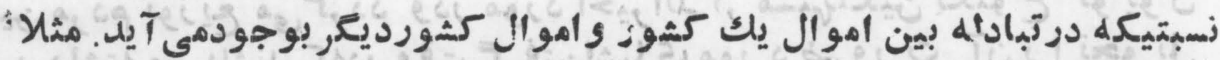

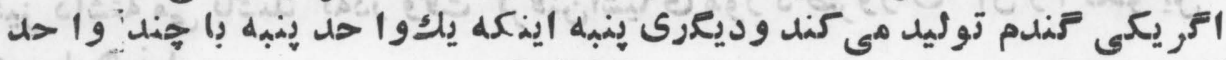

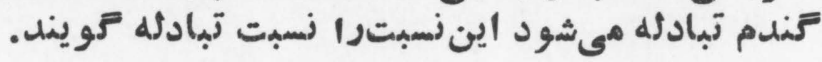

rationalization.

ه

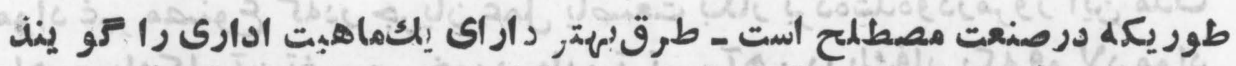

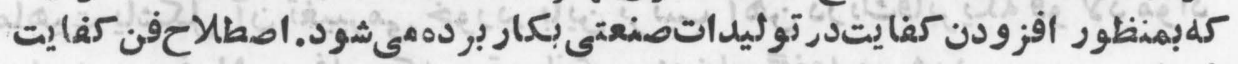

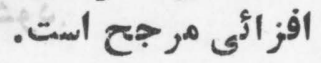

rationing of foreign exchange.

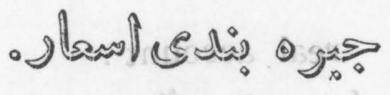

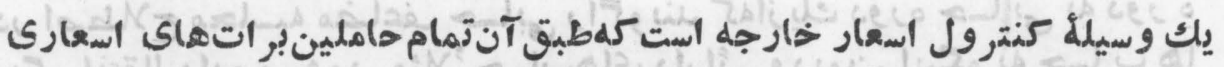

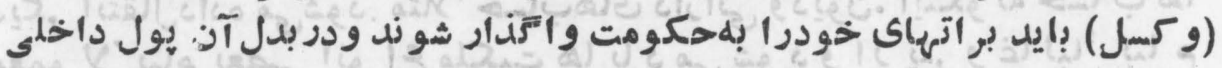

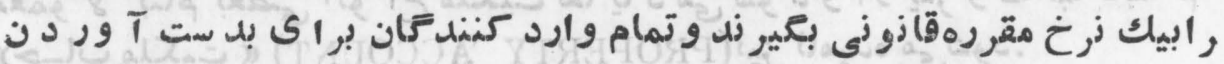

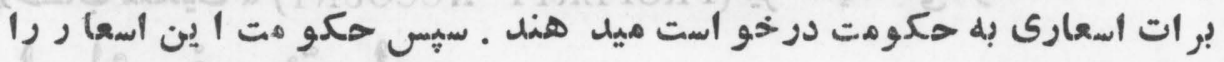

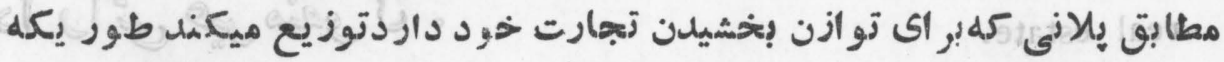

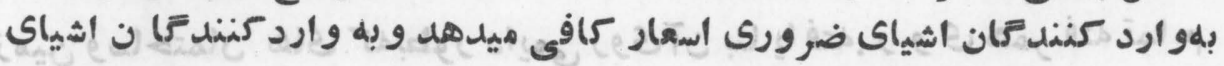
غير ضرورى اسعار نميلهد.

rationing system.

$$
\text { - Sل }
$$

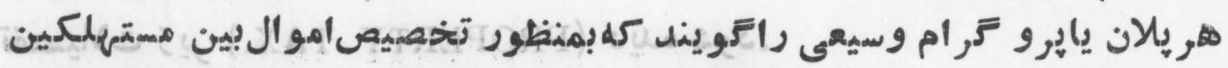

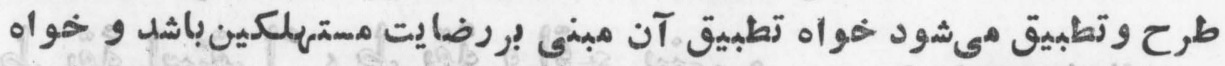

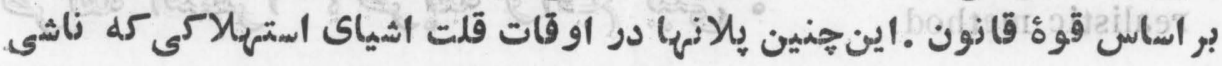




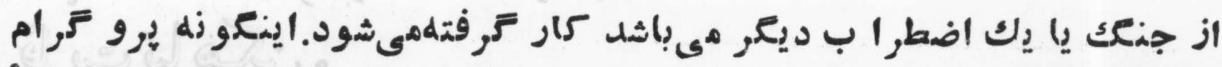

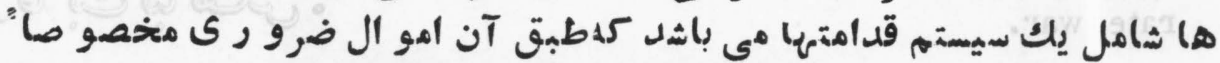

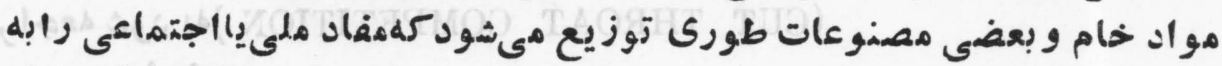

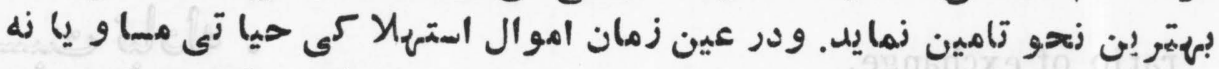

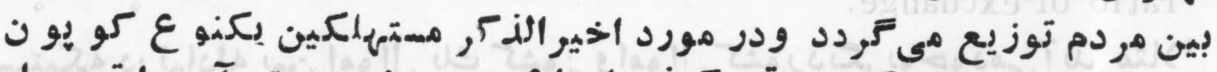

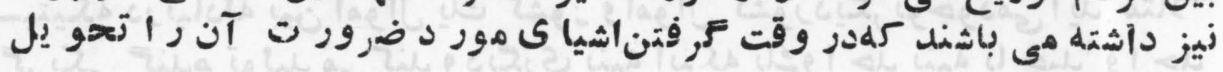

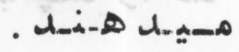

raw material.

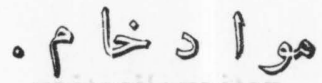

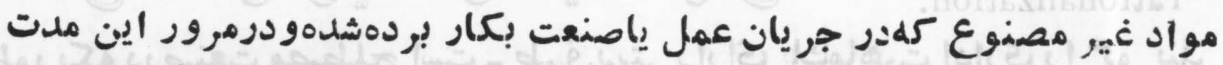

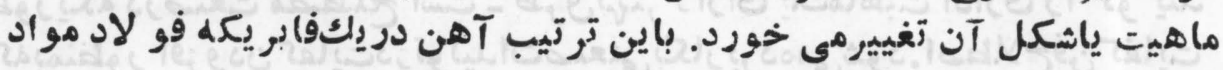

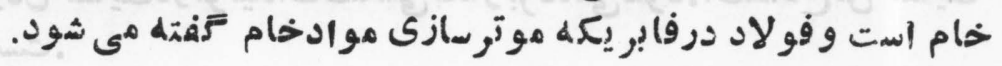

real account . -

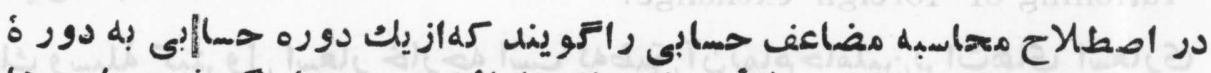

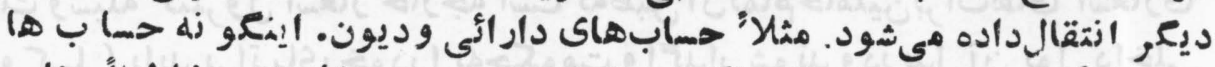

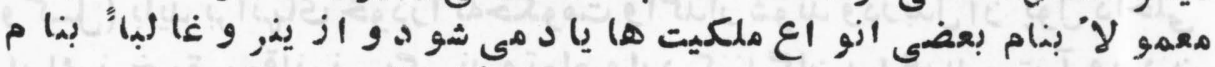

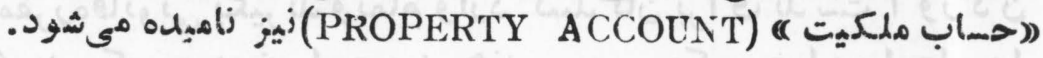

real estate. - I زمين وساختمان هاى كهبطور دايمى روى آن بنا يا فته. رو و ى همر فته تما م اشياى غير منقول. real estate tax.

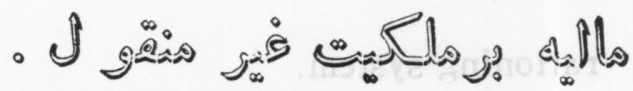
تفصيلات زير (PROPERTY TAX) ديده شود. realistic method. - ज约 ( INDUCTIVE METHOD) رجوع شود به ( 
real property -

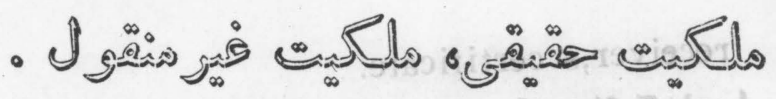

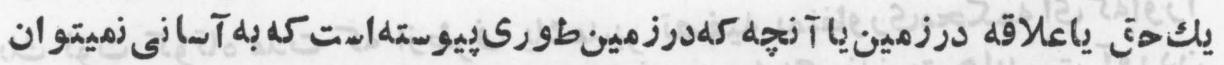

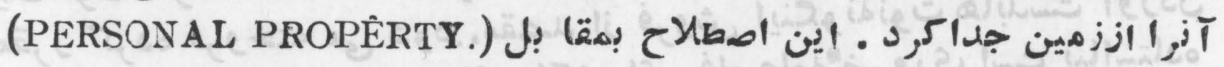

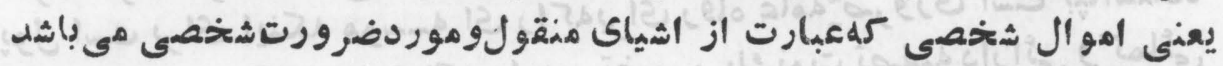
إستر

real wage.

$$
\text { - }
$$

$$
\text { آنجه راكه توسط بوليكه بعنوان مزد F, فته شده خر يده مى توا نيم. }
$$

rebate.

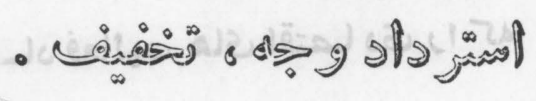

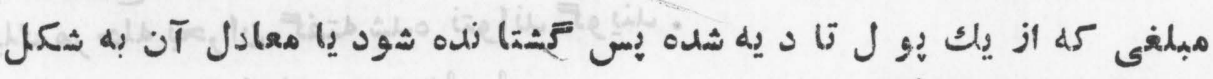

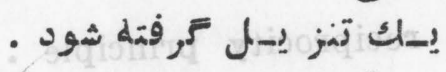

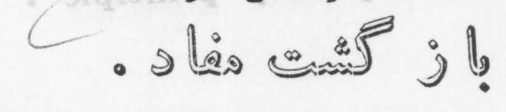

recapture of earnings

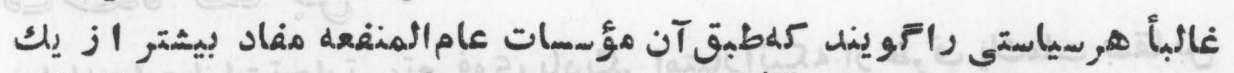

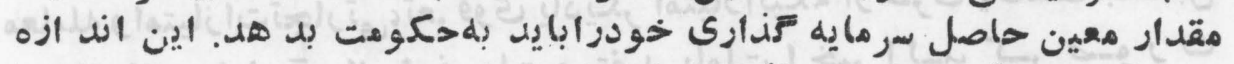

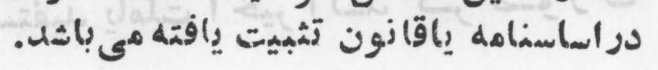

rceipt.

$$
\text { - dian }
$$

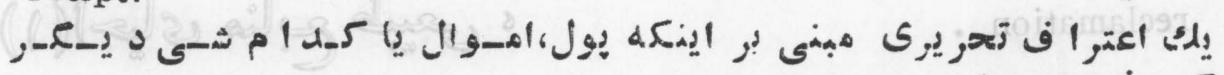

receiver .

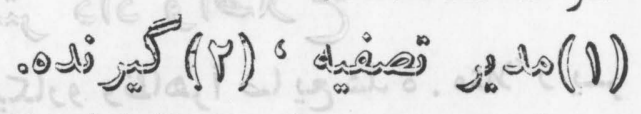

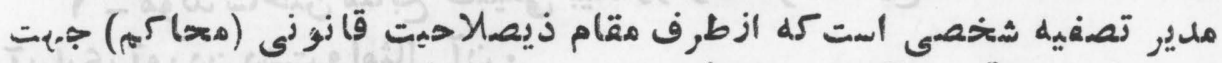

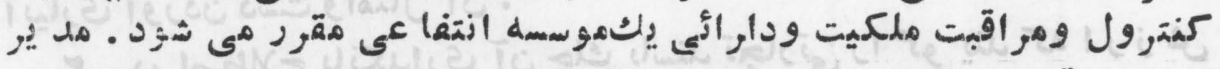

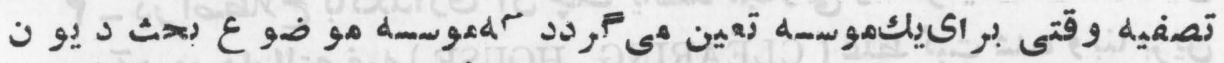

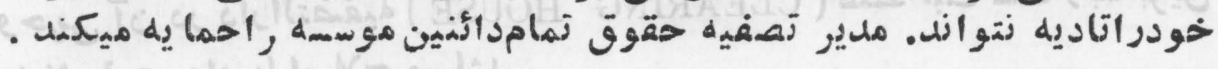
(r) (r) (r) 
REC

receiver,s certificate.

$$
\text { - }
$$

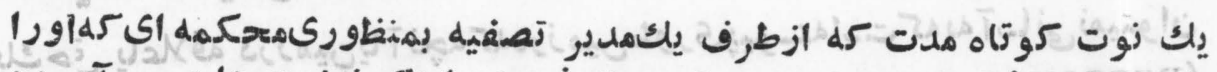

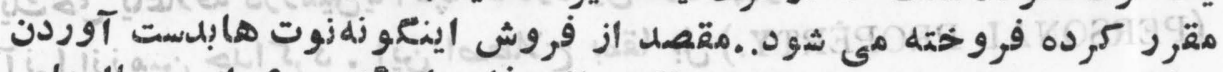

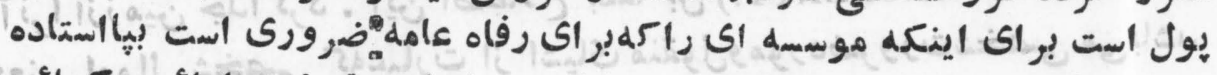

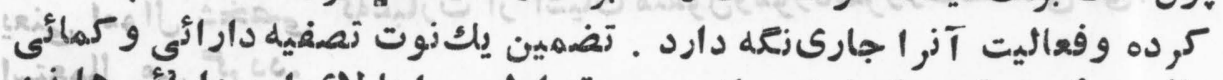

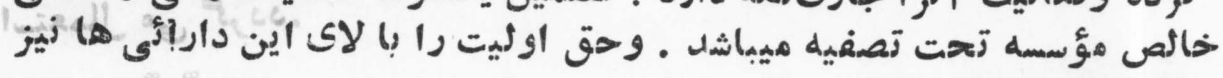

$$
\text { زوت تصفيه دارد . }
$$

recession .

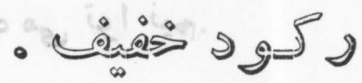

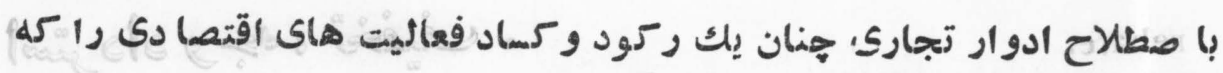

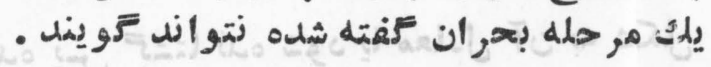

reciprocity principle.

$$
\text { o } A=0=0
$$

$$
\text { - J? }
$$

معاعله وامتياز اتتجارتى، تعروفوى ياديعر امتيازاتيكه از طرف يكماتت بمقا بل ماتل

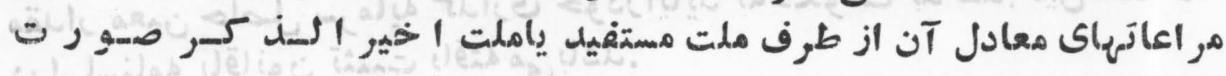

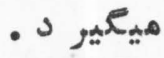
reclamation.

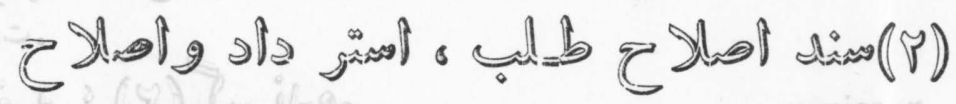

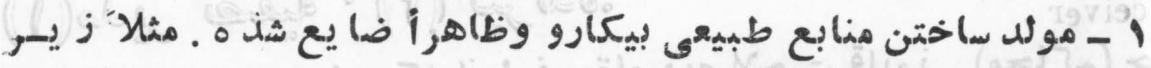

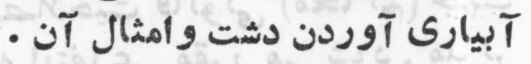

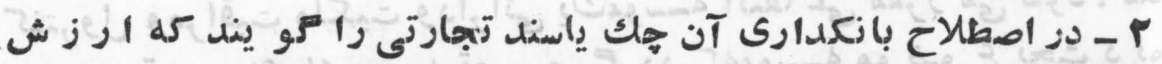

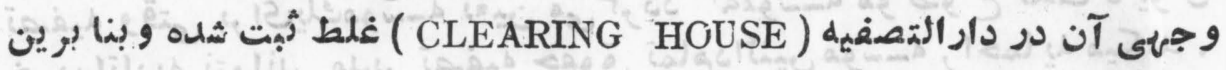

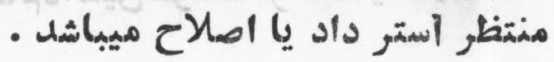


reconversion.

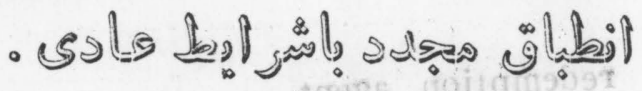

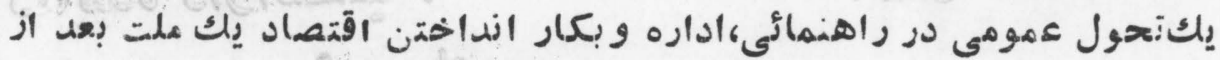

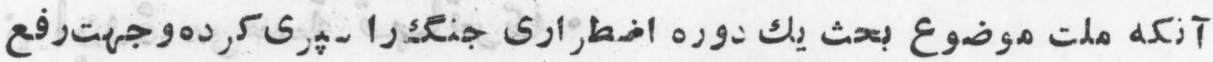

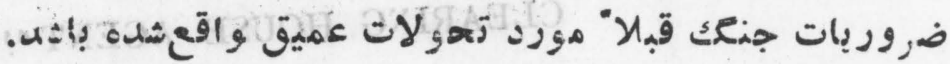

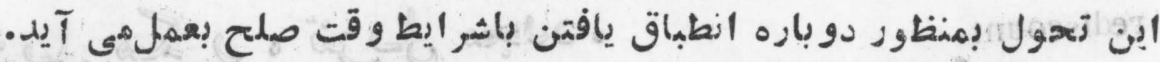

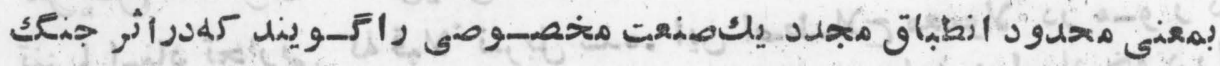

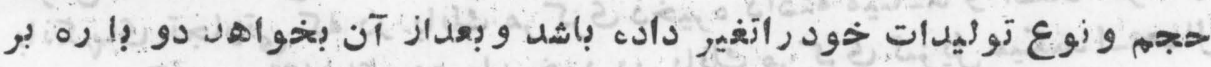
طبق شر ايط واقتضآت بإزار صلح آميز توليدات خودرا آغيير دهل. recovers . - 5 gä?

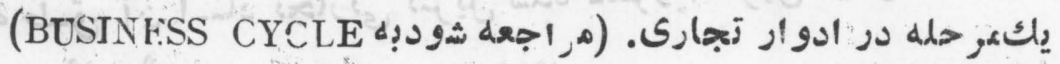

recourse.

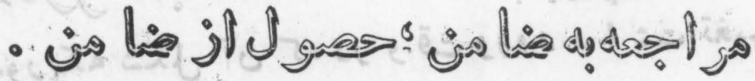

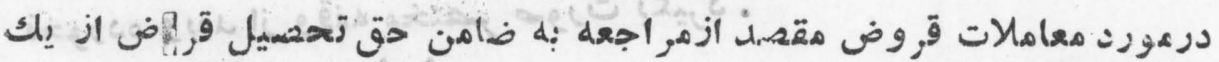

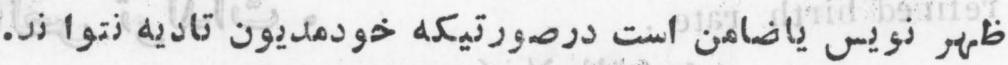

redeemable bond.

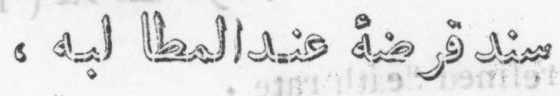

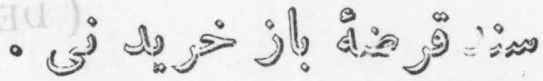

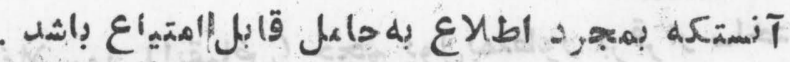
redeemable preferred stock .

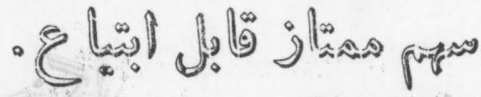
STOCK,REDEEMABLE PREFERRED • تغصيل 
RED

redemption agent .

$$
\text { - A }
$$

- 15

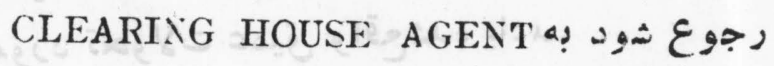

rediscount.

- Od

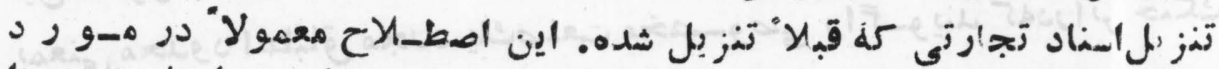

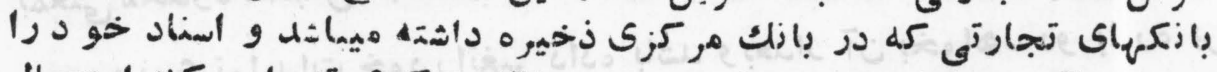

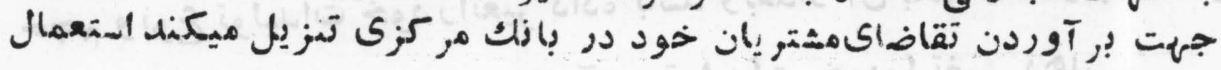

ميثود

rediscount rate

- Dds:o J

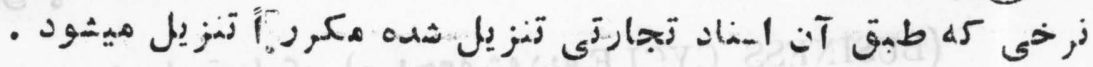

re - export .

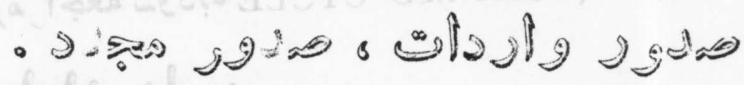

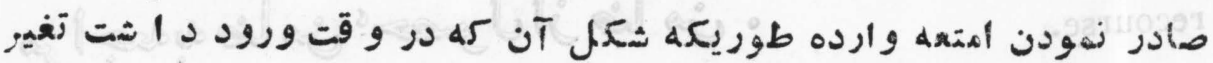

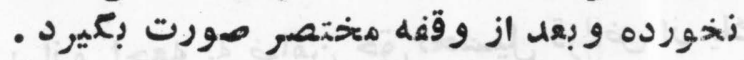

refized birth rate

-

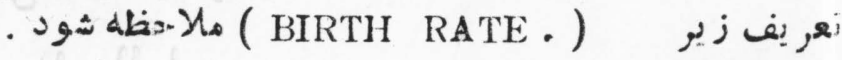

refined death rate $\cdot$

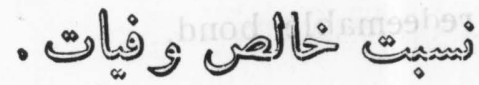

(DEATH RATE.) تفصبلات : يو

reflation .

- is

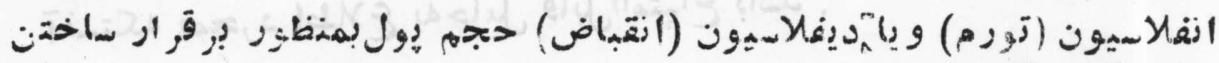

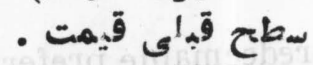

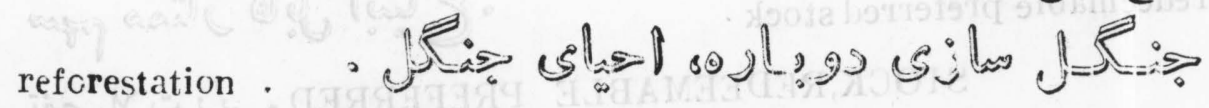

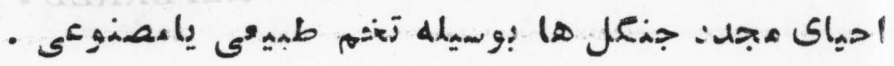


r funding •

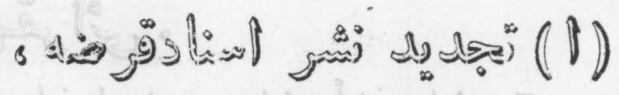

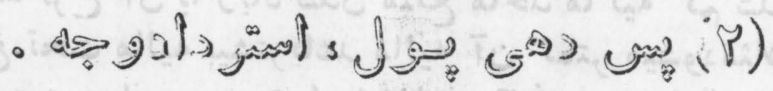

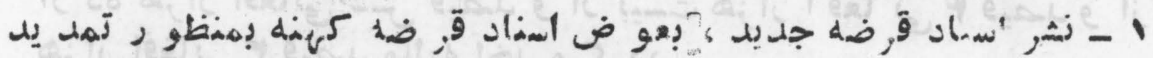

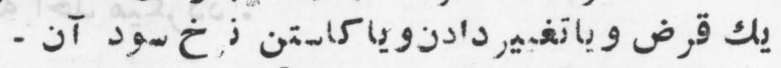

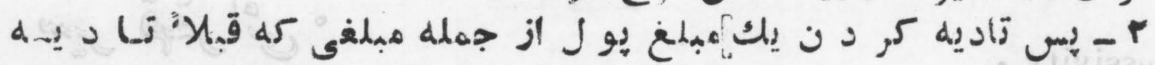

شله بود مان

re unding bond.

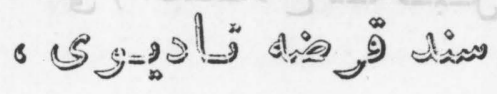

- ن

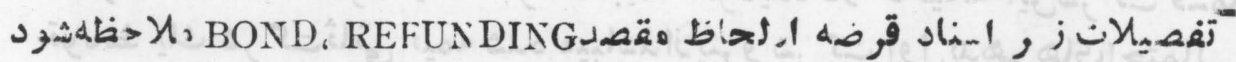

r gional division of labor .

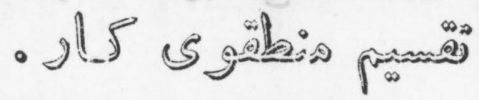

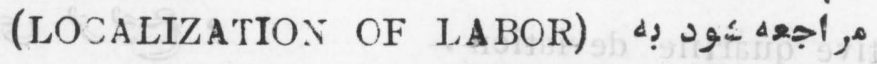

regional p nsion system.

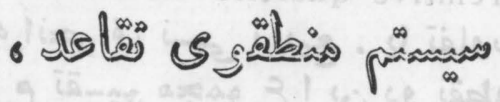
- dela

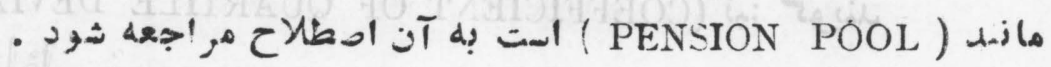

regis:ened bond.

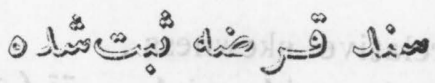

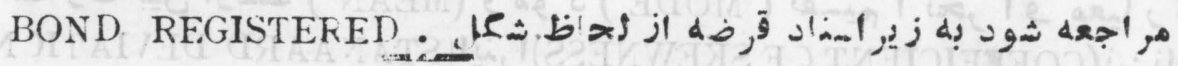

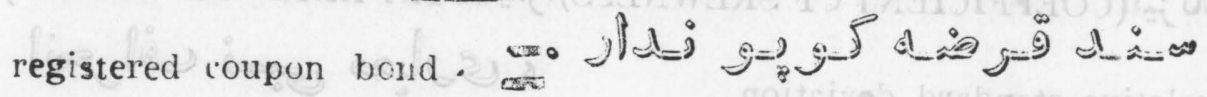
هـ

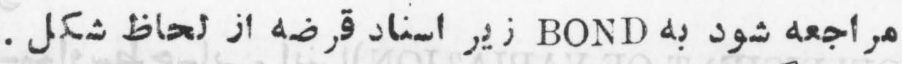
re ressive taxation - ज行 


\section{REG}

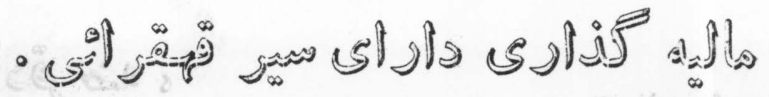

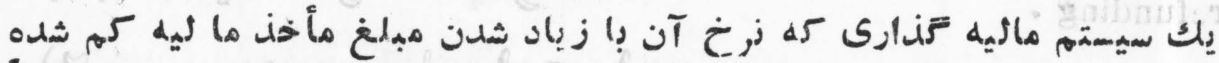

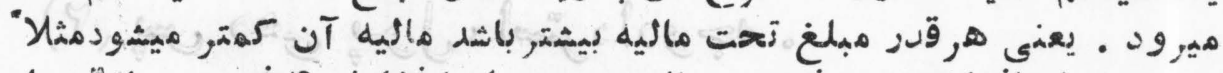

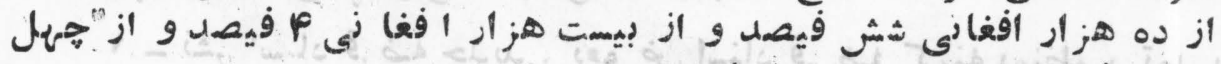

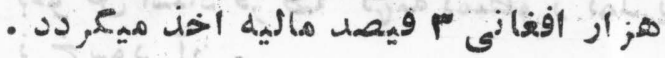

regressivity •

$$
\text { - जी }
$$

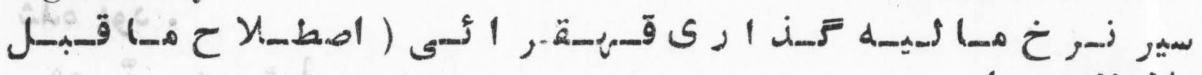
ما لاحظهشود.)

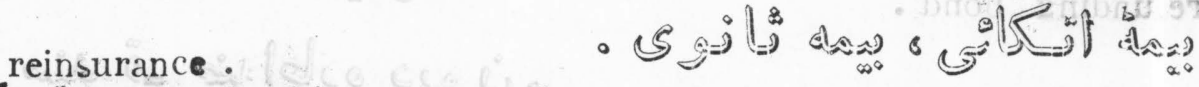

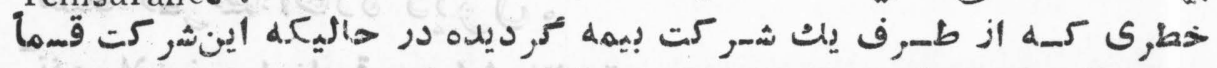

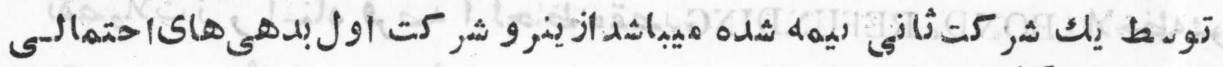
خود را ميكاهد.

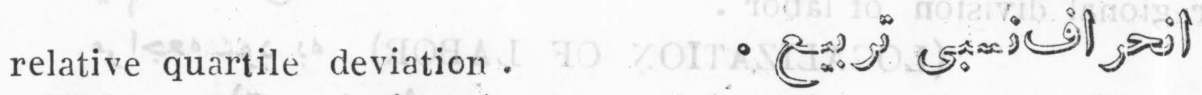

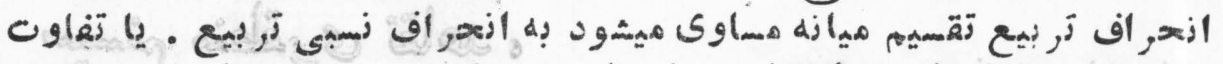

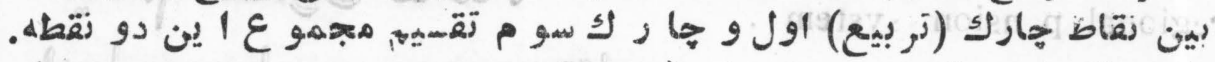

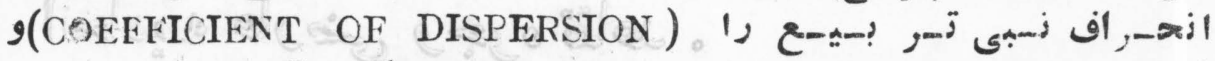
(COEFFICIENT OF QUARTILE DEVIATION)

relative skewness.

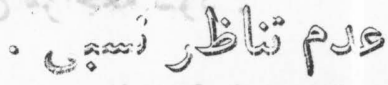

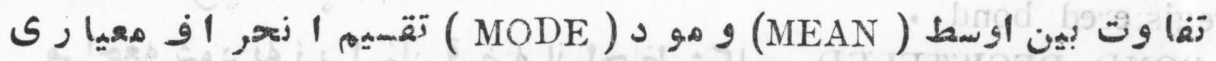

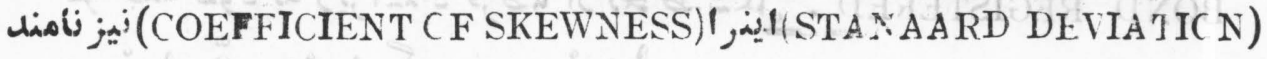

relative standard ceviation .

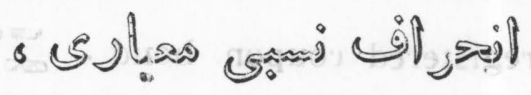

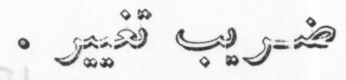

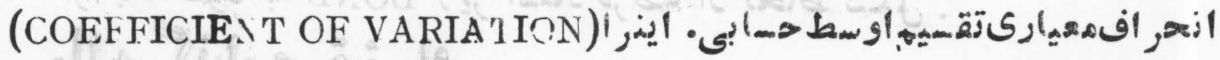

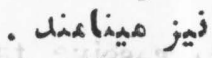




\section{REP}

remonetization.

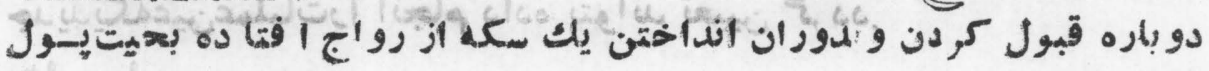

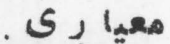

rent.

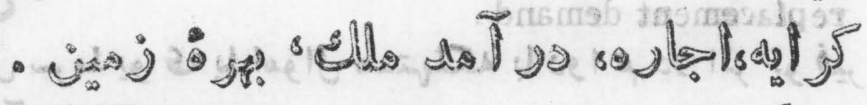

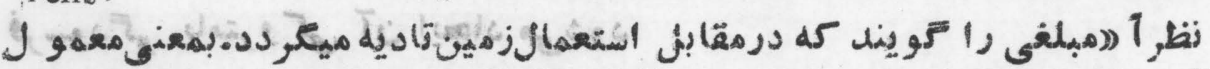

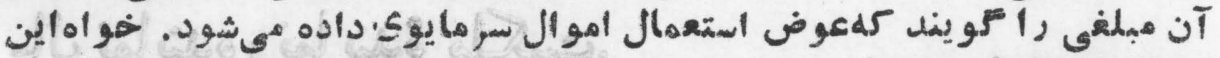

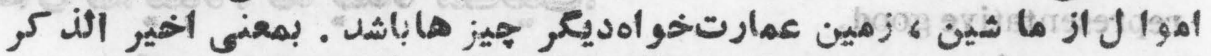

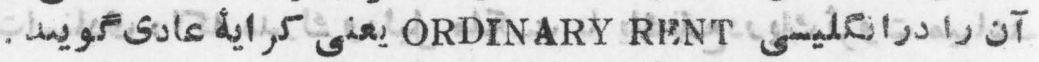

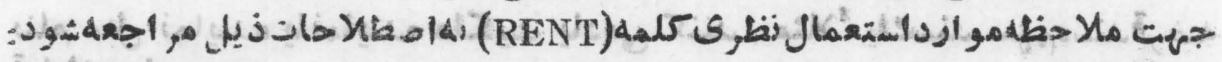
CAPITAL RENT, CONTRACT RENT, ECONOMIC RENT, EXPLICJT RENT, DEAD RENT

mentier.

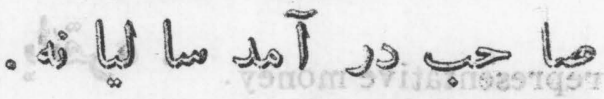

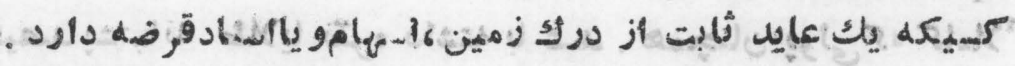
reorgonization bond.

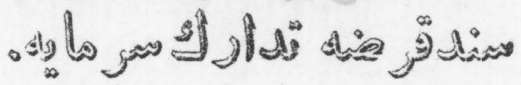

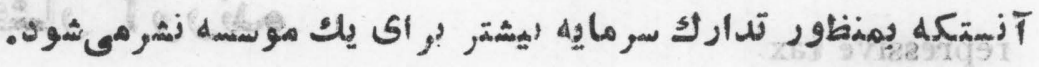
reparations. - @ ا

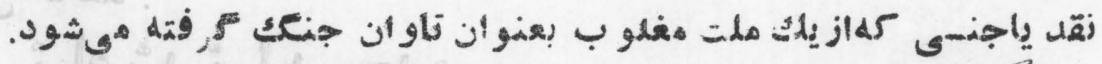
repatriation.

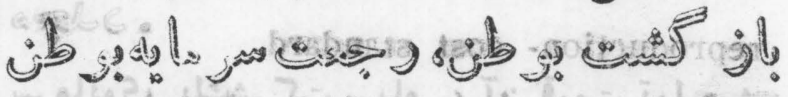

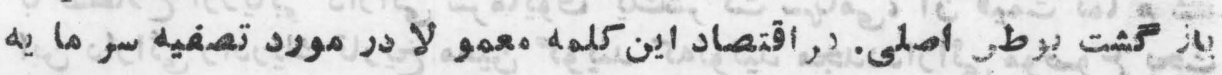
أر أستعمال ل مـ

replacement - cost standard.

- 递

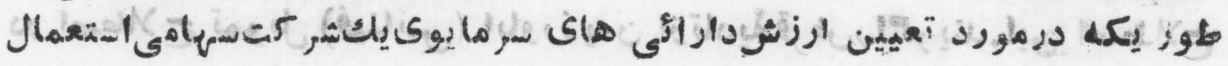




\section{REP}

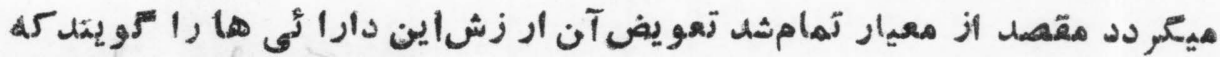

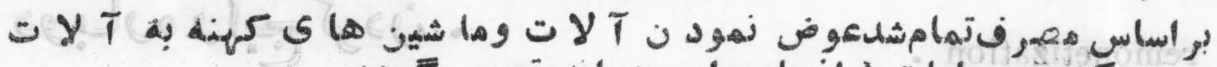

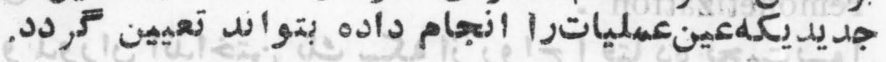

replacement demand.

- 5 slia

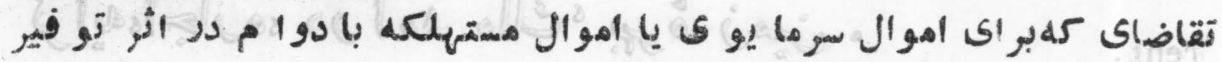

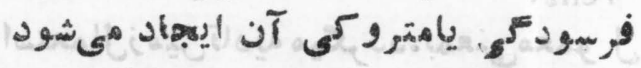

representative good.

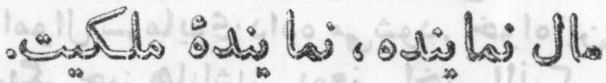

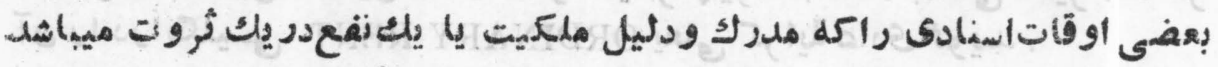

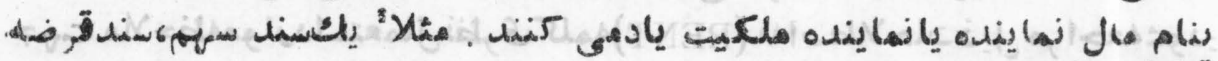

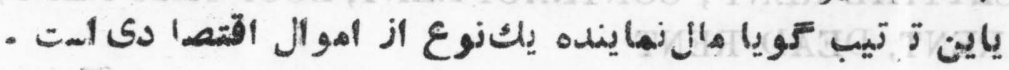

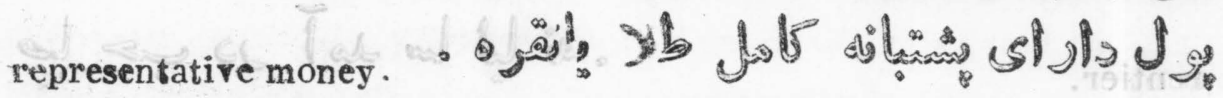

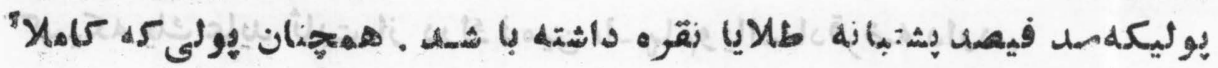

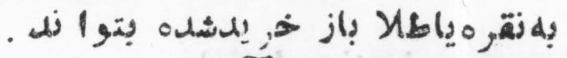
repressive tax.

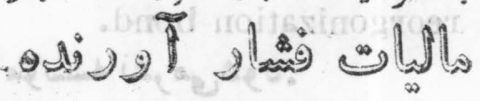

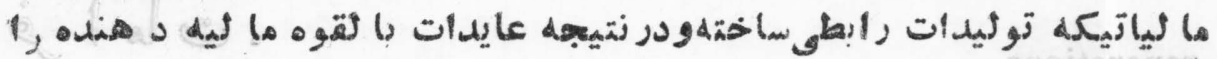
. 10015 is

reproduction- cost standard.

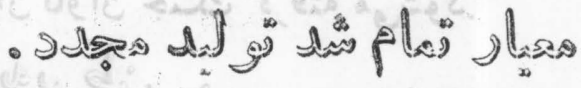

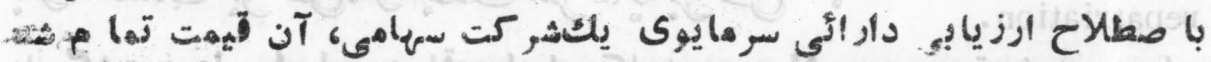

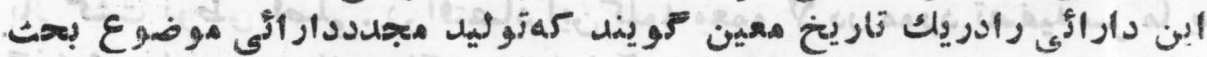

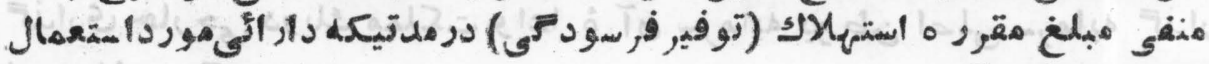
.

repudiation.

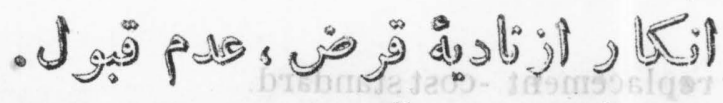

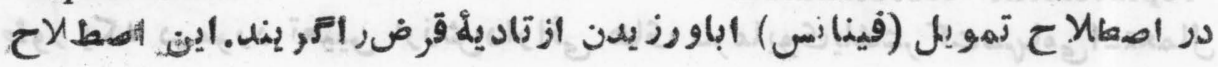




\section{KLS}

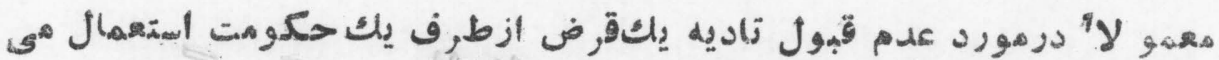

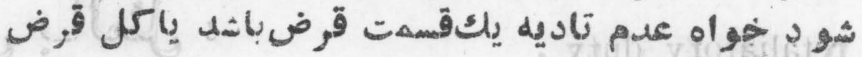

reservation price. - जु)

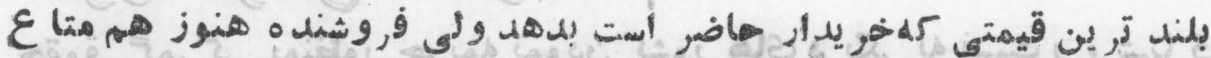

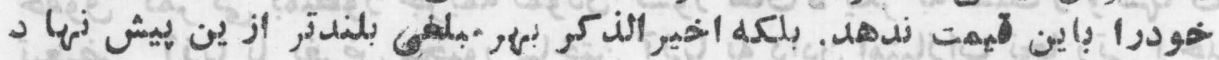

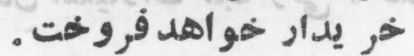

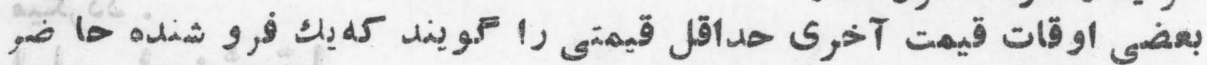

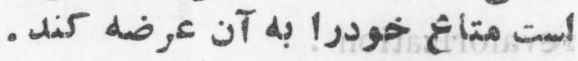

reserve ratio.

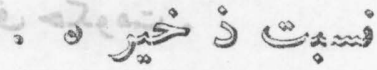

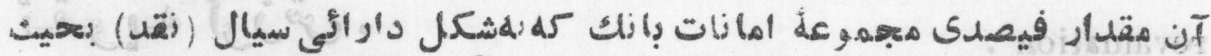

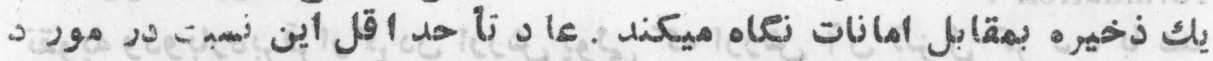

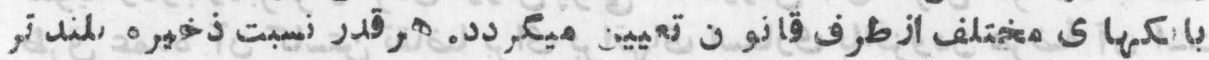

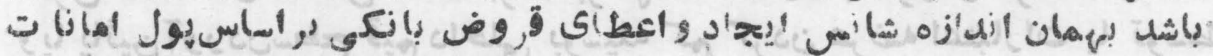

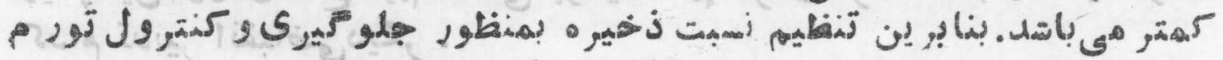

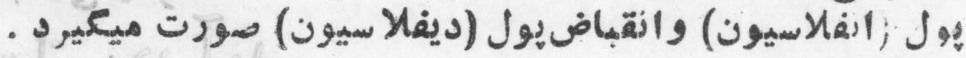

reserves . $g=0,1=0$

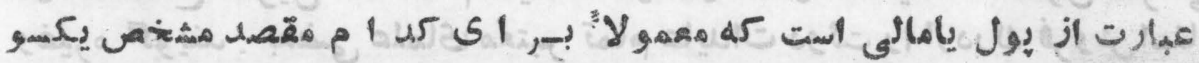

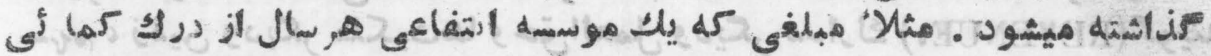

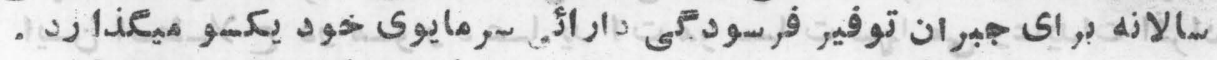

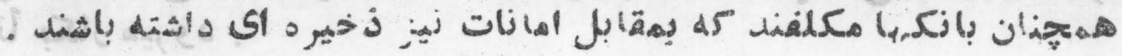

restraiut of trade.

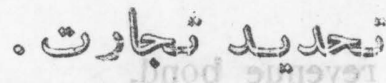

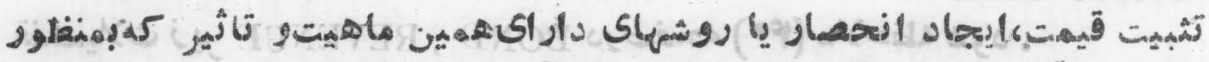

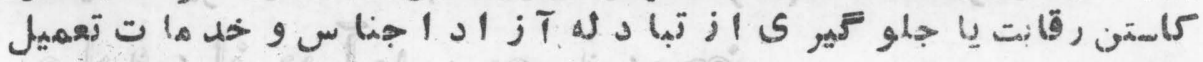

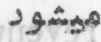

restrictive indorsement.

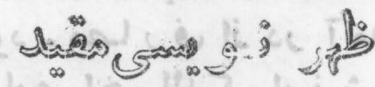

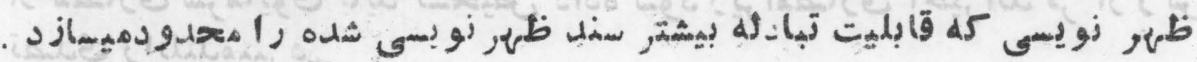


RE T

retaliatory duty.

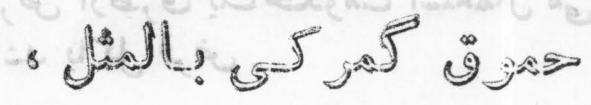

-

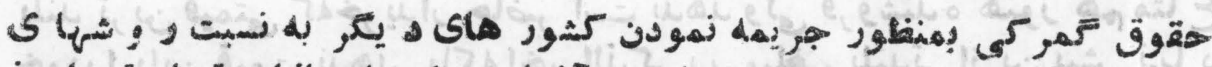

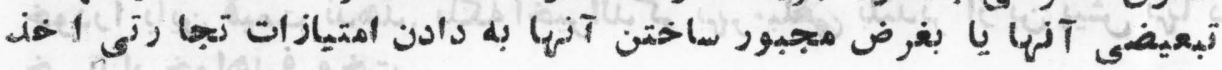

revalorization.

$$
\text { - مئر }
$$

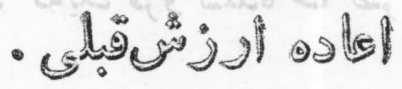

دو باره بقرار سا ختن ارزش قبلى و أهل بولى إز طرف هكومت .

revaluation .

$$
\text { - जि }
$$

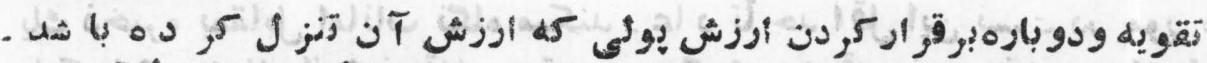

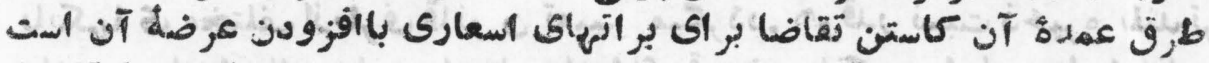

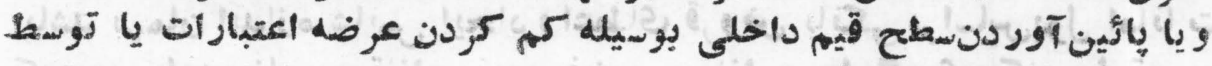

revenue .

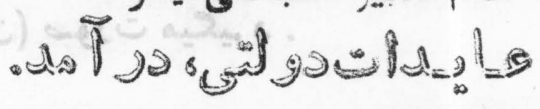

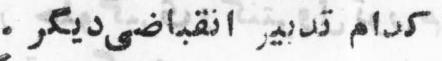

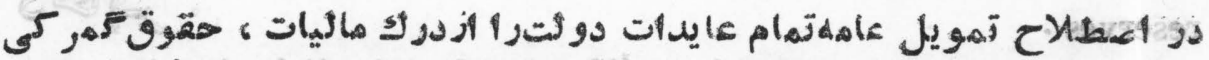

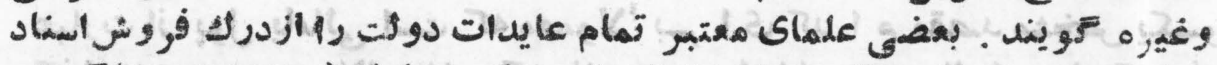
Fل Fو ينل

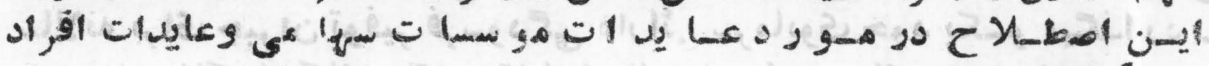

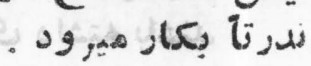

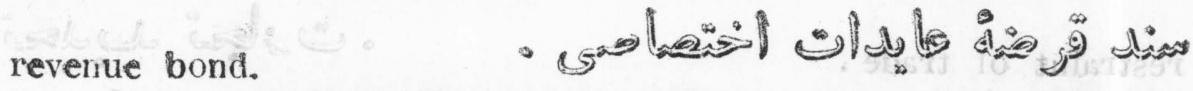

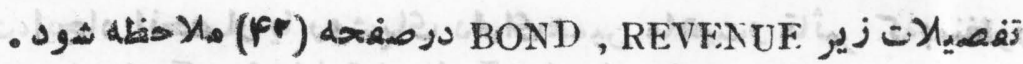

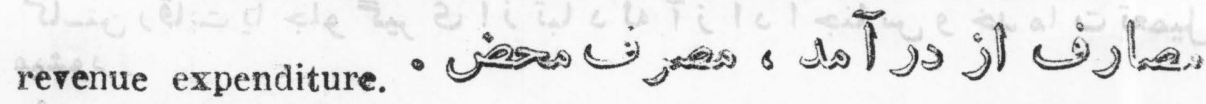

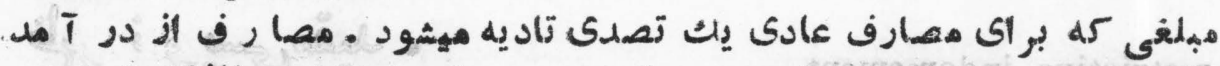

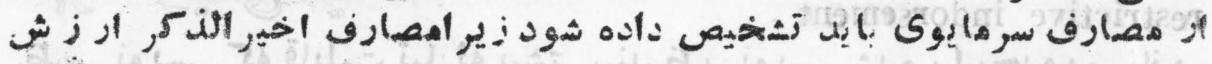

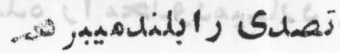




\section{RIS}

revocable letter of credit

what

$$
\begin{aligned}
& 40 \text { ob } \\
& \text { ह } \\
& \text { LETTER OF CREDIT . تعيدات زير }
\end{aligned}
$$

revolving fund .

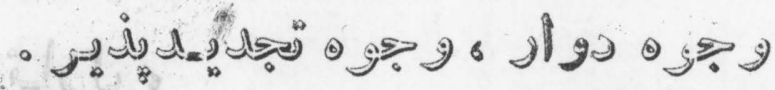

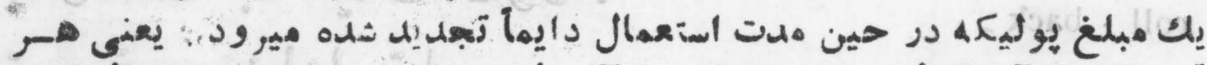

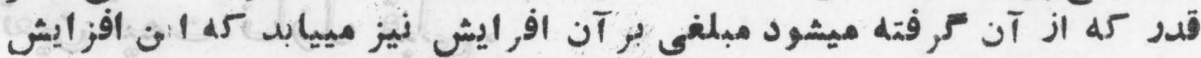

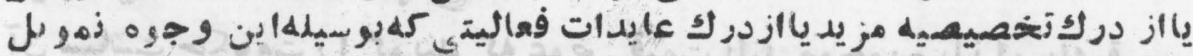

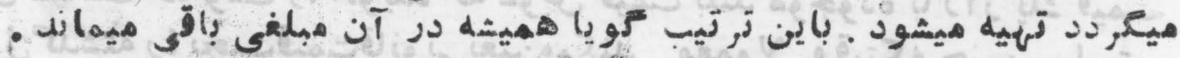

revolving letter of cridit.

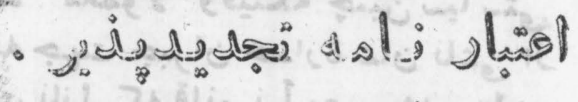

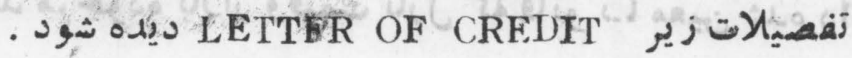

Ricardian theory of rent .

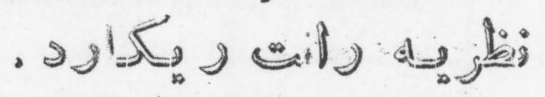

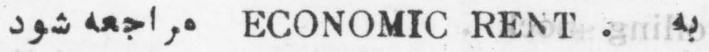

risk

$$
\text { - . }
$$

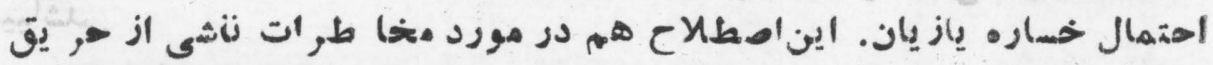

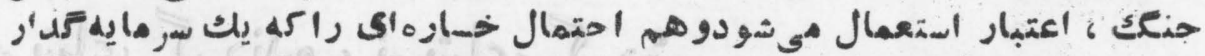

risk bearer.

$$
\begin{aligned}
& \text { در جيث دارد أفاده ميكند . } \\
& \text { - Jis: }
\end{aligned}
$$

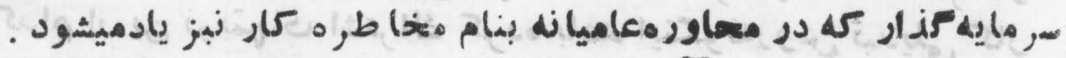

risk capital .

-

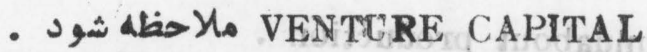

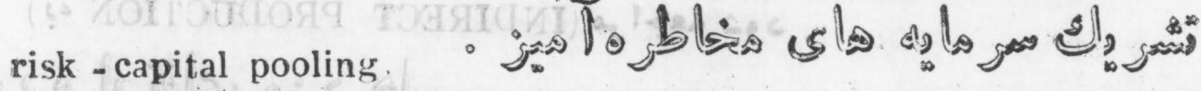

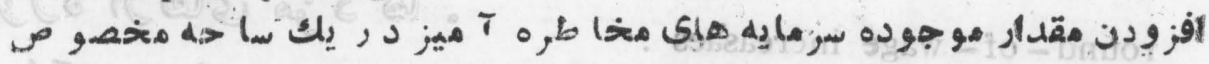




\section{ROL}

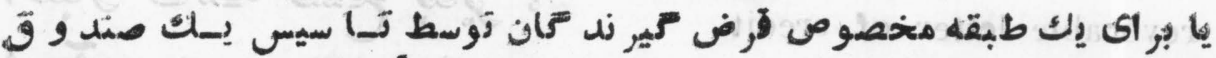
(FCND)

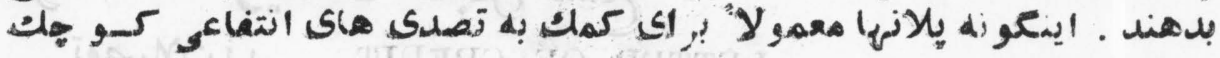

soll - back.

$$
\begin{aligned}
& \text { - Jjli }
\end{aligned}
$$

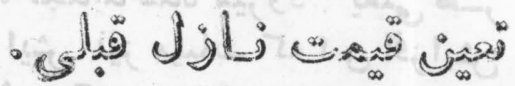

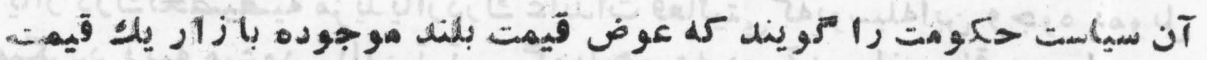

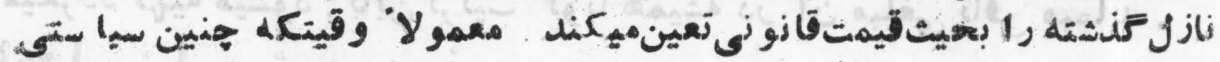

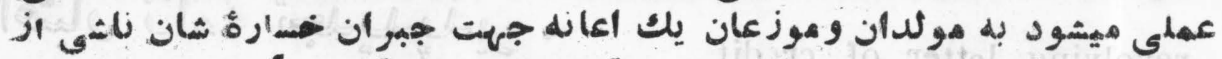

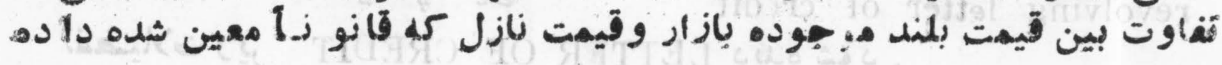
نيشيود . تماوت بين

rolling :trock.

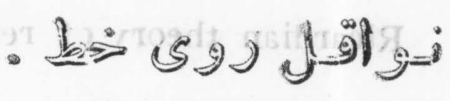

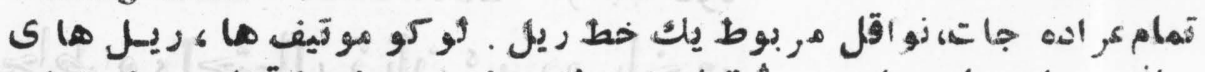

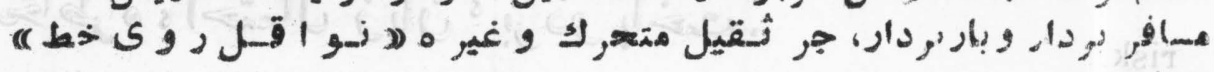

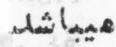

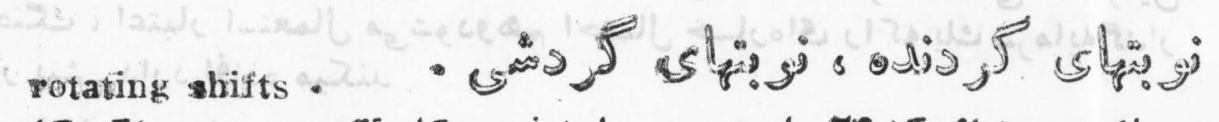

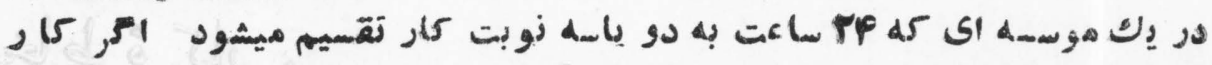

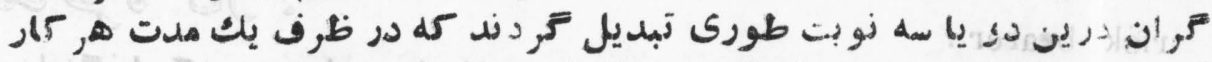

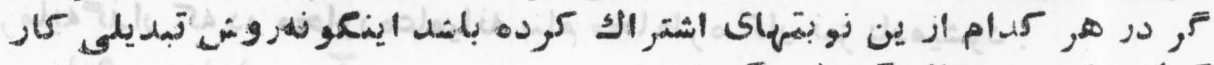

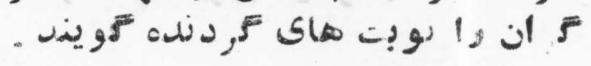
roundabout production. Neth مر إج (INDIRECT PRODUC'IION «?)

round-of-wage increasaes .

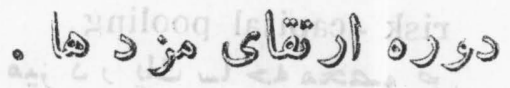

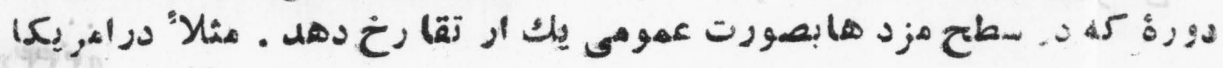




\section{RUN}

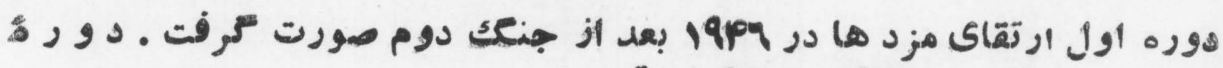

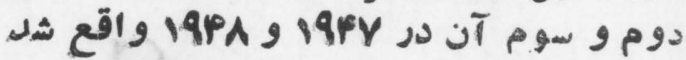

royality . -

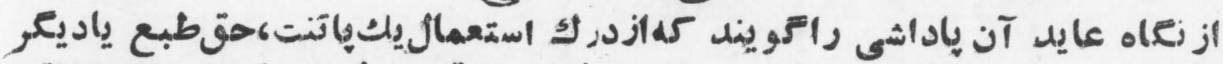

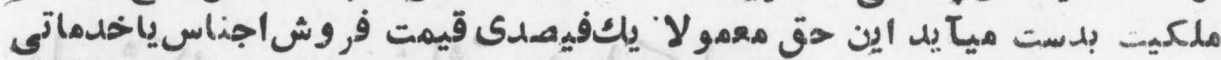

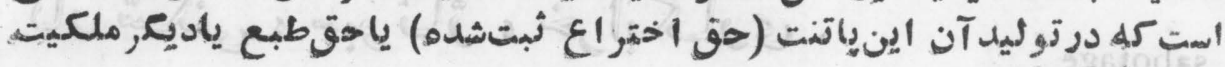
إكار بره شده

runaway shop.

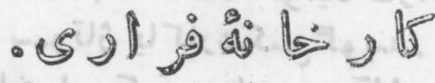

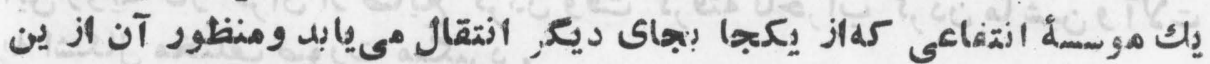

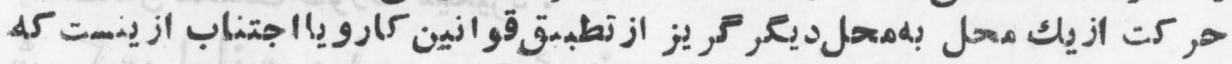
أ. is

runaway inflation.

r.

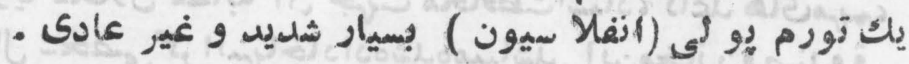

running cost .

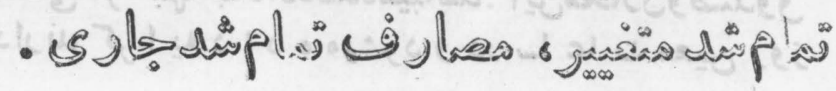
مراج (VARIABLE COST) de

run on a bank.

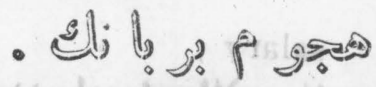

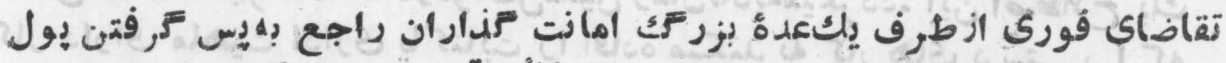

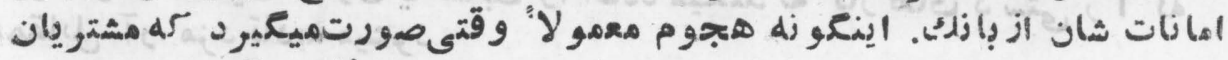

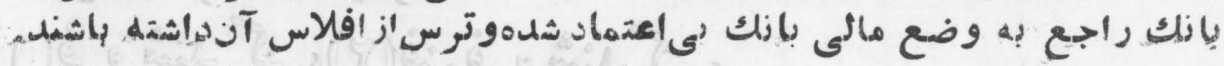

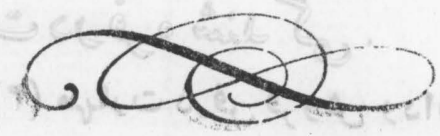


sabotage.

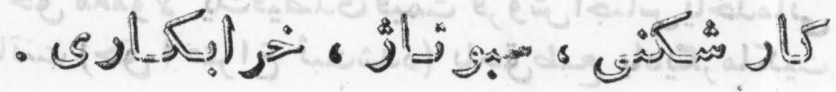

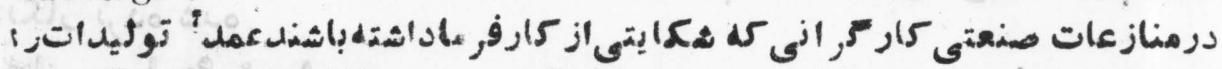

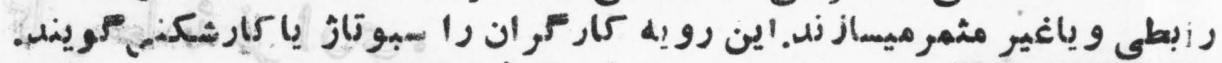

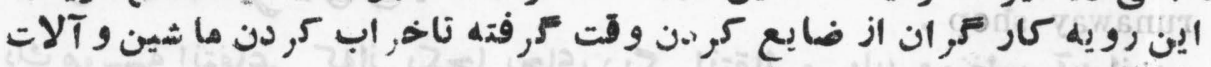

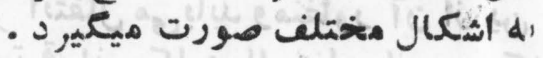

safe - deposit company.

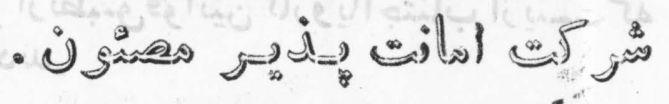

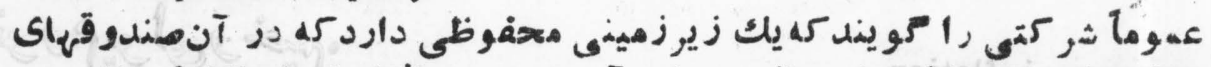

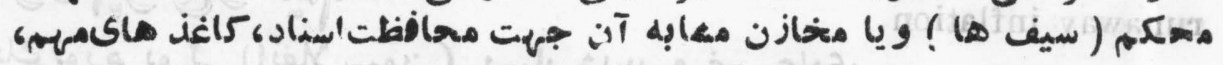

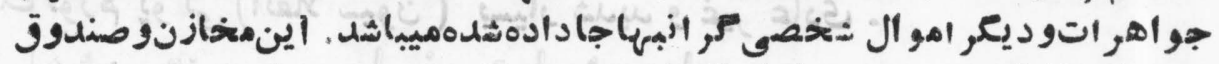

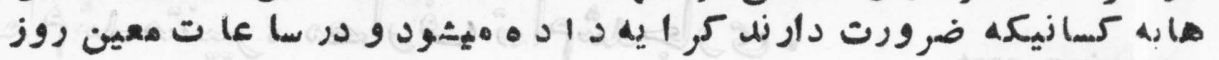

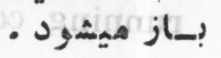

salary,

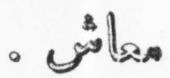

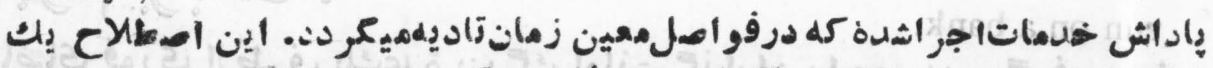

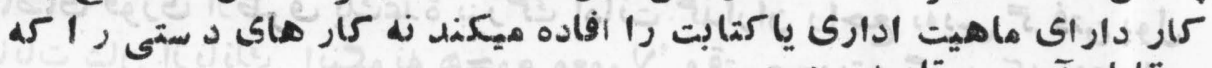

salesmanship

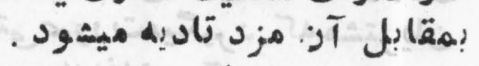

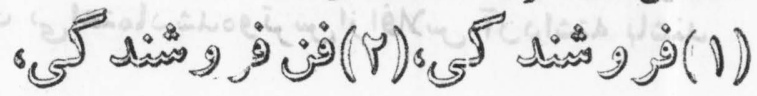

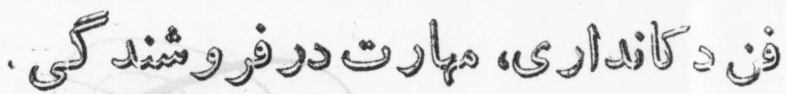

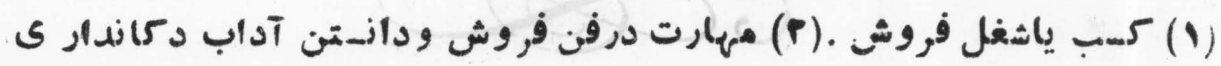

sampe

- 800

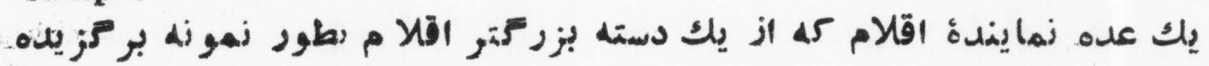


sales tax .

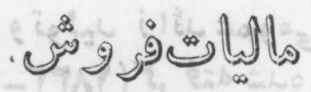

ماكياتى كله برفروش اجناس وخلمهات در إك يابيشتر مراحل عمل توز يع وضع ميغكر. دد • ماريات

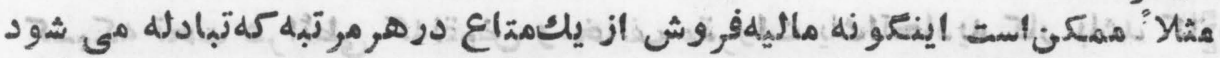

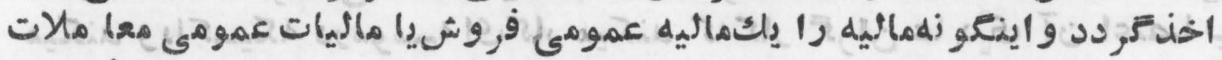
هى (TURNOVER OR TRANSACTIEN TAX)

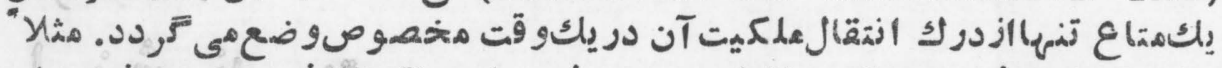

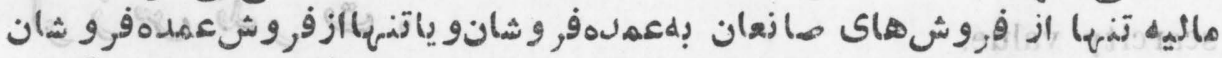

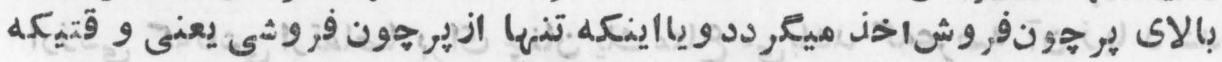

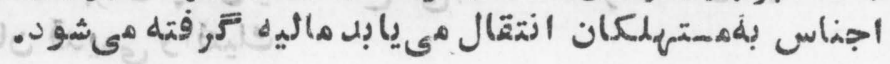

sampling

- ज

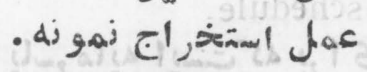

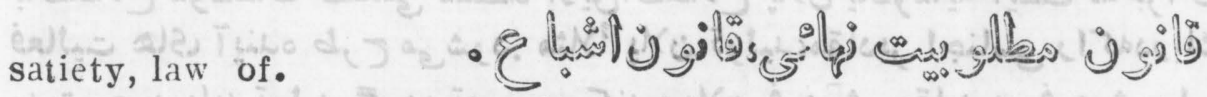

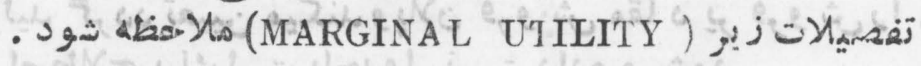

saving.

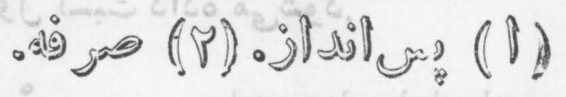

ا 1

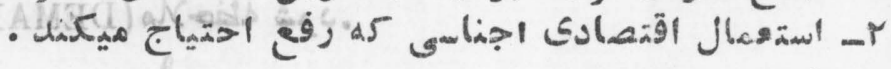

savings bank.

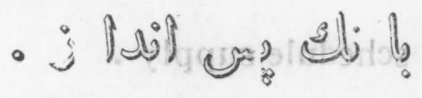

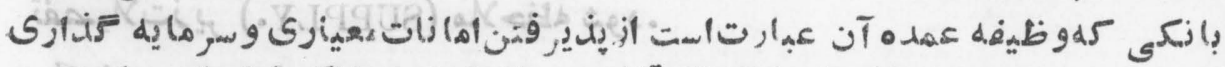

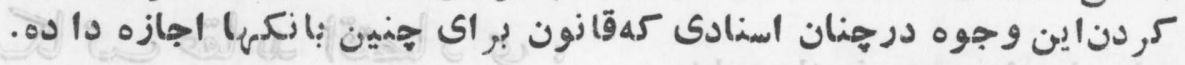

Say's law.

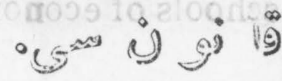

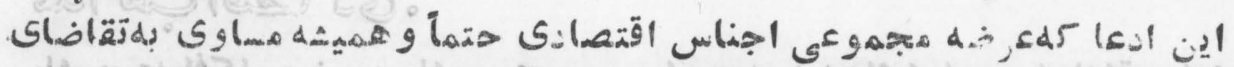

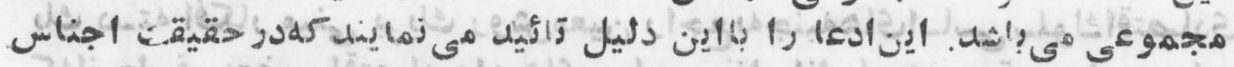

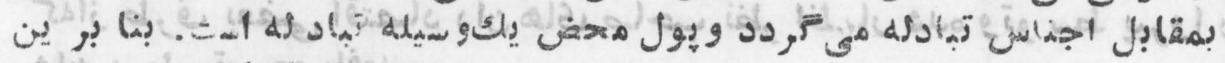

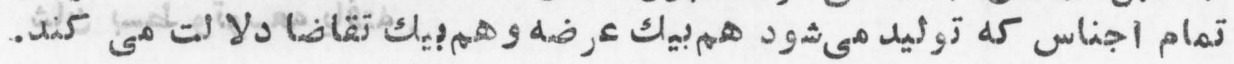




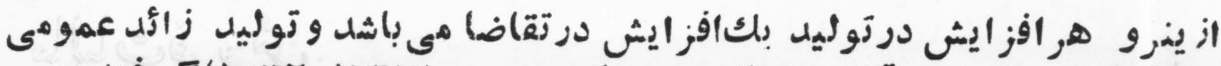

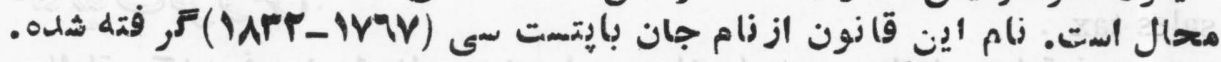

scab. - Uी

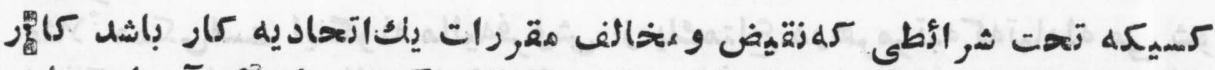

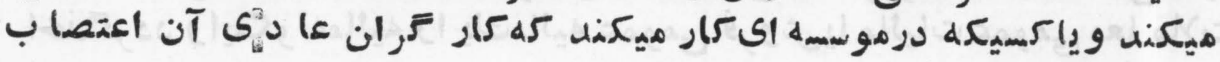
كو ده اند. .

scarcity value.

$$
\text { - } \underbrace{\infty}
$$

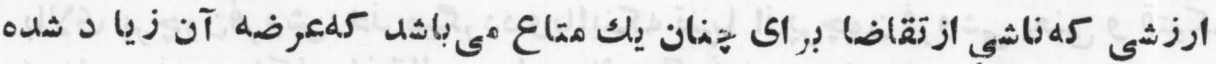

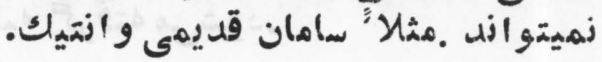

schedule.

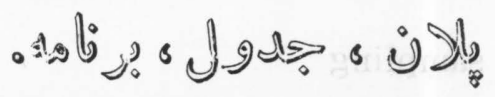

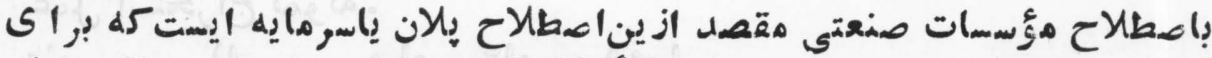

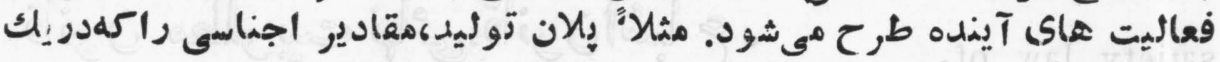

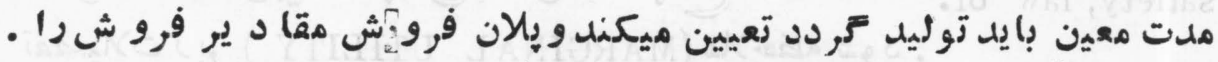

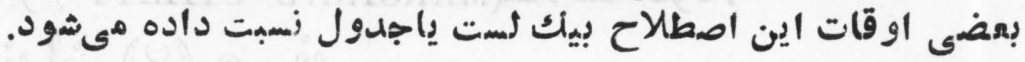

schedule demand.

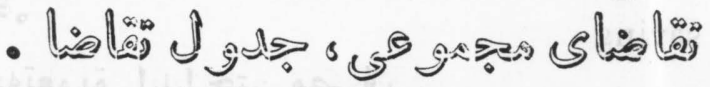
تفصيلات زير (DEMAND.) ملاحظه شود.

schedule supply .

- A تفصيلاتز ير (SUPPLY) ملاح مظه شود.

schools of economic thought .

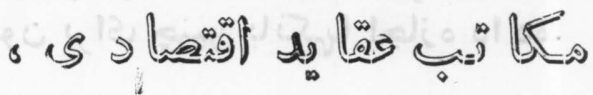
- 53 1.

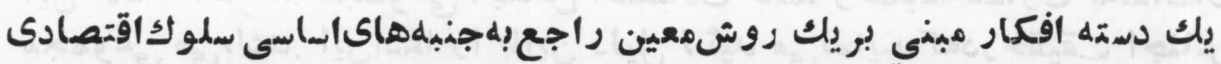

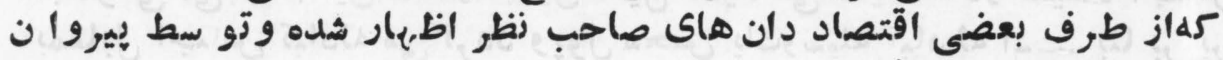
شان بسط وتوسعه يافته . 


\section{SEC}

scrip.

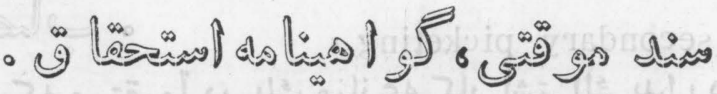

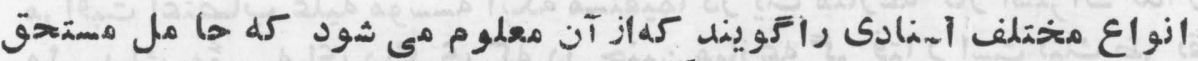

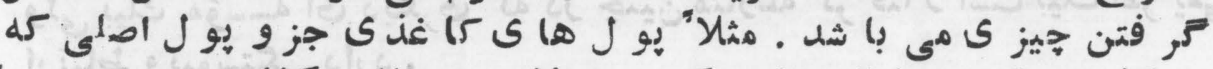

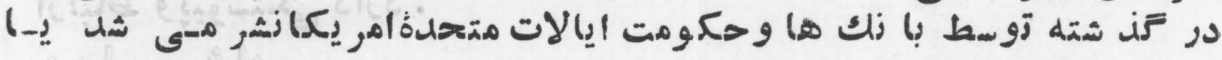

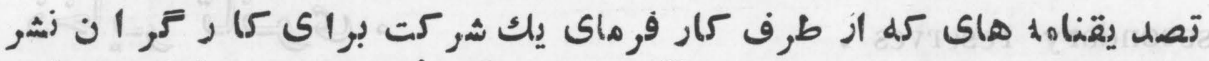

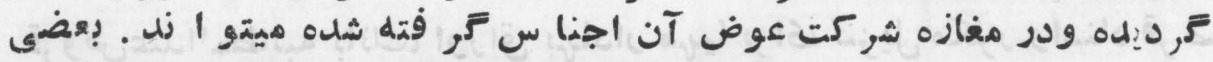

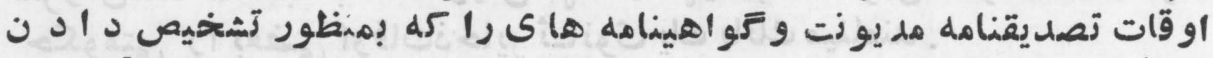

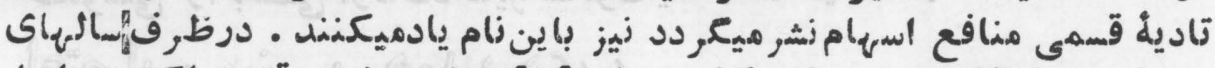

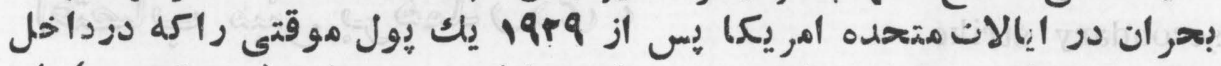

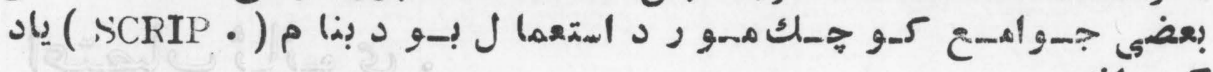
كريداندان

scrip dividend .

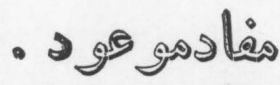

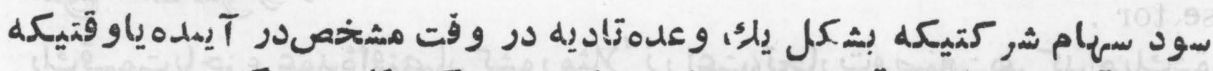

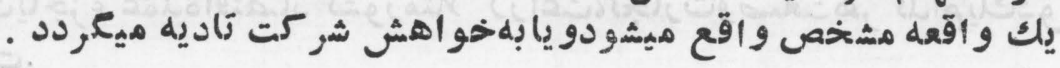

seasonal unemployment . - ज海

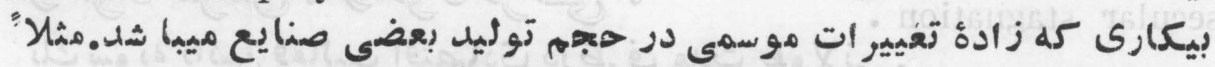

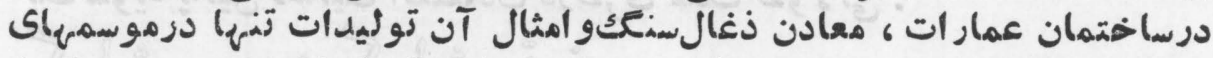

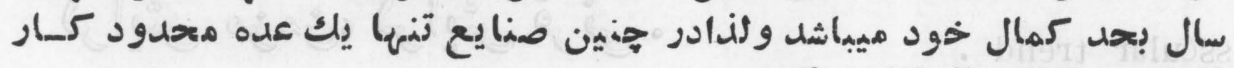

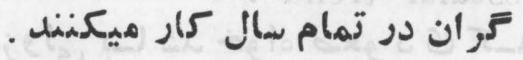

seat on the exchange Bundz=: de

$$
\begin{aligned}
& \text { - S } \\
& \text { عضو بودن در يك"بّورس . }
\end{aligned}
$$

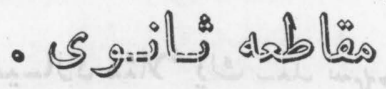

$$
\begin{aligned}
& \text { تفصيلات زير ( BOYCOTT ) ملاحظه شود م }
\end{aligned}
$$

secondary borcott 


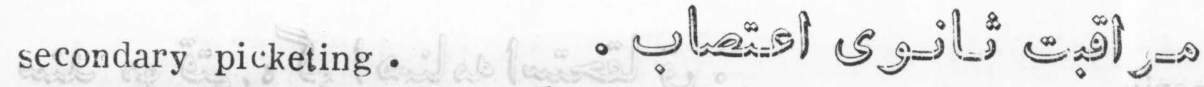

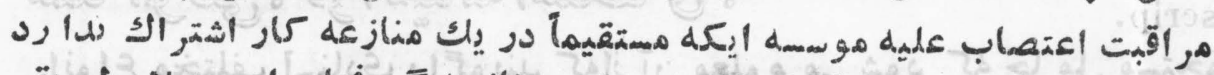

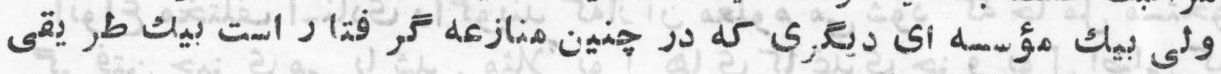

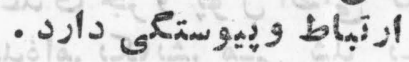

secondary reserves.

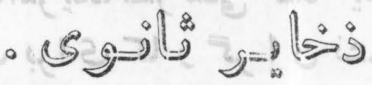

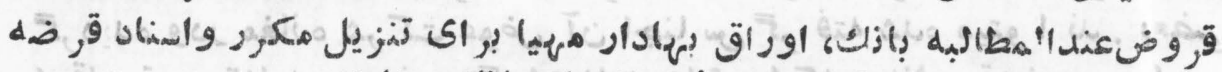

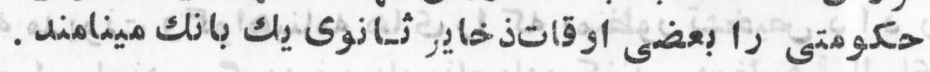

secondary strike.

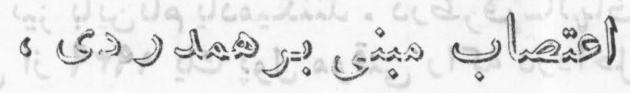

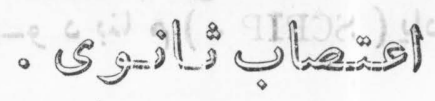

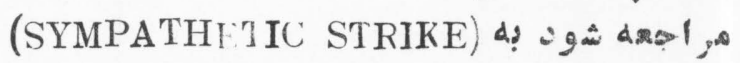

se.tor .

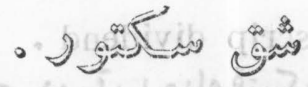

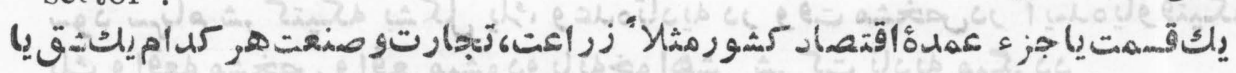
سمتور است.

secular stagnation.

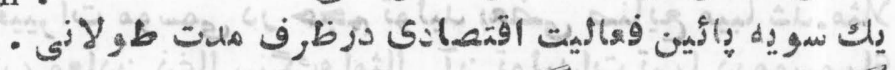

sscular trend.

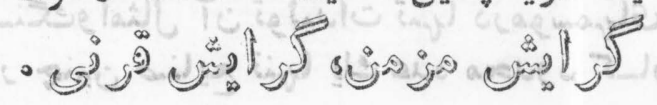

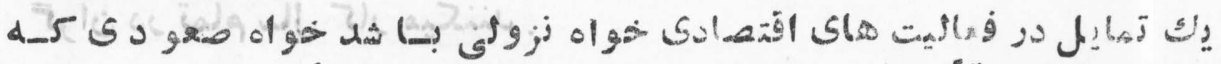

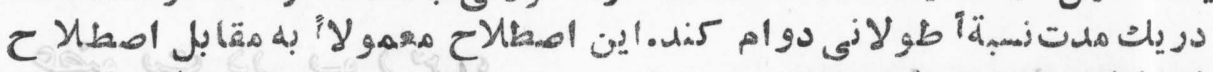

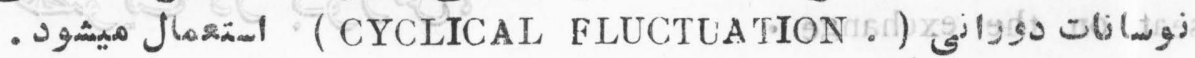

security .

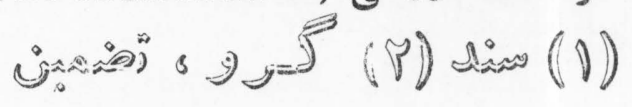

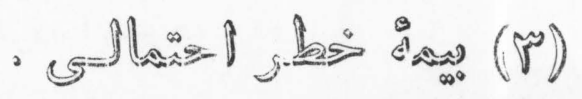

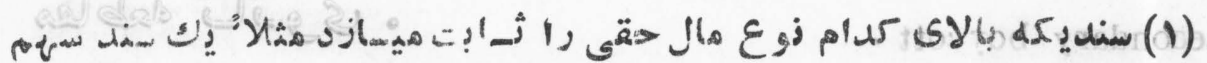

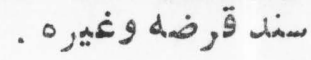




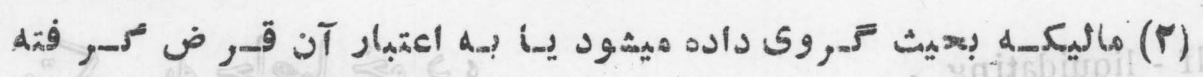

ميشמون

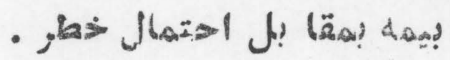

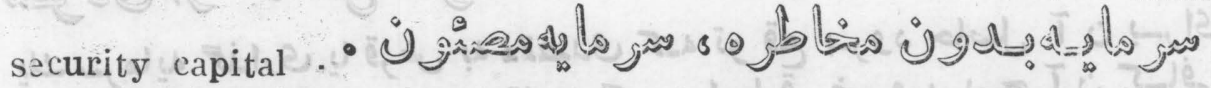

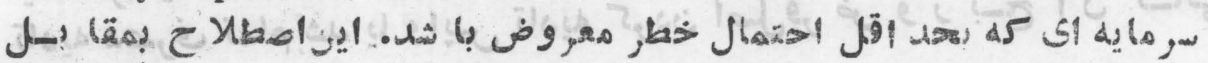

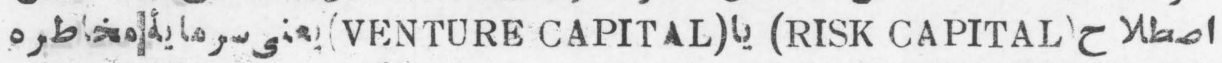

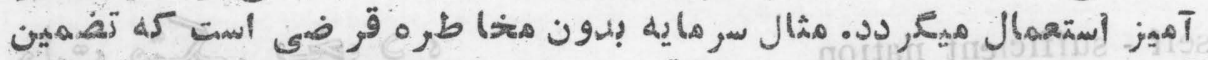

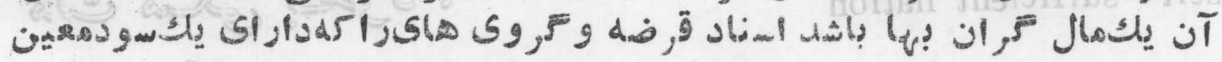

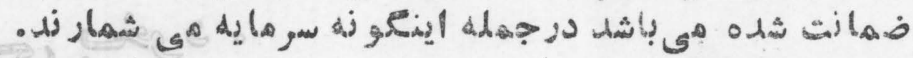
security exchange. دوث deج 1,0 (STOCK EXCHANGE 4?

segregated appropriation. - gी बं\% d زو seigniorage. $\because$ siall

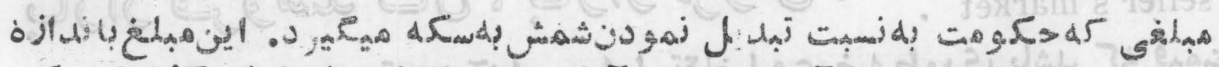

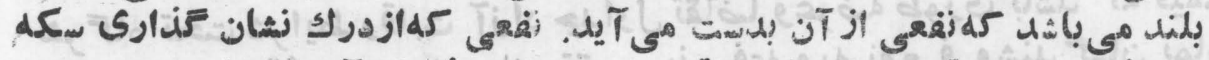

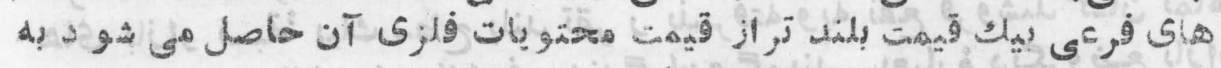
.

self interest.

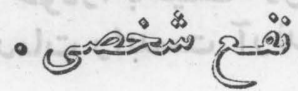

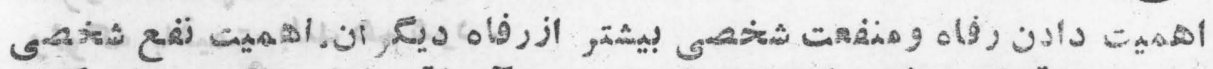

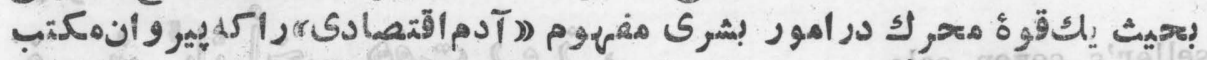

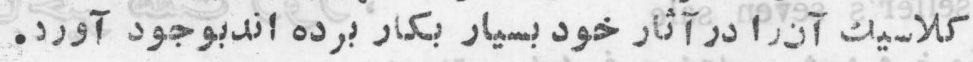

self interest, law of.

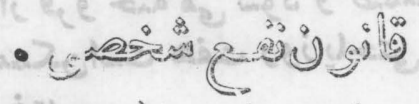

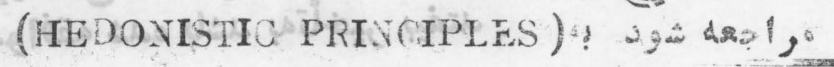


self - liquidating .

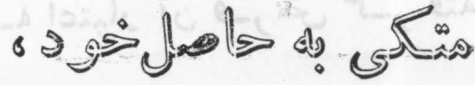

$$
\begin{aligned}
& \text { - I }
\end{aligned}
$$

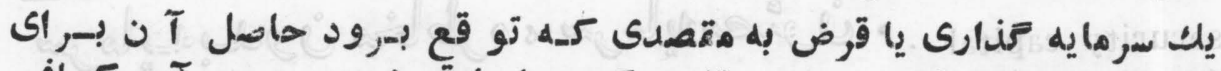

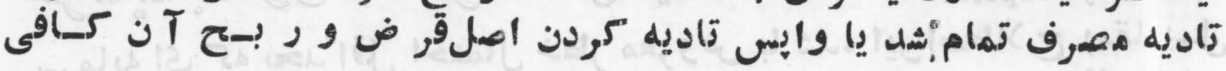

self - sufficient nation

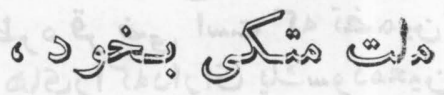

$$
\text { - Iوخ்? } \mathrm{F}
$$

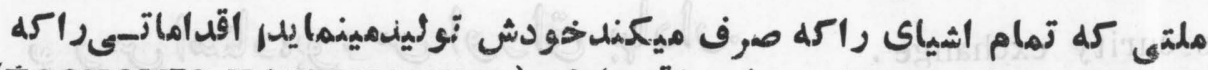

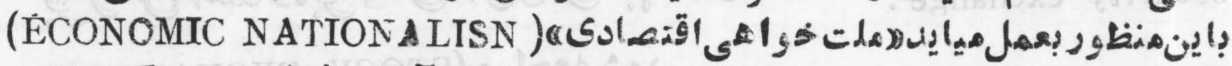

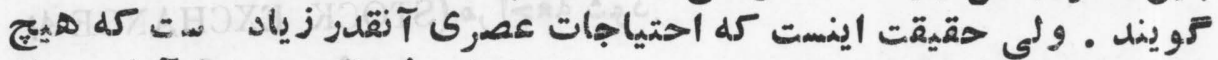

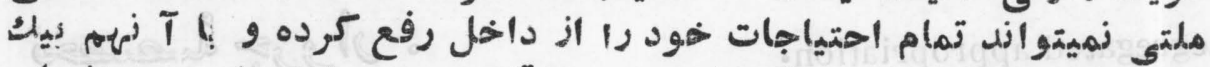

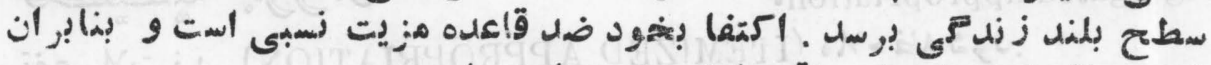

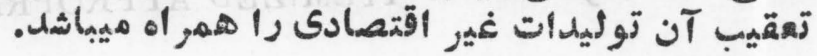
seller's market . - •

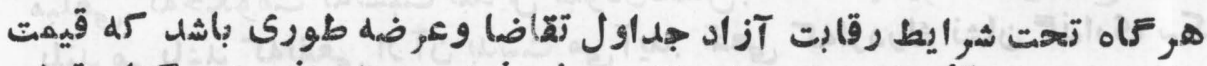

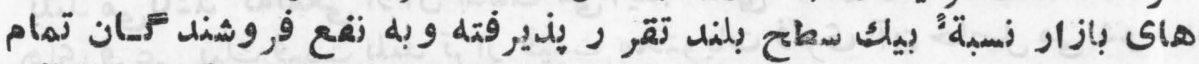

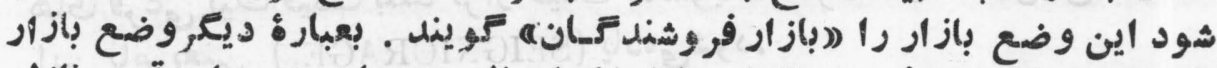

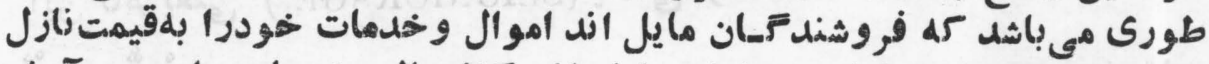

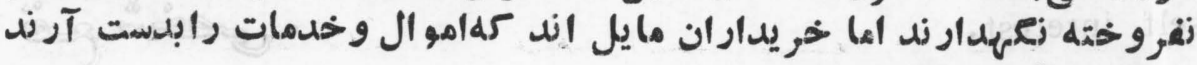

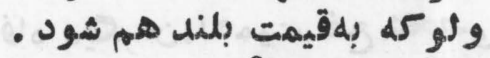

seller's seven sale

$$
\text { - jو }
$$

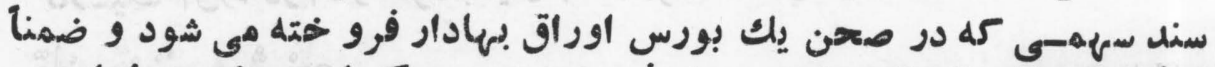

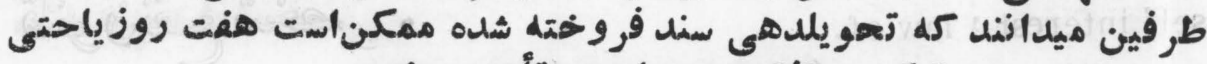

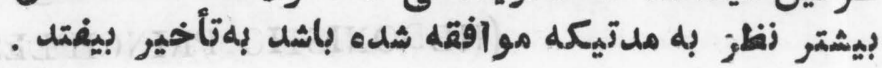




\section{SEN}

seller's surplus .

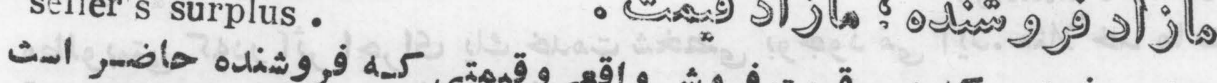

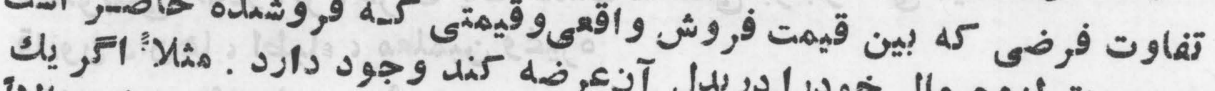

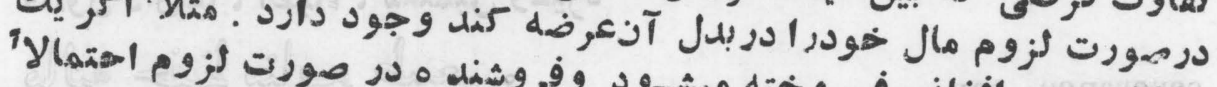

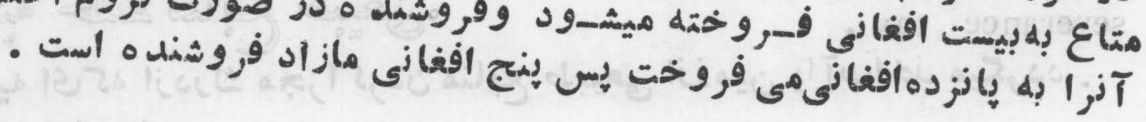

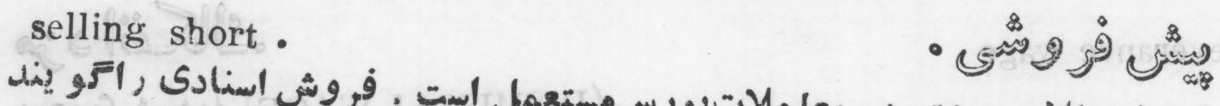

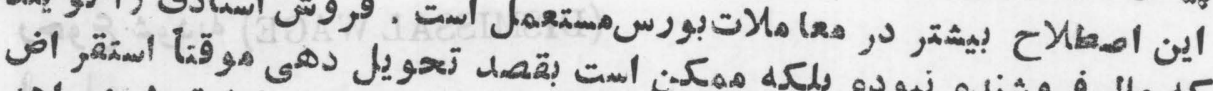

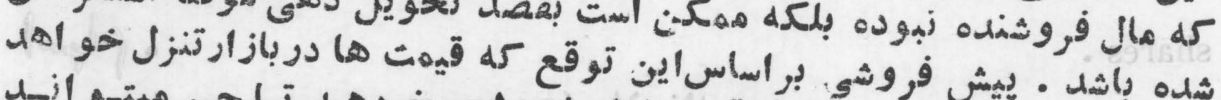

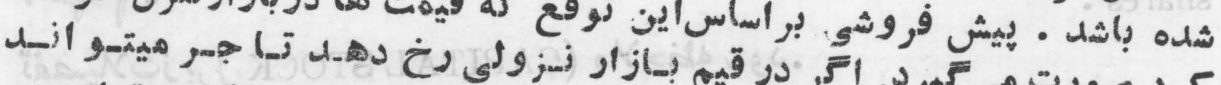

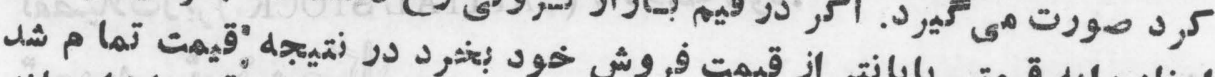

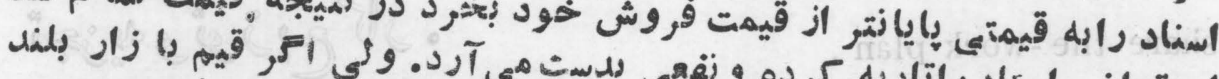

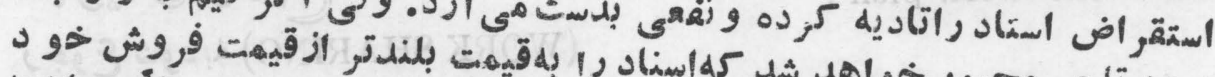

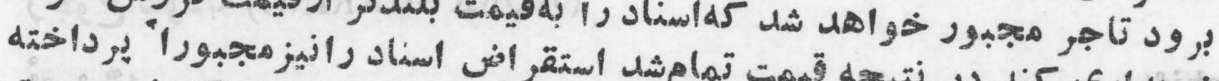

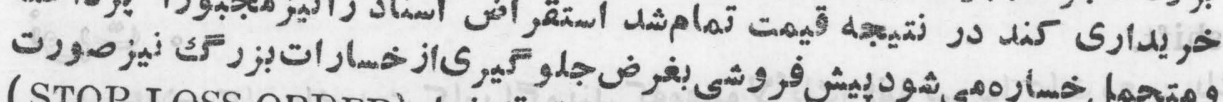

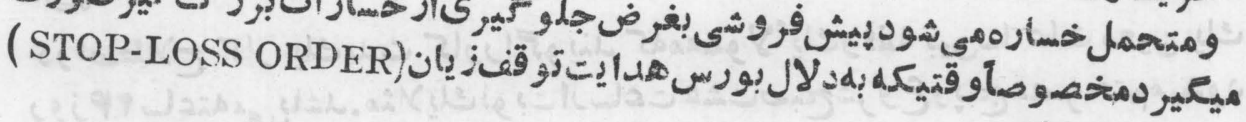
داده شهده بأشد.

seniority.

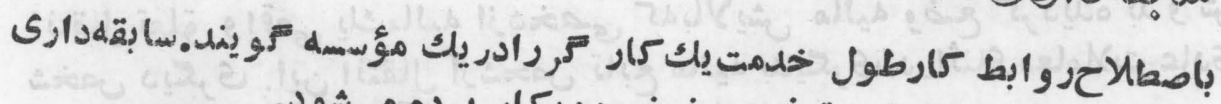

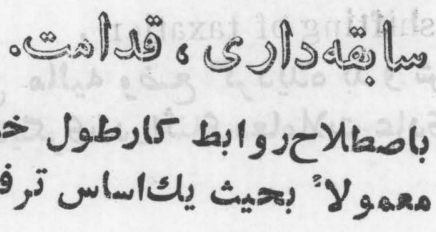

sensitive market.

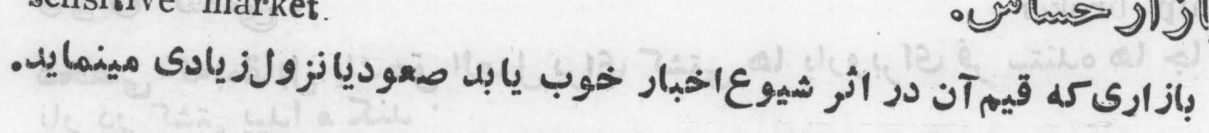
serial bond.

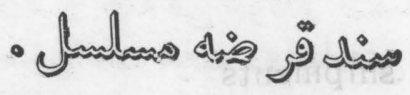

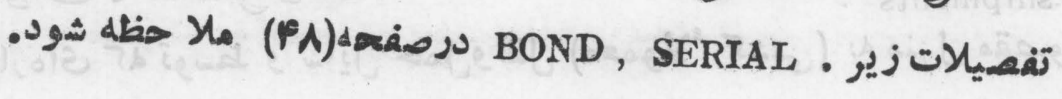




\section{SER}

service utility.

- $\Leftrightarrow$ d

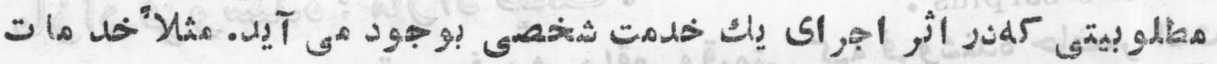

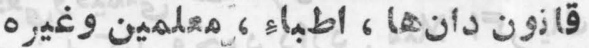
severance $\operatorname{tax}$. -

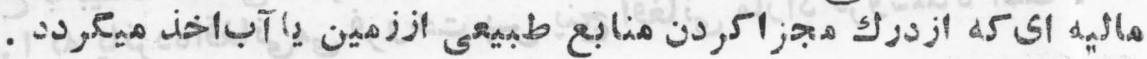
severance wage ه

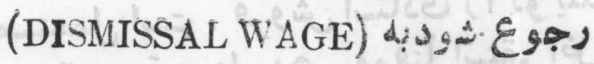
shares. - $p$ (pos

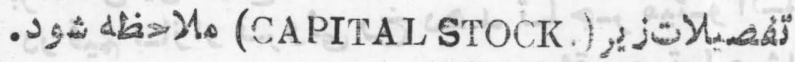
silare-the-work plan. - 25 (WORK SHARING) d د ر

shift. -

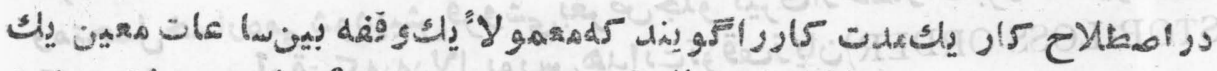

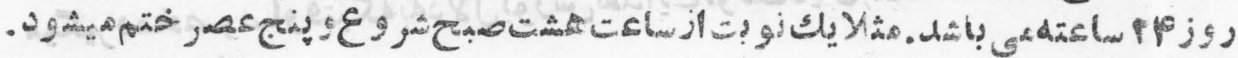
shifting of taxation .

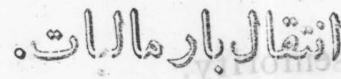

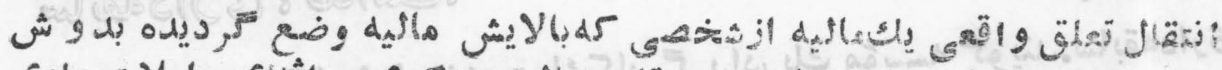

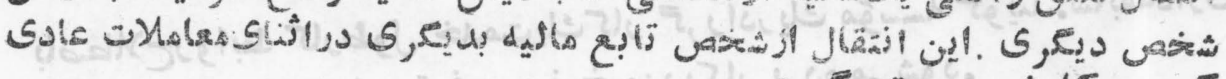

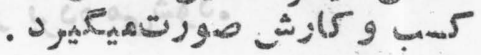

ship broker. o csisis de

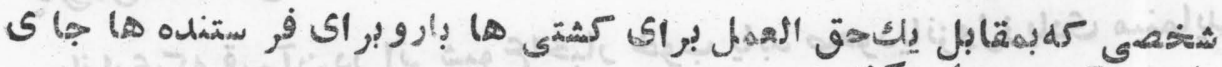

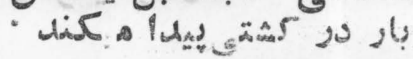

shipments .

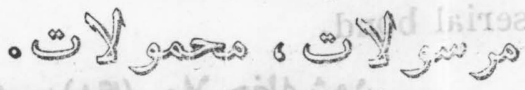

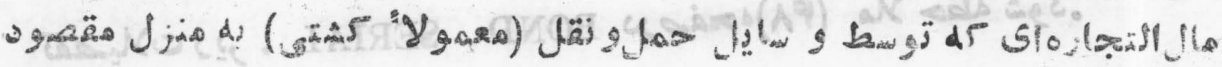


shop.

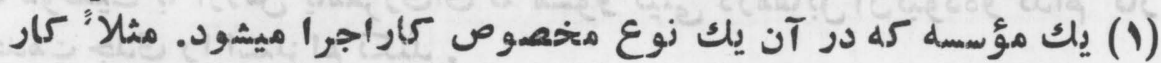

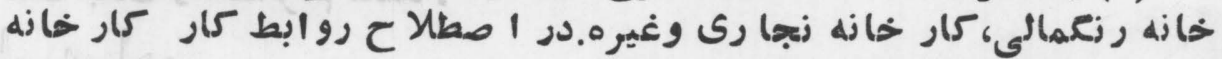

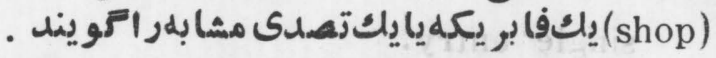

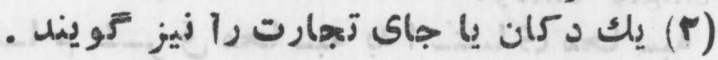

shrinkage .

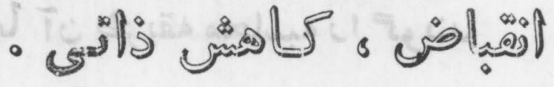

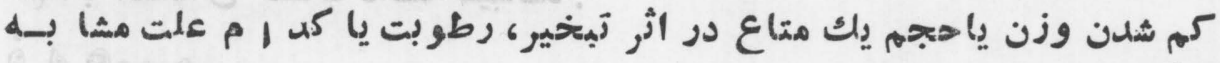

sight bill •

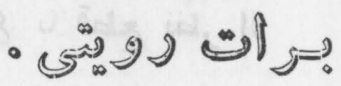

تفصيلات زيو BILL DEMAND (SIGHT BILL) ديده شو د.

sight draft

ن

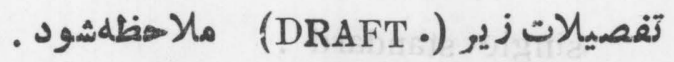

silent partner.

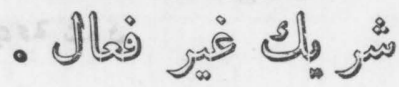

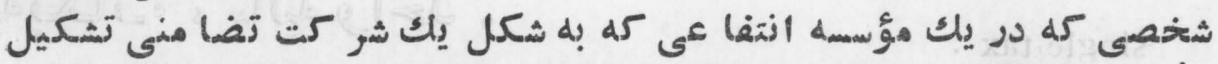

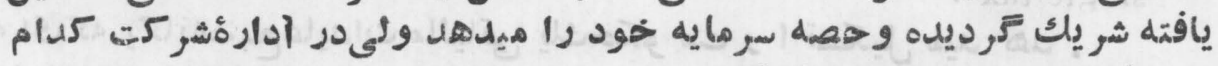

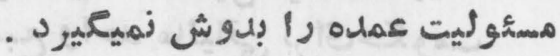

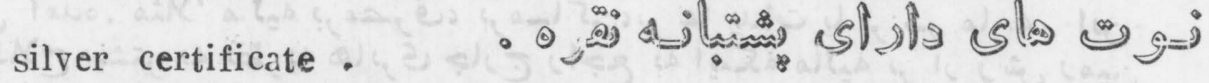

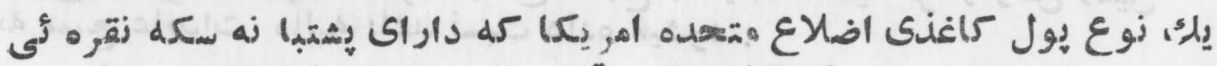

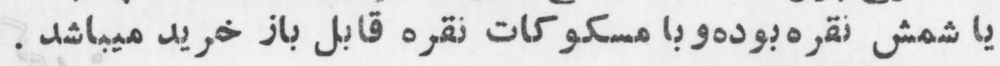

simple interest .

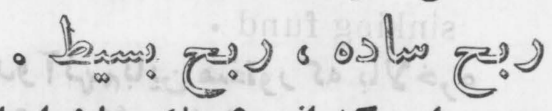

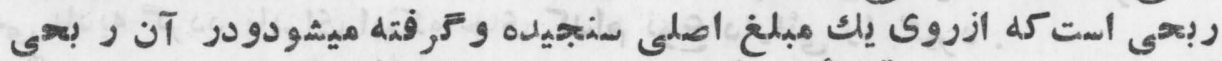

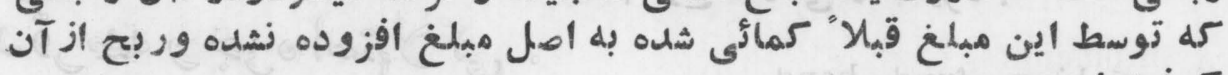

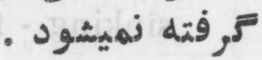


SI:

sinecure .

0 ه يك موقعيت با ارزش يامقروىاى كله مسؤو ليتى درمةا بل آن نبودهو كدام كار

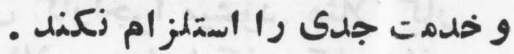

single entry.

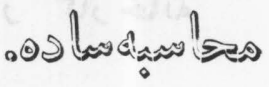

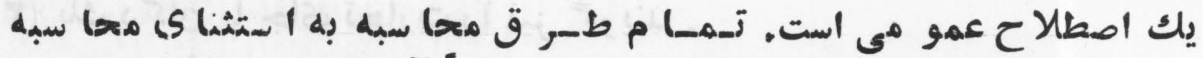

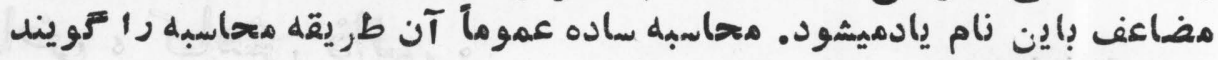
كله تنهرا با اشخاص اص حساب داشته ميبهاشد .

single schedule tariff.

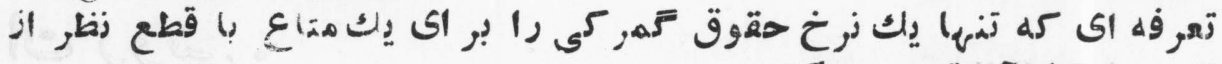

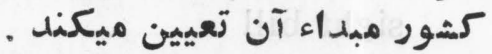

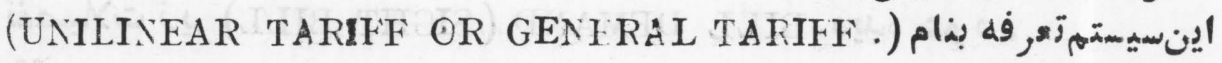
single standard . نيز ياد ميثود .

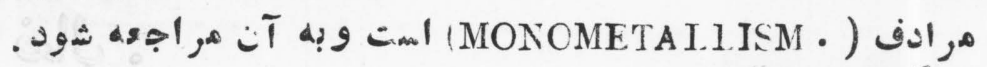
single tax

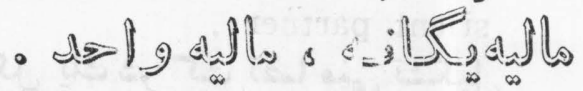

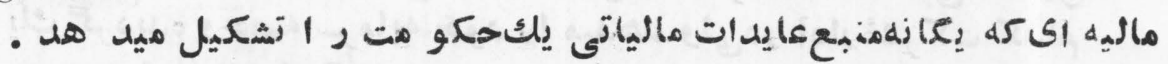

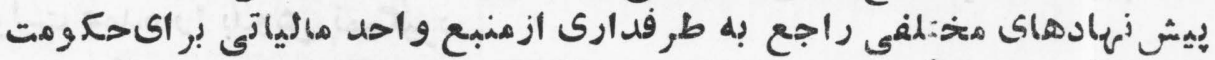

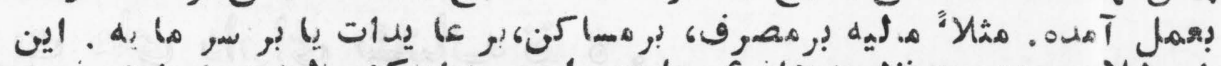

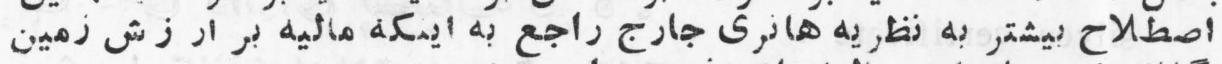

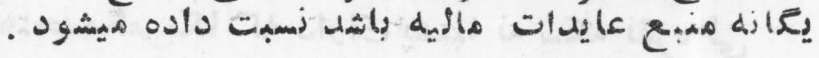

sinking fund •

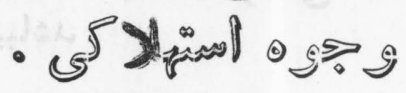

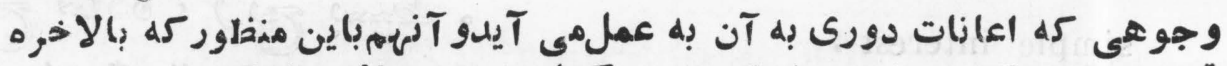

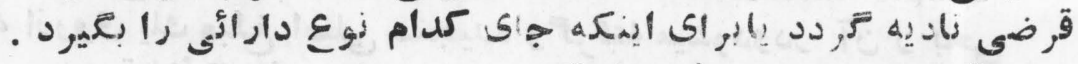
sinking - fund bond .

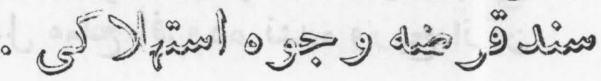

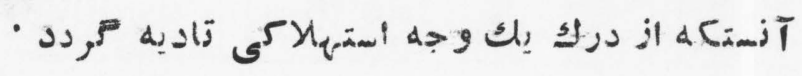


sit - down strike.

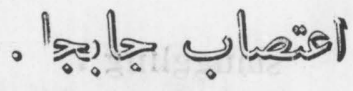

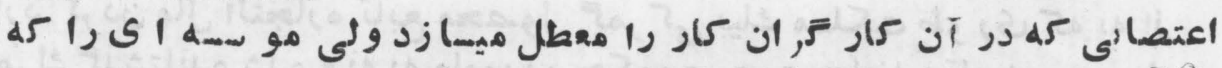

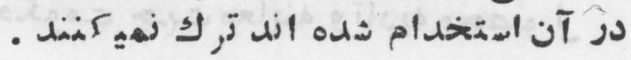

skewness

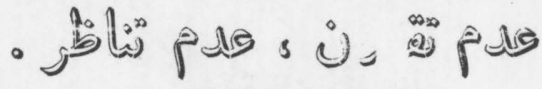

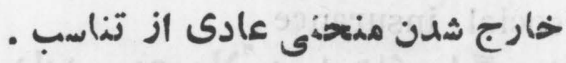

sliding - scale tariff .

o

$$
\text { - }
$$

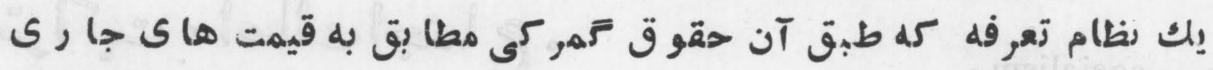

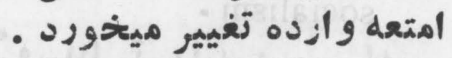

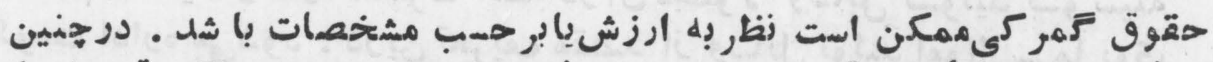

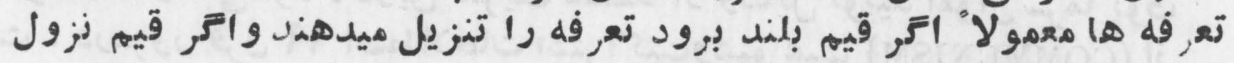

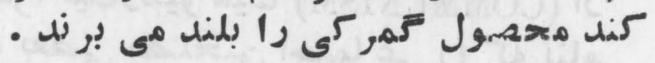
slow asset. - ज政

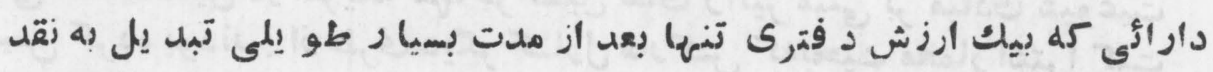
شلهه ميتوالنه

slowdown strike.

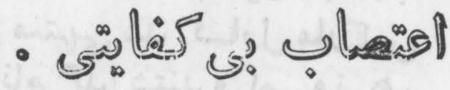

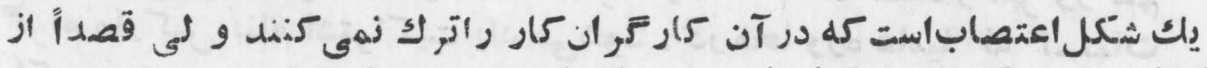

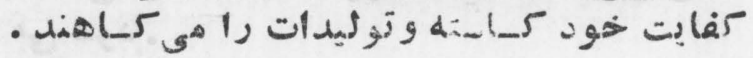

slum clearance.

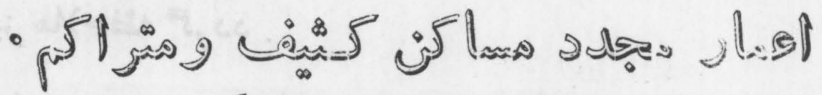

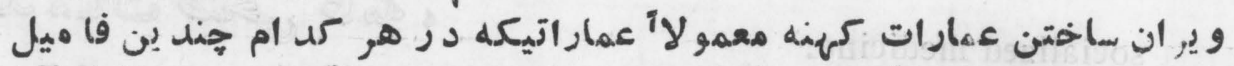

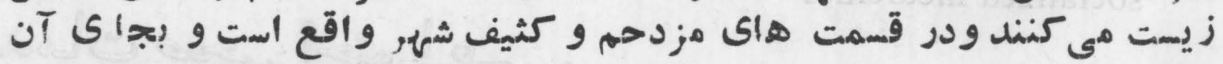

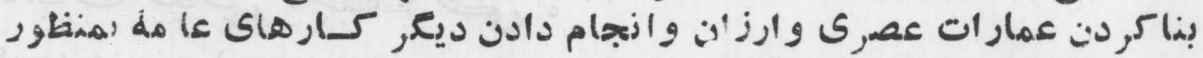

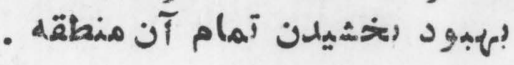


smuggling •

- @)

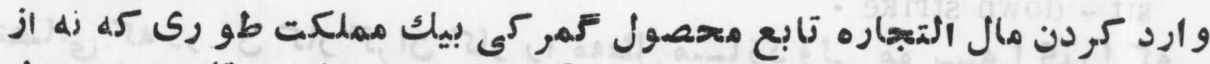

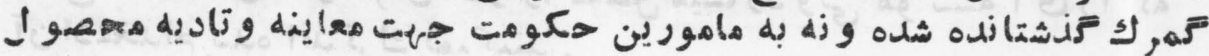

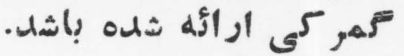

social insurance. - जlimis da:?

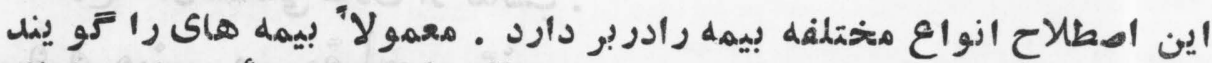

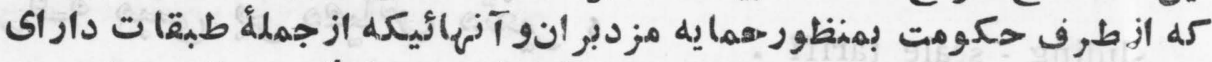

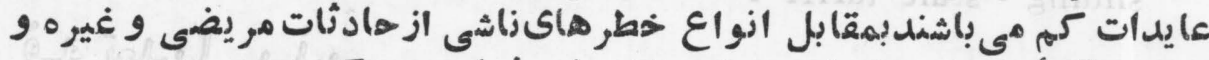

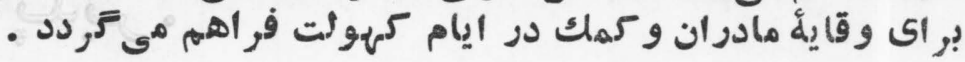

socialism •

- \& la

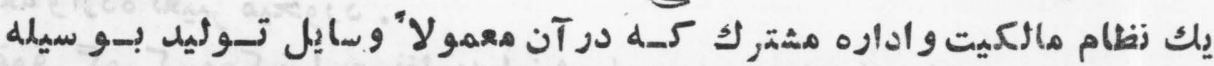

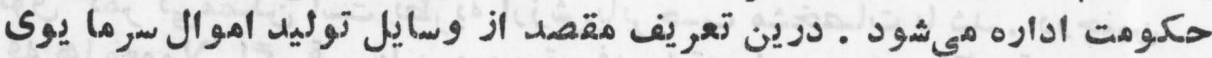

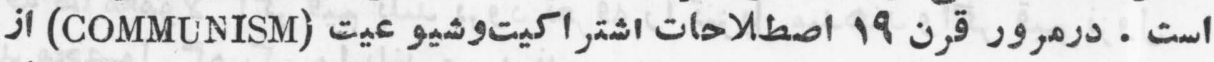

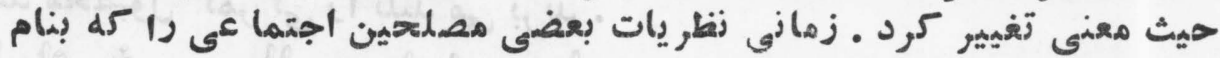

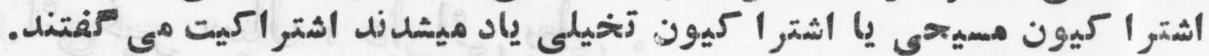

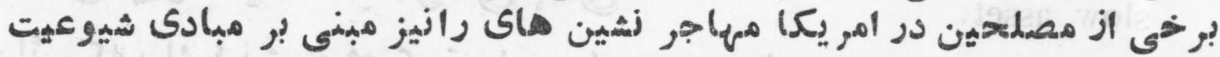

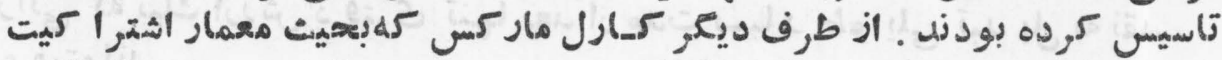

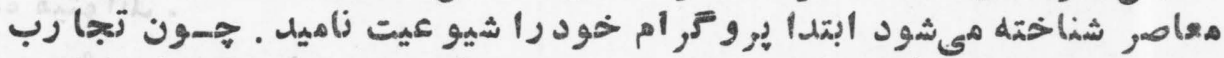

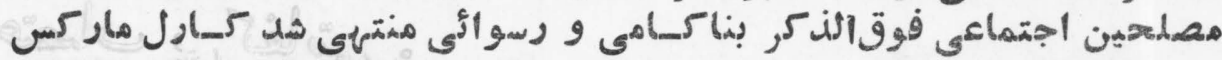

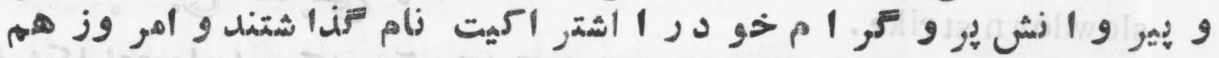

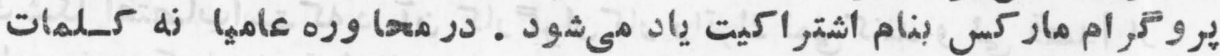

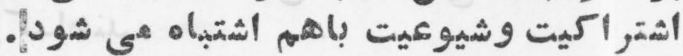

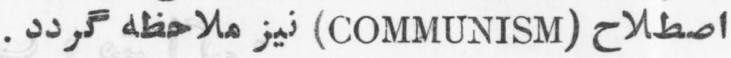

socialized medicine.

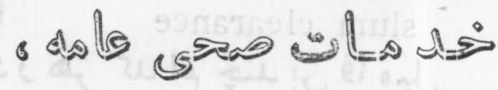

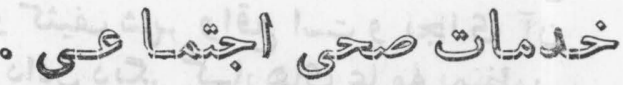

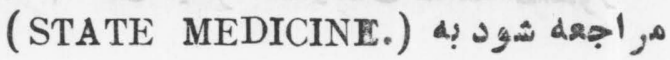


social legislation.

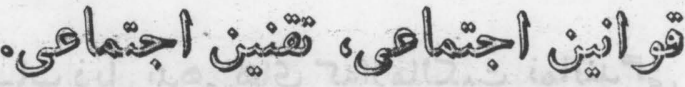

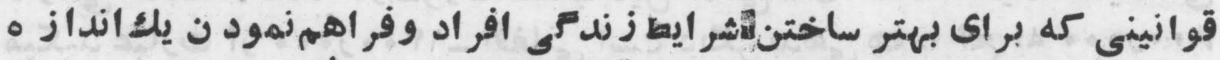

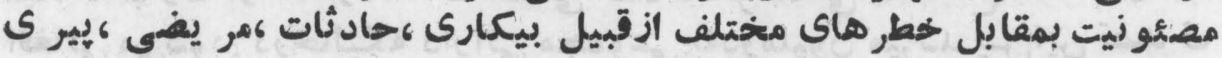
وزظاير آن براى شانوضع ميعر دهد.

social wealth.

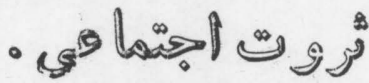

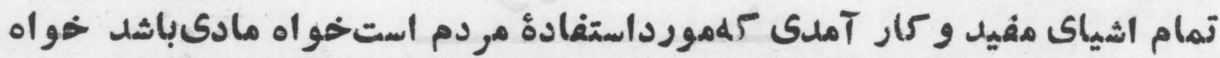

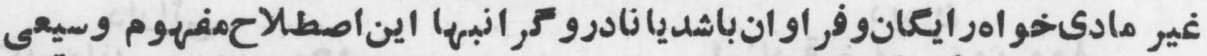

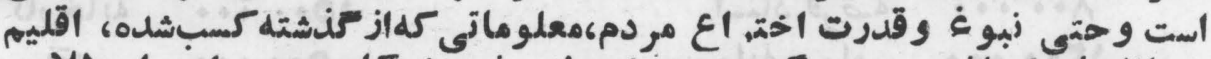

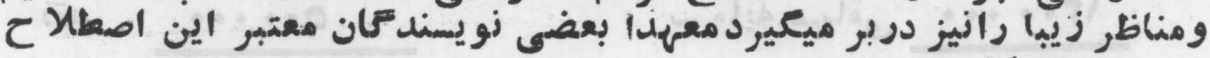

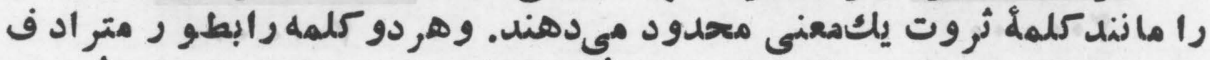

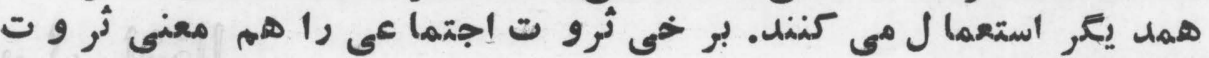

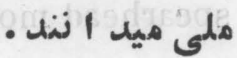
soft money.

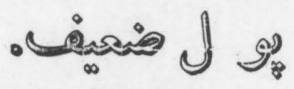

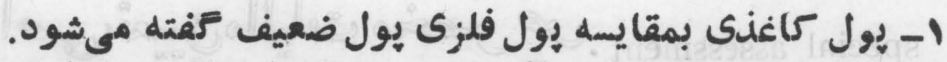

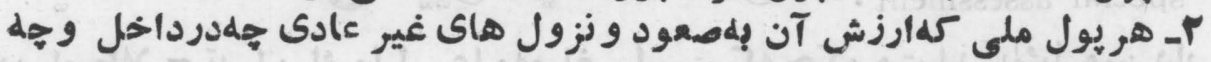

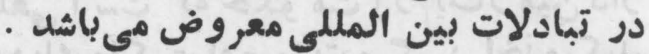

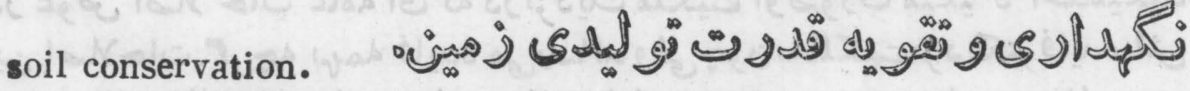

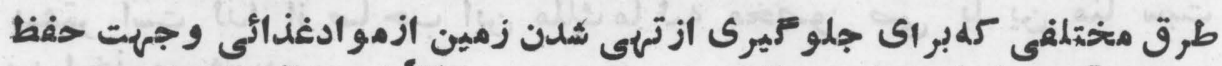

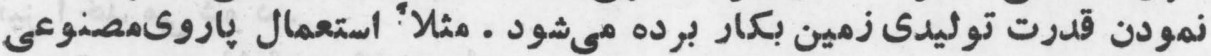

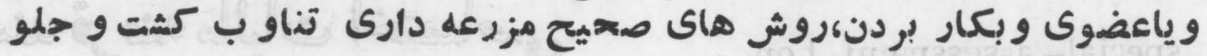

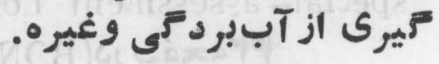

sole corporation.

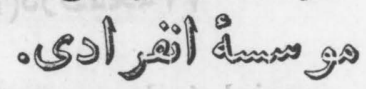

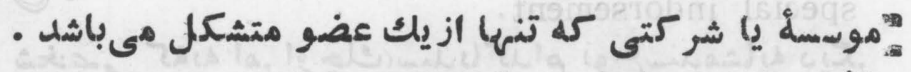

solvent.

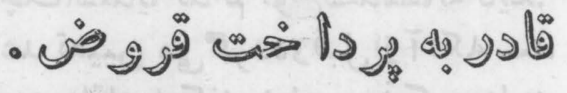

وقتيكه بله في غير از آن اقلامى كلمالكيت رازشان ميدهي كمتر از مجموع 


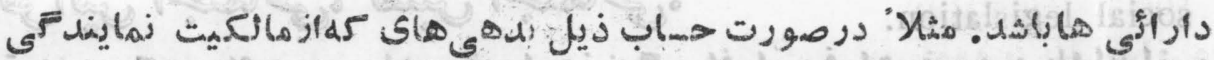

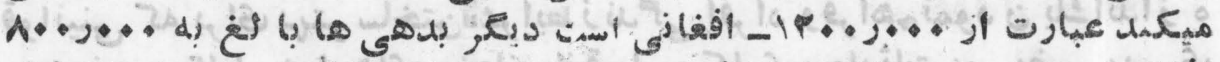

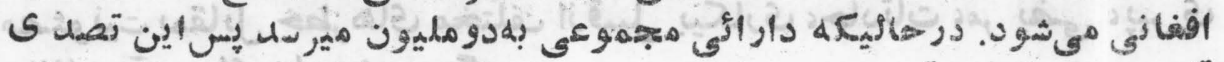

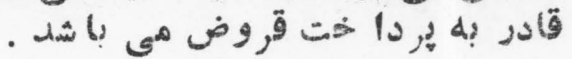

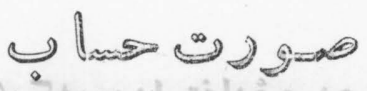

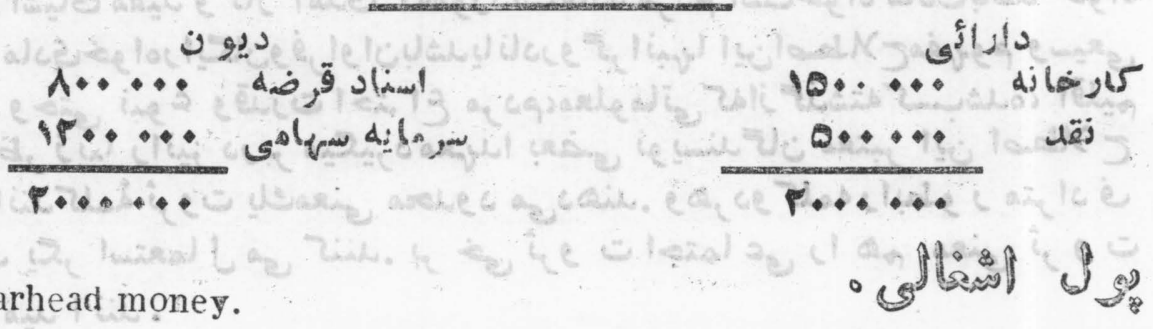

spearhead money.

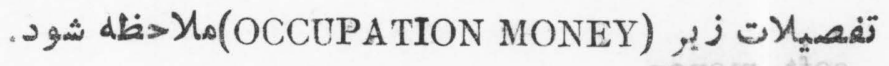

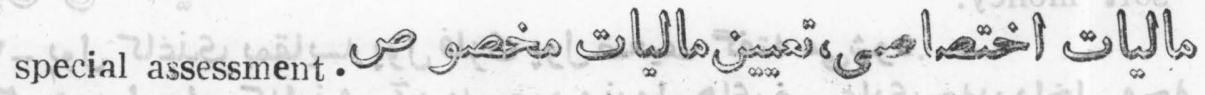

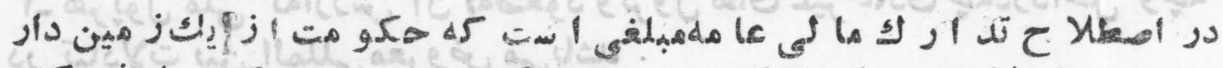

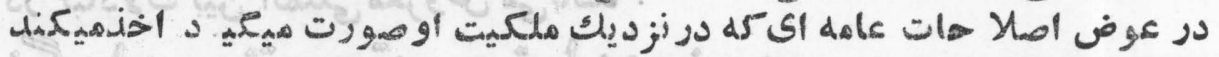

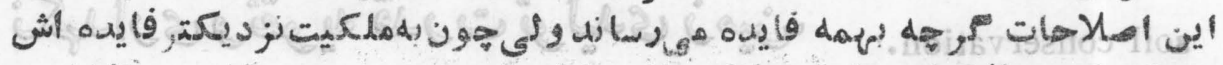

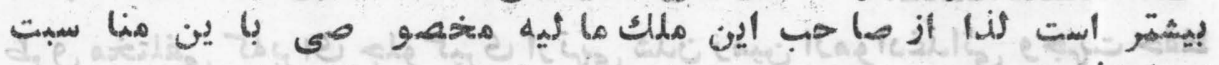

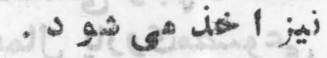
special-assessment ton.

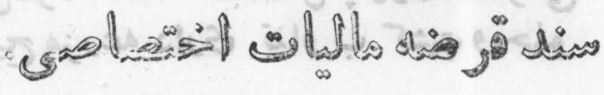
مر اججه شورد

special indorsement.

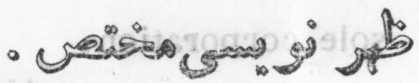

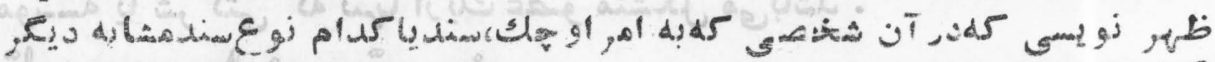

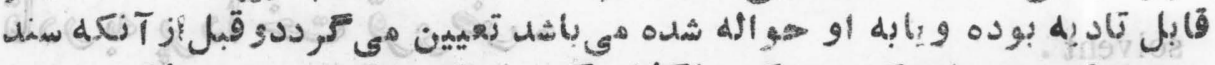

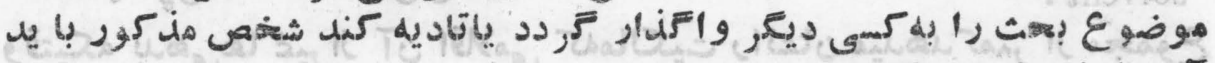

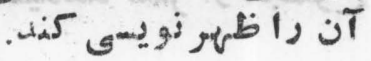


specialist.

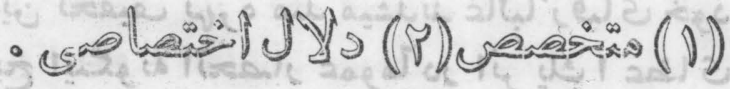

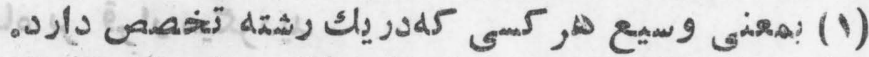

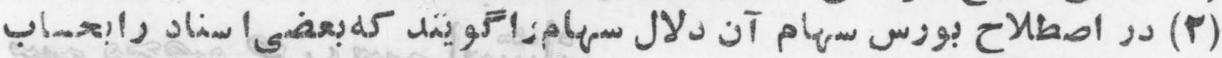
جود خجر يد وفروش اصنى كند.

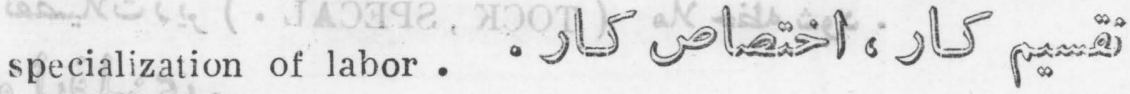

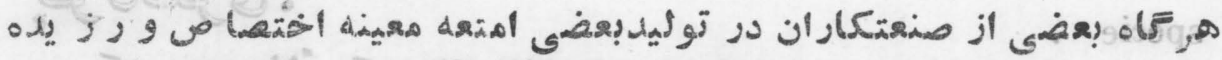

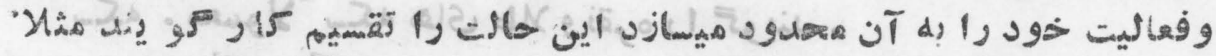

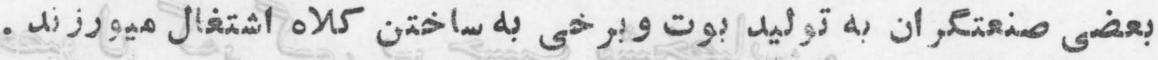

specializ d capital good.

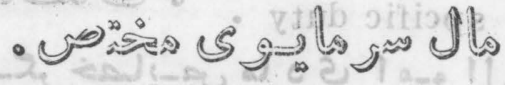

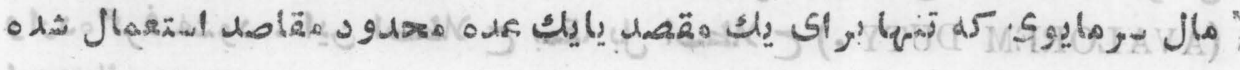
- ميتّون

specializet management trust. Sslis $a_{n} b_{\infty}=0$

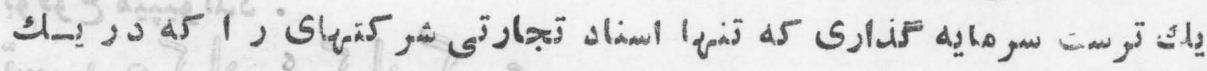

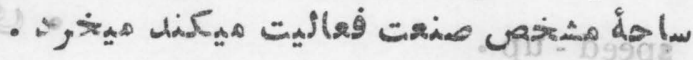

special-privilege monopoly .

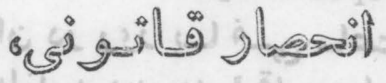
- uls il it

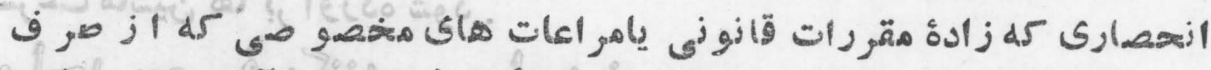

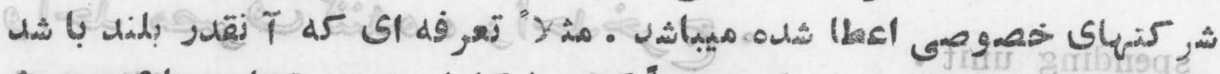

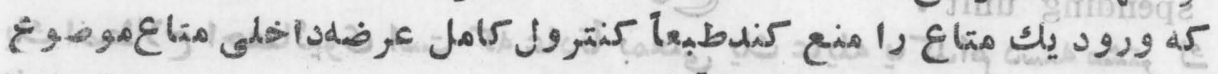

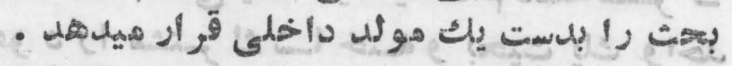

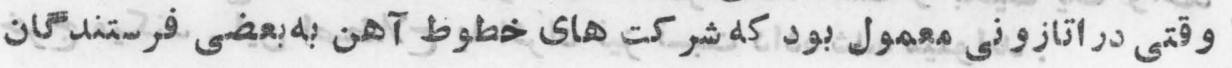




\section{SPE}

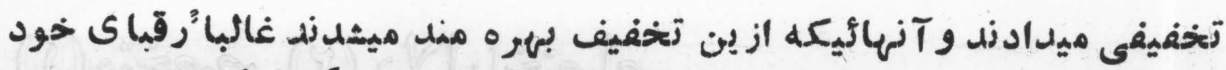

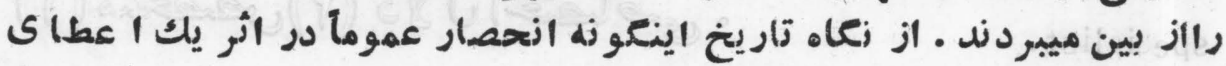

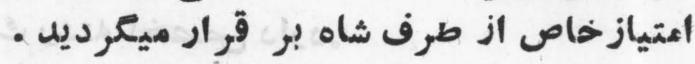

specia stock .

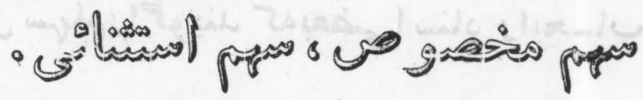

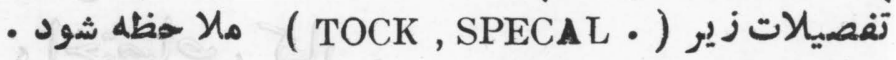
specie .

$$
\text { - } 15 ;=1 . j \int_{g}
$$

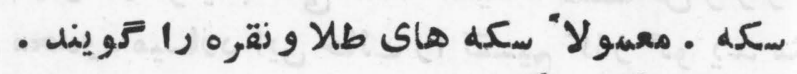

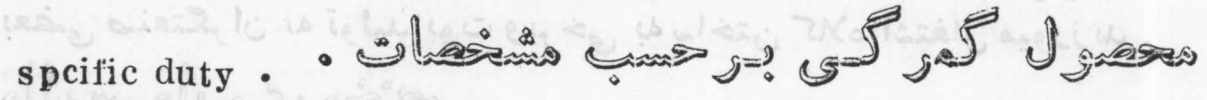

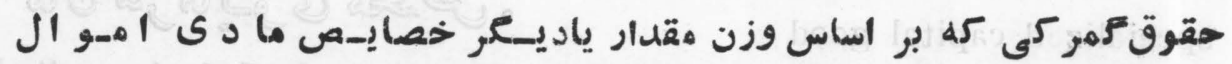

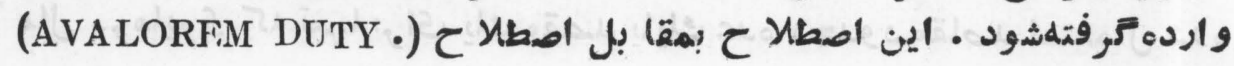
استعمال ميشود .

specuaton. - 2 is

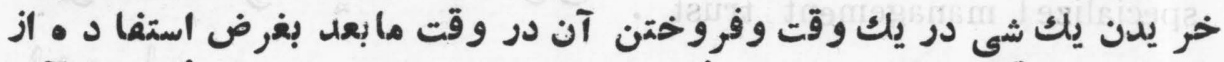

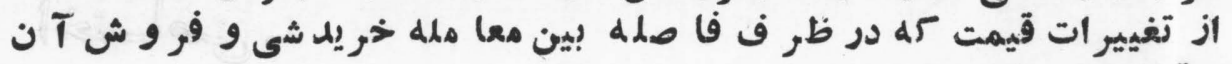

$$
\text { بوقوع ميبيو أندد فيرت }
$$

speed - up .

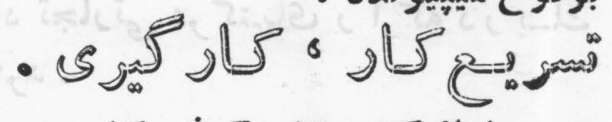

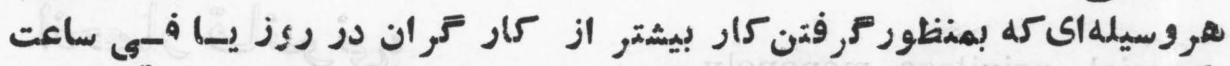

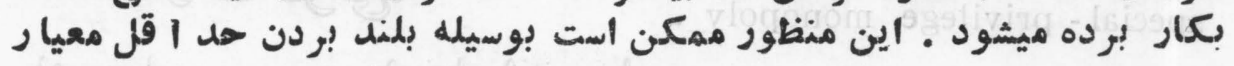

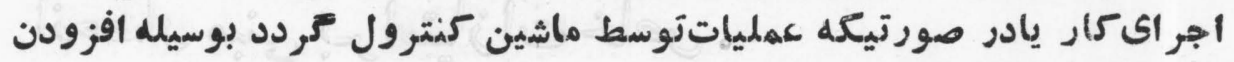
سرعت ماشين ها بر آورادر صورده شود .

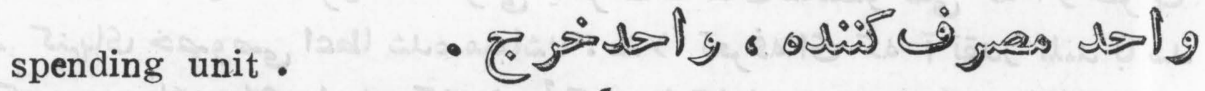
يك اصطلكاح احصائيوى است كله عادتأ بمعنى يك عايله ياكدام دسته مثتر

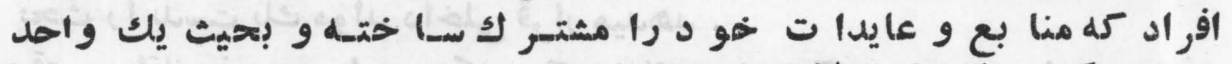

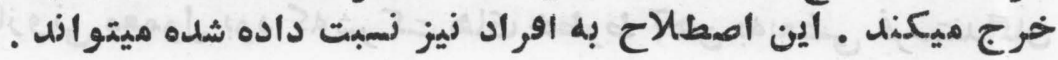


split - up. - A@

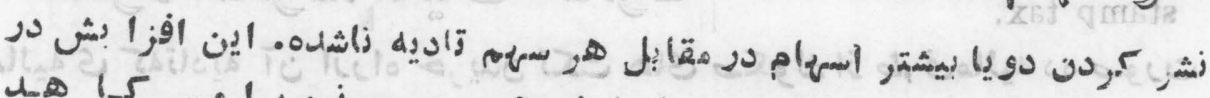

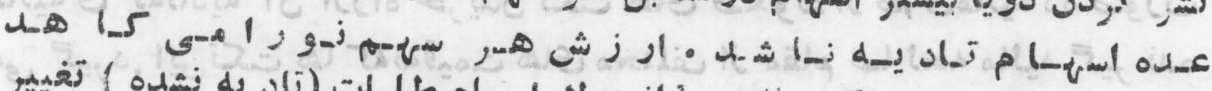

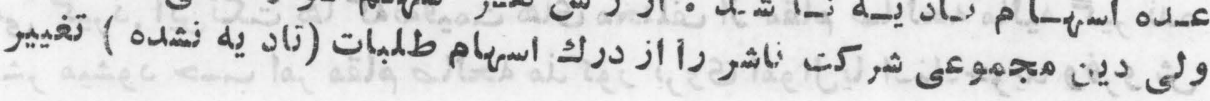
زمى دهل -

spot delivery. - ज2

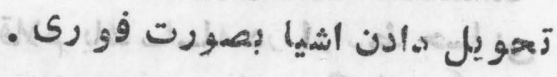

s) read - ل

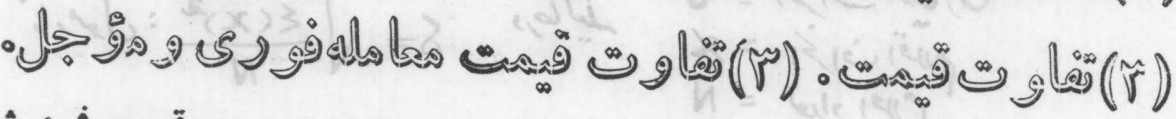

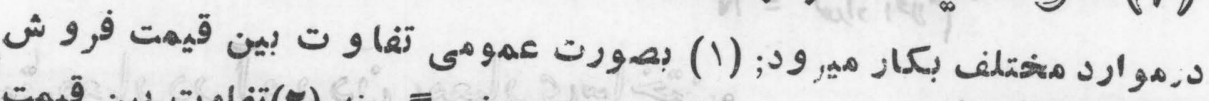

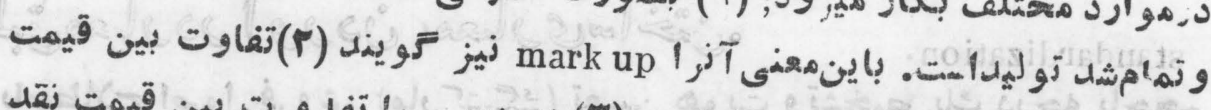

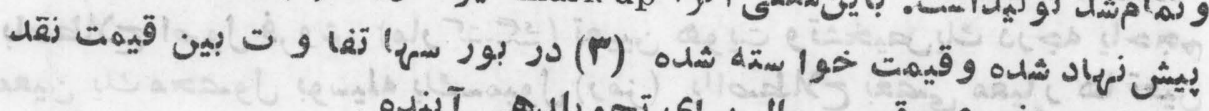

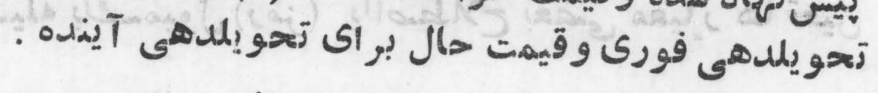

stabilization. - If

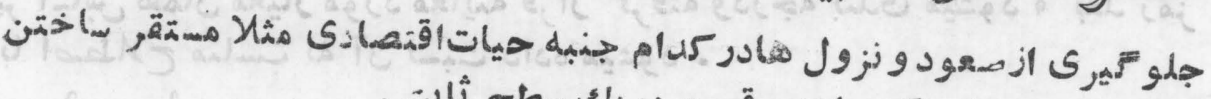

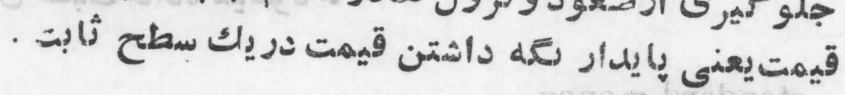

stable money.

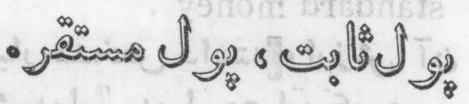

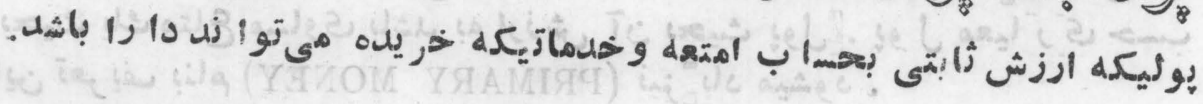
stamped bond. - C

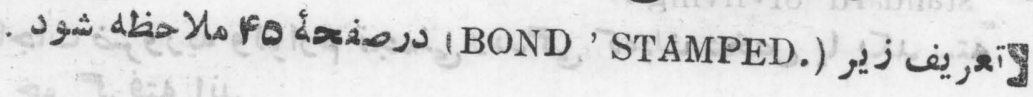


STA

stamp tax.

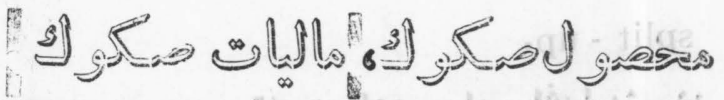

مالريهاى كلى

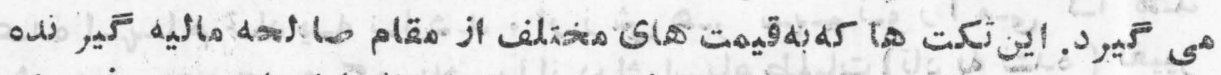

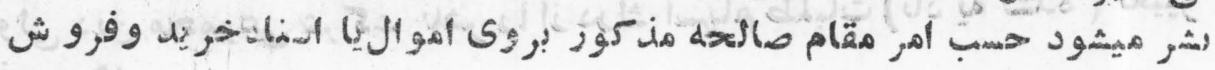

$$
\text { . as }
$$

standard deviation.

$$
\text { - } 3 \text { g) }
$$

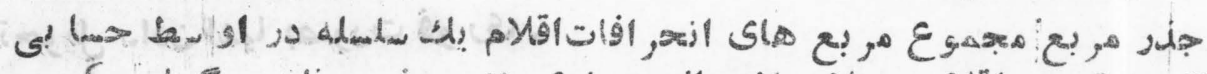

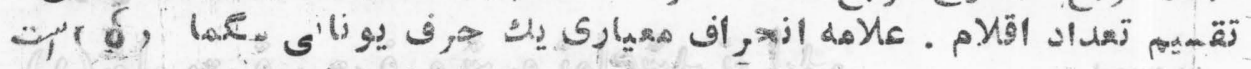

$$
\begin{aligned}
& \text { (5, }(0,2, \dot{1})=\delta \\
& \text { ن }
\end{aligned}
$$

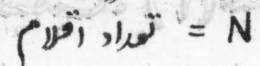$$
\delta=\sqrt{\frac{\sum(x)^{2}}{N}}: \int^{\prime}, 6
$$

standardization.

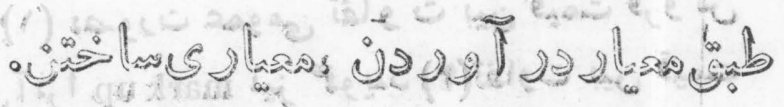

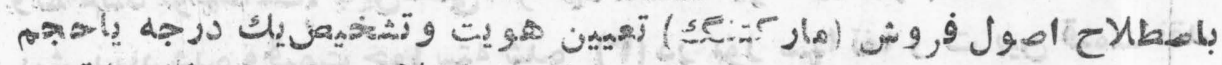

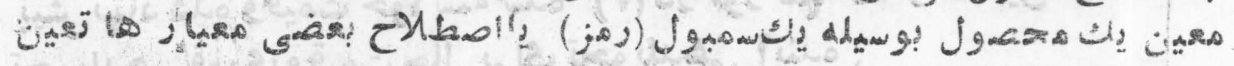
- نga $\sin ^{\circ}$

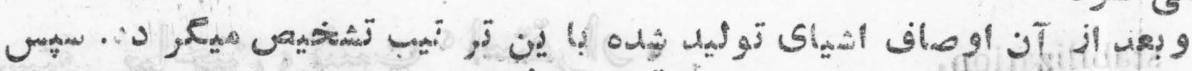

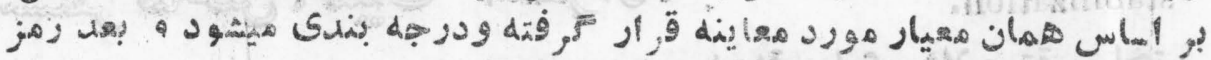

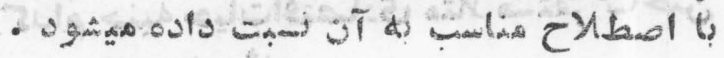

standard money . - $(5) l_{2}=0$ e $\theta=?$

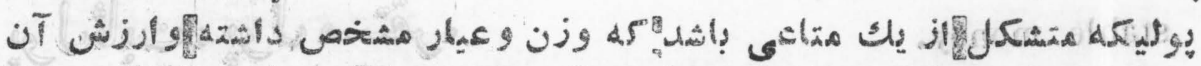

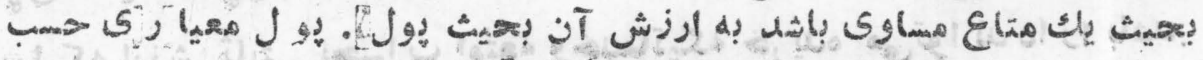

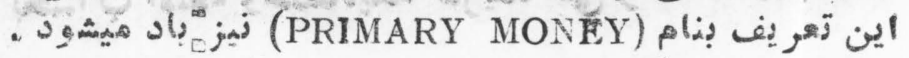
standard of living.

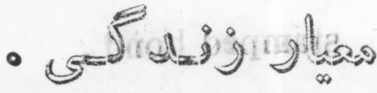

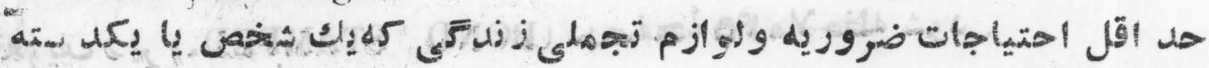

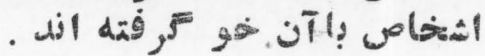


stand-by controls.

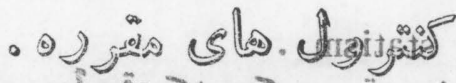

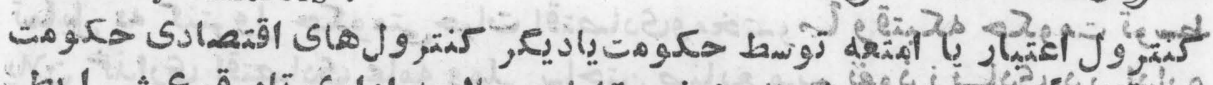

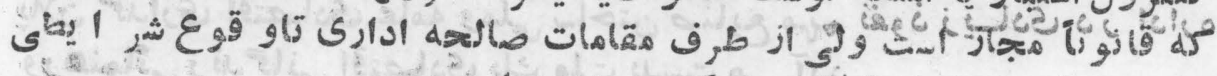

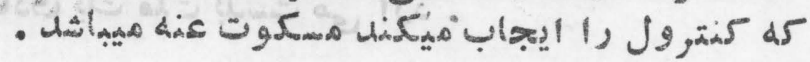

state capitalism .

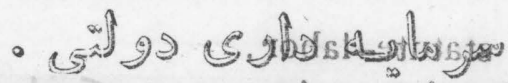

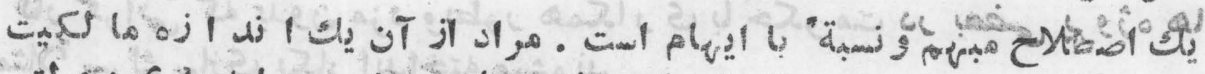

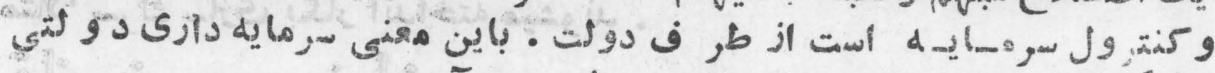

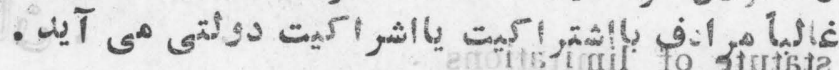

state medicine.

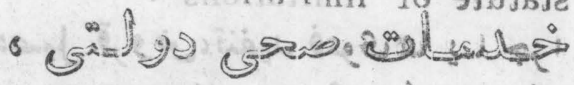

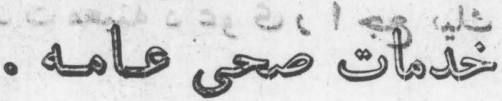

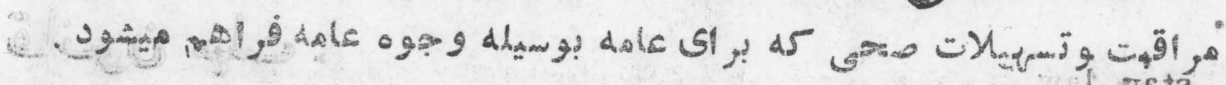

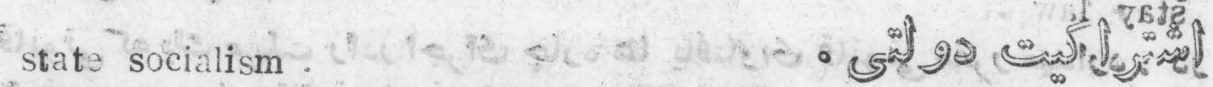

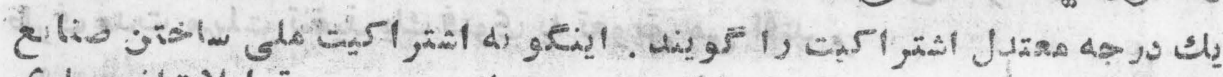

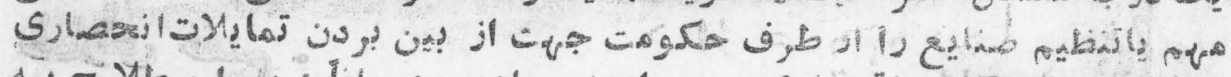

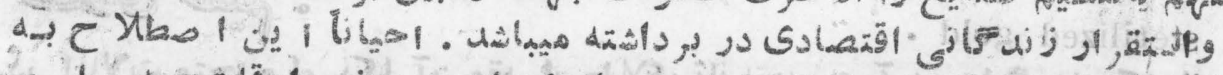

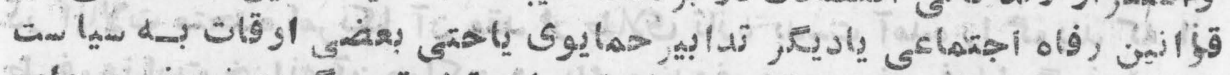

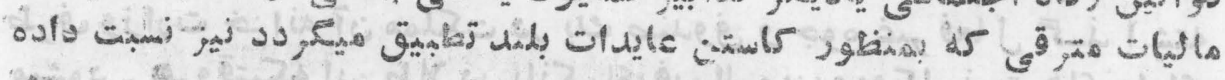
- Oginaso atate use system.

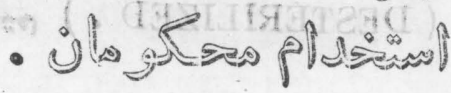

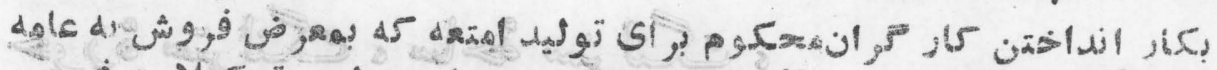

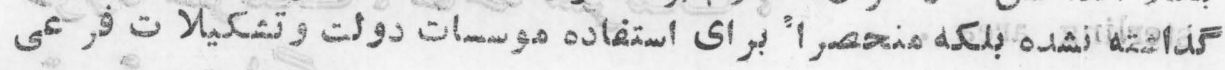
- آن با

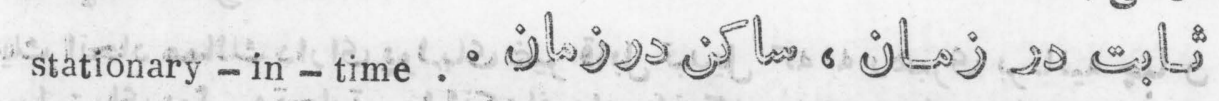

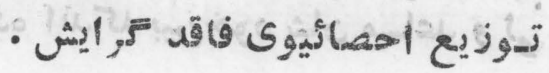


statism.

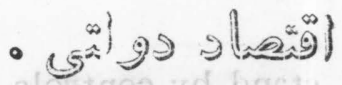

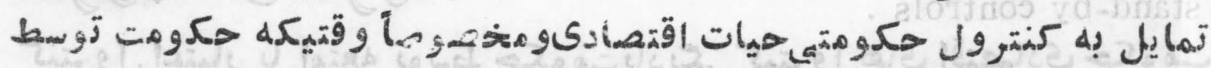

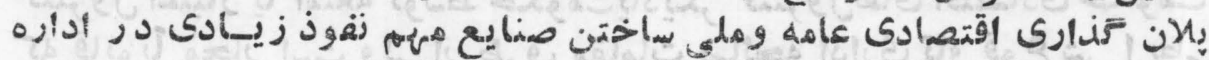

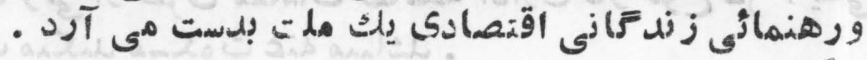

statute-labor.

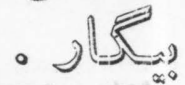

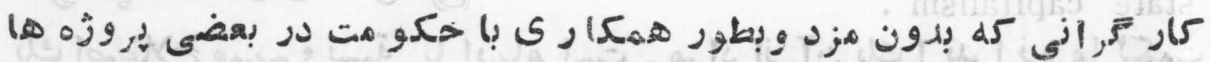

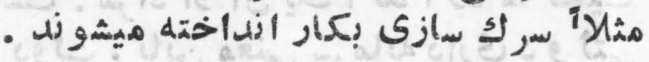

statute of limitations .

$$
\text { - iloj } 2920 \text { نे }
$$

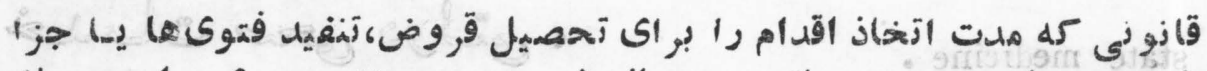

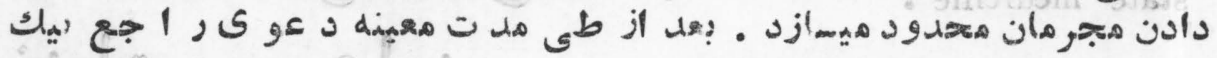

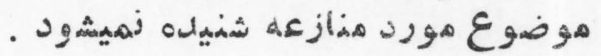

stay law. ,

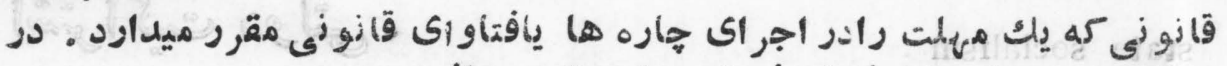

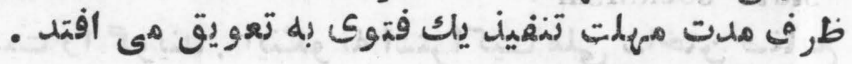

sterilized gold .

- $\int_{\infty} \in d=b$

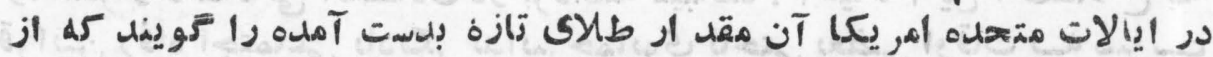

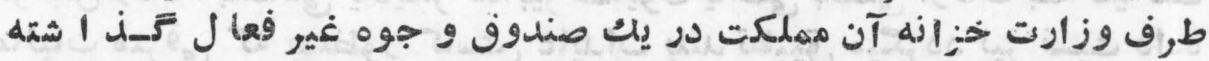

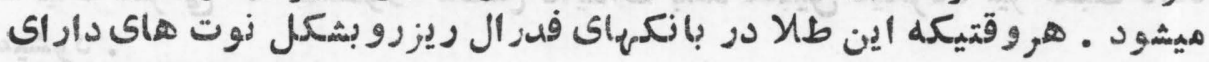

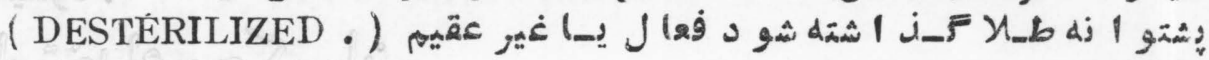

sterling area.

$$
\text { ميعر }
$$

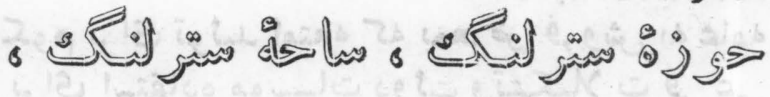

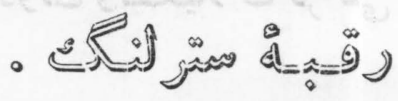

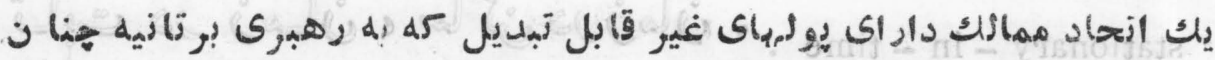

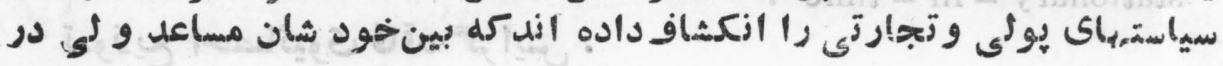




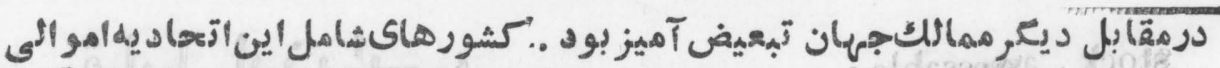

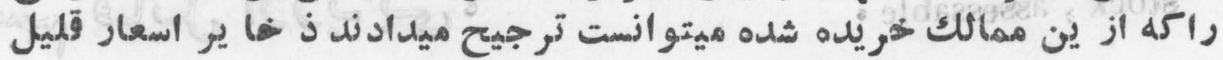

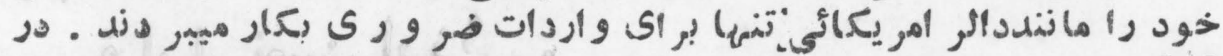

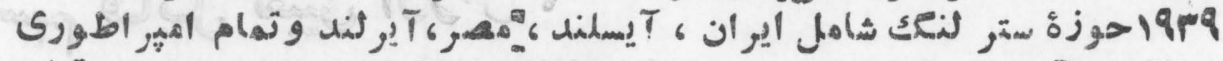

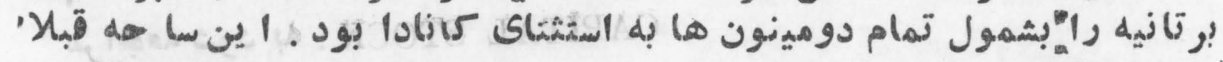

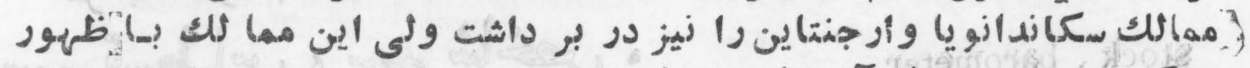

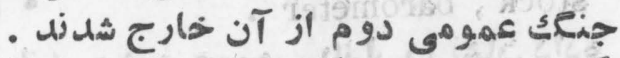

sterling bloc .

$$
\text { - } 3
$$

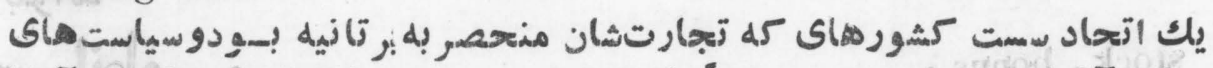

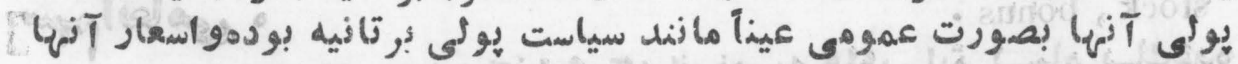

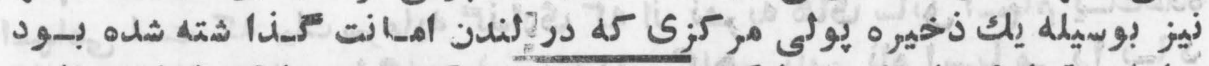

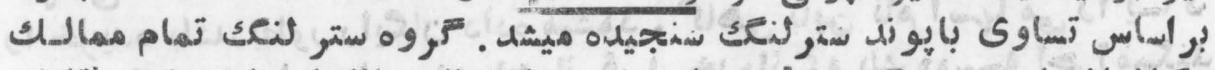

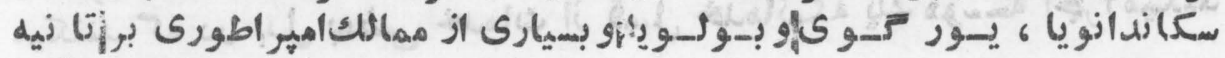

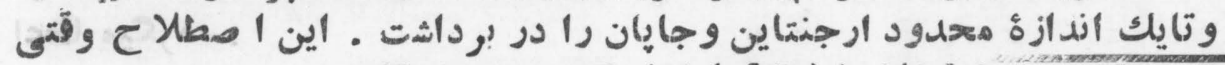

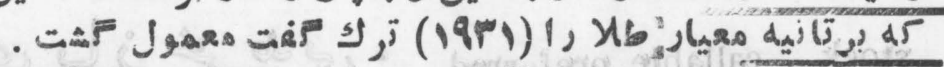

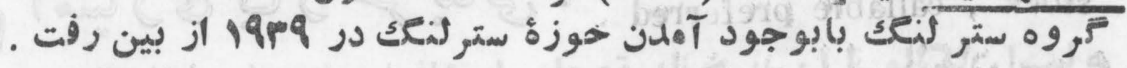

steward :

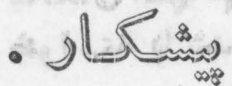

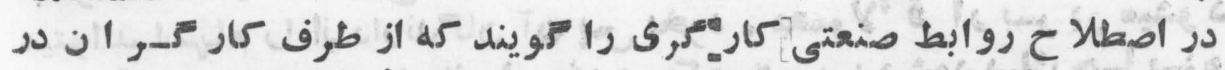

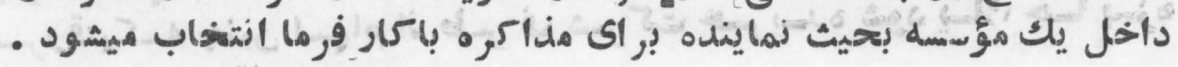

stock •

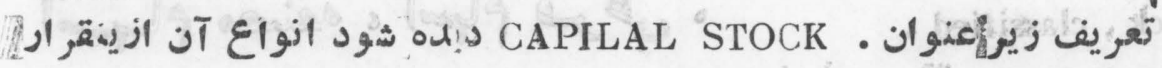

- vipan - Ent

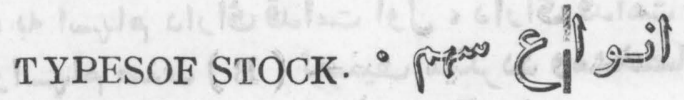

stock, active .

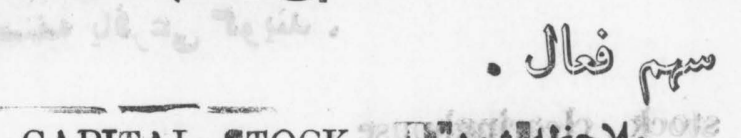

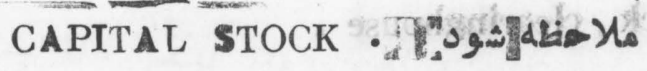


stock, assessable

stock, barometer .

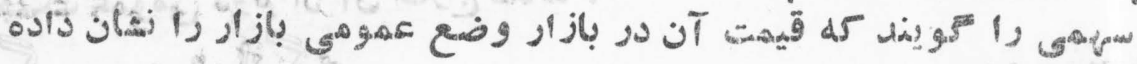

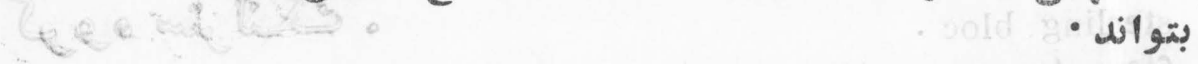

stock, bonus .

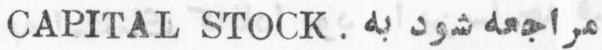

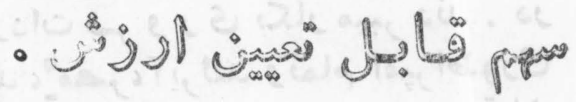

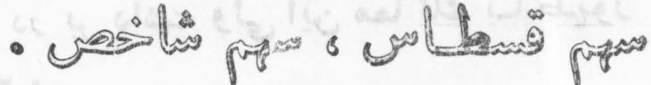

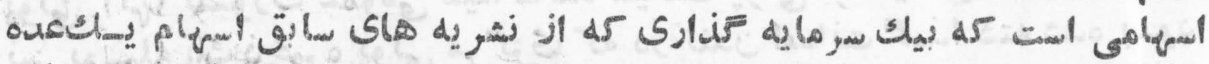

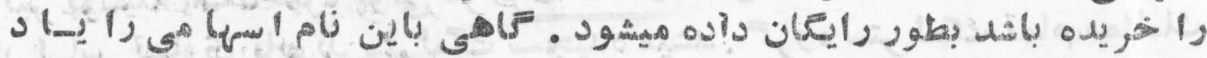

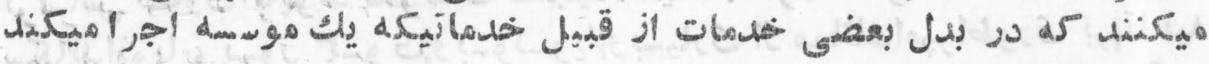

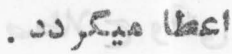

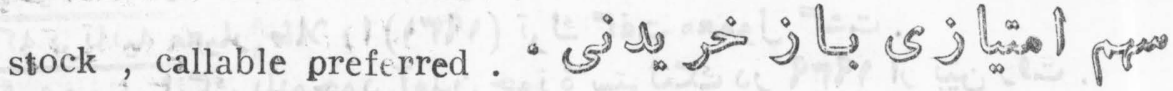

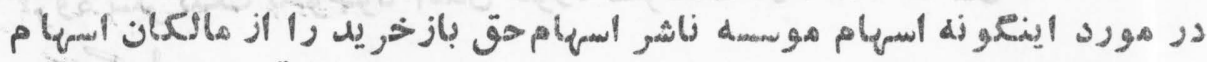

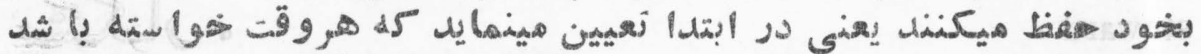

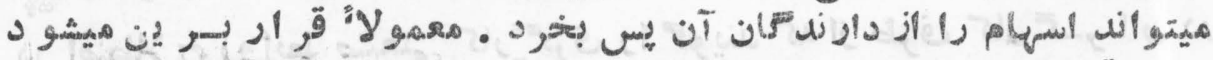

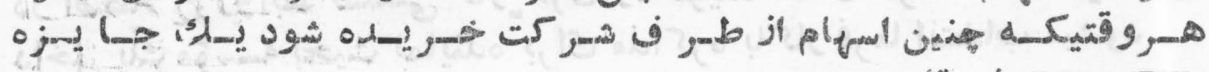
PREMIUM

stock, classified .

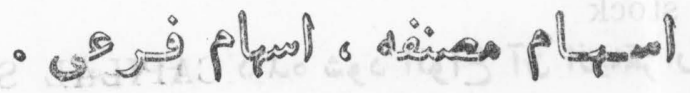

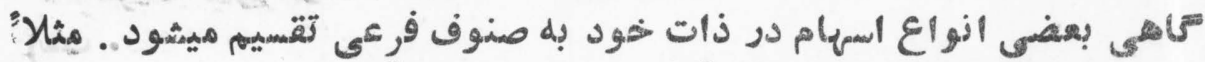

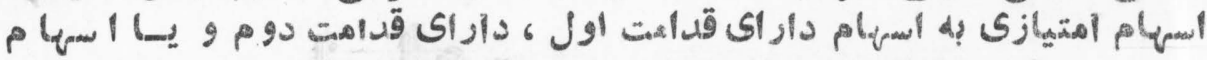

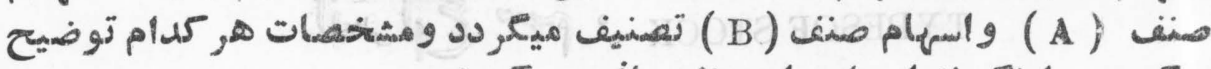

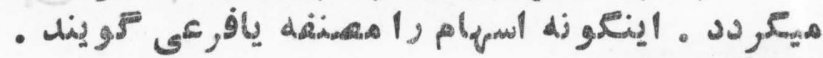

stock, clearinghouse .

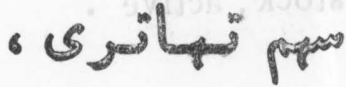

\section{(CPOA))}




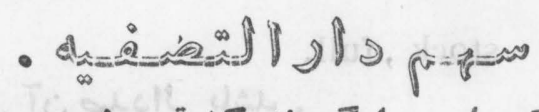

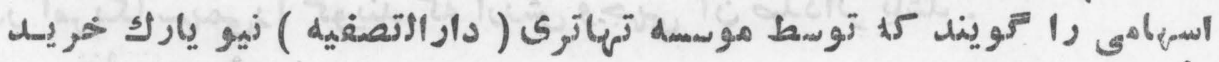

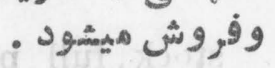

stock, common, ordinary or equity .

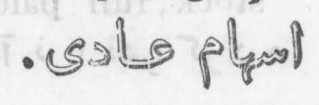

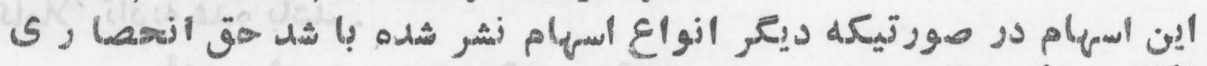

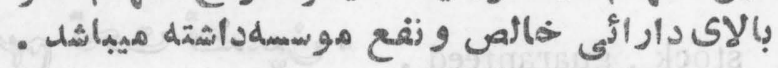

stock, convertible .

$$
\text { - له }
$$

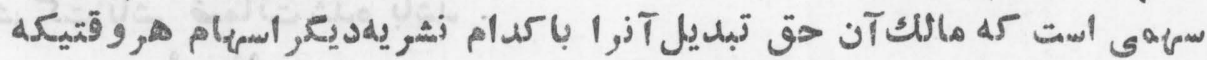

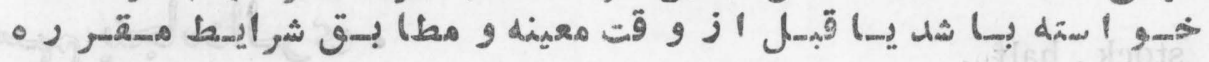

stock, cumulative .

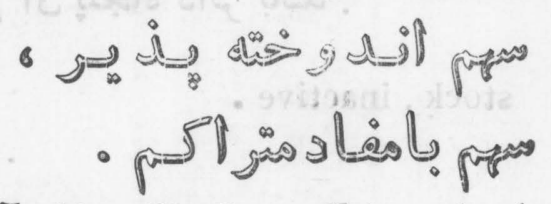

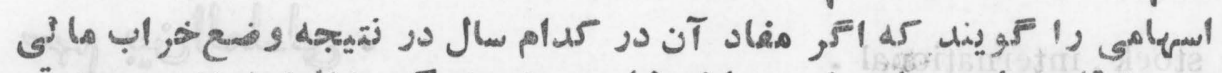

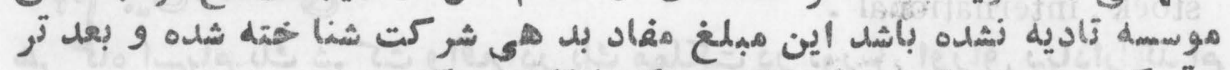

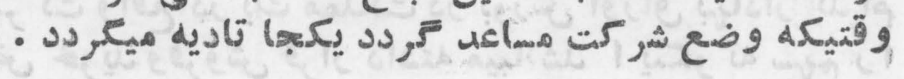

stock, curb.

$$
\text { - }
$$

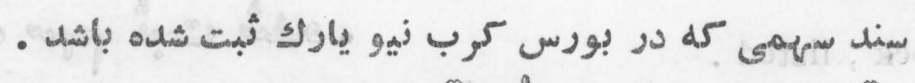

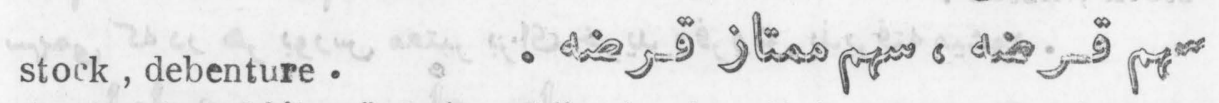

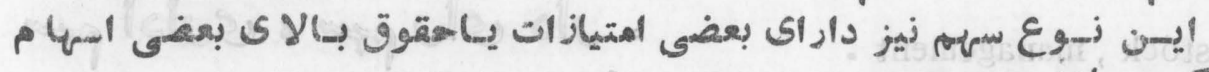
ديعر ميباشلد في ع

stock, donated .

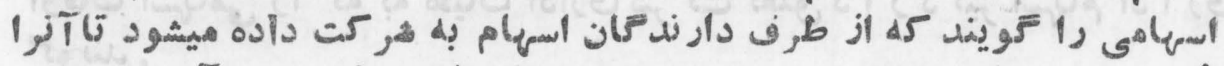

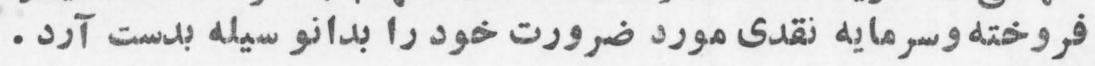


stock, full.

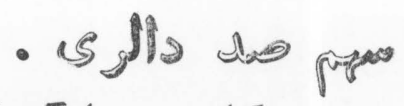

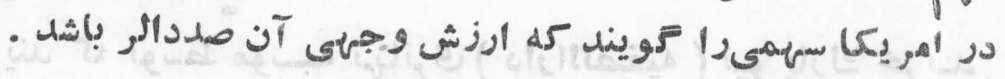

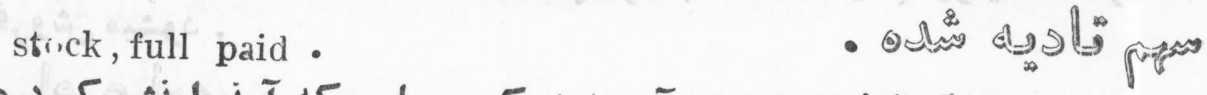

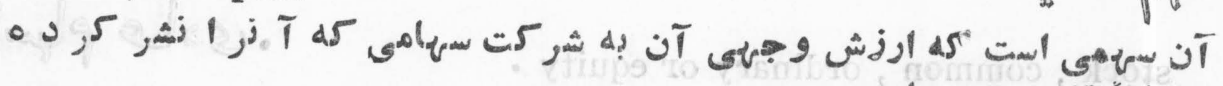

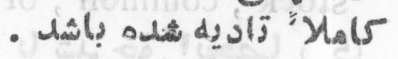

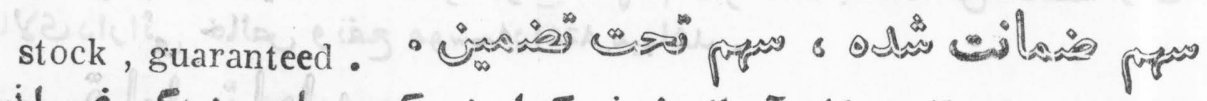

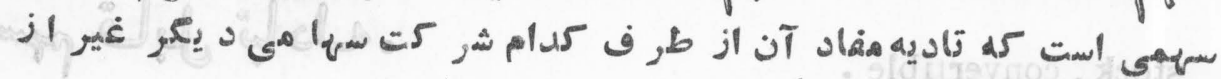

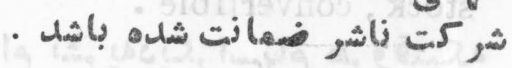

stock, half . - 5 s

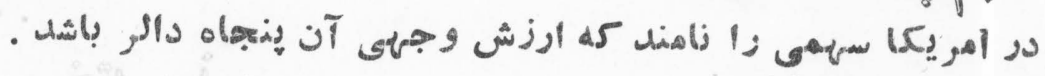
stock, inactive .

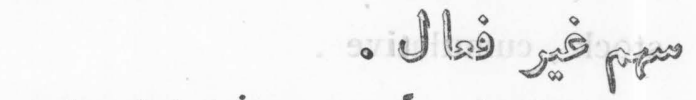

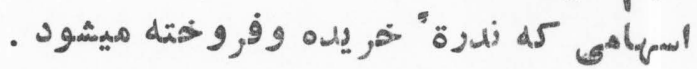

- $\mathrm{s}=d a l l i m a \cos$

stock, international .

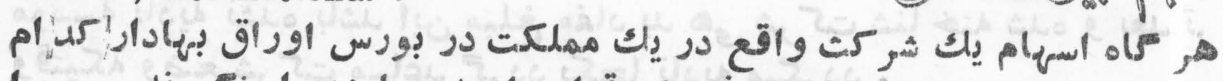

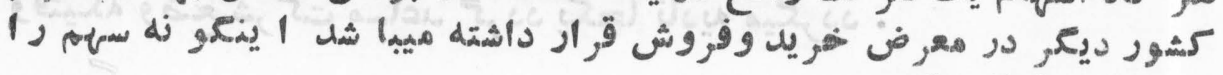

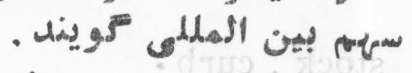

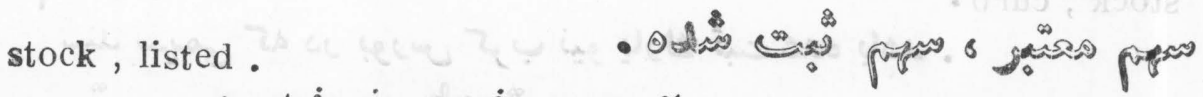

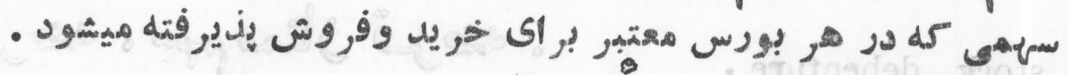
stock, management .

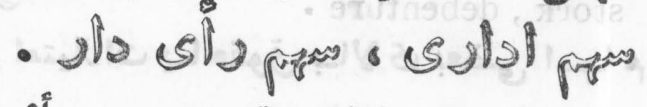

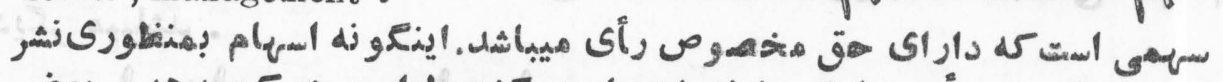

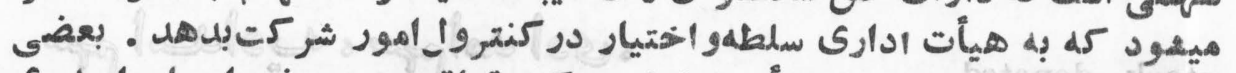

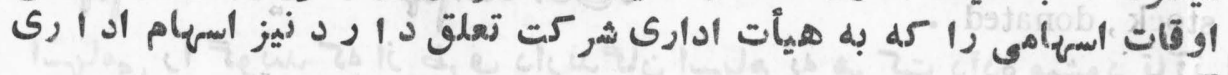
- 
stock, nonassessable.

- जol jol

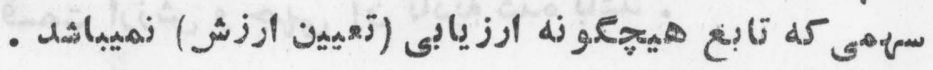

stock, nonclearinghouse .

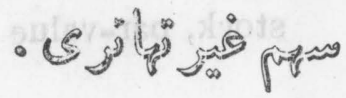

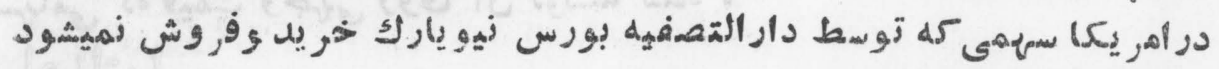
stock, noncumulativc .

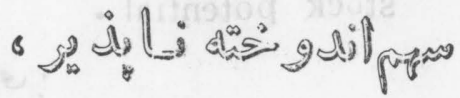

$$
\begin{aligned}
& \text { - }
\end{aligned}
$$

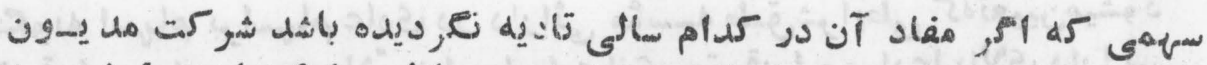

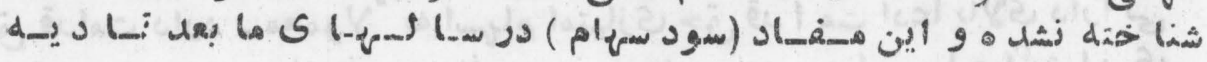

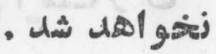

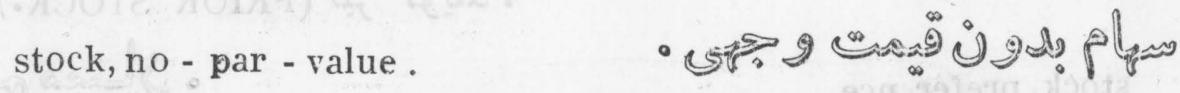

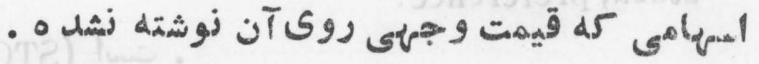
stock, original-issue . -

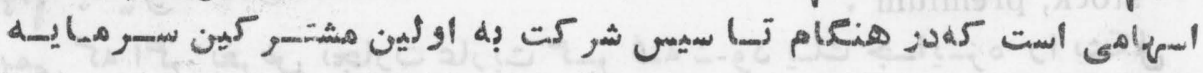

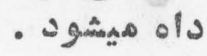

stock, paid up .

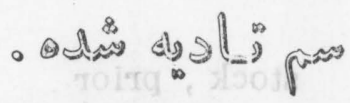

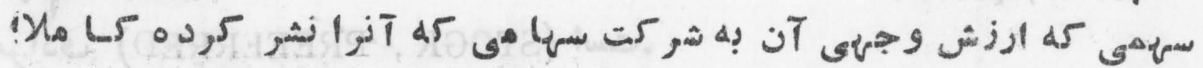
تاديه شده بأندا

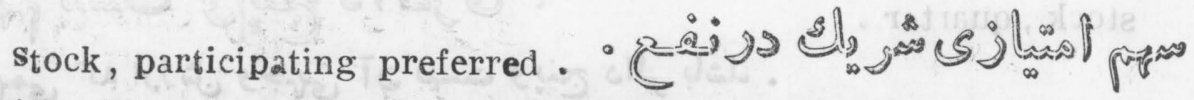

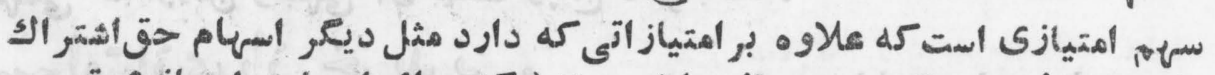

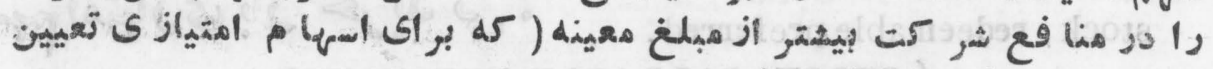

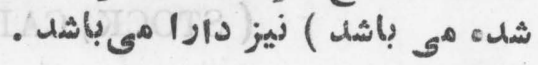


stock, part-paid .

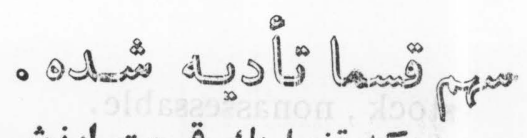

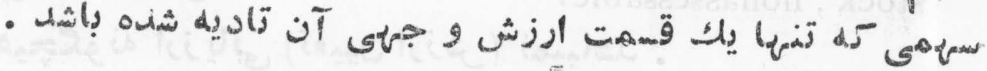

stock, par-value .

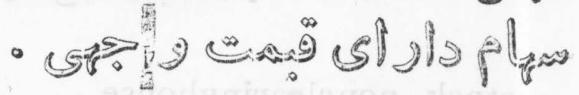

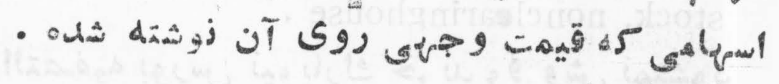

stock potential.

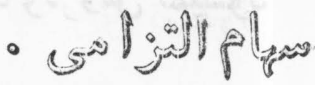

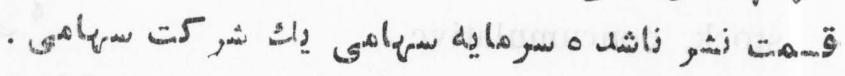

stock, preferred .

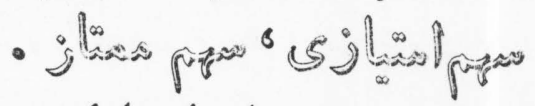

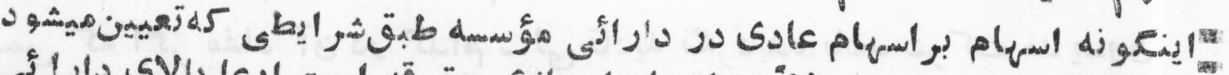

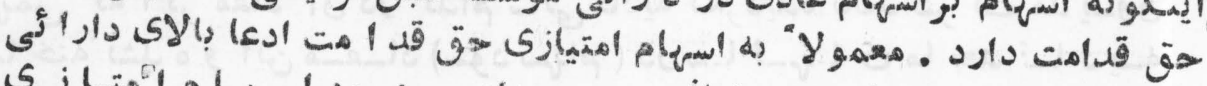

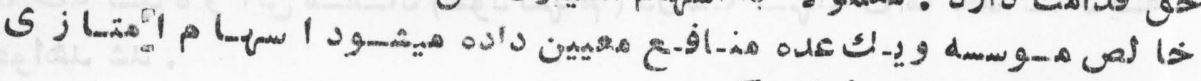

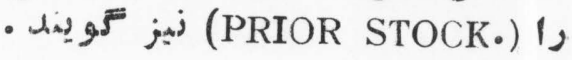

stock, prefercnce.

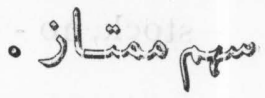

مر ادف (STOCK PREFERRED) است

stock, premium .

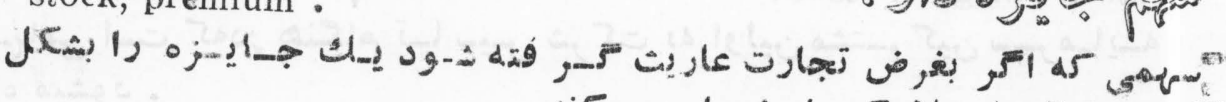
.

stock, prior.

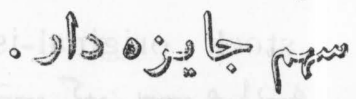

jLiso pas

هو ادف (STOGK, PREEERRED) است.

stock, quarter.

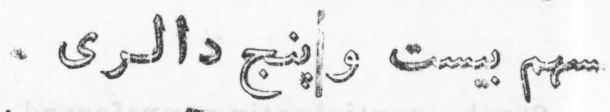

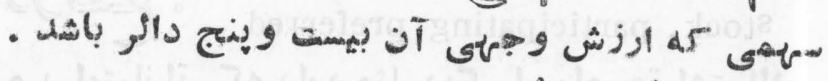

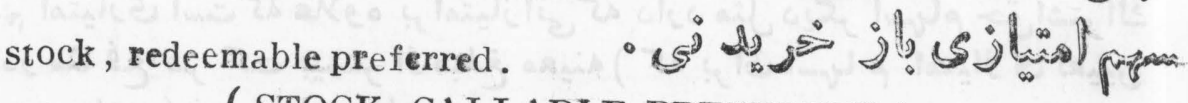

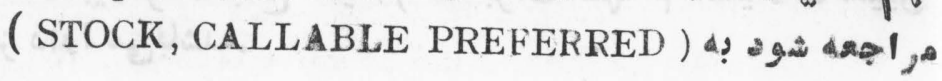


stock, treasury

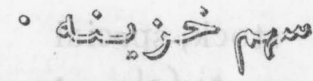

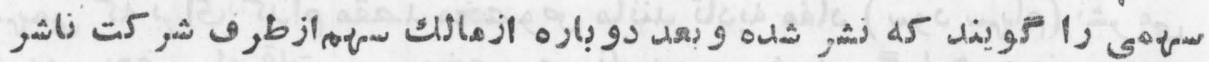

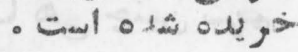

stock, unissued.

-

مر ادف ) الست

stock' unlisted .

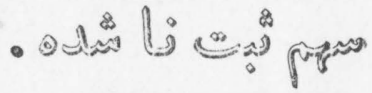

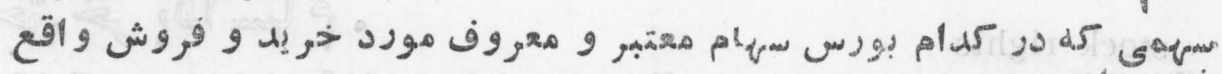

stock, watered .

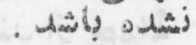

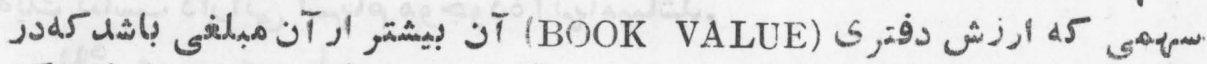

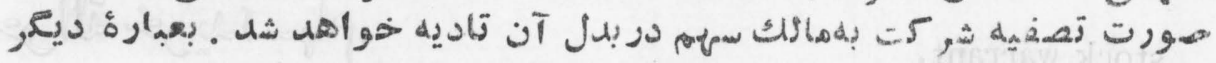

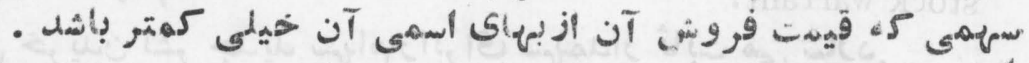

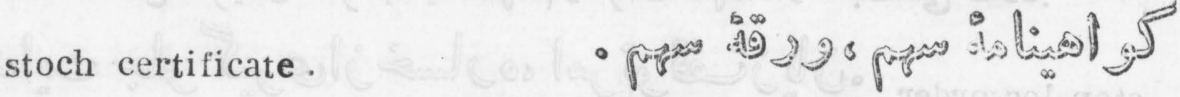
تفصيلات زير (CAPITAL STRCK) ملاحظله شود .

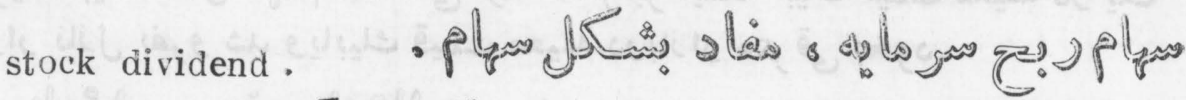

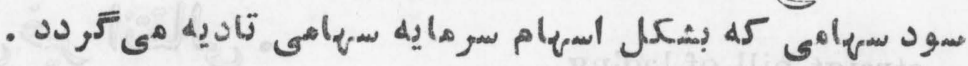

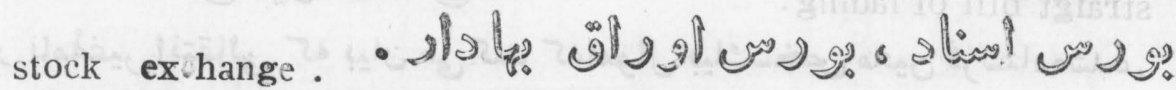

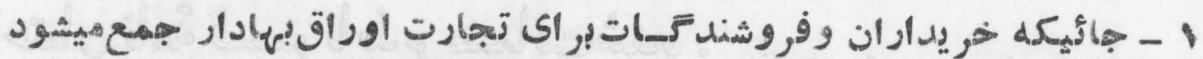

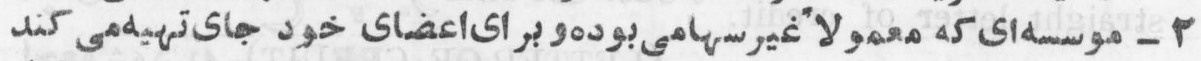

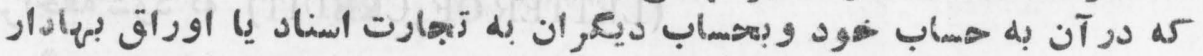

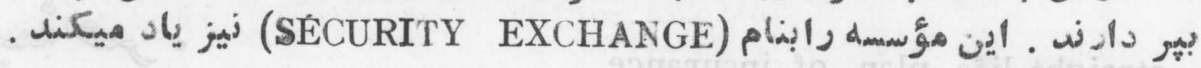

stock holder - Idapa

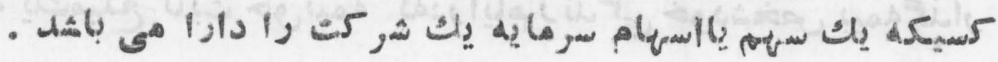




\section{STR}

stock, special

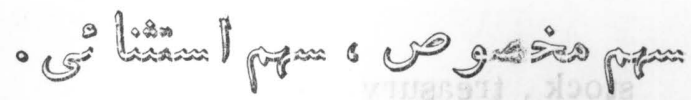

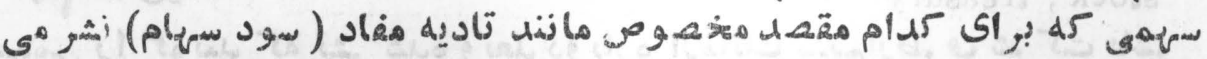

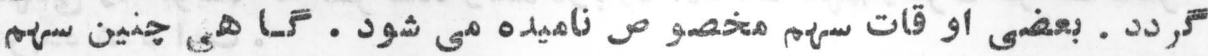

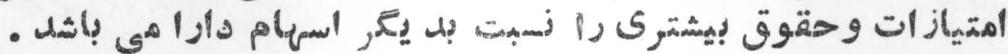

stock piling.

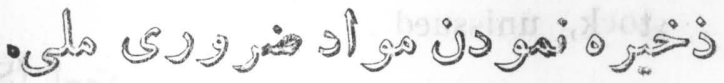
تفصيلات زير (STRATEGICMATERIAI)ديله شود .

\section{stock rights}

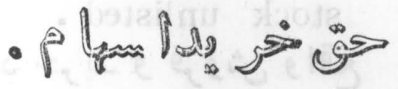

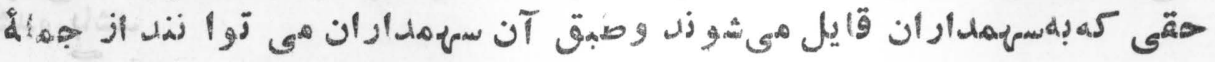

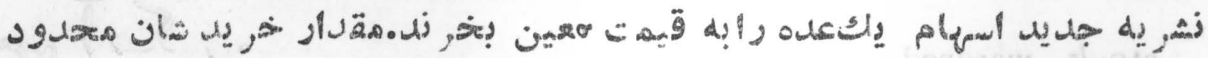

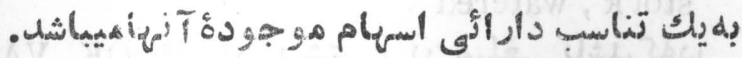

stock warrant.

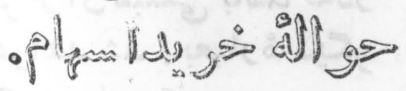

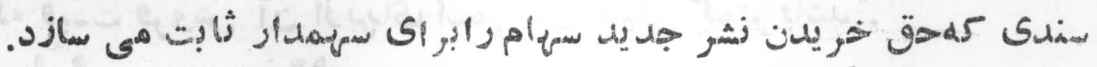
stop-lossorder - ن

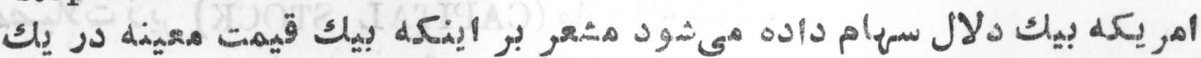

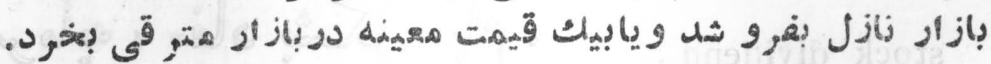
straigt bill of lading.

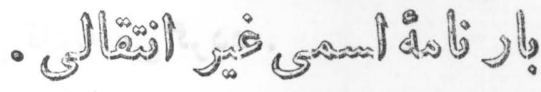

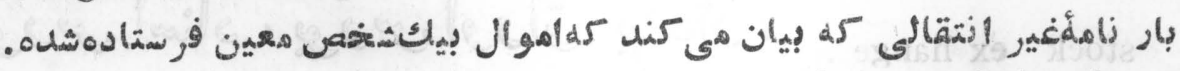

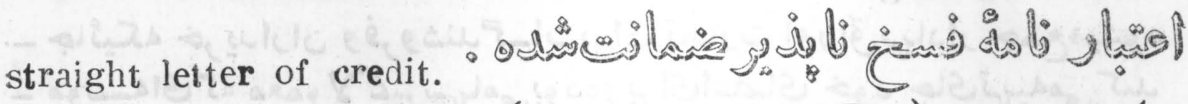

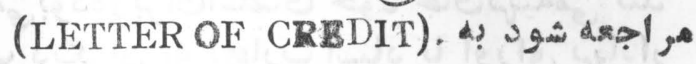

straight-life plan of insurance - बत्व

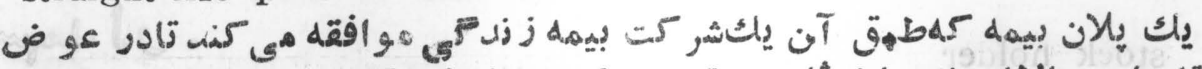

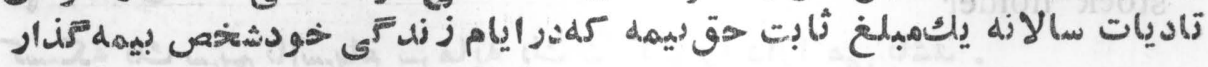




\section{SUB}

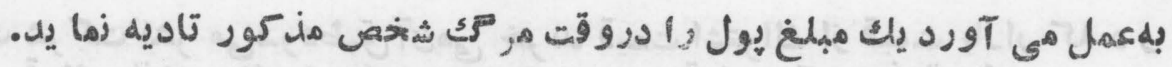

stategic materials .

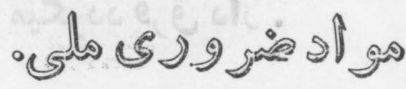

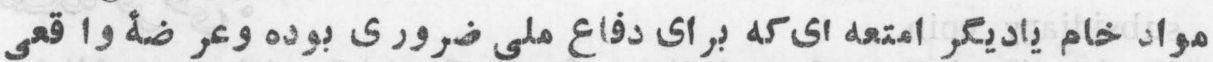

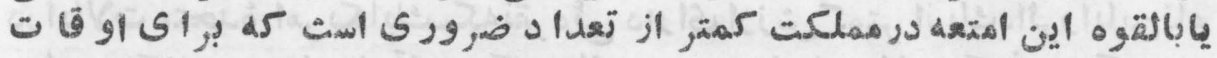

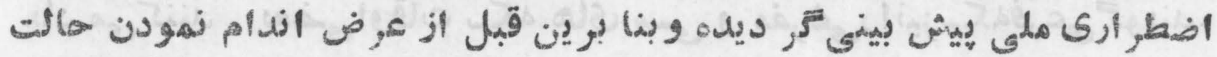

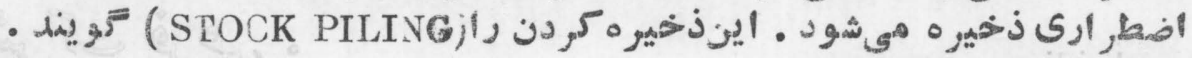

stretch - out .

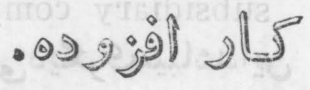

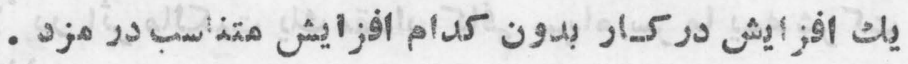

strike .

- $\underbrace{\infty}_{=0}$

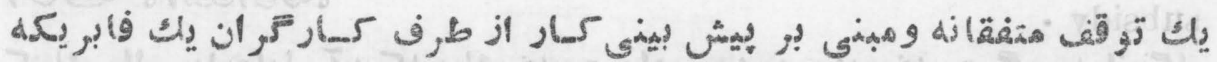

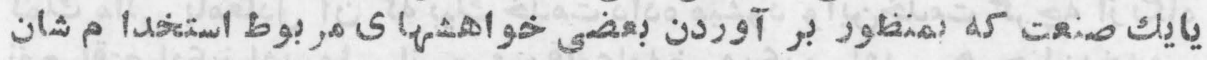

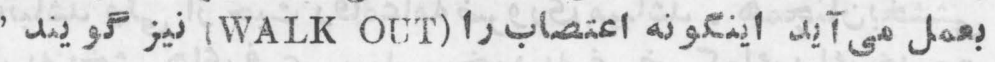

strike breaker.

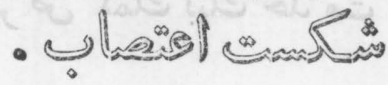

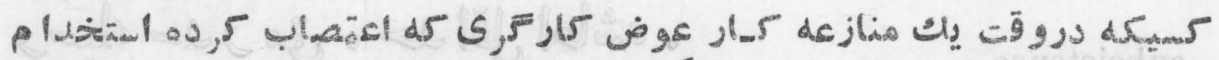
هي

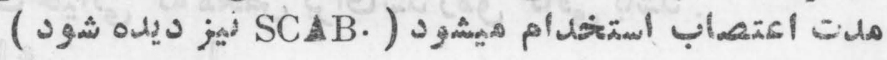

structure (economic)

- نㄴำ

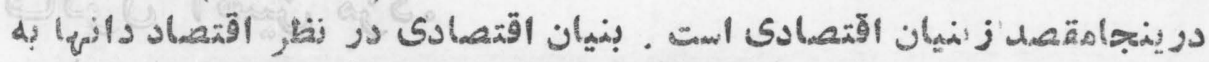

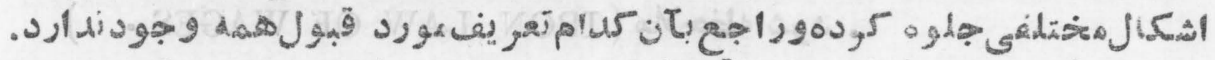

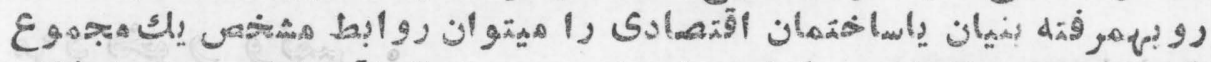

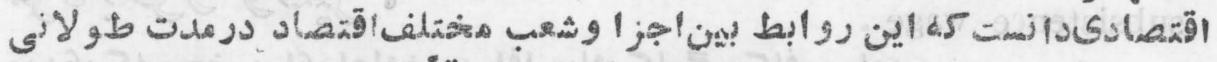

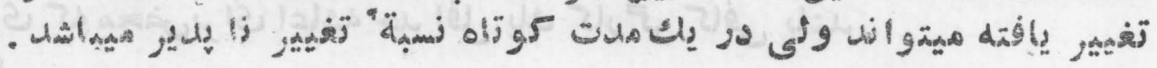

subtcribtion price.

. शी

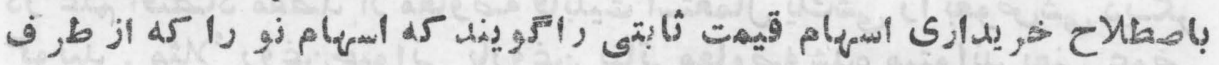




\section{SUB}

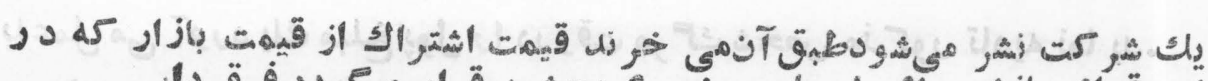

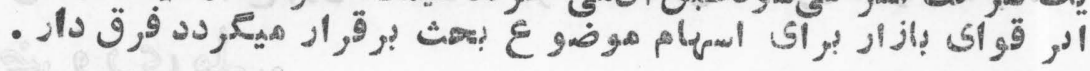

subsidiary coin.

- (s)

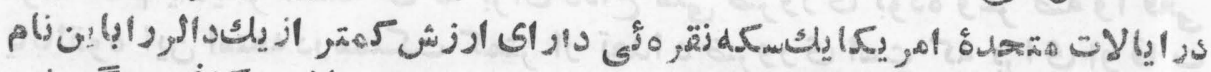

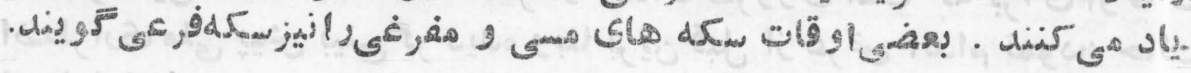

subsidiary company .

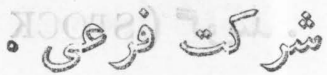

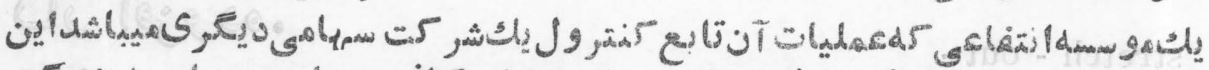

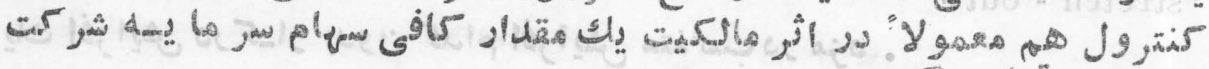

$$
\text { - دos }
$$

subsidy .

- dos

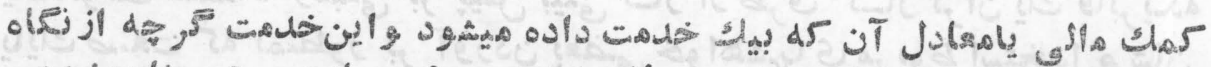
ى

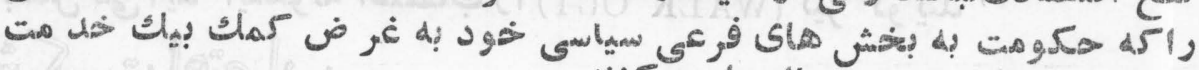

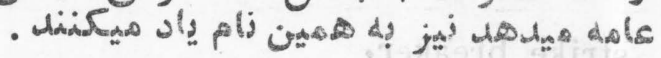

subsistence.

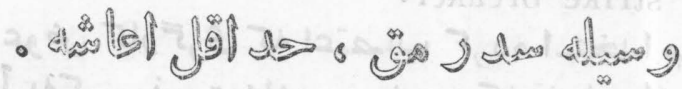

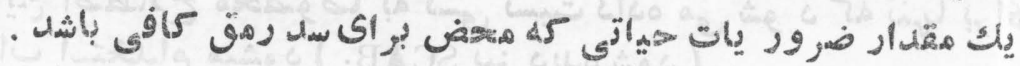

subsistence theory of wages. o

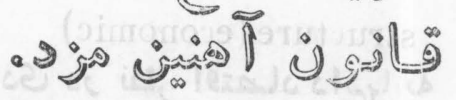

- دو ه

subsistence wage .

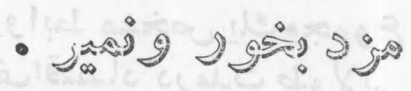

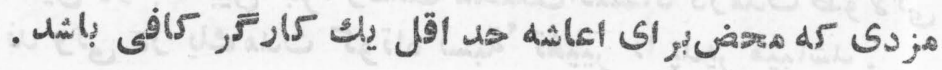

substitution.

- diog glas

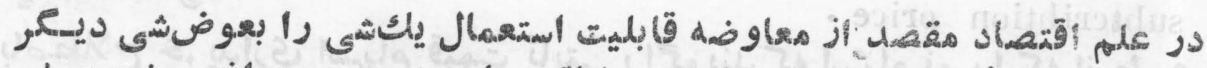

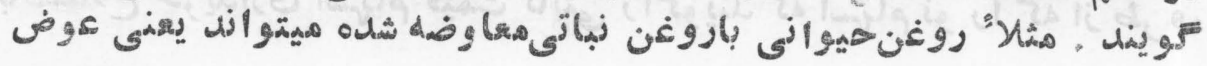




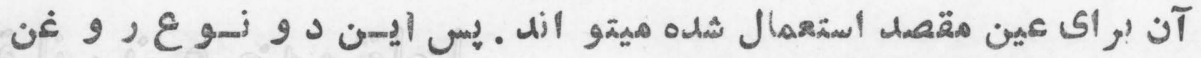

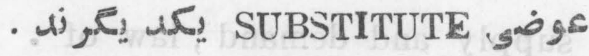

substitution, law of -

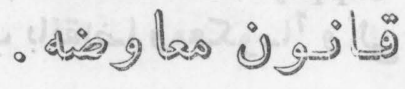

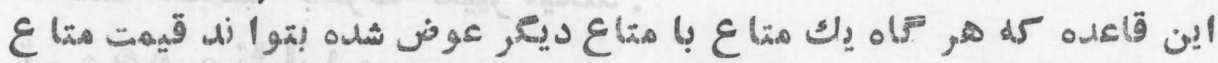

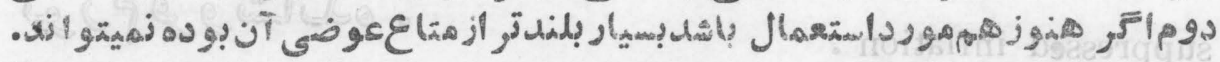
subvention.

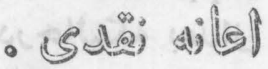

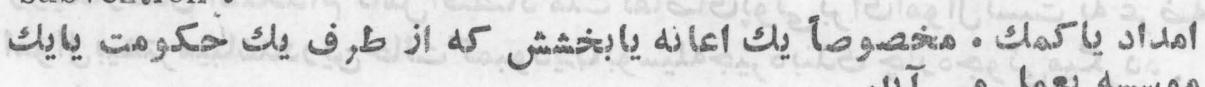
- لي

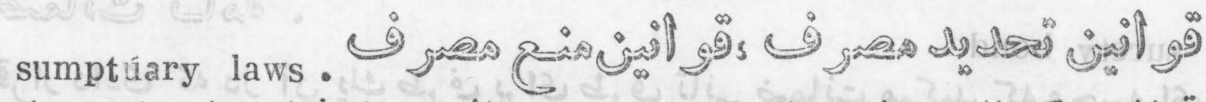

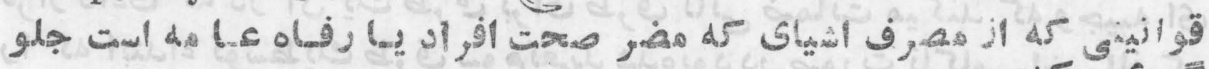
- -

superstructure. . $\operatorname{lig} 3$

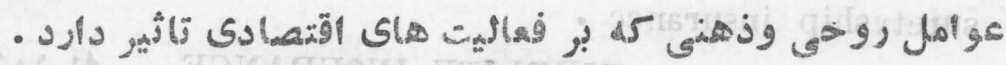
suplementary costs . FIXED COSTS . شود

supply .

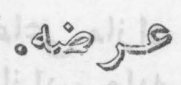

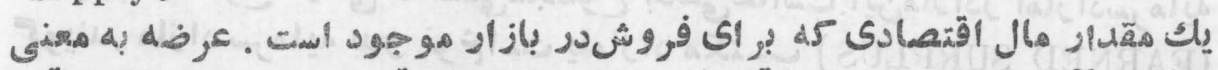

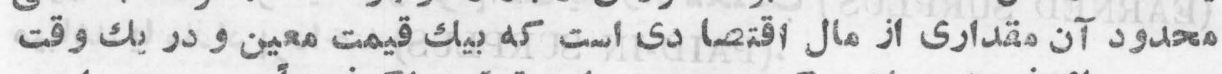

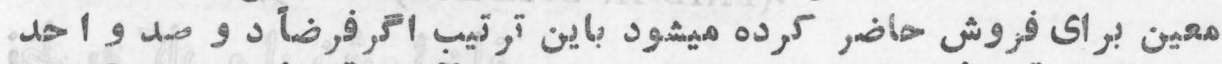

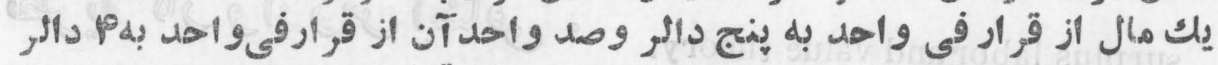

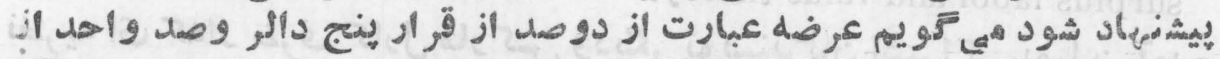

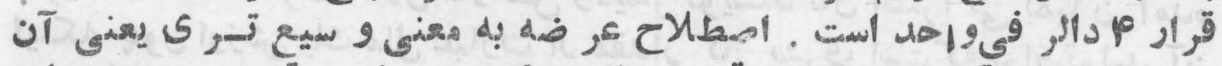

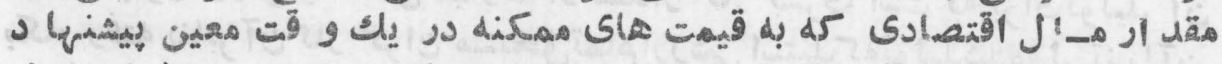

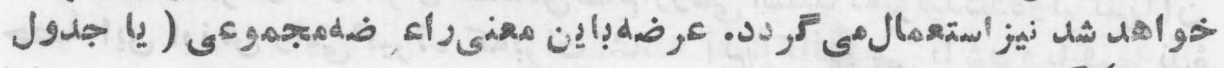

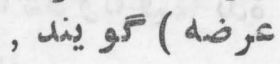




\section{SUP}

supply and demand, law of .

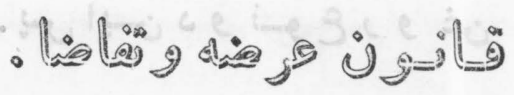

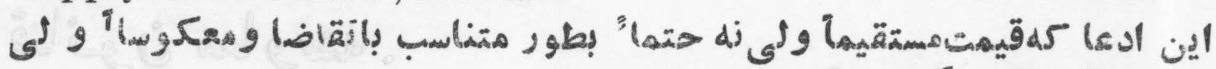

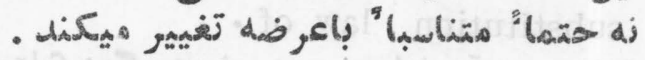

suppressed inflation.

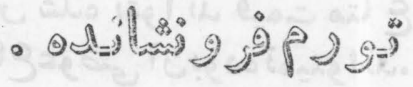

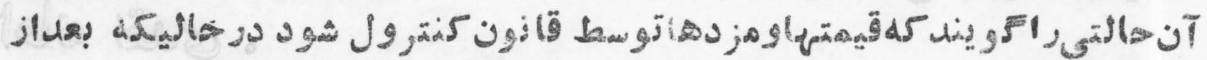

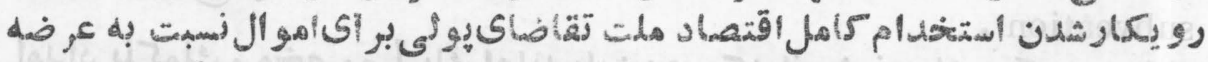

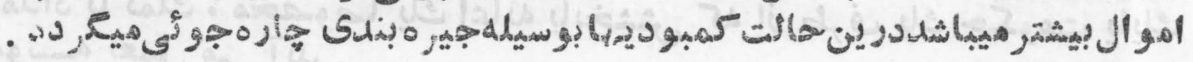
surety bond. - Ad

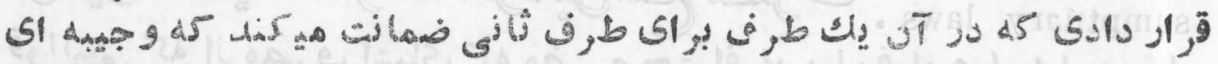

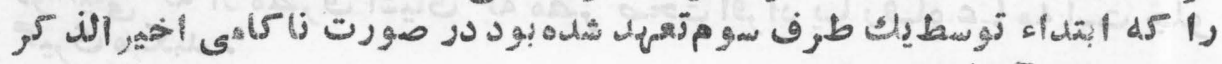

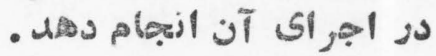
suretyship insurance .

$$
\text { - }
$$

FID

surplus .

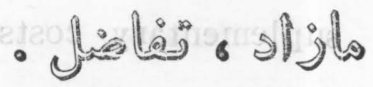

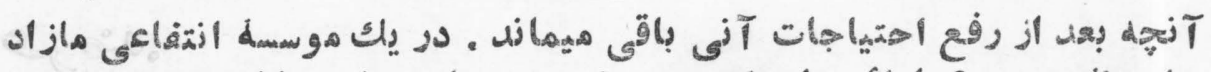

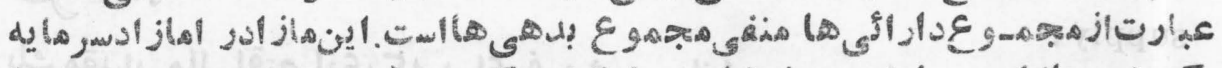
(EARNED SURPLUS) (

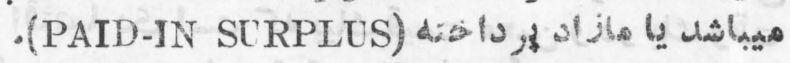

surplus labor and value theory.

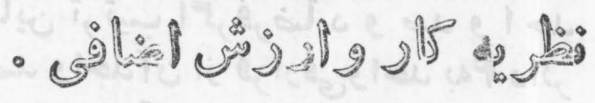

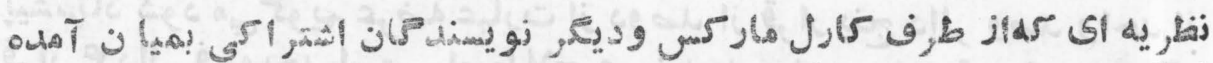

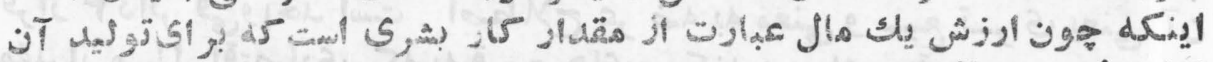

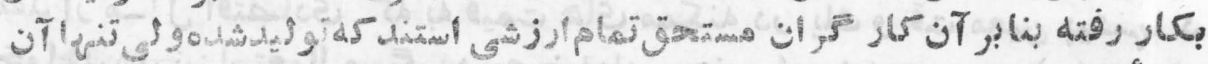

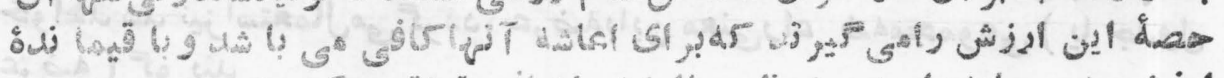

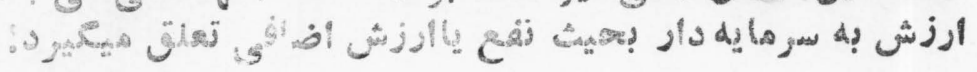




\section{SWE}

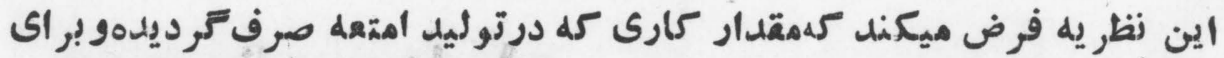

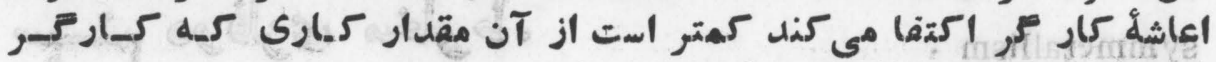
براى توليد الهتعه صرف كرده است.

surplus value, theory of.

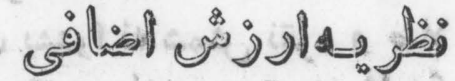

(SURPLUS ILABOR \& VALUE THEORY..) مراجعه شود به

surtax.

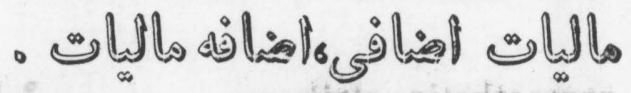

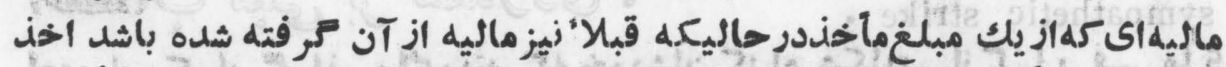

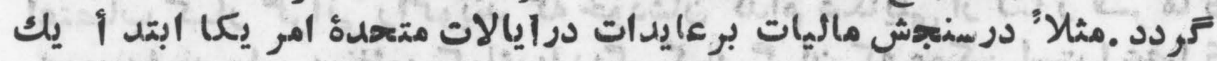

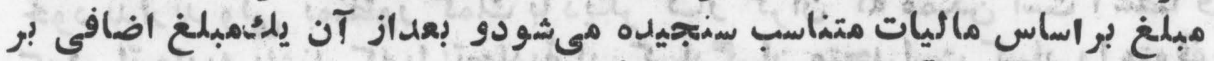

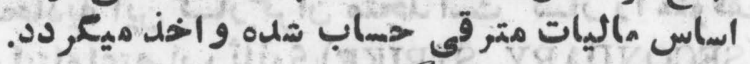

survivorship annuity.

$$
\text { - ज dilo jọ }
$$

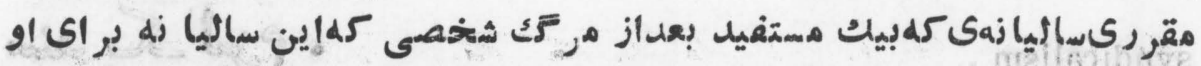

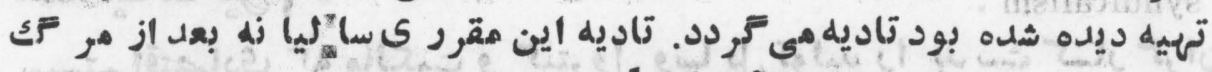

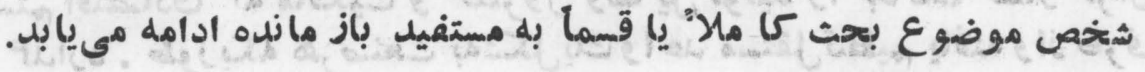

suspense account.

$$
\text { - 3) }
$$

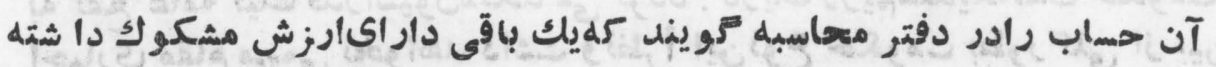

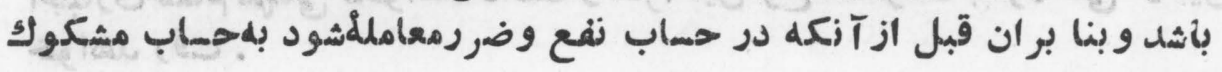

$$
\text { قيل مق ترد دود . }
$$

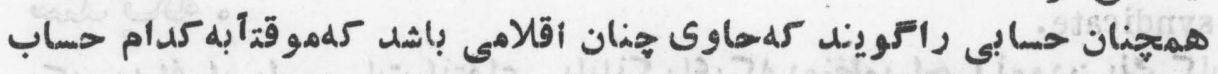

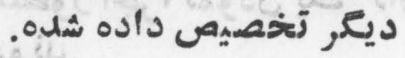

sweating.

$$
\text { - }
$$

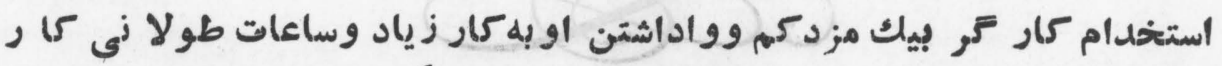

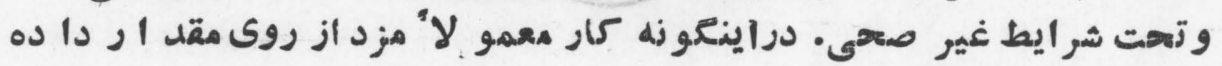




\section{SYM}

symmetallism .

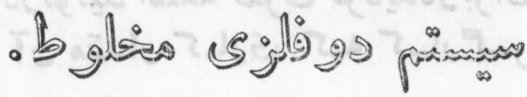

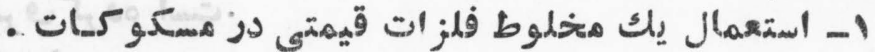

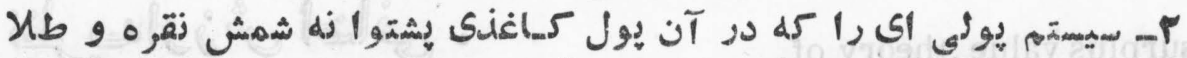

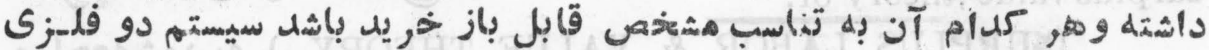
- ل

sympathetic strike •

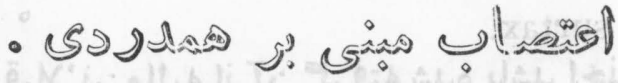

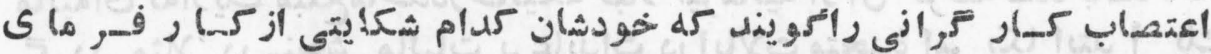

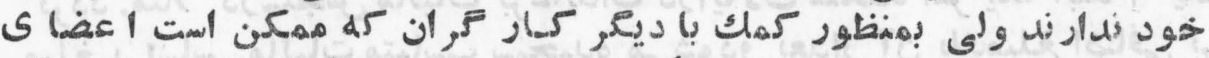

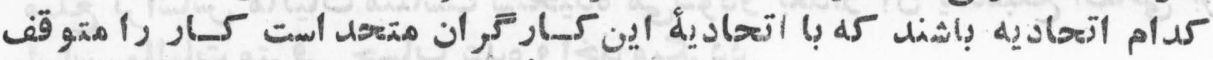
هي (SECONDARY STRIKE))

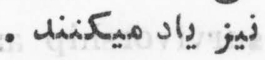

syndicalism .

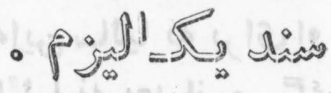

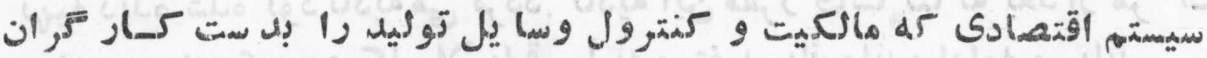

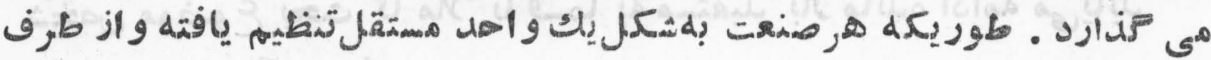

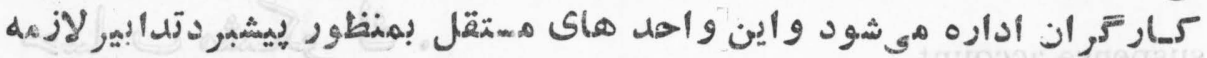

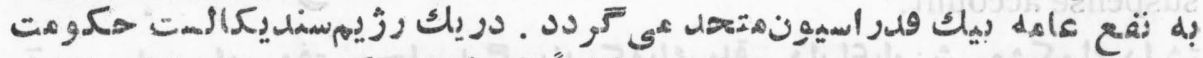

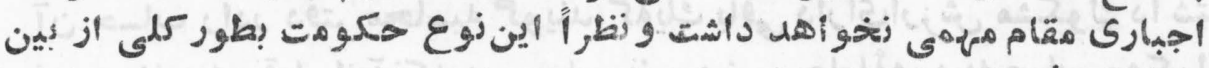
-

syndicate. - $d \int_{\infty} d i a n$

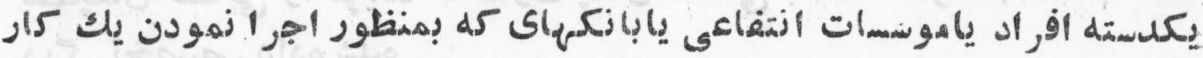

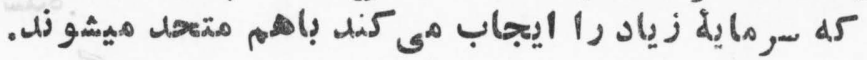

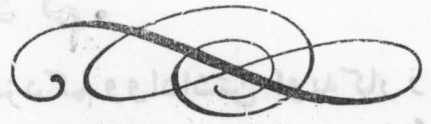




\section{Trin}

tabular stañdard of value .

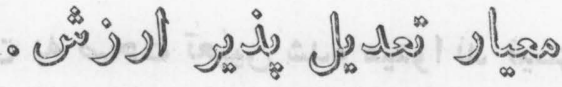

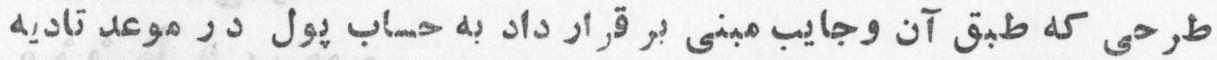

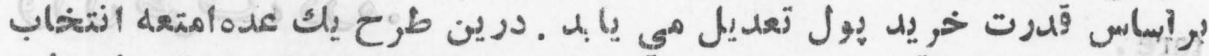

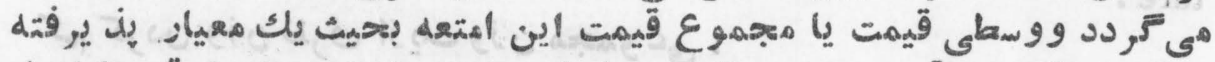

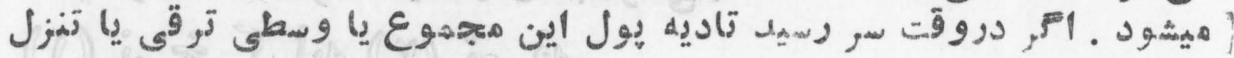

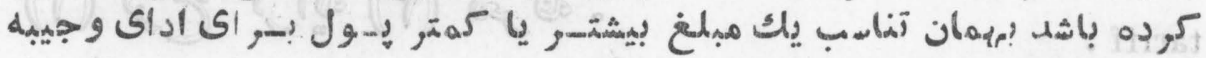

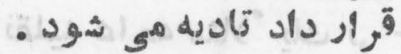

take - off . - jlgs je

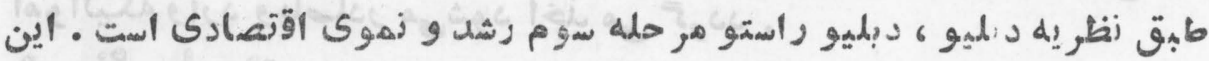

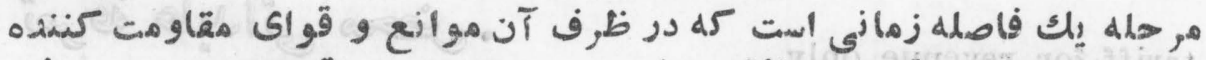

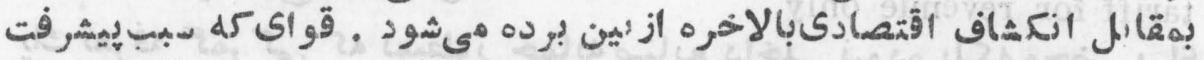

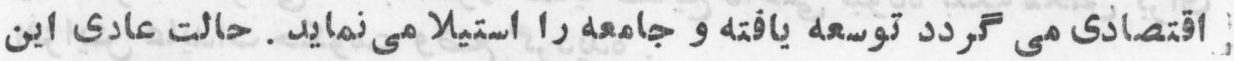

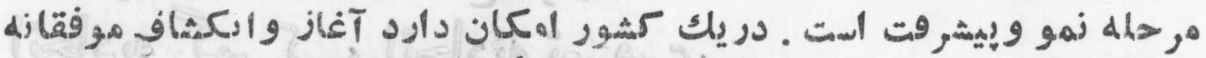

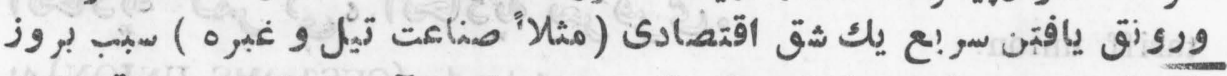

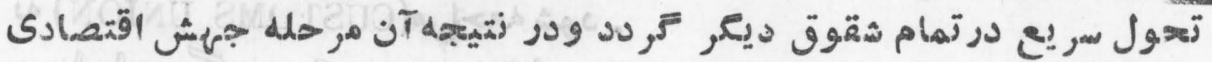

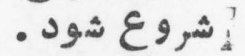

مر احل ديكر نموى دود فتصادى حسب نظر يه راستو عبارت استّاز:

1 - THE TRADITIONAL SOCIETY .

2- THE PRECONDITIONS FOR TAKE-OFF .

4 - THE DRIVE TO MATURITY -

5 - THE AGE OF HIGH MASS - CONSUMPTION. 
tangible property •

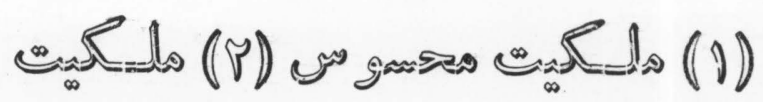

$$
\text { - }
$$

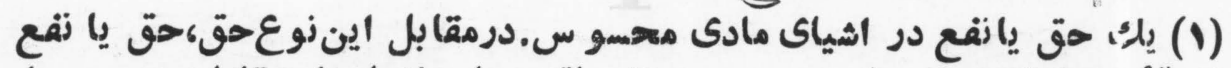

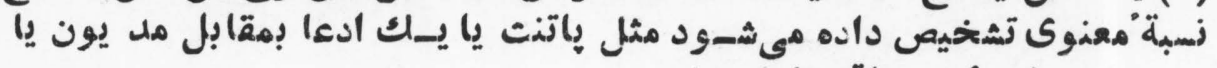

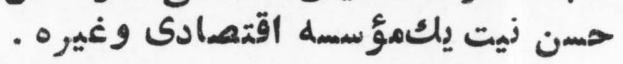

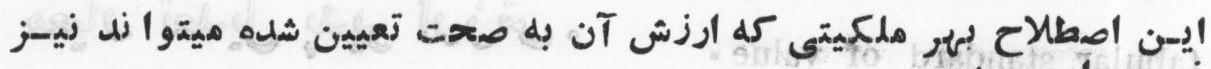

tare .

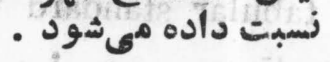

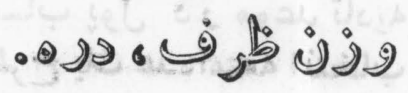

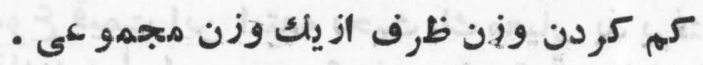

tariff .

$$
\text { - ब(פ }
$$

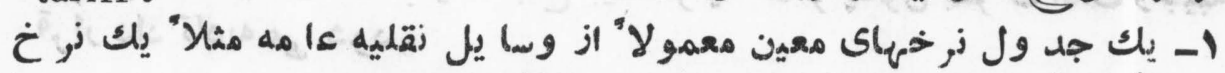

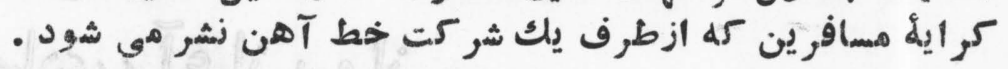

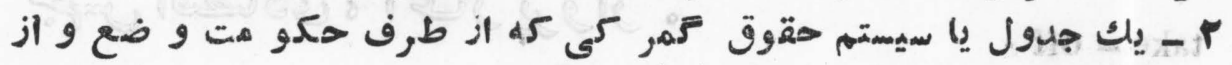

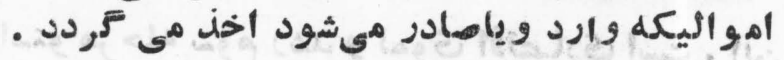

tariff for revenue only .

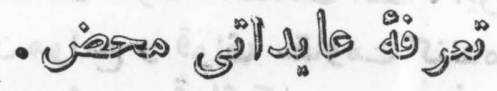

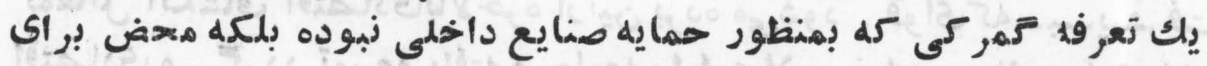

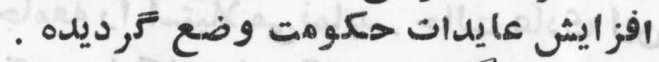
tariff union.

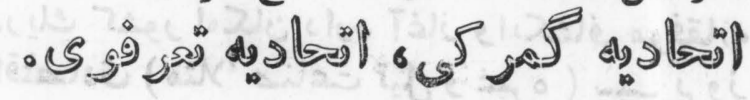
بر اجed (CUS1 UMS UNION) tariff war.

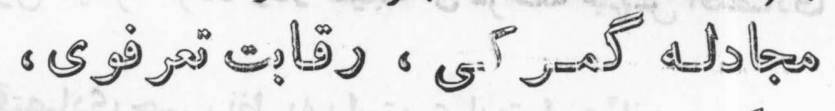
- de 200

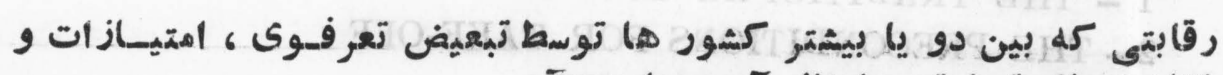

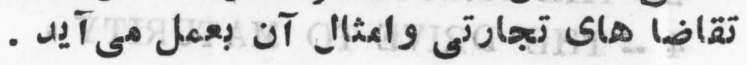




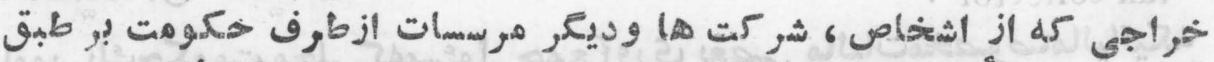

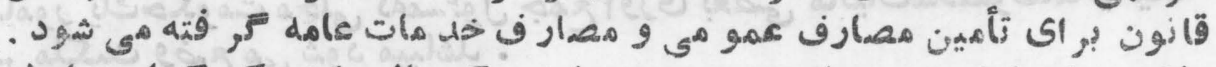

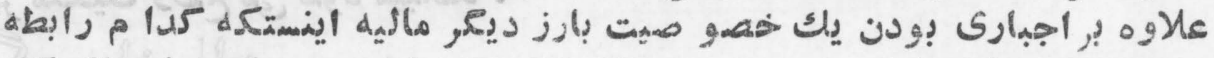

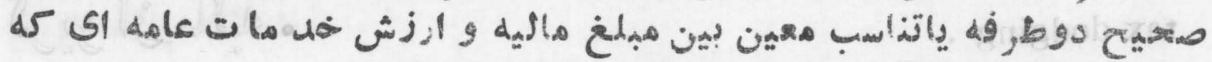

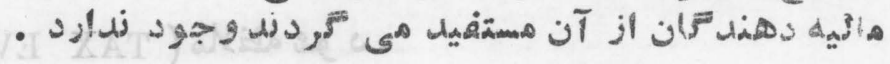

tax - anticipation bond . - ज?

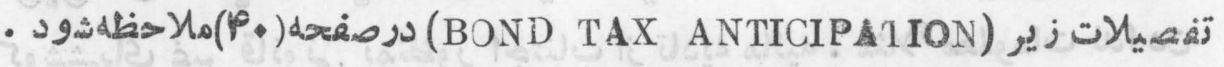
tax assessment.

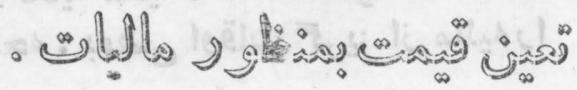

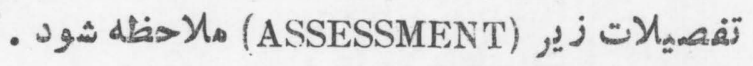

tax avoidance.

$$
\text { - 嵌 }
$$

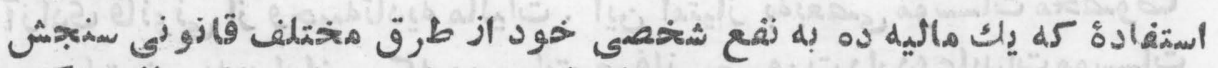

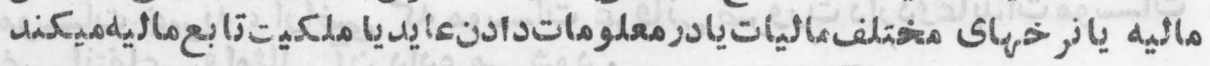

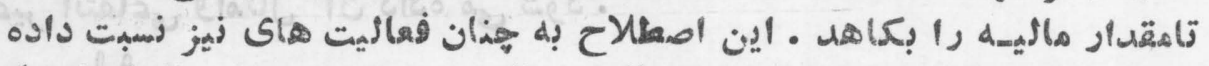

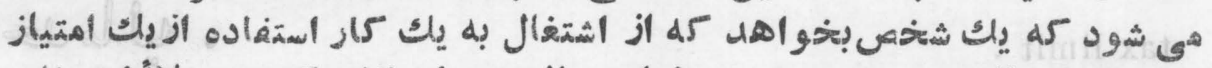

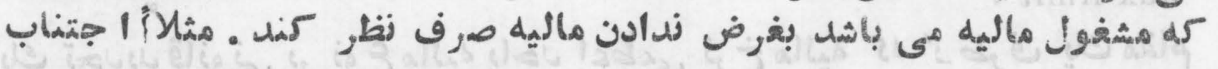

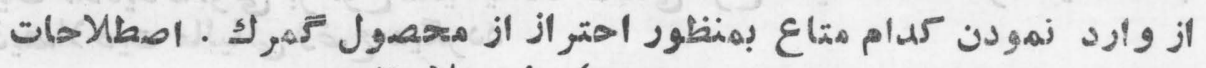
'نيز ملاحظه شود (TAX DODGING, TAX EVASION )

tax base .

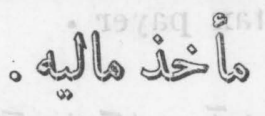

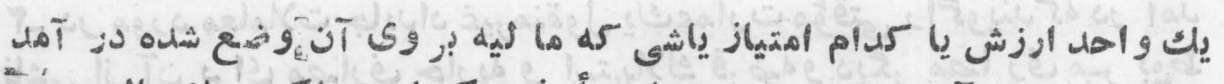

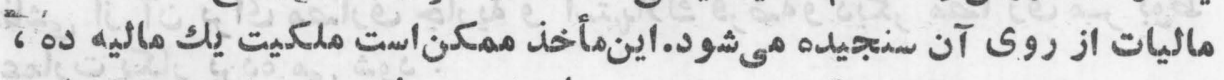

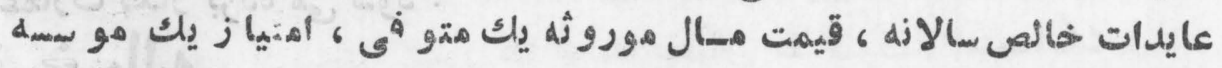

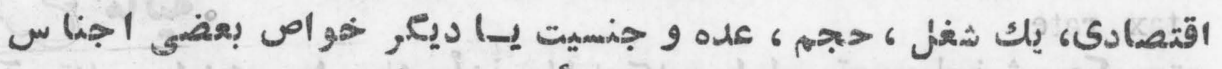

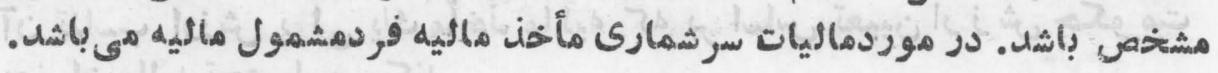




\section{TAX}

tax collector.

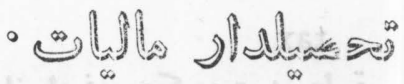

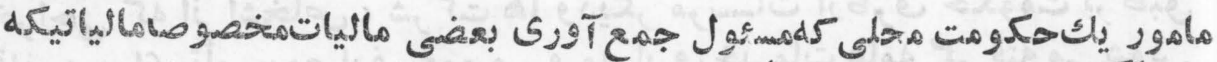

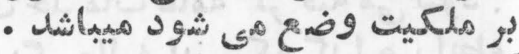

tax dodging .

$$
\text { - A. } \int_{\alpha} \text { jol }
$$

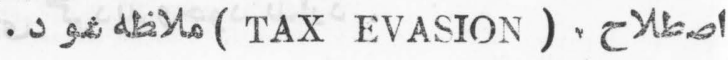

tax evasion:

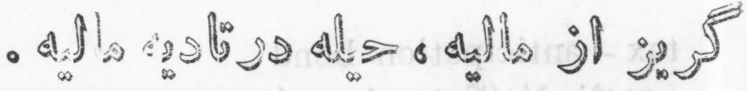

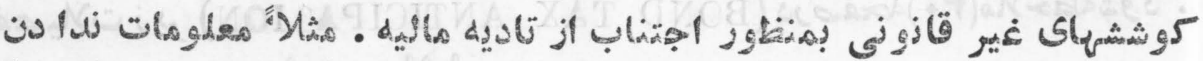
عائات - $\operatorname{lig} g$ ( TAX DODGING)

tax exemption

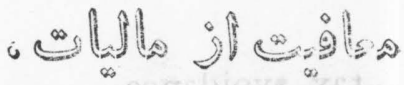

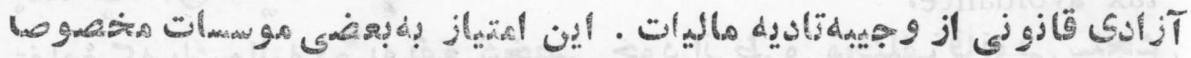

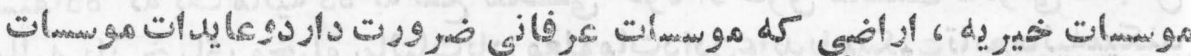

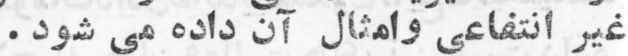

tax limit .

- du lo lo

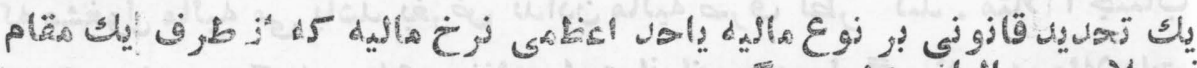

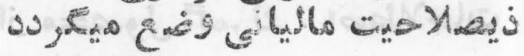

tax payer

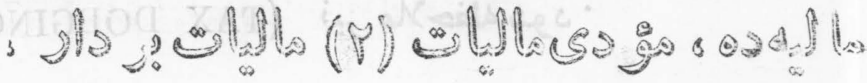

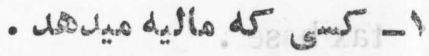
له

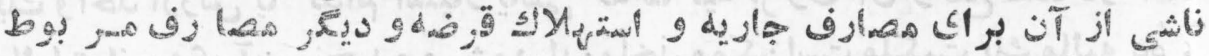

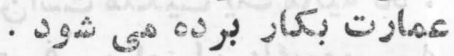

tax rate - Ala (cio

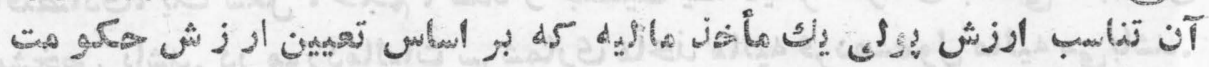

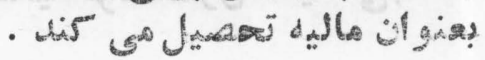


TEC

tax sell $\mathbf{i}^{\text {ng }}$.

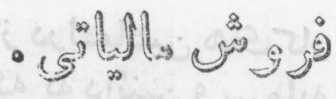

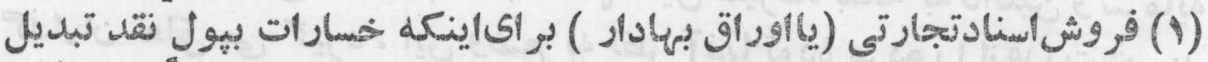

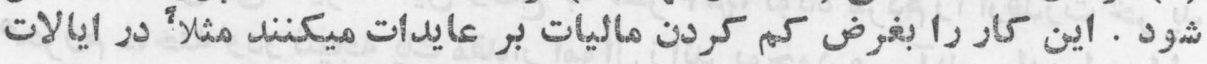

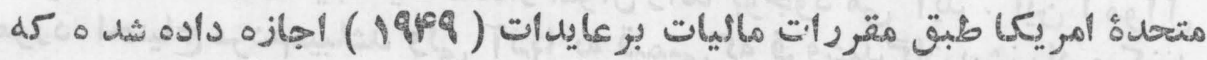

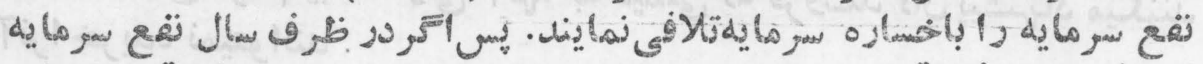

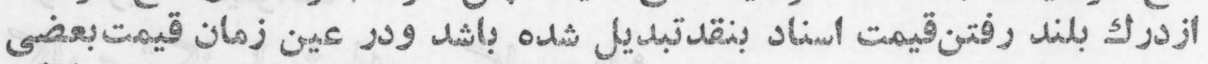

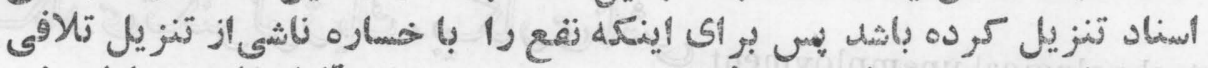

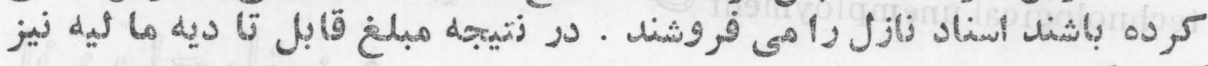

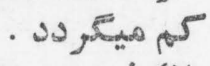

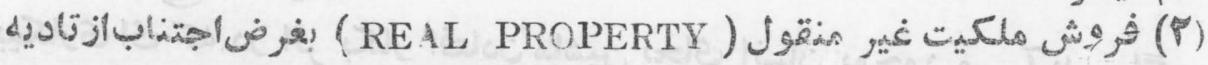
.

tax sharing ,

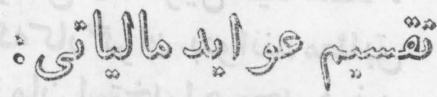

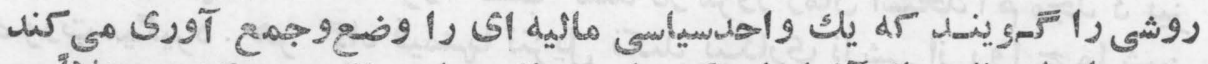

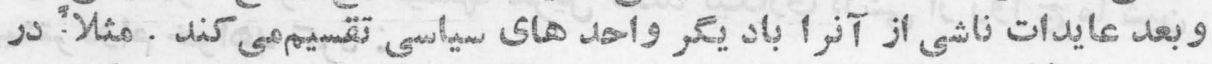

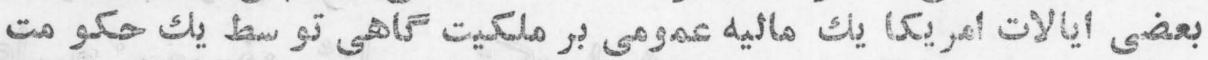

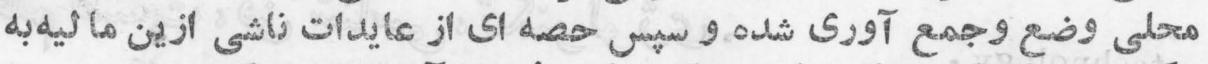

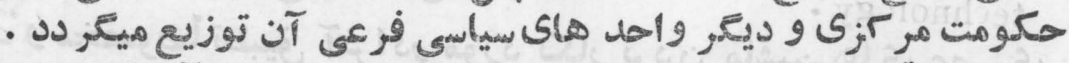

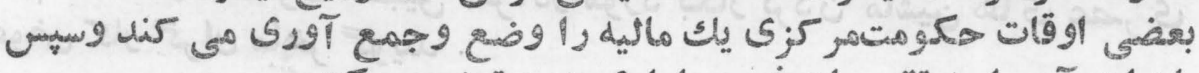

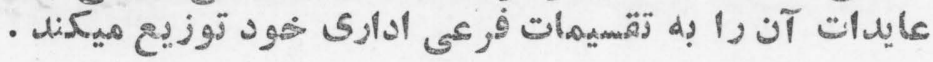

taylorism, - Pischis

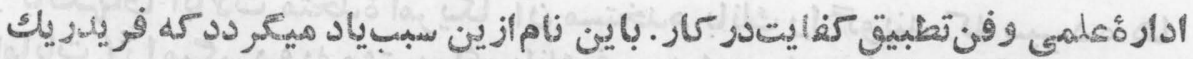

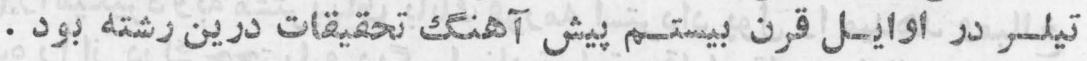

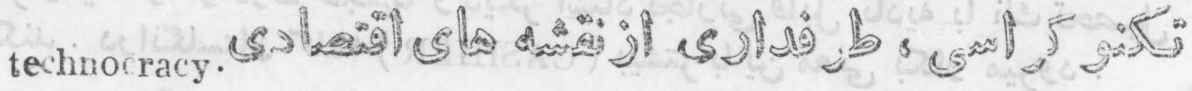

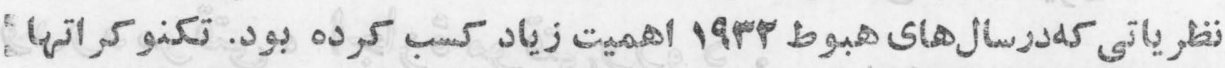

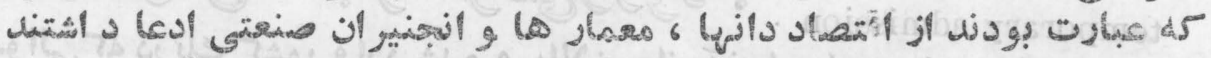

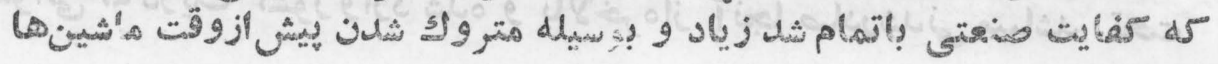




\section{TEC}

تأمين مى شود ـ آزهيا ادعامى كردند كه بـ إنس ازدازى كه از در ككماشين هاى كار

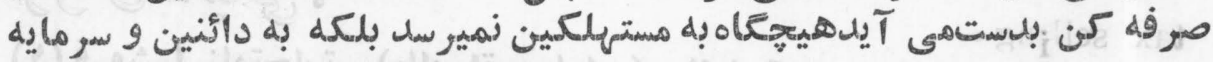

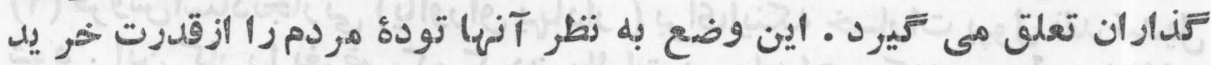

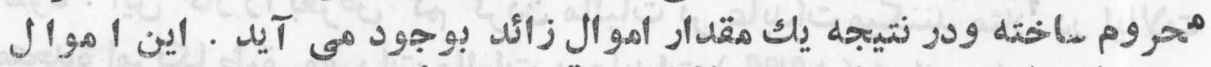

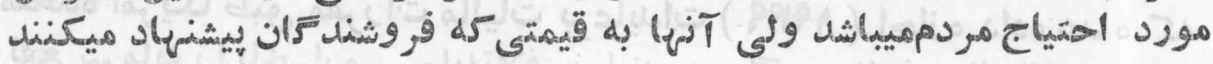

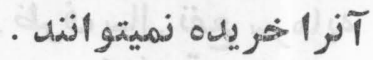

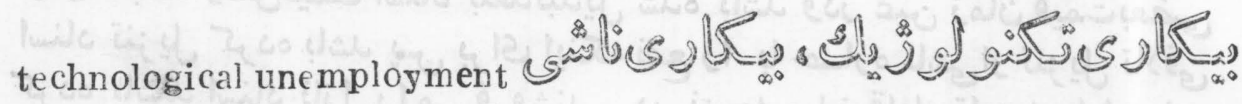

$$
\text { - is }
$$

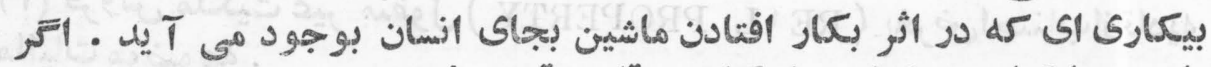

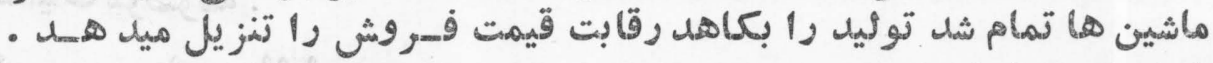

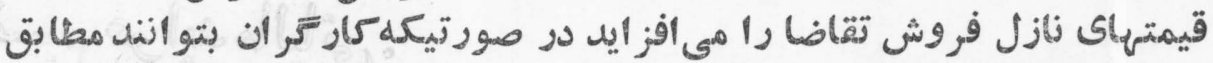

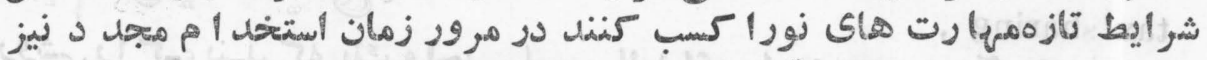

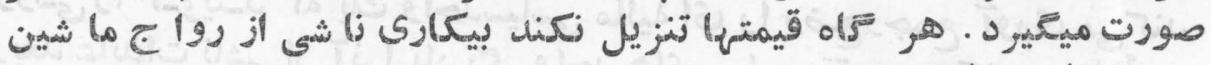
بيشتر دوام خواهونل كرد .

technology • - ज占

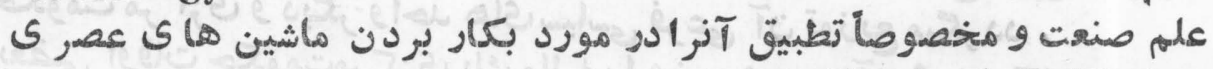

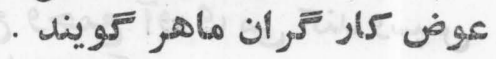

teller ,

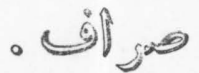

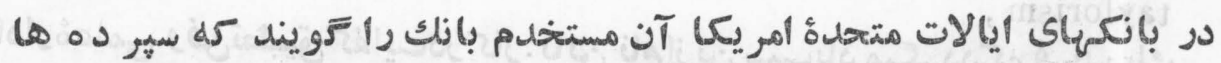

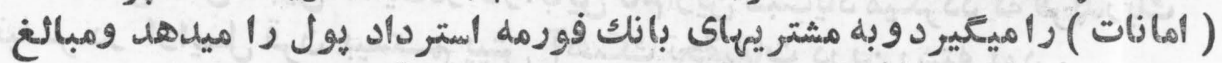

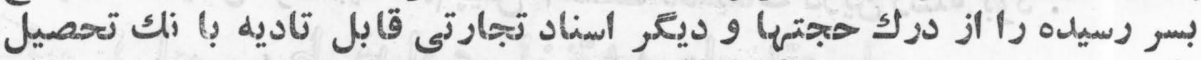

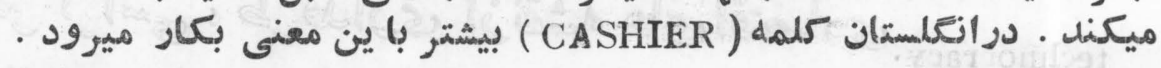

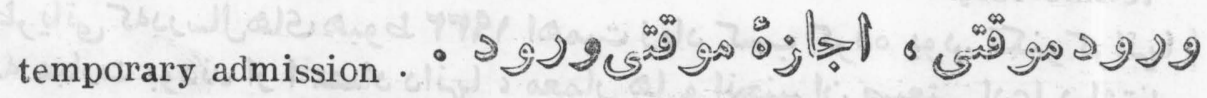
امو الى كه دريك كشود وارد شده و بالاخرهاز آنجا هادرشدنى ميباشد .تحت $\sim \vee 4$ 


\section{TER}

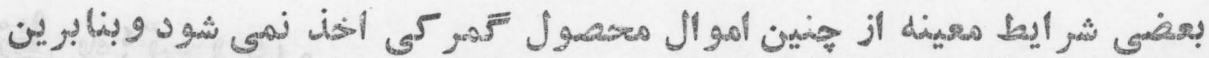

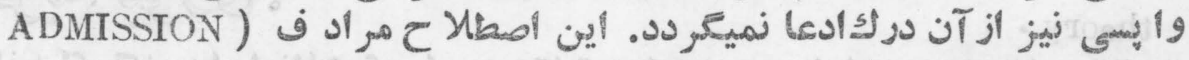

tender

. أست

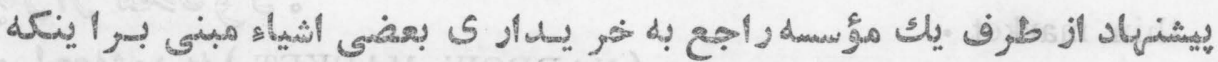

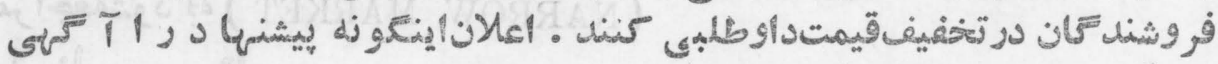

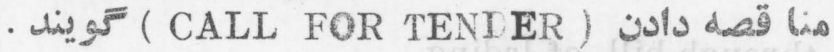

erminal bond .

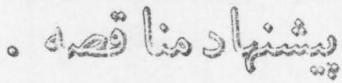

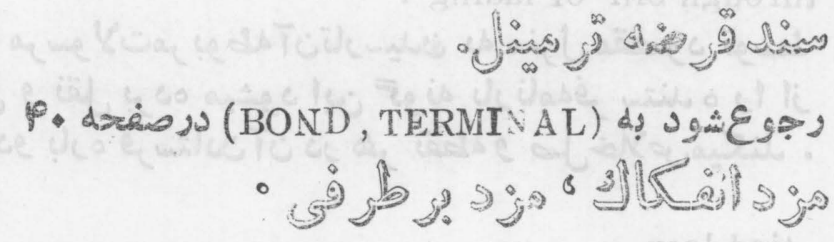

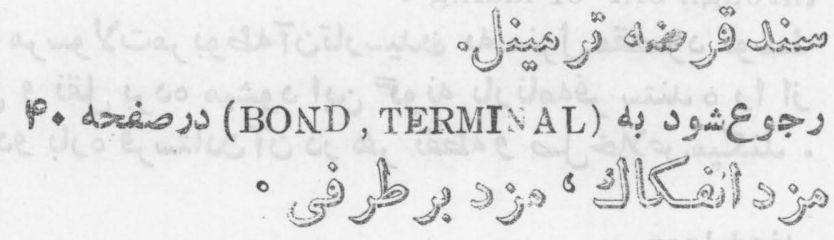

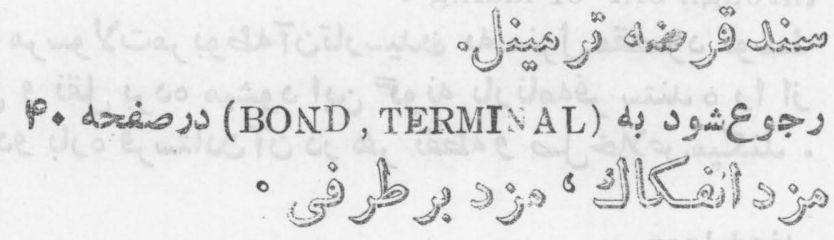

terminal wage

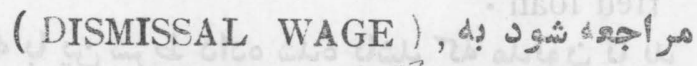
term plan of life insurance ' - $\int_{5}^{3} d i j$ duedo don

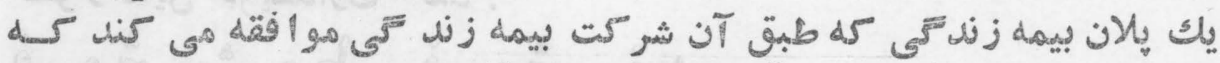

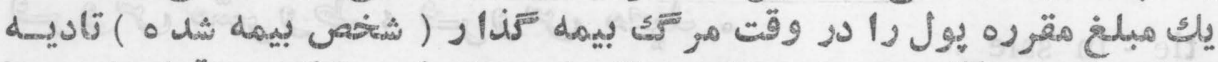

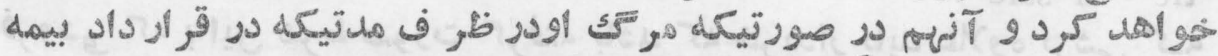

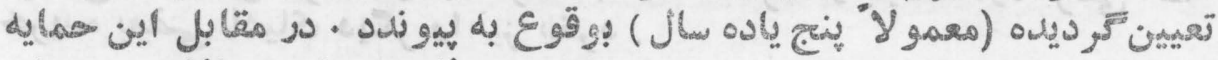

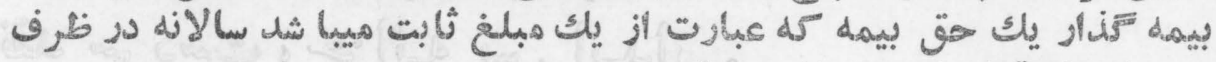

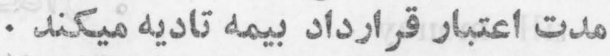

terms of trade

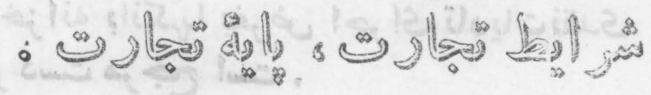

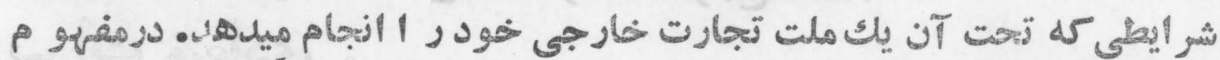

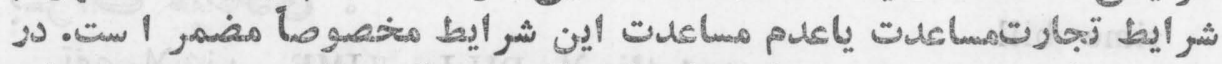

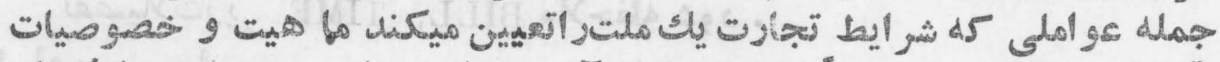

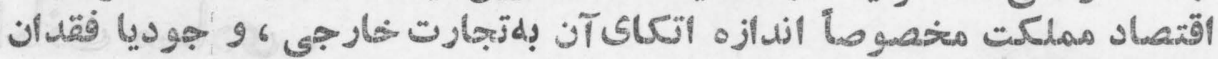

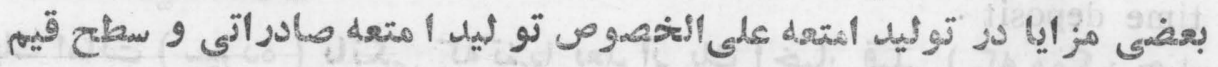
باز ار دنيا ميبالثهل - مون 


\section{THE}

theory •

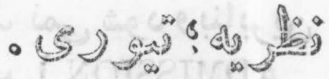

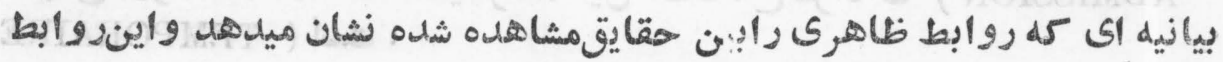

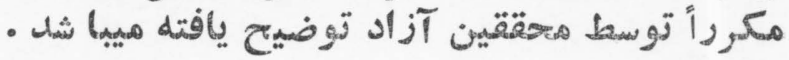

thin market

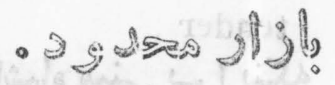

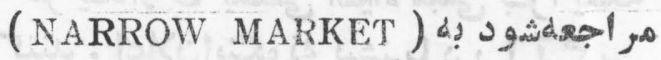

through bill of lading .

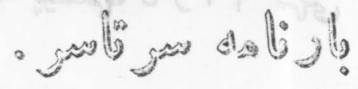

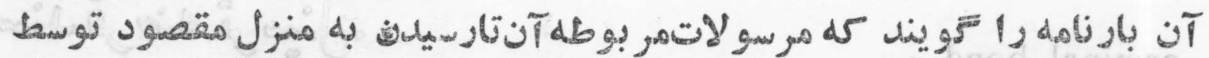

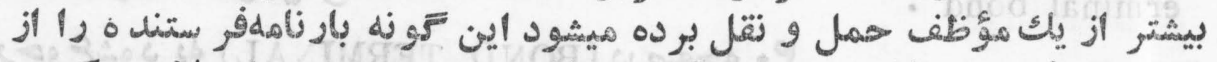

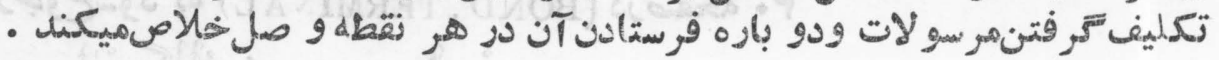

tied loan •

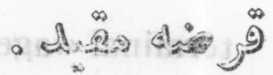

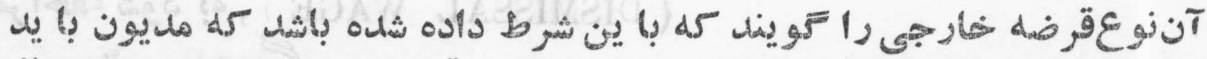

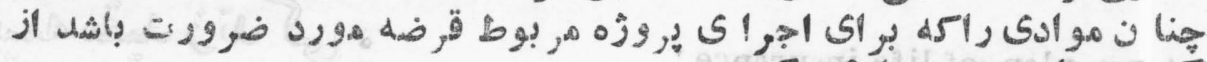

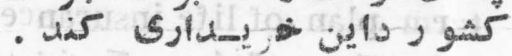

tie - in sale . $\quad$ d

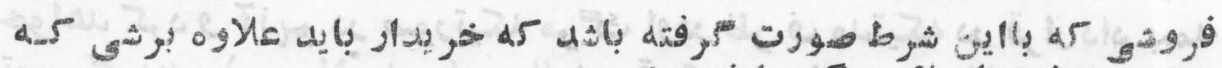

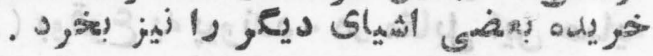

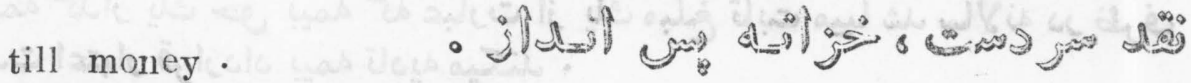

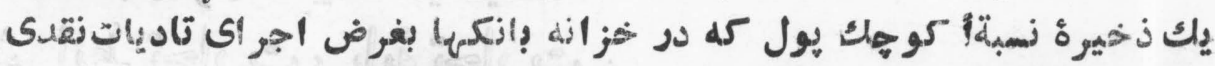

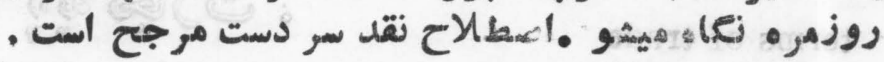

time bill .

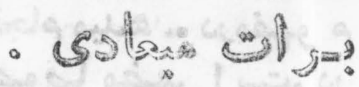

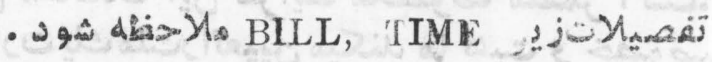

time deposit .

- Solara cibl

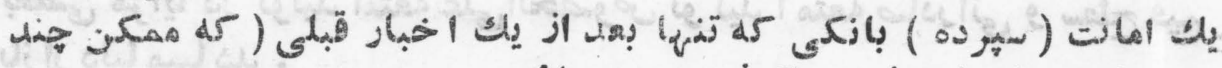

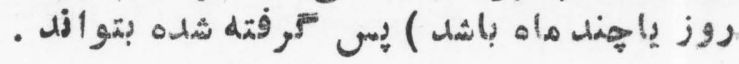


time draft .

- SSbua all

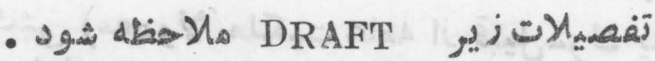

time loan .

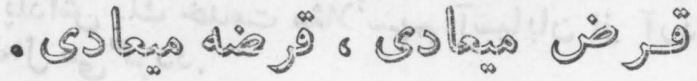

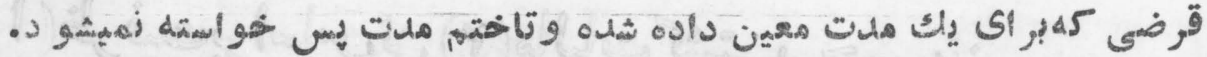

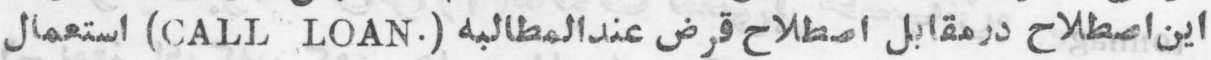

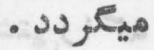

time utility .

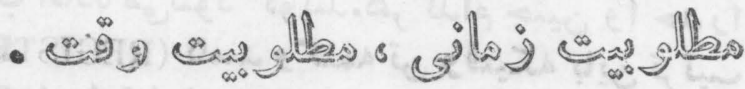

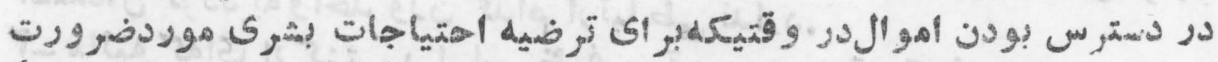

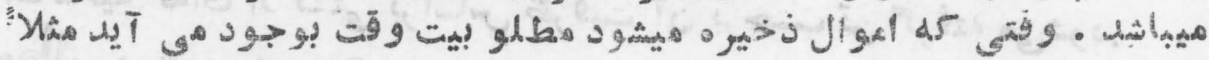

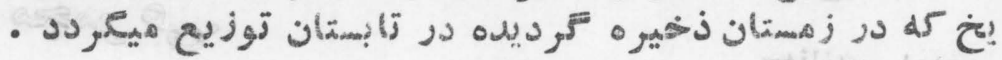

time work .

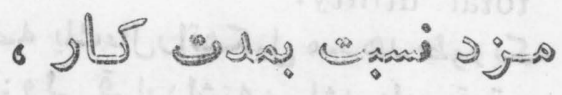

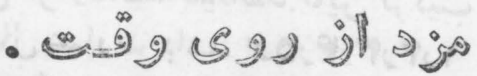

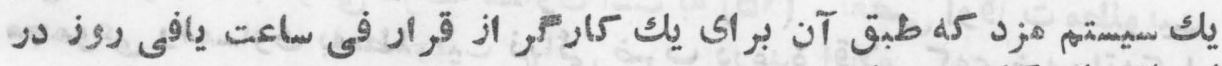

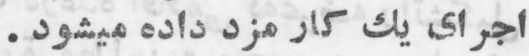

token coin -

- $\mathrm{s}^{0} \mathrm{~g}$

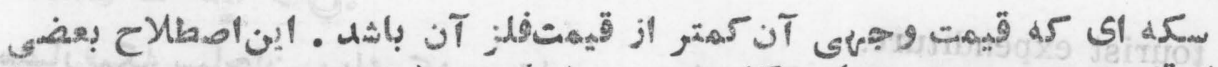
اوقات (SUBSIDIARY COINS) (MINOR COIN

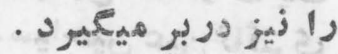

tolerance . - जि

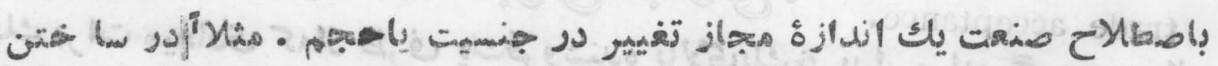

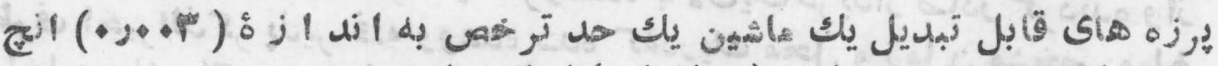

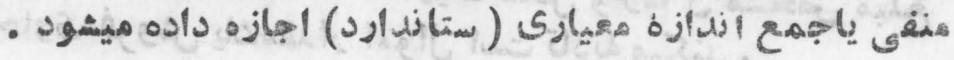


toll.

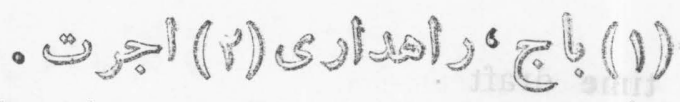

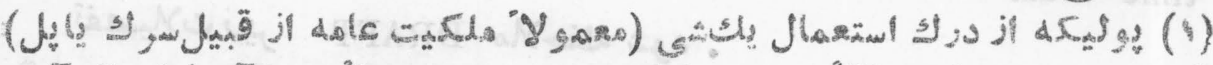

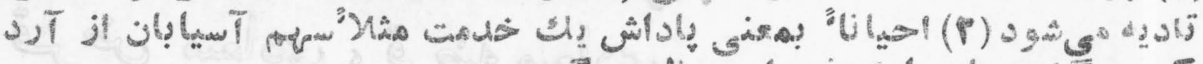

$$
\text { كورن }
$$

tonnage.

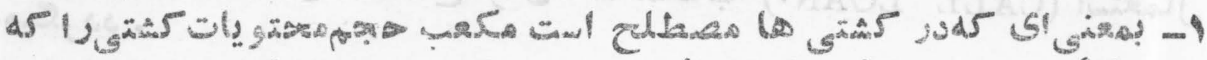

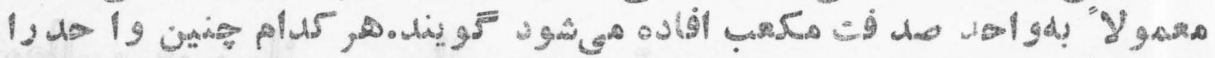

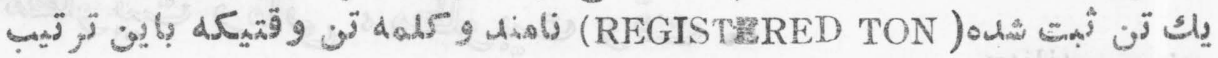

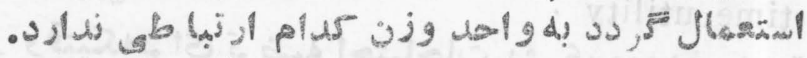

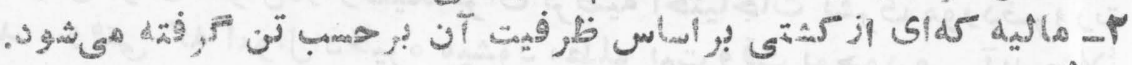
total utility.

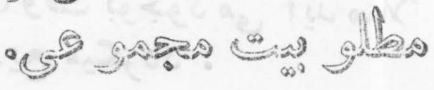

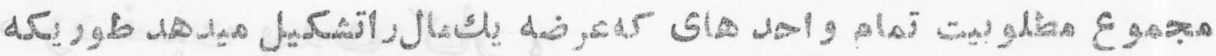

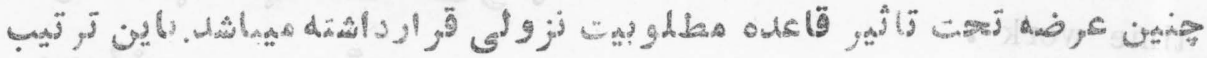

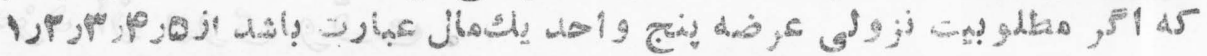

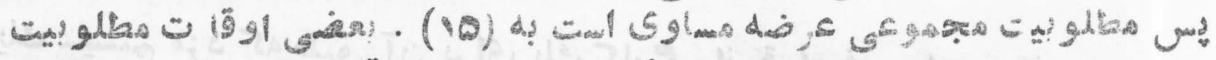

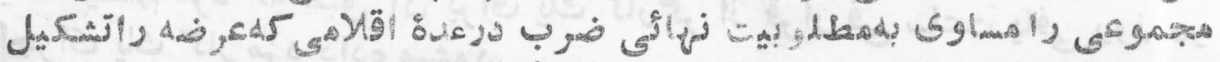

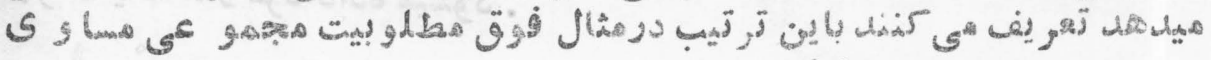

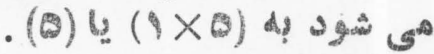
tourist expenditure.

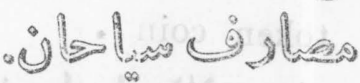
定

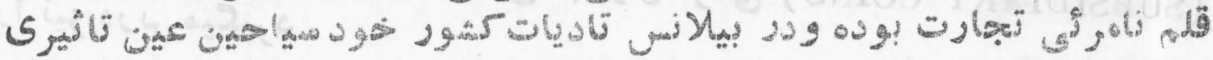

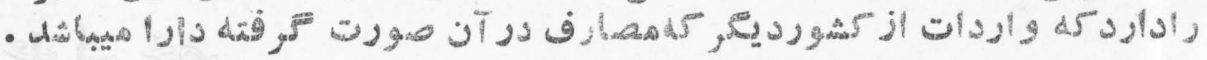

trade acceptance.

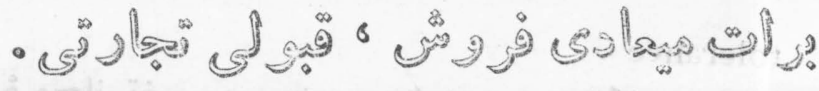

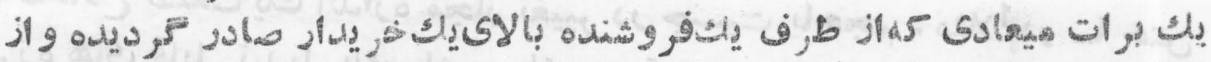

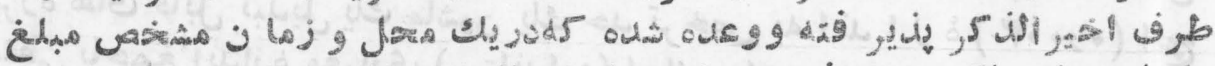

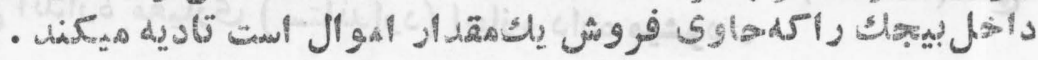




\section{TRA}

trade agreement.

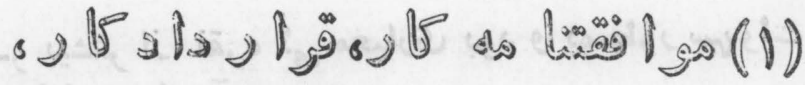

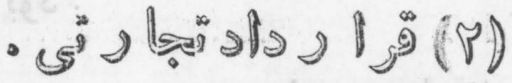

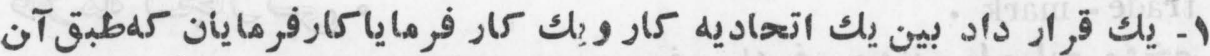

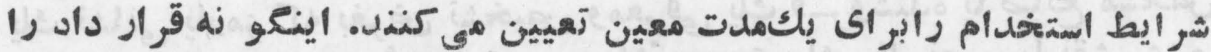

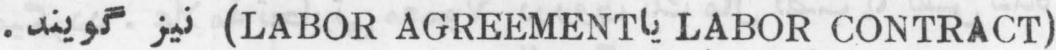
ץ- معاهدات وقرار دأدهاى تجارتى.

trade association .

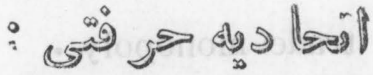

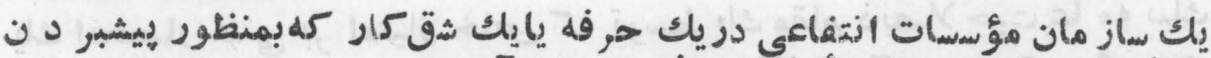

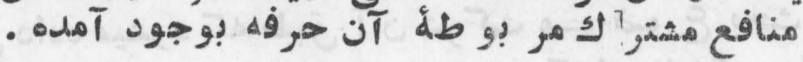

trade barrier. - $\left.)^{\infty}\right)^{\infty}$

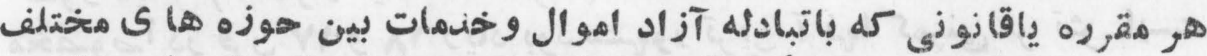

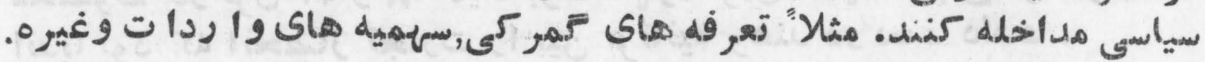

trade cycle,

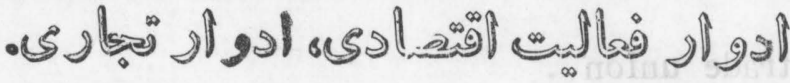

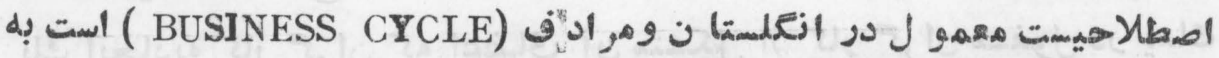

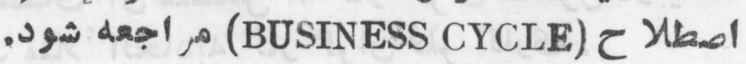

trade deficit.

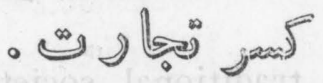

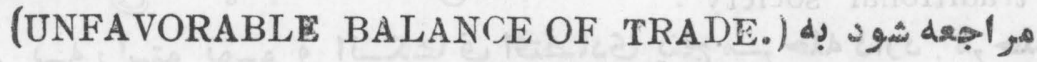

trade discount.

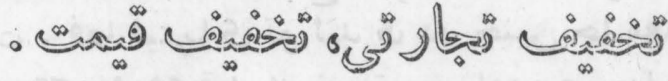

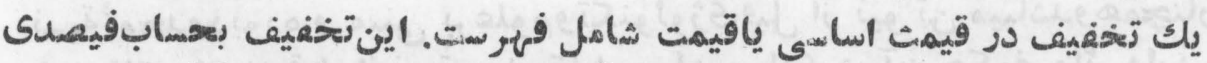

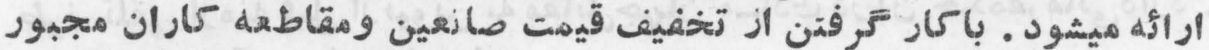

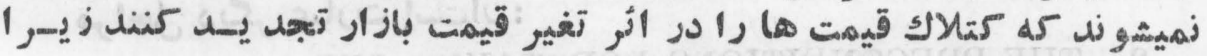

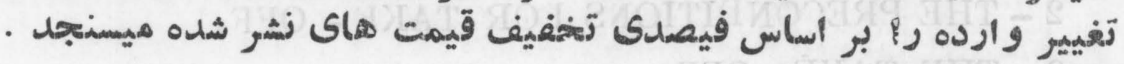

trade dollar.

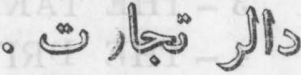

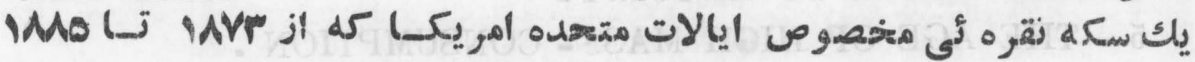




\section{TRA}

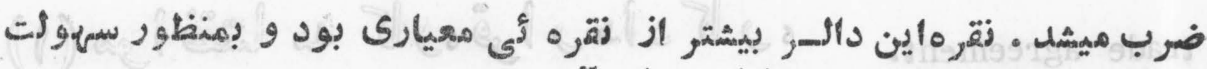

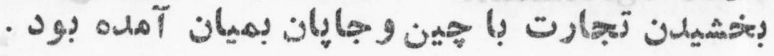

trade - mark .

- $\mathrm{s} 2$

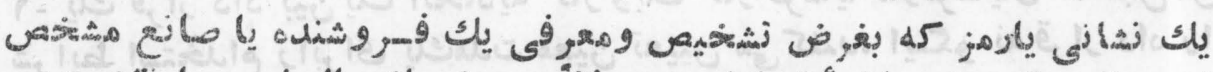

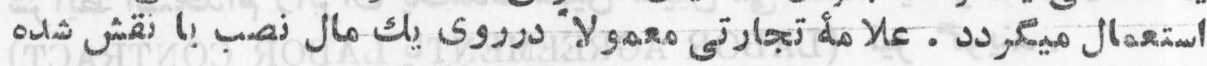

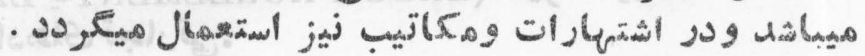

trade monopoly .

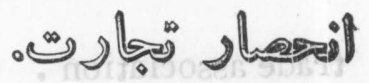

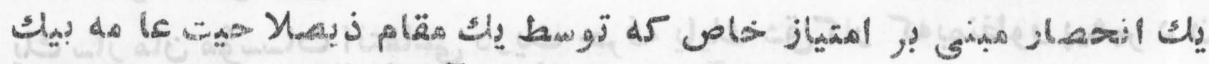

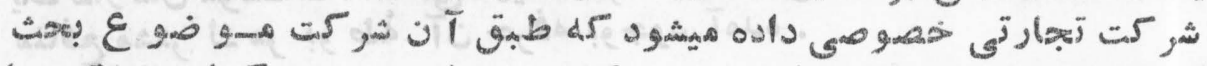

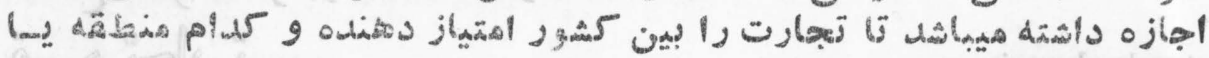
كشوز دئl

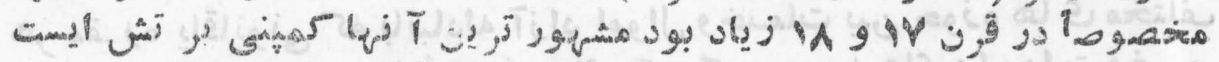

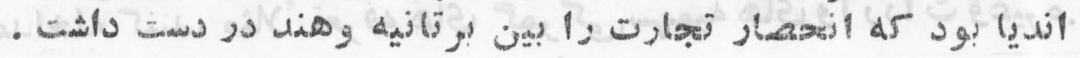

trade union .

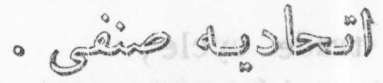

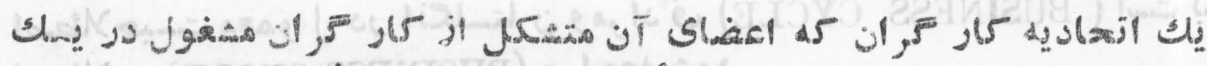

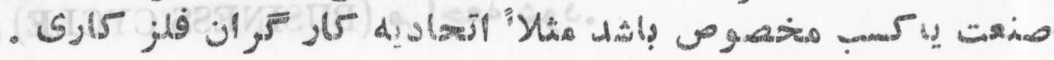

traditional society.

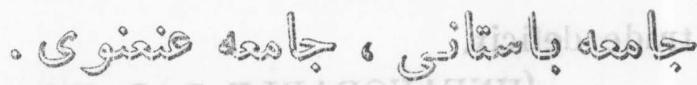

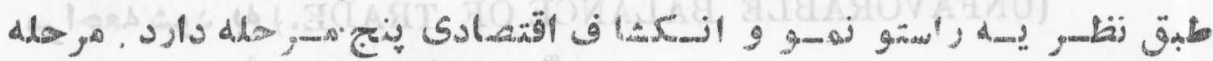

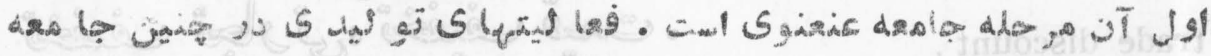

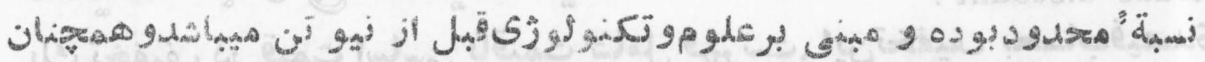

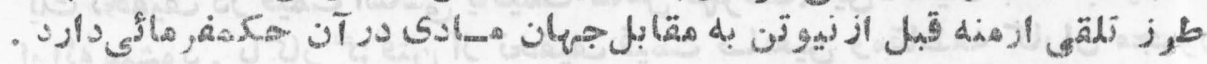

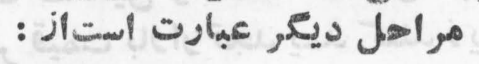

2-THE PRECONDITIONS FOR TAKE - OFF.

3 - THE TAKE - OFF .

4 - THE DRIVE TO MATURITY •

5 - THE AGE OF HIGH MASS - CONSUMPTION . 


\section{TRE}

trausactions tax .

$$
\text { s }
$$

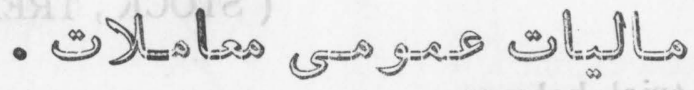

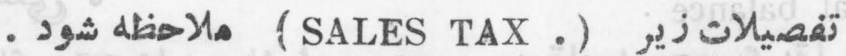

transfer agent.

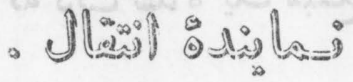

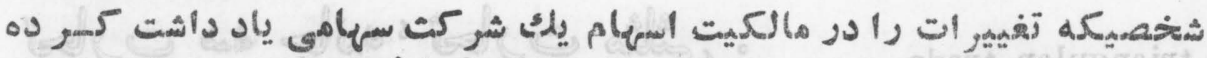

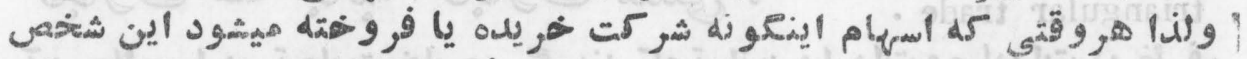

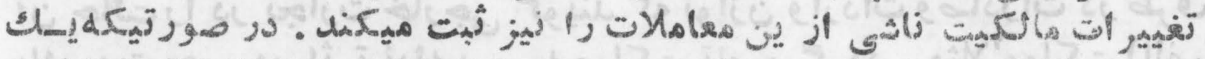

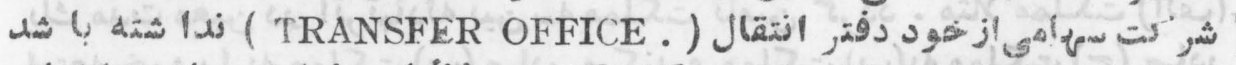

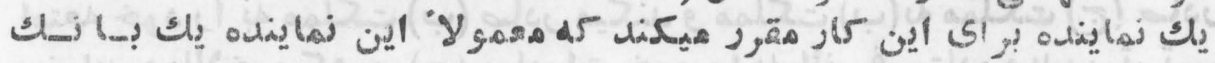
-

traveller's check .

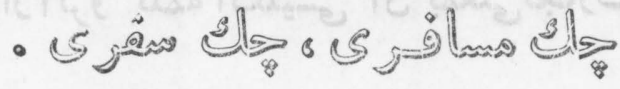

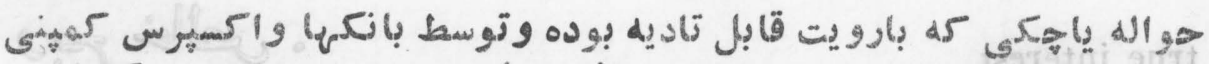

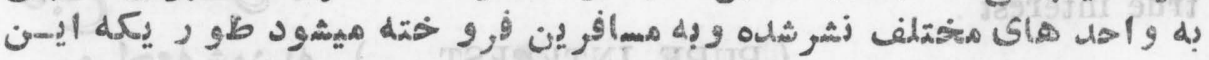

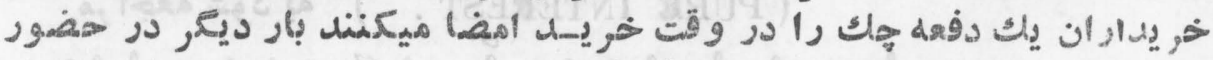

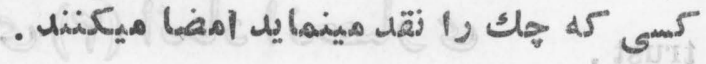

traveller's letter of (redit.

$$
\begin{aligned}
& \text { : S } \\
& \text { - CS }
\end{aligned}
$$

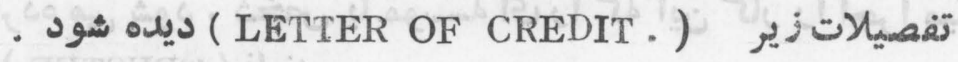

treasury bill .

- ssla difis

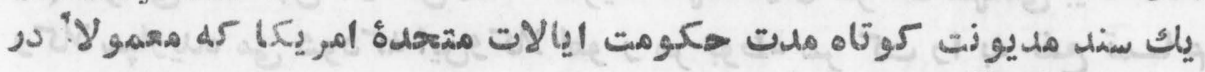

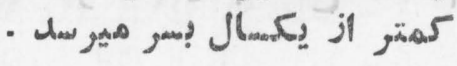




\section{TRE}

treasury stock .

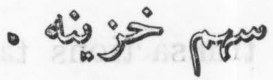

( STOCK , TREASURY .) هصيلات زير

trial balance .

- ज密

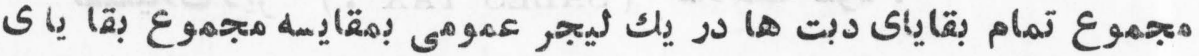

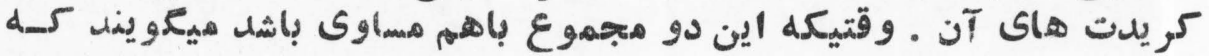

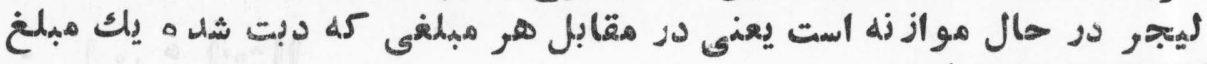

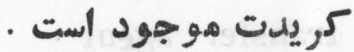
triangular trade.

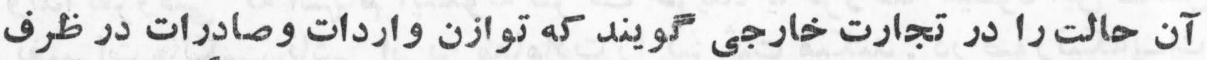

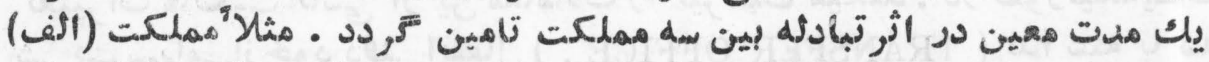

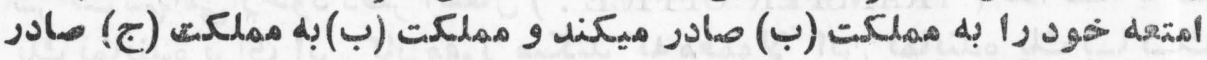

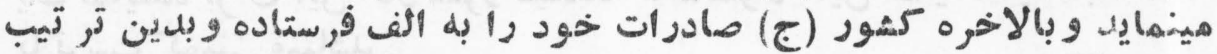

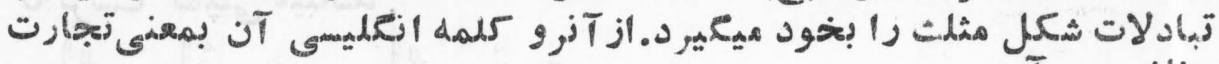

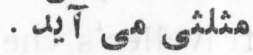
true interest

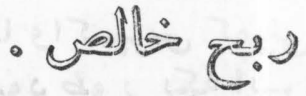
trust .

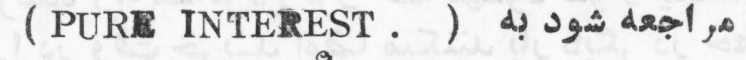

$$
\begin{aligned}
& \text { S gla } \\
& \text { - 赵事 }
\end{aligned}
$$

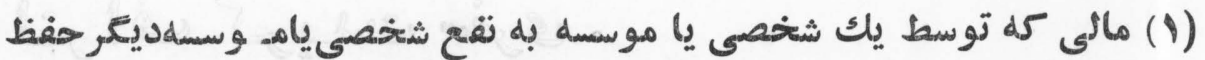

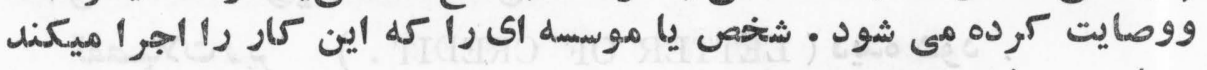

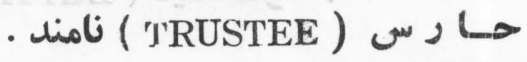

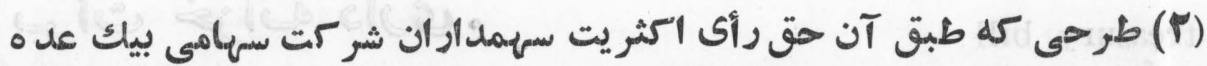

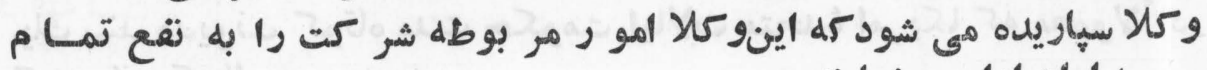

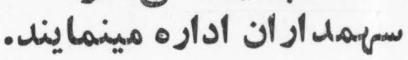




\section{TWO}

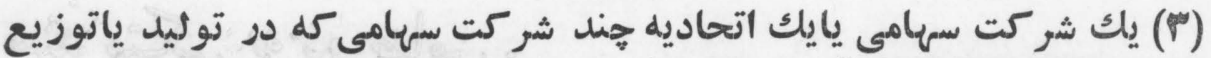
يك متاع يايك خلامت قدرت كنترول انحصارى يانيمه انحصارى آنرا داشته ميباشل.

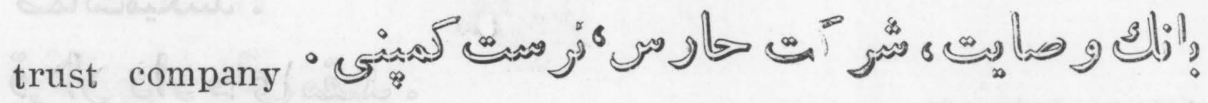

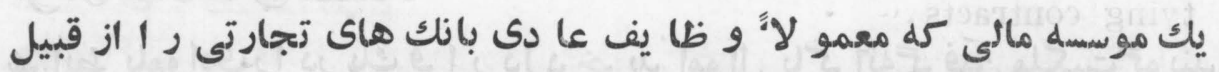

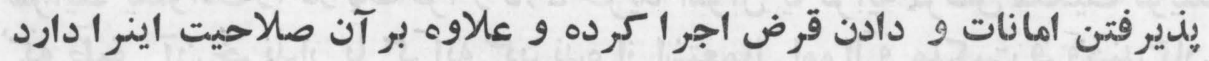

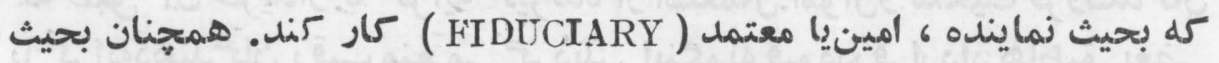

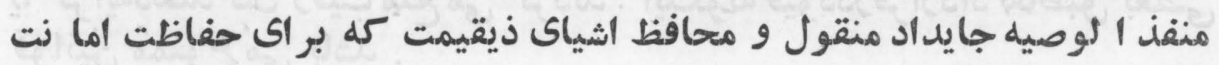

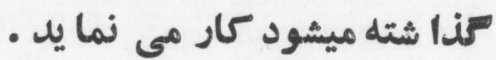
trustee

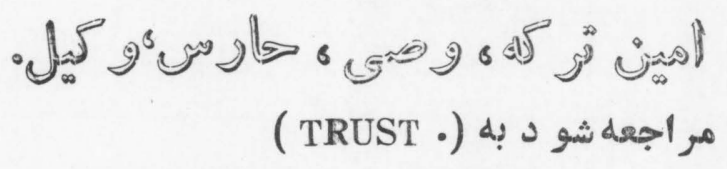

trust fund •

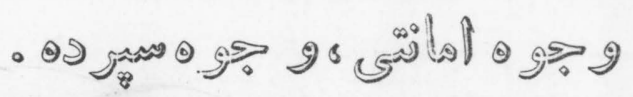

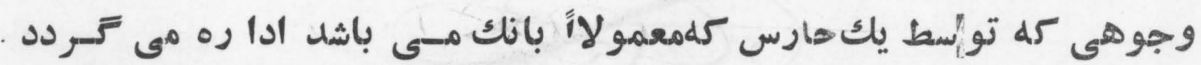

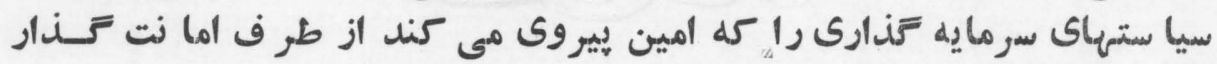

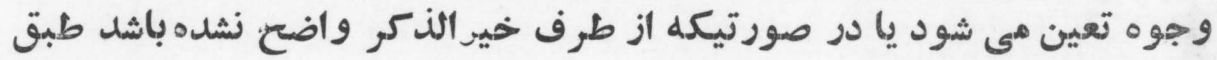
túrnover tax .

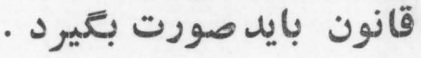

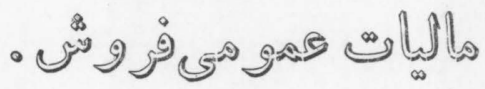
تفصيلات زير · ( • SALES TAX ) ملا حظه شود .

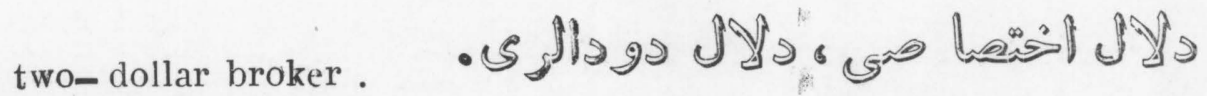

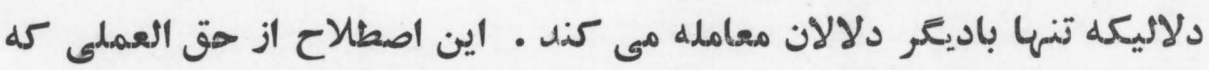

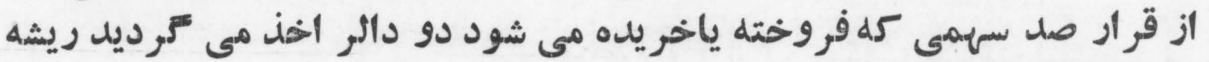

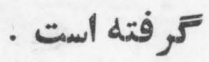


TXYI

two-name paper.

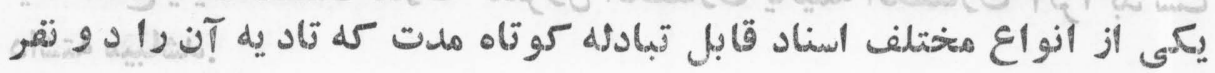

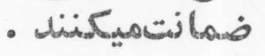

tying contracts.

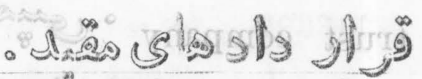

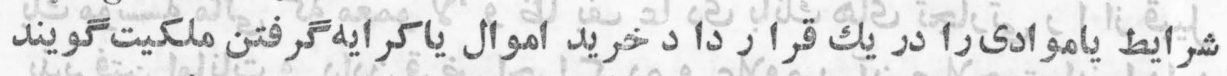

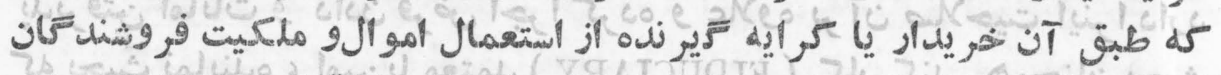

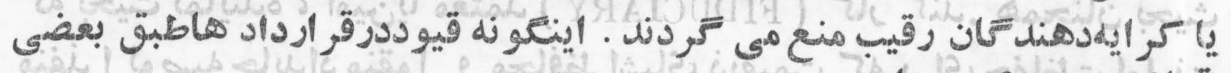

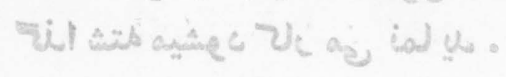

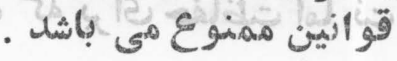

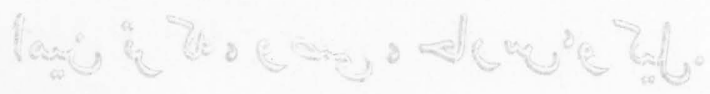

- 9 stagrt

a loabie 4 is (. T2UяT)

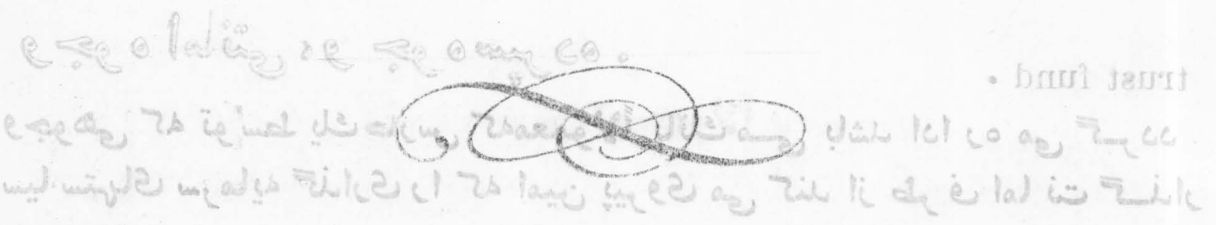

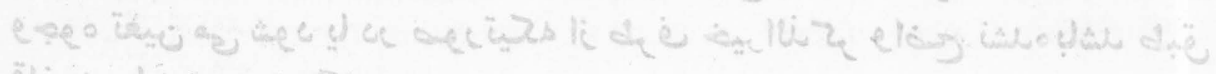

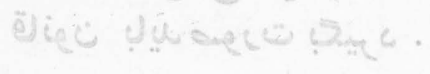

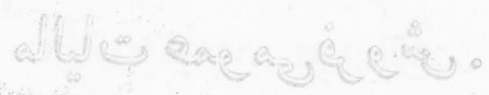

. XSt 25TOMTI

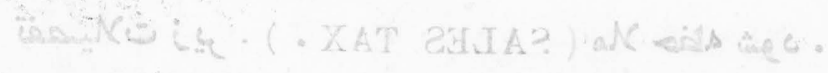

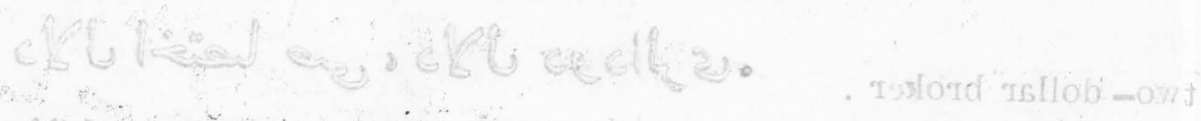

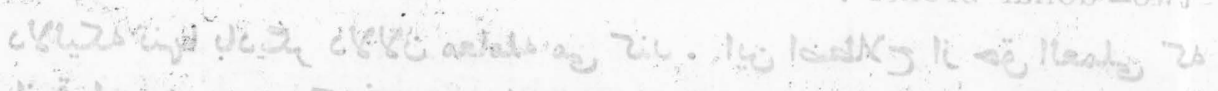

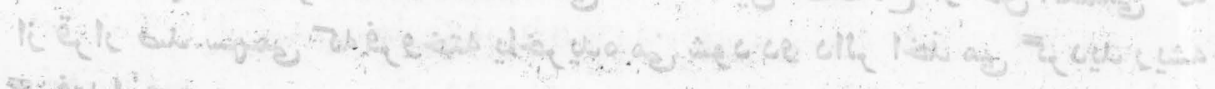

(1) 


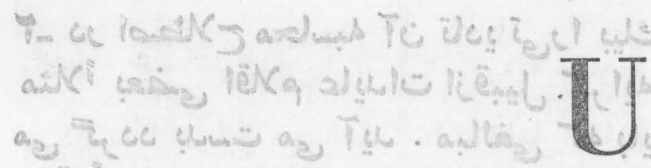

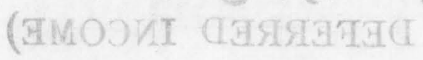

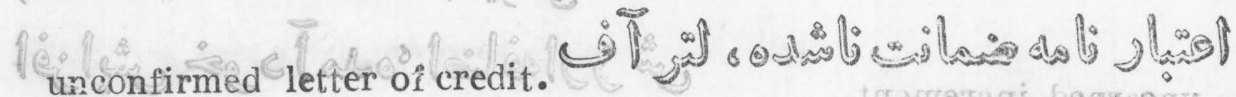
¿is alimoso.

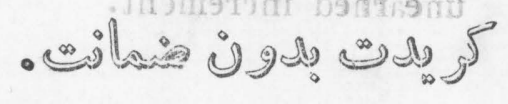

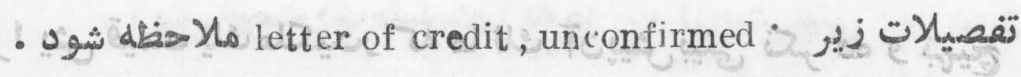
est es zetat

a underlying bond.

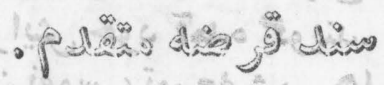

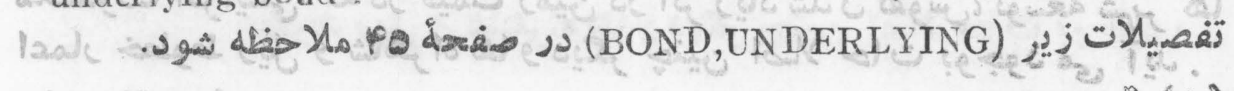

underwriting.

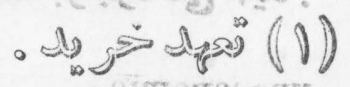

|

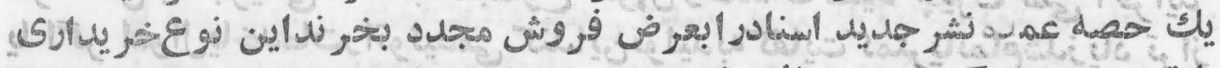

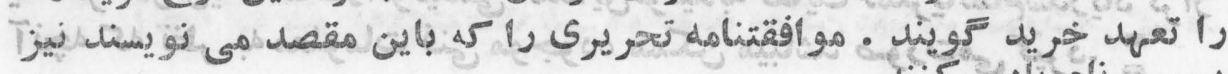
- به:

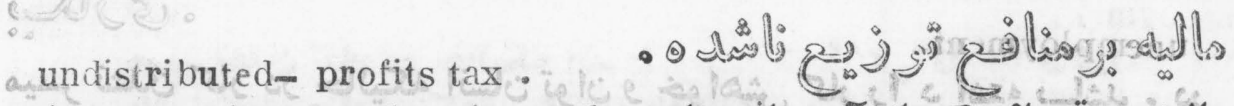

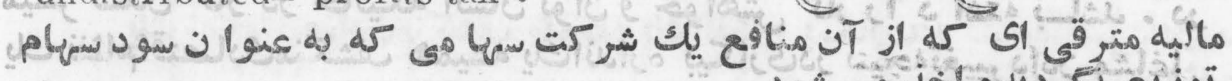

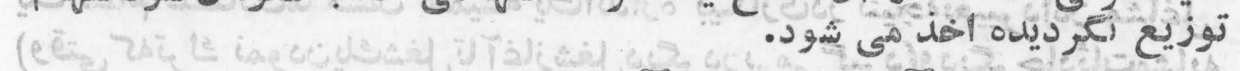

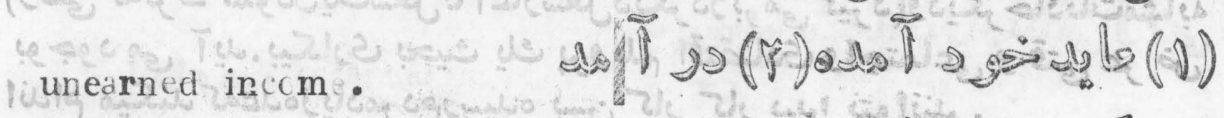

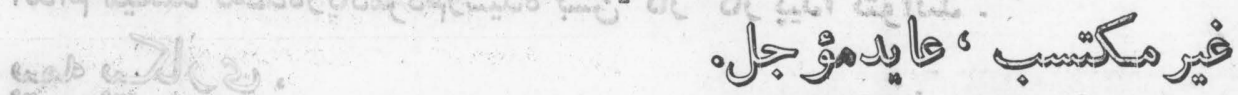
-

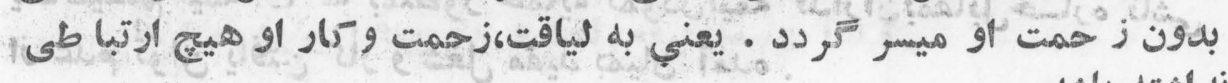
نداشته باشله ن الهمت 


\section{UNE}

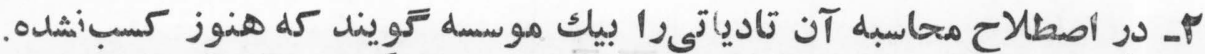

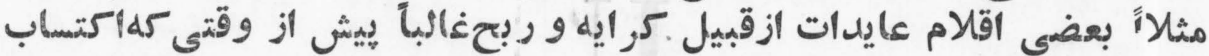

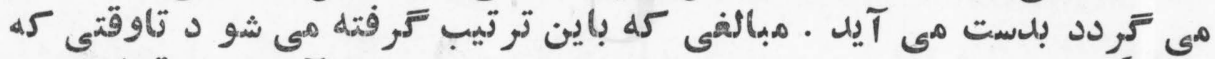

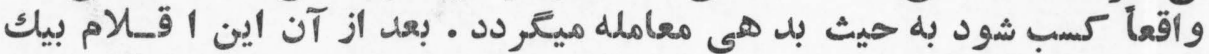

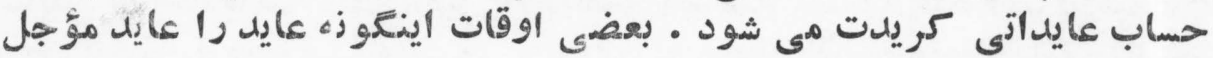

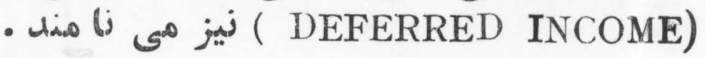

unearned increment.

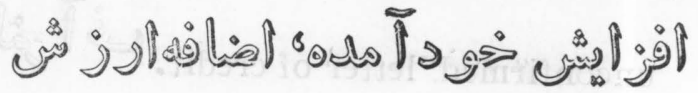

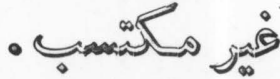

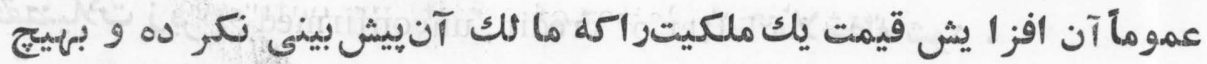

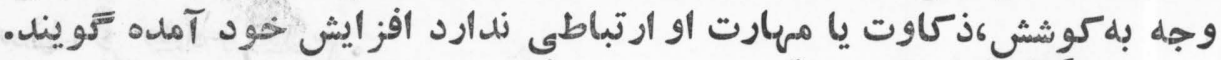

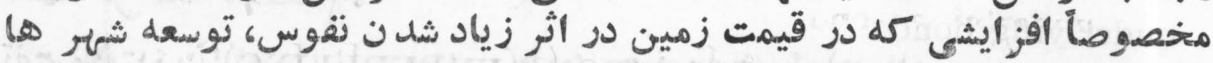

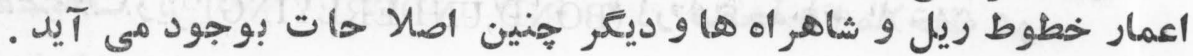

uneconomic. - SSln

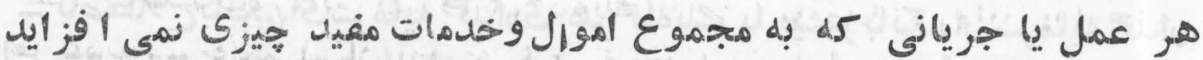

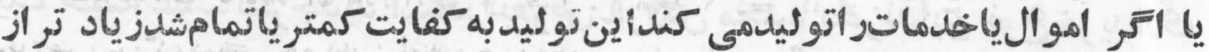

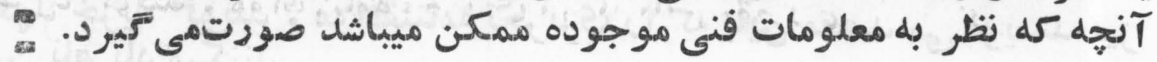

unemployment .

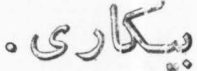

ميسر نشلن كار در حاليكه انسان توان و خواهش كار را د د اشته بساشله . در

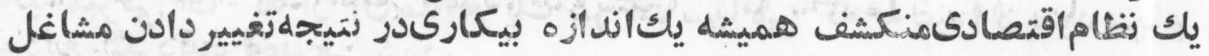

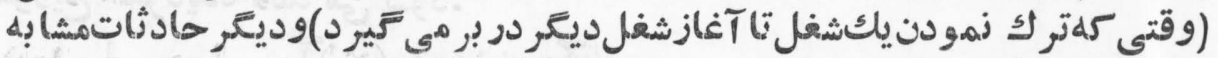

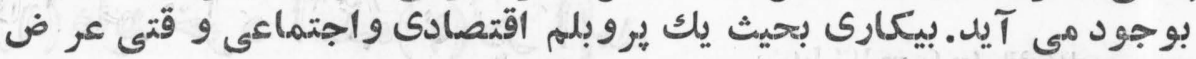

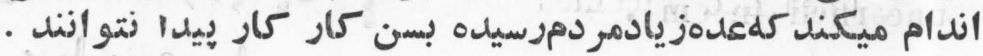

unemployment insurance .

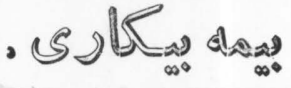

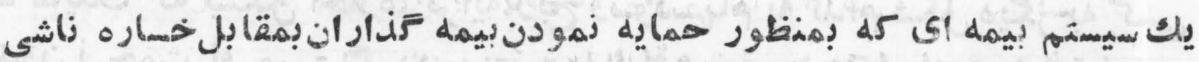

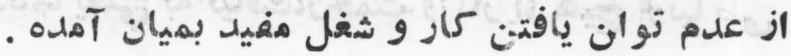




\section{UNI}

unfair trade practice.

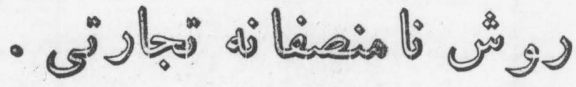

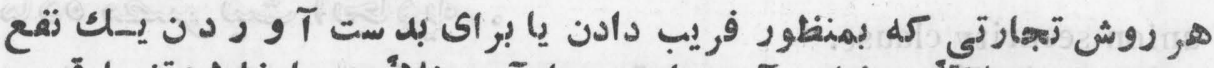

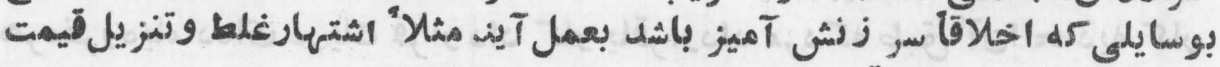

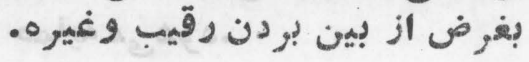

unfavorable balance of trade.

$$
0 \circlearrowleft \text { ) }
$$

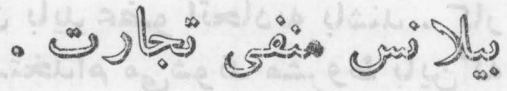

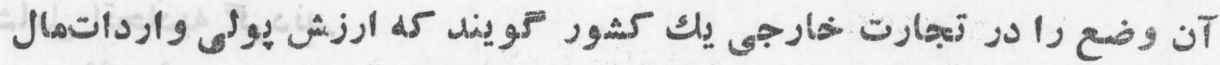

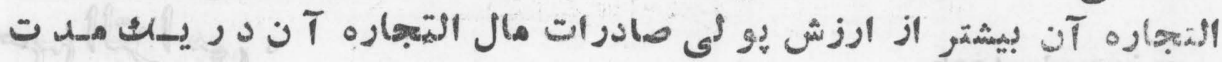

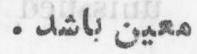

unified bond .

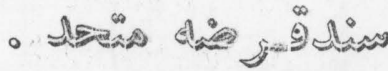

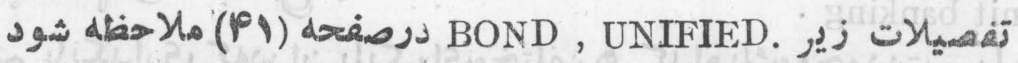

unilateral agreement .

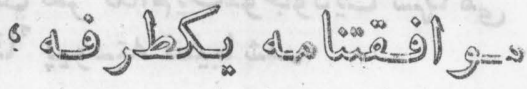

$$
\text { - Aj }
$$

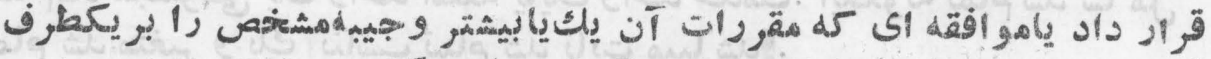

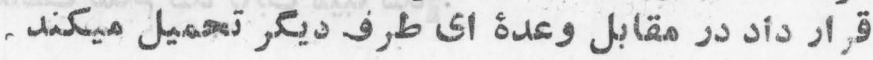

unilinear tariff . - जo

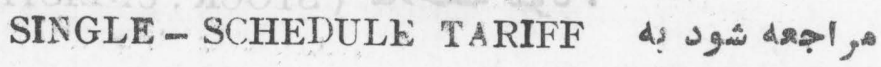

union label

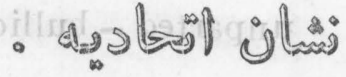

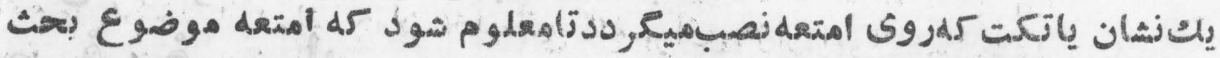

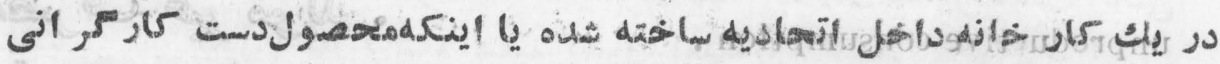

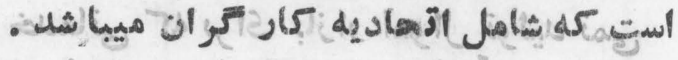


union security clause.

$$
\text { - 由 }
$$

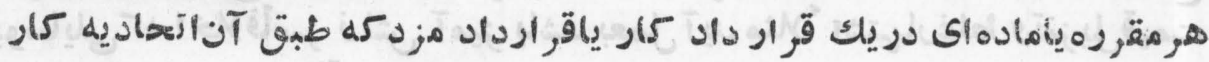

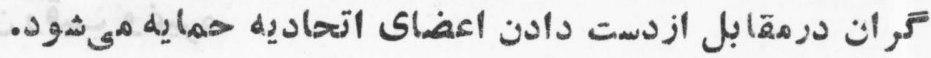

union shop.

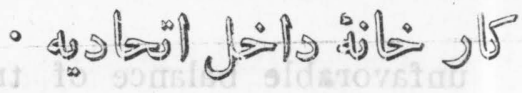

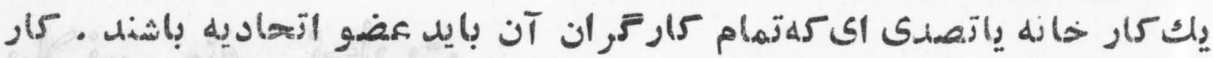

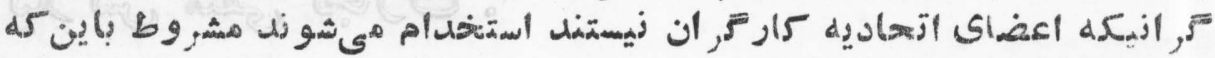

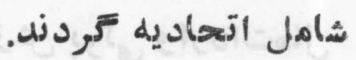

unissued stock.

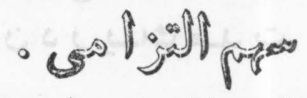
تفصيلكات زيو (STOCK,POTENTIAL)

unit banking .

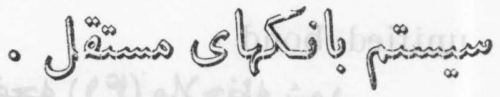

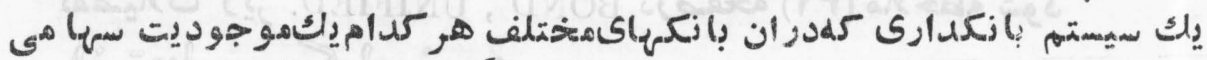

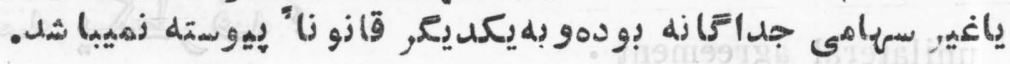

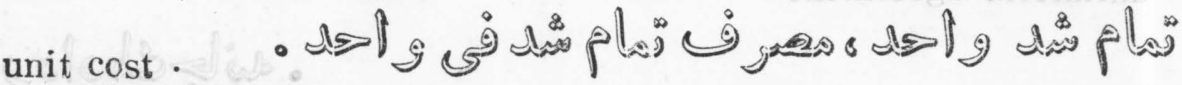
تمامشل مجمموعى يك واحل أمتعه يايك واحل خللمت. ايذغور زله تمام شل شا مل

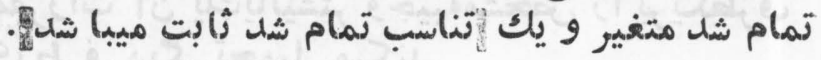
unlisted stock - Od ه تغصيات زير ) (STOCK , UNLISTFD ) unparted - bullion . شمشي كله فلزات ار زان از آن جلا نشله باشل . unproductive consumption . - Iل Ja

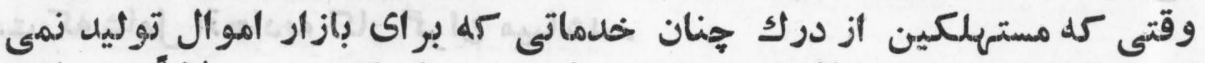

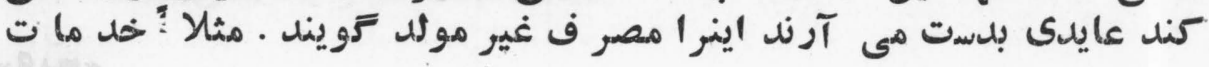




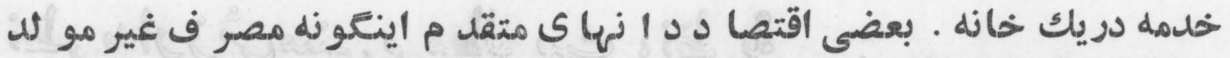

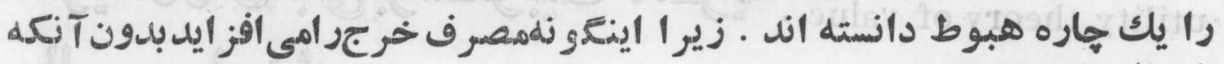

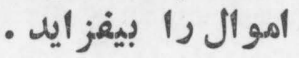

usance.

-

يك مدتمعينمبنى بر قانون يا تعامل بر اى برداخت بعضى بر اتههاى السمارى .

use-and-occupancy insurance . - لك

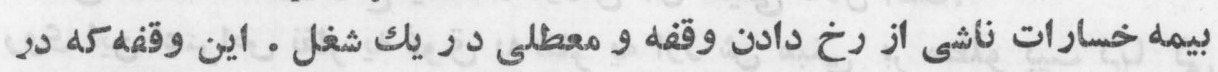

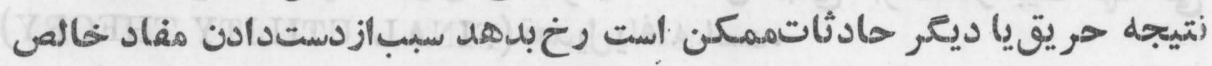

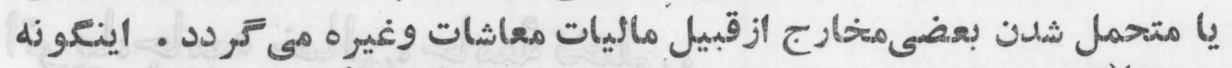

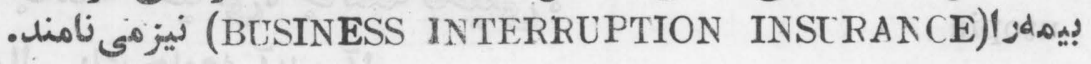

use tax :

- Ullosion

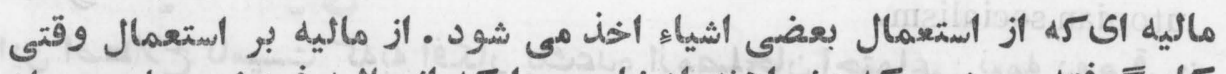

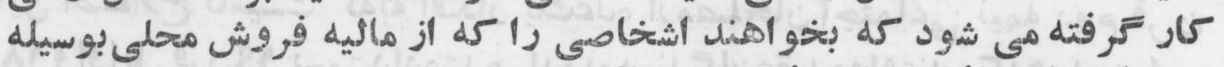

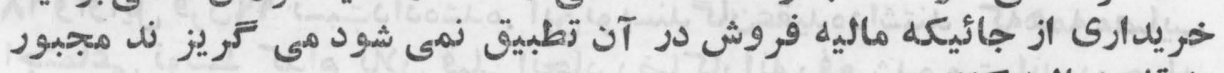
به زاديهماليه كنند .

usury •

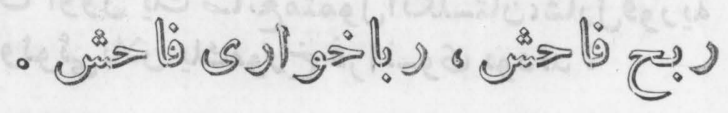

ربح بيشتر از حد اعظمىنرخى كه توسط قوانين مربوطه بر ایىانواع مختتلف

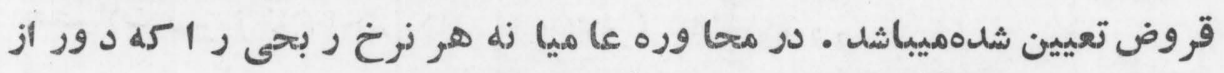

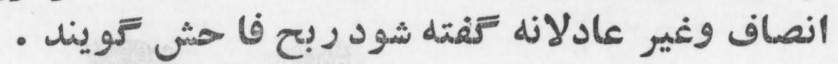

utility .

-

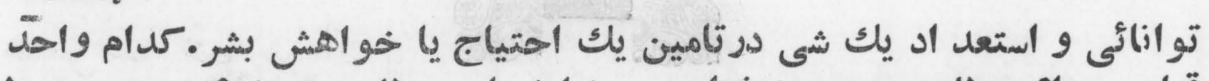

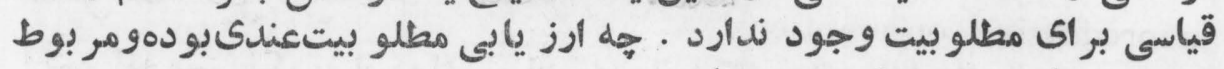
به شخص ياشى موضوع مطو بحث ميباشل . ن. ن. 


\section{UTO}

utility theory of value . ds J -

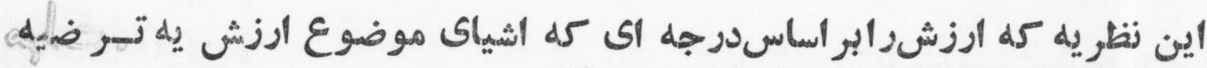

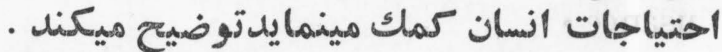

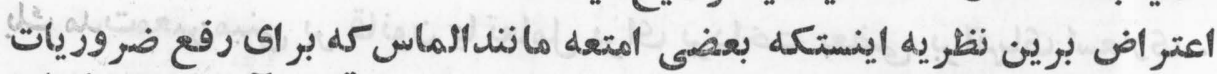

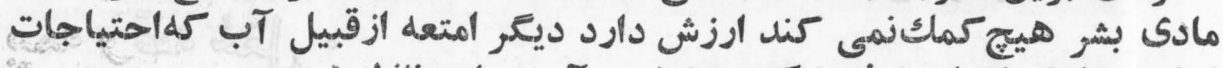

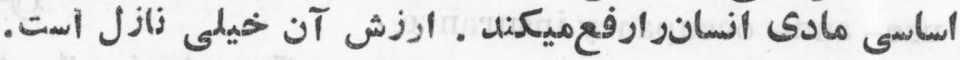

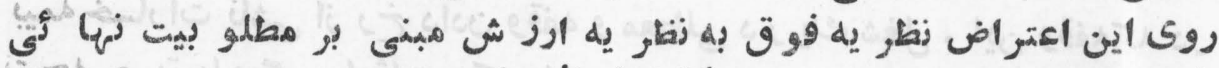

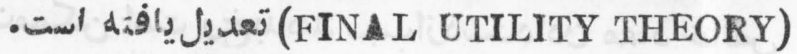

utopia

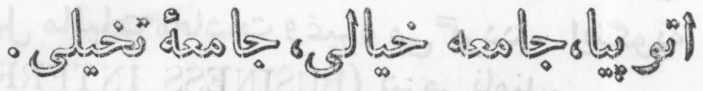

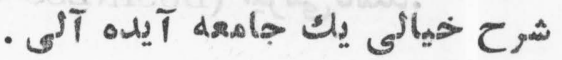

utopian socialism. $\therefore \int_{\infty}$

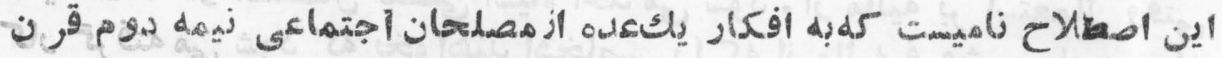

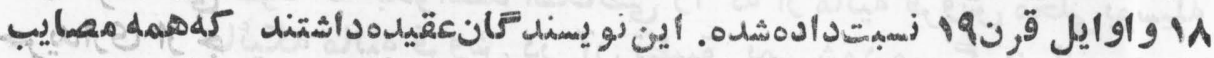

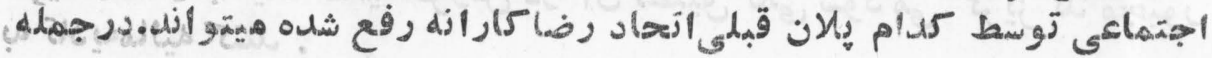

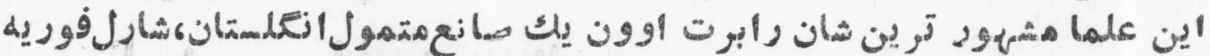

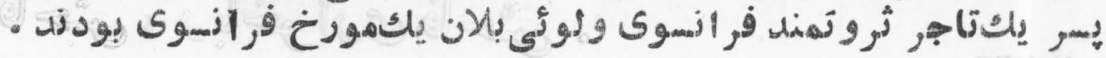

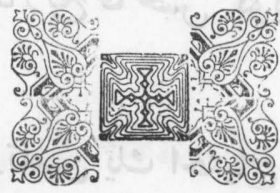




\section{V}

valorization .

$$
\text { - जstil }
$$

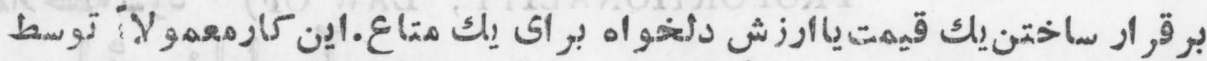

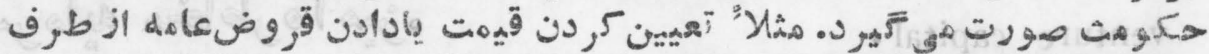

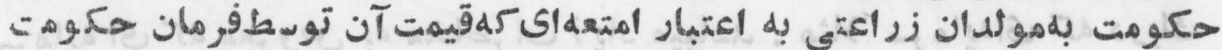

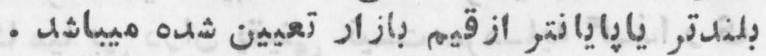

valuation.

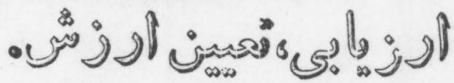

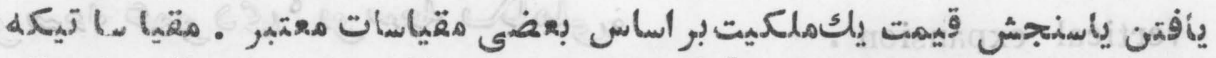

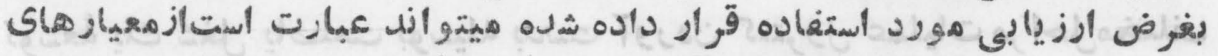

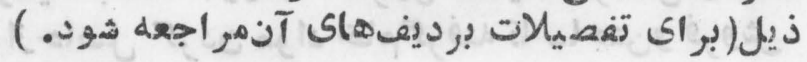

1- CAPITA LISED_ VALUE STANDARD.

2- EARNING- CAPACITY STANDARD •

3- ORIGINAL- COSTSTANDARD.

4- PRUDENT-INVESTMENT- COST STANDARD.

5- REPLACEMENT-COST STANDARD.

6- REPRODUCTION-COST STA XDARD.

value.

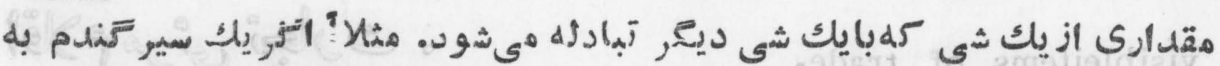

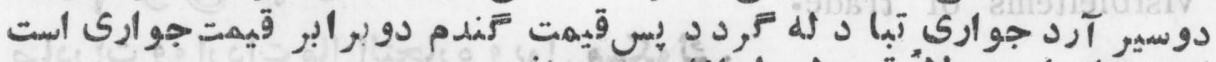

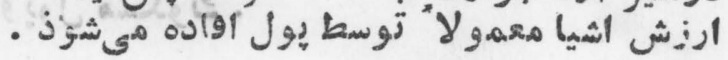

variable cost.

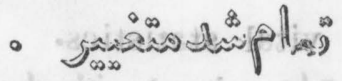

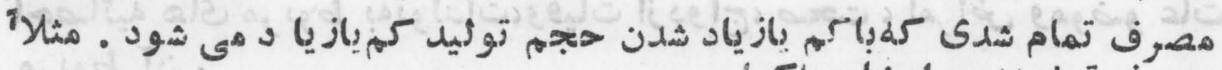

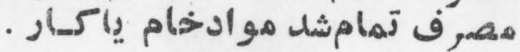




\section{VAR}

variable proportions, law of •

$$
\begin{aligned}
& \text { ○ d }
\end{aligned}
$$

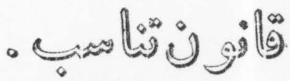

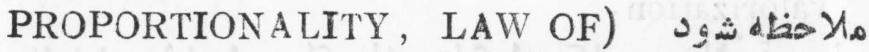

venture capital.

$$
\text { - j=a }
$$

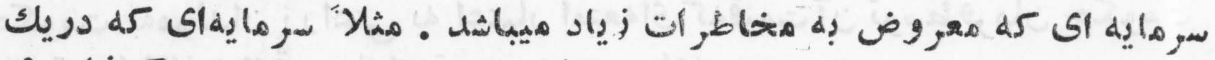

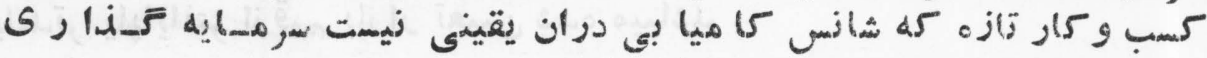

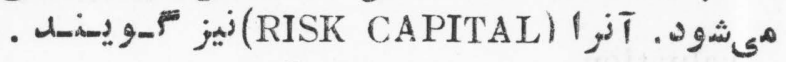

vertical expansion .

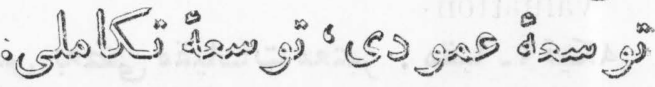

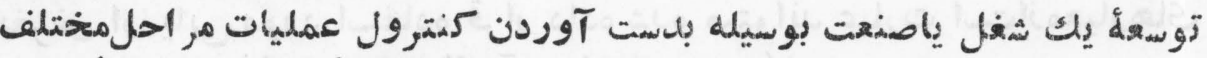

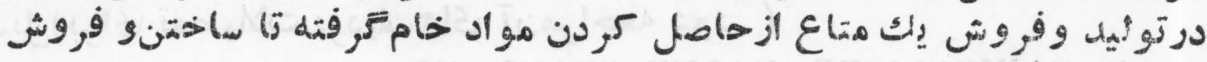

vested interests .

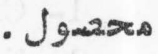

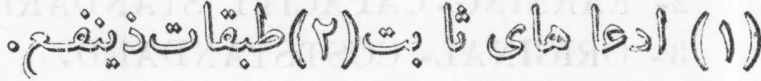

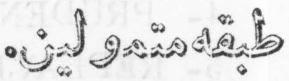

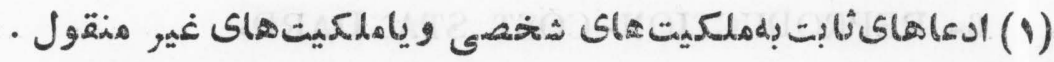

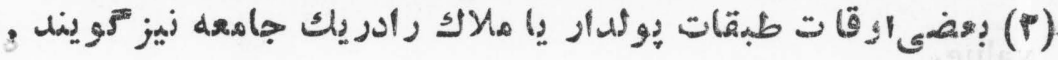

visibleitems of trade.

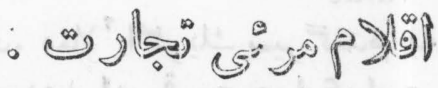
هادر ات وو اردات مال التجاره و ويول مسكو ك. . vital statistics.

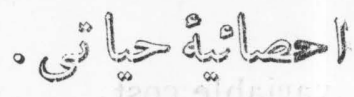

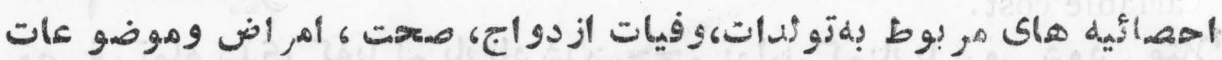

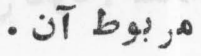

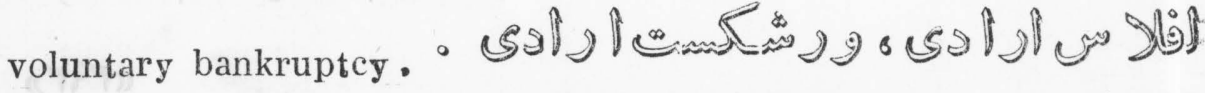
تفصيلات زير (BANKRUPTCY) ملاحظه شود . 


\section{VOU}

voluntary check off.

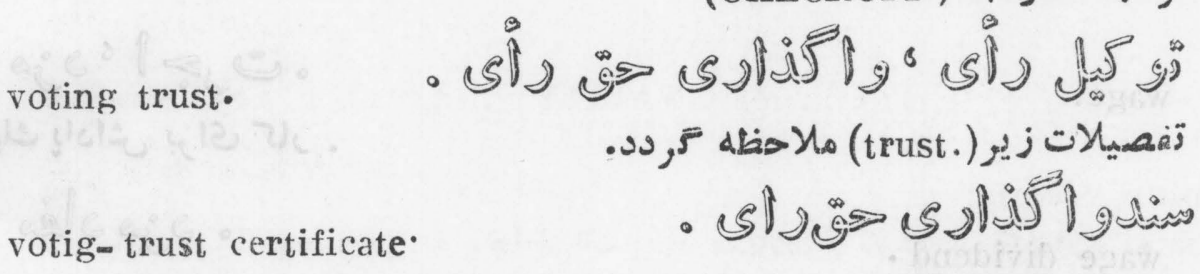

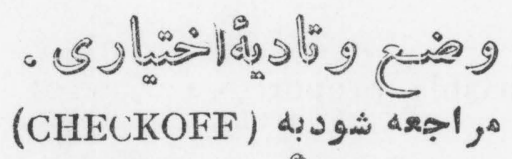

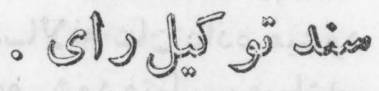

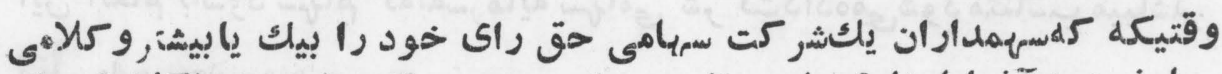

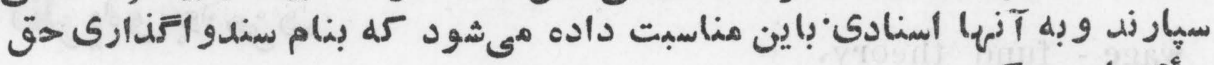

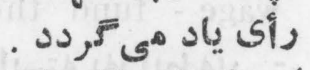

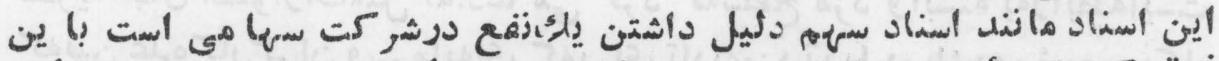

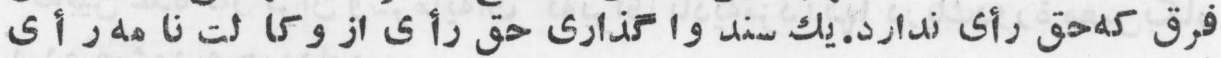

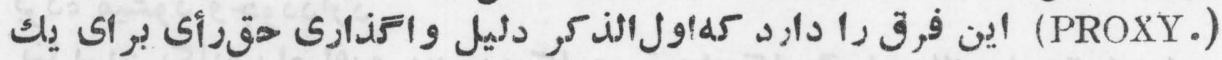

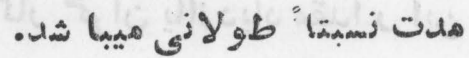

voucher .

$$
\text { - C C }
$$

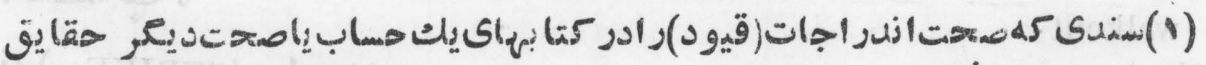

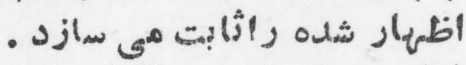

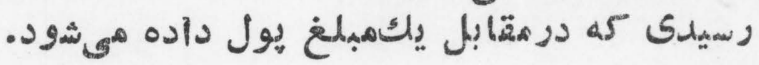

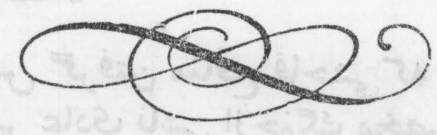




\section{W}

wage.

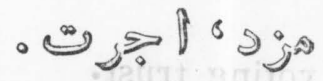

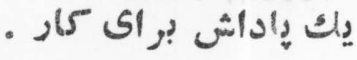

wage dividend.

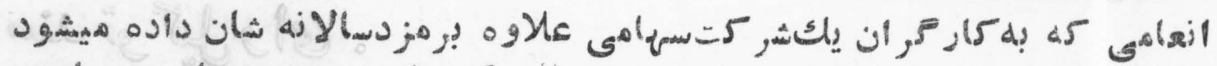

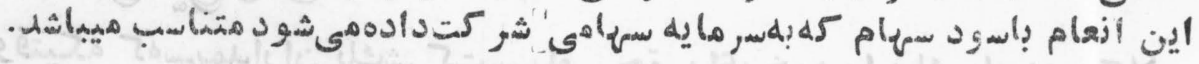

wage - fund theory. $\rightarrow$ jol $\rightarrow$ gets

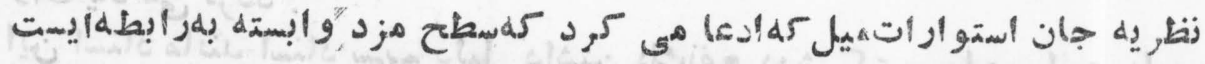

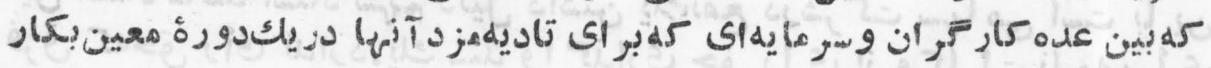

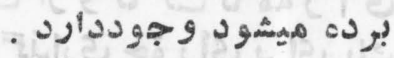

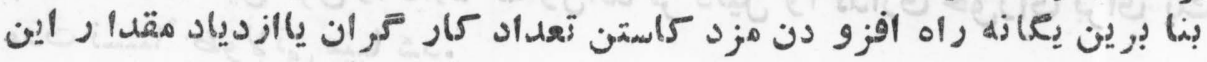

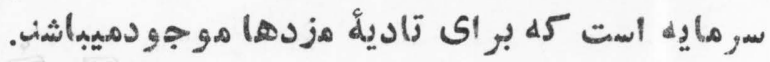
walkout .

$$
\because \log
$$

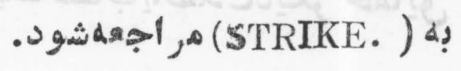

want •

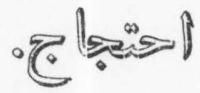

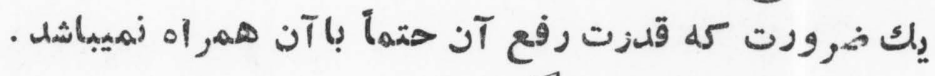

war-profit tax.

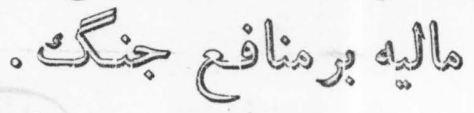

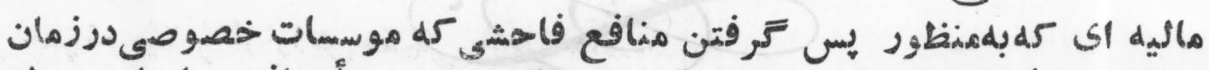

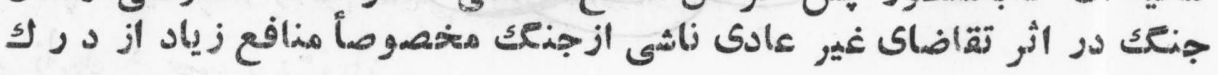




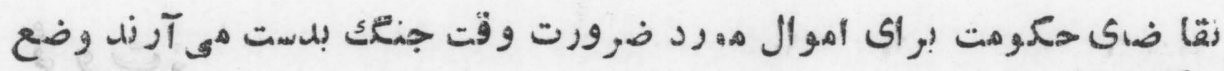

warrant.

$$
\begin{aligned}
& \text { هيع د د . } \\
& \text { all } \Rightarrow(Y) \text { (I) }
\end{aligned}
$$

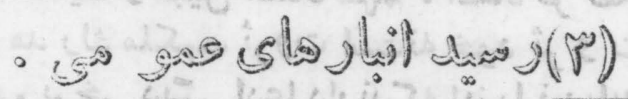

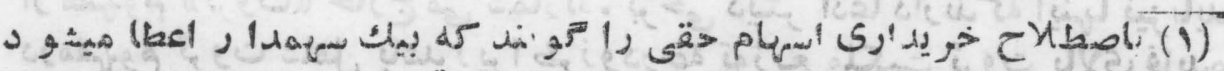

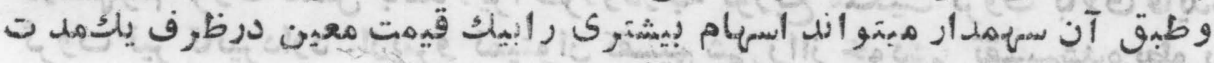

$$
\text { - تـ (STOCK KIGHT) Uijlo . د }
$$

آن آن (T)

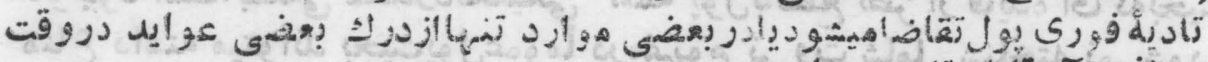

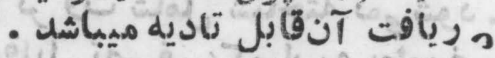

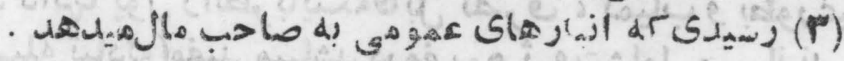

wash sale.

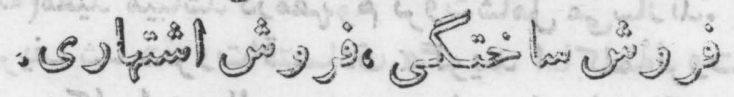

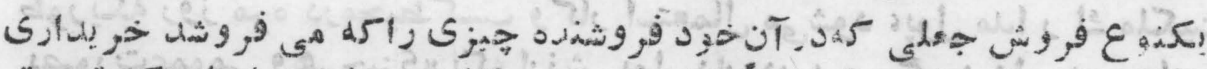

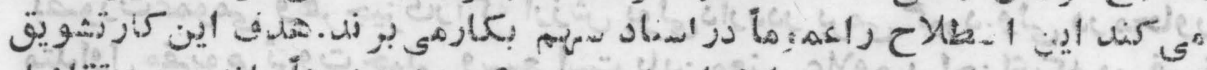

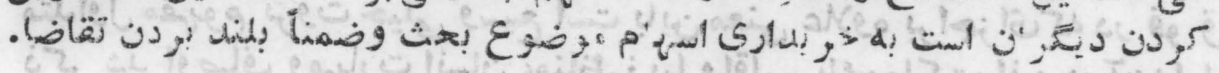

wasting asset - श्di gas of

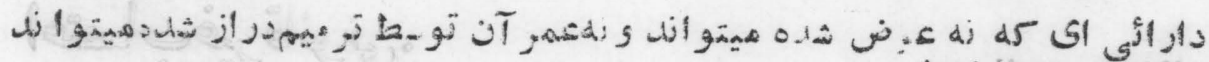

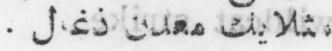

watered stock .

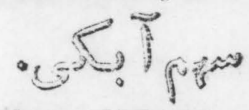

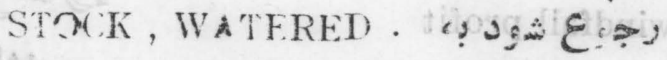

wateris.

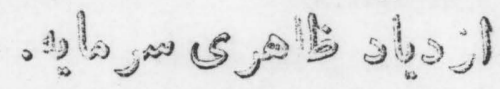
ز ش

way bill.

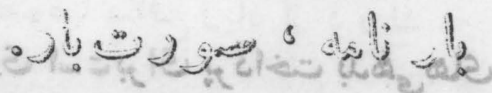

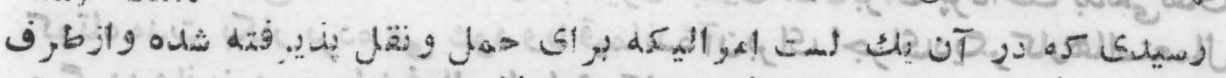

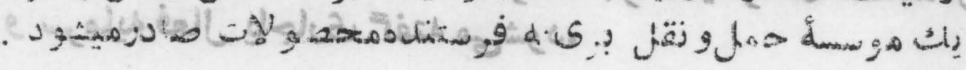




\section{Wwinl}

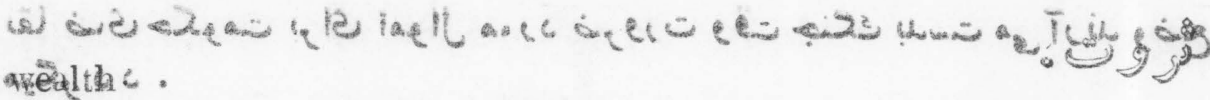

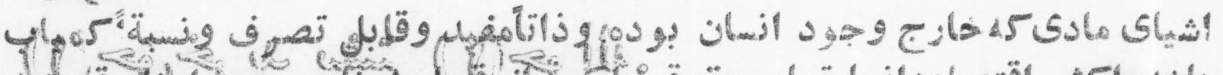
a

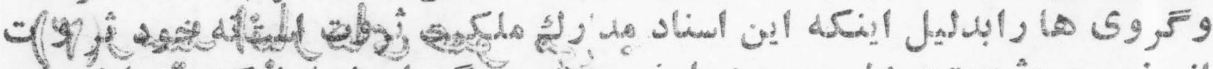

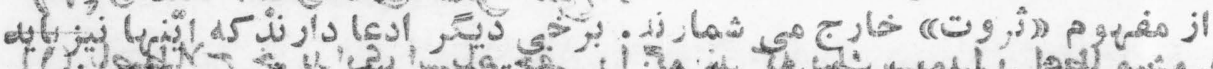
- 10 st 39 , o o

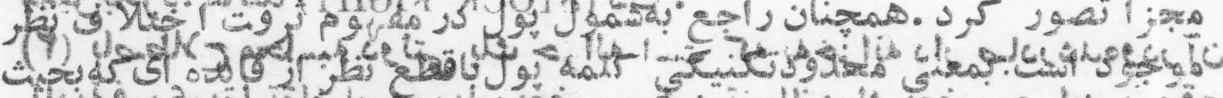

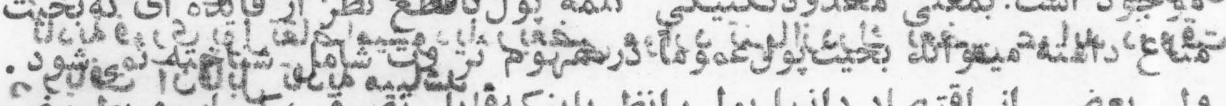

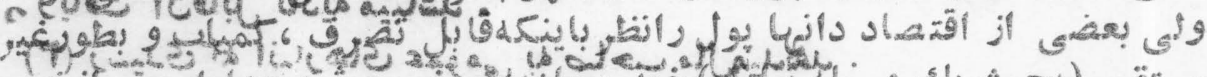

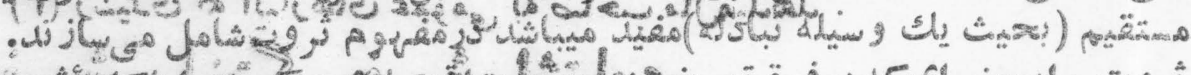
\%

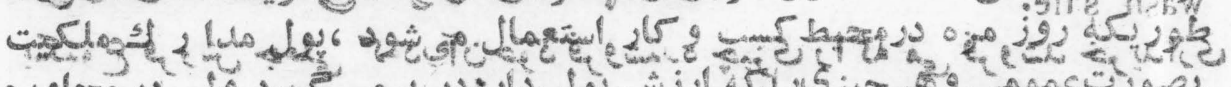

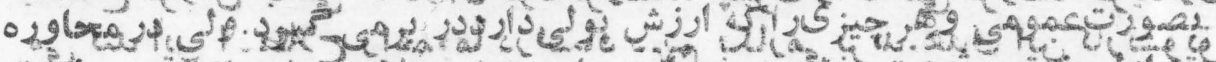

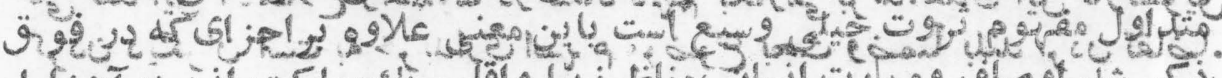
ذ ك

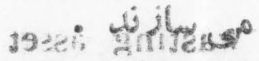

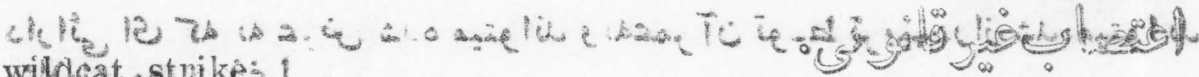
wildcat stpikés $L$

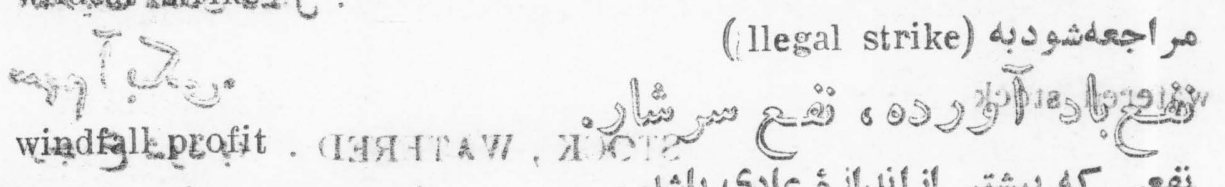

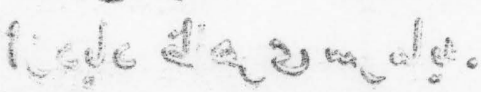
axorking capital آل

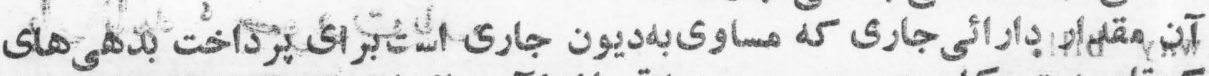

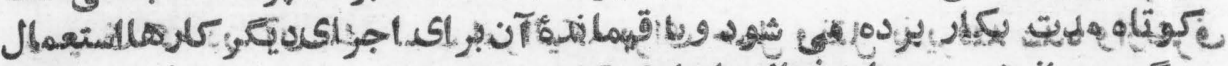

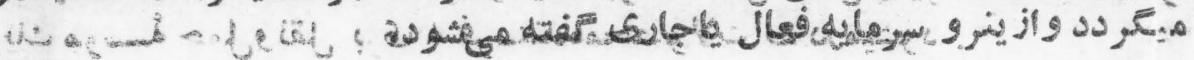




\section{W JR}

work relief.

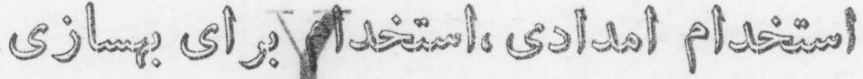

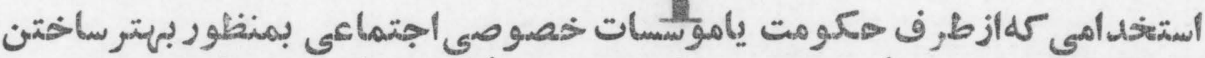

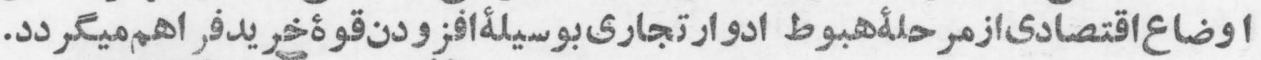

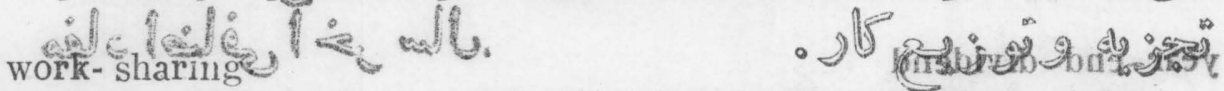

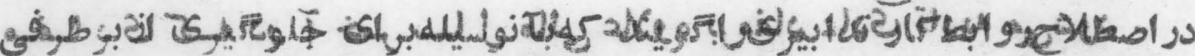

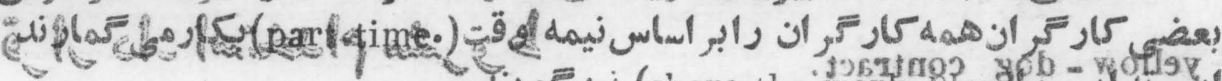

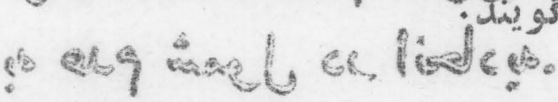

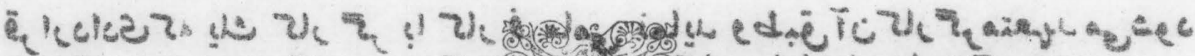

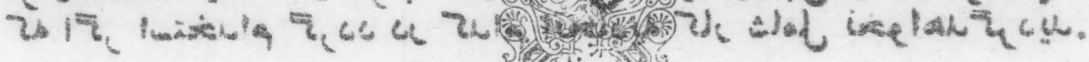
ell ice.

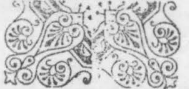

-Tallob lisse wolloy

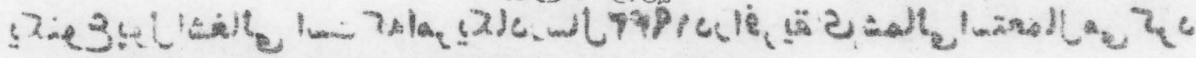
(c) (ҮЯ

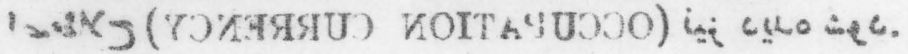

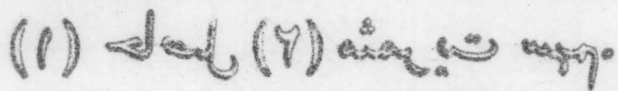

blsi?

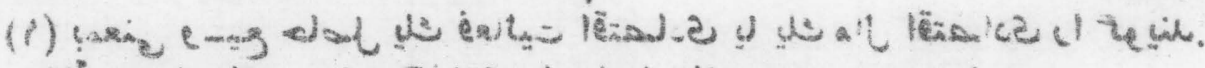

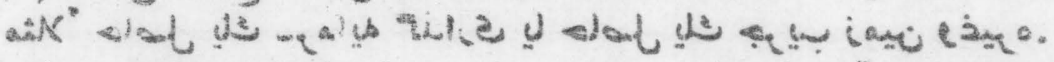

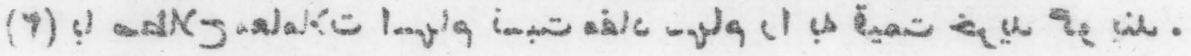
Lin

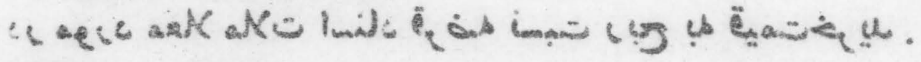

$\cdot($ (20ту) bluiv allo $x$ is

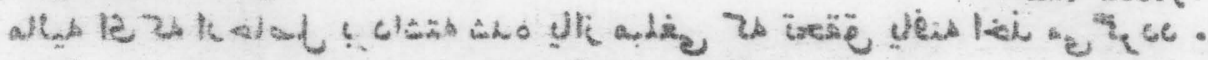

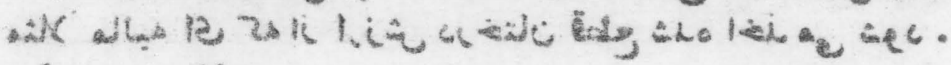

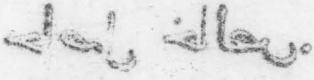

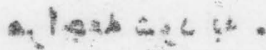
(1.I.3T T. T/)

- vjizutsm of higix 


\section{Y}

year-end dividend

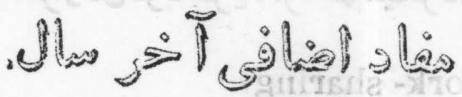

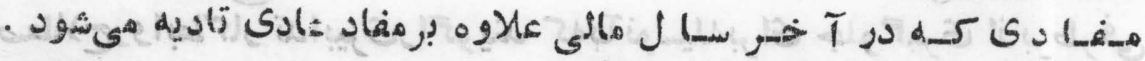

yellow - dog contract.

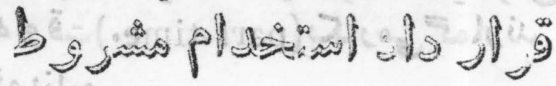

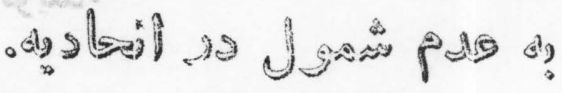

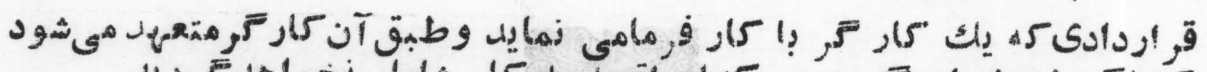

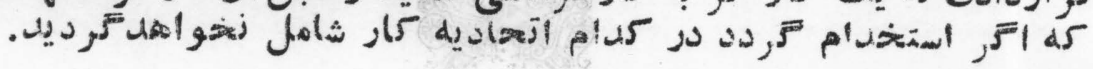

yellow seal dollar. $.9 j j^{3}$

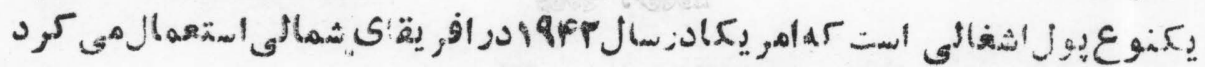

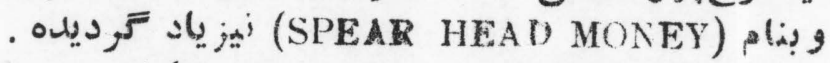

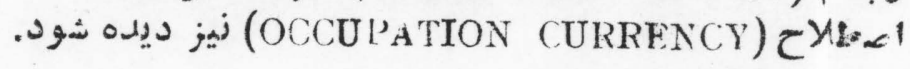

yield. opas (1)

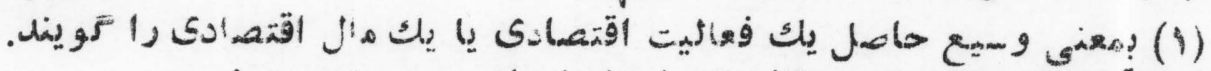

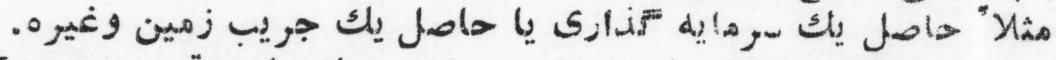

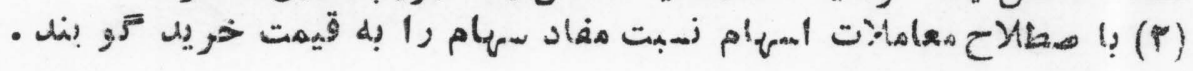
yield (gross).

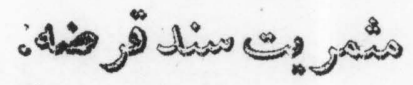

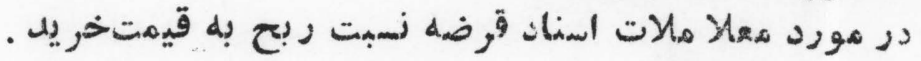

yield tax. ol

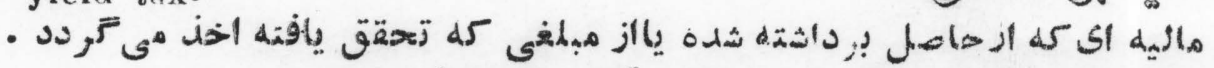

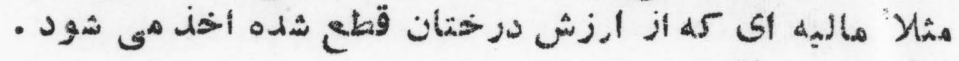
yield to maturity . पी (NET YIELD) مراج 


\section{$\mathrm{Z}$}

zollvêrein •

-

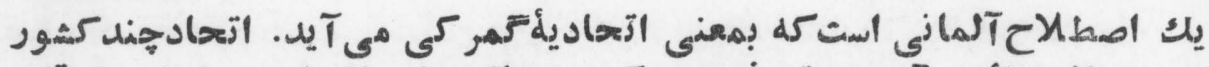

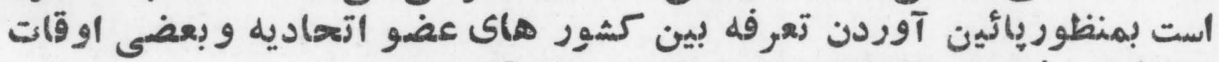

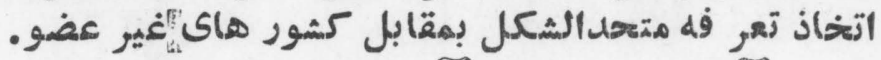
zone, free •

$$
\text { • رجنl }
$$

zoning.

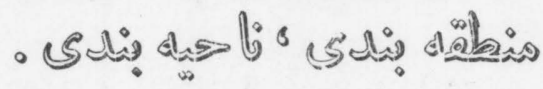

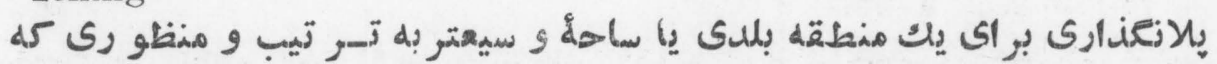

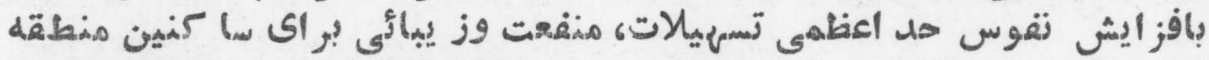

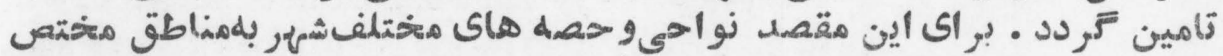

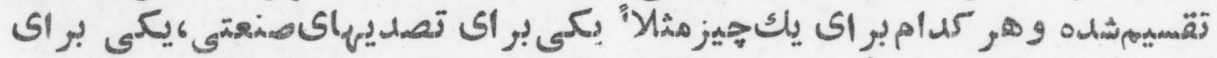

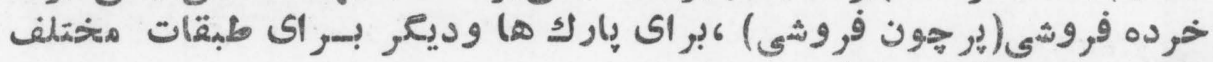

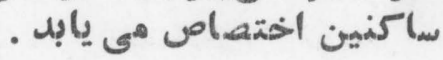
zone pricing .

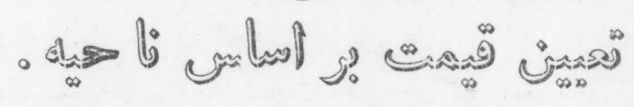

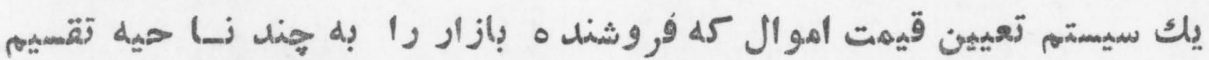

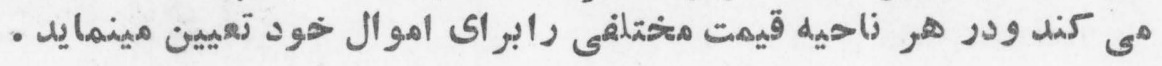

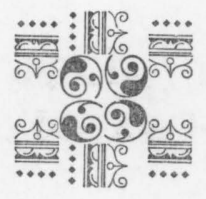




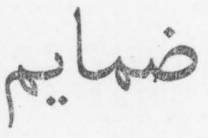

\section{A P PEN DTCÉS}

$$
\int_{I} \int^{a} \int^{a}
$$

Commercial abbreviations :

$$
\text { PQ9 }
$$

II

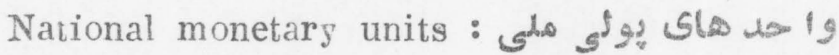




\section{Sol darsio \\ ABBREVIATIONS مخففات

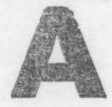

$a \cdot a \cdot$

against all risks (marine insurance)6

$\mathrm{a} / \mathrm{c}$

account of account current

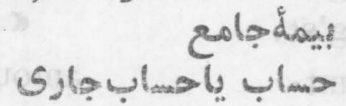

$\mathrm{A} / \mathrm{c}$

$\mathrm{A} / \mathrm{C}$

(c)

(c)

a

(

a

$\alpha$

(C

ब

$\ll$

(C)

acc.

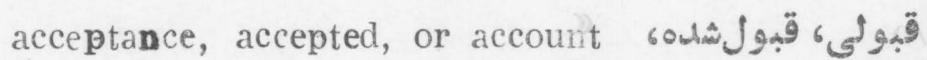

Acce. 16 acceptance

accrd. accrued

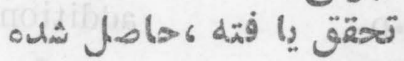

acet.

account

حماب

ack (or a kn ackn'd)

ackgt.

ackn't.

acpt.

Acpt.

a/es pay

A/cs pay

acknowledge

a

acknowledgèment

a

acieptance

'

accounts payable

(c) $\quad$

a/cs rece

acounts re eivable

$1 /$ es $\operatorname{Rec}$

ac

(

ad.

advertisement

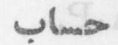

$\mathrm{adv} \cdot($ or $\mathrm{Adv}$ )

advance or advice or

«

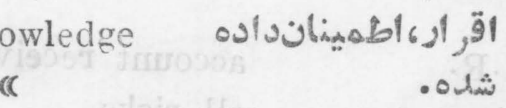

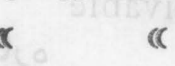


advert.

advtg.

$\mathrm{A} \cdot \mathrm{F} \cdot \mathrm{B}$.

Afft.

agcy •

Ag'y .

ag.

ag'st.

amt.

a.o.

A.O.

a/o

$\mathrm{A} / \mathrm{O}$.

a/or.

$a \cdot p$.

A.P.

$\mathrm{A} \cdot \mathrm{R}$.

$\mathrm{a} / \mathrm{r}$.

$a \cdot r$.

arbtrn.

arbtror.

arr'd.

a.s.

A.S.

A/s.

asstd.

att.

a.v.

$\mathrm{A} / \mathrm{v}$.

a.w. advertisement or advertise

advertising

air freight bill

affidavit

Agency

a

against

(r

amount

account of

«

(c

Ir

and or

additional premium

a

« or account payable
أشتمرهارو، اعلان

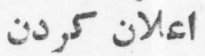

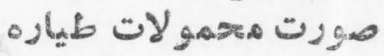

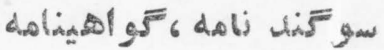

ज Jisis

(c)

flat

(c)

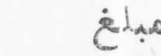

...

(C)

(C

«

69 جائزة أهـافي त) $\mathbb{2}$ (c) با account receivable

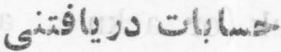
all risks ترام all risks arbitration

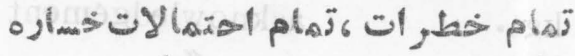
arbitrator inaros arrived (5) at sight or after sight ? account sales

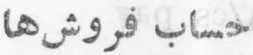
account sales or after sight $\Rightarrow$ assorted

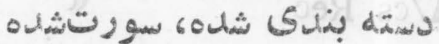
attention or attached

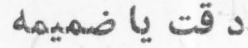
ad valorem تصs ad valorem >

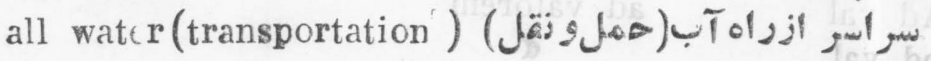


$\mathrm{a} / \mathrm{w}$.

AWB.

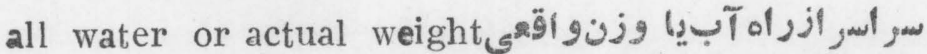
air waybill بار bal. balance

bal'd. balanced

$\mathrm{B} / \mathrm{C}$. 2 bill for collection

B.1). bills discounted

$\mathrm{B} / \mathrm{D}$

bd. board or bond

B.E. bill of exchange

$\mathrm{B} / \mathrm{F}$ brought forward

$\mathrm{B} / \mathrm{f}$. Wa $\mathbb{a}$ 《 $\mathbb{R}$

B/G. bonded goods

B.L. bill of lading

$\mathrm{B} / \mathrm{I}$.

$\mathrm{B} / \mathrm{Is}$.

$\mathrm{BN}$

$\mathrm{b} \cdot 0$.

B. 0 .

$\mathrm{B} / \mathrm{p}$

$\mathrm{B} / \mathrm{R}$

B'Rec

Brt. fwd

b.s. bills of sale or balance sheet

$\mathrm{Bs} / \mathrm{L}$ bills of lading

b・v. 2 book value banknote bills rceivable bills receivable

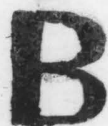

?

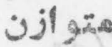

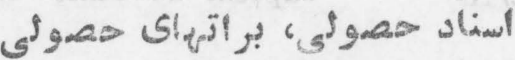

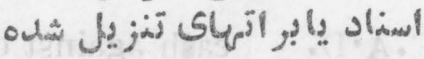

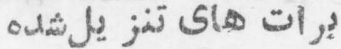

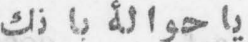
ض

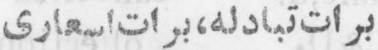

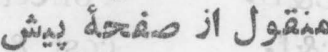
a se زلا (C

(a) 40 ij ت gixi!

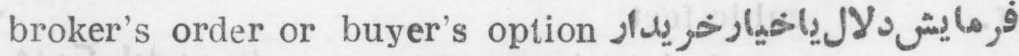
buyer's option or braneh office

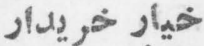

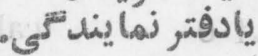

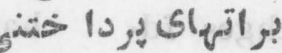
-

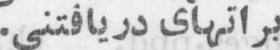

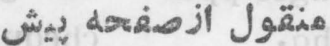

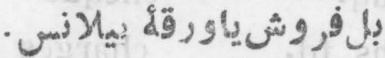
lodoli ازرش دفترى. 
$\mathrm{C} / \mathrm{A} \cdot \quad$ capital account or credit account

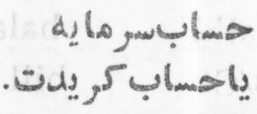

C.A.T. cash against documents (at port of entry)

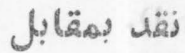

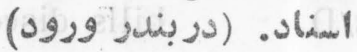

$c \cdot a \cdot f . \quad$ cost, assurance, freight

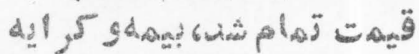

canc,d. cancelled

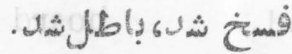

C\&D. collection and delivery

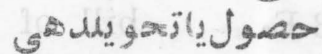

c\&f.

cost \& freight

c\&i.

cost \& insurance

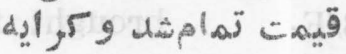

cash B/L. cash against bill of lading

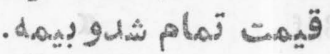

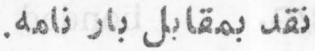

C/D.

cash discount

or certificate of deposit

or certificate of delivery

تمنز بيل زيقن.

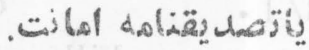

() )

c.f. cubic feet

فت همكعبـ.

c.f.i.

cost freight insurance

c.f $\cdot 0$.

calling for orders

chges fd. charges forward

chges $f, d$.

«

chges.ppd. charges prepaid

chq.

cheque

chs $\mathrm{fd}$.

charges forward

$\mathrm{C} / \mathrm{I}$.

certificate of insurance

C.I.A.

cash in advance 
C.I.F.

CIF\&C

F.I.F\&I

CIF\&e

$\mathrm{cl} \cdot \mathrm{B} / \mathrm{L}$.

cld.

c.o.

c/o

cons.

corp.

c. $0 \cdot \mathrm{S}$

$\mathrm{C} \cdot \mathrm{P} \cdot \mathrm{A}$

Cr.

$\mathrm{CY}$ cost, insurance \& freight cost, insurançe, freight \& commission قيمهت تمامش -

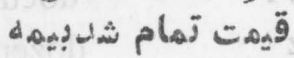

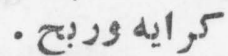

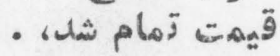
cost' insurance freight \& exchange

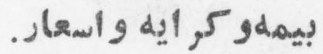
clean bill of lading cleared

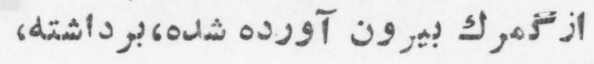

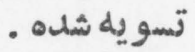
cash order حمواله نقاله نداه carried over consigiment corporation.

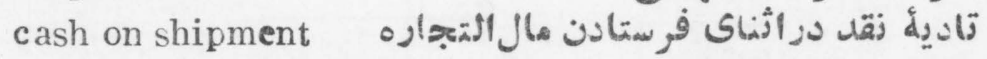
Certified Public Accountant credit or creditor currency or capacity

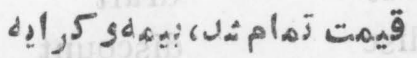
ق 

Dft. draft
dSl 9
disc
discount
تمنزيل
doç.
document
$\mathrm{D} / \mathrm{P}$
documents against payment
lim
$\mathrm{dz}$
dozen
المسناد
is

$\begin{array}{ll}\text { e.u. } & \text { for example } \\ \text { encl. } & \text { enclosure } \\ \text { end. } & \text { endorsed }\end{array}$

TYio 4.

- Ola

f.a.

free alongside

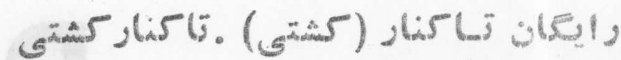
free at factory

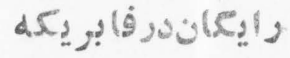

$\mathrm{F} \cdot \mathrm{a} \cdot \mathrm{f}$. freight \& demurrage

$\mathrm{F} \& \mathrm{D}$. fair average quality

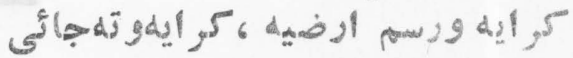
$\mathrm{f} \cdot \mathrm{a} \cdot \mathrm{q}$. or free at quay

f.a.s. free alongside ship

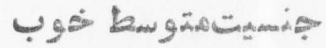

f.b.h. free on board (in) harbor يا

F.C.S free of capture \& seizure  ران $f \cdot d$. free delivery or free at doçk olf , eisids 
f.f•d.

free from damage or free from duty. هـئون ازخسارة ازمول

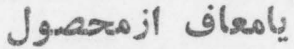

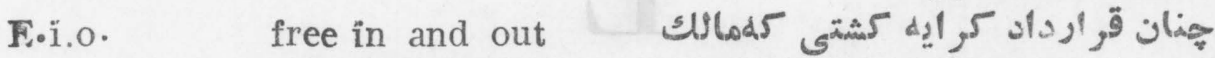

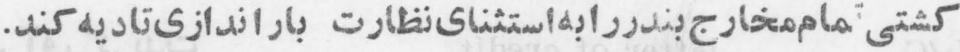

F.O.B. free on board

F.O.C. free of charge

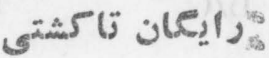

F.O.I. free of interest

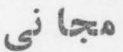

F.C.T. free on truek

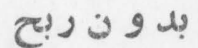

f.x.

foreign exchange

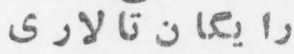

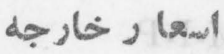

Gr. T. gross ton

gtd.

guaranteed

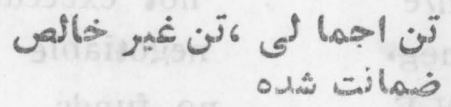

inv.

I.O.U.

irrev.

$\mathrm{I} \cdot \mathrm{T} \cdot \mathrm{O}$.

invoice

I owe you

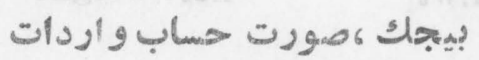

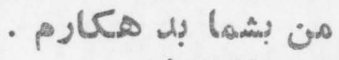

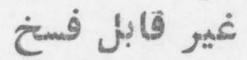

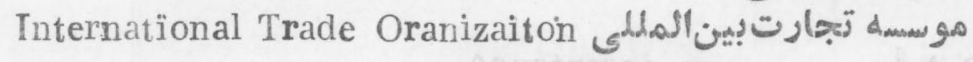

j॰a.

joirst account

حساب هشترك

$(d i \cdot A)$ 


\section{L}

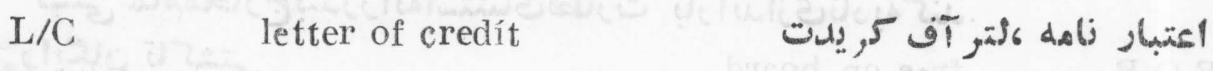

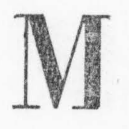

M.I.P. قوارداد بيمه بحرئ

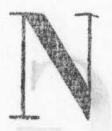

n•a. no accoúnt or non-acceptance $\mathrm{n} / \mathrm{e} \quad$ not exceeding

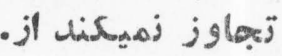

neg. negotiable

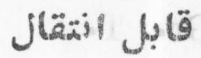

$\mathrm{N} \cdot \mathrm{F}$.

no funds

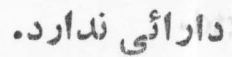

$\mathrm{N} \cdot \mathrm{O}$.

no orders

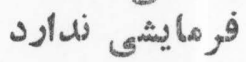

$n \cdot p \cdot f$

not províded for

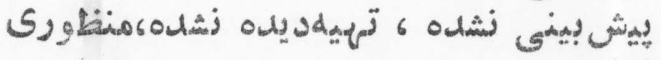

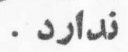

n.wt net weight

وزن خالص.

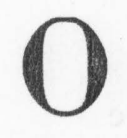

O.A.

on acceptancé

بهوقبو

$\mathrm{O} / \mathrm{Ace}$

on account

بلهاب

$\mathrm{O} / \mathbf{A}$

open account

حساب مغنتوح

O.D.

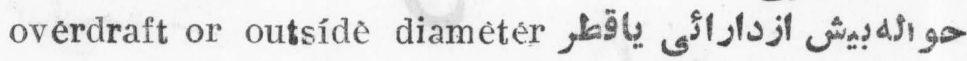

$$
\text { بيرونى (ه) }
$$


$\mathrm{O} / \mathrm{i}$

O.E.

$\mathrm{O} / \mathrm{O}$

OK

OK'd

on bd

$\mathrm{o} / \mathrm{O}$

$\mathrm{O} \cdot \mathrm{NO}$.

o $\mathrm{p}$.

$\mathrm{o} \cdot \mathrm{p} 0$.

o.r.

() $\mathrm{R} \cdot \mathrm{B}$.

$\mathrm{O} \cdot \mathbf{R} \cdot \mathrm{D}$.

O.R.F.

$\mathrm{O} \cdot \mathrm{R} \cdot \mathrm{L} \cdot$

0.5 . overdraft or on Cemardor on ceck

lis jall go

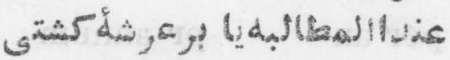

ommissions excepted

order of:

approved

)

on bosit

orier of

order number

open policy

one price only

owner's risk

owner's risk of breakage

owner's risk of damage

owner's risk of fire

owner,s risk of leakage

on spot ty

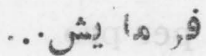

U Igtino

$$
\text { D) }
$$

(o)tabl

$$
\text { فر فر في }
$$

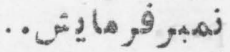

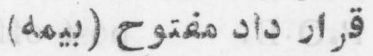

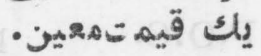

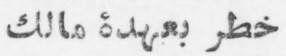

خط

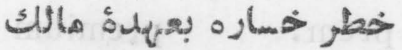

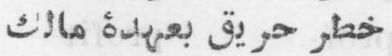
خط, تر اوش s د:0:0

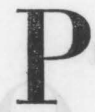

$\mathrm{p} \cdot \mathrm{a}$.

p r annum or particular areri

سوأ

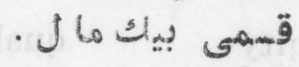

p.\&l.

profit and loss

زن

piyt.

payment

- djalj

p.c.

per cent or price current

pkege.

package

$\mathrm{p}: \mathrm{l}$.

parcel

P U.

post dated

$\mathrm{pd}$.

paid.

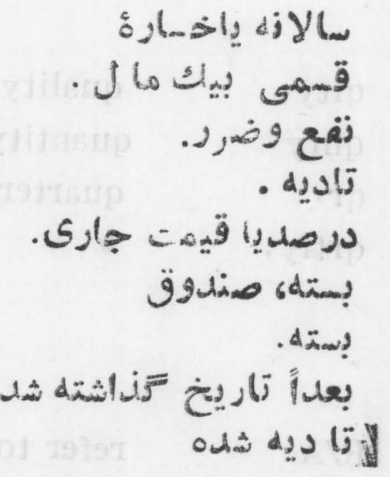

(c) $1 \cdot)$ 

pèr an.
pr annum

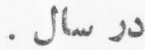
re?ct p'a cent
- ira
per pro
per pro uration (By power of authoity)
, $815 \%$
per pro?
《
(c

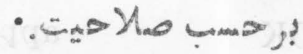
$\mathrm{p} . \mathrm{g} \mathrm{t}$.
pêr gross ton
$\mathrm{p} \cdot \mathrm{h}$.
per hour
pm
premium
$\mathrm{p} \cdot \mathrm{n} \cdot \quad$ promissory note
Y.O.B. post officé bax

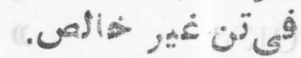
- $\approx$ ela gargata
P.O.C.
port of call
60 0.j6
ت
iglino

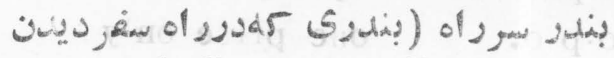

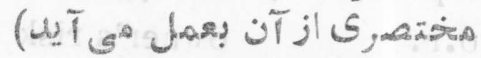
pol,y
policy
prem.
premium

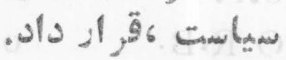
prof.
profit
prox.
proximo (next)
. 0 j)
prs.
pairs
ps.
pieces
psf.
pounds spuare foot

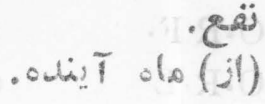 두 6 0رgج
لك. $\varepsilon$ en

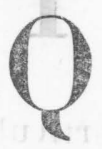
qlty
quality
quty
quantity
qr.
quarterly
qútly.
๖)
)

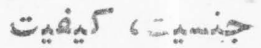 تص olo d a s ,
》) $)$

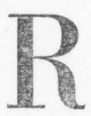
$\mathrm{R} / \mathrm{A}$ refer to acceptor 


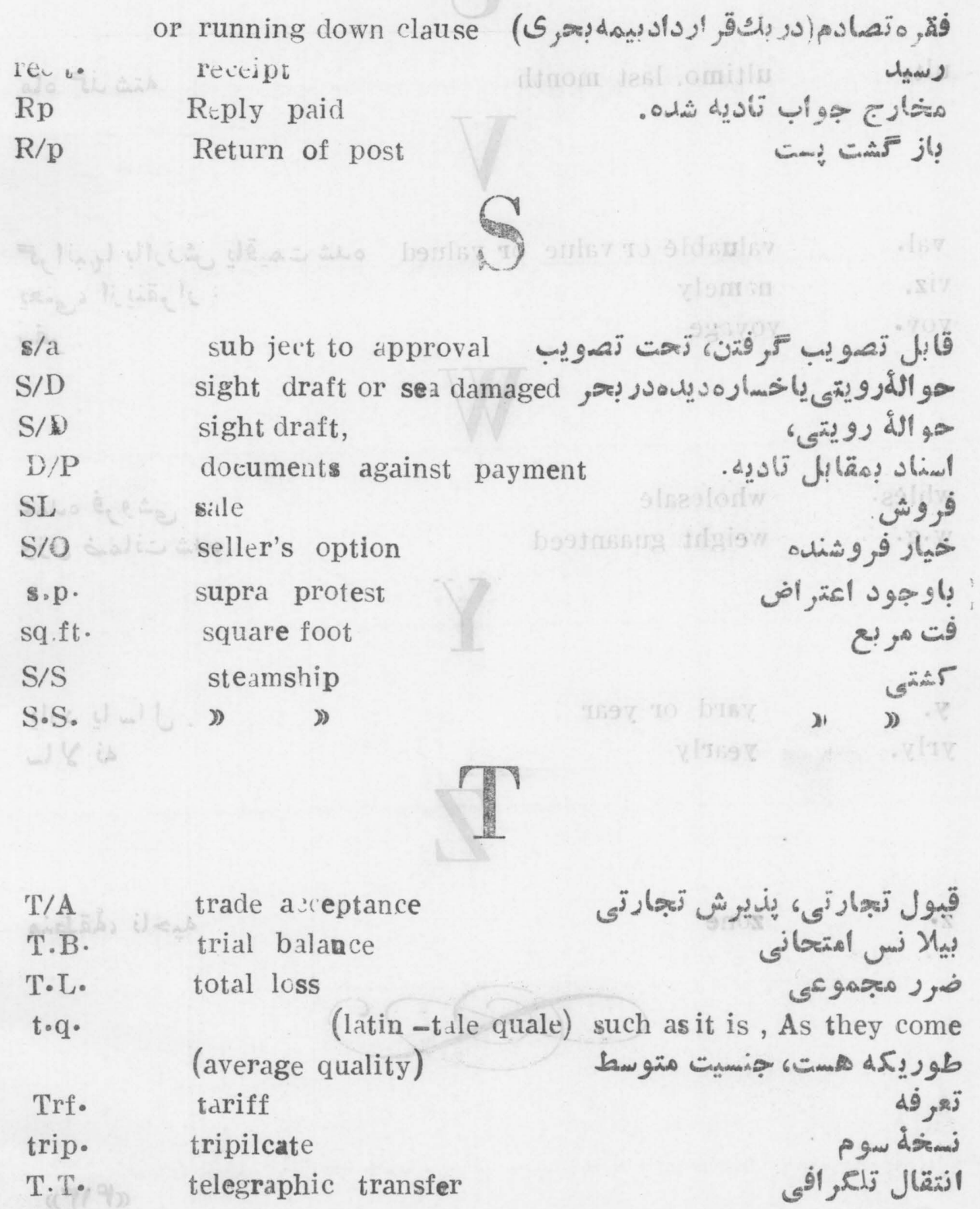




\section{U}

ult.

ultimo. last month

$$
\text { dis olo }
$$

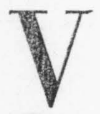

val.

valuable cr value or valued

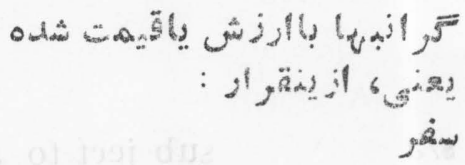
namely voyage

voye

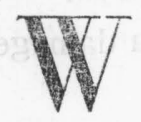

whlès

$\mathrm{w} \cdot \mathrm{g}$.

y.

yrly. wholesalé

weight guaanteed

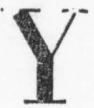

yard or year

yearly

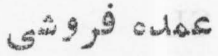

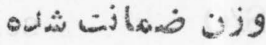

$\mathrm{z} \cdot$

zone

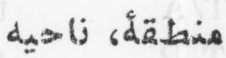

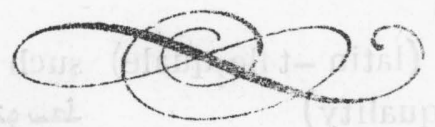




$$
\text { P. }
$$

National monetary units

Country

1- Afghanistan

2- Albania

3- Argentina

4- Austria

5- Austria

6- Belgium

6. 7- Bolivia

8- Brazil

9- Bulgaria

10 - Burma

11- Canaria

12. Ceylon

I3- Chile

14- China

15- Colombia

16- Costa Rica

17- Cuba

18- Cze hoslovakia

19- Denmark

20- Dominican republic

21- Egypt (UAR)

22- El S lvador

23- Equador

24- Ethiopia

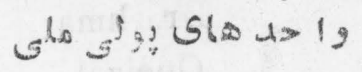

monetary units

$$
\text { Afghani }
$$

Frine

peso

Pound

Schilling

Frane

Boliviano

Cruzeiro

Lev

Fupee

Dollar

Rupee

Peso

Yuan

Peso

Culón

Pes?

Koruna

Krone

Peso

Pound

Colòn

Sucre

Dollar 


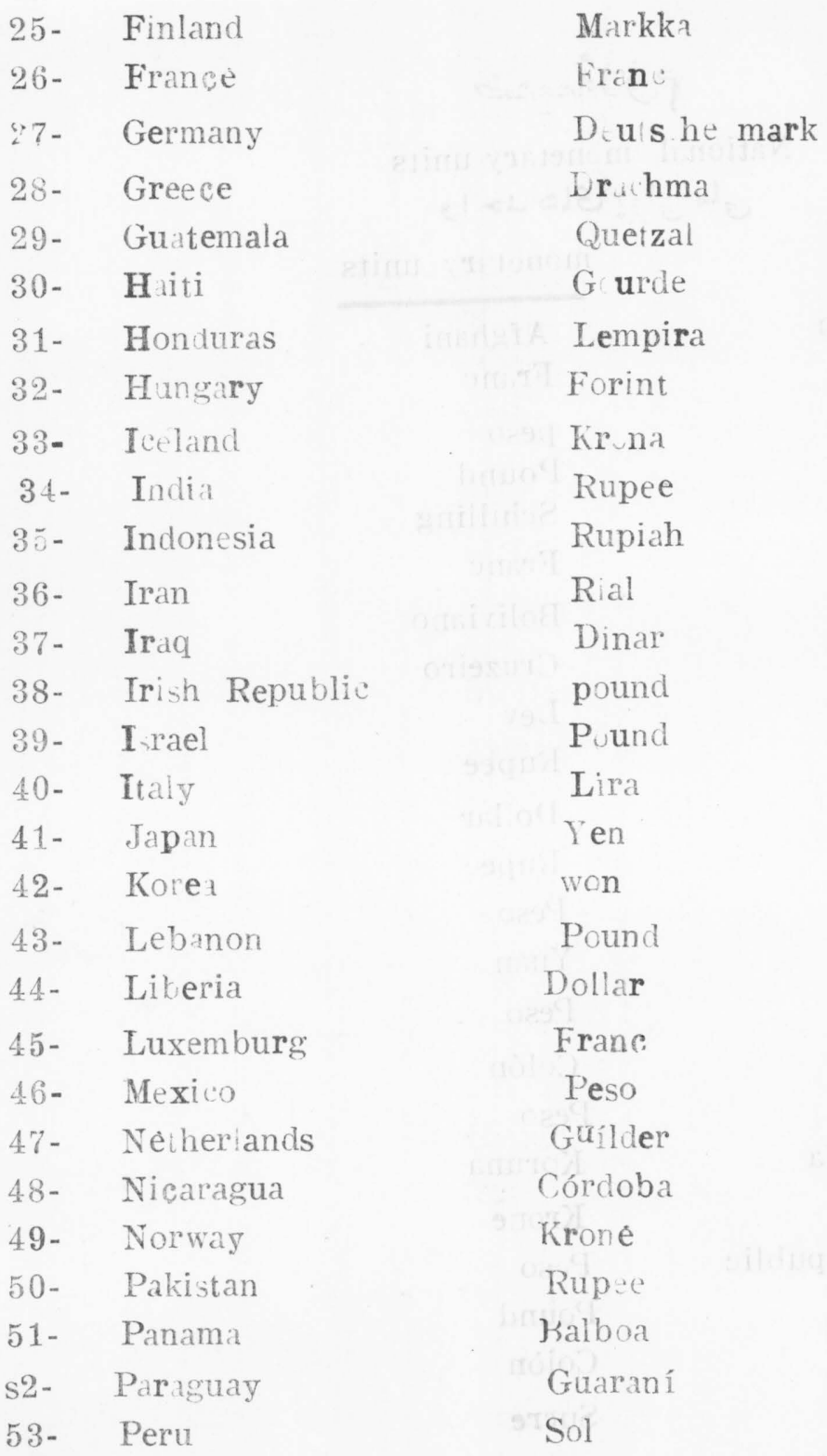

Markka

Druhma

Quetzal

G urde

Lempira

Forint

Kr $\sim$ In

Rupee

Ripiah

Dinar

pound

Pumna

Lira

yen

P

Dorund

Dollar

Frane

Guílder

Córdoba

Kroné

Rupse

Guaraní

Sol 
54- Philippine Republie

Peso

5อั- Poland

56- Portugal

Zloty

57- Rumınia

58- Spain

59- Sweden

Es :udo

60- Switzerland

Leu

Peseta

61- Seria

Krona

62- Thailand

63- Turkey

Franc

64- Union of South

Pound

Bant

Lira

Africa 19 Pund

65- U \& S R

66- United kingdom

Rouble

67- United states

Pound

68- Uruguay

Dollar

69- venezuelit

$\mathrm{Pe}$ :

70- Yugoslavia

Bolivar

Din $x$ 


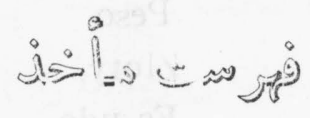

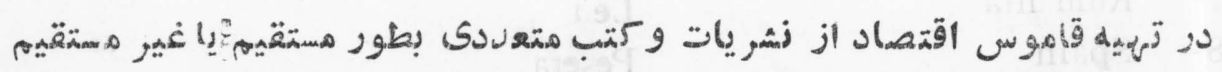

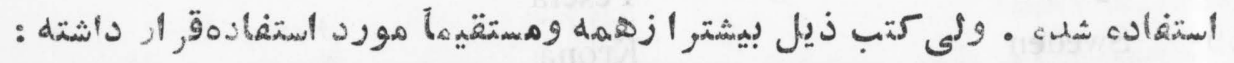

1 - Dictionary of Jiconomics . Burnes \& Nob!es Inc. 1949 and 1959) by

Harold S S Sloan and

$$
\text { Arnold } f \cdot \text { Zur her }
$$

2- Dictionary of Economics and Businéss (Littlefield ، Admis \& ço. $1959^{\prime}$

$$
\text { b y }
$$

Erwin $\cdot \mathrm{E} \cdot$ Nemmers

$$
\text { and }
$$

Carnelïus C • Janzen

?- A (ilossary of Public Acministraticn Terms.

University of $\mathrm{T}$ thran

4-Dictionary of Foreign Trare ( Prentice-Ha'l 1947).

b y

Frank Heinus

5 - A Glossary of Economic Jerms (A.R.A 1657)

by

Howard Wilson

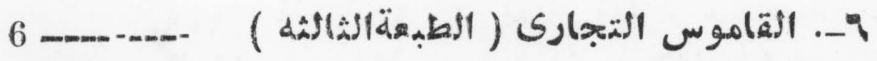

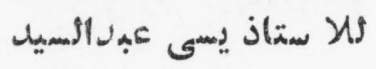




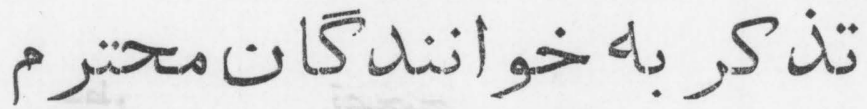

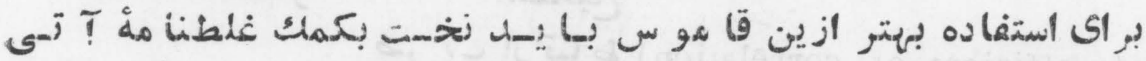

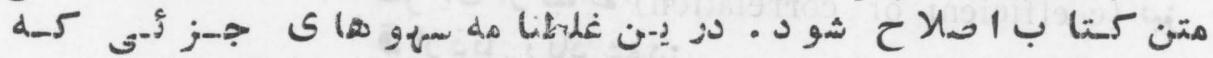

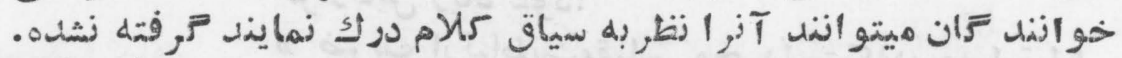

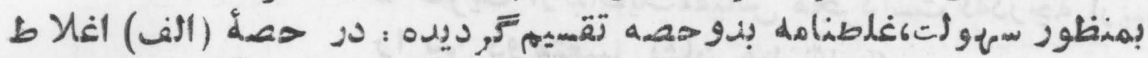

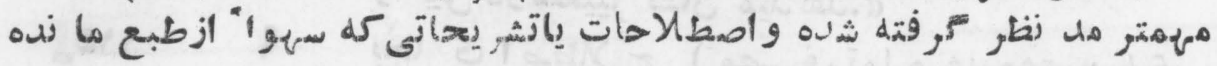

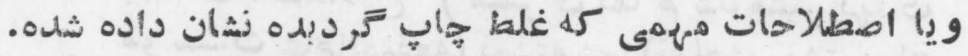

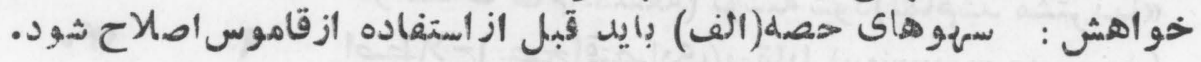

\section{ERkATA : S :}

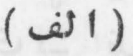

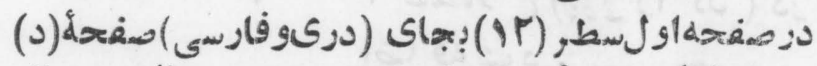

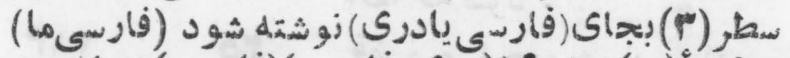

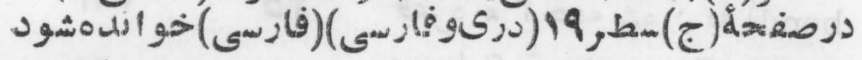

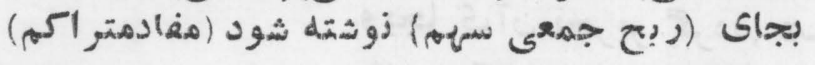

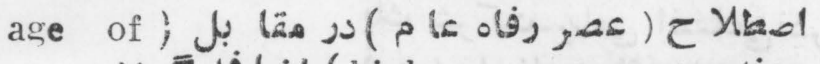
اض (high mass - consumption

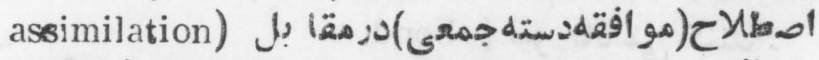

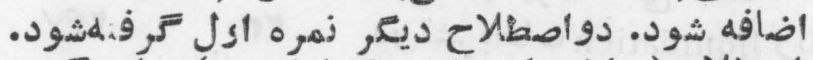

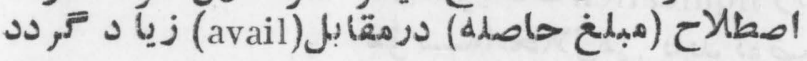

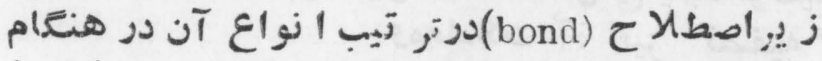

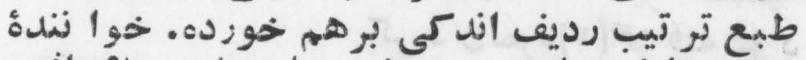

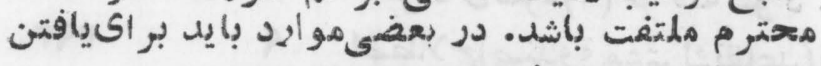

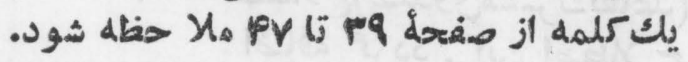

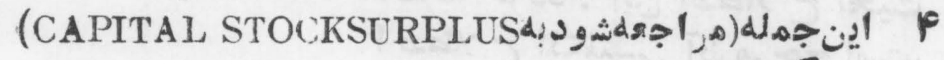
صنف drib 


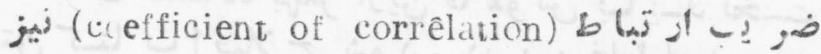

$$
\text { قوار ذيل زيان شيود: }
$$

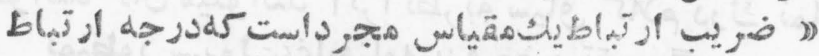

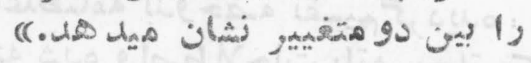

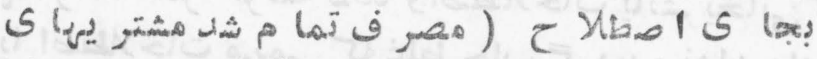

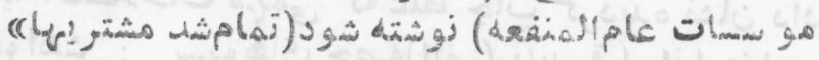

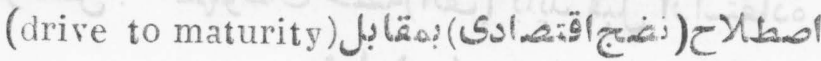

$$
\text { زيادتر دود. }
$$

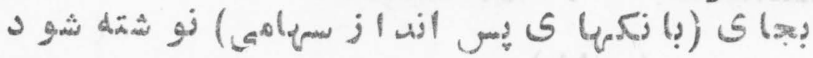
$8 \quad 110$.

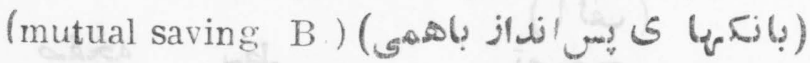

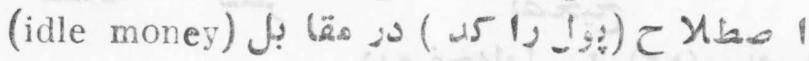

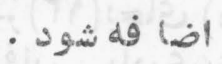

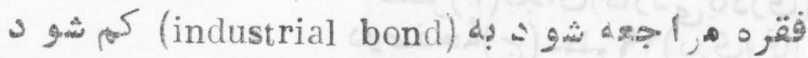

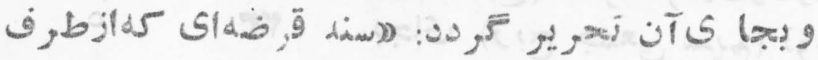

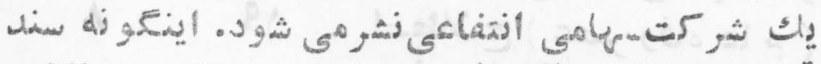

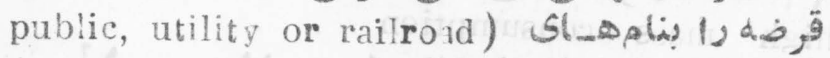

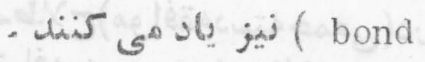

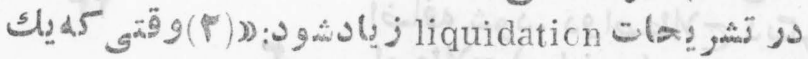

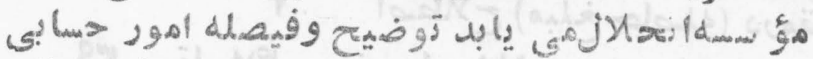

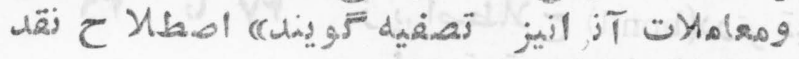

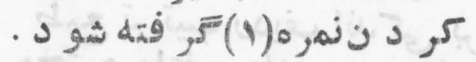

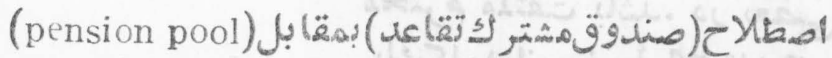

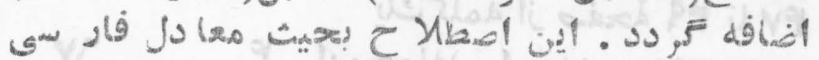
.

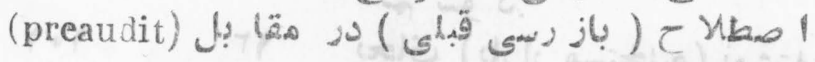

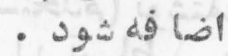

$p 99$

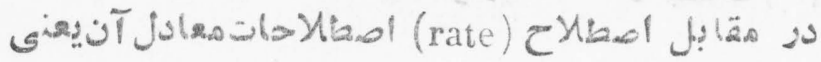
0 ppo 


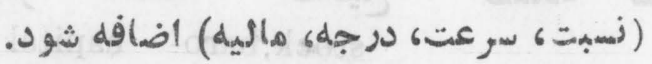

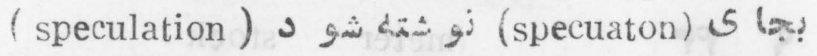

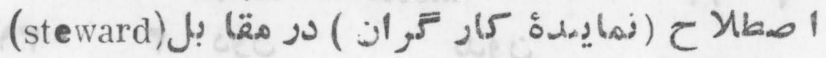

ir

Par

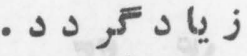

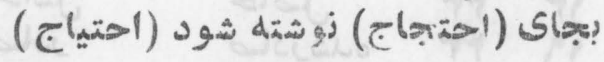

$$
\text { (ب) }
$$

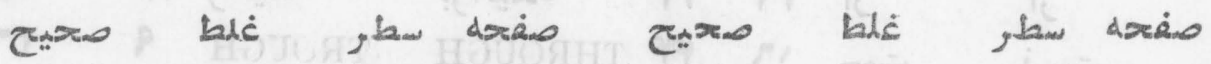
19 19 assay ass y p ir abandoned adondoned I । NON- NON 18 iV principle priniple $\checkmark$ I ASSENTEI ASSENTED

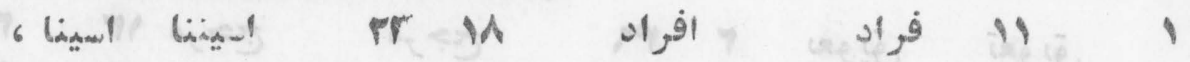

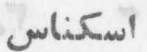

19 19

$$
\mathbf{A}=\frac{\mathrm{L}}{\mathrm{F}} \quad \mathbf{A}: \frac{\mathrm{L}}{\mathrm{E}}
$$

IV

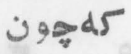

u $>$ iv PI premium

براى

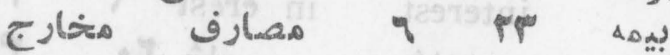

ballast. b llast in pq s $>$ ilkel

هتوازن

متوزن

18

pq

pln $\ln$

10

مقدار ه مت ه

p.

بلدست

(I)

r.

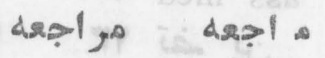

9 iv

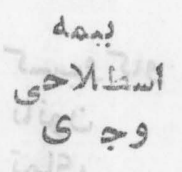

iv

10

rov

pqq

$$
\text { همجندينه }
$$

DERTVA - ERIVAT - Pr rA

مجصو ل TIVE IVE

remittance emittan e q $p$.

A مئى

$$
\text { قرضه }
$$$$
\text { in }
$$$$
\text { (9) } 19
$$

(قيهت قبه

-

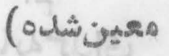

$$
\text { P. }
$$

$\checkmark$

$(d P p \cdot)$ 


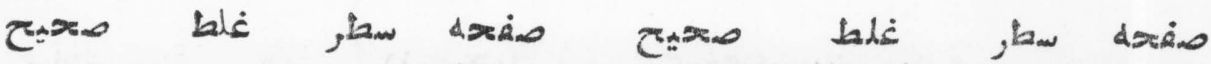
Gi preter stock

\begin{tabular}{|c|c|c|c|c|c|c|}
\hline $\begin{array}{l}\text { BOND } \\
\text { BOND }\end{array}$ & $\begin{array}{l}\text { BCND } \\
\text { DOND }\end{array}$ & $\begin{array}{l}14 \\
19\end{array}$ & $\begin{array}{l}\text { pep } \\
\text { pr }\end{array}$ & صاصل بلدون & صاسئ & $\begin{array}{l}p \\
\text { pr } \\
\text { p. }\end{array}$ \\
\hline آنست & $ث j T$ & $r_{1}$ & $\mathrm{pr}$ & سود يكه & سودركه & ir \\
\hline از از & ار & p & $P p$ & بر اتيكه & واتيكه & iv \\
\hline زسبت & سبمت & 19 & pro & THROUGH & TRUI゙GH & 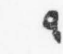 \\
\hline
\end{tabular}

T PI PP BILL OF BILL OF deferred de erred 19 Po LADING LA DING

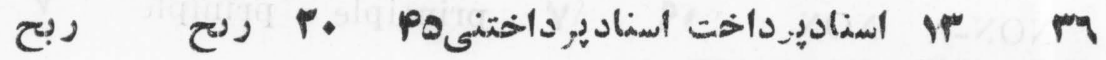
receivable receivalbe in $r q$

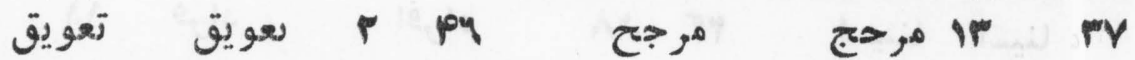
bond,gold. bond gold $p$ Fqblanket bond blanketlond * $\Gamma_{\wedge}$ $\mathbf{b}_{\text {ond, legal hond legal ip pq }}$

tender tender

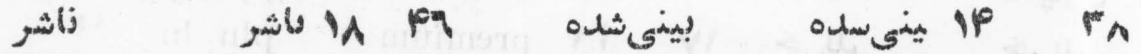
BOND AOND $r$ PY DIRECTOR DIRETOR PI rA

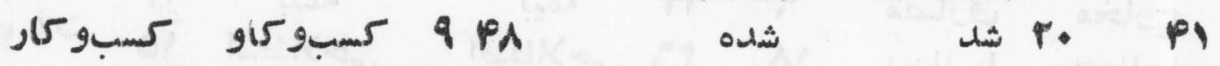

قانون

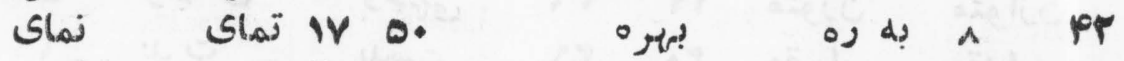

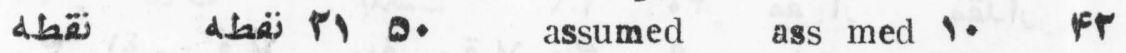

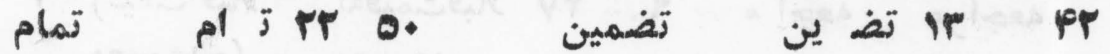

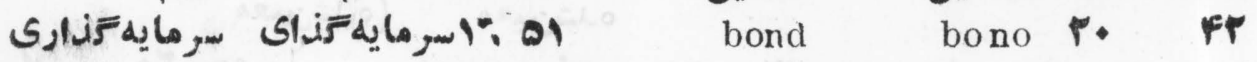

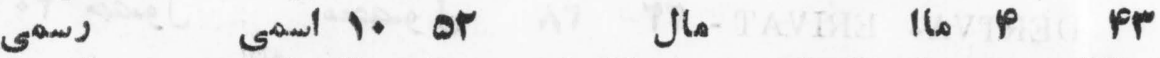

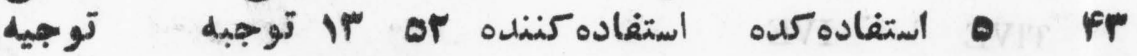

plan plon P. or 


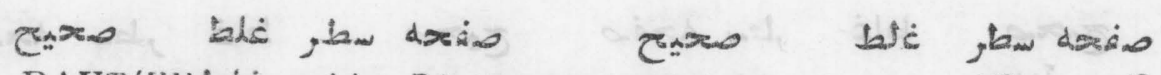

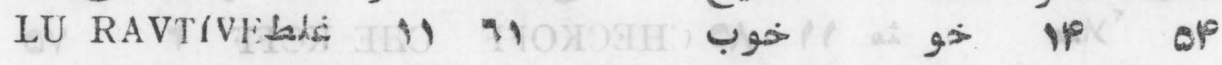
LUCRATIVE cison

with a witha $1 \mathrm{~A}$ ap

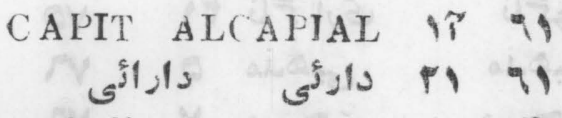

capitalization cap zation 1 . ap
Ggiflesel

çycle

0 ly 5

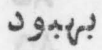

زفروفوختو staudird Lec

standard $C \times \infty$

pp qp

SHARES SERAHS $\wedge$ ๆ

أWor

st i.

av

captive aptive 9 a

زهـ,

زيقداً

$1, x, 000$

1)y 2 gx.

budget

مو

public

هو ادف أد

إداد

i, j. 1. 4V

जij I $M$

osts

$020 \mathrm{Po}$

QY

ن

cclé 8

of $\operatorname{los} 19$

igates $1 \%$

(6)

(2) 


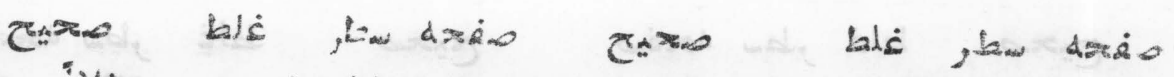
"VAि

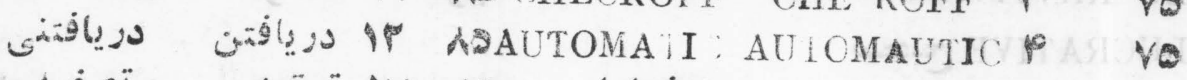

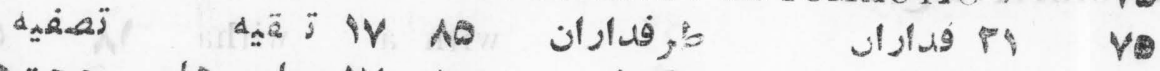

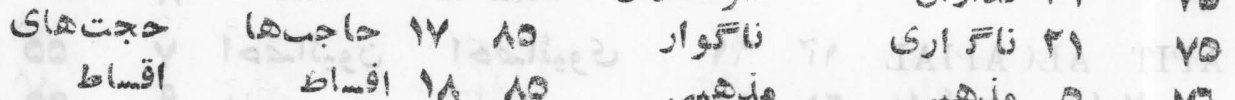

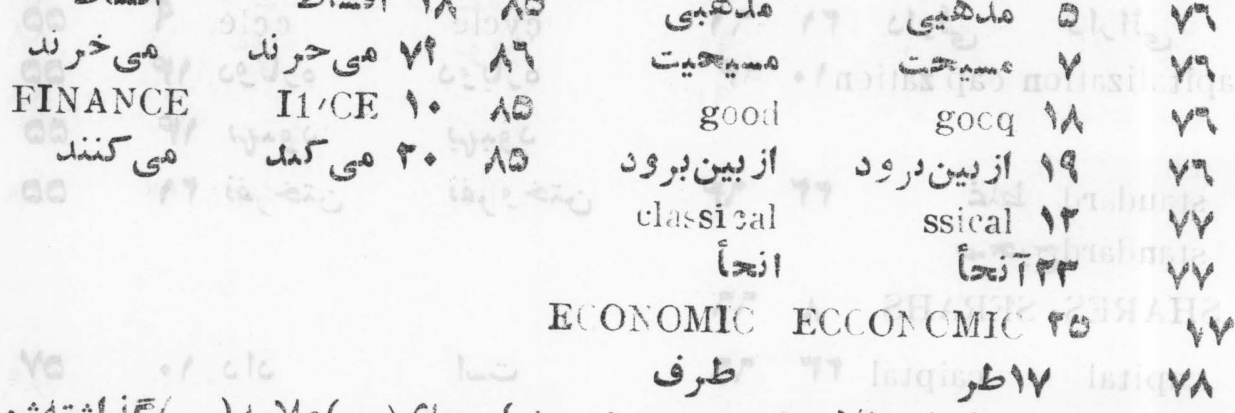

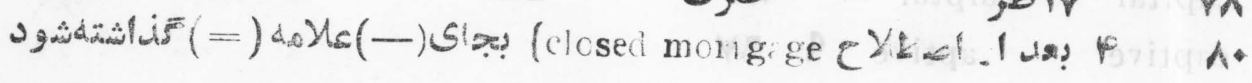
cobwebtheorem: Sals it cobweb the rem : $c=0$

paper piper $\vee$

treaty treat $M A$

commi sioner: Lali \& AV

of custnms Tasen
تو

Si!

\&ing
•

Silg, thow 13 commission $\mathbf{r}$ of customs:

bo p

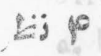

Jgän Jgän A AY commerial e mmeriel

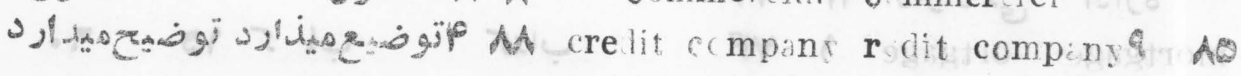

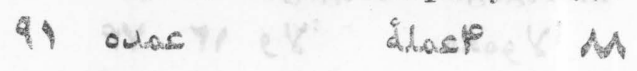
ecmm dity cmmodíly $q$

s

$$
\text { ज }(x) \text { ). }
$$

AA

(बippy 
صف:ه سيطر غلط compersated : حئ ap dollar .

$\int \stackrel{\theta}{a} d y$

iste

is

I) UT bali tan dxas

تو

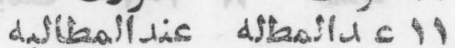

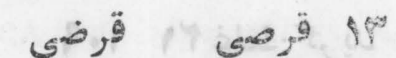

dholo alos 10

ige

$19 \mathrm{iV}$

AN

Ad

A

AA

$M$

$M$

AA

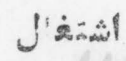

linnt pp

$1 \rightarrow 1 p p$

commodity commoditf $q p$

demand emand $A$ AP
1

(j)
هـ:هأت

हो)

تlol 19

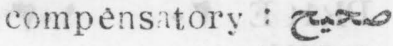

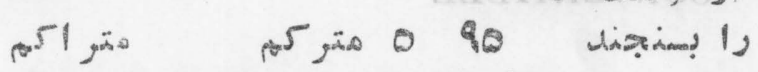
ig, DgA concession doncesson 95 ilsil diacinols $P$

An

ใ?

i) $b_{1} 1$

i,

98

abuld

$15-19$

คร

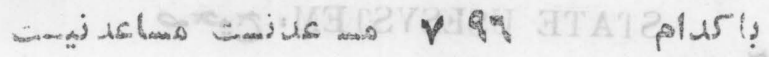

abest, 9

A 9

dolic $\therefore$ bo $A$ \&

4. plur!y 9

Q.

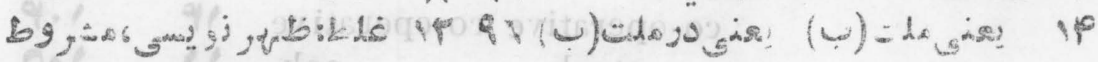

8.

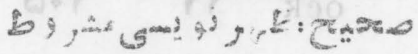

1.ttr of redit iads 19 \&q

$=20$

Eadao 89

8.

lettêr of credit:gases

CREUI! CELIT P० बุ

$\operatorname{Lin} \vec{\theta}$

$=1 n$

8.

confise rion : Lis

?onfiscation :

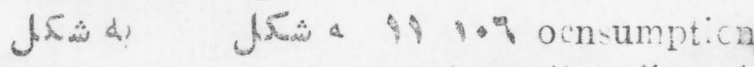

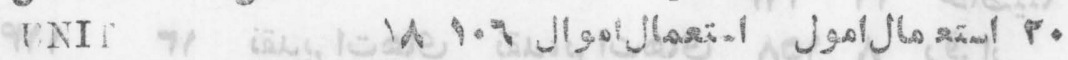

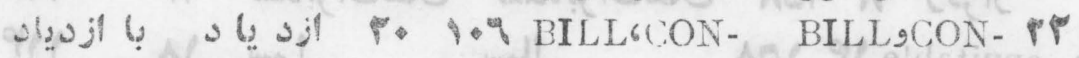

8)

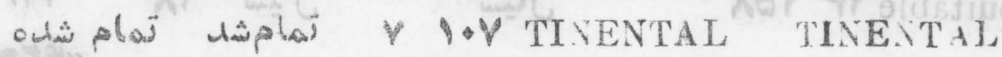

(c) Fै 


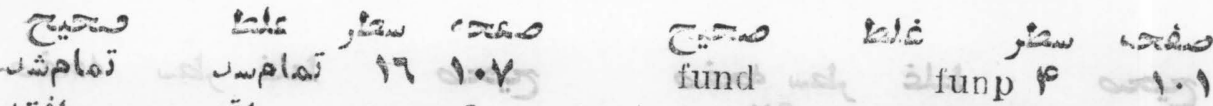

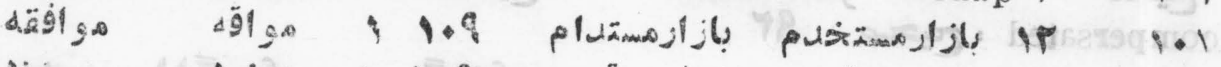

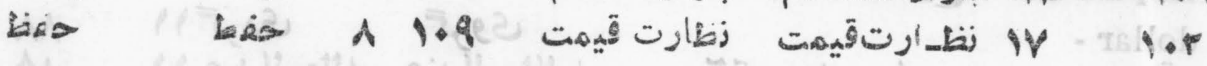
زئ日)

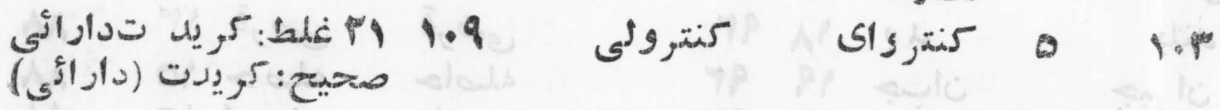

controlling $\quad$ Q
SPRICE d! PK1CE F. BONI) BOND

business bus ness |

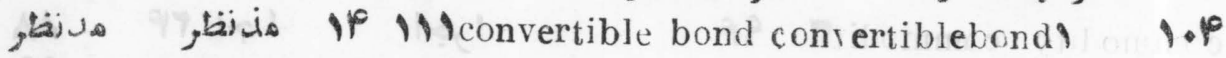

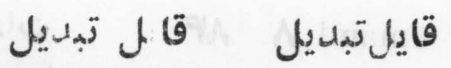
Pو 19 19 CONVERTIBLE

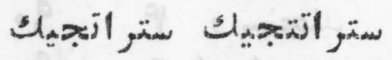

IIP convertible conve rible e P.P

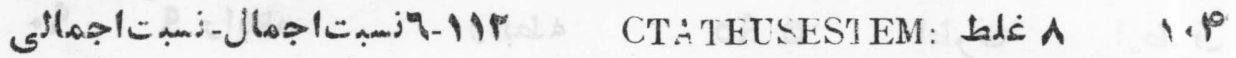

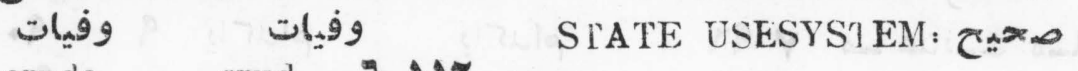
crnde crud of IP

$\begin{array}{crrr}\text { co-operative co-cperative } & \text { if } & 1 \cdot p \\ \text { stock } & \text { ock } & \text { if } & 1 \cdot 0\end{array}$

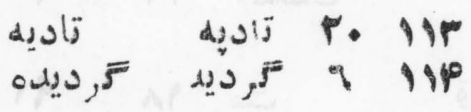

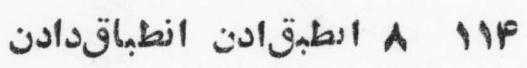

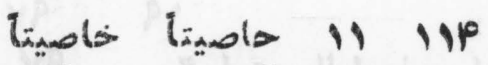

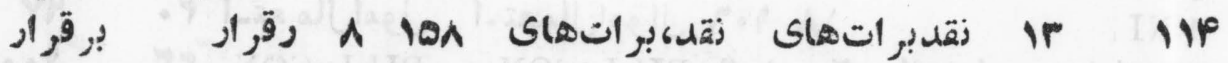
équitable epuitable IF 101 سيl IA IP 


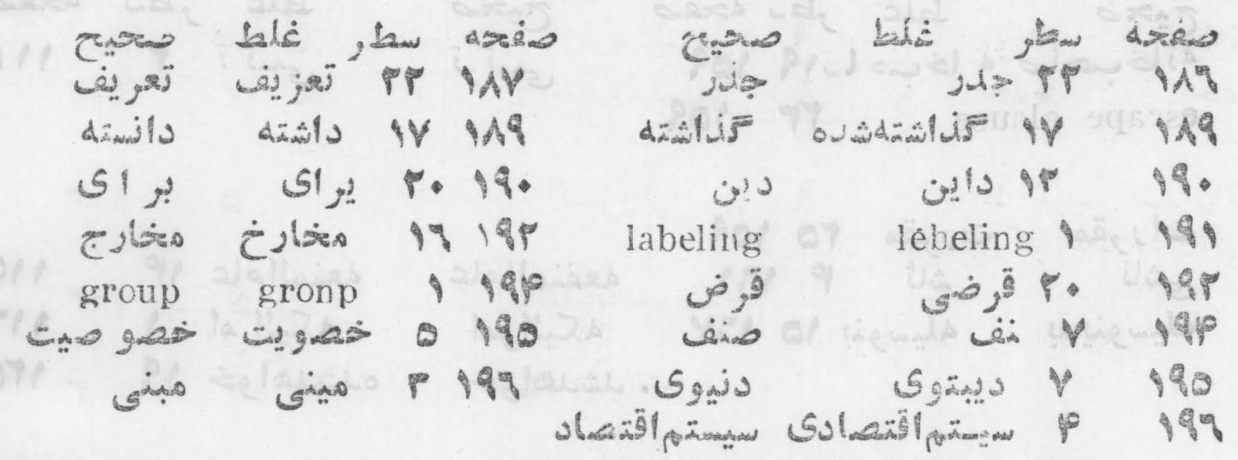

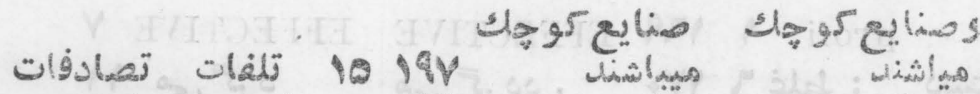

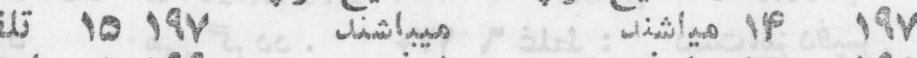
198 19 191

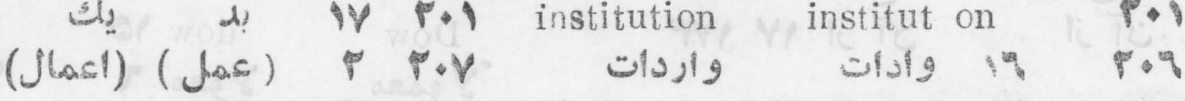

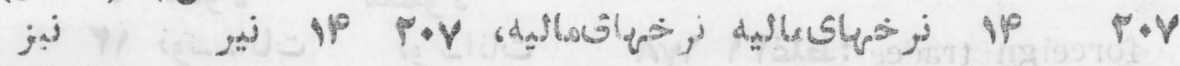

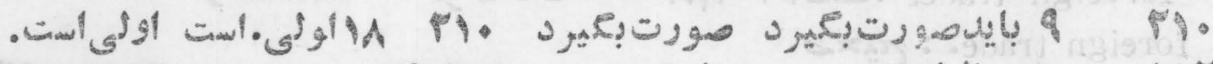

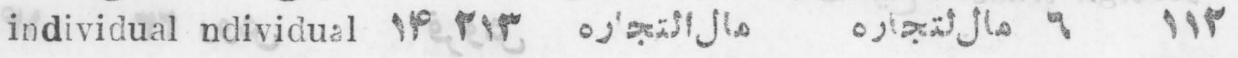
indorsement ndorsémentpo-pir indorsed 7 ndorsed in pip

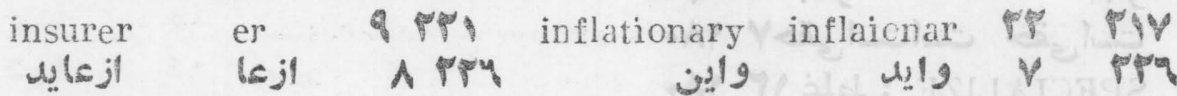
فlan is A P P jettison in- jetison irau- $Q$ Pr. surance. rance.

S) 5 ر نإن PrA

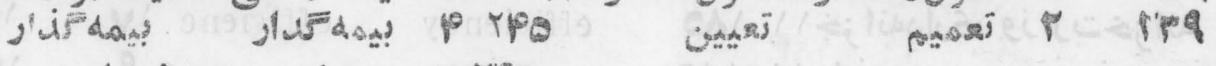

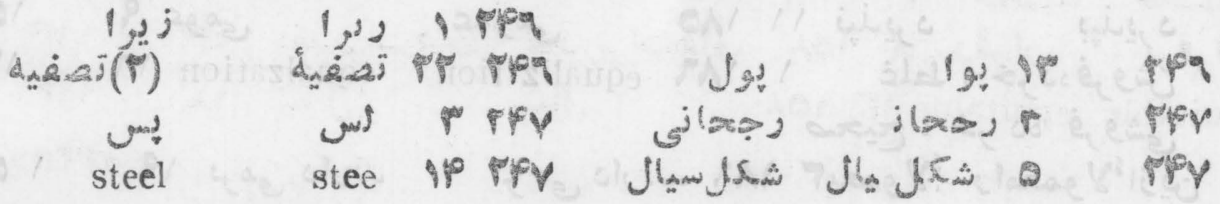




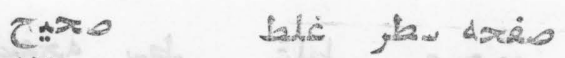

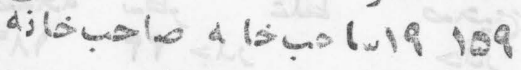
escape clause pr 129 cises $4+\pi^{3}$ blis, baw drino 110

ㄴ,

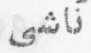

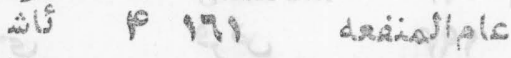
delis

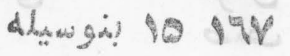
destgol daraftate 110 110

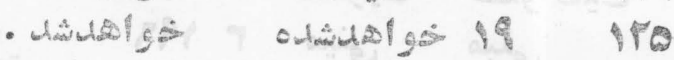
profit profi 199 EFEECTIVE EFECIIVE $\vee$ P ungorans :

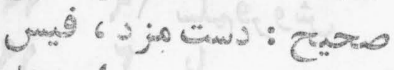
\&. 2 $\Leftrightarrow$, $M$ dis riminating liminating $p$ if pro نा if I IV AMP

$$
\text { Dow dow } 12
$$
1fक्ष "Yoase Voses q 1 เต

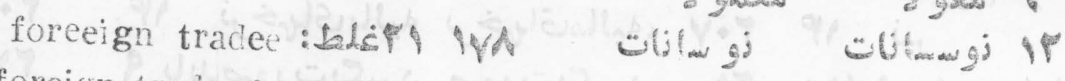
foreign trade. : $\mathbb{W}$

فورش

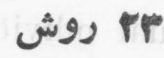
19 ب ب ب P P

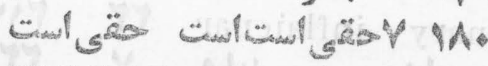
SPECIALIZE: Ledc ip $A$. SPECIALISED : ?as=

(فी) Eg g ت ت ع و و

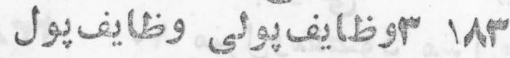
dif daxing is $d=p$ تtols ils Plo PPP prq ف요 efficiency $\omega, g r r$ 181 د د 11 IAO efficienc iV 1 SP

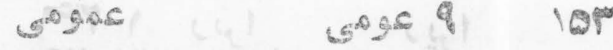

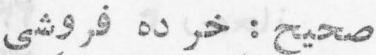

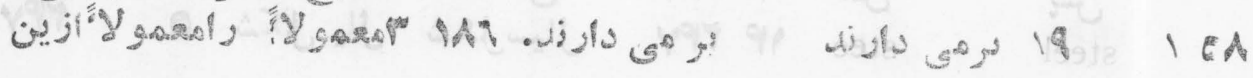




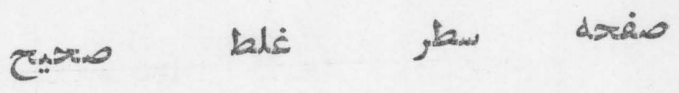
EXPLICIT EXP-ICIT \& PFA INTEREST INIEREST

$$
\begin{aligned}
& \text { doي doي PP PPA } \\
& \text { DIVISION DIIVSIONF I } \\
& \text { 1 preq }
\end{aligned}
$$

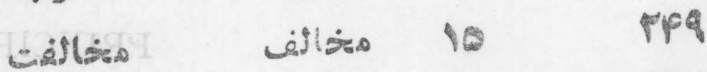

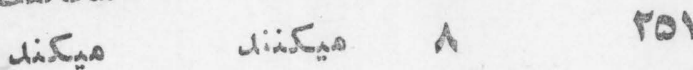

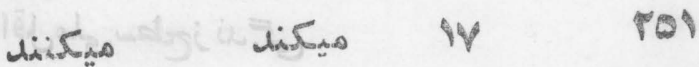

$$
\begin{aligned}
& \text { g gor por }
\end{aligned}
$$

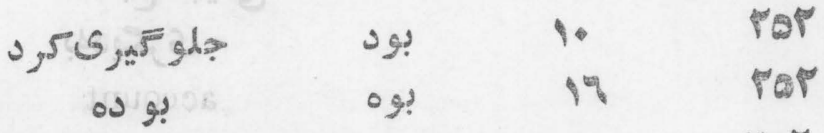

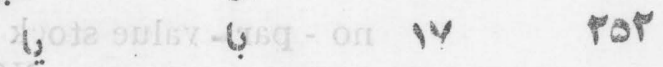

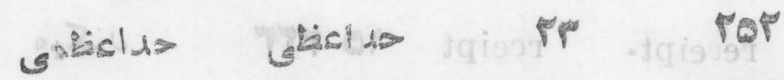

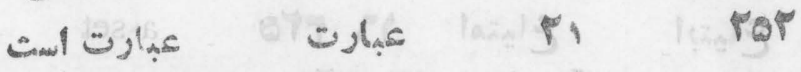

$$
\begin{aligned}
& \text { (s) } \mathrm{H}_{0} \text { ) (s) }
\end{aligned}
$$

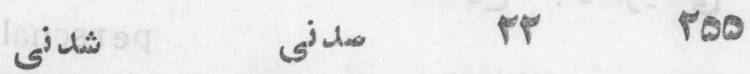

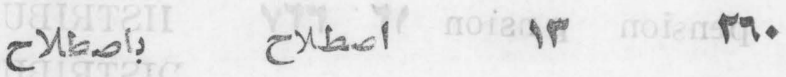

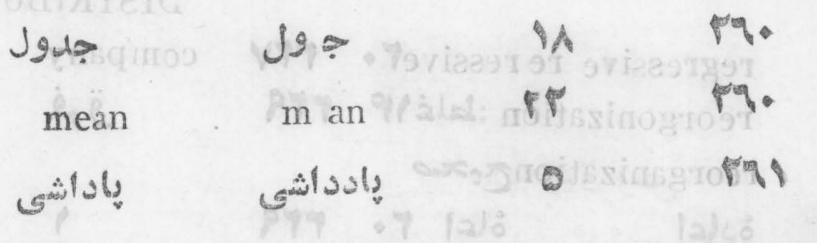




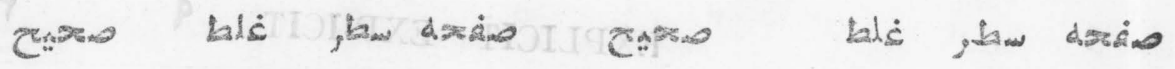

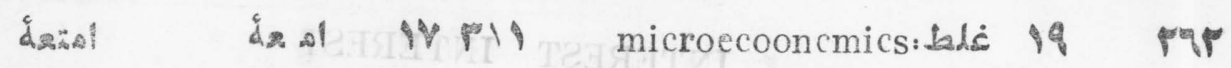

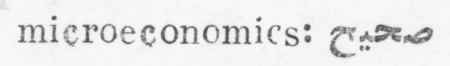

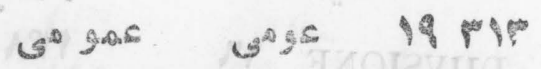
N

व PRINCIPLE PRINCIPL \& Pq

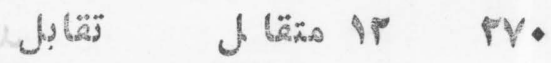

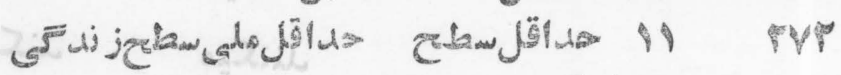
Fij

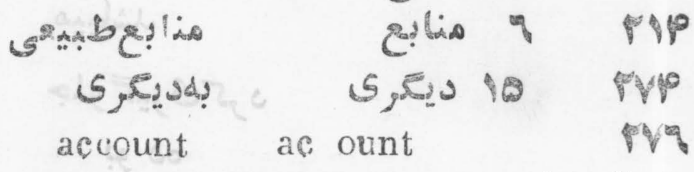

no - par-value stock non-par-value stock P P $\mathrm{PA}$ NO NON \& PMA

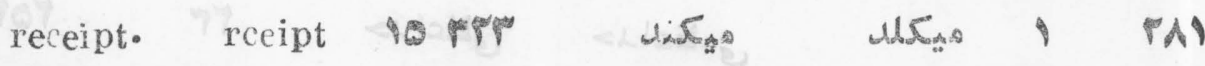
ELي! EläAl 19 PPQ asset asst $P$ PAP E

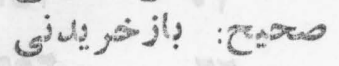

personal perrsonal if pip pension pnsion ip prp IISTRIBUTION : ble i P PQp DISTRIBUTION: ص: מש:

regressive re ressiver. PrP company eompauy iA P\$P

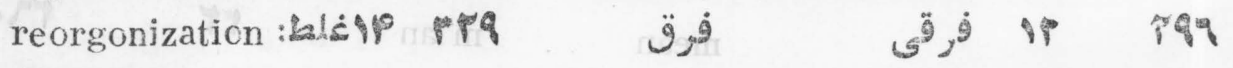
reorganizationceres Sulst sts p. pq

$\frac{p}{p}$

$1-p$ ip pq 
Con bli bis dow

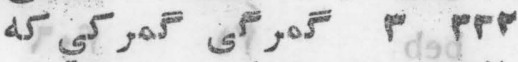

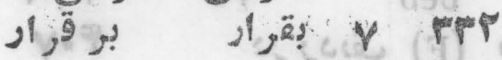

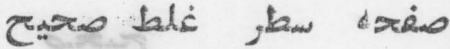

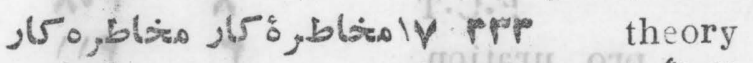

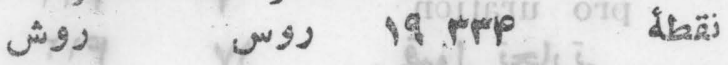

sample sampe $18 \mathrm{prq}$ و

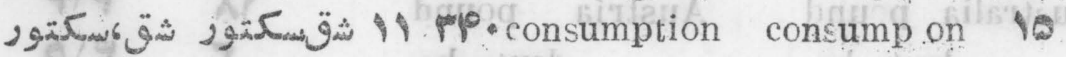

sector

\section{se tor ip p.}

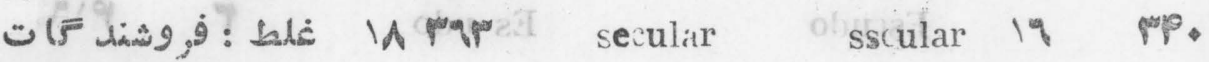
صحيح:فروشنل ترونان

NATIONALISN : bls \& PP

NATIONALISM:CA:

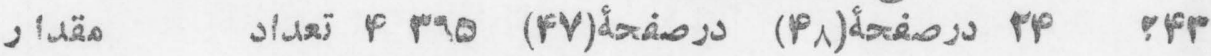

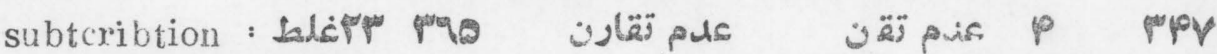

subscription :صحتح:

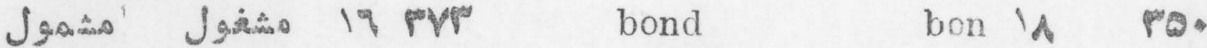

TENDER TENIl: $Y$ PrV special specia $P$ POP

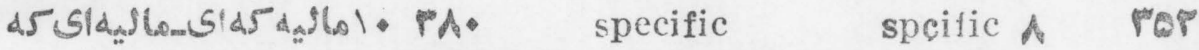

P. PAPAD VALOREM AVALOREM 1. PQP

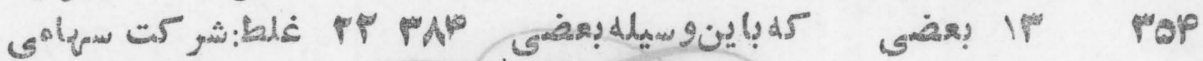

管

lo

visibleitems: bads i of pap

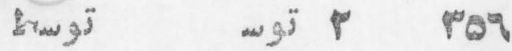

visible items:حي

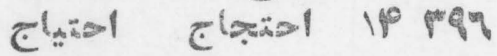

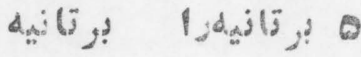

PoV

illegal llegal $r \cdot p$

Pror stock stoch ip prop exchnge ex hange iv pur 


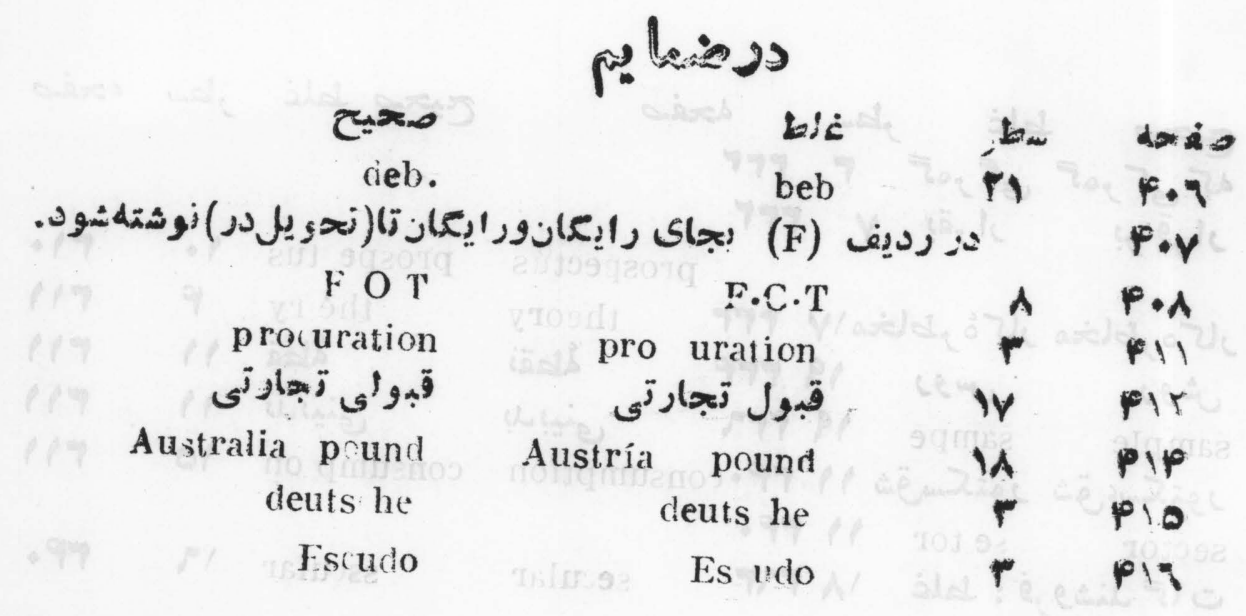




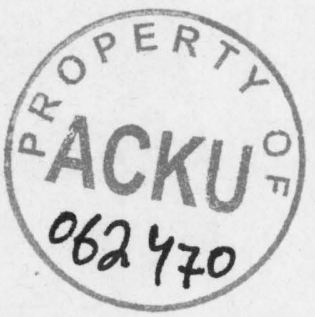

AFGHANISTAN CENTRE AT KABUL UNIVERSTTY 


\title{
PICTONART
}

\section{OB}

\section{ECONOMTCS AND BUSIXESS}

\author{
Inglish - Persian
}

by

s

\section{MOHAMMAD AREF GIIAUSSI}

\author{
Instructor of Economics :
}

Kabul University

Published by:

Iqtesad Journal, Chamber of Commer:e 